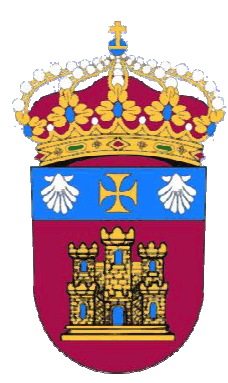

Universidad de Burgos

Departamento de Ciencias Históricas y Geografía

\title{
LA COMUNICACIÓN SANITARIA Y SUS IMPLICACIONES EN LAS ACTITUDES E INFORMACIÓN ACCESIBLE A LOS CIUDADANOS. ESTUDIO COMPARATIVO ENTRE CASTILLA Y LEÓN Y GALICIA
}

Bajo la dirección de los doctores

Alfredo Arceo Vacas

Universidad Complutense de Madrid

Miguel Ángel Moreno Gallo

Universidad de Burgos 



\section{Agradecimientos}

A mis directores de tesis, Alfredo Arceo Vacas y Miguel Ángel Moreno Gallo. Al primero por guiarme y demandarme la exigencia que requiere un trabajo de este nivel. Al segundo por ayudarme en todos los ámbitos y estar siempre, siempre ahí.

A los responsables de comunicación de los hospitales de Castilla y León y de Galicia por su ayuda y predisposición a la hora de colaborar desinteresadamente en el estudio.

A mis compañeros de la Universidad de Burgos por su apoyo y compañerismo. 



\section{ÍNDICE GENERAL}

\section{PRESENTACIÓN}

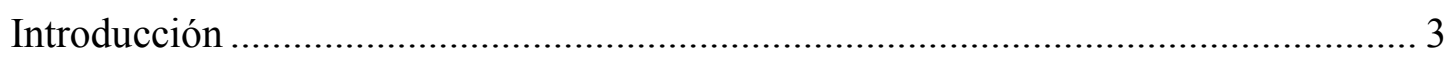

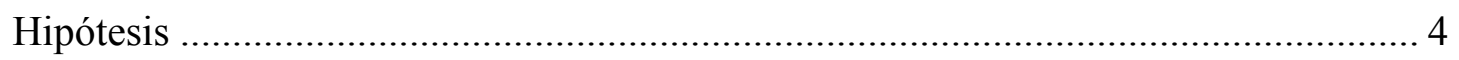

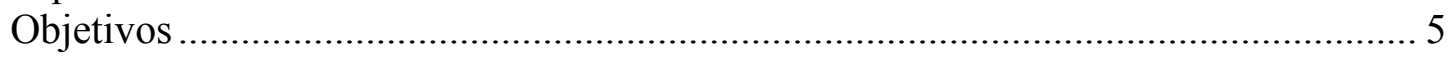

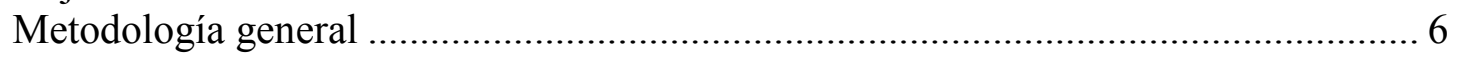

CAPÍTULO UNO: MARCO TEÓRICO

\subsection{APROXIMACIÓN TEÓRICA A LAS RELACIONES PÚBLICAS}

1.1.1. DEFINICIÓN Y DIFERENCIACIÓN CON OTRAS DISCIPLINAS 13

1.1.1.1. Definiciones de relaciones públicas .............................................. 13

1.1.1.2. Diferencias entre relaciones públicas y otras disciplinas ................. 17

1.1.1.2.1. Diferencias entre relaciones públicas y publicidad .............. 18

1.1.1.2.2. Diferencias entre relaciones públicas y propaganda............. 21

1.1.1.2.3. Diferencias entre relaciones públicas y marketing ............... 23

1.1.2. PRINCIPIOS DE DIRECCIÓN DE LAS RELACIONES PÚBLICAS. ESFERAS DE

LA COMUNICACIÓN EXCELENTE................................................................ 25

1.1.2.1. Conocimiento de los comunicadores ........................................... 26

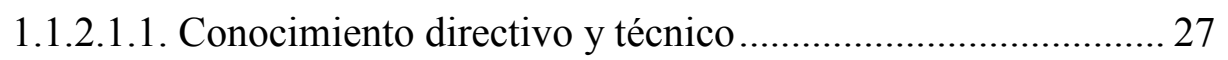

1.1.2.1.2. Conocimientos de comunicación bidireccional ................... 29

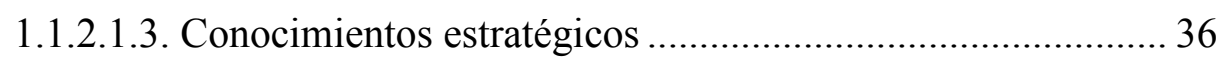

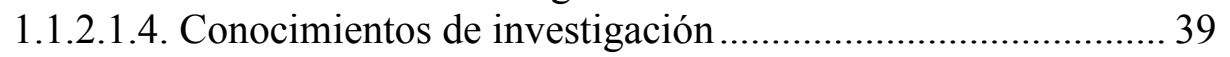

1.1.2.1.5. Conocimientos sobre nuevas tecnologías ........................... 48

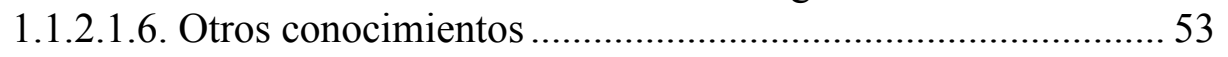

1.1.2.2. Expectativas comunes, poder y relación con la dirección..................56 56

1.1.2.2.1. Expectativas comunes acerca de la comunicación ................ 56

1.1.2.2.2. Poder del departamento de comunicación ............................ 57

1.1.2.2.3. Relación del responsable de comunicación con la dirección 59

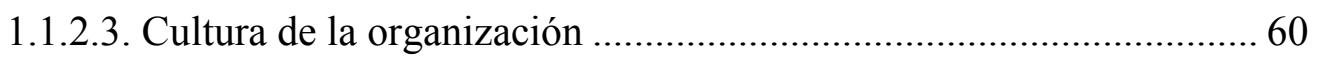

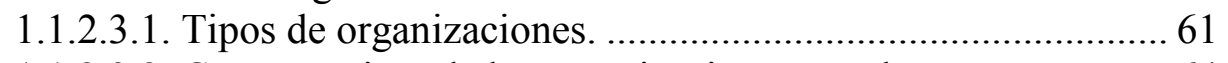

1.1.2.3.2. Características de las organizaciones excelentes .................. 64

1.1.3. APLICACIÓN DE LA GESTIÓN ESTRATÉGICA. FASES DE UN PROGRAMA

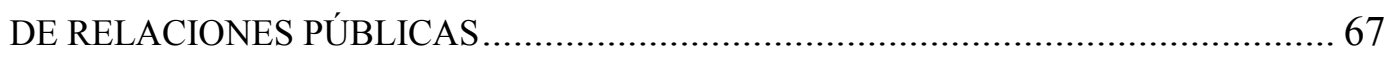

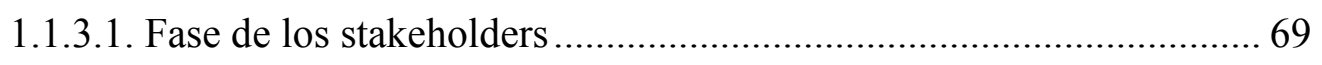

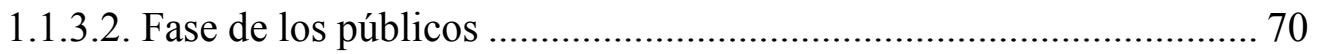

1.1.3.3. Fase de los conflictos potenciales ............................................ 78 


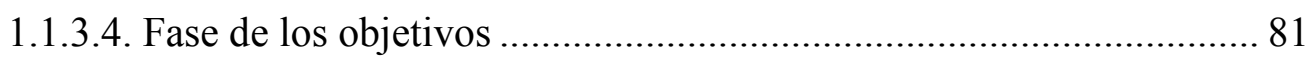

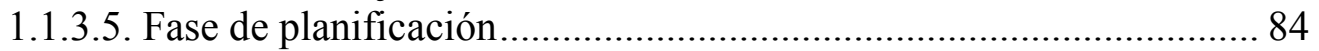

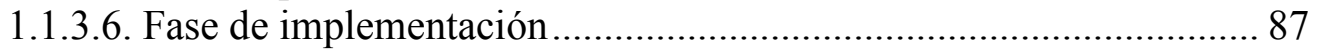

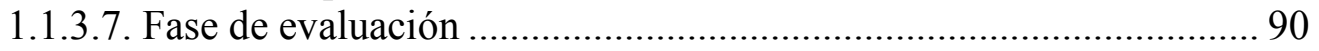

\subsection{USO DE LAS RELACIONES PÚBLICAS EN EL ÁMBITO SANITARIO. ESTADO DE LA CUESTIÓN}

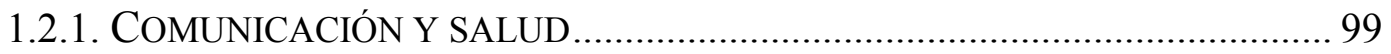

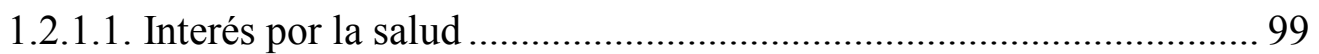

1.2.1.2. Aumento de las fuentes sobre la salud ......................................... 101

1.2.1.3. Consecuencias de un alto interés en la salud ................................ 103

1.2.1.4. Una gran oferta no implica una calidad alta................................. 104

1.2.1.5. Necesidad de comunicación en el ámbito sanitario ........................ 106

1.2.2. ESFERAS DE LA COMUNICACIÓN EXCELENTE EN EL ÁMBITO SANITARIO

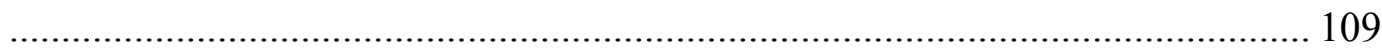

1.2.2.1. Conocimientos de los comunicadores ......................................... 109

1.2.2.1.1. Conocimientos directivos y técnicos ................................. 109

1.2.2.1.2. Conocimientos de comunicación bidireccional ................... 111

1.2.2.1.3. Conocimientos estratégicos ............................................ 117

1.2.2.1.4. Conocimientos de investigación ......................................... 119

1.2.2.1.5. Otros conocimientos ........................................................ 122

1.2.2.2. Relación con la dirección, estructura y cultura organizativa y poder

1.2.3. FASES DE UN PROGRAMA DE RELACIONES PÚBLICAS EN LOS

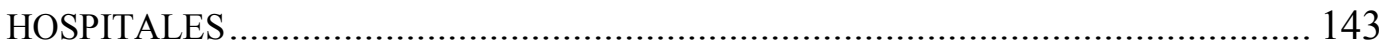

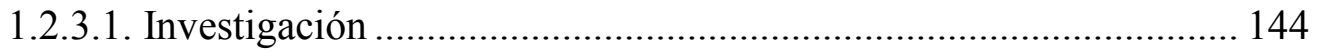

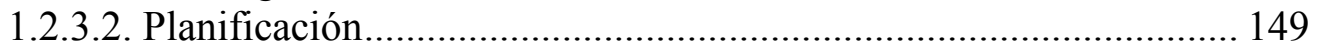

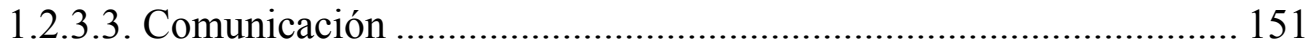

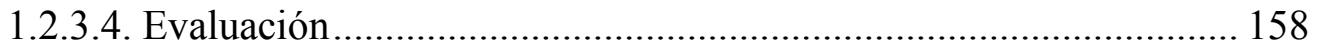

\subsection{FUNCIONAMIENTO Y SITUACIÓN DEL SISTEMA SANITARIO ESPAÑOL}

1.3.1. LEGISLACIÓN EN TORNO A LA SANIDAD .............................................. 163

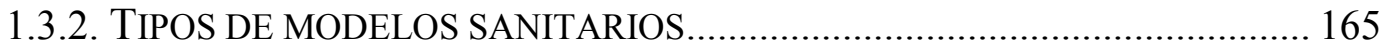

1.3.2.1. El modelo de seguro social obligatorio (SSO) ............................. 165

1.3.2.2. El modelo de SNS: hacia una sanidad universal ............................ 166

1.3.2.3. Año 2012: vuelta a la condición de asegurado.............................. 169

1.3.3. ORGANIZACIÓN DEL SISTEMA NACIONAL DE SALUD.......................... 171

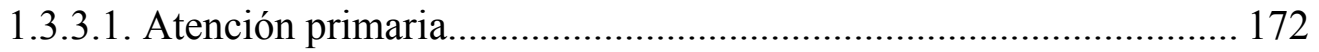

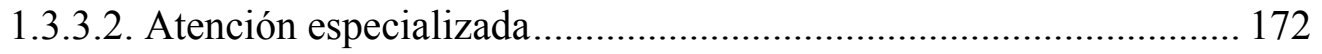

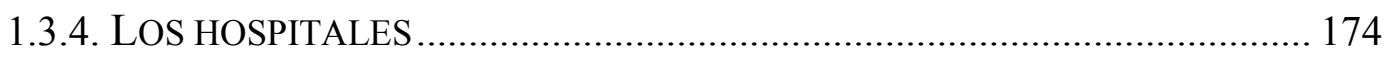

1.3.4.1. Evolución de los hospitales en España y situación actual............... 175 
1.4. COMPARATIVA DEL SISTEMA SANITARIO EN CASTILLA Y LEÓN Y GALICIA

1.4.1. SIMILITUDES Y DIFERENCIAS SOCIALES, DEMOGRÁFICAS Y ECONÓMICAS ENTRE CASTILLA Y LEÓN Y GALICIA........................................ 187

1.4.2. EQUIPAMIENTO SANITARIO EN CASTILLA Y LEÓN Y EN GALICIA ..... 191

CAPÍTULO DOS: MARCO EXPERIMENTAL

2.1. METODOLOGÍA

2.1.1. ANÁLISIS CUALITATIVO: ENTREVISTAS A LOS RESPONSABLES DE COMUNICACIÓN DE LOS HOSPITALES 198

2.1.2. ANÁLISIS CUANTITATIVO: ENCUESTAS A LOS RESPONSABLES DE COMUNICACIÓN DE LOS HOSPITALES 204

2.1.3. ANÁLISIS DE PRENSA: MEDICIÓN DE LA EXPOSICIÓN 214

2.1.4. MEDICIÓN DE LA OPINIÓN Y ACTITUD DEL PÚBLICO 217

2.2. RESULTADOS 219

2.2.1. CARACTERÍSTICAS DE LA ESTRUCTURA SANITARIA Y DE LOS

DEPARTAMENTOS DE COMUNICACIÓN DE LOS HOSPITALES 219

2.2.1.1. Estructura sanitaria en Galicia 219

2.2.1.2. Estructura de comunicación en Galicia. 225

2.2.1.3. Estructura sanitaria en Castilla y León. 229

2.2.1.4. Estructura de comunicación en Castilla y León 233

2.2.2. FUNCIONES Y TAREAS DE LOS DEPARTAMENTOS DE COMUNICACIÓN DE LOS HOSPITALES. RESULTADOS DE LAS ENTREVISTAS PERSONALES. 237

2.2.2.1. Resultados de las entrevistas a los responsables de comunicación de los hospitales de Galicia.. 237

2.2.2.2. Resultados de las entrevistas a los responsables de comunicación de

Castilla y León 300

2.2.3. USO DE LAS RELACIONES PÚBLICAS EN LOS DEPARTAMENTOS DE COMUNICACIÓN DE LOS HOSPITALES. RESULTADOS DE LA ENCUESTA....... 319

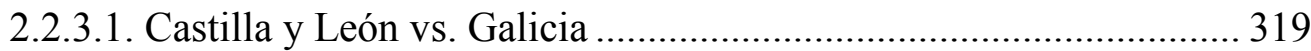

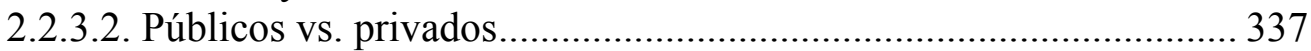

2.2.3.3. Trabajador en plantilla vs. empresa externa.................................. 354

2.2.4. IMAGEN PROYECTADA EN LOS MEDIOS DE COMUNICACIÓN.

RESULTADOS DEL ANÁLISIS DE PRENSA ..................................................... 373

2.2.4.1. Número de noticias según los periódicos.................................... 373

2.2.4.2. Sección en la que aparece la información ..................................... 376 


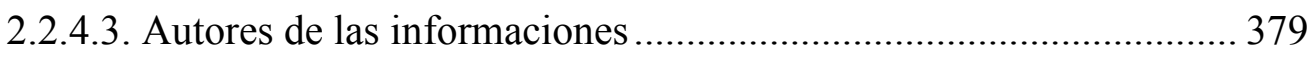

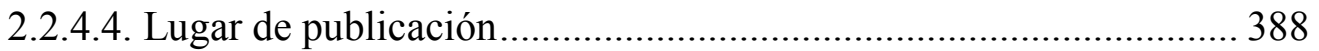

2.2.4.5. Género de las informaciones ........................................................... 392

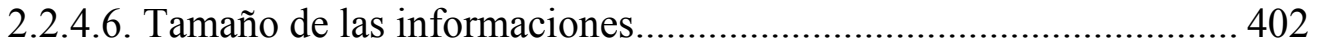

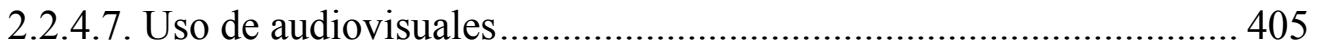

2.2.4.8. Tema de las noticias ....................................................................... 408

2.2.4.9. Neutralidad de las noticias ............................................................ 410

2.2.4.10. Organizaciones informadoras................................................... 414

2.2.4.11. Contraste, archivo y segundas fuentes de las informaciones ........ 426

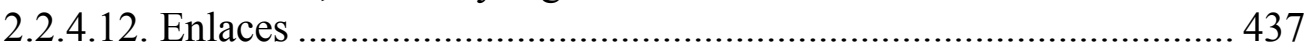

2.2.4.13. Interacción del lector.............................................................. 442

2.2.5. VALORACIÓN Y SATISFACCIÓN DE LOS CIUDADANOS ACERCA DEL

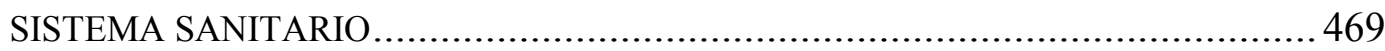

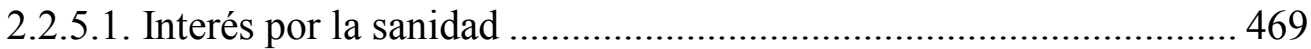

2.2.5.2. Valoración del funcionamiento del sistema sanitario .................... 470

2.2.5.3. Satisfacción con el sistema sanitario .......................................... 472

2.2.5.4. La elección de un centro sanitario en base a su titularidad ............. 480

2.2.5.4.1. Motivos para la elección de una determinada titularidad ... 487

CAPÍTULO TRES: CONCLUSIONES

495

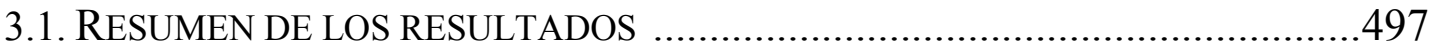

3.2. VERIFICACIÓN DE LAS HIPÓTESIS ......................................................511

3.3. CONCLUSIONES FINALES........................................ 515

CAPÍTULO CUATRO: BIBLIOGRAFÍA

CAPÍTULO CINCO: ANEXOS

5.1. CARACTERÍSTICAS ACTUALES Y EVOLUCIÓN DE LOS HOSPITALES EN

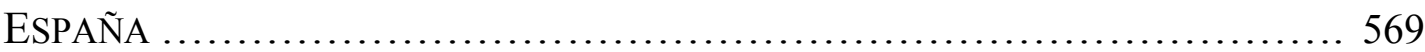

5.2. CARACTERÍSTICAS ACTUALES Y EVOLUCIÓN DE LOS HOSPITALES EN CASTILLA Y LEÓN Y GALICIA........................................6613

5.3. CiTAS LITERALES EN SU IDIOMA ORIGINAL..........................6639

CAPÍTULO SEIS: ÍNDICES DE ELEMENTOS GRÁFICOS

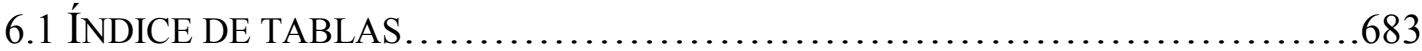

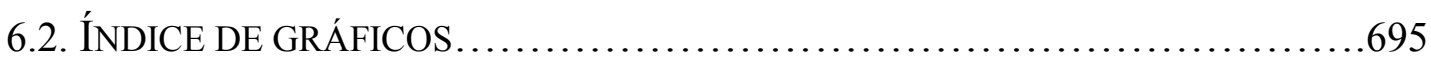

6.3. ÍNDICE DE ILUSTRACIONES...........................................697 


\section{PRESENTACIÓN}

Introducción

Hipótesis

Objetivos

Metodología general 


\section{INTRODUCCIÓN}

La salud y la sanidad son temas cada vez más trascendentes para los ciudadanos, tal y como muestran diversos estudios de opinión. Respecto al pasado, los pacientes se informan más acerca de sus necesidades y ya no se someten únicamente a las instrucciones de su médico; ahora juegan un papel más activo en las decisiones relacionadas con su salud. Esto es debido, principalmente, al aumento de documentos sobre esta temática, así como de fuentes de información. Así, las noticias aparecidas en los medios de comunicación se han multiplicado en los últimos años. Sin embargo, estos no son la única fuente para informarse sobre asuntos sanitarios. En la actualidad, las personas aprenden sobre medicina y salud a través de familiares y amigos, series de televisión, publicidad, folletos, páginas web, foros, blogs, redes sociales, etc.

En consecuencia, la comunicación en el ámbito sanitario es cada vez más necesaria. El público de los centros dedicados a la salud ya no es simplemente el paciente, sino que otros grupos, como los empleados, los familiares y visitas, la comunidad, las agrupaciones, etc., también son relevantes. Esto cobra especial importancia en el caso de los hospitales, dada su gran capacidad tecnológica y humana, desde donde puede proporcionarse abundante información tanto de actividad hospitalaria como de divulgación sanitaria. Los departamentos de comunicación de estos centros constituyen un nexo entre la organización y sus diferentes públicos. Entre sus labores se encuentra conocer y cubrir las necesidades de los ciudadanos, transmitir información fiable, servir de enlace entre los periodistas y la comunidad científica, completar o corregir informaciones erróneas, etc.

La comunicación, no obstante, no debe dejarse a la improvisación, sino que tiene que gestionarse estratégicamente. Esto implica elaborar un método para construir relaciones con los públicos estratégicos. De esta manera, el departamento se comunica con estos públicos para hacer llegar sus voces a la dirección estratégica, haciendo posible que los públicos interesados participen en las decisiones de la organización que les afectan. Para ello, es conveniente, entre otras cosas, que los publirrelacionistas mantengan un papel directivo, estén presentes en la dirección de la entidad, obtengan retroalimentación del público y evalúen los resultados conseguidos.

Así, esta tesis doctoral se enmarca dentro de la visión de las relaciones públicas, que servirá como marco teórico para conseguir una comunicación excelente. Cuando esto sucede, esta práctica contribuye a la efectividad de la organización, dado que ayuda a gestionar las relaciones con los grupos de su entorno. De esta manera, este trabajo se centra en las esferas de la comunicación excelente propuestas por los miembros del Excellence Study - un proyecto subvencionado por la fundación de la International Association of Business Communicators (IABC) y que se considera el proyecto de investigación más amplio de este ámbito-, que incluyen los conocimientos de los comunicadores, las expectativas comunes entre estos y los directivos de la organización 
y la cultura participativa de la entidad. Asimismo, se utilizan las etapas propuestas por James E. Grunig y otros como guía a la hora de abordar un programa de relaciones públicas.

\section{HIPÓTESIS}

La presente tesis doctoral pretende dar respuesta a una serie de hipótesis de partida que giran en torno a la presencia y características de los departamentos de comunicación en los hospitales y en las consecuencias que estos tienen tanto en la información publicada en prensa como en las percepciones de los ciudadanos acerca de los temas médicos. Tanto a nivel general como enfrentando las dos comunidades analizadas, este estudio se estructura según las siguientes hipótesis:

H1. Debido a la competencia comunicativa, cuando una gran parte de los hospitales de una región posee departamentos de comunicación, las relaciones públicas que se adoptan deberían ser más excelentes.

Dado que en Galicia existen más hospitales con gabinetes de comunicación que en Castilla y León, las relaciones públicas que se realizan deberían ser más efectivas, en el sentido de que sus trabajadores gestionan la comunicación de forma estratégica, se comunican con varios públicos, utilizan modelos bidireccionales, planifican las labores de comunicación, emprenden acciones novedosas, utilizan nuevas tecnologías, otorgan una gran importancia a todas las fases de un programa de relaciones públicas, están prevenidos ante posibles crisis mediante planes de acción, etc.

H2. La presencia de departamentos de comunicación en los hospitales debe tener una repercusión en el número y calidad de las informaciones sobre salud y sanidad que publican los medios de comunicación de la región.

Debido a que los departamentos de comunicación de los hospitales pueden influir en que los periodistas publiquen un mayor número de historias sobre sus centros, en Galicia, que cuenta con más unidades de este tipo, se deberían publicar más noticias y con una mayor calidad sobre salud y sanidad que en Castilla y León, que cuenta con menos gabinetes de este tipo.

H3. Los ciudadanos de las zonas que cuentan con departamentos de comunicación en la mayor parte de los hospitales han de ser más activos en el consumo de información sanitaria y salud, en el sentido de que comentan más frecuentemente estos temas, los valoran y los comparten con sus conocidos.

El análisis de las noticias sobre salud y sanidad en Galicia y en Castilla y León permitirá saber dónde tienen los ciudadanos más posibilidades de estar informados 
sobre estos temas. También será posible conocer en qué región se opina más sobre las noticias, dónde se añade su valoración personal y si se comparte en las redes sociales.

H4. Los ciudadanos de las zonas en las que existen departamentos de comunicación deberían tener una mejor valoración y un grado de satisfacción más alto hacia el sistema sanitario.

Debido a una mayor actividad informativa por el número de departamentos de comunicación, los ciudadanos con mayor información deberían tener un mayor interés por los temas sanitarios y otorgar una mejor valoración a los servicios que ofrece este sistema.

También se quiere estudiar las diferencias que existen entre gestionar la comunicación desde el ámbito público al privado y desde una empresa externa o interna. Por ello, también se establecen las siguientes hipótesis:

H5. Los departamentos de comunicación de los hospitales públicos y de los privados pueden tener diferencias en cuanto a su interés por la opinión pública, en el uso de métodos más o menos tradicionales y en las nuevas acciones de comunicación.

Como hipótesis, los hospitales públicos, al depender de las administraciones que gobiernan en cada momento las comunidades autónomas, están más centrados en transmitir información a la población para alcanzar sus fines electorales. Por ello, en principio recurren a los medios de comunicación como vehículo principal para emitir información y emplean los modelos unidireccionales de relaciones públicas. Los centros privados no comparten este objetivo y necesitan clientes para mantener sus prestaciones, por lo que utilizarán métodos diferentes.

H6. Los hospitales gestionados por empresas externas de comunicación ejercerían unas relaciones públicas más excelentes que aquellos que cuentan con uno o dos empleados en plantilla debido a la diversidad de personal.

La diversidad del personal contratado en las empresas externas y, por ende, de perfiles profesionales permitiría un mayor abanico de propuestas que repercutiría en la excelencia de la comunicación.

\section{OBJETIVOS}

Los objetivos de este trabajo están íntimamente ligados a dar respuesta a las hipótesis propuestas. A través de ellas, se pretende hallar el grado de excelencia de las relaciones públicas en el ámbito hospitalario en España, más concretamente en las comunidades autónomas de Castilla y León y Galicia. Asimismo, se procura determinar 
si un número elevado de departamentos de comunicación en un mismo territorio influye en la calidad de las relaciones públicas. También se estudian las diferencias entre gestionar la información desde el ámbito público al privado y desde un gabinete interno a una empresa externa.

Por otra parte, también se quiere comprobar si la presencia de departamentos de comunicación en los centros de atención especializada tiene alguna repercusión en la cantidad y calidad de las informaciones aparecidas en prensa. Por otra parte, se estudia si hay una relación entre una mayor presencia de servicios de información en los hospitales con una mayor participación de los ciudadanos en las noticias que aparecen en internet.

Finalmente, se quiere detectar si una mayor actividad comunicativa mantiene una correlación con la valoración y satisfacción que tiene la población sobre el sistema sanitario. Así, las preguntas de investigación a las que se pretende dar respuesta en esta tesis doctoral son las siguientes:

1. ¿Cómo se gestiona la comunicación desde los centros de atención especializada?

2. ¿Existe alguna diferencia entre las regiones que poseen múltiples departamentos de comunicación frente a los que cuentan con unos pocos?

3. ¿Se dan discrepancias entre el ámbito público y el privado?

4. ¿Qué diferencias existen entre gestionar la comunicación de un hospital de manera interna o externa?

5. ¿Ejercen estos departamentos alguna influencia en las informaciones que publican los periodistas sobre sanidad y salud?

6. ¿Hay una correlación entre la presencia de departamentos de comunicación en los hospitales y la participación de los ciudadanos en las informaciones sobre salud?

7. ¿Se detecta una relación entre la existencia de departamentos de comunicación en los hospitales y la valoración y satisfacción del público hacia el sistema sanitario?

\section{METODOLOGÍA GENERAL}

El desarrollo de la presente tesis doctoral puede dividirse en dos apartados claramente diferenciados: la parte teórica y la parte empírica. Para la primera sección, se han consultado diferentes manuales, artículos en revistas científicas, actas de congresos, tesis doctorales, leyes e informes. Las citas en su idioma original, en el caso de que no sea en español, se incluyen en el anexo número tres. Gracias a esta revisión bibliográfica, se pretende mostrar la teoría y práctica de las relaciones públicas, tanto en el ámbito general como en el sanitario. Asimismo, se analiza el funcionamiento y 
situación del sistema sanitario español y se comparan las comunidades objeto de estudio: Castilla y León y Galicia.

En la parte empírica se ha optado por utilizar varias metodologías propias de las ciencias sociales. Así, se ha procedido a realizar entrevistas presenciales a los responsables de comunicación de los centros hospitalarios de los territorios de análisis para obtener valoraciones cualitativas sobre su trabajo. A estos empleados también se les ha entregado una encuesta sobre diferentes aspectos de relaciones públicas con el fin de conseguir datos cuantitativos y estadísticamente comparables. Por otra parte, se ha realizado un análisis de prensa para detectar si existen diferencias en el número y calidad de las noticias sobre salud que aparecen en los periódicos de internet según el número de servicios de comunicación de las comunidades autónomas. Vinculado con esta parte se encuentra el análisis de la participación de los ciudadanos de cada territorio en las noticias examinadas, canalizándolo a través de las valoraciones, los comentarios y los enlaces a redes sociales. Finalmente, se hace uso de diferentes informes para hallar la valoración y satisfacción de los ciudadanos de cada región con el sistema sanitario y comprobar si existen diferencias remarcables.

De esta manera, la parte empírica de la tesis doctoral conjuga tanto el paradigma cualitativo como el cuantitativo. El primer enfoque persigue crear tendencias generalizables y sus datos son susceptibles de tratamiento estadístico (Lozano Rendón, 2007: 10). Por el contrario, el segundo ayuda a contextualizar y encuadrar hipótesis, algo que no se puede realizar desde un punto de vista exclusivamente cuantitativo (Wimmer y Dominick, 1996: 148).

Con la unión de ambas metodologías se logra el fenómeno de la triangulación, un método que se está convirtiendo en un esquema común de las empresas y las universidades (Casetti y Di Chio, 1999: 333), ya que compensa las debilidades de un método con otro distinto y así se consiguen los resultados "más fiables y enteramente satisfactorios" (Elías, 2000: 38). Se trata de la fase más avanzada de la integración de varias metodologías (complementación, combinación y triangulación), puesto que convergen los resultados de todas las metodologías para que alcancen las mismas conclusiones (Rodríguez Breijo, 2009). Se produce una triangulación metodológica cuando se emplean al menos dos técnicas de investigación (pueden ser cualitativa y cualitativa) o dos metodologías distintas con el objetivo de conocer y analizar un mismo objeto.

La tesis doctoral se divide en varias fases claramente diferenciadas y que, en general, coinciden tanto en el tiempo de realización como en la organización del presente documento. A continuación se resumen las etapas del estudio y la distribución del trabajo expuesto. 


\section{Fase teórica}

Búsqueda de información bibliográfica sobre relaciones públicas. La primera etapa de la investigación se ha basado en la indagación de material bibliográfico sobre relaciones públicas. En un primer momento, se han consultado los manuales de los autores más relevantes de esta disciplina, tanto a nivel nacional como internacional. En un segundo lugar, se ha procedido a consultar las investigaciones académicas realizadas hasta la actualidad sobre estos asuntos, ya fuese en revistas científicas, actas de congresos, tesis doctorales, etc. Todas estas referencias han sido leídas, analizadas e introducidas en una base de datos atendiendo a autores, temáticas, conceptos clave, definiciones, etc.

Búsqueda del estado de la cuestión sobre relaciones públicas en el ámbito sanitario. En una segunda fase, se ha acudido a revistas científicas, tanto nacionales como internacionales, a bases de datos de tesis doctorales y a actas de congresos para conocer las investigaciones realizadas hasta el momento acerca de las relaciones públicas en el terreno sanitario. Toda esta información también se han introducido en una base de datos para conseguir un mejor manejo según los autores, los temas, la metodología, etc.

Búsqueda de información sobre el sistema sanitario español. En un tercer momento, se ha procedido a consultar la legislación actual y anterior para conocer el funcionamiento y regulación del sistema sanitario en España. Para ello, se han examinado las diferentes leyes que regulan las características de las prestaciones, así como los informes que detallan la evolución y situación actual de la atención especializada, como la Estadística de centros sanitarios de atención especializada y la Estadística de establecimientos sanitarios con régimen de internado. Aquí se expone el número de hospitales, la dependencia funcional, la finalidad asistencial, la distribución geográfica... Asimismo, se han señalado otras variables que caracterizan este ámbito, como el montante de camas instaladas y en funcionamiento, la cifra de quirófanos o las características de las altas, entre otras cosas.

Análisis de las diferencias y similitudes entre Castilla y León y Galicia. En esta fase, se comparan demográficamente, poblacionalmente y económicamente las comunidades objeto de estudio. Asimismo, se hace un repaso de las características del sistema sanitario de cada zona y se detallan las prestaciones que tiene cada una, como el número de hospitales, la cantidad de camas, la cifra de quirófanos, etc. 


\section{Fase empírica}

Entrevistas a los responsables de comunicación de los hospitales de Castilla y León y Galicia. Una vez definido el marco teórico, y con el fin de conocer el funcionamiento y características de los departamentos de comunicación de los centros de atención especializada, se han mantenido unas entrevistas presenciales con los responsables de estos servicios. En total, se han realizado 19, de las cuales 15 se efectuaron en Galicia y cuatro en Castilla y León. Gracias a estos encuentros, se han obtenido datos cualitativos del día a día de los entrevistados, sus principales públicos, las herramientas que utilizan, las presiones que sufren, las mejoras que implantarían...

Encuestas a los responsables de comunicación de los hospitales de Castilla y León y Galicia. Dado que las entrevistas personales proporcionan valoraciones únicamente cualitativas, se ha diseñado un cuestionario con preguntas referentes a las relaciones públicas y se les ha entregado a los responsables de comunicación de los hospitales para que lo cumplimentasen. De esta manera, se obtienen datos cuantitativos y analizables estadísticamente acerca de aspectos como los modelos y roles adoptados, la gestión estratégica, la planificación, los principales públicos, las herramientas de comunicación, los planes de crisis, etc.

Análisis de prensa sobre las informaciones sobre sanidad y salud. Con el fin de comprobar la hipótesis número dos (la presencia de departamentos de comunicación en los hospitales debe tener una repercusión en el número y calidad de las informaciones sobre salud y sanidad que publican los medios de comunicación de la región), se ha realizado un estudio de las noticias sobre sanidad y salud que aparecen en los periódicos locales, provinciales y regionales de cada comunidad. Mediante un muestreo de las apariciones del año 2012, se ha anotado el número de textos compuestos en cada zona, así como las características de estos, tales como la extensión, la autoría, el acompañamiento de material multimedia, las fuentes consultadas, la neutralidad, etc. Todos estos aspectos se han confrontado según la comunidad en la que se ha publicado para comprobar si existen diferencias significativas.

Investigación de la participación de los ciudadanos en las noticias aparecidas en prensa. Dado que una de las hipótesis de este estudio sostiene que en las zonas donde existen más gabinetes de comunicación y, en consecuencia, más novedades sobre sanidad en prensa, los ciudadanos deberían ser más activos en el consumo de información, se analiza su grado de participación en las noticias de internet. Para ello, se contrastan los comentarios, las valoraciones y los enlaces a varias redes sociales por parte de los habitantes de las dos comunidades objeto de estudio. 
Estudio de la valoración y satisfacción de los ciudadanos sobre la sanidad. En este apartado se comprueba la opinión y comportamiento del público hacia los temas sanitarios. De esta manera, se determina si los habitantes de alguna de las zonas estudiadas poseen una mayor estimación de las prestaciones y servicios que reciben y los motivos de selección de unos hospitales a otros.

Valoración general y conclusiones. Después de finalizar la parte teórica y la empírica, se enuncian una serie de conclusiones que resumen los principales resultados y contribuciones de la tesis doctoral al ámbito de las relaciones públicas y la comunicación sanitaria. 


\section{MARCO TEÓRICO}

1.1. Aproximación teórica a las relaciones públicas

1.2. Uso de las relaciones públicas en el ámbito sanitario. Estado de la cuestión

1.3. Funcionamiento y situación del sistema sanitario español

1.4. Comparativa del sistema sanitario en Castilla y León y Galicia 


\title{
1.1. APROXIMACIÓN TEÓRICA A LAS RELACIONES PÚBLICAS
}

\author{
1.1.1. Definición y diferenciación con otras disciplinas \\ 1.1.2. Principios de dirección de las relaciones públicas. Esferas de la \\ comunicación excelente \\ 1.1.3. Aplicación de la gestión estratégica. Fases de un programa de \\ relaciones públicas.
}

\subsubsection{DEFINICIÓN Y DIFERENCIACIÓN CON OTRAS DISCIPLINAS}

\subsubsection{DEFINICIONES DE RELACIONES PÚBLICAS}

Definir las relaciones públicas "no es tarea pacífica" (Xifra Triadú, 2006). En ocasiones, "se confunden y se usan como un sinónimo práctico de algunas de sus partes funcionales, como la publicity, el agente de prensa, la propaganda y la publicidad institucional" (Cutlip y Center, 1964: 3). Tampoco ayuda que en determinadas zonas, como en Europa y también en España, a pesar de ser ampliamente practicadas, rara vez se las identifique con su propio término (Huertas y Cavia, 2006; van Ruler y Verčič, 2004: 1), lo que puede contribuir a que una persona media rara vez entienda en qué consisten (J. E. Grunig y Hunt, 1984: 4). Según Alfredo Arceo (2012b: 29), al menos en España, esto se debe a que hay una "excesiva carga de la parte comunicativa" y a una "falta del conocimiento exacto de la dimensión gerencial de la materia".

La confusión se incrementa con la vinculación del concepto de relaciones públicas a otras prácticas que poco tienen que ver con esta disciplina. Tal y como James E. Grunig se quejaba en una entrevista publicada en La Vanguardia (Amiguet, 2007), "la comunicación de verdad es la que decide al más alto nivel, lo demás son maquillajes, 
parches y tonterías. Y yo me niego a participar en ellos", y llega al punto de afirmar que "como ha habido demasiado incompetente y hasta corrupto dispuesto a hacerlo, es por lo que ahora no puedo llamar a mi trabajo relaciones públicas; se le llama comunicación o cualquier otro eufemismo".

De hecho, tal y como señala Fernández Muñoz (2012: 15), la misma patronal de relaciones públicas en España evita este concepto y prefiere definirse bajo el título Asociación de Empresas Consultoras en Comunicación (ADECEC), al igual que sucede con la asociación Dircom (acrónimo de Directivos de Comunicación), que integra a unos 350 profesionales de empresas, instituciones y agencias de relaciones públicas de España. De acuerdo con Fernández Muñoz (2012: 15), estas dos agrupaciones sostienen que "muchas consultoras en España consideran que el término está desprestigiado". Aun así, al menos la ADECEC, "se refiere a sí misma públicamente en muchas ocasiones como Asociación de Empresas Consultoras en Relaciones Públicas y Comunicación, aunque las RRPP no aparezcan, como decimos, en sus siglas oficiales" (Fernández Muñoz, 2012: 15).

Las diferentes características en cuanto a tareas, estatus y salarios entre unos profesionales y otros, por otra parte, hacen que, en apariencia, sea "casi imposible" llegar a una sola definición ${ }^{2}$ (J. E. Grunig y Hunt, 1984: 6). Siendo realistas, puede delimitarse poco más como "lo que hacen los publirrelacionistas"3 (J. E. Grunig, 1992b: 32). En palabras de estos últimos (J. E. Grunig y Hunt, 1984: 6):

"Las relaciones públicas pueden ser practicadas por un vicepresidente de una gran compañía que gana 200.000 dólares anuales, que encabeza un departamento de 100 o más profesionales. Pueden ser practicadas por un trabajador a media jornada o un voluntario que produce un panfleto o una nota de prensa para una organización benéfica de una ciudad pequeña. Un profesional de las relaciones públicas puede dedicar todo su tiempo escribiendo notas de prensa, noticias para la publicación de los empleados, anuncios de servicio público o panfletos informativos. Otro profesional puede que casi nunca escriba y dedique su tiempo a dirigir a otros profesionales, reunirse con la dirección o tratar con los medios de comunicación"4.

Una muestra de la multitud de concepciones que existen sobre esta especialidad la proporciona un estudio del pionero en relaciones públicas Rex Harlow (1976). En parte gracias a una beca económica de la Foundation for Public Relations Research and Education, analizó 472 opciones de otros autores existentes en esa época, llegando a su versión final, la cual sigue siendo en la actualidad una de las más citadas: 
"Las relaciones públicas son una función directiva independiente que ayuda a establecer y mantener líneas de comunicación, comprensión, aceptación y cooperación mutuas entre una organización y sus públicos; implica la gestión de problemas y conflictos; ayuda a los directivos a estar informados y a ser receptivos ante la opinión pública; define y enfatiza la responsabilidad de la dirección para servir al interés público; ayuda a la dirección a mantenerse al día y a utilizar los cambios de manera eficaz, sirviendo como un sistema de alerta temprana para ayudar a anticipar posibles tendencias y utiliza la investigación y las técnicas éticas de comunicación como principales herramientas"

Y es que a pesar del asentamiento de las relaciones públicas en el mundo tanto académico como profesional, en la actualidad aún no existe un acuerdo común sobre su concepto. Por ello, la Public Relations Society of America (Corbett, 2012) decidió llevar a votación popular el problema y conseguir así una opción renovada, ante las críticas a su versión anterior [ver, por ejemplo, J. E. Grunig (1992b: 458-459)]. Tras 1.447 votos recibidos, la institución anunció en marzo de 2012 la versión ganadora:

"Las relaciones públicas son un proceso estratégico de comunicación que construye relaciones mutuamente beneficiosas entre las organizaciones y sus públicos"6.

Incluso teniendo versiones más modernas, como esta última de la Public Relations Society of America, los estudiosos siguen utilizando las ideadas décadas atrás por los grandes eruditos de la materia. Así, una definición que goza de un gran respaldo por parte de los académicos es la de Cutlip, Center y Broom (2000), que conciben las relaciones públicas como "la función directiva que entabla y mantiene relaciones mutuamente beneficiosas entre una organización y los públicos de los que depende su éxito o fracaso" ${ }^{7}$, que actualiza la que propusieron en las cinco primeras ediciones del mismo libro (J. E. Grunig, 1992b: 622), y que sostenía que las relaciones públicas son "el esfuerzo planeado para influir en la opinión a través de actuaciones aceptables y de comunicación bidireccional"8 (Cutlip y Center, 1964: 3).

Sin embargo, quizás la más citada la proporcionan J. E. Grunig y Hunt (1984: 6), que, de manera más escueta, perciben esta disciplina como "la gestión de la comunicación entre una organización y sus públicos"9. De esta forma, mantienen los autores, todas las actividades que, según otras definiciones, realizan los profesionales de las relaciones públicas se engloban dentro de la propia comunicación, se eliminan las condiciones en los efectos conseguidos y la responsabilidad de las prácticas (J. E. Grunig y Hunt, 1984: 8). Los miembros del Excellence Study, por ejemplo, han 
adoptado esta versión (J. E. Grunig, 1992b: 4; L. A. Grunig, J. E. Grunig y Dozier, 2002: 2). Se trata de un proyecto subvencionado por la fundación de la International Association of Business Communicators (IABC) en 1985 por un importe de 400.000 dólares y que se considera el proyecto de investigación más amplio de las relaciones públicas (J. E. Grunig, 1992b: xiii).

Hay, no obstante, muchas más definiciones sobre esta especialidad, tanto de organismos internacionales como académicos. A continuación, se muestran algunas de las más relevantes:

- "Las relaciones públicas son la función directiva que evalúa las actitudes del público, identifica las políticas y procedimientos de un individuo o de una organización con el interés público, y planifica y ejecuta un programa de acción para lograr la comprensión y aceptación del público"10. Editorial de la revista PR News (Cutlip y Center, 1964: 4; J. E. Grunig y Hunt, 1984: 8).

- "El esfuerzo deliberado, planeado y prolongado para establecer y mantener un entendimiento mutuo entre una organización y sus públicos" $"$. British Institute of Public Relations, citado en J. E. Grunig y Hunt (1984: 7).

- "Las relaciones públicas tratan sobre reputación. Es el resultado de lo que haces, lo que dices y lo que otros dicen sobre ti. Las relaciones públicas es la disciplina que se preocupa de la reputación con el objetivo de conseguir entendimiento y soporte e influir en las opiniones y los comportamientos. Es el esfuerzo planificado y prolongado para establecer y mantener la buena voluntad y el entendimiento mutuo entre una organización y sus públicos"12. Chartered Institute of Public Relations (n.d.).

- "Relaciones Públicas es una disciplina socio-técnico-administrativa mediante la cual se analiza y evalúa la opinión y actitud del público, y se lleva a cabo un programa de acción planificado, continuo y de comunicación recíproca, basado en el interés de la comunidad, destinado a mantener una afinidad y comprensión provechosa con el público". Federación Interamericana de Relaciones Públicas (1963), citado en Wilcox, Cameron y Xifra (2007: 9).

- "Las relaciones públicas son la disciplina científica que estudia la gestión del sistema de comunicación a través del cual se establecen y mantienen relaciones de adaptación e integración mutua entre una organización o persona y sus públicos”. Foro Interuniversitario de Investigadores en Relaciones Públicas de España, citado en Wilcox, Cameron y Xifra (2007: 8-9). 
- "El esfuerzo deliberado, planeado y prolongado por establecer y mantener un entendimiento mutuo entre una organización (o individuo) y su (o sus) públicos"13. Public Relations Institute of Australia (2013).

- "Las relaciones públicas constan de todas las formas de comunicación planificada, hacia fuera y hacia dentro, entre una organización y sus públicos, con el propósito de conseguir objetivos específicos en lo que se refiere a la comprensión mutua". Jefkins (1985: 18).

- "Las relaciones públicas son una función gerencial cuya meta final es crear, mantener o modificar la relación de una persona natural o jurídica con sus públicos para que ambos se comporten de manera complementaria en el tiempo. Desde la responsabilidad social, la persona natural o jurídica conseguirá más fácilmente y de manera más estable el entendimiento con sus públicos, y así la posible serie de comunicaciones persuasivas, usualmente con apariencia informativa, y de otras posibles acciones no comunicacionales que se utilizan, tendrán mayor eficacia". Alfredo Arceo (2004a, 2009).

- “Las relaciones públicas son la disciplina científica que estudia la gestión del sistema de comunicación a través del cual se establecen y mantienen relaciones de adaptación e integración mutua entre una estructura social o persona y sus públicos". Xifra (2006).

- “Actividad profesionalizada mucho más seria y rigurosa encaminada a prestigiar la imagen de una empresa, una marca, un producto, una entidad cualquiera o una persona física así como a favorecer la creación de climas de cordialidad necesarios para un trabajo en común y buenas relaciones entre personas diversas que, de alguna manera, están llamadas, de cualquier forma, a relacionarse y comunicarse". Fernández Souto (2006).

\subsubsection{DIFERENCIAS ENTRE RELACIONES PÚBLICAS Y OTRAS DISCIPLINAS}

Como se ha podido comprobar, las relaciones públicas suelen confundirse con otras especialidades relacionadas con la comunicación, en especial con la publicidad, la propaganda y el marketing. Todas ellas, no obstante, sirven a diferentes objetivos, a pesar de que algunas herramientas o canales puedan coincidir, que es el motivo principal de las confusiones. 


\subsection{DIFERENCIAS ENTRE RELACIONES PÚBLICAS Y PUBLICIDAD}

Una de las especialidades con la que más se suele vincular las relaciones públicas es la publicidad. Y es que, normalmente, ambas se complementan: "La publicidad acostumbra a utilizarse como una herramienta de comunicación al servicio de las relaciones públicas y que, a su vez, la actividad del publirrelacionista suele respaldar las campañas publicitarias, lo que nos lleva a la conclusión de que ambas actividades resultan complementarias" (Fernández Souto, 2006). En España, de hecho, no existe una carrera universitaria propia de relaciones públicas, sino que los grados actuales y las licenciaturas del pasado correspondían a estudios conjuntos de Publicidad y Relaciones Públicas. Lejos de beneficiar a las relaciones públicas, esta unión ha sido "muy perjudicial", especialmente para la investigación de posgrado (Castillo Esparcia y Xifra Triadú, 2006), debido a que son acciones diferenciadas que persiguen objetivos distintos y tienen diferentes ámbitos de acción. La publicidad es "el pago directo de la presentación de un bien, servicio o producto"14 (Berkowitz, 2007) "con el fin de promover de forma directa o indirecta la contratación” (Fernández Souto, 2006). Tiene, por tanto, una finalidad eminentemente comercial (Fernández Souto, 2006). Las relaciones públicas, por su parte, son "la ciencia que se ocupa de los procesos de comunicación a través de los cuales se establecen y gestionan relaciones de adaptación mutua entre una persona públicamente relevante o una organización y los públicos de su entorno" (Xifra Triadú, 2003).

Así, mientras que la primera disciplina se centra en la imagen del producto, la segunda se esfuerza en conseguir confianza, prestigio o popularidad corporativa (Kreps, 2008). Según destaca Alfredo Arceo (2012b: 32), los profesionales de las relaciones públicas "dirigen, planifican y ejecutan la comunicación para la organización como un todo. Gestionan el discurrir de los mensajes dentro de la organización, por ejemplo, cuando realizan investigaciones sobre el conocimiento, actitudes y comportamientos de los públicos y luego utilizan esa información para aconsejar a los directivos sobre políticas o actuaciones de la organización".

Al contrario de lo que algunas personas creen, las relaciones públicas no constituyen una forma de publicidad, no son ninguna clase de "publicidad gratuita" o de “publicidad no pagada". Según Jefkins (1985: 20), "no hay nada «gratuito» en las RP: consume tiempo, y el tiempo cuesta dinero. Este dinero puede estar representado por sueldos del personal o por honorarios de asesores".

Además, mientras que la publicidad "está limitada a la venta y compra de artículos de promoción, compra de suministros o selección de personal”, las relaciones públicas son una actividad "mucho más amplia que ésta" (Jefkins, 1985: 20): abarcan "a todos y a todo", dado que tienen que ver con "las comunicaciones totales de una organización" (Jefkins, 1985: 20-21). En consecuencia, estas últimas son una actividad "más extensa y global” (Jefkins, 1985: 21). Y es que una organización puede o no echar mano de los 
anuncios de pago, "pero siempre tendrá que hacer uso de las relaciones públicas" (Jefkins, 1985: 20). Por ello, todas las empresas, de un modo u otro, hacen uso de esta especialidad en su trato con los diferentes públicos (Wilcox, 2006). Esta idea es tan importante que "hasta que no se comprenda esto, no se tendrá una idea clara de la imagen de las RP” (Jefkins, 1985: 20).

La forma de financiar acciones de ambas especialidades también difiere sustancialmente. Tal y como explica Jefkins (1985: 21), las agencias de publicidad reciben sus ingresos, normalmente, por el sistema de comisión sobre el espacio o tiempo que compran. El asesoramiento en relaciones públicas, no obstante, únicamente se puede vender por "horas-hombre" y experiencia, que está representado por sueldos del personal o por honorarios de consulta.

Además, las exposiciones procedentes de acciones de relaciones públicas no pueden medirse de la misma forma que se hace con la publicidad porque no cuesta lo mismo. Enfrentando los anuncios de pago con las noticias publicadas procedentes de labores de publicity, se observa que "las historias periodísticas tienen más credibilidad que los mensajes publicitarios", debido al hecho de que existen "percepciones más positivas hacia las noticias que hacia la publicidad"15 (Choi y Park, 2011). Esto es debido a que "se sabe que los anuncios en vallas publicitarias, radio o revistas son publicidad de pago y que la empresa tiene un interés particular en mostrar ese mensaje al público"16, explica Berkowitz (2007).

En resumen, estas dos disciplinas se diferencian en las herramientas que utilizan, en los públicos a los que se dirigen, en el alcance de las acciones y en los objetivos. Según señalan Wilcox, Cameron y Xifra (2007: 21-22):

"La publicidad está presente fundamentalmente en medios de comunicación social; las relaciones públicas utilizan multitud de herramientas de comunicación: folletos, presentaciones multimedia, acontecimientos especiales, discursos, comunicados de prensa, informaciones con la prensa, etcétera.

La publicidad se dirige a públicos externos, fundamentalmente a consumidores de bienes y servicios; las relaciones públicas presentan sus mensajes a públicos externos específicos (accionistas, proveedores, líderes de la comunidad, grupos ecologistas, etcétera) y a un público interno (empleados).

La publicidad suele identificarse como una función de comunicación especializada; las relaciones públicas tienen un mayor alcance, y se ocupan de las políticas y resultados de toda la organización, desde la ética de los empleados hasta la forma de responder al teléfono. 
La publicidad suele utilizarse como una herramienta de comunicación en las relaciones públicas, y la actividad de relaciones públicas suele respaldar a las campañas publicitarias. La función de la publicidad consiste en vender bienes $\mathrm{y}$ servicios; la función de las relaciones públicas consiste en crear un entorno en el que la organización pueda desarrollarse. Trata de gestionar los factores económicos, sociales y políticos que pueden afectar a la organización".

\section{Influencia de la publicidad en la aceptación de las relaciones públicas}

Ahora bien, aunque la publicidad y las relaciones públicas sean disciplinas diferentes, vista la bajada de inserción publicitaria que están sufriendo los medios de comunicación -en especial los periódicos-, algunos investigadores han abierto el debate sobre si la publicidad puede tener consecuencias positivas en el tratamiento informativo de algunas herramientas de relaciones públicas, como la publicity. Así, Rinallo y Basuroy (2009), por ejemplo, observan que los redactores otorgan más consideración a los productos y servicios de los anunciantes que los de los no anunciantes. Choi y Park (2011), por su parte, atestiguan que los periodistas sí que tienen en cuenta las firmas que compran espacios a la hora de seleccionar las notas de prensa, pero solo parcialmente. Han descubierto, por ejemplo, que los locales prestan más atención que los nacionales a la publicidad y que las empresas con los anuncios más largos también obtienen las notas de prensa divulgadas de manera más extensa.

En España, en una investigación de aproximación con una muestra de nueve empresas nacionales e internacionales y seis periódicos de diferente tirada se aprecia que cuanto más amplio es el ámbito geográfico de un diario, más anuncios insertan las empresas y más posibilidades existen de que una nota de prensa sea publicada. Además, los titulares de las informaciones que aparecen en los diarios que reciben más publicidad tienden a repetir más a menudo la idea condensada en el título original del comunicado. No obstante, algunos aspectos referentes a la relevancia que le otorga el periodista a la nota no varían significativamente entre anunciantes y no anunciantes, como, por ejemplo, el tamaño de las informaciones publicadas, la inserción y la extensión de fotografías o la mención del nombre de la empresa en el titular. Por lo tanto, se establece que la publicidad, aunque pueda ayudar, no implica automáticamente que las notas de prensa se publiquen y de mejor manera, puesto que sus características noticiosas continúan siendo el principal baremo para su publicación (Busto Salinas, 2013). 


\subsection{DIFERENCIAS ENTRE RELACIONES PÚBLICAS Y PROPAGANDA}

Otra de las disciplinas con la que se confunden las relaciones públicas debido a su origen es la propaganda. La profesión de las relaciones públicas, efectivamente, tiene sus raíces en el agente de prensa y en la propaganda (J. E. Grunig y Hunt, 1984: 4), aunque, en la actualidad, estos elementos, junto con la publicity y la publicidad, se han convertido en herramientas de las relaciones públicas, no en sus equivalentes (Cutlip y Center, 1964: 3).

La principal diferencia entre la propaganda y las relaciones públicas radica en que la primera "prejuzga a favor de su propio interés", mientras que la segunda se ha de basar en "hechos y ser imparciales" (Caldevilla Domínguez, 2008: 27). Para que tengan éxito, por lo tanto, las acciones que emprendan los publirrelacionistas deben resultar creíbles, mientras que la propaganda "siempre está envuelta en un halo de sospecha" (Caldevilla Domínguez, 2008: 27).

De esta manera, la propaganda puede definirse como "la expresión de una opinión o de una acción por individuos o grupos deliberadamente orientada a influir opiniones o acciones de otros individuos o grupos para unos fines predeterminados", dice Fernández Souto (2006) sobre Quintero (1993). También se puede definir, llanamente, como “el medio de conseguir apoyo para una opinión, credo o creencia" (Caldevilla Domínguez, 2008: 27; Jefkins, 1985: 23).

Esta práctica trata de "vender" un producto normalmente con finalidad ideológica. Aunque se identifica con el objetivo de lograr la máxima difusión de una idea, no vale cualquiera, "sino de unas creencias que se tienen por decisivas y trascendentales para la orientación de la propia existencia" (Noguero, 1997). Por ello, suele tratar temas emocionales, intelectuales o espirituales, como la política o la religión (Fernández Souto, 2006; Jefkins, 1985: 23).

Para diferenciar de manera práctica ambas disciplinas, a modo de ejemplo, en los departamentos gubernamentales, la "propaganda estará dirigida a mantener al Gobierno en el poder, mientras que las RP se dirigirán a hacer inteligibles sus servicios y a que se utilicen adecuadamente" (Jefkins, 1985: 24).

Otras diferencias percibidas por Desantes (1986: 115-123) y recogidas por Castillo Esparcia en su libro Relaciones públicas. Teoría e historia (2009: 30-31) se muestran en la siguiente tabla: 
Tabla 1. Diferencias entre la propaganda y las relaciones públicas según Desantes (1986: 115-123)

\begin{tabular}{|c|c|}
\hline Propaganda & Relaciones públicas \\
\hline $\begin{array}{l}\text { "Es comunicación del mundo interior } \\
\text { del hombre. }\end{array}$ & Mensaje completo. \\
\hline $\begin{array}{l}\text { Es la única posible comunicación } \\
\text { pura o simple del mundo interior del } \\
\text { comunicador. }\end{array}$ & $\begin{array}{l}\text { El mensaje tiene una función probatoria para el } \\
\text { emisor que, en cuanto participada por el receptor, } \\
\text { es comprobatoria (probare cum). }\end{array}$ \\
\hline $\begin{array}{l}\text { Comunica, entre otros objetos } \\
\text { posibles, sustancia intelectual o } \\
\text { ideas, en sentido estricto. }\end{array}$ & $\begin{array}{l}\text { Su mensaje, con independencia de que sea } \\
\text { intencionalmente probatorio o no, cumple la } \\
\text { función social de verificar que la organización }-\mathrm{O} \\
\text { la persona física que de ella forme parte cumple } \\
\text { con su fin natural, convencional o normativo. }\end{array}$ \\
\hline $\begin{array}{l}\text { Es persuasiva, es decir, no solamente } \\
\text { se dirige a la voluntad sino que } \\
\text { tiende por sí misma a captar la } \\
\text { voluntad. }\end{array}$ & $\begin{array}{l}\text { El segundo de los elementos del mensaje consiste } \\
\text { en los hechos o dación de cuentas de la actuación } \\
\text { organizativa o personal dentro de la organización. }\end{array}$ \\
\hline $\begin{array}{l}\text { Es difusiva: genera ideas en los } \\
\text { individuos adultos quienes, a su vez, } \\
\text { actúan de focos de generación. }\end{array}$ & Se ha de regir por el principio de verdad. \\
\hline $\begin{array}{l}\text { Capta y difunde, en cuanto presenta } \\
\text { el bien o la apariencia de bien. }\end{array}$ & $\begin{array}{l}\text { El proceso difusivo del mensaje relacional } \\
\text { público produce la comparación entre fines y } \\
\text { hechos. De esa comparación surge una identidad } \\
\text { que legitima ante el público a una organización o } \\
\text { una divergencia que, si es excepcional, también } \\
\text { legitima el comportamiento general. }\end{array}$ \\
\hline \multirow[t]{3}{*}{$\begin{array}{l}\text { Se convierten en un factor de } \\
\text { convivencia y armonía social. }\end{array}$} & $\begin{array}{l}\text { La difusión de la apariencia del bien, o del mal en } \\
\text { lugar del bien, condena la comunicación de ideas } \\
\text { y las priva de llamarse ortodoxamente } \\
\text { propaganda. }\end{array}$ \\
\hline & $\begin{array}{l}\text { En ningún caso pueden tener un fin interesado, } \\
\text { mercantil, de imagen de producto o de } \\
\text { organización. Si estos efectos se producen, son } \\
\text { siempre accidentales, no esenciales a la naturaleza } \\
\text { del mensaje. }\end{array}$ \\
\hline & $\begin{array}{l}\text { Es indiferente para la naturaleza de su mensaje el } \\
\text { medio a través del cual se difundan y el régimen } \\
\text { contractual o no que rija la relación informativa. } \\
\text { El modo, en relación con el medio, ha de partir de } \\
\text { la naturaleza del mensaje". }\end{array}$ \\
\hline
\end{tabular}

Fuente: Castillo Esparcia (2009: 30-31). 


\subsection{DIFERENCIAS ENTRE RELACIONES PÚBLICAS Y MARKETING}

La consulta en diferentes referencias de renombre sobre la práctica del marketing ofrece similares resultados. El Instituto Británico de Marketing (The Chartered Institute of Marketing, n.d.), por ejemplo, define esta práctica como "el proceso de gestión responsable de identificar, anticipar y satisfacer las necesidades del consumidor obteniendo beneficios" "17. Según la Real Academia Española (2014), la mercadotecnia es el "conjunto de principios y prácticas que buscan el aumento del comercio, especialmente de la demanda", y "el estudio de los procedimientos y recursos tendentes a este fin". Algo similar aporta la Enciclopedia Británica (1990): "La suma de actividades relacionadas con la gestión del flujo de bienes y servicios de los productores a los consumidores" $"$.

Si se comparan estas definiciones con las propias de las relaciones públicas, se detecta la principal diferencia: el objeto. El marketing se centra en los mercados, es decir, en "personas que compran productos o que usan los servicios de una organización"19 (Hunt y J. E. Grunig, 1994: 6). Así, los mercados "están limitados al segmento de consumidores del entorno de una organización" (Ehling, White y J. E. Grunig, 1992: 357), y, por lo tanto, los profesionales de esta disciplina pueden crearlos segmentando el gran mercado en pequeños grupos (Hunt y J. E. Grunig, 1994: 6). Además, normalmente, los mercados no presionan a las compañías para que creen productos (Hunt y J. E. Grunig, 1994: 6), dado que suelen ser pasivos y comprensivos (Hunt y J. E. Grunig, 1994: 7), por lo que los directivos suelen apoyar este enfoque cuando se encuentran en entornos "benignos" (Ehling, White y J. E. Grunig, 1992: 361).

En cambio, las relaciones públicas se centran en los diferentes públicos, los cuales "se crean solos y persiguen a la organización cuando están descontentos"20 (Hunt y J. E. Grunig, 1994: 6). Normalmente son activos y con frecuencia antagónicos (Hunt y J. E. Grunig, 1994: 7), y pueden surgir de cualquier categoría de stakeholder, ya sean empleados, comunidades, accionistas, estudiantes, contribuyentes, etc. (Ehling, White y J. E. Grunig, 1992: 357). Esto hace que "mientras que el marketing se preocupa concretamente de los bienes y servicios destinados al consumidor, las relaciones públicas se centran en los consumidores simplemente como un público de otros tantos" $^{21}$ [King y Scrimger (1993) hablando sobre Ehling y White (1992)]. Cuando el entorno es turbulento y amenazante, las relaciones públicas deben primar frente al marketing (Ehling, White y J. E. Grunig, 1992: 361).

El propósito de las dos especialidades también es desigual: "La gestión en marketing identifica un solo objetivo económico en una organización: producir bienes y servicios para un único grupo (los consumidores). La gestión en relaciones públicas, por otra parte, presupone que una organización (no siempre de negocios) tiene diferentes compromisos y sirve a diversos grupos, ninguno de los cuales son necesariamente cordiales, ya que pueden entrar en conflicto con la organización, obstruir o bloquear sus 
actividades",22 (Ehling, White y J. E. Grunig, 1992: 363). En resumidas cuentas, el propósito del marketing es "mantener una pendiente positiva de la curva de la demanda",23, mientras que el de las relaciones públicas es "ahorrar dinero a la organización gestionando las amenazas que ponen en peligro su misión o consiguiendo apoyo para ello"24 (J. E. Grunig y L. A. Grunig, 1991). Y es que esta última práctica "contribuye principalmente a ahorrar dinero, más que a crearlo" ${ }^{25}$ (L. A. Grunig, J. E. Grunig y Dozier, 2002: 129).

Resumiendo, la comunicación que se desarrolla desde la perspectiva de las relaciones públicas "está enfocada bajo las relaciones interpersonales, se diseña bilateralmente, se orienta bidireccionalmente y se organiza en dos etapas" ${ }^{26}$. Por el contrario, la comunicación bajo la disciplina del marketing "está diseñada unilateralmente, el mensaje fluye de manera unidireccional y en una etapa: persuadir para fomentar las ventas o incrementar el mercado de la compañía",27 (Ehling, White y J. E. Grunig, 1992: 389).

Normalmente, mientras que el marketing depende de la publicidad y de otros métodos de pago controlados, las relaciones públicas usan "técnicas periodísticas, se esfuerzan por lograr espacios gratuitos en los medios, producen publicaciones y utilizan los medios de comunicación interpersonales" ${ }^{28}$ (J. E. Grunig y L. A. Grunig, 1991). La confusión, entonces, surge porque "las técnicas de relaciones públicas a menudo se usan como apoyo a la teoría de marketing y las técnicas de marketing a menudo se usan en apoyo a la teoría de las relaciones públicas"29 (J. E. Grunig y L. A. Grunig, 1991). Es decir, a menudo unas y otras se utilizan con diferentes fines.

De acuerdo con Hunt y J. E. Grunig (1994: 7), la publicidad, por ejemplo, es una técnica de marketing que puede ser usada para apoyar los objetivos de relaciones públicas. Asimismo, la publicity, las relaciones con los medios, los folletos o los eventos especiales, todos ellos pertenecientes a las relaciones públicas, son usados con frecuencia para conseguir las metas de marketing. La clave, avanzan estos autores, es "ser capaz de distinguir si se usan para propósitos de marketing o de relaciones públicas" 30 .

Por ello, aunque algunos investigadores opinen lo contrario [por ejemplo, Vela y Bocigas (1992)], las relaciones públicas no tienen naturaleza mercadotécnica y emplear las estrategias propias del marketing "no tiene por qué conducirnos a calificar la actividad como tal” (Xifra Triadú, 2006). Así, “es lícito y eficaz [...] que el márketing utilice técnicas y actividades propias de las relaciones públicas para conseguir el éxito del producto o servicio en el mercado en el que compite. O incluso, el departamento de márketing podrá utilizar el asesoramiento del departamento de relaciones públicas para comprobar las repercusiones (en términos de imágenes, actitudes e intenciones de los públicos hacia la compañía) de una decisión concreta: política de precios, lanzamientos de nuevos productos, etc." (Arceo Vacas, 1995). 
En ningún caso, por tanto, las relaciones públicas contienen al marketing ni tampoco al contrario (Arceo Vacas, 1995, 1988). Cuando los profesionales de marketing dirigen la función de las relaciones públicas, esta práctica suele reducirse a una competencia técnica en vez de estratégica (Kotler y Andreasen, 1987: 577) y los publirrelacionistas se convierten en meros técnicos trabajando para el departamento de marketing en vez de para unos objetivos de relaciones públicas (J. E. Grunig y L. A. Grunig, 1991). Además, no existen "razones conceptuales, organizacionales o administrativas" que motiven que las relaciones públicas estén dirigidas por el marketing (Ehling, White y J. E. Grunig, 1992: 390). Solo cuando ambas disciplinas se encuentran al mismo nivel, y no las relaciones públicas por debajo del marketing, se pueden lograr unas relaciones públicas excelentes (L. A. Grunig, J. E. Grunig y Dozier, 2002: 286).

\subsubsection{PRINCIPIOS DE DIRECCIÓN DE LAS RELACIONES PÚBLICAS. ESFERAS DE LA COMUNICACIÓN EXCELENTE}

A pesar de que cada zona geográfica y ámbito de actuación tiene sus propias peculiaridades, la comunicación excelente resulta ser "universal", dado que "involucra experiencia o conocimientos que trascienden cualquier público particular, división o unidad organizativa, tipo de organización o marco nacional"31 (Dozier, L. A. Grunig y J. E. Grunig, 1995: 4). Cuando se las califica de excelentes, las relaciones públicas contribuyen a la efectividad de la organización, dado que ayudan a la entidad a gestionar las relaciones con los grupos de su entorno (L. A. Grunig, J. E. Grunig y Ehling, 1992).

Existen elementos que facilitan que las compañías consigan una comunicación excelente. Tras numerosos años de revisión bibliográfica e investigación empírica, los miembros del Excellence Study resumen la esencia del factor de la excelencia como tres esferas, una dentro de la otra, las cuales contienen tres aspectos fundamentales (Dozier, L. A. Grunig y J. E. Grunig, 1995: 10). En el núcleo se halla el conocimiento, después, las expectativas comunes $\mathrm{y}$, finalmente, la cultura participativa. 
Ilustración 1. Representación gráfica de las esferas de la comunicación excelente de Dozier, Grunig y Grunig (1995: 10).

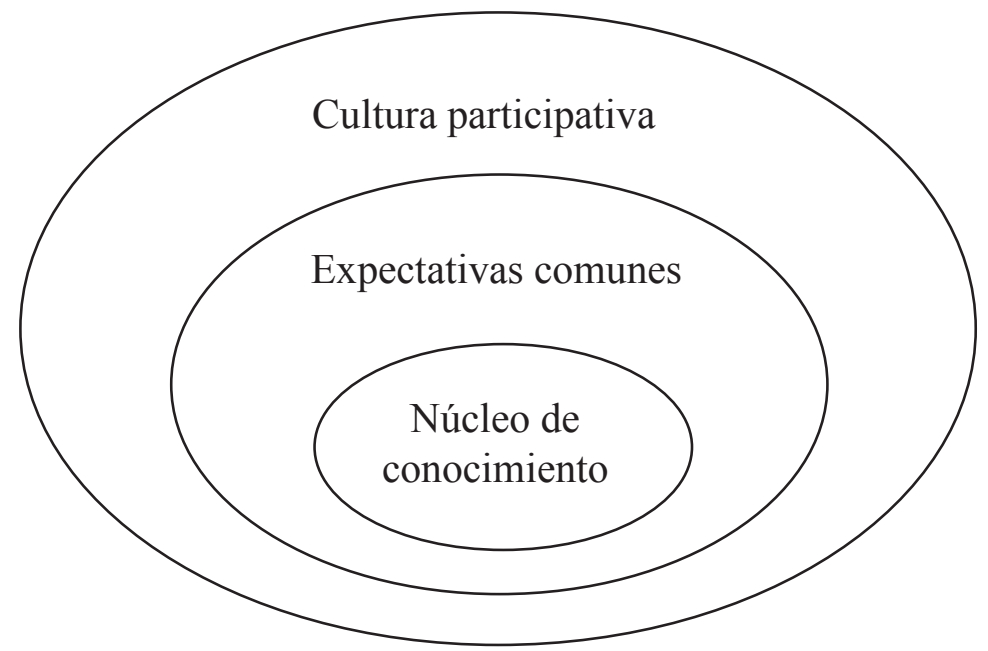

Fuente: elaboración propia a partir del diseño de Dozier, L. A. Grunig y J. E.Grunig (1995: 10).

Dentro de la división más profunda se engloban los conocimientos directivos, los bidireccionales, los estratégicos, los de investigación y demás. En la segunda fracción, se encuentran las expectativas comunes entre el departamento de relaciones públicas y la dirección de la entidad acerca de la comunicación, el poder que tienen los comunicadores y la relación que mantienen ambas partes. Finalmente, en la esfera exterior, se incluyen las características y estructura de las entidades.

\subsubsection{CONOCIMIENTO DE LOS COMUNICADORES}

L. A. Grunig, J. E. Grunig y Ehling (1992), en el capítulo "What is an effective organization" del libro Excellence in Public Relations and Communication Management, opinan que las relaciones públicas ayudan a crear entidades más efectivas al usar programas de comunicación para crear relaciones con sus públicos estratégicos, los cuales tienen el poder de limitar o mejorar la habilidad de la organización a la hora de alcanzar sus metas. Para lograr este objetivo, añaden una serie de condiciones (L. A. Grunig, J. E. Grunig y Ehling, 1992): 
"Las relaciones públicas contribuyen a la efectividad de la organización cuando ayudan a reconciliar los objetivos de la organización con las expectativas de sus públicos estratégicos. Esta contribución tiene valor económico para la organización. Las relaciones públicas contribuyen a la efectividad creando relaciones de calidad y duraderas con los públicos estratégicos. Es más probable que las relaciones públicas contribuyan a la efectividad cuando el responsable es un miembro de la dirección, donde él puede moldear los objetivos de la organización y ayudar a determinar qué públicos externos son más estratégicos" 32 .

Esta sentencia evidencia la necesidad de emprender un rol directivo, utilizar comunicación bidireccional, gestionar la comunicación de forma estratégica y ser miembro (o al menos tener acceso, como se verá más adelante) de la coalición dominante. También resulta vital, de acuerdo con los planteamientos de Dozier, L. A. Grunig y J. E. Grunig (1995), investigar informal y formalmente, tener conocimientos sobre presupuestos y compartir con la dirección de la entidad la visión de la comunicación.

\subsection{CONOCIMIENTO DIRECTIVO Y TÉCNICO}

La forma en que los profesionales de las relaciones públicas gestionan la comunicación de una entidad suele definirse según roles y modelos. Como Dozier, L. A. Grunig y J. E. Grunig explican (1995: 40), "así como los roles describen patrones de las actividades de los comunicadores como individuos en las organizaciones, los modelos describen los valores y el patrón de comportamiento (prácticas) de los departamentos de comunicación para tratar con los públicos"33.

En cuanto a los roles de relaciones públicas, estos han sido objeto de numerosas investigaciones porque "definen las actividades diarias de los profesionales de relaciones públicas”34 (Dozier, 1992: 327). Según Dozier (1992: 327), esta división es esencial para entender la función de las relaciones públicas y de la comunicación organizacional: "Los roles de los profesionales son el nexo de una red de conceptos que afectan a los logros profesionales de los practicantes, a las estructuras y procesos de la actividad en las organizaciones y a las capacidades de la organización para controlar y cooperar con sus entornos" ${ }^{35}$.

La primera clasificación, realizada por Broom y Smith (1978) en la década de 1970, aporta cinco tipos de roles: presciptor experto, técnico en comunicación, mediador en la resolución de problemas, mediador de comunicación y representante legítimo ${ }^{36}$. Con el 
ánimo de simplificar, esta división ha sido mermada a dos grandes bloques: el de director y el de técnico (Dozier, 1992: 335). El primero de ellos "conceptualiza y dirige los programas de relaciones públicas"37 (J. E. Grunig, 1992a: 19), mientras que el segundo tiende a facilitar servicios como "redacción, edición, fotografía, contacto con los medios o producción de publicaciones"38 (J. E. Grunig, 1992a: 19).

Bajo un rol técnico, los publirrelacionistas poseen funciones técnicas y su tarea principal es implementar los programas de comunicación, dejando a un lado el sentido directivo y bidireccional (Dozier, L. A. Grunig y J. E. Grunig, 1995: 58-59). Como lo definen Dozier y Broom (1995), un técnico es "un creador y divulgador de mensajes, que está íntimamente envuelto en la producción, que opera independientemente de las decisiones de la dirección, de la planificación estratégica, de la gestión de conflictos potenciales, de la exploración del entorno y de la evaluación de los programas" ${ }^{\text {"2 }}$. No hay que dejarse engañar por el título que adquiera un profesional en su puesto de trabajo, dado que "son demasiados los profesionales que, ocupando un cargo denominado «director relaciones públicas (o de comunicación)» ejercen en realidad funciones técnicas" (Xifra Triadú, 2008). Dos acciones que diferencian el rol directivo del técnico es el uso de la investigación para segmentar a los públicos y realizar investigación evaluativa (Dozier, L. A. Grunig y J. E. Grunig, 1995: 30).

Los expertos del rol directivo, por el contrario, han de saber manejar las respuestas de una organización hacia diferentes temas, utilizar la investigación para segmentar públicos, desarrollar los goles y objetivos departamentales y hacer uso de la investigación evaluativa para preparar presupuestos (Dozier, L. A. Grunig y J. E. Grunig, 1995). Efectivamente, es recomendable que use la investigación tanto formativa como evaluativa en su trabajo (Broom y Dozier, 1986) y sobre todo la formal además de la informal (Dozier, L. A. Grunig y J. E. Grunig, 1995: 115). Un trabajador en estas funciones debe formar parte de la planificación y gestión de los programas de relaciones públicas, tiene que asesorar a la alta dirección y ha de tomar decisiones sobre la política comunicativa (Broom y Dozier, 1986).

En teoría, las personas que avanzan en su carrera profesional pasan de un nivel técnico a uno directivo (J. E. Grunig y Hunt, 1984: 90). Los gestores "tienen una mente más científica y creen en la planificación y en la evaluación"40 (J. E. Grunig y Hunt, 1984: 92). Este rol es el único que, por sí solo, contribuye a la excelencia de las relaciones públicas y a la efectividad de la organización (L. A. Grunig, J. E. Grunig y Dozier, 2002: 255). De hecho, es uno de los tres aspectos más importantes de las veinte características propuestas tras los resultados del Excellence Study para lograr unas relaciones públicas excelentes. Por detrás se encuentra la habilidad para practicar el modelo bidireccional simétrico y el asimétrico (Dozier, L. A. Grunig y J. E. Grunig, 1995: 7), que se detallarán más adelante. 
Pese a lo que pueda parecer a simple vista, las acciones técnicas juegan un papel imprescindible en los departamentos de relaciones públicas excelentes, los cuales, además de poseer un alto nivel directivo, también cuentan con una gran pericia técnica (L. A. Grunig, J. E. Grunig y Dozier, 2002: 255). Es decir, "los departamentos con el conocimiento base para establecer programas de comunicación excelentes también tienen altos niveles de experiencia técnica"41 (Dozier, L. A. Grunig y J. E. Grunig, 1995: 55). No obstante, esta habilidad no es la que convierte los departamentos en excelentes (Dozier, L. A. Grunig y J. E. Grunig, 1995: 53), sino "la aplicación del craft del comunicador [es decir, la utilización de las habilidades técnicas] en la persecución de las metas estratégicas"42 (Dozier, L. A. Grunig y J. E. Grunig, 1995: 60-61). Por ello, lo más recomendable es llegar a una sinergia entre los dos papeles (Dozier, L. A. Grunig y J. E. Grunig, 1995: 6). Tal y como puntualizan estos autores, "la experiencia del comunicador en la planificación estratégica y en la investigación no reemplaza o reduce la importancia de las habilidades tradicionales del comunicador, como la escritura, la edición, los gráficos, las relaciones con los medios y demás. De hecho, la nueva experiencia se añade a las habilidades tradicionales del comunicador para construir un departamento equilibrado y excelente"43 (Dozier, L. A. Grunig y J. E. Grunig, 1995: 27). Sería como una especie de yin yang, opinan estos últimos autores (1995: 57), en el que ambas fuerzas se encuentran en tensión y equilibrio.

\subsection{CONOCIMIENTOS DE COMUNICACIÓN BIDIRECCIONAL}

En cuanto a los modelos, estos se utilizan para "describir una serie de valores y un patrón de comportamiento de la estrategia usada por un departamento de relaciones públicas o por un profesional individual en todos sus programas o, en algunos casos, en programas o campañas específicas"44 (J. E. Grunig y L. A. Grunig, 1992: 286).

Tal y como detallan J. E. Grunig y L. A. Grunig (1992: 286), "usamos aquí el término modelo en el sentido en el que se usa en las ciencias -como una representación simplificada de la realidad. Aunque todos los modelos son «falsos» en el sentido de que ninguna representación puede capturar la realidad perfectamente, no tendríamos ninguna comprensión de la realidad si no tuviéramos unos modelos con los que trabajar" 45 . En otras palabras, aunque sean "simplificaciones, y las simplificaciones son siempre falsas en parte, porque siempre se dejan algo fuera" y aunque "no todas y cada una de las personas que trabajan en relaciones públicas encajan perfectamente en uno de los modelos", "deben acercarse suficientemente como para que los profesionales de relaciones públicas que conozcas encajen en uno de los modelos"46 (J. E. Grunig y Hunt, 1984: 21). 


\section{Los modelos de Grunig y Hunt (1984)}

J. E. Grunig y Hunt (1984) fueron los primeros en definir los modelos de relaciones públicas, lo cuales, en la actualidad, aún tienen vigencia. De esta manera, idearon cuatro patrones, dependiendo de la dirección (unidireccional-bidireccional) y de los efectos (asimétrico-simétrico). Cada uno con su propio propósito, son el de agente de prensa, el de información pública, el asimétrico bidireccional y el simétrico bidireccional. La comunicación en los dos primeros fluye de manera unidireccional de la organización a los públicos, ya que conciben la comunicación "como contar, no como escuchar" (J. E. Grunig y Hunt, 1984: 23). En cambio, en los modelos bidireccionales, se produce un diálogo en vez de un monólogo (J. E. Grunig y Hunt, 1984: 23).

Dozier, L. A. Grunig y J. E. Grunig (1995: 42) utilizan otras denominaciones para referirse a la misma idea. Estos académicos dividen las dos clases de modelos en profesionales o "mañosos" basan en una base de conocimiento y conjunto de técnicas usadas para propósitos estratégicos: gestionar los conflictos y establecer relaciones con los públicos”,48. En cambio, los unidireccionales se engloban dentro de la segunda clase, dado que las técnicas de comunicación "se usan para generar mensajes, como si los mensajes fueran el fin en sí mismo" "49. Además, según señalan, los profesionales que usan los modelos unidireccionales realizan mucha menos investigación que los que utilizan los bidireccionales, que echan mano tanto de indagaciones formales como informales más a menudo (Dozier, L. A. Grunig y J. E. Grunig, 1995: 44).

\section{El modelo de agente de prensa}

El agente de prensa apareció entre 1850 y 1900 (J. E. Grunig y Hunt, 1984: 21) y hoy en día "mantiene su operatividad" (Xifra Triadú, 2008). Surgió gracias el empresario circense estadounidense Phineas Taylor Barnum (Cutlip y Center, 1964: 2425) y su único propósito es conseguir información favorable en los medios de comunicación, por lo que es una postura común en el trabajo de los publicistas que promocionan deportes, artistas de cine o políticos, entre otros (Hunt y J. E. Grunig, 1994: 8). Las relaciones públicas, en este caso, sirven a modo de propaganda (J. E. Grunig y Hunt, 1984: 21), dado que su principal objetivo es atraer la atención en vez de lograr un entendimiento (Cutlip y Center, 1964: 10). Tal y como Castillo Esparcia (2004) relata: 
"Se recurre a todo tipo de acciones sin importar el componente ético en la acción, ya que se recurre a la desinformación o a la manipulación, por ejemplo. La relación con los periodistas es de engaño con el único objetivo que aquello que aparezca sobre la organización sea siempre positivo $\mathrm{y}$, como elemento esencial, que lo intente conseguir a cualquier precio, ya sea comprando periodistas, dando información distorsionada o con verdades a medias".

La relación que se consigue, por tanto, es de una "linealidad directa" de la entidad hacia los periodistas (Castillo Esparcia, 2004), caracterizada, asimismo, por una falta de investigación, salvo, en todo caso, por observaciones informales o recuentos de las apariciones en prensa (J. E. Grunig y Hunt, 1984: 24). "Sería como un monólogo de la organización con un sentido estrictamente unidireccional", apostilla Castillo Esparcia (2004). Según José Luis Arceo (2006), "ha protagonizado la mayor parte de la aún pequeña historia de esta disciplina y profesión" e, incluso, "parece que sigue siendo el basamento de concepto y actuación profesional de una parte importante en este sector publirrelacionista".

\section{El modelo de información pública}

Por su parte, el modelo de información pública surgió después del agente de prensa, a comienzos del siglo XX (J. E. Grunig y Hunt, 1984: 21), y aún hoy está vigente, sobre todo en los poderes públicos y en las organizaciones sin ánimo de lucro (Xifra Triadú, 2008). De hecho, para J. E. Grunig y Hunt (1984: 22 y 26), la mitad de las organizaciones utilizan este modelo, muy por delante del siguiente más empleado, el bidireccional asimétrico, que, estiman, adoptan dos de cada diez entidades. El principal propósito es la difusión de información (J. E. Grunig y Hunt, 1984: 21).

Aunque se considera también unidireccional, funciona más como un "periodista interno"50 (J. E. Grunig y Hunt, 1984: 22), ya que la misión principal es "diseminar información relativamente objetiva a través de los medios de comunicación y controlar algunos materiales, como los boletines informativos, los folletos y el mailing directo"51 (Hunt y J. E. Grunig, 1994: 8). Tanto el agente de prensa como el de información pública no están basados en la investigación y en la planificación estratégica y pretenden cambiar el comportamiento de los públicos "pero no el de la organización"52 (Hunt y J. E. Grunig, 1994: 8). La investigación que se lleva a cabo, ciertamente, es limitada y suele concentrarse en el análisis de contenido y en el test de legibilidad (Grunig y J. E. Hunt, 1984: 24). El más claro exponente de esta visión es Ivy Ledbetter Lee (Grunig y J. E. Hunt, 1984: 22). 


\section{El modelo asimétrico bidireccional}

El modelo asimétrico bidireccional, desarrollado en los años 1920 (J. E. Grunig y Hunt, 1984: 21) y también conocido por su "persuasión científica" (J. E. Grunig y Hunt, 1984: 22), usa la investigación para elaborar mensajes que ayuden a persuadir a los públicos estratégicos a actuar como quiere la organización (J. E. Grunig, 1992b: 8). Dado que estudia la actitud de los públicos, resulta "más efectivo",53 que los modelos unidireccionales (Hunt y J. E. Grunig, 1994: 8).

Aun así, se trata de un modelo "egoísta", 54 ya que "la organización que lo usa cree que tiene la razón (y no el público) y considera que cualquier cambio que sea necesario para resolver un conflicto debe provenir del público y no de la organización" "55 (Hunt y J. E. Grunig, 1994: 8). Esto resulta efectivo, por lo tanto, "cuando la organización tiene pocos conflictos con un público y el público parece beneficiarse de su cambio de comportamiento"56 (Hunt y J. E. Grunig, 1994: 8).

\section{EI modelo simétrico bidireccional}

El modelo simétrico bidireccional, por su parte, comenzó a utilizarse en las décadas de 1960 y 1970 (J. E. Grunig y Hunt, 1984: 21), aunque no se consolidó hasta finales del siglo XX (Xifra Triadú, 2008). Su principal misión es conseguir el entendimiento mutuo entre la organización y sus públicos, así que los profesionales de las relaciones públicas trabajan como mediadores (J. E. Grunig y Hunt, 1984: 22). Estos últimos autores (1994: 9) detallan que "se basa en la investigación y utiliza la comunicación para gestionar los conflictos y mejorar el entendimiento con los públicos estratégicos"57. Tal y como señalan estos académicos de Pearson (1989), "generalmente es más ético que los otros modelos" través de la negociación, ya que casi cualquier parte del conflicto -como la energía nuclear, el aborto o el control de armas- considera que su posición es la correcta"59. Sería como "una calle de dos direcciones ${ }^{\underline{1}}$. Ambos sentidos del tráfico deben tener el mismo derecho de paso" ${ }^{60}$ (Cutlip y Center, 1964: 112).

De esta manera, si se da una persuasión, "es igual de probable que las actitudes y comportamientos de la organización se modifiquen por el público como que las actitudes y comportamientos del público se modifiquen por la gestión de la organización"61 (J. E. Grunig y Hunt, 1984: 23). Además, prosiguen estos autores, "lo ideal sería que tanto la dirección como los públicos cambien algo después de un esfuerzo de relaciones públicas" $"$. La norma en las organizaciones con una visión simétrica es la "reciprocidad"63 (J. E. Grunig y White, 1992: 48); es decir, "se dan cuenta de que pueden tener más de lo que quieren dando a los públicos algo que ellos quieran"64 (J. E. Grunig y White, 1992: 46).

\footnotetext{
${ }^{I}$ La cursiva es del autor.
} 


\section{Bidireccional simétrico vs. Bidireccional asimétrico}

La principal diferencia entre los modelos bidireccionales es que el simétrico se centra en encontrar una comunicación equilibrada entre la organización y sus públicos (J. E. Grunig, L. A. Grunig y Toth, 2007); es decir, busca el entendimiento (J. E. Grunig y L. A. Grunig, 1992: 289). La esencia de este modelo es que tanto la organización como la audiencia quieran acomodar sus intereses a los del otro (L. A. Grunig, J. E. Grunig y Dozier, 2002: 315). De hecho, este enfoque contribuye a la eficacia de la entidad en general (Gordon y Kelly, 1999; L. A. Grunig, J. E. Grunig y Dozier, 2002). En cambio, en el asimétrico, los efectos están "desequilibrados" a favor de la compañía: "La organización no cambia como resultado de las relaciones públicas, sino que trata de cambiar las actitudes y comportamientos del público"65 (J. E. Grunig y Hunt, 1984: 23). Se trata, por tanto, de una visión menos ética y socialmente responsable (J. E. Grunig, 1989).

El uso que hacen de la investigación también es desigual. Mientras que el bidireccional asimétrico usa la investigación formativa para averiguar qué aceptará y tolerará el público, el simétrico emplea este tipo de indagación para aprender cómo el público percibe una organización y determinar las consecuencias que tiene la organización hacia el público. En cuanto a la evaluativa, el primer modelo lo usa para medir las actitudes y comportamientos antes y después de una campaña y así determinar sus efectos; el segundo lo hace para calcular si los esfuerzos de relaciones públicas han mejorado el entendimiento de los públicos hacia la organización y viceversa (J. E. Grunig y Hunt, 1984: 24-25).

\section{Utilización de los modelos según las circunstancias}

Aunque parece lógico pensar que el modelo ideal es el bidireccional simétrico, J. E. Grunig y Hunt (1984: 43) reconocen que "hay organizaciones que se enfrentan a problemas para los cuales otros modelos pueden proporcionan las mejores soluciones" ${ }^{\prime 66}$. Tal y como se detallará más adelante, las entidades tradicionales estarían vinculadas al agente de prensa, las mecánicas al de información pública y las mixtas al bidireccional simétrico (Dozier y J. E. Grunig, 1992: 403-406). Cuanto más estático sea el entorno, más posibilidades existen también de que se emplee el agente de prensa y de información pública (J. E. Grunig y Hunt, 1984: 97), al igual que sucede en las organizaciones mecánicas (L. A. Grunig, J. E. Grunig y Dozier, 2002: 534-535). 


\section{Alternativas a los modelos de Grunig y Hunt (1984)}

Hay, no obstante, detractores de los cuatro modelos propuestos por J. E. Grunig y Hunt (1984), bajo la premisa de que pueden ser correctos en teoría, pero que no funcionan en la práctica, explican J. E. Grunig y L. A. Grunig (1992: 291). Según su punto de vista, se trata de un enfoque "irreal o idealista"67 (J. E. Grunig y White, 1992: 45). Los autores del Excellence Study replican que se trata, sobre todo, de una teoría normativa, es decir, "define cómo alguna actividad debe ser o la forma en que debe hacerse" ${ }^{68}$ (J. E. Grunig y L. A. Grunig, 1992: 291). Además, concretan que los modelos siguen proporcionando una "herramienta precisa y útil para describir la práctica y visión de las relaciones públicas" ${ }^{\prime 69}$, dado que los directivos y los jefes de comunicación piensan de esta manera cuando se trata de relaciones públicas y los modelos describen los programas que llevan a cabo (L. A. Grunig, J. E. Grunig y Dozier, 2002: 377). Pese a ello, han surgido nuevas teorías que pretenden actualizar o completar los cuatro modelos propuestos por J. E. Grunig y Hunt (1984).

\section{Teoría de los juegos}

Una de esas nuevas visiones la facilitan Dozier, L. A. Grunig y J. E. Grunig (1995: 47-51), que utilizan la concepción de Murphy (1991) de mixed-motive para sugerir que los dos modelos bidireccionales construyen un solo enfoque, por el cual "se usan prácticas asimétricas a corto plazo dentro de un contexto filosófico más amplio de simetría" persiguen sus propios intereses, pero ambas partes también se dan cuenta de que el resultado del juego (la relación en este contexto) debe ser satisfactoria para ambas partes" ${ }^{, 71}$ (Dozier, L. A. Grunig y J. E.Grunig, 1995: 47). Aplicando esta visión a las relaciones públicas, Dozier, L. A. Grunig y J. E. Grunig (1995: 47-48) llegan a la siguiente idea:

"A la vez que las organizaciones persiguen su propio interés en sus relaciones con los públicos, los comunicadores tratan -de vez en cuando- de persuadir a los públicos de que sus organizaciones tienen razón sobre un tema. Otras veces, los comunicadores tratan de convencer a los públicos para que se comporten como quieren sus organizaciones. A veces, los comunicadores usan la teoría de las actitudes y la investigación para manipular estratégicamente a los públicos. Además, los públicos activistas seguirán similares estrategias para persuadir, convencer y manipular a las organizaciones" ${ }^{\text {72 }}$. 
Otra teoría proviene de los resultados del Excellence Study, cuyos autores sugirieron tras la finalización del estudio que existe una zona beneficiosa tanto para las organizaciones como para los públicos. Según este enfoque, ambas partes tienen intereses distintos y a veces conflictivos. No obstante, la negociación y el compromiso permiten encontrar un terreno común; es decir, una zona beneficiosa para los dos bandos. De esta manera, los comunicadores negocian tanto con los públicos como con la dirección para alcanzar una posición provechosa para los dos. El modelo bidireccional, por lo tanto, trataría a la coalición dominante como otro público (Dozier, L. A. Grunig y J. E. Grunig, 1995: 48-49).

\section{Modelo bidireccional simétrico persuasivo}

El modelo bidireccional simétrico persuasivo fue propuesto por José Luis Arceo Vacas (2006) y mezcla el tercer y cuarto modelo de J. E. Grunig y Hunt (1984). Según esta versión, el penúltimo objetivo de la comunicación con los públicos es la relación y el último, la persuasión. En palabras de Arceo (2006): "No hay persuasión posible sin buena relación previa, pero la buena relación, sin otro esfuerzo añadido posterior de comunicación persuasiva, no lleva necesariamente a dicho efecto persuasivo en el público, éste no cambia lo suficiente, en general, si — aun con una adecuada relaciónno se le solicita ese cambio mediante esa última tanda de comunicación". Da la impresión de que Wilcox, Cameron y Xifra (2007: 222) no descartan este modelo, al asegurar lo siguiente:

"En realidad, la investigación ha demostrado que la mayoría de las organizaciones tiene motivaciones mixtas cuando establece una comunicación bidireccional con los públicos objetivo. Aunque es cierto que pueden utilizar el diálogo para lograr una visión más precisa de cómo pueden ajustarse a las necesidades de un público, su motivo suele ser asimétrico: convencer al público del punto de vista de la organización a través del diálogo".

\section{Modelo de influencia personal}

Sriramesh (1995), por su parte, introdujo en la década de 1990 un nuevo enfoque llamado modelo de influencia personal. Según esta versión, la confianza interpersonal tiene una gran influencia en la práctica de las relaciones públicas. Sriramesh y Takasaki (1999: 285) explican que los practicantes de esta disciplina construyen relaciones personales con públicos claves de tal manera que puedan solicitar favores cuando la organización para la que trabajen necesite ayuda. Se da, sobre todo, en las relaciones con la prensa (Xifra Triadú, 2008). Ha sido probado en el entorno universitario, obteniendo resultados positivos (Candace, Antoaneta y Gena, 2010). 


\subsection{CONOCIMIENTOS ESTRATÉGICOS}

Otro requisito dentro de la esfera de conocimiento para lograr unas relaciones públicas excelentes, según Dozier, Grunig y Grunig (1995: 23-37), es desarrollar una gestión estratégica de la comunicación; es decir, hacer "balance de los procesos internos de las organizaciones con los factores externos"73 (Dozier, Grunig y Grunig, 1995: 27). Dos aspectos son los que miden este aspecto: la gestión de las respuestas de la organización y establecer metas y objetivos. "Esto implica que los comunicadores deben tener la experiencia para identificar las relaciones deseadas por una organización con los stakeholders o públicos clave. Los comunicadores especifican las relaciones deseadas a través de las metas u objetivos de los programas de comunicación" "74, dicen Dozier, L. A. Grunig y J. E. Grunig (1995: 28).

Dozier y L. A. Grunig (1992) indican que la mayoría de las organizaciones desarrollan sus programas estratégicamente en algún momento de su historia, más concretamente cuando la presencia de un público estratégico aporta la motivación para iniciar programas de relaciones públicas. Sin embargo, con el paso del tiempo, las entidades olvidan la razón principal y continúan elaborando acciones para públicos que ya no son relevantes. Esto es lo que Broom (1986) llama "el enfoque historicista"75: "Cuando las relaciones públicas se practican como se ha hecho históricamente, los programas de comunicación se vuelven rutinarios e ineficaces porque ayudan muy poco a que la organización se adapte a ambientes dinámicos"76, aseguran J. E. Grunig y L. A. Grunig (1991). El dato triste es que la mayor parte de las entidades continúan con esta óptica hasta que confrontan una crisis (J. E. Grunig y L. A. Grunig, 1991; Weaver Lariscy y Springston, 2007). Alternativamente, la teoría normativa-prescriptiva estipula que las agrupaciones deben planear las relaciones públicas de manera estratégica, especialmente cuando se encuentran a entornos turbulentos (J. E. Grunig y L. A. Grunig, 1991).

Y es que un programa de relaciones públicas, para ser efectivo, "debe adaptarse a la industria o institución a la que sirve",77 (Cutlip y Center, 1964: 13). Las empresas que usan la gestión estratégica se caracterizan por vincular sus objetivos a las peculiaridades de su ambiente: "Usan la gestión estratégica para identificar oportunidades y peligros en el entorno, para desarrollar estrategias que puedan explotar las oportunidades y minimizar los peligros y para desarrollar, implementar y evaluar estrategias" ${ }^{, 78}$ (Hunt y J. E. Grunig, 1994: 11). En consecuencia, las agrupaciones planifican estratégicamente los programas de relaciones públicas cuando "identifican los públicos que son más propensos a limitar o potenciar el objetivo de la organización y cuando diseñan programas de comunicación que ayudan a la organización a gestionar su interdependencia con los públicos estratégicos"79 (Hunt y J. E. Grunig, 1994: 11).

Las ventajas son considerables: "Si las relaciones públicas pueden identificar los públicos estratégicos del entorno y gestionar la respuesta de la organización hacia estas 
interdependencias, las teorías de la efectividad muestran que las relaciones públicas pueden ayudar a la organización reduciendo la incertidumbre, reduciendo el conflicto y estabilizando las relaciones con los públicos clave de los que depende la organización" 80 (L. A. Grunig, J. E. Grunig y Ehling, 1992). Y es que las "malas relaciones, en otras palabras, pueden costar mucho una organización a pesar de que las buenas relaciones no hagan necesariamente dinero. Al mismo tiempo, las buenas relaciones pueden hacer dinero a través de trabajadores productivos, consumidores satisfechos y donantes, inversores o legisladores comprensivos" ${ }^{\prime 1}$ (L. A. Grunig, J. E. Grunig y Ehling, 1992).

Además, la gestión estratégica es la variable que más incrementa el valor que otorgan los directivos a las relaciones públicas (L. A. Grunig, J. E. Grunig y Dozier, 2002: 88). De hecho, los directores con departamentos de relaciones públicas excelentes valoran casi el doble más esta función que los que cuentan con relaciones públicas menos excelentes (L. A. Grunig, J. E. Grunig y Dozier, 2002: 88).

Por el contrario, si las relaciones públicas se relegan a una función técnica sin ayudar a desarrollar los objetivos de la organización, "normalmente implementa las estratégicas de otros departamentos, como los de marketing o recursos humanos, y se restringe a la aplicación de técnicas en vez de a la formulación de políticas" ${ }^{\$ 2}$ (J. E. Grunig y Repper, 1992: 121). Tal y como señalan Hunt y J. E. Grunig (1994: 11) de Heath (1990), las entidades deben contar con un plan estratégico general, pero también con unas directrices por cada departamento y por cada nivel de la institución.

Gestionar estratégicamente la comunicación implica "realizar investigaciones con el fin de comprender los puntos de vista de los públicos específicos (ya sean estos el personal médico, los pacientes, los políticos o los donantes) y otorgar asesoramiento a la dirección para que pueda tomar decisiones con pleno conocimiento de las opiniones de los públicos en cuestión. También implica tener un entendimiento completo de las decisiones y comportamientos de la dirección de manera que esas decisiones y comportamientos puedan ser a su vez explicados" ${ }^{\$ 33}$ (J. E. Grunig y Hunt, 1984). Asimismo, conlleva identificar "los públicos que son más propensos a contener o realzar la capacidad de la organización para alcanzar su misión y desarrollar programas para comunicarse con esos públicos" ${ }^{\$ 4}$ (L. A. Grunig, J. E. Grunig y Ehling, 1992).

La principal labor bajo esta visión es elaborar "un método para construir relaciones con los públicos estratégicos de una organización" 85 (Wise, 2003). Gracias a este vínculo, en una organización que desarrolle relaciones públicas excelentes, “el departamento se comunica con estos públicos para hacer llegar sus voces a la dirección estratégica, haciendo posible que los públicos interesados participen en las decisiones de la organización que les afectan"86 (L. A. Grunig, J. E. Grunig y Dozier, 2002).

La gestión estratégica y la implicación en la toma de decisiones por parte de los publirrelacionistas (White y Dozier, 1992) es tan importante para una entidad que "puede representar la mayor diferencia entre la excelencia y la mediocridad" 
Grunig, J. E. Grunig y Dozier, 2002). De hecho, la gestión estratégica de las relaciones "puede incrementar la efectividad de la organización" gestionan estratégicamente sus uniones "son más propensas a alcanzar sus objetivos" (Wise, 2003). El motivo reside en que estas firmas "son más dadas a escoger objetivos apropiados"90 (Wise, 2003) porque "concilian las metas de la organización con las expectativas de los grupos estratégicos"91 (L. A. Grunig, J. E. Grunig y Ehling, 1992).

Cutlip, Center y Broom (2000), de hecho, definen las relaciones públicas como la "función gestora que entabla y mantiene relaciones mutuamente beneficiosas entre una organización y los públicos, de los cuales depende su éxito o fracaso" "92. Y es que se estima que el $80 \%$ de los problemas directivos tienen implicaciones para esta disciplina (Wise, 2007). Incluso en algunos ámbitos, como el sanitario, cuando se habla de marketing en vez de relaciones públicas, hay un componente con una clara orientación estratégica [Wrenn (2002) hablando sobre Kotler y Clarke (1987)]. Por ello, siempre se necesita seguir una "gestión proactiva"93 (Fitzgerald y Embrey-Wahl, 1987).

El profesional ideal "debe ser miembro de un grupo que tome decisiones para la organización (o al menos que tenga acceso a ese grupo). En teoría, el profesional más alto de relaciones públicas tendría que liderar su propio departamento e informar directamente al CEO"94 (Wise, 2007). Esto puede mejorar mucho la reputación de la organización, dado que, aunque el "acceso al CEO de la organización no garantice que la organización se vaya a librar de los escándalos", "al menos hay una probabilidad de que los CEOs tomen menos decisiones desafortunadas después de recibir los consejos adecuados de relaciones públicas" 95 (Wise, 2007).

Bajo la idea de las relaciones públicas excelentes, esta disciplina debe integrarse en una única sección separada de otras funciones (como por ejemplo, el marketing) y que pueda actuar libremente (Wise, 2007). Diversos artículos [entre ellos, los de J. E. Grunig y L. A. Grunig (1989a), J. E. Grunig (1976) y Schneider (1985a, 1985b)] revelan que las organizaciones no suelen hacer uso de las relaciones públicas como indica la teoría normativa. Un estudio de The International Association of Business Communicators (IABC), por ejemplo, señala que los departamentos de relaciones públicas contribuyen más a operaciones rutinarias y como respuesta a temas sociales que a participar en iniciativas mayores y, en particular, a la planificación estratégica (J. E. Grunig y L. A. Grunig, 1998). Sin embargo, "los CEOs valoran más las relaciones públicas cuando cumplen un papel de gestión estratégica" 96 (J. E. Grunig y L. A. Grunig, 1998). Como J. E. Grunig (1992b) concluye de su revisión de la bibliografía existente, las entidades excelentes planifican estratégicamente y los departamentos excelentes están integrados en el proceso de planificación estratégica (Gordon y Kelly, 1999). Las características de gestión actuales propias de esta especialidad se resumen, según Wilcox (2006), de la siguiente manera:

- "Relacionar los objetivos de comunicación con los de la organización. 
- Desarrollar relaciones a largo plazo (confianza y credibilidad) con las audiencias claves.

- Hacer hincapié en la comprensión mutua y la resolución de conflictos.

- Formular mensajes coherentes a nivel global usando múltiples canales.

- Formar a la gerencia para implementar estrategias globales a escala local.

- Coordinar las actividades de comunicación de los gerentes locales y los consultores en todo el mundo.

- Mantener y mejorar la reputación de la organización en varios niveles.

- Seguir y analizar las tendencias y los problemas que pueden afectar a la organización",97.

\subsection{CONOCIMIENTOS DE INVESTIGACIÓN}

La investigación se puede definir como la "colecta controlada, objetiva y sistemática de información con el propósito de describir y entender"98 (Broom y Dozier, 1990: 4), como el “enfoque científico para responder preguntas, proporcionar respuestas más fiables en la mayoría de las situaciones en vez de a través de precedentes autoritarios, experiencia personal o histórica"99 (Broom y Dozier, 1990: 4) o, simplemente, como la "colección sistemática e interpretación de información" (Pavlik, 1987: 16). Utilizando métodos científicos de colecta de información, se puede "reducir la influencia del investigador u observador en los hallazgos"100 (Broom y Dozier, 1990: 4), de tal manera que estos "relejen con exactitud la realidad, no solo la percepción del investigador acerca de la realidad" (Broom y Dozier, 1990: 4). Haciendo esto, la investigación se encuentra "en el centro de cómo la función [las relaciones públicas] es gestionada"102 (Broom y Dozier, 1990: 18) y "se eleva desde una visión intuitiva del artista a una parte del sistema de gestión de la organización" 103 (Broom y Dozier, 1990: 18).

La investigación estratégica, a su vez, se define como "la habilidad para recoger sistemáticamente información fiable de públicos grandes y pequeños que afectan a la organización, organizar esa información de una manera manejable y compartir esa información con la coalición dominante para mejorar las decisiones estratégicas" "104 (Dozier, L. A. Grunig y J. E. Grunig, 1995: 42). A lo largo de los años, la importancia que se le otorga a esta faceta dentro de las relaciones públicas ha ido en aumento (Pavlik, 1987: 16-17). James E. Grunig (2006), en su artículo "Research in Public Relations: Current Status and New Directions", expone que, en el campo de la investigación en relaciones públicas, "creo que se ha hecho un gran progreso". Tal y como explica: "Cuando comencé en la profesión (hace 40 años), era probablemente uno de los cinco académicos que investigaban sobre este tema. En la actualidad, hay varios cientos de académicos y estudiantes de doctorado llevando a cabo investigaciones en torno a las relaciones públicas y se publican un buen número de revistas académicas"105. 
Además, hace 40 años, solo unos pocos practicantes utilizaban la investigación en su trabajo, mientras que ahora se emplea habitualmente por numerosos departamentos y firmas de esta disciplina (J. E. Grunig, 2006). De hecho, Botan y Taylor (2004) consideran que "las relaciones públicas pueden estar a punto de convertirse en una de las áreas de la comunicación más investigadas" $" 106$.

Aun así, J. E. Grunig (2006) explica: "La profesión de las relaciones públicas está aún lejos de convertirse en una profesión basada en la investigación. La mayoría de su práctica aún no incluye investigación y mucha de la que se realiza en la práctica de las relaciones públicas solo mide los efectos a corto plazo de los programas de comunicación de marketing"107. Otros autores también lamentan que las relaciones públicas en el contexto europeo no se estudien "a un nivel científico"108 (van Ruler y Verčič, 2004: 4), ni que se realice investigación en las universidades, vistos los pocos artículos publicados en revistas científicas escritos por investigadores europeos. Todo ello lleva a la conclusión de que "las relaciones públicas no se han desarrollado (aún) como un área de alto perfil investigador y docente" "109 (van Ruler y Verčič, 2004: 4). Pavlik (1987: 20) lo achaca a la diferencia de mira (las empresas norteamericanas, al menos en esa época, destinaban más dinero a la publicidad que a las relaciones públicas), a la falta de objetivos concretos y a la característica reactiva de la disciplina. Con más dinero destinado al departamento de relaciones públicas, en cambio, "los profesionales de las relaciones públicas tendrían más libertad para investigar"110 (Pavlik, 1987: 21).

Se debe separar, no obstante, la investigación dentro, para y sobre las relaciones públicas (in, on and for public relations) (J. E. Grunig, 2006). El primer tipo lo utilizan los publirrelacionistas en su trabajo diario, pero "no conlleva un amplio entendimiento teórico de la profesión de las relaciones públicas"" (J. E. Grunig, 2006). La segunda clase es conducida normalmente por los académicos usando un marco teórico que ellos mismos construyen, con el objetivo de identificar las mejores prácticas y mejorar la profesión o, en el caso de los críticos, mostrar las actividades negativas y las debilidades de esas teorías. Finalmente, la tercera modalidad resulta de la investigación sobre la profesión, con la excepción de los críticos. Tal y como explica J. E. Grunig (2006) de esta última visión, "por ejemplo, los investigadores han identificado las mejores prácticas en la comunicación de crisis, en la gestión de conflictos potenciales, en el análisis del entorno y en las relaciones con los medios, y han difundido estas prácticas a los profesionales"112. Una gran parte de la exploración en la actualidad carece de una base conceptual básica y pocas veces se lleva a cabo para y sobre las relaciones públicas (on and for public relations) con el fin de desarrollar un marco conceptual (J. E. Grunig, 2006).

La falta de interacción entre académicos y practicantes es otro impedimento a la hora de avanzar en un mayor campo de conocimiento (J. E. Grunig, 2006), dadas las ideas establecidas de que los primeros se encuentran "en una torre de marfil" mientras 
que los profesionales trabajan "en el «mundo real»"113 (J. E. Grunig, 1979). Recordando lo que J. E. Grunig (2006) piensa al respecto:

"Dado que hay tan pocos profesionales que presten atención a la investigación académica, incluso aquellos que usan la investigación para su trabajo, la profesión sufre de una falta de conceptualización. Los profesionales realizan, compran o hablan sobre la medición, pero la mayoría no piensa (conceptualiza) lo que están midiendo, por qué lo están midiendo o cómo sus mediciones pueden usarse para conseguir unas relaciones públicas o una organización más efectiva" ${ }^{\prime 14}$.

Sin embargo, el papel de los educadores e investigadores "debe ser mantener la profesión - realizar investigación que avance en la profesión y formar la siguiente generación de practicantes", mientras que "los profesionales tienen que acudir a los académicos en busca de ideas para poner en práctica y con ideas que necesiten ser investigadas y analizadas"115 (J. E. Grunig, 1979). En resumen, la relación ideal sería "una simbiosis - cada uno debe proporcionar algo que el otro no pueda"116 (J. E. Grunig, 1979).

\section{Tipos de investigación}

\section{Investigación formal, informal y mixta}

Existen tres modos de abordar la investigación: la formal (o científica), la informal y la mixta (Dozier, L. A. Grunig y J. E. Grunig, 1995: 43-44). La primera es la única que está relacionada con el modelo bidireccional simétrico y, aunque en menor medida, con el bidireccional asimétrico. Este tipo de indagación engloba tanto el análisis científico del entorno (para conocer las perturbaciones del ambiente, como nuevas competencias, huelgas, boycotts, regulaciones, etc.) como la evaluación científica (encaminada a conocer si las estrategias de comunicación han funcionado). Las técnicas de la investigación formal o científica incluyen "encuestas para monitorizar temas, agencias de investigación de la opinión pública y el seguimiento de otras investigaciones del terreno público"117. Tal y como J. E. Grunig y Hunt (1984: 77) señalan, "los profesionales no son científicos, pero deben confiar en las teorías científicas desarrolladas por comunicadores científicos" $" 118$. Asimismo, prosiguen: "Los educadores en relaciones públicas, por otra parte, deben ser tanto científicos como profesionales que realizan investigaciones y aplican esas investigaciones a los problemas de los profesionales" $" 119$. 
La investigación informal, por su parte, conlleva "estar en contacto con los miembros del público, hacer llamadas a las personas que han asistido a una presentación de una organización y comprobar con el personal de campo"120 (Dozier, L. A. Grunig y J. E. Grunig, 1995: 44). Aquí, se hace uso de contactos personales a través de teléfono o correo electrónico, de comités consultivos, de análisis del correo electrónico de la organización, de informes de agentes o vendedores sobre sus evaluaciones u opiniones acerca de la organización, de la cobertura en prensa sobre un determinado tema, de conferencias de las personas envueltas en un determinado asunto, de estudios de encuestas nacionales para hallar el clima y las tendencias, de estudios del voto para conocer la opinión en determinados asuntos, de los discursos de líderes de opinión reconocidos, de los registros de ventas... (Cutlip y Center, 1964: 119-122). Se ha de tener en mente las debilidades de la investigación informal, dado que peca de falta de "representatividad y objetividad"121 (Cutlip y Center, 1964: 119). Por tanto, "mientras que la monitorización informal y oportunista del entorno puede alertar de un problema potencial, se ha de usar las observaciones formales y sistemáticas para explorar, confirmar y describir el problema"122 (Broom y Dozier, 1990: 25). La investigación mixta, por su parte, es la que combina las técnicas científicas con las informales.

Lo más habitual es que los comunicadores utilicen investigación informal, seguida de la mixta (Wilcox, Cameron y Xifra Triadú, 2007: 164). Dividiendo los profesionales por los roles adoptados, se aprecia que los directivos están relacionados significativamente con el método científico e informal, mientras que los técnicos no utilizan ninguno de los dos (Dozier, 1984). Según recogen Wilcox, Cameron y Xifra (2007: 164) de Walter K. Lindenmann, vicepresidente ejecutivo y director de investigación de la firma de relaciones públicas Ketchum, las tres cuartas partes de los publirrelacionistas describen sus técnicas de investigación como informales, más que como científicas, y las herramientas más empleadas son el análisis bibliográfico y la búsqueda de información en bases de datos. La formal, en cambio, es la menos utilizada, probablemente por el tiempo y dinero que consume (Dozier, L. A. Grunig y J. E. Grunig, 1995: 44). Aparte del aspecto económico, para Cutlip y Center (1964: 119), se debe a varios factores más: el lapso de tiempo entre el estudio de opinión y los resultados, la falta de interés de la dirección en conocer la opinión del público, el escaso conocimiento sobre las herramientas de investigación y la reducida confianza en la precisión de estas herramientas.

\section{Investigación básica, introspectiva y aplicada}

Existen diferentes clases de investigación aplicables a las relaciones públicas, y se utilizan unas u otras dependiendo del tema, de la situación y, cómo no, del presupuesto y del tiempo que se posee (Wilcox, Cameron y Xifra Triadú, 2007: 161). La más "abstracta y conceptual"123 es la básica (Pavlik, 1987: 24), que intenta fundamentar la 
disciplina "con nuevas teorías, propuestas metodológicas y descubrimientos" (Martínez Mendoza, 2007). No demasiado abundante en la bibliografía existente, pretende "construir teoría - no contestar a problemas prácticos específicos"124 (Pavlik, 1987: 17). Normalmente, la llevan a cabo "personas experimentadas, con un camino largo y perspicaz en el campo, capaces de refutar viejas concepciones y establecer nuevas miradas y teorías" (Martínez Mendoza, 2007).

Esta clase de exploración "asume que hay una uniformidad en la naturaleza y que el papel del investigador es desarrollar teorías o «leyes» que articulen esa uniformidad" 125 (J. E. Grunig, 1979). Tal y como explica Martínez Mendoza (2007), "sin investigación básica es imposible construir la disciplina de las relaciones públicas", ya que "es necesario sistematizar los conocimientos, crear nuevas teorías, refutar las existentes, intentar definir la opinión pública, el público y la imagen". A pesar de su naturaleza eminentemente teórica, algunos académicos argumentan que en realidad es la más práctica, "porque a través de la articulación de leyes de la naturaleza, el investigador básico puede ayudar al profesional a entender y a intervenir en muchos problemas explicados a través de leyes abstractas - no solo de un único problema" ${ }^{\text {"126 }}$ (Xifra Triadú, 2006). Y es que intenta "incrementar el entendimiento, explicar las relaciones causa-efecto y predecir situaciones o condiciones futuras"127 (Pavlik, 1987: 24).

Otro tipo de investigación es la introspectiva. Es una especie de "examen interno"128 (Pavlik, 1987: 24), dado que representa "estudios que miran por dentro la profesión" 129 (Pavlik, 1987: 23), así como el sistema educativo que sostiene la función (Pavlik, 1987: 24). Se trata de "examinar el campo de las relaciones públicas, sus problemas, desenvolvimientos y singularidades específicas, como la alta participación femenina en la profesión o la actitud ética de los publirrelacionistas". En otras palabras, esta clase de indagación pretende "auscultar el propio campo, conocer su situación, sus actores, dificultades y avances". Una gran parte de la investigación introspectiva se centra, de hecho, en la presencia de mujeres en las relaciones públicas (Martínez Mendoza, 2007).

El tercer tipo de investigación es la aplicada, que está diseñada para "resolver problemas específicos"130 (Pavlik, 1987: 22) y tiene "poca relevancia más allá de solventar ese problema particular"131 (Xifra Triadú, 2006).

Dentro de la investigación aplicada se encuentran la estratégica, la de evaluación (Pavlik, 1987: 23) y, según Broom y Dozier (1990: 18), la de monitorización. La primera constituye un "primer acercamiento a la organización y su valor reside en que presenta un inventario de las deficiencias, logros y posibles reveses de una institución" (Martínez Mendoza, 2007). Se diferencia notablemente de la investigación táctica, la cual recoge información únicamente para generar o distribuir mensajes (Dozier, L. A. Grunig y J. E. Grunig, 1995: 42). Normalmente se analiza la situación (las circunstancias que rodean a la entidad, sus oportunidades y obstáculos), la organización 
[el ambiente interno, la percepción pública y el ambiente externo (competidores y oponentes)] y los públicos (Smith, 2012). Se trata de la exploración encaminada a desarrollar campañas y programas, por lo que se usa normalmente en el proceso de planificación y ayuda a determinar los objetivos y a establecer un punto de partida (Pavlik, 1987: 23). Dozier y Repper (1992: 186) la denominan "monitorización del entorno" o "escaneo del entorno" 132 y es parte de "la etapa de definición del problema de la planificación en relaciones públicas"133 (Dozier, 1986). Se mueve a través de las tres etapas de detección, exploración y descripción del problema (Broom y Dozier, 1990) y, contrariamente a la evaluativa, es "por naturaleza, abierta, inconclusa"134 (Broom y Dozier, 1990).

Dentro de la gestión estratégica de las relaciones públicas se encuentran dos grandes tipos de investigación: la exploración del entorno y la investigación evaluativa. El primer tipo es "exploratorio por naturaleza y vulnerable a un fin prematuro"135 (Dozier y Repper, 1992: 186), ya que se trata de "la detección, exploración y descripción de los problemas de relaciones públicas a través de investigación informal y formal"136 (Broom y Dozier, 1990: 24), entendiendo problemas como "condiciones en los que alguien cree que hay una diferencia entre lo que se percibe y lo que se desea"137 (Broom y Dozier, 1990: 24). La exploración del entorno permite, por panto, la “detección temprana de problemas emergentes así como la cuantificación de problemas existentes o conocidos en el entorno"138 (Dozier y Repper, 1992: 186-187). Para ello utiliza técnicas como grupos focales o cuestionarios a públicos específicos (Dozier y Repper, 1992: 187).

La de monitorización, que es el tercer tipo de investigación aplicada según Broom y Dozier (1990: 18) se utiliza para diferentes fines. El principal es para comprobar los esfuerzos y actividades del programa con el fin de detectar "dónde y cómo el programa necesita ser ajustado"139 (Broom y Dozier, 1990: 69). También sirve para conocer la responsabilidad de la ejecución y para hallar qué ha causado los cambios que se evaluarán posteriormente (Broom y Dozier, 1990: 18, 50 y 69). Esto puede hacerse cambiando los objetivos que se hayan propuesto como esfuerzos por resultados, analizando el contenido de los mensajes y vincularlos a las consecuencias, calculando la legibilidad, siguiendo los efectos y describiendo las audiencias y estudiando su atención a los mensajes (Broom y Dozier, 1990: 51-68).

En cambio, la de evaluación se utiliza "para medir el impacto o efectividad del programa con respecto a las metas y objetivos" ${ }^{\prime 10}$ (Broom y Dozier, 1990: 18) para incrementar la credibilidad (Broom y Dozier, 1990: 75). Es decir, está diseñada para "determinar en qué medida los programas de relaciones públicas funcionan correctamente"141 (Dozier y Repper, 1992: 186). A pesar de que es una técnica muy descuidada, dado que a los publirrelacionistas "les agrada más actuar y comunicar que evaluar sus propios procesos" (Martínez Mendoza, 2007), John Marston (1990) recomienda analizar los esfuerzos por lo menos una vez al año. "Ignorar esta última 
etapa de las relaciones públicas- dice Martínez Mendoza (2007)- dejaría inconcluso el trabajo". Y es que la investigación evaluativa "ayuda a reducir la incertidumbre en la toma de decisiones"142 y puede usarse "para mejorar futuros programas"143 (Broom y Dozier, 1990: 88). Normalmente son los profesionales que adoptan el rol directivo los que más emplean este tipo de investigación (Vieira Jr. y Grantham, 2014). En esta etapa se recomienda medir los objetivos propuestos en la fase de planificación y se han de emplear las mismas herramientas de medición antes y después de la campaña (Broom y Dozier, 1990: 82). Se pueden calcular, por ejemplo, tres variables que, según el modelo de co-orientación, describen las relaciones: el entendimiento mutuo, la precisión y la congruencia (Broom, 1977).

\section{Investigación de preparación, de implementación y de impacto}

Tal y como señalan Dozier y Repper (1992: 187-190) de Cutlip, Center y Broom (1985), la investigación contiene tres niveles: la evaluación de preparación, la evaluación de la implementación y la evaluación del impacto. El primer tipo, a su vez, se subdivide en adecuación de la información contextual, lo apropiado del contenido del mensaje y la organización y la calidad de las presentaciones del mensaje (Dozier y Repper, 1992: 187). Las técnicas más comunes para lograrlo son los test de mensajes y los grupos focales, aunque también se suele hacer uso de test de legibilidad para conocer la dificultad para entender un texto (Dozier y Repper, 1992: 187). En la evaluación de la implementación se incluyen medidas para determinar los mensajes enviados (la distribución), los publicados (la cobertura), los recibidos (la circulación y el alcance) y los atendidos por los públicos [Dozier y Repper (1992: 188) citando a Cutlip, Center y Broom (1985)]. La evaluación del impacto, por su parte, es la que tiene "una mayor relevancia a la hora de determinar el impacto del programa" (Dozier y Repper, 1992: 188). La herramienta básica de esta fase, dicen estos autores, es la encuesta (Dozier y Repper, 1992: 189), aunque destacan que debe integrarse en un diseño experimental o cuasi-experimental que pueda aislar los efectos del programa de otros ajenos (Dozier y Repper, 1992: 190).

\section{Otros tipos de investigación}

También existen otras clasificaciones de los distintos tipos de aproximación. Pavlik (1987: 15), por ejemplo, las divide en investigación descriptiva (la que se encarga de relatar un proceso, una situación o un fenómeno), explicativa (se ocupa de narrar porqué sucede algo) y la investigación de pronóstico (trata qué sucederá o qué es más probable que ocurra). También puede realizarse de manera pre-experimental (cuando no se permiten inferencias causales), experimental (los que permiten fuertes inferencias causales) o cuasi-experimental (aquellos que usan muestras distintas como sustitutas de 
los grupos de control y tratamiento por no poder asignarse grupos aleatoriamente) (Broom y Dozier, 1990: 100-101 y 110). Ana Belén Fernández Souto (2004: 36) proporciona otra clasificación: investigación motivacional (ayuda a fijar objetivos y estrategias persuasivas), pretest, postest e investigación de medios y soportes. También existe la división entre investigación primaria ("en la que se recopila información nueva y original a través del diseño de una investigación específica, dirigida a responder a necesidades concretas") y la secundaria ("se extrae de la información existente en libros, artículos de revistas, bases de datos electrónicos, etcétera") (Wilcox, Cameron y Xifra Triadú, 2007: 164-165).

\section{Paradigmas de investigación}

Una investigación desde el punto de las relaciones públicas se puede abordar desde un paradigma cualitativo, cuantitativo o híbrido. El primero persigue crear tendencias generalizables y sus datos son susceptibles de tratamiento estadístico (Lozano Rendón, 2007: 10). Esta técnica, herencia del positivismo norteamericano, sostiene la tesis de que todo fenómeno puede ser experimentado y medido y sus resultados suelen expresarse en números (Martínez Mendoza, 2007).

El paradigma cualitativo, por su parte, ayuda a contextualizar y encuadrar hipótesis, algo que no se puede realizar desde un punto de vista exclusivamente cuantitativo (Wimmer y Dominick, 1996: 148). Intenta contestar la pregunta “¿por qué sucede?”, en lugar de “¿qué sucede?”, que es la que fórmula del enfoque cuantitativo (Martínez Mendoza, 2007). Las relaciones públicas, por su nacimiento y crecimiento en Estados Unidos, han recibido una influencia mayor de este último, aunque "el cualitativo se ha ido abriendo paso, con resultados cada vez más alentadores” (Martínez Mendoza, 2007).

En la actualidad, está aumentando el número de trabajos que fusionan las ópticas cuantitativas y cualitativas bajo lo que se denomina como paradigma mixto o híbrido. La fusión de estos perfiles, no obstante, no ha cuajado en el seno de ninguna de las partes implicadas, ya que consideran que las visiones son "irreconciliables" (Martínez Mendoza, 2007).

No obstante, la utilización del método cualitativo y cuantitativo de forma independiente pero apoyados en el mismo fin dentro de una misma investigación compone lo que muchos teóricos denominan el fenómeno de la triangulación, un método que se está convirtiendo en un esquema común de las empresas y las universidades (Casetti y Di Chio, 1999: 333), aunque no muy empleado en las relaciones públicas (Lim y Jones, 2010). Se produce una triangulación metodológica cuando se emplean al menos dos técnicas de investigación (pueden ser cualitativa y cualitativa) o dos metodologías distintas con el objetivo de conocer y analizar un mismo objeto. Se trata de la fase más avanzada de la integración de varios enfoques 
(complementación, combinación y triangulación), puesto que convergen los resultados de todos ellos para que alcancen las mismas conclusiones (Rodríguez Breijo, 2009). Gracias a esta mezcla, se compensan las debilidades de un método con otro distinto y así se consiguen los resultados "más fiables y enteramente satisfactorios" (Elías, 2000: $38)$.

\section{Herramientas de investigación}

Las herramientas de investigación pueden agruparse en tres bloques, según Pavlik (1987: 32): las encuestas, los métodos no obstructivos y las observaciones. Las dos primeras son las más frecuentes, puesto que el tercer tipo, "aunque bastante poderoso, normalmente es más caro y requiere un mayor compromiso de tiempo y recursos humanos"144 (Pavlik, 1987: 32). Dentro de las dos primeras, las encuestas son el método más utilizado en investigación en relaciones públicas (Pavlik, 1987: 32). Pueden ser descriptivas ("para obtener una imagen de la situación o condición actual"145) o analíticas ("diseñadas para responder cuestiones que las descriptivas no pueden hacer"146, tales como el porqué) (Pavlik, 1987: 33). Pueden tomar muchas formas (estructuradas, no estructuradas, abiertas, cerradas...), administradas de varios modos (por teléfono, por correo postal o electrónico, cara a cara, etc.) y estadísticamente o no estadísticamente fiables (Pavlik, 1987: 32-38).

Por su parte, los métodos no obstructivos ofrecen al investigador la oportunidad de "estudiar el comportamiento humano sin «entrometerse» en ese comportamiento" "147 (Pavlik, 1987: 38). Aquí se engloban, entre otros, el análisis de contenido y los estudios de legibilidad (Pavlik, 1987: 38-40). Los servicios de clipping también se encontrarían en este grupo. Son unas herramientas útiles sobre todo en la investigación de implementación, de donde se puede determinar el número de impactos, la modificación del contenido, los medios que publican las noticias, etc. (Dozier y Repper, 1992: 194196). Hay que tener en cuenta, pese a todo, que la publicity no puede evaluarse de la misma forma que la publicidad y que las noticias divulgadas "son necesarias pero no una condición suficiente para que ocurra un impacto sobre el programa""148 (Dozier y Repper, 1992: 194). Tal y como indican estos autores, "solo porque un miembro de un público objetivo esté suscrito a una revista donde el mensaje ha sido colocado no garantiza que realmente lea el mensaje, lo entienda y lo retenga" ${ }^{\text {149 }}$ (Dozier y Repper, 1992: 196).

El análisis de contenido, por su parte, permite conocer la "calidad de esos mensajes"150, es decir, "cuantificar lo que se dice sobre una organización"151 (Dozier y Repper, 1992: 198). Para ello, se suele anotar el nombre y tipo de publicación, la fecha de publicación, la sección en la que aparece, la longitud, las valoraciones de la información, la presencia o ausencia de temas concretos, los adjetivos utilizados, etc. (Dozier y Repper, 1992: 198-199). Hay que tener en cuenta, no obstante, que el 
contenido de los medios no equivale a impacto del programa (Dozier y Repper, 1992: 199).

Finalmente, los métodos de observación son aquellos que permiten "una medida directa del comportamiento humano" personas en su entorno natural a observaciones controladas en un laboratorio"153 (Pavlik, 1987: 41). Aquí entrarían los experimentos -tanto en laboratorio como sobre el terreno (Broom y Dozier, 1990: 101) y definidos como intensivos, extensivos o mixtos (Broom y Dozier, 1990: 143-144)-, que son la herramienta "más poderosa para determinar la causa-efecto"154 (Broom y Dozier, 1990: 102). En este grupo también se englobarían las entrevistas en profundidad y los grupos focales (Broom y Dozier, 1990: 145-149). Estos últimos son una herramienta eficaz para detectar conflictos emergentes y escanear el entorno y son relativamente baratos y rápidos de organizar, a pesar de que no permiten generalizaciones por no ser estadísticamente fiables (Dozier y Repper, 1992: 191-194). También pueden servir para probar mensajes antes de emitirlos o para evaluar cualitativamente los resultados de una campaña.

Al margen de las expuestas, existen otras técnicas para conocer la opinión y valores del público: las encuestas de corte transversal, los paneles de encuestas, la prueba del diferencial semántico (Cutlip y Center, 1964: 122-124) o las auditorías, los estudios de caso y la etnografía, por ejemplo (Martínez Mendoza, 2007). La búsqueda de materiales propios de la organización, las bases de datos online, Internet, los test de mensajes o los muestreos científicos son otras herramientas a favor de la investigación (Wilcox, Cameron y Xifra Triadú, 2007: 164-185). También se puede echar mano de las publicaciones gubernamentales y comerciales, de bibliotecas, de periódicos, de informes industriales, etc. (Cutlip y Center, 1964: 116).

\subsection{CONOCIMIENTOS SOBRE NUEVAS TECNOLOGÍAS}

Aunque no fueron propuestas como parte del conocimiento que contribuyen a lograr unas relaciones públicas excelentes, según Dozier, L. A. Grunig y J. E. Grunig (1995: 10), las nuevas tecnologías están cada vez más presentes en el mundo de la comunicación. La mayoría de las herramientas de este universo son gratuitas, fáciles de usar y permiten obtener retroalimentación o feedback de la audiencia. En general, las empresas de nuevas tecnologías son, precisamente, las primeras en adoptar este tipo de tácticas (Porter y Sallot, 2003; Porter et al., 2001; Taylor y Perry, 2005), aunque poco a poco se están haciendo un hueco en toda clase de entidades. Respecto a la importancia de este universo en las relaciones públicas, algunos autores piensan que "es prácticamente imposible practicar relaciones públicas eficaces actualmente sin utilizar internet"155 (Newsom, Turk y Kruckeberg, 2000). 
El uso de la investigación que se ha realizado hasta el momento al respecto se ha centrado únicamente en las herramientas (Facebook, Twitter, etc.). A pesar de ello, tal y como asegura Kent (2014), la cuestión importante son los stakeholders, los públicos, la comunicación, los asuntos relacionales y el avance en el cuerpo de conocimiento de la profesión. Es decir, es más importante decidirse por la información que se suministra y se obtiene y por los públicos en vez de obcecarse por los canales (Kent, 2014).

En consecuencia, dicen Kent y Saffer (2014), los publirrelacionistas deben expandir su entendimiento más allá de la "visión miope" y considerar sus implicaciones sociales y relacionales en vez de centrarse únicamente en su práctica. Y es que, según Ginesta y Ordeix (2011), se han producido tres tipos de modificaciones en la gestión de los valores de las organizaciones durante la era digital: organizativos, comunicativos y actitudinales. Respecto al primer tipo, los autores opinan que se ha experimentado un "cambio de paradigma en la tipología de sistemas organizativos", por lo que se ha adoptado un sistema más abierto y dinámico, que se adapta al entorno. En cuanto a la segunda clase de transformación, se encuentran las nuevas tecnologías de la información y comunicación, que "han provocado un cambio fundamental en los procesos comunicativos, especialmente en los campos estratégicos, como los recursos humanos, las relaciones públicas y el márketing". Finalmente, los actitudinales reflejan "nuevas actitudes de marca y nuevas concepciones en la gestión de la cultura organizativa, y viceversa", puesto que las entidades se muestran más éticas (en cuanto a "honestidad, transparencia, humanidad, compromiso").

La verdadera importancia del uso de las nuevas tecnologías reside, entonces, en su empleo como método dialógico, y por ello, el modelo simétrico bidireccional es el más idóneo para obtener una mayor interacción (Cho, Schweickart y Haase, 2014). Kent y Taylor (1998) proponen cinco principios básicos para establecer una comunicación en internet -entablar un círculo de diálogo, suministrar información útil, generar visitas de retorno, proporcionar una interface intuitiva y sencilla y conservar a los visitantes-, a los que Pettigrew y Reber (2011) añaden un sexto: iniciación y mejora de la relación. Y es que las personas prefieren los mensajes basados en el diálogo, aunque sean más propensas a compartir mensajes unidireccionales (Saxton y Waters, 2014). Asimismo, los mensajes que llaman a la acción son los que obtienen un mayor compromiso (Saxton y Waters, 2014). También hay evidencias de que la interactividad (sobre todo a través de los enlaces y de la participación) de un sitio web influye en la reputación de la organización (Guillory y Sundar, 2014), así como que las compañías que responden a los comentarios se consideran más fiables, más comprometidas y se tiene la percepción de que poseen un mayor control de la mutualidad, de las relaciones comunales y una mayor satisfacción que las que no responden (Lee y Park, 2013).

Aunque las organizaciones suelen ser excelentes en niveles de usabilidad en internet, no están sacando pleno partido a los elementos de framing o encuadre (Zoch et al., 2008) y a las posibilidades dialógicas (Adams y McCorkindale, 2013; Auger, 2013; 
Avidar et al., 2013; Bortree y Seltzer, 2009; Capriotti y Moreno, 2007; Capriotti y Pardo Kuklinski, 2012; Capriotti, 2007; Connolly-Ahern y Broadway, 2007; Etter, 2013; Gomez y Chalmeta, 2011; Gordon y Berhow, 2009; Ingenhoff y Koelling, 2009; Jun, 2011; Kang y Norton, 2004, 2006; Kim, Nam y Kang, 2010; Kirat, 2007; Lee, 2012; Linvill, McGee y Hicks, 2012; Lovejoy, Waters y Saxton, 2012; McAllister y Taylor, 2007; McAllister, 2012; Muralidharan et al., 2011; Park y Reber, 2008; Searson y Johnson, 2010; Sebastião, 2013; Sommerfeldt, Kent y Taylor, 2012; Uzunoğlu y Misci Kip, 2014; Waters et al., 2009; Yang y Taylor, 2010; Zerfass y Schramm, 2014). Únicamente se ha encontrado un artículo en el que se afirme que las organizaciones (en este caso de la American Red Cross) hace uso de los medios de comunicación social de manera bidireccional y dialógica (Briones et al., 2011) y otro que sostiene que las compañías del Fortune 500 han incrementado su presencia en la web y que los componentes dialógicos para los periodistas están mejorando (Pettigrew y Reber, 2010).

Tampoco ayuda que, hasta el momento, no se hayan aportado marcos teóricos que ofrezcan una guía de uso de nuevas tecnologías, que exista una dominancia de la investigación cuantitativa frente a la cualitativa y un énfasis demasiado acentuado en el uso de internet sobre otro tipo de herramientas (Ye y Ki, 2012). Los publirrelacionistas no suelen evaluar los resultados, ni conectan las acciones que realizan a la estrategia de comunicación ni obtienen medidas concretas y significativas del impacto (DiStaso, McCorkindale y Wright, 2011).

Además, estos profesionales han adoptado las herramientas más establecidas e institucionales (como el correo electrónico y la intranet), pero aún se sienten incómodos con las herramientas más modernas (como los blogs y los podcasts) y no utilizan prácticamente nunca otros medios como los mundos virtuales, los marcadores, los agregadores de noticias, los videojuegos, los micro-blogs... (Alikilic y Atabek, 2012; Eyrich, Padman y Sweetser, 2008; Verhoeven et al., 2012). También existen otra serie de herramientas de las que pueden echar mano, como los vídeo ipods (Wilcox, 2006), los videocomunicados (Saura Pérez, 2000), intranet, las videoconferencias o la realidad aumentada (Castillo Esparcia, 2006), entre otras muchas.

Con todo, Kent (2008) aconseja esperar a que los académicos de las relaciones públicas determinen la influencia de las herramientas tecnológicas. Efectivamente, se necesita que las publicaciones científicas incluyan estudios colaborativos entre profesionales y académicos y que se propicie un diálogo entre ambos sobre estos temas (Taylor y Kent, 2010). Algunos estudios realizados por PEW Internet y American Life Project, por ejemplo, sugieren que los nuevos medios de comunicación social son herramientas más personales que de negocios [algo que también corrobora el estudio de Friedl y Verčič (2011), aunque poco después se detectase lo contrario con estudiantes universitarios (Tkalac Verčič y Verčič, 2013)], a pesar del auge de estos medios en el mundo empresarial. Y es que los medios de comunicación social pueden jugar un papel a la hora de incrementar la visibilidad de una organización, pero la investigación ha 
demostrado que su papel es mucho más pequeño de lo que se pensaba (Yang y Kent, 2014).

A pesar de estas alertas del mundo académico, los profesionales siguen usando estas herramientas como si fueran primordiales (Kent y Saffer, 2014). Lo más recomendable, no obstante, es preguntarse qué entidades necesitan los nuevos medios de comunicación social (ya que probablemente no lo necesitan todas) y cómo pueden estas plataformas ayudar a la comunicación offline (en vez de intentar concretar el beneficio económico directo), tal y como destacan Kent y Saffer (2014). Las compañías no han de pensar que Facebook, por ejemplo, es la "panacea", concretan Kinsky et al. (2014), sino que tienen que verlo como otro vehículo más. Resumiendo, la estrategia del social media debe estar supeditada por las decisiones estratégicas (Agostino, 2013).

Asimismo, se debe disponer de personal capacitado. Hablando sobre blogs, pero aplicable a cualquier otra herramienta, Kent (2008) recomienda no embarcarse en ninguno hasta que una entidad encuentre a alguien que lo mantenga, que esté entrenado en comunicación efectiva dialógica y que tenga la confianza de individuos y públicos. Al fin y al cabo, las páginas web, los blogs, las redes sociales, etc., son solo herramientas y depende de la experiencia de los publirrelacionistas utilizar una u otra (Rybalko y Seltzer, 2010).

Introducir nuevas tecnologías en una organización, no obstante, no es una tarea sencilla, ya que requiere de una serie de requisitos básicos. Según Castillo Esparcia (2006), en primer lugar se ha de sopesar si la herramienta que se quiere introducir es realmente útil. Si es así, el paso siguiente es establecer una estrategia de comunicación. Asimismo, aparte de la mera implantación, se ha de explicar y fomentar su uso entre los diferentes públicos para que la utilicen adecuadamente. Castillo Esparcia (2006) propone una lista de recomendaciones a tener en cuenta cuando se quieren implantar este tipo de canales:

"Implementar los instrumentos de comunicación para preparar y educar a los empleados en la predisposición a participar en los cursos de formación. Con explicación de las ventajas que va a aportar la participación y los posibles inconvenientes.

Adoptar una dinámica gradual en la que las personas se puedan ir adaptando al cambio.

Pensar que es un proceso dinámico y permanente que no finaliza con la instalación del material, sino que posteriormente es imprescindible saber utilizarlo y eso exige formación.

Apostar decididamente por la acción y sin ambivalencia, ya que los que deban utilizarla también adoptarán la misma posición. 
Estimular la participación de los empleados con sugerencias en la mejora de su utilización.

Modular la introducción en los momentos más adecuados, entendiendo que existe mayor pertinencia en unas situaciones que en otras.

Conocer las inquietudes del público interno ante la aplicación e introducción de las tecnologías; para ello es necesario averiguar su actitud ante esa decisión para poder realizar las actividades comunicativas pertinentes".

Hay evidencias de que las nuevas tecnologías ayudan a conseguir unas relaciones públicas más excelentes. Por ejemplo, adoptar estas herramientas incrementa el poder e influencia de los publirrelacionistas dentro de sus organizaciones (Porter y Sallot, 2003; Porter et al., 2001). No existen diferencias entre el rol técnico y directivo en el uso de redes sociales (Diga y Kelleher, 2009), pero los usuarios frecuentes de los medios de comunicación social consideran que tienen más altas percepciones de tres tipos de poder (estructural, experto y prestigio) (Diga y Kelleher, 2009; Porter y Sallot, 2005; Porter et al., 2007), a los cuales Sallot, Porter y Acosta-Alzuru (2004) añaden un cuarto: propiedad. Asimismo, el uso de redes sociales, más concretamente de Twitter, se relaciona directamente con la motivación interna y negativamente con la falta de motivación (Sweetser y Kelleher, 2011).

Por otra parte, la interactividad (es decir, utilizar la comunicación como una herramienta bidireccional) en Twitter de una compañía influye en la calidad de las relaciones (Saffer, Sommerfeldt y Taylor, 2013). Asimismo, funciona como un vehículo para transmitir información rápida en la fase inicial de una crisis y así evitar la escalada del conflicto y poder enmarcar la negociación y el posicionamiento (Van der Meer y Verhoeven, 2013). Por otra parte, las personas que leen blogs perciben un menor nivel de crisis que aquellas que no están expuestas a estas plataformas, siempre y cuando este tenga credibilidad, que suele conseguirse con más frecuencia en los blogs organizacionales, seguidos de los personales (Sweetser y Metzgar, 2007). Asimismo, hay un efecto directo entre el uso de la página web de una compañía por parte de los consumidores y las percepciones de responsabilidad social corporativa y la confianza en la empresa. También tiene efectos indirectos en el boca-oreja positivo debido a la confianza alcanzada (Hong y Rim, 2010). Y es que los mensajes publicados por la audiencia en los medios de comunicación social son predictores importantes de las evaluaciones de los públicos, por lo menos en situaciones de crisis (Schwarz, 2012).

Otro ejemplo de las bondades de las nuevas tecnologías es que las compañías que postean con frecuencia en internet reciben menos comentarios negativos, aunque solo si adoptan una comunicación bidireccional (Wigley y Lewis, 2012). En cambio, las que no escriben apenas en Twitter son las que reciben más menciones en esta red social, debido 
al vacío que dejan y que tiene que llenarse con información por parte de la audiencia, la cual no puede controlarse (Wigley y Lewis, 2012). Aunque el uso de Twitter no está relacionado directamente con la evaluación de las organizaciones, sí que afecta directamente a la percepción de liderazgo y evaluación del CEO, lo que puede influir, finalmente, en la actitud hacia la organización (Hwang, 2012).

Asimismo, existe un vínculo entre la participación online y offline, al menos en el terreno político; es decir, aquellas personas activas en la red sobre estos temas también lo son en la vida real (Vesnic-Alujevic, 2012). Así, las experiencias con los servicios online informales y con el social media están asociados a una mayor confianza con el gobierno local y estatal (Hong, 2013). De hecho, el uso de Twitter incrementa significativamente las posibilidades de ganar unas elecciones presidenciales, incluso controlando por cargo y afiliación.

Aun así, el simple hecho de twittear no asegura que se vayan a conseguir los objetivos propuestos, sino que es la interacción lo que modifica el resultado de las elecciones (LaMarre y Suzuki-Lambrecht, 2013). No hay que olvidarse, por ello, de los canales tradicionales cuando se empiezan a utilizar los nuevos (Moody, 2011), dado que son los medios de comunicación tradicionales los que afectan significativamente la visibilidad en los nuevos medios y no tanto al contrario (Yang y Kent, 2014).

\subsection{OTROS CONOCIMIENTOS}

Existen otros conocimientos al margen de los ya expuestos que ayudan a crear unas relaciones públicas excelentes. Uno de ellos es el conocimiento global, dada la "tendencia a la globalidad" que está experimentando la sociedad actualmente, que "supera los principios de multinacionalidad y transnacionalidad" y que "genera una dinámica que se interpreta, en cierta medida, en la cultura de las organizaciones, tanto en el ámbito nacional como internacional" (Noguero i Grau, 2006). Tanto es así que incluso el apoyo de la opinión pública de fuera de un país puede resultar en una mayor aceptación y autoridad de las políticas de gobierno de ese territorio, como comprobaron Ordeix y Ginesta (2011) con el caso de Estados Unidos. En consecuencia, algunos autores recomiendan que desde los estudios universitarios se enseñe cómo manejar y coordinar campañas internacionales lideradas por multinacionales o trabajar para organizaciones extranjeras (García, 2010). Y es que los países que invierten más en relaciones públicas internacionales gozan de un número mayor de importaciones, reciben más inversiones directas de inversores y reciben un mayor número de turistas, al menos, nuevamente, en Estados Unidos (Lee y Yoon, 2010).

Con el fin de ayudar a construir unas relaciones públicas globales, Verčič, Grunig y Grunig (1996: 37-52) introdujeron nueve principios generales y cinco variables del entorno. Los primeros son: la participación en la gestión estratégica, el empoderamiento 
en la coalición dominante o informar directamente a la alta dirección, integrar la función de relaciones públicas, emplearla como una función estratégica separada de otras secciones, el rol directivo de los practicantes, el modelo simétrico bidireccional, un modelo simétrico de comunicación interna, conocimiento potencial del rol directivo y las relaciones públicas simétricas y diversidad plasmada en todos los roles. J. E. Grunig (2009) añade a esta selección la ética y responsabilidad social. Por otra parte, las cinco variables del entorno son: el sistema político-económico, la cultura, el alcance del activismo, el nivel de desarrollo y el sistema mediático. Posteriormente, Sriramesh y Verčič (2003: 2-17) reducirían estas cinco variables a tres factores. El primero de ellos es la infraestructura del país, dentro de la cual se engloba el sistema político, el nivel de desarrollo económico, el activismo y el sistema legal. El segundo factor es la cultura, tanto la social como la corporativa. Finalmente, el tercer factor hace referencia a los medios de comunicación, en cuanto a su papel para crear la imagen de la nación y el control, difusión y acceso a los medios.

Dozier, L. A. Grunig y J. E. Grunig (1995: 63-72), por su parte, proponen siete modos para adquirir conocimiento con el fin de adoptar unas relaciones públicas excelentes: conocer el negocio, autoaprendizaje, seminarios de asociaciones profesionales, tutorizar alumnos, formación del departamento, acreditación y educación superior $^{157}$. Según indican estos autores, conocer la empresa donde se trabaja proporciona "más comprensión de los desafíos y oportunidades que afronta la organización" "158, así como una "mayor credibilidad con los altos directivos, que esperan que todos los trabajadores de alto nivel de la organización entiendan el negocio"159 (Dozier, L. A. Grunig y J. E. Grunig, 1995: 65).

Dentro del conocimiento del negocio que proponen Dozier, L. A. Grunig y J. E. Grunig (1995: 63-72) se podrían incluir dos propuestas lanzadas por dos grupos de autores. Uno de ellos es el de economía y dirección, sugerido por Verčič y Grunig (2008: 9-58), disciplinas necesarias para "explicar las contribuciones que la gestión de las relaciones públicas hacen a la gestión general de las organizaciones"160 (Verčič y Grunig, 2008: 9). El otro, más específico, tiene que ver con el conocimiento sobre presupuestos. Según indican Dozier, L. A. Grunig y J. E. Grunig (1995: 35), al margen de los conocimientos directivos, bidireccionales y de investigación, también es importante saber calcular y sopesar costes, dado que "cuanto más estratégico sea un departamento de comunicación, más sofisticados se convertirán los temas sobre presupuesto"161 (Dozier, L. A. Grunig y J. E. Grunig, 1995: 35). Esto es así porque "los departamentos de comunicación excelentes ajustan y reestructuran los programas constantemente para responder dinámicamente y cambiar las relaciones con los públicos estratégicos" $" 162$ (Dozier, L. A. Grunig y J. E. Grunig, 1995: 35).

El segundo consejo que proporcionan Dozier, L. A. Grunig y J. E. Grunig (1995: 63-72) para lograr unas relaciones públicas excelentes es el autoaprendizaje, que, aunque requiera motivación y tiempo personal, es barato, flexible y autodidacta. Los 
seminarios y grupos de trabajo de las asociaciones profesionales ofrecen una enseñanza intensiva sobre varios temas donde se puede interactuar con otros participantes, aunque, normalmente, se requiere el apoyo activo de la empresa para que los profesionales de las relaciones públicas puedan acudir (J. E. Grunig y Hunt, 1984: 70-72). La tutorización, es decir, "el entrenamiento estructurado o no estructurado de comunicadores junior para que aprendan los entresijos de la organización y desarrollen habilidades avanzadas, proporcionado por un superior $\mathrm{u}$ otro individuo apropiado de la organización" "163 (Dozier, L. A. Grunig y J. E. Grunig, 1995: 67), puede ser otra buena forma para aprender nuevas habilidades.

Los talleres destinados al departamento de comunicación incrementan el nivel de conocimiento de toda la unidad, aunque necesitan planearse y adaptarse a las necesidades del gabinete y requieren el apoyo activo de la dirección, así como el tiempo y los recursos económicos. Al intentar acreditarse profesionalmente, los aspirantes repasan o fomentan los conocimientos sobre la gestión de la comunicación y obtienen un reconocimiento profesional (J. E. Grunig y Hunt, 1984: 72). Por ello, no se sostiene la idea de que la edad y la experiencia profesional sean sustitutos suficientes de una acreditación (Sha, 2011). A pesar de ello, solo de una cuarta parte a un tercio de los profesionales de Estados Unidos, por ejemplo, están acreditados (J. E. Grunig y Hunt, 1984: 72).

El último aspecto que destacan Dozier, L. A. Grunig y J. E. Grunig (1995: 63-72) es la educación superior, donde se adquieren "los conocimientos más profundos" "164 (Dozier, L. A. Grunig y J. E. Grunig, 1995: 70). A pesar de ello, aún no todos los profesionales de las relaciones públicas cuentan con diplomas superiores. J. E. Grunig y Hunt (1984: 77-78), por ejemplo, explican que, en 1984, "muchos, si no la mayoría"165 de los profesionales no contaban con educación formal en relaciones públicas. Pudiéndose impartirse en diversos departamentos universitarios, el currículo de esta disciplina debería contar con una educación liberal amplia, habilidades de comunicación, conocimientos para la gestión en relaciones públicas, conocimientos sobre la organización para la cual trabaja el publirrelacionista y experiencia práctica (J. E. Grunig y Hunt, 1984: 78-79). Los miembros de los departamentos excelentes de relaciones públicas han estudiado esta disciplina formalmente y suelen leer publicaciones profesionales, a pesar de que no tienden a pertenecer a este tipo de asociaciones profesionales más a menudo que los empleados de departamentos menos excelentes (L. A. Grunig, J. E. Grunig y Dozier, 2002: 88).

Finalmente, otro aspecto cada vez más instaurado en las relaciones públicas actuales es la responsabilidad social corporativa. Las grandes empresas utilizan esta táctica "como forma de reafirmar la identidad y personalidad y de cohesionar la cultura corporativa", así como para "determinar públicamente sus compromisos culturales, sociales o medioambientales" (Ordeix Rigo y Tió Bragado, 2010). No obstante, las empresas tienen "una doble moral en la justificación y razones" que aportan (Ordeix 
Rigo y Tió Bragado, 2010). Tal y como explican, "muchas empresas alardean de trabajar por el interés general, pero, por otro lado, este interés general parece convertirse en interés privado cuando observamos que las empresas que desarrollan estas políticas obtienen elevados beneficios, en parte, gracias a ello. Los efectos de la opinión pública y las influencias que puedan tener los medios en estos aspectos afectan de forma muy evidente el valor de la cotización de sus acciones y, a su vez, el valor intangible de la marca". En conclusión, "ser ético acaba siendo rentable a medio y largo plazo, pues existe una mayor fidelidad de sus públicos y una mejor construcción de los principios que definen la marca" (Ginesta y Ordeix Rigo, 2011).

\subsubsection{EXPECTATIVAS COMUNES, PODER Y RELACIÓN CON LA DIRECCIÓN}

\subsection{EXPECTATIVAS COMUNES ACERCA DE LA COMUNICACIÓN}

La práctica de las relaciones públicas en una entidad está condicionada por la visión que tengan los gerentes acerca de ella, ya que, tal y como Cutlip y Center (1964: 206) señalan, "la dirección de una empresa determina el ámbito, lugar y, en gran parte, la efectividad de las funciones del personal”. Según destacan estos autores de Clarence J. Myers cuando era presidente de New York Life Insurance Company, "si la dirección piensa en la función de las relaciones públicas de manera limitada, ocupará un espacio pequeño en la estrategia de la compañía y su contribución será pequeña. Si la dirección piensa que es importante, ocupará un espacio prominente y su contribución será significativa" ${ }^{" 166}$. Así, la coalición dominante es la que tiene el poder para decidir qué modelo de relaciones públicas se practica, incluso aunque los miembros de esta disciplina pertenezcan a la élite de la entidad (J. E. Grunig y L. A. Grunig, 1989b).

Tal y como Dozier, L. A. Grunig y J. E. Grunig (1995: 59) mantienen, "la comunicación excelente sucede cuando las organizaciones demandan prácticas bidireccionales a sus departamentos de comunicación"167. Y es que la adopción de prácticas bidireccionales requiere el entendimiento y apoyo de la coalición dominante; en las organizaciones con una comunicación menos excelente, la dirección suele concebir la comunicación como un apoyo técnico y, por lo tanto, no exige tan a menudo prácticas bidireccionales (Dozier, L. A. Grunig y J. E. Grunig, 1995: 90). Conviene señalar, no obstante, que las direcciones de las organizaciones no diferencian claramente los dos modelos bidireccionales y que tienden a englobar ambas en uno solo (Dozier, L. A. Grunig y J. E. Grunig, 1995: 100-101).

La falta de adopción de prácticas bidireccionales simétricas sucede, normalmente, por "el aislamiento de los comunicadores de la planificación estratégica y de la toma de 
decisiones"168 (Dozier, L. A. Grunig y J. E. Grunig, 1995: 94). En cambio, cuando lo que falta es una comunicación bidireccional asimétrica, suele ser debido a la escasa experiencia o conocimiento de los comunicadores acerca de este modelo, ya que no son capaces de proporcionarlo (Dozier, L. A. Grunig y J. E. Grunig, 1995: 95). Y es que "la experiencia normalmente -aunque no siempre- va primero. Las coaliciones dominantes tienden a valorar y apoyar a los comunicadores que primero demuestran su valor" 169 (Dozier, L. A. Grunig y J. E. Grunig, 1995: 104).

Con todo, resumen los autores del Excellence Study, "la excelencia sucede cuando las coaliciones dominantes esperan que sus departamentos de comunicación practiquen los modelos bidireccionales y los jefes de comunicación entiendan esas expectativas" (Dozier, L. A. Grunig y J. E. Grunig, 1995: 91). Por ello, una de las primeras medidas que debe tomar la dirección de una entidad es "clarificar lo que las relaciones públicas tienen que hacer, dónde se encuentran y qué tareas llevarán a cabo"171 (Cutlip y Center, 1964: 209). Los publirrelacionistas pueden ganar la confianza de las personas influyentes de la organización aprendiendo su lenguaje, sus problemas y su forma de pensar (Cutlip y Center, 1964: 216). Para ello, indican Cutlip y Center (1964: 217), "un profesional efectivo de relaciones públicas debe operar a través de canales, mantener sus promesas, preservar en el anonimato los problemas que le cuentan y buscar la imparcialidad. Debe curar sus propias heridas en privado" ${ }^{172}$. Si no posee el respeto de la gerencia, lamentan Cutlip y Center (1964: 217), "lo más probable es que no sea muy útil en los asuntos directivos"173.

Y es que tal y como Dozier, L. A. Grunig y J. E. Grunig (1995: 5) puntualizan: "Puedes tener el potencial para la excelencia en el departamento de comunicación, pero hasta que la alta dirección valore y poye la comunicación y hasta que los comunicadores y la alta dirección compartan la visión de la función y papel de la comunicación, no podrás establecer un programa excelente" ${ }^{174}$.

\subsection{PODER DEL DEPARTAMENTO DE COMUNICACIÓN}

El poder, en general, es "la capacidad para ejercer influencia, una transacción en la cual haces que otros cambien sus comportamientos de la manera en la que tú quieres"175 (Dozier, L. A. Grunig y J. E. Grunig, 1995: 75). En el terreno de la comunicación, es "la habilidad del comunicador para influir en las decisiones sobre los bienes y productos de una organización, sus políticas y sus comportamientos" $" 176$ (Dozier, L. A. Grunig y J. E. Grunig, 1995: 75). Los departamentos débiles, es decir, los que utilizan modelos unidireccionales, "están limitados a implementar las decisiones de otros"177 (Dozier, L. A. Grunig y J. E. Grunig, 1995: 77). Tal y como puntualizan Dozier, L. A. Grunig y J. E. Grunig (1995: 77), "al igual que la comunicación fluye de un solo lado, lo mismo ocurre con la influencia". 
Una de las clasificaciones más comunes la suministran French y Raven (1959), que diferencian entre poder de recompensa (que se basa en el derecho a ofrecer incentivos por realizar conductas esperadas), coercitivo (la posibilidad de castigar aquellos comportamientos que no se consideran adecuados), referente o carismático (la capacidad de un individuo para influir en otros debido a su carisma), legítimo (el poder oficial por la condición que se ostenta) y experto (autoridad conseguida por los conocimientos que se poseen). La visión de Finkelstein (1992) también ha sido empleada como marco teórico en varias investigaciones. Este profesor diferencia entre poder estructural (el que proviene de la posición formal de una persona dentro de una organización), de experto (que refleja las habilidades para desenvolverse en el entorno), de prestigio (que proviene del estatus y de la reputación) y de pertenencia (los vínculos que proporcionan a los grupos internos y externos una relación con una entidad).

Aunque el poder de los departamentos de comunicación, independientemente del tipo, suele ser "informal", es decir, "sin un poder formal o autoridad para hacerlo"178, sus representantes "deben ser jugadores poderosos en la toma de decisiones de la organización”"179 (Dozier, L. A. Grunig y J. E. Grunig, 1995: 76). Los miembros de los departamentos excelentes de relaciones públicas tienen más poder que aquellos que pertenecen a gabinetes menos excelentes, ya que tienen una mayor autonomía para tomar decisiones (L. A. Grunig, J. E. Grunig y Dozier, 2002: 193).

De hecho, las coaliciones dominantes de las organizaciones con relaciones públicas excelentes apoyan aproximadamente tres veces más la comunicación que en las entidades menos excelentes, según la opinión de sus directores generales y de los jefes de comunicación (Dozier, L. A. Grunig y J. E. Grunig, 1995: 80). El poder de influencia también aumenta para aquellos profesionales que tienen una responsabilidad social corporativa "bien desarrollada" (Ordeix Rigo y Tió Bragado, 2010). Se trata de un aspecto relevante, ya que el valor que otorga la dirección de una institución al departamento de comunicación afecta en el poder del jefe de la sección para conservar o aumentar su presupuesto (Dozier, L. A. Grunig y J. E. Grunig, 1995: 81).

Y es que el poder del departamento de comunicación viene dado por la coalición dominante, aunque la influencia es circular: "El poder es necesario para dar la oportunidad de contribuir. Las contribuciones estratégicas, a su vez, incrementan el valor y apoyo que las coaliciones dominantes dan a los departamentos de comunicación" 180 (Dozier, L. A. Grunig y J. E. Grunig, 1995: 88). Además, tal y como recuerdan estos autores, tanto los directores generales como los jefes de comunicación deben estar de acuerdo en las mediciones de poder. 


\subsection{RELACIÓN DEL RESPONSABLE DE COMUNICACIÓN CON LA DIRECCIÓN}

Muchos autores opinan que los departamentos de comunicación "no pueden hacer a las organizaciones más efectivas a no ser que las relaciones públicas funcionen como una parte integral de la dirección"181 (White y Dozier, 1992: 91). Por ello, continúan, el responsable de esta sección "debe formar parte de la dirección, ha de funcionar a un nivel alto en la toma de decisiones y participar en la gestión estratégica"182 (White y Dozier, 1992: 91). Cuanto más amplia es la coalición dominante y más base de conocimientos tenga el jefe de comunicación, más probabilidades existen de que forme parte de ella (L. A. Grunig, J. E. Grunig y Dozier, 2002: 192). Es entonces, piensan, cuando hay más probabilidades de que las relaciones públicas sean excelentes (Dozier, Grunig y Grunig, 1995: 83), y es en los entornos turbulentos e inciertos donde los profesionales de esta especialidad tienden a participar más en la toma de decisiones (White y Dozier, 1992: 91).

No obstante, los autores del Excellence Study no observaron evidencias claras de que el jefe de comunicación deba ser parte de la coalición dominante; simplemente detectaron que tiene que tener acceso a esta sección, a pesar de que su inclusión en este grupo "está claro que ayuda" "183 (Dozier, L. A. Grunig y J. E. Grunig, 1995: 83). Por lo tanto, los jefes de comunicación en las organizaciones excelentes "son miembros clave del equipo de dirección, aunque en el organigrama no diga eso"184 (Dozier, L. A. Grunig y J. E. Grunig, 1995: 128). Las acciones que verdaderamente marcan la diferencia entre las organizaciones excelentes y las demás son la participación en la planificación y gestión estratégica (Dozier, L. A. Grunig y J. E. Grunig, 1995: 87).

Con todo, los autores del Excellence Study concluyen que un responsable de comunicación "debe ser parte del equipo de la alta dirección, tener un papel en la toma de decisiones estratégicas de la organización, ser un miembro de la coalición dominante o tener acceso a este grupo poderoso de líderes de la organización y tener una autonomía relativa frente a reglas excesivamente estrictas para desempeñar el rol estratégico"185 (L. A. Grunig, J. E. Grunig y Dozier, 2002: 191). Esto no se consigue con los años de experiencia profesional, sino con la adopción del rol directivo (Broom y Dozier, 1986).

Los comunicadores, de esta manera, "hacen contribuciones sustanciales en la planificación estratégica y en la toma de decisiones. Usando técnicas de investigación formal e informal, ayudan en el diagnóstico y solución de problemas y ejecutan programas de comunicación efectivos para establecer relaciones duraderas y a largo plazo con los grupos clave"186 (Dozier, L. A. Grunig y J. E. Grunig, 1995: 128). 


\subsubsection{CULTURA DE LA ORGANIZACIÓN}

Aunque las anteriores esferas -la del conocimiento del departamento en practicar el rol directivo y la comunicación bidireccional, así como las expectativas comunes, el poder y la relación con la dirección- son prerrequisitos para obtener unas relaciones públicas excelentes (Dozier, L. A. Grunig y J. E. Grunig, 1995: 148), la cultura de la organización también tiene su influencia en el tipo de comunicación que se lleva a cabo. Esta se puede definir como "el conjunto de valores compartidos por los miembros de una organización, manifestados en su propio comportamiento y expresiones culturales, símbolos, ceremonias, rituales, lenguaje, estilo de comunicación, etc., que guía las actitudes de sus miembros y determina las relaciones tanto internas como externas de la organización, a la vez que, lógicamente, también ejerce una influencia en la motivación y en el nivel de implicación y en el compromiso que los trabajadores tienen con la compañía"187 (Ordeix Rigo, 2013: 61).

La cultura de una entidad depende de "las capacidades y competencias de las personas que lideran un proyecto, de sus métodos de comunicación y de su forma de preservar las actitudes individuales y colectivas en forma de compromisos hacia valores organizativos, columna vertebral de la personalidad colectiva" (Ordeix Rigo y Navío Gámez, 2007). Cuando se alcanza una "cohesión cultural y un consenso" a través de la cultura organizativa, se contribuye "al equilibrio y simbiosis del interés entre la organización y sus stakeholders"188 (Ordeix Rigo, 2013: 158). A nivel interno, también implica el desarrollo competencial, que favorece las relaciones y la comunicación interna (Ordeix Rigo y Navío Gámez, 2007). La identidad y los valores son elementos "definitorios" de la personalidad de las organizaciones y "decisivos" en la mejora de la credibilidad y conocimiento de las entidades (Ordeix Rigo, 2006).

El tamaño de la entidad es otro factor determinante. En palabras de Wise (2007), "las organizaciones grandes con cuantioso personal de relaciones públicas pueden implementar sistemas más sofisticados de gestión de relaciones que las organizaciones con un único publirrelacionista responsable de toda la función de esta disciplina"189. También lo participativas que estas sean: respecto a las autoritarias, las participativas consiguen niveles de satisfacción individual y organizacional más altos y unos patrones de comunicación interna bidireccional más elevados (Dozier, L. A. Grunig y J. E. Grunig, 1995: 141-143). De hecho, las organizaciones participativas y sobre todo las que poseen una fuerte cultura organizacional son más propensas a desarrollar una comunicación excelente (Dozier, L. A. Grunig y J. E. Grunig, 1995: 148). También entran dentro de estas características las que valoran la diversidad, tanto de género como de etnia (Dozier, L. A. Grunig y J. E. Grunig, 1995: 151). 


\subsection{TIPOS DE ORGANIZACIONES.}

La clase de entidad y el entorno que le rodea influyen en la efectividad de las relaciones públicas que se ejecutan, y existen diferentes teorías que ayudan a visualizar las consecuencias de estas variables. Aunque gozar de un buen contexto no garantiza una buena comunicación (L. A. Grunig, J. E. Grunig y Dozier, 2002: 533), en general, se considera que las organizaciones que establecen un "entorno hospitalario"190 para las relaciones públicas excelentes son aquellas "con estructuras orgánicas, con culturas participativas, con sistemas simétricos de comunicación y con oportunidades para las minorías raciales o culturales y las mujeres" ${ }^{191}$ (L. A. Grunig, J. E. Grunig y Dozier, 2002: 533). A continuación, se muestran algunas de las teorías más frecuentes sobre las características de las entidades y su predilección por un tipo de relaciones públicas u otro.

\section{Entornos dinámicos y estáticos}

J. E. Grunig y Hunt (1984: 97) dividen los entornos en estáticos o dinámicos, y opinan que "cuanto más dinámico o cambiante sea el entorno, más debe usar la organización las funciones proporcionadas por el modelo bidireccional asimétrico y simétrico de las relaciones públicas" ${ }^{" 192}$. Los entornos se diferencian entre estas dos clases según los cambios en tecnología, el grado de mecanización, la estabilidad de la demanda de los productos y servicios de la organización, la cantidad de competencia, el grado de apoyo social y político y el crecimiento del conocimiento que usa la organización (J. E. Grunig, 1976). Así, J. E. Grunig y Hunt (1984: 97) sostienen que “el modelo asimétrico, si funciona, ayuda a la organización a controlar los cambios en el entorno. El modelo simétrico también ayuda a la organización a cambiar el entorno, pero también ayuda a que cambie la organización cuando cambia el entorno"193. En cambio, si el entorno es estático, "la organización puede comportarse rutinariamente y puede pasar usando el modelo de agente de prensa y de información pública"194. Estos modelos "simplemente proporcionan publicity o información sobre la organización tal y como es, sin proporcionar la retroalimentación necesaria para cambiar la organización o los sistemas en el entorno" "195 (Grunig y Hunt, 1984: 97).

\section{Teoría general de sistemas}

Adaptando la teoría general de sistemas propuesta en sus inicios por Ludwig von Bertalaniffy (1950) desde el mundo de la biología, las organizaciones pueden considerarse cerradas o abiertas. Cuando son completamente autónomas, es decir, capaces de perseguir sus objetivos y metas sin trabas por parte de sus entornos, operan como sistemas cerrados. En cambio, los sistemas abiertos dedican parte de sus recursos 
a adaptarse al entorno, por lo que el intercambio de información en los sistemas adaptativos tiene mayor importancia (Dozier y L. A. Grunig, 1992: 397-398).

Según este enfoque, puede haber profesionales "funcionarios", que no monitorizan o escanean el entorno de la organización ni evalúan el impacto de sus programas, o puede haber profesionales "funcionales", que participan en la toma de decisiones y son proactivos. Aunque los profesionales del primer tipo pueden encontrarse en entidades cerradas, la última opción es la más recomendable, en especial en sistemas abiertos (Dozier y L. A. Grunig, 1992: 398).

En cuanto a los públicos, en los entornos cerrados no es tan necesario monitorizar continuamente sus cambios, mientras que en los ambientes abiertos se deben definir dinámicamente, dado que los medios turbulentos y amenazantes no permiten la delineación de públicos estáticos. Tal y como indican Dozier y L. A. Grunig (1992: 399), "el subsistema adaptativo detecta los cambios y peligros que amenazan la supervivencia y crecimiento de una organización en su entorno"196.

A pesar de que no existe un ideal para todas las organizaciones y entornos, en los subsistemas adaptativos, por sus características, los departamentos de relaciones públicas deben tener acceso a la toma de decisiones, con información actualizada sobre las decisiones de la organización y las acciones en consideración. Asimismo, esta función debería tener su propio departamento, donde los trabajadores puedan trabajar autónomamente. La estructura horizontal [es decir, "la división del trabajo en un solo nivel de autoridad" o, dicho de otra forma, "los roles y tareas de las subunidades de un departamento" "197 (J. E. Grunig y Hunt, 1984: 101)] deben ser flexibles, de manera que si la situación cambia, identificándose nuevos problemas y definiéndose otros públicos, se pueda modificar a su vez la estructura horizontal (Dozier y L. A. Grunig, 1992: 396402).

\section{Tipología Hage-Hull}

Hage y Hull (1981) también desarrollaron una tipología que une la estructura general de las organizaciones con el entorno en el que se encuentran. Así, proponen cuatro clases de entidades atendiendo a la escala o tamaño y a la complejidad o sofisticación técnica: tradicionales, mecánicas, orgánicas y mixtas entre mecánicas y orgánicas $^{198}$. Las primeras son pequeñas y tienen poco conocimiento de base; las segundas son grandes pero con una baja complejidad estructural; las terceras son pequeñas pero cuentan con una gran complejidad y las cuartas son grandes y tienen operaciones muy complejas.

Bajo este paradigma, y mezclándolo con los modelos de relaciones públicas propuestos por J. E. Grunig y Hunt (1984), las entidades tradicionales estarían vinculadas al agente de prensa, las mecánicas al de información pública, las orgánicas al 
bidireccional asimétrico y las mixtas al bidireccional simétrico y al bidireccional asimétrico. Vinculándolos con la teoría general de sistemas, los dos primeros casos se corresponden con sistemas cerrados y los últimos, con abiertos. Cuanto más turbulento y amenazante es el entorno, más probable es que las estructuras horizontales sean flexibles (Dozier y L. A. Grunig, 1992: 403-406).

\section{Mecánicas vs. orgánicas}

James E. Grunig (1992c: 531-576), después de una revisión de la bibliografía existente, redujo las clases de organizaciones en mecánicas y orgánicas. Las primeras no permiten a los trabajadores participar en la toma de decisiones y se caracterizan por estar centralizadas, formalizadas, estratificadas y ser menos complejas. Las segundas, en cambio, a pesar de ser más complejas, están descentralizadas, son menos formalizadas y estratificadas y facilitan la participación en la toma de decisiones. Así, estas últimas se vinculan a los sistemas de comunicación simétricos y con una mayor satisfacción de los empleados, mientras que las primeras suelen usar los modelos asimétricos y cuentan con una menor satisfacción de los trabajadores (L. A. Grunig, J. E. Grunig y Dozier, 2002: 534-535). Los jefes de comunicación, por tanto, deben colaborar con la coalición dominante para implementar una estructura orgánica a la vez que desarrollan un sistema de comunicación simétrico (L. A. Grunig, J. E. Grunig y Dozier, 2002: 535). Aunque esta teoría no coincide siempre con la práctica, puede considerarse normativa, es decir, lo que se debería realizar (Fabiszak, 1985).

\section{La perspectiva de poder y control}

Al contrario de lo que sucede con la teoría general de sistemas, la perspectiva de poder y control sugiere que las estructuras mecánicas predominan sobre las orgánicas, dado que la dirección busca mantener su posición dominante a través de la centralización, la formalización y la simplificación, dicen Dozier y L. A. Grunig (1992: 407) citando a Bourgeois, McAllister y Mitchell (1978) y Pfeffer (1978). Esta perspectiva mantiene que "el entorno de la organización, junto con otros factores, limitan las opciones estratégicas de la estructura de la organización que están al alcance de la coalición dominante"199 (Dozier y L. A. Grunig, 1992: 413). Según estos autores, este enfoque proporciona un "camino provocativo y prometedor" "200 para futuras investigaciones (Dozier y L. A. Grunig, 1992: 413), dado que la teoría general de sistemas utilizada junto con la tipología de Hage-Hull (1981) tiene "poco poder

predictivo"201 [J. E. Grunig y L. A. Grunig (1986), citado en Dozier y L. A. Grunig (1992: 413)]. Aquella se trata más de una teoría normativa en vez de positiva [es decir, "cómo deberían practicar las organizaciones las relaciones públicas en vez de lo que 
realmente hacen”202, a excepción de las organizaciones mixtas (L. A. Grunig, 1992a: 472)], mientras que esta supone una representación más fiel de la realidad.

\section{Control vs. adaptación}

James E. Grunig (1984) desarrolla otra visión atendiendo a la relación entre el entorno y la estructura. Así, considera que hay organizaciones que tratan de controlar el entorno y otras que se adaptan a él. Aquellas entidades que prefieren la primera opción tienden a emplear los modelos de agente de prensa y el bidireccional asimétrico. En cambio, las agrupaciones que se adaptan a sus circunstancias externas suelen preferir el de información pública o el bidireccional simétrico.

\section{La perspectiva de la incertidumbre}

Otra forma de estudiar el flujo de información que existe en una entidad es a través de la incertidumbre tanto de su presente como de su futuro. Aquellas que poseen un alto nivel de incertidumbre, dice Grunig (1984), se esfuerzan por obtener información de su entorno y por diseminar datos. Así, prefieren los modelos bidireccionales. En cambio, cuando las corporaciones poseen un nivel de incertidumbre bajo, no sienten tanta necesidad de obtener retroalimentación, por lo que se decantan por enfoques unidireccionales.

\subsection{CARACTERÍSTICAS DE LAS ORGANIZACIONES EXCELENTES}

Dejando a un lado las teorías sobre los tipos de entidades, y tras la revisión bibliográfica sobre relaciones públicas del Excellence Study, J. E. Grunig (1992d: 219) concluyó que "la comunicación excelente es una característica de las organizaciones excelentes" y que "la comunicación excelente puede ayudar a que las organizaciones sean excelentes" ${ }^{\prime 203}$. Detectó doce características comunes en todas las referencias que trataban sobre excelencia, algunas de las cuales "están lógicamente conectadas unas con otras"204 (J. E. Grunig, 1992d: 248). Esto implica que las organizaciones "tendrán dificultades inculcando uno de los atributos sin inculcar simultáneamente el resto"205, puesto que "las relaciones públicas excelentes parecen ser el pegamento que mantiene unidas a las organizaciones excelentes" ${ }^{206}$ (J. E. Grunig, 1992d: 248). Las características que J. E. Grunig (1992d: 223-247) encontró hacen referencia, entre otras cosas, a la estructura de la institución, a los sistemas de comunicación, a la responsabilidad social, a la planificación estratégica, etc.: 
Recursos humanos: las organizaciones excelentes otorgan poder a sus empleados a través de la autonomía y de la capacidad para tomar decisiones. Asimismo, prestan atención al crecimiento personal y a la calidad de la vida laboral de los trabajadores. Enfatizan la interdependencia en vez de la independencia, apoyan la integración en vez de la segmentación y buscan un punto intermedio entre el trabajo en equipo y el esfuerzo individual.

Estructura orgánica: las organizaciones excelentes no son burocráticas ni jerárquicas, sino que adoptan una estructura orgánica. Así, descentralizan las decisiones y evitan la estratificación de los empleados eliminando símbolos de estatus, como comedores para ejecutivos o plazas de parking reservadas, al mismo tiempo que fomentan el liderazgo, la colaboración y la cultura.

Espíritu emprendedor interno: las organizaciones excelentes poseen un espíritu innovador y emprendedor hacia los empleados.

Sistemas de comunicación simétricos: las organizaciones excelentes usan sistemas de comunicación simétricos tanto para públicos externos como internos con el fin de "permanecer cerca" de sus públicos estratégicos.

Liderazgo: los líderes de las organizaciones excelentes confían en el trabajo en red y no en sistemas autoritarios. Además, otorgan poder a los empleados al mismo tiempo que proporcionan una visión y dirección a la entidad, creando orden dentro del caos que el empoderamiento de los trabajadores puede crear.

Culturas fuertes y participativas: los trabajadores de las organizaciones excelentes tienen un sentimiento de misión y están integrados dentro de una fuerte cultura que valora a sus empleados, utiliza estructuras orgánicas, fomenta la innovación y se apoya en la comunicación simétrica.

Planificación estratégica: las organizaciones excelentes tratan de maximizar su balance final identificando las oportunidades y las coacciones más importantes del entorno.

Responsabilidad social: las organizaciones excelentes prestan atención a los efectos que sus decisiones tienen en la sociedad y en la propia entidad.

Apoyo a las mujeres y a las minorías: las organizaciones excelentes valoran la diversidad y contratan a mujeres y minorías y trabajan para fomentar sus trayectorias profesionales.

La calidad como prioridad: la calidad no solo se tiene en cuenta como filosofía de la entidad, sino también cuando se realizan las acciones, se toman las decisiones y se distribuyen los recursos. 
Sistemas operativos eficaces: las organizaciones excelentes crean sistemas para la gestión diaria de las anteriores características.

Cultura social colaborativa: es más probable que una organización sea excelente si se encuentra en una sociedad cuya cultura enfatiza la colaboración, la participación, la confianza y la responsabilidad mutua.

Algunas de estas ideas se mantienen en los factores de excelencia que propusieron los autores del Excellence Study tras finalizar el estudio. Las 20 características que diferencian a las organizaciones excelentes de las menos excelentes son las siguientes (Dozier, L. A. Grunig y J. E. Grunig, 1995: 7):

Base de conocimientos del departamento de comunicación:

- Conocimientos para adoptar el rol de director de comunicación.

- Conocimientos para usar el modelo simétrico bidireccional.

- Conocimientos para usar el modelo asimétrico bidireccional.

Expectativas comunes sobre comunicación con la alta dirección:

- El valor que la coalición dominante (la alta dirección) otorga a la comunicación.

- El apoyo que la coalición dominante (la alta dirección) da a la comunicación.

- Las contribuciones del departamento de comunicación a la planificación estratégica.

- El jefe de comunicación reporta adoptar el rol de director de comunicación.

- El jefe de comunicación reporta adoptar el papel de asesor de comunicación.

- La demanda percibida hacia prácticas bidireccionales simétricas.

- La demanda percibida hacia prácticas bidireccionales asimétricas.

- El apoyo que la coalición dominante (la alta dirección) da a la comunicación

- El valor que la coalición dominante (la alta dirección) otorga a la comunicación.

- Importancia del conocimiento y comunicación con grupos externos.

- La demanda de prácticas bidireccionales simétricas por parte de la coalición dominante.

- La demanda de prácticas bidireccionales asimétricas por parte de la coalición dominante.

- La demanda del rol directivo por parte de la coalición dominante.

- La demanda del rol de asesor de comunicación por parte de la coalición dominante.

- Las contribuciones del departamento de comunicación a la planificación estratégica.

Cultura de la organización:

- Apoyo a las mujeres trabajadoras de la organización.

- Cultura organizativa participativa. 


\subsubsection{APLICACIÓN DE LA GESTIÓN ESTRATÉGICA. FASES DE UN PROGRAMA DE RELACIONES PÚBLICAS}

Una vez que se tienen claros los conocimientos y poder de los comunicadores, se ha determinado la relación y las expectativas entre el responsable de comunicación y la coalición dominante y se han aclarado las características de la organización y de su entorno, se pueden comenzar a diseñar campañas de relaciones públicas.

Muchos investigadores promueven un proceso de cuatro fases, todas ellas bajo la misma premisa. El primer modelo conocido fue propuesto por John Marston en 1963 bajo el acrónimo RACE (investigación, acción, comunicación y evaluación, por las siglas en inglés Research, Action, Communication y Evaluation). Cutlip y Center (1964: 108) también propusieron uno similar: investigación-escuchar, planear-toma de decisiones, comunicación y evaluación ${ }^{207}$. Después de estos modelos se sucedieron otros, cada uno con su propio acrónimo. REPACE, que significa investigación, planificación y acción, comunicación y evaluación ${ }^{208}$, fue introducido por Wilcox, Ault y Agee en 1986 [(citado en Diggs-Brown (2011)]. ROSIE (objetivos, estrategias e implementación entre investigación y evaluación ${ }^{209}$ ), por su parte, fue concebido por Sheila Crifasi (2000). En Public Relations Campaign Strategies, Robert Kendall (1977) incluyó la fórmula RAISE: investigación, adaptación, implementación de la estrategia y evaluación $^{210}$ [citado en (Smith, 2011: 9)]. Hendrix, Hayes y Kumar (2012) explican en Public Relations Cases su opción: ROPE (investigación, objetivos, programación y evaluación ${ }^{211}$ ). Aunque similar, Hainsworth y Wilson (1992) y Guth y Marsh (2011) se decantan por el siguiente modelo: investigación, planificación, comunicación y evaluación $^{212}$. Hunt y J. E. Grunig (1994: 28-29) señalan como el modelo más frecuente el proporcionado por la Public Relations Society of America (PRSA) en el Silver Anvil Awards, que divide las etapas en investigación, planificación, ejecución y evaluación.

Existen otros modelos algo más complejos. J. E. Grunig y Hunt (1984: 104-110), por ejemplo, proponen la teoría de la molécula conductual, un "modelo simple que describe cómo las personas toman las decisiones sobre lo que hacer -cómo comportarse- y cómo los directivos organizan sistemas extensos para producir comportamientos individuales para esos sistemas"213 (J. E. Grunig y Hunt, 1984: 105). Esta teoría, que contribuye a usar un método científico, contiene varios segmentos que describen los procesos individuales y los sistemas: detectar, construir, definir, seleccionar, confirmar, comportarse, detectar... Se trata de un proceso cíclico, en el cual "los investigadores recogen información para los segmentos de detección y construcción. Los planificadores toman la responsabilidad para el resto del segmento de construcción y trabajan con los técnicos de comunicación para definir las alternativas. Los directivos toman las decisiones finales y seleccionan y confirman los segmentos. 
Los técnicos de comunicación toman el control en el segmento del comportamiento $^{2,214}$ (J. E. Grunig y Hunt, 1984: 107-108).

La investigación es muy importante en la teoría de la molécula conductual, tanto la formativa en los segmentos de construcción, definición, selección y confirmación, como la evaluativa en el segmento de detección. Sin la investigación, señalan J. E. Grunig y Hunt (1984: 108), "la molécula de comportamiento de un director de relaciones públicas consistirá en poco más que en el segmento del comportamiento ${ }^{\underline{3}, 215}$. Y es que las relaciones públicas pueden semejarse, dicen Cutlip y Center (1964: 110), a un iceberg: "tres cuartas partes de lo que no se ve está por debajo de la superficie. La cuarta parte que se ve -la publicity- con frecuencia se confunde con el iceberg completo. Las tres cuartas partes que no se ven -la investigación, la planificación y la evaluación- son generalmente más importantes a largo plazo" ${ }^{\text {216. }}$.

Noguero i Grau (1985: 5, 1990: 137-139, 1995: 111), por su parte, propone un modelo de gestión basado en cuatro fases cíclicas que responden a la "máxima axial" de "hacerlo bien (doing), y hacerlo saber (telling)" (Noguero i Grau, 1995: 137). Comienza con la fase de investigación (tanto formativa como evaluativa) para continuar con la de organización, que atiende a tres acepciones: la planificación, la organización departamental y la organización técnica. Posteriormente, se encuentra la fase de información, que "comprende la creación y estudio de la actividad informativa (publicity), así como su evaluación y producción de acuerdo con la selección de medios" (Noguero i Grau, 1995: 138). Finalmente, se encuentra la comunicación, "el proceso exógeno inherente a la actividad de las relaciones públicas" (Noguero i Grau, 1995: 138).

J. E. Grunig y otros (J. E. Grunig y Repper, 1992: 124; Hunt y J. E. Grunig, 1994: 12-19 y 20), en cambio, proponen siete fases en la gestión estratégica de las relaciones públicas. La primera es la de los stakeholders, en la que se debe realizar investigación formativa del entorno y del comportamiento de la organización con el fin de estudiar las relaciones con estas personas. En esta etapa se puede realizar un mapa de stakeholders con su valor de impacto para la organización a través del análisis del entorno, que a su vez puede llevarse a cabo por medio de encuestas de opinión pública, análisis de prensa, revistas legales o académicas, etc. En segundo lugar, se ha de proceder a realizar la fase de los públicos, en la que los publirrelacionistas deben identificar y segmentar los grupos que reconocen una o más consecuencias como un problema y se organizan para hacer algo al respecto y trasladar sus voces a la coalición dominante. Finalmente, la de los conflictos potenciales anticipa los conflictos y gestiona la respuesta de la organización ante ellos. Si las dos anteriores etapas han sido satisfactorias, "se habrá resuelto casi todos los problemas con los públicos antes de convertirse en

\footnotetext{
$\underline{2}$ Las cursivas son del autor.

$\underline{3}$ La cursiva es del autor.
} 
conflictos $^{4,217}$. Y es que "cuando las organizaciones retrasan los programas de relaciones públicas hasta la fase de conflictos potenciales, normalmente son forzados a desarrollar programas de comunicación de crisis" ${ }^{218}$. Por ello, lo ideal es crear un programa de gestión de conflictos potenciales para "identificar los conflictos mientras que son aún problemas y gestionar la respuesta de la organización hacia los problemas y conflictos" $^{219}$ [Hunt y J. E. Grunig (1994: 17) citando a Chase (1984)]. Si se cumplen estos tres pasos, posteriormente queda por desarrollar los objetivos, planificar los programas y las campañas, implementar estas acciones y evaluar los resultados obtenidos; es decir, se seguiría con la fase de objetivos, la de planificación, la de implementación y la de evaluación. En esta parte de la tesis doctoral se ha utilizado esta versión.

\subsubsection{FASE DE LOS STAKEHOLDERS}

A partir de la década de 1990, el término public (público) ha coexistido con el vocablo stakeholder (grupo de interés), especialmente en la bibliografía anglosajona (Míguez González, 2007). Estos dos vocablos se usan a veces como sinónimos, "pero no deberían"220 (Rawlins, 2006); hay una "diferencia sutil que ayuda a entender la planificación estratégica de las relaciones públicas”221 (J. E. Grunig y Repper, 1992: 125).

A pesar de que algunos académicos consideran ambos términos sinónimos [como Bussy y Ewing (1998), Govoni (2004) y Weiner (1996), todos ellos citados por Míguez González (2007)], tienen diferente origen. Como explica Rawlins (2006), "los stakeholders han sido identificados en la bibliografía empresarial según su relaciones con las organizaciones. Los públicos, en la bibliografía sobre relaciones públicas y otros medios masivos de comunicación, se identifican normalmente según su relación con los mensajes ${ }^{\underline{5}, 222}$.

Los stakeholders se considera el término más amplio. Es "cualquier grupo o individuo afectado por la consecución de los objetivos de una organización"223 (Freeman, 1984), "cualquier grupo o individuo identificable sobre el cual depende la supervivencia de una organización"224 (Freeman y Reed, 1983) o, dicho de otra manera, "las personas que están ligadas a una organización porque ellos y la organización tienen consecuencias sobre la otra parte"225 (J. E. Grunig y Repper, 1992: 125). En el momento en el que los stakeholders se vuelven más conscientes y activos acerca de la entidad es cuando se convierten en públicos (J. E. Grunig y Repper, 1992: 125).

En consecuencia, el primer paso de la planificación estratégica es crear una lista con las personas que "están vinculadas o que tienen interés en la organización"226 (J. E.

\footnotetext{
${ }^{4}$ Las cursivas son del autor.

${ }^{5}$ Las cursivas son del autor.
} 
Grunig y Repper, 1992: 126) o lo que es lo mismo, crear un mapa de stakeholders (Freeman, 1984). Esto se puede realizar a través del análisis del entorno, usando encuestas de opinión, analizando los medios de comunicación, leyendo revistas científicas, etc. (J. E. Grunig y Repper, 1992: 126). Tal y como J. E. Grunig y Repper (1992: 126) puntualizan de Freeman (1984), un documento típico de esta clase engloba los dueños, los defensores de los consumidores, los consumidores, la competencia, los medios de comunicación, los empleados, los grupos de interés, los defensores del medio ambiente, los proveedores, las administraciones y las organizaciones locales.

Conviene asignar el peso que cada stakeholder tiene para la organización (J. E. Grunig y Hunt, 1984: 171-177) y desarrollar programas de comunicación con los más relevantes (J. E. Grunig y Repper, 1992: 126). La comunicación en esta fase es "especialmente importante porque ayuda a desarrollar relaciones estables y duraderas que necesita la organización para conseguir el apoyo de los stakeholders y gestionar los conflictos cuando surjan"227 (J. E. Grunig y Repper, 1992: 126-127).

\subsubsection{FASE DE LOS PÚBLICOS}

La segunda fase propuesta por J. E. Grunig y otros (J. E. Grunig y Repper, 1992: 124; Hunt y J. E. Grunig, 1994: 12-19 y 20) es la de los públicos. La importancia de esta etapa se refleja en la misma noción de relaciones públicas, que se ha definido tradicionalmente como "la gestión de la comunicación entre una organización y sus públicos"228 (J. E. Grunig y Hunt, 1984: 6). Estos se consideran "aquellos grupos de personas, internas o externas, con las que se comunica una organización" (Jefkins, 1985: 57) o como "un sistema holgadamente estructurado cuyos miembros detectan el mismo problema o conflicto, interactúan ya sea cara a cara o a través de canales mediados y se comportan como si fueran un solo ente" 229 (J. E. Grunig y Hunt, 1984: 144).

Ciertos investigadores consideran los públicos como un grupo más o menos permanente, el cual "la organización lo ha elegido como colectivo con el que comunicarse, porque se relaciona de un determinado modo con la organización o porque sus integrantes presentan unos intereses comunes derivados de su posición" (Míguez González, 2007). Sin embargo, otros autores, J. E. Grunig y Repper (1992) entre ellos, consideran a los públicos como unos colectivos situacionales que "surgen por sí solos y eligen a la organización para llamar la atención" ${ }^{, 230}$. J. E. Grunig y Hunt (1984: 143144) confían en el juicio de John Dewey (1927), el cual proporciona una concepción similar de público: un grupo de personas que se enfrentan a un problema similar, reconocen el problema y se organizan para hacer algo al respecto. Desde este punto de vista, "los públicos se organizan entre las filas de los grupos de interés cuando reconocen un problema y deciden hacer algo al respecto"231 (Rawlins, 2006). 
Bajo esta perspectiva, la principal característica de las personas que conforman un público es que tienen algo en común (Aldoory, 2001). Por ejemplo, Cutlip y Center (1964: 70) definen un público como "simplemente un nombre colectivo para un grupo un grupo de individuos unidos bajo algún vínculo de interés común- y que comparten un sentimiento de unión ${ }^{\underline{6}}$. Puede ser un grupo pequeño o un grupo grande; puede ser un grupo mayoritario o un grupo minoritario",232. Como indican J. E. Grunig y Hunt (1984: 144), los miembros de esta unión "detectan los mismos problemas y planean comportamientos similares para lidiar con esos problemas"233. Sara Magallón (2006) también resalta la unión de varias personas. Según dice, un público es un "conjunto de personas físicas i/o jurídicas determinado por alguna circunstancia que les da unidad y vincula expresamente a una empresa o institución".

Así pues, las entidades no pueden destinar sus mensajes a "un todo monolítico", sino a "una compleja mezcla de grupos con diversos rasgos culturales, étnicos, religiosos y económicos, y cuyos intereses unas veces coinciden y otras veces entran en conflicto con terceros" (Wilcox, Cameron y Xifra Triadú, 2007: 341). De ahí que se hable de públicos (en plural) en vez de público (en singular), puesto que "las actividades de relaciones públicas no se dirigen al «público en general»: están dirigidas a grupos cuidadosamente seleccionados de personas que constituyen divisiones del gran público en general" (Jefkins, 1985: 57). Mientras que el público general es heterogéneo, un público es homogéneo (J. E. Grunig y Hunt, 1984: 143), por lo que es un error concebir estas divisiones como "un grupo masivo y monolítico"234 (Cutlip y Center, 1964: 80). Larissa A. Grunig (1992b), de hecho, sugiere el término "publics relations" (en plural), para referirse a las relaciones públicas, ya que considera que así se hace referencia explícita a los diferentes públicos que tienen que atender las organizaciones.

Los programas de relaciones públicas que se dirigen al público general "pueden crear relaciones accidentalmente", pero lo que suele suceder con más frecuencia es que "no se comunican con nadie importante para la organización. Y, en el proceso de no hacer nada, cuestan una gran cantidad de dinero a la organización"235 (J. E. Grunig y Repper, 1992: 118). Y es que, aunque una campaña destinada a una audiencia masiva conlleva pocos gastos de investigación, “el coste de la campaña por sí sola será mucho mayor porque los mensajes se dirigen a públicos pasivos o no-públicos, así como a los públicos activos"236 (J. E. Grunig y Repper, 1992: 145).

Hay que tener presente que las personas pueden formar parte de varios grupos a la vez: "Los individuos se forman en públicos de varias maneras -políticamente en partidos, religiosamente en iglesias, socialmente en clubes y hospedajes, económicamente en agrupaciones empresariales, sindicatos o bloques de trabajo. Un individuo puede y de hecho pertenece a una larga lista de públicos simultáneamente"237 (Cutlip y Center, 1964: 80). Por ello, prosiguen estos autores, "es peligroso clasificar a

\footnotetext{
${ }^{6}$ La cursiva es del autor.
} 
las personas de manera rígida como «empleados» o «consumidores» cuando, de hecho, estas personas juegan muchos papeles"238. Y es que los miembros de un público "están continuamente cambiando"239, ya sea por "grupos de edad, intereses económicos y políticos y cambios de residencia" ${ }^{240}$; sería como "comunicarse con un desfile, no con un ejército permanente"241 (Cutlip y Center, 1964: 117).

\section{Segmentar los distintos públicos}

Por todo ello, conviene separar los públicos (J. E. Grunig y Repper, 1992: 127). Tal y como destacan L. A. Grunig, J. E. Grunig y Ehling (1992) de varios estudios de Larissa A. Grunig, la coalición dominante decide el modelo de relaciones públicas utilizado en una entidad, pero la determinación de qué públicos son estratégicos pasa a formar parte de la responsabilidad del departamento de relaciones públicas, que tiene mayores posibilidades de acertar si su responsable forma parte de la coalición dominante. Así, los públicos pueden diferenciarse atendiendo a varias características: geográficas, demográficas, psicográficas, poder encubierto, posición, reputación, afiliación, papel en la toma de decisiones y comportamiento comunicativo (Broom y Dozier, 1990: 32-36).

A través de su investigación, Larissa A. Grunig (1987) detectó que hay públicos que presentan más problemas para las organizaciones, como los activistas, y otros grupos que suelen tener una buena relación con las empresas, como los medios de comunicación. Aunque los publirrelacionistas dedican más tiempo y esfuerzo normalmente a estos últimos, opina que debe ser al contrario, ya que los que menos inconvenientes dan proporcionan unas posibilidades casi aseguradas de obtener una relación satisfactoria. En conclusión, opina que se ha de estudiar el entorno y se ha de centrar primero en los activistas, luego en los accionistas, después en los posibles inversores y finalmente en los sindicatos y empleados. Una vez están controlados estos grupos, se puede prestar atención a los medios, a la comunidad y a los gobiernos locales, regionales y nacionales.

A la hora de definir los públicos de una entidad, Cutlip y Center (1964: 118), por su parte, recomiendan comenzar "por el corazón de la organización", es decir, "en su estructura de poder" ${ }^{242}$. Así, explican:

"Los legisladores clave deben ser la primera preocupación.

Saliendo de este círculo cercano, se encuentran los ejecutivos junior, los supervisores, los empleados, comunidades locales, consumidores, inversores, donantes y todos los demás. Desde estos públicos inmediatos, la atención se mueve a lo largo de un amplio frente de públicos de especial interés dentro del público general. Aquí se incluyen los sindicatos, las asociaciones 
industriales, grupos de agricultores, grupos políticos, grupos de mujeres, grupos de profesionales, educadores, veteranos $\mathrm{y}$ agrupaciones con similares intereses comunes" ${ }^{243}$.

\section{Categorías de público}

Cutlip y Center (1964: 118) aseguran que "cuanto más detenidamente definas los varios públicos, más formas descubrirás para alcanzarles e influirles"244. Por ello, varios investigadores se han alzado a buscar categorías de públicos que ayuden a clasificarlos acordemente, más allá de los aspectos demográficos y psicosociales.

J. E. Grunig y Hunt (1984: 140-142), por ejemplo, opinan que las organizaciones mantienen cuatro tipos de vínculos con el entorno. Uno de ellos son los vínculos posibilitadores, que son las uniones con los grupos que permiten que la entidad exista, como los accionistas, los legisladores, las juntas directivas, los líderes de la comunidad, etc. Un segundo tipo de vínculos son los funcionales, que pueden ser de salida o de entrada, como los empleados, las uniones, los proveedores, los consumidores, etc. En un tercer lugar se hallan los normativos, que son aquellos que se forman con otras organizaciones que se enfrentan a problemas similares o que mantienen valores parecidos. Aquí entrarían asociaciones, grupos políticos o sociedades profesionales. Finalmente, los vínculos difusos hacen referencia a los enlaces con las personas que no pueden incluirse dentro de grupos formales pero que aparecen cuando la organización tiene consecuencias hacia ellos. En consecuencia, en este grupo cabrían todo tipo de colectivos, como alumnos, votantes, defensores del medio ambiente, ciudadanos, los medios de comunicación, etc.

Desde este punto de vista, las organizaciones con entornos cambiantes y complejos tendrán más vínculos, los cuales se transformarán con frecuencia, tal y como señalan J. E. Grunig y Hunt (1984: 143) de Aiken y Hage (1968). Además, cuanto más numerosos e inestables sean estos enlaces, más necesidad tendrán las organizaciones de utilizar los modelos bidireccionales de relaciones públicas, en particular el bidireccional simétrico (J. E. Grunig y Hunt, 1984: 143).

J. E. Grunig y Hunt (1984: 145-146), por su parte, dividen las personas en cuatro grupos: los no-público, los latentes, los conscientes y los activos. El primer colectivo no tiene consecuencias para la organización ni tampoco lo tiene ella para ese conjunto, por lo que no es necesario crear programas para ellos. Los latentes son aquellos que se enfrentan a un problema similar creado por una entidad pero sin ser conscientes de ello. En consecuencia, los publirrelacionistas deben comunicarse con ellos para evitar que lleguen a los siguientes niveles. Así, los conscientes son los que sufren consecuencias similares y reconocen el problema. Si una institución no se relaciona con este grupo, este "buscará activamente la información de otras fuentes, lo cual puede distorsionar la 
naturaleza o severidad de las consecuencias de la organización" 245 , dado que "la información de otras fuentes no explicará el punto de vista de la organización sobre esas consecuencias tal y como lo haría la propia organización" 246 y "es más probable que los aspectos negativos lo digan otros si ellos cuentan la historia"247 (Cutlip y Center, 1964: 157). Además, cuando las personas tienen un acceso limitado a los hechos reales, suelen confiar fuertemente en estereotipos (Cutlip y Center, 1964: 154). Y es que muchos malentendidos pueden aparecer "no solo por la mala información, sino también por la falta de información"248 (Cutlip y Center, 1964: 157).

Los públicos se convierten en activos cuando se organizan para debatir y hacer algo con el problema. Los profesionales de relaciones públicas tienen un mayor problema para influir en este colectivo, dado que "ya han tomado una decisión y se encuentran en el segmento del comportamiento de la molécula comportamental"249 (J. E. Grunig y Hunt, 1984: 146). Además, "buscan y retienen selectivamente información que refuerza las actitudes y comportamientos que han elegido anteriormente" ${ }^{250}$ (J. E. Grunig y Hunt, 1984: 146). La mejor manera para influir en el público, por tanto, es a través del consciente, para intentar llegar a un acuerdo antes de que se conviertan en activos (J. E. Grunig y Hunt, 1984: 146-147).

J. E. Grunig y L. A. Grunig (1991), posteriormente, reducirían la lista a dos grandes unidades: activos y pasivos. Los académicos explican esta separación de la siguiente manera: "Los públicos activos son los que definen qué asuntos son importantes para las organizaciones y amenazan su misión. Los públicos pasivos pueden consumir información al azar en los medios de comunicación u otras fuentes, pero esta comunicación pasiva rara vez consigue efectos cognitivos y menos aún de actitud o de conducta" 251 . Por lo tanto, los individuos activos son aquellos que "reconocen un conflicto potencial como un problema, creen que les afecta personalmente y que tienen suficientemente capacidad para hacer algo al respecto" ${ }^{252}$ (J. E. Grunig y L. A. Grunig, 1991), mientras que los pasivos rara vez desarrollan ideas cognitivas o soluciones para los problemas; retienen solamente trozos y piezas desorganizadas de información.

Las personas activas, por tanto, tienen una mayor influencia en las compañías porque "desarrollan comportamientos individuales para hacer algo sobre las consecuencias de las acciones de una organización" 253 , tales como "boicotear un producto, apoyar la regulación del gobierno u oponerse a un aumento de precios"254 (J. E. Grunig y Repper, 1992: 137). Comunicarse con los grupos activos es más sencillo porque "buscan información en vez de recibirla pasivamente" 255 , aunque también es más difícil persuadirles dado que "buscan información de muchas fuentes y persuaden ellos mismos más que lo que hacen los demás"256 (J. E. Grunig y Repper, 1992: 137).

J. E. Grunig y Hunt (1984) también diferencian los públicos según la teoría situacional, la cual sostiene que "las personas pueden evaluar tu organización favorablemente en algunas situaciones, como el rendimiento en la producción de un 
producto de calidad, pero desfavorablemente en otras, como en los registros de contaminación de aire"257 (J. E. Grunig y Hunt, 1984: 147). En consecuencia, los profesionales de esta disciplina "deben revisar constantemente las consecuencias de la organización e investigar cómo el público reacciona ante esas consecuencias de tal manera que los programas de relaciones públicas no se dirijan a públicos que ya no existen"258 (J. E. Grunig y Hunt, 1984: 147).

La teoría situacional del público se basa en tres variables independientes: reconocimiento del problema ["el grado en que las personas reconocen los asuntos o eventos como problemas de los que tienen que preocuparse" ${ }^{\text {259 }}$ (Aldoory, 2001)], las restricciones percibidas ["el grado en que los individuos creen que hay restricciones $-\mathrm{u}$ obstáculos- en una situación que limitan la libertad para planear su propio comportamiento" 260 (J. E. Grunig y Hunt, 1984: 151)] y el nivel de implicación ["la medida en que las personas conectan con la situación" ${ }^{261}$ (J. E. Grunig y Hunt, 1984: 152)]. Existen, asimismo, dos variables dependientes: la búsqueda de información (que sería un comportamiento activo) y el procesamiento de la información (comportamiento pasivo) (J. E. Grunig y Hunt, 1984: 149). El reconocimiento del problema incrementa las posibilidades de procesar o buscar la información, así como los efectos de la comunicación. Por su parte, las restricciones percibidas disminuyen la probabilidad de procesar y buscar información y, por tanto, los efectos de la comunicación. Asimismo, el nivel de implicación aumenta la búsqueda de información y reduce el procesamiento de información pasiva (Dozier y Ehling, 1992: 171). Finalmente, el nivel de implicación generalmente incrementa el reconocimiento del problema y disminuye las restricciones percibidas (J. E. Grunig y Hunt, 1984: 154).

Desde este punto de vista, los públicos son clasificados también como personas con alta implicación y baja implicación. Los primeros se pueden dividir a su vez como de alta implicación y con ánimo para afrontar los problemas (que serán aquellos con una alta implicación y reconocimiento del problema y con un nivel bajo de restricciones percibidas) y las personas con una gran implicación pero limitados (hombres con alta implicación y reconocimiento del problema pero que observan muchos obstáculos para solucionarlo) (J. E. Grunig y Ipes, 1983). En resumen, los públicos son más propensos a hablar activamente sobre un tema "cuando perciben el asunto como un problema, perciben que el asunto les concierne y creen que no tienen barreras para hacer algo contra ese asunto"262 (J. E. Grunig y Ipes, 1983).

El tamaño y cohesión afecta al grado de implicación de los públicos. Así, cuando el colectivo es muy grande y difuso, raramente evolucionan de la etapa de consciencia a la activa, por lo que un grupo local pequeño puede llegar a hacer más daño a una entidad que un grupo grande. Es lo que Mancur Olson (1971) denomina la teoría de la competición monopolística, por la cual "cuando hay muchos miembros en un público, ningún miembro tiene una incentivo grande de convertirse en activo para garantizar los beneficios de organizaciones grandes o del gobierno. Todos los miembros piensan que 
otro hará ese trabajo necesario",263 (J. E. Grunig y Hunt, 1984: 147). En cambio, cuando se trata de colectivos reducidos, "cada miembro sabe que sin él o sin ella el grupo puede fracasar porque nadie más hará ese trabajo. Por ello, cada miembro de un público pequeño y cohesivo trabaja duro para solucionar el problema que hizo crearse al público"264 (J. E. Grunig y Hunt, 1984: 147).

J. E. Grunig y Hunt (1984: 160), a la vista de las investigaciones realizadas al respecto por J. E. Grunig, resaltan cuatro tipos de públicos: los que son activos en todos los temas (los activistas, los cuales suponen una amenaza para las organizaciones en muchos asuntos), los que son apáticos en todos los asuntos (los no-públicos, a los cuales no se les ha de prestar atención), los que se vuelven activos solo si el asunto involucra a casi toda la población y los que surgen por temas concretos. También se puede separar a la audiencia mediante el modelo de activismo del enfado (en inglés, anger activism model), que mantiene la premisa de que el miedo tienen un gran impacto en la persuasión. Así, se detectan cuatro grupos de personas: los grupos activistas, el grupo empoderado, las audiencias enfadadas y el grupo desinteresado ${ }^{265}$ (Turner, 2007).

Asimismo, un publirrelacionista tiene que estar atento a las tendencias que experimentan las diferentes audiencias y que pueden ser más acentuadas en algunas agrupaciones que en otras. Según Wilcox, Cameron y Xifra (2007: 347), las características de la población actualmente y en un futuro cercano son las siguientes:

“El público está cada vez más orientado hacia lo visual.

Se genera un apoyo ferviente para temas puntuales.

Se da mucha importancia a los personajes públicos y a los famosos.

Hay una fuerte desconfianza hacia la autoridad y se puede instalar la teoría de la conspiración gracias al sensacionalismo de algunos reportajes de investigación.

El público internacional de las relaciones públicas ha crecido rápidamente".

Con el fin de tener todas las audiencias controladas, Magallón (2006) propone el diseño de un mapa de públicos, lo que facilitará al autor "las claves de actuación y que permitirá programar acciones armónicas a los mutuos intereses de Sujeto PromotorEjecutor". Se deben tener en cuenta tanto los colectivos permanentes como otras agrupaciones potenciales, que con el tiempo "pueden desaparecer o perder peso específico" (Magallón, 2006).

El modelo de públicos de Noguero i Grau (1982: 144, 1990: 132-134, 1995: 105107) se asimila al mapa de públicos que señala Magallón (2006). Basándose en Cutlip y Center (1963: 139), Prost (1967) y Noguero i Grau (1976: 309), este profesor de la Universidad Autónoma de Barcelona clasifica las organizaciones en tres categorías 
(empresa agrícola, industrial o de servicios, organismo o servicio de la Administración pública y universidades e instituciones culturales) y especifica una serie de públicos para cada una de ellas. Para las del primer tipo incluye los proveedores, los clientes (fijos y potenciales), el personal, los distribuidores, la administración pública (nacional, provincial y local), el público de la vecindad, los accionistas y otros públicos. Para los segundos circunscribe los proveedores, el personal, las segmentaciones de públicos políticos, los organismos internacionales, los administrados que utilizan el servicio, los contribuyentes, los organismos de la administración pública y otros públicos. Finalmente, en el cuarto tipo de entidades se encuentran los proveedores, el personal (docente y administrativo), la comunidad, la administración pública, los públicos internacionales, las fundaciones, los estudiantes y los antiguos alumnos.

Este mapa ha de ser modificado constantemente según los cambios sociales, legales, políticos o de los grupos en sí. Esta continua rectificación "marca el camino de cualquier estrategia de relaciones públicas e impide el tratamiento clónico de las acciones a realizar en las sucesivas planificaciones" (Magallón, 2006). Al respecto, esta autora aporta los siguientes ejemplos:

"Así pues, una empresa o institución siempre considerará a sus empleados como público; sin embargo, la plantilla puede envejecer, o renovarse o ambas cosas; puede mejorar el nivel de formación, puede cambiar la procedencia geográfica de los trabajadores, puede permutarse el porcentaje de hombres y mujeres, etc., por lo que intrínsecamente, como colectivo, cambiarán sus características $\mathrm{y}$, en consecuencia, la organización debe replantearse el vínculo, y muy especialmente la manera como ese vínculo de confianza se manifiesta. Igualmente, a título de ejemplo, una nueva organización o grupo de opinión que se muestre activo respecto al sector de actividad de nuestro sujeto promotor debe ser considerado como un nuevo público, y se debe actuar al respecto".

Si no se realiza esta división, las consecuencias negativas pueden multiplicarse. De acuerdo con Jefkins (1985: 61), los resultados de no definir los públicos podrían ser los siguientes:

"Se dispersarán esfuerzos y fondos indiscriminadamente en el intento de alcanzar a muchos públicos;

Puede lanzarse el mismo mensaje sin tener en cuenta su adaptación a diferentes grupos de personas.

No se medirá el tiempo para hacer el uso más eficaz posible en cuanto a costos de hombres-hora, materiales y equipo; 
No se conseguirán los objetivos (aunque se definan);

La gerencia (o el cliente) estarían insatisfechos con la ausencia de resultados, y estarían justificados al contemplar las RP [relaciones públicas] como intangibles y, pero aún, como una pérdida de dinero, podrían considerar al profesional de las RP como incompetente; el profesional o la asesoría de RP podría perder su puesto de trabajo o su contrato".

\subsubsection{FASE DE LOS CONFLICTOS POTENCIALES}

Un conflicto se crea "cuando uno o más agentes humanos añaden importancia a una situación o a un problema"266 (Crable y Vibbert, 1985). Tal y como señalan J. E. Grunig y Repper (1992: 146), "si una organización ha realizado unas relaciones públicas excelentes en las anteriores dos etapas del proceso de gestión estratégica, habrá resuelto muchos de los problemas con los públicos antes de que se conviertan en conflictos potenciales" 267 . Y es que los públicos "crean conflictos potenciales de los problemas que no han sido resueltos"268 (J. E. Grunig y Repper, 1992: 146), por lo que si las entidades retrasan la aplicación de un programa de relaciones públicas hasta la etapa de conflictos potenciales en vez de en las de stakeholder y de públicos, "normalmente son forzadas a desarrollar programas de comunicación de crisis"269 (J. E. Grunig y Repper, 1992: 149). En cambio, es más difícil que las entidades pasen por crisis si la diversidad de opiniones se tiene en cuenta en la planificación y si la comunicación es sensible con las percepciones del mundo de los ciudadanos (Heath, Lee y Ni, 2009).

Por todo ello, la gestión de conflictos potenciales se ha convertido en "un elemento importante de las relaciones públicas y de la planificación estratégica" (Wilcox, Cameron y Xifra Triadú, 2007: 316). Esta especialización puede definirse como "un proceso proactivo de supervisión y análisis de nuevos asuntos y potencialmente emergentes que pueden tener un impacto en la organización"270 (Heath, 1997) o como "la capacidad para comprender, movilizar, coordinar y dirigir todas las funciones estratégicas y de planificación y todas las habilidades de relaciones públicas o asuntos públicos hacia la consecución de un objetivo: la participación significativa en la creación de políticas públicas que afectan al destino personal y al de la institución" (Chase, 1982).

Este procedimiento trata de predecir problemas, anticipar amenazas, minimizar las sorpresas, resolver temas potencialmente conflictivos y evitar situaciones de crisis (Wilcox, Cameron y Xifra Triadú, 2007: 316). En resumidas cuentas, la gestión de conflictos "permite a una organización anticiparse y evitar actividades que las audiencias puedan encontrar desfavorables"272 (Springston y Weaver Lariscy, 2005). Y es que las relaciones públicas no solo solucionan problemas, sino que también son "un 
instrumento preventivo"273 (van Ruler y Verčič, 2002: 8). La "gran función social" de esta disciplina, indica Rosa Torres (2011), "radica en la prevención de conflictos procurando la simetría comunicacional y el equilibrio de intereses, de modo que las organizaciones se hagan y se perciban confiables". Para ello, se ha de emprender un análisis del entorno, es decir, "escuchar, leer y observar continuamente los temas de actualidad fijándose en los intereses de la organización" (Wilcox, Cameron y Xifra Triadú, 2007: 308). Cuando se detecta un asunto que puede ser potencialmente peligroso, se tienen que definir los planes estratégicos específicos. Además, se ha de elaborar un plan de crisis general por si se alcanzan dichas proporciones, donde se especifique el equipo prefijado de personas que dirigirán estas situaciones. Asimismo, se ha de revisar y poner en práctica con frecuencia (Shelton, 1993; Weaver Lariscy y Springston, 2007).

Los medios de comunicación juegan un papel importante en la creación y expansión de estos temas (Hunt y J. E. Grunig, 1994: 12), aunque las organizaciones con relaciones públicas excelentes no necesitan tanto a los medios porque resuelven los problemas externos antes de que los públicos los conviertan en conflictos potenciales (J. E. Grunig y Repper, 1992: 149).

Tal y como Wise (2001) explica de los resultados de Lauzen y Dozier (1994), "la investigación sugiere que los profesionales de las relaciones públicas que están envueltos en la gestión de conflictos potenciales tienen más poder dentro de sus organizaciones que aquellos practicantes que no están inmersos en la gestión de conflictos potenciales. Y la participación en la gestión de conflictos potenciales está fuertemente relacionada con la participación en la toma de decisiones de la coalición dominante de una organización" ${ }^{274}$. De hecho, existen evidencias de que el tipo de administración que realiza una entidad sobre este asunto está vinculada con el tipo de actividades de relaciones públicas que normalmente ejecuta (Lauzen, 1997).

Hay diferentes modos para comprobar si una materia puede ser conflictiva y cada entidad debe diseñar su modelo según sus características y las de su entorno. La empresa Bader Rutter \& Associates, por ejemplo, utiliza una matriz para clasificar los asuntos eventualmente problemáticos. Tal y como explican Wilcox, Cameron y Xifra (2007: 317) sobre este sistema y que puede observarse en la posterior tabla, "si un determinado tema potencialmente conflictivo alcanza una puntuación de «10» en cuanto al impacto potencial sobre las actividades del cliente, y de «8» en cuanto a la capacidad del cliente de influenciar el resultado, se situará en el cuadrante superior derecho de la matriz, lo que implica que debería ser una situación a la que hay que prestar la máxima prioridad". 


\section{Ilustración 2. Matriz de gestión de conflictos potenciales}

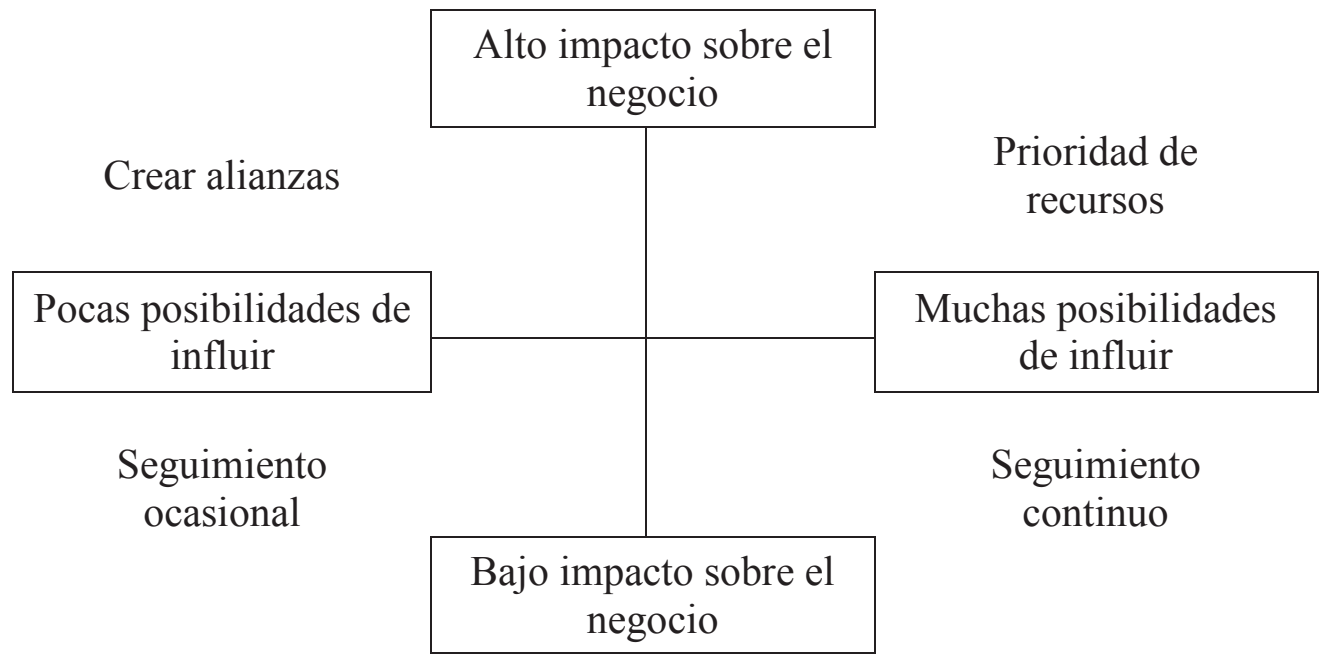

Fuente: Wilcox, Cameron y Xifra (2007: 317).

En cuanto a la evolución, los conflictos recorren "un ciclo de desarrollo bastante predecible", en vez de simplemente encontrarse "ausentes en un momento y después estallar de repente" ${ }^{, 275}$ (Botan y Taylor, 2004). Crable y Vibbert (1985), por ejemplo, proporcionan cinco etapas: potencial, inminente, actual, crítico y latente. También existen diferentes clases según sus características: preconflictos, potenciales, públicos, críticos y latentes (Crable y Vibbert, 1985).

Los preconflictos son "incidentes en el entorno a los cuales los públicos aún no han añadido importancia, pero podrían" potenciales "cuando un grupo o unos individuos importantes les añaden importancia"277, aunque existen significativamente menos potenciales que preconflictos "porque no todos estos últimos evolucionan hasta el punto anterior",278 (Botan y Taylor, 2004). Cuando los potenciales obtienen cobertura mediática y alcanzan grandes audiencias evolucionan a conflictos públicos. En cambio, alcanzan un nivel crítico cuando "se encuentran en el momento de decisión"279 (Crable y Vibbert, 1985). En esta etapa, normalmente hay "poco tiempo o espacio para negociar" porque "para la mayoría de los públicos es el momento de que el conflicto llegue a una solución"280 (Botan y Taylor, 2004). De hecho, cuando se demanda un desenlace en poco tiempo y este representa un "punto de inflexión"281 para una compañía que implica que "es poco probable que vuelva por completo al estado en el que se encontraba antes de la crisis"282, el conflicto habrá alcanzado el nivel de crisis. Finalmente, cuando estos se "resuelven o simplemente se desvanecen" hablando sobre Crable y Vibbert (1985)].

Como se ha señalado, encargarse adecuadamente de la gestión de conflictos potenciales, a través de una buena planificación y prevención, puede "a menudo marcar la diferencia entre una situación de crisis y otra que no lo es" (Wilcox, Cameron y Xifra 
Triadú, 2007: 317). Por ello, diversos autores se afanan en proporcionar fases para evitar en la medida de lo posible que un tema llegue al nivel de crisis. Jones y Chase (1979), por ejemplo, plantean las siguientes etapas: identificación de los temas potencialmente conflictivos, análisis de los mismos, opciones estratégicas para cambiarlos, plan de acción y evaluación de los resultados.

En la primera fase se debe hacer un seguimiento de los diferentes medios de comunicación, de internet, de grupos de activistas, etc., para saber qué temas e intereses se están debatiendo. Posteriormente, una vez que se ha reconocido un tema emergente, se ha de proceder a valorar su efecto potencial sobre la organización. Cuando se completa este paso, se ha de analizar qué es lo que se puede hacer y definir unas pautas de acción que, en una cuarta etapa, han de ser comunicadas a los agentes implicados. Finalmente, conviene analizar los resultados de esta gestión. Una herramienta eficaz para detectar conflictos emergentes y escanear el entorno son los grupos focales, que son relativamente baratos y rápidos de organizar, a pesar de que no permiten generalizaciones por no ser estadísticamente fiables (Dozier y Repper, 1992: 191-194).

Otros autores ofrecen otra serie de fases para abordar cualquier conflicto. Según Heath (1997), por ejemplo, se deben cumplir las siguientes etapas:

Anticipar y analizar los conflictos.

Desarrollar las posiciones ante esos conflictos.

Identificar a las audiencias claves cuyo apoyo es necesario para manejar esos conflictos.

Determinar los comportamientos deseables de las audiencias.

Finalmente, según indican J. E. Grunig y Repper (1992: 149) de Buchholz, Evans y Wagley (1989: 63), los enfoques que puede tomar una organización acerca de un conflicto potencial es: reactivo (luchan contra el cambio), acomodativo (se adaptan a la modificación), proactivo (influyen en la variación) e interactivo (se ajustan e influyen en la transformación). Esta última es la que se debería emplear para lograr unas relaciones públicas excelentes (J. E. Grunig y Repper, 1992: 149).

\subsubsection{FASE DE LOS OBJETIVOS}

La cuarta etapa propuesta por J. E. Grunig y otros (J. E. Grunig y Repper, 1992: 124; Hunt y J. E. Grunig, 1994: 12-19 y 20) en un programa de relaciones públicas es la fase de objetivos. J. E. Grunig y Hunt (1984: 115) opinan que "juegan un papel extremadamente importante en la gestión de las relaciones públicas" ${ }^{284}$, a pesar de que puede ser "una de las tareas más difíciles y confusas"285 (Broom y Dozier, 1990: 39). Según puntualizan estos autores (1984: 115), "sin ellos, uno no puede decir de verdad que está gestionando"286. Por ello, "cualquier programa de relaciones públicas debe 
comenzar con un objetivo que se intenta alcanzar -es decir, debe gestionarse por objetivos” ${ }^{287}$ (Hunt y J. E. Grunig, 1994: 17). A pesar de ello, los publirrelacionistas con frecuencia los ignoran, ya que piensan en términos de procesos (la producción que se realiza) en vez de en términos de efectos (los resultados conseguidos) (J. E. Grunig y Hunt, 1984: 115).

Llegados a este punto, conviene diferenciar dos elementos recurrentes en esta fase, las metas y los objetivos, que se diferencian por su especificidad (Hunt y J. E. Grunig, 1994: 27). Los primeros son normalmente los fines "que proporcionan un marco para la toma de decisiones y el comportamiento pero que son demasiado generales para ayudar en las decisiones diarias"288. En cambio, los segundos son los fines a la vista, "las soluciones esperadas para los problemas del día a día" ${ }^{289}$. Las metas, por tanto, son amplias y abstractas y no pueden medirse directamente; los objetivos se derivan de las metas y son específicos y medibles (Grunig y J. E. Hunt, 1984: 116), dado que especifican el periodo de tiempo y el número de personas o proyectos involucrados (Hunt y J. E. Grunig, 1994: 27). Tal y como Cutlip y Center (1964: 131) opinan con diferente terminología, la planificación tiene dos direcciones generales, los programas de largo alcance y los planes a corto plazo, y los segundos siempre deben estar subordinados a los primeros.

También conviene señalar los tipos de objetivos disponibles para los trabajadores de relaciones públicas basándose en el target (externo o un subsistema de la organización), la dirección del efecto (asimétrico o simétrico) y de la naturaleza del efecto (comunicación, retención de los mensajes, aceptación de las cogniciones, formación o cambio en la actitud o cambio explícito del comportamiento) (J. E. Grunig y Hunt, 1984: 134). La mayoría de los profesionales intentan alcanzar los dos primeros, dado que los tres últimos dependen "de una combinación de variables (predisposición al mensaje, refuerzo por parte de los más allegados, accesibilidad a la acción sugerida, y contexto, por nombrar sólo algunas)" (Wilcox, Cameron y Xifra Triadú, 2007: 219220).

Es recomendable "ser realista con los objetivos"290 (J. E. Grunig y Hunt, 1984: 133), teniendo en cuenta que, con frecuencia, lo único que se consigue es una comunicación, precisión o entendimiento. Lo más aconsejable es buscar cambios en las cogniciones ("la forma en que las personas piensan o en las ideas o creencias que tienen"291) (Hunt y J. E. Grunig, 1994: 17), ya que "uno solo puede esperar en realidad cambios en la conciencia o importancia de asuntos o en la prioridad que las personas ponen en esos asuntos"292 (Pavlik, 1987: 99). Si, pese a estas recomendaciones, se opta por cambiar actitudes y comportamientos, J. E. Grunig y Hunt (1984: 133) recuerdan: "No esperes afectar a más del 20 por ciento del target group" 293.

Esto es debido a que las actitudes "no causan el comportamiento: son simplemente conclusiones mentales que las personas hacen cuando piensan en asuntos específicos"294 
(J. E. Grunig y Hunt, 1984: 130). En otras palabras: "las actitudes son parte del pensamiento consciente; no son predisposiciones escondidas que causan que las personas hagan cosas"295 (J. E. Grunig y Hunt, 1984: 130). Además, resultan ser situacionales y específicas, es decir, las personas "cambian sus actitudes y comportamientos para encajar en la situación”296 (J. E. Grunig y Hunt, 1984: 130).

En consecuencia, los publirrelacionistas "pueden proveer a la gente la información que necesitan para formar y cambiar actitudes, pero esas actitudes son específicas y situacionales y por lo tanto no durarán mucho. Puedes ser capaz de persuadir a alguien sobre un asunto, pero tendrás que empezar nuevamente con otro tema. Y, entonces, puede que no tengas éxito en ese"297 (J. E. Grunig y Hunt, 1984: 131).

Los objetivos deben contener lo que se quiere conseguir como resultado, el criterio de los resultados que se quieren alcanzar, el cambio exacto o mantenimiento que se desea lograr y la fecha en la que se quieren obtener las consecuencias (Broom y Dozier, 1990: 42-44). Todo esto debe plasmarse por escrito, revisándose y discutiéndose con regularidad (Broom y Dozier, 1990: 44).

Los objetivos de comunicación estarán mejor vinculados a los de la compañía en general y serán más adaptativos a su entorno si el jefe del departamento de relaciones públicas se encuentra dentro de la coalición dominante. J. E. Grunig y Hunt (1984: 121) exponen la importancia de este aspecto con tres ideas:

"Primero, las metas de relaciones públicas se convierten en metas de la organización cuando el ejecutivo de relaciones públicas o los públicos externos clave forman parte de la coalición dominante de la organización. Cuando las metas de relaciones públicas se convierten en las metas de la organización, será posible mostrar que las relaciones públicas contribuyen a la efectividad de la organización.

Segundo, los goles de relaciones públicas de la organización son más propensos a ser adaptativos en vez de controladores cuando los públicos clave están en la coalición dominante y cuando el ejecutivo de relaciones públicas está en la coalición dominante y entiende el modelo bidireccional simétrico de las relaciones públicas.

Finalmente, si ninguno de los públicos clave o el ejecutivo de relaciones públicas forman parte de la coalición dominante, será difícil justificar la función de las relaciones públicas a la coalición dominante, independientemente de lo bien que las personas de relaciones públicas puedan cumplir los objetivos de comunicación" $" 298$. 


\subsubsection{FASE DE PLANIFICACIÓN}

El siguiente paso de un programa de relaciones públicas es la planificación. En esta etapa, los objetivos propuestos se traducen en el diseño de campañas o programas (Hunt y J. E. Grunig, 1994: 18). Aquí, "uno se tiene que preguntar qué clase de técnica comunicará más eficazmente con un público y cómo esa técnica debe ser ejecutada"299 (Hunt y J. E. Grunig, 1994: 18). Este período tiene que ser estratégico, es decir, "debe ser una herramienta eficaz para respaldar los objetivos de negocios, marketing y comunicación de la organización" (Wilcox, Cameron y Xifra Triadú, 2007: 193). Tal y como explican estos autores de Broom y Dozier (1990: 23), "la planificación estratégica consiste en decidir dónde se quiere estar en el futuro (el objetivo) y cómo llegar hasta ahí (las estrategias). Define proactivamente la dirección de la organización, evitando la «deriva» y la repetición rutinaria de actividades ${ }^{\text {} 300}$.

Dentro de la fase de planificación se deben definir las estrategias y las tácticas. Las primeras describen "cómo se va a alcanzar, en teoría, un objetivo, ofreciendo líneas directrices y temáticas para el programa global"; es decir, son las "grandes orientaciones" (Wilcox, Cameron y Xifra Triadú, 2007: 204-205). En cambio, las tácticas definen "el cómo hacerlo" (Wilcox, Cameron y Xifra Triadú, 2007: 205). Por ello, se corresponden con "iniciativas puntuales" (Wilcox, Cameron y Xifra Triadú, 2007: 205).

Los plazos temporales pueden llegar a ser clave, dado que "los diversos elementos de un programa [...] deben estar espaciados en el tiempo y programados en fechas determinadas para producir los efectos esperados en un momento concreto de tiempo"301 (Cutlip y Center, 1964: 141). Asimismo, se han de tener en cuenta los siguientes puntos: “(1) decisión de cuándo debe realizarse la campaña; (2) determinación de la secuencia adecuada de actividades; y (3) recopilación de la lista de actividades que deben llevarse a cabo para obtener el producto final" (Wilcox, Cameron y Xifra Triadú, 2007: 207-208). Además de estipular el presupuesto concreto del departamento o de las acciones concretas de relaciones públicas, se ha de tener en cuenta el tiempo necesario para llevarlas a cabo, algo que suele ser más flexible que el presupuesto (J. E. Grunig y Hunt, 1984: 166). Para ello, existen diversas herramientas, como los diagramas de Gantt, los diagramas PERT o el método de la ruta crítica (J. E. Grunig y Hunt, 1984: 166-171).

Según el público al que se dirigen las acciones y los objetivos que se quieran conseguir, los profesionales de las relaciones públicas deben decantarse por unos canales en detrimento de otros. De hecho, hay evidencias de que, en ocasiones, el medio importa más que el mensaje (Schultz, Utz y Göritz, 2011; Utz, Schultz y Glocka, 2013). Hunt y J. E. Grunig (1994: 37) lo aclaran con el siguiente ejemplo: 
"Si el objetivo es informar al mayor número posible de personas para que (1) conozcan un programa que está desarrollando la organización y (2) tener una visión positiva del programa, los medios de comunicación -televisión, radio y prensa- pueden ser los mejores canales. Pero si debes convencer a los líderes de organizaciones profesionales pequeñas pero influyentes para apoyar un asunto, los artículos especializados en revistas de negocios o de asuntos públicos serán un mejor método para explicar asuntos complejos y convencer a los líderes para que "entreguen" el apoyo a los miembros de sus organizaciones" $" 302$.

La planificación y la determinación del presupuesto "van de la mano"303 (Cutlip y Center, 1964: 136). Este último debe ir acorde a las metas y objetivos propuestos y ha de perseguir la identificación de los públicos clave (Hunt y J. E. Grunig, 1994: 34). Se debe realizar un cálculo con anterioridad a la ejecución del programa, aunque es recomendable que exista cierta flexibilidad a lo largo de la comunicación y la evaluación (Cutlip y Center, 1964: 136). También es aconsejable dividir el presupuesto en dos partes: los gastos de personal (que recibirá la mayor proporción) y los extraordinarios (que son los desembolsos necesarios para llevar a cabo las distintas actividades divulgativas). También se suele asignar un 10\% a imprevistos (Wilcox, Cameron y Xifra Triadú, 2007: 211). J. E. Grunig y Hunt (1984: 164), por su parte, aconsejan dividir los gastos en administrativos y de programas. El primer tipo es el del departamento completo de relaciones públicas durante un periodo concreto de tiempo, normalmente un año. Por el contrario, el presupuesto de los programas hace referencia a la cantidad de dinero destinada a las acciones de comunicación concretas. Por ejemplo, a modo de guía, estos autores sugieren tener en cuenta los gastos de salarios y beneficios, la producción, el equipamiento, los gastos generales, los costes de proyectos especiales, los viajes y otros gastos (J. E. Grunig y Hunt, 1984: 165).

Es extremadamente difícil calcular los beneficios económicos de las relaciones públicas, por lo que es más recomendable, indican J. E. Grunig y Hunt (1984: 172), utilizar una fórmula de coste-beneficio para elegir los programas que maximicen los beneficios de los recursos disponibles. También se puede elegir el valor de la recompensa ${ }^{304}$ que, aunque resulta complicado cuantificar monetariamente, puede medirse de otras maneras, como con escalas de relaciones con cada público (J. E. Grunig y Hunt, 1984: 172-173).

Una vez se ha decidido el enfoque de la planificación, se debe proceder a la elaboración de un plan estratégico que ha de redactarse por escrito (Bonilla Loyo, 2008; Cutlip y Center, 1964: 133). Los programas bien planeados deben ser sinceros en cuanto al propósito y la ejecución, duraderos en el propósito y características de la 
organización, firmes en enfoque y recursos, completos en el alcance y aplicación, claros y simbólicos y beneficiosos tanto para la organización como para los públicos (Cutlip y Center, 1964: 135).

Existen diversas versiones de lo que se ha de incluir en este escrito. Shirley Harrison (2002: 64-68), por ejemplo, propone la siguiente lista, que tiene que ver con los objetivos, los mensajes, el público, las acciones y la valoración:

Por qué: metas y objetivos.

Qué: el mensaje.

Quién: el receptor.

Cómo: el programa de actividad.

Cuál es la eficacia: evaluación.

De acuerdo con esta versión, en la primera fase se define "la dirección general en la que se quiere ir" (las metas) y "lo que se quiere conseguir" (los objetivos) (Harrison, 2002: 64). Asimismo, se debe seleccionar el mensaje o los mensajes, teniendo en mente que han de "detraer críticas de la empresa y reforzar su reputación por la atención que presta a sus consumidores" (Harrison, 2002: 65). Se tienen que precisar los distintos grupos de públicos, al igual que los tipos de mensajes que se van a transmitir a cada uno de ellos. El plan de actividad incluye "el cuándo, el dónde y el cuánto: un programa de plazos y costes de la actividad" (Harrison, 2002: 65); es decir, determinar minuciosamente cómo se van a divulgar los datos. En cuanto a la evaluación, se ha de determinar cómo se van a evaluar los resultados de un programa de relaciones públicas según un estándar que se haya establecido en esta fase. Para ello, las metas deben ser "mesurables" y los criterios de evaluación, "realistas, creíbles, específicos y ajustados a las expectativas del cliente o empresario" (Wilcox, Cameron y Xifra Triadú, 2007: 208). Según sentencia Shirley Harrison (2002: 66), "si no sabe lo que piensa la gente de usted antes de poner en marcha un programa de relaciones públicas, no sirve de mucho preguntar a la gente qué piensa cuando se ha realizado el programa, puesto que no será capaz de extraer conclusiones sensatas sobre la eficacia".

Otra versión la proporcionan Wilcox, Cameron y Xifra (2007), que amplían la lista de elementos que ha de contener cualquier planificación de un programa de relaciones públicas, llegando hasta los ocho. Según estos autores, los puntos que deben quedarse definidos en esta fase son: situación, objetivos, público, estrategia, tácticas, calendario o plazos temporales, presupuesto y evaluación.

A pesar de estas recomendaciones, cada compañía debe diseñar su planificación según sus propias características y su entorno. Así, la agencia Ketchum, por ejemplo, divide su planificación inicial en cuatro elementos: hechos, metas, públicos y mensaje clave (Wilcox, Cameron y Xifra Triadú, 2007: 195-196). Estos, a su vez, se fragmentan en diferentes elementos, que se articulan en torno al estado actual de la organización, las 
características de la competencia, las peculiaridades del público y los objetivos a cumplir:

○ Hechos:

- Categorías de hechos.

- Aspectos de los productos / servicios.

- Hechos sobre la competencia.

- Hechos sobre los consumidores.

o Metas:

- Objetivos empresariales.

- Rol de las relaciones públicas.

- Fuentes de nuevos negocios.

○ Públicos:

- Públicos objetivo.

- Mentalidad actual.

- Mentalidad deseada.

- Mensaje clave:

- Mensaje clave.

\subsubsection{FASE DE IMPLEMENTACIÓN}

En la fase de comunicación o implementación es donde se ponen en práctica los planteamientos de la planificación. Se trata de la etapa más visible, puesto que las estrategias y tácticas adoptan la forma de comunicados y conferencias de prensa, acontecimientos especiales, marketing viral, discursos, concursos, etc. (Wilcox, Cameron y Xifra Triadú, 2007: 217). Las siete C de la comunicación según Cutlip y Center (1964: 166-167) a las que tienen que prestar atención los profesionales de las relaciones públicas durante esta etapa son la credibilidad, el contexto, el contenido, la claridad, la continuidad y consistencia, los canales y la capacidad de la audiencia.

Todas las publicaciones o acciones de comunicación han de tener su propio objetivo (Cutlip y Center, 1964: 184). Ginesta y Ordeix (2011) proporcionan cuatro áreas de gestión de las relaciones públicas dentro de las cuales pueden englobarse diferentes acciones: la corporativa (que se ocupa de la identidad de la entidad a partir de la filosofía organizativa, explicando sus políticas de gestión y los valores y actuaciones de sus órganos de representación), la social (la cual incluye actividades encaminadas al interés general, como temas medioambientales, culturales o de equilibrio social), la comercial (las que están vinculadas al marketing, como la comunicación viral, las redes de fidelizaciones de socios, las presentaciones de producto, etc.) y la periodística (las actividades proyectadas a la ciudadanía a través de los medios de comunicación). 
Tabla 2. Esferas de gestión de las relaciones públicas

\begin{tabular}{|l|l|}
\hline \multicolumn{1}{|c|}{ Área comercial } & \multicolumn{1}{c|}{ Área corporativa } \\
\hline Comunicación de márketing & Políticas corporativas \\
Reuniones públicas de producto & Valores de marca \\
$\begin{array}{l}\text { Eventos con celebridades } \\
\text { Red de fidelización con socios y y } \\
\text { aficionados }\end{array}$ & $\begin{array}{l}\text { Directrices de comunicación } \\
\text { Acciones de publicity }\end{array}$ \\
\hline \multicolumn{1}{|c|}{ Área periodística } & \multicolumn{1}{c|}{ Área social } \\
\hline $\begin{array}{l}\text { Acciones de publicity } \\
\text { Gabinetes de prensa } \\
\text { Gestión de medios propios } \\
\text { Creación de contenidos }\end{array}$ & $\begin{array}{l}\text { Mecenazgo y patrocinio social y cultural } \\
\text { Responsabilidad social corporativa }\end{array}$ \\
\hline
\end{tabular}

Fuente: Ginesta y Ordeix (2011: 183).

Los publirrelacionistas deben otorgar una gran importancia a la retroalimentación o feedback en la fase de comunicación. Esto es debido a que una buena campaña no se vale únicamente de la simple transmisión del mensaje, puesto que es posible que el público no preste atención a la información. Además, los datos se reciben y asimilan de diferente forma según personas. Tal y como resaltan Wilcox, Cameron y Xifra (2007: 222) del profesor emérito de Ohio State University Walt Seifert, "no todos los que reciban el mensaje lo publicarán, y no todos los que lo lean o escuchen lo comprenderán o actuarán en consecuencia”. La clave de la comunicación efectiva, por tanto, es que "las palabras del remitente deben significar lo mismo para el receptor que lo que significan para el remitente"305 (Cutlip y Center, 1964: 147).

Los mensajes, en consecuencia, han de ser diferentes según el público al que se dirigen, dado que "un análisis cuidadoso muestra que cada público tiene un interés distinto en la organización”306 (Hunt y J. E. Grunig, 1994: 33). El vocabulario y expresiones que se seleccionen también han de adecuarse al conocimiento del grupo al que se envían, por lo que conviene individualizar los datos a cada tipo de target. El diálogo, por tanto, ha de personalizarse (Bruning, Dials y Shirka, 2008). "Un modelo rígido y con un único enfoque de relaciones con los medios no es adecuado para los encargados de la información pública que trabajan en el actual entorno mediático sobre la salud"307, indican Lariscy, Avery y Sohn (2010) sobre el caso concreto de la sanidad.

Viendo las diferencias entre estas personas, parece lógico pensar que las tácticas comunicativas deben diseñarse de manera distinta para cada uno de ellos. Por ejemplo, los públicos pasivos "perciben con frecuencia limitaciones que les impiden actuar sobre un problema, y esas restricciones deben ser eliminadas antes de iniciar una campaña de comunicación"308 (J. E. Grunig y Ipes, 1983). Y es que este tipo de personas "rara vez desarrollan cogniciones organizadas o soluciones para los problemas. Solo retienen trozos y piezas de información desorganizada” ${ }^{309}$ (J. E. Grunig y Ipes, 1983). 
Los profesionales de las relaciones públicas no deben personalizar únicamente sus propios mensajes, sino que también deben "traducir" los de los distintos integrantes de una organización. Los trabajadores de esta disciplina sirven, así, de "enlace entre los departamentos y sus públicos"310 (Cutlip y Center, 1964: 219). A nivel interno, también pueden ayudar a que las personas capacitadas aunque reticentes participen en actividades para los empleados o para la comunidad, así como a que los introvertidos formen parte de aquellas acciones que los extrovertidos dan por hecho que no acudirán (Cutlip y Center, 1964: 219).

Las herramientas disponibles para trasladar y recibir mensajes de los diferentes públicos durante este periodo son muy numerosas. A nivel interno se puede hacer uso de boletines internos, tablones de anuncios, del teléfono, de mensajes de la alta dirección, de reuniones y seminarios, de proyecto de empresa, de buzón de sugerencias, de intranet, de e-learning, de videoconferencias, de foros de discusión, de blogs, de wikis y de podcasts (Xifra Triadú, 2007), de boletín o de newsletters, de cursos de formación de portavoces, de la memoria anual, de revistas, de folletos (Rojas Orduña, 2008), de reuniones informativas, de círculos de calidad o de circulares (Castillo Esparcia, 2006), entre otras cosas.

Con los medios de comunicación se puede emplear el teléfono, la nota de prensa, la rueda de prensa, el dossier de prensa, el correo electrónico, la sala de prensa virtual, los encuentros con la prensa (Xifra Triadú, 2007), las fotografías, los audio y video comunicados, las pitch letters, los anuncios de servicio público, la publicidad, las giras o presencia en programas, los emplazamientos de productos o de temas (Wilcox, Cameron y Xifra Triadú, 2007), los viajes de prensa, los artículos firmados, las cartas al director, las declaraciones, los estudios de caso, los regalos, los publirreportajes, los infomerciales (Rojas Orduña, 2008), las comidas, las visitas a la organización, las sesiones informativas, los cursos, los premios de divulgación (Palencia-Lefler, 2011), etc.

Con la población general se puede echar mano de la publicity y la publicidad, la jornada de puertas abiertas, la participación en ferias y salones, el mecenazgo, el patrocinio, la captación de fondos (Xifra Triadú, 2007), los blogs, el emplazamiento de productos y temas (Wilcox, Cameron y Xifra Triadú, 2007), las páginas web, las dark sites, las redes sociales, las wikis, los videojuegos, la comunicación a través de dispositivos móviles, las exposiciones, los congresos, los seminarios, los showrooms (Rojas Orduña, 2008), el lobismo, la donación, los premios, las ayudas, las becas, la contratación social, la fundación-empresa, el marketing relacionado con una causa (Palencia-Lefler, 2011), la realidad virtual (Castillo Esparcia, 2006), etc.

También es relevante conocer qué medios son más eficaces para trasladar datos a un colectivo en concreto. Así, se recomienda usar los medios impresos para transmitir un mensaje "que exija que el receptor asimile detalles y preste atención", la televisión 
para conseguir que "las situaciones parezcan cercanas al telespectador" y la radio para emitir datos de manera rápida y económica (Wilcox, Cameron y Xifra Triadú, 2007: 348-349). Dado que los públicos activos "buscan información por sí solos"311, se pueden utilizar los medios impresos, mientras que para alcanzar a las personas pasivas "se debe llamar su atención”,312, por lo que es más aconsejable usar medios visuales, con mensajes sencillos y cortos e insertando imágenes e ilustraciones (J. E. Grunig y Hunt, 1984: 171). Los canales online, por su parte, son aconsejables como "un medio complementario de llegar a un público, por lo general de alto nivel cultural y relativamente acomodado, interesado en nuevas ideas y enfoques frescos", aunque se ha de tener en cuenta que las personas que utilizan este medio son cada día más numerosas y variadas (Wilcox, Cameron y Xifra Triadú, 2007: 348-349). Y es que, en cuanto a credibilidad, el tipo de canal resulta ser más determinante que la clase de contenido (Tkalac Verčič, Verčič y Laco, 2008).

\subsubsection{FASE DE EVALUACIÓN}

La última etapa de la gestión estratégica propuesta por J. E. Grunig y otros (J. E. Grunig y Repper, 1992: 124; Hunt y J. E. Grunig, 1994: 12-19 y 20) y por otros autores (Crifasi, 2000; Cutlip y Center, 1964; Guth y Marsh, 2000; Hainsworth y Wilson, 1992; Hendrix, Hayes y Kumar, 2012; Kendall, 1977; Marston, 1963; Wilcox, Ault y Agee, 1986) (1964: 108) es la de evaluación. Se trata de una fase de gran relevancia dado que es el único modo de comprobar si los esfuerzos comunicativos que se han realizado han sido exitosos. Tal y como señalan Hunt y J. E. Grunig (1994: 19), un programa de relaciones públicas gestionado estratégicamente "no debe acabar cuando los técnicos han ejecutado el programa"313, puesto que "la difusión no equivale a comunicación"314 (Cutlip y Center, 1964: 170). Pero el problema de la evaluación, como dice Pavlik (1987: 65), es “doble. Primero, ¿qué medimos? Segundo, ¿cómo lo medimos?”315

Las relaciones públicas efectivas tienen lugar "cuando las actividades comunicativas alcanzan los objetivos de comunicación (de una manera rentable)"316 (Hon, 1998), de tal manera que la evaluación tiene que estar vinculada a los propósitos de relaciones públicas (que deben derivarse de las metas de la organización en general) (Henderson, 2005). Como consecuencia, y con el fin de "conseguir un impacto que sea medible",317 (Guth y Marsh, 2000), se ha de emplear el mismo criterio tanto en los objetivos y metas como en la evaluación (J. E. Grunig y Hunt, 1984: 76). Por ello, se recomienda medir el objeto de estudio antes y después de poner en práctica los esfuerzos comunicativos; es decir, se ha de emprender un pretest y un postest (Cutlip y Center, 1964: 170). En palabras de Hon (1998): 
"Aunque las definiciones de efectividad abundan en el campo de las relaciones públicas, el tema más importante en la bibliografía académica y en la prensa comercial es que las relaciones públicas efectivas aparecen cuando las actividades comunicativas alcanzan los objetivos de comunicación (de una manera rentable). Lo que se desprende de este modelo es que las metas de relaciones públicas se derivan de la misión, goles y objetivos de la organización en general. Además, a través de la evaluación en relaciones públicas, los profesionales pueden demostrar tanto directa como indirectamente el papel que tienen en la consecución de los objetivos de las entidades" ${ }^{318}$.

Quizás por ello, las relaciones públicas han experimentado en los últimos años "repetidas llamadas para desarrollar métodos que midan la evaluación"319 (Henderson, 2005), hasta el punto de que, en la actualidad, el cálculo de sus esfuerzos es uno de los "temas más populares en las conferencias profesionales, en las conferencias a distancia y seminarios virtuales y en las publicaciones comerciales" ${ }^{\prime 320}$ (Kreps, 2008). No obstante, aunque parece haber un consenso en que la evaluación es necesaria en cualquier programa, "no ha surgido ningún sistema universalmente acordado para definir los resultados de las relaciones entre una organización y su público"321 (Wise, 2007).

Existen otros problemas cuando se trata de medir la eficacia de la comunicación. Como Wise (2003) explica de Cameron y Whetten (1993), hay cuatro grandes dificultades: "1) las personas con frecuencia no pueden informar con exactitud sobre su propio criterio acerca de la efectividad de la organización; 2) la efectividad es un concepto subjetivo que cambia con el tiempo; 3) diferentes personas dentro de una organización pueden tener diferentes métodos para medir la efectividad y 4) la estrategia sobre grupos estratégicos puede contener diferentes valores sobre lo que constituye la efectividad para una organización en particular"322. Cutlip y Center (1964: 169), en cambio, resumen los obstáculos simplemente en "tiempo, dinero y habilidad",323.

Además, los publirrelacionistas encuentran resistencia en sus entidades cuando emprenden labores de medición porque "los fondos destinados a la investigación evaluativa son fondos que no se destinan a programas"324 (Springston y Weaver Lariscy, 2005). De acuerdo con J. E. Grunig (2006), otro inconveniente reside en la falta de conceptualización, dado que muy pocos publirrelacionistas prestan atención a la investigación que se realiza en el entorno académico: "Los profesionales realizan, compran o hablan sobre la medición, pero la mayoría no piensa (conceptualiza) lo que está midiendo, por qué lo está midiendo o cómo sus mediciones pueden usarse para conseguir unas relaciones públicas o una organización más efectiva» ${ }^{\text {325 }}$. Hasta que estos 
profesionales no comiencen a pensar teóricamente antes de calcular cualquier resultado, “sus mediciones normalmente tendrán poco o ningún valor más allá de la medición para su propio beneficio",326 (J. E. Grunig, 2006).

Muy pocas compañías dedican parte de su presupuesto a la fase de evaluación o emplean la rentabilidad de la inversión en sus actividades, algo erróneo, dado que "solo aquellos programas -y personal- de relaciones públicas que puedan mostrar «valor» estarán presentes el próximo año" 327 (Wilcox, 2006). Sin embargo, tal y como explica J. E. Grunig (2006):

"Demasiado a menudo, esta investigación se realiza únicamente para justificar el dinero destinado a los programas de relaciones públicas, para intentar probar que la publicity en los medios tiene valor para una organización o para que las relaciones públicas consigan más dinero del que se destina a la publicidad en los programas de comunicación de marketing",328.

En cualquier caso, se realiza investigación en relaciones públicas "para que los resultados sean usados". "Primero, eso significa que las averiguaciones deben ser «traducidas» a una forma en que las personas que toman las decisiones pueden aplicar a sus problemas de gestión. Segundo, si la investigación se va a usar, los resultados deben llegar a las manos de los que toman las decisiones. Tercero, la naturaleza práctica de la investigación significa que los que toman las decisiones deben entender el informe de los hallazgos y sus interpretaciones" ${ }^{329}$ (Broom y Dozier, 1990: 176). Los cambios pueden realizarse a nivel organizativo, de públicos, de escenario, de estrategias de programa, de resultados, etc. (Broom y Dozier, 1990: 276-279). De hecho, Dozier y Ehling (1992: 182) sostienen que "al final del programa, el éxito o fracaso del programa está determinado por la cantidad de cambios en la coalición dominante así como en los públicos objetivo" ${ }^{\text {330. }}$.

Las tácticas al servicio de la medición son múltiples. Pueden ir desde estudios de interés de lectura, test de legibilidad, análisis de la audiencia, pruebas para detectar la reacción del público ante los programas, entrevistas en profundidad, análisis del impacto, experimentos (Cutlip y Center, 1964: 174-178), encuestas, observaciones, contextualizaciones, análisis de contenido... (J. E. Grunig y Hunt, 1984: 184-198)

La evaluación se puede realizar tanto por personas en plantilla como a través de empresas externas. Dado que pocas organizaciones tienen hoy en día profesionales de relaciones públicas entrenados como investigadores y los evaluadores externos son “generalmente más objetivos"331, J. E. Grunig y Hunt (1984: 183-184) proponen la fórmula de contratar personal capaz de hacer investigaciones internas y continuas como parte del proceso de gestión y a su vez hacer uso de consultores externos cuando aparezcan nuevas ideas o se necesite objetividad. 
Las compañías de monitorización y medición pueden usarse para obtener datos evaluativos a tiempo real. Aunque parecen ser un modo sencillo para evaluar esfuerzos, "el punto clave que se tiene que recordar es que estas firmas pueden producir datos, pero el análisis y la toma de decisiones sobre lo que se ha de hacer al respecto lo tienen que realizar los empleados de relaciones públicas" 332 (Wilcox, 2006).

\section{Etapas y tipos de evaluación}

Tal y como J. E. Grunig y Hunt (1984: 182) proponen adoptando la visión de Weiss (1972) y de Jacobson (1977), la evaluación tiene cinco etapas: la de especificar los objetivos, la de medir los objetivos, la de recoger y analizar los datos, la de reportar los resultados a las personas que toman las decisiones y la de aplicar los resultados a las decisiones. Asimismo, se puede llevar a cabo una evaluación "del proceso" o de "los resultados"333 (Weiss, 1972). En el primer caso se determina "si un programa se está administrando efectivamente",334, mientras que en el segundo se analizan "los efectos de los programas"335 (J. E. Grunig y Hunt, 1984: 183). Por su parte, Cultip, Center y Broom (2000) proponen tres clases: la evaluación de la preparación, la evaluación de la implementación y la evaluación del impacto. Según Wilcox, Cameron y Xifra (2007), los diferentes tipos de medición son de producción (recuento de los materiales producidos), de exposición (el impacto que tienen los elementos emitidos), de opinión y actitud del público y de acciones y comportamientos del público. Además, se puede llevar a cabo desde un paradigma cuantitativo (cuyos resultados son más objetivos y sus datos más fácilmente analizables) o cualitativos (que proporcionan más detalle y contexto) (J. E. Grunig y Hunt, 1984: 184).

La medición de las actividades comunicativas de una firma puede determinarse desde diferentes niveles. Según Springston y Weaver Lariscy (2005), existen dos en concreto: el nivel micro (o evaluación del programa) y el nivel macro (o nivel institucional). Según el Excellence Study (L. A. Grunig, J. E. Grunig y Dozier, 2002), no obstante, pueden darse hasta cuatro categorías: nivel del programa, nivel operativo, nivel de la organización y nivel social.

De acuerdo con los primeros autores, en el nivel micro, se pueden valorar los siguientes elementos: la producción y exposición del mensaje y las opiniones, actitudes, acciones y comportamientos del público o audiencia (Springston y Weaver Lariscy, 2005). El nivel macro, por otra parte, evalúa la efectividad global de una organización, especialmente en términos de reputación y de relaciones con los públicos (Springston y Weaver Lariscy, 2005). Tal y como indican estos autores de Hon (1998) y del Institute for Public Relations (2003), "mientras que sigue siendo importante documentar el número de clippings y otro tipo de emisiones, hay cada vez más evidencias que sugieren que las relaciones públicas deben estar vinculadas sustancialmente a los objetivos y misiones de la institución",336. 
Según la división realizada por el Excellence Study (L. A. Grunig, J. E. Grunig y Dozier, 2002), el nivel del programa hace referencia a las acciones de comunicación individuales. Las relaciones con los medios de comunicación, con la comunidad, con los clientes y con los empleados pueden categorizarse dentro de este marco. El operativo implica la medición de las relaciones públicas en conjunto. Es diferente del anterior porque "aunque los programas de comunicación individuales pueden cumplir satisfactoriamente sus objetivos, la función general de las relaciones públicas puede no ser tan efectiva hasta que no se integre en todos los procesos de dirección de una organización y se escojan los públicos y objetivos apropiados para cada programa individual"337 (J. E. Grunig, 2006).

El nivel organizacional, por su parte, valora la contribución que realiza esta especialidad para el éxito global de una empresa (Kreps, 2008). En palabras de este autor:

"Las relaciones públicas contribuyen a la efectividad de la organización cuando ayudan a integrar los objetivos $\mathrm{y}$ comportamientos con las expectativas y necesidades de los públicos estratégicos. Esta contribución añade valor -a veces, pero no siempre, valor económico- a la organización. Las relaciones públicas añaden valor creando buenas relaciones a largo plazo con los públicos estratégicos, y la investigación ayuda a controlar y evaluar la calidad de esas relaciones estratégicas"338.

Finalmente, el nivel social mide la contribución que una entidad realiza para el bien general de la sociedad (Kreps, 2008). Aunque pueda parecer que no es un público importante para una agrupación, "no puede decirse que las organizaciones sean eficaces hasta que sean socialmente responsables",339 (Kreps, 2008). Aquí, las relaciones públicas tienen un papel trascendental "contribuyendo al comportamiento ético y la responsabilidad social de las organizaciones" ${ }^{\text {340 }}$ (Kreps, 2008).

Existe otra versión, por la cual se añaden dos nuevos niveles (el de proyecto y el individual) a los propuestos por J. E. Grunig (2006) para crear una red de investigación en relaciones públicas. Se trata de la proposición de Van Ruler, Verčič y Verčič (2010: 4-9), la cual supone seis niveles con orden ascendente en cuanto a complejidad: individual, proyecto, programa, función, organización y sociedad. Estas categorías, a su vez, pueden usarse para tres tipos de propósitos: sobre los roles y consecuencias de las relaciones públicas, para el desarrollo de tecnología de relaciones públicas y para la ejecución de la práctica de relaciones públicas. Gracias a esta propuesta se sostiene la idea de que "un concepto viable de relaciones públicas necesita más indicadores que las relaciones por sí solas para reflejar la naturaleza plural de sus servicios a las

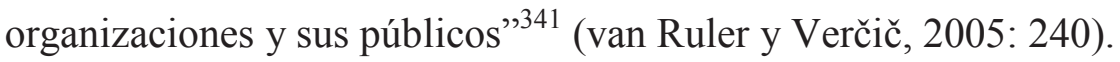

Juan Carlos Molleda (2009) forma un modelo aplicado agrupando todos los aspectos de autenticidad (elementos, asociaciones, géneros, axiomas, elementos, formas 
y tipos) y aplicándolos a las relaciones públicas. Este enfoque sirve para evaluar tanto las campañas que se quieren exponer al público como para saber las percepciones de esa audiencia una vez admitidas. Con esta configuración se puede medir "tanto la efectividad de comunicaciones controladas (boletín de prensa, blog corporativo, portal) y no-controladas (cobertura de medios, blog independiente), como las percepciones de los líderes, consumidores y públicos objetivos sobre los niveles de autenticidad de una organización y sus promesas corporativas" (Molleda, 2009). Por lo tanto, también es posible analizar la asociación entre las estrategias de comunicación y las percepciones que las audiencias tengan de esas tácticas, en el sentido de que "cuantos más elementos de autenticidad, mejor es la campaña de relaciones públicas” (Molleda, 2009). El modelo se expone de manera gráfica a continuación:

Ilustración 3. Modelo integrado de autenticidad

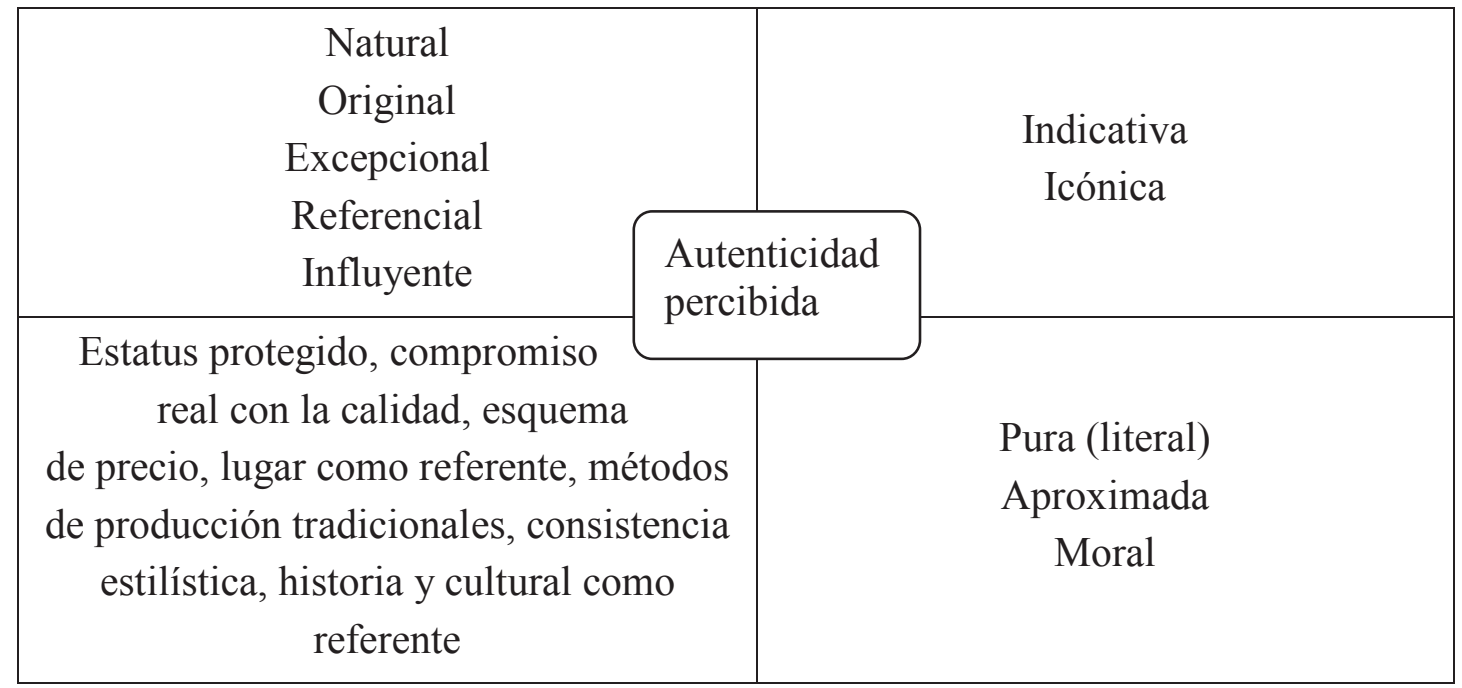

Fuente: Molleda (2009).

Huang (2012) propone un nuevo modelo para medir el valor de las relaciones públicas llamado PRVA (por sus siglas en inglés Public Relations Value Assessment) y que se basa en mediciones de la publicity en los medios, en la relación organizaciónpúblico, en la reputación de la organización, en la reducción de costes y en la creación de beneficios. J. E. Grunig (2006), por su parte, señala una serie de indicadores para calcular el efecto global de las relaciones públicas, que a su vez definen la calidad de las relaciones a largo plazo. De acuerdo con él, estas varían según el tipo de trato (comunitario o de intercambio) y según los resultados de ese vínculo (confianza, reparto del control, satisfacción y compromiso). Para cada uno de estos seis puntos, Hon y Grunig (1999) suministran una lista numerosa de preguntas para calcular la calidad de las interacciones. El listado puede encontrarse en el informe realizado por estos académicos y publicado por el Institute for Public Relations titulado Guidelines for Measuring Relationships in Public Relations. 
A pesar de todas estas guías para abordar la evaluación, los publirrelacionistas normalmente lo hacen basándose en su experiencia previa y de una manera informal: observando las apariciones en los medios o haciendo entrevistas o grupos focales desestructurados, por ejemplo (Arceo Vacas, 2004b). Una solución para desarrollar métodos más sofisticados de medición podría ser "asignar un valor económico a la reputación de la compañía"342, apostilla Arceo (2004b) hablando sobre Kim (2001).

La rentabilidad de la inversión (ROI, por sus siglas en inglés Return On Investment), de acuerdo con Wilcox (2006), ha dotado de mayor valor a las relaciones públicas. En Gran Bretaña, como muestra, el 66,7\% de los publirrelacionistas usan regularmente esta táctica (Watson, 2011). Gracias a esta táctica, la multinacional Procter\&Gamble ha descubierto que obtiene mayor rendimiento de las relaciones públicas que de cualquier herramienta de marketing, a pesar de que únicamente destina el uno por ciento de sus cuatro mil millones de dólares del presupuesto de marketing a las relaciones públicas, según señala Wilcox (2006). Y es que tanto los directores de las compañías como los jefes de comunicación coinciden en que esta disciplina recupera significativamente más de lo que cuesta y más de lo que hace cualquier otro departamento típico de una entidad (L. A. Grunig, J. E. Grunig y Dozier, 2002: 137). Así, los miembros del Excellence Study descubrieron que el retorno de la inversión es del $100 \%$ en las entidades con relaciones públicas menos excelentes y puede alcanzar el 225\% en condiciones de excelencia (L. A. Grunig, J. E. Grunig y Dozier, 2002: 137). Señalan, no obstante, que el retorno de la inversión es "amontonado, a largo plazo y con frecuenta el resultado de algo que no ha ocurrido"343 y que puede tener su punto álgido a los 10 o 20 años (L. A. Grunig, J. E. Grunig y Dozier, 2002: 137).

Algunos de los instrumentos para evaluar la rentabilidad de la inversión son: “(1) las visitas a una página web, (2) el número de consultas hechas por email o teléfono, (3) las discusiones sobre un producto en los tablones de anuncios de internet, (4) las ventas de los productos o servicios y (5) la comparación entre los reportajes de la organización y los de la competencia"344 (Wilcox, 2006). Aunque hay muchas maneras de determinar la eficacia, como se ve, "el punto determinante es llevar a cabo la ROI según lo que sea importante para tu dirección" "345, dice Wilcox (2006). Ketchum, por ejemplo, ha desarrollado su propio criterio de medición, según enumera este último autor:

"Los impactos en los medios. Equiparar la cobertura con el coste para obtenerla.

Equivalencia entre la publicidad y las relaciones públicas. ¿Cuánto vale la cobertura?

Comparar las ventas según la cobertura mediática.

Encuestar a las audiencias clave sobre dónde han oído hablar del producto o servicio"346. 
Lo que no es apropiado es equiparar las relaciones públicas con la publicidad, el mailing directo o las promociones, ya que puede llegar a ser "comparar manzanas con naranjas" "347 (Wilcox, 2006). "La publicidad se ha diseñado tradicionalmente para impulsar los ingresos a través de las ventas. Las relaciones públicas con frecuencia se usan para, entre otras cosas, incrementar el conocimiento de la marca y mejorar su reputación, unos conceptos que pueden ser medidos fácilmente a través de técnicas corrientes de ROI"348 (Wilcox, 2006).

Determinar la eficacia de las relaciones públicas según los esfuerzos de publicity tampoco es un método conveniente. "Solo porque se envíen 1.000 notas de prensa (1) no significa que el programa sea eficaz. Incluso si 100 periódicos usan las notas de prensa, (2) estos tienen que ser adecuados para la audiencia clave (3). Y solo porque la audiencia clave esté expuesta al mensaje (3) no significa que se fije en él (4)"349, sentencia Henderson (2005). 


\title{
1.2. USO DE LAS RELACIONES PÚBLICAS EN EL ÁMBITO SANITARIO. ESTADO DE LA CUESTIÓN
}

\begin{abstract}
1.2.1. Comunicación y salud
1.2.2. Esferas de la comunicación excelente en el ámbito sanitario 1.2.3. Fases de un programa de relaciones públicas en el ámbito sanitario
\end{abstract}

\subsubsection{COMUNICACIÓN Y SALUD}

\subsubsection{INTERÉS POR LA SALUD}

La inclinación por las informaciones acerca de la medicina y de la salud ha experimentado un gran crecimiento en los últimos años. Cangelosi, Ranelli y Markham (2009) indican incluso que el atractivo hacia algunos temas, como la nutrición y la sanidad preventiva, "nunca ha sido tan alto" 350 . En palabras de Castiel y Álvarez-Dardet (2005): "Independientemente de las motivaciones, no se puede negar el interés de la población por los temas relativos a la salud. Basta ver el espacio ocupado por el periodismo vinculado a cuestiones de salud y medicina".

Ciertamente, tanto los medios audiovisuales como los impresos han aumentado la extensión otorgada a la salud desde hace 25 años (Viswanath, 2006). Roessler (2007), incluso, asegura que las noticias médicas son "omnipresentes" en la programación contemporánea. Tal y como apuntan Weaver Lariscy y Johnson Avery (2010), “el público tiene mucho interés por las noticias médicas, y los medios de comunicación están actuando acordemente" "351. Ahora, "las noticias sobre avances médicos, fármacos prometedores y nuevos tratamiento para enfermedades desde la diabetes hasta el VIH = SIDA son temas dominantes tanto en los medios impresos como en los audiovisuales" 352 [Avery et al. (2010) hablando sobre Eggener (1998) y Viswanath 
(2006)]. Por ello, las historias sanitarias aparecen a menudo en las primeras páginas de los periódicos y en el prime-time televisivo (Eggener, 1998; Viswanath, 2006). En España, por ejemplo, el número de noticias publicadas en conjunto en los periódicos $E l$ País, El Mundo, ABC, La Vanguardia y El Periódico de Catalunya en diez años (más concretamente de 1997 a 2006) ha sufrido un aumento del 132\% (Observatorio de la Comunicación Científica, 2008). En Estados Unidos, por su parte, estas informaciones han crecido un 34\% entre 1997 y 2000 (Brodie, Glynn y Van Durme, 2002).

No solamente los informativos están respondiendo a la moda por los asuntos sanitarios, sino que también lo está haciendo la industria del entretenimiento. Amador Romero (2004) resume de un editorial de Scott Rozman publicado en The Journal of Health Communication que este sector se ha convertido en la fuente principal de estos temas en Estados Unidos. Como muestra, Rozman indica que el 32\% de la audiencia del programa Urgencias considera que la serie le ayudó a tomar decisiones sobre su salud en su entorno familiar y que el 12\% acudió a su médico después de ver algún episodio.

El alto número de noticias responde al interés general de la población por asuntos médicos. En Estados Unidos, por ejemplo, el Pew Research Center for the People y the Press (2004a), que es el encargado de medir las actitudes del público hacia las diferentes noticias, muestra continuamente en sus estudios que las informaciones sobre la salud son uno de los cinco temas más leídos por los consumidores. Como Len-Ríos, Hinnant y Park (2009) señalan de una de estas indagaciones realizada en 2006, el 24\% de los americanos aseguraban seguir este tipo de novedades "muy de cerca" (Pew Research Center, 2006b), superadas únicamente por el tiempo, el crimen y la sociedad. En España, el área de mayor valor para los ciudadanos durante muchos años ha sido la sanidad, solo suplantada por el "trabajo" en el año 2012, ejercicio en el que se introdujo esta respuesta (Centro de Investigaciones Sociológicas, 2012).

El interés por las noticias médicas depende, no obstante, de las características de cada individuo. Por ejemplo, la mayoría de las mujeres de más de 40 años o que tienen una salud debilitada son más sensibles hacia su estado físico y mental y, por lo tanto, hacia los mensajes de este tipo (Aldoory, 2001). Este estudio también muestra que las chicas heterosexuales euro-americanas, de clase media, con trabajo, que definen su salud como buena y que tienen hijos ya crecidos leen más revistas y periódicos sobre temas sanitarios y lo comparten con amigos que el resto de personas. En el otro lado se hallan las de menos de 35 años, que raramente hablan sobre sus preocupaciones, y las estudiantes universitarias, que pocas veces se involucran en estos temas. Asimismo, se puede afirmar que el interés por la salud crece con la edad: las personas mayores son más propensas a cuidarse, a participar en actividades preventivas y a buscar información adicional (American Dietetic Association, 1997; Dutta-Bergman y Youn, 1999; Goldberg, Gershoff y McGandy, 1990; Kearney et al., 1998; Lahmann y Kumanyika, 1999; Landmann et al., 1990; Medeiros et al., 1996). 


\subsubsection{AUMENTO DE LAS FUENTES SOBRE LA SALUD}

Como resultado del creciente interés de la población por los temas médicos, la multiplicación de departamentos de comunicación en las instituciones sanitarias y la relevancia de esta clase de información en la agenda de los medios de comunicación (Becerra Muñoz, 2006), las fuentes y la cantidad de indicaciones a disposición de la audiencia ha aumentado. En palabras de Amador Romero (2004): "Los ciudadanos obtienen cada vez más información sobre salud, no sólo de la que consideran su fuente más respetada-valorada, el médico (no debemos olvidar que hasta el $54 \%$ de lo que el médico comunica en consulta se olvida al salir de ella (Ley, 1979)), sino de otras fuentes: personal de enfermería, asociaciones, grupos de autoayuda y, sobre todo, de los medios de comunicación". Frente a la cantidad de orígenes de información disponibles para el usuario, el médico sigue siendo uno de los principales (Avery, 2010), junto con la televisión (Avery, 2010), internet (Lupiáñez Villanueva, 2009) y los familiares y amigos (Jiménez Pernett et al., 2009).

Los lugares donde se pueden adquirir esta clase de datos, además, se han multiplicado, y ahora se puede consultar en casa, oficinas, colegios, clínicas, hospitales... (Kreps, Bonaguro y Query, 1998). Incluso a través de internet: "Desde vídeos en Youtube hasta actualizaciones en Twitter y blogs individuales específicos"353, dicen Freberg, Palenchar y Veil (2013). Según indica Wrenn (2002) sobre la información preventiva ( $\mathrm{PHC}$, por las siglas en inglés Preventive Health Care Information):

"Los consumidores obtienen información PHC a través de una variedad de fuentes personales, comerciales, no-comerciales, institucionales y mediáticas, que a su vez pueden ser clasificadas como formales o informales. Las institucionales como los centros comerciales o los supermercados proporcionan información nutricional y acogen ferias sobre la salud (Mueller, 1989). Dentro de las fuentes personales se enmarcan los amigos, la familia, los vecinos, los socios y demás. Los médicos y otros trabajadores sanitarios también suministran información PHC más formal y autoritaria. Las fuentes mediáticas abundan, como los medios impresos (revistas, periódicos y boletines informativos) y los electrónicos (radio y televisión). Una de las fuentes electrónicas de información PHC que está reemplazando a la mayor parte de fuentes tradicionales como el primer recurso informativo es internet (Thomas, 2005)"354.

Efectivamente, los medios de comunicación no son la única fuente para instruirse sobre estos asuntos; actualmente, los canales de consulta son numerosos: pueden ser 
conversaciones cara a cara [el mecanismo más efectivo, según Roessler (2007)] entre proveedores y consumidores, miembros de equipos médicos y grupos de apoyo, etc. (Kreps, Bonaguro y Query, 1998). Las nuevas tecnologías también han emergido como un origen importante de datos, sobre todo para los jóvenes, que son "más abiertos a nuevos recursos para mejorar su condición física" 355 (Roessler, 2007). Un ejemplo de ello se encuentra en unas asambleas públicas realizadas en 2009 sobre la reforma de la sanidad de Estados Unidos, cuya retransmisión en vídeo logró la mayor audiencia de YouTube (Pew Research Center, 2009a).

Y es que el número de lugares en internet que ofrecen información sobre la salud se ha expandido tanto en la última década que la American Medical Association ha publicado unas directrices para orientar a los consumidores sobre la validez de esos sitios (Winker et al., 2006). A pesar de que puede haber textos fraudulentos, colgar aclaraciones sanitarias en la red tiene, en general, consecuencias positivas. Schulz et al., (2007) analizaron el impacto de una página web diseñada para paliar necesidades individuales y observaron que, después de su uso, los internautas acudieron menos veces al médico y tomaron menos pastillas contra el dolor. Por encima de todo, sostienen los autores, "lo más sorprendente de estas consecuencias es que su estado de salud incluso mejoró"356.

Los medios sociales (o social media, en inglés) son otros cauces con una popularidad creciente. Según Avery et al. (2010), la comunicación sanitaria se encuentra "bien adaptada al medio: es uno de los temas más deseados en las noticias, responden a un nivel tanto personal como político y las personas tienden a querer información inmediata que esté disponible en línea de manera urgente cuando se enfrentan a un problema de salud complicado"357. Asimismo, una ventaja exclusiva de los medios sociales sobre otras herramientas es su habilidad para "emplear a un incontable número de electores en la comunicación bidireccional, incluso cuando una organización tiene una estructura de financiación limitada"358, dicen Avery et al. (2010) del Pew Research Center (2004a).

La preferencia de una fuente sobre otras también depende de las peculiaridades personales. Las mujeres, en general, suelen recopilar más información que los hombres (Neumark-Sztainer et al., 1998). Por otra parte, las universitarias euro-americanas prefieren revistas de chicas y programas televisivos de entretenimiento. En otras palabas, "este grupo de estudiantes prefieren personajes mediáticos que se parezcan a ellas o que sean como a ellas les gustaría llegar a ser" ${ }^{359}$ (Aldoory, 2001). Las personas entre 65 y 69 años, en cambio, se decantan por su médico en vez de internet (SeematterBagnoud y Santos-Eggimann, 2007).

El uso de canales interpersonales, actividades comunitarias, medios de comunicación y cauces informativos están asociados a diferentes comportamientos en referencia al bienestar (Zillmann y Bryant, 1985). Por ejemplo, los individuos 
preocupados por este tema son más propensos a buscar y consumir medios que incluyan datos sobre la salud (Lichtenstein y Rosenfeld, 1983; Rubin y Rubin, 1982; Rubin, 1983). En otras palabras, es más probable que estas personas se involucren en noticias de este tipo a través de canales eminentemente informativos ( Dutta-Bergman y Youn, 1999) y, como consecuencia, emprendan en su vida cotidiana prácticas saludables. Resumiendo, "los consumidores responsables eligen contenidos sobre la salud basados en la información, lo que a su vez produce un comportamiento acorde y provoca una creciente brecha entre los consumidores conscientes de su salud (buena salud) y los que no prestan atención a su salud (mala salud) ${ }^{„ 360}$ (Dutta-Bergman, 2004).

\subsubsection{CONSECUENCIAS DE UN ALTO INTERÉS EN LA SALUD}

Quizás debido al alto interés que muestran acerca de este tema, "los pacientes se informan más acerca de sus necesidades y ya no se someten únicamente a las instrucciones de su médico, sino que juegan un papel más activo en las decisiones relacionadas con su salud"361 (Gbadeyan, 2010). Tal y como indican del Pozo y Ferreras (2011: 111), el paciente, "al contrario, realiza comparaciones, consulta diferentes fuentes y las analiza de manera crítica, hasta conformar y formarse una opinión”. La búsqueda de estos datos conlleva una serie de consecuencias positivas. Gatigono y Robertson (1985) sugieren que las personas que usan fuentes de información externas tienden a adoptar comportamientos vinculados a esos datos. Por lo tanto, puede asumirse que el público que consume información preventiva sobre la salud es más propenso a practicar en su vida cotidiana esas acciones (Cangelosi, Ranelli y Markham, 2009).

Gracias a una encuesta nacional realizada en Estados Unidos, Cangelosi, Ranelli y Markham (2009) observaron que dos tercios de los 550 participantes estaban de acuerdo en que la comunicación ha cambiado sus hábitos o visiones hacia el tabaco y más del $40 \%$ asegura que este tipo de información es importante en su concepción del consumo de alcohol y la pérdida de peso. Hay, no obstante, diferencias en la búsqueda y el impacto de estos datos según las características de cada uno. Los autores resumen su conclusión de la siguiente forma:

"Podemos decir con confianza que las personas que buscan, se informan y se impactan por la información PHC [información preventiva sobre la salud] son más cultas, tienen ingresos más altos, suelen ser mujeres, por lo general mayores, y están casadas. Los cambios más importantes en el estilo de vida que emanan de la información PHC son los cambios en los hábitos alimenticios, hacerse chequeos médicos periódicos, tener en cuenta el etiquetado nutricional y apuntarse a un gimnasio o a un 
centro de bienestar. Los cambios en la vida social, los hábitos de sueño, hacer ejercicio regularmente y la asistencia a ferias y seminarios sobre la salud también se asociaron con la utilización de información PHC, aunque en menor medida"362.

\subsubsection{UNA GRAN OFERTA NO IMPLICA UNA CALIDAD ALTA}

Aunque el número de informaciones y fuentes ha aumentado en los últimos años, esto no significa necesariamente que la calidad haya crecido. Tal y como Amador Romero (2004) indica, este incremento, "a criterio de muchos profesionales sanitarios, no se ha visto correspondido en igual medida en cuanto a su calidad". Analizando el papel de los medios de comunicación, por ejemplo, que, durante años, han sido una de las principales fuentes de información para estos temas, se observa que los redactores y los científicos y sanitarios han mantenido tradicionalmente "una relación pasiva, de desconfianza mutua, cuando no discrepancia abierta sobre el tratamiento de una determinada noticia de salud" (Amador Romero, 2004). Según continúa este autor, esto ha podido producirse por "la excesiva celeridad del trabajo periodístico, que puede llevar a conclusiones erróneas y escasamente meditadas y caer en el sensacionalismo o lograr un objetivo contrario al que se ha querido transmitir". Y es que los medios de comunicación, "necesitados de audiencia y frecuentemente encorsetados por el factor tiempo, han evitado la obligada actitud reflexiva y de análisis que toda noticia ha de conllevar, más aún en el campo de la salud, cayendo con mayor frecuencia de lo deseado en informaciones que han podido ocasionar situaciones de alarma social («vacas locas», «epidemia» de meningococo, aceite de orujo, etc.), lejos del loable objetivo de informar” (Amador Romero, 2004). Martínez Solana (2011: 52-53) lo explica de la siguiente manera:

"Condicionantes derivados de la línea editorial de los medios informativos y de las empresas de las que estos dependen. Predilección por la noticia sensacionalista de patrón agudo, en detrimento del seguimiento informativo de un tema a largo plazo. Ello se ve favorecido por la falta de hábito y los condicionantes de tiempo y espacio. Además existe una excesiva dependencia de las agendas institucionales y de las informaciones de este origen al tiempo que no existe un método científico aplicado al proceso informativo en el ámbito que nos ocupa, lo que fomenta el periodismo de denuncia en detrimento del divulgativo y de investigación (en lugar de combinar los tres). Asimismo, y con frecuencia, no se atiende a la etiología de una crisis, sino solamente a sus repercusiones sociales o de consumo". 
Existen numerosos estudios que señalan la mala cobertura en prensa de los temas relacionados con la salud. A los periodistas les gusta enfatizar la singularidad de los eventos individuales [“el «primer» descubrimiento, el mayor «logro»",363 ... (Nelkin, 1996)], crear polaridades y a veces simplificar en exceso los estudios científicos "para presentar un tema complejo de manera comprensible y atrayente"364 (Dunwoody, 1982).

Uno de los temas peor tratados, según la bibliografía existente, es el VIH/SIDA. Brown y Steele (1996), por ejemplo, llevaron a cabo un estudio sobre la información en torno esta enfermedad en programas de televisión, radio, revistas y spots publicitarios. Observaron que estos medios contienen abundantes referencias relacionadas con la sexualidad y el SIDA, pero adolecen de una representación realista de la misma. Según señalan, estaba repleta de estereotipos sobre la masculinidad (Aguilera y Pindado, 2006). Posiblemente por el tinte sensacionalista de muchos medios, las informaciones relacionadas con este tema [el mayor desafío comunicativo desde la II Guerra Mundial, según Reardon (1989)] han disminuido a lo largo de los últimos años, ha decrecido el género interpretativo sobre ellas y se publican, en la mayoría de ocasiones, debido a ciertos eventos (Terrón Blanco, 2011). Además, adolecen de una representación realista al estar repletas de estereotipos sobre la masculinidad (Brown y Steele, 1996). Las enfermedades mentales también son retratadas de manera inexacta, puesto que a lo largo de los años han sido "predominantemente antisociales"365 (Martínez-Brawley y Brawley, 2003). Estos autores incluyen en su artículo numerosos estudios que respaldan este planteamiento.

Los periodistas también comenten numerosas inexactitudes. Así lo constata un estudio de dos años elaborado por Moyer et al. (1995) sobre la precisión de los periódicos y revistas sobre temas de salud. Los resultados indican que el $70 \%$ de las informaciones analizadas contenían "inexactitudes de contenido"366. Según indican Castiel y Álvarez-Dardet (2005) con el caso concreto de la epidemiología, "los epidemiólogos argumentan que los periodistas enfatizan en exceso hallazgos específicos de estudios, sin dimensionar aspectos metodológicos y el contexto de la investigación. Los representantes de la prensa se justifican señalando el afán de espectáculo de algunos investigadores y sus correspondientes instituciones".

Todos estos inconvenientes pueden resolverse con más profesionales que tengan conocimientos sobre "metodologías específicas para analizar, seleccionar, sistematizar y transmitir información" (Bonilla Loyo, 2008). Incorporar competencias de comunicación en los estudios sanitarios ayudaría a los profesionales de la salud a informar y conectar de mejor manera con los diferentes sistemas de información (Bonilla Loyo, 2008). También es importante controlar la relación entre científicos y la divulgación de sus hallazgos (Davo y Álvarez-Dardet, 2003), ya que es “inadmisible la generación de discrepancias o conflictos con perjuicios para los propios investigadores y profesionales de salud, y especialmente para el público" (Castiel y Álvarez-Dardet, 2005). Para Hernán Díaz (2013), la especialización en comunicación y salud y la 
recuperación de las buenas prácticas periodísticas (como el contraste riguroso de las fuentes o la consulta a expertos) son los “dos principales antídotos para garantizar una cobertura informativa que evite caer en prejuicios y representaciones sociales estigmatizantes".

\subsubsection{NECESIDAD DE COMUNICACIÓN EN EL ÁMBITO SANITARIO}

Visto el interés que la población tiene por los temas de la salud y la sanidad y la multitud de canales para conseguir información, parece evidente que las organizaciones que se dedican a estos asuntos necesitan incorporar funciones de relaciones públicas en su actividad diaria. Tal y como dice Díaz (2011: 33), "ya nadie duda que la comunicación y la salud son una pareja de hecho desde hace mucho tiempo". Los beneficios de poseer un departamento de comunicación en estas entidades son numerosos y muy importantes; algunos estudios incluso llevan a vincular la calidad de la comunicación con la calidad de la asistencia que se ofrece (Anand y Chakravarti, 1981; Keller et al., 2014; Scott et al., 2005).

Tanto es así que la comunicación se ha convertido en una "aliada estratégica" en el ámbito sanitario. Según Menéndez y Vadillo (2010: 13), "no solo como canal de transmisión de información, sino también porque contribuye a mejorar la imagen y la notoriedad de cualquier entidad del sector, desde la Administración a una sociedad científica, pasando por un centro hospitalario, un laboratorio e incluso un producto o servicio".

También sirve como base de la relación entre los profesionales sanitarios y el usuario, como parte del servicio identificable, como elemento que facilita su adaptación al proceso de hospitalización y como mecanismo educativo (Costa Sánchez, 2012). Y es que se estima que el $80 \%$ de los problemas que afectan a la dirección de un hospital tienen implicaciones para las relaciones públicas (Anand y Chakravarti, 1981). En realidad, si el vínculo entre una organización de este tipo y sus audiencias es negativo, “es cuando más se necesitan las relaciones públicas eficaces"367 (Meath, 2006).

Algunas prácticas de intercambio de información, o al menos de mero traslado, aportan un impacto positivo en el funcionamiento general de las organizaciones relacionadas con la salud. Por ejemplo, divulgar los datos de rendimiento de un centro sanitario incrementa su cuota de mercado y conlleva ventajas en ciertas áreas clínicas (Hibbard, Stockard y Tusler, 2005). Otro ejemplo similar se halla en los informes sobre calidad, que sirven como incentivo para dedicar más recursos a programas de investigación y de mejora de calidad (Pham, Coughlan y O’Malley, 2006).

Como se ve, hoy en día, las relaciones públicas están presentes en el ámbito de la salud, a pesar de que no se tenga tanto conocimiento en este campo como en otros 
(Wise, 2001). Esta idea la corroboran varios autores. Por ejemplo, Milano (2010) opina llanamente que "sabemos poco sobre la práctica de las relaciones públicas en entidades sanitarias" $^{\text {,368 }}$. Fletcher (1989), en su tesis doctoral de 1989 sobre la práctica de esta disciplina en California del Norte advierte que "hay una limitada información disponible sobre el estado general de las relaciones públicas en los hospitales en cualquier localización, y prácticamente nada se ha hecho en Carolina del Norte específicamente"369. Así, llega a la conclusión que su estudio representa "uno de los primeros retratos" ${ }^{, 370}$ de las relaciones públicas en este ámbito (Fletcher, 1989).

Se sabe, al menos, que el punto de partida son otras ciencias sociales, en especial la psicología y la sociología, ya que estas especialidades estudiaban activamente el sistema sanitario (Kreps, Bonaguro y Query, 1998). Tal y como explican estos autores:

"La disciplina de la comunicación lleva tiempo adoptando teorías y métodos propios de estas ciencias sociales; la adopción del contexto sanitario como un tema de estudio fue una tendencia disciplinaria natural. Además, los académicos de estas ciencias sociales comenzaron a examinar las variables comunicativas en el ámbito de salud (Bandura, 1969; Feldman, 1966; Kosa, Antonovsky y Zola, 1969; McGuire, 1969, 1984; Tichenor, Donohue y Olien, 1970; Zola, 1966), lo que estimuló a los investigadores de la comunicación a seguir esta tendencia" ${ }^{\prime 371}$.

La información sobre la salud también tiene influencias de la psicología humanística, de la bibliografía psicológica sobre persuasión e influencia social, de la sociológica médica y, en general, de la del campo de la medicina (Kreps, Bonaguro y Query, 1998). Sin embargo, al contrario de otras ciencias establecidas, las relaciones públicas en los hospitales es una función relativamente nueva (Gordon y Kelly, 1999) sobre todo en los países iberoamericanos (Díaz y Cuesta Cambra, 2014). Las primeras actividades de este tipo emprendidas por estos centros tuvieron lugar en la década de 1920 en forma de newsletters (Kurtz, 1969). Estas piezas eran básicamente folletos con información sobre las actividades de la organización destinados al público general (Guy et al., 2007).

No fue hasta la formalización de los hospitales después de la Segunda Guerra Mundial cuando las relaciones públicas comenzaron a expandirse y a normalizarse en estos centros (Guy et al., 2007). Desde los años 1960 hasta el inicio de la década de 1980, estas actividades tomaron la forma de "programas" (Guy et al., 2007) y las clínicas empezaron a competir por los pacientes (Lewton, 1991). Tal y como Mills (1965: 8) especifica, estos proyectos tenían la intención de formar "un esfuerzo dirigido consciente dirigido por una institución concreta para crear y fortalecer los contactos que 
contribuyen al desarrollo del entendimiento mutuo, la buena voluntad y el respecto entre esa institución y su público"372.

Desde entonces, la práctica de las relaciones públicas, especialmente en el área médica, ha experimentado un gran crecimiento y evolución (Henderson, 2005). La comunicación hoy en día constituye "un valor añadido" para cualquier hospital (Costa Sánchez, 2011: 19) y se ha llegado a un punto en que es "inevitable" crear estos departamentos en hospitales, dado que "las relaciones humanas son la base de las relaciones públicas"373 (Kirdar, 2007). Por ello, la necesidad y el uso de las relaciones públicas estratégicas "nunca ha sido mayor de lo que es hoy"374 (Springston y Weaver Lariscy, 2005), básicamente porque sirven a un fin, proporcionan valor y propician una mayor demanda de noticias sobre la salud e información para el consumidor (Springston y Weaver Lariscy, 2005). Además, para algunos investigadores, esta práctica en el mundo hospitalario se ha vuelto más reconocida, más necesaria y más importante (Henderson, 2005), incluso su valor ha aumentado (Springston y Weaver Lariscy, 2005).

Los estudios que existen en la actualidad sobre la gestión estratégica en España en el terreno de la salud, no obstante, no ofrecen resultados demasiados positivos. Díaz y Cuesta (2014), por ejemplo, estudiaron las organizaciones no lucrativas del ámbito de la salud y hallaron que tienen una visión a corto plazo, que no tienen planes de comunicación, que su principal objetivo es tener visibilidad pública a los públicos externos y que no usan evaluación. Asimismo, ven que las organizaciones profesionales usan un modelo de información pública, mientras que las de pacientes adoptan un modelo bidireccional simétrico. Carmen Costa (2012), por su parte, a través de entrevistas personales y cuestionarios a los responsables de comunicación de los hospitales gallegos, observa que "los recursos humanos son pocos, la comunicación externa es la apuesta principal y todavía queda mucho camino a la hora de concebir la comunicación como una herramienta estratégica de gestión”. Tampoco es mucho más halagüeña la situación en Latinoamérica. Según una encuesta de Bruno et al. (2012) a comunicadores de las áreas, direcciones y programas del Ministerio de Salud de la Nación de Argentina para conocer su formación, experiencia y actividades actuales, los autores llegan a la conclusión de que se da una insuficiente capacitación, presupuesto, equipamiento tecnológico y recursos humanos. 


\subsubsection{ESFERAS DE LA COMUNICACIÓN EXCELENTE EN EL ÁMBITO SANITARIO}

Vista el deficiente empleo de las relaciones públicas en el ámbito sanitario, se hace necesaria una revisión de los parámetros de excelencia aplicados al caso concreto de las organizaciones sanitarias, en especial de los hospitales o centros de atención especializada. Para ello, al igual que se ha realizado en la parte teórica general de las relaciones públicas, se utiliza la propuesta realizada por Dozier, L. A. Grunig y J. E. Grunig (1995: 5), que resumen la esencia del factor de la excelencia como tres esferas, una dentro de la otra, las cuales contienen tres aspectos fundamentales. En el núcleo se halla el conocimiento de los comunicadores; después, las expectativas comunes entre el departamento de relaciones públicas y la coalición dominante y, finalmente, la cultura participativa de la entidad.

\subsubsection{CONOCIMIENTOS DE LOS COMUNICADORES}

Dentro del apartado de conocimientos de los comunicadores, Dozier, L. A. Grunig y J. E. Grunig (1995: 5) incorporan varias características que ayudan a conseguir unas relaciones públicas excelentes. Uno de ellos es conocer y ejecutar tanto un papel directivo como técnico, con el fin de tener profesionales que sepan manejar las respuestas de la organización hacia diferentes asuntos y desarrollen metas y objetivos, a la vez que se disponga de las personas capaces de implementar los programas de comunicación. Asimismo, se ha de emplear modelos de comunicación bidireccionales para obtener retroalimentación del público, en especial sabiendo acomodar de igual manera la postura de la organización y la de los públicos para lograr una reciprocidad.

También es recomendable, señalan Dozier, L. A. Grunig y J. E. Grunig (1995: 5), disponer de habilidades estratégicas para identificar los públicos, mensajes y canales más relevantes para la entidad. Por otra parte, también se deben emplear herramientas de investigación formal e informal, tanto para la etapa formativa como la evaluativa, así como disponer de conocimientos sobre cómo afrontar los conflictos potenciales y las crisis y saber hacer un uso apropiado de las nuevas tecnologías, entre otras cosas.

\subsection{CONOCIMIENTOS DIRECTIVOS Y TÉCNICOS}

Los roles de relaciones públicas son uno de los conceptos teóricos más importantes y más estudiados dentro de esta disciplina porque reflejan cómo se comportan las personas en su labor diaria y predice los resultados de estas acciones. De manera general, se considera que hay dos tipos de roles: el directivo y el técnico, cada uno de ellos con sus determinados objetivos y funciones. 
Los centros de atención especializada, como cualquier otra institución, deben tener profesionales que se adecúen a ambos enfoques. Un gabinete compuesto únicamente por técnicos "contribuye poco a la efectividad global de la organización. Su trabajo carece de objetivos y de una dirección clara y cualquier impacto depende de la planificación y de las decisiones de otras personas que no pertenecen al departamento"375 (Gordon y Kelly, 1999). Los gabinetes de relaciones públicas son más propensos a realizar una gestión estratégica y a utilizar modelos bidireccionales "si cuentan con gestores de comunicación, que conceptualizan y dirigen los programas de relaciones públicas, así como con técnicos, que proporcionan apoyo técnico en tareas de redacción, edición, fotografía, contacto con los medios y producción de publicaciones”376 (J. E. Grunig y L. A. Grunig, 1991).

Además, "manejar las relaciones públicas bajo un rol directivo en vez de bajo uno técnico respalda a otras funciones de la dirección"377 (J. E. Grunig, 2006) y se relaciona con un mayor poder dentro de las organizaciones sanitarias (Fletcher, 1989). En este tipo de entidades en concreto, existen dos tipos de actuaciones esenciales. Una de ellas es "aconsejar a la alta dirección" 378 y la otra, "crear programas de comunicación y de fortalecimiento de relaciones que vinculen a la organización con sus públicos"379 (Lewton, 1991).

A pesar de que existen numerosas investigaciones sobre este tema en la bibliografía sobre relaciones públicas en general, en el campo sanitario son muy escasas. Hasta la fecha, solo hay unos pocos estudios que determinen la importancia de cada rol en los hospitales (Bosilkovski, 2011; Fabiszak, 1985; Fletcher, 1989; Gordon y Kelly, 1999) y todos ellos apuntan al rol técnico como principal enfoque.

Una de estas indagaciones es, por otra parte, una de las más extensas que existen acerca de las relaciones públicas en estos centros (Gordon y Kelly, 1999). Los comunicadores que participaron en este estudio aseguraban utilizar tanto el aspecto técnico como el directivo, pero suelen dar más cabida al primero. La frase con la que se sentían más identificados es "producir publicaciones" ${ }^{\text {"30 }}$, del rol técnico. "Realizar investigación evaluativa" ${ }^{, 381}$, del directivo, fue la idea menos recurrente. Como conclusión a su estudio, Gordon y Kelly (1999) determinaron que, al igual que en el resto de agrupaciones, "el potencial [de los hospitales] para actuar mediante el rol directivo está fuertemente relacionado con la eficacia de la organización" misma investigación, Gordon y Kelly (1999) compararon los resultados ofrecidos por los hospitales con otras entidades sin ánimo de lucro y determinaron que, en ambos casos, el rol técnico es el más empleado. Sin embargo, no se hallaron tales coincidencias comparando los hospitales con las organizaciones multinacionales, cuya pericia es mayor para el papel directivo.

Fletcher (1989), aunque insiste en que le fue imposible vincular con total precisión las tareas que realizan los comunicadores con los roles de J. E. Grunig y Hunt (1984), 
encontró que la mayoría de los publirrelacionistas de los hospitales de Carolina del Norte (Estados Unidos) (que era la zona donde se centraba el estudio) realizaban tareas consideradas tradicionalmente como técnicas o de enlace.

Fabiszak (1985) llega a similares conclusiones. Observa que los hospitales "practican las actividades más técnicas como escribir notas de prensa o producir publicaciones, así como aquellas actividades más informales y generales como crear contactos informales con sus públicos"383. En esa línea, asegura Fabiszak (1985), los centros de atención especializada no investigan antes de iniciar un programa de relaciones públicas ni evalúan el alcance de esas acciones.

En otra investigación más reciente, Bosilkovski (2011) obtuvo los mismos resultados: que los publirrelacionistas en el terreno de la salud se asemejan más al rol técnico que al directivo, siendo esta diferencia estadísticamente significativa. Así, sus tres actividades principales eran escribir notas de prensa o responder a las peticiones de los medios, realizar servicios de publicidad o de marketing y sacar adelante la publicación de los empleados. Aun así, en torno a la mitad de los participantes en el estudio aseguraban dar discursos y representar al hospital en eventos $(59,2 \%)$ y dirigir personas $(55,8 \%)$. Sin embargo, los porcentajes bajan cuando se trata de desarrollar la planificación estratégica o las decisiones sobre las normas del hospital (47,3\%) o aconsejar a los directivos (43,8\%).

\subsection{CONOCIMIENTOS DE COMUNICACIÓN BIDIRECCIONAL}

Los modelos de relaciones públicas describen los valores y los patrones de comportamientos realizados por los miembros de un departamento de comunicación en su relación con los públicos (Dozier, L. A. Grunig y J. E. Grunig, 1995: 40). J. E. Grunig y Hunt (1984) idearon cuatro patrones, dependiendo de la dirección (unidireccional-bidireccional) y de los efectos (asimétrico-simétrico): el de agente de prensa, el de información pública, el asimétrico bidireccional y el simétrico bidireccional. La comunicación en los dos primeros fluye en una sola dirección desde la organización a los públicos, ya que conciben la comunicación "como contar, no como escuchar" (J. E. Grunig y Hunt, 1984: 23). En los modelos bidireccionales, en cambio, se produce un diálogo (J. E. Grunig y Hunt, 1984: 23).

Wise sugirió en 2001 en un artículo sobre las oportunidades que tiene la exploración en relaciones públicas en el entorno sanitario que los modelos y los roles son "quizás el primer tipo de investigación en relaciones públicas que debería ser realizado"384. Una aproximación a estos modelos, continúa Wise (2001), "nos daría información sobre cuánto están contribuyendo las relaciones públicas en la eficacia de órganos como los departamentos de salud estatales" ${ }^{385}$. 
De esta manera, se puede observar que las organizaciones sanitarias que utilizan los patrones unidireccionales "no estarían asociadas con funciones de marketing o de planificación estratégica" ni tendrían "un papel en la planificación estratégica"386 (Guy et al., 2007). Por el contrario, estarían interesadas básicamente en "la mejora de la imagen y en informar a la comunidad y a sus grupos de interés acerca de los servicios ofrecidos" ${ }^{387} \mathrm{y}$, en consecuencia, su principal tarea sería "simplemente entregar el mensaje a la audiencia"388 (Guy et al., 2007). Algunas tácticas comunicativas que se realizan bajo esta perspectiva en el entorno médico son "escribir boletines a los empleados; componer folletos para promover la oferta de servicios individuales o de la organización; escribir comunicados de prensa y responder a las solicitudes de los medios de información y la colaboración con agencias externas para desarrollar y colocar anuncios en los medios de comunicación"389 (Guy et al., 2007).

Las consecuencias negativas de adoptar un enfoque unidireccional se ven claramente en algunas campañas sobre la salud realizadas en África. Balima (2006) muestra que cuando se abraza esta postura "en la mayoría de casos los resultados esperados en términos de cambios de comportamiento no llegaron a obtenerse y la experiencia ha demostrado que aún es patente la influencia de la herencia de conceptos y prácticas colonialistas de la información y que son muchos los desafíos a los que todavía hay que hacer frente". También lo demuestran Seltzer et al. (2012), quienes, a través de un estudio de caso en un centro de emergencias, detectan que los antecedentes estructurales y normativos actúan como barreras en el mantenimiento de relaciones, que las estrategias de cultivo asimétricas acaban en relaciones internas pobres y que estas débiles relaciones fomentan actitudes negativas, comportamientos desobedientes y una cultura organizacional "tóxica". En cambio, con estrategias de cultivo simétricas, se fomentan relaciones internas positivas entre los trabajadores.

Bajo la perspectiva bidireccional, por el contrario, la sanidad puede mostrar sus actividades como "algo más que simplemente informar a la audiencia o promocionar la imagen de la organización" "390 (Guy et al., 2007). En otras palabras, en este contexto, los profesionales de la comunicación tratan de entender lo que necesitan sus públicos y buscan formas colaborativas para alcanzar sus deseos. Como explica Guy et al. (2007), "la interacción con los públicos no ha de hacerse de manera ad hoc o intermitente, sino regular y consistentemente, y se debe centrar en la construcción de relaciones a largo plazo que sean mutuamente beneficiosas para todas las partes involucradas" ${ }^{\text {391 }}$. Como consecuencia, dicen estos autores, "la comunicación fluye simultáneamente desde la organización sanitaria a la audiencia y de la audiencia a la organización sanitaria"392. De acuerdo con Cuesta, Gaspar y Menéndez (2012), "únicamente una comunicación activa, que no sea unidireccional, sino donde el receptor sea, al mismo tiempo, el emisor, será eficaz".

Si se eligen los enfoques bidireccionales como primera opción -es decir, establecer un diálogo con los diferentes públicos-, los profesionales de las relaciones públicas 
pueden llevar a cabo una mejor "planificación, dirección, control y gestión" de las actividades de comunicación (Guy et al., 2007). Estos académicos resumen las ventajas de estos modelos sobre los unidireccionales así:

"Una visión moderna y evolucionada de las relaciones públicas es algo más que gestionar la imagen y enviar mensajes acerca de la organización (según el modelo unidireccional o funcional), aunque estas tareas sin duda siguen siendo importantes. Los ejecutivos de la salud que comprenden la importancia de las relaciones públicas como un mecanismo para recibir las aportaciones de las partes interesadas y fomentar las relaciones mutuamente beneficiosas con sus audiencias (de acuerdo con el modelo bidireccional o co-creacional) lograrán un mayor éxito $\mathrm{y}$, a la larga, un mayor nivel de salud para las comunidades a las que sirven" $" 393$.

Practicar modelos bidireccionales proporciona otros beneficios en el mundo de la sanidad. Es más ético y socialmente responsable, pero también sirve para alcanzar unas relaciones públicas excelentes y hacer que las entidades sean exitosas con más frecuencia (J. E. Grunig y L. A. Grunig, 1991). Berkowitz (2007) ejemplifica los beneficios de estas posturas en el entorno de la salud de la siguiente manera:

"En la mayoría de los casos, es muy difícil buscar donaciones para construir un centro contra el cáncer, un centro para problemas de corazón o diseñar programas de salud para la mujer y pedir una donación de cualquier individuo antes de que la organización tenga una relación con ese donante. Como las relaciones públicas han evolucionado hacia un modelo basado en el diálogo, esta táctica ayudará a las organizaciones sanitarias en la búsqueda de donantes"394.

Las posibilidades de practicar unos modelos en detrimento de otros están vinculadas a varios aspectos organizacionales. Una de ellas es, llanamente, quién controla la organización (J. E. Grunig, 1992b). J. E. Grunig y L. A. Grunig (1991) explican que "cuando los administradores de los hospitales valoran y comprenden la función de relaciones públicas, es más probable que el hospital use el modelo bidireccional asimétrico y el bidireccional simétrico y sea menos propenso a la práctica del modelo de agente de prensa y el de información pública" ${ }^{\text {ㄱ } 395}$. En general, aseguran que "las organizaciones se decantan por unos programas u otros porque los han elegido las personas que tienen poder en esas entidades"396 (J. E. Grunig y L. A. Grunig, 1991).

\footnotetext{
${ }^{7}$ Las correlaciones más fuertes se hallaron en el modelo simétrico bidireccional.
} 
En otras palabras, "un departamento de relaciones públicas en un hospital puede tener gran experiencia en el modelo simétrico bidireccional, pero, si los administradores de alto nivel prefieren el modelo de información pública, el departamento pasará la mayor parte del tiempo realizando folletos y boletines en lugar de gestionar las relaciones con los públicos estratégicos"397 (Gordon y Kelly, 1999).

Los valores de la institución son otros factores decisivos. Tal y como indican J. E. Grunig y L. A. Grunig (1991), "las organizaciones con culturas participativas son más propensas a tener unos supuestos que favorezcan las relaciones públicas simétricas”,398, debido al hecho de que "los programas excelentes de relaciones públicas se encuentran con mayor frecuencia en las organizaciones con culturas democráticas, participativas y en las que la profesionalidad aumenta el potencial del departamento de relaciones públicas" 399 .

Los beneficios y perjuicios de cada patrón se idean, no obstante, desde el plano teórico y en base a unos pocos casos concretos. En la práctica, admite Milano (2010), "sabemos poco sobre la práctica de las relaciones públicas en entidades sanitarias"400. Por tanto, existen muy pocas indagaciones realizadas acerca de los modelos que se adoptan en este entorno, aunque se realiza principalmente de manera unidireccional (tanto interna como externa) y centrándose en la creación y establecimiento de la imagen (Guy et al., 2007). Además, abusan de las relaciones con los medios de comunicación y la comunidad (Bosilkovski, 2011).

Efectivamente, una de las pocas indagaciones acerca de los modelos en el ámbito sanitario lo proporciona Fabiszak (1985), quien detectó en su tesis doctoral que los hospitales tienden a utilizar los unidireccionales, en especial el agente de prensa [como sucede también en el resto de organizaciones (J. E. Grunig y L. A. Grunig, 1992)], seguido del de información pública y del asimétrico bidireccional. Dadas las características de la estructura y el entorno de los hospitales, la autora opina que "los hospitales no practican el o los modelos de relaciones públicas que les pondrían más en equilibrio con su entorno político y legislativo" ${ }^{, 401}$.

$\mathrm{Su}$ estudio también pone de relieve que las actividades de marketing se relacionan con los enfoques bidireccionales y que hay una correlación negativa entre la frecuencia de utilizar acciones de esta disciplina en los hospitales y el uso de las posturas de agente de prensa e información pública. Estos resultados pueden implicar que los patrones bidireccionales se realizan en las organizaciones sanitarias bajo la dirección de marketing. Como explican J. E. Grunig y L. A. Grunig (1991) sobre los descubrimientos de Fabiszak (1985), "la correlación más fuerte entre el marketing y el modelo asimétrico bidireccional apoya nuestro argumento teórico de que el marketing impone una visión asimétrica en las actividades de relaciones públicas. Sin embargo, la 
correlación moderada con el modelo simétrico muestra que el marketing también se puede practicar de forma simétrica"402.

Otra de las escasas investigaciones la condujeron Gordon y Kelly (1999) a una muestra de responsables de los departamentos de relaciones públicas de los centros de atención especializada de Estados Unidos. Los autores observaron que los participantes valoran altamente los cuatro modelos, pero sus notas para los de agente de prensa y de información pública eran bastante más altas. Esto significa, en sus palabras, que "los departamentos de relaciones públicas de los hospitales de Estados Unidos tienen más posibilidades de practicar los antiguos modelos unidireccionales antes que los sofisticados modelos bidireccionales"

En su estudio, Gordon y Kelly (1999) hallaron que las dos frases con las que los participantes están más de acuerdo son "colocar el nombre de la organización en los medios" "404 y "preparar informaciones para ser usadas por los periodistas" "405, que miden el potencial para practicar el modelo de agente de prensa y de información pública, en este orden. Por el contrario, las notas más bajas van a parar a las oraciones "negociar con grupos de presión"406 y "manipular científicamente a los públicos"407, que se asocian con el modelo bidireccional simétrico y bidireccional asimétrico, respectivamente.

A pesar de la elección por parte de los participantes de los modelos unidireccionales, Gordon y Kelly (1999) encontraron una relación positiva entre los bidireccionales y la efectividad de la organización. De esta manera, establecen que “cuanto más potencial tenga el departamento de relaciones públicas para practicar los cuatro modelos, adoptar todos los roles importantes y participar en la planificación estratégica mayor será la eficacia general del hospital"408 (Gordon y Kelly, 1999). Esta idea ha sido defendida también por otros académicos. J. E. Grunig y L. A. Grunig (1991), por ejemplo, indican que los programas más exitosos son aquellos que nacen de una gestión estratégica y de un modelo simétrico bidireccional. Esta última premisa es, de hecho, una de las sugerencias para una mejor práctica de las relaciones públicas según el Excellence Study (Dozier, L. A. Grunig y J. E. Grunig, 1995: 7).

Buffington (1988) aporta otro estudio en el entorno sanitario. En este caso, examinó diez planes de la compañía de seguros médicos Blue Cross \& Blue Shield y halló que el modelo de agente de prensa era el más recurrente, seguido del asimétrico bidireccional y del simétrico bidireccional. La principal diferencia en referencia a otros estudios es que, en este caso, el modelo de información pública era el menos utilizado. Los centros radiológicos también parecen dedicar la mayor parte de los esfuerzos a acciones unidireccionales en vez de bidireccionales. El 75\% de los participantes en una encuesta realizada a entidades medianas y grandes de radiología en 1994 (Smith y Schaaf, 1995) despachaba folletos, el $65 \%$ realizaba discursos, el $43 \%$ organizaba eventos o ferias 
sanitarias y el $37 \%$ enviaba noticias. Los autores también pudieron observar que estas entidades dedican un mayor presupuesto a las labores comunicativas de marketing que a las de relaciones públicas. Divididas por tipos de agrupaciones sanitarias, Díaz y Cuesta (2014) observan que las organizaciones profesionales usan un modelo de información pública, mientras que las de pacientes adoptan un modelo bidireccional simétrico.

Meath (2006) demuestra que los enfoques bidireccionales se asocian con una mayor excelencia gracias a un estudio sobre las cuatro residencias de ancianos más exitosas del área metropolitana de Nueva York. Allí se topó con una mezcla de encuadres bidireccionales y destaca de tres participantes que "su eficacia en la prestación de cuidados de calidad a largo plazo se vincula directamente con su capacidad para construir relaciones a largo plazo con sus pacientes, y en especial, con las familias de sus pacientes" "409. Meath (2006) concluye que "las residencias de ancianos exitosas utilizan comunicación bidireccional (tanto asimétrica como simétrica) con todos sus grupos de interés" 410 y recuerda la reflexión de Scott et al. (2005) de que "cuanto más énfasis se ponga en la comunicación, mejor serán los cuidados que recibirá la audiencia más importante para una residencia de ancianos: sus residentes" ${ }^{\text {"411. }}$.

Otra muestra de la importancia de elegir enfoques que permitan obtener retroalimentación del público lo proporciona Henderson (2005) con un estudio de caso sobre el Family HealthCare Center, un pequeño proveedor sanitario sin ánimo de lucro. El centro, al menos en el momento de la investigación, no usaba modelos bidireccionales, y menos aún con los empleados. Gracias a una auditoría de comunicación, la entidad pudo saber que, para empezar, había una falta de consenso sobre la existencia de un sistema de información. Además, había una brecha entre la cantidad de novedades que recibía la plantilla y la que ellos realmente querían obtener. La auditoría también demostró que los trabajadores no estaban al tanto de políticas y cambios en los procedimientos, "causando frustración y dificultad a la hora de completar las tareas" $" 412$.

Al margen de las auditorías, las herramientas que están al alcance de los centros médicos para comunicarse bidireccionalmente con sus públicos son numerosas. Wise (2003), por ejemplo, llevó a cabo un estudio en un departamento sanitario estatal durante cinco meses y observó que hacían uso de conferencias semanales con líderes de las oficinas centrales y con directores de la salud de los condados. También mantenían conversaciones telefónicas e intercambio de correos electrónicos con el personal del departamento y con representantes de los electores. Otras herramientas eran diálogos personales en grupos de trabajo. En general, la comunicación cara a cara y las relaciones personales eran los tipos de interacción más apreciados. Tal y como un jefe de departamento comentó a Wise (2003) durante una entrevista, "no hay nada tan bueno como sentarse con la otra persona después de un apretón de manos",413. 


\subsection{CONOCIMIENTOS ESTRATÉGICOS}

Con el fin de "contribuir a la efectividad de la organización ayudando a cumplir con su presupuesto, alcanzar sus metas y objetivos y avanzar en su misión" "414 (Gordon y Kelly, 1999), los hospitales necesitan relaciones públicas excelentes, tal y como fueron definidas en el Excellence Study, un extenso estudio financiado por la International Association of Business Communicators Foundation (IABC) (Dozier, L. A. Grunig y J. E. Grunig, 1995; J. E. Grunig, 1992b). En este estudio determinan que las agrupaciones deben gestionar estratégicamente la comunicación, y lo hacen cuando "identifican los públicos que son más propensos a limitar o potenciar el objetivo de la organización y cuando diseñan programas de comunicación que ayudan a la organización a gestionar su interdependencia con los públicos estratégicos"415 (Hunt y J. E. Grunig, 1994: 11). Para ello, es necesario tener "un entendimiento completo de las decisiones y comportamientos de la dirección de manera que esas decisiones y comportamientos puedan ser a su vez explicados" ${ }^{\$ 16}$ (J. E. Grunig y Hunt, 1984). Prueba de su importancia es que se ha convertido en el eje central de decenas de artículos sobre esta disciplina (Ki y Shin, 2006).

A pesar del crecimiento que ha experimentado en la bibliografía general, este asunto no goza del mismo desarrollo en el ámbito sanitario y, en consecuencia, solo se pueden encontrar unas pocas indagaciones al respecto. Se trata de una situación que no se corresponde exactamente con la realidad, según Gbadeyan (2010), ya que, opina, tanto las relaciones públicas como el marketing emergen ahora como funciones importantes de dirección, "no solo en organizaciones sanitarias sin ánimo de lucro, sino también en organizaciones sanitarias privadas o con ánimo de lucro" ${ }^{417}$. Esos gabinetes excelentes en el terreno sanitario "son valorados por los directores generales y otros que dependen de las relaciones públicas para gestionar las relaciones de la organización con públicos estratégicos, como consumidores, el gobierno, los medios de comunicación y los empleados" ${ }^{418}$ (Gordon y Kelly, 1999).

Pese a ello, en un estudio de Bosilkovski (2011) se observa que los publirrelacionistas de los hospitales aún no han incorporado completamente la gestión estratégica ni su participación en la toma de decisiones en sus tareas habituales. El 47,3\% de los participantes en esta indagación aseguraban tener un nivel positivo de participación en estos temas, mientras que un 43,8\% aconsejaba a los directivos. Además, no suelen reclutar personal ni estar en contacto con oficiales o legisladores.

Wise (2003), por su parte, se especializa en los departamentos de salud estatales de Estados Unidos y asegura que no hacen un uso óptimo de las interacciones con sus electores estratégicos. Aunque los empleados del gabinete interactúan regularmente con este grupo, sus opiniones no se suelen tener en cuenta. La información que se recoge de estas reuniones, por lo tanto, no se gestiona estratégicamente. Como resultado, Wise 
(2003) recomienda "contratar a directores de relaciones públicas formados no solo en las relaciones con los medios, sino también en la gestión de las relaciones" ${ }^{\circledR 19}$.

El beneficio, de hecho, es enorme. Gordon y Kelly (1999) prueban con un estudio enviado a una muestra de todos los hospitales de Estados Unidos que "cuanta más capacidad tenga el departamento de relaciones públicas para participar en la planificación estratégica, mayor será la efectividad general de la organización"420 . Los autores también observan que, en general, “cuanto más potencial tenga el departamento de relaciones públicas para practicar los cuatro modelos, adoptar todos los roles importantes y participar en la planificación estratégica mayor será la eficacia general del hospital" 421 .

Gordon y Kelly (1999) aportan los resultados de otras dos investigaciones del mundo sanitario. Una de ellas concluye que en la mayoría de las clínicas, por aquel entonces, se establecían los objetivos de manera oficial a través del proceso estratégico de planificación (Simyar y Lloyd-Jones, 1988). El otro estudio, realizado por Kotler y Clarke (1987), enfatiza la idea de que cuanto más turbulento es el entorno, mayor es la necesidad que tienen estas entidades de llevar a cabo una planificación estratégica.

Independientemente de la situación, una entidad sanitaria necesita la comunicación estratégica con el fin de suministrar a los pacientes la información y el soporte que precisan para, por ejemplo, reducir las posibilidades de padecer cáncer y mejorar los resultados de los procesos de esta enfermedad (Kreps y Bonaguro, 2007). La comunicación estratégica en este caso se refiere a "la aplicación planeada de los principios claves del marketing social en los esfuerzos de comunicación para la salud, tales como el análisis en profundidad de la audiencia para conocer más sobre ella y para segmentarla, adaptando el diseño y entrega de mensajes persuasivos a las características y orientaciones únicas de los grupos objetivo y la introducción de la intervenciones culturalmente sensibles para reforzar la adopción de conductas de salud por parte del público objetivo"422 [Kreps (2008) hablando sobre Albrecht y Bryant (1996), Andreasen (1997), Kotler y Lee (2005) y Maibach (2003)].

Gordon y Kelly (1999), por su parte, proporcionan a los profesionales de las relaciones públicas sanitarias las siguientes recomendaciones para que lleven a cabo una gestión estratégica excelente:

"Los médicos de los hospitales, en particular los jefes de los departamentos deficientes, deben tomar los pasos apropiados para adquirir la comprensión cognitiva y las habilidades asociadas con las variables de predicción. Por ejemplo, estos profesionales deben aprender a usar la investigación en su trabajo, negociar con los públicos y usar las teorías sobre la resolución de conflictos y las actitudes. Han de dominar los principios de la comunicación bidireccional y de la planificación 
estratégica. Estudiar ciencias sociales aumentaría su capacidad para desarrollar estrategias de resolución de problemas y gestionar la respuesta de la organización hacia ciertos temas. En vez de centrarse en la producción de materiales relacionados con la técnica -tales como comunicados de prensa, publicaciones y la oficina del portavoz-, los profesionales deben ganar experiencia en la planificación de programas y planes de negocios basados en metas y objetivos medibles y cimentados en los presupuestos estratégicos" ${ }^{\text {, } 23 . ~}$

Los responsables de comunicación han de hacer todos los esfuerzos posibles para adoptar estas estrategias, ya que, si no son capaces, el departamento "puede restringirse a un papel de apoyo en la preparación de bibliografía para las campañas de recaudación de fondos y puede acabar bajo la dirección del jefe de recaudación" ${ }^{424}$ [King y Scrimber (1993) hablando sobre Kelly (1992)].

\subsection{CONOCIMIENTOS DE INVESTIGACIÓN}

La investigación es un punto débil dentro de la comunicación hospitalaria, dado que hay muy pocos estudios sobre este tema en comparación con toda la bibliografía referente a las relaciones públicas en general (Gordon y Kelly, 1999). Tal y como Kreps, Bonaguro y Query (1998) indican, este ámbito se ha centrado, sobre todo, en la forma en que la comunicación interpersonal y grupal influye en la atención sanitaria y en las campañas persuasivas. Y "esa investigación es ciertamente valiosa, pero existe un vacío en la bibliografía de relaciones públicas acerca de los practicantes de esta disciplina en los organismos públicos de salud"425 (Wise, 2001).

Efectivamente, el interés por investigar en el ámbito de la salud es "relativamente reciente" (Ugarte Iturrizaga, Menéndez Hevia y Cuesta Cambra, 2009). A modo de ejemplo, Ugarte Iturrizaga et al. (2009) recuerdan los años de creación de las dos principales revistas de esta área a nivel internacional, Health Communication y Journal of Health Communication, que iniciaron sus números en 1989 y 1996, respectivamente. En España, la única revista dedicada exclusivamente a este binomio es Revista de Comunicación y Salud, que publicó su primer número en 2011. Tal y como resume Ugarte Iturrizaga (2011), "EEUU lleva más de 20 años analizando científicamente sus campañas y gestionando el conocimiento de esos estudios mediante revistas académicas especializadas, artículos, libros y encuentros de expertos. En España ese camino está comenzando a recorrerse".

La mayor parte de las investigaciones provienen del mundo anglosajón, sobre todo de Estados Unidos, dejando la producción iberoamericana como una parte residual 
(Díaz y Cuesta Cambra, 2014). Como muestra, solo uno de los 321 artículos analizados por Freimuth, Massett y Meltzer (2006) de la revista Journal of Health Communication tiene como autor principal a un investigador que trabaja en un país iberoamericano.

Además, tal y como reconocen Smith y Schaaf (1995), "mientras que una gran parte de la bibliografía sobre estrategias, técnicas y teorías de las relaciones públicas se ha aplicado al campo hospitalario, no hay muchos estudios de campo que se hayan realizado en representación de la práctica individual o independiente de las especialidades de la comunidad médica” ${ }^{\text {"26 }}$. Gordon y Kelly (1999) apoyan esta crítica y añaden que, en general, se ha realizado poca investigación de relaciones públicas en los hospitales.

Gordon y Kelly (1999) consideran que esta falta de interés por la investigación ha emergido en la Universidad. Poniendo el ejemplo de la Public Relations Society of America Educators Academy, señalan que menos del 5\% de sus afiliados logran un doctorado, "lo que sugiere que muchos -si no es la mayoría- de los profesores de relaciones públicas en la Universidad no tienen el talento suficiente para enseñar a los estudiantes a investigar" ${ }^{227}$ (Gordon y Kelly, 1999). En la actualidad, no obstante, se está experimentando un crecimiento académico en el binomio comunicación y salud (Cuesta Cambra, 2012).

Las primeras exploraciones en torno a la salud y su comunicación se enmarcan dentro del paradigma informacional-positivista. Por norma general, estas investigaciones tratan el tema de la sexualidad y el sida y son de naturaleza correlacional y/o están centradas en los efectos (Aguilera y Pindado, 2006). Bastantes estudios bajo este enfoque son contradictorios en cuanto a sus posibles efectos sobre los receptores (Aguilera y Pindado, 2006).

Un ejemplo de análisis bajo este prisma lo proporcionan Brown y Newcomer (1991), que señalan que los adolescentes consideran que el volumen de sexualidad que se expone en televisión incrementa el interés hacia estos temas. Childers y Brown (1989) también utilizan este paradigma en un estudio que concluye que los contenidos televisivos desempeñan un papel destacable en la configuración de patrones de comportamiento en las relaciones de género y en la conducta sexual. Sin embargo, y como muestra de que muchas de estas investigaciones son contradictorias, Greeson y Williams (1986) no hallaron ninguna correlación significativa entre los contenidos de la cadena televisiva MTV y las actitudes de los adolescentes hacia el sexo, la droga y la violencia.

Emprender una comunicación unidireccional propia del modelo informacionalpositivista en temas de salud conlleva, con frecuencia, "un escaso éxito" (Aguilera y Pindado, 2006). Comas et al. (2003) y Balima (2006) sostienen que el fracaso de las campañas para reducir el SIDA en África, por ejemplo, es debido a la falta de apoyo en los valores propios de sus culturas. 
Una segunda corriente, denominada lineal-positivista, se centra, sobre todo, en el estudio de la televisión como fuente de información y aprendizaje sexual. Bajo este paradigma, se engloba la investigación de Hostetter et al. (1995), que analiza las diferencias entre hispanos y anglosajones en consumo de medios. Los primeros, concluye el estudio, consumen más televisión en general y se apoyan más en ella, pero tienen menos acceso a los medios impresos y más dificultades para tratar el SIDA con amigos y familia.

Por su parte, la perspectiva interpretativa, también denominada modelo mediador, establece que aunque los medios constituyen un "potencial interventor en la acción humana", "su capacidad para influir en ella aparece a más largo plazo" (Aguilera y Pindado, 2006). Se trata de un enfoque centrado "más en la prevención que en la consecución de unos efectos inmediatos y que busca más las raíces de los problemas en los contextos en los que los actores sociales (individuales o colectivos) se desenvuelven y encuentran sentido" (Aguilera y Pindado, 2006).

Según esta visión, las personas incluyen en sus vidas cotidianas buena parte de los contenidos simbólicos de los medios. Por ello, la aplicación de esta perspectiva a la corrección de ciertos problemas de salud pública exige "examinar, entre otras cuestiones, los perfiles de cada cultura juvenil, expresada en buena medida mediante estilos de vida, como paso previo a la adopción de estrategias comunicativas adecuadas que incidan directamente sobre ellas" (Aguilera y Pindado, 2006).

Sin embargo, Aguilera y Pindado (2006) proponen una nueva óptica, donde se mezcle el examen de circunstancias objetivas y subjetivas y se utilice un método específico que use análisis cuantitativos y cualitativos. Desde esta perspectiva, que analiza los riesgos como síntoma social, dicen los autores, se deben emprender las siguientes acciones:

"Atender también a las razones subjetivas y objetivas que les muevan a ello, así como al papel legitimador e instrumental que en esos comportamientos desempeñen los medios de comunicación. Así, empleando una orientación metodológica, que combina lo cuantitativo con lo cualitativo, pretendemos observar no sólo lo que los jóvenes hacen -sus comportamientos arriesgados- sino también lo que saben sobre ellos -grado de información de que dispongan al respecto- así como lo que piensan y dicen respecto de esos comportamientos representaciones, discursos". 


\subsection{OTROS CONOCIMIENTOS}

\section{Gestión de conflictos potenciales y crisis}

Como aseguran Springston y Weaver Lariscy (2005), "independientemente de lo sofisticada que sea una organización en su gestión de conflictos potenciales, no hay forma de anticipar o eliminar todos los eventos negativos"428, y las entidades sanitarias son más propensas que otras a afrontar cambios y a enfrentarse a este tipo de situaciones (Ristino, 2007). De hecho, las dificultades por las que atraviesa comúnmente este ámbito [tales como "el SARS [síndrome respiratorio agudo y grave, por sus siglas en inglés], las intoxicaciones por E-coli y los desastres naturales, como los huracanes"429 (Weaver Lariscy, Avery y Sohn, 2010)] han influido en que hayan aumentado las noticias sobre salud (Weaver Lariscy, Avery y Sohn, 2010).

De acuerdo con Cerdá (2012), las etapas comunicativas al respecto a las que se puede enfrentar una institución sanitaria son la de riesgos y la de crisis. La primera es "el intento que hacen científicos o profesionales para aportar información que permita a una persona, a los interesados directos o a toda una comunidad tomar las mejores decisiones posibles para su bienestar cuando surge una crisis o un posible riesgo para su salud". Por su parte, la comunicación de crisis es "el tipo de comunicación del riesgo que se hace cuando tanto el miedo como el peligro son elevados y sirve para ayudar a la gente a soportar sus sentimientos y a superar eficazmente los peligros".

Poco conocemos sobre cualquiera de estas fases en el marco sanitario (Wise, 2001). Por norma general, los estudios realizados se centran en acciones determinadas o casos concretos sobrevenidos de crisis. Sin embargo, a través de estas indagaciones se puede observar que la mortificación ${ }^{430}$ (una de las posibles respuestas ante una crisis, aparte de la negación, la distancia, congraciarse y el sufrimiento ${ }^{431}$ ) está “adoptándose cada vez más en el terreno sanitario" 432 , tal vez porque "hay evidencias de que el uso de la estrategia por mortificación puede ser efectiva para reducir el número de demandas por negligencia y el dinero gastado en acuerdos financieros"433 (Weaver Lariscy y Springston, 2007).

Todas las crisis tienen "atributos únicos, lo que hace difícil anticiparse a las estrategias de relaciones de medios y de mensajes que deberían usarse" ${ }^{\text {"434 }}$ (Weaver Lariscy y Springston, 2007). No obstante, existen evidencias de que las organizaciones sanitarias (independientemente de su fin lucrativo) tienen más elementos en común que en contra gestionando apuros, aunque parece ser que el sector lucrativo tiene más dificultades implementando relaciones efectivas con los medios durante estas situaciones (Weaver Lariscy y Springston, 2007). A pesar de todo, cada entidad debe diseñar atentamente sus acciones ante cada escenario de riesgo (Weaver Lariscy y Springston, 2007). 
La gestión de crisis es tan importante para los departamentos de relaciones públicas de los centros sanitarios que uno de los objetivos generales de las organizaciones no lucrativas [así como de las lucrativas] es manejar la reacción del público ante cambios o crisis (Ristino, 2007). En el proceso de resolución de problemas, como en cualquier campaña de relaciones públicas, las entidades deben definir el problema o reto, planear y proyectar, actuar y comunicar y evaluar el programa (Ristino, 2007).

Aunque varios estudios revelan que los hospitales hacen un mayor uso de los modelos menos eficaces [por ejemplo, el de agente de prensa (Buffington, 1988; Fabiszak, 1985)], en realidad estos centros necesitan relaciones públicas excelentes para superar conflictos (Gordon y Kelly, 1999). Especialmente en época de crisis, las clínicas deben olvidarse de las tácticas marketinianas y concentrarse en las estrategias de relaciones públicas, "centrándose en el diálogo con las comunidades a las que atienden, alimentando las relaciones con las partes interesadas y haciendo cambios sustanciales para adaptarse al nuevo entorno" $" 435$ (Lewton, 1998). De hecho, cuando son preguntados acerca de la disciplina más efectiva, los ejecutivos de marketing posicionan las relaciones públicas nueve puestos más arriba sobre los 14 posibles que el marketing. Entre las ventajas que hacen situarlas en ese nivel, los ejecutivos señalan crear conciencia, reputación de marca, reputación corporativa y superación de crisis [Wilcox (2006) hablando sobre un estudio de PRWeek].

$\mathrm{Y}$ es que las funciones principales de estos gabinetes en estos contextos son "gestionar el flujo estratégico de información en apoyo a los esfuerzos de la organización para gestionar la crisis" y "proteger la imagen, la identidad y la reputación de la organización mientras se enfrenta a la crisis" "436 (Ristino, 2007). Para hacer eso, "esos planes [de gestión de crisis] han de incluir tácticas específicas con los medios de comunicación" $" 437$ (Weaver Lariscy y Springston, 2007). De hecho, las interacciones con los periodistas suelen convertirse en uno de los canales más importantes durante esos escenarios (Weaver Lariscy y Springston, 2007). Esto es especialmente importante en contextos conflictivos porque "los reporteros son más insistentes en escuchar a la dirección durante las crisis" y porque "las personas que se encargan de la comunicación dentro de una organización son las que más saben sobre habilidades en las entrevistas y conocen las características personales más relevantes de los redactores"438 (Weaver Lariscy y Springston, 2007). Además, a largo plazo, las relaciones con los medios en el terreno sanitario pueden llegar a ser más efectivas que el departamento legal (Weaver Lariscy y Springston, 2007).

Precisamente, Oriol Güell (2006), periodista de El País, opina que los responsables de comunicación de las instituciones de la salud necesitan hacer una preparación previa para anticiparse a un asunto conflictivo. Tal y como explica: 
"Como sucede en muchas otras cuestiones, cuando estalla a crisis se nota si se ha hecho o no un buen trabajo de preparación. Cuando llama el periodista ya es tarde para hacerlo y, sin una buena estrategia diseñada, el responsable de comunicación no tendrá los elementos a mano para evitar que la crisis le desborde. Pensemos sólo un momento en la avalancha de llamadas y peticiones de información que recibe un responsable de comunicación de cada uno de los diarios, radios, televisiones, agencias de información o revistas cuando trasciende un hecho noticioso. Apenas va a tener tiempo de hacer otra cosa que atenderlas y llevar a cabo el envío de información o la preparación de entrevistas con responsables del hospital o institución. Una situación angustiante si no dispone de un plan de actuación o estrategia a seguir".

Como resumen, se puede concretar que las entidades deben ser "proactivas y construir relaciones con sus públicos antes de una crisis, no durante ella"439 (Tirkkonen y Luoma-aho, 2011), algo que se ha podido comprobar en varios estudios dentro del ámbito sanitario (Kruvand, 2010; Tirkkonen y Luoma-aho, 2011).

Esa preparación de la que habla Güell (2006) conlleva la elaboración de una estrategia previa, la cual comienza por conocer "qué es lo que ha ocurrido dentro del hospital, centro de salud o la institución que se trate". Tal y como indica este periodista, "el responsable de comunicación debe conocer todo lo que ocurra en su institución, lo bueno y lo malo. Si la dirección le esconde lo malo, el responsable quedará a merced de las llamadas de los periodistas y de una crisis que ya no podrá controlar porque habrá sido el último en enterarse". Para ello, insiste, el comunicador "debe ganarse la confianza de la dirección de la institución para que ésta confíe en él y le transmita toda la información susceptible de convertirse en crisis en el futuro. Así, el responsable podrá trabajar con tiempo, diseñar un plan de actuación y aplicarlo en caso que un periodista le llame preguntando por lo que ha ocurrido. Si luego no llama ningún periodista, el plan se archiva y crisis (o no-crisis) resuelta".

Efectivamente, el primer paso estratégico propuesto por Cerdá (2012) a la hora de afrontar una crisis sanitaria es conocer los hechos. Posteriormente, este autor recomienda convocar el equipo de gestión anticrisis (el cual ha de haber tenido reuniones anteriores "para poder funcionar de forma armónica y rápida lo antes posible"), seleccionar portavoces [que ocupen un lugar determinante en la organización y que sea un buen comunicador (Reyes, 2006); una buena guía teórico-práctica se puede encontrar en Arceo (2012a)] y montar un centro de gestión anticrisis. También aconseja establecer una unidad de control, movilizar los recursos necesarios para responder de forma rápida y adecuada, establecer una estrategia de medios informativos, informar a 
los implicados y establecer comunicaciones in situ. Finalmente, se ha de identificar la posición adecuada una vez se haya terminado la crisis.

Pero lo que no puede hacerse es "mentir ni ocultar una alerta" (Rodríguez Andrés, 2012), como lamentan varios autores (Acinas, 2007; Alcat, 2005; Arroyo y Yus, 2008). Según destaca Rodríguez Andrés (2012), “callar en estos casos es un error pero, además, una irresponsabilidad que puede conllevar numerosos riesgos y también un incumplimiento de la obligación legal que tienen las administraciones de mantener informada a la población en este tipo de sucesos". Y es que, tal y como Stephens y Malone (2009) razonan, si los públicos no obtienen la información que quieren de una organización durante una crisis, probablemente busquen otras fuentes.

Por su parte, Rodríguez Andrés (2012) opina que, a la hora de actuar frente a una crisis, las entidades sanitarias deben evaluar los riesgos reales (actuales y futuros) y elaborar los mensajes acordes a ellos. Asimismo, han de conocer la audiencia y mostrar la amenaza en cuestión como próxima o cercana para que haya más persuasión. Las fuentes que se utilicen tienen que ser creíbles, y se aconseja proporcionar una recomendación clara y sin contradicciones y llevar la iniciativa a la vez que se frenan los rumores.

Precisamente, los errores más habituales de las organizaciones sanitarias a la hora de afrontar un conflicto son, según Cerdá (2012), la falta de portavoces, el desconocimiento de los hechos en profundidad, la ausencia de un mensaje único y consensuado, la lentitud en proporcionar información y la preponderancia de los políticos frente a asesores expertos.

Todo esto debe integrarse en lo que diferentes autores llaman plan de gestión de crisis [o lo que Güell (2006) denomina plan de actuación], un documento del que deben disponer todas las instituciones relacionadas con la salud ${ }^{440}$ (Springston y Weaver Lariscy, 2005). El primer paso de este documento es el plan de acción de mensajes. Springston y Weaver Lariscy (2005), hablando sobre Werner (1990), sostienen que este sistema "puede ayudar a una organización a salir de muchos de los problemas inevitables que surgen durante una crisis y que pueden entorpecer la comunicación eficaz de la entidad hacia los públicos clave. Estos problemas incluyen la emoción, la confusión, los asuntos de confidencialidad y el estrés"441. Los elementos claves que cualquier documento de este tipo debe contener son, según Springston y Weaver Lariscy (2005), los siguientes:

"Los públicos clave con los que comunicarse regularmente.

Qué mensajes deben estar presentes.

Qué técnicas de comunicación han de usarse.

Quién es responsable de varias tareas (por ejemplo, el portavoz, el recopilador de datos...). 
Cómo se van a separar en el tiempo los mensajes y las actividades.

Y cómo se deben realizar las evaluaciones postcrisis, la efectividad del plan de acción de mensajes y las condiciones que motivaron la crisis ${ }^{, 42}$.

La importancia de manejar apropiadamente un conflicto en el entorno sanitario lo pone de relieve Mullin (2002) a través del virus West Nile cuando apareció por primera vez en Nueva York en 1999. Tal y como indica la autora, "aprendimos, sobre todo, la necesidad de definir las percepciones de riesgo, a tener comunicadores creíbles y a proporcionar información de una manera oportuna y constante. En las últimas semanas, esto significaba dar los datos al público en vez de inventar modos para calmarlo"443. En otras palabras, es necesario admitir que no se conoce la respuesta y entender la necesidad de los medios y de la audiencia hacia una información que sea "creíble, clara y consistente"444 (Mullin, 2002). Saber lo que quieren los periodistas es muy beneficioso en épocas de crisis, aunque los responsables de los departamentos de comunicación no otorguen la misma importancia a todos los temas sanitarios que los redactores (Weaver Lariscy, Avery y Sohn, 2010).

Un ejemplo de buenas prácticas en entornos de crisis lo proporcionan Holdsworth et al. (1999), que relatan un incidente de tuberculosis que tuvo lugar en el verano de 1996 en el hospital Guy's and St Thomas' NHS Trust con ocho pacientes afectados. Lo primero que hizo el centro fue crear un comité sobre el suceso compuesto por un equipo multidisciplinar (más concretamente, con representación de medicina genitourinaria, torácica, control de infecciones, salud pública, salud laboral, dirección y relaciones públicas). Esta unión contactó con otras organizaciones y expertos en busca de recomendaciones y se reunió cuatro veces durante las dos primeras semanas y en varias ocasiones durante los meses siguientes. Cada departamento redactó una carta personalizada a cada paciente y se aseguró de que todos recibieran el documento el mismo día.

También informaron a otros profesionales y organizaciones de la salud (como grandes hospitales para enfermos terminales de VIH, organizaciones benéficas y de voluntarios, el departamento de salud, etc.). Todas las peticiones de los medios de comunicación se derivaron al gabinete de relaciones públicas y se creó un teléfono gratuito de ayuda con 12 líneas. El personal de este servicio fue instruido acerca de la tuberculosis y se les entregó una hoja informativa sobre esta enfermedad y una tabla con preguntas para identificar si el interlocutor estaba en riesgo o no. La clínica también divulgó un comunicado de prensa, pero únicamente después de que los pacientes, el personal y otras personas vinculadas estuvieran al tanto.

Gracias a esta reacción, la cobertura mediática no fue negativa y el hospital Trust no recibió quejas sobre su comunicación. En conclusión, cualquier incidente de estas características necesita una cuidadosa planificación y una respuesta coordinada y 
preparada por un equipo multidisciplinar. Los pacientes tienen que ser contactados personalmente a través de un profesional médico relevante y antes de que se divulgue un comunicado de prensa. Asimismo, es aconsejable disponer de un único portavoz para las entrevistas con los medios (Holdsworth et al., 1999).

Un vehículo que no fue utilizado por el Trust, pero que resulta indispensable en cualquier plan de crisis sanitaria, es internet (Avery et al., 2010). Coombs (2007) sugiere dos posibles escenarios para utilizar este canal: uno de ellos es "un sitio previo prediseñado antes de que surja cualquier necesidad" y el otro consistiría en una "respuesta a tiempo real durante una crisis",445 (Avery et al., 2010). Berkowitz (2007) explica que las entidades sanitarias normalmente no usan blogs por el miedo a recibir comentarios negativos. Sin embargo, a través de estos espacios, una organización médica puede "saber a tiempo real qué se está cociendo en el mercado" tanto, controlar ciertos asuntos para evitar que deriven en crisis (Berkowitz, 2007). Por ello, de acuerdo con este académico, "mientras que su uso en las organizaciones sanitarias es muy limitado actualmente, debería ser una fuerza poderosa en los próximos años"447.

Y es que, tal y como destacan Freberg, Palenchar y Veil (2013), durante las crisis, los publirrelacionistas se tienen que enfrentar a numerosos canales, voces e información, siendo los blogs la herramienta más popular, y Twitter la fuente más referenciada. Los podcasts también presentan utilidades similares para establecer foros críticos durante etapas problemáticas. En palabras de Berkowitz (2007):

"Ahora, en la época de los podcasts y de internet, cuando aparece una crisis, se puede cargar un podcast con la respuesta de los CEOs o de los médicos en la página web de la organización sanitaria. Así, se envía el mensaje directamente desde la organización. Se puede mandar un correo electrónico a los medios de comunicación con un enlace que redirija al podcast. Sin dudas, se producirán peticiones por parte de los periodistas, pero el mensaje directo ya se ha diseminado, dado que la organización quiere que se distribuya de una manera consistente, honesta y directa",448.

Independientemente de las herramientas que se utilicen, existen una serie de recomendaciones a la hora de abordar una comunicación de riesgos por parte de las entidades sanitarias. De acuerdo con Cerdá (2012), son las siguientes:

“1. No sobretranquilizar.

2. Tener en cuenta la situación de alarma.

3. Reconocer la incertidumbre.

4. Plantear escenarios y dilemas posibles. 
5. Reconocer la diversidad de opiniones.

6. Estar dispuesto a especular.

7. No aspirar al miedo cero.

8. Legitimar miedos de la gente.

9. Tolerar tempranas reacciones exageradas.

10. Establecer contacto con el público.

11. Decir a la gente qué se puede esperar.

12. Proponer a la gente qué cosas hacer.

13. Preguntar más a la gente.

14. No mentir y no decir verdades a medias.

15. Aspirar a la calidez, emoción y transparencia.

16. Tener cuidado con comparaciones de riesgo.

17. ¡Y más, mucho, mucho más!”

\section{Nuevas tecnologías}

Las nuevas tecnologías de la comunicación en el ámbito sanitario son indispensables para llevar a cabo unas relaciones públicas efectivas. En el actual clima global, recuerda Wilcox (2006), "las corporaciones deben incorporar divulgación y transparencia en sus valores fundamentales y trabajar como si todo el mundo estuviera observando" "449. Los publirrelacionistas, en consecuencia, han de "monitorear continuamente internet para saber lo que se está comentando acerca de la organización y corregir cualquier información falsa o engañosa"450 y echar mano de las nuevas tecnologías para "llegar a públicos y grupos muy especializados sin la necesidad de usar los medios tradicionales" "451 (Wilcox, 2006). Asimismo, han de "evaluar continuamente la forma en que las nuevas tecnologías pueden aplicarse en la difusión de mensajes"452 (Wilcox, 2006). Además, se considera que "los nuevos medios de comunicación tienen la capacidad de cambiar a los profesionales de las relaciones públicas del rol técnico al rol directivo"453 (Johnson, 1997).

Y no solo eso. Las nuevas tecnologías están propiciando un cambio de paradigma de comunicación, repite en varios foros Ubaldo Cuesta junto a otros investigadores (Cuesta Cambra y Menéndez Hevia, 2009, 2010; Menéndez Hevia y Cuesta Cambra, 2011), por el cual la audiencia ya no es un mero receptor de los mensajes, sino que se convierte en el protagonista, creando ella misma el mensaje, produciéndolo y distribuyéndolo. De este modo, dicen Cuesta y Menéndez (2009), "se produciría un doble «efecto»: por un lado, el que provocaría el «aprendizaje activo» presente al pensar y ejecutar su propia campaña (imaginemos un corto de 2 minutos para colgar en el blog del centro educativo) y por otro lado, el efecto que este corto provocaría en la red social que lo visionara". 
Este cambio de modelo se produce atendiendo a razones tecnológicas -tales como el abaratamiento de los procesos de producción y los nuevos soportes masivos y gratuitos para la distribución- y psicosociales -propiciados por una mayor cultura de los lenguajes audiovisuales y de las técnicas y herramientas de realización y distribución por parte de los jóvenes y la creación de perfiles individuales de consumo. El papel de las instituciones en el ámbito de la salud, por tanto, es impulsar activamente este proceso, creando el clima apropiado, facilitando las herramientas de creación, distribución y soporte en la red, proporcionando las estructuras y motivando el proceso (Cuesta Cambra y Menéndez Hevia, 2009). Las entidades sanitarias son las que tienen que encontrar un grupo social que cree su propio discurso persuasivo, que lo produzca y distribuya a sus grupos de iguales mediante sus propios canales, empleando sus lenguajes compartidos y sus propios conceptos o mensajes (Cuesta Cambra y Menéndez Hevia, 2010).

Del Pozo y Ferreras (2011) comparten la opinión de que se está produciendo un nuevo paradigma de información y comunicación en salud, pero ellos creen que es debido a la personalización de la información y a la adopción de una actitud activa por parte de los ciudadanos. No obstante, también mantienen que las nuevas tecnologías tienen un "papel central en la creación y en la evolución" del nuevo modelo.

Las implicaciones de este nuevo paradigma son, según Cuesta Cambra (2012), la distribución y acceso de la información y el incremento de relaciones entre sanitariosanitario, sanitario-paciente y paciente-paciente, todo ello con un abaratamiento de los costes. Asimismo, considera que el entorno virtual ha propiciado una nueva relación paciente-paciente, mediante la cual las personas crean sus propias plataformas para intercambiar experiencias e información. Tal y como explican Menéndez y Cuesta (2011), "su carácter participativo hace que los usuarios se sientan más involucrados en el desarrollo del proceso, así como motivados para conseguir buenos resultados, principalmente a través de su papel de mediadores". Por ello, en la actualidad existen "miles de grupos de apoyo de estas características en Internet que apoyan casi a cualquier tipo de enfermo con las patologías más diversas" (Cuesta Cambra, Gaspar Herrero y Menéndez Hevia, 2012). En cambio, el terreno menos abordado es la relación online sanitario-paciente (Cuesta Cambra, 2012).

$\mathrm{Y}$ es que, en general, el impacto que tienen los mensajes sobre salud transmitidos a través de las nuevas tecnologías no están siendo ampliamente investigados ni se ha desarrollado ninguna teoría que relacione la adopción de hábitos saludables con el consumo de estas tácticas (del Pozo Irribarría y Ferreras Oleffe, 2011: 114-115; del Pozo Irribarría y Nuez Vicente, 2012). Tal y como indican Jiménez Pernett et al. (2009), "esta diversidad de herramientas no ha venido asociada, en la mayoría de casos, a una evaluación (de necesidades, de impacto, de resultados y de proceso) de estas iniciativas que nos indique si estamos dirigiendo nuestros esfuerzos en la dirección adecuada y de 
qué manera podemos mejorar el trabajo ya realizado, para garantizar unas estrategias y programas de prevención más efectivos, actualizados y atractivos”.

Quizás por eso algunos autores hablan de un "fracaso en la educación sanitaria" ya que, opinan, no se ha sabido dotar de empoderamiento a nivel individual y de la comunidad en torno a la salud (del Pozo Irribarría y Nuez Vicente, 2012). Esta situación cambiará, admiten, con el empleo de las nuevas tecnologías (del Pozo Irribarría y Nuez Vicente, 2012).

Hay que tener presente, no obstante, que las nuevas tecnologías no sustituyen a las tácticas tradicionales, sino que simplemente las complementan (Baena, 2009; del Pozo Irribarría y Ferreras Oleffe, 2011: 115-116; del Pozo Irribarría, 2009). Los usuarios integran internet, por ejemplo, "dentro de su vida cotidiana pero manteniéndolo al margen del sistema de salud formal", así que "aquellos individuos más activos a la hora de interesarse por los temas de salud y que hacen un mayor uso de diferentes fuentes de información también hacen un mayor uso de Internet" (Lupiáñez Villanueva, 2009).

\section{Herramientas tecnológicas}

Las herramientas tecnológicas más frecuentemente mencionadas en la bibliografía acerca de la comunicación sanitaria son internet, la página web, el social media, los blogs, las redes sociales y los podcasts, dejando otras tácticas más novedosas sin casi referencias. A continuación se señalan algunas de las investigaciones más relevantes realizadas al respecto en el plano médico.

\section{Internet}

La web ha roto las barreras físicas en el sector sanitario hasta el punto de que, en la actualidad, "desarrollar una identidad sólida en internet es tan importante como los esfuerzos offline, especialmente para aquellas prácticas que buscan reconocimiento nacional"454 ("A healthy dose of...”, 2000). Como continúa este artículo, “internet elimina las barreras geográficas de las relaciones públicas tradicionales y permite a los consultorios promocionar sus páginas web como fuentes mediáticas a nivel local, regional y nacional" 455 .

Aunque en una encuesta realizada en 2009 a 281 publirrelacionistas de departamentos médicos de 48 estados de Estados Unidos, Lariscy, Avery y Sohn (2010) muestran que la mayoría de los participantes no vincularon internet como una fuente primaria de información para sus públicos, esto no se corresponde con la realidad. Los consumidores aseguran dedicar más tiempo a este medio que a la televisión (algo más de tres horas a la semana en el primer caso y algo menos de tres en el segundo), según un estudio de Forester (Bishop, 2005). En el caso de la salud y los hospitales, los usuarios usan esta herramienta básicamente para buscar información sobre los costes y 
la calidad de los centros (Bishop, 2005). Y es que internet es una de las fuentes más consultadas para temas de salud, solo por detrás de los médicos (Lupiáñez Villanueva, 2009) o, en el caso de los jóvenes, también de los familiares y amigos (Jiménez Pernett et al., 2009). Los individuos "reconocen que un aumento de la información disponible sobre temas de salud mejora o mantiene el estado de salud" (Lupiáñez Villanueva, 2009).

También es un recurso habitual por parte de los periodistas. La indagación realizada en 2010 por Lariscy, Avery y Sohn (2010) a redactores médicos de la American Medical Writers Association señala que cuando tienen una idea, el primer sitio donde acuden es internet, y más concretamente a páginas como Medline, Pubmed, algunos centros de prevención y control de enfermedades, institutos nacionales de salud, etc. En general, las bases de datos online y las páginas web son unos de los elementos más usados y valuados, seguidos de las bibliotecas (Weaver Lariscy, Avery y Sohn, 2010).

El universo online tiene sus inconvenientes, pese a todo. Uno de los principales problemas que encuentran las personas a la hora de buscar información en la red es la calidad de información, que, tal y como lo califica Mayer Pujadas (2009), es “extremadamente variable". De acuerdo con Pozo Irribarría y Nuez Vicente (2012):

"Lo cierto es que hoy día los usuarios, sean pacientes o proveedores de salud y, por supuesto, investigadores en salud, pueden acceder a mucha información de gran calidad. Con frecuencia a páginas oficiales de gobiernos autonómicos, hospitales, universidades y centros de investigación (MedLine, por ejemplo). En otras ocasiones, páginas de ONGs de prestigio y seriedad contrastada u otro tipo de asociaciones como Enfermos de Parkinson o Cáncer, por poner algunos ejemplos. Sin embargo, [...] las encuestas empíricas realizadas con jóvenes parecen indicar que esto no ocurre así, y que, con frecuencia, se emplean datos provenientes de fuentes de información poco fiables".

Los motores de búsqueda, por su parte, tampoco ayudan a clasificar la calidad de los textos: "Uno de los mayores problemas consiste en el hábito de empleo del buscador Google, muy potente y fiable en sus búsquedas, pero con un déficit muy claro a la hora de organizar y clasificar una información muy compleja" (del Pozo Irribarría y Nuez Vicente, 2012). Según señala Mayer Pujadas (2009) de un estudio, entre el 20 y el 30\% de los resultados que ofrecen Google y Yahoo sobre cáncer y vacunas contiene información que "se alejaba claramente de la aceptada por la comunidad médica". Incluso las páginas web de los propios hospitales, según un estudio de Doblas Arrebola (2008), son realizados por "personal poco profesional, sin tener en cuenta cómo se transmite la información y cuáles son los criterios de calidad exigidos". 
Por otra parte, algunos autores argumentan que la falta de estudios que controlen el impacto de la comunicación online entre los médicos y los pacientes hace que los profesionales de la salud se muestren escépticos a la hora de fomentar discusiones terapéuticas a través de internet (Broom, 2005; Hart, Henwood y Wyatt, 2004). Los médicos y enfermeros, en efecto, no suelen utilizar este medio para crear ni distribuir contenidos ni para comunicarse con el pacientes; en el caso de los farmacéuticos, aunque comienzan a generar contenidos y se relacionan en mayor medida con los usuarios, su uso aún es pequeño (Lupiáñez Villanueva, 2009). Sin embargo, la relación médico-paciente no tiene que restringirse únicamente a las salas de consulta, sino que estos empleados deberían tener un papel activo en el mantenimiento de páginas web y en la elaboración de contenidos sobre este tema (Butler y Foster, 2003). Además, de acuerdo con Genuis y Genuis (2005), Morahan-Martin (2004), Molassiotis y Hong (2005) y Tak y Hong (2005), han de fomentar que sus pacientes exploren datos sobre la salud en internet y asesorarlos en la búsqueda y evaluación de las fuentes.

Existen estudios que sostienen la idea de que la información on-line es útil y, por tanto, debe utilizarse, y que los médicos tienen que involucrarse en la creación de contenidos en internet. Al respecto, conviene recordar en este apartado una indagación realizada en 2007 por Schulz, Rubinell y Hartung en la que se detallan los resultados de la creación de una página web con diferentes apartados para ayudar a personas con dolores de espalda. Los autores llevan a cabo un análisis con un grupo de tratamiento (que son los que hacen uso del sitio online) y otro de control (que no son avisados de la existencia de este lugar). Observan que al final de la investigación el primer conjunto tiene menos dolores, hace más ejercicio, busca más frecuentemente información, toma menos pastillas y gana en conocimiento. Además, la mayoría de las personas estudiadas creen que la página web es útil, les ayuda a lidiar con el dolor de espalda, mejora la interacción con el médico, tiene un lenguaje claro y los contenidos son útiles.

Se trata de un cambio de mentalidad favorecido por las nuevas tecnologías, gracias a las cuales se ha pasado de una relación «paternalista» entre el médico y el enfermo a una relación más en el plano de «igualdad» o de «responsabilidad compartida». Bajo este prisma, "el paciente ha comenzado a realizar un papel más activo abandonando el papel pasivo que desempeñaba hasta el momento, en un proceso interactivo y bidireccional" (Amador Romero, 2004).

Con el fin de solucionar estos desencuentros, Choque Larrauri (2012) propone cinco competencias que deben tener los profesionales a la hora de enfrentarse a las nuevas tecnologías: el uso eficiente de las TIC, el acceso a la información y la comunicación, la gestión de la información y el conocimiento, la generación del conocimiento y la difusión del conocimiento. Otros, por su parte, piden controles en la calidad de las páginas web. Carabantes Alarcón (2009), por ejemplo, establece tres métodos diferentes: a través de códigos éticos, de sistemas de valoración de los usuarios y la acreditación de profesionales. Asimismo, puede hacerse a través de revisiones por 
parte de organizaciones independientes (García del Castillo Rodríguez y Segura Díez, 2009; Mayer Pujadas, 2009). También se han creado iniciativas propias, como LISEspaña (http://bvsalud.isciii.es/), un buscador especializado en webs de salud seleccionadas en base a su calidad, que ofrece una descripción del contenido de los sitios web y su dirección en internet (Primo Peña y Jaén Casquero, 2009).

Por otra parte, los profesionales de las relaciones públicas del ámbito sanitario deben dedicar tiempo a buscar en la red lo que se comenta acerca del centro. "Tienes que conocer todo lo que se está diciendo ahí afuera sobre ti" "456, insiste Michael Fertik, presidente y fundador de Reputation Defender (Redwood City, California) (Milano, 2010). Conviene recordar que la salud es uno de los temas más consultados en internet por personas de todas las edades (Pew Research Center, 2006a). En 2006, por ejemplo, el $80 \%$ de los usuarios americanos de la red (es decir, 113 millones de adultos) habían explorado datos sobre este asunto en la red (Pew Research Center, 2006a). En España, el $75 \%$ de los jóvenes han consultado internet para buscar información sobre salud, mientras que el $82,3 \%$ de los que sienten que tienen un problema han acudido a esta plataforma, solo por detrás de amigos y padres (Guillamón Cano y Martínez García, 2012).

Buscar información en ese entorno virtual por parte de los publirrelacionistas es una tarea altamente recomendable, sobre todo cuando existe contenido negativo, ya que este es "extremadamente visible" por un paciente acerca de un hospital puede aparecer antes en los resultados de búsqueda que los comentarios favorables" ${ }^{\text {} 458}$, según Kris Lathan, director de relaciones públicas y relaciones con los medios en el Northwestern Memorial Hospital (Chicago) (Milano, 2010).

Cuando se detectan críticas negativas acerca de una organización, sus publirrelacionistas deben actuar con precaución. Como Michael Fertik explica, "responder puede alimentar la llama. Si lo que se dice es evidentemente falso -como que tu hospital no sirve a los mayores de 60 años-, corrige educadamente la información. Para una observación negativa cortésmente realizada, haz que un buen redactor dé gracias por el comentario y describa las acciones que se van a tomar para remediar el problema" ${ }^{\text {459 }}$ (Milano, 2010).

Existen numerosos ejemplos de cómo las nuevas tecnologías pueden ayudar a transmitir mensajes sobre salud en la población. En algunos casos, como en el tratamiento del tabaco, incluso se considera que el entorno online es "el único abordaje del tabaquismo poblacional" (Baena, 2009). Algunas de las iniciativas disponibles al servicio de los usuarios son la página web www.kolokon.com, creada por el Ayuntamiento de Portugalete para mostrar a los jóvenes información sobre drogas, sexo y música (Azkarretazabal Mendiguren, 2009). El Ministerio de Sanidad y Consumo, por su parte, creó Robín, un robot que se dirige a los adolescentes vía mensajería 
instantánea Messenger sobre temas de drogas, alcohol, tabaco, sexualidad y trastornos alimenticios; el $100 \%$ de los chicos que lo utilizó calificó esta herramienta como muy práctica (March Cerdá et al., 2009). La Fundación para el Estudio, Prevención y Asistencia a las Drogodependencias (FEPAD) de la Generalitat Valenciana ha organizado exposiciones interactivas en las que incluyen, entre otras cosas, talleres lúdicos de la videoconsola Wii, charlas informativas, mensajes bluetooth, talleres musical, simulador de conducción, etc. (Osuna, 2009). En Francia, el programa Fil Santé Jeunes ofrece a través del teléfono, de Skype y de una página web temas de salud y prevención (Dubois, 2009).

Se han documentado otras iniciativas positivas de difusión de datos médicos online. Por ejemplo, la American Medical Association, consciente de las numerosas fuentes disponibles, ha elaborado un manual para ayudar a los consumidores a valorar la fiabilidad de cada sitio (Winker et al., 2006). The American Communication Association y The Emerson College Department of Communication, por su parte, han apostado por crear cada uno una página web con información de confianza (Kreps, Bonaguro y Query, 1998).

También es remarcable el estudio de Botella Arbona et al. (2009), que exponen las ventajas de la realidad virtual para el tratamiento del juego patológico. Llevan el experimento a tres pacientes y concluyen que esta herramienta es eficaz para superar el impulso a jugar. La realidad virtual, dicen, ofrece un marco terapéutico seguro y útil que puede favorecer la aplicación del tratamiento cognitivo-comportamental.

Schulz, Rubinell y Hartung (2007) exponen otros estudios que corroboran que la información de estos lugares puede tener un impacto positivo en temas relativos a la salud. Por ejemplo, una indagación de 2002 (Lorig et al.) concluye que una discusión vía email puede beneficiar a los pacientes y puede considerarse un tratamiento para las personas con dolor crónico de espalda. Por su parte, un ensayo controlado llevado a cabo en 2004 (Buhrman et al.) demuestra que la autoayuda a través de internet y con soporte telefónico tiene un efecto positivo tratando las discapacidades asociadas con el dolor de espalda.

\section{La página web}

Una de las más recurrentes e indispensables tácticas de internet es la página web. Según Hill y White (2000), los publirrelacionistas ven en estas plataformas "un modo para fortalecer las relaciones ya existentes" ${ }^{\$ 60}$. Además de poder incluir notas de prensa o los servicios médicos ofrecidos, estos sitios son unos vehículos ideales para "promover la investigación médica, para mostrar los procedimientos médicos técnicos con gráficos, para mostrar la cobertura de noticias en las que el personal médico ha sido mencionado e incluir comentarios y correcciones adicionales si es necesario, y para dar 
oportunidades a los pacientes para preguntar o hacer comentarios sobre temas claves de salud"461 ("A healthy dose of...", 2000).

La eficacia de las páginas web como medios para transmitir información sanitaria depende de la edad de las personas que reciben los datos. En un estudio de 2003 realizado a 255 pacientes, Chandra y Emmet (2003) encontraron que los individuos de menos de 60 años creían que estas plataformas eran un modo importante de transmitir información médica en mayor medida que los de más de 60 años.

Sin embargo, para que sea efectiva, la comunicación online debe ser diseñada y modificada según cada grupo objetivo, algo que en las páginas web sanitarias no ocurre demasiado a menudo (Schulz, Rubinell y Hartung, 2007). Esta falta de información personalizada crea en la mente del paciente "un laguna de información entre el conocimiento general acerca de la prevención y los tratamientos y la capacidad para desarrollar conductas correctas o para modificar y cambiar las que pueden contener errores"462, afirman Schulz, Rubinell y Hartnung (2007) de Payne y Kiel (2005), Weissenberger et al. (2004) y Skelton $(1995,1996)$.

La funcionalidad y el atractivo de los sitios web no son los únicos aspectos que atraen a los consumidores. Tener una buena optimización de motores de búsqueda (SEO, por sus siglas en inglés) también es recomendable. De acuerdo con Milano (2010), "como la búsqueda en internet domina la toma de decisiones de los consumidores, la capacidad de un hospital para atraer a los pacientes puede depender más de la forma en que aparece en los motores de búsqueda que de la belleza y la funcionalidad de su sitio Web" ${ }^{, 463}$.

\section{Los medios sociales}

Crear y mantener una página web no es suficiente para establecer un diálogo con los diferentes públicos. Los medios de comunicación social, "como la base misma de las relaciones públicas, construyen relaciones"464 (Avery et al., 2010), y por ello deben emplearse en cualquier sector, el sanitario incluido. De hecho, el contenido médico se puede insertar fácilmente en estos medios: "Es uno de los temas más deseados en las noticias, responden a un nivel tanto personal como político y las personas tienden a querer información inmediata que esté disponible en línea de manera urgente cuando se enfrentan a un problema de salud complicado" 465 , recordando las palabras de Avery et al. (2010). Una ventaja única que ofrecen los medios sociales es entablar diálogos con numerosas audiencias incluso para organizaciones que tienen un presupuesto muy bajo (Pew Research Center, 2004b).

Un estudio realizado por Avery et al. (2010) evidencia que la plantilla de los departamentos que mantienen una página web, sobre todo si son interactivas, son más propensos a utilizar las herramientas del social media. Estos autores también detectaron que aquellos que trabajaban en áreas urbanas suelen utilizar con más frecuencia estos 
medios para transmitir información. Pese a estas buenas relaciones, los autores encontraron que hay muy pocas personas empleadas en relaciones públicas en los departamentos de salud estudiados que utilicen habitualmente estas herramientas: un $17 \%$ frente a un $83 \%$ que no las usan. PRWeek también constata, al menos para el año 2009, que la adopción de los medios sociales es, en general, baja (Iacono, 2009).

Milano, en 2010, proporcionó una lista de páginas web para monitorizar el espectro de los medios de comunicación social. Estas son Yelp, Citisearch, Angie's List y sitios de quejas de consumidores como www.ripoffreport.com y www.complaintsboard.com. Si el tamaño del departamento de relaciones públicas de un hospital es demasiado pequeño para controlar todo el social media, Milano (2010) suministra una serie de servicios para facilitar este trabajo. Entre otros, destaca Melt Meltwater, Radian6 y Google. El Northwestern Memorial Hospital de Chicago, como muestra, está suscrito a estos servicios y recibe alertas a cualquier hora del día y de la semana cuando el centro es mencionado (Milano, 2010). En el momento en que esto ocurre, los responsables de relaciones públicas contactan con la persona que ha escrito el contenido, dado que "creemos que es imperativo demostrar que verdaderamente nos preocupamos, y lo hacemos respondiendo a aquellas cuestiones relativas a lo que quieren y esperan los consumidores de los servicios de salud" ${ }^{466}$, dice Milano (2010) de Kris Lathan, director de relaciones públicas y relaciones con los medios.

\section{Blogs}

Los medios de comunicación social engloban una gran cantidad de canales y uno de ellos es el blog. Berkowitz (2007) los define como "la habilidad de publicar continuamente ideas u opiniones propias" ${ }^{\text {"467 }}$. La esencia del blogging es que se puede invitar a los lectores a mantener una conversación acerca de diferentes temas (Smudde, 2005); es decir, permite sostener una comunicación bidireccional. De hecho, para Seltzer y Mitrook (2007), los blogs utilizan más elementos bidireccionales que las páginas web, lo que les hace más idóneos para construir relaciones online. Y es que los blogs interactivos pueden mejorar la conexión con la compañía, generar actitudes positivas hacia la entidad y crear intenciones positivas de boca-oreja (Yang y Kang, 2009).

Hay diversos tipos de blogs y todos ellos pueden utilizarse para transmitir información relacionada con la salud. Avery et al. (2010) exponen los siguientes: blogs personales (donde un individuo expresa su propia opinión), temáticos o de sectores (aquellos centrados en una sección o tema particular), basados en publicaciones (normalmente hacen referencia a medios de comunicación establecidos) y corporativos [los que pertenecen a una compañía (Smudde, 2005) y se utilizan para transmitir información y dialogar con los públicos]. 
Según Berkowitz, en 2007, esta herramienta "no se ha empleado a ningún nivel por parte de los relaciones públicas que trabajan en el campo de la salud"468, aunque “debería ser una fuerza poderosa en los próximos años" $" 469$. En 2010, el 39\% de los oficiales de información pública (PIOs, por sus siglas en inglés de Public Information Officers) aseguran usar blogs para en sus tareas diarias (Avery et al., 2010).

Sin embargo, el porcentaje aún es demasiado bajo viendo la importancia que tienen estos canales en la búsqueda de información médica por parte de los ciudadanos. En 2008, por ejemplo, el 37\% de los adultos generó contenidos sanitarios en estas plataformas o sitios similares. El número es incluso más alto cuando se trata de personas que buscan esos datos: el $41 \%$ leyó la bitácora o la página web de otro individuo, el $13 \%$ escuchó un podcast, el 29\% usó redes sociales y el 12\% entró en Twitter (Pew Research Center, 2009b).

El bajo uso de blogs en el entorno médico puede ser debido a la preocupación de que las respuestas que se reciban puedan ser negativas (Berkowitz, 2007). Aun así, "permite al proveedor planear una campaña de cara a una posible crisis de un modo menos reactivo de lo que han venido haciendo las relaciones públicas. Mediante el seguimiento de los comentarios de un blog, la organización sanitaria puede, en efecto, saber a tiempo real qué se está cociendo en el mercado"470 (Berkowitz, 2007). Como dice este autor, "es mejor para una organización sanitaria saber lo que se está diciendo en un blog que conocer dos trimestres después que su cuota de mercado está disminuyendo" 471 .

Ciertamente, una bitácora online puede ser considerada casi como un grupo focal en directo: "Si el director de relaciones públicas lo vigila continuamente y participa en el proceso de diálogo con los lectores, el blog se puede convertir en una forma de conseguir retroalimentación por parte del público y se podría también incluir esta información en la toma de decisiones como una exploración a tiempo real del entorno de la organización" ${ }^{\text {"47 }}$ (Berkowitz, 2007). Haciendo esto, las entidades sanitarias pueden prevenir "que una situación tensa adquiera el nivel de crisis, donde se necesita una mayor actividad e intervención"473 (Berkowitz, 2007).

Con el fin de que sean efectivos y creíbles, los blogs deben gestionarse a un alto nivel, preferentemente por el director de relaciones públicas. Esta persona es la que se pondría en contacto con los especialistas a los que les corresponde cada entrada. Berkowitz (2007) expone un ejemplo:

"El Director de Relaciones Públicas debe ser el contacto principal que difunda la información y responda y controle el blog. Aun así, un blog es una herramienta que debe ser vista como una conversación sin filtro. Así, si el tema que se está discutiendo trata sobre tasas de infección, el Director de Relaciones Públicas debe hacer que el Jefe de Control de 
Infecciones participe en la discusión, pero la persona de relaciones públicas no puede ser la que responda sobre las tasas de infección. La credibilidad del blog se vería afectada y la confianza en la organización y el valor del blog disminuirían a la propia de la publicidad más que a la de la comunicación bidireccional" ${ }^{\text {474 }}$.

Además, una bitácora virtual debe ser interactiva y animar al diálogo. Como explica Wilcox (2006), "tal vez el error más grande que una empresa puede hacer es tratar un blog como si fuese un gran folleto de promoción de la empresa. Un blog, a diferencia de un sitio web, debe ser altamente interactivo y ha de entablar un diálogo"475.

\section{Redes sociales}

Aunque los usuarios de las redes sociales aumentan año tras año, los profesionales de las relaciones públicas no parecen adaptarse a esta moda. En un estudio realizado en 2008 por Eyrich et al. se detectó que solo el 24\% de los publirrelacionistas participantes utilizan estas plataformas. Un año más tarde, el Pew Research Center (2009b) indicó que el número había subido levemente 5 puntos hasta llegar al 29\%.

Waters et al. (2009), por su parte, estudiaron 47 perfiles de Facebook dirigidos por organizaciones médicas. Encontraron que las entidades sin ánimo de lucro no habían incorporado la mayoría de las aplicaciones disponibles y que rara vez incluían archivos multimedia, notas de prensa o sumarios de sus campañas. En cambio, usaban Facebook como un mecanismo de publicidad en el que insertaban noticias externas y vínculos a su propia página web.

Avery et al. (2010) hallaron que solo el 17\% de los publirrelacionistas entrevistados en su estudio usaban los medios de comunicación social frente al $83 \%$ que no los empleaba. Entre los primeros, la táctica más usada eran las redes sociales en un $76 \%$.

\section{Podcasts}

Según Berkowitz, en 2007, los podcasts no eran utilizados "a ningún nivel”"476 entre los profesionales de las relaciones públicas sanitarias. En comparación con los blogs, esta herramienta es más tradicional, en el sentido de que permite una interacción unidireccional hacia la audiencia (aunque sea más dinámica que en los medios impresos). A pesar de ello, "los podcasts pueden convertirse en una segunda herramienta para ayudar a establecer un foro de actualidad para la comunicación de crisis, así como para crear piezas de información que estimulen la discusión en los blogs sobre la salud y así construir relaciones con las partes interesadas, que es el núcleo actual de las relaciones públicas"477 (Berkowitz, 2007). 
Berkowitz (2007) insiste en que los podcasts pueden hacer llegar a la audiencia numerosos asuntos sobre temas sanitarios, como, por ejemplo "cómo se utilizan las donaciones en un centro para problemas del corazón o cómo los centros de salud están avanzando en el control de la calidad y en mostrar esas nuevas iniciativas a los diversos públicos y que estos puedan ver y descargarse la información de su interés en internet" ${ }^{478}$.

Sin embargo, solo el 31\% de los responsables de información pública utilizan esta herramienta, según un estudio de Berkowitz (2007). Las personas que trabajan en pequeños núcleos de población o en entornos rurales son los usuarios más frecuentes (64\%), a pesar de que son los que tienen las menores tasas de uso de los medios de comunicación social en general. Solo el $26 \%$ de los publirrelacionistas que trabajan en grandes urbes, el $22 \%$ de los empleados en núcleos medianos y el $10 \%$ de los que trabajaban a las afueras de ciudades usaban los podcasts en el momento del estudio.

\section{Otros}

Aparte de las tácticas ya expuestas, existen otras de las que no se tiene constancia que se utilicen en el plano médico, pero que podrían ser adaptadas fácilmente. Es el caso de los videocomunicados, intranet, Bluetooth, videoconferencias, realidad aumentada y un largo etcétera. También se puede echar mano de los motores de búsqueda, la internet visible y la invisible, los multibuscadores, los directorios, las páginas web de salud, las obras de referencia (enciclopedias, diccionarios, tesauros, traductores, glosarios y diccionarios temáticos), las bases de datos, las revistas electrónicas, los catálogos colectivos, las listas de distribución, los foros de discusión, los bancos de imágenes... (Bojo Canales, 2004). Asimismo, existen aplicaciones para móviles que ayudan a tratar diferentes enfermedades (Patientview, 2012) e incluso se puede usar la frecuencia de la emisora de la policía para emitir campañas sobre la salud, como ha sucedido en Taiwan (Lai, 2014). El uso de unas en detrimento de otras depende de las características de la campaña de comunicación, de los recursos disponibles y del público receptor.

\section{Otros}

Al igual que cualquier otro profesional, el personal encargado de la comunicación en los centros sanitarios debe adoptar no solo habilidades de negocio, sino también conocimientos de marketing (Wilcox, 2006). Ha de ser capaz de pensar estratégicamente sobre "the big picture" y mantenerse al tanto de los acontecimientos que suceden a su alrededor (Wilcox, 2006). Finalmente, estos empleados han de adoptar un pensamiento global, como una exigencia actual de la globalización de la información y de la atención sanitaria (Wilcox, 2006). 
Los requisitos para proporcionar un buen servicio en el actual y futuro ambiente global son "un mayor conocimiento de la comunicación intercultural, trabajar sin fronteras y con una base común", así como "ser multilingüe", que es "una materia prima de creciente valor" ${ }^{\prime 49}$. Los europeos, por ejemplo, que normalmente son políglotas, "tendrán más posibilidades de ser contratados que sus equivalentes americanos"480 (Wilcox, 2006).

$\mathrm{Y}$ es que el turismo médico está creciendo en la misma medida que lo hace la globalización (Berkowitz, 2007) y, como tal, las relaciones públicas en este ámbito deben adaptarse a esta realidad. Existen varios ejemplos del nuevo contexto sanitario mundial. Como muestra, 1,1 millones de personas procedentes de Europa, Asia y Estados Unidos visitaron Tailandia en 2004 por motivos médicos (Sen, 2005). De hecho, el hospital Bumrungrad de Tailandia es el primer centro no estadounidense en recibir la acreditación de la Joint Commission, una organización sin ánimo de lucro que acredita organizaciones y programas de salud en Estados Unidos (Berkowitz, 2007). Otro ejemplo es la India, donde se aprobó una ley permitiendo los visados médicos (Berkowitz, 2007). La principal implicación en términos de competición para las clínicas de Estados Unidos, como muestra, es que "el alcance de los que podían ser hasta ahora potenciales competidores se ha ampliado de manera significativa" (Berkowitz, 2007).

Debido a la universalización, Wise (2009) aboga por la diplomacia médica, "una actividad de cambio político que cumple con el doble objetivo de mejorar la salud mundial mientras se mantienen y se refuerzan las relaciones internacionales en el extranjero, particularmente en áreas conflictivas y en entornos con recursos escasos (Novotny y Adams, 2007). Las relaciones públicas, piensa Wise (2009), deben constituir puentes hacia una atmósfera de comunicación más global y correcta: "Estamos en una posición única para ayudar en los esfuerzos de la diplomacia de la salud, y debemos aprovechar las oportunidades para conseguirlo"483 (Wise, 2009). Si esto se consigue, las corporaciones globales han de, "ahora más que nunca", "incorporar divulgación y transparencia en sus valores fundamentales y trabajar como si todo el mundo estuviera observando" $" 484$ (Wilcox, 2006). Y es que la diplomacia pública, junto con la tecnología en comunicación y el desarrollo internacional, "responde a la dinámica cambiante del siglo XXI"485 (Milam y Avery, 2012). 


\subsubsection{RELACIÓN CON LA DIRECCIÓN, ESTRUCTURA Y CULTURA ORGANIZATIVA Y PODER}

La función de las relaciones públicas no depende únicamente del responsable de comunicación, sino también de las personas que dirigen la entidad sanitaria. Tal y como Costa (2012) explica, "la conciencia de la necesidad de un departamento de comunicación y su papel central en el ámbito hospitalario depende de la filosofía de cada hospital y de su equipo de gobierno, aunque la tendencia confirma que son cada vez menos los hospitales que carecen de un departamento que organice y planifique su estrategia comunicativa". Por ejemplo, en un estudio de Dines y Schneller (1992), se observa que aunque muchos gerentes de los hospitales creen que su importancia en la sanidad está creciendo, no están seguros de qué implican como disciplina o profesión o cómo pueden encajarlas dentro de la estructura de la organización (Gordon y Kelly, 1999). Las principales razones, según Lewton (1992: 51), son la preocupación con las "tareas orientadas a la producción" personas que no están entrenadas teóricamente ni que cuentan con experiencia previa en la profesión" 487 .

Aun así, en las entidades que tienen un área específica de comunicación se desarrollan procesos más metódicos, con una asignación de roles y tareas y una calendarización de actividades (Díaz y Cuesta Cambra, 2014). Si, además, este departamento se coloca en el primer nivel del organigrama (es decir, en la toma de decisiones), se obtendrá una visión más estratégica y bidireccional (Díaz y Cuesta Cambra, 2014).

Y es que, tal y como detallan L. A. Grunig, J. E. Grunig y Dozier (2002: 191), lo más recomendable para gestionar estratégicamente la comunicación es que el jefe de este departamento forme parte o al menos tenga acceso a la coalición dominante. Este gabinete, según Costa (2012), “debería depender del órgano máximo de gestión, es decir, la Gerencia". Tal y como explica esta profesora, "de esta forma, se garantiza que el gabinete tenga contacto con los máximos representantes de la institución; tenga conocimiento del contexto para una orientación correcta de la comunicación; tenga conocimiento de las estrategias reales de la organización (acciones públicas o no) para un correcto diseño y orientación de las estrategias de comunicación y de los mensajes a transmitir". Hay que tener en cuenta, no obstante, que el acercamiento de los responsables de comunicación a las máximas autoridades de una institución sanitaria no "implica necesariamente el reconocimiento de la comunicación como una dimensión estratégica de la política sanitaria" (Bruno et al., 2012).

Uno de los pocos estudios publicados al respecto muestra que la mayoría de los publirrelacionistas de los hospitales de Carolina del Norte (Estados Unidos) aseguran reportar a personas de alto rango, en torno a la mitad de ellos al director, presidente o administrador (Fletcher, 1989). Lo más normal es que los comunicadores aprendan 
sobre las decisiones de alto nivel en encuentros personales con los gestores (Fletcher, 1989). No obstante, únicamente el $6 \%$ consideraba que su tarea principal es hacer recomendaciones a los directivos (Fletcher, 1989).

Otro estudio al respecto recoge los resultados de una encuesta realizada a los directivos de los hospitales canadienses de habla inglesa (King y Scrimger, 1993). Los autores localizaron que más del $35 \%$ de la plantilla de relaciones públicas eran miembros del comité directivo. Aunque esta disciplina no gozaba del mismo reconocimiento que la recaudación de fondos, los directores aseguraban tener mucho más contacto con los primeros que con los segundos. Más concretamente, el 76\% de los jefes de las entidades afirman estar en contacto con los publirrelacionistas diariamente o varias veces por semana. Además, el $48 \%$ calculan estar de tres a cinco horas semanales con actividades de relaciones públicas y el 23\%, seis o más. King y Scrimger (1993) señalan de Chesney (1993) que muchos de estos profesionales en las clínicas de Canadá ya habían adoptado una visión directiva y estratégica y que, por aquel entonces, el HCPRAC estaba tratando de dotar a sus miembros "con desarrollo profesional que respalde la orientación de dirección" 488 .

La estructura de la organización también influye en la satisfacción y comunicación de las entidades sanitarias. Una obra que resume las características estructurales de los hospitales es la tesis doctoral de Fabiszak (1985). En la parte teórica aplica diferentes visiones sobre la estructura de las organizaciones, teorizando que los hospitales son sistemas complejos que se enmarcan dentro de la tipología orgánica o mixta entre orgánica y mecánica de Hage y Hull (1981) y que se trata de entidades estratificadas, altamente formales y con un poder descentralizado. Después de realizar una encuesta a los miembros de comunicación de hospitales estadounidenses, llega a la conclusión de que, en cuanto a estructura, los hospitales "tienden a ser organizaciones formalizadas con una estratificación moderada y un nivel de centralización de moderado a alto"489. También observa que operan con "distintos medios entornos políticos y legislativos" 490 , y que el entorno del producto o servicio "tiende a ser complejo con una demanda tanto pequeña como grande" ${ }^{491}$.

Alonso et al. (2011) ponen de relieve la importancia de las estructuras de trabajo con las unidades de gestión clínicas de Andalucía, un modelo orientado al proceso y al paciente que se sustenta a través de un equipo multidisciplinario, en el cual el personal facultativo y el de enfermería participan en la toma de decisiones. Este enfoque, respecto a la tradicional estructura organizativa, proporciona mejores resultados, un mayor clima emocional, una comunicación interna más satisfactoria y unas valoración de los responsables directos y del centro más positivas que las organizaciones tradicionales (Alonso et al., 2011).

En cuanto al poder, los publirrelacionistas de los hospitales consideran que tienen un nivel general "bastante alto", algo que no influye según el género, la formación o la 
experiencia, pero sí según el rol adoptado (Fletcher, 1989). Efectivamente, aquellas personas que se enmarcan dentro del papel directivo tienen una mayor visión de poder dentro de su organización que los que acogen una visión técnica (Fletcher, 1989).

Cho y Cameron (2007), por su parte, estudiaron las relaciones entre los diferentes tipos de poder propuestos por French y Raven (1959) en relación con los periodistas y concluyeron que los profesionales de las relaciones públicas del ámbito sanitario que se consideran expertos en salud, comunicadores competentes en medios y que tienen relaciones cercanas con reporteros tienen un mayor poder de experto en las relaciones con los medios de comunicación. Más específicamente, los autores vinculan cinco tipos de poder (de experto, de recompensa de información, coercitivo de información, coercitivo de publicidad y de influencia ${ }^{492}$ ), con cuatro variables de los publirrelacionistas hacia los periodistas (cercanía personal con los reporteros, apertura hacia los medios, la percepción de desempeño del trabajo de los medios y la impresión de expertos en el terreno de la salud ${ }^{493}$ ). Así, encuentran que el poder de experto tiene una fuerte correlación con el desempeño del trabajo y la experiencia en salud así como una correlación moderada con la apertura hacia los medios y con la cercanía personal con los reporteros. Aquellos con experiencia y compromiso son más propensos a interactuar con los reporteros. El desempeño del trabajo está relacionado significativamente (aunque de manera negativa) con el uso del poder de recompensa de información y con el coercitivo de información. Asimismo, los profesionales que tienen una relación cercana con los reporteros usan más frecuentemente el poder de recompensa de información.

\subsubsection{FASES DE UN PROGRAMA DE RELACIONES PÚBLICAS EN LOS HOSPITALES}

Los programas de relaciones públicas en el ámbito sanitario, como sucede en cualquier otro campo, han de seguir unos pasos concretos para que puedan ser efectivos. En este apartado, se ha utilizado el modelo proporcionado por la Public Relations Society of America (PRSA) en el Silver Anvil Awards, que, según Hunt y J. E. Grunig (1994: 28-29), es el más empleado. No se han seleccionado los siete pasos de J. E. Grunig y otros (J. E. Grunig y Repper, 1992: 124; Hunt y J. E. Grunig, 1994: 12-19 y 20), como se ha hecho en la sección teórica de las relaciones públicas, por la escasa bibliografía existente en torno al ámbito sanitario, que, a su vez, se concentra en cuatro fases más generales: investigación, planificación, comunicación y evaluación. De esta manera, se obtiene la siguiente estructura, que engloba dentro de las cuatro etapas mencionadas los siete pasos de J. E. Grunig y otros: 
○ Investigación:

- Fase de los stakeholders

- Fase de los públicos

- Fase de los conflictos potenciales

o Planificación:

- Fase de los objetivos

- Fase de planificación

o Comunicación:

- Fase de implementación

o Evaluación:

- Fase de evaluación

\subsubsection{INVESTIGACIÓN}

En el campo de las relaciones públicas, la etapa de investigación constituye "la fase de descubrimiento del proceso de resolución de problemas"494 (Langmaak, Heidrich y Sjöholm, 2004: 5). De hecho, la investigación metodológica y sistemática es "la base de las relaciones públicas efectivas"495 (Cutlip y Center, 1964: 111). Para ello, se usan "métodos formales e informales de búsqueda de información con el fin de conocer la organización, sus retos y oportunidades y los públicos que son importantes para alcanzar el éxito"496 (Langmaak, Heidrich y Sjöholm, 2004: 5). El publirrelacionista, en esta fase, se convierte en "un estudiante de su entorno"497 (Cutlip y Center, 1964: 217). La investigación, por lo tanto, es "la base de cualquier campaña efectiva" y un "componente esencial" "498 de las relaciones públicas estratégicas (Langmaak, Heidrich y Sjöholm, 2004: 5). Es una "forma de escuchar" y una parte inseparable de los procesos de planificación, ejecución y evaluación (Wilcox, Cameron y Xifra Triadú, 2007: 162).

Las ventajas de la investigación son numerosas. Para empezar, permite conocer los problemas antes de pasar a la opinión pública, es decir, permite "prevenir el fuego"499 antes que "luchar contra el fuego" "500 (Cutlip y Center, 1964: 113): "La búsqueda continua de información destapará muchos problemas que son aún pequeños como para permitir tratarlos silenciosamente sin que lo observe un público crítico. La misma forma atenta de escuchar también permite atrapar los rumores antes de que se extiendan" (Cutlip y Center, 1964: 113).

Asimismo, permite dividir los públicos y conocer los canales más propensos para alcanzarlos. "La difusión de publicity no es equivalente a la comunicación. La investigación permite al profesional localizar a sus públicos, descubrir a sus líderes y aprender sus valores, puntos de vista y lenguaje" ${ }^{502}$ (Cutlip y Center, 1964: 113).

La investigación ha de usarse para diseñar programas de relaciones públicas y mejorarlos y como un medio para transmitir la información de las audiencias a las 
personas que toman las decisiones. Tanto esta actividad como la medición, por lo tanto, deben ser una parte integral de la función directiva. Y es que la investigación "afecta a todos los tipos de actividades de relaciones públicas" (Harrison, 2002: 86) porque es una herramienta "multifacética que se utiliza en todas las fases de un programa de comunicación" (Wilcox, Cameron y Xifra Triadú, 2007: 162).

Existen muy pocos estudios que analicen la fase de investigación de un programa de relaciones públicas en el campo sanitario. Uno de ellos lo aporta Shelton (1993) sobre el Bloomington Hospital, que es retratado como un ejemplo de buenas prácticas comunicativas. El centro descarga información de la Asociación de Hospitales de Indiana para determinar su porcentaje de participación en el mercado y hace uso de la exploración para asegurarse de que los panfletos y los folletos están bien diseñados y son de fácil lectura. La investigación se usa para medir la eficacia de las campañas, y las tácticas más empleadas son las encuestas a los pacientes y las preguntas a los usuarios que contactan por teléfono acerca de dónde han oído hablar de ellos. Además, aprovechan esta fase para hallar qué grupos están afectados por ciertos desórdenes médicos y así comunicarse mejor con ellos. La etapa de investigación en esta clínica está integrada dentro del proceso de diseño de una campaña de relaciones públicas y sus resultados "se tienen muy en cuenta, algo que es muy importante"

Morris (1992), por su parte, muestra un centro de atención especializada (La Porte Hospital) que abrió en 1989 una sección de consultas con el fin de conocer los aspectos de la administración que incomodaban a los clientes. Se procedió a la contratación de personal y su entrenamiento y posteriormente se llevó a cabo una encuesta para averiguar la opinión de los usuarios acerca del nuevo servicio. Tal y como indica la jefa del mismo, aunque no soluciona todos los problemas, es un buen método para saber dónde y cómo hay que realizar cambios.

No obstante, el caso del Bloomington Hospital no se corresponde con la norma general. Fabiszak (1985) descubrió a través de una encuesta nacional a los hospitales de Estados Unidos que utilizan poca investigación formativa y evaluativa. Gordon y Kelly (1999), queriendo descubrir qué rol es el más utilizado en los centros sanitarios, descubrieron que la frase con la que los participantes se sentían más en desacuerdo era "realizar investigación evaluativa" 504 . De hecho, los autores aportan un retrato negativo de la indagación en general en los escenarios médicos. Insisten en que las clínicas tienen pocas posibilidades de conseguir una comunicación excelente hasta que no dejen de contratar gente formada en otras disciplinas. Los autores facilitan el ejemplo de la Public Relations Society of America's (PRSA) Educators Academy, en la cual el 82\% de sus miembros trabajan en disciplinas diferentes a la de sus estudios (Sallot, Cameron y Weaver Lariscy, 1997). Los académicos añaden que únicamente el 6\% de los publirrelacionistas que pertenecen al PRSA se graduaron en relaciones públicas, mientras que el $31 \%$ lo hizo en periodismo. 


\subsection{IDENTIFICAR Y ESTUDIAR LOS PÚBLICOS}

Los profesionales de las relaciones públicas de los hospitales, al igual que los de cualquier otro campo, deben realizar sus funciones de manera estratégica. Es decir, han de identificar las audiencias que son más propensas a frenar o a aumentar la habilidad de la organización para alcanzar su misión $\mathrm{y}$, después, elaborar programas para comunicarse con ellas (L. A. Grunig, J. E. Grunig y Ehling, 1992). Si estos departamentos operan de esta manera, desplazarán las voces a la dirección estratégica, "haciendo así posible que los públicos interesados participen en las decisiones de la organización que les afectan”505 (L. A. Grunig, J. E. Grunig y Dozier, 2002).

Identificar y segmentar los públicos de una entidad es, de hecho, la segunda de las seis etapas propuestas por J. E. Grunig y Repper (1992) para cualquier campaña de relaciones públicas. También engloba tres de los seis pasos en cualquier modelo de planificación estratégica en la comunicación integral [Integrated Strategic Communications planning model (ISC)] (Ristino, 2007). No obstante, es algo que no se ha fomentado demasiado entre los proveedores de los servicios sanitarios (McCullough y Dodge, 2002), a pesar de que, insistiendo en lo que dice Díaz (2011: 44), “podemos decir sin temor a equivocarnos que el éxito o fracaso de una acción de comunicación para la salud depende de la adecuada identificación de los destinatarios, sus características, sus concepciones y evaluaciones y sus formas de relacionarse con su entorno social".

\subsection{CONOCER A LA AUDIENCIA}

Saber lo máximo posible acerca de las características de los stakeholders y de los públicos puede marcar la diferencia entre una campaña exitosa y una fallida. Dado que el concepto de salud difiere entre diferentes zonas poblacionales (Gudykunst y Kim, 1992), "es sumamente importante identificar y examinar las cuestiones culturales relevantes que pueden influir en las formas en que los consumidores -en particular los miembros de las poblaciones vulnerables- responden a la comunicación sobre los riesgos del cáncer, la prevención, la detección y el control" ${ }^{\text {"506 }}$ [dice Kreps (2008) sobre Chew, Bradley y Boyko (2004), Kreps y Kunimoto (1994) y Kreps (2006)]. Por ello, "la efectividad de cualquier esfuerzo promocional de la salud debe comenzar con una clara comprensión de las influencias culturales que afectan a las creencias y a las prácticas de salud de los grupos culturales claves en cuestión" ${ }^{, 507}$ (Springston y Champion, 2004).

Como prueba un estudio sobre las campañas de comunicación de la salud en África, cuando el mensajero no tiene en consideración la cultura y las características de la audiencia, y trata de que la población deje ciertos comportamientos y adopte otros sin recoger ningún tipo de retroalimentación o sin segmentar la audiencia, el único resultado posible son "unas relaciones jerárquicas entre poderes públicos y ciudadanos 
sin lograr un impacto apreciable en el seno de las comunidades rurales" (Balima, 2006). Por contra, con un diagnóstico participativo, que es a menudo la primera forma de interacción entre los educadores sanitarios y los miembros de la comunicación, se favorecería la participación entre ambas partes (Balima, 2006).

También es muy importante "evaluar las habilidades y orientaciones lingüísticas de los consumidores basadas en la cultura, sus niveles de alfabetización sobre la salud, sus motivaciones para buscar información sobre este tema y sus patrones de uso de los medios de comunicación"508 (Youmans y Schillinger, 2003). Se deben detectar las poblaciones vulnerables, ya que a veces presentan "muchas dificultades por su bajo conocimiento en temas de salud y están limitados en el acceso y comprensión de información relevante sobre la salud debido a las barreras de comunicación intercultural" ${ }^{109}$ [Kreps (2008) citando a Chang et al. (2004) y Kreps (1996, 2005)]. Este grupo suele estar compuesto por personas mayores, inmigrantes, individuos socioeconómicamente vulnerables y otras minorías (Ashton et al., 2003; Kreps, 1986, 1990). Los elementos que hay que tener en cuenta, por otra parte, son las creencias sobre la salud, los valores, las normas y las expectativas, que pueden conllevar diferentes situaciones en lo que a bienestar se refiere (Kreps y Kunimoto, 1994).

\subsection{TIPOS DE PÚBLICO}

Con el fin de facilitar una clasificación de los diferentes públicos, varios investigadores proporcionan una serie de categorizaciones. De esta manera, los profesionales de las relaciones públicas pueden elaborar diferentes tácticas según el grupo al que se dirijan. Pueden ser no-público, latentes, conscientes y activos (J. E. Grunig y Hunt, 1984: 145-146), activos o pasivos (J. E. Grunig y L. A. Grunig, 1991), de alta o baja implicación (J. E. Grunig y Ipes, 1983), etc.

Sha (1999) sostiene que el hecho de identificarse con un determinado grupo cultural condiciona el nivel de reconocimiento del problema, el nivel de implicación y las restricciones percibidas. Más concretamente, encuentra que la identificación con una cultura por parte de las mujeres afecta enormemente al nivel de implicación hacia mensajes sobre la salud y sobre sus preocupaciones. Los estudiantes que se consideran de una etnia también tienen un alto reconocimiento del problema y con el nivel de implicación, pero no sucede lo mismo con las restricciones percibidas [la identidad racial o étnica más prominente encontrada por Sha (1999) eran los estudiantes afroamericanos]. Pavlik (1988), por su parte, determina que las personas que perciben pocas restricciones tienen un conocimiento más complejo acerca de la salud, en concreto la cardiaca.

Los mensajes sanitarios deben ser diferentes según vayan predestinados a personas con una alta o baja implicación: "Los sujetos implicados tienden a prestar atención y 
reflexionar ante los argumentos de las campañas de información, por lo que para este tipo de sujetos pueden ser útiles las campañas que utilicen mensajes «racionales» y que contengan argumentos sólidos" (Igartua Perosanz, 2006). En cambio, los individuos con poca implicación acerca del tema central "carecen de la motivación suficiente para prestar atención a los argumentos de este tipo de mensajes. Por esta razón, se ha sugerido que, para este tipo de personas, serán más eficaces las apelaciones «emocionales» y «vívidas»" [Igartua (2006) hablando sobre Flora y Maibach (1990)].

Aparte de estas clasificaciones, hay múltiples tipos de públicos para un hospital y los profesionales de las relaciones públicas han de elaborar una división según las circunstancias de cada centro. Algunos pueden concentrarse en sujetos internos (como pacientes y familiares, médicos y personal) o externos (como la población en general) (Kirdar, 2007). Para otras entidades quizás sea más apropiado englobarlos en permanentes o potencialmente emergentes (Magallón, 2006).

Determinar esta faceta no es una tarea sencilla comparada con otras prácticas relacionadas (Anand y Chakravarti, 1981; Gbadeyan, 2010; Ristino, 2007). Como explica Ristino (2007), "mientras que el marketing, los recursos humanos y el desarrollo se involucran en una variedad de actividades de comunicación externas deliberadamente planeadas y ejecutadas, estas se centran en públicos específicos y separados: para el marketing es el cliente; para los recursos humanos son los empleados o los empleados potenciales; para el desarrollo son los donantes actuales y/o potenciales" ${ }^{\text {"510 }}$. Sin embargo, las relaciones públicas tienen como público objetivo todas las audiencias (Ristino, 2007).

Por ejemplo, según señalan Guy et al. (2007) de Kurtz (1969), los hospitales tienen varios públicos, incluyendo pacientes, visitas, familia, personal médico, trabajadores, voluntarios, contribuyentes, comunidad y personas de otro tipo, como pueden ser estudiantes, clérigos y miembros del gobierno u órganos de control. Kirdar (2007) engloba como grupo objetivo de los hospitales a la comunidad entera, aunque la diferencia entre interna y externa. Gordon y Kelly (1999) especifican un poco más, concretando que son los consumidores, el gobierno, los medios de comunicación y los empleados. Springston y Weaver-Lariscy (2007) también conciben de esta manera a los médicos, a los pacientes, las compañías de salud, la comunidad, los trabajadores, los socios colaboradores y los promotores. Para Anand y Chakravarti (1981), en el caso de los hospitales, se incluye al personal, a los pacientes y a sus familiares y al consejo directivo. Según estos autores, también estaría dentro de esta clasificación cualquier organización social o estatal y la población en general. En un estudio realizado en las cuatro residencias de ancianos más prestigiosas del área metropolitana de Nueva York (Estados Unidos), Meath (2006) encontró que la audiencia más importante son los residentes, los familiares y los trabajadores. 
Además de comunicarse directamente con las diferentes audiencias, los publirrelacionistas del mundo sanitario también deberían ayudar a que los empleados de sus organizaciones, vistas las características propias de este ámbito, se relacionen de mejor manera con los grupos con los que mantienen un mayor contacto. Así, se tendría que fortalecer, por ejemplo, la unión personal-paciente, recordando la importancia del compromiso y confianza para lograr una buena relación (Crutchfield y Morgan, 2010; Han, Wilson y Dant, 1993) y de la interacción con el usuario en internet (Butler y Foster, 2003; Genuis y Genuis, 2005; Molassiotis y Xu, 2004; Morahan-Martin, 2004; Schulz, Rubinell y Hartung, 2007; Tak y Hong, 2005). El equipo humano es uno de los principales motivos que llevan a los usuarios a mantenerse o, por el contrario, a cambiar de centro de salud (Abramowitz, Cote y Berry, 1987; Atkins, Marshall y Javalgi, 1996).

Otra de las relaciones que se debería potenciar es la de los profesionales médicos con los investigadores académicos y con los medios de comunicación, manteniendo un diálogo fluido y una actitud proactiva (Amador Romero, 2004; Bonilla Loyo, 2008; Cho, 2006; Donohue, Tichenor y Olien, 1973; Fitzgerald y Embrey-Wahl, 1987; Hogan, Hershey y Ritchey, 2007; Martínez-Brawley y Brawley, 2003; Meath, 2006; Springston y Weaver Lariscy, 2005; Wahl, 1995).

\subsubsection{PLANIFICACIÓN}

Al igual que sucede con la investigación, no hay demasiados estudios realizados hasta el momento acerca de la fase de planificación dentro del sistema sanitario, a pesar de que se trata de una etapa de gran importancia que permite establecer los objetivos y definir todos los elementos necesarios en los posteriores períodos. De hecho, una de las seis características que poseen las relaciones públicas según Wilcox et al. (2004) es que se trata de una práctica planificada.

Este paso "implica identificar y segmentar las audiencias claves, establecer objetivos para cada audiencia, identificar las acciones claves que deben realizarse y fabricar estrategias de comunicación que incluyan tanto los mensajes como las estrategias en medios"511 (Ristino, 2007). Dentro de esa planificación estratégica, se debe incorporar un plan de comunicación con un objetivo claro y unos sistemas de información que evalúen y vigilen el estado de bienestar de la población antes de proponer políticas eficaces (Bonilla Loyo, 2008). Para Menéndez y Vadillo (2010: 16), este documento se compone de tres partes: el estudio de la situación, los objetivos estratégicos y las modalidades de acción. Este archivo no debe servir únicamente al gabinete de relaciones públicas. Al contrario, "el Plan de Comunicación no debe ser el Plan del Departamento de Comunicación, sino del Hospital. Esto significa que, aunque sea elaborado en dicho departamento, hay que implicar en su realización a todos los 
profesionales sanitarios construyendo una estrategia de aliados en el seno del hospital" (Menéndez Prieto y Vadillo Olmo, 2010: 18).

La relevancia de este punto en el terreno de la salud lo pone de relieve Balima (2006), que explica los fallos y los procedimientos que se deberían llevar a cabo en la comunicación sanitaria en África. Entre los errores, destaca el autor, se encuentra una interacción generalmente unidireccional, general, sin atender a la retroalimentación, sin pararse en estudiar previamente la cultura y las creencias de la población y sin segmentar los diferentes públicos. La falta de investigación y planificación ha repercutido en que la mayoría de las acciones en ese continente no han dado el fruto que se esperaba, lamenta el autor. Por el contrario, para conseguir resultados positivos, concluye, se debe hacer un diagnóstico de la situación, hallar las conclusiones de las investigaciones anteriores, segmentar claramente el público objetivo y los mensajes y realizar un seguimiento y evaluación de la comunicación.

Los objetivos de relaciones públicas que se marquen en esta fase, además, han de concordar con las metas de la entidad en general (Gordon y Kelly, 1999; Henderson, 2005). James E. Grunig (1992b) ya concluyó que "las organizaciones excelentes planean estratégicamente y los departamentos excelentes están integrados en el proceso de planificación estratégica" ${ }^{212}$, algo que posteriormente atestiguarían Gordon y Kelly (1999). Conviene recordar que estos últimos académicos razonaron de este estudio que “cuanta más capacidad tenga el departamento de relaciones públicas para participar en la planificación estratégica, mayor será la efectividad general de la organización" ${ }^{\text {13 }}$.

Los centros médicos, según destacan Simyar y Lloyd-Jones (1988), parecen haberse cerciorado de la importancia de esta etapa y de sus ventajas, ya que la mayor parte de ellos establecen sus objetivos a través del "proceso de planificación estratégica"514. Además, cuanto más turbulento es el ambiente exterior, más necesidad tienen estas entidades de practicar planificación estratégica (Kotler y Clarke, 1987). A pesar de estas sentencias, no se han encontrado referencias bibliográficas explícitas que constaten el buen uso de la planificación en el terreno médico.

Una de las pocas la proporcionan Wilcox, Cameron y Xifra (2007: 204), que muestran las estrategias de relaciones públicas que se utilizaron en la campaña "Ayude a sanear el sistema sanitario de Florida":

"Convertir el sentimiento de descontento por los costes de la atención sanitaria en una disponibilidad para escuchar y respaldar la reforma sanitaria.

Centrarse en el consenso sobre el problema antes de ofrecer soluciones concretas.

Crear una amplia coalición que incluya al sector de las aseguradoras, sin andar de la mano con ella. 
Evitar desanimar a los consumidores al recurrir a la misma vieja pelea entre médicos y abogados.

Comunicar el efecto sobre los pacientes, más que sobre los proveedores de atención sanitaria, pero insistir en mensajes creíbles basados en hechos, sin recurrir a las «tácticas del miedo» sobre el acceso".

\subsubsection{COMUNICACIÓN}

En la fase de comunicación o ejecución es donde se ponen en práctica los planteamientos propuestos durante la planificación, es decir, cuando se realizan todas las acciones comunicativas. En este período se componen los mensajes, las imágenes, el sistema personalizado de información, los canales, las fuentes y los métodos de evaluación (Kreps, 2008). J. E. Grunig y L. A. Grunig (1991) explican que las organizaciones "pueden elegir ignorar los mercados si así lo desean", pero "como los públicos pasan de estar latentes a ser activos, las organizaciones no tienen otra opción que comunicarse con ellos" ${ }^{, 15}$. Los hospitales, como cualquier otra entidad, deben "construir relaciones a largo plazo" con sus audiencias a través de "relaciones estables, abiertas y basadas en la confianza" 516 (J. E. Grunig y L. A. Grunig, 1998). Es decir, es conveniente que establezcan "vínculos plausibles y deseados entre la organización en cuestión y sus públicos específicos" (Magallón, 2006) y que manejen los "vínculos de confianza entre dos (organización-un público concreto) o más elementos (organizaciónvarios públicos)" (Magallón, 2006).

Lamb y McKee (2005) insisten en que una entidad que se comunica eficientemente con sus audiencias es más exitosa, algo que probó Meath un año más tarde (2006). Este autor condujo una investigación en las cuatro residencias de ancianos más prósperas del área metropolitana de Nueva York (Estados Unidos) y encontró que los participantes consideran que su renombre está directamente relacionado con su habilidad para construir relaciones a largo plazo con sus residentes y, en especial, con los familiares.

Lewton (1998) también piensa que, en vez de propaganda, se tiene que alcanzar un consenso para "llegar a un mejor entendimiento" 517 . Con sus propias palabras, "las organizaciones sanitarias deben dejar de enviar mensajes y empezar a escuchar a los pacientes, los consumidores, los líderes de la comunidad... Reemplazar la retórica con la educación y el diálogo" ${ }^{, 518}$.

La comunidad y apertura entre los proveedores y los públicos es incluso una demanda del Institute of Medicine (IOM) (1996: 5): "Con la confianza en las instituciones públicas en situaciones de riesgo o en niveles bajos en muchas 
comunidades, las agencias gubernamentales de salud pública deben encontrar formas para mejorar su apertura y su comunicación con el público y así mantener e incrementar su confianza" $"$. A pesar de ello, los funcionarios de los servicios públicos de la salud, dice el IOM (1996: 45), "todavía no han encontrado la fórmula correcta para informar al público sobre la importancia de la salud pública. Encontrar mejores maneras de informar a los funcionarios públicos de la esencia y la importancia de la salud pública claramente merece más atención" ${ }^{\natural 20}$.

Los beneficios no se concentran únicamente en el lado del proveedor sanitario. En cambio, como dice Wise (2007) sobre Ledingham (2003), "si se gestiona adecuadamente, el objetivo de los profesionales que utilizan un enfoque relacional es que tanto una organización como sus públicos se beneficien de esa relación. Las estrategias para conseguir un beneficio mutuo pueden conllevar ganancias económicas, sociales y políticas tanto para las organizaciones como para sus públicos"521.

\subsection{SELECCIÓN DE FUENTES Y MENSAJES}

Debido a que cada audiencia tiene sus propias peculiaridades y prefiere ser contactada por diferentes medios, los profesionales de las relaciones públicas sanitarias deben tener a mano una amplia gama de herramientas para poder interactuar lo mejor posible con cada grupo. Shelton (1993) relata el caso de cómo otra entidad (el Bloomington Hospital) alcanza las audiencias a través de panfletos, folletos educacionales y anuncios en periódicos locales y en la guía telefónica. También utilizan boletines informativos, notas de prensa y artículos. Sin embargo, la mera presencia de estas herramientas no garantiza que la comunicación sea efectiva. En palabras de la autora, "los panfletos y los folletos creados por el personal están bien diseñados y son fáciles de entender. En este proceso se realizan labores de investigación y los resultados se toman muy en serio, algo que es muy importante" ${ }^{~} 522$. Además, Shelton (1993) sugiere que las clínicas deben intentar comunicarse de manera más agresiva con un grupo que puede ser de vital importancia, como son los alumnos. Según manifiesta, se pueden "repartir materiales educativos e información sobre cómo llegar al hospital, incluyendo un mapa y un número de teléfono. La información también se podría incluir en los paquetes de información de los estudiantes. Otra idea es organizar una «Feria de la salud» en el campus para proporcionar información acerca de los problemas de salud y oportunidades para colaborar como voluntario",523. También se puede interaccionar con los estudiantes a través del periódico universitario (Shelton, 1993).

Los representantes electorales prefieren una interacción en persona a través de reuniones formales (que pueden tomar forma de reuniones, grupos operativos o trabajos en grupo) (Wise, 2003). 
Adentrándose en audiencias más específicas, los directores de salud territoriales otorgan menos importancia a los círculos formales y más a las relaciones personales y a las conversaciones telefónicas (Wise, 2003). Lo más recomendable en el caso de los empleados es organizar periódicamente reuniones formales, así como asambleas de departamentos a las que toda la plantilla está invitada (Meath, 2006). Los medios de comunicación, con los que los publirrelacionistas deben mantener "un diálogo activo y continuo" "524 (Meath, 2006), pueden ser contactados a través de muchos métodos, aunque las relaciones personales dan una cierta ventaja al profesional (Di Costanzo, 1986). Tanto es así que suscita un mayor nivel de publicaciones (Walters y Walters, 1992) y ayuda a dibujar en la mente del redactor una fuente de información ética y hábil (Jeffers, 1977).

Una táctica cada vez más utilizada en el mundo sanitario para conocer la opinión de los consumidores son los grupos asesores [customer advisory groups (CAGs)] (Halm, Sabo y Rudiger, 2006). Estos son "grupos formales de clientes que se reúnen regularmente con los marketinianos para compartir sus ideas y para proporcionar información sobre las estrategias, programas y actividades de marketing existentes o en fase de pruebas" ${ }^{\text {} 525}$ (Gombeski et al., 2010). Según estos últimos autores, estas agrupaciones facilitan tres ventajas, tal y como sostienen de un caso concreto de un país de habla inglesa: "Muchas nuevas ideas que conducen a una mayor eficacia y eficiencia de los esfuerzos de marketing de HealthCare en Reino Unido; un aumento de la conciencia, la comprensión, el apoyo y la satisfacción de los médicos y trabajadores de Reino Unido con los programas de marketing; y un incremento de referencias, traspasos, nuevos pacientes, reputación, ingresos y cuota de mercado" $" 526$. También son útiles a la hora de "probar ideas y diseñar programas para que la forma de empaquetar y vender ideas estén cuidadosamente redactadas y organizadas para asegurarse de que las partes internas interesadas lo compren"527 (Gombeski et al., 2010).

Algunos centros sanitarios han incluido dentro de sus servicios el uso de intérpretes para comunicarse más correctamente con los pacientes. Según Henderson (2005), Family HealthCare Center, un pequeño proveedor sin ánimo de lucro con influencia en Fargo (Dakota del Norte) y Moohead (Minesota), fue el primero en integrar estos profesionales, de los cuales se benefició el 12\% de los clientes. En ese mismo centro, se creó un programa de ordenador para los usuarios bosnios, muchos de ellos analfabetos en su propia lengua. Para ayudarles, una voz leía la información que aparecía escrita en la pantalla. En el momento de la publicación del artículo de Henderson (2005), el centro tenía pensado convertir el programa a los idiomas español, árabe e inglés.

Otra iniciativa llevada a cabo por un centro médico es "SpeakUp", un programa creado en 2002 "para instar a los pacientes a participar activamente en su propio cuidado mediante acciones como dar su propia opinión, buscar el apoyo de su familia y la mayor comprensión posible acerca de las instalaciones y el plan de salud que se les proporciona como pacientes" ${ }^{\text {528 }}$ (JCAHO (Joint Commission on Accreditation of 
Healthcare y Organizations), 2005a, 2005b). En marcha gracias a la Joint Commission on Accreditation of Healthcare Organizations (JCAHO), después de seis meses desde su implementación, más del $47 \%$ de las organizaciones acreditadas utilizaron datos de esta plataforma en sus manuales para residentes (Meath, 2006). La publicidad y otras herramientas de promoción también se utilizan cada vez más en muchos hospitales para comunicarse con los públicos (Cooper, 1992; Galuszka et al., 1997; Petromilli y Michalczyk, 1999).

\subsection{LA IMPORTANCIA DE PERSONALIZAR}

No obstante, cada persona recibe y procesa los anuncios sanitarios de diferente manera, y por tanto, conviene llevar a cabo un "sistema de comunicación a medida" es decir, "diseñar mensajes sobre la salud que cumplan las necesidades únicas de los individuos" $" 530$ según sus antecedentes (Kreps, 2008). La teoría situacional ofrece una guía para conocer cómo recibe la audiencia las informaciones. Según esta visión, existen tres diferencias por las que las personas acogen e interiorizan de manera desigual los datos que les llegan: el reconocimiento del problema, la identificación de las dificultades y el nivel de implicación. Existen muy pocos estudios que muestren o extiendan esta teoría en temas relacionados con la salud (Aldoory, 2001). Pavlik (1988), no obstante, ha producido uno de ellos. Este académico encontró que cuanto menores sean las dificultades percibidas, más complejo será el conocimiento acerca de temas cardiacos.

Siguiendo con la teoría situacional del público, Igartua Perosanz (2006) cree que el fracaso de muchas de las campañas de concienciación del SIDA reside en que son meramente informativas o que su contenido emocional se basa demasiado en el miedo, cuando este puede ser saliente para diferentes tipos de personas o de situaciones. Algo similar opinan Edwards, Elwyn y Mulley (2002). Según exponen Castiel y ÁlvarezDardet (2005) de sus palabras, y con el ejemplo de las mamografías:

"Es relevante tener en cuenta que los datos de riesgo relativo son más persuasivos que los de riesgo absoluto; las pérdidas potenciales y los costos de no someterse a determinado screening (como la mamografía) influyen en que éste sea realizado más que por las ganancias y los beneficios; el encuadre positivo (probabilidad de supervivencia) es más efectivo que el encuadre negativo (probabilidad de muerte) para persuadir a los pacientes de que asuman tratamientos arriesgados; la información más inteligible para el paciente está asociada a mayor cautela frente a tratamientos y exámenes". 
$\mathrm{Y}$ es que las personas tienden a ser más receptivas e impulsivas hacia los eventos negativos, por lo que los mensajes de este tipo atraen más la atención que los positivos (Pratto y John, 1991; Smith y Petty, 1996). Por ello, las informaciones para dejar de fumar, por ejemplo, se emiten normalmente desde un prisma adverso, ya que suelen despertar más interés (Jung y Villegas, 2011). Pratto y John (1991) argumentan que esta clase de datos tienden a atraer más esfuerzo de procesamiento que los positivos, mientras que Meyerowitz y Chaiken (1987) encontraron que los avisos perjudiciales sobre el autoexamen de senos son más efectivos que los antagónicos.

No obstante, hay casos en los que puede ser más recomendable usar datos de índole positiva. Por ejemplo, aunque en situaciones con un nivel alto de implicación los anuncios nocivos reciben considerablemente más peso (Kanouse, 1984; Weinberger, Allen y Dillon, 1981; Wright, 1974), en escenarios de baja complicidad pueden llegar a tener el efecto contrario. Esto sucede, al menos, en informaciones para dejar de fumar (Wong y McMurray, 2002). Siguiendo con este tema, Jung y Villegas (2011) comprueban a través de un estudio con universitarios que los mensajes negativos son más eficaces en la gente fumadora, al igual que los anuncios positivos son más exitosos para los no fumadores. De la misma manera, hallan que los datos adversos influyen más en los individuos con una gran dependencia a la nicotina de los que no y viceversa.

Igartua Perosanz (2006) opina que la clave de una campaña de comunicación es crear procesamientos cognitivos en la audiencia (que suele ser pasiva) y para ello se necesita, al menos, que las personas presten atención durante la recepción del mensaje. A la gente con alta implicación se les debe enviar avisos racionales, y a los de baja complicidad se les ha de despachar anuncios emocionales, aunque, en cualquier caso, se ha de examinar la audiencia y comprender sus características particulares. Además, considera que se ha de mezclar la educación con el entretenimiento por la capacidad que tienen los humanos para contar historias, aprender por observación y crear fuertes sentimientos emocionales con las series de ficción.

Dejando a un lado la teoría situacional, según indican del Pozo y Ferreras (2011: 111-112), existen respuestas adecuadas a las características de cada interesado, como son su nivel de formación y de comprensión, su sexo y edad, el nivel de riesgo de su conducta, e incluso su lenguaje, sus preferencias estéticas, etc. Para lograr esto, algunos centros cuentan con programas informáticos que facilitan el suministro de datos según las peculiaridades del usuario. Kreps (2008) proporciona el caso de un sistema informativo que recoge los antecedentes de los consumidores en unas variables claves de comunicación:

"De esta manera, se selecciona automáticamente y se proporciona información a medida sobre riesgos $\mathrm{y}$ recomendaciones según cada consumidor en concreto, como, por ejemplo, un japonesa de avanzada edad con antecedentes de 
cáncer de pecho y diabetes. A medida que el consumidor interactúa con el sistema de información de salud a medida, dota al sistema de información adicional sobre sus antecedentes y el programa de ordenador es capaz de refinar continuamente las respuestas que envía a ese consumidor para que coincida con sus características e intereses únicos" ${ }^{\$ 331}$.

Un buen ejemplo de la importancia de personalizar las campañas de comunicación según la audiencia lo proporcionan Springston y Champion (2004). Estos investigadores realizan un estudio para determinar si los folletos diseñados para un grupo en concreto (en este caso, mujeres negras norteamericanas) tienen una mayor influencia en el conocimiento y las creencias de una enfermedad (concretamente, el cáncer de mama). Para ello, llevan a cabo dos etapas. La primera consiste en conducir entrevistas y grupos de enfoque acerca de qué elementos y diseño deben reflejar los folletos para que se vinculen más con la mentalidad de las mujeres negras. En una segunda fase, hacen un pre-test a 100 féminas para hallar su conocimiento sobre esta patología. Posteriormente, se les enseña el folleto planteado y a continuación se les realiza un post-test. Así, observan que cuando se opta por panfletos adaptados a cada grupo de la población, se reduce la ansiedad, se aprecian menos barreras y más beneficios para realizarse una mamografía, se elimina la apreciación de la fatalidad del cáncer y, en general, se obtiene un mayor conocimiento acerca de la enfermedad. Asimismo, las mujeres encuestadas valoran con un 3,7 sobre 5 el folleto y aseguran que es mejor que los que habían visto anteriormente, ya que los de antes no estaban concebidos para la población negra en concreto.

Existen otros estudios que muestran la necesidad de personalizar los datos según se dirijan a unos grupos u otros, como el de Al Khaja y Creedon (2010). El vocabulario y expresiones que se emplean en cada mensaje también tienen que adecuarse al público al que se dirigen, así como los canales. Sobre el caso concreto de información nutricional, Dutta-Bergman (2004) opina que para llegar a las personas que comen saludablemente, se pueden emplear periódicos, revistas y telediarios en televisión, mientras que para los individuos que no comen saludablemente se debe recurrir a contextos de entretenimiento (tales como comedias o internet) y no a través de facultativos. Además, en este último caso, se han de introducir factores sensoriales y afectivos. "Un modelo rígido y con un único enfoque de relaciones con los medios no es adecuado para los encargados de la información pública que trabajan en el actual entorno mediático sobre la salud" ${ }^{332}$, puntualizan Lariscy, Avery y Sohn (2010).

Según Castiel y Álvarez-Dardet (2005), la solución vendría impuesta a través de una base normativa. A modo de ejemplo, expone el caso "Pautas para la comunicación sobre ciencia y salud" 533 , promovido por el Social Issues Research Centre y The Royal Society (2001). Otra solución sería que los divulgadores, antes de redactar una noticia 
(sobre todo con connotaciones negativas), se imaginen que la va a leer una persona cercana y vulnerable que no posee más información sobre ese asunto y que de ella tiene que actuar acordemente (Castiel y Álvarez-Dardet, 2005). Mismamente en la introducción de "Pautas para la comunicación sobre ciencia y salud", dicen estos académicos, se resalta la trascendencia en la divulgación de los temas sanitarios, dado que la "información engañosa es potencialmente peligrosa: puede hasta costar vidas" (Atlan y Bousquet, 1994).

Otra muestra de la importancia de personalizar y de utilizar un lenguaje comprensible la aporta Aldoory (2001), que lleva a cabo una serie de grupos focales y entrevistas de profundidad a 50 mujeres. La autora llega a la conclusión de que las féminas prestan más atención a los mensajes que reflejan su vida personal, a los que tienen más sentido y utilizan un estilo asequible, a aquellos que hacen referencia a rituales y prácticas diarias, a los que aparecen en sus medios preferidos y a aquellos que hacen referencia a un problema de salud que ya se ha experimentado con anterioridad. Además, las chicas con una fuerte identidad particular (como lesbianas o afroamericanas) se fijan más en los avisos que se dirigen especialmente a su grupo y rehúyen aquellos que aparecen en los medios de comunicación generalistas.

Los productos comunicativos, por tanto, "deben ser diseñados cuidadosamente para que sean efectivos" $" 534$ (Kreps, 2008). Estos "deben perfilarse para que apelen a las creencias, actitudes y valores fundamentales de los miembros de la audiencia objetiva, utilizando un lenguaje familiar y común, así como imágenes y ejemplos para ilustrar los puntos clave" ${ }^{, 535}$, dice Kreps (1990).

Un modo de asegurarse de que los mensajes están bien compuestos y son fácilmente comprensibles es realizar un pre-test a algunas personas representativas de cada audiencia (Maibach y Parrott, 1995). Se trata, además, de una estrategia que incrementa la participación de las personas en los esfuerzos sobre educación para la salud. Como Kreps (2008) resume de Maibach y Parrott (1995) y de Minkler y Wallerstein (2002): "Involucrar a los consumidores, a sus familiares, a los miembros clave de sus redes sociales y a los representantes de la comunidad puede aumentar el apoyo y el estímulo social y así conseguir que presten atención, acepten y utilicen los mensajes de educación sanitaria",536.

En el caso de personas extranjeras o iletradas, la personalización de las acciones comunicativas es inevitable, por ejemplo, a través de imágenes o de ilustraciones. Estas maniobras pueden reforzar el contenido del anuncio, "especialmente para audiencias con un limitado conocimiento sobre salud y con problemas de aritmética que pueden restringir su comprensión sobre las estadísticas y las estimaciones de riesgos elaboradas con números"537, dice Kreps (2008) de Maibach y Parrott (1995), Dowse y Ehlers (2005), Hwang et al. (2005) y Knapp et al. (2005). 


\subsection{ACCIONES DE REFUERZO}

J. E. Grunig e Ipes (1983) señalan que las campañas de información, por sí solas, no modifican el comportamiento de la gente, sino que se necesita apoyo. A través de un estudio, observan que no hay diferencias significativas en el reconocimiento del problema, el grado de involucración y el reconocimiento de las restricciones antes y después de una campaña de comunicación. De hecho, este último factor es el que menos cambia, y se relaciona con la edad y con la lectura de un periódico, más concretamente The Washington Post. También encuentran que no se suscita una futura búsqueda de información en el público ni un procesamiento cognitivo de los datos. De hecho, la audiencia hace muy poco uso de los avisos que recibe y la mayoría de las informaciones sobre el problema y las soluciones que proponen proceden de los medios de comunicación (agenda-setting). Se observa que todos los sujetos tienen una fuerte actitud hacia el tema del alcohol al volante y que forman sus opiniones a partir de estas actitudes, aunque el comportamiento casi no varía. En conclusión, los autores afirman que una campaña de comunicación puede aumentar el conocimiento y la comprensión de un asunto, pero para que surta efecto en los comportamientos se deben usar también acciones de refuerzo/ejecución y apoyo.

También es aconsejable planear "estrategias de múltiples mensajes" "538 bajo el principio comunicativo de "la repetición y el refuerzo para mejorar la exposición y el impacto del mensaje" ${ }^{539}$ (Donohew, Lorch y Palmgreen, 1998). Como Kreps (2008) explica, usar "varios mensajes puede ayudar a captar la atención del público, a reforzar el contenido del mensaje y a ilustrar los conceptos clave de educación sanitaria",540.

\subsubsection{EVALUACIÓN}

La efectividad de las campañas de relaciones públicas se mide a través de la investigación evaluativa. Si esta etapa no se completa, no hay forma de determinar si los esfuerzos fueron exitosos o no. Además, como establecen Springston y Weaver Lariscy (2005), "el continuo crecimiento de la industria de las relaciones públicas depende, al menos en parte, de su capacidad para demostrar los resultados de sus iniciativas"

Valorar las acciones comunicativas es una de las fases más importantes de esta práctica. Aparte de ser la última etapa de cualquier programa de relaciones públicas (Crifasi, 2000; Cutlip y Center, 1964; Guth y Marsh, 2000; Hainsworth y Wilson, 1992; Hendrix, Hayes y Kumar, 2012; Kendall, 1977; Marston, 1963; Wilcox, Ault y Agee, 1986) -el ámbito sanitario incluido (Balima, 2006)-, es el cuarto paso en los procesos de resolución de problemas (Ristino, 2007) y el noveno en el modelo de planificación estratégica en la comunicación integral [Integrated Strategic Communications planning model (ISC) (Ristino, 2007)]. 
La investigación evaluativa en el ámbito médico, cuando se extiende a lo largo del tiempo, "puede ayudar a medir el éxito de las mejoras de los servicios, el impacto de las nuevas ofertas y los resultados de los esfuerzos de marketing o promoción" 542 (Hogan, Hershey y Ritchey, 2007). Además de esto, esta táctica conlleva beneficios adicionales. Por ejemplo, si toma forma de encuestas a los usuarios de un hospital, se creará "la creencia intangible de que el paciente es valorado bajo la premisa de que "me están preguntando qué pienso sobre mi tratamiento" 543 (Hogan, Hershey y Ritchey, 2007).

Quizás debido a estas ganancias, algunos autores indican que "nunca ha sido tan grande como lo es ahora el énfasis en la medición de la efectividad en los organismos de salud pública"544 (Wise, 2001). En efecto, parece que ha habido un progreso en la comprobación de los efectos en el terreno de la salud (Wise, 2003) y que la monitorización del rendimiento, dice el IOM (1997), “está ganando cada vez más importancia como herramienta para la gestión de los procesos y la mejora de sus resultados"545. Hay que recordar, no obstante, que esto sucede en gran medida en el ámbito anglosajón, dejando la investigación evaluativa en el contexto latinoamericano y español como algo residual (Freimuth, Massett y Meltzer, 2006).

Existen datos que corroboran esta última afirmación, pero no únicamente en los países de habla española. Gordon y Kelly (1999), por ejemplo, realizaron un estudio de los responsables de los departamentos de relaciones públicas de los hospitales de Estados Unidos y no encontraron demasiada indagación valorativa. De las ocho frases propuestas para analizar la adopción del rol técnico y directivo, "realizar investigación evaluativa"546 (que pertenece al segundo rol) obtuvo la peor puntuación. Fabiszak (1985) también encontró que los responsables de relaciones públicas de los hospitales no realizan investigación ni evaluativa ni formativa. Bosilkovski (2011), en una indagación más reciente, detecta que realizar investigación evaluativa es la actividad menos frecuente en los hospitales estadounidenses. En España, la situación es muy similar: Díaz y Cuesta (2014), por ejemplo, demostraron que las organizaciones no lucrativas del ámbito de la salud en este territorio no usan evaluación.

$\mathrm{Y}$ es que estos esfuerzos no son siempre una tarea sencilla. Uno de los problemas cuando se intenta medir la calidad de un centro de atención especializada y la satisfacción de sus pacientes es que estos suelen estar en desacuerdo con el personal médico en cuanto a los parámetros de estas variables; según el estudio de Kaya et al. (2003), esto sucede en 41 de los 60 puntos que analizaron. Baker y Taylor (1997) añaden que la satisfacción depende más de las actividades medibles que de las percepciones de la calidad.

Según el modelo de evaluación del servicio (service evaluation model), creado bajo la inspiración de la pirámide jerárquica de Maslow (Kirdar, 2007), existen varios niveles a la hora de conocer la satisfacción de las personas con su centro sanitario. Recordando lo que menciona este último autor sobre esta visión: 
"Existe una correlación positiva entre las expectativas y la calidad del hospital, y la calidad aumenta a medida que las expectativas crecen. Cumplir con la base de la pirámide [es decir, simplemente hacer el trabajo (por ejemplo, un examen médico)], significa que no hay satisfacción de los pacientes, y esto implica una atención débil y regular. El segundo nivel, que supone hacer el trabajo en sí y cumplir las expectativas del paciente, se considera como nivel medio de calidad. El tercer nivel [que conlleva la satisfacción de las expectativas en un nivel alto (por ejemplo, informar, escuchar, comprender a los pacientes, etc.)] supone, según los pacientes, una satisfacción psico-social, y esto significa ofrecer un servicio de calidad a un buen nivel. La categoría superior es cumplir con las expectativas y ofrecer alta calidad" ${ }^{, 547}$.

Independientemente de las herramientas de evaluación que se empleen, estas deben servir para conocer la efectividad global de la organización en vez del éxito individual de cada programa. Como dicen Levins y Rodgers (1998), en el actual "entorno competitivo y fragmentado sobre información sanitaria, esas mediciones por sí solas no muestran el verdadero valor de una campaña de relaciones públicas estratégicamente planeada y ejecutada" $" 548$. Por ello, "la complejidad del entorno de la salud pública exige responsabilidad a nivel institucional, por encima y más allá de los criterios de medición de mensajes o campañas específicas"549 (Springston y Weaver Lariscy, 2005). También se debe, antes de poner en práctica cualquiera de las herramientas de evaluación, establecer los estándares de medición, así como definir los mecanismos donde se aplicarán los resultados (Kreps, 2008).

Díaz y Cuesta (2014), por ejemplo, proponen una matriz de análisis "para abordar de forma integral la gestión de la comunicación de las ONL [Organizaciones No Lucrativas] del ámbito de la salud". Para crearla, se inspiran en la nueva teoría de la estrategia de Pérez y Massoni (2008), Jaramillo (2011) y Pérez (2012), de las relaciones públicas de J. E. Grunig $(1984 ; 2011)$ y Wilcox et al. (2011) y de la teoría de la reputación de Villafañe $(2003,2013)$. Así, la articulan en torno a cuatro variables: estratégicas, estructurales, de proceso y tácticas: 
Tabla 3. Matriz de análisis de la gestión de la comunicación de las ONL del ámbito de la salud

\begin{tabular}{|c|c|}
\hline Categoría & Variables \\
\hline $\begin{array}{l}\text { Variables } \\
\text { estratégicas }\end{array}$ & $\begin{array}{l}\text { V1. Planteamiento estratégico de visión, misión y valores. } \\
\text { V2. Identificación de grupos de interés. } \\
\text { V3. Concepción de comunicación. } \\
\text { V4. Objetivos de comunicación. } \\
\text { V5. Articulación entre "lo estratégico" y estrategias de } \\
\text { comunicación. }\end{array}$ \\
\hline $\begin{array}{l}\text { Variables } \\
\text { estructurales }\end{array}$ & $\begin{array}{l}\text { V6. Lugar en el organigrama. } \\
\text { V7. Denominación del área. } \\
\text { V8. Funciones asignadas. } \\
\text { V9. Carácter integral de la comunicación. } \\
\text { V11. Recursos financieros. }\end{array}$ \\
\hline $\begin{array}{l}\text { Variables de } \\
\text { proceso }\end{array}$ & $\begin{array}{l}\text { V12. Diagnóstico comunicacional. } \\
\text { V13. Planificación de la comunicación. } \\
\text { V14. Ejecución de la comunicación. } \\
\text { V15. Evaluación de la comunicación. }\end{array}$ \\
\hline $\begin{array}{l}\text { Variables } \\
\text { tácticas }\end{array}$ & $\begin{array}{l}\text { V16. Productos de comunicación. } \\
\text { V17. Comunicación en medios masivos. } \\
\text { V18. Eventos. } \\
\text { V19. Comunicación } 2.0 \text {. }\end{array}$ \\
\hline
\end{tabular}

Fuente: Díaz y Cuesta (2014).

Gombeski et al. (2010) consideran que tienen que usarse diferentes herramientas de evaluación dependiendo del tamaño de la entidad, dado que son conscientes de que los presupuestos y posibilidades de empresas grandes no se pueden comparar con las pequeñas, aunque recuerdan que es aconsejable que todas las compañías, independientemente de su situación, lleven a cabo algún tipo de estimación. Sobre las entidades pequeñas sin ánimo de lucro, Wise (2007) explica:

"Una organización sin ánimo de lucro con un presupuesto relativamente pequeño quizás solo pueda aplicar un programa modesto destinado a un único público y midiendo solamente la confianza y la satisfacción, por ejemplo. Además, es probable que ese esfuerzo se realice una vez al año. El plan puede ser implementado sin la aportación de marketing, ya que algunas instituciones sin ánimo de lucro no disponen de estos departamentos" ${ }^{550}$.

Dado que las empresas grandes suelen tener más recursos destinados a las relaciones públicas, las actividades que pueden ejecutar para medir su eficacia aumentan. En estos casos, Wise (2007) expone: 
"Una gran institución con ánimo de lucro, sin embargo, puede tener a varias personas trabajando para los departamentos de marketing y relaciones públicas, así como contar con presupuestos sustanciales. En ese caso, los profesionales de relaciones públicas pueden trabajar con sus homólogos de marketing para supervisar las relaciones con los diversos públicos, incluyendo clientes, proveedores, empleados, reguladores, funcionarios electos y líderes de la comunidad. Además podrán utilizar una medición multidimensional, como por ejemplo la escala de Bruning y Galloway (2003), para calcular la relación de la organización con sus audiencias. Los líderes de la organización pueden decidir medir las relaciones con los públicos que se consideran más importantes más de una vez al año, ya que, tal y como señaló Ledingham (2003), las relaciones cambian con el tiempo",551.

Existen numerosas maneras para medir el éxito de las actividades comunicativas, las cuales pueden ser informales, formales o mixtas (Dozier, L. A. Grunig y J. E. Grunig, 1995: 43-44). El Bloomington Hospital, por ejemplo, pregunta a los usuarios que llaman por teléfono dónde han oído hablar acerca de ellos (Shelton, 1993). También utilizan encuestas a los pacientes para conocer los medios más recurrentes y acuden a bases de datos para averiguar la cuota de mercado que han ganado. Según Hogan, Hershey y Ritchey (2007), los proveedores de salud utilizan cada vez más las encuestas para identificar los asuntos que preocupan a los usuarios y aprovechan sus resultados para suministrar respuestas.

Al margen de esta táctica, otras herramientas, como los grupos focales, las líneas de teléfono gratuitas o los servicios de asistencia, pueden usarse para seguir y evaluar la comprensión del consumidor hacia temas sanitarios (Kreps, 2008). La efectividad a nivel institucional puede ser calculada a través de investigaciones publicadas, grupos focales, análisis de contenido de la cobertura en prensa y encuestas a varios grupos, tales como los consumidores, los grupos clave de la zona, los líderes de la comunidad (Springston y Weaver Lariscy, 2005) y los asesores de consumidores (Gombeski et al., 2010). 


\title{
1.3. FUNCIONAMIENTO Y SITUACIÓN DEL SISTEMA SANITARIO ESPAÑOL
}

\author{
1.3.1. Legislación en torno a la sanidad \\ 1.3.2. Tipos de modelos sanitarios \\ 1.3.3. Organización del sistema nacional de salud \\ 1.3.4. Los hospitales
}

\subsubsection{LEGISLACIÓN EN TORNO A LA SANIDAD}

La sanidad es un tema constante de preocupación, reformas y, en algunos casos, incluso de controversias. La salud y la asistencia médica es, no obstante, un derecho reconocido mundialmente mediante la Declaración Universal de Derechos Humanos (Naciones Unidas, 1948). Este texto, en el apartado primero del artículo 25, indica:

"Toda persona tiene derecho a un nivel de vida adecuado que le asegure, así como a su familia, la salud y el bienestar, y en especial la alimentación, el vestido, la vivienda, la asistencia médica y los servicios sociales necesarios; tiene asimismo derecho a los seguros en caso de desempleo, enfermedad, invalidez, viudez, vejez u otros casos de pérdida de sus medios de subsistencia por circunstancias independientes de su voluntad".

Dentro del territorio español, la Constitución Española (España, 1978a) es la encargada de dotar de valor estas cuestiones. En el artículo 43 reconoce a los ciudadanos el "derecho a la protección de la salud" e indica que es competencia de "los poderes públicos organizar y tutelar la salud pública a través de medidas preventivas y de las prestaciones y servicios necesarios", así como fomentar "la educación sanitaria, la educación física y el deporte”. La ley, incide la Constitución, “establecerá los derechos y deberes de todos al respecto". 
En un comienzo, el Gobierno central era el encargado de gestionar el conjunto de políticas sanitarias del país, pero, con la entrada en vigor de la Constitución Española y su nueva organización del territorio nacional, las autonomías pasan a asumir ciertas competencias en materia sanitaria. Tras la reforma sobre la gestión institucional de la Seguridad Social, la salud y el empleo (España, 1978b), desaparece el Instituto Nacional de Previsión y se crea una nueva unidad gestora de la Seguridad Social encargada de administrar y gestionar los servicios sanitarios: el Instituto Nacional de la Salud (INSALUD). Paulatinamente, este órgano va traspasando las competencias a las comunidades autónomas, iniciándose en 1981 en Cataluña y acabando en 2002 con otras diez regiones.

Tabla 4. Reales decretos de traspaso de competencias sanitarias a las comunidades autónomas

\begin{tabular}{|l|l|}
\hline Comunidad autónoma & \multicolumn{1}{|c|}{ Real Decreto } \\
\hline Cataluña & $1517 / 1981$ de 8 de julio \\
\hline Andalucía & $400 / 1984$, de 22 de febrero \\
\hline País Vasco & $1536 / 1987$, de 6 de noviembre \\
\hline Comunidad Valenciana & $1612 / 1987$, de 27 de noviembre \\
\hline Galicia & $1679 / 1990$, de 28 de diciembre \\
\hline Navarra & $1680 / 1990$, de 28 de diciembre \\
\hline Canarias & $446 / 1994$, de 11 de marzo \\
\hline Asturias & $1471 / 2001$, de 27 de diciembre \\
\hline Cantabria & $1472 / 2001$, de 27 de diciembre \\
\hline La Rioja & $1473 / 2001$, de 27 de diciembre \\
\hline Murcia & $1474 / 2001$, de 27 de diciembre \\
\hline Aragón & $1475 / 2001$, de 27 de diciembre \\
\hline Castilla-La Mancha & $1476 / 2001$, de 27 de diciembre \\
\hline Extremadura & $1477 / 2001$, de 27 de diciembre \\
\hline Baleares & $1478 / 2001$, de 27 de diciembre \\
\hline Madrid & $1479 / 2001$, de 27 de diciembre \\
\hline Castilla y León & $1480 / 2001$, de 27 de diciembre \\
\hline
\end{tabular}

Fuente: Sistema de información sanitaria del Instituto de Información Sanitaria (2008).

Una vez acabado el traspaso de funciones a las distintas comunidades, el INSALUD fue reorganizado en el Instituto Nacional de Gestión Sanitaria (INGESA), "una entidad de menor dimensión, pero conservando la misma personalidad jurídica y naturaleza de entidad gestora de la Seguridad Social y las funciones de gestión de los derechos y obligaciones del INSALUD” (España, 2002). Esta unidad es la que gestiona en la actualidad la sanidad en las ciudades autónomas de Ceuta y Melilla (Ministerio de Sanidad, 2012). 
En 1984, el Real Decreto 137/1984, de 11 de enero, sobre estructuras básicas de salud da "un impulso muy importante" a la atención primaria (Cuadrado, 2007). Establece los principios normativos generales para la creación y puesta en funcionamiento de las zonas de salud, cuya estructura perdura en la actualidad, con el fin de atribuirles funciones de "promoción, prevención, asistencia y rehabilitación" individual y colectiva. Estos marcos territoriales de atención primaria quedan definidos en el mencionado texto jurídico como "la demarcación poblacional y geográfica fundamental; delimitada a una determinada población, siendo accesible desde todos los puntos y capaz de proporcionar una atención de salud continuada, integral y permanente con el fin de coordinar las funciones sanitarias afines".

Las comunidades autónomas son las encargadas de delimitar dichas zonas en función de "criterios demográficos, geográficos y sociales", cubriendo, salvo excepciones, de 5.000 a 25.000 personas, tanto en el medio rural como en el urbano. Las estructuras básicas de salud, a partir de este Real Decreto, quedan definidas de la siguiente manera:

Marco territorial: zona de salud.

Estructura física y funcional: centro de salud.

Estructura humana: equipo de atención primaria.

Ese mismo año se aprueba la Ley 53/1984, de incompatibilidades del personal al servicio de las administraciones públicas (España, 1984a), que "obligó a las distintas administraciones públicas sanitarias a proceder a la reordenación de las áreas afectadas por el nuevo sistema, facilitando innovaciones y la apertura del sistema a nuevas prestaciones" en un sistema en el que, hasta ese momento, "el pluriempleo, los cuartos y los medios de jornada e, incluso, los solapamientos horarios constituían una plaga endémica" (Rubia Vila, 2011).

\subsubsection{TIPOS DE MODELOS SANITARIOS}

\subsubsection{EL MODELO DE SEGURO SOCIAL OBLIGATORIO (SSO)}

Hasta esos momentos, el sistema sanitario español había respondido al modelo de Seguro Social Obligatorio (SSO), lo que implicaba que "la cobertura no se reconoce de forma automática a todos los residentes del país, sino que se vincula al empleo" (Perpiñán, 2013: 251). De acuerdo con esta fórmula, "se asegura inicialmente contra el riesgo de enfermar a los trabajadores y sus familias, y la asistencia sanitaria provista se 
financia habitualmente mediante cotizaciones detraídas de los salarios" (Perpiñán, 2013: 251).

Por ejemplo, la Ley de 14 de diciembre de 1942 por la que se crea el seguro obligatorio de enfermedad (España) otorgaba asistencia sanitaria en caso de enfermedad y maternidad y la indemnización para gastos funerarios a los trabajadores por cuenta propia o ajena y a sus familiares, entendiendo a estos "los cónyuges, ascendientes, descendientes y hermanos menores de dieciocho años o incapacitados de una manera permanente para el trabajo". Así, en 1953, únicamente el 30\% de la población estaba amparada por este seguro (Rubia Vila, 2011).

También mantiene esta visión el Texto refundido de la Ley general de la Seguridad Social (España, 1974), que, a pesar de ampliar la asistencia sanitaria respecto a la ley de 1942 a "los servicios médicos y farmacéuticos conducentes a conservar o restablecer la salud" y "la rehabilitación física para la recuperación profesional" por razones de "enfermedad común o profesional, las lesiones derivadas de accidente, cualquiera que sea su causa, así como el embarazo, el parto y el puerperio", sigue teniendo como beneficiarios a los afiliados a la Seguridad Social, los pensionistas o personas que reciban una prestación del mismo órgano y "los familiares o asimilados que estén a cargo de las personas indicadas".

\subsubsection{EL MODELO DE SNS: HACIA UNA SANIDAD UNIVERSAL}

Con la entrada en vigor de la Ley General de Sanidad en 1986, no obstante, "se inicia la transición del modelo de SSO hacia un modelo de SNS [Servicio o Sistema

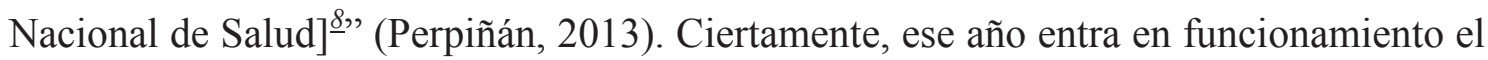
Sistema Nacional de Salud que se mantiene hasta la actualidad, definido como "el conjunto coordinado de los servicios de salud de la Administración del Estado y los servicios de salud de las comunidades autónomas que integra todas las funciones y prestaciones sanitarias que, de acuerdo con la ley, son responsabilidad de los poderes públicos" (Ministerio de Sanidad, 2012).

Con la creación de este sistema, se "presta asistencia sanitaria gratuita a todos los ciudadanos por el mero hecho de serlo" (Perpiñán, 2013: 253), en vez de por su afiliación a la Seguridad Social, como sucedía anteriormente. Efectivamente, la Ley General de Sanidad (España, 1986) establece que tienen derecho "a la protección de la salud y a la atención sanitaria todos los españoles y los ciudadanos extranjeros que tengan establecida su residencia en el territorio nacional". Por su parte, indica este texto jurídico, los extranjeros no residentes y los españoles que se encuentran fuera del país

\footnotetext{
${ }^{8}$ El contenido del corchete es propio y no se corresponde con el autor de la cita.
} 
"tendrán garantizado el derecho en la forma que las leyes y convenios internacionales establezcan".

Esta ley pretende garantizar la asistencia sanitaria pública "a toda la población española [...] en condiciones de igualdad efectiva". Además, se refleja en su contenido, "la política de salud estará orientada a la superación de los desequilibrios territoriales y sociales" y se "adecuará su organización y funcionamiento a los principios de eficacia, celeridad, economía y flexibilidad". En cuanto a la utilización de los servicios sanitarios “serán iguales para todos, independientemente de la condición en que se acceda a los mismos".

Este sistema de salud se financia "con ingresos generales (impuestos)" (Perpiñán, 2013: 253). En los países que mantienen esta fórmula, "la cobertura alcanza de forma automática, por tanto, a la práctica totalidad de la población" (Perpiñán, 2013: 253). Con este modelo, en España, se pasó del 86\% de la población cubierta en 1982 al 97\% en 1987 (Perpiñán, 2013: 255).

Ciertamente, según la Ley General de Sanidad (España, 1986), corresponde al Estado "la sanidad exterior y las relaciones y acuerdos sanitarios internacionales", entendiendo por actividad exterior "todas aquellas que se realicen en materia de vigilancia y control de los posibles riesgos para la salud derivados de la importación, exportación o tránsito de mercancías y del tráfico internacional de viajeros". Las comunidades autónomas, por su parte, ejercen "las competencias asumidas en sus Estatutos y las que el Estado les transfiera o, en su caso, les delegue", así como las "actuaciones previstas en esta Ley que no se hayan reservado expresamente al Estado". Las corporaciones locales participan en los órganos de dirección de las áreas de salud y tienen impuestas ciertas "responsabilidades mínimas", como son el control sanitario del medio ambiente, de industrias, de edificios y lugares de vivencia y convivencia humana, de cementerios, de la distribución y suministros de alimentos y bebidas...

Sería años más tarde, en 2003, con la Ley de cohesión y calidad del Sistema Nacional de Salud cuando se regula la transferencia de poder en materia de sanidad a las comunidades autónomas. Según se lee en el artículo primero de este documento, el objetivo de la ley es "establecer el marco legal para las acciones de coordinación y cooperación de las Administraciones públicas sanitarias, en el ejercicio de sus respectivas competencias, de modo que se garantice la equidad, la calidad y la participación social en el Sistema Nacional de Salud, así como la colaboración activa de éste en la reducción de las desigualdades en salud" (España, 2003a). De esta manera, se regulan "las acciones de coordinación y cooperación" entre las distintas administraciones en las siguientes materias:

a) Las prestaciones sanitarias.

b) La farmacia.

c) Los profesionales. 
d) La investigación.

e) Los sistemas de información.

f) La calidad del sistema sanitario.

g) Los planes integrales.

h) La salud pública.

i) La participación de ciudadanos y profesionales.

El Consejo Interterritorial y la Alta Inspección, muestra el texto, son los encargados del seguimiento de estas acciones. Además, tal y como establece este documento, las prestaciones "son responsabilidad financiera de las comunidades autónomas [...] sin perjuicio de la existencia de un tercero obligado al pago".

En resumen, según el reparto de competencias de la Constitución Española de 1978 (España, 1978a); de la Ley 14/1986, de 25 de abril, Ley General de Sanidad (España, 1986) y la Ley 16/2003 de 28 de mayo, de cohesión y calidad del Sistema Nacional de Salud (España, 2003a), las competencias de cada administración quedan estipuladas de la siguiente forma:

Tabla 5. Funciones en materia sanitaria de las diferentes administraciones

\begin{tabular}{|l|l|}
\hline \multicolumn{1}{|c|}{ Administración } & \multicolumn{1}{c|}{ Funciones } \\
\hline \multirow{4}{*}{ Administración del Estado } & Bases y coordinación de la sanidad \\
\cline { 2 - 2 } & Sanidad exterior \\
\cline { 2 - 2 } & Política del medicamento \\
\cline { 2 - 2 } Comunidades autónomas & Gestión de INGESA \\
\hline \multirow{4}{*}{ Corporaciones locales } & Planificación sanitaria \\
\cline { 2 - 2 } & Salud pública \\
\cline { 2 - 2 } & Gestión de los servicios de salud \\
\hline & $\begin{array}{l}\text { Salubridad } \\
\text { Selaboración en la gestión de los }\end{array}$ \\
\hline
\end{tabular}

Fuente: Sistema Nacional de Salud (Ministerio de Sanidad, 2012).

Otra novedad que aplica la Ley de cohesión y calidad del Sistema Nacional de Salud (España, 2003a) es que se amplía la cobertura sanitaria a los extranjeros que se encuentren en el territorio nacional, tal y como marca el artículo 12 de la Ley Orgánica 4/2000 sobre derechos y libertades de los extranjeros en España y su integración social (España, 2000). Las prestaciones a las que tienen acceso tanto españoles como extranjeros son las propias de "salud pública, atención primaria, atención especializada, atención sociosanitaria, atención de urgencias, la prestación farmacéutica, la ortoprotésica, de productos dietéticos y de transporte sanitario". 
Ese mismo año de 2003 se aprueban dos normas en relación con los trabajadores: el Estatuto Marco del personal estatutario de los servicios de salud (España, 2003c) y la Ley de Ordenación de las Profesiones Sanitarias (España, 2003b). En el primer caso, se establece la clasificación y ordenación del personal estatutario y se detalla la división y los grados de capacitación según el nivel de titulación en formación sanitaria. Se eliminan, así, los anteriores tres documentos que vinculaban a los distintos trabajadores del sistema sanitario: el Estatuto Jurídico del Personal Médico (España, 1966), el Estatuto de Personal Sanitario no Facultativo (España, 1973) y el Estatuto de Personal no Sanitario (España, 1971; VV.AA., 2006). En cuanto al segundo texto legislativo, se determina el ejercicio de la profesión, tanto por cuenta propia como ajena, la estructura general de la formación, el desarrollo profesional, la participación de los trabajadores en la planificación y ordenación de las profesiones sanitarias y los registros de profesionales.

Años más tarde aparecen otras dos leyes que regulan aspectos relativos a la sanidad: los medicamentos y la salud pública. La Ley 29/2006, de 26 de julio, de garantías y uso racional de los medicamentos y productos sanitarios (España, 2006), ciertamente, determina las competencias del Estado en todo lo relativo a los medicamentos de uso humano y veterinarios y los productos sanitarios, como la investigación clínica, la autorización, la fabricación, la distribución, la importación y exportación, la prescripción y dispensación, el procedimiento para la posible financiación con fondos públicos, etc. La Ley General de Salud Pública (2011), por su parte, pretende "establecer las bases para que la población alcance y mantenga el mayor nivel de salud posible" mediante, entre otras acciones, la vigilancia, la promoción, la coordinación y la evaluación de la salud. Además, dice la disposición adicional sexta, "se extiende el derecho al acceso a la asistencia sanitaria pública, a todos los españoles residentes en territorio nacional, a los que no pudiera serles reconocido en aplicación de otras normas del ordenamiento jurídico".

\subsubsection{AÑO 2012: VUELTA A LA CONDICIÓN DE ASEGURADO}

Esta bonanza de prestaciones y beneficiarios alcanza su fin con el Real Decreto-Ley de medidas urgentes para la sostenibilidad del Sistema Nacional de Salud y mejora de la calidad y la seguridad (2012). Los motivos para reducir los servicios que se ofrecen, así como las personas que tienen acceso a ellos, son ampliamente enumerados en las disposiciones generales del documento. Por incluir algunas, se muestran las siguientes líneas:

"La ausencia de normas comunes sobre el aseguramiento en todo el territorio nacional, el crecimiento desigual en las prestaciones del catálogo, la falta de adecuación de algunas de 
ellas a la realidad socioeconómica y la propia falta de rigor y énfasis en la eficiencia del sistema han conducido al Sistema Nacional de Salud a una situación de grave dificultad económica sin precedentes desde su creación. Se ha perdido eficacia en la gestión de los recursos disponibles, lo que se ha traducido en una alta morosidad y en un insostenible déficit en las cuentas públicas sanitarias [...] El Sistema Nacional de Salud viene sufriendo situaciones de descoordinación entre los servicios de salud autonómicos lo que se traduce en la aparición de considerables diferencias en las prestaciones y en los servicios a los que acceden los pacientes en las distintas comunidades autónomas. La cohesión territorial y la equidad se han visto puestas en cuestión con determinadas medidas adoptadas durante estos últimos años".

La primera modificación que añade esta ley son las personas que pueden optar a las prestaciones sanitarias o, como el texto los denomina, los "asegurados":

“a) Ser trabajador por cuenta ajena o por cuenta propia, afiliado a la Seguridad Social y en situación de alta o asimilada a la de alta.

b) Ostentar la condición de pensionista del sistema de la Seguridad Social.

c) Ser perceptor de cualquier otra prestación periódica de la Seguridad Social, incluidas la prestación y el subsidio por desempleo.

d) Haber agotado la prestación o el subsidio por desempleo y figurar inscrito en la oficina correspondiente como demandante de empleo, no acreditando la condición de asegurado por cualquier otro título".

También están "asegurados" el cónyuge "o persona con análoga relación de afectividad, que deberá acreditar la inscripción oficial correspondiente, el ex cónyuge a cargo del asegurado, así como los descendientes a cargo del mismo que sean menores de 26 años o que tengan una discapacidad en grado igual o superior al 65\%". Las personas de nacionalidad española o de algún Estado miembro de la Unión Europea, del Espacio Económico Europeo o de Suiza que residan en España y los extranjeros titulares de una autorización para residir en territorio español que no cumplan ninguno de los anteriores supuestos "podrán ostentar la condición de asegurado siempre que acrediten que no superan el límite de ingresos determinado reglamentariamente". El Instituto Nacional de la Seguridad Social, a través de sus direcciones provinciales, es el encargado de controlar "la condición de asegurado". 
Las personas que no cumplan ninguno de estos requisitos y que quieran tener acceso al sistema sanitario nacional deben pagar una "contraprestación o cuota derivada de la suscripción de un convenio especial". Aun así, detalla el documento, los extranjeros en situación irregular pueden recibir asistencia médica "de urgencia por enfermedad grave o accidente, cualquiera que sea su causa, hasta la situación de alta médica y de asistencia al embarazo, parto y postparto". Los irregulares menores de 18 años "recibirán asistencia sanitaria en las mismas condiciones que los españoles", indica el texto.

Como se ha señalado, otra de las novedades del Real Decreto-Ley de medidas urgentes para la sostenibilidad del Sistema Nacional de Salud y mejora de la calidad y la seguridad (2012) es la disminución de las prestaciones gratuitas a los beneficiarios. La cartera común comprende "las actividades asistenciales de prevención, diagnóstico, tratamiento y rehabilitación que se realicen en centros sanitarios o sociosanitarios, así como el transporte sanitario urgente". Se crea, así, una "cartera suplementaria" para las prestaciones farmacéuticas, las ortoprotésicas, los productos dietéticos y el transporte sanitario no urgente sujeto a prescripción facultativa. Todos ellos eran cubiertos anteriormente sin gasto directo para el ciudadano.

Si la Ley 16/2003, de 28 de mayo, de cohesión y calidad del Sistema Nacional de Salud (España, 2003a) "no dejaba lugar a dudas acerca de su vocación universal, desconectada por entero de la condición de asegurado", ahora, con la reforma del RealDecreto de 2012, esta condición "se invoca" (Perpiñán, 2013: 273). Por todo ello, dice este autor, esta reforma "representa una reinterpretación del derecho a la asistencia sanitaria que mira claramente hacia los orígenes del sistema sanitario español, más próximos, a un modelo de Seguro Social Obligatorio que a uno de Sistema Nacional de Salud" (Perpiñán, 2013: 273).

\subsubsection{ORGANIZACIÓN DEL SISTEMA NACIONAL DE SALUD}

La organización del Sistema Nacional de Salud no depende de la clase de beneficiarios y prestaciones que se ofrecen en cada momento y, en la actualidad, se divide en dos niveles asistenciales, cada uno de ellos con una tecnología y acceso diferente: la atención primaria y la atención especializada (Ministerio de Sanidad, 2012). 


\subsubsection{ATENCIÓN PRIMARIA}

La atención primaria se define como "el nivel básico e inicial de atención, que garantiza la globalidad y continuidad de la atención a lo largo de toda la vida del paciente, actuando como gestor y coordinador de casos y regulador de flujos" (España, 2003a). Es la que tiene lugar en los centros de salud, consultorios locales y, cuando es necesario, en los domicilios de los ciudadanos y a la cual puede acceder cualquier beneficiario de manera espontánea (es decir, no ha de prescribir la consulta un facultativo). Este nivel comprende "actividades de promoción de la salud, educación sanitaria, prevención de la enfermedad, asistencia sanitaria, mantenimiento y recuperación de la salud, así como la rehabilitación física y el trabajo social" (España, 2003a).

La Ley 16/2003, de 28 de mayo, de cohesión y calidad del Sistema Nacional de Salud (España, 2003a) incluye dentro de este nivel las siguientes actividades:

“a) La asistencia sanitaria a demanda, programada y urgente tanto en la consulta como en el domicilio del enfermo.

b) La indicación o prescripción y la realización, en su caso, de procedimientos diagnósticos y terapéuticos.

c) Las actividades en materia de prevención, promoción de la salud, atención familiar y atención comunitaria.

d) Las actividades de información y vigilancia en la protección de la salud.

e) La rehabilitación básica.

f) Las atenciones y servicios específicos relativos a la mujer, la infancia, la adolescencia, los adultos, la tercera edad, los grupos de riesgo y los enfermos crónicos.

g) La atención paliativa a enfermos terminales.

h) La atención a la salud mental, en coordinación con los servicios de atención especializada.

i) La atención a la salud bucodental".

\subsubsection{ATENCIÓN ESPECIALIZADA}

Si el tratamiento que requiere el paciente necesita una exploración mayor o un internamiento en un centro especializado se accede a la atención especializada. Es el nivel que comprende "actividades asistenciales, diagnósticas, terapéuticas y de rehabilitación y cuidados, así como aquéllas de promoción de la salud, educación sanitaria y prevención de la enfermedad, cuya naturaleza aconseja que se realicen en este nivel". Se realiza en los hospitales y en los centros especializados. Los servicios 
que comprende este nivel, de acuerdo con la Ley 16/2003, de 28 de mayo, de cohesión y calidad del Sistema Nacional de Salud (España, 2003a) son:

“a) La asistencia especializada en consultas.

b) La asistencia especializada en hospital de día, médico y quirúrgico.

c) La hospitalización en régimen de internamiento.

d) El apoyo a la atención primaria en el alta hospitalaria precoz y, en su caso, la hospitalización a domicilio.

e) La indicación o prescripción, y la realización, en su caso, de procedimientos diagnósticos y terapéuticos.

f) La atención paliativa a enfermos terminales.

g) La atención a la salud mental.

h) La rehabilitación en pacientes con déficit funcional recuperable".

A continuación se muestra un resumen de las características de los dos niveles asistenciales que existen en España actualmente:

Tabla 6. Características de la atención primaria y de la atención especializada en España

\begin{tabular}{|c|c|c|}
\hline Características & Atención primaria & Atención especializada \\
\hline General & Accesibilidad & Complejidad técnica \\
\hline Actividades & $\begin{array}{l}\text { Promoción de la salud y de } \\
\text { prevención de la enfermedad } \\
\text { con capacidad de resolución } \\
\text { técnica para abordar de forma } \\
\text { completa los problemas de } \\
\text { salud más frecuentes }\end{array}$ & $\begin{array}{l}\text { Cuenta con los medios } \\
\text { diagnósticos y terapéuticos de } \\
\text { mayor complejidad y coste } \\
\text { cuya eficiencia aumenta si se } \\
\text { concentran }\end{array}$ \\
\hline Acceso & Espontánea & $\begin{array}{l}\text { Por indicación } \\
\text { facultativos de los } \\
\text { primaria }\end{array}$ \\
\hline $\begin{array}{l}\text { Dispositivo } \\
\text { asistencial }\end{array}$ & $\begin{array}{l}\text { Centros de salud } \quad \mathrm{y} \\
\text { consultorios locales }\end{array}$ & $\begin{array}{l}\text { Centros de especialidades y } \\
\text { hospitales }\end{array}$ \\
\hline $\begin{array}{l}\text { Régimen } \\
\text { atención }\end{array}$ & $\begin{array}{l}\text { En el centro y en el domicilio } \\
\text { del ciudadano }\end{array}$ & $\begin{array}{l}\text { De manera ambulatoria o con } \\
\text { internamiento }\end{array}$ \\
\hline
\end{tabular}

Fuente: Sistema Nacional de Salud (Ministerio de Sanidad, 2012). 


\subsubsection{LOS HOSPITALES}

Los hospitales se enmarcan dentro de la estructura de la atención especializada. A pesar de que la traducción exacta de la palabra hospital en latín es valetudinarium (Segura Munguí-a, 2001: 923, vol. 1; Vicente García, 2005: 641), que significa “enfermería, hospital” (Segura Munguí-a, 2001: 819, vol. 1; Vicente García, 2005: 641), el origen de hospital proviene de hospitāl(em), el cual es traducido por el Diccionario médico-biológico, histórico y etimológico de la Universidad de Salamanca (2011), reflejando las diferentes modificaciones de significado, como: "Leng. base: lat. Antigua con cambio de significado. Docum. en 1227 en esp. En lat. significa 'propio del huésped' pero hospitāle o hospitalia también 'habitación para un huésped'. En lat. mediev. es 'hospedería' y más tarde 'asilo para necesitados', sólo a partir del s. XVI se va acercando al significado actual; otra forma derivada de la misma palabra latina que llega al esp. del fr. es hotel; docum. en esp. desde 1219 como 'hospedería"'.

La Organización Mundial de la Salud (OMS) (2014) considera los hospitales como un "componente importante del sistema de atención de salud". Se trata de "instituciones sanitarias que disponen de personal médico y otros profesionales organizados y de instalaciones para el ingreso de pacientes, y que ofrecen servicios médicos y de enfermería y otros servicios relacionados durante las 24 horas del día, los 7 días de la semana" (Organización Mundial de la Salud, 2014). Estos centros especializados ofrecen cuidados en numerosos servicios "de atención aguda, de convalecencia y de cuidados paliativos, con los medios diagnósticos y terapéuticos necesarios para responder a manifestaciones agudas y crónicas debidas a enfermedades, así como a traumatismos o anomalías genéticas. De ese modo generan información esencial para las investigaciones, la educación y la gestión" (Organización Mundial de la Salud, 2014).

Moya de Madrigal (1989: 92), por su parte, define el hospital como "un establecimiento de salud con camas para alojar personas que padecen o se supone que padecen enfermedades y traumatismos, o mujeres que van a dar luz; y que puede darles atención médica completa (observación, diagnóstico, tratamiento y rehabilitación) de larga o corta duración. Un hospital también puede tener servicios de atención ambulatoria (urgencias y consulta externa)".

La Gran Enciclopedia Planeta (2009: 5.365-5.366) ofrece una de las definiciones más completas. Según esta publicación, un hospital es un "establecimiento de carácter público o privado destinado a proporcionar a la población una asistencia medicosanitaria completa, tanto curativa como preventiva y que, a menudo, es también un centro de formación de personal sanitario y de investigación". En la entrada dedicada a la medicina, esta enciclopedia explica: "Los hospitales son instituciones complejas, con una plantilla médica y de enfermería organizadas. Poseen instalaciones permanentes, con variedad de servicios médicos. También incluyen instalaciones para atender las 
urgencias, a los recién nacidos y a los lactantes, así como diversas consultas ambulatorias".

La Enciclopedia Britannica (1990: 78, tomo 6), por su parte, concibe un hospital como "una institución equipada tecnológicamente y con personal para realizar diagnósticos y tratamientos a las personas enfermas o heridas, que permite el internamiento durante su tratamiento, la realización de exámenes físicos y la gestión de partos. Los hospitales se han ido convirtiendo en centros importantes de investigación y tecnología. La formación también se ha convertido en una parte integral de casi todos los Hospitales generales"

\subsubsection{EVOLUCIÓN DE LOS HOSPITALES EN ESPAÑA Y SITUACIÓN ACTUAL}

\subsection{NÚMERO DE HOSPITALES}

La noción tradicional que existía de un hospital hacía referencia a aquellos centros que tienen "como finalidad fundamental la prestación de asistencia sanitaria en régimen de internado" (Ministerio de Sanidad, 2013a). Así, la Estadística de Establecimientos Sanitarios con Régimen de Internado (ESCRI) establecía como hospitales (o centros con internamiento, tal y como concreta el texto) los "Centros Sanitarios destinados a la asistencia especializada y continuada de pacientes en régimen de internamiento (como mínimo una noche), cuya finalidad principal es el diagnóstico o tratamiento de los enfermos ingresados en el mismo, sin perjuicio de que también presten atención de forma ambulatoria" (Instituto de Información Sanitaria, 2013b).

La ESCRI comenzó a publicarse anualmente en 1972. En sus comienzos, el Instituto Nacional de Estadística (INE) era el encargado de elaborarlo con la colaboración del Ministerio de Defensa, las Comunidades Autónomas y del por aquel entonces Ministerio de Sanidad y Consumo (Instituto de Información Sanitaria, 2009). No obstante, desde 1996, es competencia directa del Ministerio de Sanidad y Política Social (Instituto de Información Sanitaria, 2009), posteriormente del Ministerio de Sanidad, Política Social e Igualdad y, desde diciembre de 2011, del Ministerio de Sanidad, Servicios Sociales e Igualdad.

Con la Ley General de Sanidad de 1986, no obstante, se amplía el concepto de hospital que se tenía hasta entonces y se incluye a aquellos centros que también ofrecen asistencia especializada:

“Art. 56.2.b: En el nivel de asistencia especializada, a realizar en los hospitales y centros de especialidades dependientes 
funcionalmente de aquellos se prestará la atención de mayor complejidad a los problemas de salud y se desarrollarán las demás funciones propias de los hospitales".

“Art. 65.2: El hospital es el establecimiento encargado tanto del internamiento clínico como de la asistencia especializada y complementaria que requiera su zona de influencia".

El cambio de énfasis en el internamiento a favor de la asistencia especializada favoreció el cambio de título del principal estudio estadístico sobre hospitales, pasando a recibir desde el año 2010 el nombre de Estadística de Centros Sanitarios de Atención Especializada en vez de Establecimientos Sanitarios con Régimen de Internado, tal y como recoge el Real Decreto 1708/2010, de 17 de diciembre, por el que se aprueba el Programa anual 2011 del Plan Estadístico Nacional 2009-2012 (España, 2010b). En la tabla siguiente se muestra la evolución en el número de hospitales en España según este informe:

Tabla 7. Evolución del número de hospitales según la Estadística de Centros Sanitarios de Atención Especializada y la Estadística de Establecimientos Sanitarios con Régimen de Internado

\begin{tabular}{|l|r|}
\hline \multicolumn{1}{|c|}{ Año } & $\begin{array}{c}\text { Número de } \\
\text { hospitales }\end{array}$ \\
\hline 2012 & 759 \\
\hline 2011 & 763 \\
\hline 2010 & 765 \\
\hline 2009 & 770 \\
\hline 2008 & 767 \\
\hline 2007 & 764 \\
\hline 2006 & 746 \\
\hline 2005 & 751 \\
\hline 2004 & 750 \\
\hline 2003 & 741 \\
\hline 2002 & 759 \\
\hline 2001 & 768 \\
\hline 2000 & 771 \\
\hline 1999 & 774 \\
\hline 1998 & 780 \\
\hline 1997 & 788 \\
\hline
\end{tabular}

Fuente: Estadística de Centros Sanitarios de Atención Especializada y Estadística de Establecimientos Sanitarios con Régimen de Internado. 
Aparte de la mencionada Estadística de Centros Sanitarios de Atención Especializada, existe otro documento que muestra el número de hospitales que existen en España cada año. Se trata del Catálogo Nacional de Hospitales. Lo elabora el Ministerio de Sanidad y Política Social en colaboración con las Consejerías de Sanidad de las Comunidades Autónomas, el Ministerio de Defensa, los órganos competentes de las Ciudades Autónomas de Ceuta y Melilla y los propios hospitales (Ministerio de Sanidad, 2013a). La siguiente tabla muestra la relación de centros contabilizados desde 2005 hasta 2012, que difieren ligeramente de la Estadística de Centros Sanitarios de Atención Especializada. Como se puede observar, el número ha ido incrementándose ligeramente desde 2005 hasta 2009, año de inflexión en el que la cifra comienza a bajar. El total se corresponde con los centros en funcionamiento a 31 de diciembre del año anterior:

Tabla 8. Evolución del número de hospitales según el Catálogo Nacional de Hospitales

\begin{tabular}{|l|r|}
\hline \multicolumn{1}{|c|}{ Añ } & $\begin{array}{c}\text { Número de } \\
\text { hospitales }\end{array}$ \\
\hline 2012 & 789 \\
\hline 2011 & 794 \\
\hline 2010 & 803 \\
\hline 2009 & 804 \\
\hline 2008 & 800 \\
\hline 2007 & 788 \\
\hline 2006 & 783 \\
\hline 2005 & 779 \\
\hline
\end{tabular}

Fuente: Catálogo Nacional de Hospitales.

Tal y como se indica en el informe resumen de los indicadores hospitalarios de 2000 a 2008 (Instituto de Información Sanitaria, 2009), "la ESCRI [Establecimientos Sanitarios con Régimen de Internado, posteriormente transformada en la Estadística de Centros Sanitarios de Atención Especializada] es la única fuente de información de recursos y actividad que cubre todo el ámbito de la actividad hospitalaria, pues reúne la información referida a todos los establecimientos sanitarios de asistencia especializada del territorio nacional, tanto públicos como privados". En consecuencia, los análisis de la situación actual y pasada de los centros hospitalarios se tendrán en cuenta según esta estadística. 


\subsection{DEPENDENCIA FUNCIONAL}

El número de centros hospitalarios públicos ha ido decreciendo desde 1997 hasta 2007, año en el que parece remontar la cifra y comenzar la tendencia al alza. En el caso de los privados, por otro lado, no parece haber una moda fija, dado que de unos años a otros la cantidad puede tanto subir, como mantenerse o bajar.

Hasta 2009, el porcentaje de centros privados ha sido siempre superior al de los públicos, siendo más acentuado en 2006, con un 56,43\% sobre un 43,57\%; los años más equitativos, por su parte, fueron 1999 y 2000, con un 53,62\% y 46,38\% a favor de los hospitales privados. A partir del año 2010 aumentan considerablemente el número de centros pertenecientes al Sistema Nacional de Salud en detrimento de los privados, dando como resultado 453 de los primeros y 306 de los segundos en 2012. Se trata, no obstante, de una consecuencia de la reforma de la estadística, que pasa a considerar de dependencia pública los hospitales dependientes de las Mutuas de Accidentes de Trabajo y Enfermedades Profesionales de la Seguridad Social (MATEPSS), que se entendían como de dependencia privada hasta 2009. Asimismo, hasta ese año, únicamente se consideraban como pertenecientes a la red de hospitales públicos del Sistema Nacional de Salud los generales y especializados. Desde 2010, sin embargo, todos los hospitales de la red pública, independientemente de su finalidad, han pasado a incluirse como públicos pertenecientes al Sistema Nacional de Salud (Ministerio de Sanidad, 2013b).

Tabla 9. Evolución del número de hospitales por dependencia funcional.

\begin{tabular}{|l|r|r|r|r|r|}
\hline \multirow{2}{*}{ Añ o } & \multicolumn{6}{|c|}{ Número de hospitales } \\
\cline { 2 - 6 } & SNS & \% SNS & Privados & \% Privados & Total \\
\hline 2012 & 453 & 59,68 & 306 & 40,32 & 759 \\
\hline 2011 & 452 & 59,24 & 311 & 40,76 & 763 \\
\hline 2010 & 446 & 58,30 & 319 & 41,70 & 765 \\
\hline 2009 & 353 & 45,84 & 417 & 54,16 & 770 \\
\hline 2008 & 345 & 44,98 & 422 & 55,02 & 767 \\
\hline 2007 & 335 & 43,85 & 429 & 56,15 & 764 \\
\hline 2006 & 325 & 43,57 & 421 & 56,43 & 746 \\
\hline 2005 & 330 & 43,94 & 421 & 56,06 & 751 \\
\hline 2004 & 333 & 44,40 & 417 & 55,60 & 750 \\
\hline 2003 & 336 & 45,34 & 405 & 54,66 & 741 \\
\hline 2002 & 342 & 45,06 & 417 & 54,94 & 759 \\
\hline 2001 & 351 & 45,70 & 417 & 54,30 & 768 \\
\hline 2000 & 356 & 46,17 & 415 & 53,83 & 771 \\
\hline 1999 & 359 & 46,38 & 415 & 53,62 & 774 \\
\hline 1998 & 356 & 45,64 & 424 & 54,36 & 780 \\
\hline 1997 & 360 & 45,69 & 428 & 54,31 & 788 \\
\hline
\end{tabular}

Fuente: Estadística de Centros Sanitarios de Atención Especializada y Estadística de Establecimientos Sanitarios con Régimen de Internado. 


\subsection{FINALIDAD ASISTENCIAL}

La finalidad de un centro hospitalario hace referencia a la "actividad asistencial que prioritariamente dedica el hospital la mayor parte de su actividad y recursos" (Ministerio de Sanidad, 2013b). Como norma general, dice este documento, se tendrá en cuenta a la que se dedique más del 65\% de las camas en funcionamiento.

De acuerdo con el Real Decreto 1277/2003, de 10 de octubre, por el que se establecen las bases generales sobre autorización de centros, servicios y establecimientos sanitarios (España, 2003d), los hospitales en España se clasifican en: generales, especializados (también llamados de agudos), de media y larga estancia (abreviados en ocasiones como de larga estancia), de salud mental y tratamiento de toxicomanías (o psiquiátricos) y otros centros con internamiento. Es a partir de 2010 cuando la Estadística de Centros de Atención Especializada incluye dentro de la categoría de larga estancia también a los de media-larga estancia con actividad de apoyo de hospitales de agudos. También se modifica la relación de las clínicas de salud mental, que a partir de ese año, contienen también los centros de tratamientos de toxicomanías (Ministerio de Sanidad, 2013b).

Cada uno de ellos se caracteriza, de acuerdo con este documento, en los siguientes puntos:

"Hospitales generales: hospitales destinados a la atención de pacientes afectos de diversa patología y que cuentan con las áreas de Medicina, Cirugía, Obstetricia y Ginecología y Pediatría. También se considera general cuando, aun faltando o estando escasamente desarrollada alguna de estas áreas, no se concentre la mayor parte de su actividad asistencial en una determinada.

Hospitales especializados: hospitales dotados de servicios de diagnóstico y tratamiento especializados que dedican su actividad fundamental a la atención de determinadas patologías o de pacientes de determinado grupo de edad o con características comunes.

Hospitales de media y larga estancia: hospitales destinados a la atención de pacientes que precisan cuidados sanitarios, en general de baja complejidad, por procesos crónicos o por tener reducido su grado de independencia funcional para la actividad cotidiana, pero que no pueden proporcionarse en su domicilio, y requieren un periodo prolongado de internamiento.

Hospitales de salud mental y tratamiento de toxicomanías: hospitales destinados a proporcionar diagnóstico, tratamiento $\mathrm{y}$ seguimiento de su enfermedad a los pacientes que precisan ser 
ingresados y que sufren enfermedades mentales o trastornos derivados de las toxicomanías.

Otros centros con internamiento: hospitales que no se ajustan a las características de ninguno de los grupos anteriores o reúnen las de más de uno de ellos".

De esta manera, dividiendo los hospitales por finalidad asistencial, se puede comprobar que los generales ocupan la mayor parte del mapa hospitalario español (en 2012, por ejemplo, constituían el $61,53 \%$ del total). Mucho más atrás se halla el segundo grupo más numeroso, los de larga y media estancia, que suman el $16,60 \%$ en ese mismo año. El resto de centros no proporcionan apenas diferencias: en 2012, los hospitales de agudos agrupaban el 10,94\% y los psiquiátricos, el 10,94\%.

Tabla 10. Evolución del número de hospitales por finalidad asistencial.

\begin{tabular}{|c|c|c|c|c|}
\hline \multirow{2}{*}{ Año } & \multicolumn{4}{|c|}{ Número de hospitales } \\
\hline & $\begin{array}{l}\text { Hospitales } \\
\text { generales }\end{array}$ & $\begin{array}{c}\text { Otros hospitales } \\
\text { de agudos }\end{array}$ & $\begin{array}{l}\text { Hospitales de } \\
\text { larga estancia }\end{array}$ & $\begin{array}{l}\text { Hospitales } \\
\text { psiquiátricos }\end{array}$ \\
\hline 2012 & 467 & 83 & 126 & 83 \\
\hline 2011 & 463 & 87 & 127 & 86 \\
\hline 2010 & 458 & 85 & 134 & 88 \\
\hline 2009 & 453 & 110 & 121 & 86 \\
\hline 2008 & 449 & 108 & 122 & 88 \\
\hline 2007 & 454 & 105 & 118 & 87 \\
\hline 2006 & 436 & 112 & 111 & 87 \\
\hline 2005 & 427 & 117 & 117 & 90 \\
\hline 2004 & 431 & 115 & 119 & 85 \\
\hline 2003 & 424 & 121 & 110 & 86 \\
\hline 2002 & 436 & 123 & 111 & 89 \\
\hline 2001 & 447 & 119 & 116 & 86 \\
\hline 2000 & 447 & 125 & 112 & 87 \\
\hline 1999 & 440 & 134 & 114 & 86 \\
\hline 1998 & 443 & 137 & 115 & 85 \\
\hline 1997 & 456 & 130 & 115 & 87 \\
\hline $\begin{array}{l}\text { Diferencia } \\
\text { 2011-1997 }\end{array}$ & 7 & -43 & 12 & -1 \\
\hline $\begin{array}{l}\text { \%Diferencia } \\
\text { 2011-1997 }\end{array}$ & 1,54 & $-33,08$ & 10,43 & $-1,15$ \\
\hline
\end{tabular}

Fuente: Estadística de Centros Sanitarios de Atención Especializada y Estadística de Establecimientos Sanitarios con Régimen de Internado. 
Calculando las diferencias entre la finalidad asistencial y la titularidad de los centros, se observa que los públicos priman sobre todo en los generales y en los de larga y media estancia. En 2012, por ejemplo, se contabilizan 184 hospitales generales de titularidad privada en comparación con los 283 públicos, una tendencia que no ha cambiado trascendentalmente con el paso de los años. Los hospitales de larga estancia del Sistema Nacional de Salud también sobrepasan a los privados ampliamente (por ejemplo, en el último año contabilizado, 92 de los primeros frente a 34 de los segundos), aunque esta balanza ha cambiado a partir del año 2010, puesto que anteriormente eran más numerosos los privados (en 2009, como muestra, 91 frente a 30). Se debe, no obstante, al cambio de metodología de la estadística.

El número de hospitales agudos privados, por el contrario, ha descendido con los años, dando más cancha a los de la red sanitaria pública. En 2012, un total de 49 se correspondían con centros privados y 34 con su competencia. Lo mismo sucede con los psiquiátricos. Mientras que en 2008, que fue el año en el que se registró una mayor cantidad de este tipo de clínicas de titularidad privada (había 59 privados frente a 29 públicos) para 2012 cambió la tendencia y pasó a contabilizarse 39 del primer tipo y 44 , del segundo.

Tabla 11. Evolución del número de hospitales por finalidad asistencial y dependencia funcional

\begin{tabular}{|c|c|c|c|c|c|}
\hline \multirow[b]{2}{*}{ Año } & \multirow[b]{2}{*}{ Titularidad } & \multicolumn{4}{|c|}{ Número de hospitales } \\
\hline & & $\begin{array}{c}\text { Hospitales } \\
\text { generales }\end{array}$ & $\begin{array}{c}\text { Otros } \\
\text { hospitales } \\
\text { de agudos }\end{array}$ & $\begin{array}{c}\text { Hospitales } \\
\text { de larga } \\
\text { estancia }\end{array}$ & $\begin{array}{c}\text { Hospitales } \\
\text { psiquiátricos }\end{array}$ \\
\hline \multirow{2}{*}{2012} & SNS & 283 & 34 & 92 & 44 \\
\hline & Privados & 184 & 49 & 34 & 39 \\
\hline \multirow{2}{*}{2011} & SNS & 279 & 35 & 92 & 46 \\
\hline & Privados & 184 & 52 & 35 & 40 \\
\hline \multirow{2}{*}{2010} & SNS & 278 & 33 & 92 & 43 \\
\hline & Privados & 180 & 52 & 42 & 45 \\
\hline \multirow{2}{*}{2009} & SNS & 271 & 22 & 30 & 30 \\
\hline & Privados & 182 & 88 & 91 & 56 \\
\hline \multirow{2}{*}{2008} & SNS & 265 & 21 & 30 & 29 \\
\hline & Privados & 184 & 87 & 92 & 59 \\
\hline \multirow{2}{*}{2007} & SNS & 260 & 18 & 28 & 29 \\
\hline & Privados & 194 & 87 & 90 & 58 \\
\hline \multirow{2}{*}{2006} & SNS & 248 & 21 & 26 & 30 \\
\hline & Privados & 188 & 91 & 85 & 57 \\
\hline \multirow{2}{*}{2005} & SNS & 246 & 21 & 30 & 33 \\
\hline & Privados & 181 & 96 & 87 & 57 \\
\hline
\end{tabular}




\begin{tabular}{|c|c|c|c|c|c|}
\hline \multirow[b]{2}{*}{ Año } & \multirow[b]{2}{*}{ Titularidad } & \multicolumn{4}{|c|}{ Número de hospitales } \\
\hline & & $\begin{array}{l}\text { Hospitales } \\
\text { generales }\end{array}$ & $\begin{array}{c}\text { Otros } \\
\text { hospitales } \\
\text { de agudos }\end{array}$ & $\begin{array}{c}\text { Hospitales } \\
\text { de larga } \\
\text { estancia }\end{array}$ & $\begin{array}{c}\text { Hospitales } \\
\text { psiquiátricos }\end{array}$ \\
\hline \multirow{2}{*}{2004} & SNS & 248 & 22 & 28 & 35 \\
\hline & Privados & 183 & 93 & 91 & 50 \\
\hline \multirow{2}{*}{2003} & SNS & 248 & 25 & 28 & 35 \\
\hline & Privados & 176 & 96 & 82 & 51 \\
\hline \multirow{2}{*}{2002} & SNS & 250 & 26 & 28 & 38 \\
\hline & Privados & 186 & 97 & 83 & 51 \\
\hline \multirow{2}{*}{2001} & SNS & 254 & 27 & 31 & 39 \\
\hline & Privados & 193 & 92 & 85 & 47 \\
\hline \multirow{2}{*}{2000} & SNS & 259 & 26 & 31 & 40 \\
\hline & Privados & 188 & 99 & 81 & 47 \\
\hline \multirow{2}{*}{1999} & SNS & 260 & 28 & 32 & 39 \\
\hline & Privados & 180 & 106 & 82 & 47 \\
\hline \multirow{2}{*}{1998} & SNS & 259 & 28 & 32 & 37 \\
\hline & Privados & 184 & 109 & 83 & 48 \\
\hline \multirow{2}{*}{1997} & SNS & 261 & 20 & 41 & 38 \\
\hline & Privados & 195 & 110 & 74 & 49 \\
\hline
\end{tabular}

Fuente: Estadística de Centros Sanitarios de Atención Especializada y Estadística de Establecimientos Sanitarios con Régimen de Internado.

\subsection{DISTRIBUCIÓN GEOGRÁFICA DE LOS HOSPITALES}

La comunidad autónoma con un mayor número de hospitales es Cataluña, que en 2012 cuenta con 194, seguida, aunque con una gran diferencia, de Andalucía, que tiene 102, y de Madrid, con 81. Navarra, con 11 ese mismo año, Cantabria, con 8, La Rioja, con 6, y Ceuta y Melilla, con 2 en conjunto, se encuentran en el otro lado de la balanza.

Siete comunidades autónomas han visto aumentar su conjunto de hospitales en los últimos años, mientras que el mismo número los han visto disminuir y dos se han quedado con el mismo montante. En el primer caso se encuentran: Andalucía, Aragón, Cataluña, Comunidad Valenciana, Comunidad de Madrid, Región de Murcia y La Rioja. El caso más significativo lo aporta esta última comunidad, que pasando de 4 a 6 centros aumenta un 50,0\% su número de hospitales de 1997 a 2012. Después se encuentra Andalucía, que pasa de 87 a 102, es decir, un 17,24\% más. Cataluña, con un 9,60\% más pasando de 177 a 194 y Murcia, con un 8,33\% más gracias a dos nuevos centros, son otros ejemplos sobresalientes.

En el lado opuesto, es decir, aquellas comunidades que han visto menguar sus centros hospitalarios, se encuentran: Asturias, Islas Baleares, Islas Canarias, Cantabria, 
Castilla y León, Galicia, Navarra, País Vasco y Ceuta y Melilla como conjunto. La bajada más significativa la aportan estas dos ciudades autónomas, que al pasar de tener 4 en 1997 a 2 en 2012 presentan una disminución del 50,00\%. Galicia, que tuvo 60 en 1997 y 37 en 2012, presenta una disminución del -38,33\%. Castilla y León se encuentra en tercer lugar con un 28,85\% menos, dado que ha pasado de tener 52 en 1997 a 37 en 2012. Cantabria, con un $-27,27 \%$, y Navarra, con un $-21,43 \%$, son otras de las grandes afectadas.

Por su parte, Castilla-La Mancha y Extremadura cuentan con los mismos hospitales en 2012 que en 1997 ( 29 en la primera región y 18 en la segunda), si bien han visto aumentar y disminuir ese número en los años intermedios.

Tabla 12. Evolución del número de hospitales según las comunidades autónomas

\begin{tabular}{|c|c|c|c|c|c|c|c|c|c|}
\hline \multirow{2}{*}{$\begin{array}{c}\text { Comunidad } \\
\text { autónoma }\end{array}$} & & \multicolumn{8}{|c|}{ Número de hospitales } \\
\hline & 2012 & 2011 & 2010 & 2009 & 1999 & 1998 & 1997 & $\begin{array}{l}\text { Diferencia } \\
\text { 2012-1997 }\end{array}$ & $\begin{array}{c}\text { \%Diferencia } \\
\text { 2012-1997 }\end{array}$ \\
\hline Andalucía & 102 & 101 & 100 & 102 & 85 & 86 & 87 & 15 & 17,24 \\
\hline Aragón & 29 & 29 & 29 & 30 & 27 & 27 & 27 & 2 & 7,41 \\
\hline Asturias & 20 & 20 & 20 & 20 & 19 & 19 & 21 & -1 & $-4,76$ \\
\hline Baleares & 21 & 22 & 22 & 22 & 23 & 23 & 23 & -2 & $-8,70$ \\
\hline Canarias & 36 & 36 & 37 & 37 & 48 & 48 & 50 & -14 & -28 \\
\hline Cantabria & 8 & 8 & 8 & 9 & 9 & 10 & 11 & -3 & $-27,27$ \\
\hline $\begin{array}{l}\text { Castilla y } \\
\text { León }\end{array}$ & 37 & 37 & 37 & 40 & 51 & 51 & 52 & -15 & $-28,85$ \\
\hline $\begin{array}{l}\text { Castilla-La } \\
\text { Mancha }\end{array}$ & 29 & 29 & 29 & 30 & 31 & 30 & 29 & 0 & 0 \\
\hline Cataluña & 194 & 194 & 195 & 189 & 177 & 177 & 177 & 17 & 9,60 \\
\hline $\begin{array}{l}\text { Comunidad } \\
\text { Valenciana }\end{array}$ & 61 & 62 & 60 & 61 & 60 & 58 & 60 & 1 & 1,67 \\
\hline Extremadura & 18 & 18 & 18 & 19 & 16 & 17 & 18 & 0 & 0 \\
\hline Galicia & 37 & 37 & 39 & 39 & 54 & 59 & 60 & -23 & $-38,33$ \\
\hline Madrid & 81 & 81 & 80 & 81 & 77 & 77 & 75 & 6 & 8 \\
\hline Murcia & 26 & 26 & 26 & 26 & 24 & 25 & 24 & 2 & 8,33 \\
\hline Navarra & 11 & 11 & 13 & 13 & 14 & 14 & 14 & -3 & $-21,43$ \\
\hline País Vasco & 41 & 44 & 44 & 44 & 51 & 51 & 52 & -11 & $-21,15$ \\
\hline La Rioja & 6 & 6 & 6 & 5 & 4 & 4 & 4 & 2 & 50 \\
\hline $\begin{array}{l}\text { Ceuta y } \\
\text { Melilla }\end{array}$ & 2 & 2 & 2 & 3 & 4 & 4 & 4 & -2 & -50 \\
\hline
\end{tabular}

Fuente: Estadística de Centros Sanitarios de Atención Especializada y Estadística de Establecimientos Sanitarios con Régimen de Internado. 
En la actualidad, la comunidad que cuenta con un mayor número de centros hospitalarios enmarcados dentro del Sistema Nacional de Salud respecto a los privados es Cataluña. En esta región, hay 118 hospitales públicos más que privados, dando una tasa entre unos y otros del 4,11. Después se encuentran Castilla-La Mancha (con 2,63 veces más de públicos que de privados) y Aragón (con 2,22). La Rioja, con 5 de la primera clase y uno de la segunda, ofrece una diferencia de 5 puntos.

En el lado contrario, es decir, los lugares donde existen más clínicas en manos privadas que administrativas es en Canarias (con 8 unidades de diferencia, lo que convierte la tasa en 0,64), seguido de Murcia $(0,73)$, de Castilla y León $(0,76)$, de Navarra $(0,83)$, de Andalucía $(0,87)$ y de la Comunidad de Madrid $(0,88)$. Como se aprecia, son tasas mucho más bajas que las que ofrecen las comunidades con una mayor cantidad de centros públicos.

Tabla 13. Diferencia entre el número de hospitales públicos y privados en 2012

\begin{tabular}{|l|r|r|r|r|}
\hline $\begin{array}{c}\text { Comunidad } \\
\text { autónoma }\end{array}$ & Públicos & Privados & $\begin{array}{c}\text { Públicos - } \\
\text { privados }\end{array}$ & $\begin{array}{c}\text { Diferencia } \\
\text { públicos - } \\
\text { privados }\end{array}$ \\
\hline Andalucía & 47 & 55 & -8 & 0,85 \\
\hline Aragón & 20 & 9 & 11 & 2,22 \\
\hline Asturias & 11 & 9 & 2 & 1,22 \\
\hline Baleares & 12 & 9 & 3 & 1,33 \\
\hline Canarias & 14 & 22 & -8 & 0,64 \\
\hline Cantabria & 5 & 3 & 2 & 1,67 \\
\hline Castilla y León & 16 & 21 & -5 & 0,76 \\
\hline Castilla-La & 21 & 8 & 13 & 2,625 \\
Mancha & 156 & 38 & 118 & 4,11 \\
\hline Cataluña & 38 & 23 & 15 & 1,65 \\
\hline Comunidad & 10 & 8 & 2 & 1,25 \\
\hline Valenciana & 19 & 18 & 1 & 1,06 \\
\hline Extremadura & 38 & 43 & -5 & 0,88 \\
\hline Galicia & 11 & 15 & -4 & 0,73 \\
\hline Madrid & 6 & 5 & 1 & 1,2 \\
\hline Murcia & 22 & 19 & 3 & 1,16 \\
\hline Navarra & 5 & 0 & 4 & 5 \\
\hline País Vasco & 2 & -1 & - \\
\hline La Rioja & & & & \\
\hline Ceuta y Melilla & & & & \\
\hline
\end{tabular}

Fuente: Estadística de Centros Sanitarios de Atención Especializada y Estadística de Establecimientos Sanitarios con Régimen de Internado. 
Observando la evolución a lo largo de los años, se aprecian varios casos especiales. En Baleares, por ejemplo, de 1997 a 2012 se han incorporado tres nuevos hospitales públicos (dando un aumento del 33,33\%), mientras que en el caso de los privados, bajan de 14 a 9. En Castilla y León, aunque el número de centros privados se mantiene casi constante, el número de hospitales públicos bajan drásticamente de 29 a 16 (incluso en 2008 y 2007 se contabilizaron 15). En Galicia, son los privados los que ven descender su cifra fuertemente, pasando de 41 en 1997 a 18 en 2012. En cambio, los públicos, con alguna pequeña variación en algunos años, se mantienen prácticamente constantes.

En Castilla-La Mancha, aumenta la cifra de hospitales públicos en cuatro (pasando de 17 a 21 , es decir, un 23,53\% más), mientras que los centros privados bajan de 12 a 8 $(-33,33 \%)$. Unas cifras similares ofrece Asturias: $22,22 \%$ y $-25 \%$, en este orden. En Cataluña la diferencia es incluso más marcada: de 1997 a 2012 se han incrementado los centros públicos un $102,60 \%$ y los privados han reducido en un $62 \%$.

En el resto de casos, o aumentan o disminuyen todos los hospitales de la misma manera independientemente de la titularidad, o presentan diferencias pequeñas. Se puede ver más información sobre la evolución y situación actual de los hospitales en el anexo número 1.

Tabla 14. Evolución del número de hospitales según las comunidades autónomas y dependencia funcional

\begin{tabular}{|c|c|c|c|c|c|c|c|c|}
\hline \multirow{2}{*}{$\begin{array}{l}\text { Comunidad } \\
\text { autónoma }\end{array}$} & \multicolumn{8}{|c|}{ Número de hospitales } \\
\hline & Régimen & 2012 & 2011 & 2010 & 1998 & 1997 & $\begin{array}{l}\text { Diferencia } \\
\text { 2012-1997 }\end{array}$ & $\begin{array}{c}\text { \%Diferencia } \\
\text { 2012-1997 }\end{array}$ \\
\hline \multirow{3}{*}{ Andalucía } & SNS & 47 & 47 & 47 & 37 & 37 & 10 & 27,03 \\
\hline & Privados & 55 & 54 & 53 & 49 & 50 & 5 & 10 \\
\hline & Total & 102 & 101 & 100 & 86 & 87 & 15 & 17,24 \\
\hline \multirow{3}{*}{ Aragón } & SNS & 20 & 20 & 20 & 20 & 21 & -1 & $-4,76$ \\
\hline & Privados & 9 & 9 & 9 & 7 & 6 & 3 & 50 \\
\hline & Total & 29 & 29 & 29 & 27 & 27 & 2 & 7,41 \\
\hline \multirow{3}{*}{ Asturias } & SNS & 11 & 11 & 10 & 9 & 9 & 2 & 22,22 \\
\hline & Privados & 9 & 9 & 10 & 10 & 12 & -3 & -25 \\
\hline & Total & 20 & 20 & 20 & 19 & 21 & -1 & $-4,76$ \\
\hline \multirow{3}{*}{ Baleares } & SNS & 12 & 12 & 12 & 9 & 9 & 3 & 33,33 \\
\hline & Privados & 9 & 10 & 10 & 14 & 14 & -5 & $-35,71$ \\
\hline & Total & 21 & 22 & 22 & 23 & 23 & -2 & $-8,70$ \\
\hline \multirow{3}{*}{ Canarias } & SNS & 14 & 14 & 14 & 20 & 22 & -8 & $-36,36$ \\
\hline & Privados & 22 & 22 & 23 & 28 & 28 & -6 & $-21,43$ \\
\hline & Total & 36 & 36 & 37 & 48 & 50 & -14 & -28 \\
\hline \multirow{3}{*}{ Cantabria } & SNS & 5 & 5 & 5 & 5 & 5 & 0 & 0 \\
\hline & Privados & 3 & 3 & 3 & 5 & 6 & -3 & -50 \\
\hline & Total & 8 & 8 & 8 & 10 & 11 & -3 & $-27,27$ \\
\hline
\end{tabular}




\begin{tabular}{|c|c|c|c|c|c|c|c|c|}
\hline \multirow{2}{*}{$\begin{array}{c}\text { Comunidad } \\
\text { autónoma }\end{array}$} & \multicolumn{8}{|c|}{ Número de hospitales } \\
\hline & Régimen & 2012 & 2011 & 2010 & 1998 & 1997 & $\begin{array}{l}\text { Diferencia } \\
\text { 2012-1997 }\end{array}$ & $\begin{array}{c}\text { \%Diferencia } \\
\text { 2012-1997 }\end{array}$ \\
\hline \multirow{3}{*}{$\begin{array}{l}\text { Castilla } \\
\text { León }\end{array}$} & SNS & 16 & 16 & 16 & 28 & 29 & -13 & $-44,83$ \\
\hline & Privados & 21 & 21 & 21 & 23 & 23 & -2 & $-8,70$ \\
\hline & Total & 37 & 37 & 37 & 51 & 52 & -15 & $-28,85$ \\
\hline \multirow{3}{*}{$\begin{array}{l}\text { Castilla-La } \\
\text { Mancha }\end{array}$} & SNS & 21 & 21 & 21 & 18 & 17 & 4 & 23,53 \\
\hline & Privados & 8 & 8 & 8 & 12 & 12 & -4 & $-33,33$ \\
\hline & Total & 29 & 29 & 29 & 30 & 29 & 0 & 0 \\
\hline \multirow{3}{*}{ Cataluña } & SNS & 156 & 154 & 153 & 75 & 77 & 79 & 102,60 \\
\hline & Privados & 38 & 40 & 42 & 102 & 100 & -62 & -62 \\
\hline & Total & 194 & 194 & 195 & 177 & 177 & 17 & 9,60 \\
\hline \multirow{3}{*}{$\begin{array}{l}\text { Comunidad } \\
\text { Valenciana }\end{array}$} & SNS & 38 & 38 & 36 & 30 & 30 & 8 & 26,67 \\
\hline & Privados & 23 & 24 & 24 & 28 & 30 & -7 & $-23,33$ \\
\hline & Total & 61 & 62 & 60 & 58 & 60 & 1 & 1,67 \\
\hline \multirow{3}{*}{ Extremadura } & SNS & 10 & 10 & 10 & 10 & 11 & -1 & $-9,09$ \\
\hline & Privados & 8 & 8 & 8 & 7 & 7 & 1 & 14,29 \\
\hline & Total & 18 & 18 & 18 & 17 & 18 & 0 & 0 \\
\hline \multirow{3}{*}{ Galicia } & SNS & 19 & 19 & 18 & 19 & 19 & 0 & 0 \\
\hline & Privados & 18 & 18 & 21 & 40 & 41 & -23 & $-56,10$ \\
\hline & Total & 37 & 37 & 39 & 59 & 60 & -23 & $-38,33$ \\
\hline \multirow{3}{*}{ Madrid } & SNS & 38 & 38 & 37 & 32 & 31 & 7 & 22,58 \\
\hline & Privados & 43 & 43 & 43 & 45 & 44 & -1 & $-2,27$ \\
\hline & Total & 81 & 81 & 80 & 77 & 75 & 6 & 8 \\
\hline \multirow{3}{*}{ Murcia } & SNS & 11 & 11 & 11 & 11 & 10 & 1 & 10 \\
\hline & Privados & 15 & 15 & 15 & 14 & 14 & 1 & 7,14 \\
\hline & Total & 26 & 26 & 26 & 25 & 24 & 2 & 8,33 \\
\hline \multirow{3}{*}{ Navarra } & SNS & 6 & 5 & 6 & 6 & 6 & 0 & 0 \\
\hline & Privados & 5 & 6 & 7 & 8 & 8 & -3 & $-37,5$ \\
\hline & Total & 11 & 11 & 13 & 14 & 14 & -3 & $-21,43$ \\
\hline \multirow{3}{*}{ País Vasco } & SNS & 22 & 24 & 24 & 20 & 20 & 2 & 10 \\
\hline & Privados & 19 & 20 & 20 & 31 & 32 & -13 & $-40,63$ \\
\hline & Total & 41 & 44 & 44 & 51 & 52 & -11 & $-21,15$ \\
\hline \multirow{3}{*}{ La Rioja } & SNS & 5 & 5 & 4 & 3 & 3 & 2 & 66,67 \\
\hline & Privados & 1 & 1 & 2 & 1 & 1 & 0 & 0 \\
\hline & Total & 6 & 6 & 6 & 4 & 4 & 2 & 50 \\
\hline \multirow{2}{*}{$\begin{array}{l}\text { Ceuta y } \\
\text { Melilla }\end{array}$} & SNS & 2 & 2 & 2 & 4 & 4 & -2 & -50 \\
\hline & Total & 2 & 2 & 2 & 4 & 4 & -2 & -50 \\
\hline
\end{tabular}

Fuente: Estadística de Centros Sanitarios de Atención Especializada y Estadística de Establecimientos Sanitarios con Régimen de Internado. 


\title{
1.4. COMPARATIVA DEL SISTEMA SANITARIO EN CASTILLA Y LEÓN Y EN GALICIA
}

\author{
1.4.1. Similitudes y diferencias sociales, demográficas y económicas entre \\ Castilla y León y Galicia
}

1.4.2. Equipamiento sanitario en Castilla y León y en Galicia

Tal y como se ha señalado en el apartado correspondiente a la metodología, se han seleccionado las comunidades autónomas de Castilla y León y Galicia porque tienen unos sistemas de información sobre la salud muy dispares a pesar de contar con unas estructuras sanitarias muy similares. También son parecidas en cuanto a características económicas y demográficas. En lo único en lo que se diferencian a simple vista es en la superficie y en la densidad de población.

\subsubsection{SIMILITUDES Y DIFERENCIAS SOCIALES, DEMOGRÁFICAS Y ECONÓMICAS ENTRE CASTILLA Y LEÓN Y GALICIA}

Así, mientras que Galicia cuenta con $29.574,69 \mathrm{~km}^{2}$, Castilla y León ocupa un territorio de $94.226,91 \mathrm{~km}^{2}$, es decir, más del triple. En cuanto a población, en cambio, la cuantía es similar: 2.765 .940 en la primera y 2.519.875 en la segunda. Así, la comunidad castellana tiene un $8,9 \%$ menos de ciudadanos, una cifra reducida teniendo en cuenta las diferencias entre la región más poblada de España, como es Andalucía con 8.440.300 habitantes, y la menos, La Rioja, con 322.027. 
Al tener unas cifras de habitantes similares en unas superficies tan dispares, registran unas densidades poblacionales radicalmente diferentes: la de Galicia se encuentra en 93,52 personas por $\mathrm{km}^{2}$ y la de Castilla y León, en 26,74 [Instituto Nacional de Estadística (INE), 2013 e Instituto Geográfico Nacional, 2012]:

Tabla 15. Población, superficie y densidad de Castilla y León y Galicia en 2013

\begin{tabular}{|l|r|r|}
\hline Variable & $\begin{array}{c}\text { Castilla y } \\
\text { León }\end{array}$ & \multicolumn{1}{c|}{ Galicia } \\
\hline Población & 2.519 .875 & 2.765 .940 \\
\hline Superficie & 94226,91 & 29574,69 \\
\hline Densidad & 26,74 & 93,52 \\
\hline
\end{tabular}

Fuente: Padrón municipal del Instituto Nacional de Estadística (2013) y Territorio del Instituto Nacional de Estadística e Instituto Geográfico Nacional (2012).

Divididos por sexo, el 49,46\% (o 1.246.377) de los castellanoleoneses son hombres y el 50,54\% (o 1.273.498), mujeres (Instituto Nacional de Estadística (INE), 2013). La división en Galicia es similar: 1.335 .122 (es decir, el 48,27\%) son varones y 1.430 .818 (o el 51,73\%), mujeres.

Dividiendo la población por edad, se observa que hay un mayor porcentaje de personas de entre 30 a 44 años y de entre 60 a 69 en Galicia que en Castilla y León. Por el contrario, en esta última región hay más residentes mayores de 80 años. No se trata, en ningún caso, de diferencias demasiado marcadas.

Tabla 16. Población en Castilla y León y Galicia por grupos de edades

\begin{tabular}{|l|r|r|r|r|}
\hline \multicolumn{1}{|c|}{$\begin{array}{c}\text { Grupos de } \\
\text { edad }\end{array}$} & $\begin{array}{c}\text { Castilla y } \\
\text { León }\end{array}$ & Galicia & $\begin{array}{c}\text { \% Castilla } \\
\text { y León }\end{array}$ & \% Galicia \\
\hline 0 a 4 años & 101.659 & 111.951 & 4,04 & 4,05 \\
\hline 5 a 9 años & 104.082 & 111.767 & 4,13 & 4,05 \\
\hline 10 a 14 años & 100.739 & 105.311 & 4,00 & 3,81 \\
\hline 15 a 19 años & 103.959 & 107.910 & 4,13 & 3,91 \\
\hline 20 a 24 años & 120.511 & 127.638 & 4,78 & 4,62 \\
\hline 25 a 29 años & 141.183 & 155.401 & 5,61 & 5,63 \\
\hline 30 a 34 años & 171.367 & 205.115 & 6,80 & 7,43 \\
\hline 35 a 39 años & 189.984 & 227.829 & 7,54 & 8,25 \\
\hline 40 a 44 años & 192.014 & 216.697 & 7,62 & 7,85 \\
\hline 45 a 49 años & 198.435 & 206.194 & 7,88 & 7,47 \\
\hline 50 a 54 años & 192.430 & 198.121 & 7,64 & 7,17 \\
\hline 55 a 59 años & 167.642 & 179.667 & 6,66 & 6,51 \\
\hline 60 a 64 años & 148.816 & 170.129 & 5,91 & 6,16 \\
\hline 65 a 69 años & 136.523 & 163.800 & 5,42 & 5,93 \\
\hline
\end{tabular}




\begin{tabular}{|l|r|r|r|r|}
\hline \multicolumn{1}{|c|}{$\begin{array}{c}\text { Grupos de } \\
\text { edad }\end{array}$} & $\begin{array}{c}\text { Castilla y } \\
\text { León }\end{array}$ & \multicolumn{1}{c|}{ Galicia } & $\begin{array}{c}\text { \% Castilla } \\
\text { y León }\end{array}$ & \% Galicia \\
\hline 70 a 74 años & 110.251 & 125.576 & 4,38 & 4,55 \\
\hline 75 a 79 años & 123.324 & 139.296 & 4,90 & 5,04 \\
\hline 80 a 84 años & 108.445 & 110.239 & 4,31 & 3,99 \\
\hline 85 a 89 años & 69.633 & 63.998 & 2,76 & 2,32 \\
\hline 90 a 94 años & 29.042 & 27.357 & 1,15 & 0,99 \\
\hline 95 a 99 años & 7.143 & 6.819 & 0,28 & 0,25 \\
\hline 100 y más años & 1.346 & 1.156 & 0,05 & 0,04 \\
\hline Total & 2.518 .528 & 2.761 .971 & 100 & 100 \\
\hline
\end{tabular}

Fuente: Padrón municipal del Instituto Nacional de Estadística (2013).

\section{Ilustración 4. Población en Castilla y León y Galicia agrupada por grupos de edad}

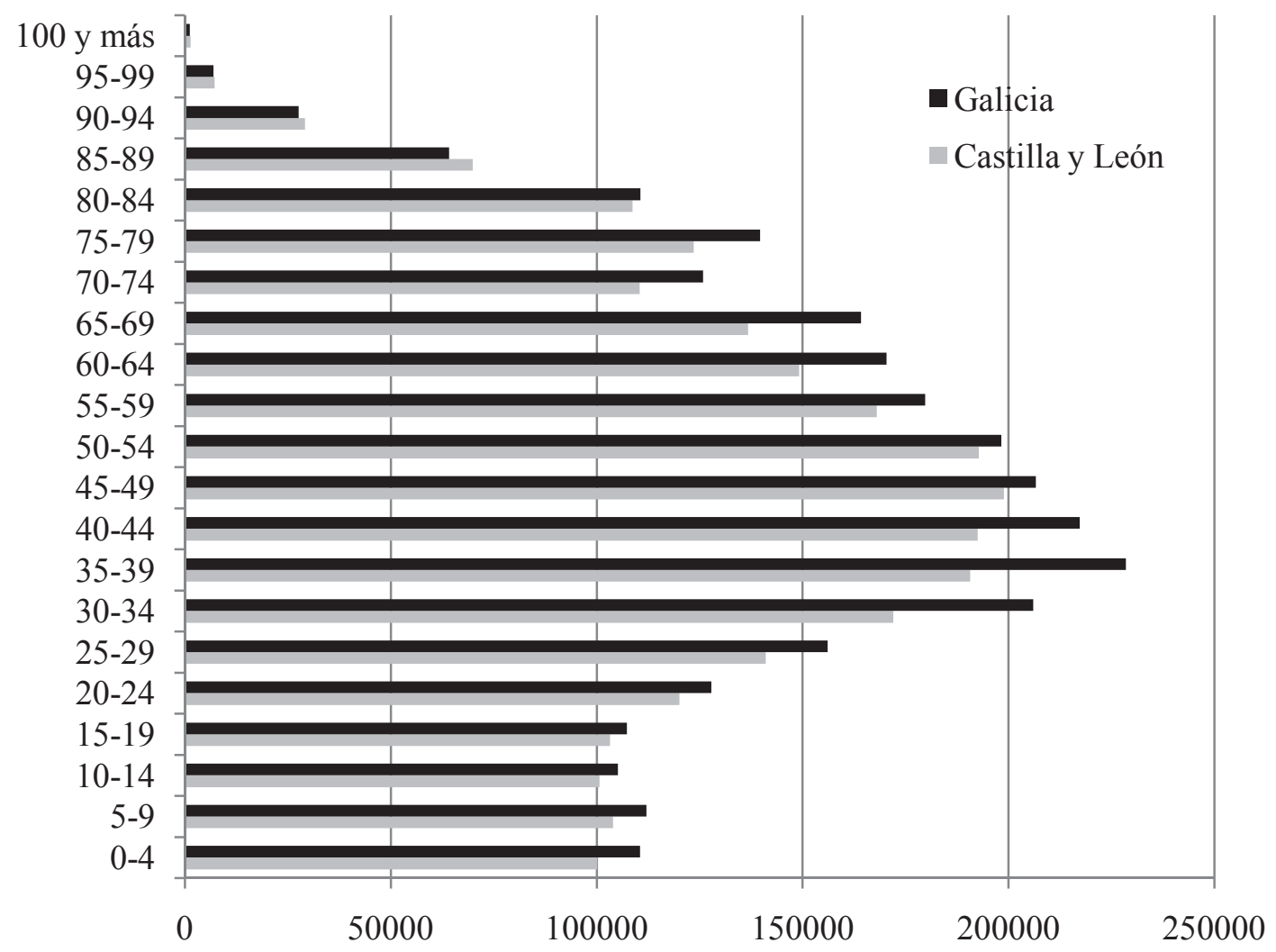

Fuente: Padrón municipal del Instituto Nacional de Estadística (2013).

La riqueza económica de las dos regiones no se diferencia demasiado. En 2012, el producto interior bruto de Castilla y León era muy similar al del conjunto nacional: 21.994 y 22.291, respectivamente. La cifra en Galicia es algo más reducida. Concretamente, se sitúa en la undécima posición de las 19 comunidades y ciudades 
autónomas del país, con 20.330 euros por habitante. Esas casi 2.000 unidades de diferencia no resultan demasiado acusadas si se comparan las dos zonas con un mayor y menor PIB: País Vasco, cuya cuantía sube hasta 30.043 y Extremadura, que registra 15.129 (Instituto Nacional de Estadística (INE), 2012).

Tabla 17. Producto interior bruto (PIB) per cápita en 2012 en las distintas comunidades autónomas

\begin{tabular}{|l|r|}
\hline $\begin{array}{c}\text { Comunidad } \\
\text { autónoma }\end{array}$ & $\begin{array}{c}\text { PIB per } \\
\text { cápita }\end{array}$ \\
\hline País Vasco & 30.043 \\
\hline Madrid & 28.906 \\
\hline Navarra & 28.491 \\
\hline Cataluña & 26.412 \\
\hline La Rioja & 25.185 \\
\hline Aragón & 24.805 \\
\hline Illes Balears & 23.589 \\
\hline Total nacional & $\mathbf{2 2 . 2 9 1}$ \\
\hline Castilla y León & 21.994 \\
\hline Cantabria & 21.692 \\
\hline Asturias & 20.862 \\
\hline Galicia & 20.330 \\
\hline Comunitat & 19.480 \\
Valenciana & 18.935 \\
\hline Canarias & 18.833 \\
\hline Ceuta & 18.027 \\
\hline Murcia & 17.688 \\
\hline $\begin{array}{l}\text { Castilla- La } \\
\text { Mancha }\end{array}$ & 16.739 \\
\hline Andalucía & 16.704 \\
\hline Melilla & 15.129 \\
\hline Extremadura & \\
\hline & \\
\hline$c a s$ \\
\hline
\end{tabular}

Fuente: Cuentas económicas. Contabilidad regional de España. Base 2008. Instituto Nacional de Estadística (2012). 


\subsubsection{EQUIPAMIENTO SANITARIO EN CASTILLA Y LEÓN Y EN GALICIA}

\subsubsection{NÚMERO DE HOSPITALES}

Tanto Castilla y León como Galicia ofrecen cifras de equipamiento sanitario muy similares. El número de hospitales en ambas zonas en 2012 es exactamente el mismo: 37. Además, las dos regiones han sufrido una disminución acusada del número de centros de atención especializada a lo largo de los años. En el caso de Castilla y León, se trata de una bajada de 15 desde 1997 hasta 2012, pasando de tener 52 a 37 (en porcentaje se corresponde con -28,85\%). Galicia ha pasado de contar con 60 en 1997 a 37 en 2012, es decir, 23 menos (-38,33\%). Se trata de descensos muchos más acusados de los que muestra la media nacional, cuya disminución entre los dos años señalados se queda en un $-3,68 \%$.

Tabla 18. Evolución del número de hospitales de Castilla y León y Galicia

\begin{tabular}{|c|c|c|c|}
\hline \multirow[b]{2}{*}{ Año } & \multicolumn{3}{|c|}{ Número Hospitales } \\
\hline & $\begin{array}{c}\text { Castilla y } \\
\text { León }\end{array}$ & Galicia & $\begin{array}{c}\text { Total } \\
\text { nacional }\end{array}$ \\
\hline 2012 & 37 & 37 & 759 \\
\hline 2011 & 37 & 37 & 763 \\
\hline 2010 & 37 & 39 & 765 \\
\hline 2009 & 40 & 39 & 770 \\
\hline 2008 & 39 & 40 & 767 \\
\hline 2007 & 41 & 44 & 764 \\
\hline 2006 & 39 & 46 & 746 \\
\hline 2005 & 41 & 47 & 751 \\
\hline 2004 & 44 & 47 & 750 \\
\hline 2003 & 45 & 47 & 741 \\
\hline 2002 & 52 & 49 & 759 \\
\hline 2001 & 54 & 48 & 768 \\
\hline 2000 & 53 & 51 & 771 \\
\hline 1999 & 51 & 54 & 774 \\
\hline 1998 & 51 & 59 & 780 \\
\hline 1997 & 52 & 60 & 788 \\
\hline $\begin{array}{l}\text { Diferencia } \\
\text { 2012-1997 }\end{array}$ & -15 & -23 & -29 \\
\hline $\begin{array}{l}\text { \%Diferencia } \\
\text { 2012-1997 }\end{array}$ & $-28,85$ & $-38,33$ & $-3,68$ \\
\hline
\end{tabular}

Fuente: Estadística de Centros Sanitarios de Atención Especializada y Estadística de Establecimientos Sanitarios con Régimen de Internado. 


\subsubsection{DEPENDENCIA FUNCIONAL}

La situación por dependencia funcional es similar, aunque en Castilla y León hay un mayor predominio de los hospitales privados que en Galicia. En 2012, la primera región cuenta con 16 centros pertenecientes al Sistema Nacional de Salud y 21 privados, mientras que la segunda tiene 19 públicos y 18 privados. Lo que llama la atención es la evolución que este factor ha tenido a lo largo del tiempo. En 1997, por ejemplo, Castilla y León mantenía más centros públicos que privados (29 frente a 23). No obstante, el caso de Galicia es lo opuesto: había 19 hospitales públicos y los 41 restantes eran privados. Por lo tanto, en la región castellana, no se ha modificado prácticamente la suma de clínicas privadas a lo largo de los años, a pesar de que las públicas se han concentrado considerablemente. En cambio, en Galicia las públicas han aumentado levemente, pero el cambio realmente significativo lo ofrecen las privadas, que han visto reducirse su cuantía a casi la mitad.

Tabla 19. Evolución del número de hospitales por dependencia funcional en Castilla y León y Galicia

\begin{tabular}{|c|c|c|c|c|c|c|}
\hline \multirow{3}{*}{ Año } & \multicolumn{6}{|c|}{ Número Hospitales } \\
\hline & \multicolumn{3}{|c|}{ Públicos } & \multicolumn{3}{|c|}{ Privados } \\
\hline & $\begin{array}{l}\text { Castilla } \\
\text { y León }\end{array}$ & Galicia & $\begin{array}{c}\text { Total } \\
\text { nacional }\end{array}$ & $\begin{array}{l}\text { Castilla } \\
\text { y León }\end{array}$ & Galicia & $\begin{array}{c}\text { Total } \\
\text { nacional }\end{array}$ \\
\hline 2012 & 16 & 19 & 453 & 21 & 18 & 306 \\
\hline 2011 & 16 & 19 & 452 & 21 & 18 & 311 \\
\hline 2010 & 16 & 18 & 446 & 21 & 21 & 319 \\
\hline 2009 & 17 & 16 & 353 & 23 & 23 & 417 \\
\hline 2008 & 15 & 16 & 345 & 24 & 24 & 422 \\
\hline 2007 & 15 & 17 & 335 & 26 & 27 & 429 \\
\hline 2006 & 16 & 17 & 325 & 23 & 29 & 421 \\
\hline 2005 & 16 & 17 & 330 & 25 & 30 & 421 \\
\hline 2004 & 18 & 17 & 333 & 26 & 30 & 417 \\
\hline 2003 & 19 & 19 & 336 & 26 & 28 & 405 \\
\hline 2002 & 26 & 18 & 342 & 26 & 31 & 417 \\
\hline 2001 & 27 & 18 & 351 & 27 & 30 & 417 \\
\hline 2000 & 27 & 17 & 356 & 26 & 34 & 415 \\
\hline 1999 & 28 & 17 & 359 & 23 & 37 & 415 \\
\hline 1998 & 28 & 19 & 356 & 23 & 40 & 424 \\
\hline 1997 & 29 & 19 & 360 & 23 & 41 & 428 \\
\hline \begin{tabular}{|l|} 
Diferencia \\
2012-1997
\end{tabular} & -13 & 0 & 93 & -2 & -23 & -122 \\
\hline \begin{tabular}{|l} 
\%Diferencia \\
2012-1997
\end{tabular} & $-44,83$ & 0 & 25,83 & $-8,70$ & $-56,10$ & $-28,50$ \\
\hline
\end{tabular}

Fuente: Estadística de Centros Sanitarios de Atención Especializada y Estadística de Establecimientos Sanitarios con Régimen de Internado. 


\subsubsection{FINALIDAD ASISTENCIAL}

En Castilla y León hay dos hospitales más de larga estancia que en Galicia. La primera comunidad cuenta con 7 y la segunda, con dos. El resto pertenecen al ámbito general (o de agudos, según la estadística que se tenga en cuenta $^{\underline{9}}$ ). La región de la meseta dispone de 30 de este tipo, y la gallega de 32.

Tabla 20. Número de hospitales en Castilla y León y Galicia por finalidad asistencial

\begin{tabular}{|c|c|c|c|c|c|c|c|c|}
\hline \multirow{3}{*}{ Año } & \multicolumn{8}{|c|}{ Número Hospitales } \\
\hline & \multicolumn{2}{|c|}{$\begin{array}{l}\text { Hospitales } \\
\text { generales }^{10}\end{array}$} & \multicolumn{2}{|c|}{$\begin{array}{c}\text { Otros hospitales } \\
\text { de agudos }\end{array}$} & \multicolumn{2}{|c|}{$\begin{array}{l}\text { Hospitales de } \\
\text { larga estancia }\end{array}$} & \multicolumn{2}{|c|}{$\begin{array}{c}\text { Hospitales } \\
\text { psiquiátricos }\end{array}$} \\
\hline & $\begin{array}{l}\text { Castilla } \\
\text { y León }\end{array}$ & Galicia & $\begin{array}{l}\text { Castilla } \\
\text { y León }\end{array}$ & Galicia & $\begin{array}{l}\text { Castilla } \\
\text { y León }\end{array}$ & Galicia & $\begin{array}{l}\text { Castilla } \\
\text { y León }\end{array}$ & Galicia \\
\hline 2012 & 30 & 32 & - & - & 7 & 5 & - & . \\
\hline 2011 & 30 & 32 & - & - & 7 & 5 & - & - \\
\hline 2010 & 30 & 32 & - & - & 7 & 7 & - & - \\
\hline 2009 & 29 & 27 & 3 & 5 & 3 & 2 & 5 & 5 \\
\hline 2008 & 28 & 27 & 4 & 5 & 3 & 3 & 4 & 5 \\
\hline 2007 & 31 & 29 & 3 & 6 & 3 & 3 & 4 & 6 \\
\hline 2006 & 26 & 29 & 5 & 7 & 3 & 4 & 5 & 6 \\
\hline 2005 & 27 & 29 & 5 & 8 & 3 & 4 & 6 & 6 \\
\hline 2004 & 29 & 30 & 5 & 8 & 3 & 3 & 7 & 6 \\
\hline 2003 & 30 & 29 & 5 & 9 & 3 & 3 & 7 & 6 \\
\hline 2002 & 34 & 30 & 7 & 10 & 3 & 3 & 8 & 6 \\
\hline 2001 & 38 & 30 & 5 & 9 & 3 & 3 & 8 & 6 \\
\hline 2000 & 34 & 31 & 7 & 12 & 4 & 2 & 8 & 6 \\
\hline 1999 & 33 & 32 & 7 & 14 & 3 & 2 & 8 & 6 \\
\hline 1998 & 32 & 36 & 7 & 14 & 4 & 2 & 8 & 7 \\
\hline 1997 & 34 & 37 & 6 & 13 & 3 & 2 & 9 & 8 \\
\hline $\begin{array}{l}\text { Diferencia } \\
2012-1997\end{array}$ & -4 & -5 & & & 4 & 3 & & \\
\hline $\begin{array}{l}\text { \%Diferencia } \\
\text { 2012-1997 }\end{array}$ & $-11,76$ & $-13,51$ & & & 133,33 & 150,00 & & \\
\hline
\end{tabular}

Fuente: Estadística de Centros Sanitarios de Atención Especializada y Estadística de Establecimientos Sanitarios con Régimen de Internado.

Se puede ver más información sobre la evolución y situación actual de los hospitales en Castilla y León y Galicia en el anexo número 2.

\footnotetext{
9 Desde 2010, la Estadística de Centros Sanitarios de Atención Especializada únicamente contabiliza las plazas de día en hospitales de agudos y de larga estancia, mientras que la Estadística de Establecimientos Sanitarios con Régimen de Internado también mostraba la cifra de hospitales de agudos y psiquiátricos.

${ }^{10}$ Desde 2010, la Estadística de Centros Sanitarios de Atención Especializada únicamente contabiliza las plazas de día en hospitales de agudos y de larga estancia. En este caso, se ha traspasado los datos de la columna de agudos a los generales por ofrecer una mayor continuidad con los años anteriores, en los que estaba en vigor la Estadística de Establecimientos Sanitarios con Régimen de Internado.
} 

2. MARCO EXPERIMENTAL

2.1. Metodología

2.2. Resultados 


\title{
2.1. METODOLOGÍA
}

\author{
2.1.1. Análisis cualitativo: entrevistas a los responsables de comunicación \\ de los hospitales
}

2.1.2. Análisis cuantitativo: encuesta a los responsables de comunicación de los hospitales

2.1.3. Medición de la exposición: análisis de prensa 2.1.4 Medición de la opinión y satisfacción del público: encuestas de satisfacción

La parte empírica de la tesis doctoral gira en torno a tres metodologías diferentes. Por una parte, se han realizado entrevistas personales a los responsables de comunicación de los hospitales de las dos comunidades autónomas a estudio con el fin de obtener información cualitativa sobre su trayectoria, sus labores, su independencia, las mejoras que implantarían, etc. Por otro lado, esas mismas personas han cumplimentado una encuesta con la que se obtienen datos cuantitativos que ayudan a medir el uso de las relaciones públicas en el ámbito hospitalario. Asimismo, se ha realizado un análisis de prensa para conocer si existen diferencias en la exposición que tienen los temas sanitarios en los medios de comunicación según las características comunicativas de cada región. Finalmente, se han consultado varias encuestas sobre el interés que tiene la población sobre estos asuntos y su satisfacción con el funcionamiento del sistema sanitario.

De esta manera, la parte empírica de la tesis doctoral conjuga tanto el paradigma cualitativo como el cuantitativo. El primer enfoque persigue crear tendencias generalizables y sus datos son susceptibles de tratamiento estadístico (Lozano Rendón, 2007: 10); el segundo ayuda a contextualizar y encuadrar hipótesis, algo que no se puede realizar desde un punto de vista exclusivamente cuantitativo (Wimmer y Dominick, 1996: 148). Con la unión de ambas metodologías se logra el fenómeno de la triangulación, un enfoque que compensa las debilidades de un método con otro distinto, consiguiendo así unos resultados "más fiables y enteramente satisfactorios" (Elías, 2000: 38). Se trata de la fase más avanzada de la integración de varias metodologías (complementación, combinación y triangulación), puesto que convergen los resultados de todas las metodologías para que alcancen las mismas conclusiones (Rodríguez Breijo, 2009). 


\subsubsection{ANÁLISIS CUALITATIVO: ENTREVISTAS A LOS RESPONSABLES DE COMUNICACIÓN DE LOS HOSPITALES}

Con el fin de conocer de primera mano las características propias de la comunicación en los hospitales de Castilla y León y de Galicia, se decidió realizar entrevistas personales a los responsables de comunicación de estos centros, tanto públicos como privados. Para ello, se consultó el Catálogo Nacional de Hospitales (Ministerio de Sanidad, 2013a) para conocer los centros de atención especializada de cada zona. Posteriormente, se procedió a contactar por teléfono con cada uno de ellos para dar con el responsable de comunicación de cada hospital y solicitarle su colaboración en el estudio.

Paralelamente, se creó una página web con información sobre la tesis doctoral para que los responsables de comunicación conociesen con más detalle las características del estudio. En esta plataforma se incluyó un resumen general, los objetivos, la estructura, los currículum vítae abreviados de la autora y de los directores, la encuesta que se les entregaría en las reuniones y los datos de contacto. A la hora de solicitar la participación de los responsables de comunicación, se les explicó por teléfono las particularidades de la tesis doctoral y se les envió por correo electrónico un resumen del trabajo y un enlace a la página web.

Ilustración 5. Capturas de pantalla de la página web explicativa de la tesis doctoral

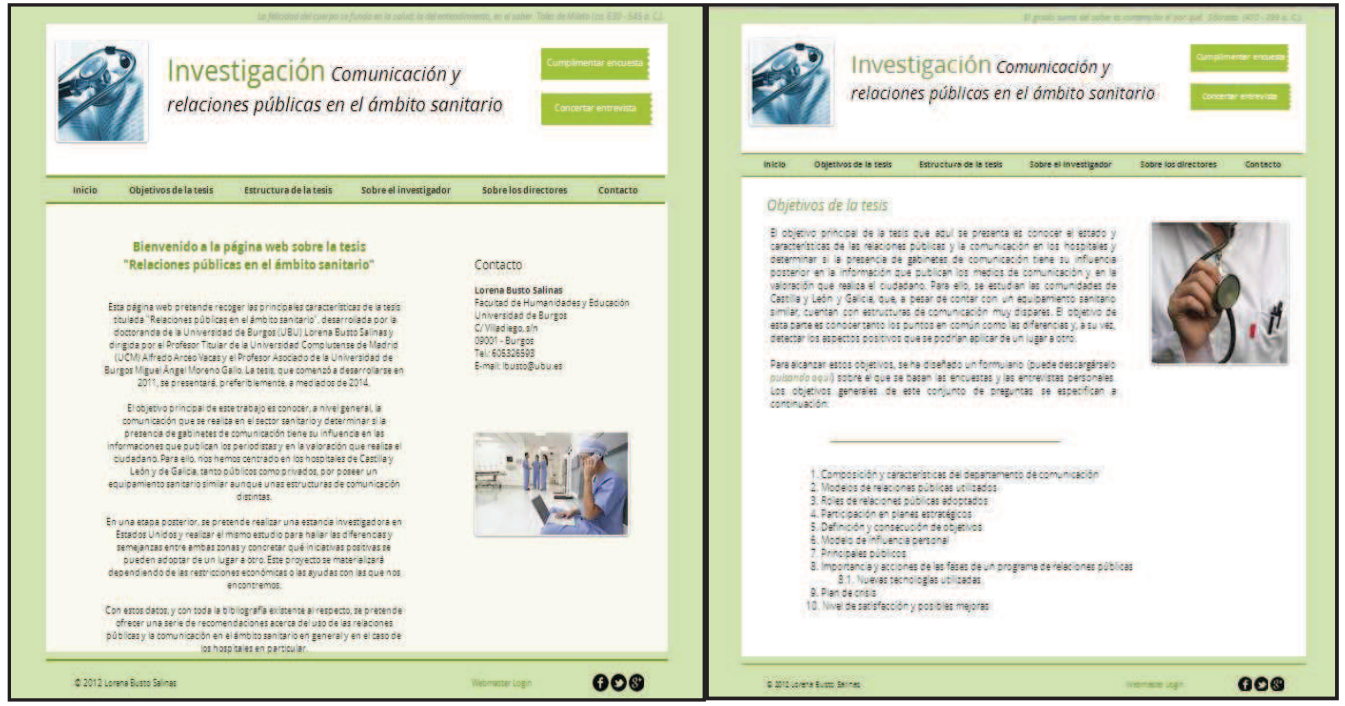




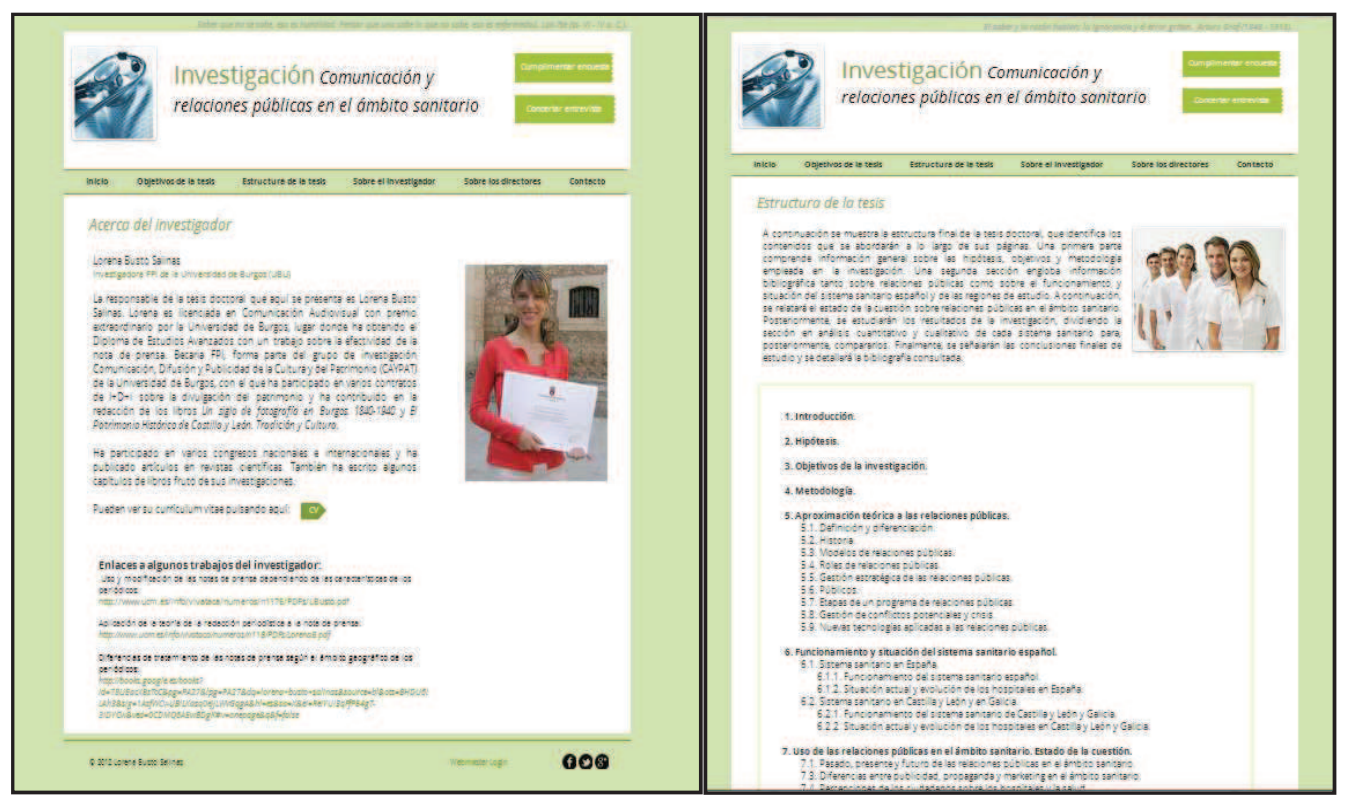

Fuente: elaboración propia.

\subsubsection{ENTREVISTAS A LOS RESPONSABLES DE COMUNICACIÓN DE LOS HOSPITALES DE GALICIA}

El procedimiento que se llevó a cabo para conseguir los encuentros con los responsables de comunicación de los hospitales en la región gallega comenzó a través del jefe de prensa de la Consellería de Sanidade de la Xunta de Galicia, Félix Cabanas Muiños, el cual se mostró desde un principio dispuesto a colaborar en el estudio. Mediante conversación telefónica, explicó que los hospitales se encuentran englobados dentro de gerencias de gestión integradas, para las cuales trabajan uno o dos comunicadores -según los casos-, que se ocupan tanto de los centros de atención especializada como de los de atención primaria. El jefe de prensa de la Xunta de Galicia trasladó la solicitud de colaboración a los responsables de cada una de las gestiones integradas $\mathrm{y}$, con su visto bueno, proporcionó los datos de contacto de estos trabajadores. Posteriormente, la autora de la tesis contactó por teléfono y por correo electrónico con cada uno de ellos para explicarles los objetivos de estudio y solicitar su participación.

Por su parte, a los encargados de comunicación de los centros privados se les localizó a través de las secciones de información de cada hospital, que derivaron la consulta a los empleados en plantilla o a las empresas externas, según el caso. Con estos trabajadores, también se hizo uso del correo electrónico y del teléfono para explicar las características de la investigación.

Conviene señalar que ningún responsable de comunicación de los hospitales de Galicia se negó a ser entrevistado para el estudio, sino que todos se mostraron abiertos a 
colaborar de cualquier manera disponible, lo que implica que son dados a cooperar con el ámbito universitario y que no son reacios a que estudien sus características y modos de trabajo. Hay que matizar que a posteriori un entrevistado no dio autorización para mostrar su nombre junto con sus declaraciones por encontrarlas "demasiado textuales" y pensar que las entrevistas servirían simplemente "como base de conocimiento" para la tesis doctoral. En consecuencia, no se identifica a esta persona con ninguna de sus frases.

Los encuentros se produjeron durante los meses de mayo y junio de 2013 y se desarrollaron, en su mayoría, en los despachos de los propios comunicadores, ya estuviesen en los propios hospitales o en las empresas externas. Además de a los responsables del departamento, en dos casos, más concretamente en la estructura de gestión integrada de Santiago de Compostela y en la Fundación Pública Urxencias Sanitarias de Galicia-061, se contó también con la opinión de los otros trabajadores del servicio de comunicación. En cambio, en la estructura de gestión integrada de Coruña se entrevistó a Kiko Fernández Porto en vez de a la responsable, Cristina de la Vega Jiménez, al encontrarse de baja en esa época. La relación de comunicadores sanitarios, así como la estructura de gestión integrada o los hospitales para los que trabajan se muestra en la siguiente tabla:

Tabla 21. Relación de entrevistados de los centros de atención especializada de Galicia

\begin{tabular}{|l|l|l|l|}
\hline \multicolumn{1}{|c|}{$\begin{array}{c}\text { Estructura de gestión } \\
\text { integrada u hospital }\end{array}$} & \multicolumn{1}{|c|}{ Entrevistado } & $\begin{array}{c}\text { Segundo } \\
\text { entrevistado }\end{array}$ & Empresa externa \\
\hline EXI A Coruña & $\begin{array}{l}\text { Kiko Fernández } \\
\text { Porto }\end{array}$ & - & - \\
\hline EXI Ferrol & María José Iglesias & - & - \\
\hline $\begin{array}{l}\text { EXI Santiago de } \\
\text { Compostela }\end{array}$ & Ana López Pimentel & $\begin{array}{l}\text { Beatriz Senra } \\
\text { López }\end{array}$ & - \\
\hline $\begin{array}{l}\text { EXI Pontevedra y O } \\
\text { Salnés }\end{array}$ & $\begin{array}{l}\text { Raúl Álvarez } \\
\text { Salcedo }\end{array}$ & - & - \\
\hline EXI Vigo & Irene Pazo Manzano & - & - \\
\hline $\begin{array}{l}\text { EXI Lugo, Cervo y } \\
\text { Monforte de Lemos }\end{array}$ & Paz Teijeira Fanego & - & - \\
\hline $\begin{array}{l}\text { EXI Ourense, Verín y O } \\
\text { Barco de Valdeorras }\end{array}$ & $\begin{array}{l}\text { Myriam Sierra } \\
\text { Gómez }\end{array}$ & - & - \\
\hline $\begin{array}{l}\text { Fundación Pública } \\
\text { Urxencias Sanitarias } \\
\text { de Galicia-061 }\end{array}$ & Marta Castro Pérez & $\begin{array}{l}\text { Arantza Briegas } \\
\text { Arenas }\end{array}$ & - \\
\hline
\end{tabular}




\begin{tabular}{|l|l|l|l|}
\hline \multicolumn{1}{|c|}{$\begin{array}{c}\text { Estructura de gestión } \\
\text { integrada u hospital }\end{array}$} & \multicolumn{1}{|c|}{ Entrevistado } & $\begin{array}{c}\text { Segundo } \\
\text { entrevistado }\end{array}$ & Empresa externa \\
\hline $\begin{array}{l}\text { Centro Oncológico de } \\
\text { Galicia }\end{array}$ & Pepe Losada & - & - \\
\hline $\begin{array}{l}\text { Hospital Quirón A } \\
\text { Coruña }\end{array}$ & $\begin{array}{l}\text { Patricia Forteza } \\
\text { Monfort }\end{array}$ & - & - \\
\hline $\begin{array}{l}\text { Hospital Modelo y } \\
\text { Maternidad Belén }\end{array}$ & Irene Montero Díaz & - & Octo \\
\hline $\begin{array}{l}\text { Hospital General Juan } \\
\text { Cardona }\end{array}$ & $\begin{array}{l}\text { Antolín Hermida } \\
\text { Armesto }\end{array}$ & - & $\begin{array}{l}\text { Larín } \\
\text { Comunicación }\end{array}$ \\
\hline $\begin{array}{l}\text { Hospital Policlínico La } \\
\text { Rosaleda }\end{array}$ & Tomás Valín López & - & Global ${ }^{11}$ \\
\hline Hospital Povisa & Álvaro Otero & - & Atlántica \\
\hline $\begin{array}{l}\text { Hospital Vithas Nuestra } \\
\text { Señora De Fátima }\end{array}$ & $\begin{array}{l}\text { Xabier López } \\
\text { Escalante }\end{array}$ & - & Autónomo \\
\hline
\end{tabular}

Fuente: elaboración propia.

\subsubsection{ENTREVISTAS A LOS RESPONSABLES DE COMUNICACIÓN DE LOS HOSPITALES DE CASTILLA Y LEÓN}

Los encuentros con los jefes de comunicación de los hospitales de Castilla y León se produjeron en marzo de 2014. Como los pertenecientes al Sistema Nacional de Salud no cuentan con una persona dedicada a la comunicación, sino que centralizan toda esta labor en el departamento de comunicación de la Consejería de Sanidad, se entrevistó a la jefa de este servicio, Blanca Saravia Ibañes. Se accedió a ella a través de la centralita de la mencionada sección de la Junta de Castilla y León. En cuanto a los hospitales privados, se realizó una tanda de llamadas telefónicas a las secciones de información de cada centro para comprobar si existía alguna persona al frente de estas actividades. Ya fuesen trabajadores pertenecientes a la plantilla del centro o empresas externas, se contactó con ellos por teléfono y se les envió un correo electrónico con información sobre la tesis doctoral y un enlace a la página web creada por la investigadora.

\footnotetext{
$\underline{11}$ En el momento de la entrevista, la empresa Larín Comunicación Global era la encargada de realizar las labores comunicativas del Hospital General Juan Cardona. Desde marzo de 2014, no obstante, esta tarea está encomendada a la compañía Kaotic Medios Digitales, tal y como precisó Antolín Hermida Armesto a la autora de la tesis doctoral.
} 
De los 37 hospitales que se contabilizan en Castilla y León en 2013 según el Catálogo Nacional de Hospitales (Ministerio de Sanidad, 2013a), únicamente seis cuentan con servicio de comunicación. Los 15 centros públicos centralizan la comunicación en la Consejería de Sanidad o, en su defecto y como se verá posteriormente, en las delegaciones de salud de la Junta de Castilla y León en cada provincia. En cuanto a los 22 privados, existen tres agrupaciones que engloban una buena parte de ellos. Estas son, según el Catálogo Nacional de Hospitales (Ministerio de Sanidad, 2013a), Grupo Recoletas (que incluye el Hospital Recoletas Burgos, el Hospital Recoletas Palencia, el Hospital Recoletas Segovia, el Hospital Recoletas Zamora, el Hospital Campo Grande y el Hospital Felipe II), las Hermanas Hospitalarias (que cuentan con el Centro Hospitalario Benito Menni y el Complejo Hospitalario San Luis) y los Hermanos de San Juan de Dios (que gestionan el Hospital San Juan de Dios de Burgos, el Hospital San Juan de Dios de León y el Centro Asistencial San Juan de Dios de Palencia). El primer grupo mantiene una persona en plantilla encargada de la comunicación, el segundo confía su comunicación a una agencia que gestiona la comunicación de sus dos hospitales y el tercero únicamente contrata servicios externos para el centro San Juan de Dios de León.

Después de contactar con todos los hospitales y comprobar en cuáles existe servicio de comunicación, se procedió a concertar entrevistas personales con los responsables. En total, de los siete centros que poseen este departamento, cuatro aceptaron colaborar. El resto -Clínica Ponferrada, Grupo Recoletas y Protección Civil (112)-, bien por silencio de la gerencia, por motivos de confidencialidad o por extralimitación de competencias, en este orden, decidieron no participar en la tesis. Al final, las personas entrevistadas fueron las siguientes:

Tabla 22. Relación de entrevistados de los centros de atención especializada de Castilla y León

\begin{tabular}{|l|l|l|}
\hline \multicolumn{1}{|c|}{ Hospital } & \multicolumn{1}{c|}{ Entrevistado } & \multicolumn{1}{c|}{ Empresa } \\
\hline $\begin{array}{l}\text { Consejería de Sanidad de la Junta de } \\
\text { Castilla y León }\end{array}$ & Blanca Saravia Ibañes & - \\
\hline Hospital San Juan de Dios de León & Meritxell Moya Revilla & DLV-La Central \\
\hline Clínica San Francisco & Pedro Lechuga Mallo & - \\
\hline $\begin{array}{l}\text { Hospital Psiquiátrico San Luis y } \\
\text { Complejo Hospitalario Benito Menni }\end{array}$ & Francisco Suárez & $\begin{array}{l}\text { Comunicación } \\
\text { Profesional }\end{array}$ \\
\hline
\end{tabular}

Fuente: elaboración propia. 


\subsubsection{CONTENIDO DE LAS ENTREVISTAS}

En los encuentros se trataron temas como los estudios que habían cursado, la trayectoria profesional, su día a día, los principales públicos y las acciones con cada uno de ellos, la libertad o presiones que sufren, etc. Los encuentros tenían una duración de entre 45 minutos a una hora y media. Las preguntas generales sobre las que giraba el cuestionario, y a partir de las cuales podían surgir otras nuevas, son las siguientes:

1. Trayectoria profesional.

2. Día a día en el hospital.

3. Principales públicos, a saber: pacientes, familiares y visitas, empleados, agentes políticos e institucionales, inversores o accionistas (en su caso), medios de comunicación, población en general...

4. ¿Cómo se comunica con cada público?

5. ¿Alguna acción de comunicación novedosa?

6. Organigrama: ¿de quién depende el departamento de comunicación?

7. ¿Influye la persona que gobierne la comunidad o el gerente del hospital? Ejemplos.

8. ¿Conoce su presupuesto? ¿Le supone una gran traba?

9. ¿Cuánta libertad tiene para realizar las acciones (contenidos, presupuesto, ideología...)?

10. ¿Cuáles son las presiones que tiene que soportar (derecho a la intimidad, derecho a la información...)?

11. ¿Qué diferencias cree que existen entre gestionar la comunicación dentro de la institución o a través de una empresa externa? ¿Qué considera que es mejor?

12. Beneficios de un departamento de comunicación para el hospital y la sanidad en general.

13. Errores comunicativos que se comenten (tanto en el hospital como en el ámbito de la salud en general).

14. Mejoras que implantaría (tanto en el hospital como en general).

15. ¿Por qué no se llevan a cabo esas acciones (tanto en el hospital como en general)?

Para el análisis de esta parte, se han agrupado sus opiniones según la comunidad autónoma y la temática y se han incorporado declaraciones textuales así como ejemplos reales que han proporcionado los trabajadores. En algunos casos, bien por petición expresa de los encuestados o por iniciativa propia de la investigadora, no se atribuyen las citas a un personaje en concreto por las repercusiones que podrían tener en su entorno. 


\subsubsection{ANÁLISIS CUANTITATIVO: ENCUESTAS A LOS RESPONSABLES DE COMUNICACIÓN DE LOS HOSPITALES}

Para conseguir datos cuantitativos que determinen el uso de las relaciones públicas por parte de los departamentos de comunicación de los hospitales, se ha diseñado una encuesta acerca de los diferentes aspectos de esta disciplina. Algunas preguntas han sido redactadas por la investigadora de esta tesis y otras han sido adaptadas de otras investigaciones relacionadas.

Se ha optado por cuatro clases de recogida de datos. En su mayoría, se trata de preguntas de escala Likert de 1 a 5, donde el uno equivale a "totalmente en desacuerdo" y el cinco a "totalmente de acuerdo". También hay varias tablas de verificación o checkboxs, para las cuales el entrevistado únicamente debe seleccionar las variables con las que esté de acuerdo dentro de unas opciones fijas. Asimismo, unas preguntas se responden o con respuesta "sí o no" y en unos pocos casos, se debe seleccionar la respuesta de una lista desplegable.

Las preguntas para determinar el uso de los cuatro modelos de J. E. Grunig (1984) han sido adaptadas del cuestionario del Excellence Study, empleado también en otras investigaciones, como las de Gordon y Kelly (1999) y Xifra (2008). Así, se ofrecen cuatro ideas por cada modelo estudiado, dando un total de 16 preguntas. También se ha querido estudiar la presencia del bidireccional simétrico persuasivo, propuesto por José Luis Arceo Vacas (2006), por lo que se han redactado otras cuatro afirmaciones para determinar su uso, quedando la cifra, finalmente, en 20, pudiendo ser contestados en una escala de 1 a 5 .

En cuanto a los roles de relaciones públicas empleados, se ha tenido en cuenta la selección que inicialmente realizó Kelly (1994) y que posteriormente se adaptaría en otras investigaciones, como la de Gordon y Kelly (1999). Esta investigadora redujo las 16 preguntas de J. E. Grunig (1992b) a ocho, cuatro por cada rol estudiado. En este caso, también se ha empleado una escala Likert.

La siguiente serie de afirmaciones de la encuesta trata sobre la definición y consecución de objetivos concretos y sobre la participación en planes estratégicos. Las referentes a la primera cuestión son de elaboración propia, mientras que las del segundo aspecto se han tomado de Gordon y Kelly (1999). Más concretamente, las dos ideas que se han seleccionado de estas investigadoras son: el equipo estratégico de planes suele consultar al departamento de comunicación y algún miembro del departamento forma parte del equipo estratégico del hospital. Exceptuando una respuesta de "sí o no", el resto se han diseñado mediante escala. 
Para determinar el modelo de influencia personal propuesto por Sriramesh (1991), se ha empleado el cuestionario utilizado por Xifra (2008) en su análisis de los modelos de relaciones públicas en Cataluña, que incluye las siguientes cuestiones: tengo buenas relaciones interpersonales con otros empleados, tengo buenas relaciones interpersonales con las personas externas de mi organización, las relaciones sociales es una de mis actividades más importantes y procuro beneficios (comidas, regalos) para ganar influencia con mis contactos personales. Los encuestados podían responder en una escala de 1 ("totalmente en desacuerdo") a 5 ("totalmente de acuerdo").

Una vez determinada la importancia que los responsables de comunicación le otorgan a las relaciones sociales, se ha querido comprobar qué público es el más relevante para el departamento. Para ello, se ha seleccionado una serie de colectivos que, a priori, engloba todas las audiencias de los hospitales. Estos son: los pacientes, los familiares y las visitas, los empleados, los agentes políticos e institucionales, los inversores o accionistas (en su caso), los medios de comunicación y la población en general. De esta lista, los encuestados debían elegir de 1 a 5 el nivel de importancia que otorgan a cada colectivo.

Dado que una gestión estratégica de las relaciones públicas exige una planificación concreta, se ha querido determinar el grado de relevancia que se le otorgan a las diferentes fases mediante una escala. De los modelos existentes, se ha seleccionado la versión de Hainsworth y Wilson (1992) y Guth y Marsh (2011), que dividen las etapas de una campaña en: investigación, planificación, comunicación y evaluación.

Para hallar las herramientas que usan los departamentos de comunicación en cada etapa, se han creado unas tablas de verificación o checkboxs con una amplia lista de opciones. Asimismo, se ofrecía la posibilidad de completar estas respuestas con una casilla de libre cumplimentación. En cuanto a la fase de investigación, muchas de las tácticas se han seleccionado del manual Relaciones Públicas: estrategias y tácticas, de Wilcox, Cameron y Xifra (2007), mientras que otras son de elaboración propia. En cuanto a la planificación, todas ellas provienen del citado manual. Dada la cantidad de herramientas disponibles para ejecutar la fase de comunicación y los públicos a los que se puede dirigir, se ha dividido las tablas de verificación según las audiencias principales para las que se utilizan: empleados, pacientes y visitas, medios de comunicación y población. Así, tanto para esta sección como para la de evaluación, se han consultado y adoptado algunas opciones de Wilcox, Cameron y Xifra (2007), Xifra (2007), Castillo Esparcia (2006), Rojas (2008), Palencia-Lefler (2011) y otras de inclusión propia.

Asimismo, se han estudiado, tal y como Wilcox, Cameron y Xifra (2007) dividen, los diferentes tipos de medición: producción, exposición, opinión y actitud del público y acciones y comportamientos del público. Para ello, se ha utilizado una escala Likert. Posteriormente, se ha demandado a los responsables de comunicación si poseen un plan 
de crisis, cada cuánto se revisa y se pone en práctica (estas dos preguntas con respuestas fijas de una lista desplegable) y si existe un equipo prefijado de personas para posibles conflictos. Finalmente, se les ha preguntado cómo de importante consideran su departamento para el hospital y cómo de satisfechos están con las actividades de comunicación que lleva a cabo el centro en una escala de 1 a 5.

Una vez las encuestas han sido cumplimentadas, se han introducido las respuestas en el programa estadístico SPSS y se han realizado diversos análisis, sobre todo descriptivos y frecuencias, dividiendo los resultados según las hipótesis de partida. También se han ejecutado varias pruebas estadísticas, como la prueba de chi-cuadrado o la prueba $\mathrm{T}$ de Student, para hallar las relaciones estadísticamente significativas La significación se ha fijado en igual o menor de 0,05. De esta forma, se puede establecer que existe una relación estadística y que los resultados no son frutos del azar. Así, se ha analizado la diferencia de las respuestas entre Castilla y León y Galicia, entre el ámbito público y el privado y entre los gabinetes internos y externos. 


\section{$\frac{1}{2}$ \\ ENCUESTA SOBRE LA PRÁCTICA DE LAS RELACIONES PÚBLICAS EN EL ÁMBITO SANITARIO}

Universidad de Burgos

El objetivo de la encuesta es conocer el estado actual de la práctica de las relaciones públicas en el ámbito sanitario, más concretamente en los hospitales de Castilla y León y de Galicia. Las respuestas serán tratadas de manera confidencial y los resultados únicamente se utilizarán para fines científicos. Por favor, cumplimente todas las preguntas de este documento.

1. Conteste a las siguientes cuestiones relativas a la composición y características del departamento de comunicación:

\begin{tabular}{|l|l|}
\hline Nombre de la institución: & \\
\hline Finalidad asistencial: & Elija un elemento. \\
\hline Dependencia funcional: & Elija un elemento. \\
\hline Nombre del departamento de comunicación: & \\
\hline $\begin{array}{l}\text { Pertenece el departamento de comunicación al } \\
\text { hospital o se trata de una empresa externa }\end{array}$ & Elija un elemento. \\
\hline $\begin{array}{l}\text { De quién depende directamente el } \\
\text { departamento de comunicación: }\end{array}$ & \\
\hline $\begin{array}{l}\text { Número de personas que trabajan en el } \\
\text { departamento de comunicación: }\end{array}$ & Elija un elemento. \\
\hline
\end{tabular}

2. Conteste a las siguientes cuestiones relativas a los trabajadores del departamento de comunicación. Por favor, dentro de sus posibilidades, intente rellenar el máximo número posible de casillas. Puede rellenar los apartados que considere oportunos o dejar todos en blanco.

\begin{tabular}{|l|l|l|l|l|l|}
\hline & Edad & Sexo & Nivel de estudios & \multicolumn{1}{|c|}{$\begin{array}{c}\text { Rama de } \\
\text { conocimiento }\end{array}$} & $\begin{array}{c}\text { Años de } \\
\text { experiencia }\end{array}$ \\
\hline Trabajador 1 & & Elija & Elija & Elija & \\
\hline Trabajador 2 & & Elija & Elija & Elija & \\
\hline Trabajador 3 & & Elija & Elija & Elija & \\
\hline Trabajador 4 & & Elija & Elija & Elija & \\
\hline Trabajador 5 & & Elija & Elija & Elija & \\
\hline Trabajador 6 & & Elija & Elija & Elija & \\
\hline Trabajador 7 & & Elija & Elija & Elija & \\
\hline Trabajador 8 & & Elija & Elija & Elija & \\
\hline Trabajador 9 & & Elija & Elija & Elija & \\
\hline
\end{tabular}


3. Señale otros posibles hospitales de los que sea miembro del departamento de comunicación o cualquier otro comentario que le resulte relevante:

4. Indique su grado de aceptación de las siguientes afirmaciones $(1=$ totalmente en desacuerdo; 5 = muy de acuerdo):

\begin{tabular}{|c|c|c|c|c|c|}
\hline & 1 & 2 & 3 & 4 & 5 \\
\hline $\begin{array}{l}\text { Convencemos al periodista para que dé a conocer nuestra } \\
\text { organización }\end{array}$ & $\square$ & $\square$ & $\square$ & $\square$ & $\square$ \\
\hline $\begin{array}{l}\text { Colocamos el nombre de nuestra organización en los } \\
\text { medios }\end{array}$ & $\square$ & L & & 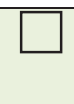 & $L$ \\
\hline Eliminamos la cobertura mediática negativa & & $\square$ & & & \\
\hline Queremos la máxima cobertura en nuestros eventos & & & & & \\
\hline $\begin{array}{l}\text { Suministramos información objetiva sobre nuestra } \\
\text { organización }\end{array}$ & $\square$ & $\square$ & & $\square$ & \\
\hline Entendemos los valores informativos de los periodistas & & & & & \\
\hline $\begin{array}{l}\text { Preparamos informaciones para ser usadas por los } \\
\text { periodistas }\end{array}$ & $\square$ & 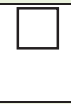 & & $\bar{\square}$ & \\
\hline $\begin{array}{l}\text { Actuamos como un periodista interno de nuestra } \\
\text { organización }\end{array}$ & $\square$ & ${ }^{\square}$ & & & \\
\hline $\begin{array}{l}\text { Queremos que los públicos actúen como quiere la } \\
\text { organización }\end{array}$ & $\square$ & $\square$ & & 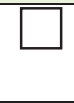 & \\
\hline Aplicamos la teoría de las actitudes en una campaña & L & L & & & \\
\hline Manipulamos científicamente a los públicos & & & & & \\
\hline $\begin{array}{l}\text { Persuadimos al público de que nuestra organización tiene } \\
\text { razón sobre un determinado tema }\end{array}$ & \begin{tabular}{|c|c|} 
\\
\end{tabular} & L & & & \\
\hline $\begin{array}{l}\text { Determinamos cómo el público reacciona ante la } \\
\text { organización }\end{array}$ & $\square$ & $\square$ & & $\mathbf{L}^{-1}$ & $\square$ \\
\hline Negociamos con grupos de presión & & & & & \\
\hline $\begin{array}{l}\text { Utilizamos las teorías de la resolución de conflictos en } \\
\text { nuestro trato con los públicos }\end{array}$ & $\square$ & $\square$ & & & $\square$ \\
\hline $\begin{array}{l}\text { Ayudamos a los dirigentes a entender la opinión de } \\
\text { públicos particulares }\end{array}$ & $\square$ & L & & $\square$ & $\square$ \\
\hline $\begin{array}{l}\text { Uno de nuestros principales objetivos es mantener una } \\
\text { buena relación con los públicos }\end{array}$ & $\square$ & $\square$ & & L & $\square$ \\
\hline $\begin{array}{l}\text { De esa buena relación, pretendemos crear un ambiente en } \\
\text { el que se reciban mejor nuestras propuestas o } \\
\text { informaciones }\end{array}$ & $\square$ & $\square$ & & & $\square$ \\
\hline $\begin{array}{l}\text { Creemos que una buena relación con los públicos, sin un } \\
\text { ejercicio de persuasión, no ayuda a que los públicos se } \\
\text { sientan persuadidos a hacer los que queremos }\end{array}$ & $\square$ & L & & $\square$ & $\square$ \\
\hline $\begin{array}{l}\text { El objetivo final es conseguir que los públicos acepten y } \\
\text { adopten mejor nuestras propuestas y acciones }\end{array}$ & $\square$ & $\square$ & $\square$ & $\square$ & $\square$ \\
\hline
\end{tabular}


5. Indique la frecuencia con la que su departamento lleva a cabo las siguientes tareas $(1=$ nunca; 5 = muy habitualmente $)$ :

\begin{tabular}{|l|l|l|l|l|l|}
\hline $\begin{array}{l}\text { Coordinar ruedas de prensa o concertar cobertura } \\
\text { mediática para un evento }\end{array}$ & $\square$ & $\square$ & $\square$ & $\square$ & $\square$ \\
\hline Elaborar publicaciones & $\square$ & $\square$ & $\square$ & $\square$ & $\square$ \\
\hline Crear y dirigir la oficina del portavoz & $\square$ & $\square$ & $\square$ & $\square$ & $\square$ \\
\hline Tomar fotografías y coordinar la fotografía & $\square$ & $\square$ & $\square$ & $\square$ & $\square$ \\
\hline Dirigir personas & $\square$ & $\square$ & $\square$ & $\square$ & $\square$ \\
\hline Conducir investigación evaluativa & $\square$ & $\square$ & $\square$ & $\square$ & $\square$ \\
\hline $\begin{array}{l}\text { Desarrollar estrategias para solucionar problemas de } \\
\text { comunicación }\end{array}$ & $\square$ & $\square$ & $\square$ & $\square$ & $\square$ \\
\hline $\begin{array}{l}\text { Manejar las respuestas de la organización hacia } \\
\text { diferentes asuntos }\end{array}$ & $\square$ & $\square$ & $\square$ & $\square$ & $\square$ \\
\hline
\end{tabular}

6. Señale hasta qué punto son ciertas las siguientes afirmaciones sobre la definición y consecución de objetivos concretos y sobre la participación en planes estratégicos ( 1 = totalmente en desacuerdo; 5 = muy de acuerdo):

\begin{tabular}{|l|l|l|l|l|l|}
\hline & $\mathbf{1}$ & $\mathbf{2}$ & $\mathbf{3}$ & $\mathbf{4}$ & $\mathbf{5}$ \\
\hline Existe una guía o un plan de comunicación & $\square$ & $\square$ & $\square$ & $\square$ & $\square$ \\
\hline Hay una serie de objetivos concretos definidos & $\square$ & $\square$ & $\square$ & $\square$ & $\square$ \\
\hline $\begin{array}{l}\text { Los objetivos de comunicación están vinculados a los } \\
\text { objetivos del hospital en general }\end{array}$ & $\square$ & $\square$ & $\square$ & $\square$ & $\square$ \\
\hline Normalmente se cumplen todos los objetivos propuestos & $\square$ & $\square$ & $\square$ & $\square$ & $\square$ \\
\hline $\begin{array}{l}\text { El equipo estratégico de planes suele consultar al } \\
\text { departamento de comunicación }\end{array}$ & $\square$ & $\square$ & $\square$ & $\square$ & $\square$ \\
\hline $\begin{array}{l}\text { Algún miembro del departamento forma parte del equipo } \\
\text { estratégico del hospital }\end{array}$ & Elija un elemento. \\
\hline
\end{tabular}

7. Señale hasta qué punto son ciertas las siguientes afirmaciones sobre su influencia personal con otros públicos $(1=$ totalmente en desacuerdo; $5=$ muy de acuerdo):

\begin{tabular}{|l|l|l|l|l|l|l|} 
& $\mathbf{1}$ & $\mathbf{2}$ & $\mathbf{3}$ & $\mathbf{4}$ & $\mathbf{5}$ \\
\hline $\begin{array}{l}\text { Tengo buenas relaciones interpersonales con otros } \\
\text { empleados }\end{array}$ & $\square$ & $\square$ & $\square$ & $\square$ & $\square$ \\
\hline $\begin{array}{l}\text { Tengo buenas relaciones interpersonales con las } \\
\text { personas externas de mi organización }\end{array}$ & $\square$ & $\square$ & $\square$ & $\square$ & $\square$ \\
\hline $\begin{array}{l}\text { Las relaciones sociales son una de mis actividades más } \\
\text { importantes }\end{array}$ & $\square$ & $\square$ & $\square$ & $\square$ & $\square$ \\
\hline $\begin{array}{l}\text { Procuro beneficios (comidas, regalos) para ganar } \\
\text { influencia con mis contactos personales }\end{array}$ & $\square$ & $\square$ & $\square$ & $\square$ & $\square$ \\
\hline
\end{tabular}


8. ¿Cómo de importantes son los siguientes públicos para el departamento de comunicación? $(1=$ muy poco importante; 5 = muy importante $)$ :

\begin{tabular}{|l|c|c|c|c|c|}
\hline & $\mathbf{1}$ & $\mathbf{2}$ & $\mathbf{3}$ & $\mathbf{4}$ & $\mathbf{5}$ \\
\hline Pacientes & $\square$ & $\square$ & $\square$ & $\square$ & $\square$ \\
\hline Familiares y visitas & $\square$ & $\square$ & $\square$ & $\square$ & $\square$ \\
\hline Empleados & $\square$ & $\square$ & $\square$ & $\square$ & $\square$ \\
\hline Agentes políticos e institucionales & $\square$ & $\square$ & $\square$ & $\square$ & $\square$ \\
\hline Inversores o accionistas (en su caso) & $\square$ & $\square$ & $\square$ & $\square$ & $\square$ \\
\hline Medios de comunicación & $\square$ & $\square$ & $\square$ & $\square$ & $\square$ \\
\hline Población en general & $\square$ & $\square$ & $\square$ & $\square$ & $\square$ \\
\hline
\end{tabular}

9. Indique cuánta importancia le da el departamento de comunicación a las siguientes fases de un programa de relaciones públicas ( $1=$ nada; $5=$ mucho):

\begin{tabular}{|l|l|l|l|l|l|}
\cline { 2 - 7 } \multicolumn{1}{c|}{} & $\mathbf{1}$ & $\mathbf{2}$ & $\mathbf{3}$ & $\mathbf{4}$ & $\mathbf{5}$ \\
\hline Investigación & $\square$ & $\square$ & $\square$ & $\square$ & $\square$ \\
\hline Planificación & $\square$ & $\square$ & $\square$ & $\square$ & $\square$ \\
\hline Comunicación & $\square$ & $\square$ & $\square$ & $\square$ & $\square$ \\
\hline Evaluación & $\square$ & $\square$ & $\square$ & $\square$ & $\square$ \\
\hline
\end{tabular}

10. Señale las acciones de investigación que lleva a cabo su departamento de comunicación:

\begin{tabular}{|l|l|l|}
\hline $\begin{array}{l}\text { Búsqueda de de } \\
\text { materiales propios de la } \\
\text { organización }\end{array}$ & $\begin{array}{l}\square \text { Búsqueda de } \\
\text { bibliografía y estudios } \\
\text { ajenos }\end{array}$ & $\begin{array}{l}\square \text { Análisis de la cobertura } \\
\text { en prensa de la organización }\end{array}$ \\
\hline$\square$ Test de mensajes & $\square$ Grupos de discusión & $\begin{array}{l}\square \text { Auditoría de } \\
\text { comunicación }\end{array}$ \\
\hline$\square$ Encuestas & $\square$ Entrevistas & $\square$ Internet \\
\hline$\square$ Pruebas piloto & $\begin{array}{l}\square \text { Mensajes de doble } \\
\text { versión }\end{array}$ & $\square$ Análisis de la percepción \\
\hline$\square$ Experimentos & $\begin{array}{l}\square \text { Técnicas de reflexión } \\
\text { en voz alta }\end{array}$ & Otros: \\
\hline
\end{tabular}

11. Señale las acciones de planificación que lleva a cabo su departamento de comunicación:

\begin{tabular}{|l|l|l|l|}
\hline$\square$ Situación & $\square$ Objetivos & $\square$ Públicos & $\square$ Estrategias \\
\hline$\square$ Tácticas & $\begin{array}{l}\square \text { Plazos } \\
\text { temporales }\end{array}$ & $\square$ Presupuesto & $\begin{array}{l}\square \text { Técnicas de } \\
\text { evaluación }\end{array}$ \\
\hline Otros:
\end{tabular}


12. Señale las acciones de comunicación que lleva a cabo su departamento de comunicación dependiendo del tipo de público al que se dirigen:

\subsection{Con los empleados:}

\begin{tabular}{|c|c|c|}
\hline Página web & Correo electrónico & Intranet \\
\hline Blog & Foro & Videoconferencias \\
\hline $\begin{array}{l}\square \text { Realidad aumentada o } \\
\text { virtual }\end{array}$ & Podcasts & Vídeos \\
\hline$\square$ Mensajería instantánea & Wikis & Bluetooth \\
\hline $\begin{array}{l}\text { Pantallas de } \\
\text { información }\end{array}$ & SMS & Correo ordinario \\
\hline$\square$ Manual del empleado & $\begin{array}{ll}\square & \text { Reuniones } \\
\text { presenciales } & \end{array}$ & $\begin{array}{l}\square \text { Dossier de las apariciones } \\
\text { en los medios }\end{array}$ \\
\hline$\square$ Círculos de calidad & $\square$ Tablón de anuncios & $\square$ Buzón de sugerencias \\
\hline$\square$ Circulares & Revista & Periódico \\
\hline $\begin{array}{l}\square \text { Boletín interno } \\
\text { impreso }\end{array}$ & $\square$ Teléfono & Entrevistas \\
\hline $\begin{array}{l}\square \underset{\text { Reuniones } \quad y}{ } \\
\text { seminarios }\end{array}$ & $\begin{array}{l}\square \text { Mensajes de la alta } \\
\text { dirección }\end{array}$ & $\begin{array}{l}\square \text { Curso de formación de } \\
\text { portavoces }\end{array}$ \\
\hline $\begin{array}{l}\square \text { Curso sobre } \\
\text { comunicarse con los } \\
\text { medios de comunicación } \\
\end{array}$ & $\square$ Proyecto de empresa & $\square$ Formación continua \\
\hline$\square$ Reuniones virtuales & $\square$ e-learning & $\begin{array}{l}\square \text { Buzón de anuncios } \\
\text { electrónicos }\end{array}$ \\
\hline $\begin{array}{l}\square \text { Buzón virtual de } \\
\text { sugerencias }\end{array}$ & $\begin{array}{l}\square \text { Boletín interno } \\
\text { electrónico }\end{array}$ & $\square$ Organización de eventos \\
\hline $\begin{array}{ll}\square \text { Cursos para } \\
\text { comunicarse con los } \\
\text { pacientes y visitas }\end{array}$ & $\square$ Redes sociales & Otros: \\
\hline
\end{tabular}

\subsection{Con los pacientes y visitas:}

\begin{tabular}{|c|c|c|}
\hline Página web & Correos electrónicos & Foro de discusión \\
\hline $\begin{array}{l}\text { Realidad aumentada o } \\
\text { virtual }\end{array}$ & Vídeos & Mensajería instantánea \\
\hline$\square$ Bluetooth & $\begin{array}{l}\square_{\text {información }} \text { Pantallas de } \\
\text { de }\end{array}$ & $\square$ SMS \\
\hline Correo postal & $\square$ Revista & Periódico \\
\hline Hoja de reclamaciones & Planos & Redes sociales \\
\hline Buzón de sugerencias & Blogs & Wikis \\
\hline$\square$ Podcasts & $\begin{array}{l}\square \text { Número de teléfono } \\
\text { gratuitos }\end{array}$ & $\begin{array}{l}\square \text { Números de teléfono de } \\
\text { respuesta automática }\end{array}$ \\
\hline
\end{tabular}




\subsection{Con los medios de comunicación social:}

\begin{tabular}{|c|c|c|}
\hline Llamadas telefónicas & Notas de prensa & Ruedas de prensa \\
\hline Dossier de prensa & Fotografías & Vídeos \\
\hline Audio & Entrevistas & Pitch letters \\
\hline Sala de prensa virtual & Artículo firmado & Cartas al director \\
\hline Viajes de prensa & Giras por los medios & Regalos \\
\hline$\square$ Comidas & Publicidad & $\square$ SMS \\
\hline $\begin{array}{l}\square \text { Anuncios de servicio } \\
\text { público }\end{array}$ & $\square$ Redes sociales & $\begin{array}{l}\square \text { Emplazamiento de } \\
\text { productos }\end{array}$ \\
\hline$\square$ Blogs & $\begin{array}{l}\square \text { Emplazamiento de } \\
\text { temas }\end{array}$ & $\begin{array}{l}\square \text { Visitas y "media-tours" a } \\
\text { la organización }\end{array}$ \\
\hline $\begin{array}{l}\square \quad \text { Retransmisión } \\
\begin{array}{l}\text { acontecimientos } \\
\text { internet }\end{array} \\
\end{array}$ & $\begin{array}{l}\square \text { Premios } \\
\text { divulgación }\end{array}$ & $\begin{array}{l}\square \text { Cursos de formación de } \\
\text { periodistas }\end{array}$ \\
\hline \multicolumn{3}{|l|}{ Otros: } \\
\hline
\end{tabular}

\subsection{Con la comunidad:}

\begin{tabular}{|c|c|c|}
\hline $\begin{array}{l}\square \text { Jornada de puertas } \\
\text { abiertas }\end{array}$ & $\begin{array}{l}\square \text { Participación en feria } \\
\text { o salón }\end{array}$ & $\square$ Mecenazgo \\
\hline$\square$ Patrocinio & $\square$ Captación de fondos & $\begin{array}{l}\square \text { Sesión o jornada } \\
\text { informativa }\end{array}$ \\
\hline $\begin{array}{l}\square \text { Premios, ayudas y } \\
\text { becas }\end{array}$ & $\square$ Contratación social & $\square$ Fundación-empresa \\
\hline $\begin{array}{l}\square \text { Marketing relacionado } \\
\text { con una causa }\end{array}$ & $\begin{array}{l}\square \text { Lobbying o grupos de } \\
\text { presión }\end{array}$ & $\begin{array}{l}\square \text { Evento lúdico (fiesta, } \\
\text { concierto...) }\end{array}$ \\
\hline$\square$ Actividad deportiva & $\square$ Página web & $\square \mathrm{B} \log$ \\
\hline Wiki & $\square$ Redes sociales & $\square$ Publicidad \\
\hline$\square$ Folletos & $\begin{array}{l}\square \text { Número de teléfono } \\
\text { gratuitos }\end{array}$ & $\begin{array}{l}\square \text { Números de teléfono de } \\
\text { respuesta automática }\end{array}$ \\
\hline
\end{tabular}

\section{Señale las acciones de evaluación que lleva a cabo su departamento de comunicación:}

\begin{tabular}{|l|l|l|}
\hline$\square$ Impacto en los medios & $\square$ Visitas en internet & $\square$ Equivalencia publicitaria \\
\hline \hline$\square$ Seguimiento & $\begin{array}{l}\square \text { Solicitudes de } \\
\text { información y números de } \\
\text { seléfono gratuitos }\end{array}$ & $\square$ Coste por persona \\
\hline$\square$ Asistencia del público & $\begin{array}{l}\square \text { Auditorías de } \\
\text { comunicación }\end{array}$ & $\begin{array}{l}\square \text { Asistencia a reuniones y } \\
\text { acontecimientos }\end{array}$ \\
\hline$\square$ Número de lectores de & $\begin{array}{l}\square \text { Recuento de los } \\
\text { los boletines y revistas de } \\
\text { empresa }\end{array}$ & $\begin{array}{l}\text { Otros: } \\
\text { comunicación producidos }\end{array}$ \\
\hline
\end{tabular}


14. Indique la importancia que le otorga el departamento de comunicación a los siguientes tipos de evaluación ( 1 = nada; $5=$ mucho):

\begin{tabular}{|l|l|l|l|l|l|}
\hline & $\mathbf{1}$ & $\mathbf{2}$ & $\mathbf{3}$ & $\mathbf{4}$ & $\mathbf{5}$ \\
\hline Medición de la producción & $\square$ & $\square$ & $\square$ & $\square$ & $\square$ \\
\hline Medición de la exposición & $\square$ & $\square$ & $\square$ & $\square$ & $\square$ \\
\hline Medición de la opinión y actitud del público & $\square$ & $\square$ & $\square$ & $\square$ & $\square$ \\
\hline Medición de las acciones y comportamientos del público & $\square$ & $\square$ & $\square$ & $\square$ & $\square$ \\
\hline
\end{tabular}

15. Responda a las siguientes preguntas sobre su posible plan de crisis:

\begin{tabular}{|l|l|}
\hline Existe un plan de crisis & Elija un elemento. \\
\hline Cada cuánto se revisa el plan de crisis & Elija un elemento. \\
\hline Cada cuánto se pone en práctica & Elija un elemento. \\
\hline $\begin{array}{l}\text { Existe un equipo prefijado de personas para las } \\
\text { posibles crisis }\end{array}$ & Elija un elemento. \\
\hline
\end{tabular}

16. Conteste a las siguientes preguntas sobre el nivel de satisfacción y los aspectos a mejorar de su departamento de comunicación $(1=$ muy poco importante; $5=$ muy importante):

\begin{tabular}{|l|l|l|l|l|l|l|}
\hline & $\mathbf{1}$ & $\mathbf{2}$ & $\mathbf{3}$ & $\mathbf{4}$ & $\mathbf{5}$ \\
\hline $\begin{array}{l}\text { ¿Cómo de importante considera al departamento de } \\
\text { relaciones públicas o comunicación para el hospital? }\end{array}$ & $\square$ & $\square$ & $\square$ & $\square$ & $\square$ \\
\hline $\begin{array}{l}\text { ¿Cómo de satisfecho está con las actividades de } \\
\text { relaciones públicas o comunicación que lleva a cabo el } \\
\text { centro? }\end{array}$ & $\square$ & $\square$ & $\square$ & $\square$ & $\square$ \\
\hline
\end{tabular}

17. ¿Qué aspectos considera que se podrían modificar o mejorar?

18. ¿Cuáles son los principales motivos por los que no se llevan a cabo esas acciones? 


\subsubsection{ANÁLISIS DE PRENSA: MEDICIÓN DE LA EXPOSICIÓN}

Para comprobar la hipótesis número dos (la presencia de departamentos de comunicación en los hospitales debe tener una repercusión en el número y calidad de las informaciones sobre salud y sanidad que publican los medios de comunicación de la región), se ha procedido a analizar las noticias que aparecen publicadas en los periódicos de cada comunidad. Para ello, se ha empleado la herramienta Iconoce. Se trata de una base de datos con artículos publicados en medios de comunicación online tanto a nivel nacional como internacional con un servicio de hemeroteca que permite hacer búsquedas introspectivas de las noticias que han aparecido en internet desde el año 2001 (Iconoce, 2014). El periodo de estudio se ha limitado al año 2012 y se han seleccionado todos los periódicos generalistas locales, provinciales y regionales de ambas regiones que mantienen el acceso abierto a las informaciones de ese espacio. De esta manera, los lugares web consultados en cada comunidad ascienden a 15, dando un total de 30 periódicos analizados. La relación de las publicaciones de cada región se muestra en la siguiente tabla.

Tabla 23. Relación de periódicos online consultados

\begin{tabular}{|l|l|}
\hline \multicolumn{1}{|c|}{ Periódicos de Castilla y León } & \multicolumn{1}{c|}{ Periódicos de Galicia } \\
\hline Diario de Ávila & De Luns a Venres \\
\hline Diario de Burgos & Diario de Pontevedra \\
\hline Diario de la Ribera & El Correo Gallego \\
\hline Diario Palentino & El Ideal Gallego \\
\hline La Opinión de Zamora & El Progreso de Lugo \\
\hline El Adelantado de Segovia & Faro de Vigo \\
\hline El Día de Valladolid & Galicia Confidencial \\
\hline El Diario de León & Galicia Diario \\
\hline El Norte de Castilla & Galicia Hoxe \\
\hline Heraldo de Soria & Galiciae \\
\hline I-Bejar.com & La Opinión de La Coruña \\
\hline La Crónica de León & La Región de Ourense \\
\hline La Gaceta de Salamanca & La Voz de Galicia \\
\hline Leonoticias & Vigo al minuto \\
\hline RTVCYL.es & Xornal Galicia \\
\hline
\end{tabular}

Fuente: elaboración propia.

Dado que muy pocos periódicos electrónicos poseen una sección fija dedicada a la salud, las noticias que componen el universo de estudio han sido obtenidas buscando en todas las divisiones de cada medio y a través de varias palabras clave. En el caso de 
Castilla y León, los vocablos elegidos han sido: sanidad, salud, medicina, médico, hospital, ambulatorio, farmacia, farmacéutico, enfermedad y Sacyl. Para encontrar las noticias de Galicia, se ha añadido la traducción al gallego de los términos en español en los casos en los que difiere, así como el Servicio Galego de Saúde (Sergas), de tal manera que se han buscado las informaciones a través de la siguiente cadena: sanidad, salud, sanidade, saúde, medicina, médico, hospital, ambulatorio, farmacia, farmacéutico, enfermedad, enfermidade y Sergas.

\subsubsection{MUESTREO Y MARGEN DE ERROR}

Ya que Iconoce solo ofrece 200 resultados como máximo en una sola búsqueda, y por lo tanto es muy complicado determinar el número de noticias que publican los medios de comunicación sobre salud en un periodo largo de tiempo, se ha procedido a realizar un muestreo para calcular las noticias que divulgan los diferentes medios en un año, más concretamente en 2012. Para ello, se ha seleccionado al azar un día de cada uno de los doce meses del año, intentando, además, que se tratara de diferentes semanas y días de la semana. Se ha comenzado con un martes de la primera semana de enero, se ha proseguido con un miércoles de la segunda semana de febrero, se ha continuado con un jueves de la tercera semana de marzo y así sucesivamente.

El número total de noticias recopiladas en los 12 días que se han seleccionado en el muestreo asciende a 714 en Castilla y León y 844 en Galicia, o lo que es lo mismo: 60 noticias diarias de media en la primera región y 70 en la segunda. La relación de días consultados y el número de noticias conseguidas se muestran en las siguientes tablas.

Tabla 24. Número de noticias en el muestreo de Castilla y León

\begin{tabular}{|l|r|l|r|}
\hline \multicolumn{1}{|c|}{ Mes } & Día & $\begin{array}{c}\text { Día de la } \\
\text { semana }\end{array}$ & $\begin{array}{c}\text { Número } \\
\text { de noticias }\end{array}$ \\
\hline Enero & 3 & Martes & 46 \\
\hline Febrero & 15 & Miércoles & 82 \\
\hline Marzo & 22 & Jueves & 57 \\
\hline Abril & 27 & Viernes & 80 \\
\hline Mayo & 5 & Sábado & 54 \\
\hline Junio & 10 & Domingo & 41 \\
\hline Julio & 16 & Lunes & 49 \\
\hline Agosto & 21 & Martes & 59 \\
\hline Septiembre & 26 & Miércoles & 66 \\
\hline Octubre & 4 & Jueves & 72 \\
\hline Noviembre & 9 & Viernes & 56 \\
\hline Diciembre & 22 & Sábado & 51 \\
\hline Total & - & - & 713 \\
\hline
\end{tabular}

Fuente: elaboración propia. 
Tabla 25. Número de noticias en el muestreo de Galicia

\begin{tabular}{|l|r|l|r|}
\hline \multicolumn{1}{|c|}{ Mes } & Día & $\begin{array}{c}\text { Día de la } \\
\text { semana }\end{array}$ & $\begin{array}{c}\text { Número } \\
\text { de noticias }\end{array}$ \\
\hline Enero & 3 & Martes & 84 \\
\hline Febrero & 15 & Miércoles & 104 \\
\hline Marzo & 22 & Jueves & 68 \\
\hline Abril & 27 & Viernes & 97 \\
\hline Mayo & 5 & Sábado & 77 \\
\hline Junio & 10 & Domingo & 35 \\
\hline Julio & 16 & Lunes & 38 \\
\hline Agosto & 21 & Martes & 76 \\
\hline Septiembre & 26 & Miércoles & 69 \\
\hline Octubre & 4 & Jueves & 82 \\
\hline Noviembre & 9 & Viernes & 73 \\
\hline Diciembre & 22 & Sábado & 39 \\
\hline Total & - & - & 842 \\
\hline
\end{tabular}

Fuente: elaboración propia.

De esta forma, el muestreo determina que en Castilla y León hay 21.717 noticias sobre salud en un año y en Galicia, 25.672. Para conseguir una muestra que sea representativa según el universo de estudio, se ha examinado el tamaño de la muestra según el tamaño del universo y el margen de error deseado.

Tabla 26. Tamaño de la muestra según distintos márgenes de error y el tamaño del universo

\begin{tabular}{|l|r|r|r|r|r|r|}
\hline \multirow{2}{*}{$\begin{array}{c}\text { Tamaño } \\
\text { del }\end{array}$} & \multicolumn{6}{|c|}{ Tamaño de la muestra según el margen de error aceptado } \\
\cline { 2 - 7 } & $\mathbf{1 \%}$ & $\mathbf{2 \%}$ & $\mathbf{3 \%}$ & $\mathbf{4 \%}$ & \multicolumn{1}{c|}{$\mathbf{5 \%}$} & \multicolumn{1}{c|}{$\mathbf{1 0 \%}$} \\
\hline 500 & - & - & - & - & 222 & 83 \\
\hline 1.000 & - & - & - & 385 & 286 & 91 \\
\hline 1.500 & - & - & 638 & 441 & 316 & 94 \\
\hline 2.000 & - & - & 714 & 476 & 333 & 95 \\
\hline 2.500 & - & 1.250 & 769 & 500 & 345 & 96 \\
\hline 3.000 & - & 1.364 & 811 & 517 & 353 & 97 \\
\hline 3.500 & - & 1.458 & 843 & 530 & 359 & 97 \\
\hline 4.000 & - & 1.538 & 870 & 541 & 364 & 98 \\
\hline 4.500 & - & 1.607 & 891 & 549 & 367 & 98 \\
\hline 5.000 & - & 1.667 & 909 & 556 & 370 & 98 \\
\hline 6.000 & - & 1.755 & 938 & 566 & 375 & 98 \\
\hline 7.000 & - & 1.842 & 949 & 574 & 378 & 99 \\
\hline
\end{tabular}




\begin{tabular}{|l|r|r|r|r|r|r|}
\hline \multirow{2}{*}{$\begin{array}{c}\text { Tamaño } \\
\text { del } \\
\text { universo }\end{array}$} & \multicolumn{6}{|c|}{ Tamaño de la muestra según el margen de error aceptado } \\
\cline { 2 - 7 } & $\mathbf{1 \%}$ & $\mathbf{2 \%}$ & $\mathbf{3 \%}$ & \multicolumn{1}{c|}{$\mathbf{4 \%}$} & \multicolumn{1}{c|}{$\mathbf{5 \%}$} & \multicolumn{1}{c|}{$\mathbf{1 0 \%}$} \\
\hline 8.000 & - & 1.905 & 976 & 580 & 381 & 99 \\
\hline 9.000 & - & 1.957 & 989 & 584 & 383 & 99 \\
\hline 10.000 & 5.000 & 2.000 & 1.000 & 588 & 385 & 99 \\
\hline 15.000 & 6.000 & 2.143 & 1.034 & 600 & 390 & 99 \\
\hline 20.000 & 6.667 & 2.222 & 1.053 & 606 & 392 & 100 \\
\hline 25.000 & 7.143 & 2.273 & 1.064 & 610 & 394 & 100 \\
\hline 50.000 & 8.333 & 2.381 & 1.087 & 617 & 397 & 100 \\
\hline 100.000 & 9.091 & 2.439 & 1.099 & 621 & 398 & 100 \\
\hline$\infty$ & 10.000 & 2.500 & 1.111 & 625 & 400 & 100 \\
\hline
\end{tabular}

Fuente: Arkin y Colton, Tables for Statisticians. Tomado de J. Bugeda, Manual de Técnicas de Investigación Social. I.E.P. Madrid, 1970.

Para obtener un margen de error del 5\% y que la muestra sea significativa, se han de examinar entre 392 y 394 noticias de Castilla y León y entre 394 y 397 de Galicia. Con el fin de redondear las cifras, se ha acordado estudiar 400 de cada región.

Los resultados se han introducido en el programa estadístico SPSS y se han realizado diversos análisis, como frecuencias, descriptivos, tablas de contingencia, prueba de chi-cuadrado, prueba $\mathrm{T}$ de Student, etc. La significación en las pruebas estadísticas se ha fijado en igual o menor de 0,05. De esta forma, se puede establecer que existe una relación estadística y que los resultados no son frutos del azar.

\subsubsection{MEDICIÓN DE LA OPINIÓN Y ACTITUD DEL PÚBLICO}

Con el fin de conocer la opinión y la actitud de la población hacia la sanidad, se ha hecho uso del Barómetro Sanitario que publica anualmente el Ministerio de Sanidad, Servicios Sociales e Igualdad, y cuyos últimos resultados corresponden al ejercicio 2013. Se trata de un informe que recoge la valoración de los ciudadanos sobre el funcionamiento del sistema sanitario español y su satisfacción con la calidad de las prestaciones, en los dos casos en referencia al ámbito público. Es el único que divide los resultados por comunidades autónomas y permite la comparación entre las dos regiones que nos ocupan. La muestra total se compone de 7.800 entrevistas con cuestionario estructurado realizadas de manera personal en los domicilios de 237 municipios de las 17 comunidades y de las 2 ciudades autónomas (Instituto de Información Sanitaria, 
2013d). Posee un error de muestreo, en conjunto, del $\pm 1,13 \%$ para un nivel de confianza del 95,5\%. En Castilla y León se realizaron 423 entrevistas para el último número y en Galicia, 441 (Instituto de Información Sanitaria, 2013c).

De este informe se han analizado dos aspectos en los que las relaciones públicas pueden tener implicación: la opinión y actitud, y las acciones y comportamientos del público. Para hallar el primer aspecto, se ha consultado el interés que tiene la sanidad tanto para los castellano-leoneses como para los gallegos, así como la valoración que realizan del sistema sanitario y su satisfacción con diferentes aspectos. Por el contrario, para determinar las acciones y comportamientos de los ciudadanos, se han utilizado las mediciones acerca de la elección de los hospitales y de los motivos que impulsan a tener esa determinación. Este último análisis divide las elecciones por centros de dependencia pública y privada. Así, se contraponen los resultados de Castilla y León y de Galicia para comprobar si hay diferencias considerables. 


\subsection{RESULTADOS}

2.2.1. Características de la estructura sanitaria y de los departamentos de comunicación de los hospitales

2.2.2. Funciones y tareas de los departamentos de comunicación de los hospitales. Resultados de las entrevistas personales

2.2.3. Uso de las relaciones públicas en los departamentos de comunicación de los hospitales. Resultados de la encuesta

2.2.4. Imagen proyectada en los medios de comunicación. Resultados del análisis de prensa 2.2.5. Medición de la opinión y actitud del público: opinión de los ciudadanos acerca del sistema sanitario

\subsubsection{CARACTERÍSTICAS DE LA ESTRUCTURA SANITARIA Y DE LOS DEPARTAMENTOS DE COMUNICACIÓN DE LOS HOSPITALES}

\subsubsection{ESTRUCTURA SANITARIA EN GALICIA}

Antiguamente, el Gobierno central era el encargado de gestionar la sanidad de todo el país, hasta que la Constitución Española estableció una nueva organización del territorio que confirió a las autonomías ciertas competencias en materia sanitaria. El Real Decreto 1679/1990, del 28 de diciembre, sobre traspaso a la Comunidad Autónoma de Galicia de las funciones y servicios del Instituto Nacional de Salud (España, 1990), fue el documento en el que se basó la transferencia de las actividades sanitarias del Estado a la región gallega. Así, en la actualidad, la Consellería de Sanidad es el órgano encargado de gestionar esta competencia. Está presidida por Rocío Mosquera Álvarez bajo la dirección del Partido Popular, que es la agrupación que gobierna en la región. A esta división administrativa le corresponde (España, 1989): 
a) "Elaborar la planificación general sanitaria de Galicia y proponer al Consello de la Xunta, para su aprobación, el plan de salud de la comunidad autónoma.

b) La fijación de criterios de actuación del organismo para el desarrollo y ejecución de la política de salud en Galicia.

c) Proponer al Consello de la Xunta de Galicia el nombramiento o cese del director general del organismo.

d) La elevación, para su aprobación, al Consello de la Xunta del anteproyecto de reglamento general del organismo.

e) La aprobación el anteproyecto de presupuesto del organismo.

f) Elevar al Consello de la Xunta, para su aprobación, el anteproyecto de plantilla de personal que elabore el servicio gallego de salud.

g) La aprobación de la memoria anual de actuación del Servicio Gallego de Salud, de la que se dará cuenta al Consello de la Xunta de Galicia.

h) La inspección del Servicio Gallego de Salud.

i) La aprobación de la estructura básica del sistema de información sanitaria de Galicia.

j) La aprobación, evaluación, seguimiento y control de la investigación y docencia sin perjuicio de las competencias atribuidas a la Consellería de Educación y ordenación universitaria.

k) El nombramiento o remoción del personal directivo de las áreas de salud.

1) La política general de relación con otras administraciones públicas”.

De la Consellería de Sanidad depende el Servicio Gallego de Salud (conocido de manera más abreviada como Sergas), que es la entidad que administra la red de centros públicos de la comunidad. Se creó en 1989 (España) gracias a la Ley 1/1989, de 2 de enero como "un organismo autónomo de carácter administrativo, dotado de personalidad jurídica propia, que tiene como finalidad la gestión de los servicios sanitarios de carácter público dependientes de la Comunidad Autónoma de Galicia y la coordinación integral de todos los recursos sanitarios y asistenciales".

La Ley 8/2008, de 10 de julio, de salud de Galicia (España, 2008), señala que el objetivo del Servicio Gallego de Salud es "la provisión de los servicios y prestaciones de atención sanitaria individual de cobertura pública en el ámbito de la Comunidad Autónoma de Galicia, dentro del marco básico de financiación del Sistema Público de Salud de Galicia, garantizando los derechos sanitarios reconocidos en la presente ley". Dentro de este servicio se integran "los centros, servicios y establecimientos sanitarios y administrativos creados por la Administración de la Xunta de Galicia o procedentes de transferencias, así como las entidades sanitarias de naturaleza pública que se le adscriban” (España, 2008). 
De esta manera, concreta el decreto 43/2013, de 21 de febrero, por el que se establece la estructura orgánica del Servicio Gallego de Salud (Galicia, 2013a), este organismo "ejerce el gobierno, la dirección y la gestión de los centros, servicios y establecimientos sanitarios propios o adscritos, garantizando la provisión de los servicios y prestaciones de asistencia sanitaria de cobertura pública; coordina la gestión de los recursos humanos, materiales y financieros que tenga asignados, y ejercerá aquellas funciones que le delegue o encomiende la Consellería de Sanidad".

Su distribución, regulada por decreto 43/2013, de 21 de febrero, por el que se establece la estructura orgánica del Servicio Gallego de Salud (Galicia, 2013a), se divide en los siguientes órganos:

1. Órganos centrales de dirección:

a) Órganos colegiados:

i. Consejo de Dirección.

ii. Comité Ejecutivo.

b) Órganos unipersonales:

i. La Presidencia.

ii. La Gerencia del Servicio Gallego de Salud.

iii. La Dirección General de Asistencia Sanitaria.

iv. La Dirección General de Recursos Económicos.

v. La Dirección General de Recursos Humanos.

2. Órganos de coordinación y asesoramiento del Servicio Gallego de Salud:

a) Consejo Asesor Técnico.

b) Consejo Asesor de Pacientes.

3. Órganos periféricos de dirección:

a) Las estructuras de gestión integrada.

Las estructuras organizativas de gestión integrada son un "instrumento de organización, sin personalidad jurídica, en el ámbito periférico del Servicio Gallego de Salud" que tienen como objetivo "el avance de la accesibilidad, la eficiencia y la búsqueda de la mayor calidad de las prestaciones sanitarias" (Galicia, 2010). Estas estructuras asumen "con autonomía funcional, de forma integrada la gestión de los recursos, prestaciones y programas de la atención sanitaria, tanto del nivel de atención primaria como especializada, así como sociosanitaria y de promoción y protección de la salud" (Galicia, 2010). La ordenación de estas organizaciones se divide en órganos unipersonales y colegiados (Galicia, 2010):

1. Órganos unipersonales:

a. Gerencia de Gestión Integrada.

b. Dirección de Procesos Asistenciales.

c. Dirección de Recursos Económicos.

d. Dirección de Recursos Humanos. 
e. Gerente o gerentes ejecutivos.

f. Otras unidades directivas dependientes creadas por orden de la Consellería.

2. Órganos colegiados:

a. Comisión de dirección

b. Otras comisiones que puedan constituirse para asesorar sobre la gestión clínica, gestión por procesos, docencia e investigación, calidad, seguridad y atención a la ciudadanía y cualquier otro campo que se considere de interés.

En la actualidad, existen siete estructuras de este tipo repartidas por Galicia. En la provincia de La Coruña hay tres: una en la zona de Ferrol, otra en La Coruña y una tercera en Santiago de Compostela. En la provincia de Pontevedra, en cambio, existen dos: la de Pontevedra y O Salnés y la de Vigo. En Ourense y en Lugo solamente se halla una en cada demarcación:

Tabla 27. Estructuras de gestión integrada y su ordenamiento jurídico

\begin{tabular}{|l|l|}
\hline \multicolumn{1}{|c|}{ Estructura } & \multicolumn{1}{c|}{ Ordenamiento } \\
\hline A Coruña & $\begin{array}{l}\text { ORDEN de 22 de julio de 2011 por la que se desarrolla la } \\
\text { estructura organizativa de gestión integrada de A Coruña y de } \\
\text { Santiago de Compostela (Galicia, 2011a). }\end{array}$ \\
\hline $\begin{array}{l}\text { Santiago de } \\
\text { Compostela }\end{array}$ & $\begin{array}{l}\text { ORDEN de 22 de julio de 2011 por la que se desarrolla la } \\
\text { estructura organizativa de gestión integrada de A Coruña y de } \\
\text { Santiago de Compostela (Galicia, 2011a). }\end{array}$ \\
\hline $\begin{array}{l}\text { Ourense, Verín y O } \\
\text { Barco de }\end{array}$ & $\begin{array}{l}\text { ORDEN de 28 de septiembre de 2011 por la que se desarrolla la } \\
\text { estructura organizativa de gestión integrada de Ourense, Verín y } \\
\text { O Barco de Valdeorras y se delegan competencias en sus órganos } \\
\text { directivos (Galicia, 2011b). }\end{array}$ \\
\hline $\begin{array}{l}\text { Pontevedra y O } \\
\text { Salnés }\end{array}$ & $\begin{array}{l}\text { ORDEN de 28 de septiembre de 2011 por la que se desarrolla la } \\
\text { estructura organizativa de gestión integrada de Pontevedra y O } \\
\text { Salnés y se delegan competencias en sus órganos directivos } \\
\text { (Galicia, 2011c). }\end{array}$ \\
\hline Ferrol & $\begin{array}{l}\text { ORDEN de 28 de septiembre de 2011 por la que se desarrolla la } \\
\text { estructura organizativa de gestión integrada de Ferrol y se } \\
\text { delegan competencias en sus órganos directivos (Galicia, 2011d). }\end{array}$ \\
\hline $\begin{array}{l}\text { ORDEN de 25 de marzo de 2013 por la que se desarrolla la } \\
\text { estructura organizativa de Gestión Integrada de Vigo (Galicia, } \\
\text { 2013b). }\end{array}$ \\
\hline Vigo
\end{tabular}




\begin{tabular}{|l|l|}
\hline \multicolumn{1}{|c|}{ Estructura } & \multicolumn{1}{c|}{ Ordenamiento } \\
\hline $\begin{array}{l}\text { Lugo, Cervo y } \\
\text { Monforte de Lemos }\end{array}$ & $\begin{array}{l}\text { ORDEN de 12 de abril de 2013 por la que se desarrolla la } \\
\text { estructura organizativa de gestión integrada de las áreas de Lugo, } \\
\text { Cervo y Monforte de Lemos (Galicia, 2013c). }\end{array}$ \\
\hline
\end{tabular}

Fuente: elaboración propia.

\subsection{HOSPITALES PÚBLICOS}

Cada una de estas estructuras engloba los centros de atención primaria $\mathrm{y}$ especializada dependientes del Sistema Nacional de Salud de su zona de influencia. A continuación, se muestran los hospitales que se encuentran dentro de cada una de estas divisiones organizativas (Ministerio de Sanidad, 2013a):

1) Gestión integrada de A Coruña:

a) Complexo Hospitalario Universitario A Coruña:

i) Hospital Universitario A Coruña.

ii) Hospital Materno Infantil Teresa Herrera.

iii) Hospital Marítimo De Oza.

iv) Hospital Abente y Lago.

b) Hospital Virxe da Xunqueira.

2) Gestión integrada de Santiago de Compostela:

a) Complexo Hospitalario Universitario de Santiago:

i) Hospital Clínico Universitario.

ii) Hospital Profesor Gil Casares.

iii) Hospital Médico-Quirúrxico De Conxo.

iv) Hospital Psiquiátrico de Conxo.

b) Hospital de Barbanza:

3) Gestión integrada de Ourense, Verín y O Barco de Valdeorras:

a) Complexo Hospitalario Universitario de Ourense:

i) Hospital Nosa Señora do Cristal.

ii) Hospital Santo Cristo de Piñor.

iii) Hospital Santa María Nai.

b) Hospital de Verín.

c) Hospital Comarcal de Valdeorras.

4) Gestión integrada de Pontevedra y O Salnés:

a) Complexo Hospitalario de Pontevedra:

i) Hospital Montecelo.

ii) Hospital Provincial de Pontevedra.

b) Hospital do Salnés. 
5) Gestión integrada de Ferrol:

a) Complexo Hospitalario Arquitecto Marcide-Novoa Santos:

i) Hospital Arquitecto Marcide.

ii) Hospital Basico de La Defensa.

6) Gestión integrada de Vigo:

a) Complexo Hospitalario Universitario De Vigo:

i) Hospital Psiquiátrico Provincial Rebullón.

ii) Hospital do Meixoeiro.

iii) Hospital Xeral de Vigo.

iv) Policlínico Cies.

v) Hospital Nicolas Peña.

7) Gestión integrada de Lugo, Cervo y Monforte de Lemos:

a) Complexo Hospitalario Xeral-Calde de Lugo:

i) Hospital de Calde.

ii) Hospital Lucus Augusti.

b) Hospital Comarcal de Monforte.

c) Hospital da Costa.

\subsection{HOSPITALES PRIVADOS}

Al margen de los 24 centros de atención especializada pertenecientes al Sistema Nacional de Salud, existen otros 24 que se encuentran bajo la gestión de diferentes entidades privadas. Uno es una mutua de accidentes de trabajo y enfermedades profesionales (MATEP), dos son privados benéficos y los 21 restantes, privados no benéficos. Según el Catálogo Nacional de Hospitales (Ministerio de Sanidad, 2013a), son los siguientes:

1. Centro Oncolóxico de Galicia.

2. Hospital Quirón A Coruña.

3. Hospital San Rafael.

4. Hospital Modelo $\underline{12}$.

5. Maternidad Belén $\underline{\underline{13}}$.

6. Hospital General Juan Cardona.

7. Sanatorio La Robleda.

8. Hospital Nuestra Señora de la Esperanza.

9. Hospital Policlínico La Rosaleda.

10. Policlínico Lucense.

11. Sanatorio Nosa Señora Dos Ollos Grandes.

$\underline{12}$ A efectos de gestión, integrado en el Grupo Hospitalario Modelo.

$\underline{13}$ A efectos de gestión, integrado en el Grupo Hospitalario Modelo. 
12. Centro Médico El Carmen.

13. Clínica Santa Teresa.

14. Sanatorio Santa María.

15. Hospital Miguel Domínguez.

16. Clínica Médica La Merced $\stackrel{14}{ }$.

17. Fremap, Hospital de Vigo.

18. Hospital Povisa.

19. Centro Médico El Castro-Clínica Ntra. Sra. del Perpetuo Socorro.

20. Hospital Nosa Señora de Fátima.

21. Sanatorio Concheiro.

22. Centro Médico Pintado.

23. Sanatorio Psiquiátrico San José.

24. Clínica Residencia El Pinar.

\subsubsection{ESTRUCTURA DE COMUNICACIÓN EN GALICIA}

\subsection{HOSPITALES PÚBLICOS}

La comunicación en Galicia tiene mucho que ver con su estructura sanitaria. Existe un departamento de comunicación en la Consellería de Sanidad y otro en cada una de las estructuras organizativas de gestión integrada. Para los temas exclusivamente locales (por ejemplo, que un médico de un hospital recibe un premio), normalmente son las estructuras las que responden a los medios de comunicación. Cuando son temas más amplios, suelen coordinarse entre la estructura en cuestión y la consejería. En cambio, si se trata de asuntos muy trascendentales, normalmente se derivan a la consejería.

Lo más habitual es que en cada gabinete de información de las estructuras trabaje una única persona, pero también hay casos en los que están empleados dos. Más concretamente, esto último sucede en A Coruña, en Santiago de Compostela y en Ourense. En cambio, en la zona de Pontevedra, Ferrol, Vigo y Lugo, solo se cuenta con un individuo en cada una. También posee departamento de comunicación la Fundación Pública Urgencias Sanitarias de Galicia - 061, en la que trabajan dos personas: una dedicada más habitualmente a la relación con los medios de comunicación y otra a las publicaciones. Todos ellos trabajan coordinados y en red:

\footnotetext{
${ }^{14} \mathrm{~A}$ efectos de gestión, integrado en el Grupo Hospital Miguel Domínguez.
} 
Tabla 28. Estructuras de gestión integrada y sus responsables de comunicación

\begin{tabular}{|l|l|l|}
\hline Estructura de gestión integrada & \multicolumn{1}{|c|}{ Responsable } & Segundo trabajador \\
\hline A Coruña & $\begin{array}{l}\text { Cristina de la Vega } \\
\text { Jiménez }\end{array}$ & Kiko Fernández Porto \\
\hline Santiago de Compostela & Ana López Pimentel & Beatriz Senra López \\
\hline $\begin{array}{l}\text { Ourense, Verín y O Barco de } \\
\text { Valdeorras }\end{array}$ & Myriam Sierra Gómez & Carlos Bermello Arce \\
\hline Pontevedra y O Salnés & Raúl Álvarez Salcedo & - \\
\hline Ferrol & María José Iglesias & - \\
\hline Vigo & Irene Pazo Manzano & - \\
\hline Lugo, Cervo y Monforte de Lemos & Paz Teijeira Fanego & - \\
\hline $\begin{array}{l}\text { Fundación Pública Urxencias } \\
\text { Sanitarias de Galicia-061 }\end{array}$ & Marta Castro Pérez & $\begin{array}{l}\text { Arantza Briegas } \\
\text { Arenas }\end{array}$ \\
\hline
\end{tabular}

Fuente: elaboración propia.

También hay una persona dedicada a la comunicación en el Centro de Transfusión de Sangre de Galicia (María de los Ángeles Pazos del Olmo). Dado que se encontraba de baja en el momento de las entrevistas, no se pudo contar con su testimonio.

\subsection{HOSPITALES PRIVADOS}

En Galicia hay 23 hospitales de dependencia privada y uno de MATEP (Mutua de accidentes de trabajo y enfermedades profesionales). De ellos, ocho cuentan con servicio de comunicación, ya sea a través de un propio departamento, mediante una empresa externa o con un trabajador por cuenta propia. En dos centros, más concretamente en el Centro Oncológico de Galicia y en el Hospital Quirón de A Coruña, se mantiene la primera fórmula, y en el Vithas Nuestra Señora de Fátima, la tercera. En las cinco clínicas restantes se trabaja la comunicación mediante una entidad externa, dentro de la cual, en ocasiones, pueden trabajar con el hospital una o más personas. 
Tabla 29. Hospitales de titularidad privada y sus responsables de comunicación, si procede

\begin{tabular}{|c|c|c|c|}
\hline Hospital & $\begin{array}{l}\text { Responsable de } \\
\text { comunicación }\end{array}$ & $\begin{array}{l}\text { Segundo } \\
\text { trabajador }\end{array}$ & Empresa \\
\hline Centro Oncolóxico de Galicia & Pepe Losada & - & - \\
\hline Hospital Quirón A Coruña & Patricia Forteza & - & - \\
\hline Hospital San Rafael & - & - & - \\
\hline Hospital Modelo $\underline{15}$ & Irene Montero Díaz & - & Octo \\
\hline Maternidad Belén $\underline{\underline{16}}$ & Irene Montero Díaz & - & Octo \\
\hline $\begin{array}{l}\text { Hospital General Juan } \\
\text { Cardona }\end{array}$ & $\begin{array}{l}\text { Antolín Hermida } \\
\text { Armesto }\end{array}$ & $\begin{array}{l}\text { Raquel } \\
\text { González Tejero } \\
\text { Campo }\end{array}$ & $\begin{array}{l}\text { Larín } \\
\text { Comunicación } \\
{\text { Global }{ }^{17}}\end{array}$ \\
\hline Sanatorio La Robleda & - & - & - \\
\hline $\begin{array}{l}\text { Hospital Nuestra Señora de la } \\
\text { Esperanza }\end{array}$ & - & - & - \\
\hline $\begin{array}{l}\text { Hospital Policlínico La } \\
\text { Rosaleda }\end{array}$ & Tomás Valín López & $\begin{array}{l}\text { Teresa } \\
\text { Rocamonde } \\
\text { Iglesias } \\
\end{array}$ & Bolanda \\
\hline Policlínico Lucense & - & - & - \\
\hline $\begin{array}{l}\text { Sanatorio Nosa Señora Dos } \\
\text { Ollos Grandes }\end{array}$ & - & - & - \\
\hline Centro Médico El Carmen & - & - & - \\
\hline Clínica Santa Teresa & - & - & - \\
\hline Sanatorio Santa María & - & - & - \\
\hline Hospital Miguel Domínguez & - & - & - \\
\hline Clínica Médica La Merced ${ }^{18}$ & - & - & - \\
\hline Fremap, Hospital de Vigo & - & - & - \\
\hline Hospital Povisa & Álvaro Otero & $\begin{array}{l}\text { Otros dos } \\
\text { trabajadores }\end{array}$ & $\begin{array}{l}\text { Atlántica } \\
\text { Comunicación }\end{array}$ \\
\hline $\begin{array}{l}\text { Centro Médico El Castro- } \\
\text { Clínica Ntra. Sra. del Perpetuo }\end{array}$ & - & (1) & (a) \\
\hline $\begin{array}{l}\text { Hospital Vithas Nuestra } \\
\text { Señora de Fátima }\end{array}$ & $\begin{array}{l}\text { Xabier López } \\
\text { Escalante }\end{array}$ & - & $\begin{array}{l}\text { Trabajador por } \\
\text { cuenta propia }\end{array}$ \\
\hline
\end{tabular}

$\underline{15}$ A efectos de gestión, integrado en el Grupo Hospitalario Modelo.

16 A efectos de gestión, integrado en el Grupo Hospitalario Modelo.

${ }^{17}$ En el momento de la entrevista, la empresa Larín Comunicación Global era la encargada de realizar las labores comunicativas del Hospital General Juan Cardona. Desde marzo de 2014, no obstante, esta tarea está encomendada a la compañía Kaotic Medios Digitales, tal y como señala Antolín Hermida Armesto.

${ }^{18}$ A efectos de gestión, integrado en el Grupo Hospital Miguel Domínguez. 


\begin{tabular}{|l|l|l|l|}
\hline \multicolumn{1}{|c|}{ Hospital } & $\begin{array}{c}\text { Responsable de } \\
\text { comunicación }\end{array}$ & $\begin{array}{c}\text { Segundo } \\
\text { trabajador }\end{array}$ & Empresa \\
\hline Sanatorio Concheiro & - & - & - \\
\hline Centro Médico Pintado & - & - & - \\
\hline Sanatorio Psiquiátrico San José & - & - & - \\
\hline Clínica Residencia El Pinar & - & - & - \\
\hline
\end{tabular}

Fuente: elaboración propia.

En resumen, de los 38 hospitales que se contabilizan en Galicia en 2013 según el Catálogo Nacional de Hospitales (Ministerio de Sanidad, 2013a), 22 poseen, al menos, una persona encargada de la comunicación. Esto implica que casi seis de cada diez centros (es decir, el 57,89\%) dispone de servicio de comunicación. Todas las clínicas públicas están englobadas dentro de una estructura de gestión integrada concreta y, por ello, se encuentran dentro del ámbito de actuación de un departamento de comunicación. En cuanto a los de titularidad privada o del MATEP, ocho de los 24 cuentan con un servicio de estas características, lo que otorga un porcentaje del 33,33\%. 


\subsubsection{ESTRUCTURA SANITARIA EN CASTILLA Y LEÓN}

El Real Decreto 1480/2001, de 27 de diciembre sobre traspaso a la Comunidad de Castilla y León de las funciones y servicios del Instituto Nacional de la Salud (España, 2001) es el documento de transferencia de las actividades sanitarias del Estado a la región castellana después de que desapareciera el Instituto Nacional de la Salud (INSALUD) creado tras la reforma sobre la gestión institucional de la Seguridad Social, la salud y el empleo (España, 1978b). Así, en la actualidad, la sección regional encargada de estas materias es la Consejería de Sanidad, actualmente dirigida por Antonio María Sáez Aguado, del Partido Popular, que gobierna en la comunidad.

Hoy por hoy está regulada por el Decreto 80/2007, de 19 de julio, por el que se establece la estructura orgánica de la Consejería de Sanidad (Castilla y León, 2007a) y le compete "bajo la superior dirección del Consejero, dirigir, promover y ejecutar la política sanitaria, así como el ejercicio de las funciones de coordinación e inspección en la materia, y cuantas otras pudieran corresponderle en el marco de la Constitución y del Estatuto de Autonomía”. Asimismo, se compone de los siguientes órganos directivos centrales (Castilla y León, 2007a):

- Secretaría General.

- Dirección General de Salud Pública e Investigación, Desarrollo e Innovación.

- Dirección General de Planificación, Calidad, Ordenación y Formación.

- Agencia de Protección de la Salud y Seguridad Alimentaria.

Existen más órganos de dirección del Sistema de Salud en Castilla y León al margen de la Consejería de sanidad, así como otros propios de participación. El Decreto 48/2003, de 24 de abril, por el que se regulan los órganos de dirección y participación del sistema de salud de Castilla y León (Castilla y León, 2003a) los organiza de la siguiente manera:

1. Órganos de dirección:

a. La Consejería de Sanidad y Bienestar Social.

b. El Consejo de Dirección del Sistema de Salud.

c. Los Consejos de Dirección de Área.

d. Los Directores de Área.

2. Órganos de participación:

a. E1 Consejo Regional de Salud.

b. Los Consejos de Salud de Área.

c. Los Consejos de Salud de Zona.

Adscrito a la Consejería de Sanidad se encuentra el organismo autónomo encargado de gestionar las prestaciones sanitarias públicas, la Gerencia Regional de Salud de Castilla y León, conocida también como Sacyl. Fue creada mediante la Ley 1/1993, de 6 
de abril, de Ordenación del Sistema Sanitario (Castilla y León, 1993), que constituyó el Sistema de Salud de Castilla y León y creó la Gerencia Regional de Salud. También reguló las actividades sanitarias en la comunidad desde ese año hasta 2010, momento en que fue desplazada por la Ley 8/2010, de 30 de agosto, de Ordenación del Sistema de Salud de Castilla y León (España, 2010a).

La Gerencia Regional de Salud es un ente público institucional adscrito a la Consejería de Sanidad, con "personalidad jurídica propia y plena capacidad de obrar para el cumplimiento de sus fines". Hasta 2001, estuvo regulada por el Decreto 287/2001, de 13 de diciembre, por el que se aprueba el reglamento general de la Gerencia Regional de Salud de Castilla y León (Castilla y León, 2001), y, a partir de entonces, por el Decreto 40/2011, de 7 de julio, por el que se modifica el Decreto 287/2001, de 13 de diciembre, por el que se aprueba el Reglamento General de la Gerencia Regional de Salud de Castilla y León (Castilla y León, 2011). Así, este órgano queda estructurado de la siguiente manera:

- Dirección General de Administración e Infraestructuras.

- Dirección General de Asistencia Sanitaria.

- Dirección General de Planificación e Innovación.

- Dirección General de Recursos Humanos.

Otra legislación relevante que ha surgido en el ámbito sanitario es la Ley 8/2003, de 8 de abril, sobre derechos y deberes de las personas en relación con la salud (Castilla y León, 2003b) y la Ley 2/2007, de 7 de marzo, del Estatuto Jurídico del Personal Estatutario del Servicio de Salud de Castilla y León (Castilla y León, 2007b).

\subsection{HOSPITALES PÚBLICOS}

Actualmente, existen 11 áreas de salud, dentro de las cuales se enmarcan 248 zonas básicas y los centros y complejos hospitalarios. En 2012, se contabilizaron 37 de estos últimos (Ministerio de Sanidad, 2013a), de los cuales 16 pertenecen al Sistema Nacional de Salud, mientras que los 21 restantes recaen en manos privadas. A continuación, se muestran los hospitales públicos ordenados por provincias:

\section{Provincia de Ávila:}

a. Complejo asistencial de Ávila:

i. Hospital Nuestra Señora de Sonsoles.

ii. Hospital Provincial de Ávila.

\section{Provincia de Burgos:}

a. Complejo asistencial universitario de Burgos:

i. Hospital Fuente Bermeja.

ii. Hospital Universitario de Burgos. 
b. Hospital Santos Reyes (Aranda de Duero, Burgos).

c. Hospital Santiago Apóstol (Miranda de Ebro, Burgos).

\section{Provincia de León:}

a. Complejo asistencial universitario de León:

i. Hospital de León.

ii. Hospital Monte San Isidro.

iii. Hospital Santa Isabel.

b. Hospital el Bierzo (Ponferrada, León).

c. Hospital Valle de Laciana (Villablino, León).

\section{Provincia de Palencia:}

a. Complejo asistencial de Palencia:

i. Hospital Río Carrión.

ii. Hospital San Telmo.

\section{Provincia de Salamanca:}

a. Complejo asistencial universitario de Salamanca:

i. Hospital Universitario de Salamanca.

ii. Hospital Virgen del Castañar.

iii. Hospital Los Montalvos.

\section{Provincia de Segovia;}

a. Complejo asistencial de Segovia:

i. Hospital general de Segovia.

b. Unidad de rehabilitación psiquiátrica Nuestra Señora de la Fuencisla.

\section{Provincia de Soria:}

a. Complejo asistencial de Soria:

i. Hospital Santa Bárbara.

ii. Hospital Virgen del Mirón.

\section{Provincia de Valladolid:}

a. Hospital Universitario Río Ortega (Valladolid).

b. Hospital Clínico Universitario de Valladolid.

c. Hospital Medina del Campo (Medina del Campo, Valladolid).

\section{Provincia de Zamora:}

a. Complejo asistencial de Zamora:

i. Hospital Virgen de la Concha.

ii. Hospital Provincial de Zamora.

iii. Hospital de Benavente. 


\subsection{HOSPITALES PRIVADOS}

Los 21 hospitales restantes se encuentran bajo titularidad privada. Sobresale la provincia de León, que suma seis, en comparación con la segunda zona con un mayor número, Valladolid, que tiene cuatro. La siguiente lista muestra todos los centros privados de la comunidad de Castilla y León:

1. Provincia de Ávila:

a. Clínica Santa Teresa.

\section{Provincia de Burgos:}
a. Hospital Recoletas de Burgos.
b. Hospital San Juan de Dios de Burgos.
c. Hospital Residencia Asistida de la Luz.

\section{Provincia de León:}
a. Obra Hospitalaria Nuestra Señora de Regla.
b. Sanatorio López Otazu.
c. Clínica San Francisco.
d. Hospital de la Reina.
e. Clínica Ponferrada.
f. Hospital San Juan de Dios.
g. Clínica Altollano.

\section{Provincia de Palencia:}
a. Hospital Psiquiátrico San Luis.
b. Unidad de Rehabilitación Psiquiátrica Centro Asistencial San Juan de Dios.
c. Hospital Recoletas de Palencia.

\section{Provincia de Salamanca:}

a. Hospital General de la Santísima Trinidad.

\section{Provincia de Segovia:}

a. Hospital Recoletas Segovia Nuestra Señora de la Misericordia.

\section{Provincia de Valladolid:}
a. Sanatorio Sagrado Corazón.
b. Centro Hospitalario Benito Menni.
c. Hospital de Valladolid Felipe II.
d. Hospital Campo Grande.

\section{Provincia de Zamora:}

a. Hospital Recoletas de Zamora. 


\subsubsection{ESTRUCTURA DE COMUNICACIÓN EN CASTILLA Y LEÓN}

\subsection{HOSPITALES PÚBLICOS}

La comunicación en la sanidad pública en Castilla y León se centraliza en el departamento de comunicación de la Consejería de Sanidad, donde trabajan cuatro empleados y cuya sede se encuentra en Valladolid. Es decir, los hospitales y complejos hospitalarios pertenecientes al Sistema Nacional de Salud repartidos a lo largo de esta región no cuentan con ninguna persona encargada únicamente a las labores de información. También existe un gabinete de prensa en la Agencia de Protección Civil de la Junta de Castilla y León, que se encarga de emitir información de los heridos tratados por el Servicio de Emergencias 112.

\subsection{HOSPITALES PRIVADOS}

En los centros privados, en cambio, la situación es distinta. En el grupo Recoletas, por ejemplo, que cuenta con seis hospitales en distintas provincias de Castilla y León, existe una persona encargada de la comunicación para todos ellos, aunque su centro de trabajo se centre en Valladolid. La Clínica Ponferrada también cuenta con gabinete de información, aunque la persona encargada de ella comparta su tiempo con el resto de centros del grupo y sitúe su centro de trabajo en Oviedo. No pasa lo mismo con el encargado de esta tarea en la Clínica San Francisco, que pertenece a la plantilla del centro y trabaja a jornada completa.

En cuanto a los Hermanos de San Juan de Dios, que tienen tres clínicas dentro del territorio de estudio, únicamente posee servicio de comunicación una de ellas, más concretamente la de León. No obstante, esta labor está encomendada a una agencia externa, DLV-La Central. Lo mismo ocurre con el Complejo Hospitalario San Luis y el Centro Hospitalario Padre Benito Menni, gestionados por las Hermanas Hospitalarias, que confían esta a una Agencia: Comunicación Profesional.

En el resto de hospitales, no existe una persona ni una empresa que dirija la comunicación; cuando existe algún tema puntual que divulgar, señalan los gerentes, se encargan directamente ellos o alguna persona de administración o de información. En la Obra Hospitalaria Nuestra Señora de Regla, por su parte, cuando se trata de asuntos muy importantes o trascendentales se encarga el Obispado de León, que es de quien depende el hospital.

En total, la relación de centros de atención especializada, con sus correspondientes responsables, se incluyen a continuación: 
Tabla 30. Relación de hospitales y sus responsables de comunicación

\begin{tabular}{|c|c|c|c|}
\hline Hospital & $\begin{array}{l}\text { Responsable de } \\
\text { comunicación }\end{array}$ & $\begin{array}{c}\text { Segundo } \\
\text { trabajador }\end{array}$ & Empresa \\
\hline $\begin{array}{l}\text { Consejería de Sanidad de } \\
\text { la Junta de Castilla y León }\end{array}$ & Blanca Saravia Ibañes & $\begin{array}{l}* \text { Otros tres } \\
\text { trabajadores* }\end{array}$ & - \\
\hline Hospital Recoletas Burgos & Mireya Santoyo & - & - \\
\hline $\begin{array}{l}\text { Hospital Recoletas } \\
\text { Palencia }\end{array}$ & Mireya Santoyo & - & - \\
\hline $\begin{array}{l}\text { Hospital Recoletas } \\
\text { Segovia }\end{array}$ & Mireya Santoyo & - & - \\
\hline Hospital Campo Grande & Mireya Santoyo & - & - \\
\hline Hospital Felipe II & Mireya Santoyo & - & - \\
\hline $\begin{array}{l}\text { Hospital Recoletas } \\
\text { Zamora }\end{array}$ & Mireya Santoyo & - & - \\
\hline Clínica Ponferrada & $\begin{array}{l}\text { Carolina Rodríguez } \\
\text { Sobrecueva }\end{array}$ & - & - \\
\hline Hospital de la Reina & - & - & - \\
\hline $\begin{array}{l}\text { Hospital San Juan de Dios } \\
\text { de León }\end{array}$ & $\begin{array}{l}\text { Meritxell Moya } \\
\text { Revilla }\end{array}$ & - & $\begin{array}{l}\text { DLV-La } \\
\text { Central }\end{array}$ \\
\hline $\begin{array}{l}\text { Hospital San Juan de Dios } \\
\text { de Burgos }\end{array}$ & 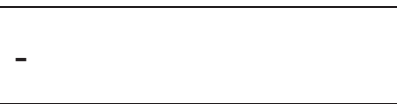 & - & - \\
\hline $\begin{array}{l}\text { Centro asistencial San } \\
\text { Juan de Dios de Palencia }\end{array}$ & - & - & - \\
\hline Clínica Altollano & - & - & - \\
\hline Sanatorio López Otazu & - & - & - \\
\hline Clínica San Francisco & Pedro Lechuga Mallo & - & - \\
\hline $\begin{array}{l}\text { Obra Hospitalaria Nuestra } \\
\text { Señora de Regla }\end{array}$ & 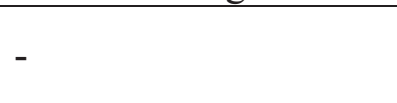 & - & - \\
\hline $\begin{array}{l}\text { Hospital Psiquiátrico San } \\
\text { Luis }\end{array}$ & Francisco Suárez & $*$ Otra persona* & $\begin{array}{l}\text { Comunicación } \\
\text { Profesional }\end{array}$ \\
\hline $\begin{array}{l}\text { Centro Hospitalario } \\
\text { Benito Menni }\end{array}$ & Francisco Suárez & *Otra persona* & $\begin{array}{l}\text { Comunicación } \\
\text { Profesional }\end{array}$ \\
\hline $\begin{array}{l}\text { Hospital Residencia } \\
\text { Asistida de La Luz }\end{array}$ & - & - & - \\
\hline $\begin{array}{l}\text { Sanatorio Sagrado } \\
\text { Corazón }\end{array}$ & - & - & - \\
\hline $\begin{array}{l}\text { Unidad de Rehabilitación } \\
\text { Psiquiátrica Ntra. Sra. de } \\
\text { La Fuencisla }\end{array}$ & - & - & - \\
\hline $\begin{array}{l}\text { Hospital General de la } \\
\text { Santísima Trinidad }\end{array}$ & - & - & - \\
\hline Clínica Santa Teresa & - & - & - \\
\hline $\begin{array}{l}\text { Protección Civil (112) de } \\
\text { la Junta de Castilla y León }\end{array}$ & Carlos Molero Colina & - & - \\
\hline
\end{tabular}

Fuente: elaboración propia. 
Después de contactar con todos los hospitales y comprobar en cuáles existe servicio de comunicación, se procedió a concertar entrevistas personales con los responsables. En total, de los siete centros que poseen este departamento, cuatro aceptaron colaborar. El resto -Clínica Ponferrada, Grupo Recoletas y Protección Civil (112)-, bien por silencio de la gerencia, por motivos de confidencialidad o por extralimitación de competencias, en este orden, decidieron no participar en la tesis. En total, las personas entrevistadas fueron las siguientes:

Tabla 31. Relación de responsables de comunicación entrevistados en Castilla y León

\begin{tabular}{|l|c|c|c|}
\hline \multicolumn{1}{|c|}{ Hospital } & $\begin{array}{c}\text { Responsable de } \\
\text { comunicación }\end{array}$ & $\begin{array}{c}\text { Segundo } \\
\text { trabajador }\end{array}$ & Empresa \\
\hline $\begin{array}{l}\text { Consejería de } \\
\text { Sanidad de la Junta } \\
\text { de Castilla y León }\end{array}$ & Blanca Saravia Ibañes & $\begin{array}{c}* \text { Otros tres } \\
\text { trabajadores* }\end{array}$ & - \\
\hline $\begin{array}{l}\text { Hospital San Juan de } \\
\text { Dios de León }\end{array}$ & $\begin{array}{c}\text { Meritxell Moya } \\
\text { Revilla }\end{array}$ & - & $\begin{array}{c}\text { DLV-La } \\
\text { Central }\end{array}$ \\
\hline $\begin{array}{l}\text { Clínica San } \\
\text { Francisco }\end{array}$ & Pedro Lechuga Mallo & - & - \\
\hline $\begin{array}{l}\text { Hospital Psiquiátrico } \\
\text { San Luis }\end{array}$ & Francisco Suárez & $*$ Otra persona* & $\begin{array}{c}\text { Comunicación } \\
\text { Profesional }\end{array}$ \\
\hline $\begin{array}{l}\text { Centro Hospitalario } \\
\text { Benito Menni }\end{array}$ & Francisco Suárez & $*$ Otra persona* & $\begin{array}{c}\text { Comunicación } \\
\text { Profesional }\end{array}$ \\
\hline
\end{tabular}

Fuente: elaboración propia. 


\subsubsection{FUNCIONES Y TAREAS DE LOS DEPARTAMENTOS DE COMUNICACIÓN DE LOS HOSPITALES. RESULTADOS DE LAS ENTREVISTAS PERSONALES}

\subsubsection{RESULTADOS DE LAS ENTREVISTAS A LOS RESPONSABLES DE COMUNICACIÓN DE LOS HOSPITALES DE GALICIA}

\subsection{ESTUDIOS Y TRAYECTORIA PROFESIONAL DE LOS COMUNICADORES}

La práctica de la comunicación dentro de una organización puede llevarse a cabo desde diferentes prismas, ya sea este periodístico, marketiniano, publicitario, de relaciones públicas... Esto puede depender de la visión que tenga el gerente acerca de la información, pero, también, de los estudios, de los conocimientos y de la experiencia previa que posea el responsable del departamento. Para comprobar el componente teórico y práctico de las personas que difunden la comunicación relativa a la salud en Galicia, se ha demandado a sus responsables los estudios que han cursado, así como la trayectoria profesional que han desarrollado antes de dedicarse al sector sanitario.

\section{Estudios}

La mayor parte de las personas encargadas de la comunicación de los hospitales en esta comunidad son licenciados en Ciencias de la Información. Los graduados en esta disciplina son: Myriam Sierra (por la Universidad Complutense de Madrid), Carlos Bermello (por la Universidad Complutense de Madrid), Ana López Pimentel (por la Universidad Complutense de Madrid), Beatriz Senra (por la Universidad Santiago de Compostela), Paz Teijeira (por la Universidad Complutense de Madrid), Álvaro Otero (por la Universidad Complutense de Madrid), Raúl Álvarez (por la Universidad del País Vasco), Marta Castro, Irene Pazo (por la Universidad de Pamplona), María José Iglesias Iglesias (por la Universidad de Santiago) y Cristina de la Vega. Aunque no sean licenciados en Ciencias de la Información, otros pocos han cursado estudios universitarios relacionados con la comunicación. Más concretamente, Kiko Fernández y Antolín Hermida cursaron Publicidad y Relaciones Públicas y José Losada, Periodismo por la Universidad de Salamanca. 
El resto se decantó por otras ramas, como Patricia Forteza, que estudió Marketing, y por ello tiene una visión “más marketiniana de la comunicación”. Dos personas encargadas de la comunicación sanitaria en el ámbito privado cursaron estudios universitarios que poco tienen que ver con la información. Es el caso de Irene Montero, que estudió Filología Inglesa, o de Xabier López, que es licenciado en Psicología.

Solamente dos personas han señalado tener algún estudio complementario al margen de las licenciaturas: Myriam Sierra posee un diploma en Publicidad e Irene Montero estudió un máster en Medios de Comunicación (de ahí, dice, se "enganchó" al periodismo). Ana López Pimentel, por su parte, asegura tener una especialización en comunicación de empresas.

No obstante, muchos afirman haber recibido cursos o asistido a conferencias sobre marketing, comunicación hospitalaria, gestión de crisis, nuevas tecnologías, etc. A este respecto, algunos de los entrevistados lamentan la escasez de estudios especializados en comunicación sanitaria respecto a los que se imparten sobre comunicación común. Según indica Patricia Forteza, "hay mucho de comunicación en general, pero de comunicación hospitalaria hay poco movimiento".

La única formación innovadora la ofrece Patricia Forteza, que ha participado en una estrategia de benchmark acudiendo durante un mes a los hospitales neoyorkinos Mount Sinai y Memorial Sloan-Kettering Cancer Center.

\section{Trayectoria profesional}

La práctica totalidad de los responsables de información de los hospitales gallegos poseen experiencia previa en diferentes medios de comunicación, ya sea mediante prácticas durante la etapa universitaria o a través de contratos laborales posteriores. Esta destreza facilita "poder ponerte en la piel de la otra persona: saber qué datos necesita, cuándo lo requiere y por qué te lo pide", comenta Arantza Briegas.

Myriam Sierra, por ejemplo, antes de entrar en la Consellería, colaboró con EFE y con La Voz de Galicia. Paz Teijeira hizo prácticas todos los años de la carrera en El Progreso. Al finalizar los estudios, trabajó cuatro meses para Radio Nacional, un año en El Mundo y otro en la Voz de Galicia. Irene Pazo también hizo prácticas en Radio Vigo, El Faro de Vigo y en la televisión gallega. María José Iglesias realizó alguna colaboración "muy, muy puntual" con la Cadena Ser y Europa Press. Por su parte, Raúl Álvarez, tras ejercer el periodismo en las emisoras de Onda Cero Radio en Bilbao y Santiago de Compostela, se introdujo en la prensa escrita como redactor y reportero de la sección de Sociedad del periódico El Ideal Gallego y como jefe de Deportes de $A B C$ en Galicia. Fue después de estas experiencias cuando recaló en la Consellería de Sanidade-Servizo Galego de Saúde en Pontevedra, del cual es responsable de su 
gabinete de comunicación desde el año 1998 y con plaza por oposición pública desde 2005 .

José Losada trabajó en radio, en televisión y en agencias de marketing. Ocupó su puesto actual ocho años atrás, cuando ofreció al hospital la página web y, gracias a esta experiencia, fue contratado a jornada parcial para finalmente conseguir una dedicación a tiempo completo. Beatriz Senra también pasó por la radio y la televisión antes de adentrarse a la comunicación sanitaria. Ana López Pimentel inició su andadura profesional en el mundo de la radio y la prensa escrita (al igual que su compañera Arantza Briegas) para después incorporarse en distintos sectores de comunicación de la Xunta de Galicia. Más concretamente, trabajó en el gabinete de comunicación del presidente de la Xunta de Galicia y fue la jefa de prensa de la Consellería de Sanidad durante cinco años. Irene Montero comenzó en prensa y radio y después se volcó en la consultoría de comunicación. Cristina de la Vega, al margen de los gabinetes de comunicación, trabajó durante un año en Antena3 Radio. Por su parte, Álvaro Otero fue redactor de varios periódicos y revistas y jefe de prensa de la Consellería de Economía de la Xunta de Galicia. Después de ello, trabajó en una consultoría.

Antes de ocupar el cargo que ostentan actualmente, algunos entrevistados colaboraron con otras empresas dedicadas a la información sanitaria. Como ejemplo, Marta Castro, que, salvo un reducido tiempo en televisión, empezó su etapa profesional directamente en comunicación sanitaria, más concretamente en dos hospitales de Madrid: el Puerta de Hierro y el de Alcorcón. Algo parecido sucede con Xabier López, que a pesar de estudiar Psicología, realizó desde el tercer curso de carrera prácticas en medios de comunicación y, al finalizar los estudios, fue corresponsal de El Diario Médico y de El Correo Farmacéutico. Finalizó esta etapa en 2005, año en el que entró en la Consellería de Sanidade como jefe de prensa. Cuatro años más tarde, con el cambio de Gobierno en la comunidad, dejó el puesto, y en 2011 comenzó a colaborar con el hospital Vithas Fátima. Antolín Hermida, antes de emprender su trabajo unos años atrás con el Hospital General Juan Cardona, había hecho contribuciones con el Colegio de Farmacéuticos y con distintos laboratorios de la misma rama. Patricia Forteza inició su carrera directamente en centros sanitarios, contabilizando en total 17 años dedicada a la comunicación de la salud; 5 de ellos en el ámbito público y los 12 restantes, en el privado.

Los empleados de los centros públicos entraron, en su mayoría, al poco tiempo de acabar sus estudios y, en algunos casos, gracias a las prácticas realizadas en ese mismo gabinete durante la carrera. Myriam Sierra, por ejemplo, entró a formar parte del Sergas, con distintos tipos de contratos, un año después de terminar sus clases (finalizó la universidad en 1992 y comenzó en la institución gallega en 1993), al igual que Irene Pazo (se incorporó en 1993, siendo la primera persona que dirigía la comunicación de una dirección provincial). María José Iglesias, de hecho, se integró en la Consellería de Sanidade con unas prácticas realizadas en tercer y cuarto curso de carrera, para, al 
finalizar sus estudios, quedarse contratada por la misma entidad. A Kiko Fernández también le pasó esto: entró como becario y continuó con un contrato laboral. Él ingresó en 1995 y Cristina de la Vega, unos tres años antes.

La trayectoria de las personas que llevan la comunicación desde una empresa externa es algo diferente, ya que normalmente colaboran con otras firmas que poco tienen que ver con el ámbito de la salud. Irene Montero entró a formar parte de Octo como responsable del área de publicaciones en 1998 y pasó por distintos puestos hasta ocupar el cargo de directora general en 2009. Colabora con otras tantas entidades, al igual que Tomás Valín, que lleva nueve años trabajando para el Hospital Policlínico La Rosaleda en el momento de la entrevista. Álvaro Otero creó Atlántica Comunicación en 1998, siendo el hospital Povisa su primer cliente, aunque en la actualidad ofrece sus servicios de manera frecuente a varias entidades. Algo similar sucede con Antolín Hermida Hermida, como se ha detallado.

\subsection{UBICACIÓN DETRO DEL ORGANIGRAMA}

La comunicación en los hospitales gallegos está concebida como una tarea de dirección, al menos orgánicamente. Solamente un centro, más concretamente el Vithas Nuestra Señora de Fátima, no depende directamente de gerencia o de dirección, sino que está supeditado por la dirección de promoción, que está subordinada, a su vez, a gerencia. Aún así, sostiene su responsable de comunicación, "tengo acceso directo a todo el equipo directivo, gerente incluido". El resto de centros hospitalarios estudiados tienen vinculación directa con dirección, a pesar de que, en algunos casos, como en la estructura de gestión integrada de Ferrol, no figure expresamente en el organigrama del centro.

Efectivamente, tal y como indica María José Iglesias, la comunicación "es una herramienta de la gerencia porque somos los encargados de seleccionar las noticias del centro. Pese a ello, no figuro en el oficial porque el gabinete no forma parte del organigrama. El departamento de comunicación es como calidad o como formación, es una herramienta más, es un departamento más". Pese a ello, admite María José Iglesias, "mi dependencia es de gerencia".

Este es el caso también de la comunicación externalizada a través de una agencia. El Hospital Policlínico La Rosaleda, por ejemplo, cuya comunicación es conducida por Bolanda, mantiene las labores informativas dependientes de gerencia, al igual que sucede con el Juan Cardona. Según explica Tomás Valín, “los temas comunicativos no se tratan en dirección día a día, salvo asuntos de relevancia, como en época de crisis, pero tenemos reuniones periódicas. Ahí es cuando se definen los temas que hay que dar a conocer, concretamos el hilo que tenemos que seguir y buscamos las herramientas necesarias para llegar al fin". 
El Hospital Modelo y el Maternidad Belén, que confía su comunicación a Octo, no incluyen expresamente esta actividad dentro del organigrama del centro. Sin embargo, indica Irene Montero, el tratarse de un servicio externo no impide que dependan directamente de gerencia. En el caso de Povisa, la comunicación también depende de dirección, más concretamente del consejero delegado. Y es que Álvaro Otero entiende que "un gabinete de comunicación debe depender de la figura más alta de una entidad porque así los empleados son más receptivos a las peticiones del gabinete de comunicación y le otorgan más importancia”.

La situación del hospital Quirón de La Coruña es algo más especial, ya que se trata de un centro privado englobado en un grupo hospitalario. El departamento de comunicación tiene dos dependencias. Por una parte, está incluido dentro del comité de dirección. Este comité lo forma la gerente, que es la persona que más autoridad tiene dentro del hospital, el director médico, la directora de enfermería, la directora financiera, la directora de recursos humanos, la directora de calidad y el servicio de comunicación. Esta elevación hasta el comité de dirección, según Patricia Forteza, es positiva, ya que permite obtener "una visión del conjunto del hospital. No solamente desde tu punto de vista como periodista, sino de un aspecto mucho más financiero, por decirlo de alguna forma, y de líneas estratégicas de la compañía". Y lo muestra con un ejemplo: "Tú imagínate que se ha incorporado un cirujano general que es muy bueno en temas de proctología, por ejemplo, y se ha montado una unidad de este tipo. Desde el comité de dirección deciden potenciarla. No solo te enteras de que se va a potenciar esa área, sino que te has enterado de muchos detalles de toda esa negociación: te has enterado de cómo se ha montado la unidad, te has enterado de qué tecnología se va a poner, etc. O sea, tienes tanta información que puedes verdaderamente vender muy bien el tema. Por eso es importante". Por otra parte, continúa Patricia Forteza, se encuentra la dirección corporativa que depende del director de comunicación de la compañía Quirón. De esta manera, se establecen anualmente unos objetivos a nivel corporativo de forma anual que deben ir en consonancia con las metas del hospital de A Coruña.

Una peculiaridad del departamento de comunicación del Complejo Hospitalario Universitario de Ourense es que logró en 2012 el rango de servicio dentro de la estructura de gestión integrada. Esto implica que coordinan a otros colectivos que colaboran con ellos y que tienen dependencia funcional, tales como celadores, mantenimiento, etc. Por ahora, es el único departamento de comunicación que ostenta este rango.

\subsection{DÍA A DÍA}

El trabajo cotidiano del gabinete de comunicación, dicen los entrevistados, "fluctúa muchísimo". Como indica María José Iglesias, el día a día "es muy caprichoso. Una 
jornada estás aquí hasta las 10 de la noche y otra te pones a hacer archivo", ya que insiste en que la carga de trabajo entre unos días y otros puede ser radicalmente opuesta. Raúl Álvarez lo expresa de la siguiente forma: "Sabes cuando empiezas, pero nunca cuándo, ni dónde, ni cómo terminas". La mayoría de las jornadas son "estresantes", afirman, dado que "el tema de sanidad es muy amplio y genera muchísimas informaciones cada día en prensa", asegura Paz Teijeira.

En teoría, el horario de aquellos que trabajan para la sanidad pública es de 8:00 a 15:00 horas. Sin embargo, en ocasiones acuden a su puesto de trabajo por las tardes y todos ellos están localizables las 24 horas del día durante toda la semana. Algunos, incluso, como Kiko Fernández, comienzan su jornada a las siete de la mañana por propia voluntad. Esto lo hacen, comenta, por "el sentimiento de pertenencia a la institución”. En algunos casos, como explica Ana López Pimentel, también se llevan trabajo a casa. Según señala, "debido a la estratégica ubicación que tiene el gabinete de comunicación dentro de Hospital Clínico estás muy expuesto y recibes muchas visitas de compañeros e incluso pacientes, que resultan fundamentales para nuestro trabajo. Sin embargo, las interrupciones son constantes y ciertos trabajos acabas realizándolos por las tardes en casa, con un poco más de tranquilidad".

Todos insisten en que podrían cumplir "a rajatabla" su horario oficial y desconectar el teléfono móvil fuera de esas horas (las cuales no son remuneradas, al contrario de otro personal, que posee un plus por el tiempo que se encuentra de guardia), pero "tienes una implicación que te impide hacer eso", asegura Kiko Fernández. Además, como relata Raúl Álvarez, "si haces eso, mañana cuando abras no te asustes porque llevan desde las cuatro de la tarde intentando localizarte y esto no se para". Y es que los medios impresos, sobre otros, redactan sus noticias bien entrada la tarde, y, por ello, detalla Paz Teijeira, algunos reciben "una gran parte de las llamadas a partir de las cinco de la tarde".

A veces, como recuerda Marta Castro, los periodistas han llegado a llamar incluso a las tres de la madrugada. No obstante, esto sucedía más a menudo los primeros meses de funcionamiento del gabinete, ya que con el tiempo les han ido "reeducando": "Ahora ya saben que a partir de una hora solo pueden llamar cuando es algo urgente, pero antes, $\mathrm{y}$ ahora aunque rara vez, te llaman porque ha derrapado una moto", afirma la responsable de comunicación del 061. Por ello, se consideran "funcionarios atípicos", como lo define un entrevistado que no quiere que su nombre figure. Ni en verano, insiste, "que es una época en la que parece que todas las áreas tienen menos trabajo, podemos estar tranquilos".

La agenda del día la marca la actualidad de la jornada. Normalmente, hay temas cíclicos que se repiten a lo largo del tiempo y ante los cuales los responsables de comunicación suelen estar prevenidos. Estos pueden ser el sol y las banderas azules en 
verano, la gripe en invierno, los días internacionales relacionados con la salud, la bienvenida y despedida de los MIR, etc.

Además, algunos manifiestan saber "más o menos" lo que va a aparecer el día siguiente en las noticias, puesto que han conseguido que los periodistas llamen la jornada anterior y contrasten las informaciones. Aunque también reconocen: "Sé lo que va a salir, lo que no sé es cómo. Dependiendo de cómo salga, eso va a marcar nuestro día. Si sale un breve, pues nada, pero si sale en portada ya te están llamando todas las radios, las teles...", explica un comunicador.

Si la jornada se complica por los acontecimientos ocurridos, la mayor parte del tiempo la dedican a contestar a los medios y a proporcionarles datos, mientras que si se considera "tranquila", los comunicadores intentan ser "proactivos" y proporcionar ellos las noticias, normalmente de índole positiva (como revela un participante) o se meten con el archivo (tal y como hace María José Iglesias). Kiko Fernández, por ejemplo, se marca como objetivo que las noticias que pueden considerarse negativas "nunca sean el $10 \%$ de las positivas". Y por el momento, afirma, "lo vamos cumpliendo".

Sin embargo, insisten todos, hay acontecimientos que son imposibles de prever, ya que la sanidad es un campo "muy complejo" y "es muy raro el día que no hay nada: puedes estar haciendo archivo tranquilamente cuando te salta una llamada y ya tienes el día a tope", asevera un entrevistado. Además, en algunos centros públicos, no siguen ninguna política comunicativa: "No hay estratega, yo en mi caso cuando hablan de los ideólogos y de los teóricos de la comunicación se me queda grande. Mi estrategia es contestar a lo que se pueda y vender lo vendible. O sea, intentar contar las cosas positivas nosotros, porque las malas ya las cuentan otros", comenta esta trabajadora.

En otros sí que se siguen unas ciertas pautas. Patricia Forteza, que posee un plan de comunicación, asegura dedicar la mitad o algo más de su tiempo a alcanzar los resultados de ese plan y el resto del tiempo, a labores "no planificadas".

En el hospital Povisa existen dos clases de informaciones. La primera trata temas del día a día, lo que demandan los medios de comunicación (es decir, accidentes, atropellos, sucesos, etc.). Es un tipo muy recurrente y que suele cambiar según modas (Álvaro Otero recuerda una temporada en la que se cubrían continuamente casos de niños atacados por perros, una tendencia que desapareció al poco tiempo). Con este tipo, la empresa Atlántica no actúa de forma proactiva, sino que son los medios los que llaman para obtener información (la labor proactiva que llevan a cabo en estos casos es la del restablecimiento de la imagen, que puede ser dañada por algunos de estos sucesos). El segundo tipo es la proactiva, es decir, cuando Atlántica busca el contacto con los medios de comunicación para transmitirles contenidos, por ejemplo, a través de reportajes o notas de prensa. 


\section{Tareas}

Los gabinetes de comunicación de los hospitales funcionan de manera independiente, dice Marta Castro, aunque, "en teoría", están coordinados por el departamento de comunicación de la Consellería de Sanidade. Algunas personas, sobre todo los encargados de las estructuras de gestión integradas, canalizan la comunicación de más de un hospital. Pese a ello, intentan "ser prácticos en el tiempo" y apilan los actos que tengan en un determinado centro a unas horas determinadas para "no tener que estar yendo y viniendo", como revela María José Iglesias.

Independientemente del lugar, la primera tarea que realizan normalmente casi todos los responsables de comunicación de los hospitales de Galicia al comenzar su jornada laboral es leer los periódicos y, con ello, elaborar el dosier de prensa. En este informe incluyen tanto la prensa local, como la regional y la nacional. No adjuntan solamente las informaciones relativas al centro en cuestión, sino cualquier noticia que pueda ser de interés para el personal sanitario.

Esos dosieres pueden enviarse únicamente a los directivos (como es el caso de Irene Montero, que se lo manda al gerente, o de Kiko Fernández, que se lo hace llegar a unas 30 personas del equipo dirigente y del personal intermedio) o bien a todo el personal, ya sea a través de Intranet o del correo electrónico (como María José Iglesias o Myriam Sierra). Algunos realizan un proceso más complejo. Kiko Fernández, por ejemplo, envía a los directivos y cargos intermedios el informe completo y en la Intranet sube únicamente las noticias más relevantes; eso sí, siempre que sean positivas: "Sinceramente, no vamos a colgar una que nos digan «Una protesta en el centro de salud por una gotera», por ejemplo, esa no la colgamos; colgamos siempre las cosas positivas del hospital".

Los trabajadores de las clínicas públicas cuentan, además, con el dosier que elabora todos los días de la semana el departamento de comunicación de la Consellería de Sanidade (es decir, los servicios centrales). De ahí consiguen "muchas publicaciones a las que nosotros no accedemos", dice María José Iglesias. Los responsables de comunicación lo reciben a las 9:30 horas aproximadamente, concreta Kiko Fernández, y algunos, como este último, vuelven a enviar las noticias más importantes de este informe nuevamente a los destinatarios marcados.

Después, trabajan "un poco a demanda tanto interna (de los empleados), como externa (según lo que nos piden los medios de comunicación)", comenta Beatriz Senra. Desde el primer prisma, según el día y época en particular, pueden ayudar en los congresos, en la redacción y edición de folletos, en el diseño de carteles, en la preparación de entrevistas, etc. Por ejemplo, cuando hay actos internos, se encargan de informar "sobe el protocolo, establecer quién los recibe, dónde tienen que ir, si va a haber declaraciones, dónde van a atender a los medios...", detalla Beatriz Senra. Otros, como María José Iglesias, acompañan al personal interno en sus relaciones con los 
medios, ya sean entrevistas dentro del hospital o tertulias externas y fuera del horario oficial del gabinete.

Además de esto, los responsables de comunicación dedican cierto tiempo a labores "sordas", en el sentido de que "haces muchísimas cosas que al final parece que no se ven", tales como actualizar la intranet, las agendas de guardias, de despachos, etc., cuenta María José Iglesias. "Hacemos bastante trabajo que no tiene demasiada visibilidad y que a los periodistas nos parece más desagradable, ya que no tiene su resultado visible en una página en un periódico, en un programa en una radio, en un espacio televisivo...", se lamenta esta periodista.

En cuanto a la comunicación externa, pueden tanto actuar a demanda de los periodistas como de forma proactiva. Las rutinas periodísticas, de todas formas, ya las conocen: "Sabemos cuáles son los flujos: a primera hora llaman las teles y las radios, que normalmente necesitan la información muy rápidamente. Después, sobre las 12, empiezan las peticiones de los medios impresos, que pueden ser para el mismo día o no, eso varía más", relata Beatriz Senra.

Diariamente, suelen trabajar con la prensa local, de vez en cuando con la autonómica y muy puntualmente con la nacional, reconoce Raúl Álvarez. Las noticias que cobran nivel regional suceden "una, dos, tres veces al año como mucho" y suele tratarse, por ejemplo, de casos de meningitis. En cambio, el ámbito nacional rara vez se alcanza y suele deberse a accidentes graves o según las peculiaridades de cada centro. Por ejemplo, en el caso del hospital Povisa, esto sucede sobre noticias de la unidad de quemados, ya que es una especialidad importante en la clínica.

Muchas veces, los periodistas demandan información sobre algún paciente accidentado para elaborar las secciones de sucesos. Normalmente es el 061 el que proporciona el lugar donde se produjo el incidente, los recursos utilizados, las iniciales de las personas involucradas, la edad y una escueta información sobre el estado de los implicados. Después, son los responsables de comunicación de los hospitales los que se encargan de conseguir el parte médico y otros datos de interés en el caso de que algún periodista lo solicite. Únicamente en casos muy concretos de accidentes con múltiples víctimas se emite un parte médico unificado, como puede ser el caso de vuelcos o choques de autobús, según especifica Marta Castro.

Aparte de contestar a los medios de comunicación, que suele ocupar "gran parte del tiempo", asegura Paz Teijeira, también difunden noticias desde dos vertientes: de información hospitalaria y de divulgación sanitaria. En el primer campo se incluyen las actividades propias de los centros: cierre de camas, adquisición de equipos, actos del personal, etc. En el segundo grupo se engloban aquellos datos en torno a la salud que puedan ser de interés para la población: consejos para el calor, alergias, prevención, etc.

Los responsables de comunicación de los hospitales mantienen reuniones con el equipo directivo para obtener información y para programar las acciones comunicativas. 
Kiko Fernández, por ejemplo, se entrevista con el gerente todos los días "para comentar las cosas que han salido en los medios y planear las actividades que tenemos en el hospital, como congresos, entrevistas, etc."

Las empresas externas también organizan encuentros periódicos con los directivos de las clínicas. Tomás Valín, por ejemplo, lo hace anualmente (para concretar la estrategia comunicativa a seguir), mensualmente (con el fin de corregir, si procede, esas líneas) y en ocasiones semanal y diariamente. Irene Montero también dialoga frecuentemente con el gerente o con otras fuentes en el hospital, ya sea por teléfono, correo electrónico o "café mediante". Antolín Hermida asegura estar en contacto diario con el gerente el hospital, ya sea por teléfono o correo electrónico, mientras que de manera presencial se ven una vez a la semana aproximadamente, según las circunstancias del momento, apostilla.

\subsection{PÚBLICOS}

Los públicos de un hospital pueden llegar a ser muy numerosos si se tiene en cuenta tanto a los pacientes, como a los familiares, los medios de comunicación, el personal empleado, la población en general, etc. Prácticamente todas las personas entrevistadas para este trabajo tienden a enfocar sus acciones en uno o como máximo dos de estas audiencias. Esto sucede en la práctica, ya que son conscientes de que para llevar a cabo una comunicación eficaz no se debería olvidar a ningún público objetivo. Tal y como María José Iglesias detalla:

"Un gabinete de comunicación no puede en ningún momento olvidar ninguno de sus públicos objetivos [...]. Para mí es tan público objetivo los periodistas, como mis profesionales, como los pacientes, porque los pacientes a fin de cuentas son los que van a recibir ese mensaje [...]. Yo no creo en el concepto del gabinete solo como marketing de la empresa, ni tampoco solo como intermediario entre la prensa y el hospital".

Pese a esta sentencia, María José Iglesias opina que es "muy difícil" llevar una comunicación excelente con todos los públicos involucrados, aunque, en cualquier caso, "tu objetivo tiene que ser ese".

\section{Comunicación externa}

En cuanto a la información de puertas para afuera, los entrevistados se encuentran algo divididos. Algunos opinan que los medios de comunicación son el principal público objetivo de su gabinete, como sucede con Ana López Pimentel o Raúl Álvarez. 
Según Ana López Pimentel, es el principal "en cuanto a tiempo de trabajo que le dedicas, tanto por el volumen de información pública que genera el hospital como por el interés que despierta dentro de la población y, por tanto, en los medios de comunicación local". En cambio, otros los consideran una vía para llegar a, en realidad, su audiencia primordial: la población en general. En este lado se hallan Tomás Valín, Xabier López, Álvaro Otero, Antolín Hermida o Marta Castro. Según indica el primero, "los medios de comunicación no son nuestro principal público, pero exponencialmente son los que nos hacen llegar a un público mayor". Álvaro Otero también considera que la población es su segundo gran colectivo objetivo (por detrás de los pacientes), y que a veces llega a ella a través de los medios. De hecho, indica Álvaro, en 2014, el hospital pasa de tener adscripción obligatoria a adscripción voluntaria (es decir, que la población puede elegir este $\mathrm{u}$ otro hospital, independientemente de que se encuentre cerca de su domicilio). "Por lo tanto - dice el responsable de comunicación-, la importancia de la población en general se acentuará".

Marta Castro suele trasladar información a dos grandes grupos: a la población en general teniendo en cuenta que cualquier persona puede hallarse en algún momento en una situación de emergencia y tenga que llamar al $061 \mathrm{y}$, por otro lado, a colectivos determinados que tienen ciertas características en común, como personas que han sufrido un infarto o que tienen patologías psiquiátricas. A estos últimos se les suele orientar a través de programas concretos. Sin embargo, no se comunican directamente con ellos, sino que suelen hacer uso "casi siempre" de los medios de comunicación.

Antolín Hermida también concibe como público objetivo la población en general, dado que "desde la gerencia y desde nuestro gabinete estamos tratando de amplificar y buscar otros targets, otros públicos objetivos que vayan hacia problemas o especialidades que ofrecemos en el hospital".

Ana López Pimentel, por su parte, indica que suele "tener presente" a la población en general en sus informaciones, pero que no se comunica directamente con ellos. En cambio, centra la mayor parte de sus esfuerzos en los medios de comunicación.

\section{Comunicación interna}

La mayoría de las personas entrevistadas creen que no se trabaja suficientemente la comunicación interna, aunque reconocen que es un aspecto importante para cualquier departamento de esas características. Para Álvaro Otero, por ejemplo, la comunidad médica (que sería un subgrupo dentro del personal interno) ocupa el tercer lugar en su ranking de público objetivo, por detrás de los pacientes y de la sociedad en conjunto.

Patricia Forteza, en cambio, considera que "es igual de importante que la externa, sobre todo en una empresa de servicios en la que el producto verdaderamente lo hace la persona". Ella lo ejemplifica así: "Esto no es una fábrica en la que hacemos piezas de 
tornillos, no, es una empresa de servicios, y el producto lo hace en ese momento la persona, la enfermera, el médico, etc." No obstante, considera que no se dedica mucho tiempo a la comunicación interna, por lo que se ha convertido en "una asignatura pendiente" para todos los hospitales y "la hermana pobre" de la familia. Opina, por ejemplo, que no hay nada peor que "un empleado se entere por la prensa de que el hospital ha abierto una unidad de mama, por ejemplo". Antolín Hermida considera que no se le otorga la importancia que se le debería "por dejadez": "Andamos todos cada uno en lo suyo y a veces las cosas no se dan a conocer ni se saben", explica.

Con el fin de dotar de más relevancia a la vertiente interna, en el hospital Quirón mantienen tablones de anuncios, boletines internos, revista del grupo, charlas piramidales, etc. También organizan actos para empleados, como la fiesta de Navidad, que es gratuita y a la que todos los trabajadores del centro están invitados. Patricia Forteza justifica la organización de este acontecimiento de la siguiente manera: "Estos actos son muy importantes para propiciar un momento distendido donde la gente se vea en otro ambiente".

En el Complejo Hospitalario Universitario de Santiago, consideran que se le está dando cada vez más importancia, pero aun así no se le otorga toda la relevancia que se debería. Por ejemplo, indican que el personal interno acude al departamento de comunicación cuando quieren presentar una candidatura a congresos, con el fin de que les echen una mano con la redacción. También se encargan de ciertas actividades, como protocolo, reserva de salas, etc. Pero al margen de esto, la actividad que les ocupa casi todo su tiempo son los medios de comunicación.

Lo mismo sucede con Paz Teijeira. Los medios de comunicación dominan la mayor parte de su actividad, dejando al personal interno como el segundo mayor target. Estos, dice Paz Teijeira, "demandan fundamentalmente apoyo: si tienen que acceder a los medios de comunicación contactan conmigo para que le facilite el intercambio, para que les aconseje sobre cómo tienen que hacer una entrevista, etc." Esta es su faceta a demanda. Al margen de ella, también organizan eventos, como por ejemplo la recepción y despedida de los médicos MIR, la despedida de los jubilados, etc. Xabier López también reconoce que dedica más tiempo a la comunicación externa que a la interna, aunque reconoce que le gustaría dedicarle, "por lo menos, el mismo tiempo, sino más a la interna que a la externa. Para mí, los trabajadores de un hospital, sobre todo los asistenciales, son también transmisores de información a los pacientes".

Por las cifras que proporciona, Kiko Fernández es de las personas que más tiempo destinan a la comunicación interna; él calcula que dedica el $40 \%$ de sus esfuerzos a la interna frente al $60 \%$ restante de la externa. No todo el intercambio de información debe provenir de canales formales. Pepe Losada, por ejemplo, reconoce que la mayor parte de la comunicación interna la realiza "cara a cara", aunque también mantiene un portal interno donde vuelca información. 


\section{Pacientes}

Curiosamente, únicamente dos personas identifican los pacientes como el principal público del hospital. Ellos son Álvaro Otero y Patricia Forteza. Esta última, además, incluye dentro de este grupo a la familia del enfermo.

En el hospital Policlínico La Rosaleda se suelen realizar acciones de comunicación con los familiares, pero no con los pacientes. Lo mismo ocurre con Kiko Fernández, que asegura que nunca se comunica con ellos: "El paciente ya hablará con el médico o con la enfermera, nosotros hablamos con el médico o con la enfermera, y él le traslada la información [...] Le da mucho más confianza la enfermera o el médico que yo". Cuando tiene que poner en contacto a un paciente con los medios de comunicación por algún asunto que haya trascendido a la opinión pública, prefiere que sea el doctor el primero en informarle de que un periodista está interesado en su historia. De esta manera, dice Kiko Fernández, cuando desde el gabinete de comunicación llaman al paciente, este ya está al tanto.

Hasta el momento, que él recuerde, no ha habido ninguna negativa a través de este procedimiento. Aunque, eso sí, siempre fuera del edificio, ya sea en su casa porque lleva un tiempo allí o a la salida tras recibir el alta; nunca en las plantas o en las habitaciones. $Y$ es que no permite la entrada de cámaras de televisión ni fotógrafos que puedan tomar imágenes de los pacientes dentro del centro: "Si vienen al salón de actos o vienen a hacer un reportaje sobre una unidad, les pedimos que no salgan pacientes. Y en el caso de salir, les pedimos que nunca salgan caras. No sirve difuminar, sino que tienen que grabar de cuello para abajo; es decir, que no haya forma de identificar a esa persona salvo el padre, la madre o el hermano, porque saben que lleva esa ropa o por el motivo que sea, pero que otra persona no pueda identificarla. De momento no hemos tenido problema".

\section{Agentes institucionales y políticos e inversores y accionistas}

Ningún responsable de comunicación ha nombrado por iniciativa propia a las personalidades políticas e institucionales como público. Aun cuando se les preguntaba por ellos, no se les concibe como un target propio del gabinete, más allá de que, en algunos casos, les enviaban un dosier de prensa. Álvaro Otero es uno de los pocos que reconoce la importancia de este grupo, pero insiste en que no tiene relación directa con ellos (salvo algunos pocos casos), sino que transmiten información a los medios de comunicación conscientes de que los agentes políticos e institucionales la verán. 


\section{Aseguradoras}

Las aseguradoras pueden llegar a ser un público objetivo de los hospitales porque tienen convenios con diferentes centros privados. Pese a ello, nadie las identifica como un público al que destinar demasiados esfuerzos. Tomás Valín explica que antes existía más comunicación con estos grupos. Ahora, prácticamente sin competencia, la aseguradora quien generalmente acude a negociar los convenios: "Se invierte un poco la dirección o sentido que existía antes. Quizás antes era bidireccional y ahora es la aseguradora la que viene a buscar", resume Tomás Valín.

\subsection{ACCIONES CON CADA PÚBLICO}

Con el fin de conocer si los entrevistados se comunican de igual modo con todas las audiencias expuestas, se les ha preguntado acerca de las herramientas que utilizan con cada uno de ellos y la relación que mantienen con cada colectivo.

\section{Medios de comunicación}

Antiguamente, los periodistas tenían sus propias fuentes médicas dentro de los hospitales e interactuaban directamente con ellos para conseguir información. Debido a estos contactos, algunos responsables de comunicación de estos centros recuerdan sus inicios "desayunando" noticias que no habían gestionado, como cuenta María José Iglesias. Álvaro Otero, por ejemplo, se acuerda del caso de una persona que fue tiroteada y acudió al hospital Povisa, un hecho que despertó el interés de los medios. A las 9 de la mañana recibió una llamada de El Faro de Vigo pidiendo una entrevista, pero el paciente, al ser preguntado por el responsable de información, negó su colaboración. Pese a ello, al día siguiente salió publicada en un periódico de la competencia una entrevista a esa persona (se entiende que algún redactor de ese diario había contactado por su cuenta con el paciente y finalmente accedió). "Me sentó muy mal, eso debería haber pasado por este gabinete, porque dio la impresión de que facilité la entrevista a un medio de comunicación y a otro no", lamenta Álvaro Otero.

No obstante, con el asentamiento en el tiempo de los gabinetes de información, "va cambiando la actitud de los periodistas", agradece María José Iglesias. Ahora, en la mayoría de los casos, cuando un redactor intenta ponerse en contacto con la recepción del hospital o con un trabajador en concreto, normalmente estos le derivan al gabinete de prensa. Así lo aseguran prácticamente todos los entrevistados. Es algo que, tal y como indica Álvaro Otero, “años ha costado conseguir". Además, en muchos casos, aunque la información se origine desde otra fuente, contactan con el hospital para contrastar la noticia. Esto sucede, por ejemplo, con el Complejo Hospitalario 
Universitario de Vigo, aunque para conseguirlo costase "mucho marcaje y estar muy encima de los periodistas".

De hecho, los medios funcionan en ocasiones como un servicio de atención al usuario o, como bromea esta última entrevistada, "la hoja de reclamaciones del Sergas". Esto es debido a que, a veces, los propios pacientes contactan directamente con la prensa para quejarse sobre algún servicio. Entonces, los redactores hablan con el gabinete de comunicación comentándoles lo ocurrido para que estos, a su vez, se pongan en contacto con el paciente y solucionen el malentendido, explica un participante.

Mantener un "contacto personal" con los periodistas es fundamental para que la relación sea "fructífera en ambos sentidos", detallan, entre otros, Ana López Pimentel, Raúl Álvarez o Irene Montero. Tal y como indica esta última, "yo les proporciono noticias y contactos y ellos divulgan informaciones que son beneficiosas para el hospital. Sin embargo, para que haya una buena relación tenemos que mantenernos en contacto continuo: hablamos cada dos por tres, de vez en cuando nos tomamos un café y nos vemos en cada evento que organizamos". Raúl Álvarez procura conocer a los periodistas que llevan la sección de salud y, como muestra de afecto, en Navidad, por ejemplo, les llama por teléfono deseándoles felices fiestas y les entrega un "aguinaldillo".

Beatriz Senra (de la estructura de gestión integrada de Santiago de Compostela), opina que "el hecho de que te conozcan, de que sepan que eres una persona responsable y seria le da un plus a la información que estás dando; tiene más peso que si se la da a una persona que no conoce y que no ha visto nunca o que vieron un par de veces en su vida". Esto es muy importante cuando surgen conflictos o malentendidos que afectan al hospital y se ha de dar una respuesta o explicación desde el gabinete de comunicación: "A una persona desconocida, al fin y al cabo, la puedes creer o no", resume Beatriz Senra.

Esa buena relación no sirve de nada, no obstante, si se emiten informaciones que carecen de interés informativo: "A mí no me gusta colocarles noticias que no tienen ningún valor [...]. En algunos casos, podría conseguir que me lo publiquen, pero como un favor. Y sería un favor baldío porque no le va a aportar nada ni al lector ni al periódico, únicamente al médico correspondiente. Y no nos va a valer para nada más que para quemar un cartucho para cuando realmente lo necesitemos", asevera Irene Montero.

Incluir un punto de vista local ayuda a que los periodistas puedan divulgar más fácilmente una noticia: "Yo no puedo vender una información a El País, sería muy difícil, pero, oye, a La Voz [de Galicia]...”, conjetura Patricia Forteza. Para ello, incide, "siempre tiene que haber un enfoque local. ¿Por qué? Porque tienes que pensar en lo que va a resultar atractivo para el lector. Entonces, por ejemplo, si tú cuentas que acabas 
de adquirir una máquina muy novedosa, que hace esto y lo otro, seguramente no te lo divulguen. Pero si lo enfocas como que una máquina que acaba de comprar el centro ofrece la posibilidad de tal operación o servicio pionero en Coruña y que se diferencia, así, con el resto de hospitales, y que es una novedad porque apostamos a la ciudad... Esto sí que tiene atractivo".

El enfoque local funciona no solamente con los temas, sino también con los autores de las declaraciones. Raúl Álvarez, por ejemplo, recurre a los profesionales de la misma comarca cuando quiere ofrecer una fuente de información para los periodistas: "Aunque sea una campaña autonómica genérica, le llega más al usuario que le hable un profesional sanitario de aquí, que no que le hable un director o subdirector general de Santiago, que habla prácticamente lo mismo pero a nivel autonómico. Aquí, tú como comunicador, vas a preguntar más sobre la población de la comarca, si es más o menos susceptible de tener esa enfermedad, etc.” Estos trucos, opina Raúl Álvarez, te los da el "haber sido antes cocinero que fraile"; es decir, haber trabajado previamente en los medios de comunicación que en los departamentos de las entidades.

No obstante, los periodistas que cubren la sección de sanidad no son siempre los mismos e, incluso, a veces son estudiantes en prácticas. "Es una de las cruces o de los caballos de batalla que tenemos las empresas porque no son conocedores de la realidad; todos los que entramos en una profesión nos falta experiencia, nos falta a veces calibrar las cosas. Entonces, como tengas algún conflicto en verano en plenas vacaciones, que suele haber muchos becarios, tiembla, tiembla porque no hay por donde abordar eso", se queja Tomás Valín. En esa parte de gabinete de crisis, indica este entrevistado, "tienes que explicar las cosas muchas veces con mucho más cariño y mucho más esfuerzo de lo habitual. Porque hay periodistas que buscan el punto exacto de la noticia real, pero a veces hay informaciones que se prestan a confusiones y que pueden hacer mucho daño al hospital. En ese caso procuramos intervenir para explicarlo adecuadamente".

Existe otro inconveniente entre los centros de atención especializada y los periodistas, y es que estos últimos no suelen estar especializados en sanidad y esto les crea dudas sobre la trascendencia que tienen las novedades de este tipo. Esto le ha costado a un responsable de comunicación, más concretamente a Xabier López, tener que esperar varias semanas hasta ver publicado un reportaje ya realizado. El problema, indica, no es que haya problemas concretos con el hospital, porque le consta que ha sucedido lo mismo en otras clínicas, sino por "desconocimiento, por falta de información para calibrar adecuadamente la dimensión de la noticia", incide. "Creo que en algunos casos los periodistas prefieren no publicarlo antes que elaborar una amplia noticia cuando en realidad es una chorrada o darlo mal y que sea algo realmente importante". Por ello, insiste Xabier López, tiene una mayor relevancia el periodista y el jefe de la sección de local que trabajen el día de divulgación de una noticia que la ideología del periódico en sí. 
Actualmente, son dos las vías de comunicación con los periodistas por parte de los gabinetes de cada hospital: de forma proactiva (a través de notas de prensa, ruedas de prensa, llamadas telefónicas, etc.) o bien de forma reactiva gestionando peticiones (ya sean cifras, material de archivo, declaraciones, etc.). Según indica un entrevistado que no quiere ser vinculado con esta afirmación, "a veces tenemos poco margen para ser proactivos porque estamos continuamente apagando fuegos. En ocasiones tienes en mente redactar una nota de prensa sobre un tema en concreto y tienes que dejarlo apartado para otro día porque empiezas a recibir llamadas debido a un caso de meningitis, por poner un ejemplo".

\section{Exclusivas}

Dentro de la vertiente proactiva, los responsables de comunicación pueden difundir una información a todos los medios de comunicación sin discriminación alguna o pueden hacer llegar la noticia a una sola plataforma a través de una exclusiva. Normalmente, las noticias importantes (o las informaciones como tal) son divulgadas a todos los medios por igual. Según afirma un entrevistado, conceder exclusivas, cuando se trata de temas relevantes, "al final te pasa factura. Encima, no sirve para nada, porque cuando te tienen que meter caña no se van a acordar de que el otro día les diste una exclusiva. Eso lo tengo clarísimo".

No obstante, en informaciones menores o en datos para elaborar reportajes, sí que suelen hacer uso de esta técnica. Es decir, contactan con un determinado medio para ofrecerles los datos y se lo dejan de manera exclusiva solamente a ellos. Es el caso de Xabier López. En la primera edición de un taller de seguridad vial para embarazadas, incluido dentro de los cursos posparto del hospital, se convocó a toda la prensa para que cubrieran el acto. Sin embargo, en el segundo año, se llamó a un solo medio para relatar la jornada. "A lo mejor, al cabo de seis meses llamamos a otro medio y le ofrecemos lo mismo u otra cosa de similares características". Xabier López insiste en que "intentamos repartir e intercalar estas exclusivas. Normalmente siempre del mismo nivel; no le ofrecemos a uno el aperitivo y a otro el postre, ¿no? Siempre procuramos que todo sea el mismo menú o por lo menos el mismo rango. Porque, desde luego, todos tienen que comer", mantiene.

Ana López Pimentel explica la conveniencia de esta técnica de la siguiente manera: "Somos un hospital público, una institución pública, tenemos clarísimo que es un lugar de servicio y que tiene que haber una transparencia con los medios de comunicación [...]. Pero también eres consciente de que hay pugna entre ellos, entonces hay cosas más pequeñas para las cuales muchas veces llamas a un determinado periodista [...], porque sabes que si se lo mandas a todos no va a tener mucho éxito. Entonces, si se lo das a alguno y le das tiempo para que maneje sus espacios suele tener bastante éxito. Pero siempre se hace con cosas más transversales, más pequeñas". Una exclusiva no siempre tiene que crearse a iniciativa del propio gabinete: muchas veces, son los periodistas los que demandan alguna información para poder componer algún reportaje. También 
aclara Beatriz Senra: "Procuramos mimarlos a todos por igual; si no ahí sí que tendríamos un problema".

Las herramientas más empleadas para contactar con los periodistas suelen ser el correo electrónico y el teléfono. Por ejemplo, María José Iglesias, aunque envíe por email una nota de prensa, a veces llama a los redactores para avisarles de que les va a despachar una noticia relevante, porque "es muy novedosa o es una cosa muy particular o algo que hacemos por primera vez aquí". Patricia Forteza, de hecho, siempre llama para tener en cuenta los redactores y fotógrafos que van a acudir a las ruedas de prensa, sobre todo si se trata de eventos de relevancia. Xabier López, por su parte, suele mandar un SMS al móvil a los periodistas (a todos o a aquellos que más le interesen, según las circunstancias) del tipo: "El hospital Vithas Fátima ha emitido la nota de prensa: titular". La Consellería de Sanidade, por su parte, vuelca las notas de prensa que les envían diariamente los diferentes responsables de comunicación de las estructuras de gestión integradas en su página web.

Los formatos para transmitir información de manera más formal son la rueda de prensa y, sobre todo, la nota de prensa. Esta última fórmula es la más común porque "si tú le facilitas a la redacción una nota de prensa del tema, es más difícil que se vayan del guión", reconoce Patricia Forteza, haciendo referencia a que los periodistas, en temas médicos, pueden llegar a cometer errores importantes de conceptos. Esta, no obstante, ha de ser sencilla: "Como le metas a un periodista un ladrillo con tecnicismos, con cosas farragosas, al día siguiente prepárate a morir, porque puede haber enfocado la noticia totalmente al revés del dato que tú querías transmitirle”, explica Raúl Álvarez.

Por ello, este comunicador insiste en que "todo lo que dices tiene que ser sencillo" y proporciona un caso práctico: "No te puedes poner a hablar de vitrectomía. A partir de ahí, el periodista dice: «¿Qué me dices?», y el médico te responde: «Hombre, claro, la vitrectomía...» Entonces le tienes que preguntar: «A ver doctor, ¿qué es la vitrectomía», y es cuando te responde: «Pues una intervención en la córnea». Ahí es cuando lo entiendes: "Vale, una operación de córnea»". La elección del interlocutor médico, por lo tanto, es importante para que el periodista comprenda e interiorice adecuadamente los conceptos que se están tratando: "Al día siguiente te llama el médico escandalizado de lo que ha publicado el periodista. Pero claro, si empieza hablando en chino, ¿qué quiere?", se pregunta Raúl Álvarez.

Además, si una noticia contenida en una nota de prensa no acaba siendo divulgada por los medios porque ha ocurrido un acontecimiento que absorbe la mayor parte de la agenda mediática, "siempre tienes la opción de reportajearlo", como declara Ana López Pimentel. Esta entrevistada, al igual que Paz Teijeira, por ejemplo, casi nunca envía notas "frías", tal y como las denomina, sino que siempre ofrecen la posibilidad de ampliar la información o de conseguir declaraciones de expertos en el tema. María José Iglesias, de hecho, suele enviar las notas de prensa a los responsables de ese tema a 
tratar para que las corrijan antes de enviarlas a los medios de comunicación y colgarlas en la intranet.

\section{Publicidad}

Solo en unos casos concretos se utiliza la publicidad para promocionar un centro hospitalario. Antolín Hermida es de los pocos que emplea este método, y solo recurre a él en uno o dos anuncios al año. Povisa es otro de los escasos hospitales que contrata espacios de pago, aunque "muy pocos" y únicamente en los periódicos de la ciudad.

La radio ofrece muy buenos resultados a corto plazo, según Patricia Forteza, y por ello se suele utilizar en el hospital Quirón de La Coruña, aunque en muy pocas ocasiones. El problema que ve su responsable de comunicación en este método es que "si insertas un anuncio en $\mathrm{La} \mathrm{Voz} \mathrm{[de} \mathrm{Galicia],} \mathrm{al} \mathrm{día} \mathrm{siguiente} \mathrm{ya} \mathrm{tienes} \mathrm{a} \mathrm{todos} \mathrm{los}$ comerciales de los otros periódicos llamándote. Y, claro, ¿a quién insertas publicidad?” Frente a esta indecisión, Patricia Forteza opta por "acuerdos no tan visibles" como puede ser la suscripción por parte de la entidad a una determinada cabecera. Pepe Losada es la única persona trabajando para un centro privado que nunca ha pagado por divulgar mensajes.

La publicidad en el 061 se empleaba anteriormente junto con el merchandising, pero a raíz de la crisis económica han dejado de usarse estas vías, asegura Marta Castro. Actualmente, los anuncios sobre temas sanitarios en el ámbito público se gestionan desde servicios centrales, por lo que los hospitales no insertan anuncios en los medios motu proprio. Además, tal y como indica Raúl Álvarez, no es necesario, porque el nivel de penetración a través de notas y ruedas de prensa "es seguro, los periódicos te sacan prácticamente todos los anuncios de interés general". De hecho, bromea con que no necesitan campañas financiadas: "somos como Inditex".

Además, de acuerdo con Álvaro Otero, la publicidad funciona cada vez menos por tres razones: porque cada vez hay más dispersión de medios, porque las noticias son consideradas como más importantes ("por ejemplo, a nadie oirás decir: «Es cierto porque lo he visto en un anuncio»; no, dicen: «Es así porque lo he leído en el periódico»") y porque se recuerdan más las noticias que los anuncios. A este respecto, este comunicador aclara: "Si te pregunto qué anuncio has visto hoy en el periódico que lees habitualmente, no me sabrás decir ninguno; en cambio, si te pregunto qué noticia o reportaje has leído, seguro que me sabes decir varios".

\section{Ruedas de prensa}

Casi todos los responsables de comunicación coinciden en que cada vez convocan menos ruedas de prensa. Algunos, de hecho, admiten que nunca han realizado demasiadas. Por ejemplo, María José Iglesias calcula que ha hecho "cuatro o cinco" desde que está en ese puesto. Este bajo número se debe a las reducidas plantillas de los medios, que obligan a los redactores a cubrir varias secciones sin llegar a ser especialistas en ninguna de ellas: "Los medios locales están muy limitados, tienen muy 
pocos trabajadores para un ámbito tan amplio. Desde que yo llegué, las redacciones han pasado de tener a una persona encargada de sanidad a que la sanidad lo lleve cualquiera de la redacción. Y eso te condiciona muchísimo el trabajo. Da igual que lleven sanidad junto con otra sección, pero yo agradecería que hubiera periodistas que tengan un perfil para las informaciones sobre salud". Esa falta de tiempo hace pensar a María José Iglesias que "hacerles venir para una cosa en la que tú te pones a disposición de ellos facilitándoles el corte de voz, el contacto para que consigan declaraciones, etc. no me parece útil [...] Además, yo creo que ellos agradecen que no les hagas venir por tonterías o por noticias que podrías haber contado en una nota de prensa".

De la misma opinión es otro comunicador cuyo nombre no quiere que aparezca en estas líneas. Al margen de la agenda política, que tiene un calendario fijo (como es el caso de las listas de espera, para las cuales cada gerente convoca una rueda de prensa) en los temas del propio hospital no suele citar a los medios: "Yo la utilizo poco porque me parece que hay que utilizarla cuando hay que utilizarla. Es decir, para vender cosas muy importantes y significativas". Lo mismo considera Beatriz Senra: "No solemos abrumar a los medios con demasiadas convocatorias ni con demasiadas notas. Solemos hacer una selección de lo que es importante y, entonces, cuando nosotros convocamos a los medios a una rueda de prensa es porque consideramos que es interesante, y ellos así lo entienden. El resultado es que nuestras convocatorias suelen tener éxito". También, reconoce un entrevistado, depende de quién tenga que "vender" lo que se anuncia, ya que "hay gente que da mucho juego y gente que no", haciendo referencia a los médicos o portavoces que se ponen delante de los periodistas en una rueda de prensa.

El Hospital Vithas Nuestra Señora de Fátima, por su parte, no suele convocar muy a menudo este tipo de encuentros, y cuando lo hacen no suelen hacer grandes anuncios, ya que se trata de un centro en el que "prefieren pisar sobre seguro y actuar cuando las cosas están hechas". "Yo no estoy acostumbrado a esta lentitud porque llegué al hospital procedente de la Consellería de Sanidade, pero no me siento capacitado para juzgarlo porque puede que sea una estrategia comercial, en el sentido que si dices que vas a hacer algo estás dando pistas a la competencia”, piensa Xabier López.

\section{Personal}

Dentro del personal interno, normalmente, no existe un grupo que sobresalga frente a otros. María José Iglesias, por ejemplo, remite a todos los trabajadores, tanto de los hospitales como de los centros de salud, todas las informaciones que envía a los medios de comunicación. De esa manera, dice esta entrevistada, "mantengo informado a todo el personal antes de que salga en el periódico al día siguiente [...], ya que me parece importante que ellos lo sepan antes de verlo publicado". 
La herramienta más comúnmente utilizada con este colectivo es la intranet. María José Iglesias, por ejemplo, mantiene dentro de esta plataforma un tablón de anuncios, el organigrama, una descripción de cada centro, los cuadros de mando de cada uno de ellos, las memorias, los protocolos administrativos y clínicos, los diferentes servicios... Según recuerda esta comunicadora, "al principio partíamos solo casi de farmacia, medicina interna y recursos humanos, pero cada vez son más servicios los que vienen a demandar tener un hueco".

En intranet también se vuelcan documentos de utilidad para el trabajador, como pueden ser certificaciones de maternidad, comisiones técnicas, consentimientos informados, las dietas, los formularios de pruebas, las solicitudes... Asimismo, algunos también incluyen ahí las notas de prensa y las apariciones del hospital en los medios de comunicación. Según destaca María José Iglesias de su Intranet, "no es nada ambiciosa, ni tiene grandes imágenes, ni movimientos ni demás. Pero queríamos que fuese una página más de contenido que de forma”. A pesar de que María José Iglesias constata que "es una página cada vez más utilizada por la demanda que se recibe", admite que no hay forma de ver el número de visitantes, lo que considera una "debilidad".

El Sergas en Ourense, explica Myriam Sierra, incluye, además de muchas de las herramientas anteriormente citadas, la imagen corporativa con diferentes documentos de uso. "Nosotros somos un gabinete de «mejor es que sobre, que no que falte»", bromea Myriam Sierra. Otros comunicadores vuelcan información del hospital, pero también de otros focos que puedan interesar al personal del centro.

Casi todos los entrevistados producen un dosier de prensa con las apariciones del centro y de otras noticias relevantes. Conviene recordar que, en algunos casos (como María José Iglesias o Myriam Sierra), este documento es visible para todos los empleados, bien porque se cuelga en la intranet, bien porque se envía por correo electrónico. No obstante, en otros centros, se considera una herramienta de dirección y, por lo tanto, solo se entrega a algunos responsables.

También suelen hacer uso del correo electrónico, aunque algunos de ellos consideran que el "cara a cara" es lo más efectivo, como relata Pepe Losada o María José Iglesias. Dado que en el ámbito público los encargados de la comunicación de las estructuras de gestión integrada también tienen que hacerse cargo del resto de hospitales y centros de salud de la zona, que haya una buena logística es muy importante. Por ejemplo, María José Iglesias, que trabaja en la zona de Ferrol, opina: "El tamaño de mi área me facilita muchísimo mi labor porque es una zona mediana en la que los hospitales están muy cercanos. Esto me permite ir personalmente a las entrevistas, moverme de un hospital a otro. Por ejemplo, de aquí al Naval voy andando y al Novoa son dos minutos en coche [hablando desde el Hospital Arquitecto Marcide]".

Xabier López admite que utiliza diferentes herramientas con cada una de las audiencias internas en función del uso que cada uno de ellas hace: "Hay gente que se 
maneja mejor con el Whatsapp que con el correo electrónico, otros prefieren los SMS, etc." Por ejemplo, con el equipo directivo emplea el teléfono, el correo electrónico, Whatsapp, etc. Con el resto de personal, en cambio, usa, normalmente, solo el correo electrónico, debido a la "imposibilidad de segmentar en grupos (los habituados al correo electrónico, los que prefieren el SMS, los que quieren un Whatsapp...) a los más de 400 trabajadores del hospital". Este comunicador compone un boletín o periódico que, aunque no tiene una periodicidad fija, con menos de dos años en el momento de la entrevista cuenta con 14 números. En su opinión, se trata de una plataforma asentada en el hospital porque "ya he recibido peticiones del personal para aparecer en el boletín".

A nivel interno, Xabier López también se preocupa por que todos los trabajadores utilicen la imagen corporativa del grupo que acaba de tomar las riendas del centro: Vithas. "Todo lo que es implantación y conocimiento de la marca lo hacemos desde el gabinete de comunicación ${ }^{19}$. Ya no solo que estén todos los logos bien, sino también recordar al personal que el hospital ya no es el hospital Fátima, sino el Vithas Fátima". Lo mismo ocurre con el Modelo, que antiguamente era un sanatorio y algunas personas siguen llamándolo así, tal y como lamenta Irene Montero. Por otra parte, continúa Xabier López, "al ser un hospital en el que trabaja no solo gente de plantilla sino profesionales de fuera que traen sus propios materiales, como los uniformes, hay que recordarles que usen los propios del hospital". En ocasiones, también realizan labores de organización o de coordinación entre servicios.

La Rosaleda encarga anualmente a la empresa Bolanda una memoria de actividades, que se entrega a la Consellería de Sanidade, al presidente de la Xunta, a los accionistas principales y a otras entidades. Tal y como indica Tomás Valín, se presenta cuando se pretende llevar a cabo alguna actividad o proyecto conjuntamente con una empresa o con una entidad financiera. Por ello, solo se editan unas "50 o 100". El 061 también produce publicaciones enfocadas, sobre todo, al personal sanitario, concreta Marta Castro.

\section{Pacientes}

Tal y como asegura Patricia Forteza, la tecnología ha dejado de ser un elemento diferenciador entre los hospitales y, ahora, la razón principal para elegir uno frente a otro es "porque está su médico". "Ponte en el caso de que tienes una enfermedad y tienes que decidir a qué hospital acudir. No eliges uno u otro porque sea Quirón o porque sea Modelo, sino porque está un médico especialista en ese tipo de enfermedad", incide. "Pero claro -continúa-, para ello tienes que conocer". Patricia Forteza reconoce

\footnotetext{
$\underline{19}$ Xabier Vigo concreta que la implantación y reconocimiento de marca se realiza desde el departamento de promoción en todo el grupo hospitalario, aunque en el caso de este Vigo se le ha encargado al gabinete de comunicación.
} 
que hay diferentes herramientas, como la página web, con las que se puede atraer a un número elevado de pacientes. Para ello, se han de tener actualizados los cuadros médicos e incorporar buenos reportajes fotográficos de cada especialidad, concreta. En la página web del grupo Quirón, por ejemplo, aparecen los médicos agrupados por áreas y se incluye una fotografía de algunos de ellos, su especialidad, datos de contacto y su currículum vítae. Además, se incorporan noticias tanto del hospital como sanitarias en general.

Las guías de hospitalización son bastante habituales en los centros gallegos. En Ferrol, por ejemplo, poseen una con información útil durante la estancia, como las horas de comidas y de limpieza, las instrucciones para encender la televisión, etc. Asimismo, se les entregan, en forma de marcalibros, los derechos y obligaciones que poseen como pacientes. Cada servicio, aclara María José Iglesias, hace llegar los documentos de una manera u otra. En el Complejo Hospitalario Universitario de A Coruña, antiguamente, encargaban a una imprenta la impresión de folletos, pero, actualmente, han de hacerlo en las propias impresoras del centro. "Se deben hacer en blanco y negro por el coste que supone hacerlas en color y, como te puedes imaginar, a veces quedan un poco fuleros", lamenta Kiko Fernández. Según los diferentes documentos, son los servicios en cuestión los que redactan el contenido, mientras que el gabinete de comunicación se encarga de editar y, en mayor o menor medida, maquetar, incide este entrevistado.

En el hospital Quirón se dejan en recepción diversos ejemplares de la revista del grupo, que es, por otra parte, "muy marketiniana", o lo que es lo mismo, "vende mucho", asegura Patricia Forteza. También se llevan a cabo diferentes encuestas de satisfacción al paciente, aunque no se dirigen desde el departamento de comunicación, sino desde atención al paciente. Por formar parte del comité de dirección, Patricia Forteza conoce los resultados de estos estudios: "Es una información valiosísima para concretar los objetivos de comunicación; ¿Qué piensan los pacientes? ¿Por qué esto les gusta, por qué esto no les gusta?, etc." En el Centro Oncológico de Galicia lo realiza una empresa externa cada dos años para hallar la satisfacción tanto de clientes como pacientes. En comparación con otros hospitales de España, Pepe Losada asegura que los resultados muestran ratios "muy altas".

\subsection{ACCIONES NOVEDOSAS}

Cada vez más, los periodistas reciben en sus redacciones numerosas novedades de diferente índole, por lo que "es complicado hacerte un hueco o que realmente se traslade la importancia que tiene lo que nosotros ofrecemos", interpreta Irene Montero. Por ello, en ocasiones lo que se requiere para hacerse notar es distanciarse de la mera relación con los medios y organizar acciones que se alejen de esta convencionalidad. Esta entrevistada lo define como hacer una "mínima puesta en escena", es decir, realizar 
charlas, conferencias, talleres, puertas abiertas, etc. En el caso de organizar un congreso, por ejemplo, "estamos diciendo que el hospital asume todas esas novedades que hay en ese seminario, y que además se preocupa por divulgar y que tiene una sensibilidad especial con ese tema". En consecuencia, aparte de las personas que por propio interés hayan acudido al evento, "se transmite la imagen de un centro cercano, con grandes profesionales y en la vanguardia de la innovación tecnológica", sentencia Irene Montero.

\section{Destinadas a la población}

Así, en el hospital Vithas Nuestra Señora de Fátima organizan ciclos de conferencias de temas clínicos, como de trasplantes o cáncer de pulmón, que se enmarcan en un programa que se llama Vithas Aula Salud. En la Rosaleda, bajo la tutela de su Fundación, se pusieron en marcha los "Martes clínicos" en colaboración con la Universidad de Santiago de Compostela. Se trata de unos ciclos de conferencias dirigidos a la población en general, pero con una alta participación de alumnos matriculados en la carrera de Medicina; para ellos, la universidad otorga un crédito de libre configuración por la asistencia. En estas jornadas se han tratado temas como los avances y las fuentes naturales de nuevos fármacos oncológicos, así como el desarrollo de ensayos clínicos y los distintos tipos de cánceres, como el de mama, el de próstata, el de piel, etc.

Desde la Fundación de este mismo hospital también coordinan el "Aula aberta", que engloba una serie de eventos de gran trascendencia que se celebran una o dos veces al año. A estos actos han acudido personalidades como el magnate mexicano Olegario Vázquez Raña, el vicepresidente primero y consejero delegado de Unión Fenosa, Honorato López Isla; el presidente de Caixanova, Julio Fernández Gayoso, o el almirante José Ángel Sande.

Los "Xoves culturais" por su parte, pretenden dar cabida a aspectos humanísticos relacionados con la medicina. Dentro de esta iniciativa, se enmarca el proyecto de literapia, que utiliza la literatura como elemento terapéutico. Darío Villanueva, miembro de la Real Academia Española (RAE), forma parte del comité científico. La Fundación La Rosaleda fomenta la lectura $\mathrm{y}$, también, la escritura. A través del proyecto "Timonel", se editan libros de cuentos escritos por niños que asisten a la escuela Camilo José Cela del Hospital Clínico de Santiago por estar sometidos a varios tratamientos.

Esta entidad también convoca el Premio Internacional de Investigación Oncológica Científica y Técnica Ramiro Carregal - Fundación La Rosaleda, que en 2013 cumplió su tercera edición, y que, según Tomás Valín, "hoy por hoy es uno de los premios de mayor relevancia y prestigio en Europa". Fruto de convenios con otras entidades, la 
Fundación convoca anualmente el premio internacional de la acción social, becas a la investigación, publicación de distintos libros y revistas, etc.

El área de gestión integrada de Pontevedra también convoca premios de investigación a los mejores artículos y trabajos publicados en revistas científicas a lo largo del año anterior y firmados por el Complexo Hospitalario de Pontevedra, el Hospital do Salnés y los centros de salud del área sanitaria.

Tal y como comenta Myriam Sierra, los centros del Sergas cuentan con un programa específico llamado "Queres", que sirve para la recepción, respuesta y seguimiento de las reclamaciones, quejas o sugerencias de los usuarios. En Ourense cuentan con buzones de sugerencias que son gestionados por el servicio de atención al paciente. El gabinete de comunicación recibe información semestral de esta iniciativa, que sirve de retroalimentación y de orientación estratégica de actuaciones. Lo mismo sucede con la red social Facebook, que además de utilizarse para difundir información propia e institucional, también se emplea como fuente informativa y de feedback.

En Povisa también se centran en las nuevas tecnologías. Ponen a disposición del público una newsletter a la que pueden suscribirse. Envían una nueva cada 20 días más o menos, aunque no tiene una periodicidad fija; la despachan únicamente cuando tienen noticias interesantes que contar. También mantienen un blog y cuentas en Facebook y Twitter. Además, realizan vídeos y los cuelgan en la primera plataforma. Álvaro Otero insiste en que las redes sociales son un complemento del resto de actividades comunicativas, pero "no las sustituye ni es lo más importante".

Xabier López, en cambio, reconoce que no realiza ningún tipo de acción especialmente novedosa, pero que le gustaría fomentar las nuevas tecnologías. "Al igual que no consideras seria una empresa que no tenga página web, aunque sea mala, no creo que un hospital como este, que invierte millones en tecnología sanitaria, se pueda permitir el lujo de no tener Twitter, Facebook... de tener más canales de comunicación con el usuario que las hojas de quejas, reclamaciones y sugerencias", algo que, según señala Xabier López, se encuentra actualmente "en vías de solución”. Eso sí, han incluido códigos Bidi en sus publicaciones.

En algunos casos se han hallado blogs supervisados o a iniciativa del servicio de comunicación, pero escritos por diferentes médicos de los hospitales de Galicia. Es el caso de del hospital Quirón, del Povisa y del Centro Oncológico de Galicia. Los espacios del primer centro responden a las líneas estratégicas del hospital, indica Patricia Forteza. Además, facilitan un buen posicionamiento en los servicios de búsqueda en internet, según dice su responsable. Para intensificarlo, asegura Patricia Forteza, también se utiliza Google Adwords a nivel de grupo. En el Complejo Hospitalario Universitario de Santiago también hay varios médicos que mantienen sendos blogs (normalmente los más jóvenes, indica Ana López Pimentel), pero no son supervisados por el gabinete de comunicación, simplemente se les informa de ellos. 
El caso del Centro Oncológico de Galicia es algo más especial. Se trata de una red social oncológica en fase beta (https://www.oncored.es) redactada por José Losada pero supervisada por diferentes médicos, donde se vuelcan noticias, eventos, enlaces, etc. También hay una sección de biblioteca donde se cuelgan archivos de interés, y un apartado de consultas donde los lectores pueden preguntar sobre diferentes cuestiones. En la sección de blogs hay varias bitácoras escritas por doctores en las que se puede dejar comentarios y los médicos, asimismo, tienen la posibilidad de contestar. En la página web colaboran tanto especialistas del Centro Oncológico de Galicia como de otros hospitales. Dado que, tal y como indica José Losada, Oncored "no acababa de funcionar", han creado paralelamente un blog con el que pretenden "hacer medicina 2.0 apoyados por la tecnología". Para ello, disponen de perfiles en Facebook, Twitter además de un canal en Youtube donde comparten información con sus pacientes, realizan vídeos explicando los tratamientos más frecuentes, etc.

Asimismo, Pepe Losada está tratando de formar un "equipo de redacción" que permita crear contenidos adecuados para conseguir que los pacientes tengan acceso en la web a las recomendaciones y explicaciones de sus facultativos. "Pretendemos hacer lo que se ha definido como medicina 2.0: ayudar a que los pacientes se hagan responsables de su tratamiento y conozcan el porqué de cada cosa. Esto es muy necesario, máxime en especialidades como la oncología, donde el paciente se ve emocionalmente desbordado en el momento del diagnóstico y donde la visita al médico se hace con mucha tensión, por las propias características de la enfermedad”, señala el responsable del Centro Oncológico de Galicia.

Bajo la premisa de que "el hospital ha de formar parte de la vida cultural y social de la ciudad", este centro especializado ha incluido en sus instalaciones una exposición de arte cuyas obras, realizadas por artistas locales, van cambiando cada dos meses, tal y como acordaron con el colectivo artístico llamado Arteu. El proyecto lleva por título "Na Espera" y "pretende acercar el arte a la sociedad, sacándolo de espacios tan formales como los museos a las salas de exposiciones", señala José Losada. Asimismo, este centro ha organizado conciertos para sus pacientes.

Una curiosa manera de hacer llegar la ciencia y la medicina al público se realiza en un bar de Santiago de Compostela que alberga periódicamente las reuniones "Escépticos en el club". Cada día acuden como invitados distintos personajes del ámbito científico para discutir, con un lenguaje claro y sencillo, diferentes particularidades del mundo de la investigación. Es de acceso libre, y, en un "ambiente distendido", se pregunta y se debate. "Hace años, todo [la comunicación sanitaria] era mucho más académico, más encorsetado; ahora, en cambio, es mucho más dinámico, más cercano a la gente de la calle", explica Ana López Pimentel.

En el Complejo Hospitalario Universitario A Coruña se organizan jornadas de puertas abiertas, tanto para los alumnos de ramas científicas y naturales de los institutos, 
como para los niños de colegios. Con ello se pretende evitar el impacto visual que puedan tener estos chavales cuando deban enfrentar a un hospital. "Es como cuando tienes que ir al dentista. Es mejor que sepas los aparatos que tiene y cómo funcionan en vez de ir allí, sentarte, que te pongan la anestesia, te empiecen a meter cosas en la boca que no conoces... Claro, eso es un impacto”, ejemplifica Kiko Fernández.

Desde un prisma deportivo, el Hospital General Juan Cardona organizó una carrera a favor de la salud para concienciar a la población acerca de la importancia de cuidarse. El hospital otorgó premios y repartió consejos previos con los medios sobre cómo preparar un precalentamiento, qué bebidas tomar, etc.

\section{Promociones}

Las promociones, indica Patricia Forteza, son recursos que utilizan los centros privados para dar a conocer ciertos servicios y así ganar clientes. En el hospital Quirón han empleado diferentes técnicas con varios servicios. Uno de ellos son las operaciones de dioptrías con la técnica $\operatorname{Lasik}^{20}$, para lo cual editan una tirada de folletos y los colocan en su red de centros y otros puntos estratégicos, como gimnasios, academias de policía, etc. Además de ofrecer una tarifa "muy competitiva", han realizado un vídeo explicativo de todo el proceso mediante una persona que decide operarse. En él intercalan declaraciones del médico y en ocasiones los vuelcan en Youtube o Vimeo. Se contratan cuñas publicitarias y se crean "una especie de cupones", los cuales los pacientes tienen que descargarse y presentar en recepción antes de operarse. Gracias a esta técnica, obtienen una base de datos de usuarios a los que posteriormente envían información de interés. "Es otra forma de saber cómo está funcionando tu campaña, porque tú tienes que medirla y saber si las personas vienen por la web, si han venido por los folletos, etc.”, explica Patricia Forteza.

Otra promoción de similares características se realizó en este hospital dentro del ámbito de la ginecología, más concretamente para la donación de ovocitos. Para ello, se organizó una cena en la universidad, se contrataron vallas publicitarias, se insertaron anuncios en los autobuses, se hizo un reparto de folletos, se colocaron manteles en los comedores universitarios, se diseñaron tarjetas, se costearon cuñas en la cadena radiofónica Los 40 principales, etc. Patricia Forteza admite que esta última vía es la que mejores resultados ha proporcionado.

\section{Destinadas al personal}

Para Patricia Forteza, "la gente se debe sentir partícipe de su trabajo. El hecho de que tú no ostentes un puesto de toma de decisiones dentro de una empresa no implica que no te tengas que sentir valorado. A veces, incluso, debería ser al contrario, porque

\footnotetext{
20 Acrónimo de Laser-Assisted in Situ Keratomileusis, un procedimiento de cirugía mediante láser para tratar la miopía, la hipermetropía y el astigmatismo.
} 
los empleados que trabajan día a día en el hospital a veces se dan cuenta de cosas en las que una persona de dirección no había caído. Entonces, cuando se habla de comunicación interna, parece que todo debería ir de arriba hacia abajo, pero ¿y de abajo hacia arriba? ¿Y el feedback?” Por ello, en el hospital Quirón van a comenzar a realizar estudios sobre el clima laboral. Además, organizan una serie de concursos para involucrar al personal en la dinámica del centro. Hasta ahora se han realizado concursos de ideas, de relatos (como, por ejemplo, sobre experiencias de enfermería con los pacientes, algo que "gustó mucho"), de pintura, reportajes fotográficos, etc. En el caso de estas dos últimas acciones, sirven para decorar las paredes de los pasillos pero también como recursos para el gabinete de comunicación.

Pepe Losada, del Centro Oncológico de Galicia, realizó también una encuesta para conocer la satisfacción de los trabajadores del hospital y detectar los puntos que se deberían mejorar. A pesar de la alta participación (contestaron 120 empleados de los 180 que tiene el hospital, según detalla), no tuvo ningún tipo de repercusión. "Hubo un par de servicios -recuerda Pepe Losada- que dieron unos resultados fatales y yo compuse una serie de recomendaciones para solucionar esos problemas, pero nadie se hizo cargo. Y tú puedes insistir, pero llega un momento en que ves que por mucho que insistas no te hacen ni puñetero caso y entonces piensas en pasar a otra cosa". Las protestas de los trabajadores, indica Pepe Losada "entraban dentro de la lógica: querían mejores canales de información, porque algunos se quejaban de que se enteran a través de las charlas informales en los pasillos, por rumores, etc. Y es tan sencillo como proponer una reunión de un servicio el lunes a primera hora para ver la actividad de la semana y, el viernes, a última hora, comprobar cómo ha ido la semana y plantear la siguiente".

Al igual que en el Quirón, en la gestión integrada de Ourense también llevan varios años convocando un concurso de fotografía de temática no sanitaria (por los problemas que podría conllevar), una herramienta que Myriam Sierra considera "de humanización". Pese a la crisis, han conseguido fondos para hacer "un buen regalo" al ganador y la participación ha sido "importante". En las primeras ediciones, los miembros del jurado eran periodistas gráficos de los medios de comunicación, a los que entregan un "detallito" y, de paso, "les enlazamos para la causa". En la actualidad, se suben las fotos a intranet y son los propios trabajadores los que eligen con sus votos la foto premiada. "Esto nos sirve a su vez para aumentar el acceso y conocimiento de los recursos incluidos en la Intranet por parte del personal”, indica Myriam Sierra. Además, al igual que en el resto de centros del Sergas, se realizan periódicamente estudios de satisfacción para los pacientes y de clima laboral para los trabajadores, cuyos resultados son accesibles para el servicio de comunicación y sirven "como referente y guía de futuras actuaciones".

El papel que ejercen los trabajadores de una organización sanitaria en el cuidado y bienestar de los pacientes es muy importante, independientemente de que sean 
facultativos o no. Tal y como incide Irene Montero, "cuando una persona se acerca o llama a un hospital no suele ser por motivos agradables, probablemente detrás de esa llamada haya una preocupación o una angustia o unas circunstancias personales complicadas. Como no es lo mismo que acercarte al Corte Inglés, lo que tenemos que hacer es no complicar la situación todavía más con ineficiencia o con mala educación, sino facilitar dudas y resolver problemas lo antes posible y de la mejor manera posible". Por ello, llevaron a cabo una auditoría de llamadas telefónicas para comprobar dos aspectos: la manera en que los empleados atendían las llamadas y el flujo de llamadas a diferentes horas del día. Este análisis obtuvo dos consecuencias: un curso sobre cómo comunicarse con los pacientes y la creación de un sistema de citas online.

El curso se llevó a cabo hace "cuatro o cinco años" y fue impartido por la encargada de comunicación. Fueron unas clases dirigidas al personal de recepción general, de secciones específicas y otros trabajadores que suelen estar en contacto con los pacientes. En esas charlas se les enseñó aspectos relacionados con el cliente, la atención telefónica y presencial, las expresiones que deben utilizar, el tono, etc.

Aunque algunos entrevistados, como Kiko Fernández, consideran que los facultativos deben aprender sobre comunicación durante sus estudios universitarios, en otros lugares, como en el hospital de Ourense, se programan cursos específicos de comunicación en función de la demanda, como pueden ser de información y atención al público, comunicación no verbal, cómo hablar en público, cómo preparar una presentación, etc. Los miembros del gabinete de comunicación pueden o no impartir los cursos, pero "sí que los programamos", mantiene Myriam Sierra.

En cuanto a las nuevas tecnologías, varios hospitales hacen uso del protector de pantalla de todos los ordenadores para transmitir información sobre ciertos temas. María José Iglesias los emplea en las grandes campañas, como la gripe o la higiene de manos. En Ourense también se usa, aunque al principio fuese mal recibido dado que "a la gente le encantaba tener a su nieto, su sobrino, su coche, su playa... Y de repente el fondo de pantalla se convierte en un "Gran Hermano», en un «corcho informativo virtual» que nos sirve para ofrecer información de interés para los trabajadores sobre prevención sanitaria, cursos, congresos, obras o traslados de unidades, etc. Con ello, el fondo de pantalla ha pasado a ser una herramienta corporativa cuando antes era de disposición individual", recuerda Myriam Sierra. Ahora lo emplean para transmitir jornadas de enfermerías, para apoyar la campaña de manos limpias de la OMS, etc.

La cita online, recuerda Irene Montero, fue difícil de introducir dado "lo reacios a los cambios" que son en el hospital. A base de insistencia, y con el apoyo del sistema informático, se desarrolló una "cita online humanizada". Es decir, se envía la solicitud por internet indicando el mayor número de observaciones posibles, como la especialidad, el médico, la franja horaria, etc. Después, cuando el personal ha recibido 
la petición y tiene tiempo para finalizar la gestión, llama por teléfono al paciente y acaba de concretar la cita.

\section{Protocolos}

En la estructura de gestión integrada de Ourense se están especializando en elaborar procedimientos para diferentes situaciones de comunicación. Es una tarea que "genera muchísimo trabajo [...], pero también una manera de poner en valor al gabinete [...] y de dotarle de la misma importancia que otros servicios", indica Myriam Sierra. El primero que pusieron en marcha fue el de información a los medios de comunicación, en el que se detallan los datos que se pueden transmitir, de qué clase de personas y de qué manera. "Hicimos este procedimiento porque, por ejemplo, llamaba un medio de comunicación a urgencias y le pedía información de un paciente. Ellos telefónicamente no podían informar, pero, realmente, no sabía muy bien qué hacer ante esto. Normalmente la opción era que llamasen al responsable de prensa, pero lo que hicimos fue establecer en un procedimiento: especificar en qué ocasiones se da información y qué tipo de información se da según el paciente (en el caso de menores, adultos tutelados o adultos). Además fijamos muy claramente las excepciones", aclara la responsable de comunicación. Dado que en Ourense no facilitan partes médicos, las excepciones se refieren a casos de interés público, como pueden ser las epidemias o los accidentes en los que hay que localizar a las familias.

Otro de los protocolos que han instaurado recientemente concierne a los tablones de anuncios de los centros sanitarios. Tal y como lamenta Myriam Sierra, "los hospitales y los centros de salud son un caos de folletos, de papeles, de pósters, de pegatinas... [...] De cara al usuario y al propio profesional hay un montón de información mural que no ayuda ni siquiera a orientarse. Y por otro lado, puede dar un efecto horrible, incluso a nivel de limpieza y de aspecto, porque muchas veces están rotos, están descuidados, son de hace un año, de un congreso pasado, etc.” Por ello, decidieron establecer unas pautas y crear unos tablones o corchos exclusivos para cada servicio y prohibir cualquier tipo de información en paredes o ascensores. Así, por ejemplo, existe uno de información de la dirección, otro de docencia, otro de sindicatos, otro de anuncios particulares, etc. Tal y como reconoce Myriam Sierra, "esto tuvo una aceptación bárbara", aunque admite que "cada cierto tiempo" tienen que pegar un "barrido" para que la gente no se olvide.

Los carteles que se quieren poner en el Complejo Hospitalario Universitario de Ourense deben pasar también por un protocolo llamado "Ordenación, solicitud y reposición de cartelería de señalización del Complexo Hospitalario Universitario de Ourense" y que en la actualidad se está extendiendo a los centros de atención primaria. Desde el departamento de comunicación han creado un manual de imagen corporativa y diseñan carteles de acuerdo a esta normativa. Así, cualquier empleado que desee colocar un texto en alguna parte del centro (como, por ejemplo "por favor, no llame a la puerta"), debe pedir autorización al supervisor o al jefe del servicio, y con ella, solicitarlo por correo electrónico o por la intranet para que los responsables de 
comunicación se lo generen. Esto les permite a los empleados de este gabinete dos cosas: "Por un lado, empezar a generar un registro de ese trabajo que se estaba haciendo y no podíamos cuantificar y, por otro lado, dar repuesta en tiempo y que no sea un cauce informal; es decir, que no sea «como yo te conozco, te pido, y me haces un cartel», sino que sea algo regulado y no pones el cartel que te da la gana”, expone Myriam Sierra.

También han colgado una serie de documentos en la intranet, según el manual de imagen corporativa, para que los trabajadores del centro los puedan usar directamente en diversas situaciones, como por ejemplo los logotipos y plantillas de PowerPoint para los congresos. Asimismo, está a disposición de los empleados una base de datos gráfica de todos los centros para usar en pósters científicos, comunicaciones, etc., así como una postal institucional navideña diseñada cada año con alguna de las imágenes que se presentan al concurso de fotografías del área.

En el momento de la entrevista, Myriam Sierra se encontraba trabajando en el desarrollo de un protocolo de publicaciones, con el cual quieren homologar y ordenar la solicitud de este tipo de servicio. Así, indica la comunicadora, desde el gabinete de comunicación "podríamos dar apoyo a la maquetación, incluso ayudar en la redacción y luego editarla". Pero todo ello, insiste, de una manera "protocolaria y ordenada", para que no haya confusiones en torno a si una publicación "está autorizada, no está autorizada, está repetida..."

De hecho, en el Complejo Hospitalario Universitario de Ourense tienen una imprenta propia en el que imprimen folletos, carteles, dípticos, etc. También pueden pedir imágenes de los concursos de fotografía a gran tamaño para decorar las paredes de los centros con ayuda de los empleados de mantenimiento.

\section{Destinadas a los pacientes}

Con el fin de "añadir valor", el hospital Quirón entrega regalos a ciertos pacientes hospitalizados. Por ejemplo, a las embarazadas se les suministra una carpeta donde se insertan sus ecografías, los folletos de maternidad, las clases de parto, etc., y una vez que el niño ha nacido, una fotógrafa profesional le toma unas imágenes (con el correspondiente consentimiento) y se las entrega a la madre, indica la responsable de comunicación.

El hospital Povisa no suministra regalos, pero todas las habitaciones cuentan con una pantalla gigante con acceso a internet, a la newsletter y al blog sobre el centro que gestiona Atlántica Comunicación. Álvaro Otero, además, asegura que supone un coste parecido al de la televisión en otros hospitales.

Aunque no tan tecnológico, el Centro Oncológico de Galicia mantiene una exposición de arte en el servicio de radiología con obras de un colectivo de artistas que 
quieren traspasar el arte de los sitios tradicionales a la calle. Cada dos meses cambian de autores, y puede observarse libremente por todos los pacientes y acompañantes.

\section{Destinadas a los medios de comunicación}

Es difícil encontrar alguna acción novedosa destinada únicamente a los medios de comunicación. La única que se ha hallado es un sistema automático de emisión de partes médicos elaborado por el 061. Cuando se reúnen ciertas características, "que por su magnitud sabes que te van a llamar un montón de medios de comunicación", mantiene Marta Castro, el jefe de sala de la central de coordinación genera un parte automático con una información establecida y se envía a las direcciones de los periodistas que están inscritos. "Así te evitas estar repitiendo cada cinco minutos la misma historia para cada redactor que llama", comenta la entrevistada.

\subsection{PRESUPUESTO}

Como norma general, los responsables de comunicación de los hospitales públicos no cuentan con un presupuesto para desarrollar sus labores, al margen de sus honorarios. En cambio, los centros privados, sí que poseen un montante concreto.

Por ejemplo, en el Hospital Policlínico La Rosaleda, se dedica el un porcentaje de su facturación a la comunicación. Aquí se incluye la organización de diversos cursos, publicaciones, dípticos, publicidad, etc. En el caso del Hospital Vithas Nuestra Señora De Fátima, el dinero reservado para la comunicación se englobaba hasta el año 2014 dentro del presupuesto del servicio de Promoción, al que pertenece según del organigrama. Aun así, Xabier López asegura que no se trataba de una partida "rígida", es decir, que "con las pertinentes autorizaciones" se podía conseguir una partida de dinero mayor de otro servicio, aunque, interpretaba, "también puede ser al revés: que un servicio necesite tanto dinero y al final te lo quiten del dinero que tenias previsto para alguna acción futura". A partir del año 2014, no obstante, ya existe una partida específica para comunicación.

El hospital Modelo lo hace de diferente manera. Proporciona una cuota mensual a la empresa Octo, que cubre "asesoramiento, redacción, cobertura, relación con los medios, etc." Sin embargo, los gastos extraordinarios que surgen de diferentes actividades que organicen corren aparte. Unas jornadas que realicen desde el hospital, por ejemplo la página web, el catering, los trípticos o la traducción simultánea "no lo podemos asumir nosotros, no cabe dentro de nuestra cuota. Lo que me puedo gastar en unas jornadas de este tipo son como dos o tres cuotas, con lo cual trabajaría más y no ganaría nada; y esto no puede ser", sentencia Irene Montero. Lo mismo sucede con el Hospital General Juan Cardona. Antolín Hermida afirma al respecto que tiene un 
presupuesto "de mantenimiento"; las acciones que se realizan a mayores "se presupuestan, se aceptan o no, y se llevan a cabo o no". El responsable de la empresa Larín Comunicación Global especifica que suelen aprobar el 50\% de las que presentan.

Otro hospital que tiene externalizado el servicio de información es Povisa, cuyos fondos en divulgación dependen de las actividades que sugiere Atlántica Comunicación. Normalmente, la dirección suele aceptar todas las sugerencias; Álvaro Otero, de hecho, no recuerda ninguna vez que se las hayan rechazado. No obstante, asegura ser cauto e incide en que no necesitan partidas presupuestarias muy grandes. Además, la publicidad, por ejemplo, la proponen, pero no la gestionan (lo hace otra empresa). Con ello se aseguran que el hospital entienda que esos anuncios valen la pena y que no los sugieren para conseguir dinero extra.

Pepe Losada, que trabaja para una entidad privada aunque como empleado propio, comenta que los gastos procedentes de su gabinete no se enmarcan dentro de un presupuesto prefijado, sino que, cada vez que surgen nuevas propuestas, pide permiso a gerencia. Explica que la filosofía del centro se basa en "soluciones imaginativas" más que en asumir costes, sobre todo los que se prolongan en el tiempo. "Mientras que no cueste mucho, más o menos, suelen aceptar. Por ahora no me quejo", asegura Pepe Losada. Aun así, relata que hace un tiempo le denegaron comprar una cámara de vídeo (el comunicador, entonces, la adquirió para su uso personal y la usa en el trabajo), pero lo que sí que abonaron fue un micrófono. Patricia Forteza, que también forma parte de la plantilla de un hospital privado, posee un plan de comunicación que se aprueba anualmente en el mes de noviembre y ahí se contempla su presupuesto específico.

En el caso de los hospitales públicos, por el contrario, "todo es producción propia"; es decir, "intentamos apañarnos con lo que tenemos", resume María José Iglesias. Con la crisis, los trabajos que antes se encargaban a empresas externas ahora se realizan directamente dentro del gabinete de comunicación. Actualmente, ellos son los que diseñan, maquetan, editan e incluso imprimen los folletos, como hacen, por ejemplo, en la estructura de gestión integrada de A Coruña y de Ourense. Para ello, muchos han tenido que aprender "sobre la marcha", tal y como considera esta última, algo que requiere una "inversión de tiempo y esfuerzo personal mucho más allá", sostiene Arantza Briegas. Esto, por otra parte, también proporciona "mucha más libertad y mucha más agilidad", insiste la encargada de publicaciones del 061. "Antes, para cualquier cambio, teníamos que llamar a la empresa o mandarles un correo electrónico contándoles el cambio, cómo lo querías de nuevo, que te lo volvieran a enviar... Era bastante complicado", recuerda Arantza Briegas.

María José Iglesias, que recuerde, solo ha echado mano en una ocasión de una empresa externa: para crear la imagen corporativa. Ana López Pimentel solía encargar a este tipo de entidades el diseño y la maquetación y, a una imprenta, la impresión de las publicaciones que se realizaban, tanto científicas como materiales de información al 
paciente o de comunicación interna. Posteriormente, se prescindió del diseñador gráfíco y se pasó a contar únicamente con la imprenta. Finalmente, a raíz de la crisis económica, se han eliminado ambas partes. Actualmente, se imprime "solamente los imprescindible, como, por ejemplo, la papelería oficial. Para publicaciones necesarias, empleamos otras fórmulas, en algunos casos se busca patrocinio externo y para aquello más sencillo, como carteles o pequeños folletos lo hacemos por nuestros propios medios, de forma más modesta. No obstante se ha reducido la impresión de documentación y nos centramos más en la creación de materiales disponibles en intranet en lo referente a comunicación interna”, comenta Ana López Pimentel. Al no disponer de un presupuesto propio, los gastos extraordinarios al margen del propio sueldo del periodista en los centros públicos, por norma general, se asumen dentro del presupuesto general del hospital, concreta Paz Teijeira.

El gabinete de comunicación de la estructura de gestión integrada de Ourense, por ejemplo, apoya a los diferentes servicios en el diseño de publicaciones, en la redacción, en la búsqueda de presupuestos si tienen que realizarlo fuera del hospital, etc. Si finalmente contratan algún servicio externo, la responsable de comunicación lo valida y lo supervisa, pero no tienen libre disposición sobre esos fondos. En otras palabras: en algunos casos, ella firma las correspondientes facturas (previo visto bueno de la dirección de recursos económicos, de la gerencia y de la dirección asistencial), pero el presupuesto depende directamente de gerencia, ya que el servicio de comunicación no tiene uno asignado.

En el 061 sí que tienen más posibilidad de lanzar publicaciones. En este caso, se realizan dos previsiones cada seis meses, siempre en la misma fecha, donde se expone lo que se pretende divulgar durante esa etapa. Normalmente, dice Arantza Briegas, no suele haber negativas. Además, para aquellos imprevistos que no se habían reflejado en las previsiones, "siempre hay modo de arreglarlo y hacerlo", responde.

\section{Mejoras con un mayor presupuesto}

Durante la entrevista, se preguntó a los responsables de comunicación si están satisfechos con el dinero destinado a su gabinete o, por el contrario, preferirían disponer de más. Al respecto, los encuestados se encuentran algo divididos. Por lo general, los que trabajan para centros privados desearían disponer de más recursos económicos; los públicos, aunque no rechazarían esta opción, consideran, en su mayoría, que comunicar actualmente no es caro y que no necesitan partidas extras.

A Tomás Valín, por ejemplo, le gustaría tener más presupuesto, pero "la coyuntura económica actual obliga a controlar mucho más los recursos que se destinan a cada acción". Aun así, considera que con un mayor presupuesto se podrían mejorar muchos aspectos. No ve necesaria una reforma de gran nivel en la comunicación sanitaria, sino 
de pequeñas acciones que refuercen las actividades ya existentes. Por ejemplo, cree que, con una mayor dotación, contaría con más personas visitando los directorios de medios de comunicación o estableciendo otras relaciones. Asimismo, organizaría jornadas de salud, obras benéficas, patrocinaría a algún equipo de fútbol o baloncesto, etc. Todo ello, insiste, "pasa por un mismo concepto, es decir, un aumento presupuestario".

Kiko Fernández considera que si pudiese "manejar un poco de presupuesto, accedería a muchísimas más cosas". No tanto como para contratar a empresas externas, sino para "pedir asesoramiento externo". Irene Montero no se queja porque el presupuesto, "aunque no sea muy alto, nunca lo han tocado", y revela que muchas empresas, debido a la crisis, han tenido que pedir reducir el dinero que le otorgan a Octo para las labores de comunicación.

La mejora que establecería Xabier López en torno al presupuesto sería separar la publicidad de las labores de información y tener una partida para cada una de las vertientes. Así, podría "llegar a un acuerdo con los medios para decirles que este año os voy a dar tanto a cada uno; ya os diré cómo lo reparto”. Esto, en boca de Xabier López, "tiene un reflejo en comunicación. Evidentemente los periódicos responden a esa aportación garantizada", refiriéndose a que si inserta publicidad en los medios, es más fácil que publiquen noticias favorables suyas. "Entiendo es un peaje, digamos, poco ético -reconoce-, pero son las normas del juego: si quieres, juegas; si no, te vas". Y prosigue: "Yo no voy a suicidarme solo, no tengo vocación de mártir por la causa para que otros saquen beneficio. Mientras esa barrera infranqueable no la establezcan los medios, los anunciantes nunca vamos a poder cambiarlo".

Algo similar piensa Antolín Hermida. Considera que tener unos fondos destinados a los anuncios de pago "influye hasta tal punto que para que te publiquen las noticias en los medios de comunicación, tienes que dar publicidad". Algunos, reconoce, "te lo dicen tal cual. Te dicen que si no le das algo no te publican".

Hay otros responsables de comunicación, no obstante, que no necesitan, en su opinión, más presupuesto. "Con dinero - dice María José Iglesias- las cosas son mucho más sencillas. Pero las cosas no se dejan de hacer porque no haya dinero". O lo que viene a ser lo mismo: "Se harían de otra manera. En vez hacer una distribución de unos folletos de 40.000 ejemplares, se hacen de 10.000 o se utiliza el correo interno". Ana López Pimentel y Beatriz Senra son de la misma opinión: consideran que con un importe fijo "se podrían hacer más cosas", pero tampoco lo ven "imprescindible".

Patricia Forteza matiza que, actualmente, la máxima en comunicación es "intentar hacer lo mejor posible con los mínimos recursos posibles". Ella estaría "encantada" de tener más presupuesto, pero es consciente de que el dinero "se tiene que optimizar y dedicarlo a aquello que realmente sea importante, sobre todo en un hospital". Además, asegura que hay herramientas de comunicación gratuitas con las que "se pueden hacer muchas cosas". Y es que, hoy en día, matiza Paz Teijeira, "la comunicación no es cara". 
La propuesta que está intentando implantar el servicio de comunicación de Ourense es algo diferente. Myriam Sierra explica que dan soporte en publicaciones y en actos a muchos servicios del hospital (los cuales, por su parte, tienen sus propios modos de financiación) y eso "no tiene un coste cero". Recuerda que hace diez años le pidieron ayuda para difundir un congreso de medicina y que por el trabajo que realizó ella, una empresa externa le habría cobrado un millón de pesetas (6.000 euros); se enteró, dice, porque la firma entregó por error a la secretaría del hospital una minuta de la cobertura de comunicación. Por ello, lo que pretenden ahora es establecer un costo de las actividades que ellos prestan con el fin de que lo puedan recuperar para el hospital. Es una novedad que "llevará tiempo", admite Myriam Sierra, pero conseguirá "dar valor económico al trabajo que prestamos". Según explica:

"Yo entiendo que la manera de que te respeten es no trabajar gratuitamente. Es decir, yo no trabajo gratis, Carlos tampoco, trabajamos porque nos paga una institución. Ahora nos falta que las sociedades médicas, es decir, los propios compañeros, entiendan que ese trabajo que nosotros generamos para una cena, unas jornadas, un congreso, etc. también tiene un costo. Por supuesto, no lo queremos para nosotros, porque es un trabajo que le está ofertando el hospital. Pero sí lo queremos recuperar a través de la fundación, $\mathrm{y}$, mediante esta, redirigir el dinero a temas que sean importantes".

\subsection{INDEPENCIA, AUTONOMÍA Y PRESIONES}

\section{Libertad}

Al ser los responsables de comunicación de unos centros tan sensibles como los hospitales, se ha demandado a los entrevistados su opinión acerca de la libertad que tienen a la hora de llevar a cabo sus tareas diarias, ya sea por presiones de la dirección para abordar ciertos temas, de los periodistas para conseguir más datos, etc. La mayoría ha afirmado tener una gran independencia, salvo en algunas excepciones frente a los periodistas. A pesar de ello, todos sostienen ser conocedores de lo que deben sacar a la luz, cuándo lo han de hacer y la manera de hacerlo.

María José Iglesias se siente "en medio del periodista y del técnico de la casa [esta entrevistada considera técnico a 'cualquier persona del hospital que tenga algo susceptible que comunicar']". Y lo explica de la siguiente manera: "El medio de comunicación piensa que eres un portavoz y que siempre vas a vender lo positivo para la casa y ocultar lo negativo, y el de dentro piensa que estás para favorecer al medio de comunicación y de alguna manera tienen miedo a cómo lo pongas, que ellos no puedan 
interferir, no puedan corregir, no puedan de alguna manera supervisar lo que hables con el medio de comunicación".

Debido a esta visión, asegura María José Iglesias, "siempre estás intentando dar a los de fuera una visión técnica de que eres un intermediario y que eres una herramienta práctica. A los de dentro, por su parte, les dices que eres uno más del hospital. De la misma manera que para ir a un congreso necesitas el apoyo de la fundación de investigación o de calidad para que te ayude con las presentaciones, yo soy una herramienta más para que esa participación en el congreso sea divulgada a la población de Ferrol".

Pepe Losada tiene una visión similar. Matiza que tiene "bastante libertad entre comillas", ya que en ocasiones se siente "en el medio entre el dueño del periódico, que es de una corriente determinada, y la gerencia, que puede tener otra. Entonces, hay que estar aquí nadando un poco entre las dos corrientes".

Marta Castro afirma que conoce "qué contenidos hay que dar y en qué determinado momento". Considera que es "de sentido común, o sea tú misma te das cuenta que a lo mejor en un momento determinado es mejor no contar ciertas cosas. No porque quieras ocultarlas, sino porque a lo mejor en ese momento creas una alarma innecesaria".

Patricia Forteza mantiene una visión parecida. Considera que tiene una libertad "total" y que es una persona "bastante seria y con bastante criterio", por lo que sabe "aquellas cosas que debo publicar y aquellas cosas que no". A pesar de ello, el proceso que tiene que seguir para emitir un comunicado es bastante laborioso: "Tú preparas el tema, vas con el médico, haces las declaraciones y lo corriges con él. Una vez que estamos de acuerdo con la nota de prensa, pasa a la dirección del centro, sobre todo a la dirección médica (estos son los que establecen si verdaderamente eso puede salir o no puede salir). Después de la dirección médica, va al comité de dirección en general, pero sobre todo a la gerencia. Y después, una vez que está aprobado dentro del hospital va a la dirección de comunicación corporativa [del grupo Quirón en Madrid]. Una vez que están esas aprobaciones de todo el mundo, entonces mandas la nota de prensa".

Xabier López opina que tiene "bastante libertad" de la siguiente forma: "En el momento en que me lo cuentan es que quieren que lo cuenten; es decir, si no quieren que se sepa, no me lo dicen". Y aclara que no cree que sea una "cuestión de desconfianza, ya que tengo una cláusula de confidencialidad pese a no pertenecer a la plantilla del hospital", sino simplemente "para no perder el tiempo, aunque a veces me informan de algo que se va a producir en el futuro; algo que posteriormente va a desencadenar en una iniciativa de comunicación $y$, aunque no se pueda decir de momento, me permite ir trabajando en ello". Álvaro Otero se muestra más extremista. Piensa que no tiene ninguna traba en cuanto a contenidos, presupuestos o ideologías. Entiende que sus compañeros de los centros públicos pueden estar algo influidos según el gerente o consejero que tengan, pero en su caso, niega que sea así. Lo mismo ocurre 
con Irene Montero, que habla del hospital como "un cliente comodísimo en la medida en que se deja asesorar - cosa que no siempre sucede- y con el que hay mucha confianza porque llevamos muchos años trabajando juntos".

Paz Teijeira tampoco percibe presión porque la mayor parte de la información sanitaria es pública. En lo único en que hay un gran control es en las imágenes que salen del centro, ya sean fotografías o filmaciones. Hoy en día, dice un entrevistado que no quiere ser identificado con la siguiente afirmación, es difícil controlarlo porque "un periodista puede acceder a cualquier habitación sin que te enteres; no es como antes, que traían aparatos grandes y se veían”.

\section{Presiones}

Se ha querido comprobar si los responsables de comunicación sufren alguna presión a la hora de llevar a cabo sus actividades, ya sea por los temas a difundir, por los datos facilitados, por la consecución de objetivos, etc. En general, ninguno siente coacción por ninguno de estos aspectos y se consideran bastante independientes a la hora de transmitir contenidos. El único aspecto polémico con el que tienen que lidiar algunos, y que se detallará más adelante, son los partes médicos.

En relación a los objetivos, no se ha encontrado ninguna persona que sienta una verdadera coacción si no consigue alcanzar las metas fijadas. La única que los menciona al ser preguntada es Patricia Forteza. Asegura, no obstante, que no conlleva una "presión verdaderamente inaguantable", y más bien cree que "todo el mundo debería tenerlo", puesto que lo ve como "una forma de trabajar y de tener tu meta y sobre todo de tener una forma de superación".

Por otra parte, los hospitales, por su naturaleza, tienen que contar con una serie de herramientas que garanticen el derecho a la intimidad de aquellos que se acercan. Y para controlarlo, muchos centros han optado por conseguir consentimientos "prácticamente para casi todo", como manifiesta Patricia Forteza. Pueden ir desde la grabación de vídeos, la toma de imágenes, la emisión de datos... Incluso para el mismo personal interno: ya sea para tomar fotografías de ellos o para publicar en su nombre nuevas entradas para los blogs, como sucede en el Hospital Quirón. Normalmente, indica Patricia Forteza, no hay ningún problema con estos asuntos, "pero el día que lo tengas... la multa es multimillonaria, además de que daña enormemente la imagen del hospital y la del propio paciente".

El problema se acrecienta con la disminución del tamaño de los aparatos tecnológicos, ya que, tal y como se queja Kiko Fernández, "cualquier persona que entra por el hospital puede coger una cámara o un teléfono móvil y grabar y hacer fotos a lo que quiera", Y es que "ni siquiera se entera el de seguridad", lamenta un entrevistado que no quiere ser identificado con la afirmación. El departamento de comunicación no 
tiene ninguna responsabilidad sobre estos actos, dice Kiko Fernández, pero los usuarios, a título individual, indica este mismo entrevistado, sí que pueden denunciar.

\section{Partes médicos}

La evolución de las personas que ingresan en un hospital por algún accidente es una fuente importante de datos para la sección de sucesos de muchos medios. Sin embargo, no existe una postura uniformada en la emisión de partes médicos en los centros gallegos y cada gabinete de comunicación posee una regla propia. En dos áreas, la de Ourense y la de Vigo, no se ofrece ningún tipo de información de los pacientes. En otros centros, como el Quirón, ofrecen los datos que el enfermo o la familia aceptan difundir. Si estos no quieren reconocer ni siquiera que está ingresado, "tú no le puedes dar la información”, aclara Patricia Forteza. Otros, como Irene Montero, únicamente informan de si el sujeto en cuestión está o no ingresado en el centro, pero no proporcionan ni el nombre ni un parte detallado. Según incide, "lo primero es la privacidad del paciente y después pues ya se ve. Y si tengo que hacer de muro de contención, pues lo hago". Algunos, en cambio, facilitan el parte médico de los pacientes que ingresan, con su propio consentimiento, dicen, y siempre ofreciendo únicamente las iniciales. Finalmente, unos pocos facilitan el parte médico con iniciales y evolución del paciente sin consentimiento alguno. Se ha de especificar que, en el caso de menores, ninguno facilita ningún tipo de referencia, normalmente ni siquiera si está o no está ingresado el niño en el hospital.

El procedimiento para proporcionar un parte médico es el siguiente, según especifica María José Iglesias: "Me llaman y me dicen: «Mira ha habido un accidente y creo que el 061 lo ha trasladado hasta ahí». Yo, entonces, tengo que llamar al 061 para conseguir el nombre porque yo a ellos no les puedo facilitar ningún dato de identificación. Mi compañera de prensa del 061 me facilita el nombre y yo llamo al servicio de admisión de urgencias o directamente a la coordinadora de urgencias. Pido información al respecto, me lo dan y yo doy solo un parte escueto: «Sí, está aquí, es un paciente de tantos años y está por un traumatismo, está grave»". Según María José Iglesias, no facilita ningún dato más, "ni qué tipo de traumatismo ni nada".

\section{Consentimiento}

La emisión de partes médicos está íntimamente ligada a la Ley de Protección de Datos, mediante la cual cualquier información que se difunda de un paciente ingresado en un hospital tiene que contar con la autorización del afectado. En consecuencia, algunos responsables de comunicación aseveran que buscan al paciente o a la familia para explicarles sus derechos y obtener el consentimiento apropiado antes de dirigirse a los medios de comunicación. Sin embargo, otros ponen en duda este procedimiento. 
Xabier López, por ejemplo, opina que "aunque en teoría hay que tener el consentimiento, en la práctica dudo que se tuviera", haciendo referencia a su etapa como jefe de prensa de la Consellería de Sanidade. Y lo razona de la siguiente manera: "Vamos, por la cantidad de accidentes que hay, por la cantidad de noticias que se veía entonces cuando yo era jefe de prensa de Sanidad, dudo muchísimo, muchísimo, que alguien del hospital vaya a pedirles permiso a los pacientes o familiares. Muchísimo".

Algunos, efectivamente, reconocen fuera de micrófono que no piden expresamente ese consentimiento aunque la ley se lo exija. A otros no les importa admitir abiertamente que no se solicita este permiso o que depende de los $\operatorname{casos}^{\underline{21}}$, "porque nunca damos el nombre, jamás, y le exigimos al periodista que no dé el nombre". Aun así, tal y como lamentan Raúl Álvarez y Myriam Sierra, los periodistas acaban encontrando el nombre completo del paciente y lo publican. "Ese es uno de los motivos que nos llevó a dejar de dar información (salvo excepciones derivadas del interés o servicio público), ya que aunque desde los hospitales demos iniciales e información desvinculada de identidad, los medios los identifican y publican nombres de personas anónimas que tal vez no quieran ver ni su nombre ni su estado de salud hecho público", explica Myriam Sierra.

\section{Cese de emisión de partes médicos}

Debido a los problemas que lleva aparejados, dos zonas han dejado de facilitar partes médicos. Ourense fue la primera y un tiempo más tarde, Vigo. Según Myriam Sierra, se tomó esta decisión porque "no aporta valor a la institución sanitaria de ningún tipo y como información es despreciable; es decir, al propio medio de comunicación le genera un montón de trabajo y al final es un módulo en el periódico, o sea no aporta nada. Con la información que tienen ya de la Guardia Civil es más que suficiente".

Xabier López es de la misma opinión. Tal y como reconoce: "Más allá de dejar en el imaginario colectivo que muchos accidentes de tráfico vienen al Vithas Fátima, no nos aporta absolutamente nada. En ese sentido, da igual si un paciente tiene policontusión, si tiene la pierna rota, si se teme por su vida... Yo creo que no aporta absolutamente nada desde el punto de vista de imagen del hospital y desde el punto de vista de la información, más allá del estado leve, grave o muy grave o muy leve, que eso lo da el 99\% de las veces la Policía o la Guardia Civil”.

Al principio, comenta Myriam Sierra, hubo "ciertas reticencias", pero todas las partes implicadas "lo toleraron fenomenalmente" y no han vuelto a tener "ningún problema"; es decir, "hubo alguna queja al principio, pero no murió nadie", bromea Xabier López. Irene Pazo recuerda que muchos periodistas se quejaban porque en otras provincias sí que seguían emitiendo, a lo que esta responsable de comunicación les respondía que "hasta ahora se hacía mal, es que no se puede hacer". Aun así, reconoce,

${ }^{21}$ No se indican sus nombres por posibles represalias, pero así lo expresan ampliamente al menos cuatro responsables de comunicación. 
"lo que no tiene sentido es que yo sí y otros no", por lo que planteó un criterio general para todas las áreas de gestión integrada ante la cual aún no ha obtenido respuesta.

Asimismo, con la cesión de difusión de partes médicos se han evitado los errores que se cometían al trasladar la información de unas fuentes a otras: "Que saliera esa información en los medios de comunicación nos generaba problemas internos, en el sentido de que nunca transcriben exactamente la información que les das. Entonces, el médico que te había dado los datos entiende que tú le has pasado esa información mal, porque ellos a su vez la amplían, pero te la vinculan al centro, es decir, que era una fuente de conflictos que no aportaba nada”, explica Myriam Sierra.

Por otra parte, la emisión de partes médicos puede llevar a confusiones: "Tú imagínate que mandamos un texto en el que figura que un hombre permanece en estado grave, los periódicos lo redactan así, al día siguiente se publica eso y en realidad el hombre ha fallecido por la noche...", incide un entrevistado. O incluso un caso real que aporta este comunicador: "Una familia que estaba conduciendo hacia el hospital para ver a su hijo que estaba ingresado en la UCI y oyeron por la radio del coche que el chaval acababa de fallecer".

Aun emitiendo partes médicos, se pueden solventar estos problemas dando a conocer un único informe al día, dice Kiko Fernández, de manera que todos los medios publiquen la misma información si solo utilizan como fuente el gabinete de comunicación del hospital. En el caso de que un periodista llame para comprobar la evolución de un paciente, se le remite al parte médico que emitirán el día siguiente.

Además, existe un componente ético a la hora de proporcionar información sobre el estado de salud de una persona: "Un particular que tiene un accidente en una moto no tiene por qué ver al día siguiente en los medios de comunicación que «Fulanito se accidentó cuando iba en la moto». Primero, porque a lo mejor no te apetece que nadie sepa que tú estabas en esa carretera o en esa moto o que has tenido un accidente", protesta Myriam Sierra. Asimismo, se pregunta un responsable, “¿quiénes somos nosotros para decir «evoluciona bien, no, pronóstico grave...»? Tú eres la madre, la mujer, la hermana... y dices: «¿Por qué tiene que salir en prensa que mi marido evoluciona bien? ¿O que está muy grave?» O tú mismo, pero ¿por qué?” Además de que, según indica este entrevistado de la Ley de Protección de datos, una vez que un paciente entra a un centro sanitario, "tú no puedes dar absolutamente ninguna información de él”.

Algunos, como Antolín Hermida, defienden la emisión de este tipo de historias porque consideran que son datos "públicos: el que ingresa, normalmente viene con la familia, con los compañeros de trabajo..." Marta Castro, que facilita la situación médica de los pacientes antes de su ingreso en un centro de atención especializada a través del 061, justifica esta emisión porque "solo damos información de lo que ha ocurrido en la vía pública, es decir, que a lo mejor tú pasas por allí y también lo ves”. De lo que ocurre 
en domicilios privados, continúa, no difunden nada, a menos de que "se trate de situaciones un poco públicas, como pueden ser incendios". Además, esta responsable de comunicación opina que si no difundiesen esos datos, "a los periodistas ya no les quedaría información por ningún lado".

No obstante, muchos de los centros que aún emiten partes médicos coinciden en que deberían dejar de darlos, ya que, según Ana López Pimentel, "a nosotros, como hospital, no nos aporta nada". Aun así, aseguran que dejar de facilitar estos datos sería una "faena" para los periodistas, tal y como lo define Beatriz Senra, y reitera otro entrevistado que no quiere identificarse con la afirmación que "esto es un intercambio: si yo ayudo a los periodistas, ellos me ayudan a mí". En medio de este "gran debate interno sobre qué hacer y qué no hacer", María José Iglesias ha consensuado con los gerentes "un término medio" con el fin de que los periodistas no tengan que "andar buscando la información y que la que publiquen sea errónea". Así, los datos que se proporcionan es si una persona está o no está ingresada, el tipo de accidente y la categoría estandarizada de urgencias.

Pese a todo, muchos consideran que "con el tiempo" se dejarán de dar partes médicos por los problemas que conlleva y que Beatriz Senra resume de la siguiente manera:

"A veces intranquiliza mucho, yo con estas cosas me voy muy nerviosa a casa, porque a veces te están diciendo que está vivo, pero en cualquier hora puede fallecer. Y tú a lo mejor a las diez de la noche has dicho que está vivo, pero a lo mejor a las doce se muere y al día siguiente cuando lees la prensa, el periodista ha puesto que está «muy grave» cuando en realidad ya ha muerto. Y parece que realmente no has hecho bien tu trabajo. Y a veces no puedes decirlo porque son donantes, entonces están vivos, pero vivos mantenidos, pero ya se sabe la verdad. A lo mejor la familia ya está diciendo que se murió en su pueblo, y aquí todavía no aparece como fallecido porque está conectado a una máquina para extraerle los órganos... En fin, a mí me parece que siempre corremos un riesgo que cualquier día nos explota en las narices".

Y es que, tal y como explica Tomás Valín, "el periodista quiere tirar siempre del hilo, quiere llegar hasta el centro de la cuestión y a veces no se puede dar más información de la que se da por cuestiones evidentes, porque si das más datos el paciente y la familia se te echan encima. El paciente tiene unos derechos que no puedes ir contra ellos nunca. Y al fin y al cabo también está en juego la reputación del propio centro sanitario". Por ello, insiste el entrevistado, "tienes que andar con pies de plomo", aunque detalla que los partes médicos los gestionan en el hospital. 
Otra de las razones por las que en algunas zonas se ha dejado de emitir partes médicos es "la cantidad de tiempo, sinceramente, que se perdía en ello y que no compensaba una línea en el periódico", muestra Xabier López. Es un proceso tedioso, recuerda: "Buscas que te coincidan las iniciales con la edad e intentas localizar esa historia clínica, porque no siempre ha dado tiempo a volcarlo en el sistema. Si no está en el sistema, tienes que localizar quién le atendió, que no esté saliente de guardia y por tanto descansando con el teléfono apagado, que se acuerde si no está en el hospital... Después, dar marcha atrás, localizar a la familia, pedir permiso y localizar al periodista".

Muchas de estas acciones se realizaban, además, fuera del horario oficial de los trabajadores: "¿Tú crees que hay derecho a que yo un domingo a las nueve de la noche que esté en mi casa tenga que estar haciendo gestiones porque simplemente se haya caído un ciclista en la ciudad?", se pregunta un participante que no quiere figurar como responsable de tal interrogación.

\section{Excepciones}

Aunque algunos centros tengan la política de no proporcionar datos médicos, en ocasiones puntuales han tenido que salir al paso y suministrar alguna información relacionada. Por ejemplo, en el Vithas Nuestra Señora de Fátima, tuvieron que desmentir que una persona hubiese muerto, tal y como había asegurado la policía local, después de que la familia acudiese al hospital para pedir una rectificación. "En ese caso, sí, por supuesto, dimos el parte y emitimos lo que consensuamos con la familia. Pero lo hicimos porque venía de un error de fuera y, sobre todo, porque fue la familia la que acudió a nosotros para solicitar ese servicio”, recuerda Xabier López.

El hospital Modelo también emitía partes médicos cuando se encargaba de la enfermería de la plaza de toros, ya que los toreros del ruedo "son personajes públicos". También se ofrece información en casos de salud pública (por ejemplo, epidemias o brotes epidémicos), aunque incluyan a menores, como pueden ser los casos de meningitis, manifiesta Beatriz Senra. Esto es debido a que se trata de "problemas de salud sobre los que hay que informar a la población porque se pueden ver afectados", explica Ana López Pimentel. Aún así, en estas situaciones, tal y como aclara Beatriz Senra, "no se personaliza ni se habla del estado, solo se informa del número de ingresados, porque se trata de temas que generan alerta y desconcierto y se disparan los rumores". En Ourense, poseen un protocolo en el que se detallan las excepciones y la información que se da en estos casos. Y es que aunque está prohibido difundir ningún tipo de información de este grupo de población, hay muy pocas excepciones por las cuales algunos responsables de comunicación deciden divulgar ciertas referencias. María José Iglesias relata que en un caso determinado se dio datos de un menor cuando tuvieron un incidente con una enfermera que inyectó un medicamento para el niño cuando en realidad debía ser para la madre. A causa del accidente, el menor falleció y el 
hospital tuvo que explicar qué había pasado, reconocer que se asumía el error como equipo y que se iban a tomar todas las medidas oportunas.

\section{Personas conocidas públicamente}

Cuando los responsables de comunicación se enfrentan a un paciente que resulta ser conocido públicamente, normalmente "pactan" con el susodicho, su familia o con su gabinete de prensa, si procede, afirma Patricia Forteza. Como norma general, en el Vithas Nuestra Señora de Fátima, cuando se trata de deportistas, se encarga el hospital, mientras que si el paciente en cuestión es un político, lo gestionan desde su partido. Además, no hacen distinciones entre unos medios y otros. Cuando alguna persona relevante no quiere dar información a una determinada publicación o prefiere otorgar una exclusiva, "preferimos quitarnos del medio y que sea el paciente, el club o la persona correspondiente quien lleve el tema. ¿Por qué? Porque nosotros no podemos hacer distinciones. Esa persona es muy libre de hacer lo que quiera, pero el hospital no puede ni tiene ninguna exclusiva con ningún medio", responde Xabier López.

\subsection{GERENTE}

La tónica general de los responsables de comunicación de los hospitales de Galicia es admitir que los gerentes que lideran el centro en cada momento influyen, de una manera $u$ otra, en la labor de comunicación que realizan. A pesar de que algunas personas se mostraban durante la entrevista reacias a proporcionar ejemplos o explicaciones sobre este tema, en general se aprecia que en el día a día, es decir, en las tareas de comunicación que realizan, no tiene tanto peso, pero donde sí que se nota es en la importancia que otorgan a la comunicación y lo mediático que sea o no sea. En consecuencia, se desprende que con un gerente u otro será más sencillo que aparezca en los medios, que le realicen entrevistas, que autorice actividades comunicativas más novedosas, etc., pero en lo que es la dinámica diaria (elaboración del dosier, redacción de notas de prensa, mantenimiento de la web, etc.) no afecta.

\section{Hospitales públicos}

Donde más nota la diferencia Raúl Álvarez entre unos gerentes y otros es en que algunos son más proclives a utilizar los medios de comunicación. No obstante, en su día a día, más allá de la mera coordinación, no tiene más inconveniente con un gestor $\mathrm{u}$ otro. Paz Teijeira explica que la sanidad es un tema que siempre tiene interés y es foco constante de atención. Por ello, los periodistas van a publicar siempre noticias de esta temática. No obstante, considera que si un gerente "accede a hablar con los medios, le gusta, tiene facilidad de palabra, se siente cómodo, etc.”, es más sencillo obtener un 
flujo de información con los periodistas y que el propio gerente se preste a hacer declaraciones y entrevistas más allá de resolver cuestiones que puedan surgir "con la típica nota de prensa".

Marta Castro expone que existen unas líneas generales propias de la Consellería, pero que, "como en todo", la persona que dirige el centro también influye. Un entrevistado, por ejemplo, considera que "hay gerentes que hacen mucho marcaje y otros que les importa muy poco". Además, "unos te valoran más que otros y entienden mejor la comunicación". Y pone el ejemplo de las contestaciones que el gerente otorga a la prensa a través de él: "Yo intento recoger las frases casi literalmente (porque yo ya me conozco el percal), y a veces le hago repetir las declaraciones para cerciorarme de que soy bastante ajustada. Sin embargo, al día siguiente el periodista no lo ha reflejado tan literalmente, al gerente le sienta mal y tú tienes que asegurarle que tú transmitiste exactamente lo que había dicho él”. Muchas veces, continúa el responsable de comunicación, el problema está en la propia profesión: "Tú dices que eres periodista y siempre hay recelo. Da igual que trabajes para el mismo fin". Por ello, considera que su trabajo es, en ocasiones, "ingrato", dado que "siempre atacan al mensajero, es lo más fácil”.

El dirigente también influye en las notas de prensa que se envían desde algún hospital: según la persona que ocupe este cargo, a veces da recomendaciones al responsable de comunicación sobre enviar una noticia, retenerla o desecharla. Pepe Losada tiene que pedir permiso para iniciar ciertas actividades, ya sean exposiciones, creación de blogs, elaboración de vídeos, etc. Al contrario que otros compañeros (que aseguran no tener casi negativas por parte de sus gerentes), reconoce que "hay cosas que me las acepta, pero otras que no".

María José Iglesias, por su parte, ha tenido suerte con los tres gerentes que han pasado por el hospital: "Todos estaban interesados en la misma línea, se dejaban asesorar y contaban conmigo", indica. Sucede lo mismo con Kiko Fernández, que confiesa tener "carta blanca" con todos los que han pasado por allí. Aun así, explica: "Ahora ya tienes experiencia, llevas unos años en el puesto, sabes manejarte, sabes lo que puede salir en cada momento, puedes decidir qué noticias sacar en cada momento, etc., así que no tienes que pedir constantemente permiso". Aun así, en las cuestiones más delicadas, suele avisar al gerente o a algún miembro del equipo directivo para que le confirme los datos. Asimismo, asegura tener una reunión todos los días a primera hora con el máximo dirigente del hospital para concretar, en la medida de lo posible, la agenda informativa del día.

Algo similar opina Myriam Sierra. Cree la comunicación con la gerencia debe ser “muy ágil" y por eso son "bastante autónomos". Explica que la dirección "confía en su criterio" y por ello no están "continuamente molestándolos", aunque aclara que es "muy importante" tener "acceso constante" a la gerencia. Normalmente no necesitan pedir un 
consentimiento expreso para llevar a cabo diferentes labores comunicativas porque "contamos con ello", aunque después lo ponen en su conocimiento. En casos más relevantes o fuera de lo habitual, no obstante, sí que tienden a pedir permiso.

\section{Hospitales privados}

En los hospitales privados se observan dos extremos: por un lado se encuentran Xabier López, Antolín Hermida e Irene Montero, que tienden a ser más reservados con las apariciones con los medios, y por otro Tomás Valín y Álvaro Otero, que intentan exprimir al máximo la difusión de información y de creación de marca. Adoptar una postura en detrimento de la otra tiene su fundamento en la visión del gerente acerca de la comunicación.

Las personas que ostentan este puesto en los primeros centros son muy "celosos de su intimidad", tal y como los define Xabier López, y, por ello, no les gusta dar a conocer muchas actividades que se realizan en la clínica o no son tan propensos a tratar con los medios. En el caso del Vithas Nuestra Señora de Fátima, esto sucede porque el gerente "entiende que lo que hay que potenciar es la imagen del hospital, no la suya". Xabier López le ha repetido "por activa y por pasiva" que potenciando su imagen se potencia la del centro, pero a veces lo nota "reacio". "No sé si por modestia, por pudor o porque hasta ahora le han funcionado las cosas bien así y tampoco va a cambiar a estas alturas", se pregunta. No se trata de un "periodisticofóbico", aclara, sino que ocupa "una posición de hormiguita, de trabajar y de que ya lo contará otro, ya lo contará el director general del grupo, ya lo contará el director médico... por arriba o por abajo, pero si puede contarlo alguien que no sea él, mejor". Incluso alguna vez Xabier López ha tenido que pedirle que concediera alguna entrevista: "Si él ve que es importante que esté presente en un acto, si él ve que es importante que haga una entrevista, si él ve claramente que tiene que ser él el que lo haga, no le tiene miedo", pero aun así no es muy dado a aparecer en la prensa.

Antolín Hermida tiene una visión similar. Considera que las personas que trabajan en el hospital responden al refrán "el buen paño en el arca se vende": "Ellos saben que lo hacen bien y no están preocupados porque lo sepan los demás, solamente quieren o se preocupan de que el que entra esté bien atendido y que salga curado o que salga con menos dolor". Por ello, reflexiona su responsable de comunicación, "no les importa la opinión pública, no les resulta una preocupación, ni tampoco les gusta vender las cosas, como el Sergas, por ejemplo, o como otros hospitales, que cada cosita que hacen la venden. A mí me cuesta mucho trabajo, mucho trabajo, arrancar datos". Al tratarse, además, de una empresa externa, Antolín Hermida explica que "llega un momento en que si el cliente no quiere o no se deja, no puedes hacer mucho". De media, calcula, aceptan el $50 \%$ de las propuestas que les remiten, aunque, eso sí, algunas de ellas a base de "insistencia y machaconería". El entrevistado tampoco considera que haya que 
"vender todo lo que se hace", pero sí que ve necesario llegar a un "equilibrio". Y en eso influye mucho el director: "Nuestro anterior gerente era economista, así que le interesaba muchísimo la comunicación. Él cogió el hospital con problemas económicos, con déficit, y lo puso a flote, lo puso al día, lo puso bien. Este nuevo gerente es una persona encantadora, pero es médico y tiene una visión distinta. Le interesa la comunicación, pero no desde el punto de vista de la empresa, no desde el punto de vista de centrarse en un aspecto, obtener unas determinadas cifras y conseguirlo de una manera estipulada. Anda en otras historias, esto no es una de sus mayores preocupaciones".

En la Rosaleda, en cambio, no ocurre esto. Según Tomás Valín, el objetivo del hospital en sus inicios fue "crear marca" y, en la actualidad, "consolidarla". El centro depende de una serie de accionistas, en su mayoría trabajadores en el propio centro, y de un gerente que coordina toda la estrategia de acuerdo con ellos. Prácticamente, indica Tomás Valín, el centro está capitalizado por personas de reconocido prestigio dentro de la ciudad. El gerente influye "absolutamente", y en el caso de este hospital de Santiago, se trata de una "persona tremendamente preocupada por estos temas y que sabe de la importancia de la comunicación: juega un papel determinante en todos estos aspectos". Según indica Tomás Valín, muchas de las actividades que se hacen, además de contener información relevante y de interés, consolidan marca.

Algo similar ocurre con Álvaro Otero. Considera que tiene "total libertad". Lleva 14 años trabajando con él y sabe perfectamente las noticias que pueden transmitir a los medios de comunicación y qué tipos de datos solicitan. Desde dirección, normalmente, no le imponen contenidos, más bien al contrario: les dan total libertad.

\subsection{ERRORES}

Casi todos los responsables de comunicación de los hospitales de Galicia coinciden en que se comenten errores, ya que, según aclara María José Iglesias, "somos humanos y los cometemos como cualquier humano". Así, algunas de las acciones que emprenden "son acertadas, otras medio acertadas y de vez en cuando la cagas", dice Tomás Valín.

Pocos son los entrevistados que aprecian en la comunicación externa algún error, sobre todo a la vista de una encuesta realizada hace unos años sobre la percepción de los periodistas hacia ellos: "En general, veían que éramos útiles, que éramos ágiles en la repuesta y que dentro de lo delicaita que es la información sanitaria veían que gestionábamos sus demandas con cierta celeridad; es decir, no les damos largas de vuelo hasta mañana, como en la típica ley del funcionario", relata Raúl Álvarez. En cambio, en la comunicación interna es donde se detectan más lagunas, muchas de ellas debidas a la falta de tiempo, la escasa coordinación y la poca importancia que le otorgan los profesionales sanitarios a la comunicación. 


\section{Falta de comunicación interna}

Por parte de los hospitales, dice Xabier López, "el principal problema de comunicación es, precisamente, la falta de comunicación; ya sea entre servicios, con el responsable, con el departamento de comunicación o de las gerencias con este departamento". En el hospital en el que trabaja, en concreto, esto se refleja en que no está "plenamente implantada la cultura de comunicación".

Marta Castro también atribuye como un error la falta de comunicación interna y la poca importancia que algunos empleados le otorgan a su labor. Pone el ejemplo de una nota de prensa que emitieron sobre un curso especificando que iba dirigido a un determinado grupo de médicos y enfermeros. En realidad, no estaba concebido para esta audiencia y tuvieron que enviar una corrección y avisar a todos los receptores. Este error lo atribuye Marta Castro a que los responsables del curso avisan la víspera: "Ahí falló la falta de previsión, que te sugieran enviar informaciones en el último momento y rápidamente creyendo que haces notas de prensa como churros". En cambio, propone programar un calendario y establecer una organización "para que la comunicación sea más fluida y poder sacar un mayor partido”. Programar los eventos con antelación y ser "más ordenados" también debería ser una prioridad de acuerdo con Myriam Sierra.

La comunicación interna, para Patricia Forteza, es "muy importante". Sin embargo, el problema que ella detecta es que se trata de un trabajo "muy meticuloso, de hormiguita, del día a día”, para que después no se obtenga una rentabilidad a corto o medio plazo, que es lo que demandan los gestores de los hospitales. Por ello, insiste ella, siempre se recurre primero a la comunicación externa, que es la que otorga resultados más tempranos.

Ana López Pimentel opina que no desarrollan toda la comunicación que deberían porque "nos come el día a día". "A veces no podemos hablar casi ni nosotras dos -dice Beatriz Senra sobre Ana López Pimentel y ella-, porque cuando tenemos cinco minutos los tenemos que dedicar a mirar cuatro cosas". Paz Teijeira tampoco dispone de suficiente cancha para dedicar a la comunicación interna y externa y, por lo tanto, prefiere centrarse más en la segunda y pedir apoyo al servicio de informática para que le ayuden con la primera, como puede ser subiendo noticias a la intranet.

Para Pepe Losada, existen dos grandes errores a nivel de comunicación interna. Uno de ellos está relacionado con las habilidades comunicativas del personal facultativo. Hasta hace poco, indica, los estudios de Medicina no incluían ninguna asignatura de comunicación y, por ello, "hay algunos a los que se les da más o menos bien y son gente que tienen cierta empatía, pero hay gente que es patán”. Reconoce que en su centro hay un especialista que coincide exactamente con esta última descripción: "Aquí tenemos uno... que es que vamos... la gente sale asustada de su despacho. Tiene una mala hostia... Y claro, te impone y ya no le preguntan por miedo. Y eso no está bien, porque yo creo que al final se resiente el tratamiento", lamenta. Como en otros 
terrenos, "hay gente que las tiene de manera innata y gente que no [las habilidades comunicativas]" e insiste en que "un mínimo debería ser exigible para ejercer la medicina y esto, como todo, se puede entrenar y mejorar".

El segundo error en cuanto a comunicación interna, según Pepe Losada, es la falta de foros donde los miembros de un servicio se reúnan y puedan proponer soluciones desde distintos prismas. "La organización hospitalaria es muy jerarquizada y a «los de arriba», en muchos casos, les falta tiempo para atender a «los de abajo», que por otra parte pueden detectar problemas que «los de arriba» ignoran. Los ciudadanos deberíamos estar más acostumbrados a este tipo de comunicación interna, en cualquier tipo de organización, en la que se diera una crítica constructiva. Sin embargo, la realidad es que, por regla general y por desgracia, toleramos mal la crítica", lamenta Pepe Losada.

\section{Desconocimiento de los periodistas sobre la sanidad}

En ocasiones, otra de las trabas a las que tienen que hacer frente los responsables de comunicación de los hospitales a la hora de transmitir información son los mismos periodistas. Xabier López considera que existe "un gran desconocimiento" entre el colectivo de redactores acerca del mundo sanitario. Y proporciona un ejemplo: una huelga de atención primaria que hubo hace unos años, cuando él estaba al frente de la comunicación de la Consellería de Sanidad, y a la que hacía referencia el titular de una agencia de noticias de la siguiente forma: "Los hospitales gallegos colapsados por la huelga de atención primaria ${ }^{22}$ ". Xabier López considera que la culpa no es tanto de los periodistas que cubren la información sobre la salud, porque actualmente no están demasiado especializados, sino de sus jefes o de los correctores. No sabe concretar la solución a este problema, ya que no tiene "muy claro que un curso o una jornada o algo similar para ellos fuera a suponer un cambio; si no, lo hubiéramos organizado ya, bien en la Consellería, bien en este hospital", opina. Y es que mantiene que lo ha intentado en alguna ocasión y que la acogida de los redactores fue, "en la mayoría de los casos, muy positiva, pero todos o casi todos me dijeron lo mismo: "convence tu a mi jefe de que ese día no tenga nada que cubrir y yo voy encantado»".

Para Antolín Hermida, en cambio, el problema que ve en los periodistas es que a veces contextualizan poco las informaciones, tanto sanitarias como de cualquier otro ámbito.

\footnotetext{
${ }^{22}$ La atención primaria corresponde a los centros de salud y la especializada, a los hospitales.
} 


\section{Otros}

Existen errores que, lejos de beneficiar al sistema público en cuanto a transparencia informativa se refiere, ofrecen una visión poco acertada de la realidad. Es el caso de las listas de espera, que se dan a conocer cada tres meses. Según aclara un entrevistado, esto se debe más a una decisión política que a una práctica, ya que los técnicos mismos opinan que "no tiene ningún sentido". Dos veces al año, opina, "sería más ajustado, pero cada tres no tiene sentido, porque te pilla entre medias Navidad o Semana Santa, y una semana sin rascarla se nota mucho". El responsable de comunicación "pelea" e insiste en que "no hay que publicar con esa frecuencia", pero lamenta que "me hacen caso lo justito porque la política prima sobre las decisiones técnicas".

Para Tomás Valín, el problema actual y más grave al que se enfrentan los gabinetes de comunicación de estas organizaciones "viene determinado por el histórico de publicidad que se ha estado insertando todos estos años en los medios". "Se ha alimentado tanto a los medios que se les ha hecho insaciables. Los recortes nos afectan a todos y los medios de comunicación no son ajenos a ello y todavía soportan, en algunos casos, estructuras muy pesadas que obligan a ingresar, quizá por encima de lo que marca el mercado actual, dificultando, muchas veces la función de los gabinetes [...] Con el recorte que estamos sufriendo, ellos están tan necesitados soportando las estructuras que tenían tan dimensionadas anteriormente, que actúan con cierto descontento obviando algún tema en determinados momentos. No te lo dicen, pero lo hacen", explica. Por ello, razona Tomás Valín, se ha de tener un tratamiento "adecuado y equitativo" con todos los medios en cuanto a noticias se refiere, pero sobre todo en el reparto presupuestario de la publicidad: "Si haces cualquier cosa que ellos consideren un agravio comparativo con otro medio dentro del mismo ámbito geográfico, corres el riesgo de que no te atiendan en otras ocasiones", sentencia.

\subsection{MEJORAS QUE IMPLANTARÍAN}

Dado que el principal problema o escasez que detectan los responsables de comunicación en los hospitales de Galicia es la comunicación interna, muchos de ellos lo mencionan como el primer aspecto que debería potenciarse. Según indica un participante en el estudio, "los médicos no pueden enterarse por el Faro de Vigo de alguna medida que va a implantar el gerente del hospital. No pueden enterarse así. Y es que, además, eso repercute en la externa", una idea que también apoya Paz Teijeira. Sin embargo, tal y como reconocen casi todos, "la comunicación externa absorbe muchísimo y no hay tiempo para hacer todo".

Sin embargo, mantener al personal interno informado y que sean conscientes de la importancia que tienen en el cuidado de los pacientes es una pieza fundamental. Las personas de la limpieza, por ejemplo, "pueden barrer o limpiar con un ruido tremendo a 
las cuatro de la mañana o hacerlo con cuidado para no despertar a nadie. Y esto mismamente, influye mucho", afirma Antolín Hermida.

María José Iglesias convocaría más reuniones internas entre los responsables de comunicación de la red sanitaria (algo que han venido haciendo, pero que, en los últimos años, se ha reducido), ya que "se aprende mucho de la experiencia de otros compañeros". Reconoce que hay una conexión continua por teléfono y por correo electrónico, pero ella echa de menos un mayor "tú a tú, sentarte con la otra persona y escuchar algunas entrevistas o noticias que han hecho otros y decir ijolín, yo eso no lo hago, pues podía copiárselo! ¡Mira qué efectivo es!”.

Tener a mano portavoces para dar declaraciones a los medios y "que te apoyen y que te informen de las cosas para que tú las puedas sacar" es otra de las ayudas que añade Paz Teijeira, ya que las personas con esa visión, dice la entrevistada, "facilitan muchísimo el trabajo".

Otros de los puntos flacos que debería solventarse es la falta de personal, ya que, a la vista de las reflexiones de algunos entrevistados, "hay veces que no puedo hacer nada más que coger el teléfono" (dice un entrevistado) o "me gustaría duplicar mi día" (Patricia Forteza). Sin embargo, tal y como reconocen algunos, es "muy difícil" incorporar nuevas personas a la plantilla por la situación económica actual. Por ello, en muchas ocasiones, algunos se apoyan en el servicio de informática, sobre todo en lo referente a la comunicación interna a través de la intranet. La bajada de presupuesto general también ha contribuido a reducir el número de programas, las publicaciones propias, el merchandising, el diseño gráfico externo, etc. que se realizaban anteriormente y que, por lo menos a Marta Castro, le gustaría seguir haciendo.

Ana López Pimentel considera que deberían fomentarse las relaciones institucionales y las relaciones públicas en general, mientras que María José Iglesias concreta más y opina que ha de haber "más actividad a nivel de grupo", y que debería "presentarse a los servicios en conjunto, no solo al jefe de servicio", aunque reconoce que esto último es "difícil porque tendrías que meterte en su ámbito existencial y es muchísimo más complejo".

\section{Más comunicación bidireccional}

Según Xabier López, el principal problema que detecta es que hay poco feedback, es decir, comunicación bidireccional del hospital con el paciente y del paciente con el hospital, algo que califica como "totalmente abierto" y en lo que "debemos trabajar". Y añade un ejemplo: "Una persona que haya tenido que venir de un pueblo y nada más llegar le digan que la máquina que necesitaba no funciona. Ese paciente, lógicamente, dirá: «Oiga, tiene mi teléfono fijo, mi teléfono móvil, mi correo electrónico... La próxima vez que se estropee dígamelo, dígamelo. Porque para usted no es tanta molestia 
porque vive aquí al lado, pero para mí ha supuesto pedir un día en el trabajo, recorrer no sé cuántos kilómetros y estar un buen rato buscando aparcamiento para llegar e irme a los tres minutos sin la prueba que necesito»»".

En relación a este ejemplo, Xabier López considera que hay detalles que pueden beneficiar mucho a los pacientes: "Yo creo que sería muy bien valorado que si un médico tiene una urgencia y retrasa sus consultas media hora (porque evidentemente las urgencias no las puede prever), sus pacientes reciban un SMS diciendo que la consulta se retrasa. Probablemente todos vengan a la hora que están citados, pero pueden irse a la cafetería, estar por aquí cerca o leer sin preocupaciones".

Las razones por las que, piensa Xabier López, no se ponen en práctica estas iniciativas, es porque "las organizaciones siempre tienen cierta reticencia a exponerse públicamente" y porque se requiere "mucho tiempo y mucho personal". En cualquier caso, asegura, no ha recibido ninguna notificación por parte del público de la necesidad de estas plataformas ya que, opina, este es "muy pasivo" y es "capaz de quejarse por cualquier problema a su médico antes que poner una reclamación", aunque reconoce que no ha desarrollado ninguna vía para preguntar estas cuestiones a los usuarios.

Para conseguir esa bidireccionalidad, de acuerdo con Pepe Losada, "hay que proporcionar los canales para que el paciente se relacione contigo", y los blogs y las redes sociales son herramientas que "están funcionando muy bien". El contenido que se transmite, por otra parte, adquiere una especial relevancia. Según relata el responsable de comunicación del Centro Oncológico de Galicia, "las visitas a las entradas más útiles para el paciente son exponencialmente mayores que aquellas en las que tan sólo nos damos « autobombo»". En relación con el contenido, Antolín Hermida también considera que se debería mantener a la población más informada sobre aquellas cuestiones que les puede afectar, como información sexual, drogas, tráfico, cómo controlarse la tensión, el colesterol, la glucosa, el azúcar y un largo etcétera.

\section{Otras medidas}

Tomás Valín, como se ha visto, cree que con un presupuesto mayor se podría "hacer las delicias de unos y otros". Así, contrataría más personal para visitar los directorios de medios de comunicación o establecer otras relaciones. Asimismo, organizaría jornadas de salud, obras benéficas, patrocinaría a algún equipo deportivo... Es decir, no ve necesaria una reforma de gran nivel en la comunicación sanitaria, sino pequeñas acciones que refuercen las actividades ya existentes. Sin embargo, reitera que estas acciones "pasan por un mismo concepto, es decir, un aumento presupuestario".

Álvaro Otero mejoraría la presencia y trabajo en redes sociales, aumentaría los patrocinios hacia la población en general, mejoraría la newsletter y trabajaría en la identidad corporativa. Considera, no obstante, que es algo que se debe implantar con el 
tiempo, ya que son estrategias que se visualizan a largo plazo; es decir, no son acciones que no pueda hacer ahora por ningún motivo en especial. Otros también desearían potenciar su presencia en redes sociales, aunque, indica un participante, "con inteligencia", ya que les parece una "fuente de problemas y de conflictos".

Myriam Sierra propone buscar nuevos canales para transmitir información, dado que "el mailing agota, o sea, satura, se llenan los correos". Asimismo, convendría hacer un esfuerzo "muy importante" a nivel docente, meterse "de lleno" en la formación posgrado de manera "estable y no anecdótica". Trabajar a través de metas también debería ser una de las máximas en cualquier gabinete: "Nosotros hemos conseguido desde hace dos años firmar objetivos. Establecemos unos anuales, los firmamos, y al final del año, los valoramos según la productividad". Esto permite, dice Myriam Sierra, "cuantificar nuestro trabajo". Por ello, recomienda (aunque en su departamento aún no lo hacen) elaborar una memoria anual de actividad para documentar que "tu trabajo realmente existe. Si no lo haces, fuera de tu despacho, ningún médico, ninguna enfermera sabe a lo que te dedicas", insiste.

También se pueden documentar las peticiones que se realizan a través de protocolos y procedimientos, ya sean para obtener un cartel, para ordenar una publicación o para incluir un anuncio en un tablón. Estos no "taponan, bloquean o dificultan" el trabajo, sino más bien al contrario: "Permiten agilizarlo, hacer que sea un canal formal, es decir, que todos los trabajadores del Sergas de Ourense sepan que tienen esta opción y que lo pueden pedir", opina Myriam Sierra.

Finalmente, algunos opinan llanamente que la mejora que hace falta en su trabajo es "que nos hagan un poco más de caso", ya que, a veces, "las decisiones políticas están por encima de las cívicas o de lo que opinamos los técnicos, la gente de dentro". Comentan que en ocasiones dicen a sus superiores que no es el momento de convocar un acto o una rueda de prensa, por ejemplo, pero que no les hacen caso porque "prima el criterio político". Al final, las consecuencias, como habían previsto, son negativas, por lo que se acaban sintiendo "como una mierda aquí, como si no pintase nada"르.

\subsection{BENEFICIOS DEL DEPARTAMENTO DE COMUNICACIÓN}

Todos los responsables de comunicación de los hospitales gallegos ven beneficios en las labores que llevan a cabo a diario. Algunos, como Álvaro Otero, incluso declaran esta actividad como "fundamental". Tomás Valín, por su parte, cree que un gabinete de este tipo "es beneficioso para cualquier entidad, da igual que sea una tienda de delicatessen que un hospital" y asegura que las ganancias "son las mismas que para cualquier otro tipo de cliente". Por ello, Álvaro Otero entiende que, en general, el 80\%

\footnotetext{
$\underline{23}$ No se revela el autor de las declaraciones por el posible malestar que podría causar en su entorno.
} 
de las empresas debería tener un servicio de información, exceptuando casos muy concretos en los que solo haya un único grupo objetivo muy definido". Sin un diálogo con el entorno, dice este entrevistado, cualquier organización caería en "el oscurantismo".

\section{Más información para la población}

Una de las utilidades más reiteradas es que el público conozca las actividades que se llevan a cabo en el hospital y que pueda estar al día de la realidad sanitaria, es decir, que las personas tengan "más información de entrada", dice María José Iglesias. Dado que "existe un gran interés por los temas de salud entre la población", según Álvaro Otero, un gabinete de comunicación hoy en día es imprescindible, puesto que "tienes que abrirte y darte a conocer. Ahí a la puerta es difícil que vengan a llamar”, comenta Tomás Valín. María José Iglesias recuerda la época en la que no había ninguna persona dedicada a la información en los hospitales del área de Ferrol y apenas aparecían noticias sanitarias en los periódicos; únicamente se publicaban cuestiones puntuales y de tratamiento negativo, como un error médico o una mala atención. A raíz de su llegada a esta zona, las noticias en prensa "se multiplicaron": "Ahora tres meses de textos son lo que antes eran tres años", asegura.

Aparte de los meros datos, esto también sirve para "acercar la sanidad, que muchas veces está muy endiosada, a la gente”, manifiesta Kiko Fernández. Así, se pretende informar al público "del acceso que tiene a la sanidad y de las prestaciones que se ofrecen", según Paz Teijeira, ya que "muchas personas (mayores y no tan mayores) no conocen que existen ciertas técnicas hasta que lo leen en un periódico", sostiene Álvaro Otero. Pero también es relevante para que el ciudadano "sepa qué se hace en un hospital, que no llegue con tanto miedo, porque muchas veces se llega con mucho miedo", de acuerdo con Kiko Fernández. Además, según destaca Raúl Álvarez, "le da inmediatez a la gestión de las quejas que la sociedad tiene para con él. [...] Las peticiones de la sociedad que se vinculan a través de sindicatos, de colectivos vecinales, partidos políticos, etc., se responden rápidamente a través de los medios de comunicación, que a fin de cuentas son los portavoces que transmiten la información de interés general".

Al margen del aspecto científico (donde se incluyen los congresos, las nuevas técnicas, tratamientos que se realizan en el hospital, etc.), el gabinete de comunicación es importante desde un punto de vista divulgativo. En este apartado se concentran las recomendaciones prácticas para la población, como por ejemplo consejos para la mujer embarazada en verano, cómo evitar la gastroenteritis, cómo tratar las picaduras de insectos, etc. "No sólo se trata de conseguir más información para el paciente de manera cuantitativa, sino más formación cualitativa. Un paciente bien formado, que conozca el cómo y el porqué de las diferentes etapas de su tratamiento, tiene más probabilidades de 
hacerlo bien, por lo que tiene más probabilidad de éxito médico", sentencia Pepe Losada.

Estas recomendaciones tienen su reflejo posterior en los ciudadanos. Kiko Fernández recuerda que su gabinete ha enviado durante diez o doce años dos o tres notas todos los veranos recordando a los bañistas del peligro de las zambullidas y explicándoles cómo deben sumergirse en el agua. Como consecuencia, el número de personas con lesiones medulares por estos accidentes se ha reducido, así como aquellos provenientes de otras campañas de sensibilización, tales como los accidentes de tráfico sin cinturón. En cambio, han aumentado, dice Kiko Fernández, los lesionados medulares en entornos rurales y en edades avanzadas, bien porque se les ha volcado un camión o porque se han caído de un árbol, entre otras cosas. Lo mismo sucede con las donaciones, cuyas negativas se han reducido merced a la labor de sensibilización que se lleva a cabo desde que los niños son pequeños.

En el caso de los centros privados, donde normalmente hay libre elección, la comunicación es más importante si cabe, incluso "fundamental para el futuro del hospital", destaca Xabier López. "Para acudir a un hospital, lo primero que tienes que saber es que existe, lo segundo es saber que en ese hospital te van a atender lo que tienes y lo tercero, que te van a atender bien", sentencia. Todo eso, afirma, se consigue con la comunicación.

Además, para las clínicas privadas, esta práctica es vital para crear "imagen de marca", ya que esta repercute en su "valor financiero", declara Patricia Forteza. Asimismo, la comunicación genera más actividad dentro del centro y eso se traduce en una mayor rentabilidad, prosigue esta trabajadora. Además, si se comparan las noticias que aparecen publicadas en los medios de comunicación con lo que se pagaría por ese mismo espacio en formato publicitario, el presupuesto de mantener un departamento de comunicación "se compensa con creces", argumenta la responsable del hospital Quirón. Y encima, como recalca, "esa noticia vale más que cualquier publicidad, es mucho más creíble".

Debido a la globalización de la comunicación y de las nuevas tecnologías, los retos que tienen que afrontar actualmente los responsables de estos gabinetes son muy grandes y se escapan del mundo "físico". Por ejemplo, tienen que estar pendientes continuamente de lo que se escribe en internet acerca de ellos: "Hoy en día el gran enemigo de los médicos y de los hospitales es el «doctor Google». Tú tecleas el nombre de cualquier hospital y te encuentras con opiniones a favor, en contra, cartas al director, foros... te encuentras con todo. Ya no se pregunta al médico de cabecera, sino que se teclea el nombre de un médico en el buscador o incluso se busca «el mejor médico que trata catarro» y te sale o no el hospital", explica Xabier López. Sobre todo en el caso de los centros privados, las reseñas que se realizan en este mundo virtual tienen, como se ha visto, gran importancia. 


\section{Otro servicio para los trabajadores}

"Antes, para que un trabajador consiguiera que su congreso saliera en prensa, tenía que llamar él o hacer un sobreesfuerzo; ahora, solo tiene que decirme: «María, quiero que esto salga en prensa» y yo me ocupo de todo". Así resume María José Iglesias las ventajas de un departamento de comunicación para los trabajadores de un centro hospitalario. También les ayudan en las entrevistas con los medios de comunicación, en la redacción y edición de textos, en el diseño y maquetación e incluso en la organización de eventos.

Además, aparte de facilitar el trabajo a los empleados, la comunicación, sobre todo a través de la imagen de marca, incita a otros profesionales de prestigio a trabajar para ese centro y así potenciar el cuadro médico de la clínica, de acuerdo con Patricia Forteza.

\section{Enlace con los medios de comunicación}

No hay duda de que un departamento de comunicación en un hospital sirve de gran ayuda para los periodistas, y esto puede observarse desde dos puntos de vista diferentes. Por una parte, una de sus funciones es "traducir" a un lenguaje asequible las informaciones que derivan del centro. Por otra parte, incitan a los facultativos a relacionarse con los redactores, enseñándoles qué tienen que transmitir y de qué manera. "Se nota mucho las personas que ya han sido entrevistadas por los medios de comunicación, porque hablan de una manera distinta, van progresando en su lenguaje para adaptarlo al de los periodistas. Incluso cuando hablan con nosotras ves esa adaptación”, explican Ana López Pimentel y Beatriz Senra.

Además, la comunicación hospitalaria comarcalizada, como funciona en Galicia, "te da mucha inmediatez: Lugo atiende Lugo... Ourense lo suyo... Vilagarcía [Pontevedra] lo suyo... Si una llamada de la edición de Faro de Vigo la hacen a Santiago [donde se encuentra la Consellería de Sanidade] en vez de aquí [en la gestión integrada de Pontevedra], seguramente les dirán: "Ya te responderemos...», porque están a mil cosas a la vez”, detalla Raúl Álvarez.

Dado que los periodistas están continuamente demandando información y los gabinetes de comunicación de los hospitales "son muy rápidos y muy ágiles contestando sus peticiones", los redactores "ven el gesto y lo agradecen", insiste Álvaro Otero. El responsable de comunicación de Povisa cree que ese favor "después se les devuelve", ya que se crea "una relación mutua".

No obstante, para que esta dependencia sea fructífera, el miembro del servicio de información debe conocer las rutinas periodísticas antes de comenzar a trabajar en una entidad. Para Xabier López, de hecho, lo ideal es que sea periodista, y se expone como 
ejemplo, al haber tenido que ir en alguna ocasión al antequirófano a hablar por telefonillo con un médico "porque el informativo es a una hora concreta y solo ese facultativo podía hablar del tema". Según sostiene, esto lo hace porque ha sido periodista y conoce las necesidades de los medios.

Debido al conjunto de beneficios mutuos que supone mantener un gabinete de comunicación en el mundo sanitario, la amplia mayoría de los entrevistados asegura que los redactores les aceptan todas o casi todas las noticias que les difunden. Paz Teijeira, por ejemplo, asegura que "a mí me lo publican siempre. Más grande o más pequeño, siempre lo publican". Además, dada la buena relación entre ambas partes, los reporteros contrastan las noticias en el mismo día, por lo que "a la vez que nos están haciendo esa crítica, nosotros estamos contestando, estamos dando nuestra repuesta", comenta Kiko Fernández. La consecuencia positiva es que "consigues un solo impacto negativo, mientras que si la respuesta te la publican el día siguiente, serían dos", resume.

\section{Gabinete de crisis}

Una peculiaridad de la comunicación sanitaria que coinciden en señalar varias personas entrevistadas es la función que ejercen como gabinete de crisis, algo que toma forma más habitualmente en este campo que en otros. "Los medios de comunicación se ceban bastante con todo aquello que pueda tener chicha. Y la sanidad lo tiene", resume Tomás Valín. Un entrevistado de un centro público lo explica de la siguiente manera: "Es un tema muy susceptible. Está en el debate político, y una vez que está en el debate político, se usa como arma arrojadiza porque hay muchos intereses de varios agentes: sindicatos, profesionales..." De hecho, para este trabajador, es el área "más complicada con diferencia" e incluso Myriam Sierra reconoce que hacen "casi tanta comunicación de crisis como comunicación habitual". Por ello, estos empleados consideran necesaria una figura que sirva para "canalizar", según un responsable de comunicación, y para contrastar datos.

Por ejemplo, Kiko Fernández sostiene que algunas noticias falsas del hospital no acaban saliendo a la luz porque los periodistas llaman al gabinete de prensa para que les expliquen la situación. "Tienen un grado de confianza en ti muy alto, que se consigue manteniendo una buena relación, siéndoles útiles y nunca habiéndoles mentido. Entonces se fían de lo que tú les dices, es la versión que prevalece. Te dicen: «No, no, te llamo a ti, lo que tú me digas ya está»", aclara el trabajador del Complejo Hospitalario Universitario A Coruña.

Otros entienden que "las noticias negativas la van a publicar siempre", como inciden Paz Teijeira y Beatriz Senra. Y añade la primera: "En sanidad, una información falsa genera mucha inquietud entre la población, y si no la contestas o no la explicas, ya ni te cuento. Nosotros tenemos que aclarar las cosas a la gente, yo lo considero 
importantísimo, importantísimo". Según dice un entrevistado que no quiere vincularse con la siguiente afirmación, "hay que vender lo positivo, lo que se hace bien como hospital, porque lo malo ya lo dicen otros". Ana López Pimentel, incluso, aporta un ejemplo:

"A un periódico serio de esta región, un domingo por la tarde le llegó una queja, no me acuerdo de qué era, pero una queja grave de un paciente... una mala atención o algo así. Supuestamente, dicen que llamaron a Bety [Beatriz Senra] al teléfono fijo por la tarde. No lo sé, las dos tenemos el móvil conectado, siempre, y en ese periódico todo el mundo tiene nuestros teléfonos. Además, si llaman a la centralita del hospital y preguntan por prensa, el telefonista le pasa con nosotras. Sí que se produjo una llamada a las diez menos cinco de la noche a mi teléfono, que yo no vi, pero a Bety no la llamó nadie. Con todo, al día siguiente tuvieron la osadía de poner «Intentando ponerse en contacto con el gabinete de comunicación no obtuvimos respuesta», y publicaron la información igualmente".

$\mathrm{Y}$ es que aunque "siempre proporcionamos algo a los periodistas a pesar de que no siempre damos una respuesta amplia según asuntos (como negociaciones con sindicatos o proyectos que se están preparando), ellos siempre utilizan esa pequeña información y la publican", tal y como afirma Ana López Pimentel. Además, esta entrevistada cree que "hay muchos periodistas que consideran que su trabajo solo consiste en reflejar las dos versiones; es decir: «Fulano dice tanto... Mengano dice otro tanto». Mi opinión es que la labor periodística también incluye la selección de las informaciones y la valoración de la fiabilidad de las fuentes. En los medios vemos muchas veces como conceden el mismo protagonismo y valor dos fuentes u opiniones distintas. A la pregunta de «ihay cura del cáncer?» ponen en la misma escala de valor, con igual peso, la opinión de Marujita Fernández, que pasaba por ahí, que la del mayor experto que ha estado aquí, y sinceramente a mí eso me parece confuso".

Y es que, según Ana López Pimentel, lo que sí que hacen los periodistas es "reflejar las dos versiones". Dependiendo de dónde surja la noticia, dicen algunos, titulan por una fuente o por otra o explican más extensamente una versión que otra, pero "las contestaciones que damos siempre nos las publican", es decir, los periodistas "siempre publican las dos versiones", destaca Paz Teijeira. Aun con todo, dice Ana López Pimentel, se ha notado un descenso de protestas de pacientes por mala praxis o esperas prolongadas, mientras que las denuncias judiciales son "aún más escasas". 


\subsection{COMUNICACIÓN DESDE DENTRO O MEDIANTE EMPRESA EXTERNA}

Dado que algunos hospitales de la región confían la comunicación en empresas externas, se ha querido estudiar la conveniencia de esta fórmula frente a la de mantener una plaza fija dentro de la plantilla de la entidad. Como era de esperar, los profesionales que pertenecen al personal consideran que el mejor modelo es el que poseen ellos. Por el contrario, la mayoría de los que dependen de una entidad externa replican que tiene sus beneficios y que no es necesario trabajar físicamente dentro de una organización para lograr unos resultados satisfactorios. A pesar de esta tendencia generalista, cada uno de ellos ha proporcionado una serie de razones para comprobar los puntos fuertes y débiles que tienen ambas posibilidades.

Así, María José Iglesias indica que una empresa externa "nunca te va a dar el tú a tú" de un gabinete interno. Además, cree que estando "dentro", los trabajadores del centro "te ven más como alguien de la casa y no como un mero periodista, con la inquietud que eso a veces provoca". Patricia Forteza piensa algo similar: "Lo importante es que tengas confianza con el médico y que te vea como una parte más del hospital [...]: que te cuente, que te vea, que estés en la reuniones... Y para ello es importante estar dentro, no puedes estar fuera". Además, desde el propio gabinete interno, "tienes otra visión diferente de cuáles son las cosas, de cómo se trabaja, de qué es lo que puedes decir y lo que no puedes decir...", incide Patricia Forteza. Es decir, "vives un poquito más el ambiente hospitalario", concreta Antolín Hermida. Y es que "el contacto físico sigue siendo importante. Ponerle cara a la gente, para lo bueno y para lo malo, es importante", según Beatriz Senra.

Pertenecer a la plantilla de un centro de atención especializada y dedicar el tiempo laboral en exclusiva a esa institución permite estar "más especializado", tanto con la clínica como con "la realidad sanitaria", apostilla Paz Teijeira. La labor de esta responsable, por ejemplo, que se extiende a la comunicación sanitaria del hospital y de la provincia, "no lo puede hacer de la misma forma una empresa externa que alguien que es de la casa y que está dentro del sistema". Marta Castro define esta visión en que “estás como más implicado, más centrado, tienes como una visión global”. Reconoce que "hoy en día con un ordenador puedes trabajar", pero matiza que una empresa de comunicación "está en mil cosas". Ella, en su caso, lo ilustra con que "si estás aquí [en el centro, permanentemente] tienes una visión más global de todo y haces una comunicación en conjunto para la Consellería de Sanidade, no sólo para el 061”.

Por otra parte, cuando se pertenece a un departamento propio del hospital, se obtiene más información, mantienen, entre otros, Raúl Álvarez, Ana López Pimentel e Irene Montero; es decir, "te enteras de muchas más cosas", define un responsable de comunicación. Y es que, en palabras de María José Iglesias: "Yo creo que el gabinete de comunicación, que está dentro y que convive de alguna manera con lo bueno y con lo 
malo, con las miserias y con las virtudes de un hospital, cuenta con más información. Y para un gabinete tener más información es fundamental”. En fin, en el centro hospitalario es donde "te enteras de las noticias", sentencia Patricia Forteza.

Xabier López, que colabora en régimen de autónomo en el Vithas Nuestra Señora de Fátima con una estimación de 20 a 25 horas semanales, reconoce que conoce "muchas cosas tarde o de casualidad", algo que no sucedería estando en plantilla a jornada completa, según él. Y aporta el ejemplo del cambio de imagen corporativa, para la cual se tuvo que cambiar las letras de la fachada con la ayuda de una "grúa inmensa":

"Yo me enteré el día anterior de casualidad porque vi al jefe de mantenimiento todo preocupado por reservar los sitios [de aparcamiento] y que nadie los ocupara por la noche [...]. A mí me parecía una foto preciosa, una foto estupenda de una grúa inmensa cambiando unos carteles. Es una foto curiosa. Pedí permiso para avisar a los periodistas y me dijeron que hiciese lo que quisiera, que, total, no iba a venir nadie. Y, sin embargo, fue foto en los tres periódicos de aquí. Vamos a ver, no fue foto de portada, pero es la típica foto noticia, es decir, una imagen distinta. ¿Eso es bueno para el hospital? Malo no es".

Desde el otro lado de la barrera, es decir, desde las empresas externas, se ve diferente. Antolín Hermida aclara que el hecho de trabajar en un centro sanitario no implica necesariamente una estrecha relación con los facultativos: "Cuando tú crees que tienes allí a los médicos, no es verdad: el médico está operando o se toma un café rápido y se va a su consulta privada o a la Seguridad Social (casi todos los médicos tienen un pluriempleo). No es que los pilles ahí todos los días para charlar con ellos".

Álvaro Otero, por su parte, cree que la eficacia no depende "de hacerlo de manera interna o externa, sino de que se haga de forma profesional”. Tomás Valín y Antolín Hermida, además, son de la opinión de que externalizando la comunicación se gana en "objetividad" y en "perspectiva": "Nosotros tenemos una objetividad muy clara y vivimos en el mundo real. Cuando llegamos aquí sabemos lo que cuesta un peine y lo que pide la gente, y no estamos ahí metidos como si fuera una hermandad", interpreta Antolín Hermida. Beatriz Senra, de la gestión integrada de Santiago de Compostela, no está de acuerdo con esta reflexión: "Tú eres periodista, sabes lo que es importante y lo que no. Además, estás en contacto con los periodistas, son ellos con los que hablas por la mañana, lees la prensa todos los días... En fin, te mueves en un entorno periodístico constantemente".

No hay una diferencia demasiado marcada entre dirigir la comunicación interna o externamente, según Tomás Valín, siempre que se mantenga "un contacto permanente y una buena conexión"; sin ello, asegura, "no funcionaría". Para Irene Montero, la clave es "ir tú a buscar, ir tú a proponer, interesarte, hablar con la gente... En fin, tener 
iniciativa". Especula que "a lo mejor si estoy dentro, me enteraría de más cosas, identificaría más cosas... A lo mejor, ¿no? Mm... es posible”, pero reacciona argumentando que "lo que no puedes hacer es quedarte esperando a que te encarguen algo, porque entonces no estás dando el servicio que tienes que dar: tienes que intentar hacer desde fuera lo mismo que haría desde dentro".

\subsection{PÚBLICO VS. PRIVADO}

Dado que la mitad de los centros hospitalarios que cuentan con un departamento de comunicación son privados y la otra mitad públicos, se ha preguntado a los entrevistados las diferencias que existen entre gestionar la comunicación desde una titularidad u otra. De acuerdo con Álvaro Otero, los medios de comunicación son más reacios a los hospitales privados que a los públicos, y eso se puede apreciar en el número de informaciones que publican de cada lado. Según Antolín Hermida, esto es debido a que "la Xunta, como administración en general, siempre va a estar dando un dinero importante a los medios de comunicación para que les publiquen cosas, para que les traten bien, y ahí, en ese paquete, van los hospitales". Patricia Forteza, en cambio, considera que se debe a la plantilla y a la tecnología de la red hospitalaria pública.

Xabier López, por otra parte, opina que en los centros privados "no tienes ningún conflicto político", es decir, "no tienes una campaña electoral que te obliga a ir más rápido o más lento o un político que esté deseando inaugurar lo que sea". En consecuencia, en los hospitales privados se ha de "convencer a la gente para que cuenten las cosas", mientras que en los públicos los jefes de servicio ponen más ímpetu en la comunicación "porque creen que si su servicio sale más en los medios tendrán más presupuesto".

Todo esto lo ilustra Xabier López con un ejemplo. Mientras que en los privados las obras "se anuncian únicamente cuando se terminan y ni siquiera eso cuando se trata de labores para mejorar una deficiencia, porque implica, efectivamente, que ha habido una deficiencia", en la pública "si es para mejorar una deficiencia, mucho mejor". Y lo sostiene argumentando que "has corregido algo que el anterior gobierno no había solventado, sobre todo si es de otro partido". Entonces, finaliza Xabier López, en los centros dependientes de la Xunta "anuncias que lo vas a hacer, que empiezas a hacerlo, que lo estás haciendo y que ya lo has hecho".

De hecho, los centros privados deben "buscar la frecuencia con la que enviamos información para que no se harten de nosotros”, afirma Álvaro Otero. Aunque, también replica: "Tan importante es lo que se dice como lo que no se dice o se cubre poco. A veces es incluso más importante", haciendo referencia a que, en muchas ocasiones, con que un hospital no tenga demasiada prensa negativa, es suficiente. 
Otra peculiaridad que distingue a ambas titularidades es que las instituciones públicas tienen una visión menos marketiniana de la comunicación, de acuerdo con Patricia Forteza. Y es que mientras que estas organizaciones no necesitan ampliar el número de pacientes, los privados sí que requieren aumentar su clientela, explica Ana López Pimentel. Además, como el público objetivo de estos últimos puede ser diferente al de los primeros (porque, sobre todo, intentarán captar a las aseguradoras), continúa esta entrevistada, necesitan otras herramientas de comunicación.

Por la naturaleza misma de los centros públicos, algunos responsables de comunicación también creen que tienen la obligación de dar a conocer más datos que en los privados: "Yo, que trabajo en un centro que depende de la Xunta, no le puedo decir a un periodista que no le doy tal información porque no me da la gana, mientras que en los privados no tendrán esa imposición”, sostiene Beatriz Senra.

Y es que, según Xabier López, los hospitales privados no están tan en la mira de los medios de comunicación: "En la sanidad pública, los principales problemas son las listas de espera. Aquí no hay, solo nos podemos encontrar con errores médicoasistenciales. Sin embargo, aquí no trascienden; no voy a decir que no haya, porque en todos los hospitales hay, sino que aquí no son tan graves o no suponen una reacción inmediata por parte de la oposición política".

\subsection{SISTEMA DE GALICIA VS CASTILLA Y LEÓN}

Ya que Galicia posee una red de gabinetes de comunicación distribuidos por las diferentes provincias mientras que Castilla y León centraliza toda la información en la Consejería de Sanidad, se ha preguntado a los responsables de estos departamentos qué opinan de la estructura de la comunidad opuesta. Un entrevistado, por ejemplo, imagina que la sanidad no tendrá la misma relevancia en Castilla y León que en Galicia, ya que en esta última región "es raro el día que no haya algo de sanidad en los periódicos" y considera que puede ser debido a los sindicatos, "que aquí son muy agresivos con los temas de salud, pero quizás en otras zonas no lo son tanto". En consecuencia, mantiene este empleado, si en el territorio castellano no hay gabinetes de comunicación en cada hospital, los periodistas "se buscarán la vida, porque si solo tienen como fuente a la Consejería, que un día te cogen el teléfono y otro no, te puedes imaginar..."

Todos insisten en que tener un servicio de este tipo en cada clínica frente a centralizar toda la información sanitaria en un único lugar ofrece inmediatez, mejor atención a los periodistas y un mayor volumen de datos emitidos. Con la fórmula que adopta Castilla y León, en cambio, "te pierdes, no puedes informar de todo porque ellos tendrán que anunciar básicamente las labores de la Consejería, de lo que hace el consejero, de los actos a los que va, etc. Y si haces eso, entonces, ¿cómo informas a la 
vez de lo que hacen los hospitales? No sé cómo puede ser posible", se pregunta Paz Teijeira.

Marta Castro añade que si hay una persona ubicada en un hospital "siempre puede generar más noticias, o sea más noticias en positivo, sobre todo acerca de lo que ocurre en el propio centro". También es importante como gabinete de crisis, es decir, para "parar de alguna manera ciertas informaciones negativas o, al menos, para argumentar los hechos porque conoces mejor el funcionamiento del hospital", mantiene la responsable de prensa del 061. 


\subsubsection{RESULTADOS DE LAS ENTREVISTAS A LOS RESPONSABLES DE COMUNICACIÓN DE CASTILLA Y LEÓN}

\subsection{ESTUDIOS Y TRAYECTORA DE LOS COMUNICADORES}

\section{Estudios}

Los responsables de comunicación de los hospitales de Castilla y León no siguen una tendencia común en cuanto a estudios cursados, aunque todos ellos están vinculados con la información. Blanca Saravia, por ejemplo, es licenciada en Periodismo por la Universidad Complutense de Madrid y Pedro Lechuga, licenciado en Ciencias de la Información por la Universidad Pontificia de Salamanca. Meritxell Moya, por su parte, estudió Publicidad y Relaciones Públicas en Segovia en el Colegio Universitario Domingo de Soto, dependiente de la Universidad Complutense de Madrid. Francisco Suárez hizo la licenciatura de Económicas en la Complutense de Madrid y fue en su etapa posgrado cuando se vinculó a la comunicación.

Así, este entrevistado posee un Máster en Comunicación y Publicidad Empresarial por la ESIC, es experto en Protocolo por la Escuela Internacional de Protocolo de Madrid y en Estrategia Empresarial por la Escuela de Negocios CEOE. Meritxell Moya también posee varios títulos de posgrado, más concretamente un Máster en Recursos Humanos por CEREM y es experta Universitaria en Protocolo por la Universidad de Oviedo en colaboración con la Escuela Diplomática de Madrid. Blanca Saravia, en cambio, se decanta por el ámbito investigador y cuenta con el Diploma de Estudios Avanzados en Periodismo.

\section{Trayectoria profesional}

La mayor parte de los responsables de información de los hospitales trabajaron antes de ocupar este cargo en agencias de comunicación. Francisco Suárez, por ejemplo, llevaba diez años trabajando en Madrid en una empresa de este tipo con clientes como Riofisa, el Mercado Central de Carnes, la constructora Ploder, Nokia, etc. Después, se mudó a Valladolid y creó en 2009 la agencia Comunicación Profesional. Desde 2011 colabora con las Hermanas Hospitalarias.

Meritxell Moya comenzó su etapa laboral en una agencia de comunicación especializada en el turismo de reuniones, que poseía, a su vez, una revista llamada Spain Travel \& Business. Posteriormente trabajó en otra empresa de este tipo llamada Blawcel y, desde 2004, se encuentra en León prestando sus servicios en DLV La Central. 
Blanca Saravia comenzó como jefa de comunicación de la Consejería de Sanidad de la Junta de Castilla y León después de las elecciones regionales de 2011. Anteriormente, había trabajado "unos cuatro o cinco años" en prensa y agencias de comunicación compaginándolo con una beca en el departamento de comunicación de la Consejería de Hacienda de la Junta de la misma comunidad.

Después de finalizar sus estudios universitarios, Pedro Lechuga trabajó dos años en la televisión de Mercedes, en Alemania, realizando labores de traducción y doblaje. Después de este tiempo, regresó a León y colaboró con Punto Radio, con Onda Cero y posteriormente con la Fundación Carriegos, una agrupación dedicada a la terapia ecuestre para discapacitados. Dado que su presidente es uno de los dueños de la Clínica San Francisco, desde 2005 comenzó a trabajar en este centro para, desde 2007, estar completamente dedicado a él.

\subsection{UBICACIÓN DENTRO DEL ORGANIGRAMA}

Los departamentos de comunicación de los hospitales privados de Castilla y León, ya provengan estos de una empresa externa o de una persona en plantilla, dependen de la gerencia del centro. En el caso de las clínicas que pertenecen a grupos de comunicación, en algunas ocasiones también consultan a la dirección general (como Francisco Suárez con las Hermanas Hospitalarias) o al departamento de comunicación central (tal y como hace Meritxell Moya con los temas corporativos o nacionales).

En cambio, los hospitales públicos centralizan toda la labor comunicativa en el gabinete de comunicación de la Consejería de Sanidad de la Junta de Castilla y León, cuya responsable es Blanca Saravia. Este departamento depende de la Oficina del Portavoz y Relaciones con los Medios, a su vez dependiente de la Consejería de la Presidencia.

\subsection{DÍA A DÍA}

La cantidad de tiempo que dedican los responsables de comunicación a la actividad informativa de los hospitales depende de su tipo de pertenencia al centro. Las personas que se encuentran trabajando en plantilla a jornada completa dedican las horas estipuladas en su contrato a la clínica, mientras que las empresas externas dividen su tiempo según sus clientes.

Meritxell Moya, de DLV-La Central, no sabe determinar cuánto le ocupa el hospital San Juan de Dios, ya que no tiene "un tiempo estipulado", pero asegura que "todos los días algo seguro. Depende de las acciones que estemos llevando esta semana, este mes..." Las acciones que llevan a cabo no se concretan sobre la marcha, sino que, 
en base a un presupuesto, presentan el plan anual al hospital, en el que se refleja el plan de medios y el resto de actividades. Tal y como indica Meritxell Moya, "vamos actuando en base a ese plan presentado y aprobado, aunque obviamente ese plan es flexible: si en junio surge algo se modifica y se hace".

Francisco Suárez resume su labor comunicativa con las Hermanas Hospitalarias en que "analizamos cómo hemos trabajado, qué se ha reflejado en los medios de comunicación y vemos las siguientes actividades que se van a realizar". "Básicamente dice este entrevistado- lo que hacemos es estudiar los tres hospitales ${ }^{24}$ y en función de eso ver si hay algo que comunicar. Por ejemplo, si dan una conferencia interesante en el hospital, se comunica al resto de la sociedad por si hay alguien que desea acudir. Si hay alguien que viene a visitar los centros, como hizo hace unos años Ana Pastor, la publicamos... [...]. También cuando son los aniversarios o las convivencias sociales, donde se juntan hasta 4.000 personas entre familiares, amigos, proveedores y colaboradores".

El caso de Blanca Saravia es algo más especial. Indica que la información que ellos promueven desde el departamento de comunicación de la Consejería de Sanidad está más vinculada a las labores de este órgano, por lo que los datos concretos de hospitales o actividad hospitalaria se realiza más habitualmente desde la delegación de la Junta de Castilla y León de cada provincia, aunque "depende del funcionamiento de cada uno". En estos casos, dice Blanca Saravia, desde la Consejería "solamente supervisamos". Aun así, insiste en que "intentamos estar en contacto con los hospitales, hablar con ellos, que nos digan si están haciendo algo interesante para intentar moverlo un poco". También trabajan a demanda cuando los periodistas necesitan especialistas o solicitan datos de hospitales o de pacientes heridos.

La mayor parte del tiempo, esta trabajadora la dedica al trato con los periodistas, aunque los cuatro miembros del departamento de comunicación de la Consejería de Sanidad están especializados en determinados temas; ella, por ejemplo, se dedica más a las actividades del titular de este órgano. En su día a día, concreta Blanca Saravia, "lo primero que hago es mirar la agenda del consejero, ver qué actos tiene programados y convocar a la prensa. Si por ejemplo se va a inaugurar un congreso de enfermería en Palencia, también preparo los datos de enfermería en esa provincia, porque nos lo van a preguntar. Entonces, a lo que dedico mucho tiempo es a preparar los actos y luego responder a los medios". No obstante, Blanca Saravia también matiza: "Hay días y días. Igual un día estás más parado y otro coincide que te llaman 25 para 25 temas distintos".

Al trabajar en la Administración, considera que "es mi obligación contestar, sea un sábado o cuando sea", por lo que siempre se encuentra localizable. A pesar de ello,

${ }^{24}$ Las Hermanas Hospitalarias cuentan en Castilla y León con el Complejo Hospitalario San Luis (Palencia), el Centro Hospitalario Benito Menni (Valladolid) y el Centro Asistencial Nuestra Señora de las Mercedes, este último no incluido como centro de atención especializada en el Catálogo Nacional de Hospitales. 
insiste en que los periodistas "suelen respetar [los horarios] y si me llaman [en fin de semana] es porque ha habido algo serio. Normalmente". En la Consejería se halla todas las mañanas y al menos dos tardes (aunque depende de las semanas) $\mathrm{y}$, al margen de esto, en ocasiones, trabaja desde casa.

El caso del responsable de prensa de la Clínica San Francisco también es algo peculiar. Opina que su labor va mucho más allá de la meramente relacionada con la comunicación, ya que aparte de esta tarea se encarga de otras responsabilidades que no tienen que ver con la comunicación y sí con compras de diversos departamentos. Pedro Lechuga no achaca esta situación a falta de trabajo en el área de comunicación, sino que es debido a las necesidades actuales donde en muchas ocasiones la empresa requiere un plus en algunas situaciones para así ser más competitivas.

\subsection{PÚBLICOS}

La mayor parte de los responsables entrevistados dedican casi todos sus esfuerzos a la comunicación externa. Algunos tienen como público principal los periodistas y otros, la población en general alcanzada a través de los medios de comunicación. Es lo que sucede con Francisco Suárez, por ejemplo, que asegura utilizar estas plataformas "para que las ciudades sepan que existen complejos u hospitales o centros sanitarios que hacen una labor muy importante para el resto de la sociedad". También se hace uso de estas empresas "para generar sentimiento de orgullo": "No es lo mismo decir que en Palencia no pasa nunca nada a decir que Palencia tiene los centros de referencia nacional en discapacidad intelectual, que tiene una unidad pionera como son los galgos o la unidad de la rosa o la mayor cocina industrial de Castilla y León”.

Dado que el principal objetivo del hospital San Juan de Dios tras una gran renovación e inversión era "darse en conocer", el público primordial es la población general de León, que es donde se sitúa el centro. Meritxell Moya explica la estrategia comunicativa de la siguiente forma: "Hace tres años y medio se hizo una gran inversión, se renovó, se hizo un edificio nuevo, habitaciones nuevas, quirófanos nuevos... Hubo una gran inversión en infraestructuras. El principal problema con el que nos encontramos es que la gente no conocía todo esto, no sabía todo lo que ofrecía el hospital. Entonces nuestro principal objetivo fue dar a conocer a la población de León todo esto. [...] Es un hospital que siempre ha sido de curas y la imagen que se ha tenido es que allí iban los ancianos a morir. Entonces nuestro objetivo o reto es cambiar eso, informar a la gente de que no es esto, de que hay quirófanos nuevos, habitaciones nuevas... Por ello, nuestro público es la población en general y la gente que tiene seguro privado también".

Ni Francisco Suárez, ni Meritxell Moya ni Blanca Saravia realizan comunicación interna. Según esta última, "es lo que nos falla. Sí que lo hemos intentado, lo hemos 
dicho mil veces, lo que pasa es que es muy difícil, porque Sacyl tiene treinta y tantas mil personas trabajando y es imposible”. La falta de esfuerzos en información hacia los trabajadores lleva incluso a que los propios profesionales no sepan ni que existe un gabinete de comunicación: "Los gerentes nos conocen, pero llamas a un médico y no sabe que existimos. Me pasó a mí el año pasado, que llamé a un director médico y no supo quién era yo. Yo le señalaba que era de prensa de la Consejería, y él me respondía: «¿Pero prensa de qué?» y no me quería responder".

El nexo de unión en algunos casos son los gerentes y los directores médicos. Cuando necesitan algún especialista para dar a conocer alguna noticia o para responder las peticiones de los periodistas, Meritxell Moya o Blanca Saravia, por ejemplo, suelen contactan con alguna de estas dos figuras con el fin de conseguir una fuente para los redactores. Tal y como relata Meritxell Moya, "cuando necesito una persona para una entrevista digo en el hospital que necesito un alergólogo que vaya a la radio, por ejemplo, y lo hacen ellos, me dan directamente el nombre".

Francisco Suárez se escuda en que "la comunicación externa sirve para la motivación del trabajador" y lo explica de la siguiente manera: "No es lo mismo que tú sepas que estás haciendo algo interesante (por ejemplo, la unidad de la Rosa en Palencia, que es pionera en tratamiento de personas con una descompensación aguda en un momento determinado [...]), que te digan los medios de comunicación, que te digan los políticos, que te digan los presciptores médicos: «jJo, lo que estáis haciendo en la unidad de la Rosa!», o « ¿qué terapia más chula estáis haciendo!». Eso te ayuda a sentirte orgulloso de tu trabajo y [...] verse reflejados en un periódico le sirve a todo el mundo de reconocimiento y motivación".

Aunque Pedro Lechuga es el único que realiza comunicación interna, asegura que es "complicado" determinar cuánto tiempo le dedica a esta parte respecto al resto: "Cuando tengo que sacar las revistas estoy $100 \%$ con eso. Cuando estoy con el premio a la mejor app sanitaria, estoy $100 \%$ con eso", incide. Aun así, calcula que "la mitad de la jornada hago temas de comunicación pura y dura, y la otra mitad a temas varios".

\subsection{ACCIONES CON CADA PÚBLICO}

\section{Medios de comunicación}

El principal medio que tienen los hospitales para transmitir novedades a los medios de comunicación son, en general, las notas de prensa. La Clínica San Francisco, por ejemplo, suele despachar una cada tres semanas más o menos, e intentan "no vender humo". Según Pedro Lechuga, "hay que salir, pero no salir por salir", así como no "exagerar las competencias de la clínica diciendo «somos los únicos», «somos los 
pioneros»... cuando no es así". Esto tendría consecuencias negativas tanto en los medios de comunicación, como en los lectores y en los profesionales que trabajan en el centro: "Si los médicos detectan poca profesionalidad o poca seriedad, dicen: «¿Pero dónde estoy metiendo yo mi nombre uniéndolo a la clínica equis, si luego son unos piratas y me están poniendo en los medios de comunicación que somos los únicos que hacemos tal cosa si no es cierto?»"

Meritxell Moya, por su parte, intenta enviar una o dos notas de prensa cada semana, aunque también "en función de las noticias que generan en el hospital". No obstante, no despacha todas a los periodistas, ya que "hay noticias que entendemos que no son susceptibles de enviar a medios [...], por ejemplo, un convenio interno, pero que sí que pueden tener relevancia para el personal, por lo que usamos los canales propios del hospital, como la página web o las redes sociales".

Los entrevistados dejan las ruedas de prensa para novedades muy relevantes, como la inauguración de nuevas unidades. $\mathrm{Y}$ es que, cuando se trata de asuntos de gran relevancia, en general, los hospitales suelen hacer uso de esta herramienta, que tiene el valor añadido de que "sale mejor reflejado en los medios", según Blanca Saravia.

Algunos redactores profundizan las notas de prensa recibidas e indagan más en la información para conseguir noticias más extensas u otro tipo de géneros, como el reportaje. También puede pasar que los responsables de comunicación de los hospitales reserven ciertos temas a algunos contactos: "Alguna vez sí que llamamos a algún periodista en concreto que sabemos que hace estos temas y le informamos de que un hospital va a hacer no sé qué y le preguntamos: «¿Te interesa?», dice Blanca Saravia.

El truco para conseguir que este tipo de vínculos sean fructíferos "es que no sean temas comerciales, que sean temas sociales, porque creo que es lo que interesa más a la sociedad", señala Francisco Suárez. Además, es necesario respetar las exclusivas: "Si me dice un periodista «oye me he enterado de tal», yo no voy a ir a contárselo a otro periódico", al igual que si un redactor le comenta que está interesado en un determinado tema y le pide más datos para más adelante, "tengo que cumplir mi palabra", incide este mismo entrevistado.

Pedro Lechuga, de hecho, en ocasiones elabora reportajes sobre un determinado tema de salud "de la misma manera en que sale en cualquier periódico" y se lo envía a los redactores, sobre todo de prensa escrita y digital. Se trata de textos "como los que conseguirían de cualquier agencia [de noticias] y, según puntualiza, "al final es la mejor publicidad".

\section{Publicidad}

Todos los responsables de comunicación entrevistados aseguran comprar espacios publicitarios para promocionar las clínicas para las que trabajan. Meritxell Moya y 
Pedro Lechuga poseen un presupuesto fijo anual para la publicidad y con él se acuerdan las aportaciones a cada medio. Según destaca la primera entrevistada, la influencia que tiene la publicidad para que publiquen las noticias despachadas "es tan obvio que todo el mundo lo sabe". Eso no implica que se divulguen todas las novedades recibidas, sino que "ayuda a tener una relación más fluida en todos los sentidos": "Entiendo que en igualdad de condiciones, sobre una noticia igualmente importante es posible que el medio diga «pues se lo voy a publicar a este que es un cliente en vez de a este otro que no me ha puesto publicidad en su vida». Esto no quiere decir que porque me pongas publicidad te lo voy a publicar siempre, solo que en igualdad de condiciones yo creo que debería ser así. Es igual que si tienes un bar y te va un cliente todos los días y otro nunca. Al que te va todos los días un día le invitas a una tapa y al otro no. Creo que es una relación comercial normal", opina Meritxell Moya.

Las Hermanas Hospitalarias no cuentan con una cantidad de dinero estipulada, pero "son sensibles y saben que los medios de comunicación necesitan publicidad para mantener unas plantillas", por lo que "en su modesta aportación hacen lo que pueden", resalta Francisco Suárez. Pese a ello, la agencia Comunicación Profesional no gestiona la publicidad, sino que depende directamente de la agrupación religiosa. Algo similar sucede en la Consejería de Sanidad. Tal y como señala Blanca Saravia, la publicidad depende de la dirección de comunicación, que determina la cantidad de dinero que se puede destinar a espacios de pago y, después de este dato, cada consejería decide a qué lo debe destinar. En el caso de la de Sanidad, normalmente se usa para campañas de salud pública, como la información sobre la vacunación de la gripe.

\section{Relaciones públicas}

A pesar de la importancia que algunos entrevistados otorgan a los medios de comunicación, algunos, como Pedro Lechuga, intentan dedicar parte de su tiempo a otras labores porque opina que "el mundo periodístico ha cambiado mucho a todos los niveles. ¿Por qué? Primero, hay menos periodistas. O sea no hay tiempo material para cubrir tantas informaciones. Antes, cuando venían al hospital, les decías «¡venga, quedaos y tomamos un café!»; ahora ya no tienen tiempo ni para tomar un café. Antes organizábamos una rueda de prensa a lo mejor cada mes y medio. [...] Ahora al año haremos dos o tres. ¿Por qué? Porque sé cómo está el tema y es que no tienen tiempo. Primero, hay 20 ruedas de prensa al día. Todo el mundo hace ruedas de prensa, sindicatos, asociaciones, etc., y luego porque ellos tienen que mirar muy mucho a cuál ir por interés periodístico y por interés económico".

Con todo, este entrevistado opina que "hay que buscar canales alternativos" y reflexiona: ¿Qué a veces supone una carga de trabajado añadido? Puede ser, pero, por ejemplo, si hay que dedicar media hora diaria a las redes sociales, pues las dedicas, aunque llegue a un perfil muy específico, pero hay que hacer todo lo posible para llegar 
al mayor número de público potencial y para ello tienes que diversificar los canales de comunicación".

Para Francisco Suárez, la acción más novedosa que proporcionan las Hermanas Hospitalarias es "meter a los periodistas dentro" para que "haya contacto, que se conozcan". Estas labores de relaciones públicas, dice este entrevistado, "es lo más útil hoy en día". Tal y como indica:

"Todos sabemos que en los medios había tres o cuatro personas dedicadas a un tema. Te pongo un ejemplo: inmobiliaria. Tú hablabas en Expansión de inmobiliaria y había cuatro tíos. Ahora hay una persona dedicada a la construcción, a la inmobiliaria, a la tecnología y a no sé qué más. Es imposible que esa persona sepa todo de cuatro temas, con lo cual el trabajo previo lo tenemos que hacer dentro, lo tenemos que hacer en la agencia o lo tenemos que hacer en el centro; tenemos que preparar las noticias y tenemos que sacar los datos que sean interesantes para el periodista. Si tú vas a un periodista, le metes en el hospital y sin que sepa cuál es su historia le empiezas a contar cosas, el periodista decidirá según su visión particular. Sin embargo, si tú, que eres especialista ya, y conoces el centro, la problemática del centro, las problemáticas de las personas que están ahí residiendo y les preparas un extracto de lo que es lo más importe, ese periodista, primero, te va a estar agradecido; segundo, el periodista entenderá mejor lo que pasa y conseguirá transmitir mejor a la sociedad lo que se está haciendo en estos sitios".

En consecuencia, la estrategia que está siguiente el Complejo Hospitalario San Luis es "vente a ver el centro". "Te puedo asegurar que el $80 \%$ de los periodistas que han entrado en estos centros iban con cierto resquemor ante lo se podrían encontrar ahí dentro. Hoy en día, esas personas que han estado allí te dicen: «Sois un gran descubrimiento. Tenía una idea anticuada de lo que eran los centros estos, de lo que se vivía allí»»", asegura Francisco Suárez. Y prosigue: "Hoy en día se da una imagen de un centro abierto. Los redactores no se pueden imaginar que los pacientes o los usuarios puedan salir del hospital así como así. Pensaban que estaban encerrados o cosas así. Son mitos que nadie se había preocupado de desmentir. Y cuando ves que esos usuarios son capaces de por ejemplo hacer talleres de cestería o bordados o de ayudar en las tareas diarias del centro como en la limpieza de la ropa, en la lavandería o en el vivero y con su esfuerzo tener un centro más bonito se llevan otra impresión”.

Las visitas se realizan individualmente acompañadas por una persona de comunicación y con explicaciones de los empleados del Complejo Hospitalario, que 
detallan las peculiaridades de cada unidad. Es una labor que agradecen los periodistas, "porque si no conoces la realidad de un centro es más difícil escribir sobre él", además de servir como "pistas para posibles reportajes". Y es que estos "prefieren tener reportajes propios a informaciones que provengan de notas de prensa". "Esto es más preparar el terreno para que el periodista esté interesado en hacer reportajes especiales, más sensibles. La nota de prensa al fin y al cabo es una nota que se envía a todo el mundo, es más fría, es más distante. Sin embargo, un periodista que visita el centro, que ve a alguna persona que conoce, o que ve que hay gente como tú o como yo que en un momento determinado ha tenido alguna descompensación y que tiene que estar allí, pues lo ve desde un punto de vista más humano, no tan técnico", explica Francisco Suárez.

Además, con estas acciones de relaciones públicas, "los periodistas escriben mejor sobre el centro. No significa que escriban en positivo, sino que escriben de manera más acertada, porque entienden mejor la realidad, utilizan la terminología adecuada, conocen el proyecto y sus calidades... Por ejemplo, no es lo mismo estar diciendo que es un centro de mil personas que es un centro de referencia nacional", apostilla este entrevistado.

El responsable de comunicación de la Clínica San Francisco, por su parte, se dedica, además, a las relaciones institucionales. Tal y como señala, "cuando hay que firmar un convenio con el ayuntamiento de León, por ejemplo. Yo me encargo de coordinarlo, de hablar con los medios, de decidir si va a ir a firmar el presidente o el director médico, etc." Asimismo, se encarga de las visitas a colegios o las charlas que imparten en otros edificios.

\section{Empleados}

Salvo Pedro Lechuga, ningún entrevistado en este estudio realiza ninguna actividad de comunicación dirigida exclusivamente a los empleados. El responsable de comunicación de la Clínica San Francisco se encarga de la Intranet, del buzón de sugerencias, de la página web, de enviar circulares, etc. En el resto de organizaciones, normalmente, estas labores se realizan desde el departamento de Recursos Humanos o desde la propia gerencia del centro.

El único caso en el que una agencia colabora en la comunicación interna es en el hospital San Juan de Dios de León, porque aunque se gestiona desde Recursos Humanos, el diseño de algunos materiales se realiza en DLV-La Central, como el manual del empleado, la guía del paciente, el catálogo de medidas de conciliación de vida familiar y profesional... El diseño de la revista del hospital también se elabora desde esta agencia de comunicación e incluso desde ahí se prepara el contenido de algunas secciones, como la de ocio o la entrevista a un personaje de León. "No es todo 
médico porque entendemos que tiene que ser entretenida para la gente en la zona de espera, para que se pueda leer en casa, etc.”, comenta Meritxell Moya.

\section{Pacientes}

Más tecnológica es la Clínica San Francisco, que cuenta con un canal de televisión propio en las salas de espera en el que emiten contenidos de interés general, así como de salud y ocio. Asimismo, incluyen espacios de otros anunciantes "siempre y cuando lógicamente no sean competencia directa" para sufragar parte de los gastos. Tanto la elaboración de contenidos como la contratación de anunciantes y la edición se realiza desde el propio centro. En ocasiones, se cuenta con vídeos de otras organizaciones (como la Federación Española del Corazón o el Ministerio de Sanidad, Servicios Sociales e Igualdad) y con subtítulos ya que "en las salas de espera, como hay muchísima gente, no se escucha", advierte Pedro Lechuga.

Cuando inauguran una nueva unidad o sección, el departamento de comunicación de la Clínica San Francisco elabora trípticos con información al respecto. También cuentan con la revista trimestral Salud, una publicación gratuita creada en 2005 con una tirada actual de 4.000 ejemplares. En ella, aparecen contenidos relacionados con la salud, pero también de ocio, de personalidades del ámbito político, empresarial, etc. Se distribuye por todas las salas de espera y a diferentes personas suscritas. El diseño se encarga a una empresa externa, pero tanto los contenidos como la publicidad de anunciantes ajenos se gestionan desde el departamento de comunicación. Con los espacios de pago, dice Pedro Lechuga, "intentamos que, dentro de lo que cuesta una revista, cueste lo menos posible". Además, intentan que no sea una revista corporativa: "cuando el lector la tenga entre sus manos, sea dentro de la clínica como fuera, queremos que se acerque más a una revista de las que puedes comprar en un kiosco relacionada con salud que una revista corporativa, porque cuando ves una revista corporativa, no es que dudes, pero sabes que te están vendiendo algo", detalla Pedro Lechuga.

\section{Población}

Aparte de la información o de la publicidad que aparece en los medios de comunicación, las actividades destinadas al conjunto de la población suelen ser jornadas de puertas abiertas o conferencias. En el caso de las Hermanas Hospitalarias, indica Francisco Suárez, "este año nos planteamos el reto de abrirnos todavía más” y están realizando visitas de diferentes colectivos, como asociaciones de vecinos, de autoridades y personalidades, de grupos en general, etc. Lo que no ve "muy indicado" son las excusiones de escolares, puesto que, "aunque deberíamos asumirlo con cierta normalidad, yo creo que la tarea tiene que ser más lenta. Estoy imaginándome llevar a 
un grupo de niños de colegio y puede ser que los padres no lo entiendan, que no les siente muy bien... Además, aunque no hubiese ningún problema de este tipo, los niños se podrían reír de las personas de allí que tienen enfermedades mentales. Yo creo que no sería muy beneficioso en un primer momento. Creo que deberíamos seguir haciendo esa labor con las personas más sensibles y que vaya calando poco a poco en el resto de la sociedad".

Los folletos, "que antes se hacían para todo", ahora son más escasos en la Consejería de Sanidad, dado que "hay que ahorrar en papel y se hacen más cosas virtuales", afirma Blanca Saravia. Aun así, se sigue transmitiendo información sanitaria (sobre todo de salud pública y de prevención) a través de folletos y de carteles colocados en los centros de salud. Es el departamento correspondiente el que suele encargarse de este material, aunque, en ocasiones, el departamento de comunicación participa, resalta esta entrevistada.

El Hospital San Juan de Dios es uno de los centros que realiza las actividades más llamativas, como organizar excursiones de niños en la clínica y realizar con ellos talleres de primeros auxilios, de nutrición... También han convocado un concurso de disfraces para los hijos de los empleados, un programa de radio ("León en la onda") durante un día entero desde las instalaciones del hospital, un simposio para profesionales, etc. Durante la Semana Azul, en la Clínica San Francisco, también se organizan actividades gratuitas dirigidas al público en general, como charlas, concursos, cursos de primeros auxilios, talleres de alimentación...

Una novedosa actividad que realizan en la Clínica San Francisco es conceder unos premios anuales a la mejor app sanitaria en base a dos categorías: el jurado y la votación popular. Los ganadores del primer tipo obtienen 2.000 euros en espacios publicitarios, tanto en la revista como en el canal de televisión, y los de la segunda clase consiguen, aparte de este dinero en publicidad, otro tanto en metálico para poder mejorar la aplicación o crear una nueva, apunta Pedro Lechuga.

Todos ellos utilizan las redes sociales, sobre todo Facebook y Twitter. Blanca Saravia, por ejemplo, suele usarlas para informar acerca de algún acto que se haya celebrado, adjuntando una fotografía y un enlace a la nota de prensa. Además, intenta actualizar la información a menudo y contesta cualquier pregunta que los usuarios puedan hacer por este medio. Las Hermanas Hospitalarias también poseen perfil en las redes sociales, aunque no las gestionan de forma profesional, sino que están haciendo "sus primeros pinitos", tal y como apunta Francisco Suárez. No es el caso del hospital San Juan de Dios de León, que alcanzó en abril de 2014 la cifra de 1.300 “me gustas”.

La Clínica San Francisco también está presente en Google+ y Linkedin, aparte de en las redes sociales mencionadas anteriormente. Son plataformas que intentan "mover bastante, tanto con noticias propias como con noticias de interés de salud". Tal y como especifica Pedro Lechuga, "a lo mejor por cada una nuestra, subimos dos o tres 
generales $[\ldots]$ para que sea interesante para el internauta, no simplemente un medio para anunciar noticias del tipo: «Y ahora os presentamos nuestro profesional, el podólogo tal» o «ahora os presentamos al neurofisiólogo... » No". Asimismo, hacen uso de Youtube para subir los vídeos que realizan para el canal propio de televisión y los dan a conocer a través de las distintas redes sociales.

A pesar de todo, se ha de evitar centrarse demasiado en las redes sociales. Según Pedro Lechuga, "es un poco una burbuja. Sinceramente, si sigues a 4.000 páginas de empresas, creo que mi tweet no lo vas a leer". Explica que tiene herramientas de seguimiento de sus perfiles, pero asegura que "es tirar piedras al mar. A mí no me vale de nada pegarme por tener 10.000 me gustas o 10.000 seguidores. No. Porque tengas 10.000 seguidores no significa nada [...] Nuestra labor es muy difícil de medir. Por ejemplo, un médico, a final de año, sí puede decir que ha aumentado un tanto por ciento el número de sus operaciones o consultas, ¿pero cómo podemos valorar el papel del departamento de comunicación en ese aumento de actividad? Es muy complicado, porque intervienen muchos factores, el trato del médico, de la enfermera, las instalaciones..."

\subsection{PRESUPUESTO}

El departamento de comunicación de la Consejería de Sanidad no tiene un prepuesto asignado para realizar labores de información al margen de los sueldos de los trabajadores. Tal y como señala Blanca Saravia, la publicidad, así como las diferentes campañas, dependen de la dirección de comunicación según valoren su necesidad. No sucede lo mismo en el ámbito privado, ya que todos los entrevistados en este estudio cuentan con una partida para las actividades que realizan a lo largo del año. Algunos, como el San Juan de Dios de León o en el Complejo Hospitalario San Luis y el Benito Menni, otorgan una cantidad fija. En estos dos últimos casos, la agencia Comunicación Profesional cuenta con un fijo mensual; en cambio, en el primero, DLV-La Central desarrolla el plan de comunicación en base al presupuesto anual. Según indica Meritexell Moya, "más o menos es el mismo, pero cada año lo distribuimos de manera diferente. Unos años es más para medios, otros más para acciones..."

En la Clínica San Francisco destinan una cantidad concreta a las inserciones de publicidad y "el resto va por un poco por necesidades". Según destaca Pedro Lechuga, "vamos viendo las necesidades o los temas puntuales de cada momento", aunque asegura tener "mucha libertad, siempre y cuando piense en el ahorro y en que lo poco que se gaste, se ha de gastar muy bien".

Tanto este último entrevistado como Meritxell Moya consideran que con una mayor cantidad de dinero "se podrían hacer muchas más cosas". Según destaca la segunda, "cuanto más tienes, más puedes hacer, no creo que haya nadie en el mundo que te diga 
lo contrario". Ella, por ejemplo, organizaría más actividades, haría más inserciones publicitarias y, sobre todo, se centraría en la imagen corporativa. Opina que, en general, "se invierte menos porque se ve como secundario", a pesar de que "las cosas van evolucionando, la señalética se queda obsoleta, los logos evolucionan y hacer estos cambios supone un gran coste de inversión". Pedro Lechuga se centra en el tema publicitario, incidiendo en que, con un presupuesto limitado, debes elegir entre insertar muchos anuncios o tener una persona de comunicación, una decisión que, con una gran partida, no sería tan radical. "El hospital podría prescindir de mi figura y destinar todo mi suelto a contratar espacios publicitarios en diferentes soportes, o la otra opción es invertir en contar con un responsable de comunicación y que éste rentabilice su sueldo a través de su experiencia y de la coordinación y puesta en marcha de iniciativas positivas para la organización dentro del ámbito de la comunicación”, explica.

Francisco Suárez, por el contrario, opina que la clave no es tener un gran presupuesto, sino rentabilizarlo para "crear una tendencia". Él lo sostiene así: "Yo creo que toda institución debería tener un presupuesto destinado a la comunicación. Ahora bien, ¿para hacer qué? Es como cuando dices «voy a ir al gimnasio una vez» y luego ya no vuelves. Pero si vas al gimnasio, tienes una alimentación equilibrada y no tomas ciertos productos, al cabo de medio año o un año empieza a haber resultados. Esto es lo mismo. Te dicen: «No, una vez vino un periodista e hizo un reportaje», «yo dediqué una mañana un día a hablar con un periodista y me hizo un reportaje». Y les preguntas: « $\mathrm{Y}$ qué pasó?» Y te contestan: «Nada». Pues normal". Y es que "hoy en día, el ciudadano está bombardeado de información por doscientos mil sitios, así que lo que tenemos que hacer es generar una tendencia. Si no, no lo consigues", apostilla.

Blanca Suárez, de hecho, prefiere no contar con un presupuesto adicional, dado que "no nos da tiempo". Opina que "como en todos los trabajos, tienes semanas más relajadas y otras menos: en una se te junta todo y en otras que dices «¿qué pasa que no me llama nadie?» Pero lo de hoy no me llama nadie no suele ser lo normal, y además cuando lo dices, malo".

\subsection{INDEPENCIA, AUTONOMÍA Y PRESIONES}

Todos los entrevistados aseguran tener bastante autonomía a la hora de realizar las labores de comunicación. Francisco Suárez, por ejemplo, comenta que "nos encontramos muy a gusto trabajando con ellas [las Hermanas Hospitalarias]; se fían absolutamente de nuestro criterio y de nuestro asesoramiento, lo cual se agradece". Pedro Lechuga opina que tiene "libertad plena y confianza plena tanto del presidente como del director médico" y que, por ello, confían en las decisiones y en las recomendaciones suyas. 
Meritxell explica que no tiene "presión de ningún tipo", ya que "tengo el plan, a mí me marcan el objetivo, que es dar a conocer el hospital e informar de todo lo que hace, entonces, presiones, no". Además, señala que "las cosas que hacemos de comunicación en ningún momento lo hemos mezclado con política. [...] El hospital igual luego tiene unas conversaciones y negociaciones internas que obviamente desconozco, pero a mí lo que me compete es la comunicación, así que jamás me he visto afectada ni involucrada ni he tenido ningún tipo de información al respecto. Nosotros al fin y al cabo damos a conocer lo que se hace en el hospital".

Blanca Saravia argumenta que las discrepancias que suelen darse en la Consejería de Sanidad son debidas a "diferencias de criterio, no solemos tener problemas con que nos manden y tenemos que publicarlo sí o sí, sino que suelen ser más sugerencias": "A veces sí que tenemos algunas discusiones porque nosotros pensamos que sería bueno sacar una cosa y el director general dice que no porque está habiendo problemas con eso y no es el mejor momento, algo que a lo mejor nosotros en ese momento no sabemos. Y también al revés, puede pasar que un director general te diga «tenemos esto que es muy interesante para contar» y también puedas decir «pues precisamente no porque con la movida que está habiendo estos días es mejor que no hablemos mucho de esto». Pero normalmente, si nosotros proponemos nos suelen decir que bien, si ellos nos proponen a nosotros solemos decir que bien". Sucede lo mismo con los medios que se utilizan para dar a conocer las noticias: "Igual viene un director general y te propone hacer una rueda de prensa para un tema y tú no lo ves tan importante como para convocar a los medios y le dices que quizás mejor una nota de prensa", señala Blanca Saravia.

Francisco Suárez suele consultar con la dirección de las Hermanas Hospitalarias los temas que envía a los medios de comunicación. En sus palabras, "nunca una agencia de comunicación como la nuestra va a contar algo a un periodista que no esté antes autorizado por la gerencia, porque sería un suicidio absoluto. Puede que yo tenga mi idea de comunicación pero a lo mejor el responsable jurídico del centro dice «que no, que no, que estás vulnerando un apartado de la ley de protección de datos» que igual yo no tenía ni idea. Por ello, esto tiene que ser un trabajo de equipo y de coordinación". No obstante, asegura este entrevistado, suelen aprobar el "99\%" de las propuestas que realizan.

\section{Partes médicos}

Las secciones de sucesos de los medios de comunicación se realizan con frecuencia con los partes médicos de diferentes heridos que proporcionan organismos varios. Los hospitales públicos de Castilla y León, bien sea a través de la Consejería de Sanidad o a través de las delegaciones de la Junta en cada provincia, emiten partes médicos de los pacientes que ingresan por diferentes accidentes. Además, no existe una uniformidad, ya que "dependiendo de quién sea el director médico, nos dicen «yo no lo voy a dar porque 
no me parece bien porque esto es historia clínica del paciente», otros te dicen que sí, otros a lo mejor te cuentan más de lo que deben aunque sea a mí..." En consecuencia, Blanca Saravia está "pidiendo que nos den una normativa que refleje hasta dónde se puede dar y hasta dónde no" para "un día dar 20 datos y otro no dar ninguno", aunque, a falta de una norma fija, lo que están haciendo en la actualidad es "decir lo justo para no entrar en conflicto, pero dando la información, porque a veces interesa: no es lo mismo que el herido sea por un cortecito que por arma blanca".

En los hospitales privados, por el contrario, no se facilita ningún dato de los pacientes, ya que, tal y como indica Francisco Suárez, "no se puede dar nada de información", ni tampoco realizar fotografías a los pacientes, "salvo a aquellas personas que tenemos consentimiento expreso y escrito". Según Pedro Lechuga, "los únicos partes médicos que hacemos es cuando hay una autorización plena por parte del paciente, como por ejemplo, cuando operamos a algún deportista de élite, una información que lógicamente es una publicidad indirecta muy positiva para la organización".

En el caso del hospital San Juan de León, dice Meritxell Moya, "no ha habido nunca una persona tan importante como para tener que emitir un parte médico". Se acuerda únicamente de una operación de un tumor cerebral a un paciente procedente de Senegal que llamó la atención y se emitieron algunos datos, algo que, según sostiene, "es lo que más se asemeja" a un parte médico. Salvo esta pequeña excepción, "las notas de prensa que enviamos tratan de informar de las acciones que hay en el hospital, de las nuevas especialidades, de las acciones solidarias, de los convenios que firman con la federación leonesa de rugby..." Además, asegura que nunca se ha topado con periodistas que presionen para conseguir información, algo que comparte Francisco Suárez, que añade que "los medios de comunicación son absolutamente respetuosos".

\subsection{GERENTE}

Los responsables entrevistados coinciden en asegurar que el gerente o directivo que dirige un hospital influye en la labor comunicativa que se realiza, sobre todo según la importancia que le otorga a la comunicación. "Si es una persona propensa a comunicar -argumenta Blanca Saravia- como es mi caso, pues perfecto, porque otros no quieren salir ni para atrás”. El gerente del San Juan de Dios de León, para Meritxell Moya, “es una persona que obviamente cree en la comunicación; si no, no contrataría a una agencia".

Esto influye en que "se puede hablar con él sobre cómo deberíamos hacer las cosas. A veces estás más de acuerdo y otras menos, a veces te dice «tienes razón»o «mira, no, yo creo que es mejor esto otro», lo discutes y le convenzo o no [...] Pero se deja asesorar y yo sí que siento que me hace caso", añade Blanca Sarabia hablando sobre el 
consejero de Sanidad. Además, asegura que trabaja muy ligada a él y prueba de ello es que se reúnen todos los días para tratar los temas pasados y futuros.

\subsection{ERRORES Y MEJORAS}

Los responsables de comunicación no detectan grandes fallos comunes $y$, en general, se encuentran satisfechos con las labores que realizan. Francisco Suárez es de la opinión de que "todos los hospitales en general en España y en el mundo deberían ser más abiertos". Cree que el único error que ha podido haber a lo largo de la historia ha sido "el no hablar, el no comunicar". Por ello "el trabajo que estamos haciendo ahora en las Hermanas [Hospitalarias] está tendiendo a eso, a abrirse cada vez más. Han comprendido que la sociedad también necesita saber qué es lo que se hace allí y también han visto que el periodista agradece que se le expliquen las cosas, y la sociedad también está muy agradecida". En consecuencia, considera que "ahora mismo errores no estamos cometiendo, al menos a día de hoy". Lo mismo cree Meritxell Moya, que aun sosteniendo que "todo es mejorable", mantiene que "estamos yendo poco a poco, pero creo que estamos yendo por el buen camino".

Blanca Saravia, en cambio, sostiene que a la red sanitaria pública le falta comunicación interna. "A veces estamos tan centrados en el día a día, en contestar, en lo que nos piden, en los temas políticos que igual se está haciendo una investigación súper buena y no nos enteramos". Esto lo atribuye a una "falta de comunicación interna", ya que sostiene que si "a mí no me cuentan que en el hospital de Soria un medico está investigando algo interesante, o me entero por casualidad porque vamos un día a Soria, o no me entero. Y a veces al revés, te lo cuentan pero como estás a millones de cosas dices «ya lo miraré», pero luego no lo miras porque no es un tema urgente". En resumidas cuentas, la responsable de comunicación de la Consejería de Sanidad considera que "se hacen muchas cosas que no contamos porque no se le da la suficiente importancia. Yo creo que fallamos en eso".

$\mathrm{Y}$ es que, como opina Pedro Lechuga, es un error reducir la comunicación de un hospital a los medios de comunicación. Según opina, "para mucha gente, si sales en el medio dicen «¡mira qué bueno es mi responsable de comunicación!». ¡Y no! No, porque hay muchos trabajos que se hacen que son igual de importantes que salir en el periódico". Según señala, "la comunicación no es solo enviar una nota de prensa o mandar un faldón de publicidad. Hay mucho más. Y más con los tiempos que corren”.

Entre las mejoras que implantaría este entrevistado es añadir un empleado más a su departamento. "Con esta incorporación no habría cambios importantes en cuanto a nuevos proyectos e iniciativas, pero sí que conseguiríamos una mayor rapidez y efectividad en todas las iniciativas que tenemos puestas en marcha actualmente, lo que se traduciría en una mejora tanto de comunicación interna como externa", señala. 


\subsection{BENEFICIOS DEL DEPARTAMENTO DE COMUNICACIÓN}

Para los responsables de comunicación de los hospitales de Castilla y León, su función es muy importante. Blanca Saravia lo resume con la pregunta "si no estamos nosotros, toda la información, ¿quién la iba a dar?” Según continúa, “es imprescindible. Después se puede discutir si más gente o menos gente, pero alguien yo creo que tiene que haber". De acuerdo con Francisco Suárez, "si tú no haces comunicación solo se va a oír lo malo sobre ti o lo bueno sobre otros". Además de que "por mucho que hagas, si la gente no lo sabe, no sirve de nada", lamenta Meritxell Moya.

Por todo ello, en Castilla y León, los hospitales de las Hermanas Hospitalarias, la Clínica San Francisco, San Juan de Dios de León y la Consejería de Sanidad de la Junta, entre otros, cuentan con departamento de comunicación. En el tercer caso, sirve para "dar a conocer la nueva imagen del hospital, que yo creo que no se sabía" y para "comunicar lo que hacen, estar presentes en los medios y en la sociedad", apuntilla Meritxell Moya. En el caso de la institución pública, se proporciona "respuesta a los medios de comunicación sobre muchos temas que interesan a los ciudadanos (muchas veces, porque otras están al politiqueo)".

\subsection{COMUNICACIÓN DESDE DENTRO O DESDE EMPRESA EXTERNA}

Dado que la mitad de los participantes en el estudio trabajan de manera interna y la otra mitad gestionan la comunicación desde una empresa externa, se les ha preguntado las ventajas e inconvenientes que observan en cada fórmula. Así, las principales ventajas de estar contratado y trabajar dentro de las instalaciones del hospital para la mayoría de los entrevistados es poseer más conocimiento de lo que ocurre y tener un mayor contacto con los trabajadores. Tal y como señala Francisco Suárez, que trabaja en Comunicación Profesional, "la persona contratada sabría muchísimas más cosas que al final yo no acabo de saber porque estoy fuera. Tendría más conocimiento de las acciones que pasan allí”. De hecho, la propia red pública, indica Blanca Saravia, debería tener personas dedicadas a la comunicación en al menos los grandes hospitales para servir de enlace con la Consejería de Sanidad y poder enviar más información sobre la investigación que se realiza en estos centros. De esta manera "contaríamos más cosas de lo que hacemos ahora porque no las sabemos", lamenta esta entrevistada.

En cambio, una empresa externa puede tener una "visión más objetiva": "Alguien que está dentro a veces se deja imbuir por todo lo que pasa allí y no se da cuenta de lo de afuera. Puede que pasen esas cosas, no digo que pasen, pero pueden pasar", comenta Francisco Suárez. Otra ventaja es que permite tener "más mentes pensantes", así como una mayor facilidad para cambiar de empleados dedicados a la comunicación: "Si no estás contento con el trabajo de una persona interna siempre te genera conflictos a la 
hora de despedirla, conflictos internos con el resto del personal, problemas económicos... A nosotros se nos acaba el contrato y se nos acabó; puedes cambiar de agencia más fácilmente si no estás contento con ellos", explica Francisco Suárez. A pesar de ello, la mayor ventaja que ofrece este tipo de contratación para este entrevistado es poder "trasladar experiencias de un ámbito a otro", es decir, adaptar las acciones que han sido exitosas para unos clientes al resto de firmas.

Asimismo, una empresa externa "siempre ofrece muchos más servicios", incide Meritxell Moya, como de publicidad, diseño gráfico, organización de eventos... Aunque "depende de las necesidades del cliente", considera que "es necesario tener una agencia" aunque "siempre está bien que haya una persona interna que coordine toda la comunicación [...], que sepa las necesidades de la empresa, que sepa transmitirlas a la agencia y que sea el nexo de unión entre la empresa y la agencia”.

En cuanto a las relaciones con los periodistas cuando se trabaja de forma interna, Francisco Suárez detalla que "siempre son más amplias, más intensas", aunque incide en que trabajando en una agencia "igual conoces a un periodista por un tema y ese periodista igual también está interesado en el otro". 


\subsubsection{USO DE LAS RELACIONES PÚBLICAS EN LOS DEPARTAMENTOS DE COMUNICACIÓN DE LOS HOSPITALES. RESULTADOS DE LA ENCUESTA}

\subsubsection{CASTILLA Y LEÓN VS. GALICIA}

\subsection{CARACTERÍSTICAS DE LOS DEPARTAMENTOS DE COMUNICACIÓN}

De los 17 responsables entrevistados en este estudio, nueve (52,94\%) pertenecen al ámbito privado y ocho (47,06\%) al público. La mayoría de estos últimos (el 87,5\%) provienen de hospitales gallegos.

Tabla 32. Dependencia de los hospitales donde que cuentan con servicio de comunicación

\begin{tabular}{|l|r|c|r|r|r|r|}
\hline \multirow{2}{*}{ Dependencia } & \multicolumn{2}{|c|}{ Castilla y León } & \multicolumn{2}{c|}{ Galicia } & \multicolumn{2}{c|}{ Total } \\
\cline { 2 - 7 } & \multicolumn{1}{c|}{$\mathbf{N}^{\mathbf{0}}$} & \multicolumn{1}{c|}{$\%$} & \multicolumn{1}{c|}{$\mathbf{N}^{\mathbf{0}}$} & \multicolumn{1}{c|}{$\%$} & \multicolumn{1}{c|}{$\mathbf{N}^{\mathbf{0}}$} & \multicolumn{1}{c|}{$\%$} \\
\hline Público & 1 & 25,00 & 7 & 53,85 & 8 & 47,06 \\
\hline Privado & 3 & 75,00 & 6 & 46,15 & 9 & 52,94 \\
\hline Total & 4 & 100,00 & 13 & 100,00 & 17 & 100,00 \\
\hline
\end{tabular}

Fuente: elaboración propia.

Lo más habitual es que los comunicadores trabajen dentro del hospital; es decir, que pertenezcan a la plantilla del centro. Aun así, existe un porcentaje considerable de personas $(41,18 \%)$ que están contratadas por una empresa externa. Mientras que en Castilla y León la relación es equitativa, en Galicia hay más empleados internos $(61,54 \%)$ que externos $(38,46 \%)$.

Tabla 33. Pertenencia del departamento de comunicación respecto al hospital

\begin{tabular}{|l|r|c|r|c|r|r|}
\hline $\begin{array}{c}\text { Pertenencia del departamento } \\
\text { de comunicación }\end{array}$ & \multicolumn{2}{|c|}{ Castilla y León } & \multicolumn{2}{|c|}{ Galicia } & \multicolumn{2}{c|}{ Total } \\
\cline { 2 - 7 } & $\mathbf{N}^{\mathbf{0}}$ & \multicolumn{1}{c}{$\%$} & \multicolumn{1}{c|}{$\mathbf{N}^{\mathbf{0}}$} & \multicolumn{1}{c|}{$\%$} & $\mathbf{N}^{\mathbf{0}}$ & \multicolumn{1}{c|}{$\%$} \\
\hline $\begin{array}{l}\text { Pertenece a una empresa } \\
\text { externa }\end{array}$ & 2 & 50,00 & 5 & 38,46 & 7 & 41,18 \\
\hline Pertenece al hospital & 2 & 50,00 & 8 & 61,54 & 10 & 58,82 \\
\hline Total & 4 & 100,00 & 13 & 100,00 & 17 & 100,00 \\
\hline
\end{tabular}

Fuente: elaboración propia. 
Lo más normal, tanto en Castilla y León como en Galicia, es que una sola persona se encargue de la comunicación de un hospital o de una zona sanitaria. Aun así, en varias ocasiones se han contabilizado dos (el 25,00\% en la primera región y el 30,77\% en la segunda) e incluso más. En Galicia, por ejemplo, hay tres empleados trabajando para una sola clínica, concretamente en Atlántica Comunicación con Povisa de Vigo e incluso más de diez en Bolanda con La Rosaleda de Santiago de Compostela. Según indica Tomás Valín, la persona entrevistada para el estudio, "todos los miembros de la empresa aportamos algo para el hospital".

Tabla 34. Número de personas que trabajan en los departamentos de comunicación

\begin{tabular}{|c|r|r|r|r|r|r|}
\hline \multirow{2}{*}{$\begin{array}{c}\text { Número de } \\
\text { trabajadores }\end{array}$} & \multicolumn{2}{|c|}{ Castilla y León } & \multicolumn{2}{c|}{ Galicia } & \multicolumn{2}{c|}{ Total } \\
\cline { 2 - 7 } & \multicolumn{1}{c|}{$\mathbf{N}^{\mathbf{0}}$} & \multicolumn{1}{c|}{$\%$} & \multicolumn{1}{c|}{$\mathbf{N}^{\mathbf{0}}$} & \multicolumn{1}{c|}{$\%$} & \multicolumn{1}{c|}{$\mathbf{N}^{\mathbf{0}}$} & \multicolumn{1}{c}{$\%$} \\
\hline 1 & 2 & 50,00 & 7 & 53,85 & 9 & 52,94 \\
\hline 2 & 1 & 25,00 & 4 & 30,77 & 5 & 29,41 \\
\hline 3 & 0 & 0,00 & 1 & 7,69 & 1 & 5,88 \\
\hline 4 & 1 & 25,00 & 0 & 0,00 & 1 & 5,88 \\
\hline Más de 10 & 0 & 0,00 & 1 & 7,69 & 1 & 5,88 \\
\hline Total & 4 & 100,00 & 13 & 100,00 & 17 & 100,00 \\
\hline
\end{tabular}

Fuente: elaboración propia.

Los trabajadores que fueron incluidos en las encuestas de Castilla y León son más jóvenes que los de Galicia. La media que otorgan los de la primera comunidad es de 34,83, mientras que la de la segunda región sube hasta 43,25. El empleado menor en Castilla y León tiene 30 años y el más mayor, 43, mientras que en Galicia, el más joven tiene 37 y el más veterano, 63 .

Tabla 35. Edad de los trabajadores

\begin{tabular}{|l|r|r|r|r|r|}
\hline \multicolumn{1}{|c|}{ Región } & \multicolumn{1}{c|}{$\mathbf{N}^{\mathbf{0}}$} & \multicolumn{1}{c|}{ Mínimo } & \multicolumn{1}{c|}{ Máximo } & \multicolumn{1}{c|}{ Media } & Desv. típ. \\
\hline Castilla y León & 6 & 30 & 43 & 34,83 & 4,58 \\
\hline Galicia & 16 & 37 & 63 & 43,25 & 6,14 \\
\hline
\end{tabular}

Fuente: elaboración propia.

En cuanto al sexo de los trabajadores, en Castilla y León se encuentran muy equilibrados: cuatro son mujeres y los otros cuatro, hombres. En cambio, en Galicia hay una mayor presencia de mujeres. Diez de las 16 que fueron incluidas en las encuestas son mujeres $(62,50 \%)$ y los seis restantes $(37,50 \%)$, varones.

Tabla 36. Sexo de los trabajadores

\begin{tabular}{|l|r|r|r|r|r|r|}
\hline \multirow{2}{*}{ Sexo } & \multicolumn{2}{|c|}{ Castilla y León } & \multicolumn{2}{c|}{ Galicia } & \multicolumn{2}{c|}{ Total } \\
\cline { 2 - 7 } & \multicolumn{1}{c|}{$\mathbf{N}^{\mathbf{0}}$} & \multicolumn{1}{c|}{$\boldsymbol{c}$} & \multicolumn{1}{c|}{$\mathbf{N}^{\mathbf{0}}$} & \multicolumn{1}{c|}{$\%$} & \multicolumn{1}{c|}{$\mathbf{N}^{\mathbf{0}}$} & \multicolumn{1}{c}{$\%$} \\
\hline Hombre & 4 & 50,00 & 6 & 37,50 & 10 & 41,67 \\
\hline Mujer & 4 & 50,00 & 10 & 62,50 & 14 & 58,33 \\
\hline Total & 8 & 100,00 & 16 & 100,00 & 24 & 100,00 \\
\hline
\end{tabular}

Fuente: elaboración propia. 
Dado que los empleados de comunicación son más mayores en Galicia, también cuentan con una mayor experiencia en estas labores. De media, llevan 18 años trabajando en trabajos de información, mientras que en Castilla y León cuentan con 4 menos, más concretamente 14. La persona con una mayor trayectoria en la región castellana posee 20 años de actividad y en la gallega, 23. En cambio, los que llevan menos tiempo en el mundo de la comunicación en Castilla y León contabilizan 9 y en Galicia, 14.

Tabla 37. Años de experiencia en comunicación de los trabajadores

\begin{tabular}{|l|r|r|r|r|r|}
\hline \multicolumn{1}{|c|}{ Región } & \multicolumn{1}{c|}{$\mathbf{N}^{\mathbf{0}}$} & \multicolumn{1}{c|}{ Mínimo } & Máximo & Media & Desv. típ. \\
\hline Castilla y León & 4 & 9 & 20 & 14,00 & 4,69 \\
\hline Galicia & 13 & 14 & 23 & 17,92 & 2,63 \\
\hline
\end{tabular}

Fuente: elaboración propia.

El nivel de estudios más alto que se ha registrado ha sido el diploma de estudios avanzados o similar, conseguido por la responsable de prensa de la Consejería de Sanidad de la Junta de Castilla y León. Otros cuatro (tres en Castilla y León y uno en Galicia) poseen un máster y otro (en la región castellana), un título de especialista universitario. Exceptuando una persona en Galicia que posee una diplomatura en Relaciones Públicas y Publicidad, el resto estudió una licenciatura. Como se puede apreciar en la tabla, los trabajadores en Castilla y León parecen estar más especializados, mientras que en Galicia, la mayor parte cuenta con una licenciatura como estudio reglado más alto.

Tabla 38. Nivel de estudios de los trabajadores

\begin{tabular}{|c|c|c|c|c|c|c|}
\hline \multirow{2}{*}{ Nivel de estudios } & \multicolumn{2}{|c|}{ Castilla y León } & \multicolumn{2}{|c|}{ Galicia } & \multicolumn{2}{|c|}{ Total } \\
\hline & $\mathbf{N}^{\mathbf{0}}$ & $\%$ & $\mathbf{N}^{\mathbf{o}}$ & $\%$ & $\mathbf{N}^{\mathbf{o}}$ & $\%$ \\
\hline Doctorado & 0 & 0,00 & 0 & 0,00 & 0 & 0,00 \\
\hline $\begin{array}{l}\text { Diploma de } \\
\text { estudios avanzados } \\
\text { o tesina }\end{array}$ & 1 & 12,50 & 0 & 0,00 & 1 & 2,94 \\
\hline Máster & 3 & 37,50 & 1 & 3,85 & 4 & 11,76 \\
\hline $\begin{array}{l}\text { Especialista } \\
\text { universitario }\end{array}$ & 1 & 12,50 & 0 & 0,00 & 1 & 2,94 \\
\hline Licenciatura & 3 & 37,50 & 13 & 50,00 & 16 & 47,06 \\
\hline Diplomatura & 0 & 0,00 & 1 & 3,85 & 1 & 2,94 \\
\hline $\mathrm{NS} / \mathrm{NC}$ & 0 & 0,00 & 11 & 42,31 & 11 & 32,35 \\
\hline Total & 8 & 100,00 & 26 & 100,00 & 34 & 100,00 \\
\hline
\end{tabular}

Fuente: elaboración propia.

Lo más habitual en las dos comunidades analizadas es que los empleados de comunicación hayan cursado estudios de Periodismo o de Ciencias de la Información (el $62,50 \%$ en Castilla y León y el $50,00 \%$ en Galicia). Aquellos que estudiaron 
Relaciones Públicas se reducen considerablemente, aunque más en la segunda zona $(25,00 \%$ y $3,85 \%$, en este orden), así como los que acudieron a otras carreras relacionadas con las Ciencias Sociales (3,85\% en Galicia).

Tabla 39. Rama de conocimiento de los trabajadores

\begin{tabular}{|l|r|r|r|r|r|r|}
\hline \multirow{2}{*}{ Rama de conocimiento } & \multicolumn{2}{|c|}{ Castilla y León } & \multicolumn{2}{c|}{ Galicia } & \multicolumn{2}{c|}{ Total } \\
\cline { 2 - 8 } & \multicolumn{1}{c|}{$\mathbf{N}^{\mathbf{0}}$} & \multicolumn{1}{c|}{$\%$} & \multicolumn{1}{c|}{$\mathbf{N}^{\mathbf{0}}$} & \multicolumn{1}{c|}{$\%$} & \multicolumn{1}{c|}{$\mathbf{N}^{\mathbf{0}}$} & \multicolumn{1}{c}{$\%$} \\
\hline Periodismo & 5 & 62,50 & 13 & 50,00 & 18 & 52,94 \\
\hline Relaciones públicas & 2 & 25,00 & 1 & 3,85 & 3 & 8,82 \\
\hline Otros - Ciencias Sociales & 0 & 0,00 & 1 & 3,85 & 1 & 2,94 \\
\hline NS/NC & 1 & 12,50 & 11 & 42,31 & 12 & 35,29 \\
\hline Total & 8 & 100,00 & 26 & 100,00 & 34 & 100,00 \\
\hline
\end{tabular}

Fuente: elaboración propia.

\subsection{USO DE LAS RELACIONES PÚBLICAS}

En el análisis de los modelos de relaciones públicas no se han encontrado diferencias remarcables entre Castilla y León y Galicia. En ambas zonas, el más utilizado es el de información pública. En la primera región arroja un 4,56 sobre 5 y en la segunda, 4,46. La afirmación "entendemos los valores informativos de los periodistas" es la que recibe la puntuación más alta tanto en Castilla y León $(4,75)$ como en Galicia $(4,54)$.

El siguiente modelo más utilizado es el bidireccional simétrico persuasivo, aunque en este caso es algo más recurrente en la región gallega $(3,88)$ que en la castellana $(3,44)$. Las frases "uno de nuestros principales objetivos es mantener una buena relación con los públicos" y "de esa buena relación, pretendemos crear un ambiente en el que se reciban mejor nuestras propuestas o informaciones" son las más valoradas por los responsables de comunicación de los hospitales.

El agente de prensa es el tercer modelo más recurrente. En general, obtiene un 3,38 en Castilla y León y un 3,71 en Galicia. La primera región muestra un valor más alto en la frase "queremos la máxima cobertura en nuestros eventos" (5,00 respecto al 4,38 de Galicia). En cambio, esta última comunidad ofrece unas evaluaciones más elevadas en las ideas "colocamos el nombre de nuestra organización en los medios" $(4,23$ y 3,50$)$ y "convencemos al periodista para que dé a conocer nuestra organización" (3,54 y 2,25). Esta última afirmación, de hecho, resulta ser significativa, tal y como demuestra la prueba $\mathrm{T}$ para muestras independientes $(\mathrm{r}=0,045)$; es decir, existe una relación estadísticamente fiable entre esa aseveración y los responsables de la comunidad gallega.

Los modelos menos empleados son los bidireccionales, sobre todo el asimétrico, que obtiene en Castilla y León una nota de 2,69 sobre 5 y en Galicia, 2,79. Las 
afirmaciones "manipulamos científicamente a los públicos" y "persuadimos al público de que nuestra organización tiene razón sobre un determinado tema" son las que obtienen una puntuación más baja.

En cuanto al simétrico bidireccional, los comunicadores gallegos arrojan un 3,04 sobre 5 y los castellano-leoneses, un 2,94. Con un 3,92 y 4,25, respectivamente, la frase "ayudamos a los dirigentes a entender la opinión de públicos particulares" es la mejor votada y "negociamos con grupos de presión" (con un 2,08 y 2,25, en este orden), la peor.

Tabla 40. Medias de las afirmaciones de los cinco modelos de relaciones públicas estudiados

\begin{tabular}{|c|c|c|}
\hline Modelo & $\begin{array}{l}\text { Castilla } \\
\text { y León }\end{array}$ & Galicia \\
\hline \multicolumn{3}{|l|}{ Agente de prensa } \\
\hline $\begin{array}{l}\text { Convencemos al periodista para que dé a conocer nuestra } \\
\text { organización }\end{array}$ & 2,25 & 3,54 \\
\hline Colocamos el nombre de nuestra organización en los medios & 3,50 & 4,23 \\
\hline Eliminamos la cobertura mediática negativa & 2,75 & 2,69 \\
\hline Queremos la máxima cobertura en nuestros eventos & 5,00 & 4,38 \\
\hline Total & 3,38 & 3,71 \\
\hline \multicolumn{3}{|l|}{ Información pública } \\
\hline Suministramos información objetiva sobre nuestra organización & 4,25 & 4,54 \\
\hline Entendemos los valores informativos de los periodistas & 4,75 & 4,54 \\
\hline Preparamos informaciones para ser usadas por los periodistas & 4,75 & 4,38 \\
\hline Actuamos como un periodista interno de nuestra organización & 4,50 & 4,38 \\
\hline Total & 4,56 & 4,46 \\
\hline \multicolumn{3}{|l|}{ Asimétrico bidireccional } \\
\hline Queremos que los públicos actúen como quiere la organización & 3,25 & 2,85 \\
\hline Aplicamos la teoría de las actitudes en una campaña & 5,00 & 3,85 \\
\hline Manipulamos científicamente a los públicos & 1,00 & 1,62 \\
\hline $\begin{array}{l}\text { Persuadimos al público de que nuestra organización tiene razón } \\
\text { sobre un determinado tema }\end{array}$ & 1,50 & 2,85 \\
\hline Total & 2,69 & 2,79 \\
\hline \multicolumn{3}{|l|}{ Simétrico bidireccional } \\
\hline Determinamos cómo el público reacciona ante la organización & 2,00 & 2,69 \\
\hline Negociamos con grupos de presión & 2,25 & 2,08 \\
\hline $\begin{array}{l}\text { Utilizamos las teorías de la resolución de conflictos en nuestro } \\
\text { trato con los públicos }\end{array}$ & 3,25 & 3,46 \\
\hline $\begin{array}{l}\text { Ayudamos a los dirigentes a entender la opinión de públicos } \\
\text { particulares }\end{array}$ & 4,25 & 3,92 \\
\hline Total & 2,94 & 3,04 \\
\hline \multicolumn{3}{|l|}{ Bidireccional simétrico persuasivo } \\
\hline Uno de nuestros principales objetivos es mantener una buena & 4,25 & 4,38 \\
\hline
\end{tabular}




\begin{tabular}{|l|r|r|}
\hline \multicolumn{1}{|c|}{ Modelo } & $\begin{array}{c}\text { Castilla } \\
\text { y León }\end{array}$ & Galicia \\
\hline relación con los públicos & & \\
\hline $\begin{array}{l}\text { De esa buena relación, pretendemos crear un ambiente en el que } \\
\text { se reciban mejor nuestras propuestas o informaciones }\end{array}$ & 4,00 & 4,54 \\
\hline $\begin{array}{l}\text { Creemos que una buena relación con los públicos, sin un } \\
\text { ejercicio de persuasión, no ayuda a que los públicos se sientan } \\
\text { persuadidos a hacer lo que queremos }\end{array}$ & 2,00 & 2,85 \\
\hline $\begin{array}{l}\text { El objetivo final es conseguir que los públicos acepten y adopten } \\
\text { mejor nuestras propuestas y acciones }\end{array}$ & 3,50 & 3,77 \\
\hline \multicolumn{1}{|c|}{ Total } & $\mathbf{3 , 4 4}$ & $\mathbf{3 , 8 8}$ \\
\hline
\end{tabular}

Fuente: elaboración propia.

Las relaciones personales parecen ser más relevantes en los hospitales de Castilla y León que en los de Galicia. La suma de las valoraciones para determinar el uso del modelo de influencia personal es más alto en la primera región $(3,88)$ que en la segunda $(3,56)$. Aunque en Galicia aseguran tener ligeramente mejores relaciones interpersonales tanto con otros empleados como con las personas externas a la organización, no consideran las relaciones sociales como una de sus actividades más importantes (3,54 respecto al 4,75 de Castilla y León). De hecho, la relación entre Castilla y León y esta afirmación resulta ser significativa, tal y como demuestra la prueba $T$ para muestras independientes $(r=0,010)$. Además, mientras que ningún responsable de comunicación de los hospitales gallegos intenta ganar influencia a través de beneficios como comidas o regalos, en Castilla y León un entrevistado asegura hacerlo con cierta frecuencia.

Tabla 41. Medias de las afirmaciones del modelo de influencia personal

\begin{tabular}{|l|r|r|}
\hline \multicolumn{1}{|c|}{ Modelo de influencia personal } & $\begin{array}{c}\text { Castilla } \\
\text { y León }\end{array}$ & Galicia \\
\hline Tengo buenas relaciones interpersonales con otros empleados & 4,75 & 4,85 \\
\hline $\begin{array}{l}\text { Tengo buenas relaciones interpersonales con las personas } \\
\text { externas de mi organización }\end{array}$ & 4,50 & 4,85 \\
\hline $\begin{array}{l}\text { Las relaciones sociales es una de mis actividades más } \\
\text { importantes }\end{array}$ & 4,75 & 3,54 \\
\hline $\begin{array}{l}\text { Procuro beneficios (comidas, regalos) para ganar influencia con } \\
\text { mis contactos personales }\end{array}$ & 1,50 & 1,00 \\
\hline Total & 3,88 & 3,56 \\
\hline
\end{tabular}

Fuente: elaboración propia.

Los resultados de los roles de relaciones públicas no ofrecen demasiadas diferencias entre ellos mismos. El técnico arroja, de media, un 3,81 sobre 5 y el directivo, un 3,67. Aunque tampoco se han detectado discrepancias muy marcadas entre las comunidades analizadas, las valoraciones de los dos papeles son algo más altas en 
Galicia. Así, esta comunidad arroja un 3,87 en el rol técnico y un 3,77 en el directivo, mientras que Castilla y León ofrece un 3,75 y un 3,56, respectivamente.

Los responsables de comunicación de los hospitales castellano-leoneses le dan una mejor nota a las siguientes ideas: "manejar las respuestas de la organización hacia diferentes asuntos" $(4,50)$, "elaborar publicaciones" $(4,25)$ y "desarrollar estrategias para solucionar problemas de comunicación" $(4,25)$. Los gallegos ofrecen una alta puntuación a dos de estas afirmaciones, e incluyen, en tercer lugar, otra frase propia del rol técnico: "manejar las respuestas de la organización hacia diferentes asuntos" $(4,62)$, "desarrollar estrategias para solucionar problemas de comunicación" $(4,62)$ y "coordinar ruedas de prensa o concertar cobertura mediática para un evento" $(4,46)$. En ambas comunidades, lo que menos se hace es realizar investigación evaluativa ( 2 sobre 5 en Castilla y León y 2,77 en Galicia).

Tabla 42. Medias de las afirmaciones de los dos roles de relaciones públicas estudiados

\begin{tabular}{|c|c|c|}
\hline Rol & $\begin{array}{l}\text { Castilla y } \\
\text { León }\end{array}$ & Galicia \\
\hline \multicolumn{3}{|l|}{ Rol técnico } \\
\hline $\begin{array}{l}\text { Coordinar ruedas de prensa o concertar cobertura mediática para } \\
\text { un evento }\end{array}$ & 3,50 & 4,46 \\
\hline Elaborar publicaciones & 4,25 & 3,85 \\
\hline Crear y dirigir la oficina del portavoz & 4,00 & 3,92 \\
\hline Tomar fotografías y coordinar la fotografía & 3,25 & 3,23 \\
\hline ( & 3,75 & 3,87 \\
\hline \multicolumn{3}{|l|}{ Rol directivo } \\
\hline Dirigir personas & 3,50 & 3,08 \\
\hline Conducir investigación evaluativa & 2,00 & 2,77 \\
\hline $\begin{array}{l}\text { Desarrollar estrategias para solucionar problemas de } \\
\text { comunicación }\end{array}$ & 4,25 & 4,62 \\
\hline $\begin{array}{l}\text { Manejar las respuestas de la organización hacia diferentes } \\
\text { asuntos }\end{array}$ & 4,50 & 4,62 \\
\hline $\begin{array}{ll} & \text { Total }\end{array}$ & 3,56 & 3,77 \\
\hline
\end{tabular}

Fuente: elaboración propia.

Los responsables de comunicación de los centros gallegos suelen planear y participar en planes estratégicos ligeramente más a menudo que los de los hospitales castellano-leoneses, aunque las diferencias son prácticamente mínimas: 3,90 en Castilla y León y 4,03 en Galicia. La mayor discrepancia se ha hallado en que los gallegos tienden a ligar los objetivos de comunicación a los de la organización en general $(4,85$ sobre 5 respecto al 3,50 de Castilla y León). En cambio, en la región castellana se cumplen más habitualmente los objetivos propuestos (4,00 en comparación con el 3,38 que arroja Galicia). Los resultados del resto de ideas no muestran casi ninguna diferencia. 
Tabla 43. Definición y consecución de objetivos concretos y sobre la participación en planes estratégicos

\begin{tabular}{|l|r|r|}
\hline $\begin{array}{c}\text { Objetivos concretos y participación en planes } \\
\text { estratégicos }\end{array}$ & $\begin{array}{r}\text { Castilla } \\
\text { y León }\end{array}$ & Galicia \\
\hline Existe una guía o un plan de comunicación & 4,00 & 4,00 \\
\hline Hay una serie de objetivos concretos definidos & 4,25 & 4,23 \\
\hline $\begin{array}{l}\text { Los objetivos de comunicación están vinculados a } \\
\text { los objetivos del hospital en general }\end{array}$ & 3,50 & 4,85 \\
\hline $\begin{array}{l}\text { Normalmente se cumplen todos los objetivos } \\
\text { propuestos }\end{array}$ & 4,00 & 3,38 \\
\hline $\begin{array}{l}\text { El equipo estratégico de planes suele consultar al } \\
\text { departamento de comunicación }\end{array}$ & 3,75 & 3,69 \\
\hline \multicolumn{1}{|c|}{ Total } & $\mathbf{3 , 9 0}$ & $\mathbf{4 , 0 3}$ \\
\hline
\end{tabular}

Fuente: elaboración propia.

Parece que en Galicia es igual de probable que algún miembro del departamento de comunicación forme parte del equipo estratégico del hospital que no. En cuanto a Castilla y León, no se pueden considerar datos fiables debido al bajo número de respuestas, aunque dos afirman contar con esta figura, mientras que uno no tiene esta posibilidad y un cuarto no tiene conocimiento acerca de ello. Debido a la similitud entre ambas comunidades, no se han encontrado diferencias significativas (estadístico de Fisher $\mathrm{r}=0,554)$.

Tabla 44. Frecuencia y porcentaje de los miembros del departamento de comunicación que forman parte del equipo estratégico

\begin{tabular}{|l|r|c|r|r|r|r|}
\hline \multirow{2}{*}{$\begin{array}{c}\text { Equipo } \\
\text { estratégico }\end{array}$} & \multicolumn{2}{|c|}{ Castilla y León } & \multicolumn{2}{c|}{ Galicia } & \multicolumn{2}{c|}{ Total } \\
\cline { 2 - 7 } & \multicolumn{1}{c|}{$\mathbf{N}^{\mathbf{0}}$} & \multicolumn{1}{c|}{$\boldsymbol{\%}$} & \multicolumn{1}{c|}{$\mathbf{N}^{\mathbf{o}}$} & \multicolumn{1}{c|}{$\%$} & \multicolumn{1}{c|}{$\mathbf{N}^{\mathbf{0}}$} & \multicolumn{1}{c}{$\%$} \\
\hline SÍ & 2 & 50,00 & 6 & 46,15 & 8 & 47,06 \\
\hline No & 1 & 25,00 & 6 & 46,15 & 7 & 41,18 \\
\hline NS/NC & 1 & 25,00 & 1 & 7,69 & 2 & 11,76 \\
\hline Total & 4 & 100,00 & 13 & 100,00 & 17 & 100,00 \\
\hline
\end{tabular}

Fuente: elaboración propia.

En general, los responsables de comunicación de los hospitales de Castilla y León otorgan una nota más alta a la importancia que tienen los diferentes públicos para su departamento que los gallegos, con un 4,33 sobre 5 y un 4,09, respectivamente. En ambos casos, los empleados, los pacientes y los medios de comunicación son los grupos con una mayor relevancia para los entrevistados, aunque en diferente escala según la comunidad. Para los castellano-leoneses, los periodistas son su audiencia más relevante (con un 5 sobre 5), mientras que detrás están los empleados y los pacientes a un mismo 
nivel (4,67 cada uno). En cambio, en Galicia, los empleados son el grupo más destacado $(4,85$ sobre 5$)$, seguido por los pacientes $(4,77)$ y los medios de comunicación $(4,62)$. El colectivo que menos presencia tiene para los encuestados de ambos territorios son los inversores o accionistas en los casos que corresponde, los agentes políticos e institucionales y la población en general.

Tabla 45. Importancia de los diferentes públicos para el departamento de comunicación

\begin{tabular}{|l|r|r|}
\hline \multicolumn{1}{|c|}{ Públicos } & $\begin{array}{c}\text { Castilla } \\
\text { y León }\end{array}$ & Galicia \\
\hline Pacientes & 4,67 & 4,77 \\
\hline Familiares & 4,33 & 4,38 \\
\hline Empleados & 4,67 & 4,85 \\
\hline Agentes políticos e institucionales & 4,33 & 3,62 \\
\hline Inversores o accionistas (en su caso) & 3,00 & 2,30 \\
\hline Medios de comunicación & 5,00 & 4,62 \\
\hline Población en general & 4,33 & 4,08 \\
\hline Total & 4,33 & 4,09 \\
\hline
\end{tabular}

Fuente: elaboración propia.

También son los entrevistados de Castilla y León los que otorgan una mejor nota en general a las diferentes etapas de un programa de relaciones públicas, con una media de 4,38 sobre 5 respecto al 4 de Galicia. Donde más diferencias se detectan es en la investigación y en la evaluación, con casi medio punto más en la región castellana que en la gallega (4,00 y 3,69 y 4,25 y 3,77, en este orden), mientras que la fase que menos discrepancias tiene es la de comunicación con poco más de una décima $(4,75$ y 4,62).

Tabla 46. Importancia que le otorga el departamento de comunicación a las diferentes etapas de un programa de relaciones públicas

\begin{tabular}{|l|r|r|}
\hline $\begin{array}{c}\text { Fases de un programa de } \\
\text { relaciones públicas }\end{array}$ & $\begin{array}{c}\text { Castilla } \\
\text { y León }\end{array}$ & Galicia \\
\hline Investigación & 4,00 & 3,69 \\
\hline Planificación & 4,50 & 4,23 \\
\hline Comunicación & 4,75 & 4,62 \\
\hline Evaluación & 4,25 & 3,77 \\
\hline Total & 4,38 & 4,08 \\
\hline
\end{tabular}

Fuente: elaboración propia.

La herramienta de investigación más común tomando en conjunto las dos comunidades autónomas es el análisis de la cobertura en prensa de la organización. El $100 \%$ de los participantes castellanos y el 92,31\% de los gallegos emplean este método antes de embarcarse en un programa de relaciones públicas. Estos últimos también 
buscan entre los materiales propios de la organización $(92,31 \%)$, aunque los primeros no lo hagan con tanta frecuencia (75\%), al igual que sucede con los tests de mensajes ( $23,08 \%$ y $0,00 \%$, respectivamente) y con las auditorías de comunicación y la búsqueda de bibliografía y estudios ajenos $(53,85 \%$ y $25,00 \%$ en ambos casos). Por el contrario, los castellanos usan con más frecuencia las entrevistas (100\%) que los gallegos $(76,92 \%)$.

Tabla 47. Herramientas de investigación utilizadas por comunidades

\begin{tabular}{|c|c|c|c|c|c|c|}
\hline \multirow{2}{*}{ Herramientas de investigación } & \multicolumn{2}{|c|}{ Castilla y León } & \multicolumn{2}{|c|}{ Galicia } & \multicolumn{2}{|c|}{ Total } \\
\hline & $\mathbf{N}^{\mathbf{0}}$ & $\%$ & $\mathbf{N}^{\mathbf{0}}$ & $\%$ & $\mathbf{N}^{\mathbf{o}}$ & $\%$ \\
\hline $\begin{array}{l}\text { Búsqueda de materiales propios } \\
\text { de la organización }\end{array}$ & 3 & 75,00 & 12 & 92,31 & 15 & 88,24 \\
\hline $\begin{array}{l}\text { Búsqueda de bibliografía } \mathrm{y} \\
\text { estudios ajenos }\end{array}$ & 1 & 25,00 & 7 & 53,85 & 8 & 47,06 \\
\hline $\begin{array}{l}\text { Análisis de la cobertura en } \\
\text { prensa de la organización }\end{array}$ & 4 & 100,00 & 12 & 92,31 & 16 & 94,12 \\
\hline Búsqueda general en Internet & 3 & 75,00 & 10 & 76,92 & 13 & 76,47 \\
\hline Test de mensajes & 0 & 0,00 & 3 & 23,08 & 3 & 17,65 \\
\hline Grupos de discusión & 1 & 25,00 & 2 & 15,38 & 3 & 17,65 \\
\hline Auditoría de comunicación & 1 & 25,00 & 7 & 53,85 & 8 & 47,06 \\
\hline Encuestas & 1 & 25,00 & 5 & 38,46 & 6 & 35,29 \\
\hline Entrevistas & 4 & 100,00 & 10 & 76,92 & 14 & 82,35 \\
\hline Pruebas piloto & 0 & 0,00 & 2 & 15,38 & 2 & 11,76 \\
\hline Mensajes de doble versión & 0 & 0,00 & 1 & 7,69 & 1 & 5,88 \\
\hline Análisis de la percepción & 1 & 25,00 & 4 & 30,77 & 5 & 29,41 \\
\hline Experimentos & 0 & 0,00 & 1 & 7,69 & 1 & 5,88 \\
\hline $\begin{array}{l}\text { Técnicas de reflexión en voz } \\
\text { alta }\end{array}$ & 1 & 25,00 & 4 & 30,77 & 5 & 29,41 \\
\hline Cómputo de respuestas & 20 & - & 80 & - & 100 & - \\
\hline Total respuestas únicas & 4 & - & 13 & - & 17 & - \\
\hline
\end{tabular}

Fuente: elaboración propia.

La diferencia más notable en cuanto a las herramientas de planificación utilizadas lo arrojan los públicos. Este aspecto es tenido en cuenta antes de ejecutar un programa de relaciones públicas en el $92,31 \%$ de los casos en Galicia y en el 50,00\% de los de Castilla y León. También es más frecuente que se especifiquen los presupuestos en la primera región $(46,15 \%)$ que en la segunda $(25,00 \%)$. En cambio, en la comunidad castellana suelen fijarse algo más en las tácticas $(75,00 \%$ y $61,54 \%$, en este orden) y en las técnicas de evaluación $(50,00 \%$ y $38,46 \%)$, aunque las diferencias no son tan acusadas. En el resto de variables analizadas, los resultados son prácticamente idénticos en las dos zonas geográficas. 
Tabla 48. Herramientas de planificación utilizadas por comunidades

\begin{tabular}{|l|r|r|r|r|r|r|}
\hline \multirow{2}{*}{$\begin{array}{c}\text { Herramientas de } \\
\text { planificación }\end{array}$} & \multicolumn{1}{c|}{ Castilla $\mathbf{y}$ León } & \multicolumn{2}{c|}{ Galicia } & \multicolumn{2}{c|}{ Total } \\
\cline { 2 - 7 } & \multicolumn{1}{c|}{$\mathbf{N}^{\mathbf{0}}$} & \multicolumn{1}{c|}{$\%$} & \multicolumn{1}{c|}{$\mathbf{N}^{\mathbf{0}}$} & \multicolumn{1}{c|}{$\%$} & \multicolumn{1}{c|}{$\mathbf{N}^{\mathbf{0}}$} & \multicolumn{1}{c}{$\%$} \\
\hline Situación & 3 & 75,00 & 10 & 76,92 & 13 & 76,47 \\
\hline Objetivos & 4 & 100,00 & 12 & 92,31 & 16 & 94,12 \\
\hline Públicos & 2 & 50,00 & 12 & 92,31 & 14 & 82,35 \\
\hline Estrategias & 4 & 100,00 & 11 & 84,62 & 15 & 88,24 \\
\hline Tácticas & 3 & 75,00 & 8 & 61,54 & 11 & 64,71 \\
\hline Plazos temporales & 3 & 75,00 & 10 & 76,92 & 13 & 76,47 \\
\hline Presupuesto & 1 & 25,00 & 6 & 46,15 & 7 & 41,18 \\
\hline Técnicas de evaluación & 2 & 50,00 & 5 & 38,46 & 7 & 41,18 \\
\hline Cómputo de respuestas & 22 & - & 74 & - & 96 & - \\
\hline Total respuestas únicas & 4 & - & 13 & - & 17 & - \\
\hline
\end{tabular}

Fuente: elaboración propia.

En Galicia se utilizan muchas más herramientas de comunicación destinadas a los empleados que en Castilla y León. Así, por ejemplo, los instrumentos de los que prescinden los comunicadores sanitarios en Castilla y León pero que son empleados, en mayor o menos medida, por los gallegos son los siguientes: los mensajes de la alta dirección $(69,23 \%)$, las entrevistas $(46,15 \%)$, el boletín interno electrónico $(46,15 \%)$, las pantallas de información $(38,46 \%)$, los vídeos $(38,46 \%)$, el correo ordinario $(38,46 \%)$, el buzón de anuncios electrónicos $(38,46 \%)$, el boletín interno impreso $(30,77 \%)$, los cursos para comunicarse con los pacientes y visitas $(30,77 \%)$, los cursos para comunicarse con los medios de comunicación (23,08\%), los blogs $(23,08 \%)$, los SMS (23,08\%), el proyecto de empresa (23,08\%), el periódico (15,38\%), los cursos de formación de profesores $(15,38 \%)$, la formación continua $(15,38 \%)$, las reuniones virtuales $(7,69 \%)$, los foros $(7,69 \%)$, los wikis $(7,69 \%)$ y las videoconferencias $(7,69 \%)$. Los encuestados en Castilla y León únicamente sobresalen a los gallegos en el uso de la página web para comunicarse con los empleados (100,00\% y $61,54 \%$, respectivamente), en las redes sociales $(66,67 \%$ y $46,15 \%$, en este orden) y en el dossier de apariciones en los medios $(66,67 \%$ y $61,54 \%)$.

Se han detectado tres relaciones significativas después de analizar todas las herramientas de comunicación con los empleados. Así, se ha encontrado un vínculo estadísticamente fiable entre los responsables de comunicación de Galicia y el uso de reuniones y seminarios $(r=0,029)$, correo electrónico $(r=0,022)$ y mensajes de la alta dirección $(\mathrm{r}=0,029)$. Para calcular estas relaciones, se ha empleado el estadístico exacto de Fisher, dado que varias casillas tenían una frecuencia esperada inferior a cinco. 
Tabla 49. Herramientas de comunicación utilizadas con los empleados por comunidades

\begin{tabular}{|c|c|c|c|c|c|c|}
\hline \multirow{2}{*}{ Herramientas de comunicación } & \multicolumn{2}{|c|}{ Castilla y León } & \multicolumn{2}{|c|}{ Galicia } & \multicolumn{2}{|c|}{ Total } \\
\hline & $\mathbf{N}^{\mathbf{0}}$ & $\%$ & $\mathbf{N}^{\mathbf{0}}$ & $\%$ & $\mathbf{N}^{\mathbf{o}}$ & $\%$ \\
\hline Página web & 3 & 100,00 & 8 & 61,54 & 11 & 68,75 \\
\hline $\mathrm{B} \log$ & 0 & 0,00 & 3 & 23,08 & 3 & 18,75 \\
\hline Mensajería instantánea & 1 & 33,33 & 6 & 46,15 & 7 & 43,75 \\
\hline Pantallas de información & 0 & 0,00 & 5 & 38,46 & 5 & 31,25 \\
\hline Manual del empleado & 1 & 33,33 & 9 & 69,23 & 10 & 62,50 \\
\hline Círculos de calidad & 0 & 0,00 & 4 & 30,77 & 4 & 25,00 \\
\hline Circulares & 1 & 33,33 & 8 & 61,54 & 9 & 56,25 \\
\hline Boletín interno impreso & 0 & 0,00 & 4 & 30,77 & 4 & 25,00 \\
\hline Reuniones y seminarios & 0 & 0,00 & 9 & 69,23 & 9 & 56,25 \\
\hline $\begin{array}{l}\text { Curso sobre comunicarse con los medios } \\
\text { de comunicación }\end{array}$ & 0 & 0,00 & 3 & 23,08 & 3 & 18,75 \\
\hline Reuniones virtuales & 0 & 0,00 & 1 & 7,69 & 1 & 6,25 \\
\hline Buzón virtual de sugerencias & 1 & 33,33 & 8 & 61,54 & 9 & 56,25 \\
\hline $\begin{array}{l}\text { Cursos para comunicarse con los } \\
\text { pacientes y visitas }\end{array}$ & 0 & 0,00 & 4 & 30,77 & 4 & 25,00 \\
\hline Correo electrónico & 1 & 33,33 & 12 & 92,31 & 13 & 81,25 \\
\hline Foro & 0 & 0,00 & 1 & 7,69 & 1 & 6,25 \\
\hline Wikis & 0 & 0,00 & 1 & 7,69 & 1 & 6,25 \\
\hline SMS & 0 & 0,00 & 3 & 23,08 & 3 & 18,75 \\
\hline Reuniones presenciales & 1 & 33,33 & 8 & 61,54 & 9 & 56,25 \\
\hline Tablón de anuncios & 1 & 33,33 & 9 & 69,23 & 10 & 62,50 \\
\hline Revista & 1 & 33,33 & 2 & 15,38 & 3 & 18,75 \\
\hline Teléfono & 1 & 33,33 & 8 & 61,54 & 9 & 56,25 \\
\hline Mensajes de la alta dirección & 0 & 0,00 & 9 & 69,23 & 9 & 56,25 \\
\hline Proyecto de empresa & 0 & 0,00 & 3 & 23,08 & 3 & 18,75 \\
\hline Boletín interno electrónico & 0 & 0,00 & 6 & 46,15 & 6 & 37,50 \\
\hline Redes sociales & 2 & 66,67 & 6 & 46,15 & 8 & 50,00 \\
\hline Intranet & 1 & 33,33 & 11 & 84,62 & 12 & 75,00 \\
\hline Videoconferencias & 0 & 0,00 & 1 & 7,69 & 1 & 6,25 \\
\hline Vídeos & 0 & 0,00 & 5 & 38,46 & 5 & 31,25 \\
\hline Correo ordinario & 0 & 0,00 & 5 & 38,46 & 5 & 31,25 \\
\hline Dossier de las apariciones en los medios & 2 & 66,67 & 8 & 61,54 & 10 & 62,50 \\
\hline Buzón de sugerencias & 1 & 33,33 & 5 & 38,46 & 6 & 37,50 \\
\hline Periódico & 0 & 0,00 & 2 & 15,38 & 2 & 12,50 \\
\hline Entrevistas & 0 & 0,00 & 6 & 46,15 & 6 & 37,50 \\
\hline Curso de formación de portavoces & 0 & 0,00 & 2 & 15,38 & 2 & 12,50 \\
\hline Formación continua & 0 & 0,00 & 2 & 15,38 & 2 & 12,50 \\
\hline Buzón de anuncios electrónicos & 0 & 0,00 & 5 & 38,46 & 5 & 31,25 \\
\hline Organización de eventos & 1 & 33,33 & 9 & 69,23 & 10 & 62,50 \\
\hline
\end{tabular}

Fuente: elaboración propia. 
Lo mismo ocurre con las herramientas de comunicación utilizadas con los pacientes y las visitas: en Galicia se utilizan bastantes más instrumentos que en Castilla y León. Únicamente en las redes sociales (100,00\% y 46,15\%), en el uso del periódico (33,33\% y $23,08 \%)$, las revistas $(66,67 \%$ y $23,08 \%)$ y el correo postal $(33,33 \%$ y $30,77 \%)$ adelanta la comunidad castellana a la gallega.

Tabla 50. Herramientas de comunicación utilizadas con los pacientes y visitas por comunidades

\begin{tabular}{|c|c|c|c|c|c|c|}
\hline \multirow{2}{*}{$\begin{array}{c}\text { Herramientas de } \\
\text { comunicación }\end{array}$} & \multicolumn{2}{|c|}{ Castilla y León } & \multicolumn{2}{|c|}{ Galicia } & \multicolumn{2}{|c|}{ Total } \\
\hline & $\mathbf{N}^{\mathbf{0}}$ & $\%$ & $\mathrm{~N}^{\mathbf{o}}$ & $\%$ & $\mathbf{N}^{\mathbf{0}}$ & $\%$ \\
\hline Página web & 2 & 66,67 & 11 & 84,62 & 13 & 81,25 \\
\hline Correo postal & 1 & 33,33 & 4 & 30,77 & 5 & 31,25 \\
\hline Hoja de reclamaciones & 1 & 33,33 & 5 & 38,46 & 6 & 37,50 \\
\hline Buzón de sugerencias & 0 & 0,00 & 7 & 53,85 & 7 & 43,75 \\
\hline Correos electrónicos & 1 & 33,33 & 5 & 38,46 & 6 & 37,50 \\
\hline Vídeos & 1 & 33,33 & 4 & 30,77 & 5 & 31,25 \\
\hline Pantallas de información & 1 & 33,33 & 7 & 53,85 & 8 & 50,00 \\
\hline Revista & 2 & 66,67 & 3 & 23,08 & 5 & 31,25 \\
\hline Planos & 0 & 0,00 & 3 & 23,08 & 3 & 18,75 \\
\hline Blogs & 0 & 0,00 & 3 & 23,08 & 3 & 18,75 \\
\hline Número de teléfono gratuitos & 0 & 0,00 & 2 & 15,38 & 2 & 12,50 \\
\hline Foro de discusión & 0 & 0,00 & 2 & 15,38 & 2 & 12,50 \\
\hline Mensajería instantánea & 0 & 0,00 & 2 & 15,38 & 2 & 12,50 \\
\hline SMS & 0 & 0,00 & 4 & 30,77 & 4 & 25,00 \\
\hline Periódico & 1 & 33,33 & 3 & 23,08 & 4 & 25,00 \\
\hline Redes sociales & 3 & 100,00 & 6 & 46,15 & 9 & 56,25 \\
\hline $\begin{array}{l}\text { Números de teléfono de } \\
\text { respuesta automática }\end{array}$ & 0 & 0,00 & 1 & 7,69 & 1 & 6,25 \\
\hline Cómputo de respuestas & 13 & - & 72 & - & 85 & \\
\hline Total respuestas únicas & 3 & - & 13 & - & 16 & - \\
\hline
\end{tabular}

Fuente: elaboración propia.

Todos los comunicadores entrevistados, independientemente de la comunidad, utilizan las notas y las ruedas de prensa para trasladar información a los periodistas. En Galicia, todos ellos también utilizan las llamadas telefónicas, aunque en Castilla y León la cifra de uso es algo más baja $(75,00 \%)$. De hecho, esta última región únicamente sobrepasa a la primera en las salas de prensa virtuales $(25,00 \%$ y $15,38 \%$, respectivamente), en los viajes de prensa $(25,00 \%$ y $7,69 \%)$, en las giras por los medios $(50,00 \%$ y $30,77 \%)$, en la publicidad $(75,00 \%$ y $46,15 \%)$,en las redes sociales $(75,00 \%$ y $38,46 \%)$ y en los cursos de formación de periodistas (25,00\% y 15,38\%). 
Tabla 51. Herramientas de comunicación utilizadas con los periodistas por comunidades

\begin{tabular}{|c|c|c|c|c|c|c|}
\hline \multirow{2}{*}{$\begin{array}{l}\text { Herramientas de } \\
\text { comunicación }\end{array}$} & \multicolumn{2}{|c|}{ Castilla y León } & \multicolumn{2}{|c|}{ Galicia } & \multicolumn{2}{|c|}{ Total } \\
\hline & $\mathbf{N}^{\mathbf{0}}$ & $\%$ & $\mathbf{N}^{\mathbf{0}}$ & $\%$ & $\mathbf{N}^{\mathbf{o}}$ & $\%$ \\
\hline Llamadas telefónicas & 3 & 75,00 & 13 & 100,00 & 16 & 94,12 \\
\hline Dossier de prensa & 2 & 50,00 & 11 & 84,62 & 13 & 76,47 \\
\hline Audio & 1 & 25,00 & 5 & 38,46 & 6 & 35,29 \\
\hline Sala de prensa virtual & 1 & 25,00 & 2 & 15,38 & 3 & 17,65 \\
\hline Viajes de prensa & 1 & 25,00 & 1 & 7,69 & 2 & 11,76 \\
\hline Comidas & 1 & 25,00 & 4 & 30,77 & 5 & 29,41 \\
\hline $\begin{array}{l}\text { Anuncios de servicio } \\
\text { público }\end{array}$ & 0 & 0,00 & 3 & 23,08 & 3 & 17,65 \\
\hline Blogs & 0 & 0,00 & 2 & 15,38 & 2 & 11,76 \\
\hline $\begin{array}{lr}\text { Retransmisión } & \text { de } \\
\text { acontecimientos por internet }\end{array}$ & 0 & 0,00 & 3 & 23,08 & 3 & 17,65 \\
\hline Notas de prensa & 4 & 100,00 & 13 & 100,00 & 17 & 100,00 \\
\hline Fotografías & 3 & 75,00 & 12 & 92,31 & 15 & 88,24 \\
\hline Entrevistas & 2 & 50,00 & 11 & 84,62 & 13 & 76,47 \\
\hline Artículo firmado & 2 & 50,00 & 8 & 61,54 & 10 & 58,82 \\
\hline Giras por los medios & 2 & 50,00 & 4 & 30,77 & 6 & 35,29 \\
\hline Publicidad & 3 & 75,00 & 6 & 46,15 & 9 & 52,94 \\
\hline Redes sociales & 3 & 75,00 & 5 & 38,46 & 8 & 47,06 \\
\hline Emplazamiento de temas & 0 & 0,00 & 4 & 30,77 & 4 & 23,53 \\
\hline Premios de divulgación & 0 & 0,00 & 5 & 38,46 & 5 & 29,41 \\
\hline Ruedas de prensa & 4 & 100,00 & 13 & 100,00 & 17 & 100,00 \\
\hline Vídeos & 1 & 25,00 & 4 & 30,77 & 5 & 29,41 \\
\hline Cartas al director & 1 & 25,00 & 4 & 30,77 & 5 & 29,41 \\
\hline SMS & 1 & 25,00 & 6 & 46,15 & 7 & 41,18 \\
\hline $\begin{array}{l}\text { Emplazamiento de } \\
\text { productos }\end{array}$ & 0 & 0,00 & 1 & 7,69 & 1 & 5,88 \\
\hline $\begin{array}{l}\text { Visitas y "media-tours" a la } \\
\text { organización }\end{array}$ & 0 & 0,00 & 3 & 23,08 & 3 & 17,65 \\
\hline $\begin{array}{l}\text { Cursos de formación de } \\
\text { periodistas }\end{array}$ & 1 & 25,00 & 2 & 15,38 & 3 & 17,65 \\
\hline Cómputo de respuestas & 36 & - & 145 & - & 181 & \\
\hline Total respuestas únicas & 4 & - & 13 & - & 17 & \\
\hline
\end{tabular}

Fuente: elaboración propia.

En lo referente a las herramientas de comunicación con la población en general, aunque sigue habiendo una preponderancia de uso por parte de los comunicadores sanitarios gallegos, la diferencia se recorta respecto a otros públicos. Así, once instrumentos son más frecuentemente usados en Galicia y siete, en Castilla y León. Las mayores diferencias se encuentran en el uso de la página web, que tiene más aceptación 
en la primera región $(76,92 \%)$ que en la segunda $(33,33 \%)$, en las actividades deportivas (38,46\% y $0,00 \%$, en este orden) y en las jornadas de puertas abiertas, en cuyo caso la comunidad castellana $(66,67 \%)$ adelanta a la gallega $(30,77 \%)$.

Tabla 52. Herramientas de comunicación utilizadas con la comunidad por comunidades

\begin{tabular}{|l|r|r|r|r|r|r|}
\hline \multicolumn{1}{|c}{$\begin{array}{c}\text { Herramientas de } \\
\text { comunicación }\end{array}$} & \multicolumn{1}{c|}{ Castilla y León } & \multicolumn{1}{c|}{ Galicia } & \multicolumn{2}{c|}{ Total } \\
\cline { 2 - 8 } & \multicolumn{1}{c|}{$\mathbf{N}^{\mathbf{0}}$} & \multicolumn{1}{c|}{$\mathbf{N}^{\mathbf{0}}$} & \multicolumn{1}{c|}{$\%$} & \multicolumn{1}{c|}{$\mathbf{N}^{\mathbf{0}}$} & \multicolumn{1}{c}{$\%$} \\
\hline Jornada de puertas abiertas & 2 & 66,67 & 4 & 30,77 & 6 & 37,50 \\
\hline Patrocinio & 1 & 33,33 & 4 & 30,77 & 5 & 31,25 \\
\hline Premios, ayudas y becas & 1 & 33,33 & 5 & 38,46 & 6 & 37,50 \\
\hline $\begin{array}{l}\text { Marketing relacionado con } \\
\text { una causa }\end{array}$ & 1 & 33,33 & 3 & 23,08 & 4 & 25,00 \\
\hline Actividad deportiva & 0 & 0,00 & 5 & 38,46 & 5 & 31,25 \\
\hline Folletos & 3 & 100,00 & 11 & 84,62 & 14 & 87,50 \\
\hline $\begin{array}{l}\text { Participación en feria o } \\
\text { salón }\end{array}$ & 0 & 0,00 & 1 & 7,69 & 1 & 6,25 \\
\hline Captación de fondos & 0 & 0,00 & 1 & 7,69 & 1 & 6,25 \\
\hline Contratación social & 0 & 0,00 & 1 & 7,69 & 1 & 6,25 \\
\hline Página web & 1 & 33,33 & 10 & 76,92 & 11 & 68,75 \\
\hline Redes sociales & 2 & 66,67 & 6 & 46,15 & 8 & 50,00 \\
\hline $\begin{array}{l}\text { Número de teléfono } \\
\text { gratuitos }\end{array}$ & 0 & 0,00 & 1 & 7,69 & 1 & 6,25 \\
\hline Mecenazgo & 0 & 0,00 & 1 & 7,69 & 1 & 6,25 \\
\hline Sesión o jornada informativa & 2 & 66,67 & 10 & 76,92 & 12 & 75,00 \\
\hline Fundación-empresa & 1 & 33,33 & 3 & 23,08 & 4 & 25,00 \\
\hline $\begin{array}{l}\text { Evento lúdico (fiesta, } \\
\text { concierto... }\end{array}$ & 1 & 33,33 & 1 & 7,69 & 2 & 12,50 \\
\hline Blog & 0 & 0,00 & 2 & 15,38 & 2 & 12,50 \\
\hline Publicidad & 1 & 33,33 & 7 & 53,85 & 8 & 50,00 \\
\hline Cómputo de respuestas & 16 & - & 76 & - & 92 & - \\
\hline Total respuestas únicas & 3 & - & 13 & - & 16 & - \\
\hline
\end{tabular}

Fuente: elaboración propia.

Las herramientas de evaluación más comunes tanto en Castilla y León como en Galicia son el impacto en los medios (100,00\% y 91,67\%, en este orden), el recuento de los materiales de comunicación producidos $(75,00 \%$ en ambos casos), las visitas en internet $(75,00 \%$ y $58,33 \%)$, y la asistencia a reuniones y acontecimientos por parte de los empleados $(50,00 \%$ y $66,67 \%)$. Donde más diferencias se detectan es en el seguimiento sistemático de actividades comunicativas $(75,00 \%$ y $25,00 \%$ a favor de Galicia) y en la asistencia del público a los actos programados $(50,00 \%$ y 25,00$)$. 
Tabla 53. Herramientas de evaluación utilizadas con la comunidad por comunidades

\begin{tabular}{|c|c|c|c|c|c|c|}
\hline \multirow{2}{*}{$\begin{array}{l}\text { Herramientas de } \\
\text { comunicación }\end{array}$} & \multicolumn{2}{|c|}{ Castilla y León } & \multicolumn{2}{|c|}{ Galicia } & \multicolumn{2}{|c|}{ Total } \\
\hline & $\mathbf{N}^{\mathbf{0}}$ & $\%$ & $\mathbf{N}^{\mathbf{0}}$ & $\%$ & $\mathbf{N}^{\mathbf{0}}$ & $\%$ \\
\hline Impacto en los medios & 4 & 100,00 & 11 & 91,67 & 15 & 93,75 \\
\hline Seguimiento sistemático & 1 & 25,00 & 9 & 75,00 & 10 & 62,50 \\
\hline Asistencia del público & 1 & 25,00 & 6 & 50,00 & 7 & 43,75 \\
\hline $\begin{array}{l}\text { Número de lectores de los } \\
\text { boletines y revistas de } \\
\text { empresa }\end{array}$ & 1 & 25,00 & 3 & 25,00 & 4 & 25,00 \\
\hline Visitas en internet & 3 & 75,00 & 7 & 58,33 & 10 & 62,50 \\
\hline $\begin{array}{l}\text { Solicitudes de información y } \\
\text { números de teléfono } \\
\text { gratuitos }\end{array}$ & 0 & 0,00 & 2 & 16,67 & 2 & 12,50 \\
\hline Auditorías de comunicación & 1 & 25,00 & 5 & 41,67 & 6 & 37,50 \\
\hline $\begin{array}{l}\text { Recuento de los materiales } \\
\text { de comunicación producidos }\end{array}$ & 3 & 75,00 & 9 & 75,00 & 12 & 75,00 \\
\hline Equivalencia publicitaria & 1 & 25,00 & 3 & 25,00 & 4 & 25,00 \\
\hline Coste por persona & 1 & 25,00 & 1 & 8,33 & 2 & 12,50 \\
\hline $\begin{array}{l}\text { Asistencia a reuniones y } \\
\text { acontecimientos }\end{array}$ & 2 & 50,00 & 8 & 66,67 & 10 & 62,50 \\
\hline Cómputo de respuestas & 18 & - & 64 & - & 82 & - \\
\hline Total respuestas únicas & 4 & - & 12 & - & 16 & - \\
\hline
\end{tabular}

Fuente: elaboración propia.

Curiosamente, aunque en la fase de evaluación los hospitales gallegos tenían una nota bastante más baja que los castellano-leoneses, en el conjunto de los tipos de medición, aportan una media más elevada, concretamente 4,33 sobre 5 en relación con el 4,00 que registran los sus homólogos. Las acciones producidas son las que menos se tienen en cuenta en ambas comunidades, aunque la valoración es más baja en Castilla y León $(3,00)$ que en Galicia $(3,92)$. La exposición es la clase que más se estudia en Galicia $(4,62)$, mientras que en Castilla y León se centran más en la opinión y actitud del público y en las acciones y comportamientos (4,50 cada una) que en cualquier otra medición.

Tabla 54. Importancia que le otorga el departamento de comunicación a los diferentes tipos de medición

\begin{tabular}{|l|r|r|}
\hline \multicolumn{1}{|c|}{ Tipos de medición } & $\begin{array}{c}\text { Castilla } \\
\text { y León }\end{array}$ & Galicia \\
\hline Medición de la producción & 3,00 & 3,92 \\
\hline Medición de la exposición & 4,00 & 4,62 \\
\hline Medición de la opinión y actitud del público & 4,50 & 4,46 \\
\hline Medición de las acciones y comportamientos del público & 4,50 & 4,31 \\
\hline Total & 4,00 & 4,33 \\
\hline
\end{tabular}

Fuente: elaboración propia. 
Los hospitales de Galicia poseen más planes de crisis que los de Castilla y León, aunque las diferencias no son estadísticamente significativas. En la primera comunidad, el $61,54 \%$ posee estas indicaciones por escrito, mientras que en la segunda, dos lo tienen, uno no y el cuarto no tiene conocimiento acerca de ello.

Tabla 55. Frecuencia y porcentaje de los departamentos que tienen un plan de crisis

\begin{tabular}{|l|r|r|r|r|r|r|}
\hline \multirow{2}{*}{$\begin{array}{c}\text { Plan de } \\
\text { crisis }\end{array}$} & \multicolumn{2}{|c|}{ Castilla y León } & \multicolumn{2}{c|}{ Galicia } & \multicolumn{2}{c|}{ Total } \\
\cline { 2 - 8 } & \multicolumn{1}{c|}{$\mathbf{N}^{\mathbf{0}}$} & \multicolumn{1}{c}{$\%$} & \multicolumn{1}{c|}{$\mathbf{N}^{\mathbf{0}}$} & \multicolumn{1}{c|}{$\%$} & \multicolumn{1}{c|}{$\mathbf{N}^{\mathbf{0}}$} & \multicolumn{1}{c}{$\%$} \\
\hline Sí & 2 & 50,00 & 8 & 61,54 & 10 & 58,82 \\
\hline No & 1 & 25,00 & 5 & 38,46 & 6 & 35,29 \\
\hline NS/NC & 1 & 25,00 & 0 & 0,00 & 1 & 5,88 \\
\hline Total & 4 & 100,00 & 13 & 100,00 & 17 & 100,00 \\
\hline
\end{tabular}

Fuente: elaboración propia.

Una buena parte de los encuestados no sabe concretar cada cuánto se revisa el plan de crisis (el 33,33\% en Castilla y León y el 37,50\% en Galicia). Un responsable de comunicación de cada zona admite que no se examina nunca y los pocos restantes de entre seis meses a dos años. En cuanto a probar el plan, cuatro entrevistados de las dos comunidades admite que no lo hacen nunca y los dos (uno de cada región) que lo lleva a la práctica lo hace cada dos o tres años.

Tabla 56. Frecuencia con la que se revisa el plan de crisis

\begin{tabular}{|l|r|r|r|r|r|r|}
\hline \multirow{2}{*}{ Revisión del plan de crisis } & \multicolumn{2}{|c|}{ Castilla y León } & \multicolumn{2}{c|}{ Galicia } & \multicolumn{2}{c|}{ Total } \\
\cline { 2 - 7 } & \multicolumn{1}{|c|}{$\mathbf{N}^{\mathbf{0}}$} & \multicolumn{1}{c|}{$\%$} & \multicolumn{1}{c|}{$\mathbf{N}^{\mathbf{0}}$} & \multicolumn{1}{c|}{$\%$} & \multicolumn{1}{c|}{$\mathbf{N}^{\mathbf{0}}$} & \multicolumn{1}{c|}{$\%$} \\
\hline De más de seis meses a un año & 0 & 0,00 & 3 & 37,50 & 3 & 27,27 \\
\hline $\begin{array}{l}\text { De más de un año y medio a } \\
\text { dos años }\end{array}$ & 1 & 33,33 & 1 & 12,50 & 2 & 18,18 \\
\hline Nunca & 1 & 33,33 & 1 & 12,50 & 2 & 18,18 \\
\hline NS/NC & 1 & 33,33 & 3 & 37,50 & 4 & 36,36 \\
\hline Total & 3 & 100,00 & 8 & 100,00 & 11 & 100,00 \\
\hline
\end{tabular}

Fuente: elaboración propia.

Tabla 57. Frecuencia con la que se pone en práctica el plan de crisis

\begin{tabular}{|l|r|r|r|r|r|r|}
\hline \multirow{2}{*}{ Práctica del plan de crisis } & \multicolumn{2}{|c|}{ Castilla y León } & \multicolumn{2}{c|}{ Galicia } & \multicolumn{2}{c|}{ Total } \\
\cline { 2 - 7 } & \multicolumn{1}{|c|}{$\mathbf{N}^{\mathbf{o}}$} & \multicolumn{1}{c|}{$\%$} & \multicolumn{1}{c|}{$\mathbf{N}^{\mathbf{0}}$} & \multicolumn{1}{c|}{$\%$} & \multicolumn{1}{c|}{$\mathbf{N}^{\mathbf{0}}$} & \multicolumn{1}{c|}{$\%$} \\
\hline $\begin{array}{l}\text { De más de dos años a dos años } \\
\text { y medio }\end{array}$ & 0 & 0,00 & 1 & 12,50 & 1 & 9,09 \\
\hline $\begin{array}{l}\text { De más de dos años y medio a } \\
\text { tres años }\end{array}$ & 1 & 33,33 & 0 & 0,00 & 1 & 9,09 \\
\hline Nunca & 1 & 33,33 & 3 & 37,50 & 4 & 36,36 \\
\hline NS/NC & 1 & 33,33 & 4 & 50,00 & 5 & 45,45 \\
\hline Total & 3 & 100,00 & 8 & 100,00 & 11 & 100,00 \\
\hline
\end{tabular}

Fuente: elaboración propia. 
A pesar de ello, la mayor parte de los hospitales tienen fijados un equipo de personas para afrontar las posibles crisis a las que se ven abocados. En el caso de Castilla y León, constituye el 75,00\% y en Galicia, el 69,23\%. Un responsable de cada comunidad no sabe si existe o no este conjunto de trabajadores.

Tabla 58. Departamentos que tienen un equipo prefijado de personas para las posibles crisis

\begin{tabular}{|l|r|r|r|r|r|r|}
\hline \multirow{2}{*}{$\begin{array}{c}\text { Equipo de } \\
\text { crisis }\end{array}$} & \multicolumn{2}{|c|}{ Castilla y León } & \multicolumn{2}{c|}{ Galicia } & \multicolumn{2}{c|}{ Total } \\
\cline { 2 - 7 } & \multicolumn{1}{c|}{$\mathbf{N}^{\mathbf{0}}$} & \multicolumn{1}{c|}{$\%$} & \multicolumn{1}{c|}{$\mathbf{N}^{\mathbf{0}}$} & \multicolumn{1}{c|}{$\%$} & \multicolumn{1}{c|}{$\mathbf{N}^{\mathbf{0}}$} & \multicolumn{1}{c}{$\%$} \\
\hline Sí & 3 & 75,00 & 9 & 69,23 & 12 & 70,59 \\
\hline No & 0 & 0,00 & 3 & 23,08 & 3 & 17,65 \\
\hline NS/NC & 1 & 25,00 & 1 & 7,69 & 2 & 11,76 \\
\hline Total & 4 & 100,00 & 13 & 100,00 & 17 & 100,00 \\
\hline
\end{tabular}

Fuente: elaboración propia.

Los responsables encuestados de Castilla y León otorgan ligeramente más importancia al departamento de comunicación que sus compañeros de Galicia. Sobre una escala de 1 a 5, arrojan un 4,75 respecto al 4,62 de los segundos. Además, están más considerablemente más satisfechos con las labores que llevan a cabo. Mientras que los gallegos no llegan al 4,00 (más concretamente se quedan en 3,77), los castellanoleoneses arrojan un 4,25.

Tabla 59. Importancia y satisfacción con las labores del departamento de comunicación

\begin{tabular}{|l|r|r|}
\hline \multicolumn{1}{|c|}{ Importancia y satisfacción con el departamento } & $\begin{array}{l}\text { Castilla } \\
\text { y León }\end{array}$ & Galicia \\
\hline $\begin{array}{l}\text { ¿Cómo de importante considera al departamento de } \\
\text { relaciones públicas o comunicación para el hospital? }\end{array}$ & 4,75 & 4,62 \\
\hline $\begin{array}{l}\text { ¿Cómo de satisfecho está con las actividades de } \\
\text { relaciones públicas o comunicación que lleva a cabo el } \\
\text { centro? }\end{array}$ & 4,25 & 3,77 \\
\hline
\end{tabular}

Fuente: elaboración propia. 


\subsubsection{PÚBLICOS VS. PRIVADOS}

\subsection{CARACTERÍSTICAS DE LOS DEPARTAMENTOS DE COMUNICACIÓN}

Todos los empleados que dirigen la comunicación de los hospitales públicos trabajan internamente como un trabajador en plantilla. En cambio, las clínicas privadas suelen contratar los servicios de agencias externas. Esto sucede en siete de los nueve casos de esta dependencia (77,78\%), mientras que los dos restantes $(22,22 \%)$ son trabajadores propios del centro.

Tabla 60. Número de trabajadores en plantilla respecto a las agencias externas contratadas por dependencia de los hospitales

\begin{tabular}{|l|r|r|r|r|r|r|}
\hline \multirow{2}{*}{$\begin{array}{c}\text { Pertenencia del } \\
\text { departamento de } \\
\text { comunicación }\end{array}$} & \multicolumn{2}{|c|}{ Público } & \multicolumn{2}{c|}{ Privado } & \multicolumn{2}{c|}{ Total } \\
\cline { 2 - 7 } & \multicolumn{1}{c|}{$\mathbf{N}^{\mathbf{0}}$} & \multicolumn{1}{c|}{$\%$} & \multicolumn{1}{c|}{$\mathbf{N}^{\mathbf{0}}$} & \multicolumn{1}{c|}{$\%$} & \multicolumn{1}{c|}{$\mathbf{N}^{\mathbf{0}}$} & \multicolumn{1}{c|}{$\%$} \\
\hline $\begin{array}{l}\text { Pertenece a una } \\
\text { empresa externa }\end{array}$ & 0 & 0,00 & 7 & 77,78 & 7 & 41,18 \\
\hline Pertenece al hospital & 8 & 100,00 & 2 & 22,22 & 10 & 58,82 \\
\hline Total & 8 & 100,00 & 9 & 100,00 & 17 & 100,00 \\
\hline
\end{tabular}

Fuente: elaboración propia.

Lo más normal, tanto en los centros públicos como en los privados, es que únicamente haya una persona encargada de la comunicación. Esto sucede en el 50,00\% de los públicos y en el 55,56\% de los privados. Aun así, hay ocasiones en las que prestan sus servicios dos personas (37,50\% y 22,22\%, en este orden), tres (11,11\% en los privados), cuatro $(12,50 \%$ en los públicos) e incluso en una agencia externa se ha contabilizado más de diez empleados al servicio de un mismo hospital.

Tabla 61. Número de personas que trabajan en los departamentos de comunicación según dependencia de los hospitales

\begin{tabular}{|c|r|r|r|r|r|r|}
\hline \multirow{2}{*}{$\begin{array}{c}\text { Número de } \\
\text { trabajadores }\end{array}$} & \multicolumn{2}{|c|}{ Público } & \multicolumn{2}{c|}{ Privado } & \multicolumn{2}{c|}{ Total } \\
\cline { 2 - 7 } & \multicolumn{1}{|c|}{$\mathbf{N}^{\mathbf{0}}$} & \multicolumn{1}{c|}{$\%$} & \multicolumn{1}{c|}{$\mathbf{N}^{\mathbf{0}}$} & \multicolumn{1}{c|}{$\%$} & \multicolumn{1}{c|}{$\mathbf{N}^{\mathbf{0}}$} & \multicolumn{1}{c}{$\%$} \\
\hline 1 & 4 & 50,00 & 5 & 55,56 & 9 & 52,94 \\
\hline 2 & 3 & 37,50 & 2 & 22,22 & 5 & 29,41 \\
\hline 3 & 0 & 0,00 & 1 & 11,11 & 1 & 5,88 \\
\hline 4 & 1 & 12,50 & 0 & 0,00 & 1 & 5,88 \\
\hline Más de 10 & 0 & 0,00 & 1 & 11,11 & 1 & 5,88 \\
\hline Total & 8 & 100,00 & 9 & 100,00 & 17 & 100,00 \\
\hline
\end{tabular}

Fuente: elaboración propia. 
La media de edad de los trabajadores de los centros públicos, con 40 años, es prácticamente idéntica a aquellos que prestan sus servicios a hospitales privados, 42. Aun así, en los primeros, por lo general, hay personas más jóvenes, ya que el mínimo y el máximo que se registra es 30 y 47, respectivamente. En los privados, el comunicador más joven tiene 35 y el más mayor, 63 .

Tabla 62. Edad de los trabajadores según la dependencia de los hospitales

\begin{tabular}{|l|r|r|r|r|r|r|}
\hline Dependencia & \multicolumn{1}{|c|}{$\mathbf{N}^{\mathbf{o}}$} & \multicolumn{1}{|c|}{ Mín. } & \multicolumn{1}{c|}{ Máx. } & Media & \multicolumn{1}{|c|}{$\begin{array}{c}\text { Desviación } \\
\text { típ. }\end{array}$} & $\begin{array}{c}\text { Error típ. de } \\
\text { la media }\end{array}$ \\
\hline Público & 12 & 30 & 47 & 40,00 & 5,41 & 1,56 \\
\hline Privado & 10 & 35 & 63 & 42,10 & 8,39 & 2,65 \\
\hline
\end{tabular}

Fuente: elaboración propia.

Mientras que en los centros privados existe una igualdad total en cuanto al sexo de los trabajadores, ya que de los diez que quedan reflejados en las encuestas cinco son hombres y los otros cinco, mujeres, en los hospitales públicos hay una mayor presencia de mujeres. De los 14 empleados registrados en los cuestionarios, nueve $(64,29 \%)$ son mujeres y cinco $(35,71 \%)$, varones.

Tabla 63. Sexo de los trabajadores según la dependencia de los hospitales

\begin{tabular}{|l|r|r|r|r|r|r|}
\hline \multirow{2}{*}{ Sexo } & \multicolumn{2}{|c|}{ Público } & \multicolumn{2}{c|}{ Privado } & \multicolumn{2}{c|}{ Total } \\
\cline { 2 - 7 } & \multicolumn{1}{c|}{$\mathbf{N}^{\mathbf{0}}$} & \multicolumn{1}{c|}{$\%$} & \multicolumn{1}{c|}{$\mathbf{N}^{\mathbf{0}}$} & \multicolumn{1}{c|}{$\%$} & \multicolumn{1}{c|}{$\mathbf{N}^{\mathbf{0}}$} & \multicolumn{1}{c}{$\%$} \\
\hline Hombre & 5 & 35,71 & 5 & 50,00 & 10 & 41,67 \\
\hline Mujer & 9 & 64,29 & 5 & 50,00 & 14 & 58,33 \\
\hline Total & 14 & 100,00 & 10 & 100,00 & 24 & 100,00 \\
\hline
\end{tabular}

Fuente: elaboración propia.

Al igual que sucede con la edad, la experiencia de los trabajadores de los hospitales públicos es similar al de los privados. De media, los primeros tienen casi 18, mientras que los segundos cuentan con 16. La persona que más años lleva empleada en labores de comunicación en el ámbito público posee 21 años (23 en los privados) y la que menos, 14 (9 en los privados).

Tabla 64. Experiencia en comunicación de los trabajadores según la dependencia de los hospitales

\begin{tabular}{|l|r|r|r|r|r|r|}
\hline \multicolumn{1}{|c|}{ Dependencia } & \multicolumn{1}{c|}{$\mathbf{N}^{\mathbf{o}}$} & \multicolumn{1}{c|}{ Mín. } & Máx. & Media & $\begin{array}{c}\text { Desviación } \\
\text { típ. }\end{array}$ & $\begin{array}{c}\text { Error típ. de } \\
\text { la media }\end{array}$ \\
\hline Público & 10 & 14 & 21 & 17,70 & 2,31 & 0,73 \\
\hline Privado & 7 & 9 & 23 & 16,00 & 4,76 & 1,80 \\
\hline
\end{tabular}

Fuente: elaboración propia. 
Parece ser que el nivel de estudios de los comunicadores es más elevado en el terreno privado. El 33,33\% de sus trabajadores cuenta con un máster y un 11,11\% con un título de especialista universitario. El 55,56\% restante posee una licenciatura. En el ámbito público, a pesar de que una empleada tiene el diploma de estudios avanzados o similar, la mayoría ha alcanzado el nivel de licenciatura (en el 78,57\% de los casos). Solo una persona cuenta con un máster y otro trabajador, con una diplomatura.

Tabla 65. Nivel de estudios de los trabajadores según la dependencia del hospital

\begin{tabular}{|l|r|r|r|r|r|r|}
\hline \multirow{2}{*}{ Nivel de estudios } & \multicolumn{2}{c|}{ Público } & \multicolumn{2}{c|}{ Privado } & \multicolumn{2}{c|}{ Total } \\
\cline { 2 - 7 } & \multicolumn{1}{c|}{$\mathbf{N}^{\mathbf{o}}$} & \multicolumn{1}{c}{$\boldsymbol{\%}$} & \multicolumn{1}{c|}{$\mathbf{N}^{\mathbf{0}}$} & \multicolumn{1}{c|}{$\%$} & \multicolumn{1}{c|}{$\mathbf{N}^{\mathbf{o}}$} & \multicolumn{1}{c|}{$\%$} \\
\hline Doctorado & 0 & 0,00 & 0 & 0,00 & 0 & 0 \\
\hline $\begin{array}{l}\text { Diploma de estudios } \\
\text { avanzados }\end{array}$ & 1 & 7,14 & 0 & 0,00 & 1 & 4,35 \\
\hline Máster & 1 & 7,14 & 3 & 33,33 & 4 & 17,39 \\
\hline Especialista universitario & 0 & 0,00 & 1 & 11,11 & 1 & 4,35 \\
\hline Licenciatura & 11 & 78,57 & 5 & 55,56 & 16 & 69,57 \\
\hline Diplomatura & 1 & 7,14 & 0 & 0,00 & 1 & 4,55 \\
\hline Total & 14 & 100,00 & 9 & 100,00 & 23 & 100,00 \\
\hline
\end{tabular}

Fuente: elaboración propia.

En el terreno público hay una mayor especialización en Periodismo o en Ciencias de la Información $(92,86 \%)$ que en el privado $(62,50 \%)$. Y es que en la comunicación de las clínicas privadas también se realiza con personas con formación en Relaciones Públicas $(25,00 \%)$ y en otros ámbitos de las Ciencias Sociales $(12,50 \%)$. En cambio, solo uno de los 14 individuos del terreno público reflejados en este apartado posee otra titulación que no sea Periodismo o Ciencias de la Información, más concretamente Relaciones Públicas.

Tabla 66. Rama de conocimiento de los trabajadores según la dependencia de los hospitales

\begin{tabular}{|l|r|r|r|r|r|r|}
\hline \multirow{2}{*}{$\begin{array}{c}\text { Rama de } \\
\text { conocimiento }\end{array}$} & \multicolumn{2}{|c|}{ Público } & \multicolumn{2}{c|}{ Privado } & \multicolumn{2}{c|}{ Total } \\
\cline { 2 - 8 } & \multicolumn{1}{c|}{$\mathbf{N}^{\mathbf{0}}$} & \multicolumn{1}{c|}{$\%$} & \multicolumn{1}{c|}{$\mathbf{N}^{\mathbf{0}}$} & \multicolumn{1}{c|}{$\%$} & \multicolumn{1}{c|}{$\mathbf{N}^{\mathbf{0}}$} & \multicolumn{1}{c}{$\%$} \\
\hline Periodismo & 13 & 92,86 & 5 & 62,50 & 18 & 81,82 \\
\hline Relaciones públicas & 1 & 7,14 & 2 & 25,00 & 3 & 13,64 \\
\hline $\begin{array}{l}\text { Otros - Ciencias } \\
\text { Sociales }\end{array}$ & 0 & 0,00 & 1 & 12,50 & 1 & 4,55 \\
\hline Total & 14 & 100,00 & 8 & 100,00 & 22 & 100,00 \\
\hline
\end{tabular}

Fuente: elaboración propia. 


\subsection{USO DE LAS RELACIONES PÚBLICAS}

El modelo con el que se identifican en mayor medida los departamentos de comunicación analizados, tanto públicos como privados, aunque de manera más acusada en el segundo caso, es el de información pública. En una escala de 1 a 5, los privados arrojan un 4,67, mientras que los públicos lo hacen en un 4,28. La frase más votada por los primeros es "entendemos los valores informativos de los periodistas" $(4,89)$, mientras que por los segundos es "preparamos informaciones para ser usadas por los periodistas" $(4,50)$.

En el segundo modelo más empleado ya se encuentran diferencias dependiendo de la titularidad del hospital. Por ejemplo, los públicos otorgan una cifra mayor al de agente de prensa $(3,81)$ que al bidireccional simétrico persuasivo $(3,72)$, mientras que los privados, precisamente, invierten la balanza: 3,83 para el bidireccional simétrico persuasivo y 3,47 para el agente de prensa. Los públicos, por ejemplo, están más preocupados por dar a conocer la organización (3,63 respecto al 2,89 de los privados) y a colocar el nombre del hospital en los medios (4,38 frente a 3,78), al mismo tiempo que los privados otorgan un poco más de importancia a mantener buenas relaciones con los públicos (4,44 frente al 4,25 de los públicos) y a crear un ambiente en el que se reciban mejor sus propuestas o informaciones (4,56 y 4,25, respectivamente).

El modelo simétrico bidireccional es el tercero menos usado en ambos casos; obtiene un 2,97 sobre 5,00 en los públicos y un 3,06 en los privados. Aunque ninguno de ellos suele negociar con grupos de presión (2,25 y 2,00, en este orden) ni determinan cómo el público reacciona ante la organización $(2,50$ y 3,56), sí que ayudan con cierta frecuencia a los dirigentes a entender la opinión de públicos particulares $(3,88$ y 4,11).

Finalmente, el modelo menos empleado es el asimétrico bidireccional, ya que registra sobre una escala de 1 a 5 un 2,66 en los públicos y un 2,86 en los privados. Las diferencias más marcadas se encuentran en la afirmación "queremos que los públicos actúen cómo quiere la organización", que arroja un 2,50 en el primer caso y un 3,33 en el segundo. En el resto de ideas no hay discrepancias demasiado marcadas. 
Tabla 67. Medias de las afirmaciones de los cinco modelos de relaciones públicas estudiados

\begin{tabular}{|c|c|c|}
\hline Modelo & Público & Privado \\
\hline \multicolumn{3}{|l|}{ Agente de prensa } \\
\hline $\begin{array}{l}\text { Convencemos al periodista para que dé a conocer nuestra } \\
\text { organización }\end{array}$ & 3,63 & 2,89 \\
\hline Colocamos el nombre de nuestra organización en los medios & 4,38 & 3,78 \\
\hline Eliminamos la cobertura mediática negativa & 2,88 & 2,56 \\
\hline Queremos la máxima cobertura en nuestros eventos & 4,38 & 4,67 \\
\hline Total & 3,81 & 3,47 \\
\hline \multicolumn{3}{|l|}{ Información pública } \\
\hline $\begin{array}{l}\begin{array}{l}\text { Suministramos información } \\
\text { organización }\end{array} \\
\end{array}$ & 4,25 & 4,67 \\
\hline Entendemos los valores informativos de los periodistas & 4,25 & 4,89 \\
\hline Preparamos informaciones para ser usadas por los periodistas & 4,50 & 4,44 \\
\hline Actuamos como un periodista interno de nuestra organización & 4,13 & 4,67 \\
\hline Total & 4,28 & 4,67 \\
\hline \multicolumn{3}{|l|}{ Asimétrico bidireccional } \\
\hline Queremos que los públicos actúen como quiere la organización & 2,50 & 3,33 \\
\hline Aplicamos la teoría de las actitudes en una campaña & 4,00 & 4,22 \\
\hline Manipulamos científicamente a los públicos & 1,63 & 1,33 \\
\hline $\begin{array}{l}\text { Persuadimos al público de que nuestra organización tiene } \\
\text { razón sobre un determinado tema }\end{array}$ & 2,50 & 2,56 \\
\hline Total & 2,66 & 2,86 \\
\hline \multicolumn{3}{|l|}{ Simétrico bidireccional } \\
\hline Determinamos cómo el público reacciona ante la organización & 2,50 & 2,56 \\
\hline Negociamos con grupos de presión & 2,25 & 2,00 \\
\hline $\begin{array}{l}\text { Utilizamos las teorías de la resolución de conflictos en nuestro } \\
\text { trato con los públicos }\end{array}$ & 3,25 & 3,56 \\
\hline $\begin{array}{l}\text { Ayudamos a los dirigentes a entender la opinión de públicos } \\
\text { particulares }\end{array}$ & 3,88 & 4,11 \\
\hline Total & 2,97 & 3,06 \\
\hline \multicolumn{3}{|l|}{ Bidireccional simétrico persuasivo } \\
\hline $\begin{array}{l}\text { Uno de nuestros principales objetivos es mantener una buena } \\
\text { relación con los públicos }\end{array}$ & 4,25 & 4,44 \\
\hline $\begin{array}{l}\text { De esa buena relación, pretendemos crear un ambiente en el } \\
\text { que se reciban mejor nuestras propuestas o informaciones }\end{array}$ & 4,25 & 4,56 \\
\hline $\begin{array}{l}\text { Creemos que una buena relación con los públicos, sin un } \\
\text { ejercicio de persuasión, no ayuda a que los públicos se sientan } \\
\text { persuadidos a hacer lo que queremos }\end{array}$ & 2,63 & 2,67 \\
\hline $\begin{array}{l}\text { El objetivo final es conseguir que los públicos acepten y } \\
\text { adopten mejor nuestras propuestas y acciones }\end{array}$ & 3,75 & 3,67 \\
\hline 2 & 3,72 & 3,83 \\
\hline
\end{tabular}

Fuente: elaboración propia. 
Las cifras que arrojan en conjunto las ideas para estudiar el modelo de influencia personal son casi idénticas en ambas dependencias: 3,59 para los públicos y 3,67 para los privados. Aunque los públicos aseguran tener unas relaciones interpersonales mejores tanto con otros empleados como con personas externas de su organización (5,00 y 4,88 frente al 4,67 en ambos casos de los privados), las relaciones sociales son más importantes para los privados $(4,11$ respecto a 3,50$)$ y procuran un mayor número de beneficios para ganar influencia sobre sus contactos (1,22 y 1,00 respectivamente).

Tabla 68. Medias de las afirmaciones del modelo de influencia personal

\begin{tabular}{|l|r|r|}
\hline \multicolumn{1}{|c|}{ Modelo de influencia personal } & \multicolumn{1}{|c|}{ Público } & \multicolumn{1}{|c|}{ Privado } \\
\hline Tengo buenas relaciones interpersonales con otros empleados & 5,00 & 4,67 \\
\hline $\begin{array}{l}\text { Tengo buenas relaciones interpersonales con las personas } \\
\text { externas de mi organización }\end{array}$ & 4,88 & 4,67 \\
\hline $\begin{array}{l}\text { Las relaciones sociales es una de mis actividades más } \\
\text { importantes }\end{array}$ & 3,50 & 4,11 \\
\hline $\begin{array}{l}\text { Procuro beneficios (comidas, regalos) para ganar influencia } \\
\text { lon mis contactos personales }\end{array}$ & 1,00 & 1,22 \\
\hline \multicolumn{1}{|l|}{ Total } & 3,59 & 3,67 \\
\hline
\end{tabular}

Fuente: elaboración propia.

Tanto en los hospitales públicos como en los privados prevalece el rol técnico frente al directivo, aunque solo sea ligeramente. Los primeros otorgan al papel técnico un 3,91 y al directivo, un 3,81, mientras que los centros privados, con unas cifras levemente inferiores en ambos casos, arrojan un 3,78 y un 3,64, respectivamente. Las diferencias más destacadas que se han detectado están en los públicos, que suelen coordinar ruedas de prensa o concertar cobertura mediática para un evento más a menudo (4,63 sobre 5,00 respecto al 3,89 de los privados), aunque también dirigen a otras personas con más frecuencia $(3,63$ frente a 2,78$)$.

Tabla 69. Medias de las afirmaciones de los dos roles de relaciones públicas estudiados

\begin{tabular}{|c|c|c|}
\hline Rol & Público & Privado \\
\hline \multicolumn{3}{|l|}{ Rol técnico } \\
\hline $\begin{array}{l}\text { Coordinar ruedas de prensa o concertar cobertura mediática para } \\
\text { un evento }\end{array}$ & 4,63 & 3,89 \\
\hline Elaborar publicaciones & 3,88 & 4,00 \\
\hline Crear y dirigir la oficina del portavoz & 4,00 & 3,89 \\
\hline Tomar fotografías y coordinar la fotografía & 3,13 & 3,33 \\
\hline Total & 3,91 & 3,78 \\
\hline \multicolumn{3}{|l|}{ Rol directivo } \\
\hline Dirigir personas & 3,63 & 2,78 \\
\hline Conducir investigación evaluativa & 2,63 & 2,56 \\
\hline $\begin{array}{l}\text { Desarrollar estrategias para solucionar problemas de } \\
\text { comunicación }\end{array}$ & 4,50 & 4,56 \\
\hline Manejar las respuestas de la organización hacia diferentes asuntos & 4,50 & 4,67 \\
\hline Total & 3,81 & 3,64 \\
\hline
\end{tabular}

Fuente: elaboración propia. 
Los resultados que otorgan ambas dependencias en cuanto a los planes de comunicación y a la participación en decisiones estratégicas son prácticamente idénticos. En lo que sí se visualiza una diferencia considerable es en el número de centros cuyos miembros del departamento de comunicación forman parte del equipo estratégico. Solo dos (el 25,00\%) de los encuestados que trabajan en hospitales públicos admiten tener algún empleado en este grupo, mientras que seis $(66,67 \%)$ de los privados, efectivamente, cuentan con una persona de comunicación en la dirección de la organización. Además, mientras que todos los entrevistados que pertenecen al ámbito privado tiene constancia de esta situación, dos personas (el 25,00\%) del terreno público no tienen conocimiento acerca de esta situación.

Tabla 70. Definición y consecución de objetivos concretos y sobre la participación en planes estratégicos

\begin{tabular}{|c|c|c|}
\hline Objetivos concretos y participación en planes estratégicos & Público & Privado \\
\hline Existe una guía o un plan de comunicación & 4,00 & 4,00 \\
\hline Hay una serie de objetivos concretos definidos & 4,13 & 4,33 \\
\hline $\begin{array}{l}\text { Los objetivos de comunicación están vinculados a los } \\
\text { objetivos del hospital en general }\end{array}$ & 4,63 & 4,44 \\
\hline Normalmente se cumplen todos los objetivos propuestos & 3,50 & 3,56 \\
\hline $\begin{array}{l}\text { El equipo estratégico de planes suele consultar al } \\
\text { departamento de comunicación }\end{array}$ & 3,63 & 3,78 \\
\hline Total & 3,98 & 4,02 \\
\hline
\end{tabular}

Fuente: elaboración propia.

Tabla 71. Frecuencia y porcentaje de los miembros del departamento de comunicación que forman parte del equipo estratégico

\begin{tabular}{|l|r|c|r|r|r|r|}
\hline \multirow{2}{*}{$\begin{array}{c}\text { Equipo } \\
\text { estratégico }\end{array}$} & \multicolumn{2}{|c|}{ Público } & \multicolumn{2}{c|}{ Privado } & \multicolumn{2}{c|}{ Total } \\
\cline { 2 - 7 } & $\mathbf{N}^{\mathbf{0}}$ & \multicolumn{1}{c}{$\%$} & $\mathbf{N}^{\mathbf{0}}$ & \multicolumn{1}{c|}{$\%$} & \multicolumn{1}{c|}{$\mathbf{N}^{\mathbf{0}}$} & \multicolumn{1}{c}{$\%$} \\
\hline SÍ & 2 & 25,00 & 6 & 66,67 & 8 & 47,06 \\
\hline No & 4 & 50,00 & 3 & 33,33 & 7 & 41,18 \\
\hline NS/NC & 2 & 25,00 & 0 & 0,00 & 2 & 11,76 \\
\hline Total & 8 & 100,00 & 9 & 100,00 & 17 & 100,00 \\
\hline
\end{tabular}

Fuente: elaboración propia.

En general, los responsables de comunicación de los hospitales públicos otorgan una nota más alta al conjunto de audiencias, con un 4,18 sobre una escala de 1 a 5 respecto al 4,04 que proporcionan sus homólogos. Dividiendo los colectivos, no se aprecian diferencias muy marcadas. Los medios de comunicación $(4,88)$ y los empleados $(4,88)$ son los grupos más relevantes para los centros públicos, mientras que para las clínicas privadas los periodistas pasan a una tercera posición $(4,50)$ y dejan por delante a los trabajadores y pacientes (4,75 cada uno). Los agentes políticos e institucionales están en último lugar de importancia para los privados $(3,00)$, aunque 
para los públicos ocupan la quita posición con una cifra sensiblemente más elevada $(4,50)$. De hecho, la relación resulta ser significativa $(r=0,032)$, tal y como demuestra la prueba $\mathrm{T}$ para muestras independientes. Por otra parte, la importancia que tienen los inversores o accionistas, como era de esperar, es mucho más baja para los trabajadores de centro públicos $(1,40)$ que para los privados $(3,13)$.

Tabla 72. Importancia de los diferentes públicos para el departamento de comunicación

\begin{tabular}{|l|r|r|}
\hline \multicolumn{1}{|c|}{ Públicos } & Público & Privado \\
\hline Pacientes & 4,75 & 4,75 \\
\hline Familiares & 4,38 & 4,38 \\
\hline Empleados & 4,88 & 4,75 \\
\hline Agentes políticos e institucionales & 4,50 & 3,00 \\
\hline Inversores o accionistas (en su caso) & 1,40 & 3,13 \\
\hline Medios de comunicación & 4,88 & 4,50 \\
\hline Población en general & 4,50 & 3,75 \\
\hline Total & 4,18 & 4,04 \\
\hline
\end{tabular}

Fuente: elaboración propia.

Donde sí que se aprecian discrepancias es en la valoración que ofrecen las dos dependencias de las distintas fases de un programa de relaciones públicas. Los privados se ocupan en mayor medida de todas ellas, tanto de la investigación $(3,89$ frente al 3,63 de los públicos), de la planificación (4,56 y 4,00 respectivamente), de la comunicación (4,78 y 4,50, en este orden) y, sobre todo, de la evaluación (4,33 y 3,38). Así, de media, arrojan medio punto más: 4,39 frente al 3,88 de los públicos.

Tabla 73. Importancia que le otorga el departamento de comunicación a las diferentes etapas de un programa de relaciones públicas

\begin{tabular}{|l|r|r|}
\hline $\begin{array}{c}\text { Fases de un programa } \\
\text { de relaciones públicas }\end{array}$ & Público & Privado \\
\hline Investigación & 3,63 & 3,89 \\
\hline Planificación & 4,00 & 4,56 \\
\hline Comunicación & 4,50 & 4,78 \\
\hline Evaluación & 3,38 & 4,33 \\
\hline Total & 3,88 & 4,39 \\
\hline
\end{tabular}

Fuente: elaboración propia.

Tanto los centros públicos como los privados utilizan en mayor medida el análisis de la cobertura en prensa como herramienta de investigación (100,00\% y 88,89\%, respectivamente). También son muy recurrentes las entrevistas $(87,50 \%$ y $77,78 \%$, en este orden), la búsqueda de materiales propios (100,00 y 77,78\%) y la búsqueda general en internet (62,5\% y 88,89\%). Aunque en la búsqueda de bibliografía y estudios ajenos 
$(62,50 \%$ y $33,33 \%)$ y en las técnicas de reflexión en voz alta $(37,50 \%$ y $22,22 \%)$, los hospitales públicos adelantan a los privados, estos segundos lo hacen en el análisis de la percepción $(0,00 \%$ y $55,56 \%)$ y en las pruebas piloto $(0,00 \%$ y $22,22 \%)$. La relación entre el análisis de la percepción y los centros privados es estadísticamente significativa $(\mathrm{r}=0,020)$, tal y como muestra el estadístico exacto de Fisher al tener varias casillas con una frecuencia esperada inferior a cinco.

Tabla 74. Herramientas de evaluación utilizadas por dependencia

\begin{tabular}{|c|c|c|c|c|c|c|}
\hline \multirow{2}{*}{$\begin{array}{l}\text { Herramientas de } \\
\text { investigación }\end{array}$} & \multicolumn{2}{|c|}{ Público } & \multicolumn{2}{|c|}{ Privado } & \multicolumn{2}{|c|}{ Total } \\
\hline & $\mathbf{N}^{\mathbf{0}}$ & $\%$ & $\mathbf{N}^{\mathbf{0}}$ & $\%$ & $\mathbf{N}^{\mathbf{0}}$ & $\%$ \\
\hline $\begin{array}{l}\text { Búsqueda de materiales propios } \\
\text { de la organización }\end{array}$ & 8 & 100,00 & 7 & 77,78 & 15 & 88,24 \\
\hline $\begin{array}{l}\text { Búsqueda de bibliografía y } \\
\text { estudios ajenos }\end{array}$ & 5 & 62,50 & 3 & 33,33 & 8 & 47,06 \\
\hline $\begin{array}{l}\text { Análisis de la cobertura en } \\
\text { prensa de la organización }\end{array}$ & 8 & 100,00 & 8 & 88,89 & 16 & 94,12 \\
\hline Búsqueda general en Internet & 5 & 62,5 & 8 & 88,89 & 13 & 76,47 \\
\hline Test de mensajes & 1 & 12,50 & 2 & 22,22 & 3 & 17,65 \\
\hline Grupos de discusión & 1 & 12,50 & 2 & 22,22 & 3 & 17,65 \\
\hline Auditoría de comunicación & 3 & 37,50 & 5 & 55,56 & 8 & 47,06 \\
\hline Encuestas & 3 & 37,50 & 3 & 33,33 & 6 & 35,29 \\
\hline Entrevistas & 7 & 87,50 & 7 & 77,78 & 14 & 82,35 \\
\hline Pruebas piloto & 0 & 0,00 & 2 & 22,22 & 2 & 11,76 \\
\hline Mensajes de doble versión & 0 & 0,00 & 1 & 11,11 & 1 & 5,88 \\
\hline Análisis de la percepción & 0 & 0,00 & 5 & 55,56 & 5 & 29,41 \\
\hline Experimentos & 1 & 12,50 & 0 & 0,00 & 1 & 5,88 \\
\hline $\begin{array}{l}\text { Técnicas de reflexión en voz } \\
\text { alta }\end{array}$ & 3 & 37,50 & 2 & 22,22 & 5 & 29,41 \\
\hline Cómputo de respuestas & 45 & - & 55 & - & 100 & \\
\hline Total respuestas únicas & 8 & - & 9 & - & 17 & - \\
\hline
\end{tabular}

Fuente: elaboración propia.

Los hospitales privados parecen planear más profundamente los programas de relaciones públicas. De los ocho aspectos analizados, los públicos únicamente les adelantan en dos, más concretamente en públicos (87,50\% y 77,78\%, en este orden) y en situación $(87,50$ y $66,67 \%)$. En el resto, los privados adelantan a la titularidad pública, detectándose una mayor diferencia en el presupuesto (12,50\% y 66,67\%), en las tácticas $(37,50 \%$ y $88,89 \%)$, en las técnicas de evaluación $(25,00 \%$ y 55,56\%) y en los plazos temporales $(62,50 \%$ y $88,89 \%)$. Los dos primeros instrumentos, de hecho, obtienen resultados estadísticamente significativos con los centros públicos $(\mathrm{r}=0,036$ para los presupuestos y $\mathrm{r}=0,043$ para las tácticas), según el estadístico exacto de Fisher. 
Tabla 75. Herramientas de planificación utilizadas por dependencia

\begin{tabular}{|c|c|c|c|c|c|c|}
\hline \multirow{2}{*}{$\begin{array}{c}\text { Herramientas de } \\
\text { planificación }\end{array}$} & \multicolumn{2}{|c|}{ Público } & \multicolumn{2}{|c|}{ Privado } & \multicolumn{2}{|c|}{ Total } \\
\hline & $\mathbf{N}^{0}$ & $\%$ & $\mathbf{N}^{\mathbf{0}}$ & $\%$ & $\mathbf{N}^{\mathbf{0}}$ & $\%$ \\
\hline Situación & 7 & 87,50 & 6 & 66,67 & 13 & 76,47 \\
\hline Objetivos & 7 & 87,50 & 9 & 100,00 & 16 & 94,12 \\
\hline Públicos & 7 & 87,50 & 7 & 77,78 & 14 & 82,35 \\
\hline Estrategias & 6 & 75,00 & 9 & 100,00 & 15 & 88,24 \\
\hline Tácticas & 3 & 37,50 & 8 & 88,89 & 11 & 64,71 \\
\hline Plazos temporales & 5 & 62,50 & 8 & 88,89 & 13 & 76,47 \\
\hline Presupuesto & 1 & 12,50 & 6 & 66,67 & 7 & 41,18 \\
\hline Técnicas de evaluación & 2 & 25,00 & 5 & 55,56 & 7 & 41,18 \\
\hline Cómputo de respuestas & 38 & - & 58 & - & 96 & - \\
\hline Total respuestas únicas & 8 & - & 9 & - & 17 & - \\
\hline
\end{tabular}

Fuente: elaboración propia.

En cambio, cuando se refiere a herramientas de comunicación empleadas con los empleados, los públicos adelantan a los privados. Así, por ejemplo, mientras que el $87,50 \%$ de los primeros utilizan el dossier de las apariciones en los medios, en el segundo caso el porcentaje baja hasta el 37,50\%. Lo mismo ocurre con el tablón de anuncios $(87,50 \%$ y 37,50\%, en este orden), con el buzón de anuncios electrónicos $(50,00 \%$ y $12,50 \%)$, la intranet $(87,50 \%$ y $62,50 \%)$ y los cursos sobre comunicarse con los medios de comunicación (37,50\% y 0,00\%), entre los más destacados. En cambio, los privados adelantan a los públicos con una diferencia algo destacable en el uso del periódico $(0,00 \%$ y $25,00 \%$, respectivamente) y en el boletín interno impreso $(12,50 \%$ y $37,50 \%)$.

Entre todas estas herramientas, se han encontrado tres relaciones significativas: el tablón de anuncios ( $\mathrm{r}=0,036$ a favor de los públicos), el dossier de las apariciones en los medios $(\mathrm{r}=0,036$ a favor de los públicos) y el patrocinio $(\mathrm{r}=0,020$ a favor de $10 \mathrm{~s}$ privados), detectadas a través del estadístico exacto de Fisher. 
Tabla 76. Herramientas de comunicación utilizadas con los empleados por dependencia

\begin{tabular}{|c|c|c|c|c|c|c|}
\hline \multirow{2}{*}{ Herramientas de comunicación } & \multicolumn{2}{|c|}{ Público } & \multicolumn{2}{|c|}{ Privado } & \multicolumn{2}{|c|}{ Total } \\
\hline & $\mathbf{N}^{\mathbf{0}}$ & $\%$ & $\mathbf{N}^{\mathbf{0}}$ & $\%$ & $\mathbf{N}^{\mathbf{o}}$ & $\%$ \\
\hline Página web & 5 & 62,50 & 6 & 75,00 & 11 & 68,75 \\
\hline Blog & 1 & 12,50 & 2 & 25,00 & 3 & 18,75 \\
\hline Mensajería instantánea & 4 & 50,00 & 3 & 37,50 & 7 & 43,75 \\
\hline Pantallas de información & 3 & 37,50 & 2 & 25,00 & 5 & 31,25 \\
\hline Manual del empleado & 5 & 62,50 & 5 & 62,50 & 10 & 62,50 \\
\hline Círculos de calidad & 2 & 25,00 & 2 & 25,00 & 4 & 25,00 \\
\hline Circulares & 4 & 50,00 & 5 & 62,50 & 9 & 56,25 \\
\hline Boletín interno impreso & 1 & 12,50 & 3 & 37,50 & 4 & 25,00 \\
\hline Reuniones y seminarios & 5 & 62,50 & 4 & 50,00 & 9 & 56,25 \\
\hline $\begin{array}{l}\text { Curso sobre comunicarse con los } \\
\text { medios de comunicación }\end{array}$ & 3 & 37,50 & 0 & 0,00 & 3 & 18,75 \\
\hline Reuniones virtuales & 0 & 0,00 & 1 & 12,50 & 1 & 6,25 \\
\hline Buzón virtual de sugerencias & 4 & 50,00 & 5 & 62,50 & 9 & 56,25 \\
\hline $\begin{array}{l}\text { Cursos para comunicarse con los } \\
\text { pacientes y visitas }\end{array}$ & 2 & 25,00 & 2 & 25,00 & 4 & 25,00 \\
\hline Correo electrónico & 7 & 87,50 & 6 & 75,00 & 13 & 81,25 \\
\hline Foro & 1 & 12,50 & 0 & 0,00 & 1 & 6,25 \\
\hline Wikis & 1 & 12,50 & 0 & 0,00 & 1 & 6,25 \\
\hline SMS & 1 & 12,50 & 2 & 25,00 & 3 & 18,75 \\
\hline Reuniones presenciales & 5 & 62,50 & 4 & 50,00 & 9 & 56,25 \\
\hline Tablón de anuncios & 7 & 87,50 & 3 & 37,50 & 10 & 62,50 \\
\hline Revista & 0 & 0,00 & 3 & 37,50 & 3 & 18,75 \\
\hline Teléfono & 5 & 62,50 & 4 & 50,00 & 9 & 56,25 \\
\hline Mensajes de la alta dirección & 5 & 62,50 & 4 & 50,00 & 9 & 56,25 \\
\hline Proyecto de empresa & 1 & 12,50 & 2 & 25,00 & 3 & 18,75 \\
\hline Boletín interno electrónico & 3 & 37,50 & 3 & 37,50 & 6 & 37,50 \\
\hline Redes sociales & 4 & 50,00 & 4 & 50,00 & 8 & 50,00 \\
\hline Intranet & 7 & 87,50 & 5 & 62,50 & 12 & 75,00 \\
\hline Videoconferencias & 1 & 12,50 & 0 & 0,00 & 1 & 6,25 \\
\hline Vídeos & 2 & 25,00 & 3 & 37,50 & 5 & 31,25 \\
\hline Correo ordinario & 3 & 37,50 & 2 & 25,00 & 5 & 31,25 \\
\hline $\begin{array}{l}\text { Dossier de las apariciones en los } \\
\text { medios }\end{array}$ & 7 & 87,50 & 3 & 37,50 & 10 & 62,50 \\
\hline Buzón de sugerencias & 2 & 25,00 & 4 & 50,00 & 6 & 37,50 \\
\hline Periódico & 0 & 0,00 & 2 & 25,00 & 2 & 12,50 \\
\hline Entrevistas & 4 & 50,00 & 2 & 25,00 & 6 & 37,50 \\
\hline Curso de formación de portavoces & 2 & 25,00 & 0 & 0,00 & 2 & 12,50 \\
\hline Formación continua & 1 & 12,50 & 1 & 12,50 & 2 & 12,50 \\
\hline Buzón de anuncios electrónicos & 4 & 50,00 & 1 & 12,50 & 5 & 31,25 \\
\hline Organización de eventos & 6 & 75,00 & 4 & 50,00 & 10 & 62,50 \\
\hline
\end{tabular}

Fuente: elaboración propia. 
En cambio, parece que los centros privados tienden a comunicarse con más frecuencia con los pacientes o visitas, o al menos utilizan una mayor variedad de herramientas. La mayor discrepancia se halla en el uso de revistas; mientras que el $62,50 \%$ de los hospitales de titularidad privada emplean este instrumento, no hay ninguna muestra de que esto suceda en el ámbito público. También se utiliza la página web para comunicarse con estos públicos en los centros privados $(100 \%)$ y algo menos en los públicos $(62,50 \%)$, al igual que sucede con el correo postal $(50,00 \%$ y $12,50 \%)$, las hojas de reclamaciones $(50,00 \%$ y 25,00\%), los correos electrónicos $(50,00 \%$ y $25,00 \%)$ o los periódicos $(37,50 \%$ y $12,50 \%)$. En el resto de herramientas no existen diferencias demasiado marcadas.

Tabla 77. Herramientas de comunicación utilizadas con los pacientes y visitas por dependencia

\begin{tabular}{|l|r|r|r|r|r|r|}
\hline \multirow{2}{*}{$\begin{array}{c}\text { Herramientas de } \\
\text { comunicación }\end{array}$} & \multicolumn{1}{c|}{ Público } & \multicolumn{2}{c|}{ Privado } & \multicolumn{2}{c|}{ Total } \\
\cline { 2 - 7 } & \multicolumn{1}{c|}{$\mathbf{N}^{\mathbf{0}}$} & \multicolumn{1}{c|}{$\boldsymbol{\%}$} & \multicolumn{1}{c|}{$\mathbf{N}^{\mathbf{0}}$} & \multicolumn{1}{c}{$\%$} & \multicolumn{1}{c|}{$\mathbf{N}^{\mathbf{0}}$} & \multicolumn{1}{c}{$\%$} \\
\hline Página web & 5 & 62,50 & 8 & 100,00 & 13 & 81,25 \\
\hline Correo postal & 1 & 12,50 & 4 & 50,00 & 5 & 31,25 \\
\hline Hoja de reclamaciones & 2 & 25,00 & 4 & 50,00 & 6 & 37,50 \\
\hline Buzón de sugerencias & 3 & 37,50 & 4 & 50,00 & 7 & 43,75 \\
\hline Correos electrónicos & 2 & 25,00 & 4 & 50,00 & 6 & 37,50 \\
\hline Vídeos & 2 & 25,00 & 3 & 37,50 & 5 & 31,25 \\
\hline Pantallas de información & 4 & 50,00 & 4 & 50,00 & 8 & 50,00 \\
\hline Revista & 0 & 0,00 & 5 & 62,50 & 5 & 31,25 \\
\hline Planos & 2 & 25,00 & 1 & 12,50 & 3 & 18,75 \\
\hline Blogs & 1 & 12,50 & 2 & 25,00 & 3 & 18,75 \\
\hline $\begin{array}{l}\text { Número de teléfono } \\
\text { gratuitos }\end{array}$ & 2 & 25,00 & 0 & 0,00 & 2 & 12,50 \\
\hline Foro de discusión & 1 & 12,50 & 1 & 12,50 & 2 & 12,50 \\
\hline Mensajería instantánea & 1 & 12,50 & 1 & 12,50 & 2 & 12,50 \\
\hline SMS & 2 & 25,00 & 2 & 25,00 & 4 & 25,00 \\
\hline Periódico & 1 & 12,50 & 3 & 37,50 & 4 & 25,00 \\
\hline Redes sociales & 4 & 50,00 & 5 & 62,50 & 9 & 56,25 \\
\hline $\begin{array}{l}\text { Números de teléfono de } \\
\text { respuesta automática }\end{array}$ & 0 & 0,00 & 1 & 12,50 & 1 & 6,25 \\
\hline Cómputo de respuestas & 33 & - & 52 & - & 85 & - \\
\hline Total respuestas únicas & 8 & - & 8 & - & 16 & - \\
\hline
\end{tabular}

Fuente: elaboración propia.

Las dos titularidades se encuentran bastante igualadas en las herramientas de comunicación destinadas a los periodistas. Los porcentajes de uso de casi todos los instrumentos analizados son prácticamente idénticos, a excepción de únicamente cinco: la publicidad, los vídeos, las cartas al director, los anuncios de servicio público y los 
SMS. Los dos primeros son más frecuentes en el ámbito público y los tres últimos, en el privado.

Tabla 78. Herramientas de comunicación utilizadas con los periodistas por dependencia

\begin{tabular}{|c|c|c|c|c|c|c|}
\hline \multirow{2}{*}{$\begin{array}{l}\text { Herramientas de } \\
\text { comunicación }\end{array}$} & \multicolumn{2}{|c|}{ Público } & \multicolumn{2}{|c|}{ Privado } & \multicolumn{2}{|c|}{ Total } \\
\hline & $\mathrm{N}^{\mathbf{o}}$ & $\%$ & $\mathbf{N}^{\mathbf{0}}$ & $\%$ & $\mathbf{N}^{\mathbf{o}}$ & $\%$ \\
\hline Llamadas telefónicas & 8 & 100,00 & 8 & 88,89 & 16 & 94,12 \\
\hline Dossier de prensa & 6 & 75,00 & 7 & 77,78 & 13 & 76,47 \\
\hline Audio & 3 & 37,50 & 3 & 33,33 & 6 & 35,29 \\
\hline Sala de prensa virtual & 1 & 12,50 & 2 & 22,22 & 3 & 17,65 \\
\hline Viajes de prensa & 1 & 12,50 & 1 & 11,11 & 2 & 11,76 \\
\hline Comidas & 2 & 25,00 & 3 & 33,33 & 5 & 29,41 \\
\hline Anuncios de servicio público & 3 & 37,50 & 0 & 0,00 & 3 & 17,65 \\
\hline Blogs & 0 & 0,00 & 2 & 22,22 & 2 & 11,76 \\
\hline $\begin{array}{l}\text { Retransmisión de } \\
\text { acontecimientos por internet }\end{array}$ & 1 & 12,50 & 2 & 22,22 & 3 & 17,65 \\
\hline Notas de prensa & 8 & 100,00 & 9 & 100,00 & 17 & 100,00 \\
\hline Fotografías & 7 & 87,50 & 8 & 88,89 & 15 & 88,24 \\
\hline Entrevistas & 6 & 75,00 & 7 & 77,78 & 13 & 76,47 \\
\hline Artículo firmado & 4 & 50,00 & 6 & 66,67 & 10 & 58,82 \\
\hline Giras por los medios & 3 & 37,50 & 3 & 33,33 & 6 & 35,29 \\
\hline Publicidad & 2 & 25,00 & 7 & 77,78 & 9 & 52,94 \\
\hline Redes sociales & 3 & 37,50 & 5 & 55,56 & 8 & 47,06 \\
\hline Emplazamiento de temas & 2 & 25,00 & 2 & 22,22 & 4 & 23,53 \\
\hline Premios de divulgación & 2 & 25,00 & 3 & 33,33 & 5 & 29,41 \\
\hline Ruedas de prensa & 8 & 100,00 & 9 & 100,00 & 17 & 100,00 \\
\hline Vídeos & 1 & 12,50 & 4 & 44,44 & 5 & 29,41 \\
\hline Cartas al director & 4 & 50,00 & 1 & 11,11 & 5 & 29,41 \\
\hline SMS & 5 & 62,50 & 2 & 22,22 & 7 & 41,18 \\
\hline Emplazamiento de productos & 0 & 0,00 & 1 & 11,11 & 1 & 5,88 \\
\hline $\begin{array}{l}\text { Visitas y “media-tours" a la } \\
\text { organización }\end{array}$ & 1 & 12,50 & 2 & 22,22 & 3 & 17,65 \\
\hline $\begin{array}{l}\text { Cursos de formación de } \\
\text { periodistas }\end{array}$ & 1 & 12,50 & 2 & 22,22 & 3 & 17,65 \\
\hline Cómputo de respuestas & 82 & - & 99 & - & 181 & - \\
\hline Total respuestas únicas & 8 & - & 9 & - & 17 & - \\
\hline
\end{tabular}

Fuente: elaboración propia.

Cuando se trata de herramientas utilizadas para comunicarse con la población en general, la balanza se inclina a favor de los hospitales privados. Estos adelantan a los públicos en 12 de los 18 instrumentos incluidos en la encuesta, mientras que los públicos solo toman ventaja en dos tácticas. La mayor diferencia se observa en el patrocinio $(62,50 \%$ y $0,00 \%$ a favor de los centros privados) y en la publicidad $(75,00 \%$ 
y $25,00 \%$ ), aunque también hay discrepancias en la organización de actividades deportivas $(50,00 \%$ y $12,50 \%)$ y en la página web $(87,50 \%$ y $50,00 \%)$.

Tabla 79. Herramientas de comunicación utilizadas con la comunidad por dependencia

\begin{tabular}{|l|r|r|r|r|r|r|}
\hline \multirow{2}{*}{$\begin{array}{c}\text { Herramientas de } \\
\text { comunicación }\end{array}$} & \multicolumn{2}{c|}{ Público } & \multicolumn{2}{c|}{ Privado } & \multicolumn{2}{c|}{ Total } \\
\cline { 2 - 7 } & \multicolumn{1}{c|}{$\mathbf{N}^{\mathbf{0}}$} & \multicolumn{1}{c|}{$\%$} & \multicolumn{1}{c|}{$\mathbf{N}^{\mathbf{0}}$} & \multicolumn{1}{c}{ \% } & \multicolumn{1}{c|}{$\mathbf{N}^{\mathbf{0}}$} & \multicolumn{1}{c}{$\%$} \\
\hline Jornada de puertas abiertas & 2 & 25,00 & 4 & 50,00 & 6 & 37,50 \\
\hline Patrocinio & 0 & 0,00 & 5 & 62,50 & 5 & 31,25 \\
\hline Premios, ayudas y becas & 2 & 25,00 & 4 & 50,00 & 6 & 37,50 \\
\hline $\begin{array}{l}\text { Marketing relacionado con } \\
\text { una causa }\end{array}$ & 1 & 12,50 & 3 & 37,50 & 4 & 25,00 \\
\hline Actividad deportiva & 1 & 12,50 & 4 & 50,00 & 5 & 31,25 \\
\hline Folletos & 7 & 87,50 & 7 & 87,50 & 14 & 87,50 \\
\hline Participación en feria o salón & 0 & 0,00 & 1 & 12,50 & 1 & 6,25 \\
\hline Captación de fondos & 0 & 0,00 & 1 & 12,50 & 1 & 6,25 \\
\hline Contratación social & 1 & 12,50 & 0 & 0,00 & 1 & 6,25 \\
\hline Página web & 4 & 50,00 & 7 & 87,50 & 11 & 68,75 \\
\hline Redes sociales & 4 & 50,00 & 4 & 50,00 & 8 & 50,00 \\
\hline Número de teléfono gratuitos & 1 & 12,50 & 0 & 0,00 & 1 & 6,25 \\
\hline Mecenazgo & 0 & 0,00 & 1 & 12,50 & 1 & 6,25 \\
\hline Sesión o jornada informativa & 5 & 62,50 & 7 & 87,50 & 12 & 75,00 \\
\hline Fundación-empresa & 2 & 25,00 & 2 & 25,00 & 4 & 25,00 \\
\hline $\begin{array}{l}\text { Evento lúdico (fiesta, } \\
\text { concierto...) }\end{array}$ & 1 & 12,50 & 1 & 12,50 & 2 & 12,50 \\
\hline Blog & 0 & 0,00 & 2 & 25,00 & 2 & 12,50 \\
\hline Publicidad & 2 & 25,00 & 6 & 75,00 & 8 & 50,00 \\
\hline Cómputo de respuestas & 33 & - & 59 & - & 92 & - \\
\hline Total respuestas únicas & 8 & - & 8 & - & 16 & - \\
\hline
\end{tabular}

Fuente: elaboración propia.

Al igual que sucede con la planificación, los hospitales privados tienden a evaluar con más frecuencia y con más herramientas los programas de relaciones públicas. En ninguna de las once tácticas propuestas en la encuesta adelanta la titularidad pública a la privada. Además, existen diferencias bastante acusadas a favor de los centros privados, como en la medición de la asistencia del público (62,50\% respecto al $25,00 \%$ de los públicos) y en la equivalencia publicitaria $(50,00 \%$ y $0,00 \%$, en este orden). También se han detectado diferencias en el número de lectores de los boletines y revistas de empresa $(37,50 \%$ en los privados y $12,50 \%$ en los públicos), en el recuento de las visitas en internet $(75,00 \%$ y 50,00\%), en las auditorías de comunicación $(50,00 \%$ y $25,00 \%)$, en el coste por persona $(25,00 \%$ y $0,00 \%)$ y en el recuento de los materiales de comunicación producidos $(87,50 \%$ y $62,50 \%)$. 
Tabla 80. Herramientas de evaluación utilizadas con la comunidad por dependencia

\begin{tabular}{|c|c|c|c|c|c|c|}
\hline \multirow{2}{*}{$\begin{array}{l}\text { Herramientas de } \\
\text { evaluación }\end{array}$} & \multicolumn{2}{|c|}{ Público } & \multicolumn{2}{|c|}{ Privado } & \multicolumn{2}{|c|}{ Total } \\
\hline & $\mathbf{N}^{\mathbf{0}}$ & $\%$ & $\mathbf{N}^{\mathbf{0}}$ & $\%$ & $\mathbf{N}^{\mathbf{0}}$ & $\%$ \\
\hline Impacto en los medios & 7 & 87,50 & 8 & 100,00 & 15 & 93,75 \\
\hline Seguimiento sistemático & 5 & 62,50 & 5 & 62,50 & 10 & 62,50 \\
\hline Asistencia del público & 2 & 25,00 & 5 & 62,50 & 7 & 43,75 \\
\hline $\begin{array}{l}\text { Número de lectores de los } \\
\text { boletines y revistas de } \\
\text { empresa }\end{array}$ & 1 & 12,50 & 3 & 37,50 & 4 & 25,00 \\
\hline Visitas en internet & 4 & 50,00 & 6 & 75,00 & 10 & 62,50 \\
\hline $\begin{array}{l}\text { Solicitudes de información } \\
\text { y números de teléfono } \\
\text { gratuitos }\end{array}$ & 1 & 12,50 & 1 & 12,50 & 2 & 12,50 \\
\hline Auditorías de comunicación & 2 & 25,00 & 4 & 50,00 & 6 & 37,50 \\
\hline $\begin{array}{l}\text { Recuento de los materiales } \\
\text { de comunicación } \\
\text { producidos }\end{array}$ & 5 & 62,50 & 7 & 87,50 & 12 & 75,00 \\
\hline Equivalencia publicitaria & 0 & 0,00 & 4 & 50,00 & 4 & 25,00 \\
\hline Coste por persona & 0 & 0,00 & 2 & 25,00 & 2 & 12,50 \\
\hline $\begin{array}{l}\text { Asistencia a reuniones y } \\
\text { acontecimientos }\end{array}$ & 5 & 62,50 & 5 & 62,50 & 10 & 62,50 \\
\hline Cómputo de respuestas & 32 & - & 50 & - & 82 & - \\
\hline Total respuestas únicas & 8 & - & 8 & - & 16 & - \\
\hline
\end{tabular}

Fuente: elaboración propia.

Los diferentes tipos de mediciones, en general, también ofrecen notas más elevadas en los hospitales privados $(4,39)$ que en los públicos $(4,09)$. No obstante, la discrepancia surge de la relevancia que le otorgan sus responsables de comunicación a la opinión y actitud del público y a las acciones y comportamientos del público, que son más elevadas en los privados. Así, estos otorgan una cifra de 4,78 y 4,67, en este orden, mientras que los públicos devuelven un 4,13 y un 4,00. En cambio, estos últimos prestan ligeramente más atención que los privados a la producción $(3,75$ frente a un $3,67)$ y a la exposición $(4,5$ y 4,44$)$.

Tabla 81. Importancia que le otorga el departamento de comunicación a los diferentes tipos de medición

\begin{tabular}{|l|r|r|}
\hline \multicolumn{1}{|c|}{ Tipos de medición } & Público & \multicolumn{1}{c|}{ Privado } \\
\hline Medición de la producción & 3,75 & 3,67 \\
\hline Medición de la exposición & 4,50 & 4,44 \\
\hline Medición de la opinión y actitud del público & 4,13 & 4,78 \\
\hline Medición de las acciones y comportamientos del público & 4,00 & 4,67 \\
\hline Total & 4,09 & 4,39 \\
\hline
\end{tabular}

Fuente: elaboración propia. 
Los hospitales privados son más propensos a tener un plan definido para afrontar posibles crisis. Seis de los nueve responsables de comunicación encuestados de este ámbito asegura contar con este documento, lo que se corresponde con un $66,67 \%$. Una persona no tiene conocimiento de este tema y los dos restantes reconocen no poseer esta clase de manual. En el caso de los centros públicos, las respuestas están más repartidas: la mitad de sus responsables de información afirman tener un plan de crisis mientras que la otra porción no lo posee.

Tabla 82. Frecuencia y porcentaje de los departamentos que tienen un plan de crisis

\begin{tabular}{|l|r|r|r|r|r|r|}
\hline \multirow{2}{*}{$\begin{array}{c}\text { Plan de } \\
\text { crisis }\end{array}$} & \multicolumn{2}{|c|}{ Público } & \multicolumn{2}{c|}{ Privado } & \multicolumn{2}{c|}{ Total } \\
\cline { 2 - 7 } & $\mathbf{N}^{\mathbf{0}}$ & \multicolumn{1}{c}{$\boldsymbol{\%}$} & $\mathbf{N}^{\mathbf{0}}$ & \multicolumn{1}{c|}{$\%$} & \multicolumn{1}{c|}{$\mathbf{N}^{\mathbf{0}}$} & \multicolumn{1}{c}{$\%$} \\
\hline Sí & 4 & 50,00 & 6 & 66,67 & 10 & 58,82 \\
\hline No & 4 & 50,00 & 2 & 22,22 & 6 & 35,29 \\
\hline NS/NC & 0 & 0,00 & 1 & 1,11 & 1 & 5,88 \\
\hline Total & 8 & 100,00 & 9 & 100,00 & 17 & 100,00 \\
\hline
\end{tabular}

Fuente: elaboración propia.

Una buena parte de los responsables de comunicación, tanto de las clínicas públicas $(25,00 \%)$ como privadas $(42,86 \%)$, desconoce si se revisa el plan de crisis. Los pocos que tienen conocimiento de ello aseguran que, o no se realiza nunca, o se hace de entre seis meses a dos años. También hay coincidencia entre ambas dependencias en la frecuencia con la que se pone en práctica el plan de crisis. En un alto porcentaje, o no se tiene constancia de ello (25,00\% en los públicos y 54,14\% en los privados) o no se hace nunca $(50,00 \%$ y $28,57 \%$, en este orden). El responsable de comunicación de cada titularidad que afirma llevar a la práctica el plan lo hace de entre seis meses a dos años.

Tabla 83. Frecuencia con la que se revisa el plan de crisis

\begin{tabular}{|l|r|c|r|c|r|r|}
\hline \multirow{2}{*}{ Revisión del plan de crisis } & \multicolumn{2}{|c|}{ Público } & \multicolumn{2}{c|}{ Privado } & \multicolumn{2}{c|}{ Total } \\
\cline { 2 - 7 } & \multicolumn{1}{|c|}{$\mathbf{N}^{\mathbf{0}}$} & \multicolumn{1}{c|}{$\%$} & \multicolumn{1}{c|}{$\mathbf{N}^{\mathbf{0}}$} & \multicolumn{1}{c|}{$\%$} & \multicolumn{1}{c|}{$\mathbf{N}^{\mathbf{0}}$} & \multicolumn{1}{c|}{$\%$} \\
\hline De más de seis meses a un año & 1 & 25,00 & 2 & 28,57 & 3 & 27,27 \\
\hline $\begin{array}{l}\text { De más de un año y medio a } \\
\text { dos años }\end{array}$ & 1 & 25,00 & 1 & 14,29 & 2 & 18,18 \\
\hline Nunca & 1 & 25,00 & 1 & 14,29 & 2 & 18,18 \\
\hline NS/NC & 1 & 25,00 & 3 & 42,86 & 4 & 36,36 \\
\hline Total & 4 & 100,00 & 7 & 100,00 & 11 & 100,00 \\
\hline
\end{tabular}

Fuente: elaboración propia. 
Tabla 84. Frecuencia con la que se pone en práctica el plan de crisis

\begin{tabular}{|l|r|r|r|r|r|r|}
\hline \multirow{2}{*}{ Práctica del plan de crisis } & \multicolumn{2}{|c|}{ Público } & \multicolumn{2}{c|}{ Privado } & \multicolumn{2}{|c|}{ Total } \\
\cline { 2 - 7 } & \multicolumn{1}{|c|}{$\mathbf{N}^{\mathbf{0}}$} & \multicolumn{1}{c|}{$\mathbf{\%}$} & \multicolumn{1}{c|}{$\mathbf{N}^{\mathbf{0}}$} & \multicolumn{1}{c|}{$\%$} & $\mathbf{N}^{\mathbf{0}}$ & \multicolumn{1}{c|}{$\mathbf{0}$} \\
\hline $\begin{array}{l}\text { De más de dos años a dos } \\
\text { años y medio }\end{array}$ & 1 & 25,00 & 0 & 0,00 & 1 & 9,09 \\
\hline $\begin{array}{l}\text { De más de dos años y medio } \\
\text { a tres años }\end{array}$ & 0 & 0,00 & 1 & 14,29 & 1 & 9,09 \\
\hline Nunca & 2 & 50,00 & 2 & 28,57 & 4 & 36,36 \\
\hline NS/NC & 1 & 25,00 & 4 & 57,14 & 5 & 45,45 \\
\hline Total & 4 & 100,00 & 7 & 100,00 & 11 & 100,00 \\
\hline
\end{tabular}

Fuente: elaboración propia.

Tampoco existe una gran discrepancia entre el porcentaje de hospitales públicos que tienen un equipo determinado de personas para afrontar las posibles crisis $(62,50 \%)$ frente a los privados $(77,78)$, así como los que no cuentan con este grupo $(25,00 \%$ y $11,11 \%$, respectivamente) y los que lo desconocen $(12,5 \%$ y $11,11 \%)$.

Tabla 85. Departamentos que tienen un equipo prefijado de personas para las posibles crisis

\begin{tabular}{|l|r|r|r|r|r|r|}
\hline \multirow{2}{*}{$\begin{array}{c}\text { Equipo de } \\
\text { crisis }\end{array}$} & \multicolumn{2}{|c|}{ Público } & \multicolumn{2}{c|}{ Privado } & \multicolumn{2}{c|}{ Total } \\
\cline { 2 - 7 } & $\mathbf{N}^{\mathbf{0}}$ & \multicolumn{1}{c|}{$\%$} & \multicolumn{1}{c|}{$\mathbf{N}^{\mathbf{0}}$} & \multicolumn{1}{c|}{$\%$} & \multicolumn{1}{c|}{$\mathbf{N}^{\mathbf{0}}$} & \multicolumn{1}{c}{$\%$} \\
\hline Sí & 5 & 62,50 & 7 & 77,78 & 12 & 70,59 \\
\hline No & 2 & 25,00 & 1 & 11,11 & 3 & 17,65 \\
\hline NS/NC & 1 & 12,50 & 1 & 11,11 & 2 & 11,76 \\
\hline Total & 8 & 100,00 & 9 & 100,00 & 17 & 100,00 \\
\hline
\end{tabular}

Fuente: elaboración propia.

A pesar de que tanto los responsables de comunicación de los hospitales públicos están igual de satisfechos con sus labores diarias que los de los privados (3,88 y 3,89, respectivamente), los primeros consideran que su departamento es más importante para el hospital. En una escala de 1 a 5, han otorgado a esta idea una cifra muy cercana al máximo, más concretamente un 4,88, mientras que los privados tienen casi medio punto menos, 4,44 .

Tabla 86. Importancia y satisfacción con las labores del departamento de comunicación

\begin{tabular}{|l|r|r|}
\hline \multicolumn{1}{|c|}{ Importancia y satisfacción con el departamento } & Público & Privado \\
\hline $\begin{array}{l}\text { ¿Cómo de importante considera al departamento de } \\
\text { relaciones públicas o comunicación para el hospital? }\end{array}$ & 4,88 & 4,44 \\
\hline $\begin{array}{l}\text { ¿Cómo de satisfecho está con las actividades de relaciones } \\
\text { públicas o comunicación que lleva a cabo el centro? }\end{array}$ & 3,88 & 3,89 \\
\hline
\end{tabular}

Fuente: elaboración propia. 


\subsubsection{TRABAJADOR EN PLANTILLA VS. EMPRESA EXTERNA}

\subsection{CARACTERÍSTICAS DE LOS DEPARTAMENTOS DE COMUNICACIÓN}

Si se dividen a los trabajadores por su pertenencia al hospital o a una empresa de comunicación externa, se aprecia que es más habitual que los comunicadores trabajen en plantilla dentro de los hospitales. Esto sucede en el 58,82\% de los casos analizados.

Tabla 87. Número de trabajadores en plantilla respecto a las agencias externas contratadas por pertenencia al hospital

\begin{tabular}{|c|r|r|}
\hline $\begin{array}{c}\text { Pertenencia del departamento de } \\
\text { comunicación }\end{array}$ & \multicolumn{1}{|c|}{$\mathbf{N}^{\mathbf{0}}$} & \multicolumn{1}{c|}{$\%$} \\
\hline Pertenece a una empresa externa & 7 & 41,18 \\
\hline Pertenece al hospital & 10 & 58,82 \\
\hline Total & 17 & 100,00 \\
\hline
\end{tabular}

Fuente: elaboración propia.

Lo más frecuente es que una sola persona se haga cargo del departamento de comunicación, tanto de forma interna como externa. En porcentajes, se corresponde con el $60,00 \%$ y el 50,00\%, respectivamente. El número de casos en los que dos empleados dirigen la comunicación de un hospital también es muy similar: 30,00\% y 33,33\%, en este orden.

Tabla 88. Número de personas que trabajan en los departamentos de comunicación según pertenencia al hospital

\begin{tabular}{|c|r|r|r|r|r|r|}
\hline \multirow{2}{*}{$\begin{array}{c}\text { Número de } \\
\text { trabajadores }\end{array}$} & \multicolumn{2}{|c|}{ Interno } & \multicolumn{2}{c|}{ Externo } & \multicolumn{2}{|c|}{ Total } \\
\cline { 2 - 7 } & \multicolumn{1}{|c|}{$\mathbf{N}^{\mathbf{0}}$} & \multicolumn{1}{c|}{$\%$} & \multicolumn{1}{c|}{$\mathbf{N}^{\mathbf{0}}$} & \multicolumn{1}{c|}{$\%$} & \multicolumn{1}{c|}{$\mathbf{N}^{\mathbf{0}}$} & \multicolumn{1}{c}{$\%$} \\
\hline 1 & 6 & 60,00 & 3 & 50,00 & 9 & 56,25 \\
\hline 2 & 3 & 30,00 & 2 & 33,33 & 5 & 31,25 \\
\hline 3 & 0 & 0,00 & 1 & 16,67 & 1 & 6,25 \\
\hline 4 & 1 & 10,00 & 0 & 0,00 & 1 & 6,25 \\
\hline Total & 10 & 100,00 & 6 & 100,00 & 16 & 100,00 \\
\hline
\end{tabular}

Fuente: elaboración propia.

La persona encuestada más joven tiene 30 años y pertenece a la plantilla de un hospital, mientras que la más mayor cuenta con 63 años y trabaja en una empresa externa. La media es de 39,71 a nivel interno y de 43,13 a nivel externo, con unas desviaciones típicas de 5,17 y 9,05 años, respectivamente. 
Tabla 89. Edad de los trabajadores

\begin{tabular}{|l|r|r|r|r|r|}
\hline Pertenencia & N & Mínimo & Máximo & Media & $\begin{array}{c}\text { Desviación } \\
\text { típica }\end{array}$ \\
\hline Interno & 14 & 30 & 47 & 39,71 & 5,17 \\
\hline Externo & 8 & 35 & 63 & 43,13 & 9,05 \\
\hline Total & 22 & 30 & 63 & 40,95 & 6,83 \\
\hline
\end{tabular}

Fuente: elaboración propia.

Hay más mujeres trabajando tanto a nivel interno como externo en los hospitales analizados. Concretamente, en el primer caso, se corresponde con el 56,25\% de los casos respecto al 43,75\% que arrojan los hombres. En las agencias externas, las diferencias son incluso más acusadas: $62,50 \%$ para las mujeres y 37,50\% para los hombres.

Tabla 90. Sexo de los trabajadores

\begin{tabular}{|l|r|r|r|r|r|r|}
\hline \multirow{2}{*}{ Sexo } & \multicolumn{2}{|c|}{ Interno } & \multicolumn{2}{c|}{ Externo } & \multicolumn{2}{c|}{ Total } \\
\cline { 2 - 7 } & \multicolumn{1}{c|}{$\mathbf{N}^{\mathbf{0}}$} & \multicolumn{1}{c}{$\%$} & \multicolumn{1}{c|}{$\mathbf{N}^{\mathbf{0}}$} & \multicolumn{1}{c|}{$\%$} & \multicolumn{1}{c|}{$\mathbf{N}^{\mathbf{0}}$} & \multicolumn{1}{c|}{$\%$} \\
\hline Hombre & 7 & 43,75 & 3 & 37,50 & 10 & 41,67 \\
\hline Mujer & 9 & 56,25 & 5 & 62,50 & 14 & 58,33 \\
\hline Total & 16 & 100,00 & 8 & 100,00 & 24 & 100,00 \\
\hline
\end{tabular}

Fuente: elaboración propia.

No hay demasiadas diferencias en los años de experiencia en el ámbito comunicativo de los trabajadores dividiéndolos por pertenencia al centro. Así, los que están contratados directamente tienen, como mínimo, 9 años de práctica $\mathrm{y}$, como máximo, 21, siendo la media 16,75. En el caso de los empleados a cargo de empresas externas, las cifras son ligeramente más elevadas: 12,23 y 17,60, en este orden.

Tabla 91. Años de experiencia en comunicación de los trabajadores

\begin{tabular}{|l|r|r|r|r|r|}
\hline Pertenencia & N & \multicolumn{1}{|c|}{ Mínimo } & Máximo & \multicolumn{1}{c|}{ Media } & $\begin{array}{c}\text { Desviación } \\
\text { típica }\end{array}$ \\
\hline Interno & 12 & 9 & 21 & 16,75 & 3,31 \\
\hline Externo & 5 & 12 & 23 & 17,60 & 4,28 \\
\hline Total & 17 & 9 & 23 & 17,00 & 3,50 \\
\hline
\end{tabular}

Fuente: elaboración propia.

Aunque lo más probable, en el $81,25 \%$ de los casos, es que las personas en plantilla tengan como nivel máximo de estudios una licenciatura, en las empresas externas es más frecuente que los trabajadores cuenten con un máster (42,86\%); este porcentaje, en el caso de los públicos, se reduce al 6,25\%. Por otra parte, una persona interna cuenta con un diploma de estudios avanzados, tesina o equivalente, mientras que en el terreno externo ningún encuestado refleja tener este nivel. 
Tabla 92. Nivel de estudios de los trabajadores

\begin{tabular}{|l|r|r|r|r|r|r|}
\hline \multirow{2}{*}{\multicolumn{1}{|c|}{ Nivel de estudios }} & \multicolumn{2}{c|}{ Interno } & \multicolumn{2}{c|}{ Externo } & \multicolumn{2}{c|}{ Total } \\
\cline { 2 - 7 } & \multicolumn{1}{c|}{$\mathbf{N}^{\mathbf{0}}$} & \multicolumn{1}{c}{$\%$} & \multicolumn{1}{c|}{$\mathbf{N}^{\mathbf{0}}$} & \multicolumn{1}{c|}{$\%$} & \multicolumn{1}{c|}{$\mathbf{N}^{\mathbf{0}}$} & \multicolumn{1}{c}{$\%$} \\
\hline Doctorado & 0 & 0,00 & 0 & 0,00 & 0 & 0,00 \\
\hline $\begin{array}{l}\text { Diploma de estudios } \\
\text { avanzados o tesina }\end{array}$ & 1 & 6,25 & 0 & 0,00 & 1 & 4,35 \\
\hline Máster & 1 & 6,25 & 3 & 42,86 & 4 & 17,39 \\
\hline Especialista universitario & 0 & 0,00 & 1 & 14,29 & 1 & 4,35 \\
\hline Licenciatura & 13 & 81,25 & 3 & 42,86 & 16 & 69,57 \\
\hline Diplomatura & 1 & 6,25 & 0 & 0,00 & 1 & 4,35 \\
\hline Total & 16 & 100,00 & 7 & 100,00 & 23 & 100,00 \\
\hline
\end{tabular}

Fuente: elaboración propia.

En cuanto a la rama de conocimiento principal de los estudios, se observa una predominancia del Periodismo en el ámbito interno (93,75\%), mientras que en el externo las especialidades están más divididas. Así, la mitad de los encuestados de las agencias de comunicación poseen estudios de Periodismo (50,00\%), el 33,33\% de Relaciones Públicas y el 16,67\%, de otras ramas de las Ciencias Sociales.

Tabla 93. Rama de conocimiento de los trabajadores según la dependencia de los hospitales

\begin{tabular}{|c|c|c|c|c|c|c|}
\hline \multirow{2}{*}{$\begin{array}{c}\text { Rama de } \\
\text { conocimiento }\end{array}$} & \multicolumn{2}{|c|}{ Interno } & \multicolumn{2}{|c|}{ Externo } & \multicolumn{2}{|c|}{ Total } \\
\hline & $\mathrm{N}^{\mathbf{o}}$ & $\%$ & $\mathbf{N}^{\mathbf{0}}$ & $\%$ & $\mathbf{N}^{0}$ & $\%$ \\
\hline Periodismo & 15 & 93,75 & 3 & 50,00 & 18 & 81,82 \\
\hline Relaciones públicas & 1 & 6,25 & 2 & 33,33 & 3 & 13,64 \\
\hline $\begin{array}{l}\text { Otros - Ciencias } \\
\text { Sociales }\end{array}$ & 0 & 0,00 & 1 & 16,67 & 1 & 4,55 \\
\hline Total & 16 & 100,00 & 6 & 100,00 & 22 & 100,00 \\
\hline
\end{tabular}

Fuente: elaboración propia.

\subsection{USO DE LAS RELACIONES PÚBLICAS}

Tanto con comunicadores en plantilla como con empresas externas, el modelo de relaciones públicas más frecuente en los hospitales es el de información pública, sobre todo en el segundo caso. Más concretamente, en una escala de 1 a 5, los empleados externos otorgan a este modelo un 4,75 y los internos, un 4,30. Los primeros otorgan la máxima puntuación a la idea "entendemos los valores informativos de los periodistas" 
(respecto al 4,30 de los segundos), un 4,86 a "suministramos información objetiva sobre nuestra organización" (los internos, un 4,20) y un 4,71 a "actuamos como un periodista interno de nuestra organización" (respecto al 4,20 de sus compañeros).

Después del modelo de información pública, las personas que trabajan internamente adoptan un enfoque característico del agente de prensa (3,83 en una escala de 1 a 5), mientras que los que lo hacen de forma externa hacen lo mismo con el bidireccional simétrico persuasivo $(4,07)$. Así, los primeros desean "la máxima cobertura en nuestros eventos" con un 4,40 sobre 5 y "colocar el nombre de nuestra organización en los medios" con un 4,30. En cambio, los comunicadores que trabajan de forma externa opinan que "uno de nuestros principales objetivos es mantener una buena relación con los públicos" y que "de esa buena relación, pretendemos crear un ambiente en el que se reciban mejor nuestras propuestas o informaciones", frases pertenecientes al modelo bidireccional simétrico persuasivo, con un 4,86 .

Los enfoques menos utilizados son los bidireccionales, sobre todo el asimétrico. En una escala de 1 a 5, obtiene un 2,75 para las personas que trabajan internamente y un 2,79 para los comunicadores externos. Tanto unos como otros están más de acuerdo con las frases "aplicamos la teoría de las actitudes en una campaña" (4,20 y 4,00, respectivamente) y "queremos que los públicos actúen como quiere la organización" (2,70 y 3,29, en este orden) y más en desacuerdo con "manipulamos científicamente a los públicos" (1,60 y 1,29). El modelo simétrico bidireccional, por su parte, obtiene un 3,05 para los empleados en plantilla y un 2,96 para los pertenecientes a agencias ajenas. En ambos casos, la idea más votada es "ayudamos a los dirigentes a entender la opinión de públicos particulares" (3,90 y 4,14, respectivamente) y la menos, "negociamos con grupos de presión" $(2,30$ y 1,86). 
Tabla 94. Medias de las afirmaciones de los cinco modelos de relaciones públicas estudiados

\begin{tabular}{|c|c|c|}
\hline Modelo & Interno & Externo \\
\hline \multicolumn{3}{|l|}{ Agente de prensa } \\
\hline $\begin{array}{l}\text { Convencemos al periodista para que dé a conocer nuestra } \\
\text { organización }\end{array}$ & 3,60 & 2,71 \\
\hline Colocamos el nombre de nuestra organización en los medios & 4,30 & 3,71 \\
\hline Eliminamos la cobertura mediática negativa & 3,00 & 2,29 \\
\hline Queremos la máxima cobertura en nuestros eventos & 4,40 & 4,71 \\
\hline Total & 3,83 & 3,36 \\
\hline \multicolumn{3}{|l|}{ Información pública } \\
\hline $\begin{array}{l}\begin{array}{l}\text { Suministramos información } \\
\text { organización }\end{array} \\
\end{array}$ & 4,20 & 4,86 \\
\hline Entendemos los valores informativos de los periodistas & 4,30 & 5,00 \\
\hline Preparamos informaciones para ser usadas por los periodistas & 4,50 & 4,43 \\
\hline Actuamos como un periodista interno de nuestra organización & 4,20 & 4,71 \\
\hline Total & 4,30 & 4,75 \\
\hline \multicolumn{3}{|l|}{ Asimétrico bidireccional } \\
\hline Queremos que los públicos actúen como quiere la organización & 2,70 & 3,29 \\
\hline Aplicamos la teoría de las actitudes en una campaña & 4,20 & 4,00 \\
\hline Manipulamos científicamente a los públicos & 1,60 & 1,29 \\
\hline $\begin{array}{l}\text { Persuadimos al público de que nuestra organización tiene } \\
\text { razón sobre un determinado tema }\end{array}$ & 2,50 & 2,57 \\
\hline Total & 2,75 & 2,79 \\
\hline \multicolumn{3}{|l|}{ Simétrico bidireccional } \\
\hline Determinamos cómo el público reacciona ante la organización & 2,70 & 2,29 \\
\hline Negociamos con grupos de presión & 2,30 & 1,86 \\
\hline $\begin{array}{l}\text { Utilizamos las teorías de la resolución de conflictos en nuestro } \\
\text { trato con los públicos }\end{array}$ & 3,30 & 3,57 \\
\hline $\begin{array}{l}\text { Ayudamos a los dirigentes a entender la opinión de públicos } \\
\text { particulares }\end{array}$ & 3,90 & 4,14 \\
\hline Total & 3,05 & 2,96 \\
\hline \multicolumn{3}{|l|}{ Bidireccional simétrico persuasivo } \\
\hline $\begin{array}{l}\text { Uno de nuestros principales objetivos es mantener una buena } \\
\text { relación con los públicos }\end{array}$ & 4,00 & 4,86 \\
\hline $\begin{array}{l}\text { De esa buena relación, pretendemos crear un ambiente en el } \\
\text { que se reciban mejor nuestras propuestas o informaciones }\end{array}$ & 4,10 & 4,86 \\
\hline $\begin{array}{l}\text { Creemos que una buena relación con los públicos, sin un } \\
\text { ejercicio de persuasión, no ayuda a que los públicos se sientan } \\
\text { persuadidos a hacer lo que queremos }\end{array}$ & 2,60 & 2,71 \\
\hline $\begin{array}{l}\text { El objetivo final es conseguir que los públicos acepten y } \\
\text { adopten mejor nuestras propuestas y acciones }\end{array}$ & 3,60 & 3,86 \\
\hline Total & 3,58 & 4,07 \\
\hline
\end{tabular}

Fuente: elaboración propia. 
Las valoraciones concedidas al modelo de influencia personal son prácticamente idénticas. En conjunto, alcanzan un 3,63 en el régimen interno y un 3,64 en el externo. La idea más recurrente es "tengo buenas relaciones interpersonales con otros empleados" (4,90 y 4,71, respectivamente), seguido de "tengo buenas relaciones interpersonales con las personas externas de mi organización" (4,70 y 4,86). En cambio, muy pocos procuran beneficios, tales como comidas o regalos, para ganar influencia con sus contactos personales (en este orden, 1,20 y 1,00).

Tabla 95. Medias de las afirmaciones del modelo de influencia personal

\begin{tabular}{|l|r|r|}
\hline \multicolumn{1}{|c|}{ Modelo de influencia personal } & Interno & Externo \\
\hline Tengo buenas relaciones interpersonales con otros empleados & 4,90 & 4,71 \\
\hline $\begin{array}{l}\text { Tengo buenas relaciones interpersonales con las personas } \\
\text { externas de mi organización }\end{array}$ & 4,70 & 4,86 \\
\hline $\begin{array}{l}\text { Las relaciones sociales es una de mis actividades más } \\
\text { importantes }\end{array}$ & 3,70 & 4,00 \\
\hline $\begin{array}{l}\text { Procuro beneficios (comidas, regalos) para ganar influencia } \\
\text { con mis contactos personales }\end{array}$ & 1,20 & 1,00 \\
\hline Total & 3,63 & 3,64 \\
\hline
\end{tabular}

Fuente: elaboración propia.

En cuanto a los roles, tampoco se aprecian demasiadas diferencias. Es más habitual que los comunicadores adopten una visión técnica tanto en el ámbito interno $(3,83)$ como en el externo $(3,86)$, aunque las diferencias son casi inapreciables respecto al enfoque directivo $(3,75$ y 3,68 , en este orden). Las frases con las que están más de acuerdo las dos pertenencias, aunque las valoraciones son más altas en las personas que trabajan en agencias externas, son "desarrollar estrategias para solucionar problemas de comunicación" y "manejar las respuestas de la organización hacia diferentes asuntos", ambas del rol directivo. "Dirigir personas" y "conducir investigación evaluativa", las dos restantes ideas de este enfoque, obtienen notas más elevadas cuando se trata de trabajadores en plantilla. En cuanto al rol técnico, no existen demasiadas discrepancias analizando individualmente las ideas propuestas; en ambos casos, la oración "coordinar ruedas de prensa o concertar cobertura mediática para un evento" es la más votada y "tomar fotografías y coordinar la fotografía", la que menos. 
Tabla 96. Medias de las afirmaciones de los dos roles de relaciones públicas estudiados

\begin{tabular}{|c|c|c|}
\hline Rol & Interno & Externo \\
\hline \multicolumn{3}{|l|}{ Rol técnico } \\
\hline $\begin{array}{l}\text { Coordinar ruedas de prensa o concertar cobertura mediática } \\
\text { para un evento }\end{array}$ & 4,30 & 4,14 \\
\hline Elaborar publicaciones & 3,80 & 4,14 \\
\hline Crear y dirigir la oficina del portavoz & 4,00 & 3,86 \\
\hline Tomar fotografías y coordinar la fotografía & 3,20 & 3,29 \\
\hline Total & 3,83 & 3,86 \\
\hline \multicolumn{3}{|l|}{ Rol directivo } \\
\hline Dirigir personas & 3,40 & 2,86 \\
\hline Conducir investigación evaluativa & 2,80 & 2,29 \\
\hline $\begin{array}{l}\text { Desarrollar estrategias para solucionar problemas de } \\
\text { comunicación }\end{array}$ & 4,40 & 4,71 \\
\hline $\begin{array}{l}\text { Manejar las respuestas de la organización hacia diferentes } \\
\text { asuntos }\end{array}$ & 4,40 & 4,86 \\
\hline $\begin{array}{ll} & \text { Total }\end{array}$ & 3,75 & 3,68 \\
\hline
\end{tabular}

Fuente: elaboración propia.

El cómputo total de valoraciones otorgadas a las ideas para descubrir el nivel de definición y consecución de objetivos concretos y sobre la participación en planes estratégicos son más altas en los participantes de agencias de comunicación $(4,14)$ que en los trabajadores internos $(3,90)$. Los primeros tienen a tener con más frecuencia una guía o plan de comunicación (4,29 respecto al 3,80 de los segundos) y a disponer de una serie de objetivos concretos definidos $(4,57$ y 4,00$)$. En el resto de ideas, las diferencias no son demasiado marcadas.

Tabla 97. Definición y consecución de objetivos concretos y sobre la participación en planes estratégicos

\begin{tabular}{|l|r|r|}
\hline \multicolumn{1}{|c|}{ Objetivos concretos y participación en planes estratégicos } & Interno & Externo \\
\hline Existe una guía o un plan de comunicación & 3,80 & 4,29 \\
\hline Hay una serie de objetivos concretos definidos & 4,00 & 4,57 \\
\hline $\begin{array}{l}\text { Los objetivos de comunicación están vinculados a los objetivos } \\
\text { del hospital en general }\end{array}$ & 4,60 & 4,43 \\
\hline Normalmente se cumplen todos los objetivos propuestos & 3,50 & 3,57 \\
\hline $\begin{array}{l}\text { El equipo estratégico de planes suele consultar al departamento } \\
\text { de comunicación }\end{array}$ & 3,60 & 3,86 \\
\hline Total & 3,90 & 4,14 \\
\hline
\end{tabular}

Fuente: elaboración propia. 
La principal diferencia en las respuestas acerca de la participación de los miembros del departamento de comunicación en el equipo estratégico es que los comunicadores externos están al corriente de su pertenencia o ausencia, al contrario de los trabajadores internos, los cuales, en un $20 \%$, no quieren o no saben contestar a la pregunta. Dentro de este último grupo, el porcentaje de los que, efectivamente, forman parte de este grupo es idéntico a los que no: $40 \%$. En cambio, cuando se observan los resultados de las agencias externas, el 57,14\% pertenece al equipo estratégico y el $42,86 \%$ no forma parte de él.

Tabla 98. Frecuencia y porcentaje de los miembros del departamento de comunicación que forman parte del equipo estratégico

\begin{tabular}{|c|r|r|r|r|r|c|}
\hline \multirow{2}{*}{$\begin{array}{c}\text { Equipo } \\
\text { estratégico }\end{array}$} & \multicolumn{2}{|c|}{ Interno } & \multicolumn{2}{c|}{ Externo } & \multicolumn{2}{c|}{ Total } \\
\cline { 2 - 7 } & \multicolumn{1}{c|}{$\mathbf{N}^{\mathbf{0}}$} & \multicolumn{1}{c}{$\%$} & \multicolumn{1}{c|}{$\mathbf{N}^{\mathbf{0}}$} & \multicolumn{1}{c|}{$\%$} & $\mathbf{N}^{\mathbf{0}}$ & \multicolumn{1}{c}{$\%$} \\
\hline SÍ & 4 & 40,00 & 4 & 57,14 & 8 & 47,06 \\
\hline No & 4 & 40,00 & 3 & 42,86 & 7 & 41,18 \\
\hline NS/NC & 2 & 20,00 & 0 & 0,00 & 2 & 11,76 \\
\hline Total & 10 & 100,00 & 7 & 100,00 & 17 & 100,00 \\
\hline
\end{tabular}

Fuente: elaboración propia.

Aunque, en general, la nota que ofrecen los empleados que trabajan tanto interna como externamente al conjunto de públicos es similar (4,17 en el primer caso y 4,05 en el segundo en una escala de 1 a 5), existen variaciones dentro de cada grupo. Las mayores diferencias se encuentran en los agentes políticos e institucionales (con un 4,30 y un 2,83 , en este orden, una relación estadísticamente significativa a favor de las personas internas con $\mathrm{r}=0,004)$, los inversores o accionistas $(1,86$ y 3,17) y los familiares $(4,50$ y 4,17). En el resto de agrupaciones, las diferencias no son demasiado marcadas.

Tabla 99. Importancia de los diferentes públicos para el departamento de comunicación

\begin{tabular}{|l|r|r|}
\hline \multicolumn{1}{|c|}{ Públicos } & Interno & Externo \\
\hline Pacientes & 4,80 & 4,67 \\
\hline Familiares & 4,50 & 4,17 \\
\hline Empleados & 4,90 & 4,67 \\
\hline Agentes políticos e institucionales & 4,30 & 2,83 \\
\hline Inversores o accionistas (en su caso) & 1,86 & 3,17 \\
\hline Medios de comunicación & 4,60 & 4,83 \\
\hline Población en general & 4,20 & 4,00 \\
\hline Total & 4,17 & 4,05 \\
\hline
\end{tabular}

Fuente: elaboración propia. 
Ahora bien, donde existen discrepancias claras es en la importancia de las distintas etapas de un programa de relaciones públicas. Mismamente, en conjunto, la valoración es más alta para los trabajadores de empresas externas $(4,54)$ que para los internos $(3,88)$. En ambos casos, la etapa de comunicación es la que consigue una mejor valoración, aunque es más elevada a nivel externo $(5,00)$ que externo $(4,40)$, al igual que sucede en la fase de investigación $(4,00$ y 3,60, respectivamente), en la planificación $(4,71$ y 4,00) y en la evaluación $(4,43$ y 3,50$)$.

Tabla 100. Importancia que le otorga el departamento de comunicación a las diferentes etapas de un programa de relaciones públicas

\begin{tabular}{|l|r|r|}
\hline $\begin{array}{l}\text { Fases de un programa } \\
\text { de relaciones públicas }\end{array}$ & Interno & Externo \\
\hline Investigación & 3,60 & 4,00 \\
\hline Planificación & 4,00 & 4,71 \\
\hline Comunicación & 4,40 & 5,00 \\
\hline Evaluación & 3,50 & 4,43 \\
\hline Total & 3,88 & 4,54 \\
\hline
\end{tabular}

Fuente: elaboración propia.

En cuanto a las herramientas de investigación utilizadas, se observa que las personas que trabajan en empresas externas llevan más a menudo análisis de la percepción del público $(71,43 \%)$ que los trabajadores internos $(0,00 \%)$, así como pruebas piloto $(28,57 \%$ y $0,00 \%)$. La primera relación, de hecho, resulta ser estadísticamente significativa $(\mathrm{r}=0,030$ según el estadístico exacto de Fisher). En cambio, las personas en plantilla recurren con mayor frecuencia a la búsqueda de materiales propios de la organización $(100,00 \%)$ que los externos $(71,43 \%)$, a las encuestas $(40,00 \%$ y $28,57 \%$, en este orden) y a las técnicas de reflexión en voz alta $(40,00 \%$ y $14,29 \%)$.

Tabla 101. Herramientas de investigación utilizadas por pertenencia al hospital

\begin{tabular}{|l|r|r|r|r|r|r|}
\hline \multicolumn{1}{|c|}{$\begin{array}{c}\text { Herramientas de } \\
\text { investigación }\end{array}$} & \multicolumn{1}{c|}{ Interno } & \multicolumn{2}{c|}{ Externo } & \multicolumn{2}{c|}{ Total } \\
\cline { 2 - 7 } & \multicolumn{1}{c|}{$\mathbf{N}^{\mathbf{0}}$} & \multicolumn{1}{c|}{$\%$} & \multicolumn{1}{c|}{$\mathbf{N}^{\mathbf{0}}$} & \multicolumn{1}{c|}{$\%$} & \multicolumn{1}{c|}{$\mathbf{N}^{\mathbf{0}}$} & \multicolumn{1}{c|}{$\%$} \\
\hline $\begin{array}{l}\text { Búsqueda de materiales } \\
\text { propios de la organización }\end{array}$ & 10 & 100,00 & 5 & 71,43 & 15 & 88,24 \\
\hline $\begin{array}{l}\text { Búsqueda de bibliografía y } \\
\text { estudios ajenos }\end{array}$ & 5 & 50,00 & 3 & 42,86 & 8 & 47,06 \\
\hline $\begin{array}{l}\text { Análisis de la cobertura en } \\
\text { prensa de la organización }\end{array}$ & 10 & 100,00 & 6 & 85,71 & 16 & 94,12 \\
\hline $\begin{array}{l}\text { Búsqueda general en } \\
\text { Internet }\end{array}$ & 7 & 70,00 & 6 & 85,71 & 13 & 76,47 \\
\hline Test de mensajes & 1 & 10,00 & 2 & 28,57 & 3 & 17,65 \\
\hline Grupos de discusión & 2 & 20,00 & 1 & 14,29 & 3 & 17,65 \\
\hline
\end{tabular}




\begin{tabular}{|c|c|c|c|c|c|c|}
\hline \multirow{2}{*}{$\begin{array}{l}\text { Herramientas de } \\
\text { investigación }\end{array}$} & \multicolumn{2}{|c|}{ Interno } & \multicolumn{2}{|c|}{ Externo } & \multicolumn{2}{|c|}{ Total } \\
\hline & $\mathbf{N}^{\mathbf{0}}$ & $\%$ & $\mathbf{N}^{\mathbf{o}}$ & $\%$ & $\mathbf{N}^{\mathbf{o}}$ & $\%$ \\
\hline Auditoría de comunicación & 4 & 40,00 & 4 & 57,14 & 8 & 47,06 \\
\hline Encuestas & 4 & 40,00 & 2 & 28,57 & 6 & 35,29 \\
\hline Entrevistas & 8 & 80,00 & 6 & 85,71 & 14 & 82,35 \\
\hline Pruebas piloto & 0 & 0,00 & 2 & 28,57 & 2 & 11,76 \\
\hline Mensajes de doble versión & 0 & 0,00 & 1 & 14,29 & 1 & 5,88 \\
\hline Análisis de la percepción & 0 & 0,00 & 5 & 71,43 & 5 & 29,41 \\
\hline Experimentos & 1 & 10,00 & 0 & 0,00 & 1 & 5,88 \\
\hline $\begin{array}{l}\text { Técnicas de reflexión en } \\
\text { voz alta }\end{array}$ & 4 & 40,00 & 1 & 14,29 & 5 & 29,41 \\
\hline Cómputo de respuestas & 56 & - & 44 & - & 100 & - \\
\hline Total respuestas únicas & 10 & - & 7 & - & 17 & - \\
\hline
\end{tabular}

Fuente: elaboración propia.

La situación cambia cuando se pregunta a los participantes acerca de los instrumentos que usan para planificar los programas de relaciones públicas. De los ocho propuestos, los empleados en plantilla únicamente adelantan a los externos en dos ocasiones, más concretamente en la definición de públicos $(90,00 \%$ y 71,43, respectivamente) y en el análisis de la situación (90,00\% y 57,14\%, en este orden). En cambio, las agencias de comunicación están por delante en el resto de herramientas, registrando una mayor diferencia en las tácticas $(85,71 \%$ frente al $50,00 \%$ de los internos) y en el presupuesto (57,14\% y $30,00 \%$, en este orden).

Tabla 102. Herramientas de planificación utilizadas por pertenencia al hospital

\begin{tabular}{|l|r|r|r|r|r|r|}
\hline \multirow{2}{*}{$\begin{array}{c}\text { Herramientas de } \\
\text { planificación }\end{array}$} & \multicolumn{2}{c|}{ Interno } & \multicolumn{2}{c|}{ Externo } & \multicolumn{2}{c|}{ Total } \\
\cline { 2 - 7 } & \multicolumn{1}{c|}{$\mathbf{N}^{\mathbf{0}}$} & \multicolumn{1}{c|}{$\boldsymbol{\%}$} & \multicolumn{1}{c|}{$\mathbf{N}^{\mathbf{0}}$} & \multicolumn{1}{c|}{$\%$} & \multicolumn{1}{c|}{$\mathbf{N}^{\mathbf{0}}$} & \multicolumn{1}{c}{$\%$} \\
\hline Situación & 9 & 90,00 & 4 & 57,14 & 13 & 76,47 \\
\hline Objetivos & 9 & 90,00 & 7 & 100,00 & 16 & 94,12 \\
\hline Públicos & 9 & 90,00 & 5 & 71,43 & 14 & 82,35 \\
\hline Estrategias & 8 & 80,00 & 7 & 100,00 & 15 & 88,24 \\
\hline Tácticas & 5 & 50,00 & 6 & 85,71 & 11 & 64,71 \\
\hline Plazos temporales & 7 & 70,00 & 6 & 85,71 & 13 & 76,47 \\
\hline Presupuesto & 3 & 30,00 & 4 & 57,14 & 7 & 41,18 \\
\hline Técnicas de evaluación & 4 & 40,00 & 3 & 42,86 & 7 & 41,18 \\
\hline Cómputo de respuestas & 54 & - & 42 & - & 96 & - \\
\hline Total respuestas únicas & 10 & - & 7 & - & 17 & - \\
\hline
\end{tabular}

Fuente: elaboración propia.

En cambio, los trabajadores internos usan con más frecuencia herramientas de comunicación destinadas a los empleados que los comunicadores externos. Los instrumentos más recurrentes son el tablón de anuncios $(90,00 \%$ respecto al 16,67\% de 
los externos, cuya relación resulta ser estadísticamente significativa según el estadístico exacto de Fisher con $r=0,004)$, la intranet $(90,00 \%$ y $50,00 \%$, respectivamente) y el correo electrónico $(90,00 \%$ y $66,67 \%)$. Las personas que trabajan en agencias de comunicación suelen echar mano del manual del empleado (83,33\% frente al 50,00\% de los trabajadores en plantilla), aunque también usan la página web $(70,00 \%$ y $66,67 \%$, respectivamente), las circulares $(66,67 \%$ y $50,00 \%)$, las reuniones y seminarios $(66,67 \%$ y $50,00 \%)$, el correo electrónico $(66,67 \%$ y 90,00\%) y los mensajes de la alta dirección (66,67\% y 50,00\%).

Tabla 103. Herramientas de comunicación utilizadas con los empleados por pertenencia al hospital

\begin{tabular}{|c|c|c|c|c|c|c|}
\hline \multirow{2}{*}{$\begin{array}{l}\text { Herramientas de } \\
\text { comunicación }\end{array}$} & \multicolumn{2}{|c|}{ Interno } & \multicolumn{2}{|c|}{ Externo } & \multicolumn{2}{|c|}{ Total } \\
\hline & $\mathbf{N}^{\mathbf{o}}$ & $\%$ & $\mathbf{N}^{\mathbf{o}}$ & $\%$ & $\mathbf{N}^{\mathbf{o}}$ & $\%$ \\
\hline Página web & 7 & 70,00 & 4 & 66,67 & 11 & 68,75 \\
\hline Blog & 2 & 20,00 & 1 & 16,67 & 3 & 18,75 \\
\hline Mensajería instantánea & 6 & 60,00 & 1 & 16,67 & 7 & 43,75 \\
\hline Pantallas de información & 3 & 30,00 & 2 & 33,33 & 5 & 31,25 \\
\hline Manual del empleado & 5 & 50,00 & 5 & 83,33 & 10 & 62,50 \\
\hline Círculos de calidad & 2 & 20,00 & 2 & 33,33 & 4 & 25,00 \\
\hline Circulares & 5 & 50,00 & 4 & 66,67 & 9 & 56,25 \\
\hline Boletín interno impreso & 1 & 10,00 & 3 & 50,00 & 4 & 25,00 \\
\hline Reuniones y seminarios & 5 & 50,00 & 4 & 66,67 & 9 & 56,25 \\
\hline $\begin{array}{l}\text { Curso sobre comunicarse } \\
\text { con los medios de } \\
\text { comunicación }\end{array}$ & 3 & 30,00 & 0 & 0,00 & 3 & 18,75 \\
\hline Reuniones virtuales & 1 & 10,00 & 0 & 0,00 & 1 & 6,25 \\
\hline $\begin{array}{l}\text { Buzón virtual de } \\
\text { sugerencias }\end{array}$ & 6 & 60,00 & 3 & 50,00 & 9 & 56,25 \\
\hline $\begin{array}{l}\text { Cursos para comunicarse } \\
\text { con los pacientes y visitas }\end{array}$ & 2 & 20,00 & 2 & 33,33 & 4 & 25,00 \\
\hline Correo electrónico & 9 & 90,00 & 4 & 66,67 & 13 & 81,25 \\
\hline Foro & 1 & 10,00 & 0 & 0,00 & 1 & 6,25 \\
\hline Wikis & 1 & 10,00 & 0 & 0,00 & 1 & 6,25 \\
\hline SMS & 1 & 10,00 & 2 & 33,33 & 3 & 18,75 \\
\hline Reuniones presenciales & 7 & 70,00 & 2 & 33,33 & 9 & 56,25 \\
\hline Tablón de anuncios & 9 & 90,00 & 1 & 16,67 & 10 & 62,50 \\
\hline Revista & 0 & 0,00 & 3 & 50,00 & 3 & 18,75 \\
\hline Teléfono & 6 & 60,00 & 3 & 50,00 & 9 & 56,25 \\
\hline $\begin{array}{l}\text { Mensajes de la alta } \\
\text { dirección }\end{array}$ & 5 & 50,00 & 4 & 66,67 & 9 & 56,25 \\
\hline Proyecto de empresa & 1 & 10,00 & 2 & 33,33 & 3 & 18,75 \\
\hline Boletín interno electrónico & 4 & 40,00 & 2 & 33,33 & 6 & 37,50 \\
\hline Redes sociales & 5 & 50,00 & 3 & 50,00 & 8 & 50,00 \\
\hline Intranet & 9 & 90,00 & 3 & 50,00 & 12 & 75,00 \\
\hline
\end{tabular}




\begin{tabular}{|l|r|r|r|r|r|r|}
\hline \multirow{2}{*}{\begin{tabular}{c}
\multirow{2}{*}{$\begin{array}{c}\text { Herramientas de } \\
\text { comunicación }\end{array}$} \\
\cline { 2 - 8 }
\end{tabular}} & \multicolumn{1}{c|}{ Interno } & \multicolumn{2}{c|}{ Externo } & \multicolumn{2}{c|}{ Total } \\
\hline Videoconferencias & 1 & \multicolumn{1}{c}{ \% } & \multicolumn{1}{c|}{$\mathbf{N}^{\mathbf{0}}$} & \multicolumn{1}{c|}{$\%$} & \multicolumn{1}{c|}{$\mathbf{N}^{\mathbf{0}}$} & \multicolumn{1}{c}{$\%$} \\
\hline Vídeos & 3 & 30,00 & 0 & 0,00 & 1 & 6,25 \\
\hline Correo ordinario & 3 & 30,00 & 2 & 33,33 & 5 & 31,25 \\
\hline $\begin{array}{l}\text { Dossier de las apariciones } \\
\text { en los medios }\end{array}$ & 7 & 70,00 & 3 & 50,00 & 10 & 62,50 \\
\hline Buzón de sugerencias & 3 & 30,00 & 3 & 50,00 & 6 & 37,50 \\
\hline Periódico & 1 & 10,00 & 1 & 16,67 & 2 & 12,50 \\
\hline Entrevistas & 5 & 50,00 & 1 & 16,67 & 6 & 37,50 \\
\hline $\begin{array}{l}\text { Curso de formación } \\
\text { portavoces }\end{array}$ & 2 & 20,00 & 0 & 0,00 & 2 & 12,50 \\
\hline Formación continua & 1 & 10,00 & 1 & 16,67 & 2 & 12,50 \\
\hline $\begin{array}{l}\text { Buzón de anuncios } \\
\text { electrónicos }\end{array}$ & 4 & 40,00 & 1 & 16,67 & 5 & 31,25 \\
\hline Organización de eventos & 7 & 70,00 & 3 & 50,00 & 10 & 62,50 \\
\hline Cómputo de respuestas & 143 & - & 77 & - & 220 & - \\
\hline Total respuestas únicas & 10 & - & 6 & - & 16 & - \\
\hline
\end{tabular}

Fuente: elaboración propia.

Con los pacientes y visitas, en cambio, son más frecuentes las herramientas de las personas ajenas a los hospitales. Con esto públicos, por ejemplo, la página web se utiliza en el 100,00\% de los casos (en comparación con el 70,00\% que arrojan los trabajadores internos), así como el buzón de sugerencias, que alcanza un 66,67\% de uso respecto al 30,00\% de las personas en plantilla. También son frecuentes con estas audiencias las siguientes tácticas cuando las usan las personas de empresas externas: correo postal (50,00\% respecto al $20,00 \%$ arrojado por los trabajadores internos), las hojas de reclamaciones $(50,00 \%$ y 30,00\%, respectivamente), los correos electrónicos $(50,00 \%$ y $30,00 \%)$, las pantallas de información $(50,00 \%$ y 50,00\%), las revistas $(50,00 \%$ y $20,00 \%)$ y las redes sociales $(50,00 \%$ y $60,00 \%)$. Los internos, en cambio, suelen realizar vídeos con más frecuencia (40,00\% respecto al 16,67\% de las personas ajenas al hospital). 
Tabla 104. Herramientas de comunicación utilizadas con los pacientes y visitas por pertenencia al hospital

\begin{tabular}{|c|c|c|c|c|c|c|}
\hline \multirow{2}{*}{$\begin{array}{l}\text { Herramientas de } \\
\text { comunicación }\end{array}$} & \multicolumn{2}{|c|}{ Interno } & \multicolumn{2}{|c|}{ Externo } & \multicolumn{2}{|c|}{ Total } \\
\hline & $\mathbf{N}^{\mathbf{0}}$ & $\%$ & $\mathbf{N}^{\mathbf{0}}$ & $\%$ & $\mathbf{N}^{\mathbf{o}}$ & $\%$ \\
\hline Página web & 7 & 70,00 & 6 & 100,00 & 13 & 81,25 \\
\hline Correo postal & 2 & 20,00 & 3 & 50,00 & 5 & 31,25 \\
\hline Hoja de reclamaciones & 3 & 30,00 & 3 & 50,00 & 6 & 37,50 \\
\hline Buzón de sugerencias & 3 & 30,00 & 4 & 66,67 & 7 & 43,75 \\
\hline Correos electrónicos & 3 & 30,00 & 3 & 50,00 & 6 & 37,50 \\
\hline Vídeos & 4 & 40,00 & 1 & 16,67 & 5 & 31,25 \\
\hline Pantallas de información & 5 & 50,00 & 3 & 50,00 & 8 & 50,00 \\
\hline Revista & 2 & 20,00 & 3 & 50,00 & 5 & 31,25 \\
\hline Planos & 2 & 20,00 & 1 & 16,67 & 3 & 18,75 \\
\hline Blogs & 2 & 20,00 & 1 & 16,67 & 3 & 18,75 \\
\hline $\begin{array}{l}\text { Número de teléfono } \\
\text { gratuitos }\end{array}$ & 2 & 20,00 & 0 & 0,00 & 2 & 12,50 \\
\hline Foro de discusión & 2 & 20,00 & 0 & 0,00 & 2 & 12,50 \\
\hline Mensajería instantánea & 1 & 10,00 & 1 & 16,67 & 2 & 12,50 \\
\hline SMS & 2 & 20,00 & 2 & 33,33 & 4 & 25,00 \\
\hline Periódico & 3 & 30,00 & 1 & 16,67 & 4 & 25,00 \\
\hline Redes sociales & 6 & 60,00 & 3 & 50,00 & 9 & 56,25 \\
\hline $\begin{array}{l}\text { Números de teléfono de } \\
\text { respuesta automática }\end{array}$ & 0 & 0,00 & 1 & 16,67 & 1 & 6,25 \\
\hline Cómputo de respuestas & 49 & - & 36 & - & 85 & \\
\hline Total respuestas únicas & 10 & - & 6 & - & 16 & - \\
\hline
\end{tabular}

Fuente: elaboración propia.

Todos los encuestados aseguran utilizar la nota y la rueda de prensa en su trato con los periodistas. En cambio, aunque todos los que pertenecen a la plantilla del hospital hacen uso del teléfono para mantener la relación con los redactores, en el caso de los externos lo usan en un $85,71 \%$. Estos últimos también hacen bastante uso, a diferencia de los primeros, de las entrevistas (100,00\% y 60,00\%, en este orden), de la publicidad $(85,71 \%$ y $30,00 \%$, cuya relación, según el estadístico exacto de Fisher, es estadísticamente significativa con $\mathrm{r}=0,036)$, de las comidas $(42,86 \%$ y $20,00 \%)$ y de los artículos firmados $(71,43 \%$ y 50,00\%). Los trabajadores internos, por el contrario, tiran con más frecuencia que sus compañeros de cartas al director $(50,00 \%$ y $0,00 \%$, respectivamente, siendo este vínculo estadísticamente significativa de acuerdo con el estadístico exacto de Fisher con $\mathrm{r}=0,041)$, de SMS (50,00\% y 28,57\%), de cortes de audio $(40,00 \%$ y $28,57 \%)$ y de anuncios de servicio público (30,00\% y $0,00 \%)$. 
Tabla 105. Herramientas de comunicación utilizadas con los periodistas por pertenencia al hospital

\begin{tabular}{|c|c|c|c|c|c|c|}
\hline \multirow{2}{*}{$\begin{array}{l}\text { Herramientas de } \\
\text { comunicación }\end{array}$} & \multicolumn{2}{|c|}{ Interno } & \multicolumn{2}{|c|}{ Externo } & \multicolumn{2}{|c|}{ Total } \\
\hline & $\mathbf{N}^{\mathbf{0}}$ & $\%$ & $\mathbf{N}^{\mathbf{0}}$ & $\%$ & $\mathbf{N}^{\mathbf{0}}$ & $\%$ \\
\hline Llamadas telefónicas & 10 & 100,00 & 6 & 85,71 & 16 & 94,12 \\
\hline Dossier de prensa & 7 & 70,00 & 6 & 85,71 & 13 & 76,47 \\
\hline Audio & 4 & 40,00 & 2 & 28,57 & 6 & 35,29 \\
\hline Sala de prensa virtual & 1 & 10,00 & 2 & 28,57 & 3 & 17,65 \\
\hline Viajes de prensa & 1 & 10,00 & 1 & 14,29 & 2 & 11,76 \\
\hline Comidas & 2 & 20,00 & 3 & 42,86 & 5 & 29,41 \\
\hline Anuncios de servicio público & 3 & 30,00 & 0 & 0,00 & 3 & 17,65 \\
\hline Blogs & 1 & 10,00 & 1 & 14,29 & 2 & 11,76 \\
\hline $\begin{array}{l}\text { Retransmisión de } \\
\text { acontecimientos por internet }\end{array}$ & 2 & 20,00 & 1 & 14,29 & 3 & 17,65 \\
\hline Notas de prensa & 10 & 100,00 & 7 & 100,00 & 17 & 100,00 \\
\hline Fotografías & 9 & 90,00 & 6 & 85,71 & 15 & 88,24 \\
\hline Entrevistas & 6 & 60,00 & 7 & 100,00 & 13 & 76,47 \\
\hline Artículo firmado & 5 & 50,00 & 5 & 71,43 & 10 & 58,82 \\
\hline Giras por los medios & 3 & 30,00 & 3 & 42,86 & 6 & 35,29 \\
\hline Publicidad & 3 & 30,00 & 6 & 85,71 & 9 & 52,94 \\
\hline Redes sociales & 5 & 50,00 & 3 & 42,86 & 8 & 47,06 \\
\hline Emplazamiento de temas & 2 & 20,00 & 2 & 28,57 & 4 & 23,53 \\
\hline Premios de divulgación & 3 & 30,00 & 2 & 28,57 & 5 & 29,41 \\
\hline Ruedas de prensa & 10 & 100,00 & 7 & 100,00 & 17 & 100,00 \\
\hline Vídeos & 3 & 30,00 & 2 & 28,57 & 5 & 29,41 \\
\hline Cartas al director & 5 & 50,00 & 0 & 0,00 & 5 & 29,41 \\
\hline SMS & 5 & 50,00 & 2 & 28,57 & 7 & 41,18 \\
\hline Emplazamiento de productos & 0 & 0,00 & 1 & 14,29 & 1 & 5,88 \\
\hline $\begin{array}{l}\text { Visitas y "media-tours” a la } \\
\text { organización }\end{array}$ & 1 & 10,00 & 2 & 28,57 & 3 & 17,65 \\
\hline $\begin{array}{l}\text { Cursos de formación de } \\
\text { periodistas }\end{array}$ & 1 & 10,00 & 2 & 28,57 & 3 & 17,65 \\
\hline Cómputo de respuestas & 102 & - & 79 & - & 181 & - \\
\hline Total respuestas únicas & 10 & - & 7 & - & 17 & - \\
\hline
\end{tabular}

Fuente: elaboración propia.

La herramienta de comunicación más utilizada tanto por las personas externas $(100,00 \%)$ como por las internas $(80,00 \%)$ hacia la comunidad son los folletos. Después, los que con más frecuencia utilizan otros instrumentos son los comunicadores externos. Estos hacen un gran uso de la página web (83,33\% respecto al $60,00 \%$ que arrojan los internos), de la publicidad (83,33\% y 30,00\%) y de las sesiones o jornadas informativas $(83,33 \%$ y $70,00 \%)$. 
Tabla 106. Herramientas de comunicación utilizadas con la comunidad por pertenencia al hospital

\begin{tabular}{|c|c|c|c|c|c|c|}
\hline \multirow{2}{*}{$\begin{array}{l}\text { Herramientas de } \\
\text { comunicación }\end{array}$} & \multicolumn{2}{|c|}{ Interno } & \multicolumn{2}{|c|}{ Externo } & \multicolumn{2}{|c|}{ Total } \\
\hline & $\mathbf{N}^{\mathbf{o}}$ & $\%$ & $\mathbf{N}^{\mathbf{0}}$ & $\%$ & $\mathbf{N}^{\mathbf{0}}$ & $\%$ \\
\hline Jornada de puertas abiertas & 3 & 30,00 & 3 & 50,00 & 6 & 37,50 \\
\hline Patrocinio & 1 & 10,00 & 4 & 66,67 & 5 & 31,25 \\
\hline Premios, ayudas y becas & 4 & 40,00 & 2 & 33,33 & 6 & 37,50 \\
\hline $\begin{array}{l}\text { Marketing relacionado con } \\
\text { una causa }\end{array}$ & 2 & 20,00 & 2 & 33,33 & 4 & 25,00 \\
\hline Actividad deportiva & 2 & 20,00 & 3 & 50,00 & 5 & 31,25 \\
\hline Folletos & 8 & 80,00 & 6 & 100,00 & 14 & 87,50 \\
\hline $\begin{array}{l}\text { Participación en feria o } \\
\text { salón }\end{array}$ & 0 & 0,00 & 1 & 16,67 & 1 & 6,25 \\
\hline Captación de fondos & 1 & 10,00 & 0 & 0,00 & 1 & 6,25 \\
\hline Contratación social & 1 & 10,00 & 0 & 0,00 & 1 & 6,25 \\
\hline Página web & 6 & 60,00 & 5 & 83,33 & 11 & 68,75 \\
\hline Redes sociales & 6 & 60,00 & 2 & 33,33 & 8 & 50,00 \\
\hline $\begin{array}{l}\text { Número de teléfono } \\
\text { gratuitos }\end{array}$ & 1 & 10,00 & 0 & 0,00 & 1 & 6,25 \\
\hline Mecenazgo & 0 & 0,00 & 1 & 16,67 & 1 & 6,25 \\
\hline $\begin{array}{l}\text { Sesión o jornada } \\
\text { informativa }\end{array}$ & 7 & 70,00 & 5 & 83,33 & 12 & 75,00 \\
\hline Fundación-empresa & 3 & 30,00 & 1 & 16,67 & 4 & 25,00 \\
\hline $\begin{array}{l}\text { Evento lúdico (fiesta, } \\
\text { concierto...) }\end{array}$ & 1 & 10,00 & 1 & 16,67 & 2 & 12,50 \\
\hline Blog & 1 & 10,00 & 1 & 16,67 & 2 & 12,50 \\
\hline Publicidad & 3 & 30,00 & 5 & 83,33 & 8 & 50,00 \\
\hline Cómputo de respuestas & 50 & - & 42 & - & 92 & - \\
\hline Total respuestas únicas & 10 & - & 6 & - & 16 & \\
\hline
\end{tabular}

Fuente: elaboración propia.

Al igual que sucede con la planificación, parece que las empresas externas prestan más atención a la fase de evaluación, o al menos utilizan más herramientas y más frecuentemente. Así, por ejemplo, estas personas realizan análisis de la equivalencia publicitaria $(66,67 \%$, resultando una relación estadísticamente significativa, con $\mathrm{r}=$ 0,015, según el estadístico exacto de Fisher) y estudios del coste por persona (33,33\%), cuando los trabajadores en plantilla no hacen uso de ninguno de estos instrumentos. En el resto de herramientas analizadas, los comunicadores externos adelantan siempre a los internos, con especial diferencia en el cálculo de la asistencia del público $(83,33 \%$ y $20,00 \%$, respectivamente). 
Tabla 107. Herramientas de evaluación utilizadas con la comunidad por pertenencia al hospital

\begin{tabular}{|l|r|r|r|r|r|r|}
\hline \multirow{2}{*}{ Herramientas de evaluación } & \multicolumn{2}{|c|}{ Interno } & \multicolumn{2}{c|}{ Externo } & \multicolumn{2}{c|}{ Total } \\
\cline { 2 - 7 } & \multicolumn{1}{|c|}{$\mathbf{N}^{\mathbf{0}}$} & \multicolumn{1}{c|}{$\%$} & \multicolumn{1}{c|}{$\mathbf{N}^{\mathbf{0}}$} & \multicolumn{1}{c|}{$\%$} & \multicolumn{1}{c|}{$\mathbf{N}^{\mathbf{0}}$} & \multicolumn{1}{c}{$\%$} \\
\hline Impacto en los medios & 9 & 90,00 & 6 & 100,00 & 15 & 93,75 \\
\hline Seguimiento sistemático & 6 & 60,00 & 4 & 66,67 & 10 & 62,50 \\
\hline Asistencia del público & 2 & 20,00 & 5 & 83,33 & 7 & 43,75 \\
\hline $\begin{array}{l}\text { Número de lectores de los } \\
\text { boletines y revistas de } \\
\text { empresa }\end{array}$ & 2 & 20,00 & 2 & 33,33 & 4 & 25,00 \\
\hline Visitas en internet & 6 & 60,00 & 4 & 66,67 & 10 & 62,50 \\
\hline $\begin{array}{l}\text { Solicitudes de información y } \\
\text { números de teléfono gratuitos }\end{array}$ & 1 & 10,00 & 1 & 16,67 & 2 & 12,50 \\
\hline Auditorías de comunicación & 3 & 30,00 & 3 & 50,00 & 6 & 37,50 \\
\hline $\begin{array}{l}\text { Recuento de los materiales de } \\
\text { comunicación producidos }\end{array}$ & 7 & 70,00 & 5 & 83,33 & 12 & 75,00 \\
\hline Equivalencia publicitaria & 0 & 0,00 & 4 & 66,67 & 4 & 25,00 \\
\hline Coste por persona & 0 & 0,00 & 2 & 33,33 & 2 & 12,50 \\
\hline $\begin{array}{l}\text { Asistencia a reuniones } \\
\text { acontecimientos }\end{array}$ & 6 & 60,00 & 4 & 66,67 & 10 & 62,50 \\
\hline Cómputo de respuestas & 42 & - & 40 & - & 82 & - \\
\hline Total respuestas únicas & 10 & - & 6 & - & 16 & - \\
\hline
\end{tabular}

Fuente: elaboración propia.

Las empresas externas otorgan más importancia a los diferentes tipos de evaluación. En conjunto, sobre una escala de 1 a 5, arrojan un 4,46, en comparación con el 4,10 que registran los trabajadores internos. La mayor discrepancia se halla en la medición de la opinión y actitud del público. En el primer caso se consigue un 4,86 y en el segundo, un 4,20. También hay bastante diferencia en el análisis de las acciones y comportamientos del público, con un 4,71 y un 4,10, respectivamente. En cambio, no existen apenas discrepancias en el estudio de la producción (3,71 y 3,70, en este orden) y de la exposición $(4,57$ y 4,40).

Tabla 108. Importancia que le otorga el departamento de comunicación a los diferentes tipos de medición

\begin{tabular}{|l|r|r|}
\hline \multicolumn{1}{|c|}{ Fases de un programa de relaciones públicas } & Interno & Externo \\
\hline Medición de la producción & 3,70 & 3,71 \\
\hline Medición de la exposición & 4,40 & 4,57 \\
\hline Medición de la opinión y actitud del público & 4,20 & 4,86 \\
\hline Medición de las acciones y comportamientos del público & 4,10 & 4,71 \\
\hline Total & 4,10 & 4,46 \\
\hline
\end{tabular}

Fuente: elaboración propia. 
La proporción de hospitales que tienen un plan de crisis es casi idéntica independientemente de la adscripción del gabinete de comunicación al centro. En el caso del ámbito interno, se corresponde con el 60,00\%, y en el externo, con el 57,14\%. Aquellos encuestados pertenecientes a la plantilla de la organización que no disponen de este documento ascienden al 40,00\%. Por su parte, el 28,57\% de los externos aseguran no disponer de este texto y el $14,29 \%$ no sabe concretar su presencia.

Tabla 109. Frecuencia y porcentaje de los departamentos que tienen un plan de crisis

\begin{tabular}{|l|r|c|r|c|r|r|}
\hline \multirow{2}{*}{$\begin{array}{c}\text { Plan de } \\
\text { crisis }\end{array}$} & \multicolumn{2}{|c|}{ Interno } & \multicolumn{2}{c|}{ Externo } & \multicolumn{2}{c|}{ Total } \\
\cline { 2 - 7 } & $\mathbf{N}^{\mathbf{0}}$ & \multicolumn{1}{c|}{$\%$} & $\mathbf{N}^{\mathbf{0}}$ & \multicolumn{1}{c|}{$\%$} & $\mathbf{N}^{\mathbf{0}}$ & \multicolumn{1}{c|}{$\%$} \\
\hline Sí & 6 & 60,00 & 4 & 57,14 & 10 & 58,82 \\
\hline No & 4 & 40,00 & 2 & 28,57 & 6 & 35,29 \\
\hline NS/NC & 0 & 0,00 & 1 & 14,29 & 1 & 5,88 \\
\hline Total & 10 & 100,00 & 7 & 100,00 & 17 & 100,00 \\
\hline
\end{tabular}

Fuente: elaboración propia.

La mayoría de los participantes en el estudio no saben concretar con qué frecuencia se revisa el plan de crisis. El porcentaje en el ámbito interno asciende al 60,00\% y en el externo, al 57,14\%. Aquellos que tienen constancia de este datos aseguran que se realiza de entre seis meses a un año (en el 28,57\% de los departamentos de comunicación externos y el 10,00\% de los internos) y de entre un año a un año y medio (en el 20,00\% de los internos). Aquellos que confirman que el plan de crisis no se revisa nunca asciende al $10,00 \%$ a nivel interno y al $14,29 \%$ a nivel externo.

Tabla 110. Frecuencia con la que se revisa el plan de crisis

\begin{tabular}{|l|r|r|r|r|r|r|}
\hline \multirow{2}{*}{ Revisión del plan de crisis } & \multicolumn{2}{|c|}{ Interno } & \multicolumn{2}{c|}{ Externo } & \multicolumn{2}{c|}{ Total } \\
\cline { 2 - 7 } & \multicolumn{1}{|c|}{$\mathbf{N}^{\mathbf{0}}$} & \multicolumn{1}{c|}{$\%$} & \multicolumn{1}{c|}{$\mathbf{N}^{\mathbf{0}}$} & \multicolumn{1}{c|}{$\%$} & \multicolumn{1}{c|}{$\mathbf{N}^{\mathbf{0}}$} & \multicolumn{1}{c|}{$\%$} \\
\hline De más de seis meses a un año & 1 & 16,67 & 2 & 40,00 & 3 & 27,27 \\
\hline $\begin{array}{l}\text { De más de un año y medio a } \\
\text { dos años }\end{array}$ & 2 & 33,33 & 0 & 0,00 & 2 & 18,18 \\
\hline Nunca & 1 & 16,67 & 1 & 20,00 & 2 & 18,18 \\
\hline NS/NC & 2 & 33,33 & 2 & 40,00 & 4 & 36,36 \\
\hline Total & 6 & 100,00 & 5 & 100,00 & 11 & 100,00 \\
\hline
\end{tabular}

Fuente: elaboración propia.

En cuanto a la frecuencia con la que se pone en práctica el plan de crisis, las cifras muestran resultados similares. E1 60,00\% de los trabajadores en plantilla y el 71,43\% de los externos no conocen este dato. Además, el 30,00\% de los primeros y el 14,29\% de los segundos reconoce que no se hace nunca. Únicamente una persona en el ámbito 
interno asegura que se realiza de más de dos años a dos años y medio y otra del ámbito externo, de más de dos años y medios a tres.

Tabla 111. Frecuencia con la que se pone en práctica el plan de crisis

\begin{tabular}{|l|r|r|r|r|r|r|}
\hline \multirow{2}{*}{ Práctica del plan de crisis } & \multicolumn{2}{|c|}{ Interno } & \multicolumn{2}{c|}{ Externo } & \multicolumn{2}{c|}{ Total } \\
\cline { 2 - 7 } & \multicolumn{1}{c|}{$\mathbf{N}^{\mathbf{0}}$} & \multicolumn{1}{c|}{$\mathbf{1}$} & \multicolumn{1}{c|}{$\mathbf{N}^{\mathbf{0}}$} & \multicolumn{1}{c|}{$\mathbf{\mathbf { N } ^ { \mathbf { 0 } }}$} & \multicolumn{1}{c|}{$\%$} \\
\hline $\begin{array}{l}\text { De más de dos años a dos } \\
\text { años y medio }\end{array}$ & 1 & 16,67 & 0 & 0,00 & 1 & 9,09 \\
\hline $\begin{array}{l}\text { De más de dos años y medio } \\
\text { a tres años }\end{array}$ & 0 & 0,00 & 1 & 20,00 & 1 & 9,09 \\
\hline Nunca & 3 & 50,00 & 1 & 20,00 & 4 & 36,36 \\
\hline NS/NC & 2 & 33,33 & 3 & 60,00 & 5 & 45,45 \\
\hline Total & 6 & 100,00 & 5 & 100,00 & 11 & 100,00 \\
\hline
\end{tabular}

Fuente: elaboración propia.

Es igual de probable que aquellas personas que dirigen la comunicación desde el interior del hospital tengan un equipo prefijado para las posibles crisis $(70,00 \%)$ que aquellas que lo hacen desde una empresa ajena (71,43\%). Asimismo, es muy similar la proporción de personas que no disponen de este grupo $(20,00 \%$ y 14,29\%, respectivamente) y la de los que no conocen el dato (10,00\% y $14,29 \%$, en este orden).

Tabla 112. Departamentos que tienen un equipo prefijado de personas para las posibles crisis

\begin{tabular}{|l|r|r|r|r|r|r|}
\hline \multirow{2}{*}{$\begin{array}{c}\text { Equipo de } \\
\text { crisis }\end{array}$} & \multicolumn{2}{|c|}{ Interno } & \multicolumn{2}{c|}{ Externo } & \multicolumn{2}{c|}{ Total } \\
\cline { 2 - 7 } & $\mathbf{N}^{\mathbf{0}}$ & \multicolumn{1}{c}{$\%$} & $\mathbf{N}^{\mathbf{0}}$ & \multicolumn{1}{c}{$\%$} & $\mathbf{N}^{\mathbf{0}}$ & \multicolumn{1}{c}{$\%$} \\
\hline Sí & 7 & 70,00 & 5 & 71,43 & 12 & 70,59 \\
\hline No & 2 & 20,00 & 1 & 14,29 & 3 & 17,65 \\
\hline NS/NC & 1 & 10,00 & 1 & 14,29 & 2 & 11,76 \\
\hline Total & 10 & 100,00 & 7 & 100,00 & 17 & 100,00 \\
\hline
\end{tabular}

Fuente: elaboración propia.

Aunque los comunicadores que trabajan de manera interna en un hospital consideran más importante su departamento (4,80 en una escala de 1 a 5) que aquellos que están empleados por una empresa externa $(4,43)$, no existen prácticamente diferencias en la satisfacción con las actividades comunicativas entre unos y otros. Los primeros acumulan un 3,90 y los segundos, un 3,86.

Tabla 113. Importancia y satisfacción con las labores del departamento de comunicación

\begin{tabular}{|l|r|r|}
\hline \multicolumn{1}{|c|}{ Importancia y satisfacción con el departamento } & Interno & Externo \\
\hline $\begin{array}{l}\text { ¿Cómo de importante considera al departamento de } \\
\text { relaciones públicas o comunicación para el hospital? }\end{array}$ & 4,80 & 4,43 \\
\hline $\begin{array}{l}\text { ¿Cómo de satisfecho está con las actividades de relaciones } \\
\text { públicas o comunicación que lleva a cabo el centro? }\end{array}$ & 3,90 & 3,86 \\
\hline
\end{tabular}

Fuente: elaboración propia. 


\subsubsection{IMAGEN PROYECTADA EN LOS MEDIOS DE COMUNICACIÓN. RESULTADOS DEL ANÁLISIS DE PRENSA}

\subsubsection{NÚMERO DE NOTICIAS SEGÚN LOS PERIÓDICOS}

El periódico analizado que más noticias ha publicado relativas a la salud y a la sanidad en 2012 es La Voz de Galicia. Este diario regional gallego ha difundido en las 12 jornadas que comprende el muestreo 125 informaciones, lo que significa que, de media, divulga 3.802 textos al año o 10,42 al día. El 15,63\% de todas las referencias examinadas para este estudio pertenecen a este rotativo.

Por detrás de La Voz de Galicia se sitúa otro gran periódico regional, pero esta vez de ámbito castellano-leonés. Se trata de El Norte de Castilla, que con 98 informaciones en las 12 jornadas analizadas, se sitúa en segundo lugar, agrupando el 12,25\% del total. Este diario, con 2.981 composiciones, publica de media casi mil menos al año que La Voz de Galicia. Al día, se corresponden con 8,17.

El resto de periódicos cuentan con considerablemente menos noticias. El Diario de León, con 67, La Opinión de La Coruña, con 55, y Faro de Vigo, con 54, todos ellos provinciales o locales, se hallan por detrás de los regionales. De media publican 5,58 , 4,58 y 4,50 noticias diarias, en este orden.

Las 23 publicaciones restantes no llegan a 4 textos cada jornada de promedio. Las que más se acercan son La Región de Ourense y La Gaceta de Salamanca, mientras que Heraldo de Soria, Leonoticias, La Opinión de Zamora, El Correo Gallego, El Ideal Gallego y Diario de Burgos se quedan entre las 2 y 3. Existe un grupo numeroso de periódicos que no llegan a una noticia sobre salud o sanidad en cada jornada, como son De Luns a Venres, RTVCYL.es, Diario de Pontevedra y La Crónica de León, entre otros. 
Tabla 114. Frecuencia y porcentaje de las informaciones según periódicos

\begin{tabular}{|c|c|c|c|c|}
\hline Periódico & $\begin{array}{c}\mathrm{N}^{0} \text { de } \\
\text { noticias }\end{array}$ & $\begin{array}{c}\text { Porcentaje } \\
\text { sobre el total }\end{array}$ & $\begin{array}{l}\text { Estimación de } \\
\text { noticias diarias }\end{array}$ & $\begin{array}{c}\text { Estimación de } \\
\text { noticias anuales }\end{array}$ \\
\hline La Voz de Galicia & 125 & 15,63 & 10,42 & 3.802 \\
\hline El Norte de Castilla & 98 & 12,25 & 8,17 & 2.981 \\
\hline Diario de León & 67 & 8,38 & 5,58 & 2.038 \\
\hline La Opinión de La Coruña & 55 & 6,88 & 4,58 & 1.673 \\
\hline Faro de Vigo & 54 & 6,75 & 4,50 & 1.643 \\
\hline La Región de Ourense & 44 & 5,50 & 3,67 & 1.338 \\
\hline La Gaceta de Salamanca & 36 & 4,50 & 3,00 & 1.095 \\
\hline Heraldo de Soria & 34 & 4,25 & 2,83 & 1.034 \\
\hline Leonoticias & 33 & 4,13 & 2,75 & 1.004 \\
\hline La Opinión de Zamora & 30 & 3,75 & 2,50 & 913 \\
\hline El Correo Gallego & 28 & 3,50 & 2,33 & 852 \\
\hline El Ideal Gallego & 28 & 3,50 & 2,33 & 852 \\
\hline Diario de Burgos & 24 & 3,00 & 2,00 & 730 \\
\hline El Día de Valladolid & 23 & 2,88 & 1,92 & 700 \\
\hline El Adelantado de Segovia & 17 & 2,13 & 1,42 & 517 \\
\hline Vigo al minuto & 15 & 1,88 & 1,25 & 456 \\
\hline Diario Palentino & 13 & 1,63 & 1,08 & 395 \\
\hline De Luns a Venres & 11 & 1,38 & 0,92 & 335 \\
\hline RTVCYL.es & 10 & 1,25 & 0,83 & 304 \\
\hline Diario de Pontevedra & 10 & 1,25 & 0,83 & 304 \\
\hline La Crónica de León & 9 & 1,13 & 0,75 & 274 \\
\hline Galiciae & 8 & 1,00 & 0,67 & 243 \\
\hline Galicia Hoxe & 7 & 0,88 & 0,58 & 213 \\
\hline El Progreso de Lugo & 7 & 0,88 & 0,58 & 213 \\
\hline Galicia Diario & 6 & 0,75 & 0,50 & 183 \\
\hline Diario de Ávila & 5 & 0,63 & 0,42 & 152 \\
\hline Galicia Confidencial & 2 & 0,25 & 0,17 & 61 \\
\hline I-Bejar.com & 1 & 0,13 & 0,08 & 30 \\
\hline Total & 800 & 100,00 & 66,67 & 24.335 \\
\hline
\end{tabular}

Fuente: elaboración propia. 
Si se observa la repartición de textos por periódicos en cada comunidad autónoma, no se encuentran diferencias demasiado marcadas. En ambos casos hay un periódico regional que acumula el mayor porcentaje, aunque, en la región gallega, La Voz de Galicia presenta una mayor diferencia (con el 31,25\% del total) frente a sus dos competidores más cercanos, La Opinión de La Coruña, que concentra el 13,75\%, y Faro de Vigo, con 13,50\%. En Castilla y León, la desigualdad no es tan acusada y el diario que publica más informaciones, El Norte de Castilla, solo tiene un claro competidor: Diario de León. El primero reúne el $24,50 \%$ de todas las analizadas en el muestreo y el segundo, el 16,75\%. Los otros rotativos ofrecen porcentajes mucho más bajos.

El resto de periódicos de Castilla y León van paulatinamente descendiendo en el número de informaciones sanitarias que transmiten. Así, los porcentajes van bajando del 9,00\% (La Gaceta de Salamanca), al 8,50\% (Heraldo de Soria), al 8,25\% (Leonoticias), al 7,50\% (La Opinión de Zamora), etc. En cambio, en Galicia existen diferencias más acusadas. La Región de Ourense, El Correo Gallego y El Ideal Gallego concentran el $11,00 \%, 7,00 \%$ y 7,00\%, respectivamente. La siguiente publicación con más textos, Vigo al Minuto, pasa al 3,75\%, y la subsiguiente, De Lunes a Venres, al 2,75\%.

Tabla 115. Frecuencia y porcentaje de las informaciones según periódicos en Castilla y León

\begin{tabular}{|l|r|r|r|r|}
\hline \multicolumn{1}{|c|}{ Periódico } & $\begin{array}{c}\mathbf{N}^{\mathbf{0}} \text { de } \\
\text { noticias }\end{array}$ & $\begin{array}{c}\text { Porcentaje } \\
\text { sobre el total }\end{array}$ & $\begin{array}{c}\text { Estimación de } \\
\text { noticias diarias }\end{array}$ & $\begin{array}{c}\text { Estimación de } \\
\text { noticias anuales }\end{array}$ \\
\hline El Norte de Castilla & 98 & 24,50 & 8,17 & 2.981 \\
\hline Diario de León & 67 & 16,75 & 5,58 & 2.038 \\
\hline La Gaceta de Salamanca & 36 & 9,00 & 3,00 & 1.095 \\
\hline Heraldo de Soria & 34 & 8,50 & 2,83 & 1.034 \\
\hline Leonoticias & 33 & 8,25 & 2,75 & 1.004 \\
\hline La Opinión de Zamora & 30 & 7,50 & 2,50 & 913 \\
\hline Diario de Burgos & 24 & 6,00 & 2,00 & 730 \\
\hline El Día de Valladolid & 23 & 5,75 & 1,92 & 700 \\
\hline El Adelantado de Segovia & 17 & 4,25 & 1,42 & 517 \\
\hline Diario Palentino & 13 & 3,25 & 1,08 & 395 \\
\hline RTVCYL.es & 10 & 2,50 & 0,83 & 304 \\
\hline La Crónica de León & 9 & 2,25 & 0,75 & 274 \\
\hline Diario de Ávila & 5 & 1,25 & 0,42 & 152 \\
\hline I-Bejar.com & 1 & 0,25 & 0,08 & 30 \\
\hline Total & 400 & 100,00 & 33,33 & 12.167 \\
\hline
\end{tabular}

Fuente: elaboración propia. 
Tabla 116. Frecuencia y porcentaje de las informaciones según periódicos en Galicia

\begin{tabular}{|l|r|r|r|r|}
\hline \multicolumn{1}{|c|}{ Periódico } & $\begin{array}{c}\mathbf{N}^{\mathbf{0}} \text { de } \\
\text { noticias }\end{array}$ & $\begin{array}{c}\text { Porcentaje } \\
\text { sobre el total }\end{array}$ & $\begin{array}{c}\text { Estimación de } \\
\text { noticias diarias }\end{array}$ & $\begin{array}{c}\text { Estimación de } \\
\text { noticias anuales }\end{array}$ \\
\hline La Voz de Galicia & 125 & 31,25 & 10,42 & 3.802 \\
\hline La Opinión de La Coruña & 55 & 13,75 & 4,58 & 1.673 \\
\hline Faro de Vigo & 54 & 13,50 & 4,50 & 1.643 \\
\hline La Región de Ourense & 44 & 11,00 & 3,67 & 1.338 \\
\hline El Correo Gallego & 28 & 7,00 & 2,33 & 852 \\
\hline El Ideal Gallego & 28 & 7,00 & 2,33 & 852 \\
\hline Vigo al minuto & 15 & 3,75 & 1,25 & 456 \\
\hline De Luns a Venres & 11 & 2,75 & 0,92 & 335 \\
\hline Diario de Pontevedra & 10 & 2,50 & 0,83 & 304 \\
\hline Galiciae & 8 & 2,00 & 0,67 & 243 \\
\hline Galicia Hoxe & 7 & 1,75 & 0,58 & 213 \\
\hline El Progreso de Lugo & 7 & 1,75 & 0,58 & 213 \\
\hline Galicia Diario & 6 & 1,50 & 0,50 & 183 \\
\hline Galicia Confidencial & 2 & 0,50 & 0,17 & 61 \\
\hline Total & 400 & 100,00 & 33,33 & 12.168 \\
\hline
\end{tabular}

Fuente: elaboración propia.

\subsubsection{SECCIÓN EN LA QUE APARECE LA INFORMACIÓN}

La mayor parte de las noticias publicadas en ambas comunidades se incluyen dentro de la sección local. Más de la mitad de todas las analizadas, concretamente el 55,63\%, aparecen bajo esta temática. Después se encuentran, aunque lejos, las que se divulgan con la etiqueta de sociedad (21,00\%). El resto de divisiones son mucho menos usuales. La de España, por ejemplo, que es la siguiente más empleada, contiene únicamente el $8,38 \%$ de los textos recogidos y deportes, el 5,63\%. Las demás secciones no llegan ni siquiera al 5,00\%. 
Tabla 117. Frecuencia y porcentaje de las informaciones según secciones

\begin{tabular}{|l|r|r|}
\hline \multicolumn{1}{|c|}{ Sección } & $\begin{array}{c}\text { Número de } \\
\text { noticias }\end{array}$ & Porcentaje \\
\hline Local & 445 & 55,63 \\
\hline Sociedad & 168 & 21,00 \\
\hline España & 67 & 8,38 \\
\hline Deportes & 45 & 5,63 \\
\hline Internacional & 32 & 4,00 \\
\hline Cultura & 15 & 1,88 \\
\hline Economía & 11 & 1,38 \\
\hline Opinión & 11 & 1,38 \\
\hline Televisión & 4 & 0,50 \\
\hline Tecnología & 2 & 0,25 \\
\hline Total & 800 & 100,00 \\
\hline
\end{tabular}

Fuente: elaboración propia.

Los periódicos no ofrecen grandes diferencias divididos por región, aunque Galicia tiende a difundir más noticias locales (61,25\% frente al 50,00\% de Castilla y León) y menos de ámbito nacional, que estarían catalogadas bajo la etiqueta Sociedad $(17,00 \%$ en la región gallega y $25,00 \%$ en la castellana) y España (7,25\% y 9,50\%). En conjunto, ambas divisiones suponen en torno al $75,00 \%$ del total.

Se dan otras discrepancias, pero no demasiado marcadas. Por ejemplo, Galicia incluye más textos en la sección cultura y opinión $(2,75 \%$ y $2,00 \%$, respectivamente) que Castilla y León (1,00\% y $0,75 \%$, en este orden). Por el contrario, los periódicos castellano-leoneses divulgan más informaciones internacionales y deportivas $(5,25 \%$ y $6,25 \%)$ que los gallegos (2,75\% y 5,00\%). 
Tabla 118. Tabla de contingencia entre sección y comunidad

\begin{tabular}{|c|c|c|c|c|}
\hline \multirow{2}{*}{\multicolumn{2}{|c|}{ Sección }} & \multicolumn{2}{|c|}{ Comunidad } & \multirow[b]{2}{*}{ Total } \\
\hline & & \multirow{2}{*}{$\begin{array}{r}\begin{array}{c}\text { Castilla y } \\
\text { León }\end{array} \\
4\end{array}$} & \multirow{2}{*}{$\begin{array}{r}\text { Galicia } \\
11\end{array}$} & \\
\hline \multirow{3}{*}{ Cultura } & Recuento & & & 15 \\
\hline & $\%$ de sección & $26,67 \%$ & $73,33 \%$ & $100,00 \%$ \\
\hline & $\%$ de comunidad & $1,00 \%$ & $2,75 \%$ & $1,88 \%$ \\
\hline \multirow{3}{*}{ Deportes } & Recuento & 25 & 20 & 45 \\
\hline & $\%$ de sección & $55,56 \%$ & $44,44 \%$ & $100,00 \%$ \\
\hline & $\%$ de comunidad & $6,25 \%$ & $5,00 \%$ & $5,63 \%$ \\
\hline \multirow{3}{*}{ Economía } & Recuento & 7 & 4 & 11 \\
\hline & $\%$ de sección & $63,64 \%$ & $36,36 \%$ & $100,00 \%$ \\
\hline & $\%$ de comunidad & $1,75 \%$ & $1,00 \%$ & $1,38 \%$ \\
\hline \multirow{3}{*}{ España } & Recuento & 38 & 29 & 67 \\
\hline & $\%$ de sección & $56,72 \%$ & $43,28 \%$ & $100,00 \%$ \\
\hline & $\%$ de comunidad & $9,50 \%$ & $7,25 \%$ & $8,38 \%$ \\
\hline \multirow{3}{*}{ Internacional } & Recuento & 21 & 11 & 32 \\
\hline & $\%$ de sección & $65,63 \%$ & $34,38 \%$ & $100,00 \%$ \\
\hline & $\%$ de comunidad & $5,25 \%$ & $2,75 \%$ & $4,00 \%$ \\
\hline \multirow{3}{*}{ Local } & Recuento & 200 & 245 & 445 \\
\hline & $\%$ de sección & $44,94 \%$ & $55,06 \%$ & $100,00 \%$ \\
\hline & $\%$ de comunidad & $50,00 \%$ & $61,25 \%$ & $55,63 \%$ \\
\hline \multirow{3}{*}{ Opinión } & Recuento & 3 & 8 & 11 \\
\hline & $\%$ de sección & $27,27 \%$ & $72,73 \%$ & $100,00 \%$ \\
\hline & $\%$ de comunidad & $0,75 \%$ & $2,00 \%$ & $1,38 \%$ \\
\hline \multirow{3}{*}{ Sociedad } & Recuento & 100 & 68 & 168 \\
\hline & $\%$ de sección & $59,52 \%$ & $40,48 \%$ & $100,00 \%$ \\
\hline & $\%$ de comunidad & $25,00 \%$ & $17,00 \%$ & $21,00 \%$ \\
\hline \multirow{3}{*}{ Tecnología } & Recuento & 0 & 2 & 2 \\
\hline & $\%$ de sección & $0,00 \%$ & $100,00 \%$ & $100,00 \%$ \\
\hline & $\%$ de comunidad & $0,00 \%$ & $0,50 \%$ & $0,25 \%$ \\
\hline \multirow{3}{*}{ Televisión } & Recuento & 2 & 2 & \\
\hline & $\%$ de sección & $50,00 \%$ & $50,00 \%$ & $100,00 \%$ \\
\hline & $\%$ de comunidad & $0,50 \%$ & $0,50 \%$ & $0,50 \%$ \\
\hline \multirow{3}{*}{ Total } & Recuento & 400 & 400 & 800 \\
\hline & $\%$ de sección & $50,00 \%$ & $50,00 \%$ & $100,00 \%$ \\
\hline & $\%$ de comunidad & $100,00 \%$ & $100,00 \%$ & $100,00 \%$ \\
\hline
\end{tabular}

Fuente: elaboración propia a partir de los resultados del programa estadístico SPSS. 


\subsubsection{AUTORES DE LAS INFORMACIONES}

Casi todas las informaciones referentes a salud y sanidad analizadas en este estudio mostraban el autor de la composición, ya fuera un redactor en concreto, una agencia de noticias o el periódico. Los textos que no ofrecen ninguna pista sobre el escritor, por consiguiente, son muy escasos. En Castilla y León, por ejemplo, únicamente 26 de los 400 examinados (el 6,50\%) no proporcionan este dato. En Galicia, con 35, supone el $8,75 \%$. No se han encontrado diferencias significativas, por lo tanto, entre una comunidad y otra en la incorporación o exclusión de firmas.

Tabla 119. Tabla de contingencia entre informaciones con o sin firma y comunidad

\begin{tabular}{|c|c|c|c|c|}
\hline \multirow{2}{*}{\multicolumn{2}{|c|}{$\begin{array}{l}\text { Informaciones con o sin } \\
\text { firma }\end{array}$}} & \multicolumn{2}{|c|}{ Comunidad } & \multirow[b]{2}{*}{ Total } \\
\hline & & \multirow{2}{*}{$\begin{array}{r}\begin{array}{c}\text { Castilla } \mathbf{y} \\
\text { León }\end{array} \\
374\end{array}$} & \multirow{2}{*}{$\begin{array}{r}\text { Galicia } \\
365\end{array}$} & \\
\hline \multirow{3}{*}{ Con firma } & Recuento & & & 739 \\
\hline & $\%$ de autor & $50,61 \%$ & $49,39 \%$ & $100,00 \%$ \\
\hline & $\%$ de comunidad & $93,50 \%$ & $91,25 \%$ & $92,38 \%$ \\
\hline \multirow{3}{*}{ Sin firma } & Recuento & 26 & 35 & 61 \\
\hline & $\%$ de autor & $42,62 \%$ & $57,38 \%$ & $100,00 \%$ \\
\hline & $\%$ de comunidad & $6,50 \%$ & $8,75 \%$ & $7,63 \%$ \\
\hline \multirow{3}{*}{ Total } & Recuento & 400 & 400 & 800 \\
\hline & $\%$ de autor & $50,00 \%$ & $50,00 \%$ & $100,00 \%$ \\
\hline & $\%$ de comunidad & $100,00 \%$ & $100,00 \%$ & $100,00 \%$ \\
\hline
\end{tabular}

Fuente: elaboración propia a partir de los resultados del programa estadístico SPSS.

La mitad de las composiciones publicadas en Castilla y León se firman mediante una agencia de noticias, convirtiéndose así en el tipo de autor más recurrente. En Galicia, estos textos se reducen a casi la mitad $(27,75 \%)$ y ni siquiera es la modalidad de firma más común: lo más habitual es que se divulguen bajo el nombre de un periodista o periodistas concretos $(35,50 \%$ de los casos) o con la firma genérica del periódico $(28,00 \%)$. En cambio, en Castilla y León, estas autorías no son tan numerosas: agrupan el $27,50 \%$ y el $16,00 \%$, en este orden. Las que no incluyen ninguna referencia a su autor no llegan en ninguna región al 10,00\%. 
Tabla 120. Tabla de contingencia entre tipo de autor y comunidad

\begin{tabular}{|c|c|c|c|c|}
\hline \multirow{2}{*}{\multicolumn{2}{|c|}{ Tipo de autor }} & \multicolumn{2}{|c|}{ Comunidad } & \multirow{3}{*}{$\begin{array}{r}\text { Total } \\
311\end{array}$} \\
\hline & & \multirow{2}{*}{$\begin{array}{r}\begin{array}{c}\text { Castilla y } \\
\text { León }\end{array} \\
200\end{array}$} & \multirow{2}{*}{$\begin{array}{r}\text { Galicia } \\
111\end{array}$} & \\
\hline \multirow{3}{*}{ Agencia } & Recuento & & & \\
\hline & $\%$ de tipo de autor & $64,31 \%$ & $35,69 \%$ & $100,00 \%$ \\
\hline & $\%$ de comunidad & $50,00 \%$ & $27,75 \%$ & $38,88 \%$ \\
\hline \multirow{3}{*}{ Periodista } & Recuento & 110 & 142 & 252 \\
\hline & $\%$ de tipo de autor & $43,65 \%$ & $56,35 \%$ & $100 \%$ \\
\hline & $\%$ de comunidad & $27,50 \%$ & $35,50 \%$ & $31,5 \%$ \\
\hline \multirow{3}{*}{ Periódico } & Recuento & 64 & 112 & 176 \\
\hline & $\%$ de tipo de autor & $36,36 \%$ & $63,64 \%$ & $100,00 \%$ \\
\hline & $\%$ de comunidad & $16,00 \%$ & $28,00 \%$ & $22,00 \%$ \\
\hline \multirow{3}{*}{ Sin firma } & Recuento & 26 & 35 & 61 \\
\hline & $\%$ de tipo de autor & $42,62 \%$ & $57,38 \%$ & $100,00 \%$ \\
\hline & $\%$ de comunidad & $6,50 \%$ & $8,75 \%$ & $7,63 \%$ \\
\hline \multirow{3}{*}{ Total } & Recuento & 400 & 400 & 800 \\
\hline & $\%$ de tipo de autor & $50,00 \%$ & $50,00 \%$ & $100,00 \%$ \\
\hline & $\%$ de comunidad & $100,00 \%$ & $100,00 \%$ & $100,00 \%$ \\
\hline
\end{tabular}

Fuente: elaboración propia a partir de los resultados del programa estadístico SPSS.

La diferencia de uso de noticias procedentes de agencias entre ambas regiones, de hecho, resulta ser significativa. Castilla y León publica tantas informaciones bajo el título de una empresa de esta categoría $(50,00 \%)$ como de otro tipo $(50,00 \%)$, mientras que en Galicia se usan mucho menos las novedades procedentes de agencias $(27,75 \%)$ que de otra clase $(72,25 \%)$. La prueba de chi-cuadrado de Pearson otorga un 0,000 . Al ser menor de 0,050, se puede considerar estadísticamente significativa. El coeficiente de contingencia, que puede ir de 0 a 1 según la fuerza de la relación, se queda en 0,223. 
Tabla 121. Tabla de contingencia entre agencia como autor y comunidad

\begin{tabular}{|l|l|r|r|r|}
\hline \multicolumn{2}{|c|}{ Tipo de autor } & \multicolumn{2}{c|}{ Comunidad } & \multirow{2}{*}{ Total } \\
\cline { 3 - 5 } \multicolumn{2}{|c|}{$\begin{array}{c}\text { Castilla y } \\
\text { León }\end{array}$} & Galicia & \\
\hline \multirow{3}{*}{ Agencia } & Recuento & 200 & 111 & 311 \\
& $\%$ de tipo de autor & $64,31 \%$ & $35,69 \%$ & $100,00 \%$ \\
& \% de comunidad & $50,00 \%$ & $27,75 \%$ & $38,88 \%$ \\
\hline \multirow{3}{*}{ Otros } & Recuento & 200 & 289 & 489 \\
& \% de tipo de autor & $40,90 \%$ & $59,10 \%$ & $100 \%$ \\
& \% de comunidad & $50,00 \%$ & $72,25 \%$ & $61,13 \%$ \\
\hline \multirow{3}{*}{ Total } & Recuento & 400 & 400 & 800 \\
& \% de tipo de autor & $50,00 \%$ & $50,00 \%$ & $100,00 \%$ \\
& \% de comunidad & $100,00 \%$ & $100,00 \%$ & $100,00 \%$ \\
\hline
\end{tabular}

Fuente: elaboración propia a partir de los resultados del programa estadístico SPSS.

Tabla 122. Prueba de chi-cuadrado entre agencia como autor y comunidad

\begin{tabular}{|l|r|r|r|r|r|}
\hline \multicolumn{1}{|c|}{ Prueba } & \multicolumn{1}{|c|}{ Valor } & \multicolumn{1}{c|}{ gl } & \multicolumn{1}{c|}{$\begin{array}{c}\text { Sig. } \\
\text { asintótica }\end{array}$} & \multicolumn{1}{c|}{$\begin{array}{c}\text { Sig. } \\
\text { exacta }\end{array}$} & $\begin{array}{c}\text { Sig. } \\
\text { exacta }\end{array}$ \\
\hline Chi-cuadrado de Pearson & 41,668 & 1 & 0,000 & & \\
Corrección por continuidad & 40,737 & 1 & 0,000 & & \\
Razón de verosimilitudes & 42,118 & 1 & 0,000 & & \\
Estadístico exacto de Fisher & & & & 0,000 & 0,000 \\
Asociación lineal por lineal & 41,616 & 1 & 0,000 & & \\
N de casos válidos & 800,000 & & & & \\
\hline
\end{tabular}

Fuente: elaboración propia a partir de los resultados del programa estadístico SPSS.

Tabla 123. Medidas simétricas de la prueba de chi-cuadrado entre agencia como autor y comunidad

\begin{tabular}{|ll|r|r|r|r|}
\hline \multicolumn{2}{|c|}{ Prueba } & Valor & \multicolumn{1}{c|}{$\begin{array}{c}\text { Error } \\
\text { típ. asint. }\end{array}$} & \multicolumn{1}{c|}{$\begin{array}{c}\text { T } \\
\text { aproximada }\end{array}$} & \multicolumn{1}{c|}{$\begin{array}{c}\text { Sig. } \\
\text { aproximada }\end{array}$} \\
\hline Nominal por nominal & $\begin{array}{l}\text { Coeficiente de } \\
\text { contingencia }\end{array}$ & 0,223 & & & 0,000 \\
Intervalo por intervalo & $\begin{array}{l}\text { R de Pearson } \\
\text { Correlación }\end{array}$ & 0,228 & 0,034 & 6,622 & 0,000 \\
Ordinal por ordinal & $\begin{array}{l}\text { de Spearman } \\
\text { N de casos válidos }\end{array}$ & 80,228 & 0,034 & 6,622 & 0,000 \\
\hline
\end{tabular}

Fuente: elaboración propia a partir de los resultados del programa estadístico SPSS. 


\section{Gráfico 1. Número de informaciones procedentes de agencias según comunidades}

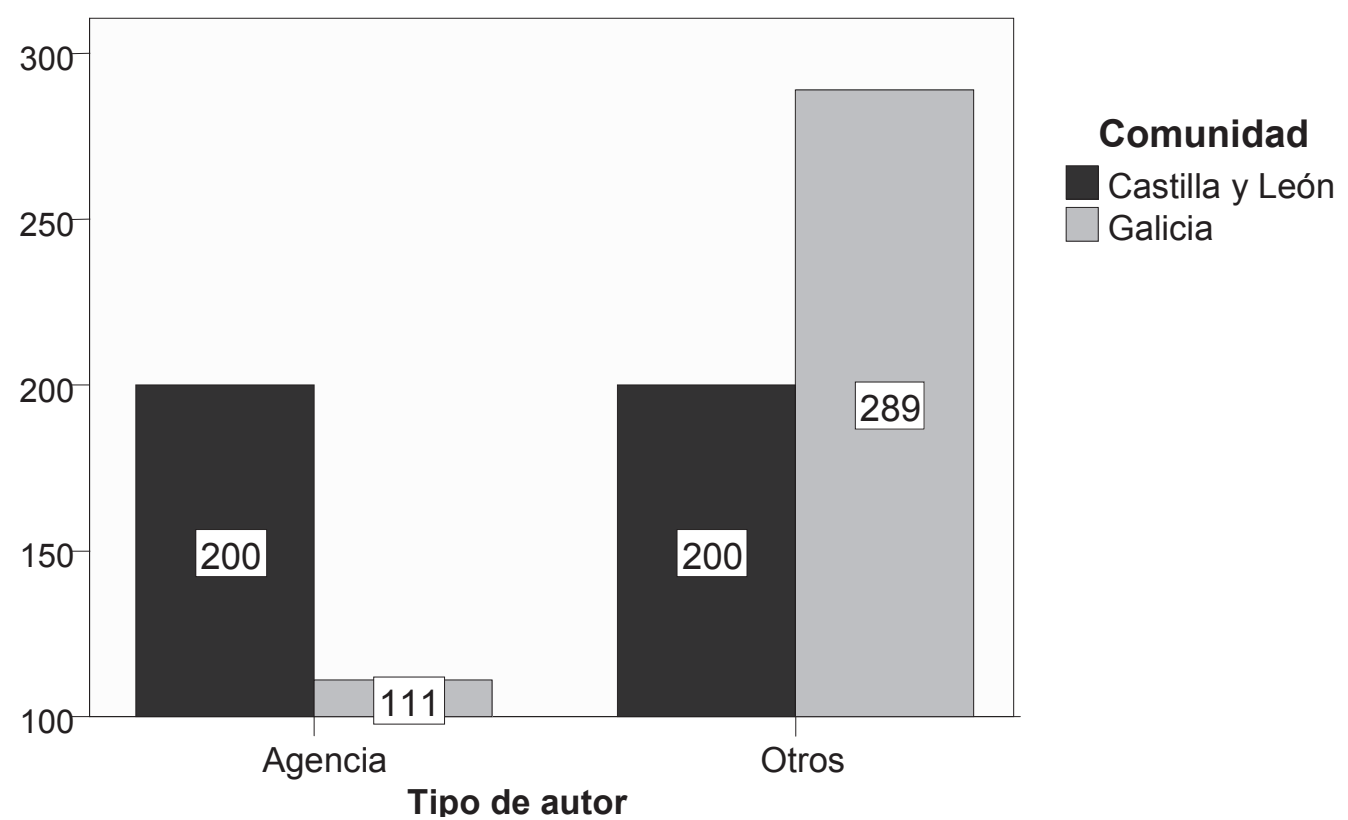

Fuente: elaboración propia a partir de los resultados del programa estadístico SPSS.

También resulta estadísticamente significativa la firma de un periodista en Galicia frente a otro tipo de autorías $(\mathrm{r}=0,009)$. Mientras que en esta comunidad 142 textos son firmados por un redactor con nombre explícito (el 35,50\% respecto al total de la región), en Castilla y León la cifra baja a 110 (el 27,50\%). Respecto a las 252 composiciones que se han registrado bajo la autoría de un redactor, se corresponde con el 56,35\% y $43,65 \%$, respectivamente. El coeficiente de contingencia en 0,086 no revela una relación demasiado fuerte, pese a todo.

Tabla 124. Tabla de contingencia entre periodista como fuente y comunidad

\begin{tabular}{|l|l|r|r|r|}
\hline \multirow{2}{*}{\multicolumn{2}{|c|}{ Tipo de autor }} & \multicolumn{2}{c|}{ Comunidad } & \multirow{2}{*}{ Total } \\
\cline { 3 - 4 } & \multicolumn{1}{|c|}{$\begin{array}{c}\text { Castilla y } \\
\text { León }\end{array}$} & Galicia & \\
\hline \multirow{3}{*}{ Periodista } & Recuento & 110 & 142 & 252 \\
& $\%$ de periodistas & $43,65 \%$ & $56,35 \%$ & $100,00 \%$ \\
& $\%$ de comunidad & $27,50 \%$ & $35,50 \%$ & $31,50 \%$ \\
\hline \multirow{3}{*}{ Otros } & Recuento & 290 & 258 & 548 \\
& $\%$ de periodistas & $52,92 \%$ & $47,08 \%$ & $100,00 \%$ \\
& $\%$ de comunidad & $72,50 \%$ & $64,50 \%$ & $68,50 \%$ \\
\hline \multirow{3}{*}{ Total } & Recuento & 400 & 400 & 800 \\
& $\%$ de periodistas & $50,00 \%$ & $50,00 \%$ & $100,00 \%$ \\
& $\%$ de comunidad & $100,00 \%$ & $100,00 \%$ & $100,00 \%$ \\
\hline
\end{tabular}

Fuente: elaboración propia a partir de los resultados del programa estadístico SPSS. 
Tabla 125. Prueba de chi-cuadrado entre periodista como fuente y comunidad

\begin{tabular}{|l|r|r|r|r|r|}
\hline \multicolumn{1}{|c|}{ Prueba } & \multicolumn{1}{|c|}{ Valor } & gl & \multicolumn{1}{c|}{$\begin{array}{c}\text { Sig. } \\
\text { asintótica } \\
\text { (bilateral) }\end{array}$} & $\begin{array}{l}\text { Sig. exacta } \\
\text { (bilateral) }\end{array}$ & $\begin{array}{c}\text { Sig. exacta } \\
\text { (unilateral) }\end{array}$ \\
\hline $\begin{array}{l}\text { Chi-cuadrado de Pearson } \\
\text { Corrección por } \\
\text { continuidad }\end{array}$ & 5,932 & 1 & 0,015 & & \\
$\begin{array}{l}\text { Razón de verosimilitudes } \\
\text { Estadístico exacto de } \\
\text { Fisher }\end{array}$ & 5,567 & 1 & 0,018 & & \\
$\begin{array}{l}\text { Asociación lineal por } \\
\text { lineal }\end{array}$ & 5,944 & 1 & 0,015 & 0,018 & 0,009 \\
N de casos válidos & 800,000 & 1 & 0,015 & & \\
\hline
\end{tabular}

Fuente: elaboración propia a partir de los resultados del programa estadístico SPSS.

Tabla 126. Medidas simétricas de la prueba de chi-cuadrado entre periodista como fuente y comunidad

\begin{tabular}{|c|c|c|c|c|c|}
\hline \multicolumn{2}{|c|}{ Prueba } & Valor & $\begin{array}{l}\text { Error } \\
\text { típ. asint. }\end{array}$ & $\begin{array}{c}\mathbf{T} \\
\text { aproximada }\end{array}$ & $\begin{array}{c}\text { Sig. } \\
\text { aproximada }\end{array}$ \\
\hline $\begin{array}{l}\text { Nominal por } \\
\text { nominal }\end{array}$ & $\begin{array}{l}\text { Coeficiente } \\
\text { de } \\
\text { contingencia }\end{array}$ & 0,086 & & & 0,015 \\
\hline $\begin{array}{l}\text { Intervalo por } \\
\text { intervalo }\end{array}$ & R de Pearson & $-0,086$ & 0,035 & $-2,442$ & 0,015 \\
\hline $\begin{array}{l}\text { Ordinal por ordinal } \\
\mathrm{N} \text { de casos válidos }\end{array}$ & $\begin{array}{l}\text { Correlación } \\
\text { de Spearman }\end{array}$ & $\begin{array}{r}-0,086 \\
800,00 \\
\end{array}$ & 0,035 & $-2,442$ & 0,015 \\
\hline
\end{tabular}

Fuente: elaboración propia a partir de los resultados del programa estadístico SPSS. 


\section{Gráfico 2. Número de noticias firmadas por periodistas según} comunidades

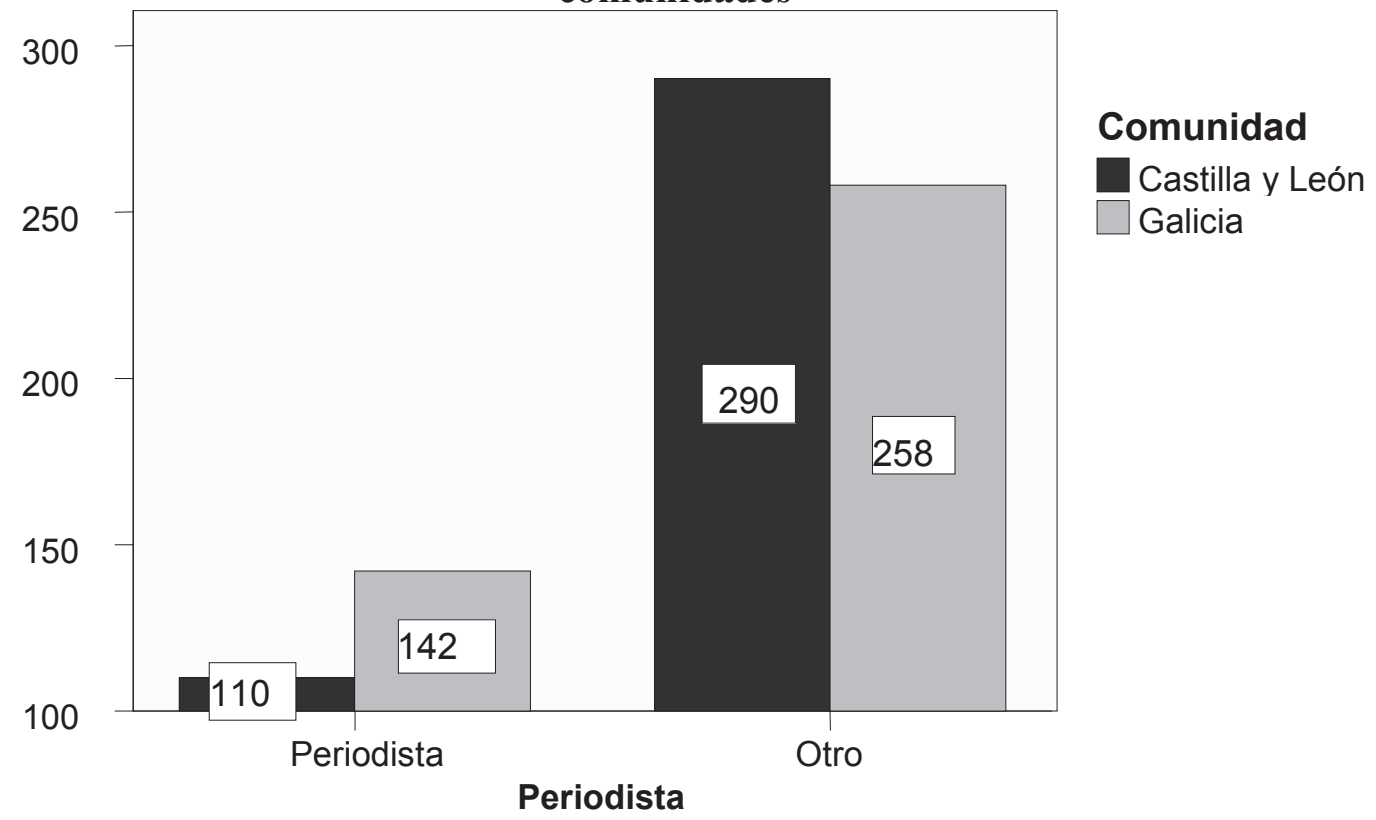

Fuente: elaboración propia a partir de los resultados del programa estadístico SPSS.

Los rotativos gallegos también firman más textos con el nombre del periódico que los castellano-leoneses, como se ha visto. La relación, de hecho, resulta ser estadísticamente significativa $(r=0,000$ y coeficiente de contingencia $=0,143)$. En la primera región, 112 composiciones se divulgaron bajo esta autoría (el 63,64\% respecto los 176 encontrados con esta característica), frente a los 64 de la segunda (el 36,36\%). Aunque en relación con las 400 informaciones analizadas en cada comunidad el porcentaje de firmas del periódico es bajo, es ligeramente más alto en Galicia que en Castilla y León: $28,00 \%$ y $16,00 \%$, en este orden.

Tabla 127. Tabla de contingencia entre periódico como autor y comunidad

\begin{tabular}{|l|l|r|r|r|}
\hline \multirow{2}{*}{\multicolumn{2}{|c|}{ Tipo de autor }} & \multicolumn{2}{c|}{ Comunidad } & \multirow{2}{*}{ Total } \\
\cline { 3 - 4 } & \multicolumn{1}{c|}{$\begin{array}{c}\text { Castilla y } \\
\text { León }\end{array}$} & \multicolumn{1}{c|}{ Galicia } & \\
\hline \multirow{3}{*}{ Periódico } & Recuento & 64 & 112 & 176 \\
& $\%$ de autor periódico & $36,36 \%$ & $63,64 \%$ & $100,00 \%$ \\
& $\%$ de comunidad & $16,00 \%$ & $28,00 \%$ & $22,00 \%$ \\
\hline \multirow{3}{*}{ Otros } & Recuento & 336 & 288 & 624 \\
& $\%$ de autor periódico & $53,85 \%$ & $46,15 \%$ & $100,00 \%$ \\
& $\%$ de comunidad & $84,00 \%$ & $72,00 \%$ & $78,00 \%$ \\
\hline \multirow{3}{*}{ Total } & Recuento & 400 & 400 & 800 \\
& $\%$ de autor periódico & $50,00 \%$ & $50,00 \%$ & $100,00 \%$ \\
& $\%$ de comunidad & $100,00 \%$ & $100,00 \%$ & $100,00 \%$ \\
\hline
\end{tabular}

Fuente: elaboración propia a partir de los resultados del programa estadístico SPSS. 
Tabla 128. Prueba de chi-cuadrado entre periódico como autor y comunidad

\begin{tabular}{|l|r|r|r|r|r|}
\hline \multicolumn{1}{|c|}{ Prueba } & \multicolumn{1}{|c|}{ Valor } & gl & $\begin{array}{c}\text { Sig. } \\
\text { asintótica } \\
\text { (bilateral) }\end{array}$ & $\begin{array}{l}\text { Sig. exacta } \\
\text { (bilateral) }\end{array}$ & $\begin{array}{c}\text { Sig. exacta } \\
\text { (unilateral) }\end{array}$ \\
\hline $\begin{array}{l}\text { Chi-cuadrado de Pearson } \\
\text { Corrección por } \\
\text { continuidad }\end{array}$ & 16,783 & 1 & 0,000 & & \\
$\begin{array}{l}\text { Razón de verosimilitudes } \\
\text { Estadístico exacto de }\end{array}$ & 16,091 & 1 & 0,000 & & \\
$\begin{array}{l}\text { Fisher } \\
\text { Asociación lineal por }\end{array}$ & 16,954 & 1 & 0,000 & 0,000 & 0,000 \\
lineal & 16,762 & 1 & 0,000 & & \\
N de casos válidos & 800,00 & & & & \\
\hline
\end{tabular}

Fuente: elaboración propia a partir de los resultados del programa estadístico SPSS.

Tabla 129. Medidas simétricas de la prueba de chi-cuadrado entre periódico como autor y comunidad

\begin{tabular}{|ll|r|r|r|r|}
\hline \multicolumn{2}{|c|}{ Prueba } & Valor & \multicolumn{1}{|c|}{$\begin{array}{c}\text { Error típ. } \\
\text { asint. }\end{array}$} & \multicolumn{1}{c|}{$\begin{array}{c}\text { T } \\
\text { aproximada }\end{array}$} & \multicolumn{1}{c|}{$\begin{array}{c}\text { Sig. } \\
\text { aproximada }\end{array}$} \\
\hline $\begin{array}{l}\text { Nominal por } \\
\text { nominal }\end{array}$ & $\begin{array}{l}\text { Coeficiente de } \\
\text { contingencia }\end{array}$ & 0,143 & & & 0,000 \\
$\begin{array}{l}\text { Intervalo por } \\
\text { intervalo }\end{array}$ & R de Pearson & $-0,145$ & 0,034 & $-4,135$ & 0,000 \\
Ordinal por ordinal & $\begin{array}{l}\text { Correlación de } \\
\text { Spearman }\end{array}$ & $-0,145$ & 0,034 & $-4,135$ & 0,000 \\
N de casos válidos & & 800,00 & & & \\
\hline
\end{tabular}

Fuente: elaboración propia a partir de los resultados del programa estadístico SPSS. 


\section{Gráfico 3. Número de noticias firmadas por el periódico según comunidades}

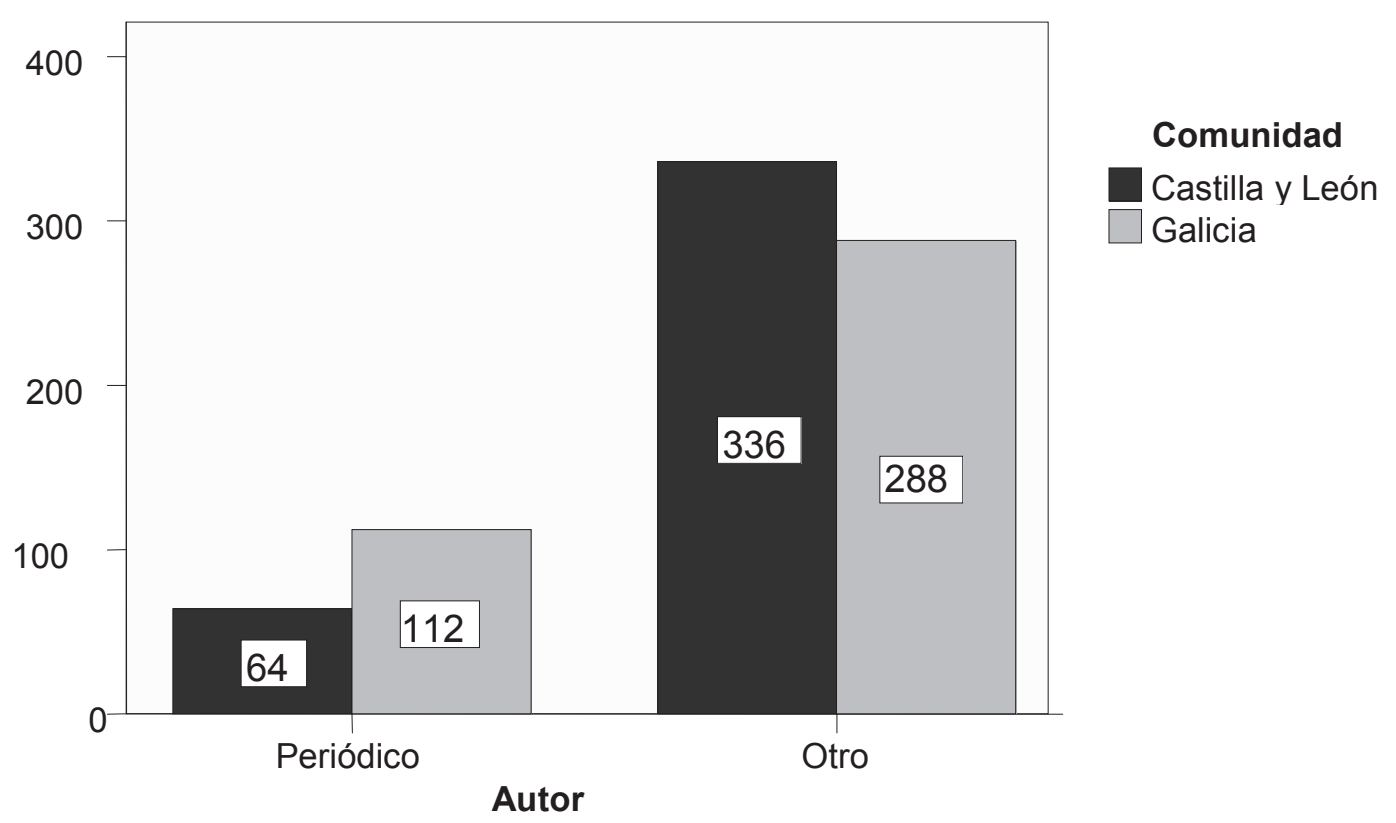

Fuente: elaboración propia a partir de los resultados del programa estadístico SPSS.

Únicamente un periódico ofrece la posibilidad de contactar con los autores de la noticia mediante correo electrónico. Se trata de La Voz de Galicia, que, a través de una ventana emergente, también muestra el rango que el redactor ostenta dentro de la publicación y, en algunos casos, se incluye una fotografía. En el 61,00\% de los textos firmados por un periodista se facilita esta información, mientras que sobre la muestra total de La Voz de Galicia se corresponde con el 32,00\%.

Este periódico hace que el $10,00 \%$ de todas las noticias emitidas en la comunidad gallega contengan un enlace para contactar con los autores del texto, mientras que en Castilla y León no se ha detectado ninguna. Las diferencias llegan a ser significativas $(\mathrm{r}=0,000$ y coeficiente de contingencia $=0,224)$, aunque como el cómputo procede de una única publicación, no puede considerarse una relación representativa de toda la muestra. 
Tabla 130. Tabla de contingencia entre contacto con el autor y comunidad

\begin{tabular}{|l|l|r|r|r|}
\hline \multirow{2}{*}{ Contacto con el autor } & \multicolumn{2}{c|}{ Comunidad } & \multirow{2}{*}{ Total } \\
\cline { 3 - 4 } \multicolumn{2}{|c|}{$\begin{array}{c}\text { Castilla y } \\
\text { León }\end{array}$} & Galicia & \\
\hline \multirow{3}{*}{ Sí } & Recuento & 0 & 40 & 40 \\
& $\%$ de contacto autor & $0,00 \%$ & $100,00 \%$ & $100,00 \%$ \\
& $\%$ de comunidad & $0,00 \%$ & $10,00 \%$ & $5,00 \%$ \\
\hline \multirow{3}{*}{ No } & Recuento & 400 & 360 & 760 \\
& $\%$ de contacto autor & $52,63 \%$ & $47,37 \%$ & $100,00 \%$ \\
& $\%$ de comunidad & $100,00 \%$ & $90,00 \%$ & $95,00 \%$ \\
\hline \multirow{3}{*}{ Total } & Recuento & 400 & 400 & 800 \\
& $\%$ de contacto autor & $50,00 \%$ & $50,00 \%$ & $100,00 \%$ \\
& $\%$ de comunidad & $100,00 \%$ & $100,00 \%$ & $100,00 \%$ \\
\hline
\end{tabular}

Fuente: elaboración propia a partir de los resultados del programa estadístico SPSS.

Tabla 131. Prueba de chi-cuadrado entre contacto con el autor y comunidad

\begin{tabular}{|l|r|r|r|r|r|}
\hline \multicolumn{1}{|c|}{ Prueba } & Valor & gl & $\begin{array}{c}\text { Sig. } \\
\text { asintótica } \\
\text { (bilateral) }\end{array}$ & $\begin{array}{l}\text { Sig. exacta } \\
\text { (bilateral) }\end{array}$ & $\begin{array}{c}\text { Sig. exacta } \\
\text { (unilateral) }\end{array}$ \\
\hline $\begin{array}{l}\text { Chi-cuadrado de Pearson } \\
\text { Corrección por } \\
\text { continuidad }\end{array}$ & 42,105 & 1 & 0,000 & & \\
$\begin{array}{l}\text { Razón de verosimilitudes } \\
\text { Estadístico exacto de }\end{array}$ & 57,026 & 1 & 0,000 & 0,000 & 0,000 \\
$\begin{array}{l}\text { Fisher } \\
\text { Asociación lineal por } \\
\text { lineal }\end{array}$ & 1 & 0,000 & & \\
N de casos válidos & 82,053 & 1 & 0,000 & & \\
\hline
\end{tabular}

Fuente: elaboración propia a partir de los resultados del programa estadístico SPSS.

Tabla 132. Medidas simétricas de la prueba de chi-cuadrado entre contacto con el autor y comunidad

\begin{tabular}{|ll|r|r|r|r|}
\hline \multicolumn{2}{|c|}{ Prueba } & Valor & \multicolumn{1}{|c|}{$\begin{array}{c}\text { Error típ. } \\
\text { asint. }\end{array}$} & \multicolumn{1}{c|}{$\begin{array}{c}\text { T } \\
\text { aproximada }\end{array}$} & \multicolumn{1}{c|}{$\begin{array}{c}\text { Sig. } \\
\text { aproximada }\end{array}$} \\
\hline $\begin{array}{l}\text { Nominal por } \\
\text { nominal }\end{array}$ & $\begin{array}{l}\text { Coeficiente de } \\
\text { contingencia }\end{array}$ & 0,224 & & & 0,000 \\
$\begin{array}{l}\text { Intervalo por } \\
\text { intervalo }\end{array}$ & R de Pearson & 0,229 & 0,019 & 6,658 & 0,000 \\
Ordinal por ordinal & $\begin{array}{l}\text { Correlación de } \\
\text { Spearman }\end{array}$ & 0,229 & 0,019 & 6,658 & 0,000 \\
N de casos válidos & 800,00 & & \\
\hline
\end{tabular}

Fuente: elaboración propia a partir de los resultados del programa estadístico SPSS. 


\section{Gráfico 4. Número de noticias con posibilidad de contactar con el autor según comunidades}

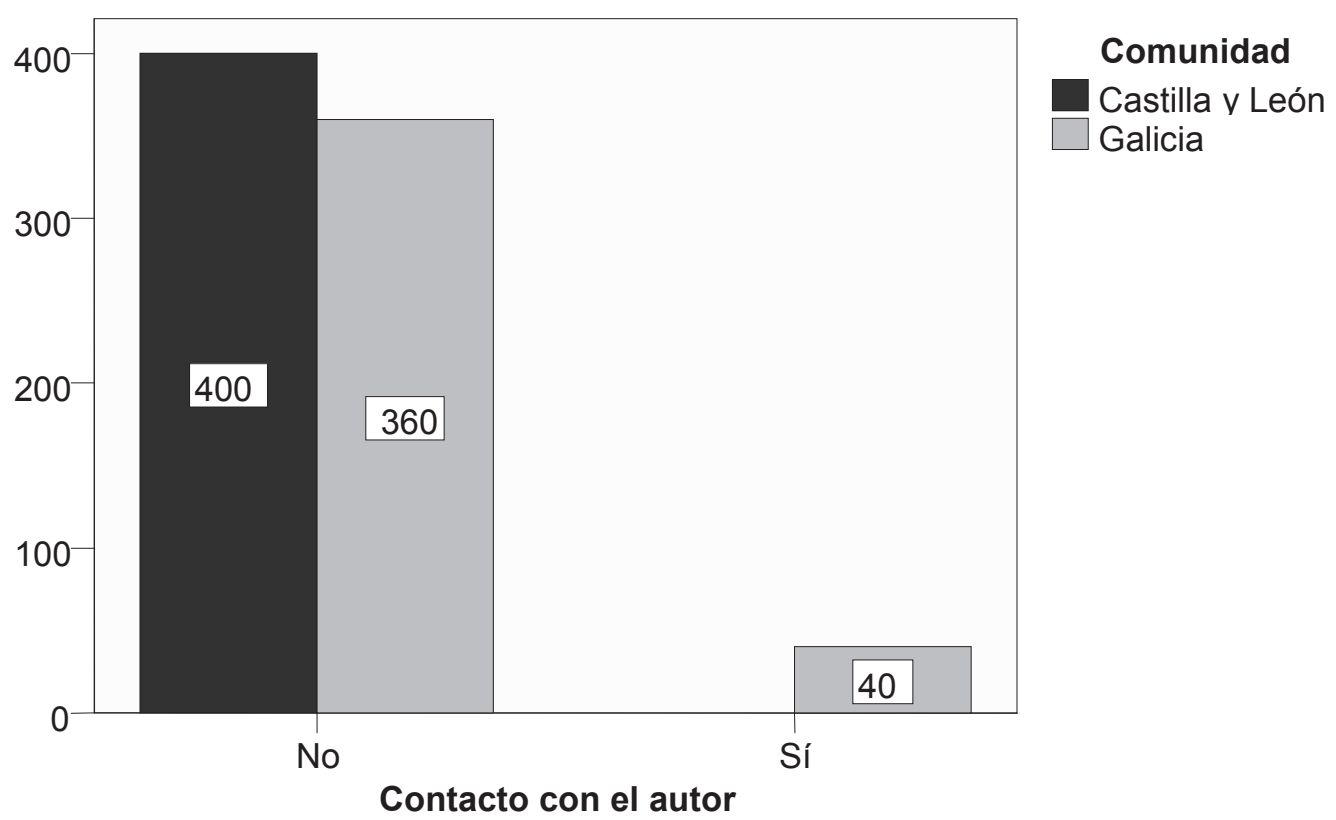

Fuente: elaboración propia a partir de los resultados del programa estadístico SPSS.

\subsubsection{LUGAR DE PUBLICACIÓN}

No existe un lugar concreto de donde procedan la mayoría de las informaciones sobre salud y sanidad: casi todas provienen de diversos lugares de la geografía, tanto nacional como internacional. Muchas de ellas, incluso, se publican sin un lugar de emisión concreto (más específicamente, el $41,50 \%$ de la muestra). La ciudad que concentra más textos, aunque sea el 10,63\%, es Madrid, que curiosamente no se encuentra dentro de los límites de las dos comunidades estudiadas. Después de la capital de España, y con poco más de la mitad de sus noticias, se halla Santiago de Compostela, que reúne el 5,75\% del total. La capital de Castilla y León, Valladolid, le sigue por detrás con un $5,25 \%$.

Llama la atención que de los diez núcleos más citados (que se sitúan entre el $10,62 \%$ y el 1,50\% del total), seis pertenecen a Galicia y solo dos a Castilla y León (los otros dos restantes no pertenecen a estos territorios, como son Madrid y Barcelona). El resto de lugares muestran menos de 8 coincidencias (que se correspondería con un 1,00\%). De hecho, hay 19 sitios con dos menciones y 52 con solo una. En total, se han hallado 100 lugares distintos. 
Tabla 133. Frecuencia y porcentaje de las informaciones según el lugar origen

\begin{tabular}{|l|r|r|}
\hline \multicolumn{1}{|c|}{ Lugar } & Frecuencia & Porcentaje \\
\hline Ninguno & 332 & 41,50 \\
\hline Madrid & 85 & 10,63 \\
\hline Santiago & 46 & 5,75 \\
\hline Valladolid & 42 & 5,25 \\
\hline A Coruña & 24 & 3,00 \\
\hline Vigo & 21 & 2,63 \\
\hline Burgos & 19 & 2,38 \\
\hline Ourense & 19 & 2,38 \\
\hline Barcelona & 15 & 1,88 \\
\hline Lugo & 13 & 1,63 \\
\hline Pontevedra & 12 & 1,50 \\
\hline León & 8 & 1,00 \\
\hline Segovia & 7 & 0,88 \\
\hline Ponferrada & 6 & 0,75 \\
\hline Alicante & 5 & 0,63 \\
\hline Murcia & 5 & 0,63 \\
\hline Palencia & 5 & 0,63 \\
\hline Ribeira & 500 & 0,63 \\
\hline Zaragoza & 3 & 100,00 \\
\hline Londres & 5 & 0,63 \\
\hline Málaga & 4 & 0,50 \\
\hline O Barco & 4 & 0,50 \\
\hline Bilbao & 3 & 0,50 \\
\hline Bogotá & 3 & 0,38 \\
\hline Caracas & 3 & 0,38 \\
\hline Carballo & 3 & 0,38 \\
\hline Madrid/Zaragoza & 3 & 0,38 \\
\hline Montevideo & 3 & 0,38 \\
\hline O Grove & 0,38 \\
\hline Valencia & 3 & 0,38 \\
\hline Otros & 3 & 0,38 \\
\hline Total & 3 & \\
\hline
\end{tabular}

Fuente: elaboración propia.

Si se comparan los lugares de las noticias según cada comunidad autónoma se observa que los periódicos publican prácticamente el mismo número sin un lugar concreto (169 en Castilla y León y 163 en Galicia) que con un sitio determinado (231 en el primer caso y 237 en el segundo). 
Tabla 134. Tabla de contingencia entre la inclusión de un lugar de origen y comunidad

\begin{tabular}{|l|l|r|r|r|}
\hline \multicolumn{2}{|c|}{ Tipo de lugar } & \multicolumn{2}{c|}{ Comunidad } & \multirow{2}{*}{ Total } \\
\cline { 3 - 4 } \multicolumn{2}{|c|}{} & $\begin{array}{c}\text { Castilla y } \\
\text { León }\end{array}$ & Galicia & \\
\hline \multirow{3}{*}{ Con lugar } & Recuento & 231 & 237 & 468 \\
& $\%$ de lugar & $49,36 \%$ & $50,64 \%$ & $100,00 \%$ \\
& $\%$ de comunidad & $57,75 \%$ & $59,25 \%$ & $58,50 \%$ \\
\hline \multirow{3}{*}{ Sin lugar } & Recuento & 169 & 163 & 332 \\
& \% de lugar & $50,90 \%$ & $49,10 \%$ & $100,00 \%$ \\
& \% de comunidad & $42,25 \%$ & $40,75 \%$ & $41,50 \%$ \\
\hline \multirow{3}{*}{ Total } & Recuento & 400 & 400 & 800 \\
& \% de lugar & $50,00 \%$ & $50,00 \%$ & $100,00 \%$ \\
& \% de comunidad & $100,00 \%$ & $100,00 \%$ & $100,00 \%$ \\
\hline
\end{tabular}

Fuente: elaboración propia a partir de los resultados del programa estadístico SPSS.

Sin embargo, donde sí que se encuentran diferencias, y de hecho resultan ser significativas $(\mathrm{r}=0,000$ y coeficiente de contingencia $=0,308)$, es en la cantidad de textos que incluyen un lugar concreto según provengan de dentro o de fuera de la comunidad. Así, Galicia contiene el 75,11\% de sus informaciones sobre salud y sanidad enmarcadas dentro de su propio territorio, mientras que en el caso de Castilla y León la cifra no llega ni a la mitad del total $(43,29 \%)$.

Tabla 135. Tabla de contingencia entre la procedencia de la información y comunidad

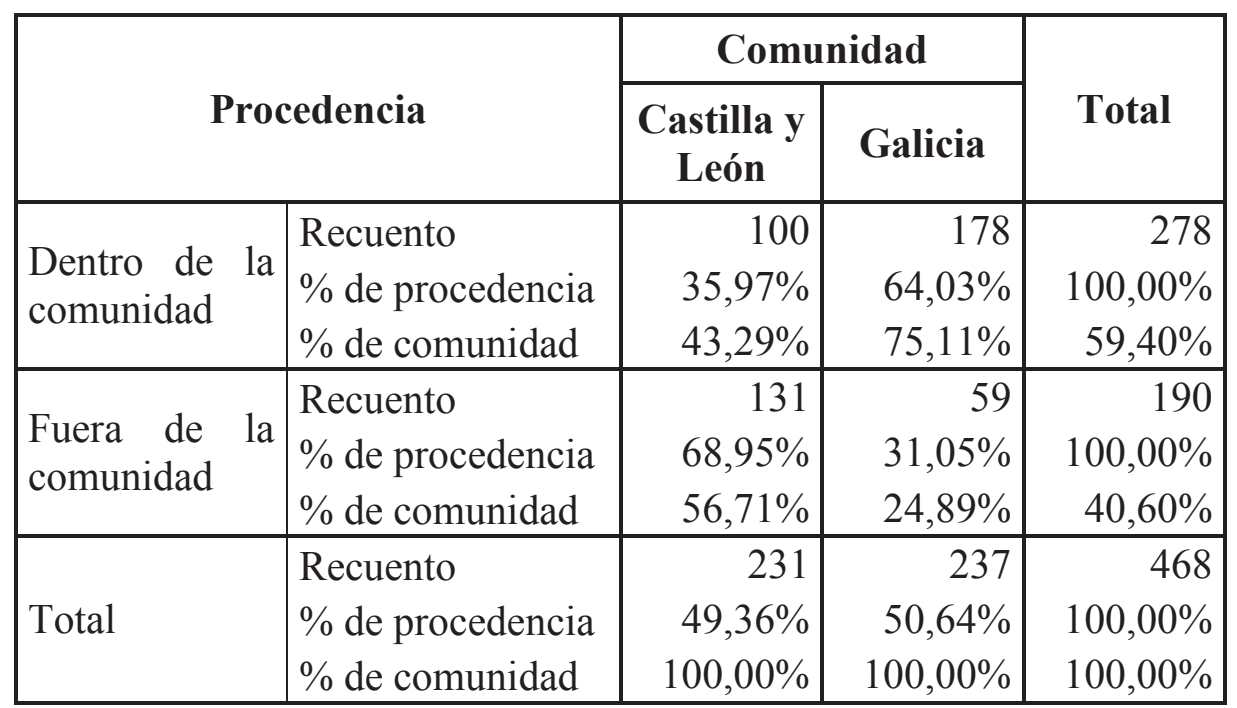

Fuente: elaboración propia a partir de los resultados del programa estadístico SPSS. 
Tabla 136. Prueba de chi-cuadrado entre la procedencia de la información y comunidad

\begin{tabular}{|c|c|c|c|c|c|}
\hline Prueba & Valor & gl & $\begin{array}{l}\text { Sig. } \\
\text { asintótica } \\
\text { (bilateral) }\end{array}$ & $\begin{array}{l}\text { Sig. exacta } \\
\text { (bilateral) }\end{array}$ & $\begin{array}{l}\text { Sig. exacta } \\
\text { (unilateral) }\end{array}$ \\
\hline Chi-cuadrado de Pearson & 49,100 & 1 & 0,000 & \multirow{5}{*}{0,000} & \multirow{5}{*}{0,000} \\
\hline $\begin{array}{l}\text { Corrección } \\
\text { continuidad }\end{array}$ & 47,790 & 1 & 0,000 & & \\
\hline Razón de verosimilitudes & 50,082 & 1 & 0,000 & & \\
\hline $\begin{array}{l}\text { Estadístico exacto de } \\
\text { Fisher }\end{array}$ & & & & & \\
\hline $\begin{array}{l}\text { Asociación lineal por } \\
\text { lineal }\end{array}$ & 48,995 & 1 & 0,000 & & \\
\hline
\end{tabular}

Fuente: elaboración propia a partir de los resultados del programa estadístico SPSS.

Tabla 137. Medidas simétricas de la prueba de chi-cuadrado entre la procedencia de la información y comunidad

\begin{tabular}{|c|c|c|c|c|}
\hline Prueba & Valor & $\begin{array}{l}\text { Error típ. } \\
\text { asint. }\end{array}$ & $\begin{array}{c}\mathbf{T} \\
\text { aproximada }\end{array}$ & $\begin{array}{c}\text { Sig. } \\
\text { aproximada }\end{array}$ \\
\hline $\begin{array}{c}\text { por Coeficiente de } \\
\text { contingencia }\end{array}$ & 0,308 & & & 0,000 \\
\hline por $\mathrm{R}$ de Pearson & $-0,324$ & 0,044 & $-7,391$ & 0,000 \\
\hline $\begin{array}{ll}\text { Ordinal por ordinal } & \begin{array}{l}\text { Correlación de } \\
\text { Spearman }\end{array} \\
\mathrm{N} \text { de casos válidos } & \end{array}$ & $\begin{array}{r}-0,324 \\
468,000\end{array}$ & 0,044 & $-7,391$ & 0,000 \\
\hline
\end{tabular}

Fuente: elaboración propia a partir de los resultados del programa estadístico SPSS. 


\section{Gráfico 5. Procedencia de las informaciones según comunidades}

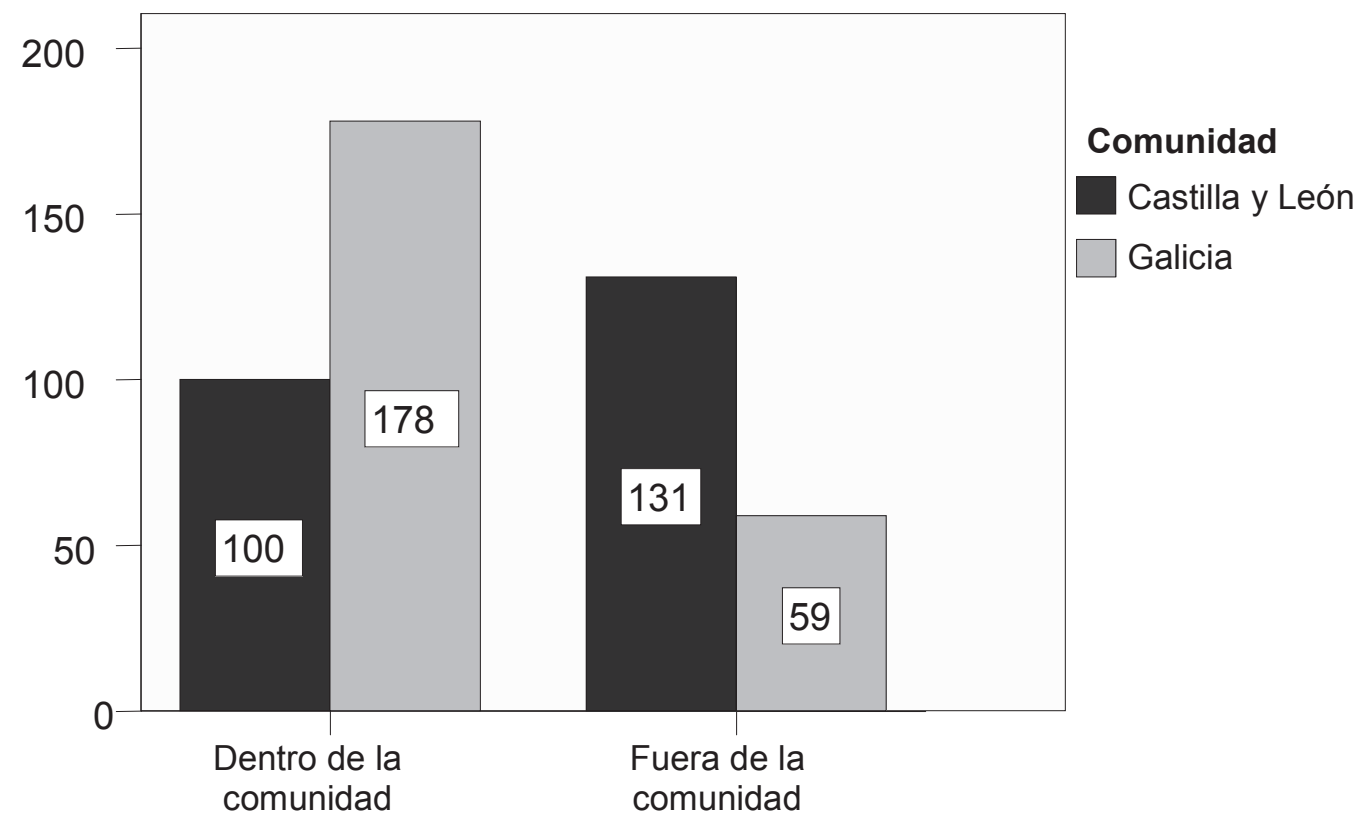

Fuente: elaboración propia a partir de los resultados del programa estadístico SPSS.

\subsubsection{GÉNERO DE LAS INFORMACIONES}

Para conocer el género de los textos que publican los diarios castellano-leoneses y gallegos sobre salud y sanidad, se ha dividido la muestra en: información, reportaje, entrevista, crónica o crítica y opinión. Así, se puede evidenciar que la mayoría de las novedades están relacionadas con hechos noticiosos. Nueve de cada diez composiciones (el 91,38\%) se engloban bajo esta temática. En cambio, otros géneros menos informativos y más creativos quedan relegados a ocasiones muy puntuales. Por ejemplo, de los 800 textos recopilados, únicamente 29 (el 3,63\%) se corresponden con reportajes, 14 son entrevistas $(1,75 \%)$ y otros tantos, crónicas o críticas $(1,75 \%)$. El género de opinión es el menos utilizado, únicamente encuadrado en 12 (1,50\%) composiciones.

Tabla 138. Frecuencia y porcentaje del género de las informaciones

\begin{tabular}{|l|r|r|}
\hline \multicolumn{1}{|c|}{ Género } & Frecuencia & Porcentaje \\
\hline Información & 731 & 91,38 \\
\hline Reportaje & 29 & 3,63 \\
\hline Entrevista & 14 & 1,75 \\
\hline Crónica-crítica & 14 & 1,75 \\
\hline Opinión & 12 & 1,50 \\
\hline Total & 800 & 100,00 \\
\hline
\end{tabular}

Fuente: elaboración propia. 


\section{Gráfico 6. Porcentaje de las informaciones por género}

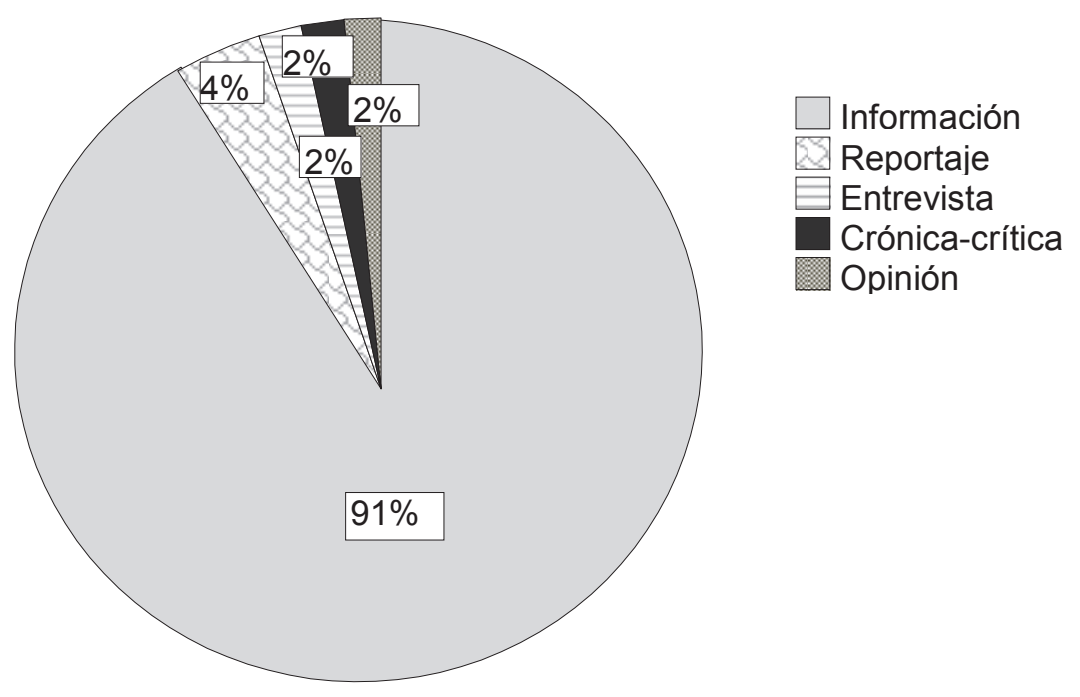

Fuente: elaboración propia.

Galicia concentra la mayor parte de los textos no puramente informativos. Ocho de cada diez $(79,71 \%)$ composiciones de este tipo son publicadas en esta región, mientras que Castilla y León solo divulga el 20,29\% del total de ambas comunidades. De esta manera, de todas las referencias escritas por los periódicos de Castilla y León, el 96,5\% son puramente informativas y el 3,5\% restante se corresponden con otros géneros, como el reportaje, la entrevista, la crónica o crítica o la opinión. En Galicia, aunque la diferencia sigue siendo muy acusada, no es tan extremista como en la región castellana. Así, los textos meramente informativos y los más creativos comprenden el 86,25\% y el $13,75 \%$, respectivamente.

Tabla 139. Tabla de contingencia entre género informativo o no informativo y comunidad

\begin{tabular}{|l|l|r|r|r|}
\hline \multicolumn{2}{|c|}{ Tipo de género } & \multicolumn{2}{c|}{ Comunidad } & \multirow{2}{*}{ Total } \\
\cline { 3 - 4 } \multicolumn{2}{|c|}{} & $\begin{array}{c}\text { Castilla y } \\
\text { León }\end{array}$ & Galicia & \\
\hline \multirow{3}{*}{ Informativo } & Recuento & 386 & 345 & 731 \\
& $\%$ de género & $52,81 \%$ & $47,20 \%$ & $100 \%$ \\
& $\%$ de comunidad & $96,50 \%$ & $86,25 \%$ & $91,38 \%$ \\
\hline \multirow{2}{*}{ No } & Recuento & 14 & 55 & 69 \\
informativo & $\%$ de género & $20,29 \%$ & $79,71 \%$ & $100,00 \%$ \\
& $\%$ de comunidad & $3,50 \%$ & $13,75 \%$ & $8,63 \%$ \\
\hline \multirow{3}{*}{ Total } & Recuento & 400 & 400 & 800 \\
& $\%$ de género & $50,00 \%$ & $50,00 \%$ & $100,00 \%$ \\
& $\%$ de comunidad & $100,00 \%$ & $100,00 \%$ & $100,00 \%$ \\
\hline
\end{tabular}

Fuente: elaboración propia a partir de los resultados del programa estadístico SPSS. 
Dentro de los géneros no puramente informativos, donde mayor diferencia se encuentra entre ambas comunidades es en la crónica o crítica. El 92,86\% (es decir, 13) provienen de la región gallega y solamente el 7,14\% (un único texto) de la castellana. También hay bastante diferencia, aunque no tanta, en las entrevistas $(78,57 \%$ frente a $21,43 \%)$ y en los reportajes $(75,86 \%$ frente a $24,14 \%)$. El tipo de textos donde se han hallado menos diferencias entre unos diarios y otros, aunque la desigualdad es amplia, es en la opinión: tres de cada cuatro composiciones han sido divulgadas en Galicia.

Tabla 140. Tabla de contingencia entre género y comunidad

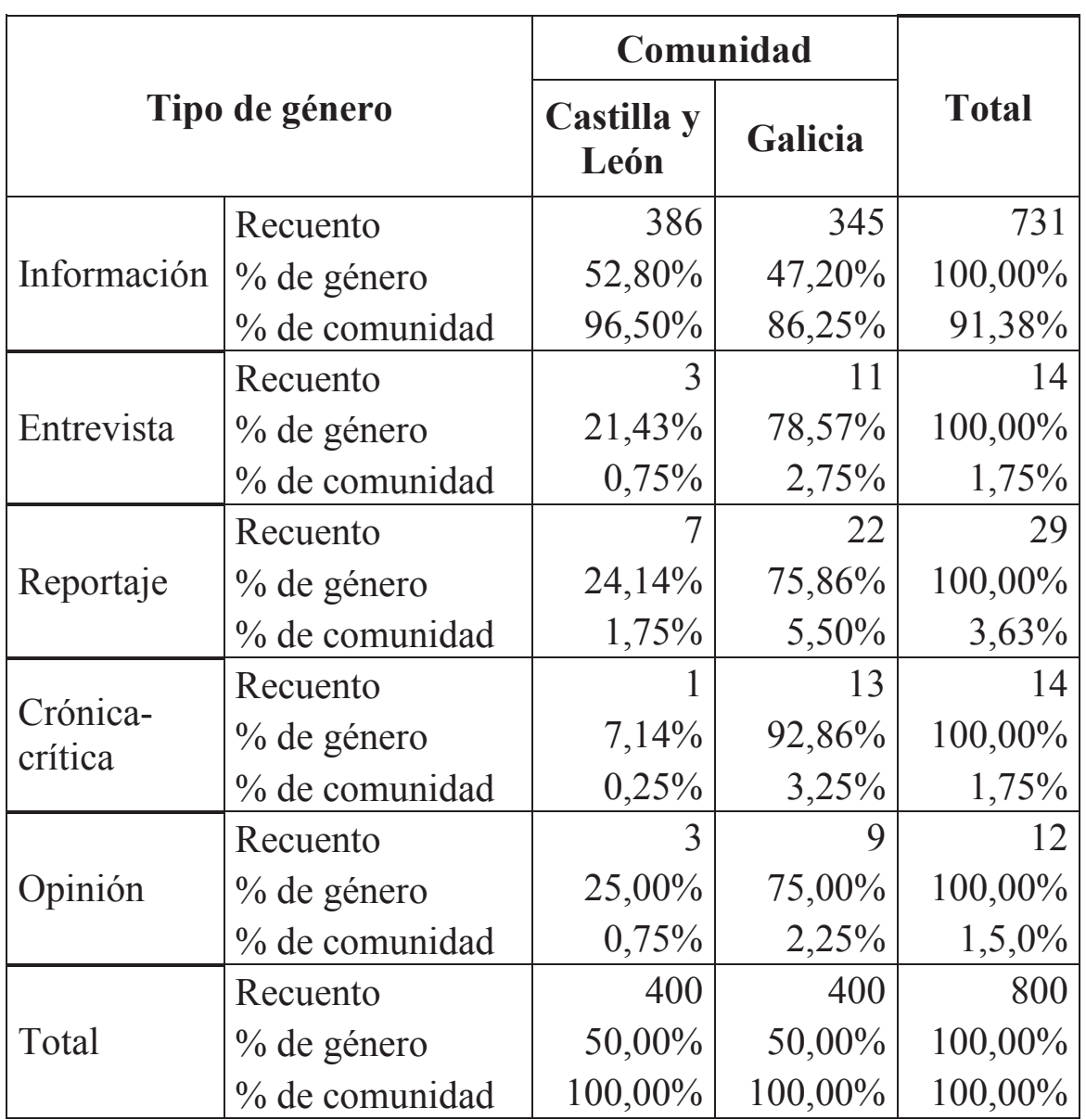

Fuente: elaboración propia a partir de los resultados del programa estadístico SPSS.

De hecho, salvo para el género opinión, estas diferencias resultan ser significativas. En cuanto a la información, la prueba de chi-cuadrado otorga un 0,000 de significación. El coeficiente de contingencia en 0,180 implica que no se trata de una relación demasiado fuerte (conviene recordar que el mínimo es 0 y el máximo, 1). 
Tabla 141. Prueba de chi-cuadrado entre género informativo y comunidad

\begin{tabular}{|l|r|r|r|r|r|}
\hline \multicolumn{1}{|c|}{ Prueba } & \multicolumn{1}{|c|}{ Valor } & gl & $\begin{array}{c}\text { Sig. } \\
\text { asintótica } \\
\text { (bilateral) }\end{array}$ & $\begin{array}{l}\text { Sig. exacta } \\
\text { (bilateral) }\end{array}$ & $\begin{array}{c}\text { Sig. exacta } \\
\text { (unilateral) }\end{array}$ \\
\hline Chi-cuadrado de Pearson & 26,662 & 1 & 0,000 & & \\
$\begin{array}{l}\text { Corrección por } \\
\text { continuidad }\end{array}$ & 25,377 & 1 & 0,000 & & \\
$\begin{array}{l}\text { Razón de verosimilitudes } \\
\text { Estadístico exacto de }\end{array}$ & 28,349 & 1 & 0,000 & 0,000 & 0,000 \\
$\begin{array}{l}\text { Fisher } \\
\text { Asociación lineal por } \\
\text { lineal }\end{array}$ & 26,629 & 1 & 0,000 & & \\
N de casos válidos & 800,000 & & & & \\
\hline
\end{tabular}

Fuente: elaboración propia a partir de los resultados del programa estadístico SPSS.

Tabla 142. Medidas simétricas de la prueba de chi-cuadrado entre género informativo y comunidad

\begin{tabular}{|c|c|c|c|c|c|}
\hline \multicolumn{2}{|l|}{ Prueba } & Valor & $\begin{array}{l}\text { Error típ. } \\
\text { asint. }\end{array}$ & $\begin{array}{c}\mathbf{T} \\
\text { aproximada }\end{array}$ & $\begin{array}{c}\text { Sig. } \\
\text { aproximada }\end{array}$ \\
\hline Nominal por nominal & $\begin{array}{l}\text { Coeficiente de } \\
\text { contingencia }\end{array}$ & 0,180 & & & 0,000 \\
\hline $\begin{array}{l}\text { Intervalo por } \\
\text { intervalo }\end{array}$ & $\mathrm{R}$ de Pearson & 0,183 & 0,031 & 5,245 & 0,000 \\
\hline $\begin{array}{l}\text { Ordinal por ordinal } \\
\mathrm{N} \text { de casos válidos }\end{array}$ & $\begin{array}{l}\text { Correlación de } \\
\text { Spearman }\end{array}$ & $\begin{array}{r}0,183 \\
800,000\end{array}$ & 0,031 & 5,245 & 0,000 \\
\hline
\end{tabular}

Fuente: elaboración propia a partir de los resultados del programa estadístico SPSS. 


\section{Gráfico 7. Número de informaciones por género informativo o no informativo según comunidades}

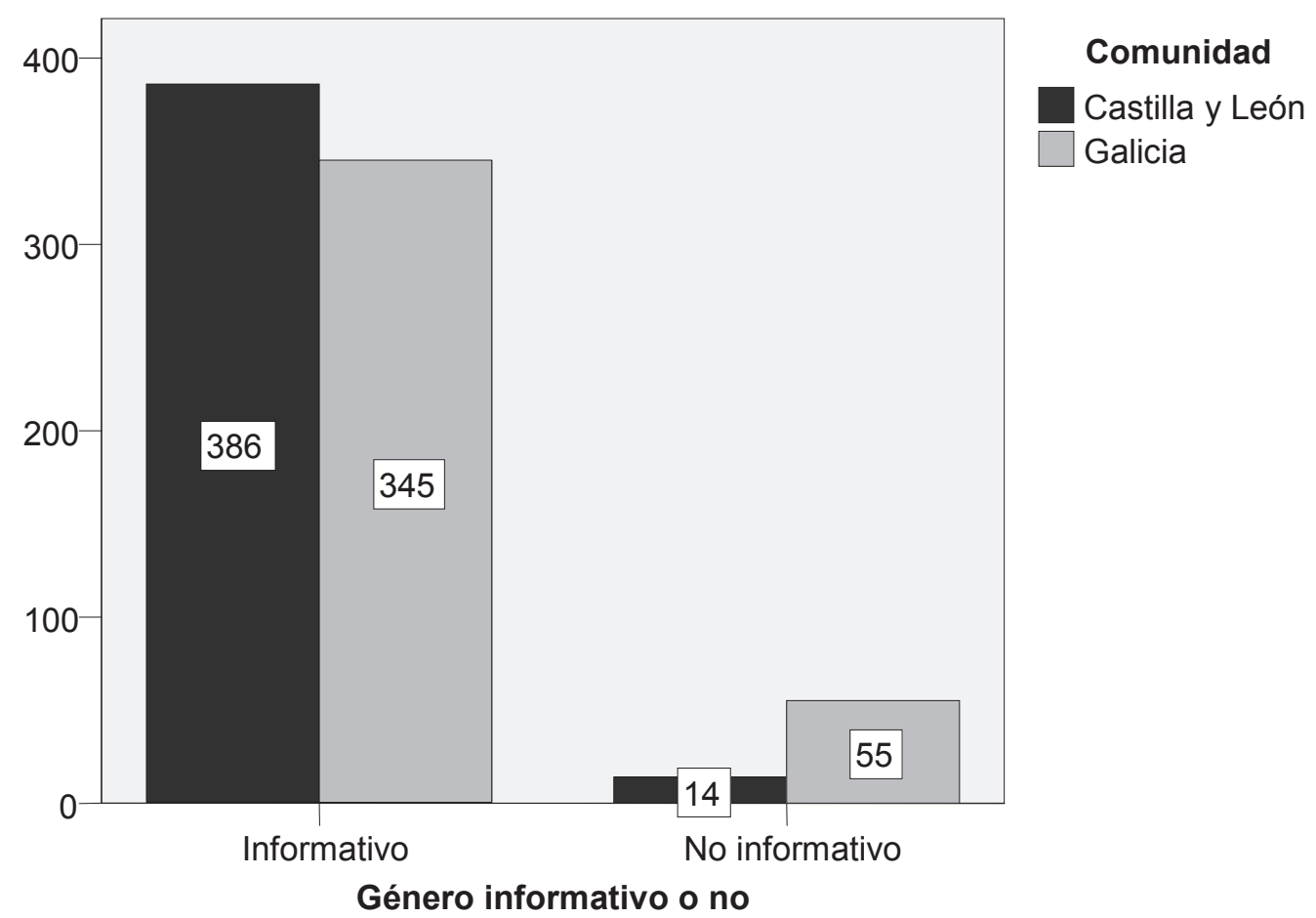

Fuente: elaboración propia a partir de los resultados del programa estadístico SPSS.

También se encuentran diferencias significativas en el uso que hacen los periódicos de cada comunidad de la entrevista. Mientras que los de Castilla y León publican únicamente tres $(0,75 \%)$, en Galicia divulgan 11 (2,75\%). La significación en 0,031 señala una relación fiable, aunque el coeficiente de contingencia en 0,076 muestra una relación con poca fuerza. 
Tabla 143. Tabla de contingencia entre entrevista y comunidad

\begin{tabular}{|l|l|r|r|r|}
\hline \multirow{2}{*}{ Tipo de género } & \multicolumn{2}{c|}{ Comunidad } & \multirow{2}{*}{ Total } \\
\cline { 3 - 4 } & \multicolumn{2}{c|}{$\begin{array}{c}\text { Castilla y } \\
\text { León }\end{array}$} & Galicia & \\
\hline \multirow{3}{*}{ Entrevista } & Recuento & 3 & 11 & 14 \\
& $\%$ de entrevista & $21,43 \%$ & $78,57 \%$ & $100,00 \%$ \\
& $\%$ de comunidad & $0,75 \%$ & $2,75 \%$ & $1,75 \%$ \\
\hline \multirow{3}{*}{ Otros } & Recuento & 397 & 389 & 786 \\
& $\%$ de entrevista & $50,51 \%$ & $49,49 \%$ & $100,00 \%$ \\
& $\%$ de comunidad & $99,25 \%$ & $97,25 \%$ & $98,25 \%$ \\
\hline \multirow{3}{*}{ Total } & Recuento & 400 & 400 & 800 \\
& \% de entrevista & $50,00 \%$ & $50,00 \%$ & $100,00 \%$ \\
& $\%$ de comunidad & $100,00 \%$ & $100,00 \%$ & $100,00 \%$ \\
\hline
\end{tabular}

Fuente: elaboración propia a partir de los resultados del programa estadístico SPSS.

Tabla 144. Prueba de chi-cuadrado entre entrevista y comunidad

\begin{tabular}{|c|c|c|c|c|c|}
\hline Prueba & Valor & gl & $\begin{array}{c}\text { Sig. } \\
\text { asintótica } \\
\text { (bilateral) }\end{array}$ & $\begin{array}{l}\text { Sig. exacta } \\
\text { (bilateral) }\end{array}$ & $\begin{array}{l}\text { Sig. exacta } \\
\text { (unilateral) }\end{array}$ \\
\hline Chi-cuadrado de Pearson & 4,653 & 1 & 0,031 & \multirow{6}{*}{0,055} & \multirow{6}{*}{0,028} \\
\hline $\begin{array}{l}\text { Corrección por } \\
\text { continuidad }\end{array}$ & 3,562 & 1 & 0,059 & & \\
\hline Razón de verosimilitudes & 4,941 & 1 & 0,026 & & \\
\hline $\begin{array}{l}\text { Estadístico exacto de } \\
\text { Fisher }\end{array}$ & & \multirow{3}{*}{1} & \multirow{3}{*}{0,031} & & \\
\hline $\begin{array}{l}\text { Asociación lineal por } \\
\text { lineal }\end{array}$ & 4,647 & & & & \\
\hline $\mathrm{N}$ de casos válidos & 800,000 & & & & \\
\hline
\end{tabular}

Fuente: elaboración propia a partir de los resultados del programa estadístico SPSS.

Tabla 145. Medidas simétricas de la prueba de chi-cuadrado entre entrevista y comunidad

\begin{tabular}{|c|c|c|c|c|c|}
\hline \multicolumn{2}{|l|}{ Prueba } & Valor & $\begin{array}{l}\text { Error típ. } \\
\text { asint. }\end{array}$ & $\begin{array}{c}\mathbf{T} \\
\text { aproximada }\end{array}$ & $\begin{array}{c}\text { Sig. } \\
\text { aproximada }\end{array}$ \\
\hline Nominal por nominal & $\begin{array}{l}\text { Coeficiente de } \\
\text { contingencia }\end{array}$ & 0,076 & & & 0,031 \\
\hline $\begin{array}{l}\text { Intervalo por } \\
\text { intervalo }\end{array}$ & $\mathrm{R}$ de Pearson & $-0,076$ & 0,031 & $-2,161$ & 0,031 \\
\hline $\begin{array}{l}\text { Ordinal por ordinal } \\
\mathrm{N} \text { de casos válidos }\end{array}$ & $\begin{array}{l}\text { Correlación de } \\
\text { Spearman }\end{array}$ & $\begin{array}{r}-0,076 \\
800,000\end{array}$ & 0,031 & $-2,161$ & 0,031 \\
\hline
\end{tabular}

Fuente: elaboración propia a partir de los resultados del programa estadístico SPSS. 
Gráfico 8. Número de entrevistas según comunidades

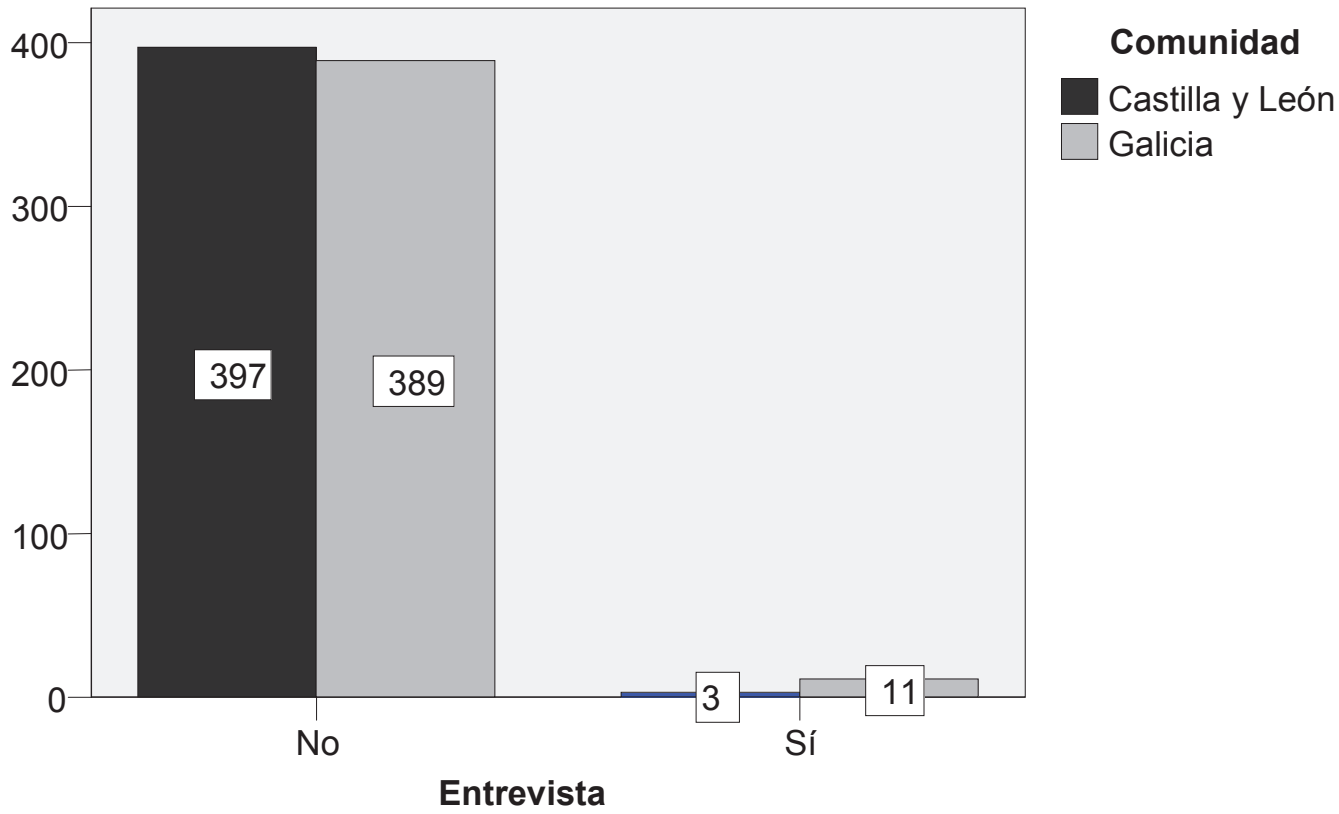

Fuente: elaboración propia a partir de los resultados del programa estadístico SPSS.

Los periódicos gallegos también divulgan estadísticamente más reportajes que los castellano-leoneses. Veintidós de los 400 (5,50\%) textos analizados en la primera comunidad se engloban dentro de este género, mientras que solo siete $(1,75 \%)$ se han difundido en la segunda. La significación devuelve un 0,005 y el coeficiente de contingencia, un 0,100 .

Tabla 146. Tabla de contingencia entre reportaje y comunidad

\begin{tabular}{|l|l|r|r|r|}
\hline \multirow{2}{*}{\multicolumn{2}{|c|}{ Tipo de género }} & \multicolumn{2}{c|}{ Comunidad } & \multirow{2}{*}{ Total } \\
\cline { 3 - 4 } \multicolumn{2}{|c|}{$\begin{array}{c}\text { Castilla y } \\
\text { León }\end{array}$} & Galicia & \\
\hline \multirow{3}{*}{ Reportaje } & Recuento & 7 & 22 & 29 \\
& $\%$ de reportaje & $24,14 \%$ & $75,86 \%$ & $100,00 \%$ \\
& $\%$ de comunidad & $1,75 \%$ & $5,5, \%$ & $3,63 \%$ \\
\hline \multirow{3}{*}{ Otros } & Recuento & 393 & 378 & 771 \\
& \% de reportaje & $50,97 \%$ & $49,03 \%$ & $100,00 \%$ \\
& $\%$ de comunidad & $98,25 \%$ & $94,50 \%$ & $96,38 \%$ \\
\hline \multirow{3}{*}{ Total } & Recuento & 400 & 400 & 800 \\
& $\%$ de reportaje & $50,00 \%$ & $50,00 \%$ & $100,00 \%$ \\
& $\%$ de comunidad & $100,00 \%$ & $100,00 \%$ & $100,00 \%$ \\
\hline
\end{tabular}

Fuente: elaboración propia a partir de los resultados del programa estadístico SPSS. 
Tabla 147. Prueba de chi-cuadrado entre reportaje y comunidad

\begin{tabular}{|l|r|r|r|r|r|}
\hline \multicolumn{1}{|c|}{ Prueba } & Valor & gl & $\begin{array}{c}\text { Sig. asintótica } \\
\text { (bilateral) }\end{array}$ & $\begin{array}{c}\text { Sig. } \\
\text { exacta } \\
\text { (bilateral) }\end{array}$ & $\begin{array}{c}\text { Sig. exacta } \\
\text { (unilateral) }\end{array}$ \\
\hline Chi-cuadrado de Pearson & 8,050 & 1 & 0,005 & & \\
Corrección por continuidad & 7,013 & 1 & 0,008 & \\
Razón de verosimilitudes & 8,440 & 1 & 0,004 & 0,007 & 0,004 \\
Estadístico exacto de & & & & & \\
Fisher & 8,040 & 1 & 0,005 & & \\
Asociación lineal por lineal & 800,000 & & & & \\
N de casos válidos & & & & \\
\hline
\end{tabular}

Fuente: elaboración propia a partir de los resultados del programa estadístico SPSS.

Tabla 148. Medidas simétricas de la prueba de chi-cuadrado entre reportaje y comunidad

\begin{tabular}{|c|c|c|c|c|c|}
\hline \multicolumn{2}{|c|}{ Prueba } & Valor & $\begin{array}{l}\text { Error típ. } \\
\text { asint. }\end{array}$ & $\begin{array}{c}\mathbf{T} \\
\text { aproximada }\end{array}$ & $\begin{array}{c}\text { Sig. } \\
\text { aproximada }\end{array}$ \\
\hline Nominal por nominal & $\begin{array}{l}\text { Coeficiente de } \\
\text { contingencia }\end{array}$ & 0,100 & & & 0,005 \\
\hline $\begin{array}{l}\text { Intervalo por } \\
\text { intervalo }\end{array}$ & $\mathrm{R}$ de Pearson & $-0,100$ & 0,032 & $-2,848$ & 0,005 \\
\hline $\begin{array}{l}\text { Ordinal por ordinal } \\
\mathrm{N} \text { de casos válidos }\end{array}$ & $\begin{array}{l}\text { Correlación de } \\
\text { Spearman }\end{array}$ & $\begin{array}{r}-0,100 \\
800,000\end{array}$ & 0,032 & $-2,848$ & 0,005 \\
\hline
\end{tabular}

Fuente: elaboración propia a partir de los resultados del programa estadístico SPSS.

\section{Gráfico 9. Número de reportajes según comunidades}

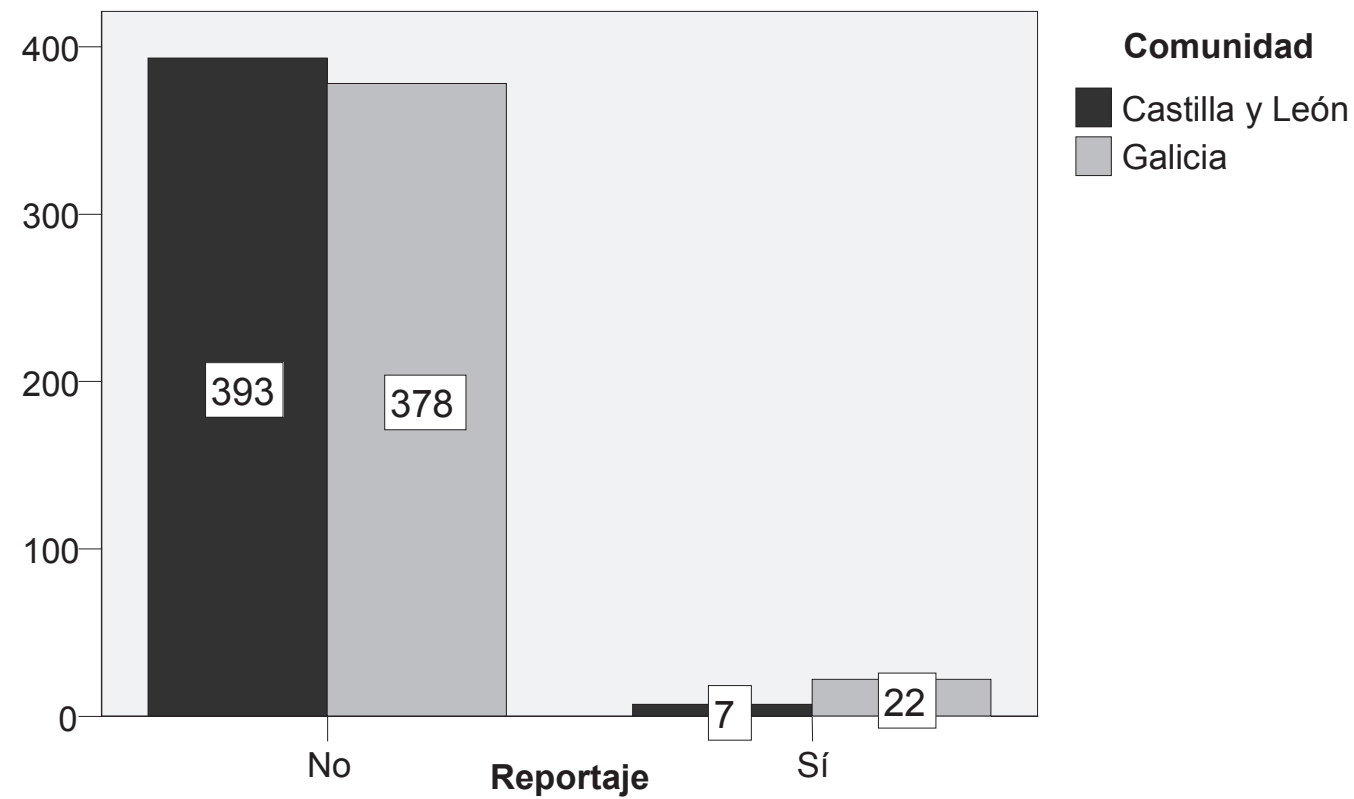

Fuente: elaboración propia a partir de los resultados del programa estadístico SPSS. 
La diferencia es aún más marcada en el caso de las crónicas o las críticas. Mientras que los diarios gallegos han difundido 13 en los 12 días analizados para el muestreo, los castellano-leoneses solo han redactado una. En porcentajes, se corresponde con el $3,25 \%$ y el $0,25 \%$, respectivamente. Se trata de una relación significativa $(\mathrm{r}=0,001)$ y algo más fuerte que en el resto de géneros (coeficiente de contingencia $=0,114$ ).

Tabla 149. Tabla de contingencia entre crónica-crítica y comunidad

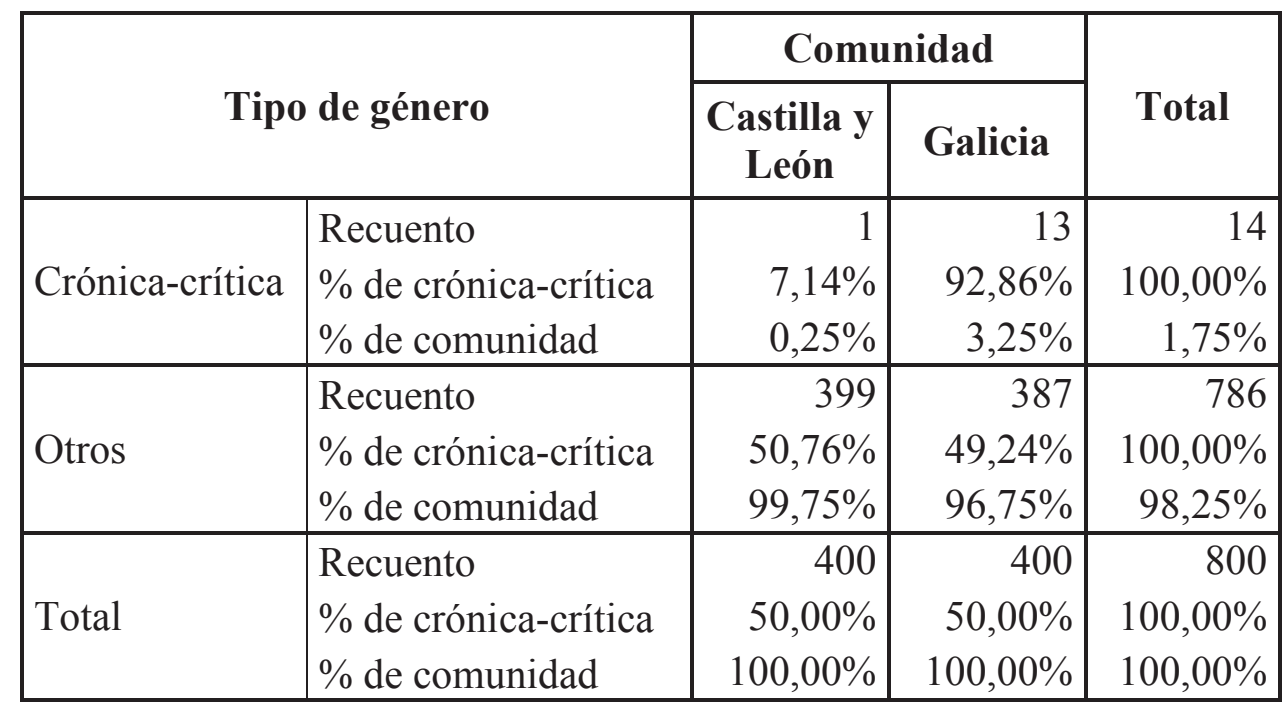

Fuente: elaboración propia a partir de los resultados del programa estadístico SPSS.

Tabla 150. Prueba de chi-cuadrado entre crónica-crítica y comunidad

\begin{tabular}{|l|r|r|r|r|r|}
\hline \multicolumn{1}{|c|}{ Prueba } & \multicolumn{1}{|c|}{ Valor } & gl & $\begin{array}{c}\text { Sig. asintótica } \\
\text { (bilateral) }\end{array}$ & $\begin{array}{l}\text { Sig. exacta } \\
\text { (bilateral) }\end{array}$ & $\begin{array}{r}\text { Sig. exacta } \\
\text { (unilateral) }\end{array}$ \\
\hline Chi-cuadrado de Pearson & 10,469 & 1 & 0,001 & & \\
Corrección por continuidad & 8,797 & 1 & 0,003 & & \\
Razón de verosimilitudes & 12,386 & 1 & 0,000 & & \\
Estadístico exacto de & & & & 0,002 & 0,001 \\
Fisher & & & & & \\
Asociación lineal por lineal & 10,456 & 1 & 0,001 & & \\
N de casos válidos & 800,000 & & & & \\
\hline
\end{tabular}

Fuente: elaboración propia a partir de los resultados del programa estadístico SPSS. 
Tabla 151. Medidas simétricas de la prueba de chi-cuadrado entre crónica-crítica y comunidad

\begin{tabular}{|c|c|c|c|c|c|}
\hline Prueba & & Valor & $\begin{array}{c}\text { Error típ. } \\
\text { asint. }\end{array}$ & $\begin{array}{c}\mathbf{T} \\
\text { aproximada }\end{array}$ & $\begin{array}{c}\text { Sig. } \\
\text { aproximada }\end{array}$ \\
\hline Nominal por nominal & $\begin{array}{l}\text { Coeficiente de } \\
\text { contingencia }\end{array}$ & 0,114 & & & 0,001 \\
\hline $\begin{array}{l}\text { Intervalo por } \\
\text { intervalo }\end{array}$ & $\mathrm{R}$ de Pearson & $-0,114$ & 0,024 & $-3,253$ & 0,001 \\
\hline $\begin{array}{l}\text { Ordinal por ordinal } \\
\mathrm{N} \text { de casos válidos }\end{array}$ & $\begin{array}{l}\text { Correlación de } \\
\text { Spearman }\end{array}$ & $\begin{array}{r}-0,114 \\
800,000\end{array}$ & 0,024 & $-3,253$ & 0,001 \\
\hline
\end{tabular}

Fuente: elaboración propia a partir de los resultados del programa estadístico SPSS.

Gráfico 10. Número de crónicas-críticas según comunidades

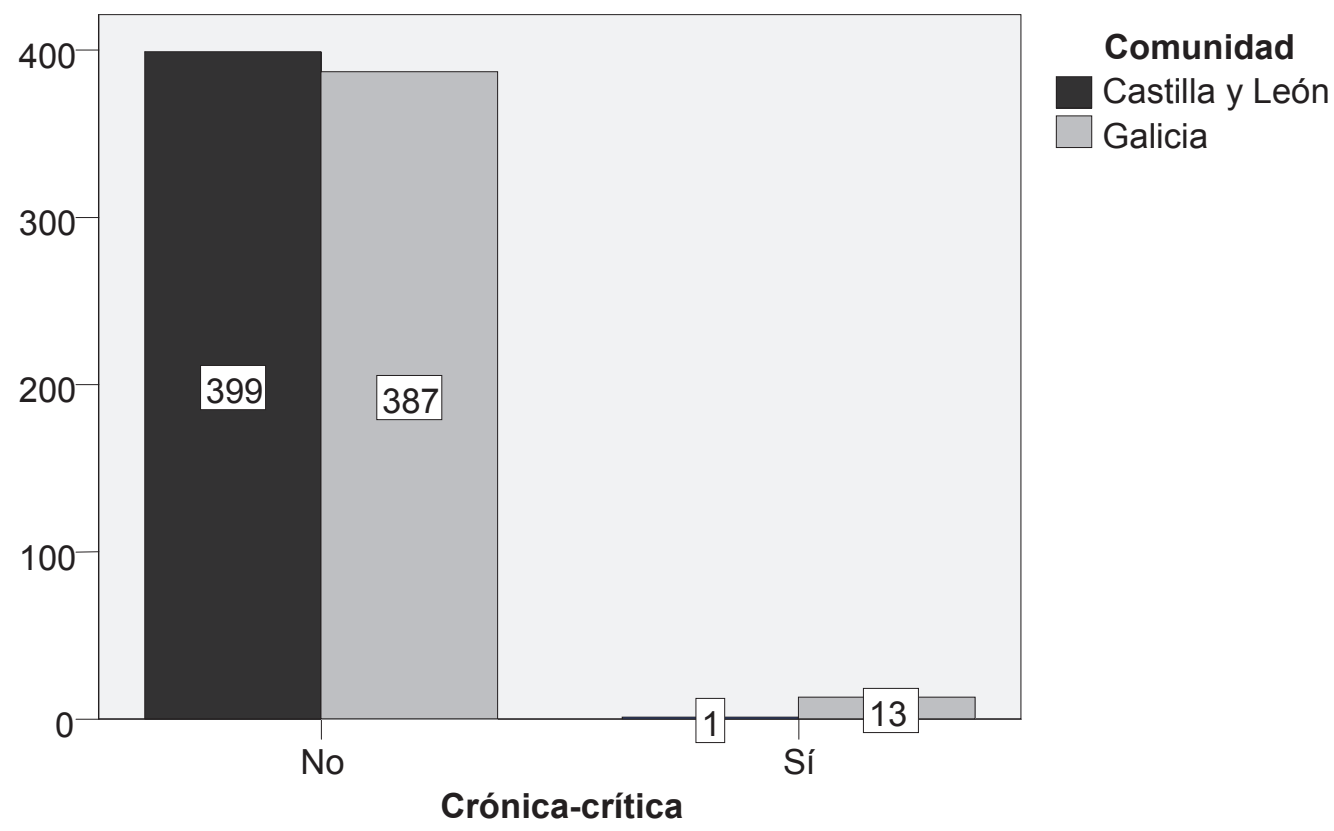

Fuente: elaboración propia a partir de los resultados del programa estadístico SPSS.

En cambio, el género de opinión no genera relaciones significativas. Pese a que las publicaciones gallegas divulgaron 9 textos de este tipo frente a los 3 de las castellanoleoneses, la diferencia no llega a ser estadísticamente significativa $(\mathrm{r}=0,081)$. 
Tabla 152. Tabla de contingencia entre opinión y comunidad

\begin{tabular}{|l|l|r|r|r|}
\hline \multirow{2}{*}{\multicolumn{2}{|c|}{ Tipo de género }} & \multicolumn{2}{c|}{ Comunidad } & \multirow{2}{*}{ Total } \\
\cline { 3 - 4 } \multicolumn{2}{|c|}{} & $\begin{array}{c}\text { Castilla y } \\
\text { León }\end{array}$ & Galicia & \\
\hline \multirow{2}{*}{ Opinión } & Recuento & 3 & 9 & 12 \\
& \% de género & $25,00 \%$ & $75,00 \%$ & $100,00 \%$ \\
& \% de comunidad & $0,75 \%$ & $2,25 \%$ & $1,50 \%$ \\
\hline \multirow{2}{*}{ Otros } & Recuento & 397 & 391 & 788 \\
& \% de género & $50,38 \%$ & $49,62 \%$ & $100,00 \%$ \\
& \% de comunidad & $99,25 \%$ & $97,75 \%$ & $98,50 \%$ \\
\hline \multirow{3}{*}{ Total } & Recuento & 400 & 400 & 800 \\
& \% de género & $50,00 \%$ & $50,00 \%$ & $100,00 \%$ \\
& \% de comunidad & $100,00 \%$ & $100,00 \%$ & $100,00 \%$ \\
\hline
\end{tabular}

Fuente: elaboración propia a partir de los resultados del programa estadístico SPSS.

Gráfico 11.Número de noticias según géneros y comunidades

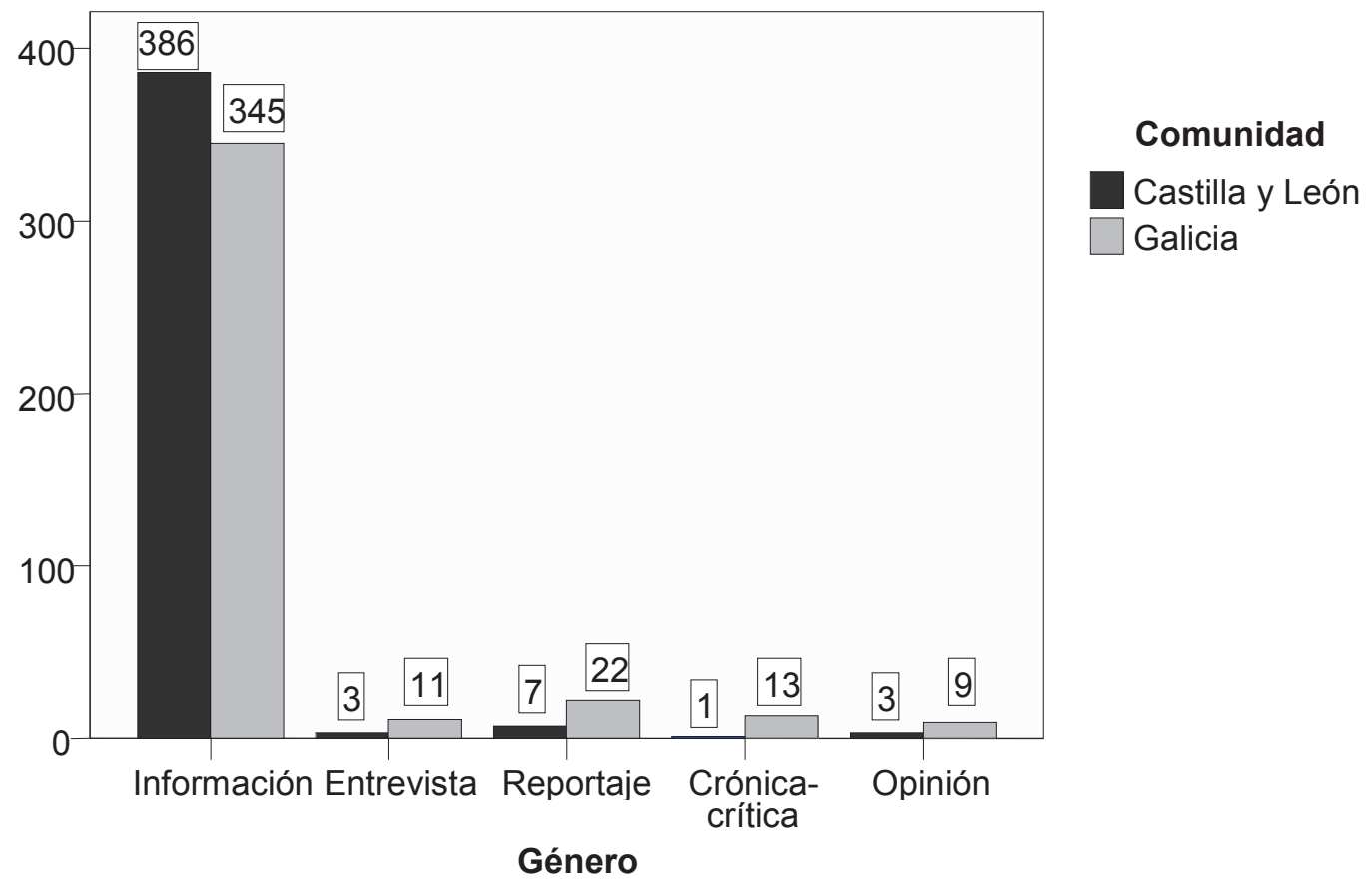

Fuente: elaboración propia.

\subsubsection{TAMAÑO DE LAS INFORMACIONES}

La noticia más pequeña que se ha recogido en el muestreo se compone de 343 caracteres con espacios y se corresponde con una charla sobre los beneficios que aportan los lácteos a la salud, impartida por la profesora de investigación del Centro Superior de Investigaciones Científicas (CSIC) Manuela Juárez y publicada en La 
Opinión de Zamora el 5 de mayo de 2012. En cambio, el texto más extenso asciende a 9.175 caracteres y trata, a través de un reportaje divulgado el 16 de julio de 2012 en Faro de Vigo, del primer mes desde la constitución oficial por parte del Sergas de la Comisión Galega de Coidados Paliativos.

A pesar de estos casos inusuales en cuanto a tamaño se refiere, lo normal es que una noticia sobre salud y sanidad ocupe 2.165 caracteres y se desvíe, por lo alto o por lo bajo, hasta 1.287. La mediana (es decir, el valor central por encima del cual se halla el $50 \%$ de los casos mayores y por debajo el otro $50 \%$ de los menores sin tener en cuenta los extremos) se sitúa en 1.900 caracteres. La suma de todos los textos analizados para el muestreo asciende a 1.731.644.

Tabla 153. Estadísticos descriptivos de la extensión de las informaciones

\begin{tabular}{|c|c|r|r|c|r|r|r|}
\hline Variable & $\mathbf{N}^{\mathbf{0}}$ & Mínimo & Máximo & Suma & Media & Desv. típ. & Mediana \\
\hline Caracteres & 800 & 343 & 9.175 & 1.731 .644 & 2.165 & 1.287 & 1.900 \\
\hline
\end{tabular}

Fuente: elaboración propia a partir de los resultados del programa estadístico SPSS.

\section{Gráfico 12. Extensión de las informaciones}

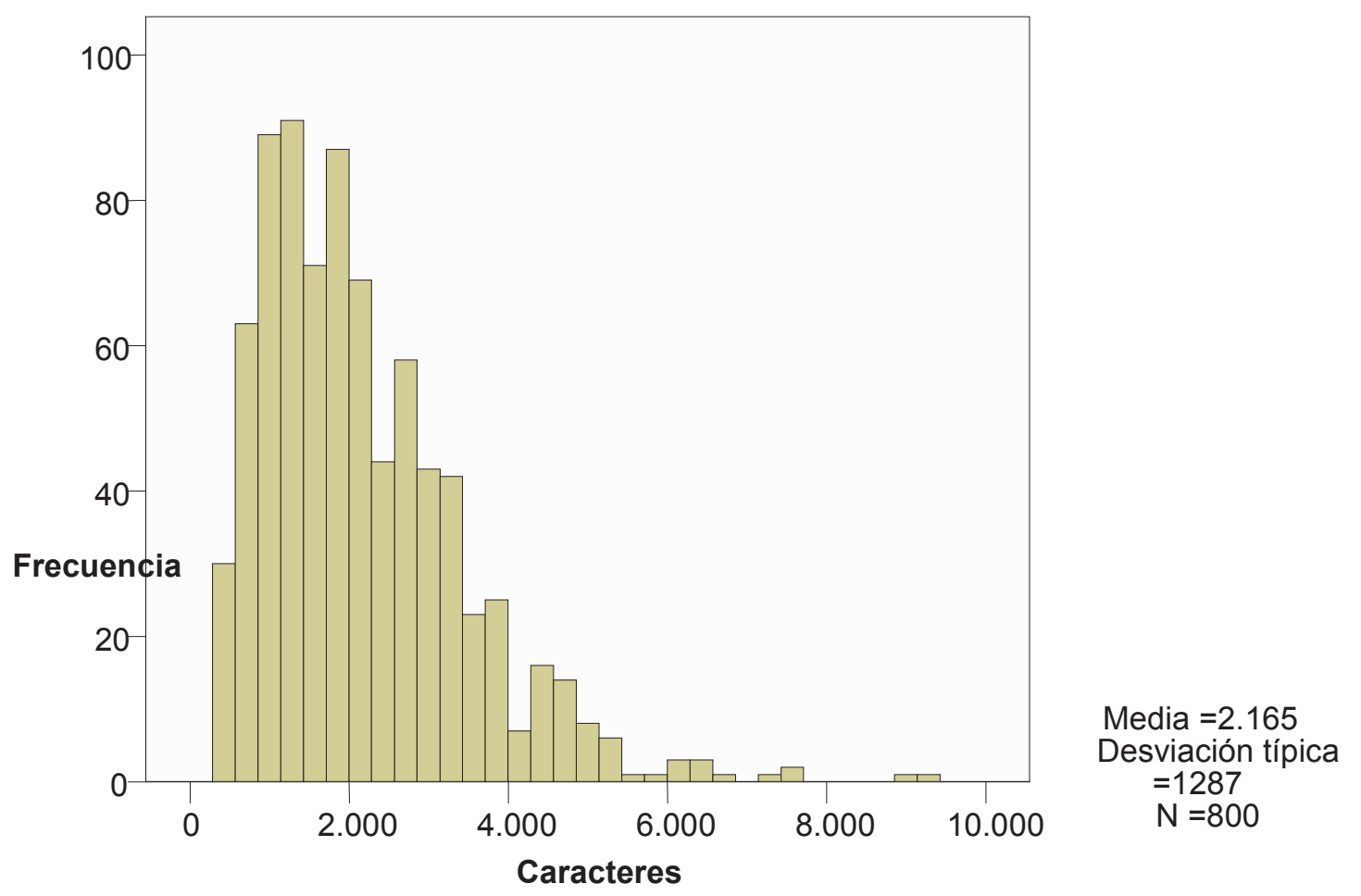

Fuente: elaboración propia a partir de los resultados del programa estadístico SPSS.

Los periódicos de Castilla y León y Galicia no ofrecen apenas diferencias en cuanto a la extensión de las informaciones. El tamaño medio es prácticamente idéntico en ambos casos (2.200 caracteres con espacios en la primera región y 2.129 en la segunda) y la desviación típica, aunque es más amplia en Galicia, sigue sin mostrar demasiadas 
desigualdades (1.189 y 1.379). La suma de todos los textos analizados es casi la misma: 879.890 en la región castellana y 851.754 en la gallega. También es muy similar la extensión de la noticia más pequeña: 343 en Castilla y León y 358 en Galicia. En lo único en lo que diferencian ambas comunidades es en la longitud de la noticia más larga: mientras que en Castilla y León es de 6.639 caracteres, en Galicia es de 9.175. Como era de esperar, estas discrepancias no son estadísticamente significativas.

Tabla 154. Estadísticos descriptivos de los caracteres de las informaciones por comunidades

\begin{tabular}{|l|r|r|r|r|r|r|r|}
\hline Comunidad & \multicolumn{1}{|c|}{$\mathbf{N}^{\mathbf{0}}$} & Mínimo & Máximo & \multicolumn{1}{c|}{ Suma } & \multicolumn{1}{c|}{ Media } & Desv. típ. & Mediana \\
\hline Castilla y León & 400 & 343 & 6.639 & 879.890 & 2.200 & 1.189 & 1.966 \\
Galicia & 400 & 358 & 9.175 & 851.754 & 2.129 & 1.379 & 1.819 \\
Total & 800 & 343 & 9.175 & 1.731 .644 & 2.165 & 1.287 & 1.900 \\
\hline
\end{tabular}

Fuente: elaboración propia a partir de los resultados del programa estadístico SPSS.

Tabla 155. Estadísticos descriptivos de los caracteres de las informaciones según comunidades

\begin{tabular}{|l|r|r|r|r|}
\hline \multicolumn{1}{|c|}{ Comunidad } & \multicolumn{1}{|c|}{$\mathbf{N}^{\mathbf{0}}$} & \multicolumn{1}{c|}{ Media } & Desv. típ. & Error típ. \\
\hline Castilla y León & 400 & 2.200 & 1.189 & 59,46 \\
Galicia & 400 & 2.129 & 1.379 & 68,94 \\
\hline
\end{tabular}

Fuente: elaboración propia a partir de los resultados del programa estadístico SPSS.

Tabla 156. Prueba T-student para muestras independientes entre los caracteres de las informaciones y las comunidades

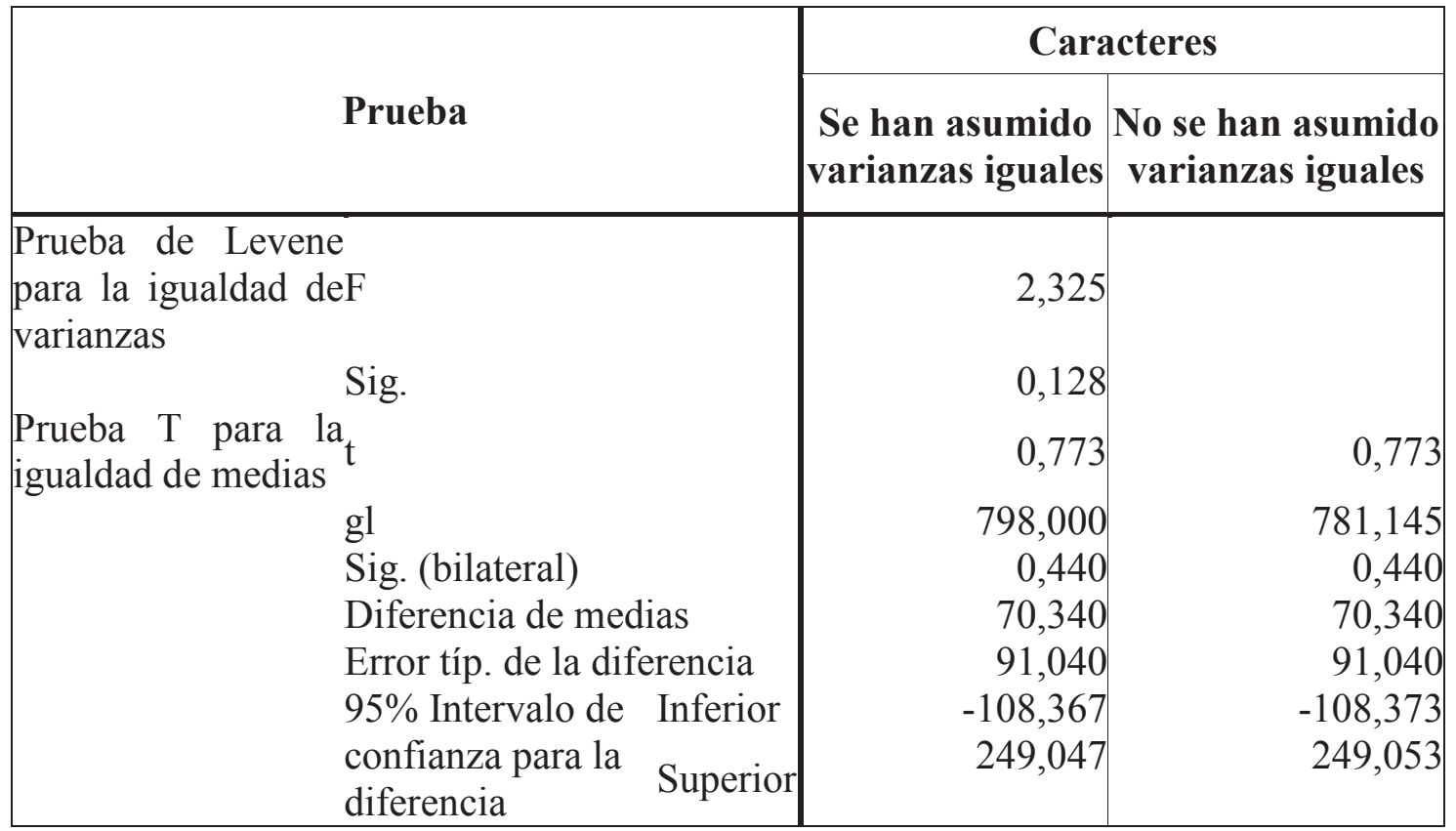

Fuente: elaboración propia a partir de los resultados del programa estadístico SPSS. 
Se han detectado, no obstante, varios casos atípicos y dos extremos. En Castilla y León, las seis noticias que sobrepasan los 5.383 caracteres con espacios se consideran del primer tipo. En Galicia, se valoran así los siete textos que superan 5.829 caracteres y los dos que van más allá de los 9.081 se juzgan como casos extremos.

Gráfico 13. Diagrama de cajas sobre la extensión de las informaciones según comunidades

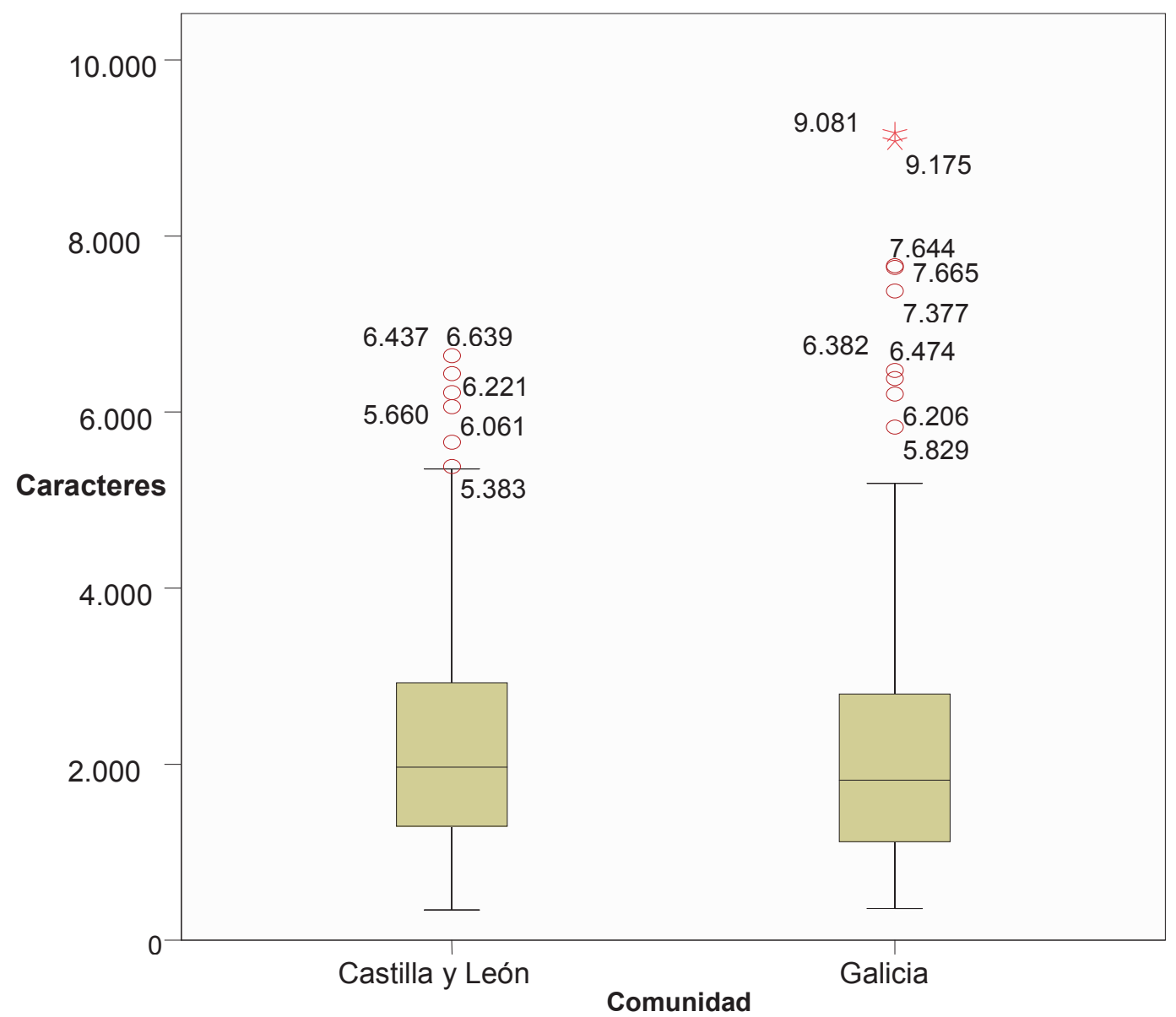

Fuente: elaboración propia a partir de los resultados del programa estadístico SPSS.

\subsubsection{USO DE AUDIOVISUALES}

Las noticias sobre salud no suelen incorporar archivos multimedia más allá de las fotografías. Por ejemplo, de las 800 informaciones analizadas para el muestreo, únicamente 21 (el 2,63\%) incluye un vídeo, mientras que solamente 3 (o el 0,38\%) son ilustradas con un gráfico o una infografía. El audio se utiliza incluso menos: solo dos informaciones (el 0,25\%) ofrecen la posibilidad de escuchar alguna grabación sonora. La fotografía, en cambio, se emplea en más ocasiones, pero aun así no llega a la mitad de los registros: el 41,88\% de las informaciones estaban acompañadas de una imagen. 
Tabla 157. Frecuencia y porcentaje de los audiovisuales de las informaciones

\begin{tabular}{|c|c|c|c|}
\hline Audiovisuales & Inserción & Frecuencia & Porcentaje \\
\hline \multirow{3}{*}{ Fotografía } & No & 465 & 58,13 \\
\hline & Sí & 335 & 41,88 \\
\hline & Total & 800 & 100 \\
\hline \multirow{3}{*}{ Vídeo } & No & 779 & 97,38 \\
\hline & Sí & 21 & 2,63 \\
\hline & Total & 800 & 100,00 \\
\hline \multirow{3}{*}{ Audio } & No & 798 & 99,75 \\
\hline & Sí & 2 & 0,25 \\
\hline & Total & 800 & 100,00 \\
\hline \multirow{3}{*}{$\begin{array}{ll}\text { Grafico } & \text { o } \\
\text { infografía } & \end{array}$} & No & 797 & 99,63 \\
\hline & Sí & 3 & 0,38 \\
\hline & Total & 800 & 100,00 \\
\hline
\end{tabular}

Fuente: elaboración propia a partir de los resultados del programa estadístico SPSS.

De los tres gráficos, dos se incorporan en Diario de León y uno en La Crónica de León. Por su parte, los dos audios provienen de El Correo Gallego. Los vídeos se encuentran más repartidos: siete son difundidos por RTCYL.es, seis por El Norte de Castilla, dos por La Gaceta de Salamanca y otros dos por La Voz de Galicia. Otras publicaciones también han facilitado un archivo de este tipo cada uno. Se trata de: Diario Palentino, La Opinión de Zamora, El Correo Gallego y Faro de Vigo. Debido al alto número de vídeos difundidos por los periódicos castellano-leoneses, la relación resulta ser significativa. Es decir, estos diarios difunden estadísticamente más vídeos que sus compañeros gallegos. De los 400 estudiados en cada comunidad, Galicia difunde únicamente 4, mientras que Castilla y León suma 17. El resto de recursos audiovisuales no han otorgado diferencias significativas.

Tabla 158. Tabla de contingencia entre vídeo y comunidad

\begin{tabular}{|l|l|r|r|r|}
\hline \multirow{2}{*}{ Uso de vídeos } & \multicolumn{2}{c|}{ Comunidad } & \multirow{2}{*}{ Total } \\
\cline { 3 - 5 } & $\begin{array}{c}\text { Castilla y } \\
\text { León }\end{array}$ & Galicia & \\
\hline \multirow{3}{*}{ Sí } & Recuento & 17 & 4 & 21 \\
& \% de vídeo & $81,00 \%$ & $19,00 \%$ & $100,00 \%$ \\
& $\%$ de comunidad & $4,30 \%$ & $1,00 \%$ & $2,60 \%$ \\
\hline \multirow{2}{*}{ No } & Recuento & 383 & 396 & 779 \\
& \% de vídeo & $49,20 \%$ & $50,80 \%$ & $100,00 \%$ \\
& \% de comunidad & $95,80 \%$ & $99,00 \%$ & $97,40 \%$ \\
\hline \multirow{3}{*}{ Total } & Recuento & 400 & 400 & 800 \\
& \% de vídeo & $50,00 \%$ & $50,00 \%$ & $100,00 \%$ \\
& $\%$ de comunidad & $100,00 \%$ & $100,00 \%$ & $100,00 \%$ \\
\hline
\end{tabular}

Fuente: elaboración propia a partir de los resultados del programa estadístico SPSS. 
Tabla 159. Prueba de chi-cuadrado entre vídeo y comunidad

\begin{tabular}{|l|r|r|r|r|r|}
\hline \multicolumn{1}{|c|}{ Prueba } & Valor & gl & $\begin{array}{c}\text { Sig. asintótica } \\
\text { (bilateral) }\end{array}$ & $\begin{array}{l}\text { Sig. exacta } \\
\text { (bilateral) }\end{array}$ & $\begin{array}{c}\text { Sig. exacta } \\
\text { (unilateral) }\end{array}$ \\
\hline Chi-cuadrado de Pearson & 8,265 & 1 & 0,004 & & \\
Corrección por continuidad & 7,042 & 1 & 0,008 & & \\
Razón de verosimilitudes & 8,879 & 1 & 0,003 & & \\
Estadístico exacto de & & & & 0,006 & 0,003 \\
Fisher & & & & & \\
Asociación lineal por lineal & 8,254 & 1 & 0,004 & & \\
N de casos válidos & 800,000 & & & & \\
\hline
\end{tabular}

Fuente: elaboración propia a partir de los resultados del programa estadístico SPSS.

Tabla 160. Medidas simétricas de la prueba de chi-cuadrado entre vídeo y comunidad

\begin{tabular}{|c|c|c|c|c|c|}
\hline \multicolumn{2}{|l|}{ Prueba } & Valor & $\begin{array}{l}\text { Error típ. } \\
\text { asint. }\end{array}$ & \begin{tabular}{|c|}
$\mathbf{T}$ \\
aproximada
\end{tabular} & $\begin{array}{c}\text { Sig. } \\
\text { aproximada }\end{array}$ \\
\hline Nominal por nominal & $\begin{array}{l}\text { Coeficiente de } \\
\text { contingencia }\end{array}$ & 0,101 & & & 0,004 \\
\hline $\begin{array}{l}\text { Intervalo por } \\
\text { intervalo }\end{array}$ & R de Pearson & $-0,102$ & 0,030 & $-2,886$ & 0,004 \\
\hline $\begin{array}{l}\text { Ordinal por ordinal } \\
\mathrm{N} \text { de casos válidos }\end{array}$ & $\begin{array}{l}\text { Correlación de } \\
\text { Spearman }\end{array}$ & $\begin{array}{r}-0,102 \\
800,000\end{array}$ & 0,030 & $-2,886$ & 0,004 \\
\hline
\end{tabular}

Fuente: elaboración propia a partir de los resultados del programa estadístico SPSS.

Gráfico 14. Número de informaciones con vídeos según comunidades

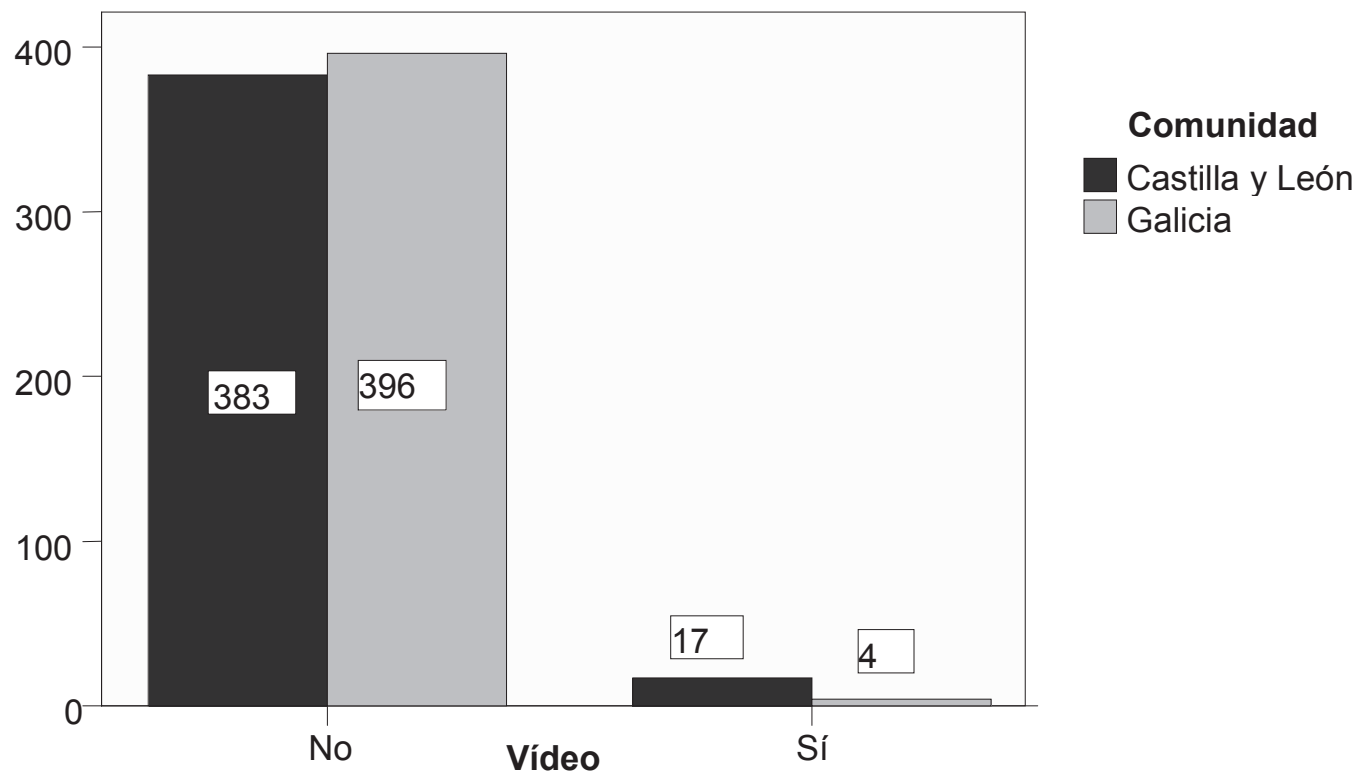

Fuente: elaboración propia a partir de los resultados del programa estadístico SPSS. 


\subsubsection{TEMA DE LAS NOTICIAS}

Con el fin de conocer sobre qué tratan exactamente las composiciones sobre sanidad que se publican en los periódicos de Castilla y León y de Galicia en internet se han establecido 13 categorías diferentes y se ha anotado a cuál pertenece cada una de las 800 analizadas. Los temas elegidos son: construcción o infraestructuras, personal sanitario, servicios que ofrece la sanidad, prevención, medicina, política, sucesos, acciones de divulgación (charlas, cursos, jornadas...), actualidad (estudios, cifras, estadísticas...), peticiones o quejas, deportes, farmacia o medicamentos y otros.

De esta forma, se puede comprobar que casi tres de cada diez noticias tratan sucesos que hacen referencia a la salud de las personas. Un total de 220 de las 800 analizadas (el 27,50\%) se enmarcan dentro de esta temática, convirtiéndose, con amplia diferencia, en la más recurrente. A continuación se sitúan los textos políticos con trasfondo sanitario, que arrojan un $12,25 \%$, y, posteriormente, todo lo referente a los servicios sanitarios $(7,88 \%)$. No existen demasiadas diferencias en las siguientes categorías, ya que de unas a otras existe un margen de $0,5 \%$ o menos: acciones de divulgación $(6,88 \%)$, personal sanitario $(6,13 \%)$, actualidad $(6,00 \%)$, deportes $(5,50 \%)$, medicina $(5,00 \%)$, peticiones $(5,00 \%)$, construcción e infraestructuras $(4,88 \%)$ y prevención $(4,75 \%)$. El terreno menos abordado tiene que ver con la farmacia y los medicamentos $(2,63 \%)$.

Tabla 161. Frecuencia y porcentaje del tema de las informaciones

\begin{tabular}{|l|r|r|}
\hline \multicolumn{1}{|c|}{ Tema } & Frecuencia & Porcentaje \\
\hline Sucesos & 220 & 27,50 \\
\hline Política & 98 & 12,25 \\
\hline Servicios & 63 & 7,88 \\
\hline $\begin{array}{l}\text { Acciones de } \\
\text { divulgación }\end{array}$ & 55 & 6,88 \\
\hline Personal & 49 & 6,13 \\
\hline Actualidad & 48 & 6,00 \\
\hline Otros & 45 & 5,63 \\
\hline Deportes & 44 & 5,50 \\
\hline Medicina & 40 & 5,00 \\
\hline Peticiones & 40 & 5,00 \\
\hline Construcción & 39 & 4,88 \\
\hline Prevención & 38 & 4,75 \\
\hline Farmacia & 21 & 2,63 \\
\hline Total & 800 & 100,00 \\
\hline
\end{tabular}

Fuente: elaboración propia. 
Las mayores diferencias entre una comunidad y otra se hallan en todo lo referente al personal sanitario y los temas de actualidad. En el primer caso, los periódicos de Castilla y León divulgan 30 textos (el $61,22 \%$ del total de este tipo de noticias del muestreo), mientras que los de Galicia emiten 19 (el 38,78\% restante). Con el segundo asunto sucede prácticamente lo mismo: los primeros diarios difunden 30 (el 62,50\% de las noticias sobre personal sanitario) y los segundos, 18 (contabilizando el 37,50\% que queda). En el resto de temas devuelven unos porcentajes cercanos al $50 \%$, por lo que no se trata de discrepancias remarcables. A pesar de todo, en ningún caso se han encontrado relaciones significativas.

Tabla 162. Tabla de contingencia entre tema y comunidad

\begin{tabular}{|c|c|c|c|c|}
\hline & \multicolumn{2}{|c|}{ Comunidad } & \multirow{2}{*}{ Total } \\
\hline & & \multirow{2}{*}{$\begin{array}{r}\begin{array}{c}\text { Castilla y } \\
\text { León }\end{array} \\
18\end{array}$} & \multirow{2}{*}{$\begin{array}{r}\text { Galicia } \\
21\end{array}$} & \\
\hline \multirow{3}{*}{ Construcción } & Recuento & & & 39 \\
\hline & $\%$ de tema & $46,15 \%$ & $53,85 \%$ & $100,00 \%$ \\
\hline & $\%$ de comunidad & $4,50 \%$ & $5,25 \%$ & $4,88 \%$ \\
\hline \multirow{3}{*}{ Personal } & Recuento & 30 & 19 & 49 \\
\hline & $\%$ de tema & $61,22 \%$ & $38,78 \%$ & $100,00 \%$ \\
\hline & $\%$ de comunidad & $7,50 \%$ & $4,75 \%$ & $6,13 \%$ \\
\hline \multirow{3}{*}{ Servicios } & Recuento & 35 & 28 & 63 \\
\hline & $\%$ de tema & $55,56 \%$ & $44,44 \%$ & $100,00 \%$ \\
\hline & $\%$ de comunidad & $8,75 \%$ & $7,00 \%$ & $7,88 \%$ \\
\hline \multirow{3}{*}{ Prevención } & Recuento & 17 & 21 & 38 \\
\hline & $\%$ de tema & $44,74 \%$ & $55,26 \%$ & $100,00 \%$ \\
\hline & $\%$ de comunidad & $4,25 \%$ & $5,25 \%$ & $4,75 \%$ \\
\hline \multirow{3}{*}{ Medicina } & Recuento & 20 & 20 & 40 \\
\hline & $\%$ de tema & $50,00 \%$ & $50,00 \%$ & $100,00 \%$ \\
\hline & $\%$ de comunidad & $5,00 \%$ & $5,00 \%$ & $5,00 \%$ \\
\hline \multirow{3}{*}{ Política } & Recuento & 50 & 48 & 98 \\
\hline & $\%$ de tema & $51,02 \%$ & $48,98 \%$ & $100,00 \%$ \\
\hline & $\%$ de comunidad & $12,50 \%$ & $12,00 \%$ & $12,25 \%$ \\
\hline \multirow{3}{*}{ Sucesos } & Recuento & 98 & 122 & 220 \\
\hline & $\%$ de tema & $44,55 \%$ & $55,45 \%$ & $100,00 \%$ \\
\hline & $\%$ de comunidad & $24,50 \%$ & $30,50 \%$ & $27,50 \%$ \\
\hline \multirow{3}{*}{ Acciones } & Recuento & 30 & 25 & 55 \\
\hline & $\%$ de tema & $54,55 \%$ & $45,45 \%$ & $100,00 \%$ \\
\hline & $\%$ de comunidad & $7,50 \%$ & $6,25 \%$ & $6,88 \%$ \\
\hline \multirow{3}{*}{ Actualidad } & Recuento & 30 & 18 & 48 \\
\hline & $\%$ de tema & $62,50 \%$ & $37,50 \%$ & $100,00 \%$ \\
\hline & $\%$ de comunidad & $7,50 \%$ & $4,50 \%$ & $6,00 \%$ \\
\hline \multirow{3}{*}{ Peticiones } & Recuento & 21 & 19 & 40 \\
\hline & $\%$ de tema & $52,50 \%$ & $47,50 \%$ & $100,00 \%$ \\
\hline & $\%$ de comunidad & $5,25 \%$ & $4,75 \%$ & $5,00 \%$ \\
\hline
\end{tabular}




\begin{tabular}{|c|c|c|c|c|}
\hline & \multirow{2}{*}{ Tema } & \multicolumn{2}{|c|}{ Comunidad } & \multirow[b]{2}{*}{ Total } \\
\hline & & $\begin{array}{c}\text { Castilla y } \\
\text { León }\end{array}$ & Galicia & \\
\hline & Recuento & 19 & 26 & 45 \\
\hline Otros & $\%$ de tema & $42,22 \%$ & $57,78 \%$ & $100,00 \%$ \\
\hline & $\%$ de comunidad & $4,75 \%$ & $6,50 \%$ & $5,63 \%$ \\
\hline & Recuento & 24 & 20 & 44 \\
\hline Deportes & $\%$ de tema & $54,55 \%$ & $45,45 \%$ & $100 \%$ \\
\hline & $\%$ de comunidad & $6,00 \%$ & $5,00 \%$ & $5,50 \%$ \\
\hline & Recuento & 8 & 13 & 21 \\
\hline Farmacia & $\%$ de tema & $38,10 \%$ & $61,90 \%$ & $100,00 \%$ \\
\hline & $\%$ de comunidad & $2,00 \%$ & $3,25 \%$ & $2,63 \%$ \\
\hline & Recuento & 400 & 400 & 800 \\
\hline Total & $\%$ de tema & $50,00 \%$ & $50,00 \%$ & $100,00 \%$ \\
\hline & $\%$ de comunidad & $100,00 \%$ & $100,00 \%$ & $100,00 \%$ \\
\hline
\end{tabular}

Fuente: elaboración propia a partir de los resultados del programa estadístico SPSS.

\subsubsection{NEUTRALIDAD DE LAS NOTICIAS}

La mayor parte de las noticias que han sido publicadas a lo largo de 2012 sobre salud y sanidad tenían connotaciones negativas, como podían ser sucesos con víctimas mortales, el aumento de enfermedades, las manifestaciones en contra de la reforma sanitaria, etc. Más de la mitad, concretamente el 51,75\%, tienen implicación adversa. En cuanto a frecuencia, después de estas se encuentran las neutras. En este apartado se han enmarcado aquellas que no pueden considerarse ni negativas ni positivas, tales como las conferencias o talleres, los nuevos nombramientos de personal en materia sanitaria o aquellas decisiones políticas que, por su naturaleza, pueden tener diferente neutralidad para distintos colectivos. Todo lo referente al aborto, a la atención sanitaria gratuita o de pago para los inmigrantes irregulares o las elecciones presidenciales, por poner algunas muestras, estaría incluido en este conjunto. El 32,50\% de los textos analizados pueden considerarse como neutros. En cambio, las noticias positivas, como el aumento de las donaciones, el reconocimiento al personal sanitario o las investigaciones que avanzan en la cura de ciertas enfermedades, por ejemplo, solamente se encuentran en 1,6 de cada 10. Un total de 126 composiciones $(15,75 \%)$ de las 800 estudiadas tienen tintes positivos. 
Tabla 163. Frecuencia y porcentaje de la neutralidad de las informaciones

\begin{tabular}{|l|r|r|}
\hline Neutralidad & Frecuencia & Porcentaje \\
\hline Positivo & 126 & 15,75 \\
\hline Neutro & 260 & 32,50 \\
\hline Negativo & 414 & 51,75 \\
\hline Total & 800 & 100,00 \\
\hline
\end{tabular}

Fuente: elaboración propia.

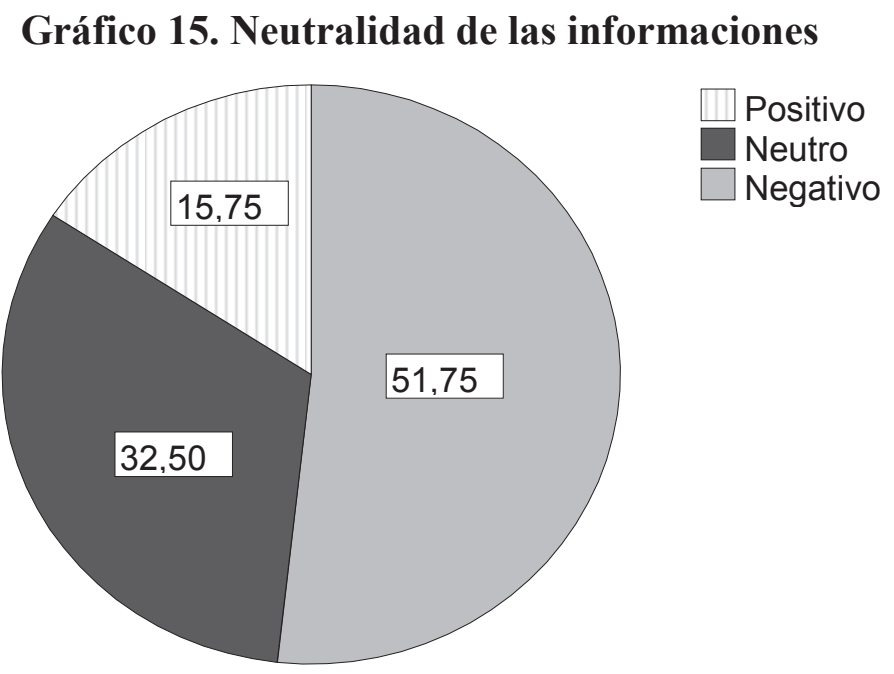

Fuente: elaboración propia.

La cantidad de noticias en cuanto a neutralidad en los diarios castellano-leoneses resulta ser muy similar a la de los gallegos, aunque los segundos tienden a difundir ligeramente más informaciones negativas y menos neutras. En ambos casos, sobresalen las adversas (192 en la primera comunidad y 222 en la segunda, lo que se corresponde con un 48,00\% y 55,50\% sobre el total de cada región), seguidas de las neutras $(35,50 \%$ y $29,50 \%$, respectivamente). Las novedades positivas son las menos recurrentes tanto en Castilla y León como en Galicia: de las 400 analizadas para cada territorio, el primero publica $66(16,50 \%$ respecto a las 400$)$ y el segundo, $60(15,00 \%)$. 
Tabla 164. Tabla de contingencia entre neutralidad y comunidad

\begin{tabular}{|l|l|r|r|r|}
\hline \multirow{2}{*}{\multicolumn{2}{|c|}{ Neutralidad }} & \multicolumn{2}{c|}{ Comunidad } & \multirow{2}{*}{ Total } \\
\cline { 3 - 4 } \multicolumn{2}{|c|}{} & $\begin{array}{c}\text { Castilla y } \\
\text { León }\end{array}$ & Galicia & \\
\hline \multirow{3}{*}{ Positivo } & Recuento & 66 & 60 & 126 \\
& $\%$ de neutralidad & $52,38 \%$ & $47,62 \%$ & $100,00 \%$ \\
& $\%$ de comunidad & $16,50 \%$ & $15,00 \%$ & $15,75 \%$ \\
\hline \multirow{3}{*}{ Neutro } & Recuento & 142 & 118 & 260 \\
& $\%$ de neutralidad & $54,62 \%$ & $45,38 \%$ & $100,00 \%$ \\
& $\%$ de comunidad & $35,50 \%$ & $29,50 \%$ & $32,50 \%$ \\
\hline \multirow{3}{*}{ Negativo } & Recuento & 192 & 222 & 414 \\
& $\%$ de neutralidad & $46,38 \%$ & $53,62 \%$ & $100,00 \%$ \\
& $\%$ de comunidad & $48,00 \%$ & $55,50 \%$ & $51,75 \%$ \\
\hline \multirow{3}{*}{ Total } & Recuento & 400 & 400 & 800 \\
& $\%$ de neutralidad & $50,00 \%$ & $50,00 \%$ & $100,00 \%$ \\
& $\%$ de comunidad & $100,00 \%$ & $100,00 \%$ & $100,00 \%$ \\
\hline
\end{tabular}

Fuente: elaboración propia a partir de los resultados del programa estadístico SPSS.

De hecho, la desigualdad en la publicación de noticias con connotaciones negativas entre los diarios de Castilla y León y Galicia resulta ser significativa. Los primeros difunden el $48 \%$ de sus noticias con estos matices y el $52 \%$ restante con tintes tanto neutros como positivos. En cambio, los diarios gallegos cambian la tendencia y exponen al público el 55,50\% de sus textos con implicaciones negativas y el 44,50\% con neutras o positivas. El coeficiente de contingencia en 0,075 revela que no se trata de una relación muy fuerte. No se han hallado diferencias significativas en el resto de neutralidades.

Tabla 165. Tabla de contingencia entre contenido negativo y comunidad

\begin{tabular}{|cl|r|r|r|}
\hline \multirow{2}{*}{ Neutralidad } & \multicolumn{2}{|c|}{ Comunidad } & \multirow{2}{*}{ Total } \\
\cline { 3 - 4 } & & $\begin{array}{c}\text { Castilla y } \\
\text { León }\end{array}$ & Galicia & \\
\hline \multirow{2}{*}{ Negativo } & Recuento & 192 & 222 & 414 \\
& \% de negativo & $46,38 \%$ & $53,62 \%$ & $100,00 \%$ \\
& \% de comunidad & $48,00 \%$ & $55,50 \%$ & $51,75 \%$ \\
\hline \multirow{2}{*}{ Otros } & Recuento & 208 & 178 & 386 \\
& \% de negativo & $53,89 \%$ & $46,11 \%$ & $100,00 \%$ \\
& \% de comunidad & $52,00 \%$ & $44,50 \%$ & $48,25 \%$ \\
\hline \multirow{2}{*}{ Total } & Recuento & 400 & 400 & 800 \\
& \% de negativo & $50,00 \%$ & $50,00 \%$ & $100,00 \%$ \\
& \% de comunidad & $100,00 \%$ & $100,00 \%$ & $100,00 \%$ \\
\hline
\end{tabular}

Fuente: elaboración propia a partir de los resultados del programa estadístico SPSS. 
Tabla 166. Prueba de chi-cuadrado entre contenido negativo y comunidad

\begin{tabular}{|l|r|r|r|r|r|}
\hline \multicolumn{1}{|c|}{ Prueba } & Valor & gl & $\begin{array}{c}\text { Sig. asintótica } \\
\text { (bilateral) }\end{array}$ & $\begin{array}{c}\text { Sig. exacta } \\
\text { (bilateral) }\end{array}$ & $\begin{array}{c}\text { Sig. exacta } \\
\text { (unilateral) }\end{array}$ \\
\hline Chi-cuadrado de Pearson & 4,506 & 1 & 0,034 & & \\
Corrección por continuidad & 4,210 & 1 & 0,040 & & \\
Razón de verosimilitudes & 4,510 & 1 & 0,034 & & \\
Estadístico exacto de & & & & 0,040 & 0,020 \\
Fisher & & & & & \\
Asociación lineal por lineal & 4,500 & 1 & 0,034 & & \\
N de casos válidos & 800,000 & & & & \\
\hline
\end{tabular}

Fuente: elaboración propia a partir de los resultados del programa estadístico SPSS.

Tabla 167. Medidas simétricas de la prueba de chi-cuadrado entre contenido negativo y comunidad

\begin{tabular}{|c|c|c|c|c|c|}
\hline Prueba & & Valor & $\begin{array}{c}\text { Error típ. } \\
\text { asint. }\end{array}$ & \begin{tabular}{|c|}
$\mathbf{T}$ \\
aproximada
\end{tabular} & $\begin{array}{c}\text { Sig. } \\
\text { aproximada }\end{array}$ \\
\hline Nominal por nominal & $\begin{array}{l}\text { Coeficiente de } \\
\text { contingencia }\end{array}$ & 0,075 & & & 0,034 \\
\hline $\begin{array}{l}\text { Intervalo por } \\
\text { intervalo }\end{array}$ & R de Pearson & $-0,075$ & 0,035 & $-2,126$ & 0,034 \\
\hline $\begin{array}{l}\text { Ordinal por ordinal } \\
\mathrm{N} \text { de casos válidos }\end{array}$ & $\begin{array}{l}\text { Correlación de } \\
\text { Spearman }\end{array}$ & $\begin{array}{r}-0,075 \\
800,000\end{array}$ & 0,035 & $-2,126$ & 0,034 \\
\hline
\end{tabular}

Fuente: elaboración propia a partir de los resultados del programa estadístico SPSS.

Gráfico 16. Número de noticias negativas según comunidades

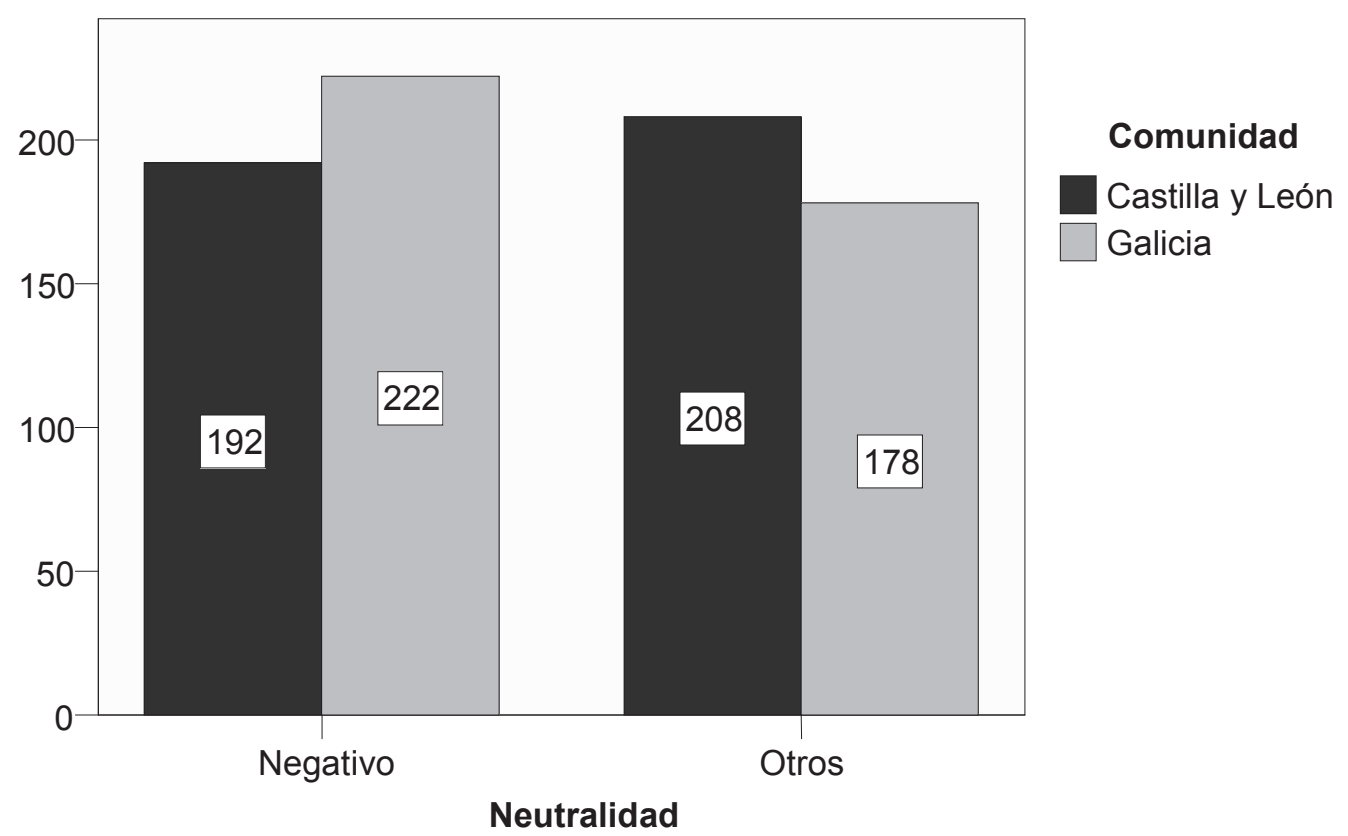

Fuente: elaboración propia a partir de los resultados del programa estadístico SPSS. 


\subsubsection{ORGANIZACIONES INFORMADORAS}

\subsection{DE LAS INFORMACIONES}

Se ha querido conocer cuál es la principal fuente de información en las noticias sobre salud y sanidad. Para ello, se han dividido estas en doce categorías atendiendo a la siguiente lista: organizaciones políticas a nivel nacional, organizaciones políticas a nivel regional, organizaciones políticas a nivel provincial, organizaciones políticas a nivel local, hospitales, centros de salud, servicios de emergencias (112, policía, guardia civil, etc.), sindicatos, personal sanitario, pacientes individuales o colectivos, centros de investigación, agrupación de médicos, agrupación de enfermeros, agrupación de farmacéuticos, otras agrupaciones vinculadas con la sanidad, fuentes judiciales, clubes deportivos, casa real, empresas, otras agrupaciones y otros. También se ha reservado una casilla para aquellos artículos donde no se especifica, ni siquiera se intuye, la fuente de origen. Los reportajes, las crónicas o críticas, las entrevistas y los artículos de opinión no se han tenido en cuenta en este análisis debido a la libertad, tanto de forma como de contenido, que ofrecen.

La fuente más consultada por los periódicos estudiados son los servicios de emergencias, ya sean estos la policía local o nacional, la guardia civil, el 112, etc. El 18,33\%, es decir, 134 textos, provenían de este ámbito. Después de ellos se hallan las fuentes políticas regionales, que agrupan un 14,64\%, o lo que es lo mismo, 107 composiciones. En este grupo se incluye las diversas áreas del gobierno regional, así como los distintos partidos a este nivel.

Los centros de investigación, donde también se incluyen las universidades, constituyen el origen de muchas menos informaciones. Concretamente, 53 de ellas (el $7,25 \%$ ), provienen de estas entidades, posicionándose así delante del gobierno central, que reúne 49 (el 6,70\%). A partir de ahí, la frecuencia de fuentes consultadas disminuye poco a poco. Seis de cada cien noticias (el 6,29\%) emanan de un centro hospitalario, mientras que los gobiernos o partidos políticos locales y los clubes deportivos obtienen la misma frecuencia: un 5,20\% o 38 textos. Las organizaciones vinculadas con el deporte obtienen más cobertura en lo referente a la sanidad y salud $(5,20 \%)$ que las propias asociaciones dedicadas exclusivamente a ello (5,06\%), las agrupaciones de médicos $(3,42 \%)$, los pacientes $(1,78 \%)$, las concentraciones de farmacéuticos $(1,23 \%)$ y las de enfermeros $(1,09 \%)$.

También resulta remarcable que, a pesar del alto número de orígenes planteados, la categoría de "otros" ocupe el quinto lugar por orden descendiente con el 6,70\% o 47 de las 731 composiciones examinadas. Este resultado pone de relieve el alto número de fuentes que utilizan los periodistas a la hora de redactar noticias referentes a la salud o sanidad. 
Tabla 168. Frecuencia y porcentaje de la fuente informante

\begin{tabular}{|l|r|r|r|}
\hline \multicolumn{1}{|c|}{ Fuente informadora } & Frecuencia & Porcentaje & $\begin{array}{l}\text { Porcentaje } \\
\text { válido }\end{array}$ \\
\hline Emergencias & 134 & 16,75 & 18,33 \\
\hline Comunidad & 107 & 13,38 & 14,64 \\
\hline Centro de investigación & 53 & 6,63 & 7,25 \\
\hline Gobierno & 49 & 6,13 & 6,70 \\
\hline Otros & 47 & 5,88 & 6,43 \\
\hline Hospital & 46 & 5,75 & 6,29 \\
\hline Ayuntamiento & 38 & 4,75 & 5,20 \\
\hline Club deportivo & 38 & 4,75 & 5,20 \\
\hline Otras agrupaciones & 37 & 4,63 & 5,06 \\
\hline vinculadas con la salud & 36 & 4,50 & 4,92 \\
\hline Justicia & 25 & 3,13 & 3,42 \\
\hline Agrupación de médicos & 21 & 2,63 & 2,87 \\
\hline Sindicato & 16 & 2,00 & 2,19 \\
\hline Casa Real & 13 & 1,63 & 1,78 \\
\hline Pacientes & 13 & 1,63 & 1,78 \\
\hline NS/NC & 13 & 1,63 & 1,78 \\
\hline Otras agrupaciones & 11 & 1,38 & 1,50 \\
\hline Personal & 11 & 1,38 & 1,50 \\
\hline Empresas & 9 & 1,13 & 1,23 \\
\hline Agrupación & 69 & 1,00 & 1,09 \\
\hline Agrupación de enfermeros & 0,75 & 0,82 \\
\hline Diputación & 91,38 & 100,00 \\
\hline Total & 8,63 & - \\
\hline No procede & 100,00 & \\
\hline Total & & & \\
\hline
\end{tabular}

Fuente: elaboración propia. 


\section{Gráfico 17. Frecuencia de las fuentes de las informaciones}

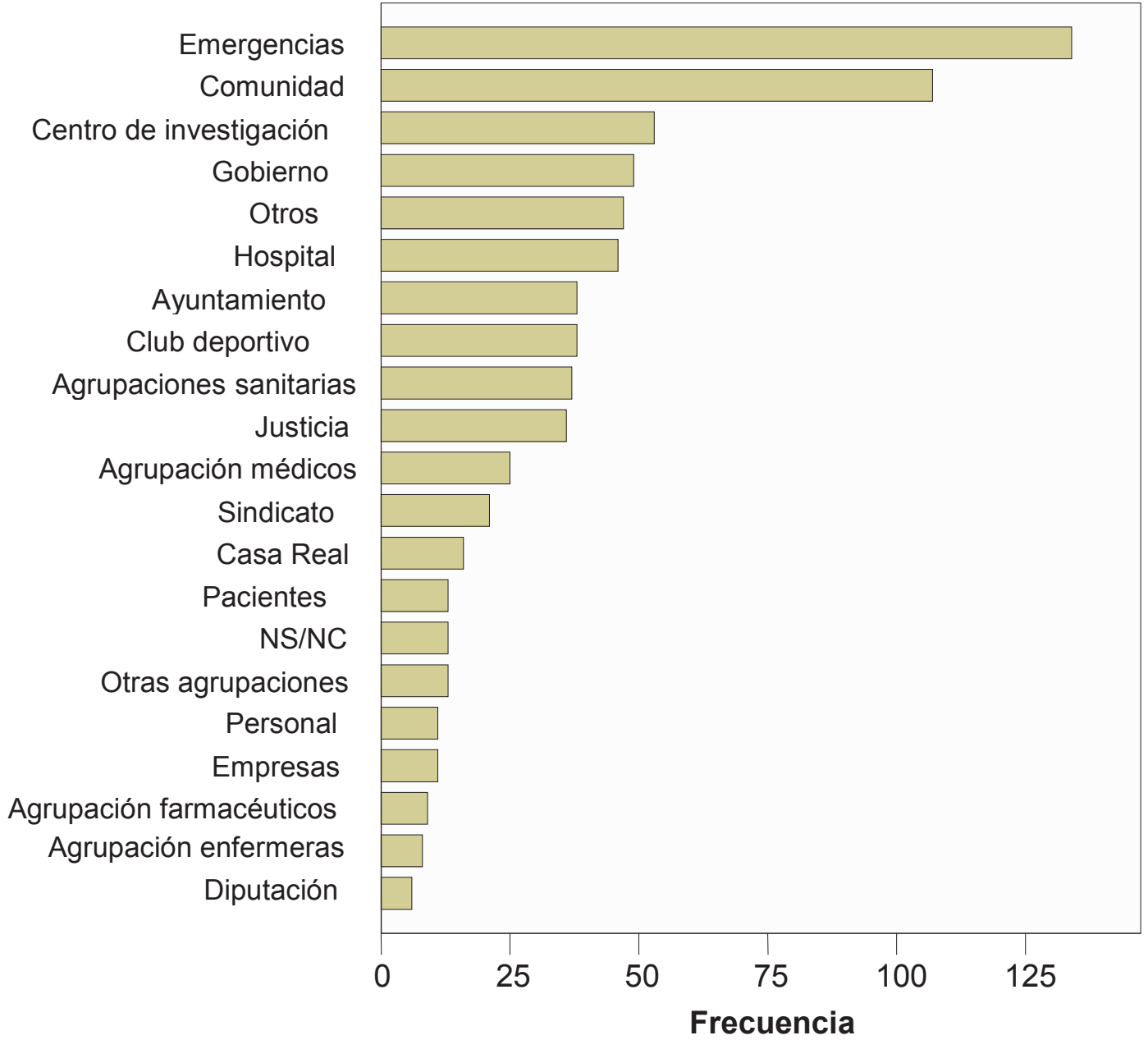

Fuente: elaboración propia a partir de los resultados del programa estadístico SPSS.

Dividiendo los periódicos por comunidad autónoma se advierte que ambas divulgan más informaciones del servicio de emergencias por encima de otras fuentes, aunque Galicia publica un número mayor. Concretamente, difunde 75 (el 21,74\% de su total), mientras que Castilla y León rebaja esta cifra hasta 59 (el 15,28\%). Las procedentes de organizaciones políticas a nivel regional están, en ambas regiones, en segundo lugar de la lista, aunque en este caso, Castilla y León sobrepasa a Galicia. La comunidad castellano-leonesa difunde $58(15,03 \%)$ informaciones de esta clase y la gallega, 49 $(14,20 \%)$. En cambio, mientras que el tercer tipo de fuente más empleada en Castilla y León es el gobierno o partidos políticos a nivel nacional, con 36 textos (el 9,33\% del total de la comunidad), en Galicia estos informantes caen a la décima posición, con casi un tercio de composiciones menos (13 o el 3,77\%). Los organismos que se sitúan en tercera posición en Galicia en cuanto a utilización de sus informaciones son los hospitales, con 27 noticias o el 7,83\% de su total, mientras que en Castilla y León estos caen a la séptima posición con 19 composiciones o 4,92\%. 
Otras diferencias notables, aunque no se pueden considerar completamente significativas por la baja frecuencia, se hallan en las novedades procedentes de agrupaciones farmacéuticas (seis publicadas en Galicia frente a tres en Castilla y León), de pacientes (diez en Castilla y León frente a las tres en Galicia) y de empresas (nueve en Castilla y León frente a dos en Galicia). Las noticias originarias de organizaciones de enfermeros también son más numerosas en la comunidad castellana que en la gallega: seis frente a dos, respectivamente.

Tabla 169. Tabla de contingencia entre fuente informante y comunidad

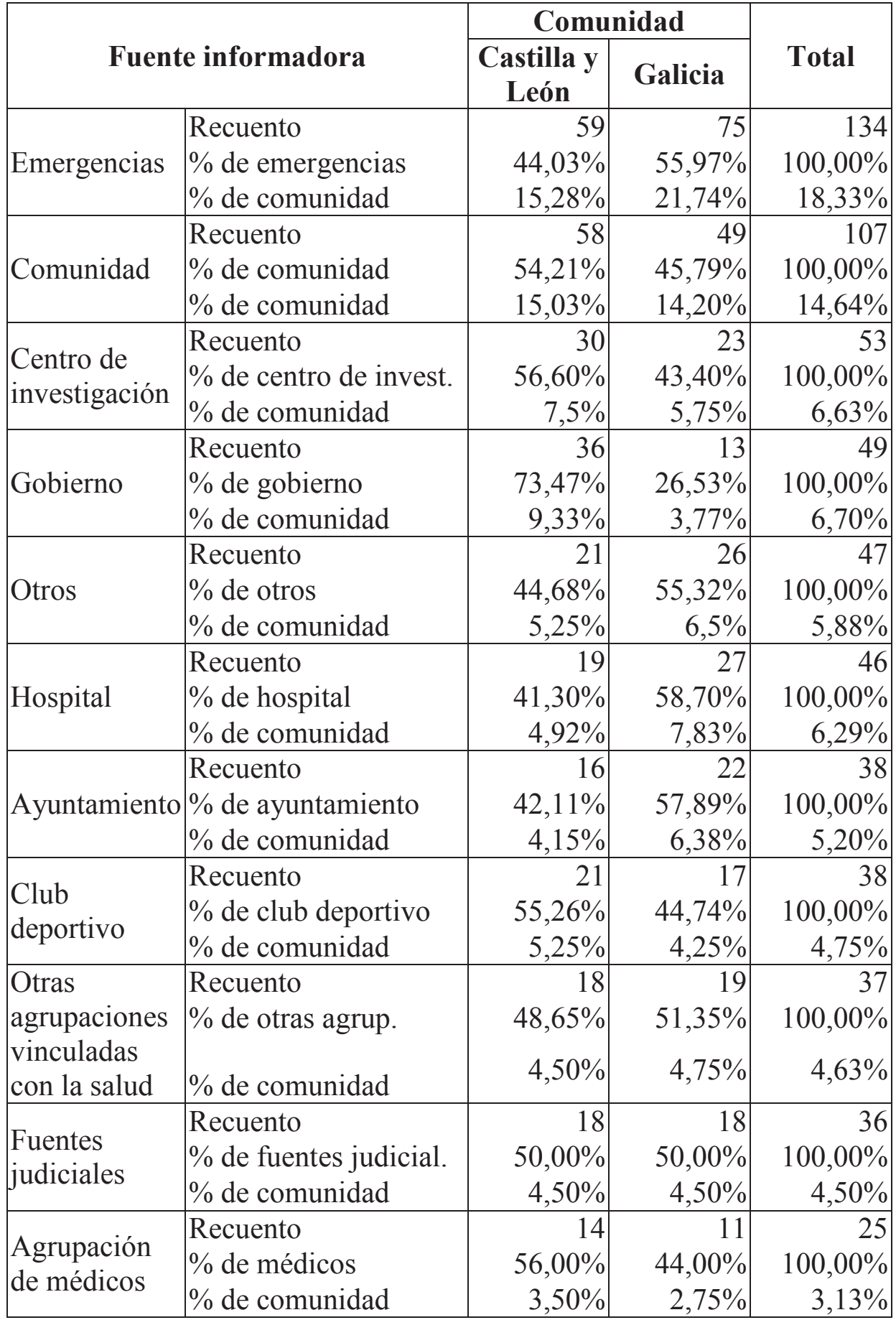




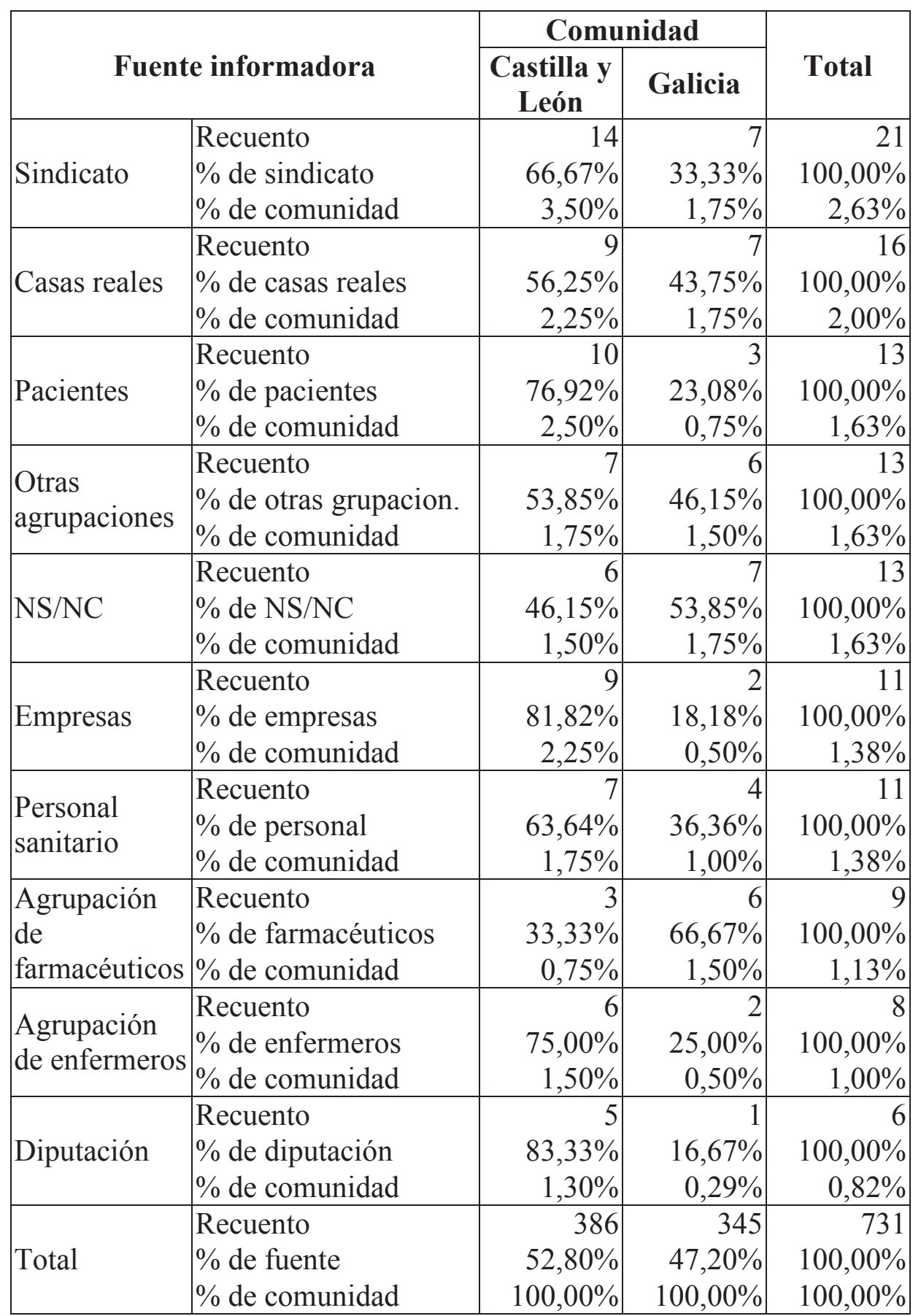

Fuente: elaboración propia a partir de los resultados del programa estadístico SPSS.

De hecho, se han hallado dos relaciones significativas. Una de ellas se establece con el uso de noticias de entidades políticas a nivel nacional, que, como se ha indicado anteriormente, son casi tres veces más numerosas en Castilla y León que en Galicia (36 frente a 13). La otra se ha encontrado en Galicia con las informaciones originarias de servicios de emergencia, tales como las diferentes secciones de la policía, la guardia civil, el 112 , etc. Casi el $22 \%$ de los textos publicados en estos diarios procedían de estas fuentes, mientras que en los castellano-leoneses apenas supera el 15\%. 
Tabla 170. Tabla de contingencia entre gobierno como fuente informante y comunidad

\begin{tabular}{|l|l|r|r|r|}
\hline \multirow{2}{*}{ Fuente informadora } & \multicolumn{2}{|c|}{ Comunidad } & \multirow{2}{*}{ Total } \\
\cline { 3 - 4 } & \multicolumn{2}{|c|}{$\begin{array}{c}\text { Castilla y } \\
\text { León }\end{array}$} & Galicia & \\
\hline \multirow{3}{*}{ Gobierno } & Recuento & 36 & 13 & 49 \\
& $\%$ de gobierno & $73,47 \%$ & $26,53 \%$ & $100,00 \%$ \\
& $\%$ de comunidad & $9,33 \%$ & $3,77 \%$ & $6,70 \%$ \\
\hline \multirow{3}{*}{ Otros } & Recuento & 350 & 332 & 682 \\
& $\%$ de gobierno & $51,32 \%$ & $48,68 \%$ & $100,00 \%$ \\
& $\%$ de comunidad & $90,67 \%$ & $96,23 \%$ & $93,30 \%$ \\
\hline \multirow{3}{*}{ Total } & Recuento & 386 & 345 & 731 \\
& $\%$ de gobierno & $52,80 \%$ & $47,20 \%$ & $100,00 \%$ \\
& $\%$ de comunidad & $100,00 \%$ & $100,00 \%$ & $100,00 \%$ \\
\hline
\end{tabular}

Fuente: elaboración propia a partir de los resultados del programa estadístico SPSS.

Tabla 171. Prueba de chi-cuadrado entre gobierno como fuente informante y comunidad

\begin{tabular}{|l|r|r|r|r|r|}
\hline \multicolumn{1}{|c|}{ Prueba } & \multicolumn{1}{|c|}{ Valor } & gl & $\begin{array}{c}\text { Sig. asintótica } \\
\text { (bilateral) }\end{array}$ & $\begin{array}{l}\text { Sig. exacta } \\
\text { (bilateral) }\end{array}$ & $\begin{array}{c}\text { Sig. exacta } \\
\text { (unilateral) }\end{array}$ \\
\hline Chi-cuadrado de Pearson & 9,000 & 1 & 0,003 & & \\
Corrección por continuidad & 8,133 & 1 & 0,004 & & \\
Razón de verosimilitudes & 9,406 & 1 & 0,002 & & 0,002 \\
Estadístico exacto de & & & & 0,003 & \\
Fisher & & & & & \\
Asociación lineal por lineal & 8,987 & 1 & 0,003 & & \\
N de casos válidos & 731,000 & & & & \\
\hline
\end{tabular}

Fuente: elaboración propia a partir de los resultados del programa estadístico SPSS. 
Tabla 172. Medidas simétricas de la prueba de chi-cuadrado entre gobierno como fuente informante y comunidad

\begin{tabular}{|ll|r|r|r|r|}
\hline \multicolumn{2}{|c|}{ Prueba } & Valor & $\begin{array}{c}\text { Error típ. } \\
\text { asint. }\end{array}$ & \multicolumn{1}{c|}{$\begin{array}{c}\text { T } \\
\text { aproximada }\end{array}$} & \multicolumn{1}{c|}{$\begin{array}{c}\text { Sig. } \\
\text { aproximada }\end{array}$} \\
\hline $\begin{array}{lll}\text { Nominal por nominal } \\
\text { Contingencia } \\
\text { contervalo por }\end{array}$ & 0,110 & & & 0,003 \\
intervalo & R de Pearson & 0,111 & 0,034 & 3,014 & 0,003 \\
Ordinal por ordinal & $\begin{array}{l}\text { Correlación de } \\
\text { Spearman }\end{array}$ & 0,111 & 0,034 & 3,014 & 0,003 \\
N de casos válidos & 731,000 & & \\
\hline
\end{tabular}

Fuente: elaboración propia a partir de los resultados del programa estadístico SPSS.

Gráfico 18. Número de informaciones con el gobierno como fuente informante según comunidades

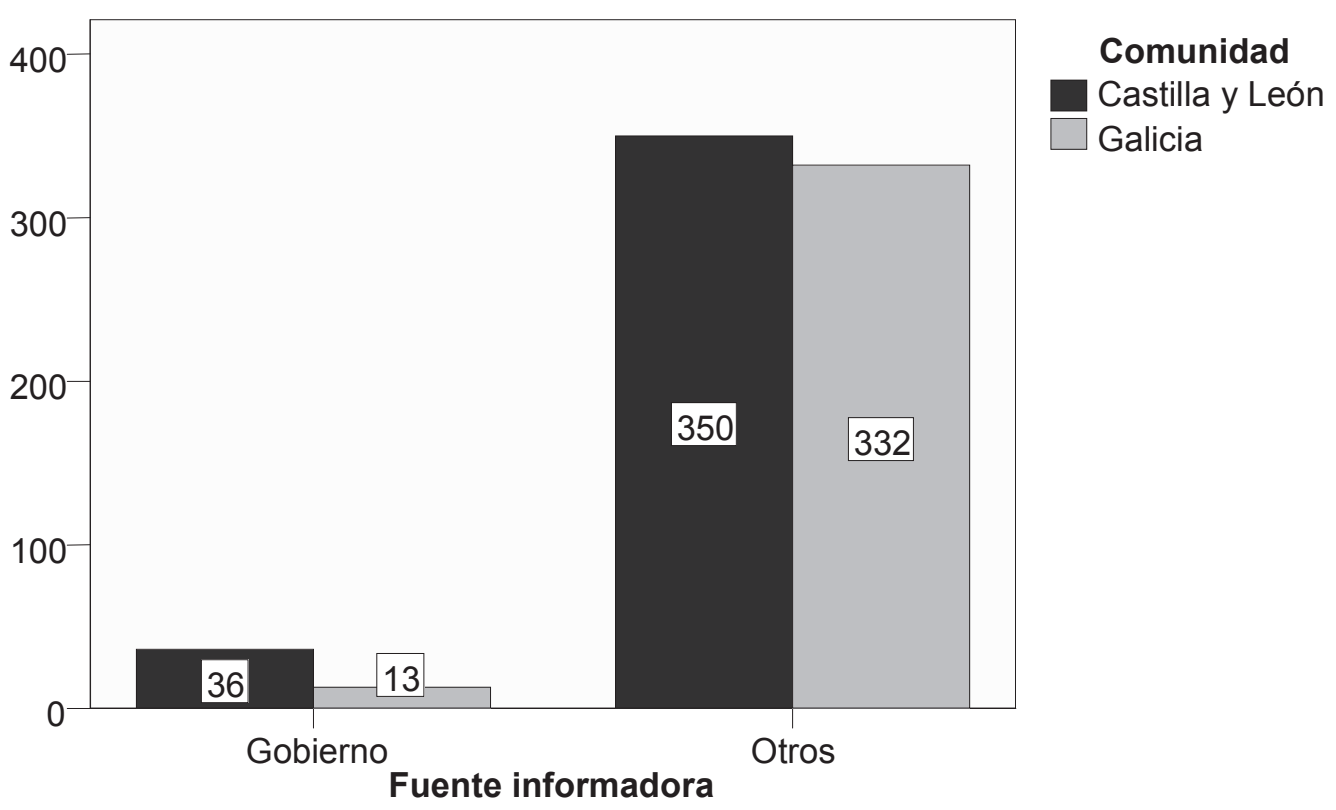

Fuente: elaboración propia a partir de los resultados del programa estadístico SPSS. 
Tabla 173. Tabla de contingencia entre emergencias como fuente informante $y$ comunidad

\begin{tabular}{|l|l|r|r|r|}
\hline \multirow{2}{*}{ Fuente informadora } & \multicolumn{2}{|c|}{ Comunidad } & \multirow{2}{*}{ Total } \\
\cline { 3 - 4 } \multicolumn{2}{|c|}{$\begin{array}{c}\text { Castilla y } \\
\text { León }\end{array}$} & Galicia & \\
\hline \multirow{3}{*}{ Emergencias } & Recuento & 59 & 75 & 134 \\
& $\%$ de emergencias & $44,03 \%$ & $55,97 \%$ & $100,00 \%$ \\
& $\%$ de comunidad & $15,28 \%$ & $21,74 \%$ & $18,33 \%$ \\
\hline \multirow{3}{*}{ Otros } & Recuento & 327 & 270 & 597 \\
& $\%$ de emergencias & $54,77 \%$ & $45,23 \%$ & $100,00 \%$ \\
& $\%$ de comunidad & $84,72 \%$ & $78,26 \%$ & $81,67 \%$ \\
\hline \multirow{3}{*}{ Total } & Recuento & 386 & 345 & 731 \\
& $\%$ de emergencias & $52,80 \%$ & $47,20 \%$ & $100,00 \%$ \\
& $\%$ de comunidad & $100,00 \%$ & $100,00 \%$ & $100,00 \%$ \\
\hline
\end{tabular}

Fuente: elaboración propia a partir de los resultados del programa estadístico SPSS.

Tabla 174. Prueba de chi-cuadrado entre emergencias como fuente informante $y$ comunidad

\begin{tabular}{|l|r|r|r|r|r|}
\hline \multicolumn{1}{|c|}{ Prueba } & Valor & gl & $\begin{array}{c}\text { Sig. asintótica } \\
\text { (bilateral) }\end{array}$ & $\begin{array}{l}\text { Sig. exacta } \\
\text { (bilateral) }\end{array}$ & $\begin{array}{l}\text { Sig. exacta } \\
\text { (unilateral) }\end{array}$ \\
\hline Chi-cuadrado de Pearson & 5,069 & 1 & 0,024 & & \\
Corrección por continuidad & 4,647 & 1 & 0,031 & & \\
Razón de verosimilitudes & 5,065 & 1 & 0,024 & & 0,016 \\
$\begin{array}{l}\text { Estadístico exacto de } \\
\text { Fisher }\end{array}$ & & & & 0,028 & 0 \\
Asociación lineal por lineal & 5,062 & 1 & 0,024 & & \\
N de casos válidos & 731,000 & & & & \\
\hline
\end{tabular}

Fuente: elaboración propia a partir de los resultados del programa estadístico SPSS.

Tabla 175. Medidas simétricas de la prueba de chi-cuadrado entre emergencias como fuente informante y comunidad

\begin{tabular}{|c|c|c|c|c|c|}
\hline \multicolumn{2}{|l|}{ Prueba } & Valor & $\begin{array}{l}\text { Error típ. } \\
\text { asint. }\end{array}$ & $\begin{array}{c}\mathbf{T} \\
\text { aproximada }\end{array}$ & $\begin{array}{c}\text { Sig. } \\
\text { aproximada }\end{array}$ \\
\hline Nominal por nominal & $\begin{array}{l}\text { Coeficiente de } \\
\text { contingencia }\end{array}$ & 0,083 & & & 0,024 \\
\hline $\begin{array}{l}\text { Intervalo por } \\
\text { intervalo }\end{array}$ & $\mathrm{R}$ de Pearson & $-0,083$ & 0,037 & $-2,256$ & 0,024 \\
\hline $\begin{array}{l}\text { Ordinal por ordinal } \\
\mathrm{N} \text { de casos válidos }\end{array}$ & $\begin{array}{l}\text { Correlación de } \\
\text { Spearman }\end{array}$ & $\begin{array}{r}-0,083 \\
731,000\end{array}$ & 0,037 & $-2,256$ & 0,024 \\
\hline
\end{tabular}

Fuente: elaboración propia a partir de los resultados del programa estadístico SPSS. 


\section{Gráfico 19. Número de informaciones con emergencias como fuente informante según comunidades}

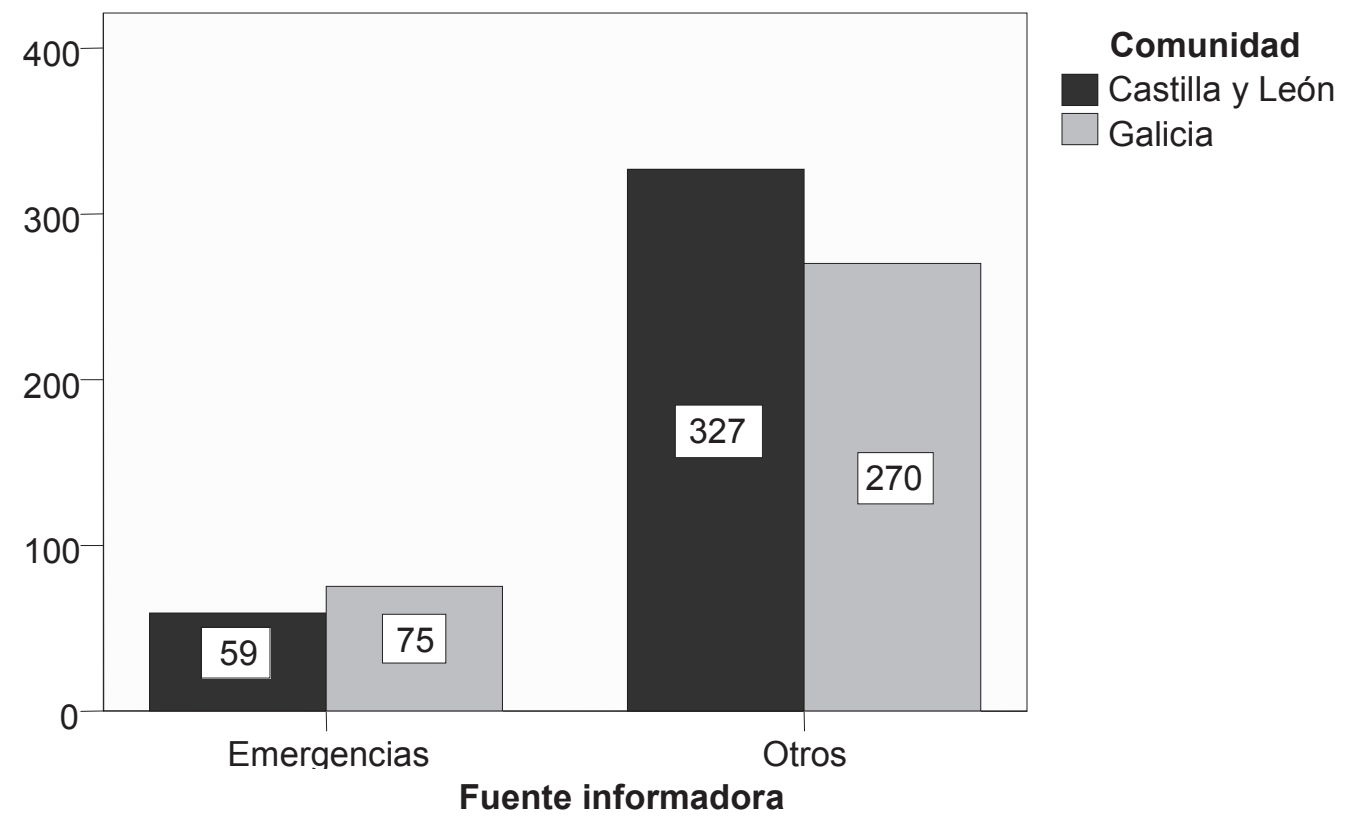

Fuente: elaboración propia a partir de los resultados del programa estadístico SPSS.

\subsection{RESTO DE GÉNEROS}

Cuando se tienen en cuenta los géneros que no pueden considerarse puramente informativos, como la entrevista, el reportaje, la opinión y la crónica y crítica, se aprecia que la fuente más recurrente son los hospitales, con un 26,09\% de los textos de este tipo. Por detrás se hallan los partidos o instituciones políticas a nivel regional $(18,39 \%)$ y los centros de investigación (11,59\%). Es notable el alto número de otros orígenes aparte de los expuestos $(13,04 \%)$, así como de las composiciones que no ofrecen una clara fuente $(10,14 \%)$. Por detrás de estas opciones, y con bastante menos frecuencia, se hallan los pacientes $(5,80 \%)$, las entidades o partidos políticos nacionales $(4,35 \%)$, el personal sanitario $(4,35 \%)$, etc. 
Tabla 176. Frecuencia y porcentaje de la fuente informadora en géneros no informativos

\begin{tabular}{|l|r|r|r|}
\hline \multicolumn{1}{|c|}{ Fuente } & Frecuencia & Porcentaje & $\begin{array}{l}\text { Porcentaje } \\
\text { válido }\end{array}$ \\
\hline Hospital & 18 & 2,25 & 26,09 \\
\hline Comunidad & 12 & 1,50 & 17,39 \\
\hline Otros & 9 & 1,13 & 13,04 \\
\hline Centro de investigación & 8 & 1,00 & 11,59 \\
\hline NS/NC & 7 & 0,88 & 10,14 \\
\hline Pacientes & 4 & 0,50 & 5,80 \\
\hline Gobierno & 3 & 0,38 & 4,35 \\
\hline Personal & 3 & 0,38 & 4,35 \\
\hline Otras agrupaciones & 2 & 0,25 & 2,90 \\
\hline Emergencias & 1 & 0,13 & 1,45 \\
\hline $\begin{array}{l}\text { Agrupación } \\
\text { farmacéuticos }\end{array}$ & 1 & 0,13 & 1,45 \\
\hline Justicia & 1 & 0,13 & 1,45 \\
\hline Total & 69 & 8,63 & 100,00 \\
\hline Género informativo & 731 & 91,38 & - \\
\hline Total & 800 & 100,00 & - \\
\hline
\end{tabular}

Fuente: elaboración propia a partir de los resultados del programa estadístico SPSS.

Los hospitales suelen usarse como base para componer principalmente reportajes, pocas veces para elaborar artículos de opinión y rara vez para entrevistas o crónicas o críticas. En cambio, los partidos políticos o instituciones a nivel regional se citan más a menudo en este último género y menos del resto. Los centros de investigación se usan tanto para componer entrevistas como reportajes. 
Tabla 177. Frecuencia de las fuentes informantes según géneros no informativos

\begin{tabular}{|l|r|r|r|r|r|}
\hline \multirow{2}{*}{ Fuente } & \multicolumn{4}{|c|}{ Genero } & \multirow{2}{*}{ Total } \\
\cline { 2 - 6 } & Entrevista & Reportaje & $\begin{array}{c}\text { Crónica- } \\
\text { crítica }\end{array}$ & Opinión & \\
\hline Hospital & 2 & 12 & 1 & 3 & 18 \\
\hline Comunidad & 1 & 3 & 7 & 1 & 12 \\
\hline Otros & 3 & 2 & 3 & 1 & 9 \\
\hline $\begin{array}{l}\text { Centro de } \\
\text { investigación }\end{array}$ & 4 & 4 & 0 & 0 & 8 \\
\hline NS/NC & 0 & 1 & 0 & 6 & 7 \\
\hline Pacientes & 1 & 3 & 0 & 0 & 4 \\
\hline Gobierno & 0 & 1 & 1 & 1 & 3 \\
\hline Personal & 2 & 1 & 0 & 0 & 3 \\
\hline Otras agrupaciones & 0 & 2 & 0 & 0 & 2 \\
\hline Emergencias & 0 & 0 & 1 & 0 & 1 \\
\hline $\begin{array}{l}\text { Agrupación de } \\
\text { farmacéuticos }\end{array}$ & 1 & 0 & 0 & 0 & 1 \\
\hline Justicia & 0 & 0 & 1 & 0 & 1 \\
\hline Total & 14 & 29 & 14 & 12 & 69 \\
\hline
\end{tabular}

Fuente: elaboración propia a partir de los resultados del programa estadístico SPSS.

Galicia adelanta sobradamente a Castilla y León en el número de composiciones no informativas que realizan sus periódicos con las instituciones o partidos políticos a nivel regional, con el $91,67 \%$ de los artículos que provienen o usan como fuente a estas agrupaciones. También está por delante, con el 83,33\%, cuando se trata de hospitales. En cambio, los diarios castellano-leoneses usan más a menudo los centros de investigación para redactar sus espacios $(62,50 \%)$. La única diferencia significativa se ha encontrado, precisamente, en este último caso (estadístico de Fisher $^{25}=0,007$ ).

\footnotetext{
$\underline{25}$ Se utiliza esta prueba en vez de la de chi-cuadrado de Pearson por haberse detectado casillas con una frecuencia observada menos del $5 \%$.
} 
Tabla 178. Tabla de contingencia entre el tipo de organización y comunidad

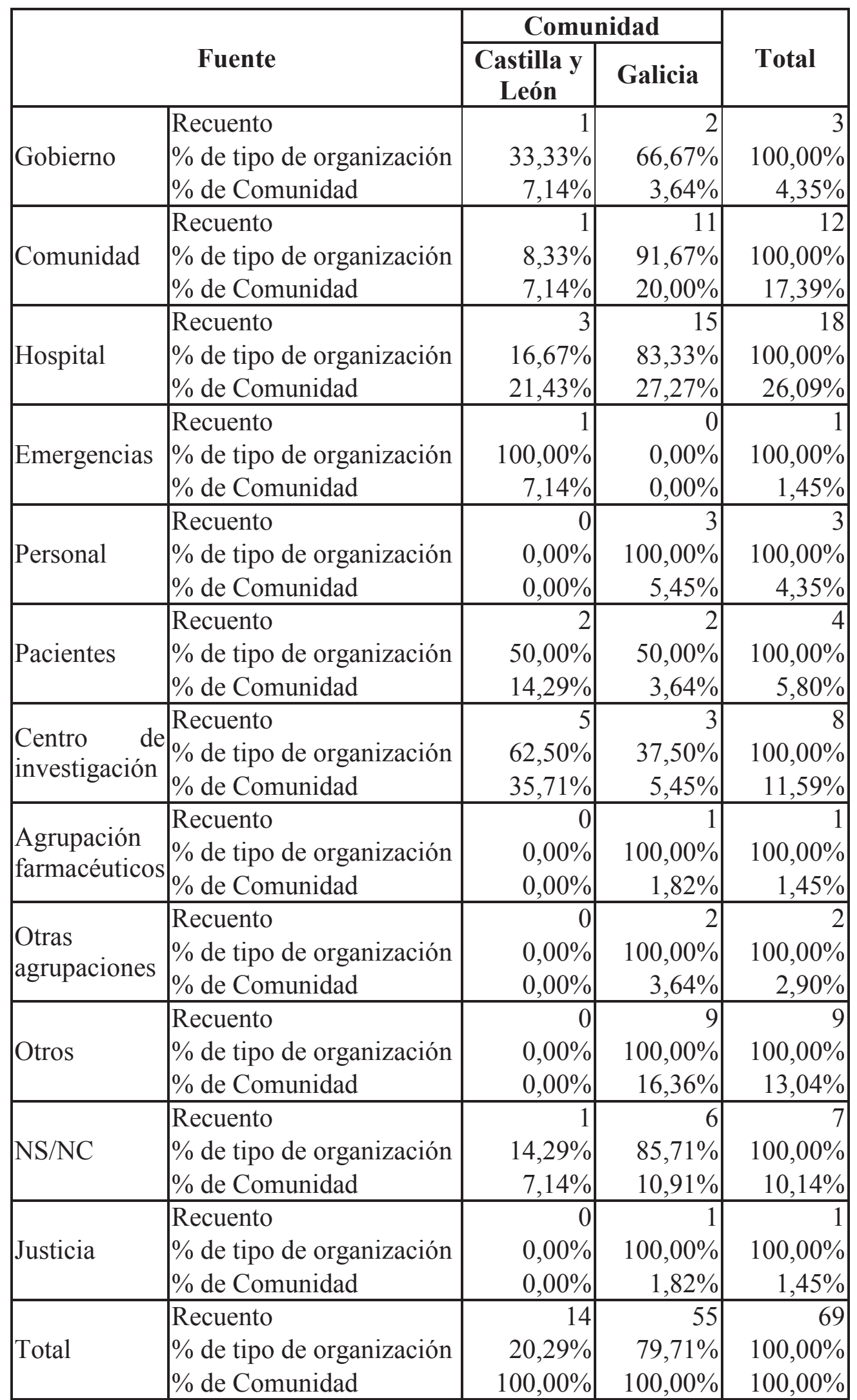

Fuente: elaboración propia a partir de los resultados del programa estadístico SPSS. 
Tabla 179. Prueba de chi-cuadrado entre los centros de investigación como fuente informadora en los géneros no informativos y las comunidades

\begin{tabular}{|l|r|r|r|r|r|}
\hline \multicolumn{1}{|c|}{ Prueba } & Valor & gl & $\begin{array}{c}\text { Sig. } \\
\text { asintótica } \\
\text { (bilateral) }\end{array}$ & $\begin{array}{l}\text { Sig. exacta } \\
\text { (bilateral) }\end{array}$ & $\begin{array}{c}\text { Sig. exacta } \\
\text { (unilateral) }\end{array}$ \\
\hline Chi-cuadrado de Pearson & $9,969(\mathrm{~b})$ & 1 & 0,002 & & \\
Corrección por continuidad & 7,235 & 1 & 0,007 & & \\
Razón de verosimilitudes & 7,974 & 1 & 0,005 & & 0,007 \\
Estadístico exacto de Fisher & & & & 0,007 & \\
Asociación lineal por lineal & 9,824 & 1 & 0,002 & & \\
N de casos válidos & 69,000 & & & & \\
\hline
\end{tabular}

Fuente: elaboración propia a partir de los resultados del programa estadístico SPSS.

\subsubsection{CONTRASTE, ARCHIVO Y SEGUNDAS FUENTES DE LAS INFORMACIONES}

Se ha querido comprobar si las noticias vinculadas con la salud ofrecen cierto grado de verificación, en el sentido de que están contrastadas, incluyen la opinión o datos de otras fuentes o poseen información de archivo o de contextualización. E1 55,75\% tienen, al menos, una referencia de este tipo. Las que no poseen ningún grado de comprobación, por lo tanto, se quedan en un $44,25 \%$.

Tabla 180. Frecuencia y porcentaje de la verificación de las informaciones

\begin{tabular}{|l|r|r|}
\hline Verificación & Frecuencia & Porcentaje \\
\hline Sí & 446 & 55,75 \\
\hline No & 354 & 44,25 \\
\hline Total & 800 & 100,00 \\
\hline
\end{tabular}

Fuente: elaboración propia.

Lo más normal entre las noticias que ofrecen al menos una clase de verificación es que solo exista de un tipo (el 66,82\%). Las que incluyen dos variedades bajan a más de la mitad (concretamente el $27,13 \%$ ) y las que contienen tres no suponen ni una de cada diez de las examinadas (exactamente el 6,05\%). Respecto a todas las noticias analizadas, los porcentajes bajan aún más: $37,12 \%, 15,13 \%$ y 3,38\%. 
Tabla 181. Frecuencia y porcentaje de las informaciones verificadas

\begin{tabular}{|l|l|r|r|r|}
\hline Verificación & $\begin{array}{c}\text { Número de } \\
\text { verificaciones }\end{array}$ & Frecuencia & Porcentaje & $\begin{array}{c}\text { Porcentaje } \\
\text { válido }\end{array}$ \\
\hline \multirow{3}{*}{ Sí } & 1 & 298 & 37,25 & 66,82 \\
\cline { 2 - 5 } & 2 & 121 & 15,13 & 27,13 \\
\cline { 2 - 5 } & 3 & 27 & 3,38 & 6,05 \\
\cline { 2 - 5 } & Total & 446 & 55,75 & 100,00 \\
\hline No & 0 & 354 & 44,25 & - \\
\hline Total & 800 & 100,00 & \\
\hline
\end{tabular}

Fuente: elaboración propia a partir de los resultados del programa estadístico SPSS.

De incorporar alguna línea de este tipo, lo más habitual es que se trate de referencias archivísticas o contextuales. El 46,65\% de las composiciones estudiadas tienen apuntes de esta clase. En uno de cada cuatro textos, más concretamente en el $25,58 \%$, los periodistas incorporan valoraciones o cifras de otras fuentes. En cambio, los redactores raramente contrastan la información con las personas o entidades directamente afectadas. Únicamente en un $12,72 \%$ del muestro se observan líneas así.

Tabla 182. Frecuencia y porcentaje del tipo de verificación

\begin{tabular}{|l|l|r|c|}
\hline \multicolumn{2}{|c|}{ Variable } & Frecuencia & $\begin{array}{c}\text { Porcentaje } \\
\text { válido }\end{array}$ \\
\hline Contraste & Sí & 93 & 12,72 \\
& No & 638 & 87,28 \\
\hline Archivo & Sí & 341 & 46,65 \\
& No & 390 & 53,35 \\
\hline Segundas & Sí & 188 & 25,58 \\
fuentes & No & 543 & 74,42 \\
\hline
\end{tabular}

Fuente: elaboración propia a partir de los resultados del programa estadístico SPSS. 


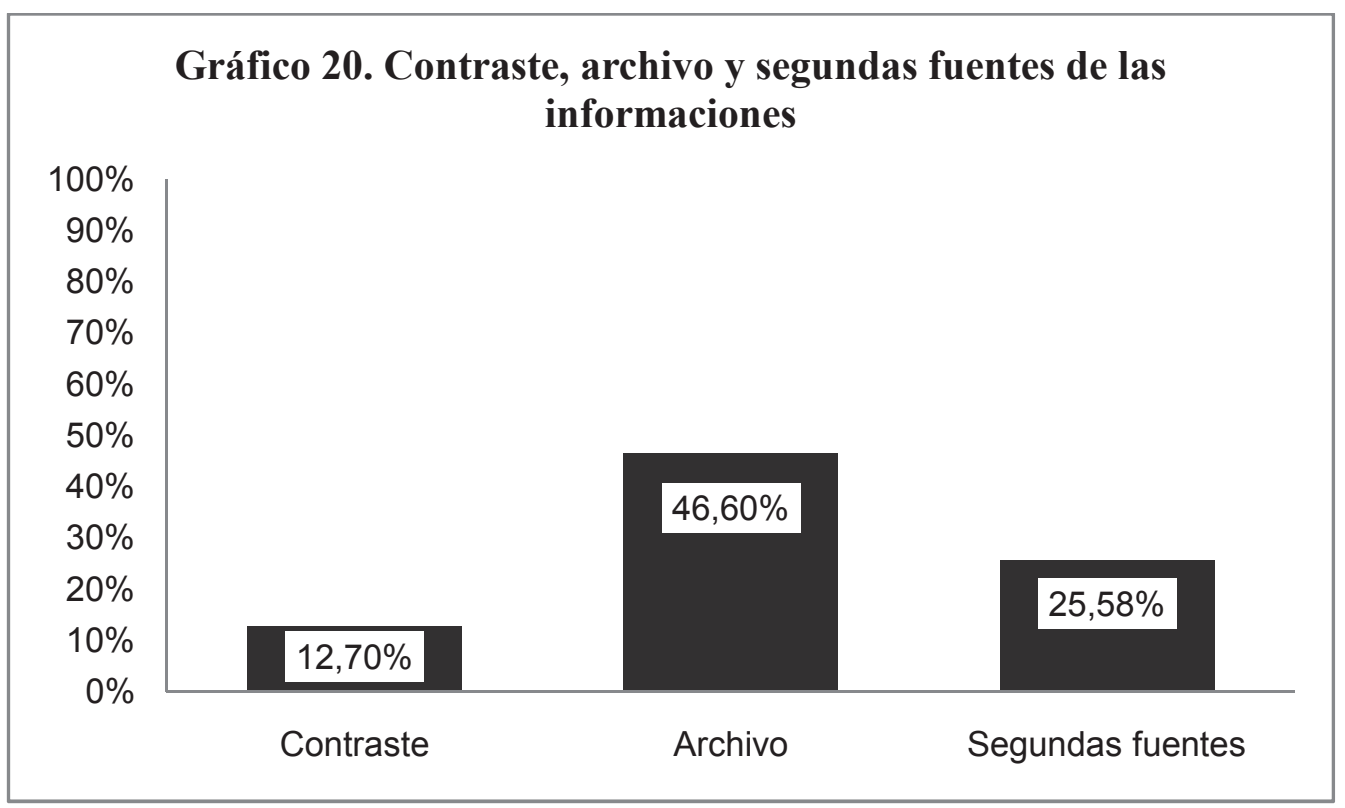

Fuente: elaboración propia.

No se han detectado relaciones significativas en la prueba de chi-cuadrado en cuanto a contraste, archivo y segundas fuentes dividiendo los periódicos por comunidades autónomas, dado que el uso en ambos territorios es muy similar. En cuanto al primer tipo, el $12,18 \%$ de las composiciones de la región castellano-leonesa poseen alguna línea, mientras que en la gallega el porcentaje sube ligeramente al 13,33\%. Los diarios gallegos también aventajan a los castellano-leoneses en el uso de segundas fuentes con un $26,09 \%$ frente a un 25,13\%. En cambio, estos últimos divulgan más noticias con información de archivo (el 47,15\%) que sus homólogos (el 46,09\%).

\subsection{CARACTERES Y PORCENTAJE RESPECTO AL TOTAL}

Además de si existe algún tipo de verificación de la noticia, se ha querido conocer la extensión de esta parte. Así, por ejemplo, se ha visualizado que la información con menos caracteres con espacios de contraste posee 29, mientras que la mayor, 2.943. En el caso de archivo, el número es ligeramente más alto: 34 para el mínimo y 3.459 para el máximo. Donde se halla mayor desnivel frente al mínimo es en las segundas fuentes: la composición que tenía menos caracteres contando este tipo de información asciende a 65, aunque la máxima no llega a superar a los de archivo: 3.412. La media en las tres clases, no obstante, es muy similar: 580, 529 y 579, respectivamente. La desviación más común a partir de esas medias son, en este orden: 555, 482 y 484. 
Tabla 183. Estadísticos descriptivos de los caracteres de verificación

\begin{tabular}{|lr|r|r|r|r|r|r|r|}
\hline \multicolumn{1}{|c|}{ Variable } & $\mathbf{N}^{\mathbf{0}}$ & Mínimo & Máximo & Suma & Media & Desv. típ. & Mediana \\
\hline $\begin{array}{l}\text { Caracteres } \\
\text { contraste }\end{array}$ & de & 93 & 29 & 2.943 & 53.920 & 580 & 555 & 367 \\
$\begin{array}{l}\text { Caracteres de } \\
\text { archivo } \\
\begin{array}{l}\text { Caracteres de } \\
\text { segundas fuentes }\end{array}\end{array}$ & 341 & 34 & 3.459 & 180.363 & 529 & 482 & 392 \\
\hline
\end{tabular}

Fuente: elaboración propia a partir de los resultados del programa estadístico SPSS.

Realizando un diagrama de cajas, se observa que todos esos niveles máximos son considerados extremos; es decir, que son casos puntuales que se alejan en gran medida de la media. Estas noticias aparecen en el gráfico con un asterisco. Los puntos, por el contrario, se corresponden simplemente con casos atípicos.

Gráfico 21. Diagrama de cajas de la extensión de los datos de contraste

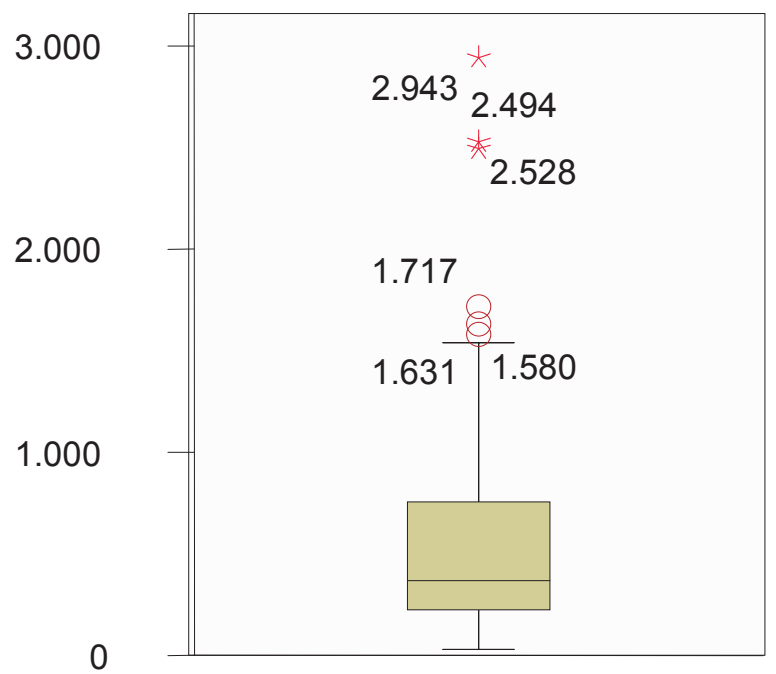


Gráfico 22. Diagrama de cajas de la extensión de los datos de archivo

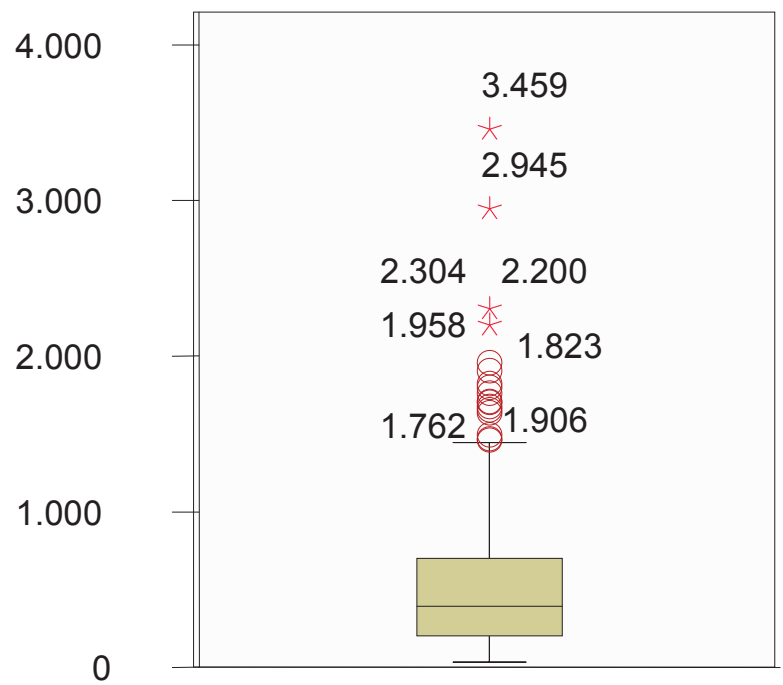

Gráfico 23. Diagrama de cajas de la extensión de los datos de las segundas fuentes

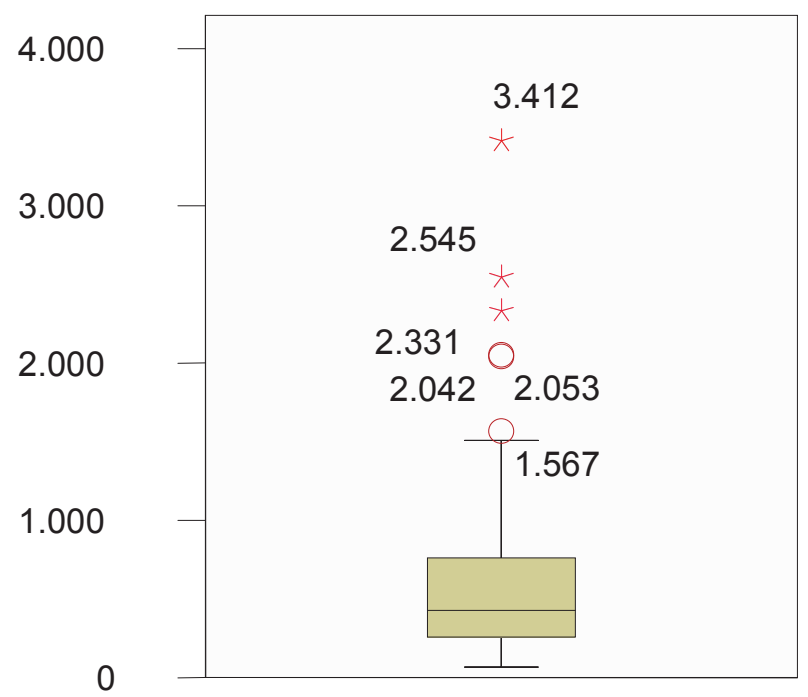

Fuente: elaboración propia a partir de los resultados del programa estadístico SPSS.

La media de caracteres de contraste y de archivo es ligeramente mayor en Castilla y León (con 603,19 y 567,30) que en Galicia (que posee, para las mismas variables, 55,87 y 485,00). En cuanto a las segundas fuentes, son los periódicos gallegos los que poseen una cifra más elevada, aunque la diferencia es mínima: 582,12 sobre 576,08 de los castellano-leoneses. En todos ellos se han detectado casos extremos y, en la mayoría, atípicos. Por otra parte, dada la similitud entre las medias de estos aspectos, no se han hallado relaciones significativas. 
Tabla 184. Estadísticos descriptivos de los caracteres de verificación por comunidades

\begin{tabular}{|l|l|r|r|r|r|}
\hline \multicolumn{1}{|c|}{ Variable } & Comunidad & \multicolumn{1}{c|}{$\mathbf{N}^{\mathbf{0}}$} & \multicolumn{1}{c|}{ Media } & $\begin{array}{c}\text { Desviación } \\
\text { típ. }\end{array}$ & $\begin{array}{c}\text { Error típ. } \\
\text { de la media }\end{array}$ \\
\hline \multirow{2}{*}{$\begin{array}{l}\text { Caracteres de } \\
\text { contraste }\end{array}$} & Castilla y León & 47 & 603,19 & 561,89 & 81,96 \\
\cline { 2 - 6 } & Galicia & 46 & 555,87 & 553,54 & 81,62 \\
\hline $\begin{array}{l}\text { Caracteres de } \\
\text { archivo }\end{array}$ & Castilla y León & 182 & 567,30 & 515,47 & 38,21 \\
\cline { 2 - 6 } & Galicia & 159 & 485,00 & 437,90 & 34,73 \\
\hline $\begin{array}{l}\text { Caracteres de } \\
\text { segundas fuentes }\end{array}$ & Castilla y León & 97 & 576,08 & 460,22 & 46,73 \\
\cline { 2 - 6 } & Galicia & 90 & 582,12 & 511,27 & 53,89 \\
\hline
\end{tabular}

Fuente: elaboración propia a partir de los resultados del programa estadístico SPSS.

Gráfico 24. Diagrama de cajas de la extensión de los datos de contraste según comunidades

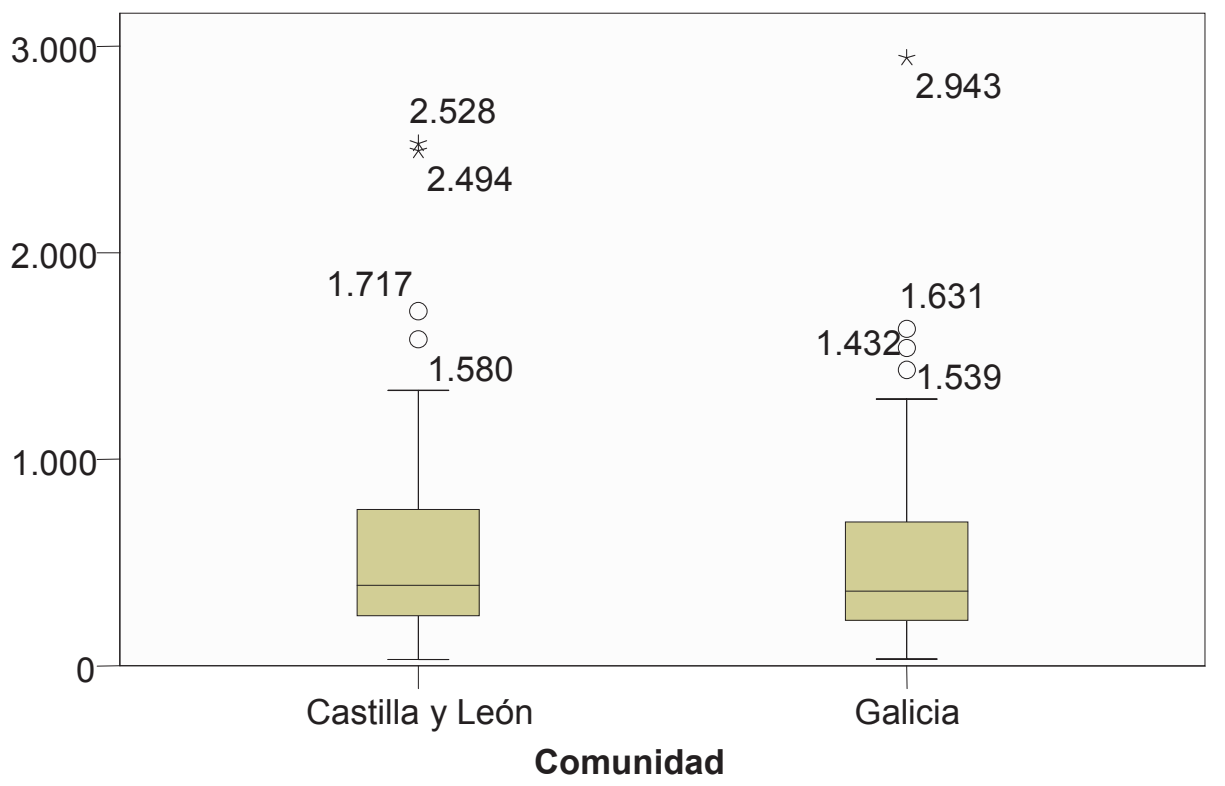


Gráfico 25. Diagrama de cajas de la extensión de los datos de archivo según comunidades

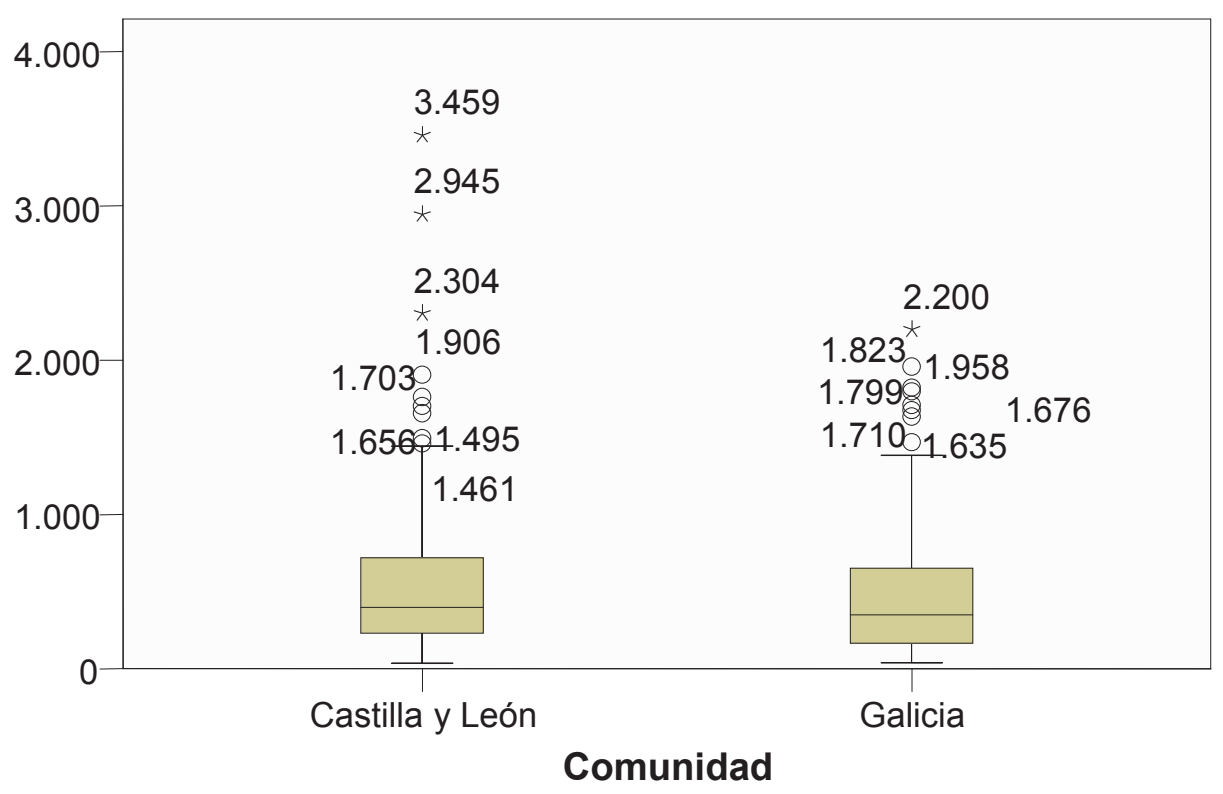

Gráfico 26. Diagrama de cajas de la extensión de los datos de las segundas fuentes según comunidades

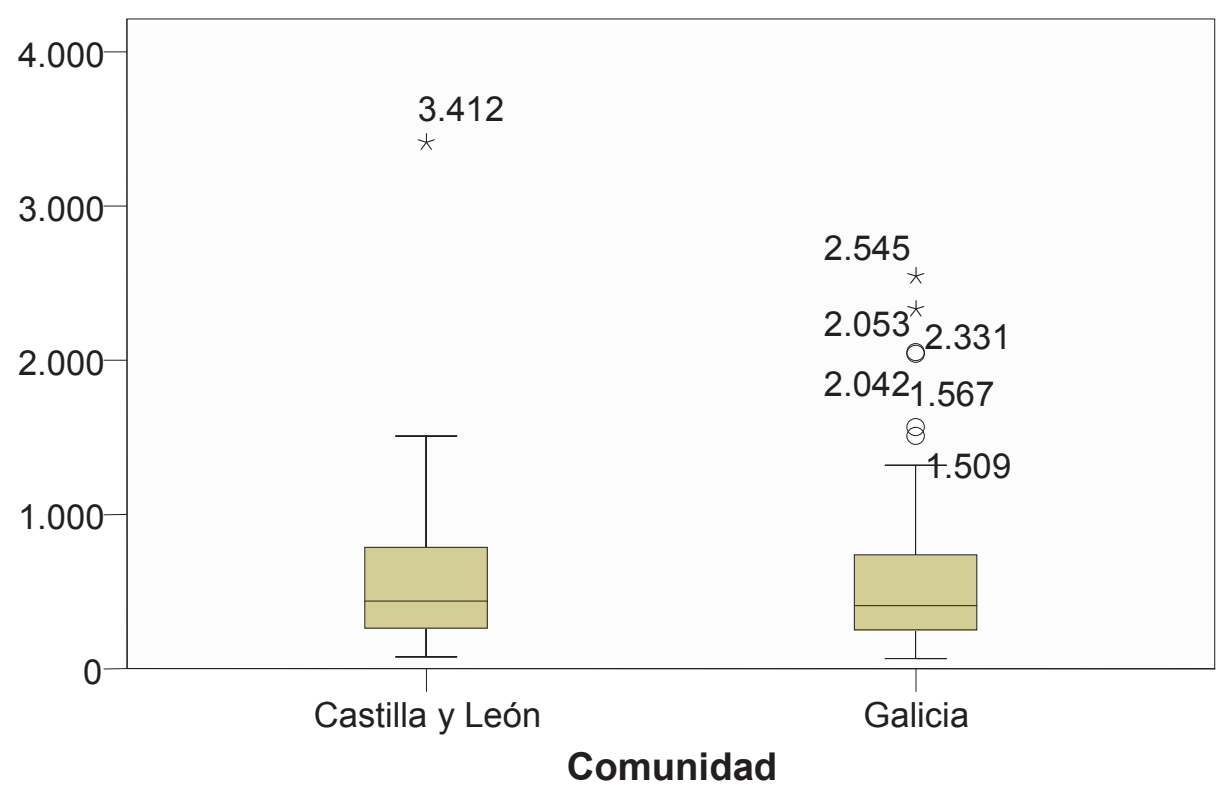

Fuente: elaboración propia a partir de los resultados del programa estadístico SPSS. 
Estos datos absolutos, pese a todo, no muestran la proporción que mantienen respecto a la noticia completa. Por ello, se ha hallado el porcentaje que tienen estos caracteres dentro del texto entero. Así, por ejemplo, se visualiza que tanto en contraste, como en archivo y en segundas fuentes, el mínimo se sitúa en torno al $1 \%$, más concretamente: $0,71 \%, 1,26 \%$ y 1,37\%, respectivamente. En cambio, los máximos se sitúan muy por encima de estas cifras. La noticia con una mayor información de archivo o contextual posee un $89 \%$ de su total. Las segundas fuentes, que están en segundo lugar, tienen un pico máximo en 69\%, mientras que el contraste baja hasta el 63\%. Las medias, no obstante, son sensiblemente más bajas: $22 \%, 24 \%$ y $25 \%$ para el contraste, archivo y segundas fuentes, en este orden.

Tabla 185. Estadísticos descriptivos del porcentaje de verificación

\begin{tabular}{|lr|r|r|r|r|r|r|r|}
\hline \multicolumn{1}{|c|}{ Variable } & \multicolumn{1}{|c|}{$\mathbf{N}^{\mathbf{0}}$} & Mínimo & Máximo & Suma & Media & Desv. típ. & Mediana \\
\hline $\begin{array}{l}\text { Porcentaje } \\
\text { contraste }\end{array}$ & $\mathrm{de}$ & 93 & 0,71 & 63,44 & 2.036 & 21,89 & 13,68 & 20,47 \\
$\begin{array}{l}\text { Porcentaje } \\
\text { archivo }\end{array}$ & $\mathrm{de}$ & 341 & 1,26 & 88,97 & 8.195 & 24,03 & 18,41 & 18,59 \\
$\begin{array}{l}\text { Porcentaje } \\
\text { segundas fuentes }\end{array}$ & 187 & 1,37 & 68,99 & 4.704 & 25,16 & 14,95 & 23,04 \\
\hline
\end{tabular}

Fuente: elaboración propia a partir de los resultados del programa estadístico SPSS.

A pesar de que se han encontrado varios casos atípicos en el diagrama de cajas, sobre todo en el porcentaje de datos de archivos, no se ha hallado ninguno extremo, lo que implica que no hay casos que se alejen en gran medida de la media.

\section{Gráfico 27. Diagrama de cajas del porcentaje de contraste}

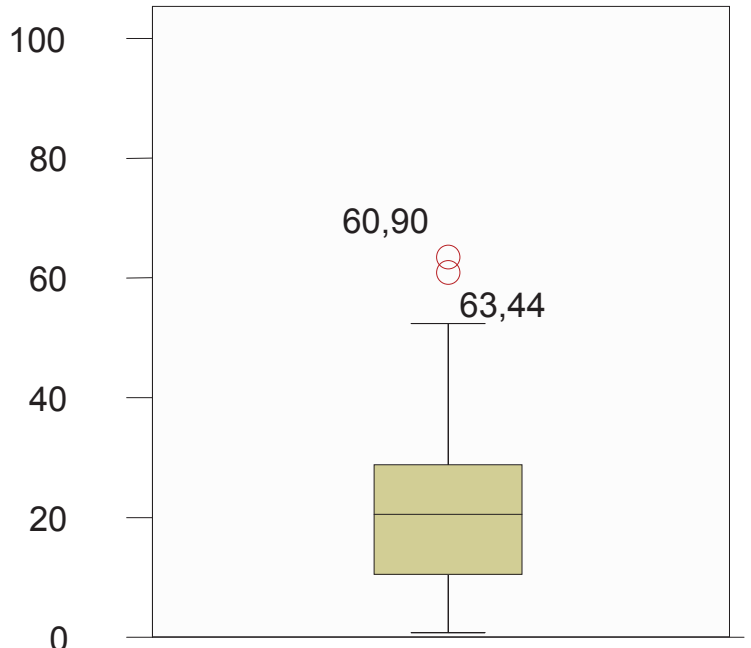




\section{Gráfico 28. Diagrama de cajas del porcentaje de archivo}

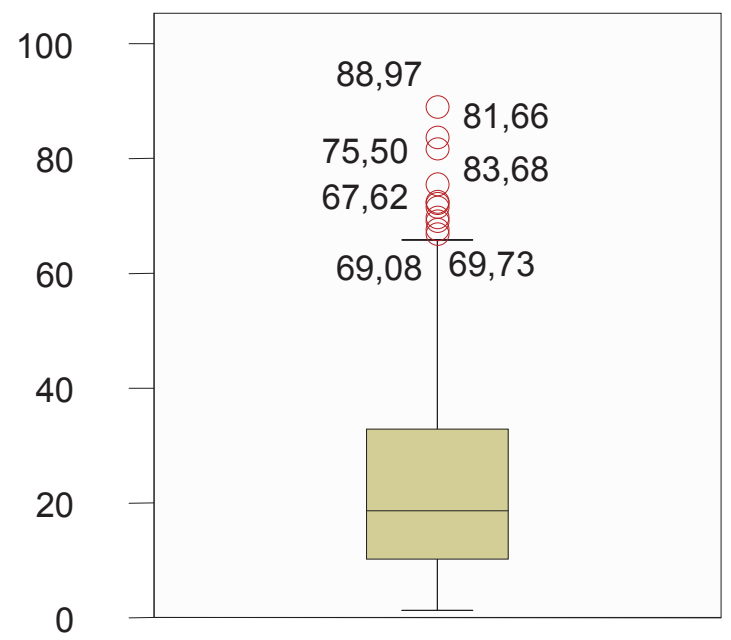

Gráfico 29. Diagrama de cajas del porcentaje de segundas fuentes

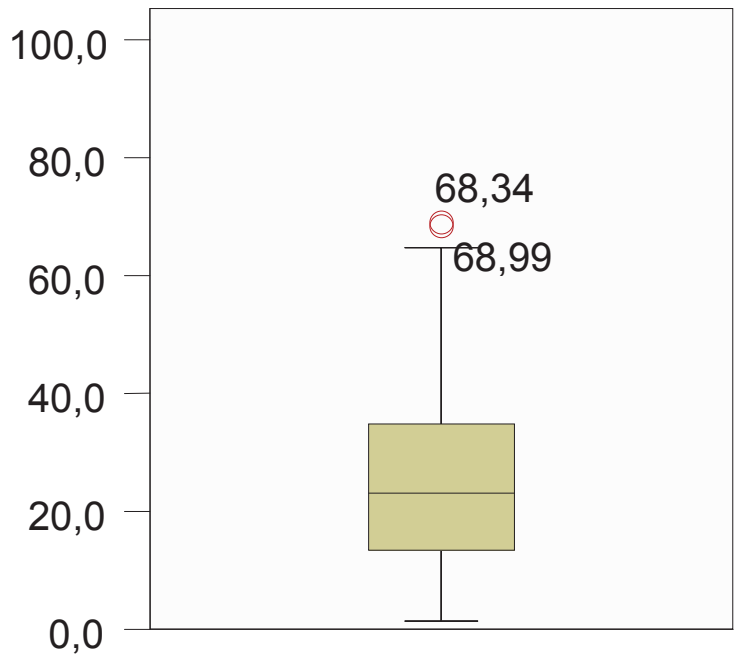

Fuente: elaboración propia a partir de los resultados del programa estadístico SPSS.

Tal y como sucede con los valores absolutos del número de caracteres, en cuanto a porcentaje de contraste y de archivo, los periódicos castellano-leoneses adelantan a los gallegos. En el primer caso, la media se queda en $22,72 \%$ y $21,04 \%$, respectivamente, y en el segundo, en 24,19\% y 23,85\%, en este orden. En cambio, en la proporción de segundas fuentes son los gallegos los que se encuentran por delante con un $27,07 \%$ frente a un 23,38\%. En los diagramas de cajas se pueden observar los casos atípicos y dónde se sitúa la mayor parte del porcentaje de verificación. En ningún caso se han encontrado diferencias estadísticamente significativas. 
Tabla 186. Estadísticos descriptivos del porcentaje de verificación según comunidades

\begin{tabular}{|l|l|r|r|r|r|}
\hline \multicolumn{1}{|c|}{ Variable } & \multicolumn{1}{c|}{ Comunidad } & \multicolumn{1}{c|}{$\mathbf{N}^{\mathbf{o}}$} & Media & $\begin{array}{c}\text { Desviación } \\
\text { típ. }\end{array}$ & $\begin{array}{c}\text { Error típ. de } \\
\text { la media }\end{array}$ \\
\hline $\begin{array}{l}\text { Porcentaje de } \\
\text { contraste }\end{array}$ & Castilla y León & 47 & 22,72 & 13,77 & 2,01 \\
\cline { 2 - 6 } & Galicia & 46 & 21,04 & 13,68 & 2,02 \\
\hline $\begin{array}{l}\text { Porcentaje de } \\
\text { archivo }\end{array}$ & Castilla y León & 182 & 24,19 & 18,09 & 1,34 \\
\cline { 2 - 6 } & Galicia & 159 & 23,85 & 18,83 & 1,49 \\
\hline $\begin{array}{l}\text { Porcentaje de } \\
\text { segundas fuentes }\end{array}$ & Castilla y León & 97 & 23,38 & 12,71 & 1,29 \\
\cline { 2 - 6 } & Galicia & 90 & 27,07 & 16,91 & 1,78 \\
\hline
\end{tabular}

Fuente: elaboración propia a partir de los resultados del programa estadístico SPSS.

Gráfico 30. Diagrama de cajas del porcentaje de contraste según comunidades

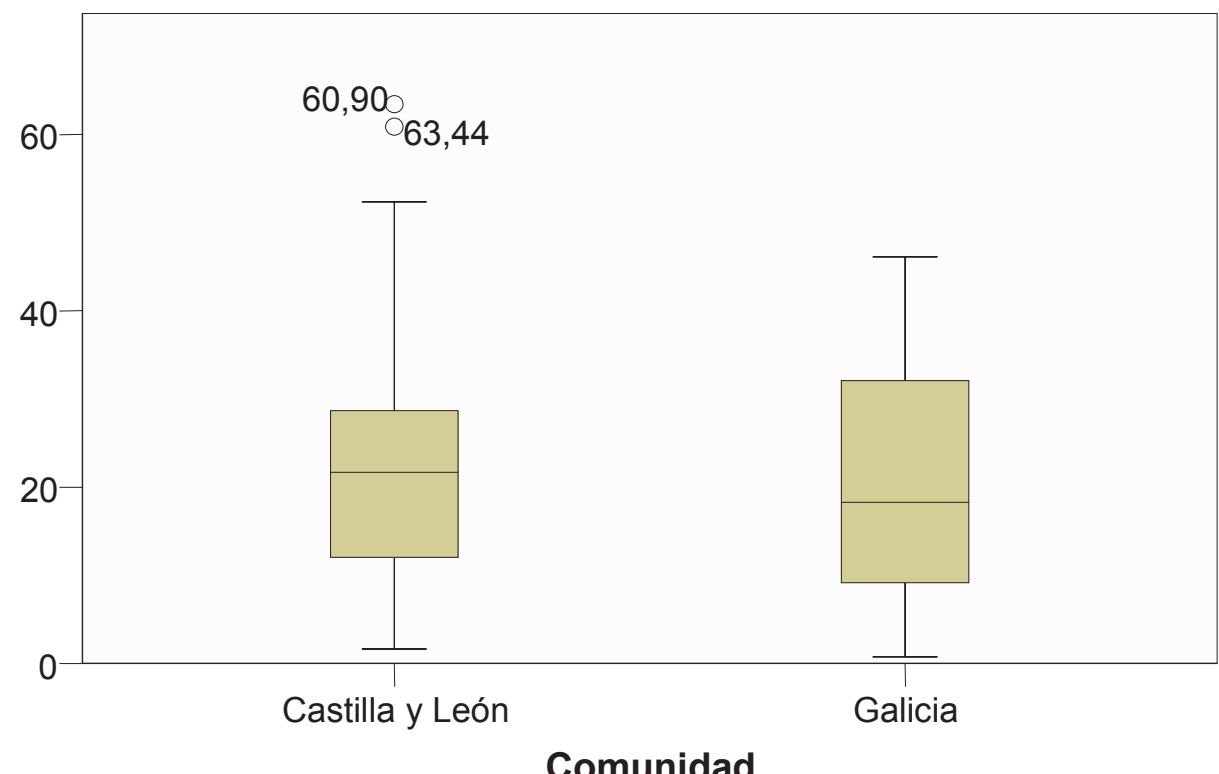


Gráfico 31. Diagrama de cajas del porcentaje de archivo según comunidades

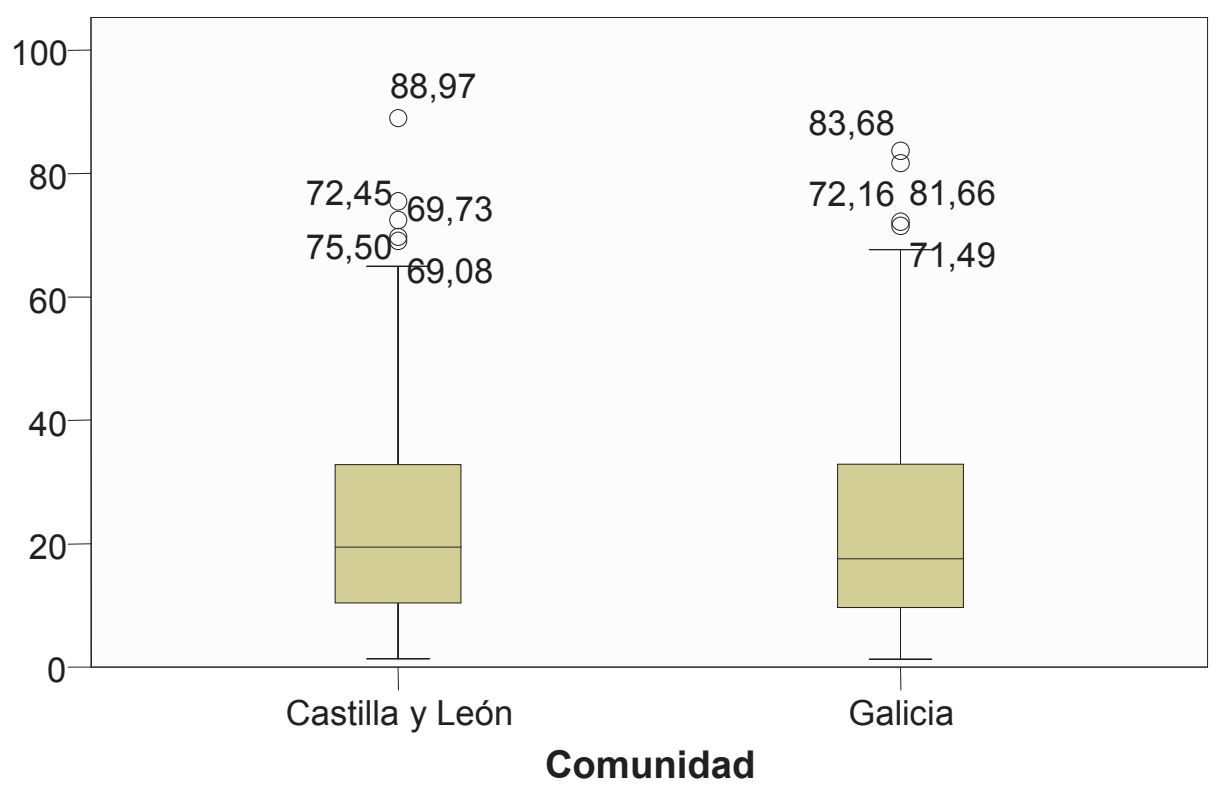

Gráfico 32. Diagrama de cajas del porcentaje de segundas fuentes según comunidades

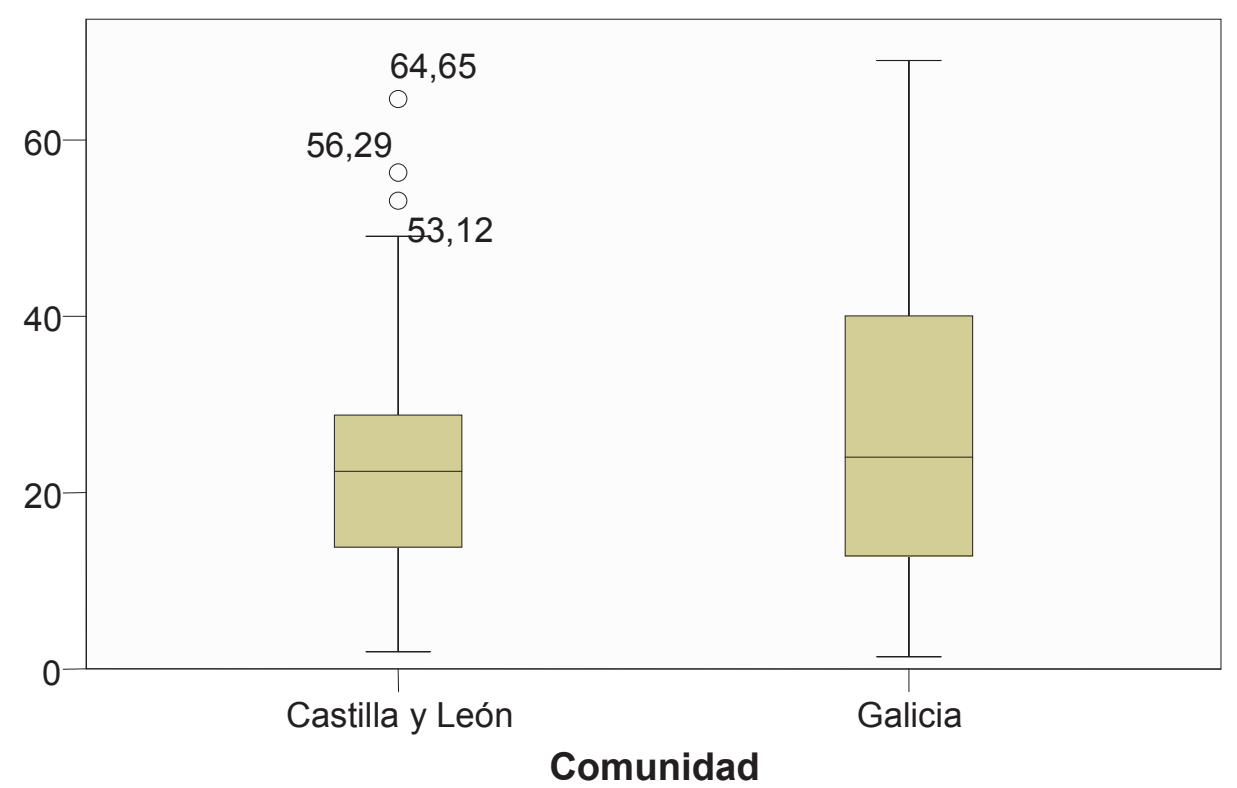

Fuente: elaboración propia a partir de los resultados del programa estadístico SPSS. 


\subsubsection{ENLACES}

Se ha querido comprobar si las informaciones periodísticas en internet acerca de la salud y la sanidad incluyen enlaces dentro del texto a otras noticias relacionadas para promover la contextualización o plena información sobre un determinado asunto. Únicamente el $7,13 \%$ de todas las estudiadas contenían al menos un vínculo a otro artículo o aclaración, por lo que la mayor parte (el 92,88\% restante) no incluyen atajos de este tipo.

Tabla 187. Frecuencia y porcentaje de la inserción de enlaces

\begin{tabular}{|l|r|r|}
\hline \multicolumn{1}{|c|}{ Enlaces } & Frecuencia & Porcentaje \\
\hline Con enlaces & 57 & 7,13 \\
\hline Sin enlaces & 743 & 92,88 \\
\hline Total & 800 & 100,00 \\
\hline
\end{tabular}

Fuente: elaboración propia a partir de los resultados del programa estadístico SPSS.

\section{Gráfico 33. Porcentaje de informaciones con enlaces}

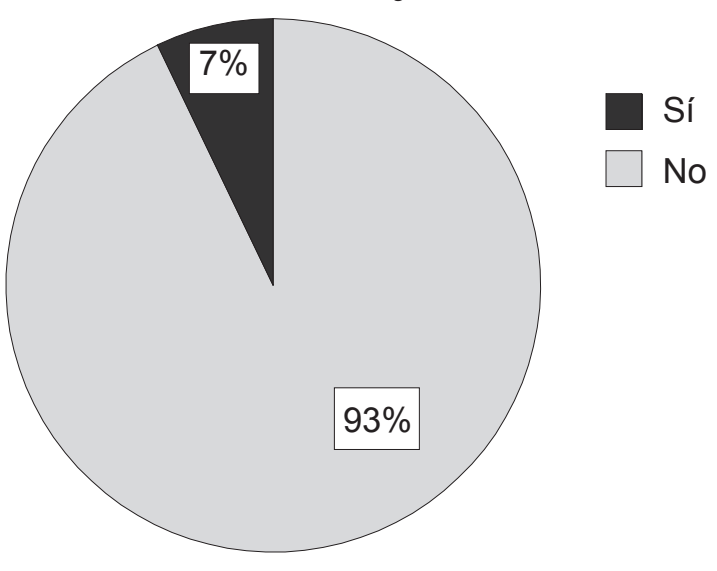

Fuente: elaboración propia a partir de los resultados del programa estadístico SPSS.

Entre las 57 informaciones que poseen algún enlace, la que ofrece un mayor cómputo asciende a 14, mientras que las que proporcionan el mínimo se queda en uno. La moda, es decir, el número que más veces se repite, es uno, al igual que la mediana. En concreto, se han hallado 32 textos que ofrecen un solo vínculo (el 56,14\% de los que facilitan esta función) y 12 proporcionan dos (21,05\%). A partir de ahí, las frecuencias son considerablemente más bajas: cinco informaciones ofrecen tres cada una $(8,77 \%)$, un texto proporciona cuatro enlaces $(1,75 \%)$ y cuatro composiciones periodísticas suministran cinco (7,02\%). También se han dado casos individuales de 6, 10 y 14 
enlaces $(1,75 \%$ cada uno). En total, la media entre aquellas informaciones que, efectivamente, tienen esta prestación, se sitúa en 2,2 y lo normal es que se desvíe un máximo de 2,3 vínculos.

Tabla 188. Estadísticos descriptivos del número de enlaces

\begin{tabular}{|l|r|r|r|r|r|r|r|r|}
\hline Variable & $\mathbf{N}^{\mathbf{o}}$ & Mínimo & Máximo & Suma & Media & Desv. típ. & Moda & Mediana \\
\hline $\begin{array}{l}\text { Número de } \\
\text { enlaces }\end{array}$ & 57 & 1 & 14 & 125 & 2,19 & 2,31 & 1 & 1 \\
\hline
\end{tabular}

Fuente: elaboración propia a partir de los resultados del programa estadístico SPSS.

Tabla 189. Frecuencia y porcentaje del número de enlaces en las informaciones

\begin{tabular}{|c|c|c|c|c|}
\hline $\begin{array}{c}\text { Posibilidad } \\
\text { de insertar } \\
\text { enlaces }\end{array}$ & $\begin{array}{l}\text { Número de } \\
\text { enlaces }\end{array}$ & Frecuencia & Porcentaje & $\begin{array}{l}\text { Porcentaje } \\
\text { válido }\end{array}$ \\
\hline \multirow{9}{*}{ Sí } & 1 & 32 & 4 & 56,14 \\
\hline & 2 & 12 & 1,50 & 21,05 \\
\hline & 3 & 5 & 0,63 & 8,77 \\
\hline & 4 & 1 & 0,13 & 1,75 \\
\hline & 5 & 4 & 0,50 & 7,02 \\
\hline & 6 & 1 & 0,13 & 1,75 \\
\hline & 10 & 1 & 0,13 & 1,75 \\
\hline & 14 & 1 & 0,13 & 1,75 \\
\hline & Total & 57 & 7,13 & 100,00 \\
\hline \multicolumn{2}{|l|}{ No } & 743 & 92,88 & - \\
\hline \multicolumn{2}{|l|}{ Total } & 800 & 100,00 & - \\
\hline
\end{tabular}

Fuente: elaboración propia a partir de los resultados del programa estadístico SPSS.

Divididos por región, los periódicos no muestran apenas diferencias. Veintiocho de las 400 informaciones analizadas en Castilla y León poseen al menos un enlace, mientras que Galicia cuenta con solo uno más, es decir, 29. En porcentajes sobre el número de textos totales con vínculos, se corresponde con el $49,12 \%$ y el 50,88\%, respectivamente. Vistas las semejanzas que arrojan ambas comunidades, no se han hallado relaciones significativas $(\mathrm{r}=0,891)$. 
Tabla 190. Tabla de contingencia entre enlaces y comunidad

\begin{tabular}{|l|l|r|r|r|}
\hline \multirow{2}{*}{\multicolumn{2}{|c|}{ Enlaces }} & \multicolumn{2}{c|}{ Comunidad } & \multirow{2}{*}{ Total } \\
\cline { 3 - 5 } \multicolumn{2}{|c|}{} & $\begin{array}{c}\text { Castilla y } \\
\text { León }\end{array}$ & Galicia & \\
\hline \multirow{3}{*}{ Con enlaces } & Recuento & 28 & 29 & 57 \\
& $\%$ de enlaces & $49,12 \%$ & $50,88 \%$ & $100,00 \%$ \\
& $\%$ de comunidad & $7,00 \%$ & $7,25 \%$ & $7,13 \%$ \\
\hline \multirow{3}{*}{ Sin enlaces } & Recuento & 372 & 371 & 743 \\
& $\%$ de enlaces & $50,07 \%$ & $49,93 \%$ & $100,00 \%$ \\
& $\%$ de comunidad & $93,00 \%$ & $92,75 \%$ & $92,88 \%$ \\
\hline \multirow{3}{*}{ Total } & Recuento & 400 & 400 & 800 \\
& $\%$ de enlaces & $50,00 \%$ & $50,00 \%$ & $100,00 \%$ \\
& $\%$ de comunidad & $100,00 \%$ & $100,00 \%$ & $100,00 \%$ \\
\hline
\end{tabular}

Fuente: elaboración propia a partir de los resultados del programa estadístico SPSS.

Donde sí que se han detectado desigualdades es en el número de nexos que incorporan los periodistas de cada comunidad. Los castellano-leoneses tienden a incluir una menor cantidad (la media se sitúa en 1,57), en comparación con los gallegos, que suelen incorporar más (de media, 2,79). Por ejemplo, mientras que ningún diario en la primera región incluye más de cinco enlaces, en la segunda se han detectado hasta 14 en una sola noticia. Así, mientras que en una sola ocasión un periódico de Castilla y León incorpora cuatro o más vínculos, Galicia suma un total de nueve composiciones. Estas diferencias tan marcadas hacen que se obtenga una relación significativa entre el número de enlaces y la comunidad autónoma de donde proviene la información $(\mathrm{r}=0,045)$.

Tabla 191. Estadísticos descriptivos del número de enlaces según comunidades

\begin{tabular}{|l|r|r|r|r|}
\hline \multicolumn{1}{|c|}{ Comunidad } & \multicolumn{1}{c|}{$\mathbf{N}^{\mathbf{o}}$} & Media & Desv. típ. & Error típ. \\
\hline Castilla y León & 28 & 1,57 & 0,96 & 0,18 \\
\hline Galicia & 29 & 2,79 & 3,00 & 0,56 \\
\hline
\end{tabular}

Fuente: elaboración propia a partir de los resultados del programa estadístico SPSS. 
Tabla 192. Prueba T-student para muestras independientes entre el número de enlaces y comunidad

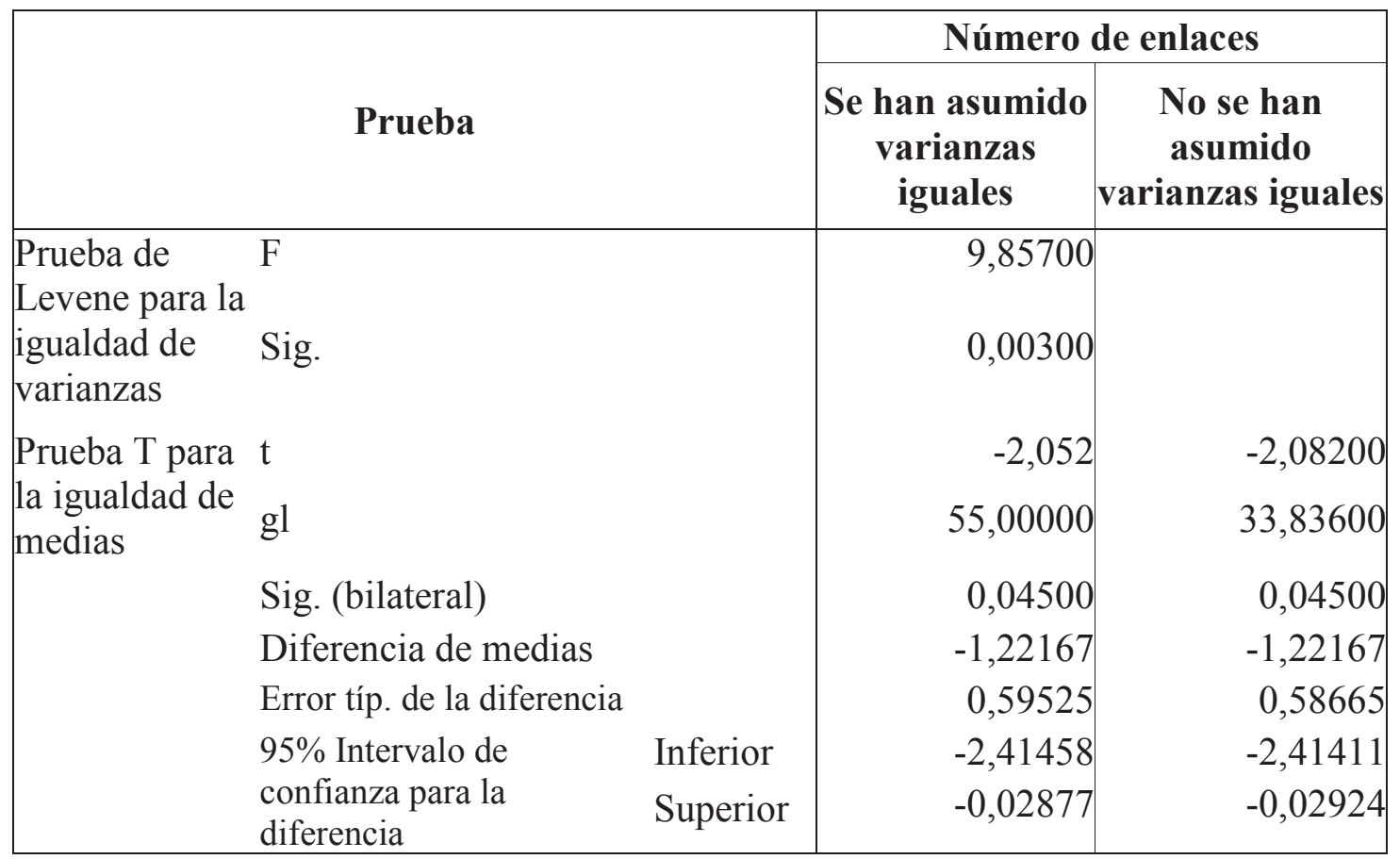

Fuente: elaboración propia a partir de los resultados del programa estadístico SPSS.

Tabla 193. Tabla de contingencia entre número de enlaces y comunidades

\begin{tabular}{|c|c|c|c|c|}
\hline \multirow{2}{*}{\multicolumn{2}{|c|}{ Número de enlaces }} & \multicolumn{2}{|c|}{ Comunidad } & \multirow[b]{2}{*}{ Total } \\
\hline & & $\begin{array}{l}\text { Castilla y } \\
\text { León }\end{array}$ & Galicia & \\
\hline \multirow{3}{*}{1} & क्षाता & 18 & 14 & 32 \\
\hline & de enlaces & $56,25 \%$ & $43,75 \%$ & $100,00 \%$ \\
\hline & $\%$ de comunidad & $64,29 \%$ & $48,28 \%$ & $56,14 \%$ \\
\hline \multirow{3}{*}{2} & & 6 & 6 & 12 \\
\hline & $\%$ de enlaces & $50,00 \%$ & $50,00 \%$ & $100,00 \%$ \\
\hline & $\%$ de comunidad & $21,43 \%$ & $20,69 \%$ & $21,05 \%$ \\
\hline \multirow{3}{*}{ ( } & & 3 & 2 & 5 \\
\hline & & $60,00 \%$ & $40,00 \%$ & $100,00 \%$ \\
\hline & $\%$ de comunidad & $10,71 \%$ & $6,90 \%$ & $8,77 \%$ \\
\hline \multirow{3}{*}{4} & Recuento & 0 & 1 & \\
\hline & & $0,00 \%$ & $100,00 \%$ & $100,00 \%$ \\
\hline & $\%$ de comunidad & $0,00 \%$ & $3,45 \%$ & $1,75 \%$ \\
\hline \multirow{3}{*}{ P } & Recuento & 1 & 3 & 4 \\
\hline & & $25,00 \%$ & $75,00 \%$ & $100,00 \%$ \\
\hline & $\%$ de comunidad & $3,57 \%$ & $10,34 \%$ & $7,02 \%$ \\
\hline
\end{tabular}




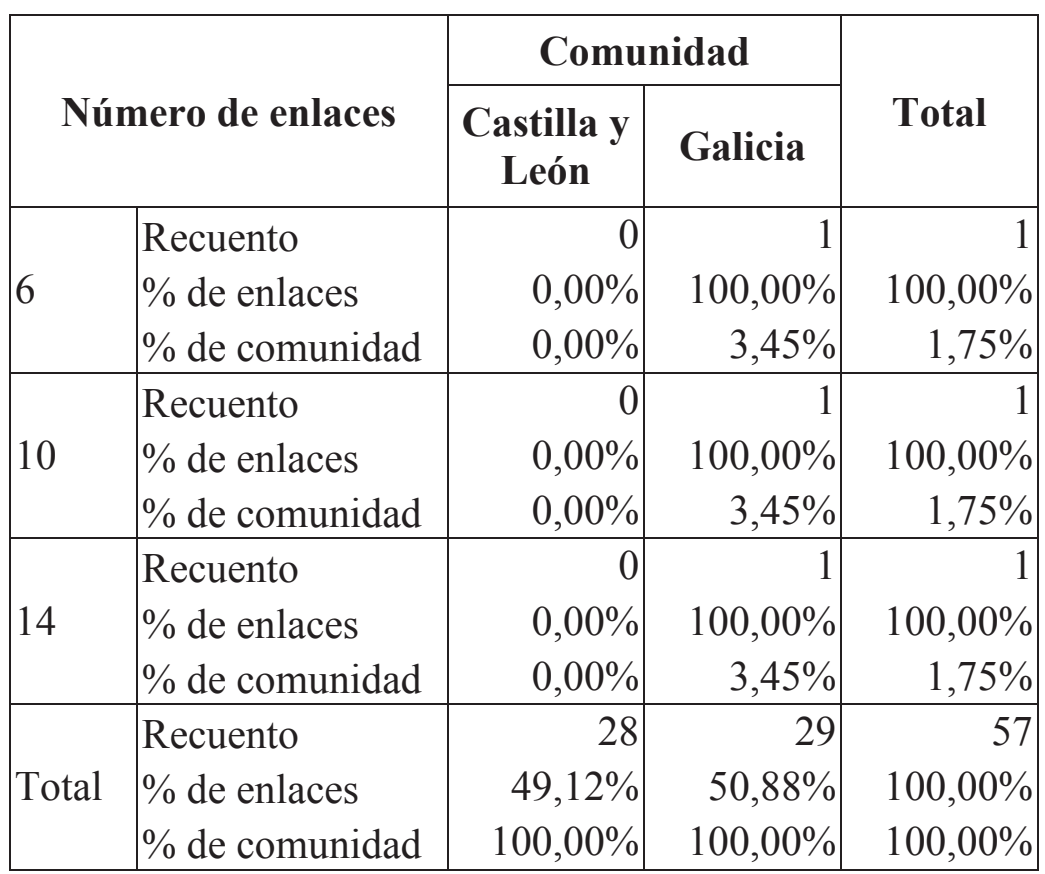

Fuente: elaboración propia a partir de los resultados del programa estadístico SPSS.

Al realizar un diagrama de cajas, no obstante, se observa que las frecuencias iguales o mayores de seis son casos extremos e incluso que las de cuatro o cinco enlaces son casos atípicos. Debido a estos resultados extremos, no se puede considerar completamente fiable que Galicia incluya un mayor número de enlaces en sus informaciones.

Gráfico 34. Diagrama de cajas del número de enlaces

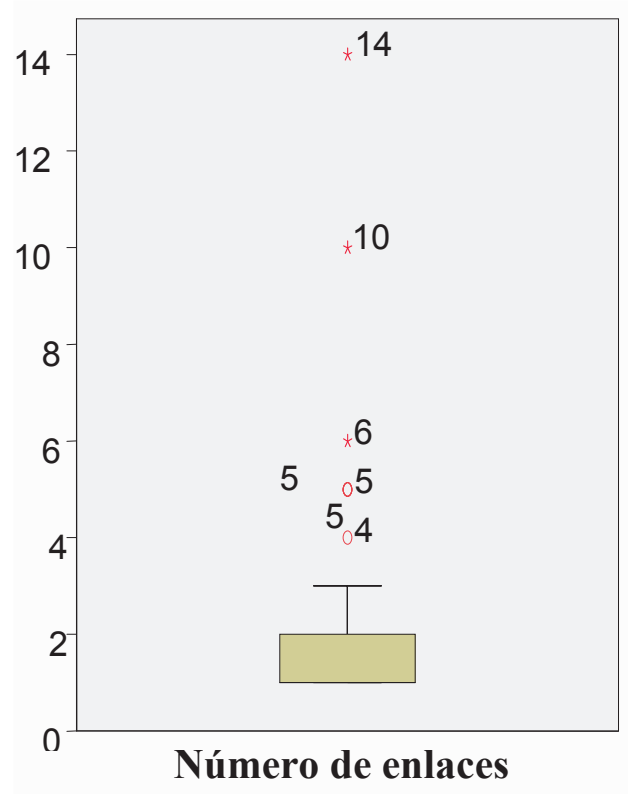

Fuente: elaboración propia a partir de los resultados del programa estadístico SPSS. 


\subsubsection{INTERACCIÓN DEL LECTOR}

\subsection{COMENTARIOS}

En más de la mitad de las informaciones analizadas, los lectores tienen la posibilidad de dejar algún comentario. Más concretamente, se corresponde con el $57,63 \%$ de la muestra. En el resto de casos, no se ofrece esta opción. Pese a todo, solo dos de cada diez noticias que proporcionan este servicio han sido comentadas por algún lector (el 18,66\%). Es decir, de las 800 noticias analizadas, únicamente 86 contenían alguna opinión.

Tabla 194. Frecuencia y porcentaje de las informaciones que permiten insertar comentarios

\begin{tabular}{|l|l|r|r|r|}
\hline $\begin{array}{c}\text { Posibilidad de } \\
\text { dejar comentarios }\end{array}$ & Comentarios & Frecuencia & Porcentaje & $\begin{array}{c}\text { Porcentaje } \\
\text { válido }\end{array}$ \\
\hline \multirow{3}{*}{ Sí } & Sí & 86 & 10,75 & 18,66 \\
& No & 375 & 46,88 & 81,34 \\
& Total & 461 & 57,63 & 100,00 \\
\hline No & 339 & 42,38 & - \\
\hline \multicolumn{2}{|l|}{ Total } & 800 & 100,00 & - \\
\hline
\end{tabular}

Fuente: elaboración propia a partir de los resultados del programa estadístico SPSS.

Lo más normal es que un artículo tenga un solo comentario, aunque se han detectado hasta 178 en la misma información. Se trata de una noticia aparecida en La Voz de Galicia el 5 de mayo de 2012 sobre una iniciativa parlamentaria presentada por el PSdeG para cesar al valedor do Pobo. De media, hay 7,60 opiniones por cada caso analizado.

Tabla 195. Número de comentarios de lectores

\begin{tabular}{|l|r|r|r|r|r|r|r|r|}
\hline \multicolumn{1}{|c|}{ Variable } & $\mathbf{N}^{\mathbf{0}}$ & Mínimo & Máximo & Suma & Media & $\begin{array}{c}\text { Desv. } \\
\text { tín. }\end{array}$ & Moda & Mediana \\
\hline $\begin{array}{l}\text { Comentarios } \\
\text { de lectores }\end{array}$ & 86 & 1 & 178 & 654 & 7,60 & 19,73 & 1 & 3 \\
\hline
\end{tabular}

Fuente: elaboración propia a partir de los resultados del programa estadístico SPSS.

Divididos por comunidad, Castilla y León ofrece más informaciones con posibilidad de introducir comentarios (concretamente el 67,25\%) que Galicia, que proporciona este servicio en algo menos de la mitad de sus noticias (48\%). De hecho, la relación entre la comunidad castellana y la libertad de insertar opiniones es significativa $(\mathrm{r}=0,000$ y coeficiente de contingencia $=0,191)$. 
Tabla 196. Tabla de contingencia entre la posibilidad de insertar comentarios y la comunidad

\begin{tabular}{|l|l|r|r|r|}
\hline \multirow{2}{*}{$\begin{array}{c}\text { Posibilidad de dejar } \\
\text { comentarios }\end{array}$} & \multicolumn{2}{c|}{ Comunidad } & \multirow{2}{*}{ Total } \\
\cline { 3 - 4 } & $\begin{array}{c}\text { Castilla y } \\
\text { León }\end{array}$ & Galicia & \\
\hline \multirow{3}{*}{ Sí } & Recuento & 269 & 192 & 461 \\
& $\%$ de comentarios & $58,35 \%$ & $41,65 \%$ & $100,00 \%$ \\
& $\%$ de comunidad & $67,25 \%$ & $48,00 \%$ & $57,63 \%$ \\
\hline \multirow{3}{*}{ No } & Recuento & 131 & 208 & 339 \\
& $\%$ de comentarios & $38,64 \%$ & $61,36 \%$ & $100,00 \%$ \\
& $\%$ de comunidad & $32,75 \%$ & $52,00 \%$ & $42,38 \%$ \\
\hline \multirow{3}{*}{ Total } & Recuento & 400 & 400 & 800 \\
& $\%$ de comentarios & $50,00 \%$ & $50,00 \%$ & $100,00 \%$ \\
& $\%$ de comunidad & $100,00 \%$ & $100,00 \%$ & $100,00 \%$ \\
\hline
\end{tabular}

Fuente: elaboración propia a partir de los resultados del programa estadístico SPSS.

Tabla 197. Prueba de chi-cuadrado entre la posibilidad de insertar comentarios y la comunidad

\begin{tabular}{|l|r|r|r|r|r|}
\hline \multicolumn{1}{|c|}{ Prueba } & Valor & gl & $\begin{array}{c}\text { Sig. asintótica } \\
\text { (bilateral) }\end{array}$ & $\begin{array}{c}\text { Sig. exacta } \\
\text { (bilateral) }\end{array}$ & $\begin{array}{c}\text { Sig. exacta } \\
\text { (unilateral) }\end{array}$ \\
\hline Chi-cuadrado de Pearson & 30,351 & 1 & 0,000 & & \\
Corrección por continuidad & 29,568 & 1 & 0,000 & & \\
Razón de verosimilitudes & 30,565 & 1 & 0,000 & & \\
Estadístico exacto de & & & & 0,000 & 0,000 \\
Fisher & & & & & \\
Asociación lineal por lineal & 30,313 & 1 & 0,000 & & \\
N de casos válidos & 800,000 & & & & \\
\hline
\end{tabular}

Fuente: elaboración propia a partir de los resultados del programa estadístico SPSS.

Tabla 198. Medidas simétricas de la prueba de chi-cuadrado entre la posibilidad de insertar comentarios y la comunidad

\begin{tabular}{|c|c|c|c|c|c|}
\hline \multicolumn{2}{|c|}{ Prueba } & Valor & $\begin{array}{c}\text { Error típ. } \\
\text { asint. }\end{array}$ & $\begin{array}{c}\mathbf{T} \\
\text { aproximada }\end{array}$ & $\begin{array}{c}\text { Sig. } \\
\text { aproximada }\end{array}$ \\
\hline Nominal por nominal & $\begin{array}{l}\text { Coeficiente de } \\
\text { contingencia }\end{array}$ & 0,191 & & & 0,000 \\
\hline $\begin{array}{l}\text { Intervalo por } \\
\text { intervalo }\end{array}$ & R de Pearson & 0,195 & 0,035 & 5,610 & 0,000 \\
\hline $\begin{array}{l}\text { Ordinal por ordinal } \\
\mathrm{N} \text { de casos válidos }\end{array}$ & $\begin{array}{l}\text { Correlación de } \\
\text { Spearman }\end{array}$ & $\begin{array}{r}0,195 \\
800,000\end{array}$ & 0,035 & 5,610 & 0,000 \\
\hline
\end{tabular}

Fuente: elaboración propia a partir de los resultados del programa estadístico SPSS. 


\section{Gráfico 35. Número de informaciones que ofrecen la posibilidad de insertar comentarios según comunidades}

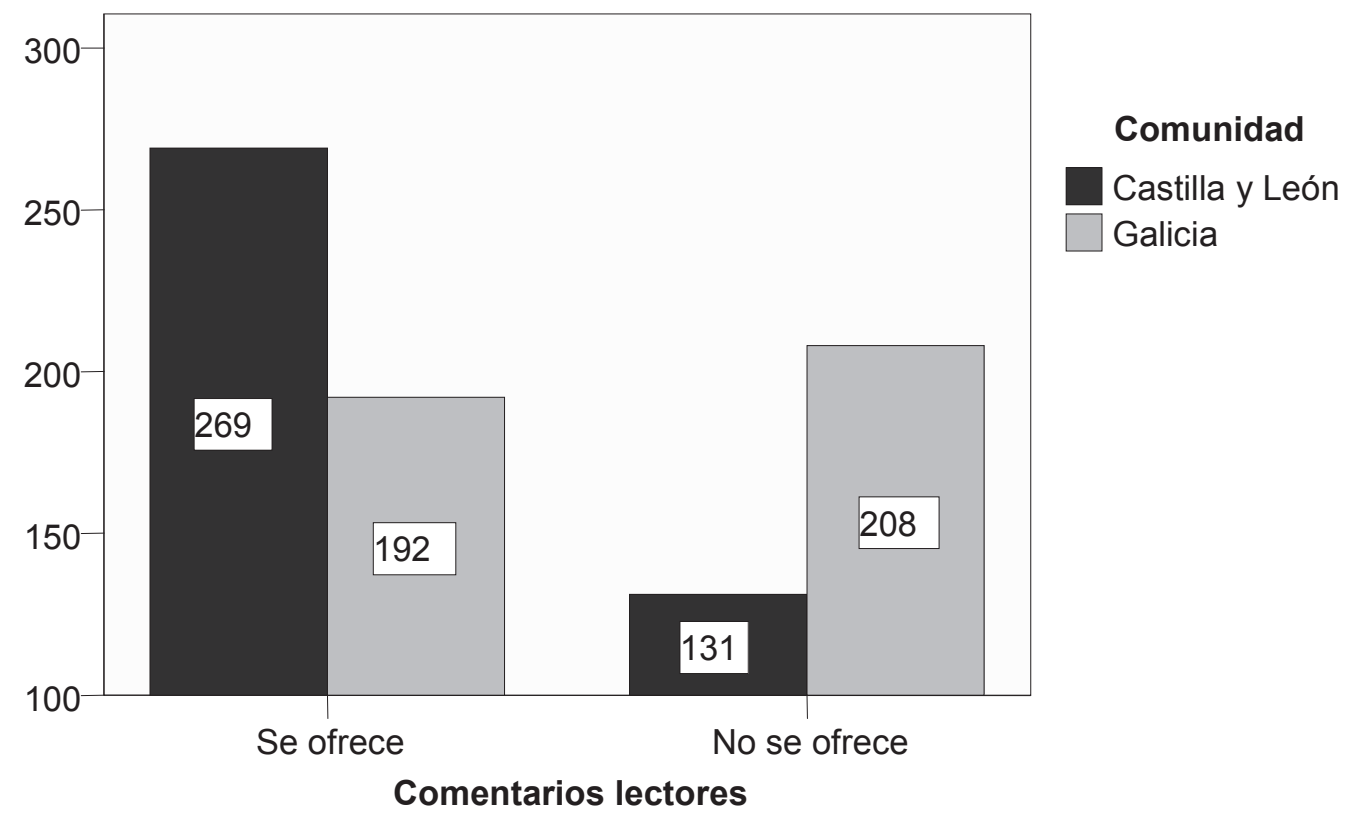

Fuente: elaboración propia a partir de los resultados del programa estadístico SPSS.

No obstante, cuando se dejan de lado las informaciones que no facilitan esta posibilidad, no hay diferencias significativas $(r=0,980)$ entre los lectores castellanoleoneses y gallegos en su inserción de comentarios. Aun así, la frecuencia sigue siendo más alta en la primera región (20,82\%) que en la segunda (15,63\%). En Castilla y León se han detectado 56 informaciones con al menos un comentario y en Galicia, 30.

Tabla 199. Tabla de contingencia entre comentarios y comunidad

\begin{tabular}{|l|l|r|r|r|}
\hline \multicolumn{2}{|c|}{ Comentarios de lectores } & \multicolumn{2}{|c|}{ Comunidad } & \multirow{2}{*}{ Total } \\
\cline { 3 - 4 } \multicolumn{2}{|c|}{$\begin{array}{c}\text { Castilla y } \\
\text { León }\end{array}$} & Galicia & \\
\hline \multirow{3}{*}{ Sí } & Recuento & 56 & 30 & 86 \\
& $\%$ de comentarios & $65,12 \%$ & $34,88 \%$ & $100,00 \%$ \\
& $\%$ de comunidad & $20,82 \%$ & $15,63 \%$ & $18,66 \%$ \\
\hline \multirow{3}{*}{ No } & Recuento & 213 & 162 & 375 \\
& $\%$ de comentarios & $56,80 \%$ & $43,20 \%$ & $100,00 \%$ \\
& $\%$ de comunidad & $79,18 \%$ & $84,38 \%$ & $81,34 \%$ \\
\hline \multirow{4}{*}{ Total } & Recuento & 269 & 192 & 461 \\
& $\%$ de comentarios & $58,35 \%$ & $41,65 \%$ & $100,00 \%$ \\
& $\%$ de comunidad & $100,00 \%$ & $100,00 \%$ & $100,00 \%$ \\
\hline
\end{tabular}

Fuente: elaboración propia a partir de los resultados del programa estadístico SPSS. 


\section{Número de comentarios}

Que se hayan encontrado 86 informaciones con comentarios de los lectores no significa que la cifra de opiniones se quede en ese número. Aunque la mayor parte de los textos ofrecen únicamente una sola (más concretamente, 27 de las 86 que permiten esta opción, es decir, el 31,4\%), hay algunos que cuentan con decenas (que suman un 18,7\%). Hay una información que contiene 40 opiniones y otra que suma 178. En el primer caso, se trata de una composición aparecida el 8 de octubre de 2012 en La Gaceta de Salamanca sobre el cierre de dos plantas en los hospitales de Los Montalvos y Virgen de la Vega. La información con 178 comentarios, por su parte, apareció en La Voz de Galicia el 5 de mayo de ese mismo año y trata sobre la iniciativa parlamentaria del PSdeG para cesar al Valedor do Pobo, Benigno López, por entender que respalda los recortes en educación y sanidad, como se ha visto.

Tabla 200. Frecuencia y porcentaje del número de comentarios

\begin{tabular}{|l|r|r|r|}
\hline $\begin{array}{c}\text { Número de } \\
\text { comentarios }\end{array}$ & Frecuencia & Porcentaje & $\begin{array}{c}\text { Porcentaje } \\
\text { válido }\end{array}$ \\
\hline 1 & 27 & 3,38 & 31,40 \\
\hline 2 & 12 & 1,50 & 13,95 \\
\hline 3 & 7 & 0,88 & 8,14 \\
\hline 4 & 8 & 1,00 & 9,30 \\
\hline 5 & 4 & 0,50 & 4,65 \\
\hline 6 & 3 & 0,38 & 3,49 \\
\hline 7 & 4 & 0,50 & 4,65 \\
\hline 8 & 1 & 0,13 & 1,16 \\
\hline 9 & 2 & 0,25 & 2,33 \\
\hline 10 & 2 & 0,25 & 2,33 \\
\hline 11 & 2 & 0,25 & 2,33 \\
\hline 13 & 2 & 0,25 & 2,33 \\
\hline 14 & 1 & 0,13 & 1,16 \\
\hline 15 & 4 & 0,50 & 4,65 \\
\hline 16 & 2 & 0,25 & 2,33 \\
\hline 17 & 1 & 0,13 & 1,16 \\
\hline 22 & 1 & 0,13 & 1,16 \\
\hline 27 & 1 & 0,13 & 1,16 \\
\hline 40 & 1 & 0,13 & 1,16 \\
\hline 178 & 1 & 0,13 & 1,16 \\
\hline Total & 86 & 10,75 & 100,00 \\
\hline Perdidos & 714 & 89,25 & - \\
\hline Total & 800 & 100,00 & - \\
\hline
\end{tabular}

Fuente: elaboración propia a partir de los resultados del programa estadístico SPSS. 
En total, se han contabilizado 654 opiniones, quedando la media en 7,60 y la mediana (es decir, el punto central del total de las informaciones), en 3. En cualquier caso, tal y como se comprueba con un diagrama de cajas, aquellos resultados que ofrecen más de 17 comentarios son considerados atípicos y los que tienen más de 27 , extremos, por lo que no pueden considerarse frecuencias fiables.

\section{Gráfico 36. Diagrama de cajas del número de comentarios}

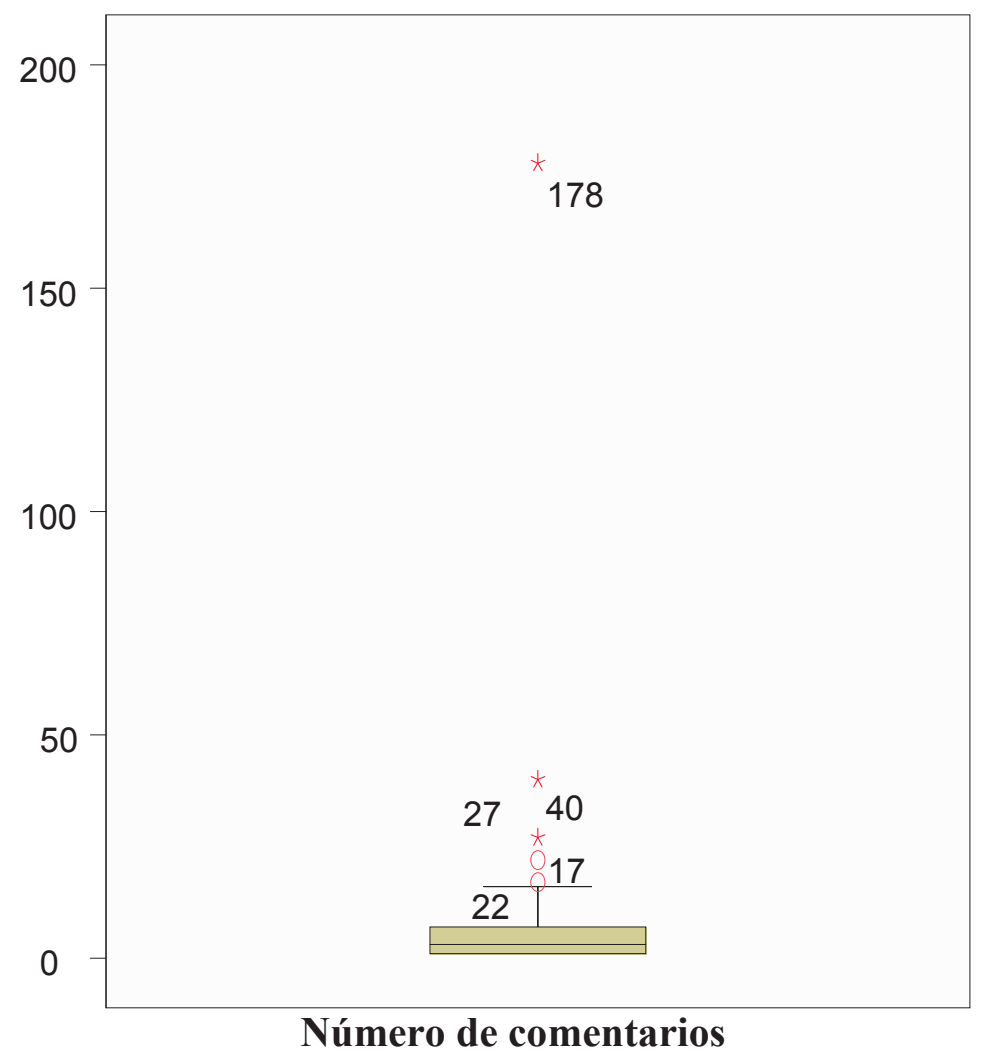

Fuente: elaboración propia a partir de los resultados del programa estadístico SPSS.

Tanto si te tienen en cuenta como si no se contemplan los casos extremos, no se han hallado disconformidades en el número de comentarios según la región de donde procede la noticia. Tomando como referencia la segunda opción, las 29 de Galicia que poseían al menos una opinión arrojan una media de 5,66, más de un punto por encima del 4,54 que proporciona Castilla y León. A pesar de esta desigualdad, no se han manifestado diferencias significativas en la Prueba $T$ para muestras independientes, que determina si existe una relación entre una variable cualitativa (en este caso, la comunidad), con una cuantitativa (el número de comentarios). 
Tabla 201. Estadísticos descriptivos del número de comentarios según comunidades

\begin{tabular}{|l|r|r|r|r|}
\hline \multicolumn{1}{|c|}{ Comunidad } & Frecuencia & Media & Desviación típ. & $\begin{array}{c}\text { Error típ. } \\
\text { de la media }\end{array}$ \\
\hline Castilla y León & 54 & 4,54 & 4,33 & 0,59 \\
\hline Galicia & 29 & 5,66 & 6,04 & 1,12 \\
\hline
\end{tabular}

Fuente: elaboración propia a partir de los resultados del programa estadístico SPSS.

Tabla 202. Prueba T-student para muestras independientes entre el número de comentarios y las comunidades

\begin{tabular}{|c|c|c|c|}
\hline & & Número come & ntarios lectores \\
\hline & Prueba & $\begin{array}{c}\text { Se han asumido } \\
\text { varianzas } \\
\text { iguales }\end{array}$ & $\begin{array}{c}\text { No se han } \\
\text { asumido } \\
\text { varianzas iguales }\end{array}$ \\
\hline $\begin{array}{l}\text { Prueba de Levene } \\
\text { para la igualdad de } \\
\text { varianzas }\end{array}$ & $\mathrm{F}$ & 6,12200 & \\
\hline & Sig. & 0,01500 & \\
\hline $\begin{array}{l}\text { Prueba T para la } \\
\text { igualdad de medias }\end{array}$ & & $-0,97300$ & $-0,88200$ \\
\hline & $\mathrm{gl}$ & 81,00000 & 43,83600 \\
\hline & Sig. (bilateral) & 0,33300 & 0,38300 \\
\hline & Diferencia de medias & $-1,11814$ & $-1,11814$ \\
\hline & Error típ. de la diferencia & 1,14910 & 1,26772 \\
\hline & $95 \%$ Intervalo de Inferior & $-3,40449$ & $-3,67332$ \\
\hline & $\begin{array}{l}\text { confianza para la Superior } \\
\text { diferencia }\end{array}$ & 1,16822 & 1,43705 \\
\hline
\end{tabular}

Fuente: elaboración propia a partir de los resultados del programa estadístico SPSS.

\subsection{VOTOS}

Un total de 537 noticias (es decir, el 67,13\%) permiten a los lectores votar y valorar el contenido, normalmente mediante una escala de 1 a 5 a través de estrellas. De esas 537 informaciones, 212 contienen, efectivamente, al menos un voto, lo que supone el $39,48 \%$ de las que ofrecen esta posibilidad. En cambio, la mayor parte $(60,52 \%)$ no poseen ninguna valoración, a pesar de suministrar este servicio. 
Tabla 203. Frecuencia y porcentaje de votos

\begin{tabular}{|l|l|r|r|r|}
\hline $\begin{array}{c}\text { Posibilidad } \\
\text { de votar }\end{array}$ & Votos & Frecuencia & Porcentaje & $\begin{array}{c}\text { Porcentaje } \\
\text { válido }\end{array}$ \\
\hline \multirow{3}{*}{ Sí } & No & 325 & 40,63 & 60,52 \\
\cline { 2 - 5 } & Sí & 212 & 26,50 & 39,48 \\
\cline { 2 - 5 } & Total & 537 & 67,13 & 100,00 \\
\hline No & 263 & 32,88 & - \\
\hline \multicolumn{2}{|l|}{ Total } & 800 & 100,00 & \\
\hline
\end{tabular}

Fuente: elaboración propia a partir de los resultados del programa estadístico SPSS.

Dividiendo estos porcentajes por comunidad autónoma, se observa que en Galicia los lectores suelen votar más a menudo que en Castilla y León. Mientras que en la primera comunidad hay una tasa de valoración del 45,45\%, en la segunda la cifra baja hasta el $29,95 \%$. Es decir, el 70,75\% de todos los textos que contienen al menos una valoración (y que, efectivamente, ofrecen este servicio) provienen de la región gallega.

Tabla 204. Tabla de contingencia entre votos y comunidad

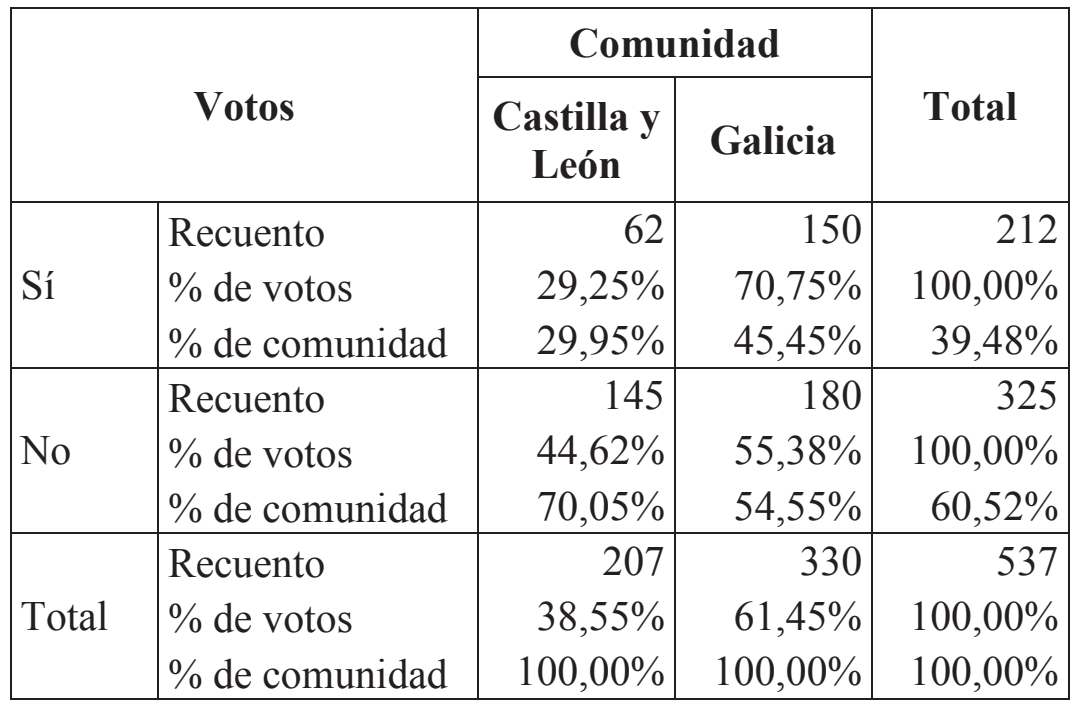

Fuente: elaboración propia a partir de los resultados del programa estadístico SPSS.

De hecho, la diferencia es tan marcada que se ha encontrado una relación significativa. Así, realizando una prueba chi-cuadrado se encuentra una significación bilateral de 0,000 y un coeficiente de contingencia de 0,153 . 
Tabla 205. Prueba de chi-cuadrado entre votos y comunidad

\begin{tabular}{|l|r|r|r|r|r|}
\hline \multicolumn{1}{|c|}{ Prueba } & Valor & gl & $\begin{array}{c}\text { Sig. asintótica } \\
\text { (bilateral) }\end{array}$ & $\begin{array}{l}\text { Sig. exacta } \\
\text { (bilateral) }\end{array}$ & $\begin{array}{l}\text { Sig. exacta } \\
\text { (unilateral) }\end{array}$ \\
\hline Chi-cuadrado de Pearson & 12,796 & 1 & 0,000 & & \\
Corrección por continuidad & 12,155 & 1 & 0,000 & & \\
Razón de verosimilitudes & 13,009 & 1 & 0,000 & & \\
Estadístico exacto de & & & & 0,000 & 0,000 \\
Fisher & & & & & \\
Asociación lineal por lineal & 12,772 & 1 & 0,000 & & \\
N de casos válidos & 537,000 & & & & \\
\hline
\end{tabular}

Fuente: elaboración propia a partir de los resultados del programa estadístico SPSS.

Tabla 206. Medidas simétricas de la prueba de chi-cuadrado entre votos y comunidad

\begin{tabular}{|ll|r|r|r|r|}
\hline \multicolumn{2}{|c|}{ Prueba } & Valor & \multicolumn{1}{c|}{$\begin{array}{c}\text { Error típ. } \\
\text { asint. }\end{array}$} & \multicolumn{1}{c|}{$\begin{array}{c}\text { T } \\
\text { aproximada }\end{array}$} & \multicolumn{1}{c|}{$\begin{array}{c}\text { Sig. } \\
\text { aproximada }\end{array}$} \\
\hline $\begin{array}{lll}\text { Nominal por nominal } \\
\text { Contingencia } \\
\text { contervalo por }\end{array}$ & 0,153 & & & 0,000 \\
$\begin{array}{ll}\text { intervalo } \\
\text { R de Pearson }\end{array}$ & 0,154 & 0,042 & 3,614 & 0,000 \\
Ordinal por ordinal & $\begin{array}{l}\text { Correlación de } \\
\text { S de casos válidos }\end{array}$ & 0,154 & 0,042 & 3,614 & 0,000 \\
\hline
\end{tabular}

Fuente: elaboración propia a partir de los resultados del programa estadístico SPSS.

\section{Número de votos}

En total, se han contabilizado 1.346 votos en las 171 informaciones que permitían esta opción. La noticia con el menor número (exceptuando las que no contenían ninguna) posee una, mientras que la que refleja más sube hasta las 100. En este caso, se trata de una boda entre dos homosexuales, uno de ellos en estado grave en la UCI del hospital Xeral de Vigo, publicada por La Voz de Galicia el 26 de septiembre de 2012.

Tabla 207. Estadísticos descriptivos del número de votos

\begin{tabular}{|l|r|r|r|r|r|r|r|r|}
\hline \multicolumn{1}{|c|}{ Variable } & $\mathbf{N}^{\mathbf{0}}$ & Mínimo & Máximo & Suma & Media & Desv. típ. & Moda & Mediana \\
\hline $\begin{array}{l}\text { Número de } \\
\text { votos }\end{array}$ & 171 & 1 & 100 & 1.346 & 7,87 & 11,32 & 1 & 4 \\
\hline
\end{tabular}

Fuente: elaboración propia a partir de los resultados del programa estadístico SPSS.

Este cómputo tan elevado hace que la media ascienda a 7,87, cuando la mediana se queda en 4. La moda, no obstante, se sitúa en uno. Esto significa que el número de votos más frecuente es uno. También es bastante habitual que aparezcan dos (reuniendo el $16,96 \%$ de los casos en los que se ofrece la posibilidad de votar) o cinco $(14,04 \%)$. 
Tabla 208. Frecuencia y porcentaje del número de votos

\begin{tabular}{|c|c|c|c|c|}
\hline Votos & \begin{tabular}{|c|}
$\begin{array}{c}\text { Número de } \\
\text { votos }\end{array}$ \\
\end{tabular} & Frecuencia & Porcentaje & \begin{tabular}{|c|}
$\begin{array}{c}\text { Porcentaje } \\
\text { válido }\end{array}$ \\
\end{tabular} \\
\hline \multirow{36}{*}{ Sí } & 1 & 33 & 4,13 & 19,30 \\
\hline & 2 & 29 & 3,63 & 16,96 \\
\hline & 3 & 15 & 1,88 & 8,77 \\
\hline & 4 & 11 & 1,38 & 6,43 \\
\hline & 5 & 24 & 3,00 & 14,04 \\
\hline & 6 & 5 & 0,63 & 2,92 \\
\hline & 7 & 3 & 0,38 & 1,75 \\
\hline & 8 & 8 & 1,00 & 4,68 \\
\hline & 9 & 2 & 0,25 & 1,17 \\
\hline & 10 & 4 & 0,50 & 2,34 \\
\hline & 11 & 5 & 0,63 & 2,92 \\
\hline & 12 & 1 & 0,13 & 0,58 \\
\hline & 13 & 2 & 0,25 & 1,17 \\
\hline & 14 & 4 & 0,50 & 2,34 \\
\hline & 15 & 1 & 0,13 & 0,58 \\
\hline & 16 & 1 & 0,13 & 0,58 \\
\hline & 17 & 1 & 0,13 & 0,58 \\
\hline & 18 & 1 & 0,13 & 0,58 \\
\hline & 19 & 1 & 0,13 & 0,58 \\
\hline & 20 & 2 & 0,25 & 1,17 \\
\hline & 21 & 2 & 0,25 & 1,17 \\
\hline & 22 & 3 & 0,38 & 1,75 \\
\hline & 23 & 1 & 0,13 & 0,58 \\
\hline & 25 & 1 & 0,13 & 0,58 \\
\hline & 26 & 1 & 0,13 & 0,58 \\
\hline & 28 & 1 & 0,13 & 0,58 \\
\hline & 29 & 1 & 0,13 & 0,58 \\
\hline & 30 & 1 & 0,13 & 0,58 \\
\hline & 31 & 1 & 0,13 & 0,58 \\
\hline & 32 & 1 & 0,13 & 0,58 \\
\hline & 34 & 1 & 0,13 & 0,58 \\
\hline & 39 & 1 & 0,13 & 0,58 \\
\hline & 45 & 1 & 0,13 & 0,58 \\
\hline & 49 & 1 & 0,13 & 0,58 \\
\hline & 100 & 1 & 0,13 & 0,58 \\
\hline & Total & 171 & 21,38 & 100,00 \\
\hline \multirow{3}{*}{ No } & 0 & 326 & 40,75 & \\
\hline & No se ofrece & 303 & 37,88 & \\
\hline & Total & 629 & 78,63 & \\
\hline Total & & 800 & 100,00 & \\
\hline
\end{tabular}

Fuente: elaboración propia a partir de los resultados del programa estadístico SPSS. 
A través de un diagrama de cajas se puede comprobar que las informaciones que poseen 28 o más votos son considerados casos extremos, y las que registran entre $19 \mathrm{y}$ 27, atípicos. Por ello, a la hora de hacer el estudio de la diferencia en el número de valoraciones entre una comunidad y otra, no se tendrán en cuenta los casos extremos, ya que desvirtuarían el resultado.

\section{Gráfico 37. Diagrama de cajas del número de votos}

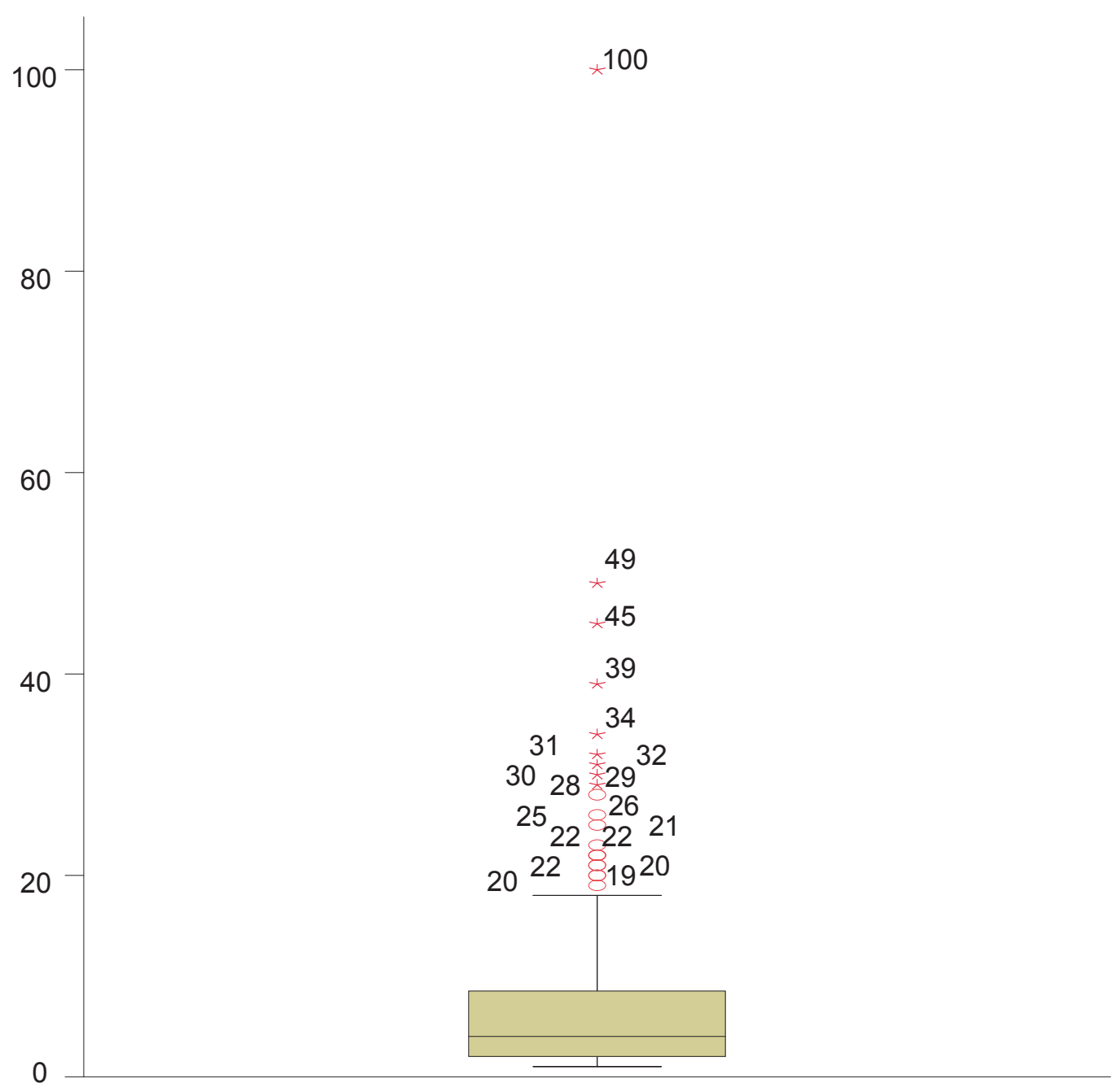

Fuente: elaboración propia a partir de los resultados del programa estadístico SPSS.

La media de número de votos en Castilla y León es de 1,52, mientras que en Galicia se sitúa en $2,18^{\underline{26}}$. A pesar de esta discrepancia, no se trata de una relación significativa

26 Para obtener unos resultados lo más fieles a la realidad, se han incluido en el cómputo las informaciones que no contaban con ningún voto. 
$(\mathrm{r}=0,820)$, por lo que se puede concretar que no hay diferencias estadísticamente fiables en el número de votos de los lectores según la región ${ }^{27}$.

Tabla 209. Estadísticos descriptivos del número de votos según comunidades

\begin{tabular}{|l|l|l|l|l|}
\hline \multicolumn{1}{|c|}{ Comunidad } & \multicolumn{1}{|c|}{$\mathbf{N}^{\mathbf{0}}$} & \multicolumn{1}{|c|}{ Media } & Desv. típ. & Error típ. \\
\hline Castilla y León & 201 & 1,52 & 3,79 & 0,28 \\
Galicia & 286 & 2,18 & 4,61 & 0,27 \\
\hline
\end{tabular}

Fuente: elaboración propia a partir de los resultados del programa estadístico SPSS.

Tabla 210. Prueba T-student para muestras independientes entre el número de votos y las comunidades

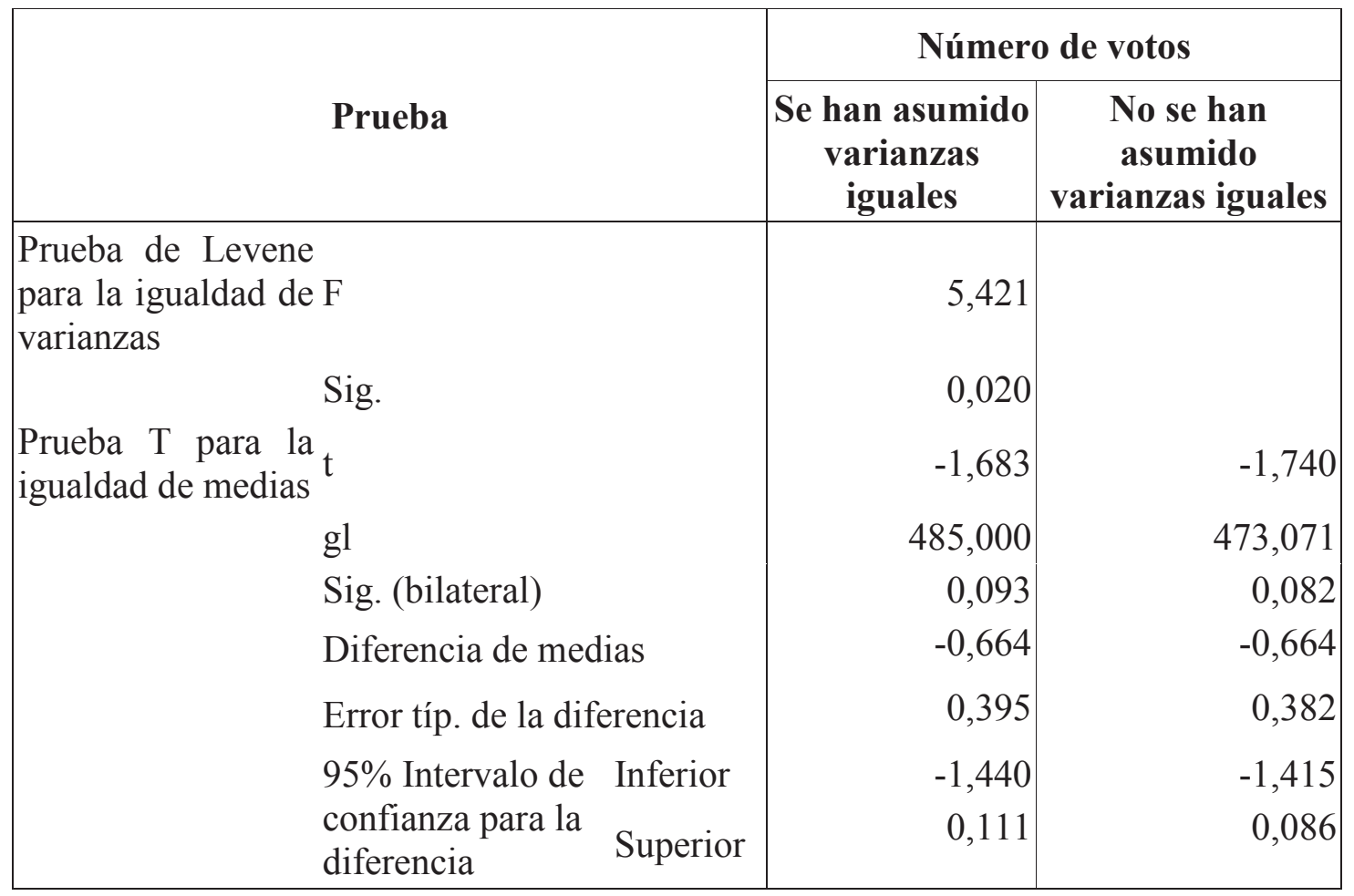

Fuente: elaboración propia a partir de los resultados del programa estadístico SPSS.

\footnotetext{
${ }^{27}$ El número de noticias en este caso no coincide con el cómputo de aquellas que ofrecen esta posibilidad. Esto es debido a que algunos periódicos no revelan el número de personas que han votado una noticia, aunque sí que proporcionan el resultado de la valoración.
} 


\subsection{VALORACIÓN DE LA NOTICIA}

Observando la valoración de las composiciones que, efectivamente, contienen algún voto, se comprueba que la media se sitúa en 7,60 sobre 10 (con una desviación típica por encima o por debajo de 2,38), aunque lo más habitual es que posean un 10 sobre una escala del mismo nivel (35,55\% de los casos). La mediana, en este caso, se queda muy cerca de la media: en 8 .

Tabla 211. Estadísticos descriptivos de la valoración de los votos

\begin{tabular}{|c|c|r|r|r|r|r|r|}
\hline Variable & \multicolumn{1}{|c|}{$\mathbf{N}^{\mathbf{0}}$} & Mínimo & Máximo & Media & Desv. típ. & Moda & Mediana \\
\hline Valoración & 211 & 2 & 10 & 7,60 & 2,38 & 10 & 8 \\
\hline
\end{tabular}

Fuente: elaboración propia a partir de los resultados del programa estadístico SPSS.

Tabla 212. Frecuencia y porcentaje de la valoración de los votos

\begin{tabular}{|c|c|c|c|c|}
\hline Votos & Valoración & Frecuencia & Porcentaje & $\begin{array}{c}\text { Porcentaje } \\
\text { válido }\end{array}$ \\
\hline \multirow{10}{*}{ Sí } & 2 & 14 & 1,75 & 6,64 \\
\hline & 3 & 1 & 0,13 & 0,47 \\
\hline & 4 & 9 & 1,13 & 4,27 \\
\hline & 5 & 4 & 0,50 & 1,90 \\
\hline & 6 & 51 & 6,38 & 24,17 \\
\hline & 7 & 4 & 0,50 & 1,90 \\
\hline & 8 & 45 & 5,63 & 21,33 \\
\hline & 9 & 8 & 1,00 & 3,79 \\
\hline & 10 & 75 & 9,38 & 35,55 \\
\hline & Total & 211 & 26,38 & 100,00 \\
\hline \multirow{3}{*}{ No } & Sin votos & 326 & 40,75 & - \\
\hline & No se ofrece & 263 & 32,88 & - \\
\hline & Total & 589 & 73,63 & - \\
\hline \multicolumn{2}{|l|}{ Total } & 800 & 100,00 & - \\
\hline
\end{tabular}

Fuente: elaboración propia a partir de los resultados del programa estadístico SPSS.

Si se aglutinan las valoraciones por grupos de clasificación en suspenso (0-4), aprobado (5-6), notable (7-8) y sobresaliente (9-10), se evidencia que lo más habitual es que las informaciones se puntúen muy positivamente con un sobresaliente $(39,34 \%)$, aunque hay una amplia muestra que obtiene un aprobado $(26,07 \%)$ y un notable $(23,22 \%)$. En cualquier caso, prácticamente todas se encuentran en cinco o más; es decir, que cuentan con un aprobado (en el 88,64\% de los casos), respecto al 11,37\% que reciben un suspenso. 
Tabla 213. Frecuencia y porcentaje del tipo de valoración

\begin{tabular}{|l|r|r|}
\hline Valoración & Número & Porcentaje \\
\hline Suspenso & 24 & 11,37 \\
\hline Aprobado & 55 & 26,07 \\
\hline Notable & 49 & 23,22 \\
\hline Sobresaliente & 83 & 39,34 \\
\hline Total & 211 & 100,00 \\
\hline
\end{tabular}

Fuente: elaboración propia a partir de los resultados del programa estadístico SPSS.

Las medias de cada comunidad no difieren demasiado: mientras que en Castilla y León se sitúa en 7,12, en Galicia es ligeramente mayor: 7,77. Por ello, no se han encontrado diferencias significativas $(\mathrm{r}=0,099)$. Este resultado implica que no hay discrepancias estadísticamente fiables entre los lectores de las comunidades en la valoración que le otorgan a las noticias una vez se deciden a evaluarlas.

Tabla 214. Estadísticos descriptivos de la valoración de los votos según comunidades

\begin{tabular}{|l|r|r|r|r|}
\hline \multicolumn{1}{|c|}{ Comunidad } & $\mathbf{N}^{\mathbf{0}}$ & Media & Desv. típ. & Error típ. \\
\hline Castilla y León & 62 & 7,18 & 2,49 & 0,316 \\
\hline Galicia & 149 & 7,77 & 2,32 & 0,190 \\
\hline
\end{tabular}

Fuente: elaboración propia a partir de los resultados del programa estadístico SPSS.

Tabla 215. Prueba T-student para muestras independientes la valoración de los votos y las comunidades

\begin{tabular}{|c|c|c|c|}
\hline \multirow{2}{*}{\multicolumn{2}{|c|}{ Prueba }} & \multicolumn{2}{|c|}{ Valoración } \\
\hline & & \begin{tabular}{|c|} 
Se han asumido \\
varianzas \\
iguales
\end{tabular} & $\begin{array}{c}\text { No se han } \\
\text { asumido } \\
\text { varianzas iguales }\end{array}$ \\
\hline \multicolumn{2}{|c|}{$\begin{array}{l}\text { Prueba de Levene } \\
\text { para la igualdad de F } \\
\text { varianzas }\end{array}$} & 1,3060 & \\
\hline & Sig. & 0,2540 & \\
\hline \multirow{7}{*}{$\begin{array}{l}\text { Prueba T para la } \\
\text { igualdad de medias }\end{array}$} & & $-1,6590$ & $-1,6120$ \\
\hline & $\mathrm{gl}$ & 209,0000 & 107,4970 \\
\hline & Sig. (bilateral) & 0,0990 & 0,1100 \\
\hline & Diferencia de medias & $-0,5944$ & $-0,5944$ \\
\hline & Error típ. de la diferencia & 0,3584 & 0,3686 \\
\hline & $95 \%$ Intervalo de Inferior & $-1,3009$ & $-1,3251$ \\
\hline & $\begin{array}{l}\text { confianza para la Superio } \\
\text { diferencia }\end{array}$ & 0,1121 & 0,1363 \\
\hline
\end{tabular}

Fuente: elaboración propia a partir de los resultados del programa estadístico SPSS. 


\subsection{RECOMENDACIONES EN FACEBOOK}

Más de la mitad de las informaciones analizadas (el 62,5\%) permiten compartir el texto con un vínculo directo a una cuenta de la red social Facebook. Las que no ofrecen este servicio se quedan, por lo tanto, en un $37,5 \%$ del total.

Tabla 216. Frecuencia y porcentaje de la posibilidad de compartir la información en Facebook

\begin{tabular}{|l|r|r|}
\hline Posibilidad de compartir & Frecuencia & Porcentaje \\
\hline Sí & 500 & 62,50 \\
\hline No & 300 & 37,50 \\
\hline Total & 800 & 100,00 \\
\hline
\end{tabular}

Fuente: elaboración propia a partir de los resultados del programa estadístico SPSS.

No obstante, la mayoría de las noticias no se vinculan a ningún perfil personal de Facebook: el 65,8\% de los artículos que suministran esta posibilidad no registran ningún enlace. Únicamente 3,4 de cada 10 informaciones relativas a la salud o a la sanidad que posibilitan este servicio son redireccionadas a la red social.

Tabla 217. Frecuencia y porcentaje de las recomendaciones en Facebook

\begin{tabular}{|l|l|r|r|r|}
\hline $\begin{array}{c}\text { Posibilidad de } \\
\text { recomendar en } \\
\text { Facebook }\end{array}$ & Recomendaciones & Frecuencia & Porcentaje & $\begin{array}{c}\text { Porcentaje } \\
\text { válido }\end{array}$ \\
\hline \multirow{2}{*}{ Sí } & Sí & 171 & 21,38 & 34,20 \\
\cline { 2 - 5 } & No & 329 & 41,13 & 65,80 \\
\cline { 2 - 5 } & Total & 500 & 62,50 & 100,00 \\
\hline No & 300 & 37,50 & - \\
\hline \multicolumn{2}{|c|}{ Total } & 800 & 100,00 & - \\
\hline
\end{tabular}

Fuente: elaboración propia a partir de los resultados del programa estadístico SPSS.

Divididos por regiones, se comprueba que los diarios gallegos ofrecen más informaciones con posibilidades de vinculación a Facebook. Concretamente, 273 noticias (el 68,25\% de las 400 analizadas en Galicia) proporcionan este servicio, en comparación con las 227 (56,75\%) de Castilla y León. De hecho, la relación resulta ser significativa $(\mathrm{r}=0,001$ y coeficiente de contingencia $=0,118)$. 
Tabla 218. Tabla de contingencia entre la posibilidad de compartir en Facebook y la comunidad

\begin{tabular}{|l|l|r|r|r|}
\hline \multicolumn{2}{|c|}{ Comunidad } & \multicolumn{2}{c|}{$\begin{array}{c}\text { Posibilidad de } \\
\text { compartir en }\end{array}$} & \multirow{2}{*}{ Total } \\
\cline { 3 - 4 } & \multicolumn{1}{|c|}{ No } & \multicolumn{1}{c|}{ Sí } & \\
\hline \multirow{3}{*}{ Castilla y León } & Recuento & 173 & 227 & 400 \\
& $\%$ de comunidad & $43,25 \%$ & $56,75 \%$ & $100,00 \%$ \\
& $\%$ de Facebook & $57,67 \%$ & $45,40 \%$ & $50,00 \%$ \\
\hline \multirow{3}{*}{ Galicia } & Recuento & 127 & 273 & 400 \\
& \% de comunidad & $31,75 \%$ & $68,25 \%$ & $100,00 \%$ \\
& $\%$ de Facebook & $42,33 \%$ & $54,60 \%$ & $50,00 \%$ \\
\hline \multirow{3}{*}{ Total } & Recuento & 300 & 500 & 800 \\
& $\%$ de comunidad & $37,50 \%$ & $62,50 \%$ & $100,00 \%$ \\
& $\%$ de Facebook & $100,00 \%$ & $100,00 \%$ & $100,00 \%$ \\
\hline
\end{tabular}

Fuente: elaboración propia a partir de los resultados del programa estadístico SPSS.

Tabla 219. Prueba de chi-cuadrado entre la posibilidad de compartir en Facebook y la comunidad

\begin{tabular}{|l|r|r|r|r|r|}
\hline \multicolumn{1}{|c|}{ Prueba } & Valor & gl & $\begin{array}{c}\text { Sig. asintótica } \\
\text { (bilateral) }\end{array}$ & $\begin{array}{l}\text { Sig. exacta } \\
\text { (bilateral) }\end{array}$ & $\begin{array}{l}\text { Sig. exacta } \\
\text { (unilateral) }\end{array}$ \\
\hline Chi-cuadrado de Pearson & 11,285 & 1 & 0,001 & & \\
Corrección por continuidad & 10,800 & 1 & 0,001 & & \\
Razón de verosimilitudes & 11,319 & 1 & 0,001 & & 0,000 \\
$\begin{array}{l}\text { Estadístico exacto de } \\
\text { Fisher }\end{array}$ & & & & 0,001 & \\
Asociación lineal por lineal & 11,271 & 1 & 0,001 & & \\
N de casos válidos & 800,000 & & & & \\
\hline
\end{tabular}

Fuente: elaboración propia a partir de los resultados del programa estadístico SPSS.

Tabla 220. Medidas simétricas de la prueba de chi-cuadrado entre la posibilidad de compartir en Facebook y la comunidad

\begin{tabular}{|c|c|c|c|c|c|}
\hline \multicolumn{2}{|l|}{ Prueba } & Valor & $\begin{array}{c}\text { Error típ. } \\
\text { asint. }\end{array}$ & \begin{tabular}{|c|}
$\mathbf{T}$ \\
aproximada
\end{tabular} & \begin{tabular}{|c|} 
Sig. \\
aproximada
\end{tabular} \\
\hline Nominal por nominal & $\begin{array}{l}\text { Coeficiente de } \\
\text { contingencia }\end{array}$ & 0,118 & & & 0,001 \\
\hline $\begin{array}{l}\text { Intervalo por } \\
\text { intervalo }\end{array}$ & R de Pearson & 0,119 & 0,035 & 3,379 & 0,001 \\
\hline $\begin{array}{l}\text { Ordinal por ordinal } \\
\mathrm{N} \text { de casos válidos }\end{array}$ & $\begin{array}{l}\text { Correlación de } \\
\text { Spearman }\end{array}$ & $\begin{array}{r}0,119 \\
800,000\end{array}$ & 0,035 & 3,379 & 0,001 \\
\hline
\end{tabular}

Fuente: elaboración propia a partir de los resultados del programa estadístico SPSS. 


\section{Gráfico 38. Número de informaciones con posibilidad de compartir en Facebook según comunidades}

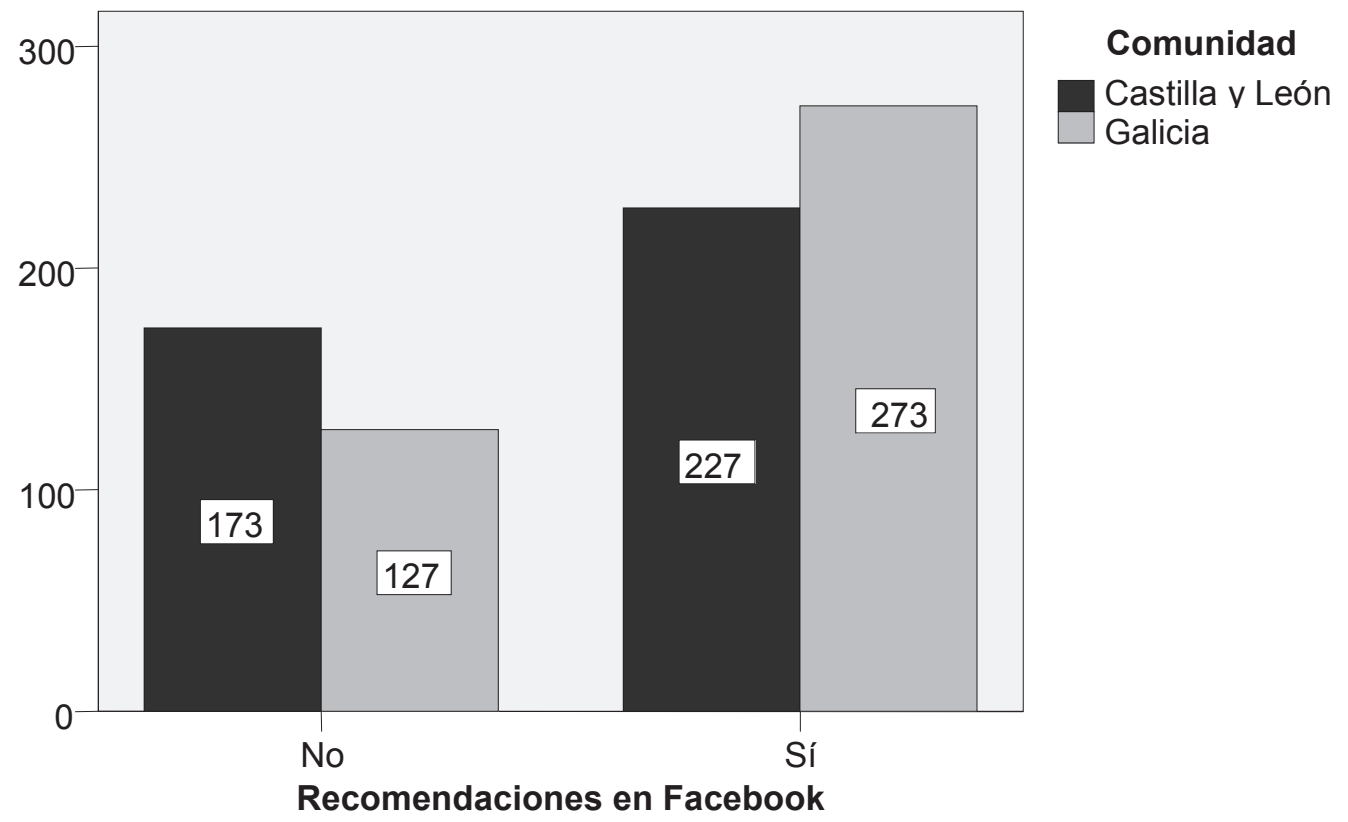

Fuente: elaboración propia a partir de los resultados del programa estadístico SPSS.

Galicia, además de contar con un cómputo mayor de informaciones con posibilidad de redireccionar a Facebook, también tiene el número más alto de recomendaciones a esta red social. Un total de 103 textos de los 171 que se han hallado con al menos una referencia de este tipo provienen de esta comunidad, lo que supone el 60,23\%. Castilla y León, en cambio, con 68, aglutina el 39,77\%.

Respecto al porcentaje en relación a las noticias de cada comunidad, en ambos casos, las informaciones con al menos una recomendación en Facebook no llegan a la mitad, aunque en Galicia la relación es más alta que en Castilla y León. La primera región registra un 37,73\% de textos con recomendaciones frente al 29,96\% de la segunda. Estas diferencias, no obstante, no son estadísticamente significativas $(\mathrm{r}=0,068)$. 
Tabla 221. Tabla de contingencia entre las recomendaciones en Facebook y comunidad

\begin{tabular}{|l|l|r|r|r|}
\hline \multirow{2}{*}{ Recomendaciones en Facebook } & \multicolumn{2}{|c|}{ Comunidad } & \multirow{2}{*}{ Total } \\
\cline { 3 - 4 } \multicolumn{2}{|c|}{$\begin{array}{c}\text { Castilla y } \\
\text { León }\end{array}$} & Galicia & \\
\hline \multirow{3}{*}{ No } & Recuento & 159 & 170 & 329 \\
& $\%$ de recomendaciones & $48,33 \%$ & $51,67 \%$ & $100,00 \%$ \\
& $\%$ de comunidad & $70,04 \%$ & $62,27 \%$ & $65,80 \%$ \\
\hline \multirow{3}{*}{ Sí } & Recuento & 68 & 103 & 171 \\
& $\%$ de recomendaciones & $39,77 \%$ & $60,23 \%$ & $100,00 \%$ \\
& $\%$ de comunidad & $29,96 \%$ & $37,73 \%$ & $34,20 \%$ \\
\hline \multirow{3}{*}{ Total } & Recuento & 227 & 273 & 500 \\
& $\%$ de recomendaciones & $45,40 \%$ & $54,60 \%$ & $100,00 \%$ \\
& $\%$ de comunidad & $100,00 \%$ & $100,00 \%$ & $100,00 \%$ \\
\hline
\end{tabular}

Fuente: elaboración propia a partir de los resultados del programa estadístico SPSS.

En total, se han encontrado 2.438 vínculos en Facebook en las 800 noticias que componen el muestreo. El mínimo de redirecciones que se ha hallado en una sola información es 1, mientras que el máximo asciende a 377 . Se trata de un texto publicado en La Voz de Galicia el 26 de septiembre de 2012 sobre un estudio que revela restos de antidepresivos y ansiolíticos en el agua de Galicia. Aunque lo más normal es que una información contenga únicamente una recomendación (en el 19,30\% de los casos que tienen al menos una), la media se sitúa en 14,26 y la mediana, en 5.

Tabla 222. Estadísticos descriptivos de las recomendaciones en Facebook

\begin{tabular}{|c|r|r|r|r|r|r|r|r|}
\hline Variable & $\mathbf{N}^{\mathbf{0}}$ & Mínimo & Máximo & Suma & Media & $\begin{array}{c}\text { Desv. } \\
\text { típ. }\end{array}$ & Moda & Mediana \\
\hline $\begin{array}{l}\text { Recomendaciones } \\
\text { en Facebook }\end{array}$ & 171 & 1 & 377 & 2438 & 14,26 & 35,31 & 1 & 5 \\
\hline
\end{tabular}

Fuente: elaboración propia a partir de los resultados del programa estadístico SPSS. 
Tabla 223. Frecuencia y porcentaje del número de recomendaciones en Facebook

\begin{tabular}{|c|c|c|c|c|}
\hline $\begin{array}{l}\text { Posibilidad de } \\
\text { recomendar en } \\
\text { Facebook } \\
\end{array}$ & $\begin{array}{l}\mathrm{N}^{\mathrm{o}} \mathrm{de} \\
\text { recomendaciones }\end{array}$ & Frecuencia & Porcentaje & $\begin{array}{l}\text { Porcentaje } \\
\text { válido }\end{array}$ \\
\hline \multirow[t]{42}{*}{ - conor } & 1 & 33 & 4,13 & 19,30 \\
\hline & 2 & 20 & 2,50 & 11,70 \\
\hline & 3 & 16 & 2,00 & 9,36 \\
\hline & 4 & 13 & 1,63 & 7,60 \\
\hline & 5 & 14 & 1,75 & 8,19 \\
\hline & 6 & 10 & 1,25 & 5,85 \\
\hline & \begin{tabular}{|l|}
7 \\
\end{tabular} & 9 & 1,13 & 5,26 \\
\hline & 8 & 3 & 0,38 & 1,75 \\
\hline & 9 & 4 & 0,50 & 2,34 \\
\hline & 10 & 5 & 0,63 & 2,92 \\
\hline & 11 & 4 & 0,50 & 2,34 \\
\hline & 12 & 1 & 0,13 & 0,58 \\
\hline & 13 & 3 & 0,38 & 1,75 \\
\hline & 14 & 3 & 0,38 & 1,75 \\
\hline & 16 & 1 & 0,13 & 0,58 \\
\hline & 17 & 2 & 0,25 & 1,17 \\
\hline & 18 & 3 & 0,38 & 1,75 \\
\hline & 20 & 1 & 0,13 & 0,58 \\
\hline & 21 & 1 & 0,13 & 0,58 \\
\hline & 22 & 1 & 0,13 & 0,58 \\
\hline & 23 & 2 & 0,25 & 1,17 \\
\hline & 27 & 1 & 0,13 & 0,58 \\
\hline & 28 & 1 & 0,13 & 0,58 \\
\hline & 29 & 1 & 0,13 & 0,58 \\
\hline & 31 & 1 & 0,13 & 0,58 \\
\hline & 32 & 1 & 0,13 & 0,58 \\
\hline & 33 & 1 & 0,13 & 0,58 \\
\hline & 36 & 2 & 0,25 & 1,17 \\
\hline & 40 & 1 & 0,13 & 0,58 \\
\hline & 43 & 1 & 0,13 & 0,58 \\
\hline & 50 & 1 & 0,13 & 0,58 \\
\hline & 58 & 1 & 0,13 & 0,58 \\
\hline & 61 & 2 & 0,25 & 1,17 \\
\hline & 62 & 1 & 0,13 & 0,58 \\
\hline & 63 & 1 & 0,13 & 0,58 \\
\hline & 74 & 1 & 0,13 & 0,58 \\
\hline & 97 & 1 & 0,13 & 0,58 \\
\hline & 104 & 1 & 0,13 & 0,58 \\
\hline & 110 & 1 & 0,13 & 0,58 \\
\hline & 160 & 1 & 0,13 & 0,58 \\
\hline & 377 & 1 & 0,13 & 0,58 \\
\hline & Total & 171 & 21,38 & 100,00 \\
\hline \multirow{3}{*}{ No } & 0 & 329 & 41,13 & \\
\hline & No se ofrece & 300 & 37,50 & - \\
\hline & Total & 629 & 78,63 & - \\
\hline Total & & 800 & 100,00 & \\
\hline
\end{tabular}

Fuente: elaboración propia a partir de los resultados del programa estadístico SPSS. 
Realizando un diagrama de cajas con el número de recomendaciones de Facebook se comprueba que todos aquellos casos con un número igual o superior a 40 se consideran extremos y los que van de entre 27 a 36 (los dos incluidos) son valorados como atípicos. Por ello, las noticias que registren 40 o más redirecciones no se tendrán en cuenta en el análisis de las medias para no desvirtuar los resultados.

\section{Gráfico 39. Diagrama de cajas del número de recomendaciones en Facebook}

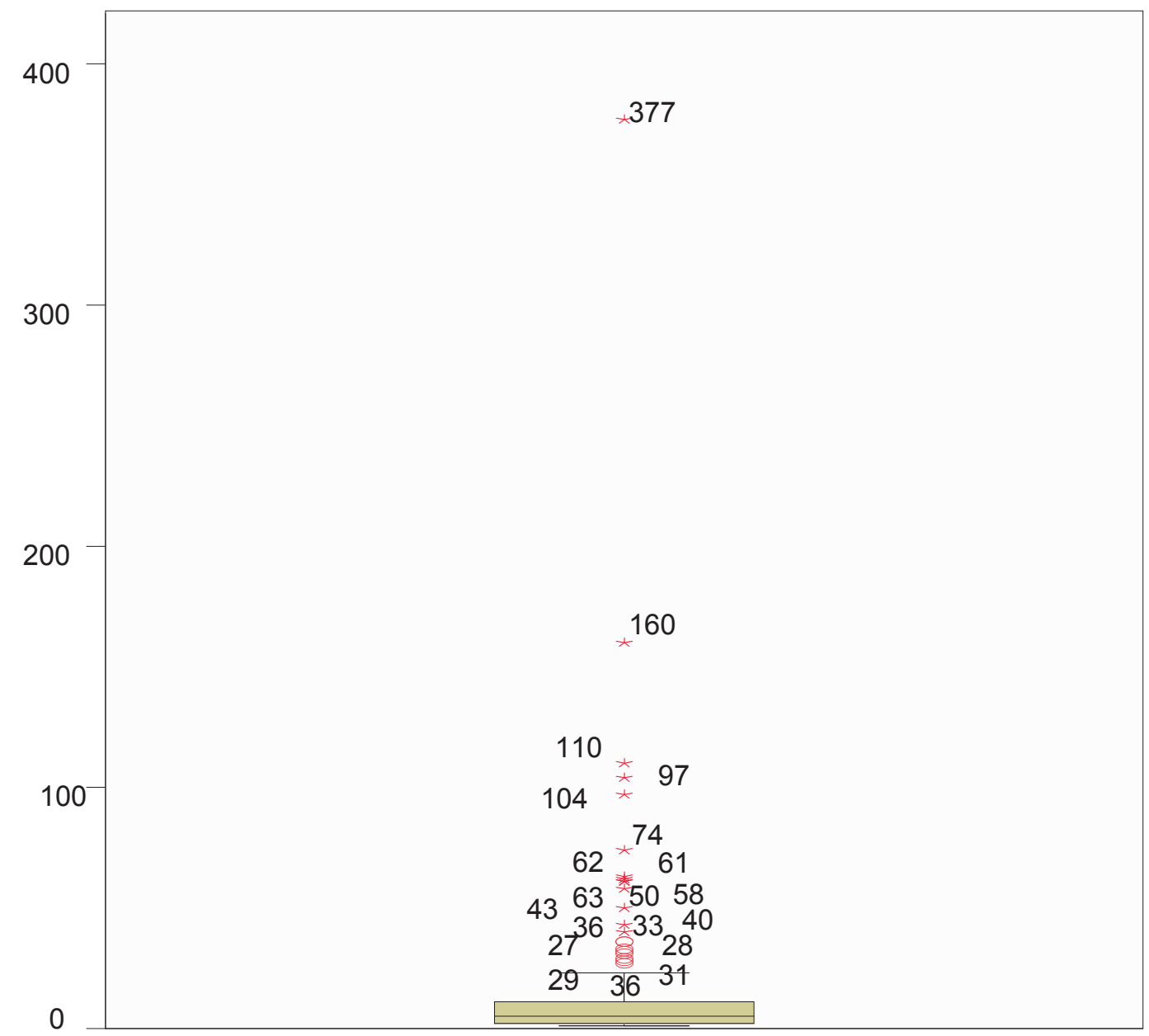

Fuente: elaboración propia a partir de los resultados del programa estadístico SPSS.

Así, la media de recomendaciones en Facebook de las noticias sobre salud y sanidad de ambas comunidades no difieren demasiado, dado que no se han hallado diferencias significativas $(\mathrm{r}=0,346)$. Sin contar las informaciones que no poseen ningún redireccionamiento, Castilla y León ofrece una media de 7,55, un punto por delante de Galicia, que cuenta con $6,38^{\underline{28}}$.

$\underline{28}$ Teniendo en cuenta las informaciones sin ninguna recomendación en Facebook, Galicia adelanta a Castilla y León en la media de enlaces con un 2,24 frente a un 2,19. En cualquier caso, en este análisis tampoco se han detectado diferencias significativas $(\mathrm{r}=0,922)$. 
Tabla 224. Estadísticos descriptivos de las recomendaciones en Facebook según las comunidades

\begin{tabular}{|l|r|r|r|r|}
\hline \multicolumn{1}{|c|}{ Comunidad } & \multicolumn{1}{c|}{$\mathbf{N}^{\mathbf{o}}$} & \multicolumn{1}{c|}{ Media } & Desv. típ. & Error típ. \\
\hline Castilla y León & 65 & 7,55 & 8,83 & 1,10 \\
\hline Galicia & 92 & 6,38 & 6,73 & 0,70 \\
\hline
\end{tabular}

Fuente: elaboración propia a partir de los resultados del programa estadístico SPSS.

Tabla 225. Prueba T-student para muestras independientes entre las recomendaciones en Facebook y las comunidades

\begin{tabular}{|ll|r|r|}
\hline & Prueba & \multicolumn{2}{c|}{ Recomendaciones de Facebook } \\
\cline { 3 - 4 } & & $\begin{array}{c}\text { Se han asumido } \\
\text { varianzas } \\
\text { iguales }\end{array}$ & $\begin{array}{c}\text { No se han } \\
\text { asumido } \\
\text { varianzas iguales }\end{array}$ \\
\hline $\begin{array}{l}\text { Prueba de Levene } \\
\text { para la igualdad de } \\
\text { varianzas }\end{array}$ & $\mathrm{F}$ & 4,836 & \\
Prueba T para la & Sig. & 0,029 & \\
igualdad de medias & $\mathrm{t}$ & 0,945 & 0,902 \\
& gl & 155,000 & 113,735 \\
& Sig. (bilateral) & 0,346 & 0,369 \\
& Diferencia de medias & 1,173 & 1,173 \\
& Error típ. de la diferencia & 1,242 & 1,301 \\
& 95\% Intervalo de Inferior & $-1,280$ & $-1,404$ \\
& confianza para la $\quad$ Superior & 3,627 & 3,750 \\
& diferencia & & \\
\hline
\end{tabular}

Fuente: elaboración propia a partir de los resultados del programa estadístico SPSS.

\subsection{TWITTER}

El número de informaciones que permiten la opción de retwittear el contenido mediante un simple enlace es muy similar a las que no ofrecen este servicio $(52,38 \%$ frente a $47,63 \%)$.

Tabla 226. Frecuencia y porcentaje de la posibilidad de twittear

\begin{tabular}{|l|r|r|r|}
\hline $\begin{array}{l}\text { Posibilidad } \\
\text { de twittear }\end{array}$ & Frecuencia & Porcentaje & $\begin{array}{c}\text { Porcentaje } \\
\text { válido }\end{array}$ \\
\hline Sí & 419 & 52,38 & 52,38 \\
\hline No & 381 & 47,63 & 47,63 \\
\hline Total & 800 & 100,00 & 100,00 \\
\hline
\end{tabular}

Fuente: elaboración propia a partir de los resultados del programa estadístico SPSS. 
Galicia es la región que más textos publica con posibilidad de retwittearlos. Concretamente, esta comunidad cuenta con 245 de las 419 noticias encontradas que ofrecen esta posibilidad, lo que supone el 58,47\% de las que ofrecen esta característica. Castilla y León, por su parte, cuenta con 174, o lo que es lo mismo, con el 41,53\%. Sobre el total de cada territorio, los artículos que suministran el servicio de enlace directo a la red social suponen el $61,25 \%$ en la región gallega y el 43,5\% en la castellano-leonesa. Estas diferencias han resultado ser significativas $(r=0,000$ y coeficiente de contingencia 0,175$)$.

Tabla 227. Tabla de contingencia entre la posibilidad de twittear y la comunidad

\begin{tabular}{|l|l|r|r|r|}
\hline \multicolumn{2}{|c|}{ Posibilidad de twittear } & \multicolumn{2}{|c|}{ Comunidad } & \multirow{2}{*}{ Total } \\
\cline { 3 - 4 } \multicolumn{2}{|c|}{$\begin{array}{c}\text { Castilla y } \\
\text { León }\end{array}$} & Galicia & \\
\hline \multirow{3}{*}{ Sí } & Recuento & 174 & 245 & 419 \\
& $\%$ de Twitter & $41,53 \%$ & $58,47 \%$ & $100,00 \%$ \\
& $\%$ de comunidad & $43,50 \%$ & $61,25 \%$ & $52,38 \%$ \\
\hline \multirow{3}{*}{ No } & Recuento & 226 & 155 & 381 \\
& $\%$ de Twitter & $59,32 \%$ & $40,68 \%$ & $100,00 \%$ \\
& $\%$ de comunidad & $56,50 \%$ & $38,75 \%$ & $47,63 \%$ \\
\hline \multirow{3}{*}{ Total } & Recuento & 400 & 400 & 800 \\
& $\%$ de Twitter & $50,00 \%$ & $50,00 \%$ & $100,00 \%$ \\
& $\%$ de comunidad & $100,00 \%$ & $100,00 \%$ & $100,00 \%$ \\
\hline
\end{tabular}

Fuente: elaboración propia a partir de los resultados del programa estadístico SPSS.

Tabla 228. Prueba de chi-cuadrado entre la posibilidad de twittear y la comunidad

\begin{tabular}{|l|r|r|r|r|r|}
\hline \multicolumn{1}{|c|}{ Prueba } & Valor & gl & $\begin{array}{c}\text { Sig. asintótica } \\
\text { (bilateral) }\end{array}$ & $\begin{array}{c}\text { Sig. exacta } \\
\text { (bilateral) }\end{array}$ & $\begin{array}{c}\text { Sig. exacta } \\
\text { (unilateral) }\end{array}$ \\
\hline Chi-cuadrado de Pearson & 25,262 & 1 & 0,000 & & \\
Corrección por continuidad & 24,555 & 1 & 0,000 & & \\
Razón de verosimilitudes & 25,398 & 1 & 0,000 & & \\
Estadístico exacto de & & & & 0,000 & 0,000 \\
Fisher & & & & & \\
Asociación lineal por lineal & 25,230 & 1 & 0,000 & & \\
N de casos válidos & 800,000 & & & & \\
\hline
\end{tabular}

Fuente: elaboración propia a partir de los resultados del programa estadístico SPSS. 
Tabla 229. Medidas simétricas de la prueba de chi-cuadrado entre la posibilidad de twittear y la comunidad

\begin{tabular}{|c|c|c|c|c|c|}
\hline Prueba & & Valor & $\begin{array}{l}\text { Error típ. } \\
\text { asint. }\end{array}$ & $\begin{array}{c}\mathbf{T} \\
\text { aproximada }\end{array}$ & $\begin{array}{c}\text { Sig. } \\
\text { aproximada }\end{array}$ \\
\hline Nominal por nominal & $\begin{array}{l}\text { Coeficiente de } \\
\text { contingencia }\end{array}$ & 0,175 & & & 0,000 \\
\hline $\begin{array}{l}\text { Intervalo por } \\
\text { intervalo }\end{array}$ & $\mathrm{R}$ de Pearson & 0,178 & 0,035 & 5,101 & 0,000 \\
\hline $\begin{array}{l}\text { Ordinal por ordinal } \\
\mathrm{N} \text { de casos válidos }\end{array}$ & $\begin{array}{l}\text { Correlación de } \\
\text { Spearman }\end{array}$ & $\begin{array}{r}0,178 \\
800,000\end{array}$ & 0,035 & 5,101 & 0,000 \\
\hline
\end{tabular}

Fuente: elaboración propia a partir de los resultados del programa estadístico SPSS.

\section{Gráfico 40. Número de informaciones con posibilidad de twittear según comunidades}

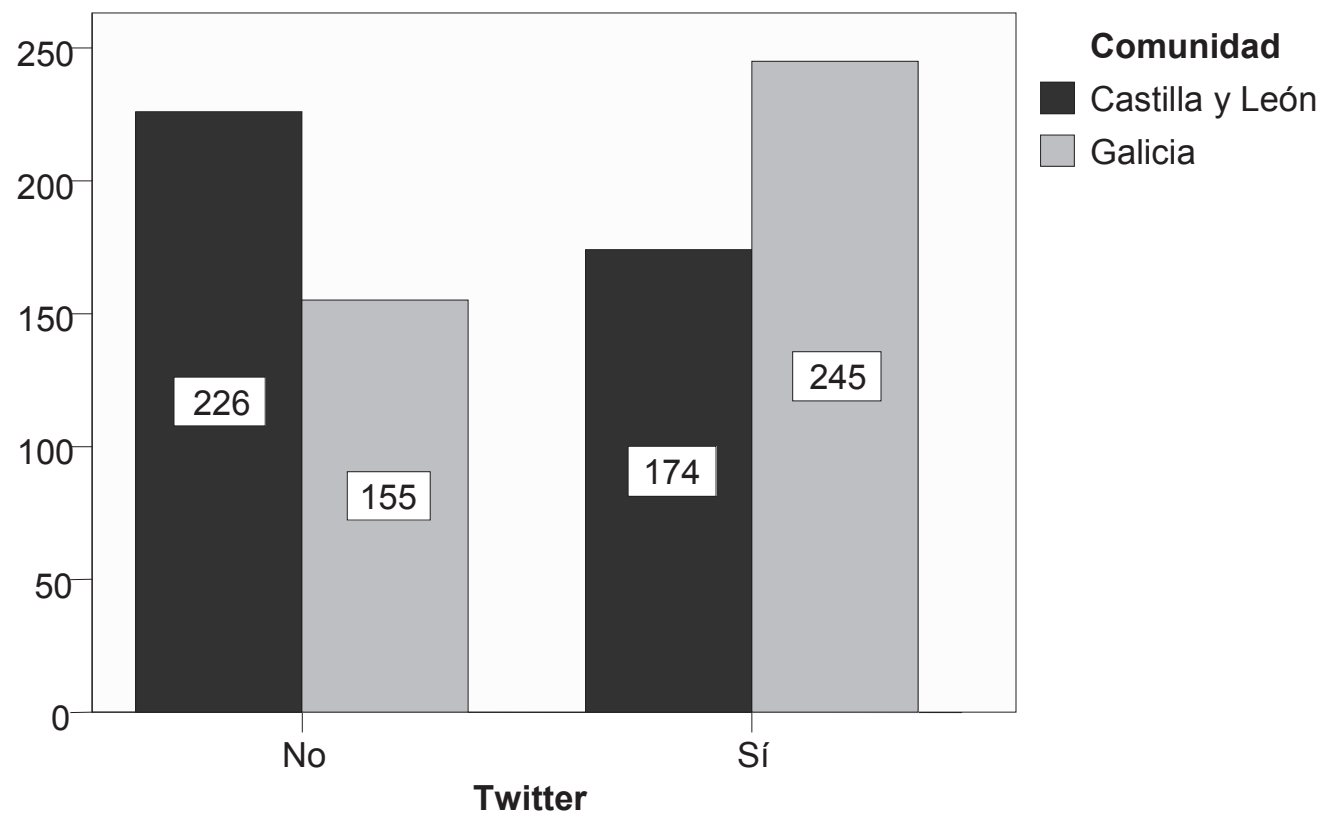

Fuente: elaboración propia a partir de los resultados del programa estadístico SPSS.

A pesar de que más de la mitad de las informaciones ofrecen un enlace directo a Twitter (concretamente el 52,38\%), los lectores no hacen el mismo uso de esta red social. Cuatro de cada 10 noticias (el $42,48 \%$ ) que suministran esta opción fueron retwitteadas. 
Tabla 230. Frecuencia y porcentaje de las informaciones retwitteadas

\begin{tabular}{|l|l|r|r|r|}
\hline $\begin{array}{c}\text { Posibilidad } \\
\text { de retwittear }\end{array}$ & $\begin{array}{c}\text { Noticias } \\
\text { retwitteadas }\end{array}$ & Frecuencia & Porcentaje & $\begin{array}{c}\text { Porcentaje } \\
\text { válido }\end{array}$ \\
\hline \multirow{3}{*}{ Sí } & Sí & 178 & 22,25 & 42,48 \\
\cline { 2 - 5 } & No & 241 & 30,13 & 57,52 \\
\cline { 2 - 5 } & Total & 419 & 52,38 & 100,00 \\
\hline No & 381 & 47,63 & - \\
\hline \multicolumn{2}{|l|}{ Total } & 800 & 100,00 & \\
\hline
\end{tabular}

Fuente: elaboración propia a partir de los resultados del programa estadístico SPSS.

Si se dividen las páginas que han sido rettwitteadas por comunidades autónomas, se visualiza que Galicia es la que aporta un número considerablemente mayor. Un total de 115 (es decir, el 64,61\% de las redireccionadas a esta red social) proceden de los periódicos de esta región, mientras que en la castellano-leonesa se han registrado 63 (el $35,39 \%$ ). Galicia también se encuentra por delante en la proporción de textos compartidos frente a los que no: 46,94\% frente al 36,21\% de Castilla y León. Las diferencias, de hecho, resultan ser estadísticamente significativas $(r=0,029$ y coeficiente de contingencia 0,106$)$.

Tabla 231. Tabla de contingencia entre noticias retwitteadas y comunidad

\begin{tabular}{|l|l|r|r|r|}
\hline \multirow{2}{*}{ Noticias retwitteadas } & \multicolumn{2}{|c|}{ Comunidad } & \multirow{2}{*}{ Total } \\
\cline { 3 - 4 } \multicolumn{2}{|c|}{$\begin{array}{c}\text { Castilla y } \\
\text { León }\end{array}$} & Galicia & \\
\hline \multirow{3}{*}{ Sí } & Recuento & 63 & 115 & 178 \\
& $\%$ de retwitts & $35,39 \%$ & $64,61 \%$ & $100,00 \%$ \\
& $\%$ de comunidad & $36,21 \%$ & $46,94 \%$ & $42,48 \%$ \\
\hline \multirow{3}{*}{ No } & Recuento & 111 & 130 & 241 \\
& $\%$ de retwitts & $46,06 \%$ & $53,94 \%$ & $100,00 \%$ \\
& $\%$ de comunidad & $63,79 \%$ & $53,06 \%$ & $57,52 \%$ \\
\hline \multirow{3}{*}{ Total } & Recuento & 174 & 245 & 419 \\
& $\%$ de retwitts & $41,53 \%$ & $58,47 \%$ & $100,00 \%$ \\
& $\%$ de comunidad & $100,00 \%$ & $100,00 \%$ & $100,00 \%$ \\
\hline
\end{tabular}

Fuente: elaboración propia a partir de los resultados del programa estadístico SPSS. 
Tabla 232. Prueba de chi-cuadrado entre noticias retwitteadas y comunidad

\begin{tabular}{|l|r|r|r|r|r|}
\hline \multicolumn{1}{|c|}{ Prueba } & Valor & gl & $\begin{array}{c}\text { Sig. asintótica } \\
\text { (bilateral) }\end{array}$ & $\begin{array}{c}\text { Sig. exacta } \\
\text { (bilateral) }\end{array}$ & $\begin{array}{c}\text { Sig. exacta } \\
\text { (unilateral) }\end{array}$ \\
\hline Chi-cuadrado de Pearson & 4,796 & 1 & 0,029 & & \\
Corrección por continuidad & 4,366 & 1 & 0,037 & & \\
Razón de verosimilitudes & 4,825 & 1 & 0,028 & & \\
Estadístico exacto de & & & & 0,035 & 0,018 \\
Fisher & & & & & \\
Asociación lineal por lineal & 4,784 & 1 & 0,029 & & \\
N de casos válidos & 419,000 & & & & \\
\hline
\end{tabular}

Fuente: elaboración propia a partir de los resultados del programa estadístico SPSS.

Tabla 233. Medidas simétricas de la prueba de chi-cuadrado entre noticias retwitteadas y comunidad

\begin{tabular}{|c|c|c|c|c|c|}
\hline \multicolumn{2}{|l|}{ Prueba } & Valor & $\begin{array}{l}\text { Error típ. } \\
\text { asint. }\end{array}$ & $\frac{\mathbf{T}}{\text { aproximada }}$ & $\begin{array}{c}\text { Sig. } \\
\text { aproximad }\end{array}$ \\
\hline Nominal por nominal & $\begin{array}{l}\text { Coeficiente de } \\
\text { contingencia }\end{array}$ & 0,106 & & & 0,029 \\
\hline $\begin{array}{l}\text { Intervalo por } \\
\text { intervalo }\end{array}$ & R de Pearson & 0,107 & 0,048 & 2,197 & 0,029 \\
\hline $\begin{array}{l}\text { Ordinal por ordinal } \\
\mathrm{N} \text { de casos válidos }\end{array}$ & $\begin{array}{l}\text { Correlación de } \\
\text { Spearman }\end{array}$ & $\begin{array}{r}0,107 \\
419,000\end{array}$ & 0,048 & 2,197 & 0,029 \\
\hline
\end{tabular}

Fuente: elaboración propia a partir de los resultados del programa estadístico SPSS.

Gráfico 41. Número de noticias retwitteadas según comunidades

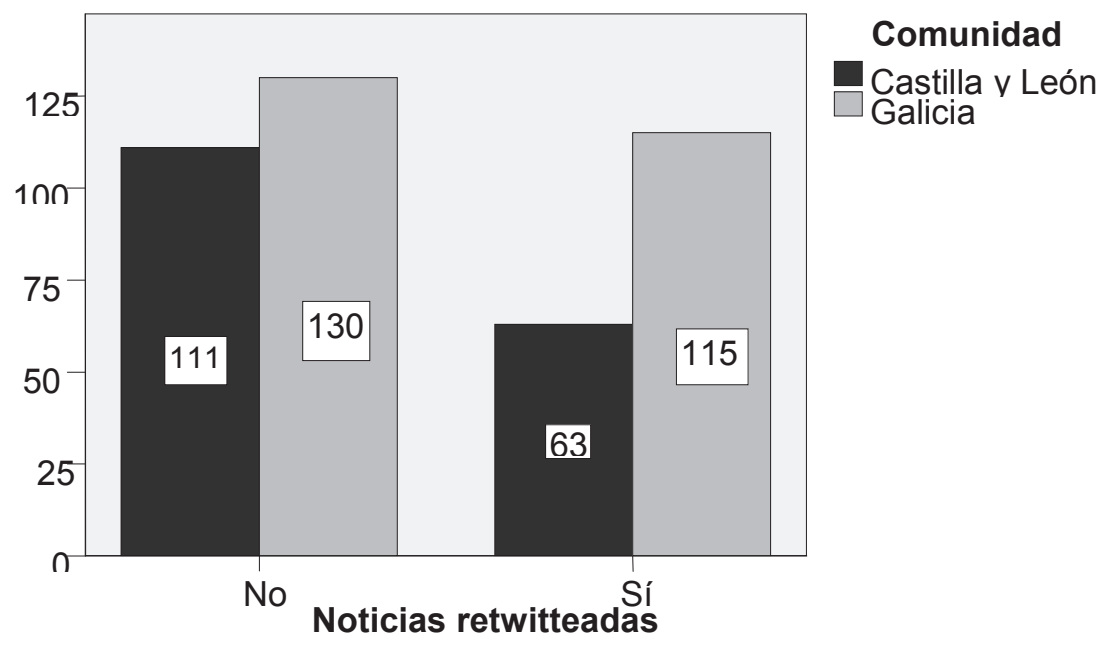

Fuente: elaboración propia a partir de los resultados del programa estadístico SPSS. 
El número más alto de enlaces a Twitter que se ha encontrado en una sola noticia asciende a 55. Se publicó en La Voz de Galicia el 15 de febrero de 2012 y trata sobre unas declaraciones del presidente de la Xunta de Galicia, Alberto Núñez Feijoo, acerca de su creencia de que pasaría a la historia como un defensor de la sanidad pública. La suma más baja de retwitts hallada por su parte, es uno, que resulta ser también el número que más se repite, con un $29,78 \%$ de todas las informaciones que tienen, al menos, una redirección a esta red social. La media, en este caso, se sitúa en 4,71 y la mediana, en 3.

Tabla 234. Estadísticos descriptivos de los enlaces a Twitter

\begin{tabular}{|l|r|r|r|r|r|r|r|r|}
\hline \multicolumn{1}{|c|}{ Variable } & $\mathbf{N}^{\mathbf{o}}$ & Mínimo & Máximo & Suma & Media & Desv. típ. & Moda & Mediana \\
\hline $\begin{array}{l}\text { Enlaces a } \\
\text { Twitter }\end{array}$ & 178 & 1 & 55 & 839 & 4,71 & 7,47 & 1 & 3 \\
\hline
\end{tabular}

Fuente: elaboración propia a partir de los resultados del programa estadístico SPSS.

Tabla 235. Frecuencia y porcentaje del número de retwitts de las informaciones

\begin{tabular}{|c|c|c|c|c|}
\hline $\begin{array}{c}\text { Posibilidad de } \\
\text { rettwittear }\end{array}$ & Número & Frecuencia & Porcentaje & $\begin{array}{l}\text { Porcentaje } \\
\text { válido }\end{array}$ \\
\hline \multirow{22}{*}{ Sí } & 1 & 53 & 6,63 & 29,78 \\
\hline & 2 & 34 & 4,25 & 19,10 \\
\hline & 3 & 25 & 3,13 & 14,04 \\
\hline & 4 & 15 & 1,88 & 8,43 \\
\hline & 5 & 14 & 1,75 & 7,87 \\
\hline & 6 & 8 & 1,00 & 4,49 \\
\hline & 7 & 7 & 0,88 & 3,93 \\
\hline & 8 & 4 & 0,50 & 2,25 \\
\hline & 9 & 5 & 0,63 & 2,81 \\
\hline & 10 & 1 & 0,13 & 0,56 \\
\hline & 12 & 1 & 0,13 & 0,56 \\
\hline & 13 & 1 & 0,13 & 0,56 \\
\hline & 15 & 1 & 0,13 & 0,56 \\
\hline & 16 & 1 & 0,13 & 0,56 \\
\hline & 17 & 1 & 0,13 & 0,56 \\
\hline & 21 & 1 & 0,13 & 0,56 \\
\hline & 24 & 1 & 0,13 & 0,56 \\
\hline & 31 & 1 & 0,13 & 0,56 \\
\hline & 32 & 1 & 0,13 & 0,56 \\
\hline & 45 & 1 & 0,13 & 0,56 \\
\hline & 48 & 1 & 0,13 & 0,56 \\
\hline & 55 & 1 & 0,13 & 0,56 \\
\hline
\end{tabular}




\begin{tabular}{|c|l|r|r|r|}
\hline $\begin{array}{c}\text { Posibilidad de } \\
\text { rettwittear }\end{array}$ & Número & Frecuencia & Porcentaje & $\begin{array}{c}\text { Porcentaje } \\
\text { válido }\end{array}$ \\
\hline & Total & 178 & 22,25 & 100,00 \\
\hline \multirow{2}{*}{ No } & 0 & 241 & 30,13 & - \\
\cline { 2 - 5 } & No se ofrece & 381 & 47,63 & - \\
\cline { 2 - 5 } & Total & 622 & 77,75 & - \\
\hline Total & 800 & 100,00 & - \\
\hline
\end{tabular}

Fuente: elaboración propia a partir de los resultados del programa estadístico SPSS.

Realizando un diagrama de cajas se observa, no obstante, que todos aquellos valores iguales o por encima de 21 se consideran casos extremos y los que se sitúan entre 12 y 17, atípicos. Por ello, no se tendrán en cuenta los primeros en el análisis de las medias de cada comunidad.

\section{Gráfico 42. Diagrama de cajas del número de retwitts}

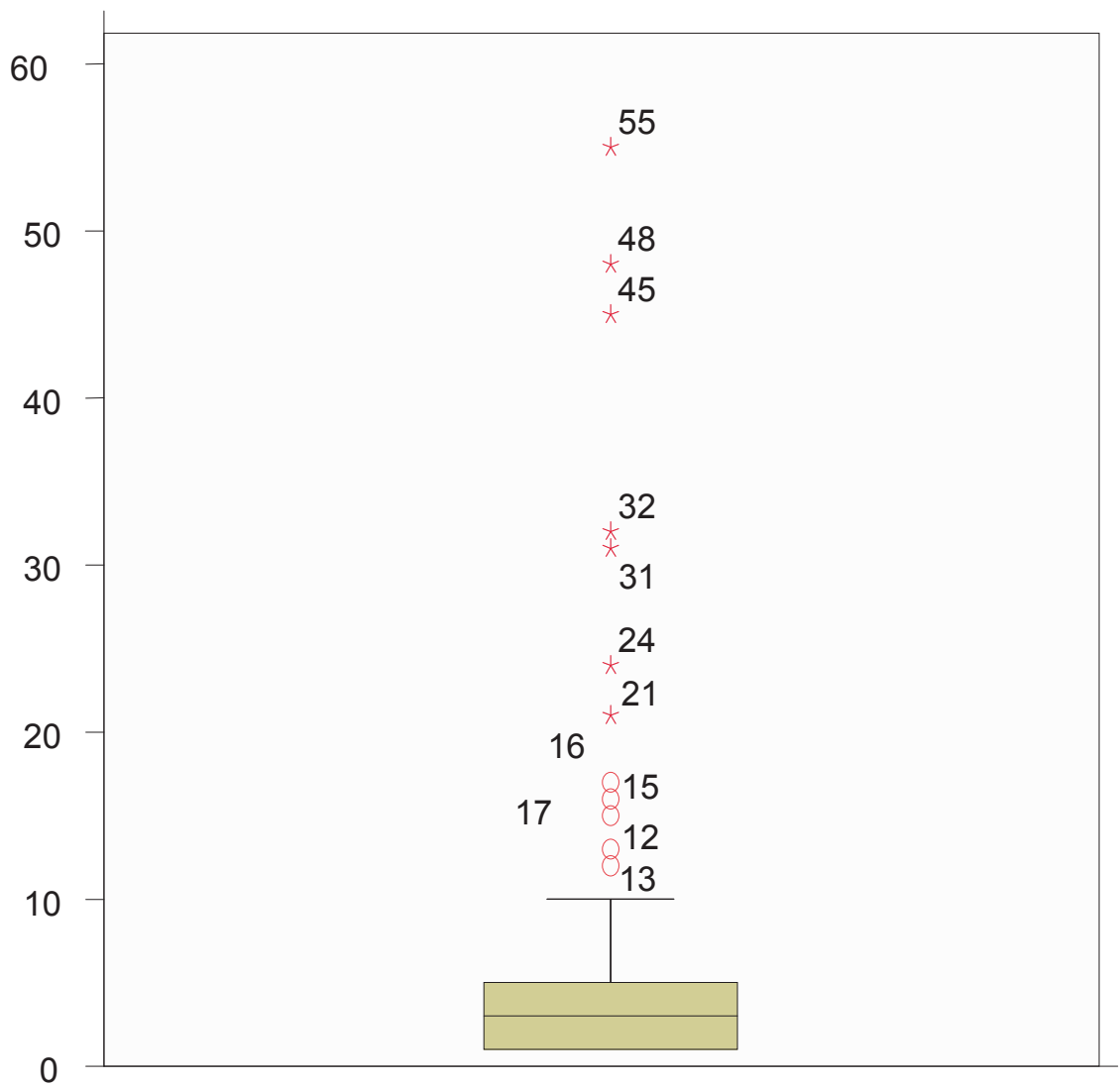

Fuente: elaboración propia a partir de los resultados del programa estadístico SPSS.

Sin tener en cuenta las noticias que no ofrecen ningún enlace a Twitter, Galicia supera en media a Castilla y León con un 3,61 frente a un 3,06, aunque la diferencia no resulta ser significativa $(r=0,252)$. No obstante, si se incluyen aquellas informaciones 
que, aunque ofrecen esta posibilidad, no registran ningún redireccionamiento, entonces sí que se detectan relaciones estadísticamente fiables $(\mathrm{r}=0,025)$. En este caso, la media en número de retwitts en Galicia es también superior a Castilla y León. La primera comunidad obtiene 1,64 y la segunda, 1,10 .

Tabla 236. Estadísticos descriptivos del número de recomendaciones en Twitter según comunidades

\begin{tabular}{|l|r|r|r|r|}
\hline \multicolumn{1}{|c|}{ Comunidad } & \multicolumn{1}{c|}{ N } & Media & Desv. típ. & Error típ. \\
\hline Castilla y León & 173 & 1,10 & 2,15 & 0,16 \\
\hline Galicia & 239 & 1,64 & 2,77 & 0,18 \\
\hline
\end{tabular}

Fuente: elaboración propia a partir de los resultados del programa estadístico SPSS.

Tabla 237. Prueba T-student para muestras independientes entre el número de recomendaciones en Twitter y las comunidades

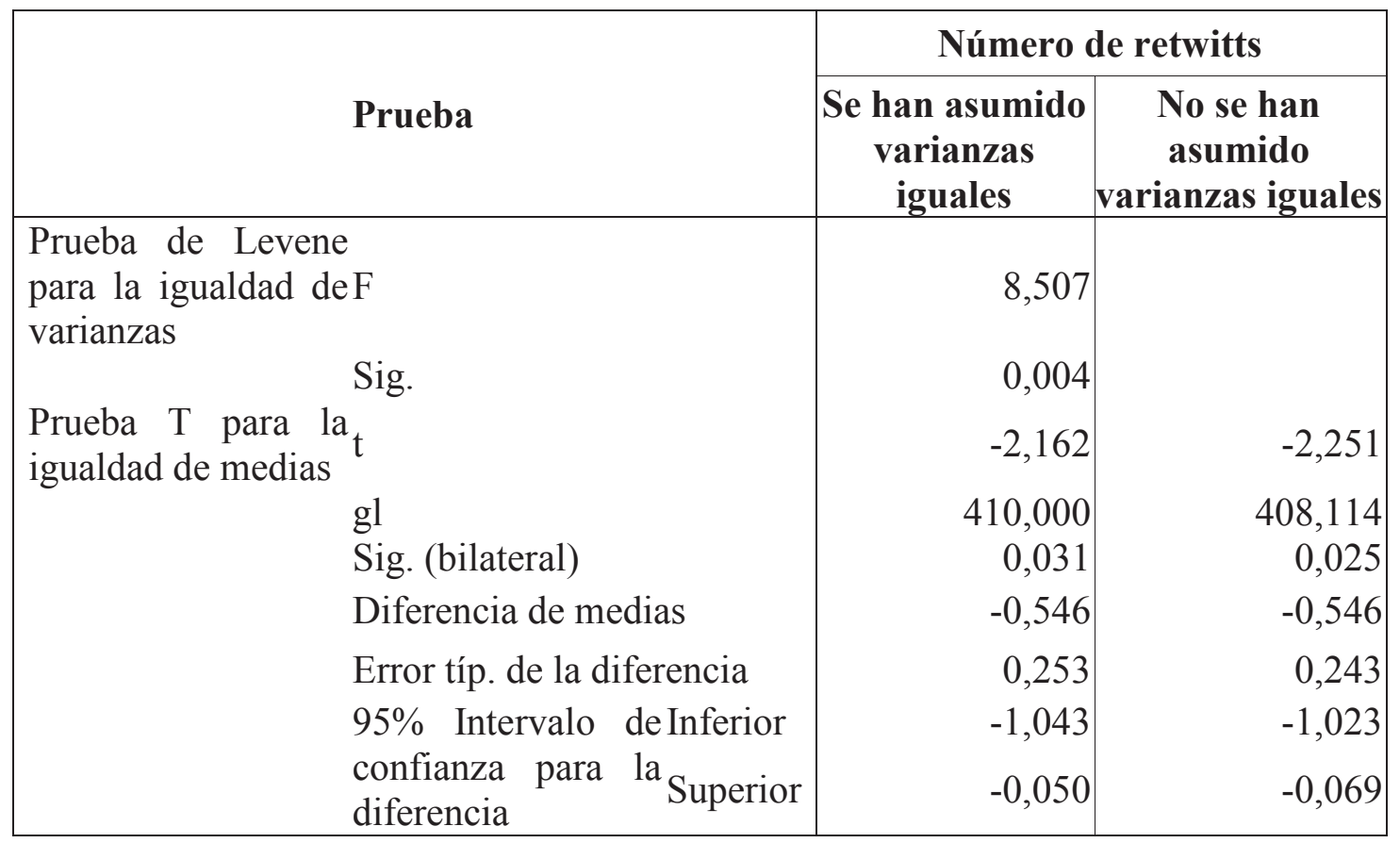

Fuente: elaboración propia a partir de los resultados del programa estadístico SPSS. 


\subsubsection{VALORACIÓN Y SATISFACCIÓN DE LOS CIUDADANOS ACERCA DEL SISTEMA SANITARIO}

Con el fin de conocer la opinión y la actitud de la población hacia la sanidad, se ha hecho uso del Barómetro Sanitario que publica anualmente el Ministerio de Sanidad, Servicios Sociales e Igualdad, y cuyos últimos resultados corresponden al ejercicio 2013. Se trata de un informe que recoge la valoración de los ciudadanos sobre el funcionamiento del sistema sanitario español y su satisfacción con la calidad de las prestaciones, en los dos casos en referencia al ámbito público. Es el único que divide los resultados por comunidades autónomas y permite la comparación entre las dos regiones que nos ocupan. La muestra total se compone de 7.800 entrevistas con cuestionario estructurado realizadas de manera personal en los domicilios de 238 municipios de las 17 comunidades autónomas y de las 2 ciudades autónomas (Instituto de Información Sanitaria, 2013d). Posee un error de muestreo, en conjunto, del $\pm 1,1 \%$ para un nivel de confianza del 95,5\%. En Castilla y León se realizaron 423 para el último número y en Galicia, 438 (Instituto de Información Sanitaria, 2013c).

\subsubsection{INTERÉS POR LA SANIDAD}

En primer lugar, se ha querido averiguar el interés que tienen los habitantes de cada territorio por la salud. Un número mayor de gallegos consideran la sanidad como el área de mayor trascendencia para los ciudadanos que los castellanoleoneses. En 2013, por ejemplo, casi 4 de cada diez gallegos (más concretamente el 38,13\%) pensaba de esta manera, en comparación con el 30,31\% de la comunidad castellanoleonesa. Ambos territorios consiguen una cifra mayor en comparación con la media nacional, que se sitúa en 26,48\%, aunque en el caso de Galicia la diferencia es considerablemente mayor. El promedio desde 1995 hasta 2013 también es más alto en Galicia que en Castilla y León.

Tabla 238. Proporción de personas que consideran que la Sanidad es el área de mayor interés para los ciudadanos

\begin{tabular}{|l|r|r|r|}
\hline Año & $\begin{array}{c}\text { Castilla y } \\
\text { León }\end{array}$ & \multicolumn{1}{c|}{ Galicia } & $\begin{array}{c}\text { Total } \\
\text { nacional }\end{array}$ \\
\hline 2013 & 30,31 & 38,13 & 26,48 \\
\hline 2012 & 28,36 & 35,83 & 25,17 \\
\hline 2011 & 32,36 & 37,19 & 33,38 \\
\hline 2010 & 33,22 & 40,45 & 29,22 \\
\hline 2009 & 33,80 & 42,30 & 29,00 \\
\hline
\end{tabular}




\begin{tabular}{|l|r|r|r|}
\hline Año & $\begin{array}{c}\text { Castilla y } \\
\text { León }\end{array}$ & \multicolumn{1}{c|}{ Galicia } & $\begin{array}{c}\text { Total } \\
\text { nacional }\end{array}$ \\
\hline 2008 & 36,17 & 34,19 & 28,06 \\
\hline 2007 & 35,04 & 35,85 & 28,31 \\
\hline 2006 & 38,42 & 33,19 & 28,32 \\
\hline 2005 & 34,70 & 36,90 & 30,30 \\
\hline 2004 & 39,97 & 35,37 & 31,40 \\
\hline 2003 & 39,08 & 38,66 & 30,15 \\
\hline 2002 & 40,23 & 39,76 & 31,01 \\
\hline 2000 & 37,01 & 40,56 & 32,06 \\
\hline 1999 & 39,12 & 39,39 & 32,36 \\
\hline 1998 & 41,45 & 41,67 & 34,15 \\
\hline 1997 & 33,79 & 36,30 & 31,75 \\
\hline 1995 & 36,26 & 40,13 & 36,11 \\
\hline Promedio & 35,84 & 37,99 & 30,43 \\
\hline
\end{tabular}

Fuente: Barómetro Sanitario del Instituto de Información Sanitaria (2013a).

\subsubsection{VALORACIÓN DEL FUNCIONAMIENTO DEL SISTEMA SANITARIO}

Lo más normal en Castilla y León y en Galicia es pensar que la sanidad pública funciona bien, pero habría que hacer algunos cambios, seguido de los que piensan que marcha bien y de los que consideran que necesita cambios fundamentales aunque algunas cosas funcionan. En la actualidad, los que creen que está tan mal que habría que rehacerlo en su totalidad suman una cifra mínima.

Sin embargo, parece que en Galicia ha mejorado la visión de la sanidad con el paso de los años. Desde 1995 hasta 2013, los que consideran que funciona bastante bien han aumentado casi diez puntos porcentuales, pasando del 15,84\% de los ciudadanos que mantenían esta afirmación en la primera fecha al 24,19\% de la segunda. En 2012, se registró una cifra incluso más alta: el 29,70\%.

También ha crecido, en casi 20 puntos porcentuales, las personas gallegas que opinan que el sistema marcha bien, pero se necesitan algunos cambios. En concreto, del $35,36 \%$ que pensaba esto en 1995, en 2013 el porcentaje ha subido hasta el 53,21\%. Debido a esta visión positiva de la sanidad gallega, el número de personas que creen que se necesitan cambios fundamentales ha decrecido de un $29,07 \%$ en 1995 a un $18,72 \%$ en 2013, y aquellos que mejorarían el sistema en su totalidad han caído de un $18 \%$ a un $3,42 \%$ en el mismo periodo. 
Las cifras de Castilla y León, aunque positivas, no adquieren el nivel de las de Galicia. Por ejemplo, el número de personas que consideran que el sistema se encuentra bastante bien se mantiene prácticamente intacto de unos años para otros $(25,17 \%$ en 1995 a un $25,22 \%$ en 2012, por ejemplo), a pesar de que en el año 2013 se ha sufrido una disminución hasta llegar al 18,25\%. Los habitantes que piensan que la sanidad funciona bien, pero se necesitan algunos cambios acumulan el 46,90\% del total, lo que supone apenas cinco puntos porcentuales más del 41,11\% que ofrecía el año 1995. Los individuos que creen que hay que hacer cambios profundos aumentan hasta llegar al $29,87 \%$ en el último año registrado (respecto al 25,4\% anotado en 1995, por ejemplo) y los que opinan que el sistema se ha de rehacer en su totalidad se reducen hasta un $3,79 \%$ en ese mismo periodo.

Tabla 239. Proporción de ciudadanos que creen que el sistema sanitario público funciona bastante bien o que se deberían hacer algunos cambios

\begin{tabular}{|l|r|r|r|r|r|r|}
\hline \multirow{2}{*}{ Año } & \multicolumn{3}{|c|}{ Funciona bastante bien } & \multicolumn{2}{c|}{$\begin{array}{c}\text { Funciona bien, pero habría que } \\
\text { hacer algunos cambios }\end{array}$} \\
\cline { 2 - 7 } & $\begin{array}{c}\text { Castilla y } \\
\text { León }\end{array}$ & Galicia & $\begin{array}{c}\text { Total } \\
\text { nacional }\end{array}$ & $\begin{array}{c}\text { Castilla y } \\
\text { León }\end{array}$ & Galicia & $\begin{array}{c}\text { Total } \\
\text { nacional }\end{array}$ \\
\hline 2013 & 18,25 & 24,19 & 20,06 & 46,90 & 53,21 & 45,81 \\
\hline 2012 & 25,22 & 29,70 & 22,92 & 47,83 & 52,84 & 47,73 \\
\hline 2011 & 25,01 & 23,36 & 24,24 & 50,24 & 55,10 & 48,88 \\
\hline 2010 & 23,90 & 19,77 & 23,86 & 55,37 & 57,73 & 50,02 \\
\hline 2009 & 18,40 & 25,20 & 21,20 & 54,90 & 49,30 & 48,00 \\
\hline 2008 & 21,88 & 17,92 & 19,22 & 52,43 & 53,69 & 48,86 \\
\hline 2007 & 22,61 & 13,78 & 20,05 & 50,18 & 55,57 & 47,34 \\
\hline 2006 & 15,97 & 12,67 & 19,16 & 59,71 & 53,44 & 50,52 \\
\hline 2005 & 25,60 & 15,70 & 19,40 & 51,00 & 54,20 & 48,30 \\
\hline 2004 & 18,16 & 15,70 & 19,80 & 53,52 & 47,16 & 47,10 \\
\hline 2003 & 30,57 & 17,49 & 18,57 & 44,14 & 53,32 & 47,61 \\
\hline 2002 & 24,59 & 17,17 & 18,40 & 46,66 & 47,81 & 47,66 \\
\hline 2000 & 18,89 & 21,25 & 21,34 & 49,30 & 49,24 & 45,45 \\
\hline 1999 & 19,21 & 21,21 & 23,35 & 48,37 & 48,48 & 45,03 \\
\hline 1998 & 13,86 & 18,48 & 21,77 & 46,88 & 50,43 & 43,47 \\
\hline 1997 & 21,38 & 19,31 & 21,26 & 45,98 & 46,42 & 41,10 \\
\hline 1995 & 25,17 & 15,84 & 20,71 & 41,11 & 35,36 & 40,57 \\
\hline Promedio & 21,69 & 19,34 & 20,90 & 49,68 & 50,78 & 46,67 \\
\hline
\end{tabular}

Fuente: Barómetro Sanitario del Instituto de Información Sanitaria (2013a). 
Tabla 240. Proporción de ciudadanos que creen que el sistema sanitario público necesita cambios fundamentales aunque algunas cosas funcionan o que funciona tan mal que habría que rehacerlo en su totalidad

\begin{tabular}{|l|r|r|r|r|r|r|}
\hline \multirow{2}{*}{ Año } & \multicolumn{2}{|c|}{$\begin{array}{c}\text { Necesita cambios fundamentales } \\
\text { aunque algunas cosas funcionan }\end{array}$} & \multicolumn{2}{|c|}{$\begin{array}{c}\text { Funciona tan mal que habría que } \\
\text { rehacerlo en su totalidad }\end{array}$} \\
\cline { 2 - 8 } & $\begin{array}{c}\text { Castilla y } \\
\text { León }\end{array}$ & Galicia & $\begin{array}{c}\text { Total } \\
\text { nacional }\end{array}$ & $\begin{array}{c}\text { Castilla y } \\
\text { León }\end{array}$ & \multicolumn{1}{c|}{ Galicia } & $\begin{array}{c}\text { Total } \\
\text { nacional }\end{array}$ \\
\hline 2013 & 29,87 & 18,72 & 26,54 & 3,79 & 3,42 & 6,07 \\
\hline 2012 & 22,19 & 15,87 & 23,60 & 4,29 & 1,36 & 4,96 \\
\hline 2011 & 21,65 & 17,69 & 21,91 & 2,62 & 2,72 & 4,20 \\
\hline 2010 & 17,44 & 20,68 & 21,60 & 2,81 & 1,36 & 3,51 \\
\hline 2009 & 23,90 & 19,40 & 25,3 & 2,40 & 5,60 & 4,70 \\
\hline 2008 & 20,09 & 23,73 & 26,17 & 3,95 & 4,18 & 4,87 \\
\hline 2007 & 22,52 & 26,02 & 26,85 & 2,56 & 4,61 & 4,69 \\
\hline 2006 & 21,29 & 28,35 & 24,97 & 2,77 & 4,61 & 4,41 \\
\hline 2005 & 19,90 & 25,60 & 26,00 & 2,70 & 3,70 & 5,10 \\
\hline 2004 & 24,82 & 30,36 & 27,10 & 3,25 & 5,89 & 5,00 \\
\hline 2003 & 19,76 & 21,40 & 26,96 & 5,06 & 5,63 & 5,60 \\
\hline 2002 & 23,91 & 28,27 & 27,30 & 4,13 & 6,30 & 5,50 \\
\hline 2000 & 25,80 & 24,29 & 25,51 & 4,60 & 4,12 & 6,38 \\
\hline 1999 & 24,53 & 24,02 & 23,84 & 7,33 & 6,76 & 7,18 \\
\hline 1998 & 31,64 & 23,26 & 27,73 & 7,62 & 7,83 & 7,03 \\
\hline 1997 & 24,14 & 25,81 & 28,39 & 7,36 & 7,16 & 7,67 \\
\hline 1995 & 25,40 & 29,07 & 28,18 & 6,93 & 18,00 & 9,57 \\
\hline Promedio & 23,46 & 23,68 & 25,76 & 4,36 & 5,49 & 5,67 \\
\hline
\end{tabular}

Fuente: Barómetro Sanitario del Instituto de Información Sanitaria (2013a).

\subsubsection{SATISFACCIÓN CON EL SISTEMA SANITARIO}

A pesar del incremento de la valoración que hacen los gallegos de su sistema de salud público, el grado de satisfacción no muestra el mismo resultado. En una escala de 1 a 10, estos ciudadanos otorgan a su sanidad en 2013 un 6,07, algo más de cinco puntos porcentuales más de lo registrado en 2002, pero por debajo de Castilla y León, cuyos habitantes califican la sanidad pública con un 6,48 . De esta manera, la primera región se sitúa por detrás de la media nacional, que se queda en un 6,41, mientras que Castilla y León la supera ligeramente. El promedio a lo largo de los años también es más alto en la comunidad castellana. 
Tabla 241. Grado de satisfacción que tienen los ciudadanos con el funcionamiento del sistema sanitario público. Calificación en una escala de 1 a 10, en la que 1 significa que se está "muy insatisfecho" y 10 que se está "muy satisfecho"

\begin{tabular}{|l|r|r|r|}
\hline Año & $\begin{array}{c}\text { Castilla y } \\
\text { León }\end{array}$ & \multicolumn{1}{c|}{ Galicia } & $\begin{array}{c}\text { Total } \\
\text { nacional }\end{array}$ \\
\hline 2013 & 6,48 & 6,07 & 6,41 \\
\hline 2012 & 6,82 & 6,47 & 6,57 \\
\hline 2011 & 7,06 & 6,26 & 6,59 \\
\hline 2010 & 7,01 & 6,10 & 6,57 \\
\hline 2009 & 6,82 & 5,91 & 6,35 \\
\hline 2008 & 6,80 & 5,87 & 6,28 \\
\hline 2007 & 6,64 & 5,84 & 6,27 \\
\hline 2006 & 6,39 & 5,52 & 6,23 \\
\hline 2005 & 6,40 & 5,56 & 6,14 \\
\hline 2004 & 6,15 & 5,41 & 6,12 \\
\hline 2003 & 6,37 & 5,62 & 6,05 \\
\hline 2002 & 6,13 & 5,40 & 5,94 \\
\hline Promedio & 6,59 & 5,84 & 6,29 \\
\hline
\end{tabular}

Fuente: Barómetro Sanitario del Instituto de Información Sanitaria (2013a).

La percepción de los ciudadanos que acudieron a un médico especialista es mayor en Castilla y León que en Galicia. En 2013, el 87,43\% de los primeros consideraron esta visita como buena o muy buena frente al 83,21\% de los gallegos. En ambos casos, suponen incrementos respecto a los primeros años contabilizados, aunque la subida es bastante más acusada en Galicia, que, como muestra, en 2003, el 74,85\% de sus habitantes pensaban de esta manera. El 29,15\% de los castellano-leoneses opina que la atención que recibió en estas consultas fue mejor o mucho mejor a como esperaba que fuese frente al 28,67\% de los gallegos. En los últimos años, esta percepción aumenta en Galicia y disminuye en Castilla y León. 
Tabla 242. Proporción de ciudadanos que acudieron a un médico especialista de la sanidad pública que manifiestan que la atención que recibieron en estas consultas fue buena o muy buena

\begin{tabular}{|l|r|r|r|}
\hline Año & $\begin{array}{c}\text { Castilla y } \\
\text { León }\end{array}$ & \multicolumn{1}{c|}{ Galicia } & $\begin{array}{c}\text { Total } \\
\text { nacional }\end{array}$ \\
\hline 2013 & 87,43 & 83,21 & 83,95 \\
\hline 2012 & 80,65 & 83,44 & 83,46 \\
\hline 2011 & 84,90 & 76,51 & 82,70 \\
\hline 2010 & 87,42 & 74,82 & 81,48 \\
\hline 2009 & 83,80 & 75,00 & 82,00 \\
\hline 2008 & 85,28 & 83,75 & 81,74 \\
\hline 2007 & 90,87 & 71,76 & 81,14 \\
\hline 2006 & 84,76 & 79,58 & 81,61 \\
\hline 2005 & 79,70 & 69,80 & 76,50 \\
\hline 2004 & 83,48 & 69,33 & 80,00 \\
\hline 2003 & 83,42 & 74,85 & 80,26 \\
\hline Promedio & 84,70 & 76,55 & 81,35 \\
\hline
\end{tabular}

Fuente: Barómetro Sanitario del Instituto de Información Sanitaria (2013a).

Tabla 243. Proporción de ciudadanos que acudieron a un médico especialista de la sanidad pública y manifiestan que la atención que recibieron en estas consultas fue mejor o mucho mejor a como esperaban que fuese

\begin{tabular}{|l|r|r|r|}
\hline Año & $\begin{array}{c}\text { Castilla y } \\
\text { León }\end{array}$ & \multicolumn{1}{c|}{ Galicia } & $\begin{array}{c}\text { Total } \\
\text { nacional }\end{array}$ \\
\hline 2013 & 29,15 & 28,67 & 28,26 \\
\hline 2012 & 30,00 & 21,90 & 28,65 \\
\hline 2011 & 32,05 & 20,80 & 28,99 \\
\hline 2010 & 33,59 & 20,00 & 30,30 \\
\hline 2009 & 32,30 & 26,80 & 30,80 \\
\hline 2008 & 27,05 & 26,84 & 28,66 \\
\hline 2007 & 33,29 & 31,28 & 32,68 \\
\hline 2006 & 40,39 & 24,49 & 29,26 \\
\hline 2005 & 30,70 & 17,60 & 24,50 \\
\hline 2004 & 26,64 & 23,30 & 27,90 \\
\hline 2003 & 36,48 & 21,05 & 25,51 \\
\hline Promedio & 31,97 & 23,88 & 28,68 \\
\hline
\end{tabular}

Fuente: Barómetro Sanitario del Instituto de Información Sanitaria (2013a). 
En cambio, cuando se trata de un ingreso en el hospital, las cosas cambian. En este caso, los gallegos piensan que la atención recibida es buena o muy buena en el 90,32\% de los casos en 2013, un porcentaje que no deja de crecer con el paso de los años y que supone un incremento de quince puntos porcentuales respecto a 2003, por ejemplo. Inversamente, el $88,36 \%$ de los castellanoleoneses comparten esta idea, una cifra prácticamente idéntica a la producida en 2003, y que baja y sube indiferentemente según los ejercicios. Aun así, el $64,52 \%$ de los gallegos recibió una atención mejor o mucho mejor de lo que esperaba, frente al 48,92\% de los castellano-leoneses. En ambos casos, la valoración se muestra irregular entre unos años y otros.

Tabla 244. Proporción de ciudadanos que consideran que la atención recibida en el hospital público fue buena o muy buena

\begin{tabular}{|l|r|r|r|}
\hline Año & $\begin{array}{c}\text { Castilla y } \\
\text { León }\end{array}$ & \multicolumn{1}{c|}{ Galicia } & $\begin{array}{c}\text { Total } \\
\text { nacional }\end{array}$ \\
\hline 2013 & 88,36 & 90,32 & 87,66 \\
\hline 2012 & 87,88 & 88,24 & 86,70 \\
\hline 2011 & 86,20 & 93,34 & 87,79 \\
\hline 2010 & 94,32 & 91,88 & 85,72 \\
\hline 2009 & 87,50 & 91,20 & 87,50 \\
\hline 2008 & 92,68 & 85,22 & 85,59 \\
\hline 2007 & 90,67 & 86,44 & 84,56 \\
\hline 2006 & 90,01 & 82,04 & 83,44 \\
\hline 2005 & 93,20 & 85,80 & 85,80 \\
\hline 2004 & 93,32 & 84,38 & 87,90 \\
\hline 2003 & 86,24 & 75,97 & 81,86 \\
\hline Promedio & 90,03 & 86,80 & 85,87 \\
\hline
\end{tabular}

Fuente: Barómetro Sanitario del Instituto de Información Sanitaria (2013a).

Tabla 245. Proporción de ciudadanos que consideran que la atención que recibieron en el hospital público fue mejor o mucho mejor de lo que esperaban que fuese

\begin{tabular}{|l|r|r|r|}
\hline Año & $\begin{array}{c}\text { Castilla y } \\
\text { León }\end{array}$ & \multicolumn{1}{c|}{ Galicia } & $\begin{array}{c}\text { Total } \\
\text { nacional }\end{array}$ \\
\hline 2013 & 48,92 & 64,52 & 46,07 \\
\hline 2012 & 66,75 & 44,11 & 46,77 \\
\hline 2011 & 51,69 & 40,00 & 46,28 \\
\hline 2010 & 55,43 & 54,06 & 46,07 \\
\hline 2009 & 43,70 & 52,90 & 45,20 \\
\hline 2008 & 61,18 & 44,10 & 40,05 \\
\hline
\end{tabular}




\begin{tabular}{|l|r|r|r|}
\hline \multicolumn{1}{|c|}{ Año } & $\begin{array}{c}\text { Castilla y } \\
\text { León }\end{array}$ & \multicolumn{1}{c|}{ Galicia } & $\begin{array}{c}\text { Total } \\
\text { nacional }\end{array}$ \\
\hline 2007 & 46,56 & 54,08 & 47,50 \\
\hline 2006 & 49,98 & 35,86 & 46,53 \\
\hline 2005 & 41,00 & 28,60 & 43,00 \\
\hline 2004 & 96,63 & 34,38 & 44,70 \\
\hline 2003 & 40,01 & 37,99 & 38,82 \\
\hline Promedio & 54,71 & 44,60 & 44,64 \\
\hline
\end{tabular}

Fuente: Barómetro Sanitario del Instituto de Información Sanitaria (2013a).

La opinión de ambos grupos acerca de la información que facilitan las administraciones sanitarias sobre los servicios que prestan es similar, aunque ligeramente mejor en la comunidad castellana. Efectivamente, los residentes en Castilla y León aprueban a sus entidades con un 5,38 y Galicia, con un 5,04. La media nacional se sitúa más cerca de esta última cifra, más concretamente 5,09.

Tabla 246. Valoración de los ciudadanos sobre la información que facilitan las administraciones sanitarias sobre los servicios que prestan

\begin{tabular}{|l|r|r|r|}
\hline Año & $\begin{array}{c}\text { Castilla y } \\
\text { León }\end{array}$ & \multicolumn{1}{c|}{ Galicia } & $\begin{array}{c}\text { Total } \\
\text { nacional }\end{array}$ \\
\hline 2013 & 5,38 & 5,04 & 5,09 \\
\hline 2012 & 5,28 & 5,22 & 5,11 \\
\hline 2011 & 5,17 & 5,09 & 5,07 \\
\hline 2010 & 5,30 & 4,93 & 5,07 \\
\hline 2009 & 5,32 & 5,18 & 4,98 \\
\hline 2008 & 4,88 & 5,04 & 4,90 \\
\hline 2007 & 5,10 & 4,97 & 4,85 \\
\hline 2006 & 5,31 & 5,06 & 5,01 \\
\hline 2005 & 5,23 & 4,95 & 4,82 \\
\hline 2004 & 4,96 & 4,72 & 4,80 \\
\hline 2003 & 5,17 & 4,78 & 4,80 \\
\hline 2002 & 4,83 & 4,76 & 4,57 \\
\hline 2000 & 5,38 & 4,98 & 5,07 \\
\hline 1999 & 5,40 & 5,39 & 5,32 \\
\hline 1998 & 5,17 & 5,91 & 5,23 \\
\hline 1997 & 5,50 & 6,03 & 5,36 \\
\hline 1995 & 5,90 & 4,98 & 5,52 \\
\hline Promedio & 5,25 & 5,12 & 5,03 \\
\hline
\end{tabular}

Fuente: Barómetro Sanitario del Instituto de Información Sanitaria (2013a). 
Castilla y León también se encuentra por delante en la información que facilitan las administraciones sanitarias sobre los principales problemas de salud de la población. En 2013, en una escala de 1 a 10, los habitantes de esta región otorgaron a esta idea un 4,53, mientras que los de Galicia se quedaron en un 4,34. En ambos casos, se trata de cifras algo más elevadas que la media nacional $(4,25)$.

Tabla 247. Valoración de los ciudadanos sobre la información que facilitan las administraciones sanitarias sobre los principales problemas de salud de la población

\begin{tabular}{|l|r|r|r|}
\hline Año & $\begin{array}{c}\text { Castilla y } \\
\text { León }\end{array}$ & \multicolumn{1}{c|}{ Galicia } & $\begin{array}{c}\text { Total } \\
\text { nacional }\end{array}$ \\
\hline 2013 & 4,53 & 4,34 & 4,25 \\
\hline 2012 & 4,77 & 4,91 & 4,62 \\
\hline 2011 & 4,62 & 4,71 & 4,59 \\
\hline 2010 & 4,71 & 4,29 & 4,58 \\
\hline 2009 & 4,78 & 4,95 & 4,48 \\
\hline 2008 & 4,33 & 4,57 & 4,42 \\
\hline 2007 & 4,61 & 4,69 & 4,39 \\
\hline 2006 & 4,76 & 4,70 & 4,46 \\
\hline 2005 & 4,71 & 4,41 & 4,19 \\
\hline 2004 & 4,34 & 4,32 & 4,20 \\
\hline 2003 & 4,61 & 4,23 & 4,12 \\
\hline 2002 & 4,27 & 4,22 & 3,88 \\
\hline 2000 & 4,47 & 4,25 & 4,33 \\
\hline 1999 & 4,63 & 4,85 & 4,54 \\
\hline 1998 & 4,56 & 5,19 & 4,39 \\
\hline 1997 & 4,48 & 5,00 & 4,38 \\
\hline 1995 & 4,90 & 4,24 & 4,36 \\
\hline Promedio & 4,59 & 4,58 & 4,36 \\
\hline
\end{tabular}

Fuente: Barómetro Sanitario del Instituto de Información Sanitaria (2013a).

Curiosamente, los ciudadanos de las dos comunidades estudiadas en este trabajo otorgaron la misma puntuación a la información de las medidas y leyes que adoptan las autoridades sanitarias: 4,45. Se trata de dos décimas más que lo que ofrece el conjunto nacional, que se queda en 4,22. Salvo Galicia en dos años (concretamente en 1997 y 1998), no se ha registrado ningún aprobado en este tipo de información. 
Tabla 248. Valoración de los ciudadanos sobre las medidas y leyes que adoptan las autoridades sanitarias

\begin{tabular}{|l|r|r|r|}
\hline Año & $\begin{array}{c}\text { Castilla y } \\
\text { León }\end{array}$ & Galicia & $\begin{array}{c}\text { Total } \\
\text { nacional }\end{array}$ \\
\hline 2013 & 4,45 & 4,45 & 4,22 \\
\hline 2012 & 4,68 & 4,60 & 4,40 \\
\hline 2011 & 4,46 & 4,43 & 4,43 \\
\hline 2010 & 4,66 & 4,13 & 4,40 \\
\hline 2009 & 4,69 & 4,66 & 4,30 \\
\hline 2008 & 4,49 & 4,25 & 4,21 \\
\hline 2007 & 4,54 & 4,43 & 4,16 \\
\hline 2006 & 4,83 & 4,38 & 4,28 \\
\hline 2005 & 4,86 & 4,39 & 4,14 \\
\hline 2004 & 4,49 & 4,19 & 4,10 \\
\hline 2003 & 4,64 & 4,25 & 4,09 \\
\hline 2002 & 4,18 & 4,09 & 3,85 \\
\hline 2000 & 4,49 & 4,32 & 4,33 \\
\hline 1999 & 4,64 & 4,88 & 4,54 \\
\hline 1998 & 4,54 & 5,29 & 4,41 \\
\hline 1997 & 4,55 & 5,07 & 4,51 \\
\hline 1995 & 4,85 & 3,91 & 4,27 \\
\hline Promedio & 4,59 & 4,45 & 4,27 \\
\hline
\end{tabular}

Fuente: Barómetro Sanitario del Instituto de Información Sanitaria (2013a).

Castilla y León también se encuentra por delante cuando se trata de los derechos de los ciudadanos y sobre cómo y dónde pueden poner una reclamación. En 2013, esta región obtuvo una puntuación de 5,65, mientras que la región gallega consiguió un 5,56 en una escala de 1 a 10. El total nacional, aunque ligeramente más bajo, es muy parecido: 5,42. Estas puntuaciones son muy similares a las alcanzadas en los primeros años del barómetro sanitario. 
Tabla 249. Valoración de los ciudadanos sobre la información que las administraciones sanitarias ponen a su disposición de sus derechos, y sobre cómo y dónde pueden presentar reclamaciones

\begin{tabular}{|l|r|r|r|}
\hline Año & $\begin{array}{c}\text { Castilla y } \\
\text { León }\end{array}$ & \multicolumn{1}{c|}{ Galicia } & $\begin{array}{c}\text { Total } \\
\text { nacional }\end{array}$ \\
\hline 2013 & 5,65 & 5,56 & 5,42 \\
\hline 2012 & 6,04 & 6,07 & 5,62 \\
\hline 2011 & 5,81 & 5,86 & 5,58 \\
\hline 2010 & 5,91 & 5,75 & 5,61 \\
\hline 2009 & 6,02 & 5,83 & 5,55 \\
\hline 2008 & 5,37 & 5,54 & 5,45 \\
\hline 2007 & 5,51 & 5,45 & 5,46 \\
\hline 2006 & 5,65 & 5,71 & 5,57 \\
\hline 2005 & 5,67 & 5,38 & 5,51 \\
\hline 2004 & 5,46 & 5,08 & 5,40 \\
\hline 2003 & 5,59 & 5,12 & 5,32 \\
\hline 2002 & 5,07 & 5,08 & 4,97 \\
\hline 2000 & 5,77 & 5,43 & 5,52 \\
\hline 1999 & 5,97 & 5,88 & 5,74 \\
\hline 1998 & 5,79 & 6,17 & 5,63 \\
\hline 1997 & 6,01 & 6,21 & 5,70 \\
\hline 1995 & 5,68 & 5,76 & 5,79 \\
\hline Promedio & 5,70 & 5,64 & 5,52 \\
\hline
\end{tabular}

Fuente: Barómetro Sanitario del Instituto de Información Sanitaria (2013a).

Castilla y León también está por delante de Galicia en la información que las administraciones sanitarias ponen a disposición de los ciudadanos sobre los trámites para acudir a la consulta de un médico especialista o ingresar en un hospital. En 2012 (no se ha realizado esta pregunta en el barómetro sanitario de 2013), la primera región obtuvo en este aspecto una nota de 5,70 en una escala de 1 a 10, en comparación con el 5,01 de la segunda comunidad. La media nacional se sitúa en 5,26. 
Tabla 250. Valoración de los ciudadanos sobre la información que las administraciones sanitarias ponen a su disposición sobre los trámites para acudir a la consulta de un médico especialista o ingresar en un hospital

\begin{tabular}{|l|r|r|r|}
\hline Año & $\begin{array}{c}\text { Castilla y } \\
\text { León }\end{array}$ & Galicia & $\begin{array}{c}\text { Total } \\
\text { nacional }\end{array}$ \\
\hline 2013 & - & - & - \\
\hline 2012 & 5,70 & 5,01 & 5,26 \\
\hline 2011 & 5,31 & 5,01 & 5,17 \\
\hline 2010 & 5,65 & 4,78 & 5,20 \\
\hline 2009 & 5,67 & 5,28 & 5,18 \\
\hline 2008 & 5,53 & 4,84 & 5,10 \\
\hline 2007 & 5,37 & 4,79 & 5,00 \\
\hline 2006 & 5,70 & 4,83 & 5,01 \\
\hline 2005 & 5,64 & 4,82 & 5,00 \\
\hline 2004 & 5,46 & 4,62 & 5,10 \\
\hline 2003 & 5,48 & 4,68 & 4,97 \\
\hline 2002 & 5,40 & 4,52 & 4,84 \\
\hline 2000 & 5,79 & 4,90 & 5,43 \\
\hline 1999 & 5,85 & 5,43 & 5,56 \\
\hline 1998 & 5,72 & 5,73 & 5,46 \\
\hline 1997 & 5,44 & 5,91 & 5,36 \\
\hline Promedio & 5,58 & 5,01 & 5,18 \\
\hline
\end{tabular}

Fuente: Barómetro Sanitario del Instituto de Información Sanitaria (2013a).

\subsubsection{LA ELECCIÓN DE UN CENTRO SANITARIO EN BASE A SU TITULARIDAD}

El barómetro sanitario del Ministerio de Sanidad, Servicios Sociales e Igualdad también muestra la proporción de residentes que, si pudieran elegir, acudirían a un centro público o privado. En general, los gallegos visitarían antes los espacios públicos que los castellano-leoneses y tendrían menos indecisión a la hora de decidirse entre ambas titularidades. Además, estos resultados tienden a acentuarse a lo largo del tiempo; es decir, los gallegos cada vez elegirían más la sanidad pública frente a la privada y tendría menos dudas a la hora de tomar esta decisión. En cambio, en Castilla y León disminuye la percepción de calidad de los centros públicos y los ciudadanos cada vez optarían más por los espacios privados o les resultaría indiferente esta decisión, a excepción de los últimos tres años contabilizados, en los que parece que se invierte la tendencia. 
Por ejemplo, en cuanto al ingreso en un hospital, el $82,88 \%$ de los gallegos preferirían quedarse en un centro público, frente al $79,14 \%$ de sus vecinos. Solo el $11,64 \%$ de ellos iría a uno privado (frente al $15,18 \%$ de los castellano-leoneses) y el $4,80 \%$ le daría igual una titularidad que otra (mientras que en Castilla y León esta cifra sube hasta el 5,20). Observando la evolución temporal, se puede apreciar que la imagen de las clínicas públicas decae en Castilla y León (salvo el año 2013, en el que cambia la tendencia), mientras que en Galicia aumenta. En cualquier caso, la apreciación que tienen los ciudadanos de estas dos comunidades de la sanidad es mayor hacia la pública y menor hacia la privada que en el conjunto nacional.

Tabla 251. Proporción de ciudadanos que, si pudieran elegir, acudirían a un centro sanitario público y privado cuando se tratara de ingreso en un hospital

\begin{tabular}{|l|r|r|r|r|r|r|}
\hline \multirow{2}{*}{ Año } & \multicolumn{2}{|c|}{ Centro sanitario público } & \multicolumn{2}{c|}{ Centro sanitario privado } \\
\cline { 2 - 7 } & $\begin{array}{c}\text { Castilla y } \\
\text { León }\end{array}$ & Galicia & $\begin{array}{c}\text { Total } \\
\text { nacional }\end{array}$ & $\begin{array}{c}\text { Castilla y } \\
\text { León }\end{array}$ & Galicia & $\begin{array}{c}\text { Total } \\
\text { nacional }\end{array}$ \\
\hline 2013 & 79,14 & 82,88 & 63,53 & 15,18 & 11,64 & 30,04 \\
\hline 2012 & 72,14 & 80,27 & 60,67 & 21,42 & 14,74 & 32,01 \\
\hline 2011 & 63,55 & 79,35 & 59,56 & 26,20 & 14,29 & 32,33 \\
\hline 2010 & 66,65 & 70,46 & 58,79 & 21,53 & 23,18 & 33,73 \\
\hline 2009 & 69,50 & 67,60 & 58,40 & 25,30 & 26,10 & 34,10 \\
\hline 2008 & 74,80 & 75,82 & 58,96 & 18,65 & 17,22 & 33,36 \\
\hline 2007 & 72,62 & 70,79 & 61,66 & 22,48 & 23,00 & 31,59 \\
\hline 2006 & 75,68 & 66,57 & 59,47 & 18,06 & 24,66 & 33,01 \\
\hline 2005 & -- & -- & -- & -- & -- & -- \\
\hline 2004 & 75,11 & 69,01 & 62,40 & 20,92 & 21,60 & 30,20 \\
\hline 2003 & 82,29 & 79,66 & 69,10 & 13,79 & 12,76 & 24,00 \\
\hline Promedio & 73,15 & 74,24 & 61,25 & 20,35 & 18,92 & 31,44 \\
\hline
\end{tabular}

Fuente: Barómetro Sanitario del Instituto de Información Sanitaria (2013a). 
Tabla 252. Proporción de ciudadanos que, si pudieran elegir, acudirían a un centro sanitario público o privado indistintamente cuando se tratara de ingreso en un hospital

\begin{tabular}{|l|r|r|r|}
\hline Año & $\begin{array}{c}\text { Castilla y } \\
\text { León }\end{array}$ & \multicolumn{1}{c|}{ Galicia } & $\begin{array}{c}\text { Total } \\
\text { nacional }\end{array}$ \\
\hline 2013 & 5,20 & 4,80 & 5,84 \\
\hline 2012 & 6,44 & 4,99 & 6,38 \\
\hline 2011 & 9,53 & 6,35 & 7,39 \\
\hline 2010 & 11,12 & 6,36 & 6,59 \\
\hline 2009 & 4,20 & 5,60 & 6,60 \\
\hline 2008 & 6,30 & 6,48 & 6,86 \\
\hline 2007 & 4,19 & 6,20 & 5,75 \\
\hline 2006 & 5,55 & 8,29 & 6,67 \\
\hline 2005 & -- & -- & -- \\
\hline 2004 & 3,27 & 8,07 & 6,60 \\
\hline 2003 & 3,67 & 7,14 & 6,10 \\
\hline Promedio & 5,95 & 6,43 & 6,48 \\
\hline
\end{tabular}

Fuente: Barómetro Sanitario del Instituto de Información Sanitaria (2013a).

La atención en urgencias proporciona resultados similares. Los habitantes de Galicia escogerían antes un centro público que uno privado (con una diferencia de un $79,23 \%$ al 15,29\% en 2013). En Castilla y León, la tendencia es parecida: el 78,91\% de su población escogería un lugar del Sistema Nacional de Salud frente al 13,75\% que se decantaría por uno privado. Los gallegos son más decididos a la hora de decretar la titularidad de la atención de urgencias (solo a un 5,02\% le da igual), mientras que la cantidad de castellanoleoneses que no sabrían elegir entre una clase de clínica u otra es algo más elevada: el 6,63\%. Al igual que sucedía con el ingreso en un hospital, Galicia ha experimentado un crecimiento de la popularidad de sus centros públicos y una disminución de los privados, así como las personas que están indecisas entre unos y otros. Por el contrario, en Castilla y León se pueden observar dos tendencias temporales: desde 2003 hasta 2011, periodo en el cual la popularidad de los centros públicos disminuye, y desde 2011 hasta 2013, durante el cual sube en más de 15 puntos porcentuales. 
Tabla 253. Proporción de ciudadanos que, si pudieran elegir, acudirían a un centro sanitario público y privado cuando se tratara de atención en urgencias

\begin{tabular}{|l|r|r|r|r|r|r|}
\hline \multirow{2}{*}{ Año } & \multicolumn{2}{|c|}{ Centro sanitario público } & \multicolumn{2}{c|}{ Centro sanitario privado } \\
\cline { 2 - 7 } & $\begin{array}{c}\text { Castilla y } \\
\text { León }\end{array}$ & \multicolumn{1}{c|}{ Galicia } & $\begin{array}{c}\text { Total } \\
\text { nacional }\end{array}$ & $\begin{array}{c}\text { Castilla y } \\
\text { León }\end{array}$ & Galicia & \multicolumn{1}{c|}{$\begin{array}{c}\text { Total } \\
\text { nacional }\end{array}$} \\
\hline 2013 & 78,91 & 79,23 & 62,92 & 13,75 & 15,29 & 30,56 \\
\hline 2012 & 72,60 & 80,50 & 60,10 & 31,51 & 14,28 & 32,17 \\
\hline 2011 & 61,41 & 76,64 & 59,94 & 25,72 & 18,60 & 31,67 \\
\hline 2010 & 66,18 & 68,64 & 59,60 & 19,74 & 24,54 & 32,99 \\
\hline 2009 & 72,10 & 67,30 & 59,70 & 19,60 & 25 & 32,90 \\
\hline 2008 & 73,13 & 76,98 & 60,74 & 17,94 & 18,60 & 31,19 \\
\hline 2007 & 76,57 & 71,01 & 62,64 & 17,79 & 22,76 & 29,62 \\
\hline 2006 & 79,84 & 67,50 & 62,11 & 13,43 & 24,88 & 30,51 \\
\hline 2005 & --- & -- & -- & -- & -- & -- \\
\hline 2004 & 75,61 & 72,06 & 64,60 & 17,88 & 18,99 & 27,70 \\
\hline 2003 & 84,13 & 80,09 & 71,85 & 9,66 & 12,54 & 21,01 \\
\hline Promedio & 74,05 & 74,00 & 62,42 & 18,70 & 19,55 & 30,03 \\
\hline
\end{tabular}

Fuente: Barómetro Sanitario del Instituto de Información Sanitaria (2013a).

Tabla 254. Proporción de ciudadanos que, si pudieran elegir, acudirían a un centro sanitario público o privado indistintamente cuando se tratara de atención en urgencias

\begin{tabular}{|l|r|r|r|}
\hline Año & $\begin{array}{c}\text { Castilla y } \\
\text { León }\end{array}$ & \multicolumn{1}{c|}{ Galicia } & $\begin{array}{c}\text { Total } \\
\text { nacional }\end{array}$ \\
\hline 2013 & 6,63 & 5,02 & 5,85 \\
\hline 2012 & 9,78 & 4,99 & 6,92 \\
\hline 2011 & 12,62 & 4,76 & 7,60 \\
\hline 2010 & 13,84 & 6,82 & 6,65 \\
\hline 2009 & 6,60 & 6,50 & 6,50 \\
\hline 2008 & 8,68 & 3,48 & 7,26 \\
\hline 2007 & 5,16 & 5,75 & 6,83 \\
\hline 2006 & 6,25 & 7,37 & 6,59 \\
\hline 2005 & --- & -- & -- \\
\hline 2004 & 6,27 & 7,64 & 6,90 \\
\hline 2003 & 5,97 & 6,71 & 6,34 \\
\hline Promedio & 8,18 & 5,90 & 6,74 \\
\hline
\end{tabular}

Fuente: Barómetro Sanitario del Instituto de Información Sanitaria (2013a). 
En atención primaria, las diferencias entre ambas comunidades son algo más acusadas, y Galicia sigue obteniendo mejores cifras para su sanidad pública. Más concretamente, el $82,65 \%$ de sus ciudadanos acudiría a un ambulatorio de este tipo en 2013, un porcentaje que aumenta conforme pasan los años. En cambio, en Castilla y León consigue un $77,01 \%$ de las respuestas en el ámbito público, una cifra que sube únicamente desde 2011. El porcentaje de personas que acudirían a una atención primaria privada en Castilla y León se queda en el 14,46\% y en Galicia, en el 12,10\%. En ambos casos, se trata de cifras muy por debajo de la media nacional, que en ese mismo año proporcionó un 26,49\%. Las personas en la región castellana que se muestran indiferentes hacia un tipo de centro $u$ otro aumentan hasta llegar al 8,30\%, mientras que en Galicia se reduce hasta el 5,02\%.

Tabla 255. Proporción de ciudadanos que, si pudieran elegir, acudirían a un centro sanitario público y privado cuando se tratara de atención primaria (consultas de medicina de familia y pediatría)

\begin{tabular}{|l|r|r|r|r|r|r|}
\hline \multirow{2}{*}{ Año } & \multicolumn{2}{|c|}{ Centro sanitario público } & \multicolumn{2}{c|}{ Centro sanitario privado } \\
\cline { 2 - 7 } & $\begin{array}{c}\text { Castilla y } \\
\text { León }\end{array}$ & \multicolumn{1}{c|}{ Galicia } & $\begin{array}{c}\text { Total } \\
\text { nacional }\end{array}$ & $\begin{array}{c}\text { Castilla y } \\
\text { León }\end{array}$ & Galicia & $\begin{array}{c}\text { Total } \\
\text { nacional }\end{array}$ \\
\hline 2013 & 77,01 & 82,65 & 68,17 & 14,46 & 12,10 & 26,49 \\
\hline 2012 & 73,09 & 78,92 & 64,36 & 20,23 & 15,19 & 29,05 \\
\hline 2011 & 71,90 & 75,50 & 63,44 & 18,32 & 19,73 & 28,60 \\
\hline 2010 & 76,09 & 70,91 & 63,86 & 15,07 & 25,00 & 29,75 \\
\hline 2009 & 77,30 & 73,40 & 62,80 & 18,00 & 20,70 & 31,30 \\
\hline 2008 & 78,53 & 76,07 & 62,94 & 16,07 & 17,88 & 30,99 \\
\hline 2007 & 73,32 & 68,02 & 61,74 & 23,40 & 26,67 & 32,30 \\
\hline 2006 & 76,38 & 64,51 & 58,69 & 18,98 & 29,49 & 34,52 \\
\hline 2005 & -- & -- & -- & -- & -- & -- \\
\hline 2004 & 73,48 & 70,10 & 59,60 & 20,45 & 21,17 & 32,90 \\
\hline 2003 & 81,83 & 75,97 & 65,10 & 15,40 & 15,80 & 27,78 \\
\hline Promedio & 75,89 & 73,61 & 63,07 & 18,04 & 20,37 & 30,37 \\
\hline
\end{tabular}

Fuente: Barómetro Sanitario del Instituto de Información Sanitaria (2013a). 
Tabla 256. Proporción de ciudadanos que, si pudieran elegir, acudirían a un centro sanitario público o privado indistintamente cuando se tratara de atención primaria (consultas de medicina de familia y pediatría)

\begin{tabular}{|l|r|r|r|}
\hline Año & $\begin{array}{c}\text { Castilla y } \\
\text { León }\end{array}$ & \multicolumn{1}{c|}{ Galicia } & \multicolumn{1}{c|}{$\begin{array}{c}\text { Total } \\
\text { nacional }\end{array}$} \\
\hline 2013 & 8,30 & 5,02 & 4,96 \\
\hline 2012 & 6,45 & 5,89 & 6,10 \\
\hline 2011 & 9,06 & 4,76 & 6,44 \\
\hline 2010 & 8,83 & 4,09 & 5,79 \\
\hline 2009 & 3,80 & 5,00 & 5,50 \\
\hline 2008 & 5,16 & 5,80 & 5,60 \\
\hline 2007 & 3,03 & 5,30 & 5,38 \\
\hline 2006 & 4,40 & 5,99 & 6,34 \\
\hline 2005 & -- & -- & -- \\
\hline 2004 & 5,37 & 7,64 & 6,70 \\
\hline 2003 & 2,52 & 7,35 & 6,43 \\
\hline Promedio & 5,69 & 5,68 & 5,92 \\
\hline
\end{tabular}

Fuente: Barómetro Sanitario del Instituto de Información Sanitaria (2013a).

También se encuentran diferencias entre centros públicos y privados en la atención especializada, es decir, en consultas de especialistas, salvo dentistas y odontólogos. A pesar de que en Galicia la variación se incrementa con el paso de los años, no es tan acusada como en otros ámbitos. Así, el 60,96\% de sus habitantes elegiría un especialista público 2013 frente al $28,76 \%$ de la población que optaría por uno privado. La indiferencia entre un tipo $u$ otro alcanza en este caso el máximo nivel para esta comunidad, hasta llegar al 10,05\%. En Castilla y León, al igual que sucede en otros casos, disminuye la valoración que tienen los ciudadanos hacia la sanidad pública y crece la privada desde 20013 hasta 2011, pero se invierte la tendencia a partir de ese segundo año. Así, en 2013, el 56,15\% de los castellano-leoneses elegirían un especialista público, el 30,83\% uno privado y al 12,78\% restante le daría igual uno que otro. 
Tabla 257. Proporción de ciudadanos que, si pudieran elegir, acudirían a un centro sanitario público y privado cuando se tratara de atención especializada (consultas de especialistas, salvo dentistas y odontólogos)

\begin{tabular}{|l|r|r|r|r|r|r|}
\hline \multirow{2}{*}{ Año } & \multicolumn{2}{|c|}{ Centro sanitario público } & \multicolumn{2}{c|}{ Centro sanitario privado } \\
\cline { 2 - 7 } & $\begin{array}{c}\text { Castilla y } \\
\text { León }\end{array}$ & \multicolumn{1}{c|}{ Galicia } & $\begin{array}{c}\text { Total } \\
\text { nacional }\end{array}$ & $\begin{array}{c}\text { Castilla y } \\
\text { León }\end{array}$ & \multicolumn{1}{c|}{ Galicia } & \multicolumn{1}{c|}{$\begin{array}{c}\text { Total } \\
\text { nacional }\end{array}$} \\
\hline 2013 & 56,15 & 60,96 & 52,93 & 30,83 & 28,76 & 38,47 \\
\hline 2012 & 59,25 & 64,17 & 51,09 & 32,39 & 26,53 & 40,37 \\
\hline 2011 & 50,95 & 60,99 & 49,48 & 37,15 & 29,94 & 41,59 \\
\hline 2010 & 54,93 & 49,09 & 47,97 & 29,98 & 38,86 & 42,94 \\
\hline 2009 & 53,20 & 46,80 & 46,80 & 35,20 & 42,60 & 45,20 \\
\hline 2008 & 61,49 & 57,20 & 47,91 & 29,13 & 30,03 & 43,60 \\
\hline 2007 & 58,84 & 56,32 & 49,75 & 34,14 & 34,02 & 42,68 \\
\hline 2006 & 59,48 & 48,60 & 46,19 & 29,40 & 39,17 & 45,62 \\
\hline 2005 & --- & -- & -- & -- & -- & -- \\
\hline 2004 & 56,72 & 52,19 & 47,50 & 32,78 & 31,21 & 42,60 \\
\hline 2003 & 68,26 & 58,72 & 53,49 & 23,23 & 25,09 & 35,94 \\
\hline Promedio & 57,93 & 55,50 & 49,31 & 31,42 & 32,62 & 41,90 \\
\hline
\end{tabular}

Fuente: Barómetro Sanitario del Instituto de Información Sanitaria (2013a).

Tabla 258. Proporción de ciudadanos que, si pudieran elegir, acudirían a un centro sanitario público o privado indistintamente cuando se tratara de atención especializada (consultas de especialistas, salvo dentistas y odontólogos)

\begin{tabular}{|l|r|r|r|}
\hline Año & $\begin{array}{c}\text { Castilla y } \\
\text { León }\end{array}$ & \multicolumn{1}{c|}{ Galicia } & $\begin{array}{c}\text { Total } \\
\text { nacional }\end{array}$ \\
\hline 2013 & 12,78 & 10,05 & 8,23 \\
\hline 2012 & 8,35 & 9,30 & 7,88 \\
\hline 2011 & 11,43 & 9,07 & 8,44 \\
\hline 2010 & 14,86 & 12,04 & 8,37 \\
\hline 2009 & 10,40 & 9,90 & 7,40 \\
\hline 2008 & 9,37 & 12,06 & 7,87 \\
\hline 2007 & 6,54 & 9,42 & 6,82 \\
\hline 2006 & 10,87 & 11,52 & 7,63 \\
\hline 2005 & -- & -- & -- \\
\hline 2004 & 10,26 & 15,94 & 9,20 \\
\hline 2003 & 8,50 & 15,97 & 9,96 \\
\hline Promedio & 10,34 & 11,53 & 8,18 \\
\hline
\end{tabular}

Fuente: Barómetro Sanitario del Instituto de Información Sanitaria (2013a). 


\subsection{MOTIVOS PARA LA ELECCIÓN DE UNA DETERMINADA TITULARIDAD}

Siguiendo con el tono general que proporciona la elección de una determinada titularidad de los hospitales, los ciudadanos de Galicia otorgan una nota acusadamente mayor a los centros públicos que a los privados en los nueve aspectos estudiados por el Barómetro Sanitario del Ministerio de Sanidad, Servicios Sociales e Igualdad para comprender los motivos por los que los habitantes se decantan por una dependencia $u$ otra. Además, las calificaciones de los centros públicos de esta comunidad son bastantes más altas que las de la media nacional, y las de los privados sensiblemente más bajas que las del conjunto del país. La popularidad de unos en detrimento de los otros se acentúa con el paso de los años; es decir, cada vez hay más personas gallegas que prefieren la sanidad pública y menos las que se decantan por la privada.

La situación de Castilla y León no es tan extrema. Existen elementos por los que los ciudadanos elegirían la sanidad pública (por ejemplo, la tecnología, la capacitación de los médicos y del personal de enfermería y la información facilitada). Sin embargo, existen dos aspectos que sobresalen en los centros privados para los castellano-leoneses y que no sucede con los gallegos. Es el caso de la rapidez en la atención recibida y el confort de las instalaciones. Además, al contrario de lo que ocurre con Galicia, la popularidad de la sanidad pública, en general, disminuye con el paso del tiempo, quedándose por debajo de la media nacional en varias ocasiones.

Una de las mayores discrepancias entre ambas regiones en cuanto a valoración de la sanidad pública se encuentra en el confort de las instalaciones, a la que Galicia otorga casi 20 puntos porcentuales más que Castilla y León (más concretamente, el 60,28\% de los ciudadanos gallegos elegirían un centro público por sus instalaciones en 2013, frente al 43,12\% de los castellano-leoneses). En cambio, casi la mitad de los habitantes de la región castellana preferiría un centro privado por este aspecto (más específicamente el $46,22 \%)$, mientras que en el caso de los gallegos se queda en el tercio $(30,14 \%)$. 
Tabla 259. Proporción de ciudadanos que, si pudieran elegir, elegirían un servicio sanitario público y privado teniendo en cuenta el confort de las instalaciones

\begin{tabular}{|l|r|r|r|r|r|r|}
\hline \multirow{2}{*}{ Año } & \multicolumn{2}{|c|}{ Centro sanitario público } & \multicolumn{2}{c|}{ Centro sanitario privado } \\
\cline { 2 - 7 } & $\begin{array}{c}\text { Castilla y } \\
\text { León }\end{array}$ & \multicolumn{1}{c|}{ Galicia } & $\begin{array}{c}\text { Total } \\
\text { nacional }\end{array}$ & $\begin{array}{c}\text { Castilla y } \\
\text { León }\end{array}$ & \multicolumn{1}{c|}{ Galicia } & \multicolumn{1}{c|}{$\begin{array}{c}\text { Total } \\
\text { nacional }\end{array}$} \\
\hline 2013 & 43,12 & 60,28 & 42,21 & 46,22 & 30,14 & 49,15 \\
\hline 2012 & 39,29 & 63,49 & 38,17 & 52,61 & 25,62 & 52,23 \\
\hline 2011 & 34,51 & 63,94 & 38,85 & 51,44 & 27,21 & 51,00 \\
\hline 2010 & 35,05 & 52,27 & 35,76 & 53,30 & 39,09 & 54,63 \\
\hline 2009 & 36,20 & 45,50 & 33,60 & 56,30 & 41,90 & 56,70 \\
\hline 2008 & 41,41 & 47,46 & 32,62 & 46,65 & 39,27 & 57,32 \\
\hline 2007 & --- & -- & -- & -- & -- & -- \\
\hline 2006 & 31,48 & 30,62 & 24,50 & 56,71 & 52,78 & 63,55 \\
\hline 2005 & -- & -- & -- & -- & -- & -- \\
\hline 2004 & 31,78 & 44,53 & 32,50 & 58,71 & 45,86 & 56,00 \\
\hline Promedio & 36,61 & 51,01 & 34,78 & 52,74 & 37,73 & 55,07 \\
\hline
\end{tabular}

Fuente: Barómetro Sanitario del Instituto de Información Sanitaria (2013a).

El trato personal recibido ofrece cifras similares. Los gallegos elegirían un centro público por este motivo en el $62,56 \%$ de los casos en 2013 y uno privado en el 24,43\%. Se trata de cifras muy dispares de las que ofrece el conjunto nacional. En general, el $49,91 \%$ de los españoles prefiere el trato recibido de la sanidad pública y el 35,75\%, de la privada. Este aspecto en Galicia crece según pasan los años: en comparación con 2004, el año 2013 registra una subida de 18,82 puntos porcentuales, y con 2006, 28,02. Ocurre inversamente lo contrario con los centros privados: bajan un 18,44 respecto a 2004 y alcanza el máximo de 22,57 puntos porcentuales más en 2006.

Castilla y León se asemeja más al conjunto del país, aunque los centros públicos tienen peor media que el total nacional y los privados, mejor puntuación. Aunque las diferencias no sean tan marcadas como en Galicia, sus habitantes sitúan por encima de la media nacional la sanidad privada en detrimento de la pública. En el siguiente orden, los castellano-leoneses prefieren el trato de los centros privados antes que el de los públicos: $44,08 \%$ y $37,21 \%$. 
Tabla 260. Proporción de ciudadanos que, si pudieran elegir, elegirían un servicio sanitario público y privado teniendo en cuenta el trato personal recibido

\begin{tabular}{|l|r|r|r|r|r|r|}
\hline \multirow{2}{*}{ Año } & \multicolumn{2}{|c|}{ Centro sanitario público } & \multicolumn{2}{c|}{ Centro sanitario privado } \\
\cline { 2 - 7 } & $\begin{array}{c}\text { Castilla y } \\
\text { León }\end{array}$ & \multicolumn{1}{c|}{ Galicia } & $\begin{array}{c}\text { Total } \\
\text { nacional }\end{array}$ & $\begin{array}{c}\text { Castilla y } \\
\text { León }\end{array}$ & \multicolumn{1}{c|}{ Galicia } & \multicolumn{1}{c|}{$\begin{array}{c}\text { Total } \\
\text { nacional }\end{array}$} \\
\hline 2013 & 44,08 & 62,56 & 49,91 & 37,21 & 24,43 & 35,75 \\
\hline 2012 & 45,72 & 64,40 & 45,14 & 35,22 & 19,72 & 38,11 \\
\hline 2011 & 37,37 & 66,21 & 44,46 & 45,00 & 22,00 & 40,19 \\
\hline 2010 & 41,21 & 50 & 41,61 & 36,81 & 36,37 & 42,34 \\
\hline 2009 & 38,80 & 49,80 & 39,90 & 38,50 & 37,60 & 44,10 \\
\hline 2008 & 46,08 & 49,34 & 40,04 & 33,58 & 37,62 & 44,30 \\
\hline 2007 & -- & -- & -- & -- & -- & -- \\
\hline 2006 & 39,34 & 34,54 & 31,93 & 41,20 & 47,00 & 47,90 \\
\hline 2005 & -- & -- & -- & -- & -- & -- \\
\hline 2004 & 34,93 & 43,74 & 37,10 & 51,76 & 42,87 & 45,40 \\
\hline Promedio & 40,94 & 52,57 & 41,26 & 39,91 & 33,45 & 42,26 \\
\hline
\end{tabular}

Fuente: Barómetro Sanitario del Instituto de Información Sanitaria (2013a).

También se encuentra por debajo de la media nacional la rapidez de la atención recibida en los centros públicos y privados de Castilla y León $(35,55 \%$ y 57,35\% en Castilla y León, respectivamente, y 36,49\% y 58,74\% en el conjunto del país). En cambio, al igual que sucede con el resto de motivos propuestos por el Barómetro Sanitario, Galicia otorga mejores cifras a su sanidad pública que privada, alejándose notablemente de la media nacional. Frente al 36,49\% del primer caso y 58,74\% del segundo en el conjunto del país, los gallegos elegirían una titularidad u otra por la rapidez de la atención en un 50,46\% y un 45,66\%, en este orden. El año 2011 parece ser un punto de inflexión para ambas comunidades. En Castilla y León, a partir de ese momento aumenta la percepción de rapidez de la atención en el ámbito público y disminuye en el privado, mientras que en Galicia es al contrario. 
Tabla 261. Proporción de ciudadanos que, si pudieran elegir, elegirían un servicio sanitario público teniendo en cuenta la rapidez de la atención

\begin{tabular}{|l|r|r|r|r|r|r|}
\hline \multirow{2}{*}{ Año } & \multicolumn{2}{|c|}{ Centro sanitario público } & \multicolumn{2}{c|}{ Centro sanitario privado } \\
\cline { 2 - 7 } & $\begin{array}{c}\text { Castilla y } \\
\text { León }\end{array}$ & \multicolumn{1}{c|}{ Galicia } & $\begin{array}{c}\text { Total } \\
\text { nacional }\end{array}$ & $\begin{array}{c}\text { Castilla y } \\
\text { León }\end{array}$ & \multicolumn{1}{c|}{ Galicia } & $\begin{array}{c}\text { Total } \\
\text { nacional }\end{array}$ \\
\hline 2013 & 35,55 & 50,46 & 36,49 & 57,35 & 45,66 & 58,74 \\
\hline 2012 & 32,12 & 53,06 & 32,64 & 63,60 & 37,64 & 61,50 \\
\hline 2011 & 29,27 & 54,19 & 33,32 & 60,96 & 39,46 & 60,76 \\
\hline 2010 & 32,63 & 37,27 & 30,27 & 59,26 & 57,27 & 63,89 \\
\hline 2009 & 33,30 & 32,00 & 28,20 & 61,90 & 62,20 & 65,60 \\
\hline 2008 & 38,63 & 37,94 & 29,32 & 52,49 & 57,39 & 64,46 \\
\hline 2007 & -- & -- & -- & -- & -- & -- \\
\hline 2006 & 31,24 & 21,63 & 22,62 & 59,72 & 71,91 & 70,20 \\
\hline 2005 & -- & -- & -- & -- & -- & -- \\
\hline 2004 & 29,20 & 33,24 & 27,20 & 66,09 & 62,32 & 65,30 \\
\hline Promedio & 32,74 & 39,97 & 30,01 & 60,17 & 54,23 & 63,81 \\
\hline
\end{tabular}

Fuente: Barómetro Sanitario del Instituto de Información Sanitaria (2013a).

También crece conforme pasan los años la creencia de que la tecnología, los medios, el personal de enfermería y los médicos están más capacitados en la sanidad pública que en la privada gallega. En el caso de Castilla y León, se observa un aumento de la popularidad de estos aspectos en el terreno público, pero únicamente a partir del año 2011.

Donde parece que hay una mayor desigualdad entre las dos regiones es en la proporción de ciudadanos que elegirían un centro sanitario público por la capacitación de sus médicos. En los últimos años la cifra no ha parado de aumentar en Galicia, en comparación con aquellas personas que se decantarían por un servicio privado, que decrece en los mismos ejercicios. Así, en 2013, el 79,91\% de los gallegos acudirían a un edificio gestionado por el Sergas frente al $8,90 \%$ que preferiría una titularidad privada. Se trata de un aumento considerable respecto a registros anteriores, como en 2004, cuyos porcentajes se quedaron en $62,00 \%$ y 20,44\%, en este orden. En Castilla y León, aunque la diferencia es proporcional, no es tan acusada $(65,41 \%$ ante un $7,59 \%)$ y no crece tan acusadamente con el paso de los años, ya que las cifras casi siempre se encuentran en esas decenas. 
Tabla 262. Proporción de ciudadanos que, si pudieran elegir, elegirían un servicio sanitario público y privado teniendo en cuenta la capacitación de los médicos

\begin{tabular}{|l|r|r|r|r|r|r|}
\hline \multirow{2}{*}{ Año } & \multicolumn{2}{|c|}{ Centro sanitario público } & \multicolumn{2}{c|}{ Centro sanitario privado } \\
\cline { 2 - 7 } & $\begin{array}{c}\text { Castilla y } \\
\text { León }\end{array}$ & Galicia & $\begin{array}{c}\text { Total } \\
\text { nacional }\end{array}$ & $\begin{array}{c}\text { Castilla y } \\
\text { León }\end{array}$ & Galicia & $\begin{array}{c}\text { Total } \\
\text { nacional }\end{array}$ \\
\hline 2013 & 65,41 & 79,91 & 65,47 & 7,59 & 8,90 & 17,19 \\
\hline 2012 & 64,51 & 76,65 & 60,99 & 7,61 & 9,75 & 18,23 \\
\hline 2011 & 58,09 & 76,18 & 60,06 & 11,90 & 13,16 & 20,14 \\
\hline 2010 & 57,38 & 69,32 & 58,10 & 13,24 & 16,14 & 20,88 \\
\hline 2009 & 57,40 & 67,10 & 57,30 & 14,90 & 17,60 & 21,10 \\
\hline 2008 & 63,61 & 66,48 & 55,84 & 10,70 & 18,60 & 21,75 \\
\hline 2007 & -- & -- & -- & -- & -- & -- \\
\hline 2006 & 56,25 & 55,74 & 49,42 & 15,04 & 18,66 & 19,26 \\
\hline 2005 & -- & -- & -- & -- & -- & -- \\
\hline 2004 & 54,72 & 62,00 & 50,10 & 13,74 & 20,44 & 20,90 \\
\hline Promedio & 59,67 & 69,17 & 57,16 & 11,84 & 15,41 & 19,93 \\
\hline
\end{tabular}

Fuente: Barómetro Sanitario del Instituto de Información Sanitaria (2013a).

El personal, pero en este caso el de enfermería, también es más destacable para los gallegos a la hora de decantarse por una dependencia $u$ otra. Las cifras con este grupo son muy similares a las que arrojan los médicos, ya que en Galicia es mucho más alta en el caso de los públicos y aumenta conforme pasan los años en detrimento de los privados. En cambio, en Castilla y León la disparidad no es tan amplia y no se observa la misma tendencia en su evolución temporal, aunque es cierto que en los últimos cuatro años la popularidad de los públicos en este territorio ha crecido. Así, como muestra, en la primera región el $81,05 \%$ de sus habitantes escogerían un centro público en 2013 frente al $7,30 \%$ que iría a uno privado, unos porcentajes más dispares respecto a los recogidos, por ejemplo, en 2004 (61,18\% y 21,41\%, respectivamente) o en 2006 (55,28\% y 18,44\%, en este orden). En Castilla y León, nuevamente, las cantidades se mantienen prácticamente siempre en la misma decena (salvo en 2012 y 2013) y no sufren unos cambios tan marcados. En 2013, el 67,30\% de los castellano-leoneses elegirían el Sistema Nacional de Salud y el 7,12\%, el mercado privado. 
Tabla 263. Proporción de ciudadanos que, si pudieran elegir, elegirían un servicio sanitario público y privado teniendo en cuenta la capacitación del personal de enfermería

\begin{tabular}{|l|r|r|r|r|r|r|}
\hline \multirow{2}{*}{ Año } & \multicolumn{2}{|c|}{ Centro sanitario público } & \multicolumn{2}{c|}{ Centro sanitario privado } \\
\cline { 2 - 7 } & $\begin{array}{c}\text { Castilla y } \\
\text { León }\end{array}$ & \multicolumn{1}{c|}{ Galicia } & $\begin{array}{c}\text { Total } \\
\text { nacional }\end{array}$ & $\begin{array}{c}\text { Castilla y } \\
\text { León }\end{array}$ & \multicolumn{1}{c|}{ Galicia } & $\begin{array}{c}\text { Total } \\
\text { nacional }\end{array}$ \\
\hline 2013 & 67,30 & 81,05 & 65,06 & 7,12 & 7,30 & 17,35 \\
\hline 2012 & 64,03 & 77,10 & 60,15 & 6,88 & 10,88 & 18,44 \\
\hline 2011 & 59,28 & 76,18 & 59,71 & 9,99 & 12,25 & 19,60 \\
\hline 2010 & 58,07 & 67,28 & 57,10 & 12,26 & 17,50 & 20,98 \\
\hline 2009 & 58,40 & 68,90 & 56,20 & 12,30 & 17,10 & 20,80 \\
\hline 2008 & 62,66 & 63,48 & 54,60 & 13,26 & 20,45 & 21,96 \\
\hline 2007 & -- & -- & -- & -- & -- & -- \\
\hline 2006 & 56,48 & 55,28 & 47,35 & 12,50 & 18,44 & 20,47 \\
\hline 2005 & -- & -- & -- & -- & -- & -- \\
\hline 2004 & 58,29 & 61,18 & 50,80 & 12,78 & 21,41 & 20,80 \\
\hline Promedio & 60,56 & 68,81 & 56,37 & 10,89 & 15,67 & 20,05 \\
\hline
\end{tabular}

Fuente: Barómetro Sanitario del Instituto de Información Sanitaria (2013a).

También existen resultados muy dispares cuando se pregunta a la población sobre la tecnología y medios de los que disponen los edificios de ambas dependencias. El $85,17 \%$ de los gallegos (en comparación con el 71,10\% de la media nacional) optaría por un centro público respecto al $9,36 \%$ que seleccionaría uno privado. Son diferencias que han aumentado desde el primer ejercicio registrado. Castilla y León también sigue estando en 2013 por encima del conjunto del país en la elección de servicios públicos (con un 81,51\%). Aunque desde 2004 hasta 2011, en general, se ha registrado una bajada de popularidad en los centros públicos a favor de los privados, a partir del segundo año revierte la tendencia. 
Tabla 264. Proporción de ciudadanos que, si pudieran elegir, elegirían un servicio sanitario público y privado teniendo en cuenta la tecnología y los medios de que dispone

\begin{tabular}{|l|r|r|r|r|r|r|}
\hline \multirow{2}{*}{ Año } & \multicolumn{2}{|c|}{ Centro sanitario público } & \multicolumn{2}{c|}{ Centro sanitario privado } \\
\cline { 2 - 7 } & $\begin{array}{c}\text { Castilla y } \\
\text { León }\end{array}$ & Galicia & $\begin{array}{c}\text { Total } \\
\text { nacional }\end{array}$ & $\begin{array}{c}\text { Castilla y } \\
\text { León }\end{array}$ & Galicia & $\begin{array}{c}\text { Total } \\
\text { nacional }\end{array}$ \\
\hline 2013 & 81,51 & 85,17 & 71,10 & 9,73 & 9,36 & 21,62 \\
\hline 2012 & 80,93 & 79,82 & 66,92 & 10,01 & 12,93 & 23,03 \\
\hline 2011 & 72,38 & 83,21 & 66,76 & 15,00 & 10,43 & 23,81 \\
\hline 2010 & 72,20 & 76,82 & 65,05 & 14,57 & 17,73 & 24,80 \\
\hline 2009 & 73,70 & 71,40 & 64,90 & 17,70 & 21,60 & 25,60 \\
\hline 2008 & 78,07 & 70,45 & 63,65 & 12,12 & 20,00 & 26,09 \\
\hline 2007 & -- & -- & -- & -- & -- & -- \\
\hline 2006 & 74,06 & 68,42 & 61,80 & 12,50 & 20,74 & 23,59 \\
\hline 2005 & -- & -- & -- & -- & -- & -- \\
\hline 2004 & 75,68 & 71,78 & 64,20 & 14,38 & 18,67 & 22,20 \\
\hline Promedio & 76,07 & 75,88 & 65,55 & 13,25 & 16,43 & 23,84 \\
\hline
\end{tabular}

Fuente: Barómetro Sanitario del Instituto de Información Sanitaria (2013a).

Aunque los resultados no son tan dispares, los ciudadanos tanto gallegos como castellano-leoneses prefieren la sanidad pública teniendo en cuenta la información facilitada sobre su problema de salud, aunque, como en anteriores apartados, la proporción es más alta en Galicia. En esta comunidad, en 2013, el 68,27\% de sus residentes elegirían un servicio de esta titularidad, en comparación con el 18,04\% que se decantaría por la competencia. En otros años la disparidad no era tan acusada, e incluso en un ejercicio, más concretamente en 2006, las cifras se tornan: $38,46 \%$ de los habitantes irían a un centro público frente al $41,01 \%$. De esta manera, se aprecia que la reputación del Sistema Nacional de Salud en este aspecto ha crecido en esta comunidad con el paso del tiempo en detrimento de los servicios privados. En cambio, en Castilla y León, la valoración de la información facilitada sube y baja indistintamente según años en ambas dependencias y las diferencias nunca son tan amplias como en Galicia. En el último año contabilizado, el 49,76\% de los castellano-leoneses habría escogido un centro público frente al 22,03\% que habría hecho lo mismo con uno privado. 
Tabla 265. Proporción de ciudadanos que, si pudieran elegir, elegirían un servicio sanitario público teniendo en cuenta la información facilitada sobre su problema de salud

\begin{tabular}{|l|r|r|r|r|r|r|}
\hline \multirow{2}{*}{ Año } & \multicolumn{2}{|c|}{ Centro sanitario público } & \multicolumn{2}{c|}{ Centro sanitario privado } \\
\cline { 2 - 7 } & $\begin{array}{c}\text { Castilla y } \\
\text { León }\end{array}$ & Galicia & $\begin{array}{c}\text { Total } \\
\text { nacional }\end{array}$ & $\begin{array}{c}\text { Castilla y } \\
\text { León }\end{array}$ & \multicolumn{1}{c|}{ Galicia } & \multicolumn{1}{c|}{$\begin{array}{c}\text { Total } \\
\text { nacional }\end{array}$} \\
\hline 2013 & 49,76 & 68,27 & 54,27 & 22,03 & 18,04 & 29,33 \\
\hline 2012 & 48,33 & 69,16 & 49,47 & 23,09 & 16,78 & 31,19 \\
\hline 2011 & 43,57 & 67,12 & 48,44 & 23,56 & 20,87 & 32,96 \\
\hline 2010 & 46,46 & 56,14 & 46,28 & 21,37 & 31,62 & 34,62 \\
\hline 2009 & 42,50 & 52,20 & 43,80 & 25,80 & 34,70 & 37,30 \\
\hline 2008 & 49,36 & 50,95 & 42,96 & 22,85 & 34,13 & 38,22 \\
\hline 2007 & -- & -- & -- & -- & -- & -- \\
\hline 2006 & 47,22 & 38,46 & 35,51 & 30,32 & 41,01 & 40,74 \\
\hline 2005 & -- & -- & -- & -- & -- & -- \\
\hline 2004 & 42,28 & 49,10 & 40 & 37,27 & 37,51 & 38,80 \\
\hline Promedio & 46,19 & 56,43 & 45,09 & 25,79 & 29,33 & 35,40 \\
\hline
\end{tabular}

Fuente: Barómetro Sanitario del Instituto de Información Sanitaria (2013a). 


\section{CONCLUSIONES}

3.1. Resumen de los resultados

3.2. Verificación de las hipótesis 3.3. Conclusiones finales 


\subsection{RESUMEN DE LOS RESULTADOS}

\subsubsection{CARACTERÍSTICAS DE LAS ESTRUCTURAS COMUNICATIVAS}

A pesar de disponer de recursos hospitalarios muy similares, las dos comunidades estudiadas presentan estructuras diferentes en cuanto a comunicación sanitaria se refiere. Por un lado, Castilla y León centraliza la comunicación de todos los hospitales públicos en el departamento de comunicación de la Consejería de Sanidad de la Junta. Así, la información que se trasmite desde este departamento está más vinculada a las labores de este órgano, mientras que los datos concretos de hospitales o actividad hospitalaria se emiten normalmente desde la delegación de la Junta de Castilla y León de cada provincia, que se ocupa de todo lo relativo a su división. En cambio, en Galicia, aparte de disponer de un departamento de comunicación en la Consellería de Sanidade de la Xunta, también hay gabinetes de este tipo en cada estructura de gestión integrada, que son divisiones de territorio que engloban tanto los centros de atención primaria como especializada. Así, se dispone de siete servicios de este tipo repartidos en estas zonas, que son los que se encargan de informar sobre la actividad hospitalaria y la divulgación sanitaria, más el de la Consellería de Sanidade, que se ocupa de las labores de dicho órgano y de los temas más relevantes.

No hay diferencias, por otro lado, en cuanto a los centros privados. En ambas regiones, hay centros que poseen este servicio y otros en los que no, por lo que no parece haber una tendencia clara. El porcentaje de hospitales privados con gabinetes de comunicación respecto al total de centros de atención especializada, además, no presenta grandes diferencias en las dos comunidades.

En resumen, el hecho de que Galicia posea departamentos de comunicación en los hospitales públicos más importantes mientras que Castilla y León concentra toda la labor comunicativa en el departamento de comunicación de la Consejería de Sanidad hace que el ratio de estos servicios respecto al cómputo total de hospitales en cada comunidad sea considerablemente desigual. Así, para los 37 hospitales que poseen ambas regiones, hay 15 departamentos de comunicación en Galicia y 7 en Castilla y León. 


\subsubsection{FUNCIONES Y TAREAS DE LOS DEPARTAMENTOS DE COMUNICACIÓN DE LOS HOSPITALES}

Tras el análisis de las entrevistas personales realizadas a los responsables de comunicación de los hospitales de Castilla y León y de Galicia, no se aprecian diferencias evidentes entre la comunicación que se ejerce en una zona u otra.

Casi todos los responsables de comunicación en Galicia son licenciados en Ciencias de la Información y cuentan con experiencia previa en medios de comunicación antes de comenzar su trabajo como miembro de un gabinete de comunicación en un hospital. Esto influye en el estilo de comunicación que llevan a cabo, puesto que se centra en la relación con los medios de comunicación. En cambio, en Castilla y León, no hay una tendencia común en cuanto a estudios cursados y existe una mayor variedad dentro de especialidades vinculadas con la información. La mayor parte de los responsables de información de los hospitales trabajaron antes de ocupar este cargo en agencias de comunicación, en vez de en medios, como sucede con los trabajadores de Galicia.

Prácticamente todos los departamentos de comunicación, independientemente de la indicación expresa en el organigrama y de la comunidad, dependen de gerencia. Hay que señalar como excepción los hospitales públicos de Castilla y León, que centralizan toda la labor comunicativa en el gabinete de comunicación de la Consejería de Sanidad de la Junta de Castilla y León.

La mayoría de los entrevistados, tanto de Castilla y León como de Galicia, se relacionan en mayor medida con los medios de comunicación, ya sea ideándolos como un público en sí o como un vehículo para transmitir información a su verdadero público objetivo: la población. En consecuencia, la mayor parte del tiempo la dedican a labores relativas a los medios de comunicación, aunque la actividad fluctúa según la agenda de cada día. Casi nadie identifica a los pacientes, a los agentes políticos e institucionales, a las aseguradoras y a los inversores o accionistas (en los casos que aplica) como públicos propios del departamento de comunicación. Además, casi todos consideran que no se le dedica el suficiente tiempo a la comunicación interna, a pesar de su importancia.

En cuanto a las herramientas utilizadas con cada grupo, los responsables de comunicación de ambas zonas suelen utilizar el teléfono, la nota de prensa y las exclusivas; las escasas ruedas de prensa que realizan (salvo en las consejerías) son para tratar temas de gran relevancia. En general, han conseguido que los periodistas contacten con ellos antes de acceder a un facultativo y viceversa: que los facultativos contacten con el gabinete de comunicación cuando un periodista contacta con ellos. Así, controlan la información que sale del hospital. Aunque no presten demasiada atención a la comunicación interna, algunos envían el dosier de prensa, otros utilizan intranet, otros el correo electrónico para transmitir información... En cuanto a la población en general, 
aparte de la información o de la publicidad que aparece en los medios de comunicación, las actividades destinadas al conjunto de la población, que no son demasiadas, suelen ser jornadas de puertas abiertas o conferencias. Cada vez más a menudo, los responsables de comunicación utilizan las redes sociales para comunicarse con los públicos. Los hospitales privados de las dos comunidades tienden a insertar más publicidad que los públicos, aunque reconocen que cada vez se utiliza menos.

Una buena parte de los responsables tanto de Galicia como de Castilla y León consideran que tienen que diferenciarse de lo que ofrecen los demás y buscar canales y tácticas alternativas a las típicas notas y ruedas de prensa. Por ello, en vez de simplemente mandar noticias, algunos utilizan las nuevas tecnologías, organizan jornadas, conferencias, exposiciones, premios, concursos, etc. Las destinadas a los pacientes se hacen más en los centros privados. Asimismo, las actividades más novedosas suelen provenir de estas últimas clínicas.

En cuanto al presupuesto, los hospitales públicos de las dos comunidades no cuentan con una cantidad destinada a realizar labores de información al margen de los sueldos de los trabajadores. No sucede lo mismo en el ámbito privado, ya que los entrevistados en este estudio cuentan con una partida para las actividades que realizan a lo largo del año. En general, los primeros están satisfechos con las labores que realizan, sosteniendo que comunicar actualmente no es caro y que no necesitan partidas extras. Una mayoría de los privados, en cambio, insisten con más frecuencia en que harían más cosas con un presupuesto más elevado.

La mayoría de los entrevistados de ambas regiones ha afirmado tener una gran independencia. Ninguno siente coacción por los temas a difundir, por los datos facilitados o por la consecución de objetivos, y se consideran bastante independientes a la hora de transmitir contenidos. Hay que señalar, no obstante, que todos sostienen ser conocedores de lo que deben sacar a la luz, cuándo lo han de hacer y la manera de hacerlo. El único aspecto polémico con el que tienen que lidiar algunos son los partes médicos. En Galicia, no existe una postura uniformada y cada gabinete de comunicación posee una regla propia: en algunas áreas, no se ofrece ningún tipo de información de los pacientes; en otras, se suministran los datos que el enfermo o la familia aceptan difundir; en algunas, únicamente se informa si el sujeto está o no ingresado en el centro; $\mathrm{y}$, finalmente, otros facilitan el parte médico de los pacientes que ingresan ofreciendo únicamente las iniciales. En Castilla y León, la adopción de una postura u otra depende de la titularidad del centro. En los hospitales privados no se facilita ningún dato de los pacientes; en los hospitales públicos, bien sea a través de la Consejería de Sanidad o a través de las delegaciones de la Junta en cada provincia, emiten partes médicos de los pacientes, pero la cantidad de información de cada caso depende del director médico del hospital involucrado. Los que emiten partes médicos, en su mayoría, reconocen que convendría tener una postura uniformada, una buena parte a favor del cese de emisión de estas informaciones. 
En general, los responsables entrevistados coinciden en asegurar que el gerente o directivo que dirige un hospital influye en la labor comunicativa que se realiza, aunque sobre otras cosas en la importancia que le otorga a la comunicación. Así, se aprecia que en el día a día, es decir, en las tareas de comunicación que realizan, el gerente no tiene demasiado peso, pero donde sí que se nota es en la importancia que otorgan a la comunicación y lo mediático que sea o no sea. En consecuencia, se desprende que con un gerente u otro será más sencillo que aparezca en los medios, que le realicen entrevistas, que autorice actividades comunicativas más novedosas, etc., pero en la dinámica diaria no afecta.

En ambas comunidades, pocos son los entrevistados que aprecian en la comunicación externa algún error. En cambio, en la comunicación interna es donde, sobre todo en los hospitales de Galicia y en los públicos de Castilla y León, se detectan más lagunas, muchas de ellas debidas a la falta de tiempo, la escasa coordinación y la poca importancia que le otorgan los profesionales sanitarios a la comunicación. En consecuencia, entre las mejoras que insertarían, casi todos opinan que se debería potenciar la comunicación interna. Otros, indistintamente de la comunidad, agradecerían un aumento de personal y, los privados, un incremento del presupuesto.

La mayor parte de los entrevistados creen que un gabinete de comunicación es beneficioso para cualquier entidad, los hospitales incluidos. Entre las bondades incluyen trasladar información, informar a la población acerca de la actividad que se realiza en los hospitales y responder a los medios de comunicación. Para los centros privados, sirve para dar a conocer al público el hospital y para crear imagen de marca. No hay diferencias remarcables entre Castilla y León y Galicia, salvo que los responsables de comunicación de la segunda comunidad señalan con más frecuencia la función que ejercen como gabinete de crisis. Preguntados acerca de las distintas fórmulas que existen en Castilla y León y en Galicia acerca de la comunicación sanitaria, los entrevistados creen que tener un departamento de comunicación en cada clínica frente a centralizar toda la información sanitaria en un único lugar ofrece inmediatez, mejor atención a los periodistas y un mayor volumen de datos emitidos. La misma responsable de comunicación de la Consejería de Castilla y León reconoce que debería haber personas dedicadas a la comunicación en al menos los grandes hospitales para servir de enlace con la Consejería de Sanidad y poder enviar más información sobre la investigación que se realiza en estos centros.

Tanto en una región como en otra los profesionales que pertenecen al personal consideran que el mejor modelo es el que poseen ellos. Por el contrario, la mayoría de los que trabajan en una empresa externa replican que tiene sus beneficios y que no es necesario trabajar físicamente dentro de una organización para lograr unos resultados satisfactorios. A pesar de ello, todos los entrevistados reconocen las ventajas de cada una de las dos fórmulas. Así, a favor de trabajar internamente se encuentra la cercanía, la confianza con el personal, la especialización, la posibilidad de enterarse de más 
asuntos... En cambio, una empresa de comunicación puede tener una visión más objetiva, disponer de más "mentes pensantes" (según el tamaño de la empresa) y la posibilidad de trasladar experiencias de un ámbito a otro, es decir, adaptar las acciones que han sido exitosas para unos clientes al resto de firmas. Asimismo, una empresa externa ofrece más servicios, como de publicidad, diseño gráfico, organización de eventos, etc.

\subsubsection{USO DE LAS RELACIONES PÚBLICAS EN LOS DEPARTAMENTOS DE COMUNICACIÓN DE LOS HOSPITALES}

Tras el análisis de los resultados de las encuestas realizadas a los responsables de comunicación de los hospitales de las dos comunidades objeto de estudio, se observa que donde más diferencias se dan es dividiendo los centros por titularidad en públicos y privados y, aunque con una menor discrepancia, por pertenencia al centro. En cambio, respaldando los resultados de las entrevistas personales, las encuestas no muestran grandes diferencias entre Castilla y León y Galicia.

\subsubsection{GALICIA VS. CYL}

En general, no existen grandes diferencias en el uso de las relaciones públicas que realizan los responsables de comunicación de los hospitales de Castilla y León respecto a los de Galicia. Poseen muchos elementos en común y, en los que discrepan, no hay una tendencia a favor de una región o de otra, si no que, dependiendo de los casos, en ocasiones se realiza un mejor uso de las relaciones públicas en Castilla y León y, en otras, en Galicia.

En cuanto a las características de los comunicadores, los que trabajan para los hospitales de Castilla y León son, en general, más jóvenes que los de Galicia, y, por ello, cuentan con una menor experiencia. A pesar de ello, los primeros suelen tener un nivel de estudios más elevado y presentan un mayor abanico de ramas de conocimiento.

En ambos casos, el uso que hacen de los modelos y roles son prácticamente idénticos. Los comunicadores de los dos territorios también tienen la misma posibilidad de formar parte del equipo estratégico y de disponer de un plan y un equipo prefijado para afrontar posibles crisis.

En los aspectos en los que se encuentran discrepancias son en la importancia que le otorgan a las relaciones personales, que es más alta en Castilla y León. En esta región, 
según indican los encuestados, se suelen alcanzar los objetivos propuestos más a menudo, a pesar de que en Galicia se tienda a vincular con más frecuencia las metas del departamento de comunicación a los del hospital. Los públicos más importantes son los mismos en las dos comunidades, aunque el orden varía: para los castellano-leoneses son los medios de comunicación, los empleados y los pacientes, mientras que para los gallegos son los empleados, los pacientes y los medios de comunicación. Sobre las herramientas que utilizan para comunicarse con ellos, los gallegos suelen emplear una mayor variedad y una frecuencia más alta, sobre todo con los empleados, los pacientes y visitas y los medios de comunicación.

En la etapa de planificación de un programa de relaciones públicas, los gallegos otorgan considerablemente más importancia a la definición de públicos y a la especificación del presupuesto que los castellano-leoneses. Por otra parte, es más frecuente que los castellano-leoneses den más relevancia a las fases de investigación y evaluación que los gallegos. Además, como tipo preferido de evaluación, mientras que los gallegos se centran en la exposición de las labores comunicativas que realizan, los castellano-leoneses prefieren estudiar más profundamente la opinión y actitud del público y las acciones y comportamientos. Finalmente, los trabajadores encuestados de Castilla y León están ligeramente más satisfechos que los de Galicia, a pesar de ambos otorgan una relevancia similar al departamento de comunicación.

\subsubsection{PÚBLICOS VS. PRIVADOS}

Dividiendo los hospitales por titularidad, se encuentran más diferencias en el uso de las relaciones públicas $\mathrm{y}$, en general, los privados son los que presentan una mejor utilización. Mismamente, en las características de los comunicadores se encuentran diferencias. Los que pertenecen al ámbito privado poseen un mayor nivel de estudios (como máster o especializaciones universitarias) $\mathrm{y}$, en general, hay una mayor dispersión de especialidades dentro del terreno de la comunicación. Por el contrario, las personas que trabajan en el terreno público suelen contar con una licenciatura, casi siempre de Periodismo.

El modelo más frecuente en ambos casos es el de información pública, pero los públicos tienen como siguientes enfoques más empleados el agente de prensa y el bidireccional simétrico persuasivo, mientras que los privados, precisamente, invierten la tendencia. Tanto en los hospitales públicos como en los privados prevalece ligeramente el rol técnico frente al directivo, pero los públicos suelen prestar más atención a los acontecimientos para la prensa aunque, a su vez, suelen dirigir más a menudo a otras personas. En cambio, las relaciones sociales son más importantes para los centros privados. También es más probable que los responsables de comunicación de los 
hospitales privados formen parte de la dirección del centro y que dispongan de un plan y un equipo prefijado para posibles crisis.

En cuanto a los grupos de públicos más destacados, los hospitales públicos se centran más en los medios de comunicación y en los empleados, mientras que para los privados son más importantes los trabajadores y pacientes. Como era de esperar, los agentes políticos e institucionales son más relevantes para las clínicas públicas, mientras que los inversores o accionistas lo son para los privados. Estos últimos otorgan una mayor importancia a las distintas fases de un programa de relaciones públicas, aunque la mayor diferencia se halla en la evaluación. No se han detectado diferencias demasiado marcadas en las herramientas de esta fase, pero sí en las de planificación, comunicación y evaluación. Por ejemplo, los hospitales privados planean más profundamente, sobre todo en lo referente a presupuesto, tácticas, técnicas de evaluación y plazos temporales.

Cuando se refiere a herramientas de comunicación empleadas con los empleados, los públicos adelantan a los privados en cuanto a número y frecuencia de uso. En cambio, los centros privados utilizan una mayor variedad de herramientas con los pacientes y visitas. En el caso de las herramientas utilizadas para comunicarse con la población en general, la balanza se inclina a favor de los hospitales privados. En cuanto a la evaluación, los hospitales privados tienden a evaluar con más frecuencia y con más herramientas. Además, suelen fijarse más en la opinión y actitud del público y en las acciones y comportamientos del público que en la producción y la exposición. Finalmente, a pesar de que los responsables de comunicación de los hospitales públicos están igual de satisfechos con sus labores diarias que los de los privados, los primeros consideran más importante su departamento para el hospital.

\subsubsection{PLANTILLA VS. EMPRESA EXTERNA}

Dividiendo a los comunicadores según su pertenencia al hospital en empleados en plantilla o trabajadores de empresas externas, se observan ciertas diferencias en el uso de las relaciones públicas, con una mejor utilización, en general, de las agencias de comunicación. La nota que arrojan los roles es prácticamente la misma, al igual que las del modelo de influencia personal. Tampoco hay diferencia en la presencia de un plan o de un equipo prefijado para posibles crisis. En ambos casos, el modelo de relaciones públicas más frecuente es el de información pública. En cambio, después de este, las personas que trabajan internamente adoptan un enfoque característico del agente de prensa, mientras que los que lo hacen de forma externa hacen lo mismo con el bidireccional simétrico persuasivo. Además, las agencias de comunicación tienden a disponer con más frecuencia de una guía o plan de comunicación, a perseguir una serie de objetivos concretos definidos y a pertenecer a la dirección del centro. En cuanto a los públicos, las mayores diferencias se encuentran en los agentes políticos e 
institucionales, que son más relevantes para los trabajadores internos, y los inversores o accionistas, que adquieren una mayor importancia para las empresas externas. Las cuatro fases de un programa de relaciones públicas obtienen notas más altas en las agencias de comunicación, con un mayor contraste en la planificación y evaluación. Estos empleados también están por delante en las herramientas de planificación, registrando la mayor diferencia en las tácticas y en el presupuesto. En cuanto a los instrumentos de comunicación con los diferentes públicos, los trabajadores internos usan más con los empleados, mientras que las empresas externas prestan más atención a los pacientes y visitas y a la comunidad que los internos. Asimismo, las empresas externas se centran más en la fase de evaluación que los internos, o al menos emplean más herramientas y más frecuentemente. Además, otorgan una mayor importancia a los diferentes tipos de evaluación, aunque hay una diferencia superior en la medición de la opinión y actitud del público y en la medición de las acciones y comportamientos. Finalmente, aunque no existen prácticamente diferencias en la satisfacción con las actividades comunicativas entre unos y otros, los comunicadores que trabajan de manera interna en un hospital consideran más importante su departamento.

\subsubsection{IMAGEN PROYECTADA EN LOS MEDIOS DE COMUNICACIÓN}

No hay diferencias entre la cantidad de noticias que publican los periódicos de cada comunidad autónoma y, en ambos casos, hay un diario regional que acumula una buena parte del total. No existe un lugar concreto de donde procedan la mayoría de las informaciones sobre salud y sanidad: casi todas provienen de diversos lugares de la geografía, tanto nacional como internacional. No obstante, Galicia contiene la mayor parte de sus informaciones sobre salud y sanidad enmarcadas dentro de su propio territorio, al contrario de lo que sucede con Castilla y León, siendo esta relación estadísticamente significativa. La mayor parte de las noticias aparecen en la sección local, con una presencia mayor en Galicia que en Castilla y León. El tamaño de los textos, no obstante, es similar en ambas regiones.

En cuanto a la autoría de las composiciones, Castilla y León suele firmar más a menudo las noticias a través de una agencia, mientras que en Galicia es más habitual es que se divulguen bajo el nombre de un periodista o periodistas concretos o con la firma genérica del periódico, siendo las tres relaciones estadísticamente significativas. La vasta mayoría no ofrece la posibilidad de interactuar con los autores de las noticias, ya que únicamente se ha detectado un periódico de los 30 analizados que ofrezca la posibilidad escribir a los escritores mediante correo electrónico. 
Nueve de cada diez composiciones son informaciones, por lo que otros géneros menos informativos y más creativos quedan relegados a ocasiones muy puntuales. Galicia, precisamente, concentra la mayor parte de los textos no puramente informativos, sobre todo los reportajes, las entrevistas y las crónicas o críticas. Todas estas relaciones han obtenido resultados estadísticamente significativos.

Ninguna de las dos comunidades suele hacer un gran uso de los audiovisuales y, cuando se hace, suele tratarse de fotografías, dejando los vídeos, los gráficos, las infografías y los audios como instrumentos casi inexistentes. Dividiendo los periódicos por comunidad, se observa que castellano-leoneses difunden estadísticamente más vídeos que sus compañeros gallegos.

Los sucesos son el tema más recurrente en ambos territorios, seguido de los asuntos políticos y de los servicios sanitarios. Como mayor diferencia entre una comunidad y otra se han encontrado los textos sobre el personal sanitario y los temas de actualidad, más comunes en Castilla y León. Asimismo, la mayor parte de las noticias tienen connotaciones negativas, seguidas, aunque de lejos, de las neutras y de las positivas. Divididos por regiones, los periódicos gallegos publican significativamente más textos negativos que los castellano-leoneses.

En cuanto a las fuentes de información, llama la atención la gran cantidad de opciones señaladas, a lo que se suma la alta presencia de la etiqueta "otros", lo que pone de relieve el alto número de orígenes que utilizan los periodistas a la hora de redactar noticias referentes a la salud o sanidad. En el género informativo, las fuentes más habituales son los servicios de emergencias, seguidas de las fuentes políticas regionales, de los centros de investigación y del gobierno central. No obstante, en Galicia, el número de textos procedentes del servicio de emergencias es estadísticamente superior. También resulta significativa la relación entre las novedades de las organizaciones políticas a nivel regional y los periódicos de Castilla y León. Los hospitales suelen ser fuentes de información más frecuentes en Galicia que en Castilla y León, ya que ocupan la tercera y séptima posición, respectivamente. En los géneros no informativos, tomando en consideración las dos comunidades, los hospitales son el origen más recurrente, por delante de los partidos o instituciones políticas a nivel regional y los centros de investigación. No obstante, en Galicia se usan más datos de los dos primeros recursos y, en Castilla y León, del último, siendo esta última relación estadísticamente significativa.

La mitad de los textos tienen, al menos, una referencia de contraste, archivo o segundas fuentes, aunque no suele ser muy habitual que posean dos o tres. Lo más normal es que se trate de referencias archivísticas o contextuales, seguido de valoraciones o cifras de otras fuentes y de información de contraste. El uso en los dos territorios analizados es muy similar. La media de caracteres de contraste y de archivo es ligeramente mayor en Castilla y León que en Galicia, no obstante. 
Muy pocas composiciones contienen enlaces a otras informaciones dentro del texto. Divididos por región, los periódicos no muestran apenas diferencias. Donde sí que se han detectado desigualdades es en el número de nexos que incorporan los periodistas de cada comunidad. Los gallegos tienden a incluir una mayor cantidad.

\section{Interacción con el lector}

En más de la mitad de las informaciones analizadas, los lectores tienen la posibilidad de dejar algún comentario. Pese a ello, solo dos de cada diez noticias que proporcionan este servicio han sido comentadas. Divididos por comunidad, Castilla y León ofrece más informaciones con posibilidad de introducir comentarios, siendo la relación estadísticamente significativa. Además, hay más comentarios en los periódicos de Castilla y León que de Galicia, aunque la diferencia no es muy amplia.

Por su parte, siete de cada diez composiciones permiten a los lectores votar y valorar el contenido, normalmente mediante una escala de 1 a 5 a través de estrellas. De esas, solo cuatro de cada diez tienen al menos un voto. En Galicia los lectores suelen votar más a menudo que en Castilla y León, siendo la relación estadísticamente significativa. También hay un mayor número de votos en la comunidad gallega. En cambio, las medias de las valoraciones de cada comunidad no difieren demasiado.

Más de la mitad de las informaciones analizadas permiten compartir el texto con un vínculo directo a una cuenta de Facebook, a pesar de que solo 3,4 de cada 10 informaciones son redireccionadas a la red social. Los diarios gallegos ofrecen más informaciones con posibilidades de vinculación a Facebook, obteniendo una relación estadísticamente significativa. Asimismo, Galicia tiene el número más alto de recomendaciones a esta red social. En cuanto a Twitter, el número de informaciones que permiten la opción de retwittear el contenido mediante un simple enlace es muy similar a las que no ofrecen este servicio. Cuatro de cada 10 noticias que suministran esta opción fueron retwitteadas. Galicia es la región que más textos estadísticamente publica con posibilidad de retwittearlos. Esta región también aporta un número considerablemente mayor de noticias redireccionadas a esta red social, siendo esta relación estadísticamente significativa. 


\subsubsection{VALORACIÓN Y SATISFACCIÓN DE LOS CIUDADANOS ACERCA DEL SISTEMA SANITARIO}

\subsubsection{INTERÉS POR LA SANIDAD Y VALORACIÓN GENERAL DEL FUNCIONAMIENTO DEL SISTEMA SANITARIO PÚBLICO}

Tras analizar los datos del Barómetro Sanitario del Instituto de Información Sanitaria se observa que un número mayor de gallegos consideran la sanidad como el área de mayor trascendencia para los ciudadanos que los castellanoleoneses. El promedio a lo largo de los años también es más alto en Galicia que en Castilla y León. Lo más normal en ambas comunidades es pensar que la sanidad pública funciona bien, pero habría que hacer algunos cambios, seguido de los que piensan que marcha bien y de los que consideran que necesita cambios fundamentales aunque algunas cosas funcionan. En la actualidad, los que creen que está tan mal que habría que rehacerlo en su totalidad suman una cifra mínima.

En Galicia, no obstante, hay una mejor valoración de la sanidad pública, bastante superior a la de Castilla y León y a la de la media nacional. Además, esta visión ha mejorado con el paso de los años. Así, en esta región hay más personas que en Castilla y León que creen que el sistema sanitario público funciona bastante bien o que funciona bien pero se deberían hacer algunos cambios. Asimismo, hay una menor proporción de los que consideran que el sistema sanitario público necesita cambios fundamentales aunque algunas cosas funcionan o que funciona tan mal que habría que rehacerlo en su totalidad.

\subsubsection{SATISFACCIÓN CON EL SISTEMA SANITARIO PÚBLICO}

A pesar de que la valoración del sistema sanitario público es superior en Galicia que en Castilla y León, cuando se trata de la satisfacción general, Castilla y León adelanta a Galicia tanto en el último año registrado como en el promedio a lo largo de los años. Castilla y León, en general, se halla por encima de la media nacional y Galicia, por debajo.

Dividiendo la satisfacción por servicios relativos a la atención médica especializada, la percepción de los ciudadanos que acudieron a un médico especialista es más positiva en Castilla y León que en Galicia, aunque en los últimos años registrados esta percepción aumenta en Galicia y disminuye en Castilla y León. Cuando se trata de un ingreso en el hospital, sin embargo, los gallegos adelantan a los 
castellano-leoneses. Además, mientras que la valoración de los primeros no deja de incrementarse con el paso de los años (pasando de ser más baja que la media nacional a más alta), la de los primeros baja y sube indiferentemente según los ejercicios (siendo en los primeros años más alta que la media nacional y en los últimos, normalmente más baja).

En cuanto a la información recibida, los castellano-leoneses otorgan una mejor puntuación a su sistema público que los gallegos. Así, Castilla y León se encuentra por delante en la información que facilitan las administraciones sanitarias sobre los principales problemas de salud de la población, a pesar de que las notas en ambas comunidades no llegan al aprobado en ningún año salvo en dos ocasiones. Castilla y León también está por delante de Galicia en la información que las administraciones sanitarias ponen a disposición de los ciudadanos sobre los trámites para acudir a la consulta de un médico especialista o ingresar en un hospital. En el último año registrado, Castilla y León aventaja a Galicia cuando se trata de los derechos de los ciudadanos y sobre cómo y dónde pueden poner una reclamación, así como en la información de las medidas y leyes que adoptan las autoridades sanitarias. La opinión de ambos grupos acerca de la información que facilitan las administraciones sanitarias sobre los servicios que prestan es similar, aunque ligeramente mejor en la comunidad castellana.

\subsubsection{LA ELECCIÓN DE UN CENTRO SANITARIO EN BASE A SU TITULARIDAD}

En general, los gallegos visitarían antes los espacios públicos que los castellanoleoneses y tendrían menos indecisión a la hora de decidirse entre ambas titularidades. Además, estos resultados tienden a acentuarse a lo largo del tiempo; es decir, los gallegos cada vez elegirían más la sanidad pública frente a la privada y tendría menos dudas a la hora de tomar esta decisión. Esto sucede tanto en los ingresos en el hospital, en atención en urgencias y en la atención primaria y especializada. En cambio, en Castilla y León disminuye la percepción de calidad de los centros públicos y los ciudadanos cada vez optarían más por los espacios privados o les resultaría indiferente esta decisión, a excepción de los últimos tres años contabilizados, en los que parece que se invierte la tendencia.

\section{Motivos para la elección de una determinada titularidad}

Siguiendo con el tono general que proporciona la elección de una determinada titularidad de los hospitales, los ciudadanos de Galicia otorgan una nota acusadamente mayor a los centros públicos que a los privados en los nueve aspectos estudiados por el 
Barómetro Sanitario del Ministerio de Sanidad, Servicios Sociales e Igualdad. Además, las calificaciones de los centros públicos de esta comunidad son bastantes más altas que la media nacional, y las de los privados sensiblemente más bajas que las del conjunto del país. La popularidad de unos en detrimento de los otros se acentúa con el paso de los años; es decir, cada vez hay más personas gallegas que prefieren la sanidad pública y menos las que se decantan por la privada.

La situación de Castilla y León no es tan extrema. Existen elementos por los que los ciudadanos elegirían la sanidad pública (por ejemplo, la tecnología, la capacitación de los médicos y del personal de enfermería y la información facilitada). Sin embargo, existen dos aspectos que sobresalen en los centros privados para los castellano-leoneses y que no sucede con los gallegos. Es el caso de la rapidez en la atención recibida y el confort de las instalaciones. Además, al contrario de lo que ocurre en Galicia, la popularidad de la sanidad pública, en general, disminuye con el paso del tiempo, quedándose por debajo de la media nacional en varias ocasiones. 


\subsection{VERIFICACIÓN DE LAS HIPÓTESIS}

Vistos los resultados conseguidos a través de la metodología propuesta, se ha procedido a dar respuesta a las hipótesis planteadas al comienzo de la investigación. De las seis propuestas, se han aceptado dos, se ha refutado una y las tres restantes se han aceptado parcialmente. A continuación, se muestra la relación de hipótesis con la explicación de los resultados conseguidos.

H1. Debido a la competencia comunicativa, cuando una gran parte de los hospitales de una región posee departamentos de comunicación, las relaciones públicas que se adoptan deberían ser más excelentes.

REFUTADA: El uso de las relaciones públicas en muy similar en las dos comunidades estudiadas. En ambos casos, el uso que hacen de los roles y modelos es prácticamente el mismo. Los comunicadores de los dos territorios también tienen la misma posibilidad de formar parte del equipo estratégico y de disponer de un plan y de un equipo prefijado para afrontar posibles crisis. Los tres principales públicos son los mismos en los dos territorios, aunque cambien ligeramente de orden. En las dos regiones se presta más atención a la comunicación externa, sobre todo la canalizada a través de los medios de comunicación, dejando como asignatura pendiente la interna. Asimismo, utilizan similares herramientas en las distintas etapas de un programa de relaciones públicas, aunque los gallegos emplean un número mayor en la fase de comunicación. La única diferencia estadísticamente significativa se ha detectado en Castilla y León, cuyos comunicadores otorgan una mayor importancia a las relaciones personales.

H2. La presencia de departamentos de comunicación en los hospitales debe tener una repercusión en el número y calidad de las informaciones sobre salud y sanidad que publican los medios de comunicación de la región.

PARCIALMENTE ACEPTADA: el número de noticias que publican los periódicos de cada comunidad relativas a la salud y sanidad es prácticamente idéntica. El uso de audiovisuales y de enlaces, así como de datos de archivo, contraste y segundas fuentes tampoco muestran diferencias reseñables. En ambos casos, hay un alto número de fuentes y de lugares de origen de la noticia. No obstante, en Galicia, donde hay más departamentos de comunicación sobre estos asuntos, las noticias suelen insertarse con más frecuencia en la sección local, las novedades se enmarcan más a menudo en lugares pertenecientes a la región y es más probable que los textos sean elaborados por los redactores del periódico en vez de por agencias de comunicación. Además, suelen divulgarse más composiciones explicativas e interpretativas, más allá de la mera información. En cuanto a los hospitales, son fuentes de información más recurrentes en 
Galicia que en Castilla y León, tanto en los géneros informativos como en los no informativos.

H3. Los ciudadanos de las zonas que cuentan con departamentos de comunicación en la mayor parte de los hospitales han de ser más activos en el consumo de información sanitaria y salud, en el sentido de que comentan más frecuentemente estos temas, los valoran y los comparten con sus conocidos.

PARCIALMENTE ACEPTADA: Aunque los lectores castellano-leoneses comentan con un poco más de frecuencia que los gallegos las noticias sobre salud y sanidad aparecidas en los periódicos de internet, estos últimos adelantan a los primeros en frecuencia y número de votos. También recomiendan las noticias con una mayor asiduidad en la red social Facebook y comparten más a menudo y con un número mayor las noticias en Twitter. La primera y las dos últimas relaciones resultan ser, de hecho, estadísticamente significativas.

H4. Los ciudadanos de las zonas en las que existen más departamentos de comunicación deberían tener una mejor valoración y un grado de satisfacción más alto hacia el sistema sanitario.

PARCIALMENTE ACEPTADA: Los ciudadanos gallegos consideran la sanidad como un tema de mayor trascendencia que los castellano-leoneses. Asimismo, realizan una mejor valoración del sistema público, una visión que, además, mejora con el paso de los años. Por ello, más gallegos elegirían los centros públicos antes que los castellano-leoneses y exponen más motivos para justificarlo. Sin embargo, cuando se trata de satisfacción relativa a la atención médica especializada, la percepción de los ciudadanos que acudieron a un médico especialista es más positiva en Castilla y León, a pesar de que para aquellos que acudieron a un hospital es más alta en Galicia. En cuanto a la satisfacción general con el sistema sanitario público, los castellano-leoneses adelantan a los gallegos.

H5. Los departamentos de comunicación de los hospitales públicos y de los privados pueden tener diferencias en cuanto a su interés por la opinión pública, en el uso de métodos más o menos tradicionales y en las nuevas acciones de comunicación.

ACEPTADA: tras las entrevistas personales y las encuestas a los responsables de comunicación de los hospitales se observa que la mayor diferencia en el uso de las relaciones públicas se encuentra según la titularidad del centro. Así, los públicos suelen prestar más atención a los medios de comunicación y a los agentes políticos e institucionales que los privados. Estos segundos, en cambio, se centran más en las relaciones personales, son más propensos a formar parte de la coalición estratégica y a 
disponer de un plan y equipo prefijado para posibles crisis. También son más conscientes de las diferentes etapas de un programa de relaciones públicas y evalúan sus acciones más frecuentemente que los trabajadores del ámbito público. Asimismo, presentan un mayor abanico de actividades novedosas, tanto en lo referente a nuevas tecnologías como en la organización de eventos.

H6. Los hospitales gestionados por empresas externas de comunicación ejercerían unas relaciones públicas más excelentes que aquellos que cuentan con uno o dos empleados en plantilla debido a la diversidad de personal.

ACEPTADA: las empresas externas tienden a formar parte del equipo estratégico de planes más a menudo que las personas que trabajan internamente. Asimismo, suelen guiarse por un plan de comunicación y prestan más atención a las distintas fases de un programa de relaciones públicas, con una mayor diferencia en la planificación y evaluación. Así, suelen guiarse por objetivos y echan mano de más herramientas y de diferentes enfoques teóricos para analizar el éxito de sus esfuerzos comunicativos. 


\subsection{CONCLUSIONES FINALES}

A la vista de los resultados conseguidos tras la fase empírica y de la aceptación o refutación de las hipótesis propuestas al comienzo de la investigación, se han redactado varias conclusiones que resumen las contribuciones de esta tesis doctoral al ámbito de las relaciones públicas y de la comunicación sanitaria:

\section{Uso de las relaciones públicas:}

1. No hay evidencias de que en un territorio se adopten relaciones públicas excelentes en el ámbito de la salud como consecuencia de una gran competencia comunicativa.

2. La mayor diferencia en el uso de las relaciones públicas se ha detectado según la titularidad del hospital. Los responsables de comunicación de los centros privados tienden a hacer un mejor uso de esta disciplina que los de los públicos.

3. En general, las empresas de comunicación externas que se encargan de la comunicación de un hospital hacen un uso más excelente de las relaciones públicas que las personas que trabajan como un empleado interno del centro.

\section{Imagen proyectada en los medios de comunicación:}

4. El número de noticias que publican los medios de comunicación sobre salud y sanidad no tiene relación con la cantidad de departamentos de comunicación que existen en un determinado territorio. Es decir, el interés por la sanidad por parte de los periodistas no depende del número de departamentos de comunicación, puesto que pueden conseguir datos de otras fuentes.

5. Aunque el número de noticias en los periódicos es similar independientemente del cómputo de departamentos de comunicación de una zona, la calidad de las informaciones es superior en los lugares que cuentan con un mayor número de gabinetes de comunicación.

\section{Participación del lector:}

6. En aquellas zonas con una mayor suma de departamentos de comunicación dedicados a la sanidad los ciudadanos votan y comparten más a menudo las informaciones de internet relativas a la salud, aunque no las comenten más frecuentemente. 


\section{Importancia otorgada a la sanidad:}

7. Los ciudadanos de las zonas con un mayor número de departamentos de comunicación en el terreno sanitario consideran este tema más trascendente que aquellos que cuentan con menos gabinetes de este tipo.

\section{Valoración y satisfacción con el sistema sanitario público:}

8. En las regiones con un mayor cómputo de hospitales públicos con departamentos de comunicación, los ciudadanos tienen una mayor valoración de la sanidad pública y elegirían antes esta titularidad y debido a una mayor cantidad de motivos.

9. En cuanto a satisfacción con el sistema sanitario público, no existen diferencias entre los ciudadanos independientemente del número de departamentos de comunicación que hay en un territorio. 


\section{BIBLIOGRAFÍA}


"A healthy dose of PR delivers distinct physicians practice identities" (2000). Healthcare PR \& Marketing News, vol. 9, n 10, pp. 1-6.

Abramowitz, Susan; Cote, Anne y Berry, Elisabeth (1987): "Analyzing Patient Satisfaction: A Multianalytic Approach". Quality Review Bulletin, vol. 13, nº 4, pp. $122-130$.

Acinas, María Patricia (2007): “Gestión de la información y mensajes a la población en situaciones de emergencia, evacuaciones y simulacros". Emergencias: Revista de la Sociedad Española de Medicina de Urgencias y Emergencias, vol. 19, n ${ }^{\mathrm{O}} 2$.

Adams, Amelia y McCorkindale, Tina (2013): "Dialogue and transparency: A content analysis of how the 2012 presidential candidates used twitter". Public Relations Review, vol. 39, n 4, pp. 357-359.

Agostino, Deborah (2013): "Using social media to engage citizens: A study of Italian municipalities". Public Relations Review, vol. 39, n 3, pp. 232-234.

Aguilera, Miguel de y Pindado, Julián (2006): "Nuevos enfoques en comunicación y salud: perspectivas de investigación". Comunicar. Revista Científica de Comunicación y Educación, vol. 26, pp. 13-20.

Al Khaja, Mai Abdul Wahed y Creedon, Pam (2010): "Evaluating the effectiveness of the first breast cancer awareness campaign in the United Arab Emirates: Lessons learned and next steps". Public Relations Review, vol. 36, n 4, pp. 386-388.

Albrecht, Terrance L. y Bryant, Carol (1996): “Advances in segmentation modeling for health communication and social marketing campaigns". Journal of Health Communication, vol. $1, \mathrm{n}^{\mathrm{o}} 1$, p. 65.

Alcat, Enrique (2005): Y ahora ¿qué?: cómo gestionar una crisis y salir fortalecido. Barcelona, Empresa Activa.

Aldoory, Linda (2001): "Making Health Communications Meaningful for Women: Factors That Influence Involvement". Journal of Public Relations Research, vol. $13, n^{\circ} 2$, pp. $163-185$.

Alikilic, Ozlem y Atabek, Umit (2012): "Social media adoption among Turkish public relations professionals: A survey of practitioners". Public Relations Review, vol. $38, \mathrm{n}^{\mathrm{o}} 1$, pp. $56-63$.

Alonso, Enrique et al. (2011): "Clima emocional y comunicación interna en una unidad de gestión clínica y dos servicios hospitalarios tradicionales". Revista de Calidad Asistencial, pp. 281-284.

Amador Romero, F. J. (2004): "Medios de comunicación y opinión pública sanitaria". Atención Primaria, vol. 33, n 2, pp. 95-98. 
American Dietetic Association (1997): Fewer American reading labels, more aware of the food guide pyramid. Chicago, American Dietetic Association.

Amiguet, Lluís (2007): "Si te interesas, eres interesante". La Vanguardia, 23 de agosto de 2007. Disponible en: http://hemeroteca-paginas.lavanguardia.com/LVE05/PUB /2007/08/23/ LVG200708230561LB.pdf Consultado el 8 de septiembre de 2014.

Anand, R. C. y Chakravarti, A. (1981): "Public Relations in Hospital". Health and Population (Perspectives \& Issues), vol. 4, n 4, pp. 252-259.

Andreasen, Alan (1997): "Investing in Social Marketing". Journal of Health Communication, vol. 2, $\mathrm{n}^{\mathrm{o}}$ 4, pp. 315-316.

Arceo Vacas, Alfredo (2012a): El portavoz en la comunicación de las organizaciones: fundamentos teórico-prácticos. Alicante, Universidad de Alicante.

--- (2012b): "Los portavoces en el concepto vanguardista de relaciones públicas". En: Arceo Vacas, Alfredo (ed.): El portavoz en la comunicación de las organizaciones. Fundamentos teóricos-prácticos. Alicante, Publicaciones de la Universidad de Alicante, pp. 27-45.

--- (2009): "Relaciones Públicas". En: Reyes, Román (ed.): Diccionario Crítico de Ciencias Sociales. Terminología Científico-Social. Madrid-México, Plaza y Valdés.

--- (2004a): "El concepto vanguardista de las relaciones públicas". En: Arceo Vacas, José Luis (ed.): Las relaciones públicas en España. Madrid, McGraw Hill, pp. 7992.

--- (2004b): "Public relations in Spain: an introduction". Public Relations Review, vol. $30, n^{\circ} 3$, pp. 293-302.

--- (1995): "Las Relaciones Públicas y el márketing: crítica a los planteamientos de Kotler". Questiones publicitarias: revista internacional de comunicación y publicidad, $\mathrm{n}^{\mathrm{o}}$ 4, pp. 121-133.

Arceo Vacas, José Luis (2006): "La investigación de relaciones públicas en España". Anàlisi: Quaderns de comunicació i cultura, $\mathrm{n}^{\mathrm{0}} 34$, pp. 111-124.

--- (1988): Fundamentos para la teoría y técnica de las relaciones públicas. Barcelona, Promociones y Publicaciones Universitarias.

Arroyo, Luis y Yus, Magali (2008): Los cien errores de la comunicación de las organizaciones. Madrid, Esic.

Ashton, Carol M. et al. (2003): "Racial and ethnic disparities in the use of health services: bias, preferences, or poor communication?" Journal of general internal medicine, vol. 18, $\mathrm{n}^{\mathrm{O}} 2$, pp. 146-52. 
Atkins, Mardeen P.; Marshall, Brenda Stevenson and Javalgi, Rajshekhar G. (1996): "Happy employees lead to loyal patients". Journal of Health Care Marketing, vol. $16, \mathrm{n}^{\mathrm{o}} 4$, pp. 14-23.

Atlan, Henri y Bousquet, Catherine (1994): Questions de vie. Entre le savoir et l'opinion. París, Seuil.

Auger, Giselle A. (2013): "Fostering democracy through social media: Evaluating diametrically opposed nonprofit advocacy organizations' use of Facebook, Twitter, and YouTube”. Public Relations Review, vol. 39, n 4, pp. 369-376.

Avery, Elizabeth (2010): "Contextual and audience moderators of channel selection and message reception of public health information in routine and crisis situations". Journal of Public Relations Research, vol. 22, n ${ }^{\circ}$ 4, pp. 378-403.

Avery, Elizabeth et al. (2010): "Diffusion of Social Media Among Public Relations Practitioners in Health Departments Across Various Community Population Sizes". Journal of Public Relations Research, vol. 22, nº 3, pp. 336-358.

Avidar, Ruth et al. (2013): "Smartphones and young publics: A new challenge for public relations practice and relationship building". Public Relations Review, vol. $39, n^{\circ} 5$, pp. 603-605.

Azkarretazabal Mendiguren, Marta (2009): "www.kolokon.com: una forma joven de entender el sexo, las drogas y el rock \& roll”. En: del Pozo Irribarría, Juan Pérez Gómez, Laura y Ferreras Oleffe, Miguel (eds.): Adicciones y nuevas tecnologías de la información y de la comunicación: perspectivas de su uso para la prevención y el tratamiento. Logroño, Gobierno de La Rioja: Consejería de Salud y Servicios Sociales, pp. 165-172.

Baena, Antoni (2009): “Tratamiento a distancia del tabaquismo en la sociedad red". En: del Pozo Irribarría, Juan Pérez Gómez, Laura y Ferreras Oleffe, Miguel (eds.): Adicciones y nuevas tecnologías de la información y de la comunicación: perspectivas de su uso para la prevención y el tratamiento. Logroño, Gobierno de La Rioja: Consejería de Salud y Servicios Sociales, pp. 221-234.

Baker, T. L. y Taylor, S. A. (1997): "Patient satisfaction and service quality in the formation of customers' future purchase intentions in competitive health service settings". Health Marketing Quarterly, vol. 15, n 1, pp. 1-15.

Balima, Serge Théophile (2006): "Comunicación para la salud en África: experiencias y desafíos". Comunicar: Revista científica iberoamericana de comunicación y educación, $\mathrm{n}^{\mathrm{O}} 26$, pp. 21-26.

Bandura, Albert (1969): Principles of behavior modification. Nueva York, Holt, Rinehart and Winston. 
Becerra Muñoz, Elena (2006): Gestión de la comunicación en las instituciones sanitarias andaluzas. Málaga, Universidad de Málaga.

Berkowitz, Eric N. (2007): "The evolution of public relations and the use of the internet: the implications for health care organizations". Health Marketing Quarterly, vol. 24, n 3-4, pp. 117-30.

Bishop, Lynn (2005): Highlight: Age-Based HealthCare Marketing. Forester Research.

Bojo Canales, Cristina (2004): Internet visible e invisible: búsqueda y selección de recursos de información en Ciencias de la Salud. Madrid, Instituto de Salud Carlos III. Ministerio de Sanidad.

Bonilla Loyo, Elizabeth (2008): "Convergencia de la comunicación, lenguajes mediáticos e información en salud pública”. Razón y palabra, $\mathrm{n}^{0} 2$.

Bortree, Denise Sevick y Seltzer, Trent (2009): "Dialogic strategies and outcomes: An analysis of environmental advocacy groups' Facebook profiles". Public Relations Review, vol. 35, n³ 3 pp. 317-319.

Bosilkovski, Christina (2011): "Public relations roles and power in United States hospitals". Gainesville (Florida), University of Florida.

Botan, Carl H. y Taylor, Maureen (2004): "Public Relations: State of the Field". Journal of Communication, vol. 54, n 4, pp. 645-661.

Botella Arbona, Cristina et al. (2009): "El uso de la realidad virtual en el tratamiento del juego patológico". En: del Pozo Irribarría, Juan Pérez Gómez, Laura y Ferreras Oleffe, Miguel (eds.): Adicciones y nuevas tecnologías de la información y de la comunicación: perspectivas de su uso para la prevención y el tratamiento. Logroño, Gobierno de La Rioja: Consejería de Salud y Servicios Sociales, pp. $235-244$.

Bourgeois, L. J.; McAllister, Daniel W. y Mitchell, Terence R. (1978): "The Effects of Different Organizational Environments Upon Decisions About Organizational Structure". Academy of Management Journal, vol. 21, pp. 508-514.

Briones, Rowena L. et al. (2011): "Keeping up with the digital age: How the American Red Cross uses social media to build relationships". Public Relations Review, vol. $37, \mathrm{n}^{\mathrm{o}} 1$, pp. 37-43.

Brodie, Roderick J.; Glynn, Mark S. y Van Durme, Joel (2002): “Towards a Theory of Marketplace Equity: Integrating Branding and Relationship Thinking with Financial Thinking". Marketing Theory, vol. 2, n 1, pp. 5-28.

Broom, Alex (2005): "Medical specialists' accounts of the impact of the Internet on the doctor/patient relationship". Health: An Interdisciplinary Journal for the Social Study of Health, Illness and Medicine, vol. 9, n 3, pp. 319-38. 
Broom, Glen M. (1986): "Public Relations Roles and Systems Theory: Functional and Historicist Causal Models". Meeting of the Public Relations Interest Group. Chicago, International Communication Association.

--- (1977): “Coorientational measurement of public issues". Public Relations Review, vol. $3, n^{\circ} 4$, pp. 110-119.

Broom, Glen M. y Dozier, David M. (1990): Using research in public relations: Applications to program management. Englewood Cliffs (Nueva Jersey), PrenticeHall.

--- (1986): “Advancement for public relations role models". Public Relations Review, vol. $12, \mathrm{n}^{\mathrm{o}} 1$, pp. $37-56$.

Broom, Glen M. y Smith, George D. (1978): "Toward an understanding of public relations roles: an empirical test of five role models' impact on clients". Meeting of the Public Relations Division. Seattle, Association for Education in Journalism.

Brown, Jane D. y Newcomer, Susan F. (1991): "Television viewing and adolescent's sexual behavior". Journal of Homosexuality, vol. 21, n 1-2, pp. 77-91.

Brown, Jane D. y Steele, Jeanne R. (1996): "Sexuality and the mass media: an overview". SIECUS Report, vol. 24, n 4, pp. 3-9.

Bruning, Stephen D.; Dials, Melissa y Shirka, Amanda (2008): "Using dialogue to build organization-public relationships, engage publics, and positively affect organizational outcomes". Public Relations Review, vol. 34, n 1, pp. 25-31.

Bruning, Stephen D. y Galloway, T. (2003): "Expanding the Organization-Public Relation Scale: Exploring the Role that Structural and Personal Commitment Play in Organization- Public Relationships". Public Relations Review, vol. 29, n ${ }^{0}$ 3, pp. 309-319.

Bruno, Daniela et al. (2012): "Mapeo nacional de capacidades en comunicación y salud pública en Argentina". Revista de Comunicación y Salud, vol. 1, nº 2.

Buchholz, Rogene A.; Evans, William D. y Wagley, Robert A. (1989): Management response to public issues. Englewood Cliffs (Nueva Jersey), Prentice-Hall.

Buffington, Jody (1988): "CEO Values and Corporate Culture: Developing a Descriptive Theory of Public Relations". College Park (Maryland), University of Maryland.

Buhrman, Monica et al. (2004): "Controlled trial of Internet-based treatment with telephone support for chronic back pain”. Pain, vol. 111, n 3, pp. 368-77. 
Bussy, Nigel de y Ewing, Michael (1998): "The stakeholder concept and public relations: Tracking the parallel evolution of two literatures". Journal of Communication Management, vol. 2, n 3, pp. 222-229.

Busto Salinas, Lorena (2013): "Advertising pressure on newspaper gatekeepers". Estudios sobre el mensaje periodístico, $\mathrm{n}^{\mathrm{0}}$ 19, pp. 75-84.

Butler, Laura y Foster, Nadine E. (2003): "Back pain online: a cross-sectional survey of the quality of web-based information on low back pain”. Spine, vol. 28, n ${ }^{\circ} 4$, pp. $395-401$.

Caldevilla Domínguez, David (2008): Manual relaciones públicas. Madrid, Visión Libros.

Cameron, Kim S. y Whetten, David Allred (1993): Organizational Effectiveness: A Comparison of Multiple Models. Nueva York, Academic Press.

Candace, White; Antoaneta, Vanc y Gena, Stafford (2010): "Internal Communication, Information Satisfaction and Sense of Community: The Effect of Personal Influence". Journal of Public Relations Research, vol. 22, n 1, pp. 65-84.

Cangelosi, Joseph D.; Ranelli, Edward y Markham, F. Scott (2009): "Who is Making Lifestyle Changes Due to Preventive Health Care Information? A Demographic Analysis". Health Marketing Quarterly, vol. 26, n 2, pp. 69-86.

Capriotti, Paul (2007): "Chemical risk communication through the Internet in Spain". Public Relations Review, vol. 33, n 3, pp. 326-329.

Capriotti, Paul y Moreno, Ángeles (2007): “Corporate citizenship and public relations: The importance and interactivity of social responsibility issues on corporate websites". Public Relations Review, vol. 33, n 1, pp. 84-91.

Capriotti, Paul y Pardo Kuklinski, Hugo (2012): “Assessing dialogic communication through the Internet in Spanish museums". Public Relations Review, vol. 38, $\mathrm{n}^{\circ} 4$, pp. 619-626.

Carabantes Alarcón, David (2009): "Evaluación de la calidad sobre drogodependencias en Internet: el sistema @racne”. En: del Pozo Irribarría, Juan Pérez Gómez, Laura y Ferreras Oleffe, Miguel (eds.): Adicciones y nuevas tecnologías de la información y de la comunicación: perspectivas de su uso para la prevención y el tratamiento. Logroño, Gobierno de La Rioja: Consejería de Salud y Servicios Sociales, pp. 131-138.

Casetti, Francesco y Di Chio, Federico (1999): Análisis de la televisión: instrumentos, métodos y prácticas de investigación. Barcelona, Paidós. 
Castiel, Luis David y Álvarez-Dardet, Carlos (2005): "Las tecnologías de la información y la comunicación en salud pública: las precariedades del exceso". Revista española de salud pública, vol. 79, n 3, pp. 331-337.

Castilla y León (2011): "Decreto 40/2011, de 7 de julio, por el que se modifica el Decreto 287/2001, de 13 de diciembre, por el que se aprueba el Reglamento General de la Gerencia Regional de Salud de Castilla y León". Boletín Oficial de Castilla y León, $\mathrm{n}^{\mathrm{o}}$ 132, pp. 54.784-54.788.

(2007a): "Decreto 80/2007, de 19 de julio, por el que se establece la estructura orgánica de la Consejería de Sanidad". Boletín Oficial de Castilla y León, n 141, pp. 2 4.

(2007b): "Ley 2/2007, de 7 de marzo, del Estatuto Jurídico del Personal Estatutario del Servicio de Salud de Castilla y León”. Boletín Oficial de Castilla y León, n 52, pp. $10-34$.

--- (2003a): "Decreto 48/2003, de 24 de abril, por el que se regulan los órganos de dirección y participación del sistema de salud de Castilla y León”. Boletín Oficial de Castilla y León, $\mathrm{n}^{\circ}$ 81, pp. 6.382-6.385.

--- (2003b): "Ley 8/2003, de 8 de abril, sobre derechos y deberes de las personas en relación con la salud". Boletín Oficial de Castilla y León, n 71, pp. 6-12.

--- (2001): "Decreto 287/2001, de 13 de diciembre, por el que se aprueba el Reglamento General de la Gerencia Regional de Salud de Castilla y León". Boletín Oficial de Castilla y León, n 243 , pp. 18.655-18.661.

--- (1993): "Ley 1/1993, de 6 abril, de ordenación del Sistema Sanitario". Boletín Oficial de Castilla y León, $\mathrm{n}^{\mathrm{0}}$ 77, p. 2.075.

Castillo Esparcia, Antonio (2009): Relaciones públicas. Teoría e historia. Barcelona, Editorial UOC.

--- (2006): "Las relaciones públicas internas como factor de gestión empresarial". Anàlisi: Quaderns de comunicació i cultura, n 34, pp. 193-208.

--- (2004): "Investigación sobre la evolución histórica de las relaciones públicas". Historia y comunicación social, $\mathrm{n}^{\mathrm{o}}$ 9, pp. 43-62.

Castillo Esparcia, Antonio y Xifra Triadú, Jordi (2006): "Investigación bibliométrica de las tesis doctorales españolas sobre relaciones públicas (1965-2005)". Anàlisi: Quaderns de comunicació i cultura, vol. 34, pp. 141-161.

Centro de Investigaciones Sociológicas (2012): Barómetro sanitario 2012 (total oleadas). Disponible en: http://www.cis.es/cis/opencm/ES/1_encuestas /estudios/ver.jsp? estudio =14096. Consultado el 26 de agosto de 2014 . 
Cerdá, Joan Carles March (2012): "El riesgo de una mala comunicación de riesgos". Revista de Comunicación y Salud, vol. 1, n 2.

Chandra, Ashish y Emmett, Dennis (2003): "Consumer's Perceptions of and Experiences with Automated Health Related Information Services". Journal of Hospital Marketing \& Public Relations, vol. 15, $\mathrm{n}^{\mathrm{0}}$ 1, pp. 31-44.

Chang, Betty L. et al. (2004): "Bridging the digital divide: reaching vulnerable populations". Journal of the American Medical Informatics Association: JAMIA, vol. $11, \mathrm{n}^{\mathrm{o}} 6$, pp. 448-57.

Chartered Institute of Public Relations (CIPR) (n.d.): "What is PR?" Disponible en: http://www.cipr.co.uk/content/careers-cpd/careers-pr/what-pr. Consultado el 28 de marzo de 2014.

Chase, W. Howard (1984): Issue management: origins of the future. Michigan, Issue Action Publications.

--- (1982): "Issue Management Conference - a special report". Corporate Public Issues and Their Management, vol. 7, $\mathrm{n}^{\mathrm{O}}$ 23, pp. 1-2.

Chase, W. Howard y Jones, Barrie L. (1979): "Managing public policy issues". Public Relations Review, vol. 5, pp. 3-23.

Chesney, Ellen (1993): "President's message". Impressions, Health Care Public Relations Association.

Chew, Lisa D.; Bradley, Katharine A. y Boyko, Edward J. (2004): "Brief questions to identify patients with inadequate health literacy". Family medicine, vol. $36, \mathrm{n}^{\circ} 8$, pp. 588-94.

Cho, Moonhee; Schweickart, Tiffany y Haase, Abigail (2014): "Public engagement with nonprofit organizations on Facebook". Public Relations Review, vol. 40, n 3, pp. $565-567$.

Cho, Sooyoung (2006): "The Power of Public Relations in Media Relations: A National Survey of Health PR Practitioners". Journalism, \& Mass Communication Quarterly, vol. 83, n 3, pp. 563-580.

Cho, Sooyoung y Cameron, Glen T. (2007): "Power to the people-health PR people that is!" Public Relations Review, vol. 33, n 2, pp. 175-183.

Choi, Jinbong y Park, Sanghee (2011): "Influence of advertising on acceptance of press releases". Public Relations Review, vol. 37, $\mathrm{n}^{\mathrm{0}}$ 1, pp. 106-108.

Choque Larrauri, Raúl (2012): "Las nuevas competencias TIC en el personal de los servicios de salud". Revista de Comunicación y Salud, vol. 1, n 2. 
Comas, Domingo et al. (2003): Jóvenes y estilos de vida: valores y riesgos en los jóvenes urbanos. Madrid. Disponible en: http://www.injuve.es/observatorio/ economia-consumo-y-estilos-de-vida/jovenes-y-estilos-de-vida-valores-y-riesgosen-los-jovenes-urbanos-fad. Consultado el 26 de junio de 2014.

Connolly-Ahern, Colleen y Broadway, S. Camille (2007): "The importance of appearing competent: An analysis of corporate impression management strategies on the World Wide Web". Public Relations Review, vol. 33, n 3, pp. 343-345.

Coombs, Wnull (ed.): (2007): Crisis management and communications. Disponible en: http://www.facoltaspes.unimi.it/files/_ITA_/COM/Lettura_Crisis_Management_an d_Communications.pdf. Consultado el 1 de julio de 2014.

Cooper, Philip D. (1992): "Positive perspectives, concerned perspectives, and action suggestions for long-term health care marketing success". Journal of health care marketing, vol. 12, $\mathrm{n}^{\mathrm{o}} 1$, pp. 2-3.

Corbett, Gerard (2012): “A Modern Definition Of Public Relations". En: Public Relations Defined. Disponible en: http://prdefinition.prsa.org/index.php/2012/ 03/01/new-definition-of-public-relations/. Consultado el 20 de marzo de 2013.

Costa Sánchez, Carmen (2012): "El gabinete de comunicación del hospital. Propuesta teórica y acercamiento a la realidad de los departamentos de comunicación de los hospitales públicos de Galicia”. Doxa Comunicación: revista interdisciplinar de estudios de comunicación y ciencias sociales, $\mathrm{n}^{\mathrm{0}} 14$.

--- (2011): La comunicación en el hospital. Zamora, Comunicación Social.

Crable, Richard E. y Vibbert, Steven L. (1985): "Managing issues and influencing public policy". Public Relations Review, vol. 11, n² 2, pp. 3-16.

Crifasi, Sheila Clough (2000): "Everything's Coming Up ROSIE". Public Relations Tactics, vol. 7, $\mathrm{n}^{\circ}$ 9, pp. 34-37.

Crutchfield, Tammy Neal y Morgan, Robert M. (2010): "Building Long-Term PatientPhysician Relationships". Health Marketing Quarterly, vol. 27, n 3, pp. 215-243.

Cuadrado, María José Allende (2007): Operaciones administrativas y documentación sanitaria. Madrid, Editorial Paraninfo.

Cuesta Cambra, Ubaldo (2012): "Las TICs y la salud desde una perspectiva psicosocial”. Revista de Comunicación y Salud, vol. 2, n 1, pp. 29-33.

Cuesta Cambra, Ubaldo; Gaspar Herrero, Sandra y Menéndez Hevia, Tania (2012): "Fundamentos psicosociales del empleo de las TIC en salud". En: Pérez Gómez, Laura Nuez Vicente, Cristina y del Pozo Irribarría, Juan (eds.): Tecnologías de la comunicación, jóvenes y promoción de la salud. Gobierno de La Rioja: Consejería de Salud y Servicios Sociales, pp. 28-49. 
Cuesta Cambra, Ubaldo y Menéndez Hevia, Tania (2010): "Drogas, comunicación y nuevas tecnologías de la información". Observatorio de drogodependencias de Castilla-La Mancha, n ${ }^{\circ}$ 6, pp. 93-104.

--- (2009): "Prevención, comunicación y nuevas tecnologías: aspectos psicológicos entre jóvenes universitarios". En: del Pozo Irribarría, Juan Pérez Gómez, Laura y Ferreras Oleffe, Miguel (eds.): Adicciones y nuevas tecnologías de la información y de la comunicación: perspectivas de su uso para la prevención y el tratamiento. Logroño, Gobierno de La Rioja: Consejería de Salud y Servicios Sociales, pp. 7792.

Cutlip, Scott M. y Center, Allen H. (1964): Effective public relations. $3^{\mathrm{a}}$ ed. Englewood Cliffs (Nueva Jersey), Prentice-Hall.

Cutlip, Scott M.; Center, Allen H. y Broom, Glen M. (2000): Effective public relations. $8^{a}$ ed. Englewood Cliffs (Nueva Jersey), Prentice Hall.

--- (1985): Effective public relations. $6^{\mathrm{a}}$ ed. Englewood Cliffs (Nueva Jersey), Prentice-Hall.

Davo, María del Carmen y Álvarez-Dardet, Carlos (2003): “The genome and its metaphors. Detectives, heroes or prophets?" Gaceta Sanitaria, vol. 17, n ${ }^{0}$ 1, pp. 59-65.

Del Pozo Irribarría, Juan (2009): "La utilización de las nuevas tecnologías de comunicación e información para la adopción de comportamientos saludables: el consumo de drogas". En: del Pozo Irribarría, Juan Pérez Gómez, Laura y Ferreras Oleffe, Miguel (eds.): Adicciones y nuevas tecnologías de la información y de la comunicación: perspectivas de su uso para la prevención y el tratamiento. Logroño, Gobierno de La Rioja: Consejería de Salud y Servicios Sociales, pp. 4556.

Del Pozo Irribarría, Juan y Ferreras Oleffe, Miguel (2011): "La telefonía móvil como instrumento de comunicación para la información y prevención del consumo de drogas". En: Cuesta Cambra, Ubaldo Menéndez Hevia, Tania y Ugarte Iturrizaga, Aitor (eds.): Comunicación y salud: nuevos escenarios y tendencias. Madrid, Editorial Complutense, pp. 111-123.

Del Pozo Irribarría, Juan y Nuez Vicente, Cristina (2012): "Las tecnologías de la comunicación y la salud pública”. En: Pérez Gómez, Laura Nuez Vicente, Cristina y del Pozo Irribarría, Juan (eds.): Tecnologías de la comunicación, jóvenes y promoción de la salud. Consejería de Salud y Servicios Sociales, pp. 72-88.

Desantes, José María (1986): “Un concepto jurídico de relaciones públicas". En: Sánchez Guzmán, José Ramón (ed.): Tratado general de Relaciones Públicas. Madrid, Fundación Universidad y Empresa, pp. 93-144.

Dewey, John (1927): The Public and Its Problems. Chicago, Swallow. 
Di Costanzo, Frank (1986): "What the Press Thinks of Press Releases". Public Relations Quarterly, vol. 31, n 4, p. 22.

Díaz, Hernán Alfredo (2013): "Especialización y rigor periodístico, antídotos contra los estigmas asociados a la enfermedad". Revista de Comunicación y Salud, vol. 3, n ${ }^{\circ}$ 2 .

-- (2011): "La comunicación para la salud desde una perspectiva relacional". En: Cuesta Cambra, Ubaldo Menéndez Hevia, Tania y Ugarte Iturrizaga, Aitor (eds.): Comunicación y salud: nuevos escenarios y tendencias. Madrid, Editorial Complutense, pp. 33-49.

Díaz, Hernán Alfredo y Cuesta Cambra, Ubaldo (2014): "La Comunicación de las Organizaciones no Lucrativas del ámbito de la Salud en España: aproximaciones a una matriz de análisis". Historia y comunicación social, n 19, pp. 209-219.

Diga, Marichris y Kelleher, Tom (2009): "Social media use, perceptions of decisionmaking power, and public relations roles". Public Relations Review, vol. 35, $\mathrm{n}^{\circ} 4$, pp. 440-442.

Diggs-Brown, Barbara (2011): Strategic public relations: an audience-centered focused approach. Boston, Cengage Learning.

Dines, Keith A. y Schneller, Eugene S. (1992): Public relations and the American hospital. Tempe (Arizona), Arizona State University Press.

DiStaso, Marcia W.; McCorkindale, Tina y Wright, Donald K. (2011): "How public relations executives perceive and measure the impact of social media in their organizations". Public Relations Review, vol. 37, n 3, pp. 325-328.

Doblas Arrebola, Salvador (2008): "Modelo de análisis de la usabilidad en sitos web de hospitales universitarios españoles". En: Cuesta Cambra, Ubaldo Ugarte Iturrizaga, Aitor y Menéndez Hevia, Tania (eds.): Comunicación y salud: avances en modelos y estrategias de intervención. pp. 49-60.

Donohew, Lewis; Lorch, Elizabeth Pugzles y Palmgreen, Philip (1998): “Applications of a theoretic model of information exposure to health interventions". Human communication research, vol. $24, \mathrm{n}^{\mathrm{O}} 3$, pp. 454-68.

Donohue, George A.; Tichenor, Phillip J. y Olien, Clarice N. (1973): "Mass media functions, knowledge, and social control". Journalism Quarterly, vol. 50, pp. 652659.

Dowse, Ros y Ehlers, Martina (2005): "Medicine labels incorporating pictograms: do they influence understanding and adherence?" Patient education and counseling, vol. $58, \mathrm{n}^{\mathrm{o}} 1$, pp. $63-70$. 
Dozier, David M. (1992): "The organizational roles of communications and public relations practitioners". En: Grunig, James E. (ed.): Excellence in public relations and communication management. Hillsdale (Nueva Jersey), Lawrence Erlbaum Associates, pp. 327-355.

--- (1986): "The environmental scanning function of public relations practitioners and participation in management decision making". Meeting of the Public Relations Division. Norman (Oklahoma), Association for Education in Journalism and Mass Communication.

--- (1984): "Program evaluation and the roles of practitioners". Public Relations Review, vol. 10, n 2, pp. 13-21.

Dozier, David M. y Broom, Glen M. (1995): "Evolution of the Manager Role in Public Relations Practice". Journal of Public Relations Research, vol. 7, $\mathrm{n}^{\mathrm{0}}$ 1, pp. 3-26.

Dozier, David M. y Ehling, William P. (1992): "Evaluation of Public Relations Programs: What the Literature Tells Us About Their Effects". En: Grunig, James E. (ed.): Excellence in Public Relations and Communication Management. Hillsdale (Nueva Jersey), Lawrence Erlbaum Associates, pp. 159-184.

Dozier, David M. y Grunig, Larissa A. (1992): "The Organization of the Public Relations Function". En: Grunig, James E. (ed.): Excellence in Public Relations and Communication Management. Hillsdale (Nueva Jersey), Lawrence Erlbaum Associates.

Dozier, David M.; Grunig, Larissa A. y Grunig, James E. (1995): Manager's Guide to Excellence in Public Relations and Communication Management. Nueva Jersey, Lawrence Erlbaum Associates.

Dozier, David M. y Repper, Fred C. (1992): "Research firms and public relations practices". En: Grunig, James E. (ed.): Excellence in Public Relations and Communication Management. Hillsdale (Nueva Jersey), Lawrence Erlbaum Associates, pp. 185-215.

Dubois, Quentin (2009): “www.filsantejeunes.com: teléfono e Internet al servicio de la relación de ayuda a distancia". En: del Pozo Irribarría, Juan Pérez Gómez, Laura y Ferreras Oleffe, Miguel (eds.): Adicciones y nuevas tecnologías de la información y de la comunicación: perspectivas de su uso para la prevención y el tratamiento. Logroño, Gobierno de La Rioja: Consejería de Salud y Servicios Sociales, pp. 209-218.

Dunwoody, Sharon (1982): "A question of accuracy". IEEE Transactions on Professional Communication, vol. PC-25, pp. 196-199.

Dutta-Bergman, Mohan J. (2004): “A Descriptive Narrative of Healthy Eating”. Health Marketing Quarterly, vol. 20, n 3, pp. 81-101. 
Dutta-Bergman, Mohan J. y Youn, Seounmi (1999): "Profiling Healthy Eating Consumers: A Psychographic Approach to Social Marketing”. Social Marketing Quarterly, vol. 5, n 4, pp. 4-21.

Edwards, Adrian; Elwyn, Glyn y Mulley, Al (2002): "Explaining risks: turning numerical data into meaningful pictures". $B M J$, vol. $324, \mathrm{n}^{0} 7.341$, pp. 827-830.

Eggener, Scotte (1998): "The power of the pen: Medical journalism and public awareness". Journal of the American Medical Association, vol. 279, $\mathrm{n}^{\mathrm{o}}$ 17, $\mathrm{p}$. 1.400 .

Ehling, William P.; White, Jon y Grunig, James E. (1992): "Public Relations and Marketing Practices". En: Grunig, James E. (ed.): Excellence in Public Relations and Communication Management. Hillsdale (Nueva Jersey), Lawrence Erlbaum Associates, pp. 357-394.

Elías, Carlos (2000): "Flujos de información entre científicos y prensa". Tesis doctoral. Universidad de La Laguna.

Encyclopaedia Britannica (1990). Chicago, Encyclopaedia Britannica.

España (2012): "Real Decreto-Ley 16/2012, de 20 de abril, de medidas urgentes para garantizar la sostenibilidad del Sistema Nacional de Salud y mejorar la calidad y seguridad de sus prestaciones". Boletín Oficial del Estado, n ${ }^{\circ}$ 98, pp. 31.27831.312 .

--- (2011): "Ley 33/2011, de 4 de octubre, General de Salud Pública”. Boletín Oficial del Estado, n 240 , pp. 104.593-104.626.

--- (2010a): "Ley 8/2010, de 30 de agosto, de ordenación del sistema de salud de Castilla y León”. Boletín Oficial del Estado, n 235, pp. 82.314-82.347.

-_- (2010b): "Real Decreto 1708/2010, de 17 de diciembre, por el que se aprueba el Programa anual 2011 del Plan Estadístico Nacional 2009-2012”. Boletín Oficial del Estado, n ${ }^{\circ} 312$, pp. 106.400-106.631.

--- (2008): "Ley 8/2008, de 10 de julio, de salud de Galicia". Boletín Oficial del Estado, n ${ }^{\mathrm{o}} 202$, pp. 35.080-35.115.

--_ (2006): "Ley 29/2006, de 26 de julio, de garantías y uso racional de los medicamentos y productos sanitarios". Boletín Oficial del Estado, n ${ }^{0} 178$, pp. $28.122-28.165$.

--- (2003a): "Ley 16/2003, de 28 de mayo, de cohesión y calidad del Sistema Nacional de Salud". Boletín Oficial del Estado, n ${ }^{0} 128$, pp. 20.567-20.588.

--- (2003b): "Ley 44/2003, de 21 de noviembre, de ordenación de las profesiones sanitarias". Boletín Oficial del Estado, n ${ }^{0} 280$, pp. 41.442-41.458. 
--- (2003c): "Ley 55/2003, de 16 de diciembre, del Estatuto Marco del personal estatutario de los servicios de salud". Boletín Oficial del Estado, n ${ }^{\circ}$ 301, pp. 44.742-44.763.

--- (2003d): "Real Decreto 1277/2003, de 10 de octubre, por el que se establecen las bases generales sobre autorización de centros, servicios y establecimientos sanitarios". Boletín Oficial del Estado, n 254, pp. 37.893-37.902.

--- (2002): "Real Decreto 840/2002, de 2 de agosto, por el que se modifica y desarrolla la estructura orgánica básica del Ministerio de Sanidad y Consumo". Boletín Oficial del Estado, $\mathrm{n}^{\mathrm{O}}$ 185, pp. 28.856-28.864.

--- (2001): "Real Decreto 1480/2001, de 27 de diciembre sobre traspaso a la Comunidad de Castilla y León". Boletín Oficial del Estado, n 311 , pp. 50.03850.044 .

--- (2000): "Ley Orgánica 4/2000, de 11 de enero, sobre derechos y libertades de los extranjeros en España y su integración social". Boletín Oficial del Estado, n ${ }^{\circ} 10$, pp. 1.139-1.150.

--- (1990): "Real Decreto 1679/1990, de 28 de diciembre, sobre traspaso a la Comunidad Autónoma de Galicia de las funciones y servicios del Instituto Nacional de la Salud". Boletín Oficial del Estado, n 313, pp. 38.937-38.939.

--- (1989): "Ley 1/1989, de 2 de enero, del Servicio Gallego de Salud”. Boletín Oficial del Estado, $\mathrm{n}^{\mathrm{O}} 37$, pp. 4.287-4.290.

--- (1986): "Ley 14/1986, de 25 de abril, General de Sanidad". Boletín Oficial del Estado, $\mathrm{n}^{\mathrm{0}}$ 102, Boletín Oficial del Estado, pp. 15.207-15.224.

--_ (1984a): "Ley 53/1984, de 26 de diciembre, de Incompatibilidades del Personal al Servicio de las Administraciones Públicas”. Boletín Oficial del Estado, n ${ }^{0} 4$, pp. $165-168$.

--- (1984b): "Real Decreto 137/1984, de 11 de enero, sobre estructuras básicas de salud". Boletín Oficial del Estado, n⿳2 27, pp. 2.627-2.629.

(1978a): Constitución Española. Disponible en: https://www.boe.es/buscar/ pdf/1978/BOE-A-1978-31229- consolidado.pdf. Consultado el 1 de septiembre de 2014.

--- (1978b): "Real Decreto Ley 36/1978, de 16 de noviembre, sobre gestión institucional de la Seguridad Social, la salud y el empleo". Boletín Oficial del Estado, no 276, pp. 26.246-26.249.

--- (1974): "Decreto 2065/1974, de 30 de mayo, por el que se aprueba el texto refundido de la ley general de la Seguridad Social". Boletín Oficial del Estado, $\mathrm{n}^{\circ}$ 173, pp. 15.081-15.097. 
- (1973): "Orden de 26 de abril de 1973 por la que se aprueba el Estatuto del personal Auxiliar sanitario titulado y Auxiliar de clínica de la Seguridad Social”. Boletín Oficial del Estado, n ${ }^{0} 102$, pp. 8.519-8.525.

--_ (1971): "Orden por la que se aprueba el Estatuto de Personal no Sanitario al Servicio de las Instituciones Sanitarias de la Seguridad Social”. Boletín Oficial del Estado, $\mathrm{n}^{\mathrm{0}}$ 174, pp. 12.015-12.024.

--- (1966): "Decreto 3160/1966, de 23 de diciembre, por el que se aprueba el Estatuto Jurídico del personal médico de la Seguridad Social”. Boletín Oficial del Estado, $n^{0} 312$, pp. 16.486-16.494.

--- (1942): "Ley de 14 de diciembre de 1942 por la que se crea el seguro obligatorio de enfermedad". Boletín Oficial del Estado, n 361 , pp. 10.592-10.597.

Etter, Michael (2013): "Reasons for low levels of interactivity. (Non-) interactive CSR communication in twitter". Public Relations Review, vol. 39, $\mathrm{n}^{\mathrm{o}}$ 5. Frederiksberg (Dinamarca), pp. 606-608.

Eyrich, Nina; Padman, Monica L. y Sweetser, Kaye D. (2008): "PR practitioners' use of social media tools and communication technology". Public Relations Review, vol. $34, n^{\circ} 4$, pp. 412-414.

Fabiszak, Debra Lynn (1985): "Public Relations in Hospitals: Testing the Grunig Theory of Organizations, Environments and Models of Public Relations" Tesis doctoral sin publicar. College Park (Maryland), University of Maryland.

Feldman, Jacob J. (1966): The dissemination of health information. Chicago, Aldine.

Fernández Muñoz, Cristóbal (2012): "Las relaciones públicas ante el reto digital y el fenómeno Twiter: estudio sobre la respuesta de las agencias de RRPP y del subsector empresarial de las bebidas fermentadas en España”. Tesis Doctoral. Madrid, Universidad Complutense de Madrid.

Fernández Souto, Ana Belén (2006): “Las relaciones públicas como elemento tangencial entre la publicidad, propaganda, información y otras áreas de la comunicación". Revista mexicana de ciencias políticas y sociales, $\mathrm{n}^{\circ} 196, \mathrm{pp}$. 159172.

--- (2004): Manual de programación e técnicas de RR.PP. Vigo, Servizo de Publicacións da Universidade de Vigo.

Finkelstein, Sydney (1992): "Power in top management teams: dimensions, measurement, and validation". Academy of Management Journal, vol. 35, n 3, pp. $505-38$. 
Fitzgerald, Paul E. y Embrey-Wahl, Lynda (1987): "Hospital study reveals strategies for improving media relations". Health care management review, vol. $12, \mathrm{n}^{\circ} 2$, pp. 5159.

Fletcher, Holly (1989): “A study of variables affecting public relations power and roles in hospitals”. San Jose (California), San Jose State University.

Flora, June A. y Maibach, Edward W. (1990): "Cognitive responses to AIDS information. The effects of issue involvement and message appeal". Communication Research, vol. 17, $\mathrm{n}^{\circ}$ 6, pp. 759-774.

Freberg, Karen; Palenchar, Michael J. y Veil, Shari R. (2013): "Managing and sharing H1N1 crisis information using social media bookmarking services". Public Relations Review, vol. 39, n 3, pp. 178-184.

Freeman, R. Edward (1984): Strategic Management: A Stakeholder Approach. Boston, Pitman Publishing.

Freeman, R. Edward y Reed, David L. (1983): "Stockholders and stakeholders: A new perspective on corporate governance". California Management Review, vol. 25, $\mathrm{n}^{\circ}$ 3, pp. 88-106.

Freimuth, Vicki S.; Massett, Holly A. y Meltzer, Wendy (2006): "A descriptive analysis of 10 years of research published in the Journal of Health Communication". Journal of health communication, vol. 11, $\mathrm{n}^{\mathrm{o}} 1$, pp. 11-20.

French, John R. P. y Raven, Bertram (1959): "The bases of social power". En: Cartwright, D. (ed.): Studies in social power. Ann Arbor (Michigan), The University of Michigan, pp. 150-167.

Friedl, Julia y Tkalac Verčič, Ana (2011): "Media preferences of digital natives' internal communication: A pilot study". Public Relations Review, vol. 37, $\mathrm{n}^{0}$ 1, pp. 84-86.

Galicia (2013a): "Decreto 43/2013, de 21 de febrero, por el que se establece la estructura orgánica del Servicio Gallego de Salud". Diario Oficial de Galicia, n ${ }^{\circ}$ 47, pp. 6.773-6.812.

--_ (2013b): “Orden de 12 de abril de 2013 por la que se desarrolla la estructura organizativa de gestión integrada de las áreas de Lugo, Cervo y Monforte de Lemos". Diario Oficial de Galicia, n ${ }^{0}$ 76, pp. 11.962-11.964.

--- (2013c): "Orden de 25 de marzo de 2013 por la que se desarrolla la estructura organizativa de Gestión Integrada de Vigo". Diario Oficial de Galicia, n ${ }^{\circ}$ 62, pp. 9.376-9.377. 
-- (2011a): "Orden de 22 de julio de 2011 por la que se desarrolla la estructura organizativa de gestión integrada de A Coruña y de Santiago de Compostela". Diario Oficial de Galicia, n ${ }^{0} 146$, pp. 21.824-21.825.

--- (2011b): “Orden de 28 de septiembre de 2011 por la que se desarrolla la estructura organizativa de gestión integrada de Ferrol y se delegan competencias en sus órganos directivos". Diario Oficial de Galicia, n 188 , pp. 28.944-28.948.

--- (2011c): "Orden de 28 de septiembre de 2011 por la que se desarrolla la estructura organizativa de gestión integrada de Ourense, Verín y O Barco de Valdeorras y se delegan competencias en sus órganos directivos". Diario Oficial de Galicia, $\mathrm{n}^{\mathrm{o}}$ 188, pp. 28.939-28.943.

--- (2011d): “Orden de 28 de septiembre de 2011 por la que se desarrolla la estructura organizativa de gestión integrada de Pontevedra y O Salnés y se delegan competencias en sus órganos directivos". Diario Oficial de Galicia, n ${ }^{0} 188$, pp. 28.934-28.938.

--- (2010): "Decreto 168/2010, de 7 de octubre, por el que se regula la estructura organizativa de gestión integrada del Servicio Gallego de Salud”. Diario Oficial de Galicia, n 199 , p. 17.203 .

Galuszka, Peter et al. (1997): "See the Doctor, Get a Toaster". En: BusinessWeek. Disponible en: http://www.businessweek.com/stories/1997-12-07/see-the-doctorget-a-toaster. Consultado el 23 de diciembre de 2013.

García, César (2010): "Integrating management practices in international public relations courses: A proposal of contents". Public Relations Review, vol. 36, $\mathrm{n}^{\circ} 3$, pp. 272-277.

García del Castillo Rodríguez, José Antonio y Segura Díez, María del Carmen (2009): "Prevención de drogas on-line: análisis y propuestas de actuación". En: del Pozo Irribarría, Juan Pérez Gómez, Laura y Ferreras Oleffe, Miguel (eds.): Adicciones y nuevas tecnologías de la información y de la comunicación: perspectivas de su uso para la prevención y el tratamiento. Logroño, Gobierno de La Rioja: Consejería de Salud y Servicios Sociales, pp. 57-76.

Gatigono, Hubert y Robertson, Thomas S. (1985): “A propositional inventory of new diffusion research". Journal of Consumer Research, vol. 11, pp. 849-867.

Gbadeyan, Rotimi Ayodele (2010): "Health Care Marketing and Public Relations in Not for Profit Hospitals in Nigeria". International Journal of Business and Management, vol. 5, $\mathrm{n}^{\mathrm{0}}$ 7, pp. 117-125.

Genuis, Stephen J. y Genuis, Shelagh K. (2005): "Implications of cyberspace communication: a role for physicians". Southern medical journal, vol. $98, \mathrm{n}^{\circ} 4$, pp. 451-455. 
Ginesta, Xavier y Ordeix Rigo, Enric (2011): "El fútbol profesional y su responsabilidad social corporativa en Cataluña (2006-2010). Mucho más que Unicef". Contratexto, vol. 20, pp. 177-194.

Goldberg, Jeanne P.; Gershoff, Stanley N. y McGandy, Robert B. (1990): “Appropriate topics for nutrition education for the elderly". Journal of Nutrition Education, vol. 22, pp. 303-310.

Gombeski, William R. et al. (2010): "Customer Advisory Groups: Another Way to Listen to the Marketplace”. Health Marketing Quarterly, vol. 27, n 1, pp. 86-96.

Gomez, Lina M. y Chalmeta, Richardo (2011): "Corporate responsibility in U.S. corporate websites: A pilot study”. Public Relations Review, vol. 37, n 1, pp. 9395.

Gordon, Chandra Grosse y Kelly, Kathleen S. (1999): "Public Relations Expertise and Organizational Effectiveness: A Study of U.S. Hospitals". Journal of Public Relations Research, vol. 11, n 2 , pp. 143-165.

Gordon, Joye y Berhow, Susan (2009): "University websites and dialogic features for building relationships with potential students". Public Relations Review, vol. 35, $\mathrm{n}^{\circ}$ 2, pp. 150-152.

Govoni, Norman A.P. (2004): Dictionary of marketing communications. Thousand Oaks, Sage Publications.

Greeson, Larry E. y Williams, Rose Ann (1986): "Social implications of music videos for youth: an analysis of the content and effects of MTV". Youth and Society, vol. 2, pp. 177-189.

Gran enciclopedia Planeta (2009). Barcelona, Planeta.

Grunig, James E. (2011): “Characteristics of Excellent Communication”. En: Gillis, Tamara (ed.): The IABC Handbook of Organizational Communication. San Francisco, International Association of Bussiness Communicators.

--- (2009): "Paradigms of global public relations in an age of digitalisation". PRism, vol. 6, pp. 1-19.

--_ (2006): "Research in Public Relations: Current Status and New Directions". Anàlisi: Quaderns de comunicació i cultura, n 34, pp. 49-65.

--- (1992a): "An Overview of the Book". En: Grunig, James E. (ed.): Excellence in Public Relations and Communication Management. Hillsdale (Nueva Jersey), Lawrence Erlbaum Associates, pp. 1-28.

--- (1992b): Excellence in Public Relations and Communication Management. $2^{\mathrm{a}}$ ed. Hillsdale (Nueva Jersey), Lawrence Erlbaum Associates. 
--- (1992c): "Symmetrical Systems of Internal Communication". En: Grunig, James E. (ed.): Excellence in Public Relations and Communication Management. Hillsdale (Nueva Jersey), Lawrence Erlbaum Associates, pp. 531-576.

--- (1992d): "What is Excellence in Management?" En: Grunig, James E. (ed.): Excellence in Public Relations and Communication Management. Hillsdale (Nueva Jersey), Lawrence Erlbaum Associates, pp. 219-250.

--_ (1989): "Symmetrical Presuppositions as a Framework for Public Relations Theory”. En: Botan, Carl H. y Hazleton, Vincent (eds.): Public Relations Theory. Hillsdale (Nueva Jersey), Lawrence Erlbaum Associates, pp. 17-44.

--_ (1984): "Organizations, environments, and models of public relations". Public Relations Research \& Education, vol. 1, n 1, pp. 6-29.

--- (1979): "Special section: The two worlds of PR research". Public Relations Review, vol. 5, $\mathrm{n}^{\circ} 1$, pp. 11-14.

--- (1976): "Organizations and Public Relations: Testing a Communication Theory". Journalism Monographs, vol. 46.

Grunig, James E. et al. (1995): "Models of Public Relations in an International Setting". Journal of Public Relations Research, vol. 7, n 3, pp. 163-186.

Grunig, James E. y Grunig, Larissa A. (1998): "The relationship between public relations and marketing in excellent organizations: Evidence from the IABC study". Journal of Marketing Communications, vol. 4, n 3, pp. 141-162.

--- (1992): "Models of public relations and communication". En: Grunig, James E. (ed.): Excellence in public relations and communication management. Hillsdale (Nueva Jersey), Lawrence Erlbaum Associates, pp. 285-325.

-_- (1991): "Conceptual differences in public relations and marketing: The case of health-care organizations". Public Relations Review, vol. 17, n 3, pp. 257-278.

--- (1989a): "The Public Relations Behavior of Organizations". En: Grunig, James E. y Grunig, Larissa A. (eds.): Public Relations Research Annual. Hillsdale (Nueva Jersey), Lawrence Erlbaum Associates, pp. 27-66.

--- (1989b): "Toward a Theory of the Public Relations Behavior of Organizations: Review of a Program of Research". Public Relations Research Annual, vol. 1, n ${ }^{\circ} 1$ 4, pp. 27-63.

--_ (1986): "Application of open systems theory to public relations: Review of a program of research". Meeting of the Public Relations Interest Group. Chicago, International Communication Association. 
Grunig, James E.; Grunig, Larissa A. y Toth, Elizabeth L. (2007): The Future of Excellence in Public Relations And Communication Management: Challenges for the Next Generation. Hillsdale (Nueva Jersey), Lawrence Erlbaum Associates.

Grunig, James E. y Hunt, Todd (1984): Managing Public Relations. Nueva York, Holt, Rinehart and Winston.

Grunig, James E. y Ipes, Daniel A. (1983): "The anatomy of a campaign against drunk driving”. Public Relations Review, vol. 9, n² 2, pp. 36-52.

Grunig, James E. y Repper, Fred C. (1992): "Strategic Management, Publics, and Issues". En: Grunig, James E. (ed.): Excellence in Public Relations and Communication Management. Hillsdale (Nueva Jersey), Lawrence Erlbaum Associates, pp. 117-157.

Grunig, James E. y White, Jon (1992): "The effect of Worldviews on Public Relations Theory and Practice". En: Grunig, James E. (ed.): Excellence in Public Relations and Communication Management. Hillsdale (Nueva Jersey), Lawrence Erlbaum Associates, pp. 31-64.

Grunig, Larissa A. (1992a): "How Public Relations/Communication Departments Should Adapt to the Structure and Environment of an Organization... And What They Actually Do". En: Grunig, James E. (ed.): Excellence in Public Relations and Communication Management. Hillsdale (Nueva Jersey), Lawrence Erlbaum Associates, pp. 467-482.

--- (1992b): "Strategic public relations constituencies on a global scale". Public Relations Review, vol. 18, n 2, pp. 127-136.

--- (1987): "Variation in Relations With Environmental Publics". Public Relations Review, vol. 13, n 3, pp. 46-58.

Grunig, Larissa A.; Grunig, James E. y Dozier, David M. (2002): Excellent public relations and effective organizations: a study of communication management in three countries. Hillsdale (Nueva Jersey), Lawrence Erlbaum Associates.

Grunig, Larissa A.; Grunig, James E. y Ehling, William P. (1992): "What Is and Effective Organization?" En: Grunig, James E (ed.): Excellence in Public Relations and Communication Management. Hillsdale (Nueva Jersey), Lawrence Erlbaum Associates, pp. 65-90.

Gudykunst, William B. y Kim, Young Yun (1992): Communicating with strangers: An approach to intercultural communication. Nueva York, McGraw-Hill.

Güell, Oriol (2006): “¿Qué es una crisis?” En: Cuesta Cambra, Ubaldo Ugarte Iturrizaga, Aitor y Menéndez Hevia, Tania (eds.): Comunicación Social y Salud. Una introducción. Madrid, Edipo, pp. 55-61. 
Guillamón Cano, Noemí y Martínez García, Montserrat (2012): “Uso de Internet y las redes sociales para la salud en adolescentes: Evaluación de necesidades para un servicio online de salud mental". En: Pérez Gómez, Laura Nuez Vicente, Cristina y del Pozo Irribarría, Juan (eds.): Tecnologías de la comunicación, jóvenes y promoción de la salud. Gobierno de La Rioja: Consejería de Salud y Servicios Sociales, pp. 100-115.

Guillory, Jamie E. y Sundar, S. Shyam (2014): "How Does Web Site Interactivity Affect Our Perceptions of an Organization?" Journal of Public Relations Research, vol. 26, $\mathrm{n}^{\mathrm{o}} 1$, pp. 44-61.

Guth, David W. y Marsh, Charles (2000): Public Relations: A Values-Driven Approach. Boston, Allyn and Bacon.

Guy, Bonnie et al. (2007): "Approaches to organizing public relations functions in healthcare". Health Marketing Quarterly, vol. 24, n 3-4, pp. 1-18.

Hage, Jerald y Hull, Frank (1981): A typology of environmental niches based on knowledge, technology and scale: The implications for innovation and productivity. College Park (Maryland), University of Maryland.

Hainsworth, Brad E. y Wilson, Laurie J. (1992): "Strategic program planning". Public Relations Review, vol. 18, n 1, pp. 9-15.

Halm, Margo A.; Sabo, Julie y Rudiger, Monica (2006): "The patient-family advisory council: keeping a pulse on our customers". Critical Care Nurse, vol. 26, n 5, pp. $58-67$.

Han, Sang-Lin; Wilson, David T. y Dant, Shirish P. (1993): "Buyer-supplier relationships today". Industrial Marketing Management, vol. 22, n ${ }^{\circ} 4$, pp. 331338.

Harlow, Rex F. (1976): "Building a public relations definition". Public Relations Review, vol. 2, n 4 , pp. 34-42.

Harrison, Shirley (2002): Relaciones públicas: una introducción. $2^{\mathrm{a}}$ ed. Madrid, Thompson.

Hart, Angie; Henwood, Flis y Wyatt, Sally (2004): “The role of the Internet in patientpractitioner relationships: findings from a qualitative research study". Journal of Medical Internet Research, vol. 6, n 3, p. 36.

Heath, Robert Lawrence (1997): Strategic Issues Management: Organizations and Public Policy Challenges. Thousand Oaks (California), Sage.

--- (1990): "Corporate Issues Management: Theoretical Underpinnings and Research Foundations". Public Relations Research Annual, vol. 2, n 1-4, pp. 29-65. 
Heath, Robert Lawrence; Lee, Jaesub y Ni, Lan (2009): “Crisis and risk approaches to emergency management planning and communication: The role of similarity and sensitivity". Journal of Public Relations Research, vol. 21, n 2, pp. 123-141.

Henderson, Julie K. (2005): "Evaluating public relations effectiveness in a health care setting". Journal of Health and Human Services Administration, vol. 28, n 1-2. Harrisburg (Pensilvania), pp. 282-321.

Hendrix, Jerry; Hayes, Darrell y Kumar, Pallavi (2012): Public Relations Cases. $9^{\mathrm{a}}$ ed. Boston, Cengage Learning.

Hibbard, Judith H.; Stockard, Jean y Tusler, Martin (2005): "Hospital performance reports: Impact on quality, market share, and reputation". Health Affairs, vol. 24, $\mathrm{n}^{\mathrm{o}} 4$, pp. $1.150-1.160$.

Hill, Laura Newland y White, Candace (2000): "Public relations practitioners" perception of the world wide web as a communications tool". Public Relations Review, vol. 26, $\mathrm{n}^{\mathrm{o}} 1$, pp. 31-51.

Hofstetter, C. Richard et al. (1995): "Patterns of Communication about AIDS Risk Factors among Hispanic and Anglo Adolescents". American Journal of Preventive Medicine, vol. 11, n 4, pp. 231-237.

Hogan, Beth; Hershey, Lewis y Ritchey, Steven (2007): “A case study using a patient satisfaction survey to improve the delivery and effectiveness of drug addiction treatment services: marketing implications and organizational impact". Health Marketing Quarterly, vol. 24, n 1-2, Routledge, pp. 93-106.

Holdsworth, Gillian M. C. et al. (1999): "Controlled management of public relations following a public health incident". Journal of public health medicine, vol. 21, $\mathrm{n}^{\circ}$ 3, pp. 251-254.

Hon, Linda Childers (1998): "Demonstrating effectiveness in public relations: goals, objectives and evaluation". Journal of Public Relations Research, vol. 10, $\mathrm{n}^{\circ} 2$, pp. $103-135$.

Hon, Linda Childers y Grunig, James E. (1999): Guidelines for Measuring Relationships in Public Relations. Institute for Public Relations. Disponible en: http://www.aco.nato.int/resources/9/Conference2011/Guidelines_Measuring_Relat ionships[1].pdf. Consultado el 11 de marzo de 2014.

Hong, Hyehyun (2013): “Government websites and social media's influence on government-public relationships". Public Relations Review, vol. 39, n ${ }^{\circ}$ 4, pp. 346356.

Hong, Soo Yeon y Rim, Hyejoon (2010): “The influence of customer use of corporate websites: Corporate social responsibility, trust, and word-of-mouth communication". Public Relations Review, vol. 36, n 4, pp. 389-391. 
Huang, Yi-Hui Christine (2012): "Gauging an Integrated Model of Public Relations Value Assessment (PRVA): Scale Development and Cross-Cultural Studies". Journal of Public Relations Research, vol. 24, n 3, pp. 243-265.

Huertas, Assumpció y Cavia, José Fernández (2006): “Centre and periphery: Two speeds for the implementation of public relations in Spain". Public Relations Review, vol. 32, n 2, pp. 110-117.

Hunt, Todd y Grunig, James E. (1994): Public Relations Techniques. Orlando (Florida), Holt, Rinehart and Winston.

Hwang, Stephen W. (2012): "The strategic use of Twitter to manage personal public relations". Public Relations Review, vol. 38, n 1, pp. 159-161.

Hwang, Stephen W.; Tram, Carolyn Q. N. y Knarr, Nadia (2005): "The effect of illustrations on patient comprehension of medication instruction labels". BMC family practice, vol. $6, \mathrm{n}^{\mathrm{o}} 1$, p. 26.

Iacono, Erica (2009): “A higher perspective". En: $P R$ Week. Disponible en: http://www.prweek.com/article/1250104/higher-perspective. Consultado el 3 de noviembre de 2014.

Iconoce (2014): "Conócenos". Disponible en: http://info.iconoce.com/servicios.php. Consultado el 21 de octubre de 2014.

Igartua Perosanz, Juan José (2006): "Comunicación para la salud y sida: la aproximación educación-entretenimiento". Comunicar. Revista Científica de Comunicación y Educación, vol. 26, pp. 35-42.

Ingenhoff, Diana y Koelling, A. Martina (2009): "The potential of Web sites as a relationship building tool for charitable fundraising NPOs". Public Relations Review, vol. 35, p. 66.

Institute for Public Relations (2003): Commission on public relations measurement and evaluation. Disponible en: www.instituteforpr.com. Consultado el 13 de mayo de 2013.

Institute of Medicine (IOM) (1997): Improving health in the community: a role for performance monotoring. Washington D.C., National Academy Press.

--- (1996): Healthy Communities: New Partnerships for the Future of Public Health. Washington D.C., National Academy Press.

Instituto de Información Sanitaria (2013a): Barómetro sanitario. Disponible en: https://www.msssi.gob.es/estadEstudios/estadisticas/BarometroSanitario/home_BS .htm. Consultado el 1 de octubre de 2014. 
--- (2013b): Estadística de centros sanitarios de atención especializada. Disponible en: http:/www.msssi.gob.es/estadEstudios/estadisticas/ estHospiInternado /inforAnual/homeESCRI.htm. Consultado el 10 de octubre de 2014.

--- (2013c): Ficha técnica del Barómetro Sanitario. Disponible en: https://www.msssi.gob.es/estadEstudios/estadisticas/docs/BS_2013/BS_2013Ficha Tecnica3oleadas.pdf. Consultado el 14 de octubre de 2014.

(2013d): Notas metodológicas del Barómetro Sanitario. Disponible en: https://www.msssi.gob.es/estadEstudios/estadisticas/docs/BS_2013/

BS_2013Metodologia.pdf. Consultado el 7 de octubre de 2014.

--- (2011): Barómetro sanitario. Madrid. Disponible en: http://www.msssi.gob.es/estadEstudios/estadisticas/sisInfSanSNS/informeAnual.ht m. Consultado el 1 de octubre de 2014.

--- (2009): Estadística de establecimientos sanitarios con régimen de internado. Indicadores hospitalarios. Evolución 2000-2008. Disponible en: https://www.msssi.gob.es/estadEstudios/estadisticas/docs/Evolutivo_20002008.pdf. Consultado el 15 de mayo de 2014.

--- (2008): Sistema Nacional de Salud. Disponible en: http://www.uv.es/=atortosa/SNS08.pdf. Consultado el 15 de mayo de 2014.

Instituto Nacional de Estadística (INE) (2013): Padrón municipal. Disponible en: $\mathrm{http}: / / \mathrm{www}$.ine.es/jaxi/menu.do?type=pcaxis\&path $=/ \mathrm{t} 20 / \mathrm{e} 260 \&$ file $=$ inebase $\& \mathrm{~L}=0$. Consultado el 22 de septiembre de 2014.

(2012): Cuentas Económicas. Contabilidad Regional de España. Base 2008. Disponible en: http:/www.ine.es/jaxi/menu.do?type=pcaxis\&path=/ t35/p010\&file=inebase \&L=0. Consultado el 20 de septiembre de 2014 .

Instituto Nacional de Estadística (INE) e Instituto Geográfico Nacional (2012): Territorio. http://www.ine.es/jaxi/menu.do?type=pcaxis\&path=/t43/a011\&file= inebase $\& \mathrm{~L}=0$. Consultado el 22 de septiembre de 2014.

Jacobson, Harvey K. (1977): "The Role of Evaluation and Research in Management". En: Rowland, A. Westley (ed.): Handbook for Institutional Advancement: Programs for the Understanding and Support of Higher Education. San Francisco, Jossey-Bass.

Jaramillo López, Juan Camilo (2011): “¿Comunicación estratégica o estrategias de comunicación? El arte del ajedrecista". VII Simposio Latinoamericano de Comunicación Organizacional. Cali (Colombia), Universidad Autónoma de Occidente. 
JCAHO (Joint Commission on Accreditation of Healthcare and Organizations) (2005a): About the Speak up Program. Chicago. Disponible en: www.jcaho.org/accredited+organizations/speak+up/speak+up.htm. Consultado el 14 de octubre de 2013.

--- (2005b): Long-Term Care National Patient Safety Goals. Chicago. Disponible en: http://www.jcaho.org/accredited+organizations/long+term+care/npsg/05_npsg_ltc. htm. Consultado el 2 de octubre de 2013.

Jeffers, Dennis W. (1977): "Performance Expectations as a Measure of Relative Status of News and PR People". Journalism Quarterly, vol. 54, n 2, pp. 299-306.

Jeffrey, Pfeffer (1978): Organizational design. Arlington Heights (Illinois), AHM Publishing.

Jefkins, Frank (1985): Relaciones públicas. Madrid, Edaf.

Jiménez Pernett, Jaime et al. (2009): "Estudio sobre salud en Internet para adolescentes y jóvenes en la ciudad de Granada". En: del Pozo Irribarría, Juan Pérez Gómez, Laura y Ferreras Oleffe, Miguel (eds.): Adicciones y nuevas tecnologías de la información y de la comunicación: perspectivas de su uso para la prevención y el tratamiento. Logroño, Gobierno de La Rioja: Consejería de Salud y Servicios Sociales, pp. 95-102.

Johnson, Melissa A. (1997): "Public Relations and Technology". Journal of Public Relations Research, vol. 9, pp. 213-236.

Jun, Jungmi (2011): "How climate change organizations utilize websites for public relations". Public Relations Review, vol. 37, n³, pp. 245-249.

Jung, Wan S. y Villegas, Jorge (2011): "The effects of message framing, involvement, and nicotine dependence on anti-smoking public service announcements". Health Marketing Quarterly, vol. 28, n 3, pp. 219-31.

Kang, Seok y Norton, Hanna E. (2006): "Colleges and universities' use of the World Wide Web: A public relations tool for the digital age". Public Relations Review, vol. $32, n^{\circ} 4$, pp. 426-428.

--- (2004): "Nonprofit organizations' use of the World Wide Web: are they sufficiently fulfilling organizational goals?" Public Relations Review, vol. 30, n 3 , pp. 279-284.

Kanouse, David E. (1984): "Explaining negativity biases in evaluation and choice behavior: Theory and research". Advances in Consumer Research, vol. 11, $\mathrm{n}^{\circ} 1$, pp. $703-708$.

Kaya, Sidika et al. (2003): “Comparing patients' and physicians' opinions on quality outpatient care". Military medicine, vol. 168, n 12, pp. 1.029-1.033. 
Kearney, M. et al. (1998): "Attitudes toward and beliefs about nutrition and health among a nationally representative sample of Irish adults: Application of Logistic Regression Modeling”. Journal of Nutrition Education, vol. 30, n 139-148, p. 139.

Keller, Anita C. et al. (2014): "The relationship between hospital patients' ratings of quality of care and communication". International Journal for Quality in Health Care, vol. 26, $\mathrm{n}^{\mathrm{o}}$ 1, pp. 26-33.

Kelly, Kathleen S. (1994): "Fund-raising encroachment and potential of the public relations department in the nonprofit sector". Journal of Public Relations Research, vol. 6, pp. 1-22.

--- (1992): "Potential of the Public Relations Department as a deterrent to fund raising encroachment". Annual Meeting of the Association for Education in Journalism and Mass Communication News. Canadá.

Kendall, Robert (1977): Public relations campaign strategies: planning for implementation. $2^{\text {a }}$ ed. Nueva York, Addison-Wesley.

Kent, Michael L. (2014): "Rethinking technology research and social media". Public Relations Review, vol. 40, $\mathrm{n}^{\mathrm{0}} 1$, pp. 1-2.

--- (2008): "Critical analysis of blogging in public relations". Public Relations Review, vol. $34, \mathrm{n}^{\mathrm{o}} 1$, pp. 32-40.

Kent, Michael L. y Saffer, Adam J. (2014): "A Delphi study of the future of new technology research in public relations". Public Relations Review, vol. 40, n 3, pp. $568-576$.

Kent, Michael L. y Taylor, Maureen (1998): "Building dialogic relationships through the world wide web". Public Relations Review, vol. 24, n³, pp. 321-334.

Ki, Eyun-Jung y Shin, Jae-Hwa (2006): "Status of organization-public relationship research from an analysis of published articles, 1985-2004". Public Relations Review, vol. $32, \mathrm{n}^{\mathrm{O}} 2$,

Kim, Daejoong; Nam, Yoonjae y Kang, Sinuk (2010): “An analysis of corporate environmental responsibility on the global corporate Web sites and their dialogic principles". Public Relations Review, vol. 36, n 3, pp. 285-288.

Kim, Yungwook (2001): "Measuring the Economic Value of Public Relations". Journal of Public Relations Research, vol. 13, $\mathrm{n}^{\mathrm{O}}$ 1, Routledge, pp. 3-26.

King, Brent y Scrimger, Judith (1993): "Public Relations Fund Raising and Marketing in Canadian Hospitals". Public Relations Quarterly, vol. 38, n 2, pp. 40-45. 
Kinsky, Emily S. et al. (2014): "Pulling ads, making apologies: Lowe's use of Facebook to communicate with stakeholders". Public Relations Review, vol. 40, n 3, pp. $556-558$.

Kirat, Mohamed (2007): "Promoting online media relations: Public relations departments' use of Internet in the UAE”. Public Relations Review, vol. 33, n 2, pp. $166-174$.

Kirdar, Yalçïn (2007): "The Role of Public Relations for Image Creating in Health Services: A Sample Patient Satisfaction Survey”. Health Marketing Quarterly, vol. 24, n $3-4$, pp. 33-53.

Knapp, Peter et al. (2005): "Interpretation of medication pictograms by adults in the UK". The Annals of pharmacotherapy, vol. 39, $\mathrm{n}^{\mathrm{0}} 7-8, \mathrm{pp} .1 .227-1.233$.

Kosa, John; Antonovsky, Aaron y Zola, Irving Kenneth (1969): Poverty and health: A sociological analysis. Cambridge, Harvard University Press.

Kotler, Philip y Andreasen, Alan R. (1987): Strategic marketing for nonprofit organizations. Englewood Cliffs (Nueva Jersey), Prentice-Hall.

Kotler, Philip y Clarke, Roberta N. (1987): Marketing for healthcare organizations. Englewood Cliffs (Nueva Jersey), Prentice Hall.

Kotler, Philip y Lee, Nancy (2005): "Best of Breed: When it Comes to Gaining A market Edge while Supporting a Social Cause, 'Corporate Social Marketing' Leads the Pack". Social Marketing Quarterly, vol. 11, n 3-4, pp. 91-103.

Kreps, Gary L. (2008): "Strategic use of communication to market cancer prevention and control to vulnerable populations". Health Marketing Quarterly, vol. 25, $\mathrm{n}^{\mathrm{o}} 1$ 2, pp. 204-216.

-- (2006): "One size does not fit all: Adapting communication to the needs and literacy levels of individuals". Annals of Family Medicine, 4.

-- (2005): "Disseminating relevant information to underserved audiences: Implications from the Digital Divide Pilot Projects". Journal of the Medical Library Association, vol. 93, n 4, pp. 65-70.

-_- (1996): "Communicating to promote justice in the modern health care system". Journal of health communication, vol. 1, n 1, pp. 99-109.

--_ (1990): "A systematic analysis of health communication with the aged". En: Giles, Howard Coupland, Nikolaus y Wiemann, John (eds.): Communication, health, and the elderly. Manchester, University of Manchester Press, pp. 135-154.

--- (1986): "Health communication and the elderly". World Communication, vol. 15, pp. 55-70. 
Kreps, Gary L. y Bonaguro, Ellen W. (2007): "Communication and cancer prevention, control, and care". En: Wright, Kevin B. y Moore, Scott (eds.): Applied health communication. Cresskill (Nueva Jersey), Hampton Press, pp. 257-269.

Kreps, Gary L.; Bonaguro, Ellen W. y Query, Jim L. (1998): “The history and development of the field of health communication". En: Duffy, Bernard K. y Jackson, Lorraine D. (eds.): Health communication research: A guide to developments and directions. Westport (Connecticut), Greenwood Press, pp. 1-15.

Kreps, Gary L. y Kunimoto, Elizabeth N. (1994): Effective communication in multicultural health care settings. Newbury Park (California), Sage Publications.

Kruvand, Marjorie (2010): "Face to face: How the Cleveland Clinic managed media relations for the first U.S. face transplant". Public Relations Review, vol. 36, n 4 , pp. 367-375.

Kurtz, Harold P. (1969): Public Relations for Hospitals. Springfield (Illinois), Charles C. Thomas Publisher.

Lahmann, Petra H. y Kumanyika, Shiriki K. (1999): "Attitudes about health and nutrition are more indicative of dietary quality in 50- to 75-year-old women than weight and appearance concerns". Journal of the American Dietetics Association, vol. $99, n^{\circ} 4$, pp. 475-479.

Lai, Cheng-Neng (2014): "Public broadcast of health communication: Extending public relations through social capital in Taiwan". Public Relations Review, vol. 40, $\mathrm{n}^{\circ} 3$, pp. 506-508.

LaMarre, Heather L. y Suzuki-Lambrecht, Yoshikazu (2013): "Tweeting democracy? Examining Twitter as an online public relations strategy for congressional campaigns". Public Relations Review, vol. 39, n 4, pp. 360-368.

Lamb, Larry F. y McKee, Kathy Brittain (2005): Applied Public Relations: Cases in Stakeholder Management. Mahwah (Nueva Jersey), Lawrence Erlbaum Associates.

Landmann, W.A. et al. (1990): "The relationship between beliefs about nutrition and dietary practices of the elderly". Journal of the American Dietetic Association, vol. 90, pp. 671-676.

Langmaak, Maike; Heidrich, Stefanie y Sjöholm, Marianne (2004): Communication as a tool to overcome crises. Grin Verlag.

Lauzen, Martha M. (1997): "Understanding the Relation Between Public Relations and Issues Management”. Journal of Public Relations Research, vol. 9, n ${ }^{\circ}$ 1, pp. 6582.

Lauzen, Martha M. y Dozier, David M. (1994): "Issues Management Mediation of Linkages Between Environmental Complexity and Management of the Public 
Relations Function". Journal of Public Relations Research, vol. 6, n 3, pp. 163184.

Ledingham, John A. (2003): "Explicating Relationship Management as a General Theory of Public Relations". Journal of Public Relations Research, vol. 15, n ${ }^{\circ} 2$, pp. 181-198.

Lee, Hyunmin y Park, Hyojung (2013): "Testing the Impact of Message Interactivity on Relationship Management and Organizational Reputation”. Journal of Public Relations Research, vol. 25, $\mathrm{n}^{\circ}$ 2, pp. 188-206.

Lee, Seow Ting (2012): "Beautifully Imperfect: Using Facebook to change a population's attitudes toward marriage". Public Relations Review, vol. 38, n 3, pp. 515-517.

Lee, Suman y Yoon, Youngmin (2010): "Return on investment (ROI) of international public relations: A country-level analysis". Public Relations Review, vol. 36, $\mathrm{n}^{\circ} 1$, pp. 15-20.

Len-Ríos, María E.; Hinnant, Amanda y Park, Sun-A (2009): "Understanding how health journalists judge public relations sources: A rules theory approach". Public Relations Review, vol. 35, $\mathrm{n}^{\mathrm{0}}$ 1, pp. 56-65.

Levins, Ilyssa y Rodgers, Colleen (1998): "Getting good ink: Measuring PR effectiveness". Pharmaceutical Executive, vol. 18, n ${ }^{\circ}$ 12, pp. 12-15.

Lewton, Kathleen Larey (1992): “Afterword”. En: Dines, Keith A. y Schneller, Eugene S. (eds.): Public relations and the American hospital. Tempe (Arizona), Arizona State University Press, pp. 51-52.

-_- (1991): Public Relations in Health Care: A Guide for Professionals. Chicago, American Hospital Publishing.

--- (1998): "From costs to confidence: Resuscitating health care". Public Relations Tactics, vol. 5, n 3 , pp. 1-6.

Ley, Philip (1979): "Memory for medical information". British Journal of Social and Clinical Psychology, vol. 18, n 2, pp. 245-255.

Lichtenstein, Allen y Rosenfeld, Lawrence B. (1983): "Uses and misuses of gratifications research: An explication of media functions". Communication Research, vol. 10, $\mathrm{n}^{\mathrm{0}}$ 1, pp. 97-109.

Lim, Jeongsub y Jones, Lois (2010): “A baseline summary of framing research in public relations from 1990 to 2009". Public Relations Review, vol. 36, n 3, pp. 292-297. 
Linvill, Darren L.; McGee, Sara E. y Hicks, Laura K. (2012): “Colleges' and universities' use of Twitter: A content analysis". Public Relations Review, vol. 38, $\mathrm{n}^{\mathrm{o}} 4$, pp. 636-638.

Lorig, Kate R. et al. (2002): "Can a Back Pain E-mail Discussion Group improve health status and lower health care costs?: A randomized study". Archives of internal medicine, vol. 162, $\mathrm{n}^{\mathrm{0}} 7$, pp. 792-796.

Lovejoy, Kristen; Waters, Richard D. y Saxton, Gregory D. (2012): "Engaging stakeholders through Twitter: How nonprofit organizations are getting more out of 140 characters or less". Public Relations Review, vol. 38, n² 2, pp. 313-318.

Lozano Rendón, José Carlos (2007): Teoría e investigación de la comunicación de masas. México, Pearson Educación.

Lupiáñez Villanueva, Francisco (2009): “Internet y salud: una aproximación empírica a los usos de Internet relacionados con la salud". En: del Pozo Irribarría, Juan Pérez Gómez, Laura y Ferreras Oleffe, Miguel (eds.): Adicciones y nuevas tecnologías de la información y de la comunicación: perspectivas de su uso para la prevención y el tratamiento. Logroño, Gobierno de La Rioja: Consejería de Salud y Servicios Sociales, pp. 103-118.

Magallón, Sara (2006): “Concepto y elementos de las relaciones públicas". Anàlisi: Quaderns de comunicació i cultura, $\mathrm{n}^{0} 34$, pp. 103-109.

Maibach, Edward W. (2003): "Explicating social marketing: what is it, and what isn't it?" Social Marketing Quarterly, vol. 8, n 4, pp. 7-13.

Maibach, Edward W. y Parrott, Roxanne (1995): Designing health messages: Approaches from communication theory and public health practice. Thousand Oaks (California), Sage Publications.

March Cerdá, Joan Carles et al. (2009): "Robin, un robot para informar en Salud a la población adolescente vía Messenger". En: del Pozo Irribarría, Juan Pérez Gómez, Laura y Ferreras Oleffe, Miguel (eds.): Adicciones y nuevas tecnologías de la información y de la comunicación: perspectivas de su uso para la prevención y el tratamiento. Logroño, Gobierno de La Rioja: Consejería de Salud y Servicios Sociales, pp. 153-164.

Marston, John E. (1990): Relaciones públicas modernas. Mexico, McGraw-Hill.

--- (1963): The nature of public relations. Nueva York, McGraw-Hill.

Martínez Mendoza, Sarelly (2007): "En torno a la investigación en relaciones públicas". Revista Latina de comunicación social, $\mathrm{n}^{\mathrm{0}} 62$.

Martínez Solana, María Yolanda (2011): "La responsabilidad de las instituciones públicas en la comunicación sobre salud”. En: Cuesta Cambra, Ubaldo Menéndez 
Hevia, Tania y Ugarte Iturrizaga, Aitor (eds.): Comunicación y salud: nuevos escenarios y tendencias. Madrid, Editorial Complutense, pp. 51-64.

Martínez-Brawley, Emilia E. y Brawley, Edward Allan (2003): "The media role in marginalizing the mentally ill: taking corrective action". Portularia: Revista de Trabajo Social, n 3, pp. 285-297.

Mayer Pujadas, Miguel Ángel (2009): "Programas de calidad y tecnologías web al servicio de los ususarios de salud". En: del Pozo Irribarría, Juan Pérez Gómez, Laura y Ferreras Oleffe, Miguel (eds.): Adicciones y nuevas tecnologías de la información y de la comunicación: perspectivas de su uso para la prevención y el tratamiento. Logroño, Gobierno de La Rioja: Consejería de Salud y Servicios Sociales, pp. 121-130.

McAllister, Sheila M. (2012): "How the world's top universities provide dialogic forums for marginalized voices". Public Relations Review, vol. 38, $\mathrm{n}^{0}$ 2, pp. 319327.

McAllister, Sheila M. y Taylor, Maureen (2007): "Community college web sites as tools for fostering dialogue". Public Relations Review, vol. 33, n² 2, pp. 230-232.

McCullough, Tammy y Dodge, H. Robert (2002): "Understanding the role consumer involvement plays in the effectiveness of hospital advertising". Health Marketing Quarterly, vol. 19, n 3, pp. 3-20.

McGuire, W.J. (1984): "Public communication as a strategy for inducing health promoting behavioral change". Preventive Medicine, vol. 13, pp. 299-319.

--- (1969): "Attitude and attitude change". En: Lindzey, Gardner y Aronson, Elliot (eds.): Handbook of social psychology. Reading (Massachusetts), Addison-Wesley, pp. 136-314.

Meath, Michael (2006): "Taking time to care: best practices in long-term care communications". Corporate Communications: An International Journal, vol. 11, $\mathrm{n}^{\mathrm{o}} 4$, pp. 336-352.

Medeiros, Denis M. et al. (1996): "Diet fat and fiber knowledge, beliefs and practices are minimally influenced by health status". Nutrition Research, vol. 16, pp. 751758.

Menéndez Hevia, Tania y Cuesta Cambra, Ubaldo (2011): "Educación para la salud en jóvenes a través de los medios sociales: desarrollo de un caso práctico sobre prevención de drogodependencias". En: Cuesta Cambra, Ubaldo Menéndez Hevia, Tania y Ugarte Iturrizaga, Aitor (eds.): Comunicación y salud: nuevos escenarios y tendencias. Madrid, Editorial Complutense, pp. 143-165. 
Menéndez Prieto, $\mathrm{M}^{\mathrm{a}}$ Dolores y Vadillo Olmo, Francisco Javier (2010): El plan de comunicación hospitalario: Herramienta de gestión sanitaria. San Vicente (Alicante), Editorial Club Universitario.

Meyerowitz, Beth E. y Chaiken, Shelly (1987): "The effect of message framing on breast self-examination attitudes, intentions, and behavior". Journal of Personality and Social Psychology, vol. 52, $\mathrm{n}^{\mathrm{o}} 3$, pp. 500-510.

Michael, Aiken y Jerald, Hage (1968): "Organizational interdependence and intraorganizational structure". American Sociological Review, vol. 33, nº 6.

Míguez González, María Isabel (2007): “Análisis del uso de los conceptos de público, stakeholder y constituent en el marco teórico de las relaciones públicas". Zer Revista de Estudios de Comunicación, vol. 23, pp. 183-197.

Milam, Lacey y Avery, Elizabeth Johnson (2012): “Apps4Africa: A new State Department public diplomacy initiative". Public Relations Review, vol. 38, n 2 , pp. 328-335.

Milano, Carol (2010): "What's Being Said About Your Hospital on the Web?" Hospital \& Health Networks, vol. 84, $\mathrm{n}^{\mathrm{0}} 4$, p. 10.

Mills, Alden B. (1965): Hospital Public Relations Today. Berwyn (Illinois), Physician's Record Company.

Ministerio de Sanidad, Servicios Sociales e Igualdad (2013a): Catálogo Nacional de Hospitales 2013. Disponible en: http://www.msssi.gob.es/ciudadanos/prestaciones /centrosServiciosSNS/hospitales/docs/CNH2013.pdf. Consultado el 13 de septiembre de 2014.

--- (2013b): Estadística de centros de atención especializada. Hospitales. Resultados año 2011. Disponible en: http://www.msssi.gob.es/estadEstudios/estadisticas/ docs/TablasSIAE2011/PUBLICACION_SIAE_2011.pdf. Consultado el 22 de mayo de 2014.

--- (2013c): Estadística de Centros de Atención Especializada. Sistema de información de atención especializada (SIAE). Manual de definiciones y glosario de términos. Disponible en: http://pestadistico.inteligenciadegestion.msssi.es/. Consultado el 21 de agosto de 2014.

--- (2013d): Registro de altas de Hospitalización - MCBD. Sistema Nacional de Salud. Glosario de términos y definiciones. Disponible en: http://pestadistico.inteligencia degestion.msssi.es/. Consultado el 22 de septiembre de 2014.

--- (2012): Sistema Nacional de Salud. España 2012. Madrid Disponible en: http://www.msssi.gob.es/organizacion/sns/libroSNS.htm. Consultado el 22 de septiembre de 2014. 
--- (2011): Registro de Altas de los Hospitales Generales del Sistema Nacional de Salud. CMBD. Disponible en: http://www.msssi.gob.es/estadEstudios/estadisticas/ cmbd.htm. Consultado el 23 de septiembre 2014.

Ministerio de Sanidad y Política Social (2009): Hospital de Día. Estándares y Recomendaciones. Madrid, Estilo Estugraf Impresores.

Minkler, Meredith y Wallerstein, Nina (2002): Community based participatory research for health. Indianápolis, Jossey-Bass.

Molassiotis, Alexander y Xu, Min (2004): "Quality and safety issues of web-based information about herbal medicines in the treatment of cancer". Complementary therapies in medicine, vol. $12, \mathrm{n}^{\circ} 4$, pp. 217-227.

Molleda, Juan Carlos (2009): "Propuesta de índice de autenticidad para desarrollar y evaluar decisiones, acciones, mensajes y programas de relaciones públicas". Razón y palabra, $\mathrm{n}^{\mathrm{o}} 70$.

Moody, Mia (2011): "Jon and Kate Plus 8: A case study of social media and image repair tactics”. Public Relations Review, vol. 37, n 4, pp. 405-414.

Morahan-Martin, Janet M. (2004): "How internet users find, evaluate, and use online health information: A cross-cultural review". CyberPsychology \& Behavior, vol. 7, p. 497.

Morris, Leigh E. (1992): "Patient accounts faces public relations challenge". Healthc Financ Manage, vol. 46, n ${ }^{\circ}$ 4, p. 92.

Moya de Madrigal, Ligia (1989): Introduccion Ala Estadistica de la Salud. San José (Costa Rica), Universidad de Costa Rica.

Moyer, Anne et al. (1995): "Accuracy of Health Research Reported in the Popular Press: Breast Cancer and Mammography". Health Communication, vol. 7, n 2, pp. 147-161.

Mueller, William (1989): “Are Americans eating better?” American Demographics, vol. 11 , pp. 30-33.

Mullin, Sandra (2002): "Public health and the media: The challenge now faced by bioterrorism". Journal of Urban Health, vol. 79, $\mathrm{n}^{\mathrm{0}}$ 1, p. 12.

Muralidharan, Sidharth et al. (2011): "Hope for Haiti: An analysis of Facebook and Twitter usage during the earthquake relief efforts". Public Relations Review, vol. $37, \mathrm{n}^{\mathrm{o}} 2$, pp. $175-177$.

Murphy, Priscilla (1991): "The Limits of Symmetry: A Game Theory Approach to Symmetric and Asymmetric Public Relations". Public Relations Research Annual, vol. $3, n^{0} 1-4$, pp. 115-131. 
Naciones Unidas (1948): “Declaración Universal de los Derechos Humanos”. París.

Nelkin, Dorothy (1996): "An uneasy relationship: The tensions between medicine and the media". Lancet, vol. $347, \mathrm{n}^{\circ} 9.015$, pp. 1.600-1.603.

Neumark-Sztainer, Dianne et al. (1998): "Adolescents engaging in unhealthy weight control behaviors: are they at risk for other health-compromising behaviors?" American Journal of Public Health, vol. 88, nº 6, pp. 952-955.

Newsom, Doug; Turk, Judy VanSlyke y Kruckeberg, Dean (2000): This is PR: The Realities of Public Relations. $7^{\mathrm{a}}$ ed. Belmont (California), Wadsworth.

Noguero, Alonso Méndiz (1997): "Diferencias conceptuales entre publicidad y propaganda: una aproximación etimológica". Questiones publicitarias: revista internacional de comunicación y publicidad, vol. 12, pp. 43-61.

Noguero i Grau, Antoni (2006): “Consideraciones acerca de las relaciones públicas en el siglo XX y su incardinación actual en el fenómeno de la globalización”. Anàlisi: Quaderns de comunicació i cultura, $\mathrm{n}^{\mathrm{0}} 34$, pp. 87-102.

--- (1995): La función social de las Relaciones Públicas: Historia, Teoría y Marco Legal. Barcelona, ESRP.

--_ (1990): "Concepto, desarrollo y función social de las relaciones públicas: perspectiva histórica, teórica y jurídica”. Barcelona, Universidad Autónoma de Barcelona.

--- (1985): Información y técnicas de relaciones públicas. Barcelona, Promociones y Publicaciones Universitarias.

--- (1982): Relaciones públicas e industria de la persuasión. Análisis gnoseológico y situacional. Barcelona, Editorial Universitaria de Barcelona.

-_- (1976): "Teoría y práctica de las relaciones públicas". Anuario Empresarial Máster, vol. 7, Barcelona, Club Master.

Novotny, Thomas y Adams, Vincanne: (2007): Global health diplomacy: A global health sciences working paper. UCSF Global Health Sciences. San Francisco, University of California at San Francisco.

Observatorio de la Comunicación Científica (2008): Medicina y salud en la prensa diaria. Informe Quiral 10 años. Barcelona Disponible en: http://www.upf.edu/pcstacademy/_docs/Quiral10.pdf. Consultado el 23 de diciembre de 2013.

Olson, Mancur (1971): The logic of collective action. Cambridge (Massachusetts), Harvard University Press. 
Ordeix Rigo, Enric (2013): "Constructing The Social Personality in Organizations: Essentials of Managing the Social Commitment According to the Parameters Reached by the Study 'Excellence in Public Relations and Communication Management"”. Tesis doctoral. Barcelona, Universitat Ramon Llull.

--- (2006): "La gestió del compromís: construir la identitat i els valors a les organitzacions a partir de les relacions públiques". Anàlisi: quaderns de comunicació i cultura, $\mathrm{n}^{\mathrm{0}} 34$, pp. 181-192.

Ordeix Rigo, Enric y Ginesta, Xavier (2011): "Beyond the Votes: A European Perspective on the Use of Public Relations to Legitimize Authority in Obama's Campaign”. American Behavioral Scientist, vol. 55, nº 6, pp. 683-695.

Ordeix Rigo, Enric y Navío Gámez, Antonio (2007): “La vertiente actitudinal de la gestión de las relaciones internas: El desarrollo de las competencias profesionales como base para la cohesión de la cultura organizativa". Sphera Pública. Revista de Ciencias Sociales y de la Comunicación, vol. 7, pp. 155-173.

Ordeix Rigo, Enric y Tió Bragado, Jacint (2010): "La responsabilidad social de las empresas: relaciones públicas o rentabilidad financiera". En: Carretón Ballester, $\mathrm{M}^{\mathrm{a}}$ Carmen y Ordeix Rigo, Enric (eds.): Las relaciones públicas en la sociedad del conocimiento. Alicante, Asociación de Investigadores en Relaciones Públicas (AIRP), pp. 32-52.

Organización Mundial de la Salud (2014): "Hospitales". Disponible en: http://www.who.int/topics/hospitals/es/. Consultado el 15 de enero de 2014.

Osuna, José (2009): "Prevención y Nuevas Tecnologías: una nueva forma de actuar". En: del Pozo Irribarría, Juan Pérez Gómez, Laura y Ferreras Oleffe, Miguel (eds.): Adicciones y nuevas tecnologías de la información y de la comunicación: perspectivas de su uso para la prevención y el tratamiento. Logroño, Gobierno de La Rioja: Consejería de Salud y Servicios Sociales, pp. 173-182.

Palencia-Lefler, Manuel (2011): 90 Técnicas de comunicación y relaciones públicas. Barcelona, Profit Editorial.

Park, Hyojung y Reber, Bryan H. (2008): "Relationship building and the use of Web sites: How Fortune 500 corporations use their Web sites to build relationships". Public Relations Review, vol. 34, n 4, pp. 409-411.

Patientview (2012): European Directory of Health Apps 2012-2013. A review by patient groups and empowered consumers. London Disponible en: http://g3ict.org/download/p/ fileId_955/productId_265. Consultado el 11 de agosto de 2014.

Pavlik, John V. (1988): "Audience Complexity as a Component of Campaign Planning”. Public Relations Review, vol. 14, n 2, pp. 12-21. 
--- (1987): Public relations: What research tells us. Newbury Park (California), Sage.

Payne, Velma y Kiel, Joan M. (2005): "Web-based communication to enhance outcomes: a case study in patient relations". Journal of Healthcare Information Management, vol. 19, $\mathrm{n}^{\circ}$ 2, pp. 56-63.

Pearson, Ron (1989): "Beyond Ethical Relativism in Public Relations: Coorientation, Rules, and the Idea of Communication Symmetry". Public Relations Research Annual, vol. 1, n 1-4, pp. 67-86.

Pérez, Rafael Alberto (2012): “2011: el año en que la comunicación se volvió estratégica". Revista DIRCOM, vol. 93, pp. 43-49.

Pérez, Rafael Alberto y Massoni, Sandra (2008): Hacia una teoría general de la estrategia. Barcelona, Ariel.

Perpiñán, José María Abellán (2013): El sistema sanitario público en España y sus comunidades autónomas: sostenibilidad y reformas. Fundacion BBVA.

Petromilli, Michael y Michalczyk, Dorothy (1999): "Your most valuable asset. Increasing the value of your hospital through its brand". Marketing Health Services, vol. 19, $\mathrm{n}^{\circ} 2$, pp. 4-9.

Pettigrew, Justin E. y Reber, Bryan H. (2011): “Journalists' opinions and attitudes about dialogic components of corporate websites". Public Relations Review, vol. 37, $\mathrm{n}^{\mathrm{o}}$ 4, pp. 422-424.

- (2010): "The new dynamic in corporate media relations: How fortune 500 companies are using virtual press rooms to engage the press". Journal of Public Relations Research, vol. 22, nº 4, pp. 404-428.

Pew Research Center (2009a): New media index. Disponible en: http://www.pewresearch.org/. Consultado el 13 de septiembre de 2013.

--_ (2009b): The social life of health information. Disponible en: http://www.pewinternet.org/Reports/2009/8-The-Social-Life-of-HealthInformation/. Consultado el 2 de julio de 2013.

--- (2006a): Online health search 2006. Disponible en: http://www.pewinternet.org/ /media//Files/Reports/2006/PIP_Online_Health_2006 .pdf.pdf. Consultado el 25 de noviembre de 2013.

--- (2006b): Online papers modestly boost newspaper readership. Maturing internet news audience-broader than deep. Washington D.C. Disponible en: http://www.people-press.org/2006/07/30/online-papers-modestly-boostnewspaper-readership/. Consultado el 14 de octubre de 2013. 
--- (2004a): Online news audience larger, more diverse: News audiences increasingly politicized. Washington D.C. Disponible en: http://www.peoplepress.org/files/legacy-pdf/215.pdf. Consultado el 31 de enero de 2014.

-- (2004b): Rural America's internet has grown but they continue to lag behind others. Disponible en: http://www.pewinternet.org/files/old-media/Files/Reports /2004/PIP_Rural_Report.pdf.pdf. Consultado el 13 de agosto de 2013.

Pham, Hoangmai H.; Coughlan, Jennifer y O'Malley, Ann S. (2006): “The impact of quality reporting programs on hospital operations". Health Affairs, vol. 25, n ${ }^{0} 5$, pp. 1.412-1.422.

Porter, Lance Vardaman et al. (2007): "Blog power: Examining the effects of practitioner blog use on power in public relations". Public Relations Review, vol. $33, \mathrm{n}^{\circ} 1, \mathrm{pp} .92-95$.

Porter, Lance Vardaman et al. (2001): "New technologies and public relations: Exploring practitioners' use of online resources to earn a seat at the management table". Journalism \& Mass Communication Quarterly, vol. 78, n 1, pp. 172-190.

Porter, Lance Vardaman y Sallot, Lynne M. (2005): "Web power: a survey of practitioners' World Wide Web use and their perceptions of its effects on their decision-making power". Public Relations Review, vol. 31, nº 1, pp. 111-119.

-- (2003): "The internet and public relations: Investigating practitioners; roles and World Wide Web use". Journalism \& Mass Communication Quarterly, vol. 80, $\mathrm{n}^{\circ}$ 3 , pp. 603-622.

Pratto, Felicia y John, Oliver P. (1991): "Automatic vigilance: the attention-grabbing power of negative social information". Journal of personality and social psychology, vol. 61, $\mathrm{n}^{\mathrm{0}} 3$, pp. 380-91.

Primo Peña, Elena y Jaén Casquero, Ma Belén (2009): "La iniciativa LIS España: sitios saludables. Webs sanitarias de calidad”. En: del Pozo Irribarría, Juan Pérez Gómez, Laura y Ferreras Oleffe, Miguel (eds.): Adicciones y nuevas tecnologías de la información y de la comunicación: perspectivas de su uso para la prevención y el tratamiento. Logroño, Gobierno de La Rioja: Consejería de Salud y Servicios Sociales, pp. 139-150.

Prost, Eugène (1967): Le temps des relations publiques. París, CELSE.

Public Relations Institute of Australia (2013): About Public Relations. Disponible en: http://www.pria.com.au/aboutus/what-is-public-relations/. Consultado el 10 de julio de 2014.

Quintero, Alejandro Pizarroso (1993): Historia de la propaganda política. Madrid, Tecnos. 
Rawlins, B.L. (2006): Prioritizing stakeholders for public relations. Disponible en: http://www.instituteforpr.org/wp-content/uploads/2006 Stakeholders 1.pdf.

Consultado el 14 de septiembre de 2013.

Real Academia Española (2014): Diccionario de la lengua española. 22 $2^{\mathrm{a}}$ ed. Madrid.

Reardon, Kathleen Kelley (1989): "Meeting the communication/persuasion challenge of AIDS in workplaces, neighbourhoods, and schools". Health Communication, vol. 2, pp. 267-270.

Reyes, Maribel (2006): "Dar la cara genera confianza". En: Cuesta Cambra, Ubaldo Ugarte Iturrizaga, Aitor y Menéndez Hevia, Tania (eds.): Comunicación Social y Salud. Una introducción. Madrid, Edipo, pp. 93-98.

Rinallo, Diego y Basuroy, Suman (2009): "Does advertising spending influence media coverage of the advertiser?" Journal of Marketing, vol. 53, pp. 33-46.

Ristino, Robert J. (2007): "Communicating with external publics: managing public opinion and behavior". Health Marketing Quarterly, vol. 24, n 3-4, pp. 55-80.

Rodríguez Andrés, Roberto (2012): "La efectividad del uso del miedo como factor persuasivo en la comunicación de riesgos en las crisis sanitarias". Revista de Comunicación y Salud, vol. 1, n 2, pp. 33-46.

Rodríguez Breijo, Vanessa (2009): "Nuevos retos para el estudio de los efectos de los medios de comunicación". Madrid, Comunicación del XI Foro Universitario de Investigación en Comunicación.

Roessler, Patrick (2007): "Public health and the media - a never-ending story". International Journal of Public Health, vol. 52, $\mathrm{n}^{\mathrm{0}}$ 5, pp. 259-260.

Rojas Orduña, Octavio Isaac (2008): Relaciones públicas: La eficacia de la influencia. Madrid, Escuela Superior de Gestión Comercial y Marketing, ESIC.

Rubia Vila, Francisco J. (2011): Libro Blanco sobre el Sistema Sanitario Español. Madrid, Academia Europea de Ciencias y Artes.

Rubin, Alan M. (1983): "Television Uses and Gratifications: The Interactions of Viewing Patterns and Motivations". Journal of Broadcasting, vol. 27, $\mathrm{n}^{\mathrm{o}}$ 1, pp. 3751 .

Rubin, Alan M. y Rubin, Rebecca B. (1982): "Contextual Age and Television Use". Human Communication Research, vol. 8, $\mathrm{n}^{\circ} 3$, pp. 228-244.

Rybalko, Svetlana y Seltzer, Trent (2010): "Dialogic communication in 140 characters or less: How Fortune 500 companies engage stakeholders using Twitter". Public Relations Review, vol. 36, $\mathrm{n}^{\circ}$ 4, pp. 336-341. 
Saffer, Adam J.; Sommerfeldt, Erich J. y Taylor, Maureen (2013): "The effects of organizational Twitter interactivity on organization-public relationships". Public Relations Review, vol. 39, n 3, pp. 213-215.

Sallot, Lynne M.; Cameron, Glen T. y Weaver Lariscy, Ruthann (1997): "Professional standards in public relations: A survey of educators". Public Relations Review, vol. 23, nº 3, pp. 197-216.

Sallot, Lynne M.; Porter, Lance V. y Acosta-Alzuru, Carolina (2004): "Practitioners' web use and perceptions of their own roles and power: a qualitative study". Public Relations Review, vol. 30, n³, pp. 269-278.

Saura Pérez, Pilar (2000): “La Comunicación de Cada Día: Una Imagen Vale Más Que Mil Palabras". Nueva Empresa.com, vol. 450, p. 111.

Saxton, Gregory D. y Waters, Richard D. (2014): "What do Stakeholders Like on Facebook? Examining Public Reactions to Nonprofit Organizations' Informational, Promotional, and Community-Building Messages". Journal of Public Relations Research, vol. 26, n 3, pp. 280-299.

Schneider, Larissa A. (1985a): "Organizational Structure, Environmental Niches, and Public Relations: The Hage-Hull Typology of Organizations as Predictor of Communication Behavior”. College Park (Maryland), University of Maryland.

--_ (1985b): "The Role of Public Relations in Four Organizational Types". Journalism Quarterly, vol. 62, pp. 567-576.

Schultz, Friederike; Utz, Sonja y Göritz, Anja (2011): "Is the medium the message? Perceptions of and reactions to crisis communication via twitter, blogs and traditional media". Public Relations Review, vol. 37, n 1, pp. 20-27.

Schulz, Peter Johannes; Rubinell, Sara y Hartung, Uwe (2007): “An internet-based approach to enhance self-management of chronic low back pain in the Italianspeaking population of Switzerland: Results from a pilot study". International Journal of Public Health, vol. 52, nº 5, pp. 286-294.

Schwarz, Andreas (2012): "How publics use social media to respond to blame games in crisis communication: The Love Parade tragedy in Duisburg 2010". Public Relations Review, vol. 38, n 3 , pp. 430-437.

Scott, Jill et al. (2005): “Assessing nursing homes' capacity to create and sustain improvement”. Journal of Nursing Care Quality, vol. 20, n 1, pp. 36-42.

Searson, Eileen M. y Johnson, Melissa A. (2010): "Transparency laws and interactive public relations: An analysis of Latin American government Web sites". Public Relations Review, vol. 36, $\mathrm{n}^{\mathrm{O}}$ 2, pp. 120-126. 
Sebastião, Sónia Pedro (2013): "Portuguese PR consultancy websites: Content and presence". Public Relations Review, vol. 39, n 5, pp. 584-586.

Seematter-Bagnoud, Laurence y Santos-Eggimann, Brigitte (2007): "Sources and level of information about health issues and preventive services among young-old persons in Switzerland". International Journal of Public Health, vol. 52, $\mathrm{n}^{\circ}$ 5, pp. 313-316.

Segura Munguía, Santiago (2001): Nuevo diccionario etimológico latín-español y de las voces derivadas. Bilbao, Universidad de Deusto.

Seltzer, Trent et al. (2012): "PR in the ER: Managing internal organization-public relationships in a hospital emergency department”. Public Relations Review, vol. $38, \mathrm{n}^{\mathrm{o}} 1$, pp. $128-136$.

Seltzer, Trent y Mitrook, Michael A. (2007): "The dialogic potential of weblogs in relationship building". Public Relations Review, vol. 33, n² 2, pp. 227-229.

Sen, Chiranjoy (2005): "Thai health tourism gives India headache". En: The Economic Times. Disponible en: http://economictimes.indiatimes.com/articleshow/ 1183459.cms. Consultado el 18 de diciembre de 2013.

Sha, B. L. (2011): "Does accreditation really matter in public relations practice? How age and experience compare to accreditation". Public Relations Review, vol. 37, $\mathrm{n}^{\circ}$ 1, pp. $1-11$.

--_ (1999): "Intercultural public relations: Exploring cultural identity as a means of segmenting publics". College Park (Maryland), University of Maryland.

Shelton, Christina M. (1993): "The Bloomington Hospital Public Relations Department”. Public Relations Quarterly, vol. 38, n 1, pp. 25-28.

Simyar, Farhad y Lloyd-Jones, Joseph Lloyd (1988): Strategic management in the healthcare sector: Toward the year 2000. Englewood Cliffs (Nueva Jersey), Prentice Hall.

Skelton, A. M. et al. (1996): "Patients' views of low back pain and its management in general practice". The British Journal of General Practice: The Journal of the Royal College of General Practitioners, vol. 46, n 404, pp. 153-156.

Skelton, A. M. et al. (1995): "Patient education for low back pain in general practice". Patient Education and Counseling, vol. 25, $\mathrm{n}^{\mathrm{o}} 3$, pp. 329-34.

Smith, Penny Pence y Schaaf, Robert E. (1995): "How public relations techniques are used by medical practices in the managed health care marketplace". Public Relations Quarterly, vol. 40, nº 4, p. 19. 
Smith, Ronald D. (2012): Strategic Planning for Public Relations. $4^{\mathrm{a}}$ ed. Taylor \& Francis.

Smith, Steven M. y Petty, Richard E. (1996): "Message Framing and Persuasion: A Message Processing Analysis". Personality and Social Psychology Bulletin, vol. $22, n^{\circ} 3$, pp. 257-268.

Smudde, Peter M. (2005): "Blogging, Ethics, and Public Relations: A Proactive and Dialogic Approach”. Public Relations Quarterly, vol. 50, n 3, pp. 35-38.

Social Issues Research Centre (2001): Royal Society and the Royal Institution of Great Britain Guidelines on science and health communication. London. Disponible en: http://sirc.org/publik/revised_guidelines.shtml. Consultado el 5 de abril de 2014.

Sommerfeldt, Erich J.; Kent, Michael L. y Taylor, Maureen (2012): “Activist practitioner perspectives of website public relations: Why aren't activist websites fulfilling the dialogic promise?" Public Relations Review, vol. 38, $\mathrm{n}^{\circ}$ 2, pp. 303312.

Springston, Jeffrey K. y Champion, Victoria L. (2004): "Public relations and cultural aesthetics: designing health brochures". Public Relations Review, vol. 30, n 4, pp. 483-491.

Springston, Jeffrey K. y Weaver Lariscy, Ruthann (2005): "Public Relations Effectiveness in Public Health Institutions". Journal of health and human services administration, vol. 28, $\mathrm{n}^{\mathrm{o}} 1-2$, pp. 218-245.

Sriramesh, Krishnamurthy (1991): "The impact of societal culture on public relations: An ethnographic study of south Indian organizations". College Park (Maryland), University of Maryland.

Sriramesh, Krishnamurthy y Verčič, Dejan (2003): The Global Public Relations Handbook: Theory, Research, and Practice. Nueva York y Londres, Taylor \& Francis.

Stephens, Keri K. y Malone, Patty C. (2009): "If the organizations won't give us information...: The use of multiple new media for crisis technical translation and dialogue". Journal of Public Relations Research, vol. 21, n² 2, pp. 229-239.

Sweetser, Kaye D. y Kelleher, Tom (2011): "A survey of social media use, motivation and leadership among public relations practitioners". Public Relations Review, vol. $37, n^{\circ} 4$, pp. $425-428$.

Sweetser, Kaye D. y Metzgar, Emily (2007): "Communicating during crisis: Use of blogs as a relationship management tool”. Public Relations Review, vol. 33, n 3, pp. 340-342. 
Tak, Sunghee H. y Hong, Song Hee (2005): "Use of the Internet for health information by older adults with arthritis". Orthopaedic Nursing / National Association of Orthopaedic Nurses, vol. 24, $\mathrm{n}^{\circ}$ 2, pp. 134-8.

Taylor, Maureen y Kent, Michael L. (2010): “Anticipatory socialization in the use of social media in public relations: A content analysis of PRSA's Public Relations Tactics". Public Relations Review, vol. 36, n 3, pp. 207-214.

Taylor, Maureen y Perry, Danielle C. (2005): "Diffusion of traditional and new media tactics in crisis communication". Public Relations Review, vol. 31, n 2, pp. 209217.

Terrón Blanco, José Luis (2011): "El tratamiento del VIH-sida en los periódicos españoles, una investigación colaborativa". Revista de Comunicación y Salud, vol. $1, \mathrm{n}^{\mathrm{o}} 1$, pp. 4-17.

The Chartered Institute of Marketing (n.d.): "An Overview of Marketing". Disponible en: http://www.cim.co.uk/marketingplanningtool/intro.asp. Consultado el $11 \mathrm{de}$ julio de 2014.

Thomas, Richard K. (2005): Marketing Health Services. Health Administration Pr.

Tichenor, Phillip J.; Donohue, George A. y Olien, Clarice N. (1970): "Mass media flow and differential growth in knowledge". Public Opinion Quarterly, vol. 34, n 2, pp. $158-170$.

Tirkkonen, Päivi y Luoma-aho, Vilma (2011): "Online authority communication during an epidemic: A Finnish example". Public Relations Review, vol. 37, n² 2, pp. 172174.

Tkalac Verčič, Ana y Verčič, Dejan (2013): "Digital natives and social media". Public Relations Review, vol. 39, n 5, pp. 600-602.

Tkalac Verčič, Ana; Verčič, Dejan y Laco, Kristina (2008): “Comparing advertising and editorials: An experimental study in TV and print”. Public Relations Review, vol. $34, n^{\circ} 4$, pp. $380-386$.

Torres Valdés, Rosa María (2011): "Relaciones Públicas y Fundraising en las Universidades. Una propuesta de modelo de gestión". Pensar la Publicidad. Revista Internacional de Investigaciones Publicitarias, vol. 5, n 1, pp. 183-202.

Turner, Monique Mitchell (2007): "Using emotion in risk communication: The Anger Activism Model”. Public Relations Review, vol. 33, n² 2, pp. 114-119.

Ugarte Iturrizaga, Aitor (2011): "Estrategias de comunicación para prevenir el consumo de drogas: algunos apuntes sobre las campañas en EEUU y España”. En: Cuesta Cambra, Ubaldo Menéndez Hevia, Tania y Ugarte Iturrizaga, Aitor (eds.): 
Comunicación y salud: nuevos escenarios y tendencias. Madrid, Editorial Complutense.

Ugarte Iturrizaga, Aitor; Menéndez Hevia, Tania y Cuesta Cambra, Ubaldo (2009): Prensa escrita y salud en Madrid. Una revisión del modelo de la Agenda Setting y su aplicación a la dinámica de las noticias sobre salud en Madrid. Madrid, Facultad de Ciencias de la Información. Universidad Complutense de Madrid.

Universidad de Salamanca (2011): "Diccionario médico-biológico, histórico y etimológico". En: Ediciones Universidad de Salamanca. Disponible en: http://dicciomed.eusal.es/palabra/hospital. Consultado el 15 de enero de 2014.

Utz, Sonja; Schultz, Friederike y Glocka, Sandra (2013): “Crisis communication online: How medium, crisis type and emotions affected public reactions in the Fukushima Daiichi nuclear disaster". Public Relations Review, vol. 39, n 1, pp. 40-46.

Uzunoğlu, Ebru y Misci Kip, Sema (2014): "Building relationships through websites: A content analysis of Turkish environmental non-profit organizations' (NPO) websites". Public Relations Review, vol. 40, n 1, pp. 113-115.

Van der Meer, Toni G.L.A. y Verhoeven, Piet (2013): "Public framing organizational crisis situations: Social media versus news media". Public Relations Review, vol. $39, n^{\circ} 3$, pp. 229-231.

Van Ruler, Betteke y Verčič, Dejan (2005): "Reflective communication management, future ways of public relations research". En: Kalbfleisch, Pamela J. (ed.): Communication Yearbook 29. Mahwah (Nueva Jersey), Lawrence Erlbaum Associates, pp. 239-273.

--- (2004): Public Relations and Communication Management in Europe: A Nationby-nation Introduction to Public Relations Theory and Practice. Berlín/Nueva York, Walter de Gruyter.

--- (2002): The Bled Manifesto on Public Relations. Ljubljana Disponible en: http://prbooks.pbworks.com/f/Bled+Manifesto.pdf. Consultado el 5 de agosto de 2014.

Van Ruler, Betteke; Verčič, Tkalac y Verčič, Dejan (2010): Public Relations Metrics: Research and Evaluation. Routledge.

Vela, Carmelina y Bocigas, Olga (1992): Fundamentos de marketing. Madrid, Esic.

Verčič, Dejan y Grunig, James E. (2008): "The origins of public relations theory in economics ans strategic management". En: Moss, Danny Verčič, Dejan y Warnaby, Gary (eds.): Perspectives on Public Relations Research. London/Nueva York, Routledge, pp. 9-58. 
Verčič, Dejan; Grunig, Larissa A. y Grunig, James E. (1996): "Global and specific principles of public relations: Evidence from Slovenia". International Public Relations: A Comparative Analysis, Lawrence Erlbaum Associates, Inc., pp. 3165.

Verhoeven, Piet et al. (2012): "How European PR practitioners handle digital and social media". Public Relations Review, vol. 38, n 1, pp. 162-164.

Vesnic-Alujevic, Lucia (2012): "Political participation and web 2.0 in Europe: A case study of Facebook". Public Relations Review, vol. 38, n 3, pp. 466-470.

Vicente García, Diego (ed.): (2005): Latín: latino-españool, español-latino: diccionario ilustrado. $21^{\text {a }}$ ed. Barcelona, Vox.

Vieira Jr., Edward T. y Grantham, Susan (2014): "Defining public relations roles in the U.S.A. using cluster analysis". Public Relations Review, vol. 40, $\mathrm{n}^{\circ}$ 1, pp. 60-68.

Villafañe, Justo (2013): La buena empresa: propuesta para una teoría de la reputación corporativa. Madrid, Pearson Educacion.

--_ (2003): La buena reputación: claves del valor intangible de las empresas. Madrid, Pirámide.

Viswanath, Kasisomayajula (2006): "Public communications and its role in reducing and eliminating health disparities". En: Thompson, Gerald E. Mitchell, Faith y Williams, Monique B. (eds.): Examining the health disparities research plan of the national institutes of health: Unfinished business. Washington D.C., National Academies Press, pp. 215-253.

Von Bertalaniffy, Ludwig (1950): "The theory of open system in physics and biology Science”. Science, vol. 111, n 2872, pp. 23-29.

VV.AA. (2006): ATS/DUE del Servicio Gallego de Salud. Temario Común. Madrid, Editorial Mad.

Wahl, Otto F. (1995): Media Madness: Public Images of Mental Illness. New Brunswick (Nueva Jersey), Rutgers University Press.

Walsh Childers, K. y Brown, Jane D. (1989): "No blank slate: Teen media awareness mirrors upbringing”. Media Values, vol. 46, pp. 8-10.

Walters, Lynne Masel y Walters, Timothy N. (1992): "Environment of confidence: Daily newspaper use of press releases". Public Relations Review, vol. 18, $\mathrm{n}^{\circ} 1$, pp. 31-46.

Waters, Richard D. et al. (2009): "Engaging stakeholders through social networking: How nonprofit organizations are using Facebook". Public Relations Review, vol. 35, pp. 102-106. 
Watson, Tom (2011): "An initial investigation on the use of 'Return on Investment' in public relations practice”. Public Relations Review, vol. 37, n 3, pp. 314-317.

Weaver Lariscy, Ruthann; Avery, Elizabeth Johnson y Sohn, Youngju (2010): "Health Journalists and Three Levels of Public Information: Issue and Agenda Disparities?" Journal of Public Relations Research, vol. 22, n 2, pp. 113-135.

Weaver Lariscy, Ruthann y Springston, Jeffrey K. (2007): "Health crises and media relations: Relationship management-by-fire". Health Marketing Quarterly, vol. 24, $n^{0} 3-4$, p. 81.

Weinberger, Marc G.; Allen, Chris T. y Dillon, William R. (1981): "Negative information: Perspectives and research directions". Advances in Consumer Research, vol. 8, n 1, pp. 398-404.

Weiner, Richard (1996): Webster's New World Dictionary of Media and Comunications. Nueva York, Macmillan.

Weiss, Carol H. (1972): Evaluation research: methods for assessing program effectiveness. Englewood Cliffs (Nueva Jersey), Prentice-Hall.

Weissenberger, Christian et al. (2004): "Breast cancer: patient information needs reflected in English and German web sites". British Journal of Cancer, vol. 91, $\mathrm{n}^{\mathrm{o}}$ 8, pp. $1.482-1.487$.

Werner, Lawrence (1990): "When crisis strikes use a message action plan". Public Relations Journal, vol. 46, $\mathrm{n}^{\mathrm{0}}$ 8, pp. 30-31.

White, Jon y Dozier, David M. (1992): "Public Relations and Management Decision Making”. En: Grunig, James E. (ed.): Excellence in Public Relations and Communications Management. Hillsdale (Nueva Jersey), Lawrence Erlbaum Associates, pp. 91-108.

Wigley, Shelley y Lewis, Bobbi Kay (2012): "Rules of engagement: Practice what you tweet". Public Relations Review, vol. 38, n 1, pp. 165-167.

Wilcox, Dennis L. (2006): "The Landscape of Today's Global Public Relations". Anàlisi: Quaderns de comunicació i cultura, $\mathrm{n}^{\mathrm{o}} 34$, pp. 67-85.

Wilcox, Dennis L.; Ault, Phillip y Agee, W. (1986): Public Relations: Strategies and Tactics. Philadelphia, Random House.

Wilcox, Dennis L.; Cameron, Glen T. y Ault, Phillip (2004): Public Relations: Strategies and Tactics. $6^{\mathrm{a}}$ ed. Allyn \& Bacon.

Wilcox, Dennis L.; Cameron, Glen T. y Xifra Triadú, Jordi (2007): Relaciones públicas: estrategias y tácticas. Madrid, Pearson Educacion. 
Wilcox, Dennis L. y Cameron, Glenn T. (2011): Public Relations: Strategies and Tactics. $10^{\mathrm{a}}$ ed. Allyn \& Bacon.

Wimmer, Roger D. y Dominick, Joseph R. (1996): La investigación cientifica de los medios de comunicación: una introducción a sus métodos. Barcelona, Bosch.

Winker, Margaret A. et al. (2006): "Guidelines for medical and health information sites on the internet: principles governing AMA web sites. American Medical Association". JAMA: The Journal of the American Medical Association, vol. 283, $\mathrm{n}^{\mathrm{o}} 12$, pp. 1.600-1.606.

Wise, Kurt (2009): "Public relations and health diplomacy". Public Relations Review, vol. $35, \mathrm{n}^{\mathrm{o}} 2$, pp. 127-129.

--_ (2007): "The organization and implementation of relationship management". Health Marketing Quarterly, vol. 24, n³-4, pp. 151-166.

--- (2003): "Linking public relations processes and organizational effectiveness at a state health department". Journal of health and human services administration, vol. $25, \mathrm{n}^{\circ} 4$, pp. $497-525$.

--_ (2001): "Opportunities for public relations research in public health". Public Relations Review, vol. 27, n 4, pp. 475-487.

Wong, Carissa O. y McMurray, Nancy E. (2002): "Framing communication: Communicating the antismoking message effectively to all smokers". Journal of Community Psychology, vol. 30, $\mathrm{n}^{\circ}$ 4, pp. 433-447.

Wrenn, Bruce (2002): "Contribution to Hospital Performance". Journal of Hospital Marketing \& Public Relations, vol. 14, $\mathrm{n}^{\mathrm{O}}$ 1, pp. 3-13.

Wright, Peter (1974): "The harassed decision maker: Time pressures, distractions, and the use of evidence". Journal of Applied Psychology, vol. 59, nº 5, pp. 555-561.

Xifra Triadú, Jordi (2006): “¿Es marketing todo lo que reluce?: la pluralidad de perspectivas conceptuales de las relaciones públicas”. Anàlisi: Quaderns de comunicació i cultura, $\mathrm{n}^{\mathrm{O}} 34$, pp. 163-180.

Xifra Triadú, Jordi (2008): Las relaciones públicas. $n^{0}$ 63. Barcelona, Ediciones UOC.

--- (2007): Técnicas de las Relaciones Públicas. Barcelona, Editorial UOC.

-_- (2003): Teoría y estructura de las relaciones públicas. Madrid, Mc Graw Hill.

Yang, Aimei y Kent, Michael (2014): "Social media and organizational visibility: A sample of Fortune 500 corporations". Public Relations Review, vol. 40, n 3, pp. $562-564$. 
Yang, Aimei y Taylor, Maureen (2010): "Relationship-building by Chinese ENGOs' websites: Education, not activation". Public Relations Review, vol. 36, n 4, pp. $342-351$.

Yang, Sung-Un y Kang, Minjeong (2009): "Measuring blog engagement: Testing a four-dimensional scale". Public Relations Review, vol. 35, n 3, pp. 323-324.

Ye, Lan y Ki, Eyun-Jung (2012): "The status of online public relations research: An analysis of published articles in 1992-2009". Journal of Public Relations Research, vol. 24, n ${ }^{0} 5$, pp. 409-434.

Youmans, Sharon L. y Schillinger, Dean (2003): "Functional health literacy and medication use: the pharmacist's role". The Annals of Pharmacotherapy, vol. 37, $\mathrm{n}^{\mathrm{o}} 11$, pp. 1.726-1.729.

Zerfass, Ansgar y Schramm, Dana Melanie (2014): "Social Media Newsrooms in public relations: A conceptual framework and corporate practices in three countries". Public Relations Review, vol. 40, nº 1, pp. 79-91.

Zillmann, Dolf y Bryant, Jennings (1985): Selective Exposure to Communication. Hillsdale (Nueva Jersey), Lawrence Erlbaum Associates.

Zoch, Lynn M. et al. (2008): "Empowering the activist: Using framing devices on activist organizations' web sites". Public Relations Review, vol. 34, n ${ }^{\circ}$, pp. 351358.

Zola, Irving Kenneth (1966): "Culture and symptoms: An analysis of patients presenting complaints". American Sociological Review, vol. 3, pp. 615-630. 


\section{ANEXOS}

Anexo 1. Características actuales y evolución de los hospitales en España Anexo 2. Características actuales y evolución de los hospitales en Castilla y León y Galicia Anexo 3. Citas literales en su idioma original 


\section{ANEXO 1. CARACTERÍSTICAS ACTUALES Y EVOLUCIÓN DE LOS HOSPITALES EN ESPAÑA}

\section{Plazas de día}

La hospitalización de día en España se entiende como "la asistencia en el hospital durante unas horas, ya sea para diagnósticos, investigaciones clínicas y/o exploraciones múltiples, así como para tratamientos que no pueden hacerse en la consulta externa, pero que no justifican la estancia completa en hospital" (Ministerio de Sanidad y Política Social, 2009: 13). La hospitalización de día en vez de la hospitalización completa responde a "la introducción de mejoras tecnológicas y organizativas", que han permitido que "procesos que anteriormente exigían hospitalización, se atiendan de forma ambulatoria en los hospitales de día” (Instituto de Información Sanitaria, 2009).

Las plazas de hospital de día no han dejado de aumentar en los últimos años, incluso por encima del crecimiento de la población española. Así, en el año 2012, se contabilizan 18.348 puestos, o lo que equivale a 39,75 por cada 100.000 habitantes. Se trata de un aumento de 14.185 a las registradas en 1997, es decir, un 340,74\% más. En cuanto al ratio por 100.000 habitantes, también ha aumentado desde el 10,52 registrado en 1997 , lo que supone un incremento del $277,85 \%$.

Tabla 266. Evolución del número de plazas de hospital de día

\begin{tabular}{|l|r|r|r|r|}
\hline \multirow{2}{*}{ Año } & \multicolumn{4}{|c|}{ Número de plazas } \\
\cline { 2 - 5 } & $\begin{array}{r}\text { Hospital de } \\
\text { día }\end{array}$ & $\begin{array}{c}\text { Incremento } \\
\text { anual }\end{array}$ & $\begin{array}{c}\text { Por 100.000 } \\
\text { hab. }\end{array}$ & $\begin{array}{c}\text { Incremento } \\
\text { anual }\end{array}$ \\
\hline 2012 & 18.348 & $6,91 \%$ & 39,75 & $6,71 \%$ \\
\hline 2011 & 17.162 & $6,90 \%$ & 37,25 & $6,92 \%$ \\
\hline 2010 & 16.054 & $36,98 \%$ & 34,84 & $36,52 \%$ \\
\hline 2009 & 11.720 & $6,81 \%$ & 25,52 & $6,03 \%$ \\
\hline 2008 & 10.973 & $4,82 \%$ & 24,07 & $3,17 \%$ \\
\hline 2007 & 10.468 & $14,91 \%$ & 23,33 & $12,84 \%$ \\
\hline 2006 & 9.110 & $3,36 \%$ & 20,67 & $1,79 \%$ \\
\hline 2005 & 8.814 & $8,81 \%$ & 20,31 & $7,04 \%$ \\
\hline 2004 & 8.100 & $10,70 \%$ & 18,97 & $8,92 \%$ \\
\hline 2003 & 7.317 & $9,83 \%$ & 17,42 & $8,03 \%$ \\
\hline
\end{tabular}




\begin{tabular}{|l|r|r|r|r|}
\hline \multirow{2}{*}{ Año } & \multicolumn{4}{|c|}{ Número de plazas } \\
\cline { 2 - 5 } & $\begin{array}{r}\text { Hospital de } \\
\text { día }\end{array}$ & $\begin{array}{c}\text { Incremento } \\
\text { anual }\end{array}$ & $\begin{array}{c}\text { Por 100.000 } \\
\text { hab. }\end{array}$ & $\begin{array}{c}\text { Incremento } \\
\text { anual }\end{array}$ \\
\hline 2002 & 6.662 & $14,78 \%$ & 16,13 & $13,14 \%$ \\
\hline 2001 & 5.804 & $4,11 \%$ & 14,25 & $2,94 \%$ \\
\hline 2000 & 5.575 & $7,69 \%$ & 13,85 & $6,79 \%$ \\
\hline 1999 & 5.177 & $17,63 \%$ & 12,97 & $17,03 \%$ \\
\hline 1998 & 4.401 & $5,72 \%$ & 11,08 & $5,35 \%$ \\
\hline 1997 & 4.163 & & 10,52 & - \\
\hline $\begin{array}{l}\text { Diferencia } \\
2011-1997\end{array}$ & 12.999 & $313,25 \%$ & 26,73 & $254,09 \%$ \\
\hline
\end{tabular}

Fuente: Estadística de Centros Sanitarios de Atención Especializada y Estadística de Establecimientos Sanitarios con Régimen de Internado.

Divididos por dependencia funcional, los públicos han aumentado en mayor medida sus plazas de hospital de día frente a los privados: un 400,15\% y un $134,19 \%$ a nivel general, respectivamente. No obstante, son los Hospitales generales privados los que ofrecen el mayor incremento: han pasado de tener 220 plazas en 1997 a 1.196 en 2012, lo que supone un 443,64\% más. Los centros de larga y media estancia en las clínicas públicas ofrecen casi el mismo porcentaje: con un incremento del 426,14\%, en 2012 cuentan con 1.389 en comparación con las 264 de 1997. Únicamente se encuentra una disminución: se trata precisamente de los hospitales privados de larga y media estancia, que han visto reducirse sus plazas un $-62,85 \%$ debido al cambio de metodología.

En cualquier caso, el número de plazas de día en los hospitales del Sistema Nacional de Salud es mucho más numeroso que aquellos que se ofrecen en los privados: en 2012, los primeros contabilizan 16.170 y los segundos, 2.178. La mayor cantidad se ofrece en los Hospitales generales (13.147 en los públicos y 1.196 en los privados), seguidos por los de larga y media estancia en el caso de los públicos (1.389) y de los psiquiátricos en el caso de los centros privados (561). 
Tabla 267. Evolución del número de plazas de día en hospitales del Sistema Nacional de Salud por finalidad asistencial

\begin{tabular}{|c|c|c|c|c|c|}
\hline \multirow[b]{2}{*}{ Año } & \multicolumn{5}{|c|}{ Plazas de hospital de día } \\
\hline & $\begin{array}{l}\text { Hospitales } \\
\text { generales }\end{array}$ & $\begin{array}{c}\text { Otros } \\
\text { hospitales } \\
\text { de agudos }\end{array}$ & $\begin{array}{c}\text { Hospitales } \\
\text { de larga } \\
\text { estancia }^{29}\end{array}$ & $\underset{\text { psiquiátricos }}{\text { Hospitales }}$ & Total \\
\hline 2012 & 13.147 & 436 & 1.389 & 1.198 & 16.170 \\
\hline 2011 & 12.436 & 465 & 1.357 & 786 & 15.044 \\
\hline 2010 & 11.538 & 333 & 1.416 & 758 & 14.045 \\
\hline 2009 & 7.811 & 204 & 403 & 697 & 9.115 \\
\hline 2008 & 7.129 & 273 & 372 & 681 & 8.455 \\
\hline 2007 & 6.742 & 194 & 413 & 671 & 8.020 \\
\hline 2006 & 5.902 & 231 & 253 & 619 & 7.005 \\
\hline 2005 & 5.472 & 242 & 272 & 547 & 6.533 \\
\hline 2004 & 5.158 & 234 & 187 & 516 & 6.095 \\
\hline 2003 & 4.643 & 229 & 210 & 473 & 5.555 \\
\hline 2002 & 4.309 & 216 & 187 & 499 & 5.211 \\
\hline 2001 & 3.708 & 203 & 189 & 436 & 4.536 \\
\hline 2000 & 3.549 & 190 & 144 & 492 & 4.375 \\
\hline 1999 & 3.273 & 149 & 139 & 395 & 3.956 \\
\hline 1998 & 2.792 & 148 & 163 & 361 & 3.464 \\
\hline 1997 & 2.547 & 104 & 264 & 318 & 3.233 \\
\hline $\begin{array}{l}\text { Diferencia } \\
\text { 2012-1997 }\end{array}$ & 10.600 & 332 & 1.125 & 880 & 12.937 \\
\hline $\begin{array}{l}\text { \%Diferencia } \\
2012-1997\end{array}$ & $416,18 \%$ & $319,23 \%$ & $426,14 \%$ & $276,73 \%$ & $400,15 \%$ \\
\hline
\end{tabular}

Fuente: Estadística de Centros Sanitarios de Atención Especializada y Estadística de Establecimientos Sanitarios con Régimen de Internado.

\footnotetext{
$\underline{29}$ Conviene recordar que, a partir de 2010, la categoría de hospitales de larga estancia de la Estadística de Centros Sanitarios de Atención Especializada pasa a incluir los centros de media-larga estancia con actividad de apoyo de hospitales de agudos (Ministerio de Sanidad, 2013b).

30 Conviene recordar que, a partir de 2010, la categoría de hospitales de salud mental de larga estancia de la Estadística de Centros Sanitarios de Atención Especializada pasa a incluir también los centros de tratamientos de toxicomanías (Ministerio de Sanidad, 2013b).
} 
Tabla 268. Evolución del número de plazas de hospital de día en hospitales privados por finalidad asistencial

\begin{tabular}{|c|c|c|c|c|c|}
\hline \multirow[b]{2}{*}{ Año } & \multicolumn{5}{|c|}{ Plazas de hospital de día } \\
\hline & $\begin{array}{l}\text { Hospitales } \\
\text { generales }\end{array}$ & $\begin{array}{c}\text { Otros } \\
\text { hospitales } \\
\text { de agudos }\end{array}$ & $\begin{array}{l}\text { Hospitales } \\
\text { de larga } \\
\text { estancia }\end{array}$ & $\begin{array}{c}\text { Hospitales } \\
\text { psiquiátricos }\end{array}$ & Total \\
\hline 2012 & 1.196 & 301 & 120 & 561 & 2.178 \\
\hline 2011 & 1.144 & 303 & 170 & 501 & 2.118 \\
\hline 2010 & 1.008 & 275 & 209 & 517 & 2.009 \\
\hline 2009 & 637 & 267 & 916 & 785 & 2.605 \\
\hline 2008 & 607 & 254 & 927 & 730 & 2.518 \\
\hline 2007 & 581 & 241 & 891 & 735 & 2.448 \\
\hline 2006 & 417 & 254 & 799 & 635 & 2.105 \\
\hline 2005 & 380 & 252 & 907 & 742 & 2.281 \\
\hline 2004 & 328 & 171 & 861 & 645 & 2.005 \\
\hline 2003 & 276 & 146 & 790 & 550 & 1.762 \\
\hline 2002 & 235 & 114 & 707 & 395 & 1.451 \\
\hline 2001 & 259 & 96 & 546 & 367 & 1.268 \\
\hline 2000 & 258 & 103 & 452 & 387 & 1.200 \\
\hline 1999 & 264 & 98 & 475 & 384 & 1.221 \\
\hline 1998 & 181 & 86 & 374 & 296 & 937 \\
\hline 1997 & 220 & 78 & 323 & 309 & 930 \\
\hline $\begin{array}{l}\text { Diferencia } \\
2012-1997\end{array}$ & 976 & 223 & -203 & 252 & 1.248 \\
\hline \begin{tabular}{|l|} 
\%Diferencia \\
2012-1997
\end{tabular} & 443,64 & 285,90 & $-62,85$ & 81,55 & 134,19 \\
\hline
\end{tabular}

Fuente: Estadística de Centros Sanitarios de Atención Especializada y Estadística de Establecimientos Sanitarios con Régimen de Internado.

\section{Quirófanos}

Los quirófanos son "salas destinadas a la intervención o asistencia quirúrgica al enfermo, dotadas de una mesa de operaciones" que cumplen las siguientes características: "Una iluminación ajustable de poder suficiente para permitir un trabajo delicado, condiciones asépticas que deben incluir la provisión de instrumentos estériles y locales para el cambio de ropas del personal y la administración de anestesia general" (Ministerio de Sanidad, 2013b). No son considerados como tal los paritorios, las salas de extracción dental u otro tipo de cirugía que contenga silla dental, las salas de radiología y las salas de curas (Ministerio de Sanidad, 2013b). 
El número de quirófanos en España ha aumentado desde 1997 un 25,98\%, de tal manera que en 2012 se contabilizan 4.267. El aumento en relación con el crecimiento de la población no ha sido tan acusado, pero aun así el porcentaje se halla en términos positivos: 7,94\%, estando en la actualidad en algo más de nueve por cada 100.000 habitantes.

Tabla 269. Evolución del número de quirófanos en funcionamiento

\begin{tabular}{|l|r|r|}
\hline \multirow{2}{*}{ Año } & \multicolumn{2}{|c|}{$\begin{array}{c}\text { Quirófanos en } \\
\text { funcionamiento }\end{array}$} \\
\cline { 2 - 3 } & Número & $\begin{array}{c}\text { Por 100.000 } \\
\text { hab. }\end{array}$ \\
\hline 2012 & 4.267 & 9,24 \\
\hline 2011 & 4.202 & 9,11 \\
\hline 2010 & 4.120 & 8,94 \\
\hline 2009 & 4.063 & 8,85 \\
\hline 2008 & 3.975 & 8,72 \\
\hline 2007 & 3.865 & 8,61 \\
\hline 2006 & 3.740 & 8,49 \\
\hline 2005 & 3.686 & 8,49 \\
\hline 2004 & 3.636 & 8,52 \\
\hline 2003 & 3.562 & 8,48 \\
\hline 2002 & 3.565 & 8,63 \\
\hline 2001 & 3.531 & 8,67 \\
\hline 2000 & 3.497 & 8,69 \\
\hline 1999 & 3.463 & 8,67 \\
\hline 1998 & 3.411 & 8,59 \\
\hline 1997 & 3.387 & 8,56 \\
\hline Diferencia & 880 & 0,68 \\
\hline $2012-1997$ & 25,98 & 7,94 \\
\hline$\%$ Diferencia & & \\
\hline $2012-1997$ & & \\
\hline & & \\
\hline
\end{tabular}

Fuente: Estadística de Centros Sanitarios de Atención Especializada y Estadística de Establecimientos Sanitarios con Régimen de Internado.

No obstante, son los Hospitales generales los que aumentan su dotación considerablemente en detrimento de los de agudos y los de larga estancia, que ven disminuidos sus quirófanos. Así, los primeros aumentan estas salas de 1997 a 2009 en un $25,25 \%$, mientras que los segundos y terceros reducen su dotación en un -14,53\% y 18,42\%, respectivamente. De esta manera, en 2009, había 3.685 quirófanos en Hospitales generales, 347 en hospitales de agudos, 31 en centros de larga estancia y ninguno en Hospitales psiquiátricos. A partir del año siguiente, se agrupan los generales y los de agudos, dando una suma de 4.174. 
Tabla 270. Evolución del número de quirófanos en funcionamiento según finalidad asistencial

\begin{tabular}{|c|c|c|c|c|c|}
\hline \multirow[b]{2}{*}{ Año } & \multicolumn{5}{|c|}{ Quirófanos en funcionamiento } \\
\hline & $\begin{array}{l}\text { Hospitales } \\
\text { generales }\end{array}$ & \begin{tabular}{c|} 
Otros \\
hospitales \\
de agudos
\end{tabular} & $\begin{array}{c}\text { Hospitales } \\
\text { de larga } \\
\text { estancia }\end{array}$ & $\begin{array}{c}\text { Hospitales } \\
\text { psiquiátricos }\end{array}$ & Total \\
\hline 2012 & $4.237^{31}$ & - & 30 & - & 4.26 \\
\hline 2011 & 4.174 & - & 28 & - & 4.202 \\
\hline 2010 & 4.082 & - & 38 & - & 4.120 \\
\hline 2009 & 3.685 & 347 & 31 & 0 & 4.063 \\
\hline 2008 & 3.569 & 369 & 37 & 0 & 3.975 \\
\hline 2007 & 3.470 & 348 & 47 & 0 & 3.865 \\
\hline 2006 & 3.337 & 365 & 38 & 0 & 3.740 \\
\hline 2005 & 3.265 & 386 & 35 & 0 & 3.686 \\
\hline 2004 & 3.223 & 368 & 45 & 0 & 3.636 \\
\hline 2003 & 3.155 & 367 & 40 & 0 & 3.562 \\
\hline 2002 & 3.156 & 374 & 35 & 0 & 3.565 \\
\hline 2001 & 3.122 & 375 & 34 & 0 & 3.531 \\
\hline 2000 & 3.062 & 397 & 38 & 0 & 3.497 \\
\hline 1999 & 3.018 & 408 & 37 & 0 & 3.463 \\
\hline 1998 & 2.953 & 410 & 46 & 2 & 3.411 \\
\hline 1997 & 2.942 & 406 & 38 & 1 & 3.387 \\
\hline $\begin{array}{l}\text { Diferencia } \\
\text { 2009-1997 }\end{array}$ & 743 & -59 & -7 & -1 & 814 \\
\hline $\begin{array}{l}\text { \%Diferencia } \\
\text { 2009-1997 }\end{array}$ & $25,25 \%$ & $-14,53 \%$ & $-18,42 \%$ & $-100,00 \%$ & $24,03 \%$ \\
\hline
\end{tabular}

Fuente: Estadística de Centros Sanitarios de Atención Especializada y Estadística de Establecimientos Sanitarios con Régimen de Internado.

Cuando se separa el número de quirófanos por titularidad y finalidad asistencial, lo primero que llama la atención es que la práctica totalidad de los públicos se encuentran en Hospitales generales, muy pocos en especializados y prácticamente ninguno en los de salud mental y toxicomanías. En porcentaje se corresponde con el 97,71\%, 2,11\% y $0,18 \%$ en 2009. Las diferencias de los privados en ese mismo año, aunque proporcionales, no son tan acusadas: $75,18 \%, 22,77 \%$ y $2,06 \%$.

31 Desde 2010, la Estadística de Centros Sanitarios de Atención Especializada únicamente contabiliza las plazas de día en hospitales de agudos y de larga estancia. En este caso, se ha traspasado los datos de la columna de agudos a los generales por ofrecer una mayor continuidad con los años anteriores, en los que estaba en vigor la Estadística de Establecimientos Sanitarios con Régimen de Internado. 
Los públicos son, con un 26,99\% más de 1997 a 2009, los que más incrementan su número de quirófanos, por delante de los privados, que arrojan un aumento del 20,53\%. En ambos casos, aumentan los quirófanos de Hospitales generales y disminuyen en Otros hospitales de agudos (en los públicos la bajada es bastante más acentuada), aunque en el caso de los Hospitales de larga estancia, disminuye en los públicos ($68,75 \%)$ y aumenta en los privados (18,28\%). Aun así, los hospitales del Sistema Nacional de Salud adelantan a los privados en número de quirófanos en más de un $50 \%$ : mientras que los primeros suman 3.049 en 2012, los segundos se quedan en 1.188.

Tabla 271. Evolución del número de quirófanos en funcionamiento en los hospitales del Sistema Nacional de Salud

\begin{tabular}{|l|r|r|r|r|r|}
\hline \multirow{2}{*}{ Año } & \multicolumn{3}{|c|}{ Quirófanos en funcionamiento en hospitales públicos - SNS } \\
\cline { 2 - 7 } & $\begin{array}{c}\text { Hospitales } \\
\text { generales }\end{array}$ & $\begin{array}{c}\text { Otros } \\
\text { hospitales } \\
\text { de agudos }\end{array}$ & $\begin{array}{c}\text { Hospitales } \\
\text { de larga } \\
\text { estancia }\end{array}$ & $\begin{array}{c}\text { Hospitales } \\
\text { psiquiátricos }\end{array}$ & Total \\
\hline 2012 & 3.049 & - & 2 & - & 3.051 \\
\hline 2011 & $2.998^{32}$ & - & 2 & - & 3.000 \\
\hline 2010 & 2.944 & - & 5 & - & 2.949 \\
\hline 2009 & 2.734 & 59 & 5 & 0 & 2.798 \\
\hline 2008 & 2.623 & 73 & 9 & 0 & 2.705 \\
\hline 2007 & 2.541 & 57 & 8 & 0 & 2.606 \\
\hline 2006 & 2.467 & 64 & 5 & 0 & 2.536 \\
\hline 2005 & 2.423 & 66 & 4 & 0 & 2.493 \\
\hline 2004 & 2.388 & 64 & 4 & 0 & 2.456 \\
\hline 2003 & 2.346 & 64 & 4 & 0 & 2.414 \\
\hline 2002 & 2.309 & 63 & 4 & 0 & 2.376 \\
\hline 2001 & 2.266 & 80 & 5 & 0 & 2.351 \\
\hline 2000 & 2.235 & 83 & 5 & 0 & 2.323 \\
\hline 1999 & 2.223 & 80 & 5 & 0 & 2.308 \\
\hline 1998 & 2.178 & 88 & 7 & 2 & 2.275 \\
\hline 1997 & 2.153 & 82 & 16 & 1 & 2.252 \\
\hline Diferencia & 581 & -23 & -11 & -1 & 747 \\
\hline $2009-1997$ & $26,99 \%$ & $-28,05 \%$ & $-68,75 \%$ & $-100,00 \%$ & $33,17 \%$ \\
\hline$\%$ Diferencia & & & & & \\
\hline $2009-1997$ & & & & & \\
\hline
\end{tabular}

Fuente: Estadística de Centros Sanitarios de Atención Especializada y Estadística de Establecimientos Sanitarios con Régimen de Internado.

\footnotetext{
32 Desde 2010, la Estadística de Centros Sanitarios de Atención Especializada únicamente contabiliza las plazas de día en hospitales de agudos y de larga estancia. En este caso, se ha traspasado los datos de la columna de agudos a los generales por ofrecer una mayor continuidad con los años anteriores, en los que estaba en vigor la Estadística de Establecimientos Sanitarios con Régimen de Internado.
} 
Tabla 272. Evolución del número de quirófanos en funcionamiento en hospitales privados

\begin{tabular}{|c|c|c|c|c|c|}
\hline \multirow[b]{2}{*}{ Año } & \multicolumn{5}{|c|}{ Quirófanos en funcionamiento en hospitales privados } \\
\hline & $\begin{array}{l}\text { Hospitales } \\
\text { generales }\end{array}$ & $\begin{array}{c}\text { Otros } \\
\text { hospitales } \\
\text { de agudos }\end{array}$ & $\begin{array}{c}\text { Hospitales } \\
\text { de larga } \\
\text { estancia }\end{array}$ & $\begin{array}{c}\text { Hospitales } \\
\text { psiquiátricos }\end{array}$ & Total \\
\hline 2012 & 1.188 & - & 28 & - & 1.216 \\
\hline 2011 & $1.176^{\underline{33}}$ & - & 26 & - & 1.202 \\
\hline 2010 & 1.138 & - & 38 & - & 1.171 \\
\hline 2009 & 951 & 288 & 26 & 0 & 1.265 \\
\hline 2008 & 946 & 296 & 28 & 0 & 1.270 \\
\hline 2007 & 929 & 291 & 39 & 0 & 1.259 \\
\hline 2006 & 870 & 301 & 33 & 0 & 1.204 \\
\hline 2005 & 842 & 320 & 31 & 0 & 1.193 \\
\hline 2004 & 835 & 304 & 41 & 0 & 1.180 \\
\hline 2003 & 809 & 303 & 36 & 0 & 1.148 \\
\hline 2002 & 847 & 311 & 31 & 0 & 1.189 \\
\hline 2001 & 856 & 295 & 29 & 0 & 1.180 \\
\hline 2000 & 827 & 314 & 33 & 0 & 1.174 \\
\hline 1999 & 795 & 328 & 32 & 0 & 1.155 \\
\hline 1998 & 775 & 322 & 39 & 0 & 1.136 \\
\hline 1997 & 789 & 324 & 22 & 0 & 1.135 \\
\hline $\begin{array}{l}\text { Diferencia } \\
2009-1997\end{array}$ & 162 & -36 & 4 & 0 & 67 \\
\hline $\begin{array}{l}\text { \%Diferencia } \\
\text { 2009-1997 }\end{array}$ & $20,53 \%$ & $-11,11 \%$ & $18,18 \%$ & & $5,90 \%$ \\
\hline
\end{tabular}

Fuente: Estadística de Centros Sanitarios de Atención Especializada y Estadística de Establecimientos Sanitarios con Régimen de Internado.

\section{Número de camas instaladas y en funcionamiento}

Cuando se habla de camas de un centro hospitalario se hace referencia a las "destinadas a la atención continuada de pacientes ingresados" que incluyen "las incubadoras fijas y camas destinadas a cuidados especiales (Intensivos, Coronarios, Quemados, etc...)" No se contabilizan en esta sección las "de observación del Servicio de Urgencias, de reanimación postquirúrgica, las destinadas a hemodiálisis ambulatoria, las de acompañantes, las de inducción preanestésica, las utilizadas para exploraciones

33 Desde 2010, la Estadística de Centros Sanitarios de Atención Especializada únicamente contabiliza las plazas de día en hospitales de agudos y de larga estancia. En este caso, se ha traspasado los datos de la columna de agudos a los generales por ofrecer una mayor continuidad con los años anteriores, en los que estaba en vigor la Estadística de Establecimientos Sanitarios con Régimen de Internado. 
especiales (endoscopia, laboratorio, etc.), las utilizadas para hospital de día, las destinadas al personal del establecimiento sanitario, las supletorias, las habilitadas, ni las cunas para los recién nacidos sin patología” (Ministerio de Sanidad, 2013b).

Existen diferencias entre las que se encuentran instaladas y las que están en funcionamiento. Las primeras son las que posee el hospital "en condiciones de funcionar, aunque no lo haga por no contar con el personal y/o equipamiento necesario, estar fuera de servicio por obras o por cualquier otra causa". En cambio, las del segundo tipo son las que han estado "efectivamente funcionando durante el año. Se considera el promedio anual de la que haya estado en servicio, con independencia del grado de utilización u ocupación que haya tenido" (Ministerio de Sanidad, 2013b).

Como excepción, se cuentan como en funcionamiento "las de observación del área de urgencia o de reanimación postquirúrgica siempre que, de forma habitual, se utilicen como camas de hospitalización, generando ingreso administrativo y estancias, debiéndose hacer constar en el cuestionario las destinadas a tal efecto" (Ministerio de Sanidad, 2013b).

El total de camas instaladas en los centros hospitalarios españoles en 2012 asciende a 159.868. Esta cifra supone un descenso del 6,13\% comparada con la que arroja el año 1997, en el que se contabilizaban 158.418. Por su parte, el número total de las que están en funcionamiento en España en el año 2012 asciende a 139.994. Al igual que sucede con las instaladas, se trata de un número inferior al que arroja el año 1997 (momento en el cual existían 151.345), es decir, un descenso del 7,50\%. Es una cifra ligeramente superior a la bajada del número de hospitales: $-3,68 \%$.

Tabla 273. Evolución del número de hospitales, camas instaladas y camas en funcionamiento

\begin{tabular}{|l|r|r|r|}
\hline Año & $\begin{array}{c}\text { Número } \\
\text { Hospitales }\end{array}$ & $\begin{array}{c}\text { Camas } \\
\text { instaladas }\end{array}$ & $\begin{array}{c}\text { Camas en } \\
\text { funcionamiento }\end{array}$ \\
\hline 2012 & 759 & 156.868 & 139.994 \\
\hline 2011 & 763 & 158.006 & 142.632 \\
\hline 2010 & 765 & 157.963 & 145.199 \\
\hline 2009 & 770 & 158.418 & 146.310 \\
\hline 2008 & 767 & 158.170 & 146.934 \\
\hline 2007 & 764 & 158.306 & 146.840 \\
\hline 2006 & 746 & 157.518 & 146.241 \\
\hline 2005 & 751 & 157.145 & 145.863 \\
\hline 2004 & 750 & 158.068 & 145.877 \\
\hline 2003 & 741 & 157.476 & 144.916 \\
\hline 2002 & 759 & 159.111 & 146.104 \\
\hline 2001 & 768 & 159.791 & 146.369 \\
\hline 2000 & 771 & 162.891 & 148.081 \\
\hline
\end{tabular}




\begin{tabular}{|l|r|r|r|}
\hline \multicolumn{1}{|c|}{ Año } & $\begin{array}{c}\text { Número } \\
\text { Hospitales }\end{array}$ & \multicolumn{1}{c|}{$\begin{array}{c}\text { Camas } \\
\text { instaladas }\end{array}$} & $\begin{array}{c}\text { Camas en } \\
\text { funcionamiento }\end{array}$ \\
\hline 1999 & 774 & 164.741 & 149.646 \\
\hline 1998 & 780 & 166.114 & 150.010 \\
\hline 1997 & 788 & 167.113 & 151.345 \\
\hline $\begin{array}{l}\text { Diferencia } \\
1997-2012\end{array}$ & -29 & -10.245 & -11.351 \\
\hline $\begin{array}{l}\text { \%Diferencia } \\
2997-2012\end{array}$ & $-3,68$ & $-6,13$ & $-7,50$ \\
\hline
\end{tabular}

Fuente: Estadística de Centros Sanitarios de Atención Especializada y Estadística de Establecimientos Sanitarios con Régimen de Internado.

No obstante, la población del país desde 1998 (en el año 1997 no se realizó revisión padronal) no ha dejado de aumentar. Así, se ha pasado de 39.852.651 habitantes en 1998 a 47.265.321 en 2012; es decir, la población española ha tenido un aumento del $18,60 \%$ en el mismo periodo en el que el número de hospitales ha descendido un $2,69 \%$ y el número de camas en funcionamiento de los hospitales, un 6,68\% (Instituto Nacional de Estadística (INE), 2013).

Tabla 274. Evolución de la población en España

\begin{tabular}{|l|r|}
\hline \multicolumn{1}{|c|}{ Año } & \multicolumn{1}{c|}{ Población } \\
\hline 2012 & 47.265 .321 \\
\hline 2011 & 47.190 .493 \\
\hline 2010 & 47.021 .031 \\
\hline 2009 & 46.745 .807 \\
\hline 2008 & 46.157 .822 \\
\hline 2007 & 45.200 .737 \\
\hline 2006 & 44.708 .964 \\
\hline 2005 & 44.108 .530 \\
\hline 2004 & 43.197 .684 \\
\hline 2003 & 42.717 .064 \\
\hline 2002 & 41.837 .894 \\
\hline 2001 & 41.116 .842 \\
\hline 2000 & 40.499 .791 \\
\hline 1999 & 40.202 .160 \\
\hline 1998 & 39.852 .651 \\
\hline-- & -- \\
\hline 1996 & 39.669 .394 \\
\hline
\end{tabular}

Fuente: Padrón municipal del Instituto Nacional de Estadística. 
En consecuencia, el ratio de camas instaladas y en funcionamiento por cada mil habitantes ha disminuido. En el caso de las instaladas, la cifra ha bajado de un 4,22 en 1997 a un 3,40 en 2012, lo que supone una disminución del 19,43\%. Es una cifra similar de la que arrojan las camas en funcionamiento, que, de haber 3,82 por cada mil habitantes en el primer año a 3,03 en el segundo, supone una diferencia negativa del $20,68 \%$.

Tabla 275. Evolución del número de hospitales y tasas de camas instaladas y en funcionamiento

\begin{tabular}{|l|r|r|r|}
\hline \multicolumn{1}{|c|}{ Año } & $\begin{array}{c}\text { Número de } \\
\text { hospitales }\end{array}$ & $\begin{array}{c}\text { Camas } \\
\text { instaladas por } \\
\mathbf{1 . 0 0 0} \text { hab. }\end{array}$ & $\begin{array}{c}\text { Camas en } \\
\text { funcionamiento } \\
\text { por 1.000 hab. }\end{array}$ \\
\hline 2012 & 759 & 3,40 & 3,03 \\
\hline 2011 & 763 & 3,43 & 3,09 \\
\hline 2010 & 765 & 3,43 & 3,15 \\
\hline 2009 & 770 & 3,45 & 3,19 \\
\hline 2008 & 767 & 3,47 & 3,22 \\
\hline 2007 & 764 & 3,53 & 3,27 \\
\hline 2006 & 746 & 3,57 & 3,32 \\
\hline 2005 & 751 & 3,62 & 3,36 \\
\hline 2004 & 750 & 3,70 & 3,42 \\
\hline 2003 & 741 & 3,75 & 3,45 \\
\hline 2002 & 759 & 3,85 & 3,54 \\
\hline 2001 & 768 & 3,92 & 3,59 \\
\hline 2000 & 771 & 4,05 & 3,68 \\
\hline 1999 & 774 & 4,13 & 3,75 \\
\hline 1998 & 780 & 4,18 & 3,78 \\
\hline 1997 & 788 & 4,22 & 3,82 \\
\hline Diferencia & -29 & $-0,82$ & $-0,79$ \\
\hline $1997-2012$ & $-3,68$ & $-19,43$ & $-20,68$ \\
\hline$\%$ Diferencia & & & \\
\hline $2997-2012$ & & & \\
\hline
\end{tabular}

Fuente: Estadística de Centros Sanitarios de Atención Especializada y Estadística de Establecimientos Sanitarios con Régimen de Internado.

Divididos por dependencia funcional, se observa que tanto el número de camas instaladas como en funcionamiento en centros públicos es considerablemente superior al de los privados; de hecho, casi constituyen el cuádruple unos que otros. Es un resultado curioso teniendo en cuenta que esa diferencia no es tan marcada en el número de hospitales según titularidad, por lo que se desprende que los privados son, en general, mucho más pequeños en número de camas que su competencia. En la actualidad, el $79,69 \%$ de las camas instaladas en España son de dependencia pública (es decir, 
125.002) en comparación con el 20,31\% que está en manos privadas (o 31.866). En cuanto a las que se encuentran en funcionamiento, los porcentajes son prácticamente idénticos: 79,60\% (o 111.430 unidades) y 20,40\% (o 28.564), respectivamente.

En cuanto a la evolución a lo largo de los años, más concretamente de 1997 a 2012 , las camas instaladas en los públicos han crecido un 10,44\% en comparación con los privados, que han descendido un 40,91\%. La cifra de las camas en funcionamiento es similar: $9,55 \%$ en el primer caso y $-42,45 \%$ en el segundo.

Tabla 276. Evolución del número de camas instaladas y en funcionamiento por dependencia funcional

\begin{tabular}{|c|c|c|c|c|c|c|}
\hline \multirow{2}{*}{ Año } & \multicolumn{3}{|c|}{ Camas instaladas } & \multicolumn{3}{|c|}{ Camas en funcionamiento } \\
\hline & Públicos & Privados & Total & Públicos & Privados & Total \\
\hline 2012 & 125.002 & 31.866 & 156.868 & 111.430 & 28.564 & 139.994 \\
\hline 2011 & 125.649 & 32.357 & 158.006 & 113.518 & 29.114 & 142.632 \\
\hline 2010 & 125.265 & 32.698 & 157.963 & 115.418 & 29.781 & 145.199 \\
\hline 2009 & 105.807 & 52.611 & 158.418 & 97.324 & 48.986 & 146.310 \\
\hline 2008 & 105.201 & 52.969 & 158.170 & 97.476 & 49.458 & 146.934 \\
\hline 2007 & 104.320 & 53.986 & 158.306 & 97.032 & 49.808 & 146.840 \\
\hline 2006 & 103.830 & 53.688 & 157.518 & 96.010 & 50.231 & 146.241 \\
\hline 2005 & 103.865 & 53.280 & 157.145 & 95.852 & 50.011 & 145.863 \\
\hline 2004 & 104.916 & 53.152 & 158.068 & 96.145 & 49.732 & 145.877 \\
\hline 2003 & 105.106 & 52.370 & 157.476 & 95.875 & 49.041 & 144.916 \\
\hline 2002 & 105.820 & 53.291 & 159.111 & 96.316 & 49.788 & 146.104 \\
\hline 2001 & 107.696 & 52.095 & 159.791 & 97.398 & 48.971 & 146.369 \\
\hline 2000 & 110.027 & 52.864 & 162.891 & 98.718 & 49.363 & 148.081 \\
\hline 1999 & 111.823 & 52.918 & 164.741 & 100.259 & 49.387 & 149.646 \\
\hline 1998 & 112.593 & 53.521 & 166.114 & 100.795 & 49.215 & 150.010 \\
\hline 1997 & 113.189 & 53.924 & 167.113 & 101.714 & 49.631 & 151.345 \\
\hline $\begin{array}{l}\text { Diferencia } \\
1997-2012\end{array}$ & 11.813 & -22.058 & -10.245 & 9.716 & -21.067 & -11.351 \\
\hline $\begin{array}{l}\text { \%Diferencia } \\
1997-2012\end{array}$ & 10,44 & $-40,91$ & $-6,13$ & 9,55 & $-42,45$ & $-7,50$ \\
\hline
\end{tabular}

Fuente: Estadística de Centros Sanitarios de Atención Especializada y Estadística de Establecimientos Sanitarios con Régimen de Internado.

Al igual que sucede con los valores absolutos, cuando se estudian las tasas de camas instaladas y en funcionamiento según la población de cada año y la titularidad del centro, se detecta que la mayor bajada se encuentra en los centros privados. Así, las instaladas en estas clínicas bajan un 49,26\% y las que están en funcionamiento, un $50,40 \%$. La disminución en las entidades públicas no es tan elevada: las instaladas por 
cada mil habitantes decrecen un 5,24\% y las de en funcionamiento, un 6,23\%. Se trata, no obstante, de unas cifras demasiado acusadas debido al cambio de metodología de las estadísticas de referencia. Si se estudia la diferencia entre 1997 y 2009 (el último año con el mismo método), la caída se queda en el -19,58\% y el -15,44\% para los públicos y el $-17,51 \%$ y el $-14,40 \%$ en los privados. En cualquier caso, en 2012, el montante de camas es de 2,71 instaladas y 2,41 en funcionamiento por cada mil habitantes en los públicos y solamente 0,69 y 0,62 , en este orden, en los privados.

Tabla 277. Evolución del número de hospitales y tasas de camas instaladas y en funcionamiento por dependencia funcional

\begin{tabular}{|l|r|r|r|r|r|r|}
\hline \multirow{2}{*}{ Año } & \multicolumn{2}{|c|}{ Número de hospitales } & $\begin{array}{r}\text { Camas instaladas por } \\
\mathbf{1 . 0 0 0} \text { hab. }\end{array}$ & \multicolumn{2}{c|}{$\begin{array}{c}\text { Camas en } \\
\text { funcionamiento por } \\
\mathbf{1 . 0 0 0} \text { hab. }\end{array}$} \\
\cline { 2 - 8 } & Públicos & Privados & Públicos & Privados & Públicos & Privados \\
\hline 2012 & 453 & 306 & 2,71 & 0,69 & 2,41 & 0,62 \\
\hline 2011 & 452 & 311 & 2,73 & 0,70 & 2,46 & 0,63 \\
\hline 2010 & 446 & 319 & 2,72 & 0,71 & 2,51 & 0,65 \\
\hline 2009 & 313 & 457 & 2,30 & 1,15 & 2,12 & 1,07 \\
\hline 2008 & 304 & 463 & 2,31 & 1,16 & 2,14 & 1,08 \\
\hline 2007 & 298 & 466 & 2,32 & 1,20 & 2,16 & 1,11 \\
\hline 2006 & 289 & 457 & 2,36 & 1,22 & 2,18 & 1,14 \\
\hline 2005 & 296 & 455 & 2,39 & 1,23 & 2,21 & 1,15 \\
\hline 2004 & 299 & 451 & 2,46 & 1,25 & 2,25 & 1,16 \\
\hline 2003 & 300 & 441 & 2,50 & 1,25 & 2,28 & 1,17 \\
\hline 2002 & 308 & 451 & 2,56 & 1,29 & 2,33 & 1,21 \\
\hline 2001 & 313 & 455 & 2,64 & 1,28 & 2,39 & 1,20 \\
\hline 2000 & 317 & 454 & 2,73 & 1,31 & 2,45 & 1,23 \\
\hline 1999 & 320 & 454 & 2,80 & 1,33 & 2,51 & 1,24 \\
\hline 1998 & 317 & 463 & 2,83 & 1,35 & 2,54 & 1,24 \\
\hline 1997 & 318 & 470 & 2,86 & 1,36 & 2,57 & 1,25 \\
\hline $\begin{array}{l}\text { Diferencia } \\
2012-1997\end{array}$ & 135 & -164 & $-0,15$ & $-0,67$ & $-0,16$ & $-0,63$ \\
\hline$\%$ Diferencia & 42,45 & $-34,89$ & $-5,24$ & $-49,26$ & $-6,23$ & $-50,40$ \\
\hline $2012-1997$ & & & & & & \\
\hline
\end{tabular}

Fuente: Estadística de Centros Sanitarios de Atención Especializada y Estadística de Establecimientos Sanitarios con Régimen de Internado.

En la actualidad, la región que cuenta con una mayor dotación en camas es Cataluña (30.862 instaladas y 28.629 en funcionamiento), Madrid (22.074 y 18.522) y Andalucía (20.913 y 18.402). Las que poseen números más bajos en relación con su población son Ceuta y Melilla (420 instaladas y 347 en funcionamiento), La Rioja (963 y 919) y Cantabria (2.039 y 1.888). 
En cuanto a la evolución temporal, las únicas que ven aumentar tanto el número de camas instaladas como en funcionamiento son la Comunidad Valenciana (10,36\% y $1 \%$ ) y, de una manera muy significativa, la Región de Murcia (17,75\% y 26,73\%). Estas zonas, a su vez, han incrementado a lo largo de los años su número de hospitales: la primera en un $1,67 \%$ y la segunda, en un $8,33 \%$.

El resto de comunidades sufre un descenso en el número de camas desde 1997 a 2012, siendo considerablemente más acusado en Cantabria, Castilla y León y en Ceuta y Melilla en conjunto. En cambio, Cataluña y Castilla-La Mancha son los territorios donde menos se rebaja el número de camas, tanto instaladas como en funcionamiento.

Tabla 278. Evolución del número de camas instaladas por comunidades autónomas

\begin{tabular}{|c|c|c|c|c|c|c|c|}
\hline \multirow{2}{*}{$\begin{array}{l}\text { Comunidad } \\
\text { autónoma }\end{array}$} & \multicolumn{7}{|c|}{ Camas instaladas } \\
\hline & 2012 & 2011 & 2010 & 1998 & 1997 & $\begin{array}{l}\text { Diferencia } \\
\text { 2012-1997 }\end{array}$ & $\begin{array}{c}\text { \%Diferencia } \\
\text { 2012-1997 }\end{array}$ \\
\hline Andalucía & 20.913 & 21.266 & 21.264 & 23.584 & 23.940 & -3.027 & $-12,64$ \\
\hline Aragón & 5.387 & 5.437 & 5.458 & 5.916 & 5.978 & -591 & $-9,89$ \\
\hline Asturias & 4.032 & 4.073 & 4.142 & 4.527 & 4.592 & -560 & $-12,20$ \\
\hline Baleares & 3.698 & 3.746 & 3.676 & 3.782 & 3.828 & -130 & $-3,40$ \\
\hline Canarias & 7.587 & 7.595 & 7.678 & 8.262 & 8.269 & -682 & $-8,25$ \\
\hline Cantabria & 2.039 & 2.051 & 2.188 & 3.018 & 3.028 & -989 & $-32,66$ \\
\hline Castilla y León & 9.634 & 9.686 & 9.629 & 11.577 & 12.196 & -2.562 & $-21,01$ \\
\hline $\begin{array}{l}\text { Castilla-La } \\
\text { Mancha }\end{array}$ & 5.806 & 5.724 & 5.739 & 5.730 & 5.539 & 267 & 4,82 \\
\hline Cataluña & 30.862 & 30.708 & 31.470 & 30.346 & 31.168 & -306 & $-0,98$ \\
\hline $\begin{array}{l}\text { Comunidad } \\
\text { Valenciana }\end{array}$ & 14.002 & 14.314 & 13.951 & 12.788 & 12.687 & 1.315 & 10,36 \\
\hline Extremadura & 4.069 & 4.216 & 4.104 & 4.573 & 4.340 & -271 & $-6,24$ \\
\hline Galicia & 10.021 & 10.125 & 10.369 & 11.073 & 11.149 & -1.128 & $-10,12$ \\
\hline Madrid & 22.074 & 22.115 & 21.430 & 23.515 & 23.139 & -1.065 & $-4,60$ \\
\hline Murcia & 4.877 & 4.829 & 4.739 & 4.283 & 4.142 & 735 & 17,75 \\
\hline Navarra & 2.325 & 2.408 & 2.423 & 2.681 & 2.687 & -362 & $-13,47$ \\
\hline País Vasco & 8.159 & 8.309 & 8.318 & 8.901 & 8.894 & -735 & $-8,26$ \\
\hline La Rioja & 963 & 962 & 961 & 1.010 & 1.037 & -74 & $-7,14$ \\
\hline Ceuta y Melilla & 420 & 420 & 424 & 548 & 500 & -80 & $-16,00$ \\
\hline Total & 156.868 & 157.984 & 157.963 & 166.114 & 167.113 & -10.245 & $-6,13$ \\
\hline
\end{tabular}

Fuente: Estadística de Centros Sanitarios de Atención Especializada y Estadística de Establecimientos Sanitarios con Régimen de Internado. 
Tabla 279. Evolución del número de camas en funcionamiento por comunidades autónomas

\begin{tabular}{|c|c|c|c|c|c|c|c|}
\hline \multirow{2}{*}{$\begin{array}{c}\text { Comunidad } \\
\text { autónoma }\end{array}$} & \multicolumn{7}{|c|}{ Camas en funcionamiento } \\
\hline & 2012 & 2011 & 2010 & 1998 & 1997 & $\begin{array}{l}\text { Diferencia } \\
\text { 2012-1997 }\end{array}$ & $\begin{array}{c}\text { \%Diferencia } \\
\text { 2012-1997 }\end{array}$ \\
\hline Andalucía & 18.402 & 18.800 & 18.989 & 21.618 & 21.607 & -3.205 & $-14,83$ \\
\hline Aragón & 4.834 & 4.958 & 5.002 & 5.255 & 5.248 & -414 & $-7,89$ \\
\hline Asturias & 3.561 & 3.579 & 3.661 & 4.026 & 4.110 & -549 & $-13,36$ \\
\hline Baleares & 3.286 & 3.289 & 3.348 & 3.473 & 3.428 & -142 & $-4,14$ \\
\hline Canarias & 6.613 & 6.710 & 6.865 & 7.612 & 7.572 & -959 & $-12,67$ \\
\hline Cantabria & 1.888 & 1.905 & 1.970 & 2.205 & 2.230 & -342 & $-15,34$ \\
\hline Castilla y León & 8.937 & 9.154 & 8.983 & 10.612 & 10.962 & -2.025 & $-18,47$ \\
\hline $\begin{array}{l}\text { Castilla-La } \\
\text { Mancha }\end{array}$ & 4.717 & 5.191 & 5.253 & 5.124 & 5.205 & -488 & $-9,38$ \\
\hline Cataluña & 28.629 & 28.921 & 30.122 & 28.752 & 29.069 & -440 & $-1,51$ \\
\hline $\begin{array}{l}\text { Comunidad } \\
\text { Valenciana }\end{array}$ & 11.616 & 11.951 & 12.282 & 11.619 & 11.501 & 115 & 1,00 \\
\hline Extremadura & 3.762 & 3.856 & 3.898 & 3.880 & 3.962 & -200 & $-5,05$ \\
\hline Galicia & 9.466 & 9.508 & 9.904 & 10.239 & 10.348 & -882 & $-8,52$ \\
\hline Madrid & 18.522 & 18.812 & 18.814 & 19.536 & 19.953 & -1.431 & $-7,17$ \\
\hline Murcia & 4.660 & 4.634 & 4.565 & 3.800 & 3.677 & 983 & 26,73 \\
\hline Navarra & 2.208 & 2.378 & 2.370 & 2.527 & 2.609 & -401 & $-15,37$ \\
\hline País Vasco & 7.627 & 7.710 & 7.896 & 8.334 & 8.403 & -776 & $-9,23$ \\
\hline La Rioja & 919 & 931 & 934 & 989 & 995 & -76 & $-7,64$ \\
\hline Ceuta y Melilla & 347 & 345 & 343 & 409 & 466 & -119 & $-25,54$ \\
\hline Total & 13.9994 & 142.632 & 145.199 & 150.010 & 151.345 & -11.351 & $-7,50$ \\
\hline
\end{tabular}

Fuente: Estadística de Centros Sanitarios de Atención Especializada y Estadística de Establecimientos Sanitarios con Régimen de Internado.

La Región de Murcia es la única comunidad donde aumenta el número de camas tanto instaladas como en funcionamiento en centros públicos y en privados. Desde 1999 a 2012, las primeras han crecido en edificios del Sistema Nacional de Salud un 4,50\% y en los privados, un 53,48\%. En cuanto a las que están en funcionamiento, se han incrementado un $16,41 \%$ en el primer caso y un $51,33 \%$ en el segundo.

Sin embargo, esta zona parece ser una excepción, ya que en la mayoría de las regiones esta dotación desciende tanto en centros privados como en públicos. Esto sucede en Andalucía, Asturias, Canarias, Cantabria, Castilla y León, Comunidad de Madrid y Navarra. Los casos más acusados tienen lugar en Asturias (donde bajan las instaladas $y$ en funcionamiento de los privados en un $38,22 \%$ y $39,26 \%$, 
respectivamente), en Castilla y León (con una disminución en los privados del 28,11\% y del $26,55 \%$, en este orden) y Cantabria (que cuenta en 2012 con un 39,43\% menos de camas instaladas en los hospitales públicos).

Cuando hay diferencias entre el crecimiento de las camas en centros públicos y privados, lo más probable es que crezcan en los primeros y disminuyan en los segundos. Esto sucede en seis comunidades: Islas Baleares, Castilla-La Mancha, Cataluña, Comunidad Valenciana, Galicia y País Vasco. Las discrepancias más acusadas las ofrecen Cataluña, Galicia y País Vasco. Estas comunidades han pasado a tener camas instaladas desde 1997 hasta 2012 un 41,18\% más de públicas y 72,19\% menos privadas, 3,33\% más públicas y 45,45\% menos de privadas, y 11,28\% más de públicas y 44,38\% menos de privadas, en este orden.

Por otra parte, las regiones donde disminuyen las públicas y aumentan las privadas son Aragón, Extremadura y La Rioja (esta última comunidad solo en camas instaladas). En ninguno de los casos se han hallado casos tan extremos como en el apartado anterior. 
Tabla 280. Evolución del número de camas instaladas por comunidades autónomas $y$ dependencia funcional

\begin{tabular}{|c|c|c|c|c|c|c|c|c|}
\hline \multirow[b]{2}{*}{$\begin{array}{c}\text { Comunidad } \\
\text { autónoma }\end{array}$} & \multicolumn{8}{|c|}{ Camas instaladas } \\
\hline & Régimen & 2012 & 2011 & 2010 & 1998 & 1997 & 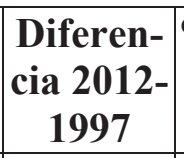 & $\begin{array}{c}\text { \%Diferen- } \\
\text { cia } 2012- \\
1997 \\
\end{array}$ \\
\hline \multirow{2}{*}{ Andalucía } & SNS & 15.646 & 15.856 & 15.956 & 18.220 & 18.506 & -2.860 & $-15,45$ \\
\hline & Privados & 5.267 & 5.410 & 5.308 & 5.364 & 5.434 & -167 & $-3,07$ \\
\hline \multirow{2}{*}{ Aragón } & SNS & 4.544 & 4.550 & 4.541 & 4.945 & 5.183 & -639 & $-12,33$ \\
\hline & Privados & 843 & 887 & 917 & 971 & 795 & 48 & 6,04 \\
\hline \multirow{2}{*}{ Asturias } & SNS & 3.374 & 3.415 & 3.363 & 3.516 & 3.527 & -153 & $-4,34$ \\
\hline & Privados & 658 & 658 & 779 & 1.011 & 1.065 & -407 & $-38,22$ \\
\hline \multirow{2}{*}{ Baleares } & SNS & 2.535 & 2.559 & 2.493 & 2.510 & 2.556 & -21 & $-0,82$ \\
\hline & Privados & 1.163 & 1.187 & 1.183 & 1.272 & 1.272 & -109 & $-8,57$ \\
\hline \multirow{2}{*}{ Canarias } & SNS & 4.784 & 4.825 & 4.813 & 5.269 & 5.308 & -524 & $-9,87$ \\
\hline & Privados & 2.803 & 2.770 & 2.865 & 2.993 & 2.961 & -158 & $-5,34$ \\
\hline \multirow{2}{*}{ Cantabria } & SNS & 1.381 & 1.392 & 1.520 & 2.280 & 2.280 & -899 & $-39,43$ \\
\hline & Privados & 658 & 659 & 668 & 738 & 748 & -90 & $-12,03$ \\
\hline \multirow{2}{*}{$\begin{array}{l}\text { Castilla y } \\
\text { León }\end{array}$} & SNS & 7.371 & 7.417 & 7.458 & 8.424 & 9.048 & -1.677 & $-18,53$ \\
\hline & Privados & 2.263 & 2.269 & 2.171 & 3.153 & 3.148 & -885 & $-28,11$ \\
\hline \multirow{2}{*}{$\begin{array}{l}\text { Castilla-La } \\
\text { Mancha }\end{array}$} & SNS & 5.338 & 5.359 & 5.370 & 5.172 & 4.980 & 358 & 7,19 \\
\hline & Privados & 468 & 365 & 369 & 558 & 559 & -91 & $-16,28$ \\
\hline \multirow{2}{*}{ Cataluña } & SNS & 27.639 & 27.448 & 28.219 & 18.698 & 19.577 & 8.062 & 41,18 \\
\hline & Privados & 3.223 & 3.260 & 3.251 & 11.648 & 11.591 & -8.368 & $-72,19$ \\
\hline \multirow{2}{*}{$\begin{array}{l}\text { Comunidad } \\
\text { Valenciana }\end{array}$} & SNS & 11.917 & 12.113 & 11.887 & 10.500 & 10.443 & 1.474 & 14,11 \\
\hline & Privados & 2.085 & 2.201 & 2.064 & 2.288 & 2.244 & -159 & $-7,09$ \\
\hline \multirow{2}{*}{ Extremadura } & SNS & 3.655 & 3.798 & 3.699 & 3.901 & 3.942 & -287 & $-7,28$ \\
\hline & Privados & 414 & 418 & 405 & 672 & 398 & 16 & 4,02 \\
\hline \multirow{2}{*}{ Galicia } & SNS & 8.344 & 8.454 & 8.549 & 8.033 & 8.075 & 269 & 3,33 \\
\hline & Privados & 1.677 & 1.671 & 1.820 & 3.040 & 3.074 & -1.397 & $-45,45$ \\
\hline \multirow{2}{*}{ Madrid } & SNS & 15.951 & 15.950 & 15.308 & 16.693 & 16.232 & -281 & $-1,73$ \\
\hline & Privados & 6.123 & 6.165 & 6.122 & 6.822 & 6.907 & -784 & $-11,35$ \\
\hline \multirow{2}{*}{ Murcia } & SNS & 3.158 & 3.150 & 3.055 & 3.071 & 3.022 & 136 & 4,50 \\
\hline & Privados & 1.719 & 1.679 & 1.684 & 1.212 & 1.120 & 599 & 53,48 \\
\hline \multirow{2}{*}{ Navarra } & SNS & 1.614 & 1.623 & 1.392 & 1.668 & 1.678 & -64 & $-3,81$ \\
\hline & Privados & 711 & 785 & 1.031 & 1.013 & 1.009 & -298 & $-29,53$ \\
\hline \multirow{2}{*}{ País Vasco } & SNS & 6.422 & 6.390 & 6.386 & 5.779 & 5.771 & 651 & 11,28 \\
\hline & Privados & 1.737 & 1.919 & 1.932 & 3.122 & 3.123 & -1.386 & $-44,38$ \\
\hline \multirow{2}{*}{ La Rioja } & SNS & 909 & 908 & 832 & 960 & 987 & -78 & $-7,90$ \\
\hline & Privados & 54 & 54 & 129 & 50 & 50 & 4 & 8,00 \\
\hline $\begin{array}{l}\text { Ceuta y } \\
\text { Melilla }\end{array}$ & SNS & 420 & 420 & 424 & 548 & 500 & -80 & $-16,00$ \\
\hline \multicolumn{2}{|l|}{ Total } & 156.868 & 157.984 & 157.963 & 166.114 & 167.113 & -9.129 & -10.245 \\
\hline
\end{tabular}

Fuente: Estadística de Centros Sanitarios de Atención Especializada y Estadística de Establecimientos Sanitarios con Régimen de Internado. 
Tabla 281. Evolución del número de camas en funcionamiento por comunidades autónomas y dependencia funcional

\begin{tabular}{|c|c|c|c|c|c|c|c|c|}
\hline \multirow[b]{2}{*}{$\begin{array}{l}\text { Comunidad } \\
\text { autónoma }\end{array}$} & \multicolumn{8}{|c|}{ Camas en funcionamiento } \\
\hline & Régimen & 2012 & 2011 & 2010 & 1998 & 1997 & \begin{tabular}{|c|} 
Diferen- \\
cia 2012- \\
1997
\end{tabular} & $\begin{array}{c}\text { \%Diferen- } \\
\text { cia 202- } \\
1997\end{array}$ \\
\hline \multirow{2}{*}{ Andalucía } & SNS & 13.854 & 14.121 & 14.392 & 16.698 & 16.765 & \begin{tabular}{|l|}
-2.911 \\
\end{tabular} & $-17,36$ \\
\hline & Privados & 4.548 & 4.679 & 4.597 & 4.920 & 4.842 & -294 & $-6,07$ \\
\hline \multirow{2}{*}{ Aragón } & SNS & 3.979 & 4.093 & 4.127 & 4.392 & 4.546 & -567 & $-12,47$ \\
\hline & Privados & 855 & 865 & 875 & 863 & 702 & 153 & 21,79 \\
\hline \multirow{2}{*}{ Asturias } & SNS & 3.018 & 3.036 & 3.002 & 3.155 & 3.216 & -198 & $-6,16$ \\
\hline & Privados & 543 & 543 & 659 & 871 & 894 & -351 & $-39,26$ \\
\hline \multirow{2}{*}{ Baleares } & SNS & 2.334 & 2.345 & 2.356 & 2.364 & 2.337 & -3 & $-0,13$ \\
\hline & Privados & 952 & 944 & 992 & 1.109 & 1.091 & -139 & $-12,74$ \\
\hline \multirow{2}{*}{ Canarias } & SNS & 4.277 & 4.336 & 4.336 & 4.869 & 4.852 & -575 & $-11,85$ \\
\hline & Privados & 2.336 & 2.374 & 2.529 & 2.743 & 2.720 & -384 & $-14,12$ \\
\hline \multirow{2}{*}{ Cantabria } & SNS & 1.285 & 1.294 & 1.350 & 1.509 & 1.551 & -266 & $-17,15$ \\
\hline & Privados & 603 & 611 & 620 & 696 & 679 & -76 & $-11,19$ \\
\hline \multirow{2}{*}{$\begin{array}{l}\text { Castilla y } \\
\text { León }\end{array}$} & SNS & 6.735 & 6.917 & 6.900 & 7.547 & 7.964 & -1.229 & $-15,43$ \\
\hline & Privados & 2.202 & 2.237 & 2.083 & 3.065 & 2.998 & -796 & $-26,55$ \\
\hline \multirow{2}{*}{$\begin{array}{l}\text { Castilla-La } \\
\text { Mancha }\end{array}$} & SNS & 4.360 & 4.839 & 4.894 & 4.626 & 4.726 & -366 & $-7,74$ \\
\hline & Privados & 357 & 352 & 359 & 498 & 479 & -122 & $-25,47$ \\
\hline \multirow{2}{*}{ Cataluña } & SNS & 25.536 & 25.792 & 27.098 & 17.763 & 18.207 & 7.329 & 40,25 \\
\hline & Privados & 3.093 & 3.129 & 3.024 & 10.989 & 10.862 & -7.769 & $-71,52$ \\
\hline \multirow{2}{*}{$\begin{array}{l}\text { Comunidad } \\
\text { Valenciana }\end{array}$} & -SNS & 10.050 & 10.253 & 10.525 & 9.615 & 9.508 & 542 & 5,70 \\
\hline & Privados & 1.566 & 1.698 & 1.757 & 2.004 & 1.993 & -427 & $-21,42$ \\
\hline \multirow{2}{*}{ Extremadura } & SNS & 3.394 & 3.467 & 3.504 & 3.518 & 3.592 & -198 & $-5,51$ \\
\hline & Privados & 368 & 389 & 394 & 362 & 370 & -2 & $-0,54$ \\
\hline \multirow{2}{*}{ Galicia } & SNS & 7.871 & 7.933 & 8.164 & 7.661 & 7.619 & 252 & 3,31 \\
\hline & Privados & 1.595 & 1.575 & 1.740 & 2.578 & 2.729 & -1.134 & $-41,55$ \\
\hline \multirow{2}{*}{ Madrid } & SNS & 13.017 & 13.297 & 13.305 & 13.230 & 13.358 & -341 & $-2,55$ \\
\hline & Privados & 5.505 & 5.515 & 5.509 & 6.306 & 6.595 & -1.090 & $-16,53$ \\
\hline \multirow{2}{*}{ Murcia } & SNS & 3.015 & 3.008 & 2.919 & 2.655 & 2.590 & 425 & 16,41 \\
\hline & Privados & 1.645 & 1.626 & 1.646 & 1.145 & 1.087 & 558 & 51,33 \\
\hline \multirow{2}{*}{ Navarra } & SNS & 1.523 & 1.611 & 1.357 & 1.607 & 1.629 & -106 & $-6,51$ \\
\hline & Privados & 685 & 767 & 1.013 & 920 & 980 & -295 & $-30,10$ \\
\hline \multirow{2}{*}{ País Vasco } & SNS & 5.964 & 5.948 & 6.035 & 5.419 & 5.485 & 479 & 8,73 \\
\hline & Privados & 1.663 & 1.762 & 1.861 & 2.915 & 2.918 & -1.255 & $-43,01$ \\
\hline \multirow{2}{*}{ La Rioja } & SNS & 871 & 883 & 811 & 939 & 945 & -74 & $-7,83$ \\
\hline & Privados & 48 & 48 & 123 & 50 & 50 & -2 & -4 \\
\hline $\begin{array}{l}\text { Ceuta y } \\
\text { Melilla }\end{array}$ & SNS & 347 & 345 & 343 & 409 & 466 & -119 & $-25,54$ \\
\hline \multicolumn{2}{|l|}{ Total } & 139.994 & 139.994 & 145.199 & 150.010 & 151.345 & -8.713 & -11.351 \\
\hline
\end{tabular}

Fuente: Estadística de Centros Sanitarios de Atención Especializada y Estadística de Establecimientos Sanitarios con Régimen de Internado. 
Actualmente, las zonas con una mayor proporción de camas públicas respecto a las privadas son, con un amplio margen, La Rioja y Castilla-La Mancha. En estas dos regiones tanto las instaladas como las que están en funcionamiento registran un número trece veces mayor en centros públicos que en privados. También hay bastante diferencia en Extremadura y en Cataluña, aunque el factor de multiplicación se queda entre el ocho y el diez. En el lado contrario, es decir, en las comunidades donde menos diferencia hay entre una titularidad y otra, es en Canarias, Murcia, Navarra y Cantabria, que poseen entorno al doble de camas del Sistema Nacional de Salud que en manos privadas. La media nacional, por su parte, se sitúa en 3,69 veces más de camas instaladas y 3,68 en funcionamiento en centros públicos que en privados.

Tabla 282. Tasa de multiplicación de camas instaladas y en funcionamiento en hospitales públicos respecto a los privados en 2012

\begin{tabular}{|l|r|r|}
\hline Comunidad autónoma & $\begin{array}{c}\text { Camas } \\
\text { instaladas }\end{array}$ & $\begin{array}{c}\text { Camas en } \\
\text { funcionamiento }\end{array}$ \\
\hline Andalucía & 2,97 & 3,05 \\
\hline Aragón & 5,39 & 4,65 \\
\hline Asturias & 5,13 & 5,56 \\
\hline Baleares & 2,18 & 2,45 \\
\hline Canarias & 1,71 & 1,83 \\
\hline Cantabria & 2,10 & 2,13 \\
\hline Castilla y León & 3,26 & 3,06 \\
\hline Castilla-La Mancha & 11,41 & 12,21 \\
\hline Cataluña & 8,58 & 8,26 \\
\hline Comunidad Valenciana & 5,72 & 6,42 \\
\hline Extremadura & 8,83 & 9,22 \\
\hline Galicia & 4,98 & 4,93 \\
\hline Madrid & 2,61 & 2,36 \\
\hline Murcia & 1,84 & 1,83 \\
\hline Navarra & 2,27 & 2,22 \\
\hline País Vasco & 3,70 & 3,59 \\
\hline La Rioja & 16,83 & 18,15 \\
\hline Ceuta y Melilla & 0,00 & 0,00 \\
\hline Total nacional & 3,69 & 3,68 \\
\hline
\end{tabular}

Fuente: Operaciones de elaboración propia a partir de los datos de la Estadística de Centros Sanitarios de Atención Especializada y la Estadística de Establecimientos Sanitarios con Régimen de Internado. 


\section{Por finalidad asistencial}

En la actualidad, hay muchas más camas en los Hospitales generales que en ningún otro tipo de centro. Respecto a las 156.868 que se contabilizan en 2012, un total de 122.001 se corresponde con esta clase de clínicas, representando el 77,77\% del cómputo. Los de media y larga estancia cuentan con el 9,36\%, los psiquiátricos con el $8,76 \%$ y el resto de hospitales de agudos, con el 4,11\%.

Con el paso de los años, el número de camas instaladas y en funcionamiento ha aumentado o decrecido considerablemente dependiendo de la finalidad de los hospitales. Por ejemplo, los de agudos tienen un 36,46\% de las del primer tipo y un 39,17\% menos de las del segundo desde 1997 a 2012. Los psiquiátricos también sufren una caída considerable: $29,28 \%$ en el primer caso y $27,97 \%$ en el segundo. La caída de los generales, en cambio, no es tan acusada. Únicamente han descendido en un $2,47 \%$ las instaladas y en un $4,35 \%$ las utilizadas.

Existe un grupo, no obstante que cuenta con un mayor cómputo conforme han pasado los años. Se trata de los de media y larga estancia, que pasan a tener 14.687 instaladas en 2012 (un 17,96\% más respecto a 1997) y 13.541 en funcionamiento (un $18,97 \%$ más).

Tabla 283. Evolución del número de camas instaladas por finalidad asistencial

\begin{tabular}{|c|c|c|c|c|c|}
\hline \multirow[b]{2}{*}{ Año } & \multicolumn{5}{|c|}{ Camas instaladas } \\
\hline & $\begin{array}{c}\text { Hospitales } \\
\text { generales }\end{array}$ & $\begin{array}{c}\text { Otros } \\
\text { hospitales de } \\
\text { agudos }\end{array}$ & $\begin{array}{c}\text { Hospitales } \\
\text { de larga } \\
\text { estancia }\end{array}$ & $\begin{array}{c}\text { Hospitales } \\
\text { psiquiátricos }\end{array}$ & Total \\
\hline 2012 & 122.001 & 6.442 & 14.687 & 13.738 & 156.868 \\
\hline 2011 & 122.520 & 6.856 & 14.572 & 14.058 & 158.006 \\
\hline 2010 & 121.681 & 6.277 & 15.637 & 14.368 & 157.963 \\
\hline 2009 & 121.407 & 8.176 & 13.758 & 15.077 & 158.418 \\
\hline 2008 & 120.831 & 8.283 & 13.825 & 15.231 & 158.170 \\
\hline 2007 & 121.025 & 7.681 & 13.681 & 15.919 & 158.306 \\
\hline 2006 & 119.051 & 8.456 & 13.261 & 16.750 & 157.518 \\
\hline 2005 & 117.726 & 8.852 & 13.425 & 17.142 & 157.145 \\
\hline 2004 & 118.666 & 8.696 & 13.714 & 16.992 & 158.068 \\
\hline 2003 & 119.007 & 8.914 & 12.534 & 17.021 & 157.476 \\
\hline 2002 & 119.888 & 9.542 & 12.011 & 17.670 & 159.111 \\
\hline 2001 & 120.200 & 9.789 & 12.141 & 17.661 & 159.791 \\
\hline 2000 & 121.919 & 10.452 & 12.569 & 17.951 & 162.891 \\
\hline 1999 & 123.180 & 10.880 & 12.166 & 18.515 & 164.741 \\
\hline 1998 & 123.759 & 11.272 & 12.888 & 18.195 & 166.114 \\
\hline 1997 & 125.097 & 10.139 & 12.451 & 19.426 & 167.113 \\
\hline $\begin{array}{l}\text { Diferencia } \\
\text { 2012-1997 }\end{array}$ & -3.096 & -3.697 & 2.236 & -5.688 & -10.245 \\
\hline \begin{tabular}{|l|} 
\%Diferencia \\
$2012-1997$
\end{tabular} & $-2,47$ & $-36,46$ & 17,96 & $-29,28$ & $-6,13$ \\
\hline
\end{tabular}

Fuente: Estadística de Centros Sanitarios de Atención Especializada y Estadística de Establecimientos Sanitarios con Régimen de Internado. 
Tabla 284. Evolución del número de camas en funcionamiento por finalidad asistencial

\begin{tabular}{|c|c|c|c|c|c|}
\hline \multirow[b]{2}{*}{ Año } & \multicolumn{5}{|c|}{ Camas en funcionamiento } \\
\hline & $\begin{array}{c}\text { Hospitales } \\
\text { generales }\end{array}$ & $\begin{array}{c}\text { Otros } \\
\text { hospitales } \\
\text { de agudos }\end{array}$ & $\begin{array}{c}\text { Hospitales } \\
\text { de larga } \\
\text { estancia }\end{array}$ & $\begin{array}{c}\text { Hospitales } \\
\text { psiquiátricos }\end{array}$ & Totales \\
\hline 2012 & 107.860 & 5.430 & 13.541 & 13.163 & 139.994 \\
\hline 2011 & 109.743 & 5.927 & 13.535 & 13.427 & 142.632 \\
\hline 2010 & 111.304 & 5.481 & 14.638 & 13.776 & 145.199 \\
\hline 2009 & 111.401 & 7.277 & 13.068 & 14.564 & 146.310 \\
\hline 2008 & 111.550 & 7.321 & 13.232 & 14.831 & 146.934 \\
\hline 2007 & 112.193 & 6.778 & 13.140 & 14.729 & 146.840 \\
\hline 2006 & 109.873 & 7.556 & 12.695 & 16.117 & 146.241 \\
\hline 2005 & 108.780 & 7.849 & 12.766 & 16.468 & 145.863 \\
\hline 2004 & 108.947 & 7.710 & 12.885 & 16.335 & 145.877 \\
\hline 2003 & 108.599 & 7.957 & 11.879 & 16.481 & 144.916 \\
\hline 2002 & 109.273 & 8.570 & 11.128 & 17.133 & 146.104 \\
\hline 2001 & 109.414 & 8.656 & 11.295 & 17.004 & 146.369 \\
\hline 2000 & 110.111 & 9.217 & 11.507 & 17.246 & 148.081 \\
\hline 1999 & 111.100 & 9.526 & 11.343 & 17.677 & 149.646 \\
\hline 1998 & 111.561 & 9.809 & 11.418 & 17.222 & 150.010 \\
\hline 1997 & 112.763 & 8.926 & 11.382 & 18.274 & 151.345 \\
\hline $\begin{array}{l}\text { Diferencia } \\
\text { 2012-1997 }\end{array}$ & -4.903 & -3.496 & 2.159 & -5.111 & -11.351 \\
\hline $\begin{array}{l}\text { \%Diferencia } \\
\text { 2012-1997 }\end{array}$ & $-4,35$ & $-39,17$ & 18,97 & $-27,97$ & $-7,50$ \\
\hline
\end{tabular}

Fuente: Estadística de Centros Sanitarios de Atención Especializada y Estadística de Establecimientos Sanitarios con Régimen de Internado.

\section{Altas}

Uno de los índices de actividad en un hospital es el de altas a pacientes, ya sea por curación o mejoría, traslado, fallecimiento, traslados interservicio y otras causas (como pueden ser huidas, altas voluntarias, por orden judicial, etc.) (Ministerio de Sanidad, 2013b).

En 20012, se contabilizaron 5.166.953 altas en los hospitales españoles, o lo que es lo mismo, 111,93 por cada 1.000 habitantes o 1,12 por cada 10 . Se puede observar en la tabla que el número de casos absolutos ha descendido desde 2008, a pesar de que desde 
1997 no se había contabilizado ni un solo año una disminución. Aun así, 2012, respecto al último año conocido estadísticamente, 1997, presenta un aumento de 641.565 altas. A pesar de esto, dado que la población española ha crecido en mayor medida, la tasa por cada 1.000 habitantes se ha reducido un 2,10\% respecto a 1997.

Tabla 285. Evolución del número y tasa de altas

\begin{tabular}{|l|r|r|}
\hline \multicolumn{1}{|c|}{ Año } & \multicolumn{1}{c|}{$\mathbf{N}^{\mathbf{0}}$ altas } & \multicolumn{1}{c|}{$\begin{array}{c}\mathbf{N}^{\mathbf{0}} \text { altas por } \\
\mathbf{1 . 0 0 0} \text { hab. }\end{array}$} \\
\hline 2012 & 5.166 .953 & 111,93 \\
\hline 2011 & 5.193 .086 & 112,59 \\
\hline 2010 & 5.239 .187 & 113,72 \\
\hline 2009 & 5.269 .855 & 114,74 \\
\hline 2008 & 5.282 .593 & 115,86 \\
\hline 2007 & 5.239 .416 & 116,76 \\
\hline 2006 & 5.157 .094 & 117,03 \\
\hline 2005 & 5.097 .150 & 117,45 \\
\hline 2004 & 5.061 .230 & 118,55 \\
\hline 2003 & 4.970 .613 & 118,34 \\
\hline 2002 & 4.889 .658 & 118,35 \\
\hline 2001 & 4.848 .459 & 119,06 \\
\hline 2000 & 4.794 .435 & 119,07 \\
\hline 1999 & 4.686 .743 & 117,38 \\
\hline 1998 & 4.592 .343 & 115,61 \\
\hline 1997 & 4.525 .388 & 114,33 \\
\hline $\begin{array}{l}\text { Diferencia } \\
2012-1997\end{array}$ & 641.565 & $-2,40$ \\
\hline$\%$ Diferencia & 14,18 & $-2,10$ \\
\hline $2012-1997$ & & \\
\hline
\end{tabular}

Fuente: Estadística de Centros Sanitarios de Atención Especializada y Estadística de Establecimientos Sanitarios con Régimen de Internado.

Divididos por finalidad asistencial, se observa que la mayor parte de las altas se suceden en los Hospitales generales (sobre todo a partir de 2010 por cambio de metodología). Reúnen, en 2012, el 98,16\% de los registrados, dejando a los de media y larga estancia muy por detrás, concretamente con un $1,84 \%$. Los generales han ido ganando fuerza en este aspecto con el paso de los años; en 1997, como muestra, suponían poco más del $90 \%$. En cuanto a la tasa por cada 1.000 habitantes, la proporción es idéntica. 
Tabla 286. Evolución del número de altas por finalidad asistencial

\begin{tabular}{|c|c|c|c|c|c|c|c|c|}
\hline \multirow[b]{2}{*}{ Año } & \multicolumn{8}{|c|}{ Número de altas } \\
\hline & $\begin{array}{l}\text { Hospitales } \\
\text { generales }\end{array}$ & $\%$ & $\begin{array}{l}\text { Otros de } \\
\text { agudos }\end{array}$ & $\%$ & $\begin{array}{l}\text { De larga } \\
\text { estancia }\end{array}$ & $\%$ & $\begin{array}{c}\text { Hospitales } \\
\text { psiquiátrico }\end{array}$ & $\%$ \\
\hline 2012 & $5.071 .791^{\frac{34}{4}}$ & 98,16 & & & 95.162 & 1,84 & & \\
\hline 2011 & 5.102 .901 & 98,26 & & & 90.185 & 1,74 & & \\
\hline 2010 & 5.141 .286 & 98,13 & & & 97.901 & 1,87 & & \\
\hline 2009 & 4.886 .424 & 92,72 & 293.236 & 5,56 & 60.337 & 1,14 & 29.858 & 0,57 \\
\hline 2008 & 4.860 .209 & 92,00 & 330.296 & 6,25 & 61.340 & 1,16 & 30.748 & 0,58 \\
\hline 2007 & 4.829 .472 & 92,18 & 317.587 & 6,06 & 61.993 & 1,18 & 30.364 & 0,58 \\
\hline 2006 & 4.716 .126 & 91,45 & 355.875 & 6,90 & 53.456 & 1,04 & 31.637 & 0,61 \\
\hline 2005 & 4.656 .261 & 91,35 & 360.219 & 7,07 & 48.615 & 0,95 & 32.055 & 0,63 \\
\hline 2004 & 4.626 .232 & 91,41 & 351.477 & 6,94 & 50.350 & 0,99 & 33.171 & 0,66 \\
\hline 2003 & 4.542 .453 & 91,39 & 349.646 & 7,03 & 44.886 & 0,90 & 33.628 & 0,68 \\
\hline 2002 & 4.468 .808 & 91,39 & 352.725 & 7,21 & 34.679 & 0,71 & 33.446 & 0,68 \\
\hline 2001 & 4.407 .985 & 90,92 & 373.075 & 7,69 & 35.022 & 0,72 & 32.377 & 0,67 \\
\hline 2000 & 4.331 .501 & 90,34 & 391.790 & 8,17 & 37.389 & 0,78 & 33.755 & 0,70 \\
\hline 1999 & 4.228 .046 & 90,21 & 386.528 & 8,25 & 37.397 & 0,80 & 34.772 & 0,74 \\
\hline 1998 & 4.139 .051 & 90,13 & 382.680 & 8,33 & 38.956 & 0,85 & 31.656 & 0,69 \\
\hline 1997 & 4.081 .816 & 90,20 & 359.698 & 7,95 & 52.073 & 1,15 & 31.801 & 0,70 \\
\hline
\end{tabular}

Fuente: Estadística de Centros Sanitarios de Atención Especializada y Estadística de Establecimientos Sanitarios con Régimen de Internado.

\footnotetext{
34 Desde 2010, la Estadística de Centros Sanitarios de Atención Especializada únicamente contabiliza las plazas de día en hospitales de agudos y de larga estancia. En este caso, se ha traspasado los datos de la columna de agudos a los generales por ofrecer una mayor continuidad con los años anteriores, en los que estaba en vigor la Estadística de Establecimientos Sanitarios con Régimen de Internado.
} 
Tabla 287. Evolución de la tasa de altas por finalidad asistencial

\begin{tabular}{|c|c|c|c|c|c|c|c|c|}
\hline \multirow[b]{2}{*}{ Año } & \multicolumn{8}{|c|}{$\mathrm{N}^{0}$ altas por 1.000 habitantes } \\
\hline & $\begin{array}{c}\text { Hospitales } \\
\text { generales }\end{array}$ & $\%$ & $\begin{array}{l}\text { Otros de } \\
\operatorname{agudos}^{\underline{35}}\end{array}$ & $\%$ & $\begin{array}{l}\text { De larga } \\
\text { estancia }\end{array}$ & $\%$ & $\begin{array}{c}\text { Hospitales } \\
\text { psiquiátricos }\end{array}$ & $\%$ \\
\hline 2012 & 109,87 & 98,16 & - & & 2,06 & 1,84 & & \\
\hline 2011 & 110,63 & 98,26 & - & - & 1,96 & 1,74 & - & - \\
\hline 2010 & 111,59 & 98,13 & - & - & 2,12 & 1,86 & - & - \\
\hline 2009 & 106,39 & 92,72 & 6,38 & 5,56 & 1,31 & 1,14 & 0,65 & 0,57 \\
\hline 2008 & 106,60 & 92,00 & 7,24 & 6,25 & 1,35 & 1,16 & 0,67 & 0,58 \\
\hline 2007 & 107,62 & 92,18 & 7,08 & 6,06 & 1,38 & 1,18 & 0,68 & 0,58 \\
\hline 2006 & 107,02 & 91,45 & 8,08 & 6,90 & 1,21 & 1,04 & 0,72 & 0,61 \\
\hline 2005 & 107,29 & 91,35 & 8,30 & 7,07 & 1,12 & 0,95 & 0,74 & 0,63 \\
\hline 2004 & 108,36 & 91,41 & 8,23 & 6,94 & 1,18 & 0,99 & 0,78 & 0,66 \\
\hline 2003 & 108,14 & 91,39 & 8,32 & 7,03 & 1,07 & 0,90 & 0,80 & 0,68 \\
\hline 2002 & 108,17 & 91,39 & 8,54 & 7,21 & 0,84 & 0,71 & 0,81 & 0,68 \\
\hline 2001 & 108,25 & 90,92 & 9,16 & 7,69 & 0,86 & 0,72 & 0,80 & 0,67 \\
\hline 2000 & 107,58 & 90,34 & 9,73 & 8,17 & 0,93 & 0,78 & 0,84 & 0,70 \\
\hline 1999 & 105,89 & 90,21 & 9,68 & 8,25 & 0,94 & 0,80 & 0,87 & 0,74 \\
\hline 1998 & 104,20 & 90,13 & 9,63 & 8,33 & 0,98 & 0,85 & 0,80 & 0,69 \\
\hline 1997 & 103,12 & 90,20 & 9,09 & 7,95 & 1,32 & 1,15 & 0,80 & 0,70 \\
\hline
\end{tabular}

Fuente: Estadística de Centros Sanitarios de Atención Especializada y Estadística de Establecimientos Sanitarios con Régimen de Internado.

Con el fin de conocer algunos datos demográficos de las personas que acuden a los centros de atención especializada, se ha acudido al Registro de altas de los Hospitales generales del Sistema Nacional de Salud, una estadística incluida en el Plan Estadístico Nacional (Ministerio de Sanidad, 2011). Incluye datos del CMBD (Conjunto Mínimo Básico de Datos al alta hospitalaria), aprobado para los hospitales del Sistema Nacional de Salud en diciembre de 1987 por el Consejo Interterritorial (Ministerio de Sanidad, 2011). De este documento se obtiene información relativa a las características de los pacientes (tales como la edad, el sexo y el lugar de residencia), al episodio de hospitalización, al diagnóstico y a los procedimientos realizados durante la hospitalización. Conviene recalcar que únicamente se aportan los datos de los Hospitales generales pertenecientes a la red de utilización pública y a los administrados públicamente o con concierto sustitutorio (Ministerio de Sanidad, 2011).

La mayor parte de las altas registradas por esta estadística se han producido en los centros públicos del Sistema Nacional de Salud. Más concretamente, en 2012, el

\footnotetext{
$\underline{35}$ La Estadística de Centros Sanitarios de Atención Especializada, a partir de 2010, distingue únicamente entre hospitales de agudos y de larga estancia.
} 
$77,23 \%$ de esta actividad hospitalaria se realizó en lugares gestionados por la sanidad pública, en comparación con el $22,77 \%$ de las manos privadas. Esta diferencia ha aumentado ligeramente con el paso de los años, puesto que en 1997, por ejemplo, se documentaron unos porcentajes del 76,31\% y 23,69\%, respectivamente, aunque a lo largo del tiempo estas cifras han subido y bajado indiscriminadamente.

Tabla 288. Evolución del número y tasa de altas por dependencia funcional

\begin{tabular}{|c|c|c|c|c|c|c|c|c|}
\hline \multirow{2}{*}{ Año } & \multicolumn{4}{|c|}{$\mathrm{N}^{0}$ altas } & \multicolumn{4}{|c|}{$\mathrm{N}^{0}$ altas por 1.000 hab. } \\
\hline & SNS & $\%$ & Privados & $\%$ & SNS & $\%$ & Privados & $\%$ \\
\hline 2012 & 3.990 .430 & 77,23 & 1.176 .523 & 22,77 & 86,44 & 77,23 & 25,49 & 22,77 \\
\hline 2011 & 4.005 .171 & 77,13 & 1.187 .915 & 22,87 & 86,83 & 77,12 & 25,75 & 22,87 \\
\hline 2010 & 4.047 .294 & 77,25 & 1.191 .893 & 22,75 & 87,85 & 77,25 & 25,87 & 22,75 \\
\hline 2009 & 3.941 .247 & 74,79 & 1.328 .608 & 25,21 & 85,81 & 74,79 & 28,93 & 25,21 \\
\hline 2008 & 3.967 .578 & 75,11 & 1.315 .015 & 24,89 & 87,02 & 75,11 & 28,84 & 24,89 \\
\hline 2007 & 3.916 .687 & 74,75 & 1.322 .729 & 25,25 & 87,28 & 74,75 & 29,48 & 25,25 \\
\hline 2006 & 3.846 .143 & 74,58 & 1.310 .951 & 25,42 & 87,28 & 74,58 & 29,75 & 25,42 \\
\hline 2005 & 3.810 .785 & 74,76 & 1.286 .365 & 25,24 & 87,81 & 74,76 & 29,64 & 25,24 \\
\hline 2004 & 3.788 .528 & 74,85 & 1.272 .702 & 25,15 & 88,74 & 74,85 & 29,81 & 25,15 \\
\hline 2003 & 3.750 .110 & 75,45 & 1.220 .503 & 24,55 & 89,28 & 75,45 & 29,06 & 24,55 \\
\hline 2002 & 3.649 .177 & 74,63 & 1.240 .481 & 25,37 & 88,33 & 74,63 & 30,03 & 25,37 \\
\hline 2001 & 3.604 .337 & 74,34 & 1.244 .122 & 25,66 & 88,51 & 74,34 & 30,55 & 25,66 \\
\hline 2000 & 3.592 .153 & 74,92 & 1.202 .282 & 25,08 & 89,21 & 74,92 & 29,86 & 25,08 \\
\hline 1999 & 3.523 .318 & 75,18 & 1.163 .425 & 24,82 & 88,24 & 75,18 & 29,14 & 24,82 \\
\hline 1998 & 3.478 .091 & 75,74 & 1.114 .252 & 24,26 & 87,56 & 75,74 & 28,05 & 24,26 \\
\hline 1997 & 3.453 .486 & 76,31 & 1.071 .902 & 23,69 & 87,25 & 76,31 & 27,08 & 23,69 \\
\hline $\begin{array}{l}\text { Diferencia } \\
\text { 2012-1997 } \\
\end{array}$ & 536.944 & 0,92 & 104.621 & $-0,92$ & $-0,81$ & 0,92 & $-1,59$ & $-0,92$ \\
\hline $\begin{array}{l}\text { \%Diferencia } \\
\text { 2012-1997 }\end{array}$ & 15,55 & 1,21 & 9,76 & $-3,88$ & $-0,93$ & 1,21 & $-5,87$ & $-3,88$ \\
\hline
\end{tabular}

Fuente: Estadística de Centros Sanitarios de Atención Especializada y Estadística de Establecimientos Sanitarios con Régimen de Internado.

Los Hospitales generales del Sistema Nacional de Salud han atendido en el intervalo comprendido entre 1997 y 2012, ambos inclusive, más de 55 millones de casos, más concretamente, 55.244.437. En el último año registrado, 2012, se contabilizaron 3.653.899. Esta cifra supone un incremento del $18,62 \%$ respecto a las registradas en 1998, que ascendían a 3.080.279. Si se compara el incremento del número de casos con el de la población, se aprecian que son prácticamente idénticos: desde 1998 (en 1997 no se realizó censo) a 2012, la población española ha ascendido un $18,60 \%$. 
Tabla 289. Evolución del número de altas del Sistema Nacional de Salud y población

\begin{tabular}{|l|r|r|}
\hline \multicolumn{1}{|c|}{ Año } & \multicolumn{1}{c|}{ Altas } & \multicolumn{1}{l|}{ Población } \\
\hline 2012 & 3.653 .899 & 47.265 .321 \\
\hline 2011 & 3.689 .540 & 47.190 .493 \\
\hline 2010 & 3.675 .430 & 47.021 .031 \\
\hline 2009 & 3.742 .850 & 46.745 .807 \\
\hline 2008 & 3.735 .945 & 46.157 .822 \\
\hline 2007 & 3.686 .655 & 45.200 .737 \\
\hline 2006 & 3.589 .728 & 44.708 .964 \\
\hline 2005 & 3.541 .107 & 44.108 .530 \\
\hline 2004 & 3.496 .238 & 43.197 .684 \\
\hline 2003 & 3.444 .541 & 42.717 .064 \\
\hline 2002 & 3.343 .711 & 41.837 .894 \\
\hline 2001 & 3.297 .074 & 41.116 .842 \\
\hline 2000 & 3.238 .022 & 40.499 .791 \\
\hline 1999 & 3.092 .087 & 40.202 .160 \\
\hline 1998 & 3.080 .279 & 39.852 .651 \\
\hline 1997 & 2.937 .331 & \\
\hline $\begin{array}{l}\text { Diferencia } \\
2012-1998\end{array}$ & 573.620 & 7.412 .670 \\
\hline $\begin{array}{l}\text { \%Diferencia } \\
2012-1998\end{array}$ & 18,62 & \\
\hline
\end{tabular}

Fuente: Conjunto Mínimo Básico de Datos Hospitalización (CMBD-H) del Ministerio del Ministerio de Sanidad, Servicios Sociales e Igualdad y Padrón municipal del Instituto Nacional de Estadística (INE).

Las mujeres contabilizan más altas que los hombres. En conjunto desde 1997 hasta 2012, ellas suponen el 53,01\%, mientras que los hombres constituyen el 46,97\%. Desde 1997 hasta 2008, las mujeres habían aumentado en número de casos, pasando del $52,62 \%$ al 53,67\% frente al 47,33\% al 46,32\% de los hombres. En los últimos años, no obstante, las desigualdades han comenzado a reducirse levemente y, en 2012, las féminas reúnen el 52,50\% de los casos frente al 47,49\% del otro sexo. 
Tabla 290. Evolución del número de altas por sexo de los pacientes

\begin{tabular}{|c|c|c|c|c|c|c|c|}
\hline \multirow{2}{*}{ Año } & \multicolumn{7}{|c|}{ Número de casos } \\
\hline & Varón & \% Varón & Mujer & $\%$ Mujer & Otros & $\%$ Otros & Total \\
\hline 2012 & 1.735 .159 & 47,49 & 1.918 .424 & 52,50 & 316 & 0,01 & 3.653 .899 \\
\hline 2011 & 1.713 .482 & 47,07 & 1.926 .354 & 52,92 & 228 & 0,01 & 3.640 .064 \\
\hline 2010 & 1.721 .082 & 46,83 & 1.954 .188 & 53,17 & 160 & 0,00 & 3.675 .430 \\
\hline 2009 & 1.747 .405 & 46,69 & 1.995 .278 & 53,31 & 167 & 0,00 & 3.742 .850 \\
\hline 2008 & 1.730 .598 & 46,32 & 2.005 .054 & 53,67 & 293 & 0,01 & 3.735 .945 \\
\hline 2007 & 1.720 .559 & 46,67 & 1.965 .820 & 53,32 & 276 & 0,01 & 3.686 .655 \\
\hline 2006 & 1.673 .671 & 46,62 & 1.915 .791 & 53,37 & 266 & 0,01 & 3.589 .728 \\
\hline 2005 & 1.653 .665 & 46,70 & 1.887 .352 & 53,30 & 90 & 0,00 & 3.541 .107 \\
\hline 2004 & 1.631 .491 & 46,66 & 1.863 .986 & 53,31 & 761 & 0,02 & 3.496 .238 \\
\hline 2003 & 1.614 .576 & 46,87 & 1.828 .481 & 53,08 & 1.484 & 0,04 & 3.444 .541 \\
\hline 2002 & 1.571 .848 & 47,01 & 1.770 .727 & 52,96 & 1.136 & 0,03 & 3.343 .711 \\
\hline 2001 & 1.555 .124 & 47,17 & 1.740 .832 & 52,80 & 1.118 & 0,03 & 3.297 .074 \\
\hline 2000 & 1.529 .994 & 47,25 & 1.707 .191 & 52,72 & 837 & 0,03 & 3.238 .022 \\
\hline 1999 & 1.463 .927 & 47,34 & 1.627 .124 & 52,62 & 1.036 & 0,03 & 3.092 .087 \\
\hline 1998 & 1.464 .258 & 47,54 & 1.614 .878 & 52,43 & 1.143 & 0,04 & 3.080 .279 \\
\hline 1997 & 1.390 .320 & 47,33 & 1.545 .752 & 52,62 & 1.259 & 0,04 & 2.937 .331 \\
\hline $\begin{array}{l}\text { Total / } \\
\text { promedio }\end{array}$ & 25.917.159 & $46,97^{36}$ & 29.267 .232 & $53,01 \frac{37}{1}$ & 10.570 & $0,02^{\frac{38}{8}}$ & 55.194 .961 \\
\hline $\begin{array}{l}\text { Diferencia } \\
\text { 2012-1997 }\end{array}$ & 344.839 & 0,16 & 372.672 & $-0,12$ & -943 & $-0,03$ & 716.568 \\
\hline $\begin{array}{l}\text { \%Diferencia } \\
\text { 2012-1997 }\end{array}$ & 24,80 & 0,33 & 24,11 & $-0,22$ & $-74,90$ & $-78,38$ & 24,40 \\
\hline
\end{tabular}

Fuente: Conjunto Mínimo Básico de Datos Hospitalización (CMBD-H) del Ministerio del Ministerio de Sanidad, Servicios Sociales e Igualdad.

Los mayores de 74 años son los que conforman el rango de edad con un mayor número de altas. Esta franja reúne con 1.053 .193 el 28,82\% de 2012, situándose por detrás los que tienen entre 15 y 44 años, que con 939.412 se quedan en un $25,71 \%$. En 2011 se experimenta un cambio de tornas, de todas formas, ya que en los ejercicios anteriores el primer grupo adelantaba siempre a los más mayores. Y es que, de hecho, desde 1997 a 2012, los pacientes con más de 74 años han experimentado un aumento del 113,90\%, es decir, han doblado el número de casos. Es la tasa más alta de crecimiento, por detrás, aunque de lejos, de los de 45 a 64 años (con un 23,45\% más) y los menores de un año (que experimentan un incremento del 12,12\%).

\footnotetext{
$\underline{36}$ Calculado el promedio de los porcentajes de los distintos años.

37 Calculado el promedio de los porcentajes de los distintos años.

$\underline{38}$ Calculado el promedio de los porcentajes de los distintos años.
} 
El único conjunto que disminuye sus altas conforme pasa el tiempo, con un 17,01\%, es el de 1 a 14 años. Aun así, en la actualidad, únicamente suman el 5,33\% del total de 3.653.899 casos registrados en 2012, detrás solamente de los menores de un año, que conforman el 3,58\%.

Tabla 291. Evolución del número de altas por edades de los pacientes

\begin{tabular}{|c|c|c|c|c|c|c|c|}
\hline \multirow[b]{2}{*}{ Año } & \multicolumn{7}{|c|}{ Número de altas } \\
\hline & $\begin{array}{c}\text { Menos } \\
\text { de } 1\end{array}$ & $\begin{array}{c}01-14 \\
\text { años }\end{array}$ & $\begin{array}{l}15-44 \\
\text { años }\end{array}$ & $\begin{array}{l}45-64 \\
\text { años }\end{array}$ & $\begin{array}{c}65-74 \\
\text { años }\end{array}$ & $\begin{array}{l}\text { Más de } \\
74 \text { años }\end{array}$ & Total \\
\hline 2012 & 130.964 & 194.833 & 939.412 & 794.429 & 541.068 & 1.053 .193 & 3.653 .899 \\
\hline 2011 & 138.435 & 199.022 & 968.170 & 780.096 & 540.477 & 1.013 .864 & 3.640 .064 \\
\hline 2010 & 141.281 & 203.453 & 1.007 .133 & 780.095 & 548.268 & 995.200 & 3.675 .430 \\
\hline 2009 & 148.245 & 212.340 & 1.061 .919 & 789.153 & 557.224 & 973.969 & 3.742 .850 \\
\hline 2008 & 157.565 & 206.601 & 1.099 .776 & 774.049 & 557.851 & 940.103 & 3.735 .945 \\
\hline 2007 & 154.554 & 210.602 & 1.088 .931 & 763.410 & 566.358 & 902.800 & 3.686 .655 \\
\hline 2006 & 155.303 & 214.753 & 1.081 .104 & 739.336 & 566.366 & 832.866 & 3.589 .728 \\
\hline 2005 & 152.383 & 205.279 & 1.067 .057 & 723.732 & 579.457 & 813.199 & 3.541 .107 \\
\hline 2004 & 149.810 & 208.287 & 1.076 .538 & 719.013 & 582.944 & 759.646 & 3.496 .238 \\
\hline 2003 & 148.910 & 215.117 & 1.064 .988 & 697.784 & 590.846 & 726.896 & 3.444 .541 \\
\hline 2002 & 142.871 & 214.229 & 1.032 .137 & 683.003 & 585.862 & 685.609 & 3.343 .711 \\
\hline 2001 & 140.838 & 221.119 & 1.020 .895 & 679.726 & 583.916 & 650.580 & 3.297 .074 \\
\hline 2000 & 142.217 & 224.594 & 998.755 & 672.440 & 578.056 & 621.960 & 3.238 .022 \\
\hline 1999 & 123.865 & 219.418 & 958.207 & 652.098 & 555.769 & 582.730 & 3.092 .087 \\
\hline 1998 & 122.036 & 226.402 & 957.948 & 669.191 & 551.767 & 552.935 & 3.080 .279 \\
\hline 1997 & 116.803 & 234.762 & 937.061 & 643.502 & 512.824 & 492.379 & 2.937 .331 \\
\hline Total & $2.266 \mathrm{k}$ & $3.411 \mathrm{k}$ & $16.360 \mathrm{k}$ & $11.561 \mathrm{k}$ & $8.999 \mathrm{k}$ & $12.598 \mathrm{k}$ & $55.195 \mathrm{k}$ \\
\hline $\begin{array}{l}\text { Diferencia } \\
\text { 2012-1997 }\end{array}$ & 14.161 & -39.929 & 2.351 & 150.927 & 28.244 & 560.814 & 716.568 \\
\hline $\begin{array}{l}\text { \%Diferencia } \\
2012-1997\end{array}$ & 12,12 & $-17,01$ & 0,25 & 23,45 & 5,51 & 113,90 & 24,40 \\
\hline
\end{tabular}

Fuente: Conjunto Mínimo Básico de Datos Hospitalización (CMBD-H) del Ministerio del Ministerio de Sanidad, Servicios Sociales e Igualdad.

Casi todas las altas de 2012 del Sistema Nacional de Salud las ha financiado la asistencia sanitaria pública $(94,88 \%)$, muy por delante de las manos privadas $(1,40 \%)$, de accidentes de trabajo $(0,93 \%)$ o de tráfico $(0,44 \%)$. Se trata, en el caso de la sanidad pública, de un porcentaje del 25,21\% más que el que se registró en 1997. Se podría decir que el $24,40 \%$ más de casos anotados entre un año y otro son asumidos casi en su integridad por la asistencia sanitaria pública. En cambio, las corporaciones locales o cabildos insulares bajan su financiación en un $88,18 \%$, aunque se ha de destacar que su participación es muy irregular de unos años a otros. También bajan sustancialmente la 
financiación mixta $(-42,18 \%)$ y los accidentes de tráfico $(-52,20 \%)$. Los únicos regímenes que aumentan, aparte de la asistencia sanitaria pública, son los accidentes de trabajo, con un $211,48 \%$ más, las mutuas de asistencia sanitaria, con un $61,13 \%$, y los privados, con un 40,48\%. Estos dos últimos grupos ofrecen datos muy diferentes de unos años a otros sin seguir, al parecer, una tendencia fija.

Tabla 292. Evolución del número de altas por tipo de financiación

\begin{tabular}{|c|c|c|c|c|c|c|c|}
\hline \multirow{2}{*}{$\begin{array}{c}\text { Tipo de } \\
\text { financiación }\end{array}$} & \multicolumn{7}{|c|}{ Número de altas } \\
\hline & 2012 & 2011 & 2010 & 1998 & 1997 & $\mid \begin{array}{c}\text { Total } \\
2012-1997\end{array}$ & $\mid \begin{array}{c}\text { \%Diferencia } \\
\text { 2012-1997 }\end{array}$ \\
\hline $\begin{array}{l}\text { Asistencia } \\
\text { Sanitaria } \\
\text { Pública }\end{array}$ & $3.467 \mathrm{k}$ & $3.473 \mathrm{k}$ & $3.546 \mathrm{k}$ & $2.844 \mathrm{k}$ & $2.769 \mathrm{k}$ & $52.601 \mathrm{k}$ & 25,21 \\
\hline $\begin{array}{l}\text { Corporaciones } \\
\text { locales/Cabildos }\end{array}$ & 695 & 764 & 786 & 8.452 & 5.881 & 52.372 & $-88,18$ \\
\hline $\begin{array}{l}\text { Mutuas de } \\
\text { Asistencia } \\
\text { Sanitaria }\end{array}$ & 11.534 & 12.117 & 11.005 & 28.361 & 7.158 & 185.636 & 61,13 \\
\hline $\begin{array}{l}\text { Accidentes de } \\
\text { trabajo }\end{array}$ & 33.805 & 31.182 & 7.475 & 12.951 & 10.853 & 190.672 & 211,48 \\
\hline $\begin{array}{l}\text { Accidentes de } \\
\text { tráfico }\end{array}$ & 16.024 & 16.987 & 17.395 & 39.867 & 33.520 & 446.701 & $-52,20$ \\
\hline Privado & 55.591 & 54.006 & 53.435 & 34.737 & 39.572 & 844.977 & 40,48 \\
\hline $\begin{array}{l}\text { Financiación } \\
\text { mixta }\end{array}$ & 1.113 & 506 & 488 & 1.620 & 1.925 & 10.797 & $-42,18$ \\
\hline Otros & 29.539 & 35.551 & 8.511 & 9.223 & 26.973 & 199.527 & 9,51 \\
\hline Desconocido & 38.625 & 65.035 & 30.322 & 101.291 & 42.570 & 663.679 & $-9,27$ \\
\hline Total & $3.654 \mathrm{k}$ & $3.690 \mathrm{k}$ & $3.675 \mathrm{k}$ & $3.080 \mathrm{k}$ & $2.937 \mathrm{k}$ & $55.195 \mathrm{k}$ & 24,40 \\
\hline
\end{tabular}

Fuente: Conjunto Mínimo Básico de Datos Hospitalización (CMBD-H) del Ministerio del Ministerio de Sanidad, Servicios Sociales e Igualdad.

Las clínicas que registran un mayor número de altas son aquellas que cuentan con entre 200 y 500 camas instaladas. En 2012, sumaron el 32,53\% de todos los casos. Por detrás se encuentran los de 501 a 1.000 camas, con un porcentaje del 27,31\% y los que tienen más de 1.000 , el 22,77\%. Los centros que cuentan con menos de 200 camas son los que reciben menos altas; en 2012, por ejemplo, el 17,39\%.

De hecho, este último grupo ve aumentar el número de casos atendidos solamente en un 3,39\% desde 1997, incluso cuando aumenta el número de altas totales en un $24,40 \%$ desde esa fecha. En cambio, el resto sube considerablemente desde 1997 hasta 2012, sobre todo los de 200 a 500 camas, que experimentan un crecimiento del $35,93 \%$. Los de 501 a 1.000 y los de más de 1.000 arrojan porcentajes más parecidos: 23,03\% y $31,88 \%$, respectivamente. 
Tabla 293. Evolución del número de altas según el tamaño de los hospitales

\begin{tabular}{|l|r|r|r|r|r|r|}
\hline \multirow{2}{*}{ Año } & \multicolumn{7}{|c|}{ Número de altas } \\
\cline { 2 - 8 } & $\begin{array}{c}\text { Menos de } \\
\text { 200 camas }\end{array}$ & $\begin{array}{c}\text { 200-500 } \\
\text { camas }\end{array}$ & $\begin{array}{c}\text { 501-1000 } \\
\text { camas }\end{array}$ & $\begin{array}{c}\text { Más de } \\
\mathbf{1 0 0 0} \text { camas }\end{array}$ & Otros & \multicolumn{1}{c|}{ Total } \\
\hline 2012 & 635.580 & 1.188 .479 & 997.777 & 832.062 & 1 & 3.653 .899 \\
\hline 2011 & 643.372 & 1.200 .640 & 1.050 .520 & 795.008 & - & 3.689 .540 \\
\hline 2010 & 600.194 & 1.184 .377 & 1.064 .188 & 826.671 & - & 3.675 .430 \\
\hline 2009 & 679.112 & 1.182 .186 & 1.076 .273 & 805.279 & - & 3.742 .850 \\
\hline 2008 & 659.941 & 1.154 .449 & 1.049 .095 & 872.134 & 326 & 3.735 .945 \\
\hline 2007 & 619.556 & 1.136 .357 & 1.082 .699 & 848.043 & - & 3.686 .655 \\
\hline 2006 & 582.530 & 1.099 .463 & 1.060 .988 & 846.747 & - & 3.589 .728 \\
\hline 2005 & 568.231 & 1.078 .237 & 1.051 .998 & 842.641 & - & 3.541 .107 \\
\hline 2004 & 562.662 & 1.072 .080 & 1.056 .271 & 804.585 & 640 & 3.496 .238 \\
\hline 2003 & 555.364 & 1.044 .619 & 1.054 .372 & 790.186 & - & 3.444 .541 \\
\hline 2002 & 561.010 & 979.305 & 1.038 .468 & 764.928 & - & 3.343 .711 \\
\hline 2001 & 600.783 & 1.001 .254 & 1.015 .484 & 679.553 & - & 3.297 .074 \\
\hline 2000 & 645.360 & 984.641 & 954.711 & 653.310 & - & 3.238 .022 \\
\hline 1999 & 503.651 & 944.327 & 974.206 & 669.107 & 796 & 3.092 .087 \\
\hline 1998 & 665.587 & 901.675 & 850.146 & 662.871 & - & 3.080 .279 \\
\hline 1997 & 614.745 & 874.307 & 810.978 & 630.935 & 6.366 & 2.937 .331 \\
\hline Total & 9.697 .678 & 17.026 .396 & 16.188 .174 & 12.324 .060 & 8.129 & 55.244 .437 \\
\hline $\begin{array}{l}\text { Diferencia } \\
2011-1997\end{array}$ & 20.835 & 314.172 & 186.799 & 201.127 & & 716.568 \\
\hline$\%$ Diferencia & 3,39 & 35,93 & 23,03 & 31,88 & - & 24,40 \\
\hline $2011-1997$ & & & & & & \\
\hline
\end{tabular}

Fuente: Conjunto Mínimo Básico de Datos Hospitalización (CMBD-H) del Ministerio del Ministerio de Sanidad, Servicios Sociales e Igualdad.

La mayor parte de las altas tramitadas en los Hospitales generales del Sistema Nacional de Salud se corresponden con ingresos urgentes. En 2012, por ejemplo, constituían el 68,62\% del total, mientras que los programados rebajan su cifra hasta el 31,28\%. Observando la evolución desde 1997 hasta 2012, se aprecia que el número de los del primer tipo asciende un 31,31\%, mientras que los programados suben casi la mitad, es decir un 14,74\%. También disminuyen los catalogados como "otros" en un $88,52 \%$. 
Tabla 294. Evolución del número de altas por tipo de ingresos

\begin{tabular}{|c|c|c|c|c|c|c|c|}
\hline \multirow[b]{2}{*}{ Año } & \multicolumn{7}{|c|}{ Número de altas } \\
\hline & Urgente & $\%$ Urgente & $\begin{array}{l}\text { Progra- } \\
\text { mado }\end{array}$ & $\begin{array}{c}\text { \%Progra } \\
\text {-mado }\end{array}$ & Otros & $\%$ Otros & Total \\
\hline 2012 & 2.507 .435 & 68,62 & 1.142 .820 & 31,28 & 3.644 & 0,10 & 3.653 .899 \\
\hline 2011 & 2.524 .764 & 68,74 & 1.162 .047 & 31,19 & 2.729 & 0,07 & 3.640 .064 \\
\hline 2010 & 2.525 .172 & 68,70 & 1.137 .331 & 30,94 & 12.927 & 0,35 & 3.675 .430 \\
\hline 2009 & 2.573 .856 & 68,77 & 1.160 .580 & 31,01 & 8.414 & 0,22 & 3.742 .850 \\
\hline 2008 & 2.580 .150 & 69,06 & 1.144 .537 & 30,64 & 11.258 & 0,30 & 3.735 .945 \\
\hline 2007 & 2.545 .075 & 69,03 & 1.129 .349 & 30,63 & 12.231 & 0,33 & 3.686 .655 \\
\hline 2006 & 2.471 .010 & 68,84 & 1.106 .708 & 30,83 & 12.010 & 0,33 & 3.589 .728 \\
\hline 2005 & 2.446 .146 & 69,08 & 1.085 .680 & 30,66 & 9.281 & 0,26 & 3.541 .107 \\
\hline 2004 & 2.405 .438 & 68,80 & 1.081 .135 & 30,92 & 9.665 & 0,28 & 3.496 .238 \\
\hline 2003 & 2.363 .611 & 68,62 & 1.069 .634 & 31,05 & 11.296 & 0,33 & 3.444 .541 \\
\hline 2002 & 2.280 .235 & 68,19 & 1.052 .256 & 31,47 & 11.220 & 0,34 & 3.343 .711 \\
\hline 2001 & 2.232 .808 & 67,72 & 1.053 .479 & 31,95 & 10.787 & 0,33 & 3.297 .074 \\
\hline 2000 & 2.169 .715 & 67,01 & 1.059 .457 & 32,72 & 8.850 & 0,27 & 3.238 .022 \\
\hline 1999 & 2.066 .910 & 66,85 & 1.017 .114 & 32,89 & 8.063 & 0,26 & 3.092 .087 \\
\hline 1998 & 1.997 .539 & 64,85 & 1.052 .109 & 34,16 & 30.631 & 0,99 & 3.080 .279 \\
\hline 1997 & 1.909 .592 & 65,01 & 995.992 & 33,91 & 31.747 & 1,08 & 2.937.331 \\
\hline $\begin{array}{l}\text { Total/ } \\
\text { promedio }\end{array}$ & 37.599 .456 & 67,99 & $\begin{array}{r}17.450 .22 \\
8 \\
\end{array}$ & 31,64 & 194.753 & 0,36 & $\begin{array}{r}55.194 .96 \\
1 \\
\end{array}$ \\
\hline \begin{tabular}{|l|} 
Diferencia \\
$2012-1997$ \\
\end{tabular} & 597.843 & 3,61 & 146.828 & $-2,63$ & -28.103 & $-0,98$ & 716.568 \\
\hline $\begin{array}{l}\text { \%Diferencia } \\
2012-1997\end{array}$ & 31,31 & 5,56 & 14,74 & $-7,77$ & $-88,52$ & $-90,77$ & 24,40 \\
\hline
\end{tabular}

Fuente: Conjunto Mínimo Básico de Datos Hospitalización (CMBD-H) del Ministerio del Ministerio de Sanidad, Servicios Sociales e Igualdad.

\section{Estancia media}

La estancia media en los hospitales de España se ha reducido en un 16,41\% desde 1997 a 2012. En ese primer año, el número de días que, de media, pasaba un paciente en un centro de atención especializada era de 8,29. Sin embargo, en 2012, el ingreso ha disminuido más de una jornada, es decir, se ha pasado a 6,93 días de media. 
Tabla 295. Evolución de la estancia media en los hospitales

\begin{tabular}{|l|r|}
\hline \multicolumn{1}{|c|}{ Año } & Estancia Media \\
\hline 2012 & 6,93 \\
\hline 2011 & 7,00 \\
\hline 2010 & 7,20 \\
\hline 2009 & 7,31 \\
\hline 2008 & 7,40 \\
\hline 2007 & 7,48 \\
\hline 2006 & 7,45 \\
\hline 2005 & 7,59 \\
\hline 2004 & 7,58 \\
\hline 2003 & 7,64 \\
\hline 2002 & 7,72 \\
\hline 2001 & 7,77 \\
\hline 2000 & 7,78 \\
\hline 1999 & 7,89 \\
\hline 1998 & 8,07 \\
\hline 1997 & 8,29 \\
\hline Media & 7,57 \\
\hline Diferencia & $-1,36$ \\
\hline $2012-1997$ & $-16,41$ \\
\hline$\%$ Diferencia & \\
\hline $2012-1997$ & \\
\hline Bas & \\
\hline
\end{tabular}

Fuente: Conjunto Mínimo Básico de Datos Hospitalización (CMBD-H) del Ministerio del Ministerio de Sanidad, Servicios Sociales e Igualdad.

Los hombres, por norma general, permanecen más tiempo ingresados que las mujeres. En 2012, por ejemplo, ellos permanecieron casi 8 días (más concretamente $7,55)$ en estos centros, frente a los 6,37 de las féminas. No obstante, se trata, en ambos casos, de valores inferiores a los registrados en años anteriores. En 1997, por ejemplo, los varones estuvieron de media en el hospital 9,01 días y las mujeres, 7,64. 
Tabla 296. Evolución de la estancia media según el sexo de los pacientes

\begin{tabular}{|l|r|r|r|r|}
\hline \multirow{2}{*}{ Año } & \multicolumn{4}{|c|}{ Estancia Media } \\
\cline { 2 - 5 } & Varón & \multicolumn{1}{c|}{ Mujer } & \multicolumn{1}{c|}{ Otros } & \multicolumn{1}{c|}{ Media } \\
\hline 2012 & 7,55 & 6,37 & 5,59 & 7,55 \\
\hline 2011 & 7,66 & 6,41 & 7,05 & 7,66 \\
\hline 2010 & 7,91 & 6,57 & 6,45 & 7,20 \\
\hline 2009 & 8,07 & 6,64 & 4,64 & 7,31 \\
\hline 2008 & 8,20 & 6,70 & 5,20 & 7,40 \\
\hline 2007 & 8,29 & 6,78 & 5,33 & 7,48 \\
\hline 2006 & 8,24 & 6,76 & 4,95 & 7,45 \\
\hline 2005 & 8,38 & 6,89 & 7,50 & 7,59 \\
\hline 2004 & 8,38 & 6,88 & 6,90 & 7,58 \\
\hline 2003 & 8,41 & 6,96 & 8,62 & 7,64 \\
\hline 2002 & 8,46 & 7,06 & 9,19 & 7,72 \\
\hline 2001 & 8,49 & 7,12 & 8,88 & 7,77 \\
\hline 2000 & 8,48 & 7,16 & 9,08 & 7,78 \\
\hline 1999 & 8,58 & 7,26 & 9,11 & 7,89 \\
\hline 1998 & 8,75 & 7,46 & 10,02 & 8,07 \\
\hline 1997 & 9,01 & 7,64 & 8,23 & 8,29 \\
\hline Media & 8,30 & 6,92 & 7,30 & 7,65 \\
\hline$\%$ Diferencia & $-16,20$ & $-16,62$ & $-32,08$ & $-8,93$ \\
\hline $2012-1997$ & & & & \\
\hline
\end{tabular}

Fuente: Conjunto Mínimo Básico de Datos Hospitalización (CMBD-H) del Ministerio del Ministerio de Sanidad, Servicios Sociales e Igualdad.

Por rangos de edades, todas las estancias medias disminuyen. La más significativa la aporta la franja de 15 a 44 años, con una bajada del 23,27\%, seguida de la de 65 a 74, con un $-23,31 \%$. En el primer caso, la estancia ha pasado de ser de 6,06 días a 4,65, mientras que, en el segundo caso, se ha pasado de 10,68 a 8,19. La banda cuya caída a lo largo de los años es menos acusada se corresponde con los menores de un año. De 1997 a 2012, el tiempo medio de ingreso en el hospital ha pasado de 7,68 a 7,25 días, lo que implica un resultado negativo de 5,60\%.

En la actualidad, los que menos tiempo pasan en el hospital son los pacientes de entre 1 y 14 años $(3,88$ días) y los de entre 15 y 44 (4,65). En cambio, los mayores de 74 suelen ocupar su cama unas 8,65 jornadas y los que se encuentran en el rango de edad de 65 a 74, una media de 8,19. 
Tabla 297. Evolución de la estancia media según las edades de los pacientes

\begin{tabular}{|c|c|c|c|c|c|c|c|}
\hline \multirow[b]{2}{*}{ Año } & \multicolumn{7}{|c|}{ Estancia media } \\
\hline & $\begin{array}{c}\text { Menos de } \\
1 \text { año }\end{array}$ & $\begin{array}{l}01-14 \\
\text { años }\end{array}$ & $\begin{array}{l}15-44 \\
\text { años }\end{array}$ & $\begin{array}{l}45-64 \\
\text { años }\end{array}$ & $\begin{array}{c}65-74 \\
\text { años }\end{array}$ & $\begin{array}{l}\text { Más de } \\
74 \text { años }\end{array}$ & Media \\
\hline 2012 & 7,25 & 3,88 & 4,65 & 7,19 & 8,19 & 8,65 & 6,64 \\
\hline 2011 & 7,26 & 3,95 & 4,68 & 7,28 & 8,34 & 8,88 & 6,73 \\
\hline 2010 & 7,23 & 3,98 & 4,77 & 7,56 & 8,66 & 9,23 & 6,90 \\
\hline 2009 & 7,22 & 4,01 & 4,87 & 7,69 & 8,92 & 9,46 & 7,03 \\
\hline 2008 & 7,17 & 4,11 & 4,95 & 7,81 & 9,11 & 9,67 & 7,13 \\
\hline 2007 & 7,23 & 4,13 & 5,06 & 7,93 & 9,21 & 9,77 & 7,22 \\
\hline 2006 & 7,16 & 4,14 & 5,10 & 7,91 & 9,28 & 9,76 & 7,22 \\
\hline 2005 & 7,28 & 4,22 & 5,20 & 8,02 & 9,47 & 9,90 & 7,35 \\
\hline 2004 & 7,27 & 4,24 & 5,27 & 8,03 & 9,51 & 9,94 & 7,38 \\
\hline 2003 & 7,32 & 4,33 & 5,38 & 8,13 & 9,61 & 9,94 & 7,45 \\
\hline 2002 & 7,35 & 4,33 & 5,45 & 8,20 & 9,71 & 10,09 & 7,52 \\
\hline 2001 & 7,18 & 4,27 & 5,59 & 8,28 & 9,80 & 10,16 & 7,55 \\
\hline 2000 & 7,28 & 4,28 & 5,60 & 8,30 & 9,87 & 10,18 & 7,58 \\
\hline 1999 & 7,40 & 4,32 & 5,72 & 8,51 & 9,98 & 10,21 & 7,69 \\
\hline 1998 & 7,48 & 4,38 & 5,92 & 8,71 & 10,27 & 10,50 & 7,88 \\
\hline 1997 & 7,68 & 4,43 & 6,06 & 9,11 & 10,68 & 10,95 & 8,15 \\
\hline Media & 7,30 & 4,19 & 5,27 & 8,04 & 9,41 & 9,83 & 7,34 \\
\hline $\begin{array}{l}\text { \%Diferencia } \\
2012-1997\end{array}$ & $-5,60$ & $-12,42$ & $-23,27$ & $-21,08$ & $-23,31$ & $-21,00$ & $-18,53$ \\
\hline
\end{tabular}

Fuente: Conjunto Mínimo Básico de Datos Hospitalización (CMBD-H) del Ministerio del Ministerio de Sanidad, Servicios Sociales e Igualdad.

Divididos por régimen de financiación, los accidentes de tráfico poseen la estancia más larga. En 2012, por ejemplo, los ingresados permanecieron 11,30 días de media, tres días más que el segundo grupo con una mayor tasa, las mutuas de asistencia sanitaria (8,23 días). Los gestionados por las corporaciones locales y cabildos insulares $(8,02)$ y la asistencia sanitaria pública $(6,96)$ también arrojan cifras altas.

Los únicos grupos que aumentan la estancia media desde 1997 a 2012 y, además, de forma considerable, son las corporaciones locales y cabildos insulares (en un $31,91 \%$ ) y las mutuas de asistencia sanitaria (4,44\%). Se ha de señalar, no obstante, que al contrario de lo que sucede en el resto de agrupaciones, las corporaciones locales o cabildos insulares poseen marcadas diferencias de unos años a otros. En el resto de casos, las estancias medias disminuyen, siendo más acusadas en los catalogados como "otros" y "desconocidos" (con un $-48,95 \%$ y un $-32,68 \%$, respectivamente), la financiación mixta $(-10,13 \%)$ y en la asistencia sanitaria pública $(-15,23 \%)$. 
Tabla 298. Evolución de la estancia media por régimen de financiación

\begin{tabular}{|l|r|r|r|r|r|r|r|r|r|}
\hline \multirow{2}{*}{ Financiación } & & \multicolumn{7}{|c|}{ Estancia media } \\
\cline { 2 - 10 } & $\mathbf{2 0 1 2}$ & $\mathbf{2 0 1 1}$ & $\mathbf{2 0 1 0}$ & $\mathbf{2 0 0 9}$ & $\mathbf{2 0 0 8}$ & $\mathbf{1 9 9 8}$ & $\mathbf{1 9 9 7}$ & Media & $\begin{array}{r}\text { Diferencia } \\
\mathbf{2 0 1 2 - 1 9 9 7}\end{array}$ \\
\hline $\begin{array}{l}\text { Asistencia } \\
\text { Sanitaria Pública }\end{array}$ & 6,96 & 7,04 & 7,18 & 7,3 & 7,37 & 8,01 & 8,21 & 7,57 & $-15,23$ \\
\hline $\begin{array}{l}\text { Corporaciones } \\
\text { locales/Cabildos }\end{array}$ & 8,02 & 7,25 & 7,64 & 6,85 & 8,15 & 5,68 & 6,08 & 8,75 & 31,91 \\
\hline $\begin{array}{l}\text { Mutuas de } \\
\text { Asistencia } \\
\text { Sanitaria }\end{array}$ & 8,23 & 8,83 & 9,26 & 9,06 & 9,26 & 9,87 & 7,88 & 8,44 & 4,44 \\
\hline $\begin{array}{l}\text { Accidentes de } \\
\text { trabajo }\end{array}$ & 4,92 & 5,18 & 8,44 & 9,01 & 9,27 & 9,09 & 8,99 & 9,29 & $-45,27$ \\
\hline $\begin{array}{l}\text { Accidentes de } \\
\text { tráfico }\end{array}$ & 11,30 & 11,08 & 11,26 & 11,76 & 12,29 & 11,67 & 12,1 & 11,87 & $-6,61$ \\
\hline Privado & 6,14 & 6,11 & 6,56 & 5,93 & 6,26 & 6,96 & 7,17 & 6,77 & $-14,37$ \\
\hline $\begin{array}{l}\text { Financiación } \\
\text { mixta }\end{array}$ & 6,83 & 6,27 & 7 & 8,36 & 6,23 & 8,14 & 7,6 & 8,05 & $-10,13$ \\
\hline Otros & 5,83 & 5,88 & 7,04 & 7,9 & 7,33 & 10,1 & 11,42 & 7,9 & $-48,95$ \\
\hline Desconocido & 6,51 & 6,03 & 6,61 & 8,14 & 8,88 & 8,36 & 9,67 & 8,81 & $-32,68$ \\
\hline Media & 7,19 & 7,07 & 7,2 & 7,31 & 7,4 & 8,07 & 8,29 & 7,61 & $-13,23$ \\
\hline
\end{tabular}

Fuente: Conjunto Mínimo Básico de Datos Hospitalización (CMBD-H) del Ministerio del Ministerio de Sanidad, Servicios Sociales e Igualdad.

Los centros que cuentan con unos ingresos más largos son los de más de 1.000 camas. Estos hospitales tratan a sus enfermos, como norma general, durante 7,84 jornadas, por delante de los de 501 a 1.000, que los tratan 7,29 días. El resto de clínicas dejan a sus clientes menos tiempo: las de 200 a 500 camas, 6,41 y los que tienen menos de 200 , una media de 6,18 .

En todos los hospitales, independientemente de su tamaño, disminuyen los días de estancia media. Así, por ejemplo, donde más se reduce es en los de 501 a 1.000 camas y en los de más de 1.000 camas. En el primer caso, los días se recortan en un 17,72\% y en el segundo, en un 19,75\%. En el lado contrario, es decir, donde la bajada ha sido menos acusada es en los centros de menos de 200 camas. En este caso, la media se ha mermado un 12,22\%, pasando de 7,04 días de media en 1997 a 6,18 en 2012. 
Tabla 299. Evolución de la estancia media según el tamaño de los hospitales

\begin{tabular}{|c|c|c|c|c|c|c|}
\hline \multirow[b]{2}{*}{ Año } & \multicolumn{6}{|c|}{ Estancia media } \\
\hline & $\begin{array}{l}\text { Menos de } \\
200 \text { camas }\end{array}$ & $\begin{array}{c}200-500 \\
\text { camas }\end{array}$ & $\begin{array}{c}501-1000 \\
\text { camas }\end{array}$ & $\begin{array}{c}\text { Más de } \\
1000 \\
\text { camas }\end{array}$ & Otros & Media \\
\hline 2012 & 6,18 & 6,41 & 7,29 & 7,84 & 1 & 5,74 \\
\hline 2011 & 6,14 & 6,46 & 7,34 & 8,08 & - & 7,00 \\
\hline 2010 & 6,27 & 6,62 & 7,52 & 8,29 & - & 7,20 \\
\hline 2009 & 6,32 & 6,73 & 7,66 & 8,51 & - & 7,31 \\
\hline 2008 & 6,28 & 6,83 & 7,73 & 8,59 & 5,16 & 7,40 \\
\hline 2007 & 6,54 & 6,85 & 7,83 & 8,59 & - & 7,48 \\
\hline 2006 & 6,36 & 6,81 & 7,88 & 8,50 & - & 7,45 \\
\hline 2005 & 6,55 & 6,85 & 8,05 & 8,65 & - & 7,59 \\
\hline 2004 & 6,27 & 6,88 & 8,10 & 8,76 & 9,56 & 7,58 \\
\hline 2003 & 6,26 & 6,88 & 8,15 & 8,94 & - & 7,64 \\
\hline 2002 & 6,49 & 6,89 & 8,16 & 9,09 & - & 7,72 \\
\hline 2001 & 6,73 & 6,93 & 8,21 & 9,28 & - & 7,77 \\
\hline 2000 & 6,92 & 7,00 & 8,16 & 9,27 & - & 7,78 \\
\hline 1999 & 6,79 & 7,04 & 8,29 & 9,28 & 36,67 & 7,89 \\
\hline 1998 & 7,09 & 7,35 & 8,51 & 9,47 & - & 8,07 \\
\hline 1997 & 7,04 & 7,57 & 8,86 & 9,77 & 8,02 & 8,29 \\
\hline Media & $-12,22$ & $-15,32$ & $-17,72$ & $-19,75$ & $-87,53$ & $-30,76$ \\
\hline $\begin{array}{l}\text { \%Diferencia } \\
\text { 2012-1997 }\end{array}$ & $-12,22$ & $-15,32$ & $-17,72$ & $-19,75$ & $-87,53$ & $-30,76$ \\
\hline
\end{tabular}

Fuente: Conjunto Mínimo Básico de Datos Hospitalización (CMBD-H) del Ministerio del Ministerio de Sanidad, Servicios Sociales e Igualdad.

Las estancias que provienen de ingresos urgentes suelen ser más largas que las admisiones programadas. Mientras que en 2012 las del primer tipo suponen una estancia media de 7,62 días, las del segundo se quedaron en 5,43. Si se compara la evolución de ambas clases desde 1997 hasta la fecha, no existen diferencias muy acusadas. Las urgentes bajan un 15,99\%, pasando así de 9,07 a 7,62, mientras que en el caso de las programadas se reducen de 6,71 a 5,43, es decir, una bajada del 19,08\%. 
Tabla 300. Evolución de la estancia media por tipo de ingreso

\begin{tabular}{|l|r|r|r|}
\hline \multirow{2}{*}{ Año } & \multicolumn{3}{|c|}{ Tipo de ingreso } \\
\cline { 2 - 4 } & Urgente & Programado & \multicolumn{1}{c|}{ Otros } \\
\hline 2012 & 7,62 & 5,43 & 4,94 \\
\hline 2011 & 7,72 & 5,45 & 4,34 \\
\hline 2010 & 7,91 & 5,66 & 3,58 \\
\hline 2009 & 8,02 & 5,75 & 3,85 \\
\hline 2008 & 8,11 & 5,82 & 3,45 \\
\hline 2007 & 8,22 & 5,88 & 3,11 \\
\hline 2006 & 8,19 & 5,85 & 2,73 \\
\hline 2005 & 8,33 & 5,95 & 2,77 \\
\hline 2004 & 8,33 & 5,94 & 4,80 \\
\hline 2003 & 8,39 & 6,02 & 4,79 \\
\hline 2002 & 8,46 & 6,14 & 5,07 \\
\hline 2001 & 8,53 & 6,19 & 5,24 \\
\hline 2000 & 8,51 & 6,31 & 7,20 \\
\hline 1999 & 8,62 & 6,41 & 6,71 \\
\hline 1998 & 8,90 & 6,52 & 8,04 \\
\hline 1997 & 9,07 & 6,71 & 10,69 \\
\hline$\%$ Diferencia & $-15,99$ & $-19,08$ & $-53,79$ \\
\hline $2011-1997$ & & & \\
\hline
\end{tabular}

Fuente: Conjunto Mínimo Básico de Datos Hospitalización (CMBD-H) del Ministerio del Ministerio de Sanidad, Servicios Sociales e Igualdad.

\section{Opinión de la población en torno a la sanidad}

El interés de los habitantes españoles por la sanidad ha ido descendiendo y ascendiendo con el paso de los años, aunque, en la actualidad, el interés es más bajo respecto a hace casi dos décadas. Por ejemplo, en 1995, el 36,11\% de los encuestados por el barómetro sanitario (Instituto de Información Sanitaria, 2011) opinaba que la sanidad era el tema más importante de los ciudadanos, frente al 26,48\% registrado en 2012. Ceuta (-53,62\%), Extremadura (-47,24\%), Melilla (-41,31\%) y Cataluña ($38,99 \%$ ) es donde, con diferencia, más baja el afán por este tema. En cambio, en otras regiones aumenta de forma considerable, como, por ejemplo, La Rioja (121,50\%). También se incrementa, aunque con porcentajes mucho más bajos, en Navarra (19,25\%) y en País Vasco (4,19\%). 
Tabla 301. Evolución de la proporción de personas que consideran que la sanidad es el área de mayor interés para los ciudadanos

\begin{tabular}{|l|r|r|r|r|r|r|r|r|r|r|}
\hline \multirow{2}{*}{$\begin{array}{l}\text { Comunidad } \\
\text { autónoma }\end{array}$} & \multicolumn{6}{|c|}{ Proporción de personas que consideran que la sanidad es el área de } \\
\cline { 2 - 12 } & $\mathbf{2 0 1 3}$ & $\mathbf{2 0 1 2}$ & $\mathbf{2 0 1 1}$ & $\mathbf{2 0 1 0}$ & $\mathbf{2 0 0 9}$ & $\mathbf{2 0 0 8}$ & $\mathbf{1 9 9 8}$ & $\mathbf{1 9 9 7}$ & $\mathbf{1 9 9 5}$ & $\begin{array}{c}\text { \%Diferencia } \\
\mathbf{2 0 1 2 - 1 9 9 5}\end{array}$ \\
\hline Andalucía & 23,24 & 17,28 & 33,97 & 27,24 & 28,1 & 27,23 & 35,85 & 32,38 & 33,84 & $-31,32$ \\
\hline Aragón & 27,35 & 27,52 & 36,3 & 34,21 & 28,6 & 39,88 & 37,36 & 29,47 & 35,79 & $-23,58$ \\
\hline Asturias & 21,60 & 16,40 & 23,78 & 25,77 & 19,6 & 24,67 & 13,18 & 15,02 & 32,25 & $-33,02$ \\
\hline Baleares & 24,29 & 23,85 & 25,33 & 23,74 & 24,4 & 15,44 & 31,08 & 26,96 & 36,44 & $-33,34$ \\
\hline Canarias & 28,61 & 28,89 & 38,7 & 33,86 & 33,6 & 31,39 & 33,55 & 24,12 & 38,26 & $-25,22$ \\
\hline Cantabria & 26,73 & 35,07 & 36,46 & 36,58 & 34,4 & 27,99 & 29,95 & 21,26 & 35 & $-23,63$ \\
\hline $\begin{array}{l}\text { Castilla } \\
\text { León }\end{array}$ & 24,28 & 37,28 & 32,36 & 33,22 & 33,8 & 36,17 & 41,45 & 33,79 & 36,26 & $-33,04$ \\
\hline $\begin{array}{l}\text { Castilla-La } \\
\text { Mancha }\end{array}$ & 30,31 & 28,36 & 41,67 & 42 & 30,5 & 27,52 & 41,4 & 42,17 & 38,86 & $-22,00$ \\
\hline Cataluña & 21,67 & 22,34 & 27,99 & 20,67 & 21,9 & 19,21 & 31,14 & 27,98 & 35,52 & $-38,99$ \\
\hline $\begin{array}{l}\text { Comunidad } \\
\text { Valenciana }\end{array}$ & 25,22 & 26,12 & 31,62 & 27,83 & 27,7 & 27,74 & 31,82 & 37,5 & 32,74 & $-22,97$ \\
\hline Extremadura & 26,18 & 34,58 & 46,11 & 38,27 & 39,5 & 44,7 & 39 & 32,45 & 49,62 & $-47,24$ \\
\hline Galicia & 38,13 & 35,83 & 37,19 & 40,45 & 42,3 & 34,19 & 41,67 & 36,3 & 40,13 & $-4,98$ \\
\hline Madrid & 27,12 & 22,68 & 31,35 & 25,11 & 24,6 & 24,9 & 32,72 & 29,64 & 41,07 & $-33,97$ \\
\hline Murcia & 30,84 & 25,45 & 37,43 & 29,34 & 37,1 & 35,44 & 32,24 & 30,38 & 43,63 & $-29,31$ \\
\hline Navarra & 36,12 & 32,19 & 38,77 & 36,32 & 41,7 & 38,46 & 29,61 & 34,3 & 30,29 & 19,25 \\
\hline País Vasco & 31,56 & 28,79 & 37,22 & 36 & 33,8 & 32,24 & 36,49 & 40,26 & 30,29 & 4,19 \\
\hline La Rioja & 44,30 & 34,90 & 46,04 & 35,96 & 37,3 & 35,28 & 34,74 & 36,41 & 20 & 121,50 \\
\hline Ceuta & 12,94 & 23,67 & 30,59 & 26,69 & 24,7 & 27,9 & -- & -- & -- & $-53,62 \underline{y}$ \\
\hline Melilla & 16,08 & 23,05 & 24,71 & 30,59 & 23,5 & 27,4 & -- & -- & -- & $-41,3140$ \\
\hline $\begin{array}{l}\text { Total } \\
\text { nacional }\end{array}$ & 26,48 & 25,17 & 33,38 & 29,22 & 29 & 28,06 & 34,15 & 31,75 & 36,11 & $-26,67$ \\
\hline
\end{tabular}

Fuente: Barómetro sanitario del Ministerio de Sanidad, Servicios Sociales e Igualdad.

\footnotetext{
${ }^{39}$ Porcentaje calculado tomando como referencia el año 2008 en vez de 1995.

40 Porcentaje calculado tomando como referencia el año 2008 en vez de 1995.
} 
La mayor parte de los ciudadanos cree que el sistema sanitario funciona bien, pero que se deberían hacer algunos cambios. Así responde, al menos, el 45,81\% de los encuestados del barómetro sanitario de 2013. El 20,06\%, por el contrario, opina que el sistema marcha bastante bien y el $26,54 \%$ considera que necesitan cambios fundamentales aunque algunas cosas funcionan. Únicamente el 6,07\% opina en 2013 que el sistema va tan mal que habría que rehacerlo en su totalidad. Se trata de un porcentaje mucho más bajo del que arroja el año 1995, cuando el 9,57\% de las personas pensaba que el sistema sanitario debería rehacerse por completo. De hecho, las dos frases con connotaciones más positivas (funciona bastante bien y funciona bien pero se deberían hacer algunos cambios) han ido incrementándose, salvo pequeñas excepciones, desde 1995. En cambio, las ideas negativas (se necesitan cambios fundamentales y se debería rehacer en su totalidad), a pesar de que desde 1995 hasta 2010 sufren una disminución en el apoyo, vuelven a popularizarse a partir de esta segunda fecha.

En la actualidad, las comunidades donde más satisfechos se encuentran los ciudadanos con el sistema sanitario - a la vista del número de respuestas dadas a la idea de que funciona bastante bien- son Asturias y Navarra, con un 45,37\% y un 40,24\%. En cambio, en Castilla y León e Islas Baleares es donde menos complacidos están con la sanidad, dado que el 13,58\% y el 10,90\% de su población, respectivamente, consideran que debería sufrir una remodelación profunda. 
Tabla 302. Evolución de la proporción de ciudadanos por comunidades autónomas que creen que el sistema sanitario funciona bastante bien

\begin{tabular}{|c|c|c|c|c|c|c|c|c|c|c|}
\hline \multirow{2}{*}{$\begin{array}{l}\text { Comunidad } \\
\text { autónoma }\end{array}$} & \multicolumn{10}{|c|}{$\begin{array}{l}\text { Proporción de ciudadanos que creen que el sistema sanitario } \\
\text { funciona bastante bien }\end{array}$} \\
\hline & 2013 & 2012 & 2011 & 2010 & 2009 & 2008 & 1998 & 1997 & 1995 & $\begin{array}{l}\text { \%Diferencia } \\
\text { 2013-1995 }\end{array}$ \\
\hline Andalucía & 18,52 & 19,63 & 20,08 & 22,44 & 15,7 & 15,71 & 13 & 19,45 & 17,44 & 6,19 \\
\hline Aragón & 32,76 & 32,56 & 25,96 & 6,31 & 25,7 & 24,35 & 26,16 & 25,61 & 24,21 & 35,32 \\
\hline Asturias & 45,37 & 52,63 & 50 & 54,29 & 50,2 & 48,04 & 55,39 & 52,19 & 21,01 & 115,94 \\
\hline Baleares & 18,06 & 24,23 & 29,08 & 26,59 & 27,3 & 25,6 & 21,93 & 16,09 & 15,56 & 16,07 \\
\hline Canarias & 8,14 & 11,73 & 10,64 & 11,55 & 8,9 & 10,35 & 9,06 & 9,32 & 15,11 & $-46,13$ \\
\hline Cantabria & 28,13 & 34,02 & 30,56 & 35,58 & 23,7 & 18,38 & 34,18 & 37,02 & 17,91 & 57,06 \\
\hline $\begin{array}{l}\text { Castilla y } \\
\text { León }\end{array}$ & 20,63 & 26,48 & 25,01 & 23,9 & 18,4 & 21,88 & 13,86 & 21,38 & 25,17 & $-18,04$ \\
\hline $\begin{array}{l}\text { Castilla-La } \\
\text { Mancha }\end{array}$ & 18,25 & 25,22 & 24,22 & 29,4 & 23,2 & 16,3 & 21,67 & 23,19 & 19,34 & $-5,64$ \\
\hline Cataluña & 15,81 & 20,85 & 24,19 & 20,4 & 19,4 & 16,86 & 20 & 16,06 & 24,39 & $-35,18$ \\
\hline $\begin{array}{l}\text { Comunidad } \\
\text { Valenciana }\end{array}$ & 16,76 & 18,89 & 23,02 & 20,21 & 20,5 & 18,83 & 23,47 & 18,75 & 22,54 & $-25,64$ \\
\hline Extremadura & 15,57 & 20,56 & 21,5 & 21,3 & 18,5 & 17,26 & 25,38 & 19,62 & 21,46 & $-27,45$ \\
\hline Galicia & 24,19 & 29,70 & 23,36 & 19,77 & 25,2 & 17,92 & 18,48 & 19,31 & 15,84 & 52,71 \\
\hline Madrid & 22,49 & 21,27 & 25,44 & 24,67 & 22,6 & 18,06 & 12,46 & 10,95 & 11,9 & 88,99 \\
\hline Murcia & 16,20 & 20,09 & 26,9 & 26,98 & 22,8 & 13,83 & 30,12 & 26,54 & 12,74 & 27,16 \\
\hline Navarra & 40,24 & 41,61 & 43,94 & 45,33 & 44,5 & 39,43 & 34,8 & 44,93 & 45,67 & $-11,89$ \\
\hline País Vasco & 24,24 & 22,98 & 26,83 & 28,98 & 24,1 & 29,5 & 31,83 & 29,02 & 27,35 & $-11,37$ \\
\hline La Rioja & 24,73 & 29,43 & 33,11 & 31,73 & 23,9 & 20,75 & 25,89 & 30,77 & 32,16 & $-23,10$ \\
\hline Ceuta & 19,61 & 15,03 & 15,69 & 19,24 & 18,4 & 14,9 & -- & -- & -- & $31,61^{41}$ \\
\hline Melilla & 25,10 & 25,04 & 17,25 & 15,29 & 22,6 & 17,9 & -- & -- & -- & $40,22^{42}$ \\
\hline $\begin{array}{l}\text { Total } \\
\text { nacional }\end{array}$ & 20,06 & 22,92 & 24,24 & 23,86 & 21,2 & 19,22 & 21,77 & 21,26 & 20,71 & $-3,14$ \\
\hline
\end{tabular}

Fuente: Barómetro sanitario del Ministerio de Sanidad, Servicios Sociales e Igualdad.

\footnotetext{
41 Porcentaje calculado tomando como referencia el año 2008 en vez de 1995.

$\underline{42}$ Porcentaje calculado tomando como referencia el año 2008 en vez de 1995.
} 
Tabla 303. Evolución de la proporción de ciudadanos por comunidades autónomas que creen que el sistema sanitario funciona bien, pero sostienen que se deberían hacer algunos cambios

\begin{tabular}{|l|r|r|r|r|r|r|r|r|r|r|}
\hline \multirow{2}{*}{$\begin{array}{l}\text { Comunidad } \\
\text { autónoma }\end{array}$} & \multicolumn{7}{|c|}{$\begin{array}{c}\text { Proporción de ciudadanos que creen que el sistema sanitario } \\
\text { funciona bien, pero consideran que habría que hacer algunos }\end{array}$} \\
\cline { 2 - 13 } & $\mathbf{2 0 1 3}$ & $\mathbf{2 0 1 2}$ & $\mathbf{2 0 1 1}$ & $\mathbf{2 0 1 0}$ & $\mathbf{2 0 0 9}$ & $\mathbf{2 0 0 8}$ & $\mathbf{1 9 9 8}$ & $\mathbf{1 9 9 7}$ & $\mathbf{1 9 9 5}$ & $\begin{array}{c}\text { \%Diferencia } \\
\mathbf{2 0 1 3 - 1 9 9 5}\end{array}$ \\
\hline Andalucía & 49,04 & 52,98 & 53,28 & 49,03 & 54 & 55,77 & 45,08 & 36,02 & 38,26 & 28,18 \\
\hline Aragón & 41,12 & 48,81 & 53,98 & 54,08 & 53,4 & 48,76 & 45,52 & 40,7 & 41,05 & 0,17 \\
\hline Asturias & 38,57 & 35,61 & 39,51 & 29,14 & 34,2 & 35,04 & 33,46 & 31,02 & 42,39 & $-9,01$ \\
\hline Baleares & 39,88 & 41,64 & 50,92 & 52,22 & 48,6 & 53,68 & 34,65 & 37,39 & 36,44 & 9,44 \\
\hline Canarias & 35,95 & 41,12 & 44,15 & 43,31 & 38 & 34,29 & 41,75 & 36,98 & 35,37 & 1,64 \\
\hline Cantabria & 42,70 & 41,32 & 41,66 & 39,97 & 42,3 & 48,31 & 36,22 & 30,77 & 46,27 & $-7,72$ \\
\hline $\begin{array}{l}\text { Castilla } \\
\text { León }\end{array}$ & 38,91 & 43,32 & 50,24 & 55,37 & 54,9 & 52,43 & 46,88 & 45,98 & 41,11 & $-5,35$ \\
\hline $\begin{array}{l}\text { Castilla-La } \\
\text { Mancha }\end{array}$ & 46,90 & 47,83 & 50,26 & 46,19 & 47,1 & 52,84 & 41,8 & 38,55 & 45,92 & 2,13 \\
\hline Cataluña & 45,36 & 41,96 & 44,08 & 51,35 & 43,7 & 44,96 & 41,1 & 46,35 & 48,3 & $-6,09$ \\
\hline $\begin{array}{l}\text { Comunidad } \\
\text { Valenciana }\end{array}$ & 45,25 & 48,12 & 49,83 & 52,16 & 51,3 & 47,59 & 42,6 & 42,14 & 39,18 & 15,49 \\
\hline Extremadura & 44,55 & 46,41 & 47,35 & 50,29 & 45,1 & 42,35 & 40,53 & 40 & 46,74 & $-4,69$ \\
\hline Galicia & 53,21 & 52,84 & 55,1 & 57,73 & 49,3 & 53,69 & 50,43 & 46,42 & 35,36 & 50,48 \\
\hline Madrid & 43,87 & 48,86 & 46,16 & 47,94 & 44,7 & 48,29 & 42,94 & 39,12 & 35,99 & 21,89 \\
\hline Murcia & 51,42 & 49,42 & 47,37 & 50,11 & 46,5 & 46,31 & 44,4 & 38,08 & 41,7 & 23,31 \\
\hline Navarra & 40,28 & 42,51 & 42,88 & 42,55 & 37,9 & 42,8 & 47,55 & 37,2 & 32,69 & 23,22 \\
\hline País Vasco & 56,07 & 59,85 & 54,18 & 55,4 & 53,6 & 50,27 & 49,07 & 51,3 & 44,5 & 26,00 \\
\hline La Rioja & 48,48 & 48,43 & 50,94 & 49,9 & 52,5 & 52,98 & 48,22 & 43,59 & 36,18 & 34,00 \\
\hline Ceuta & 43,92 & 46,63 & 42,75 & 45,47 & 38,4 & 39,3 & -- & -- & -- & 11,763 \\
\hline Melilla & 41,57 & 46,12 & 47,45 & 50,98 & 37,6 & 45,8 & -- & -- & -- & $-9,244$ \\
\hline $\begin{array}{l}\text { Total } \\
\text { nacional }\end{array}$ & 45,81 & 47,73 & 48,88 & 50,02 & 48 & 48,86 & 43,47 & 41,1 & 40,57 & 12,92 \\
\hline
\end{tabular}

Fuente: Barómetro sanitario del Ministerio de Sanidad, Servicios Sociales e Igualdad.

\footnotetext{
$\underline{43}$ Porcentaje calculado tomando como referencia el año 2008 en vez de 1995.

$\underline{44}$ Porcentaje calculado tomando como referencia el año 2008 en vez de 1995.
} 
Tabla 304. Evolución de la proporción de ciudadanos por comunidades autónomas que creen que el sistema sanitario necesita cambios fundamentales aunque algunas cosas funcionan

\begin{tabular}{|l|r|r|r|r|r|r|r|r|r|r|}
\hline \multirow{2}{*}{$\begin{array}{l}\text { Comunidad } \\
\text { autónoma }\end{array}$} & \multicolumn{3}{|c|}{$\begin{array}{r}\text { Proporción de ciudadanos que creen que el sistema sanitario necesita } \\
\text { cambios fundamentales aunque algunas cosas funcionan }\end{array}$} \\
\cline { 2 - 13 } & $\mathbf{2 0 1 3}$ & $\mathbf{2 0 1 2}$ & $\mathbf{2 0 1 1}$ & $\mathbf{2 0 1 0}$ & $\mathbf{2 0 0 9}$ & $\mathbf{2 0 0 8}$ & $\mathbf{1 9 9 8}$ & $\mathbf{1 9 9 7}$ & $\mathbf{1 9 9 5}$ & $\begin{array}{c}\text { \%Diferencia } \\
\mathbf{2 0 1 3 - 1 9 9 5}\end{array}$ \\
\hline Andalucía & 25,93 & 21,20 & 22,39 & 22,69 & 25,3 & 24,47 & 32,32 & 34,06 & 30,58 & $-15,21$ \\
\hline Aragón & 21,37 & 16,27 & 15,63 & 16,98 & 17,7 & 23,28 & 22,22 & 24,56 & 28,77 & $-25,72$ \\
\hline Asturias & 12,66 & 10,21 & 9,88 & 15,03 & 13,1 & 12,85 & 10,78 & 12,04 & 31,16 & $-59,37$ \\
\hline Baleares & 29,29 & 27,41 & 16,25 & 18,97 & 20,6 & 16,7 & 34,21 & 37,39 & 33,78 & $-13,29$ \\
\hline Canarias & 46,72 & 36,73 & 34,8 & 34,38 & 41,1 & 42,71 & 36,25 & 36,66 & 38,91 & 20,07 \\
\hline Cantabria & 23,27 & 19,46 & 23,26 & 20,28 & 24,2 & 24,13 & 23,98 & 23,56 & 23,88 & $-2,55$ \\
\hline $\begin{array}{l}\text { Castilla } \\
\text { León }\end{array}$ & 23,75 & 22,84 & 21,65 & 17,44 & 23,9 & 20,09 & 31,64 & 24,14 & 25,4 & $-6,50$ \\
\hline $\begin{array}{l}\text { Castilla-La } \\
\text { Mancha }\end{array}$ & 29,87 & 22,19 & 21,61 & 21 & 22,1 & 26,32 & 28,48 & 24,7 & 21,75 & 37,33 \\
\hline Cataluña & 32,97 & 29,43 & 25,54 & 23,85 & 28,5 & 31,98 & 31,78 & 30,41 & 21,97 & 50,07 \\
\hline $\begin{array}{l}\text { Comunidad } \\
\text { Valenciana }\end{array}$ & 28,84 & 26,80 & 21,3 & 22,8 & 24,6 & 28,42 & 28,52 & 31,61 & 29,87 & $-3,45$ \\
\hline Extremadura & 31,78 & 28,35 & 25,85 & 22,55 & 32,7 & 35,28 & 28,79 & 32,83 & 24,52 & 29,61 \\
\hline Galicia & 18,72 & 15,87 & 17,69 & 20,68 & 19,4 & 23,73 & 23,26 & 25,81 & 29,07 & $-35,60$ \\
\hline Madrid & 23,06 & 24,55 & 21,99 & 21,73 & 28,1 & 26,2 & 34,83 & 36,5 & 37,3 & $-38,18$ \\
\hline Murcia & 24,73 & 24,58 & 22,81 & 20,27 & 26,3 & 26,84 & 22,78 & 24,62 & 31,66 & $-21,89$ \\
\hline Navarra & 12,15 & 13,07 & 10,77 & 10,74 & 14,4 & 15,84 & 15,2 & 13,04 & 17,31 & $-29,81$ \\
\hline País Vasco & 14,65 & 14,48 & 17,22 & 13,6 & 19 & 16,66 & 15,38 & 15,8 & 20,91 & $-29,94$ \\
\hline La Rioja & 22,30 & 17,54 & 11,8 & 16,39 & 20 & 23,71 & 20,81 & 20,51 & 24,12 & $-7,55$ \\
\hline Ceuta & 29,41 & 30,03 & 30,2 & 27,08 & 37,3 & 34,4 & --- & -- & -- & $-14,5145$ \\
\hline Melilla & 27,45 & 19,14 & 29,02 & 18,63 & 35,1 & 30,8 & -- & -- & -- & $-10,8846$ \\
\hline $\begin{array}{l}\text { Total } \\
\text { nacional }\end{array}$ & 26,54 & 23,60 & 21,91 & 21,6 & 25,3 & 26,17 & 27,73 & 28,39 & 28,18 & $-5,82$ \\
\hline
\end{tabular}

Fuente: Barómetro sanitario del Ministerio de Sanidad, Servicios Sociales e Igualdad.

\footnotetext{
${ }^{45}$ Porcentaje calculado tomando como referencia el año 2008 en vez de 1995.

$\underline{46}$ Porcentaje calculado tomando como referencia el año 2008 en vez de 1995 .
} 
Tabla 305. Evolución de la proporción de ciudadanos por comunidades autónomas que creen que el sistema sanitario funciona tan mal que habría que rehacerlo en su totalidad

\begin{tabular}{|l|r|r|r|r|r|r|r|r|r|r|}
\hline \multirow{2}{*}{$\begin{array}{c}\text { Comunidad } \\
\text { autónoma }\end{array}$} & \multicolumn{6}{|c|}{$\begin{array}{c}\text { Proporción de ciudadanos que creen que el sistema sanitario } \\
\text { funciona tan mal que habría que rehacerlo en su totalidad }\end{array}$} \\
\cline { 2 - 12 } & $\mathbf{2 0 1 3}$ & $\mathbf{2 0 1 2}$ & $\mathbf{2 0 1 1}$ & $\mathbf{2 0 1 0}$ & $\mathbf{2 0 0 9}$ & $\mathbf{2 0 0 8}$ & $\mathbf{1 9 9 8}$ & $\mathbf{1 9 9 7}$ & $\mathbf{1 9 9 5}$ & $\begin{array}{c}\text { \%Diferencia } \\
\mathbf{2 0 1 3 - 1 9 9 5}\end{array}$ \\
\hline Andalucía & 5,11 & 4,90 & 3,61 & 3,76 & 4,3 & 3,57 & 9,6 & 8,98 & 12,67 & $-59,67$ \\
\hline Aragón & 2,67 & 2,07 & 2,36 & 2,34 & 3,2 & 2,87 & 6,09 & 7,02 & 5,61 & $-52,41$ \\
\hline Asturias & 2,78 & 1,55 & 0,62 & 1,23 & 2,4 & 4,04 & 0,37 & 3,65 & 5,43 & $-48,80$ \\
\hline Baleares & 10,90 & 5,75 & 2,19 & 2,21 & 3,2 & 3,1 & 9,21 & 5,65 & 14,22 & $-23,35$ \\
\hline Canarias & 8,93 & 9,89 & 9,62 & 9,97 & 11,7 & 12,62 & 12,94 & 15,76 & 10,29 & $-13,22$ \\
\hline Cantabria & 4,86 & 3,13 & 3,47 & 3,48 & 6,6 & 6,74 & 5,61 & 6,25 & 10,45 & $-53,49$ \\
\hline $\begin{array}{l}\text { Castilla } \\
\text { León }\end{array}$ & 13,58 & 5,77 & 2,62 & 2,81 & 2,4 & 3,95 & 7,62 & 7,36 & 6,93 & 95,96 \\
\hline $\begin{array}{l}\text { Castilla-La } \\
\text { Mancha }\end{array}$ & 3,79 & 4,29 & 3,91 & 2,89 & 7,4 & 3,91 & 8,05 & 11,45 & 10,88 & $-65,17$ \\
\hline Cataluña & 5,58 & 7,49 & 5,98 & 3,99 & 7,3 & 5,69 & 7,12 & 7,06 & 4,85 & 15,05 \\
\hline $\begin{array}{l}\text { Comunidad } \\
\text { Valenciana }\end{array}$ & 8,12 & 5,50 & 5,84 & 3,97 & 3,1 & 4,62 & 5,42 & 4,11 & 7,87 & 3,18 \\
\hline Extremadura & 7,79 & 4,67 & 4,67 & 5,87 & 3,4 & 4,31 & 5,3 & 7,17 & 7,28 & 7,01 \\
\hline Galicia & 3,42 & 1,36 & 2,72 & 1,36 & 5,6 & 4,18 & 7,83 & 7,16 & 18 & $-81,00$ \\
\hline Madrid & 7,18 & 4,63 & 4,68 & 3,52 & 3,3 & 5,68 & 9,76 & 11,53 & 13,5 & $-46,81$ \\
\hline Murcia & 5,29 & 4,13 & 1,46 & 1,76 & 3,8 & 11,51 & 2,7 & 7,69 & 13,13 & $-59,71$ \\
\hline Navarra & 4,53 & 2,45 & 1,72 & 0,69 & 1,8 & 1,91 & 2,45 & 4,35 & 2,88 & 57,29 \\
\hline País Vasco & 1,77 & 1,51 & 0,51 & 1,51 & 2,3 & 1,36 & 3,71 & 3,63 & 5,9 & $-70,00$ \\
\hline La Rioja & 4,87 & 4,61 & 3,02 & 1,58 & 2,8 & 2,03 & 5,08 & 4,62 & 7,54 & $-35,41$ \\
\hline Ceuta & 5,49 & 7,52 & 10,59 & 7,81 & 5,9 & 8 & -- & -- & -- & $-31,38-47$ \\
\hline Melilla & 5,88 & 6,07 & 5,49 & 4,71 & 4,3 & 5,5 & -- & -- & -- & 6,914 \\
\hline $\begin{array}{l}\text { Total } \\
\text { nacional }\end{array}$ & 6,07 & 4,96 & 4,2 & 3,51 & 4,7 & 4,87 & 7,03 & 7,67 & 9,57 & $-36,57$ \\
\hline
\end{tabular}

Fuente: Barómetro sanitario del Ministerio de Sanidad, Servicios Sociales e Igualdad.

\footnotetext{
${ }^{47}$ Porcentaje calculado tomando como referencia el año 2008 en vez de 1995.

${ }^{48}$ Porcentaje calculado tomando como referencia el año 2008 en vez de 1995.
} 
De hecho, estas regiones se encuentran en los extremos en el grado de satisfacción con el sistema sanitario español, según el caso. Aragón y Navarra, por ejemplo, son los territorios cuyos habitantes otorgan mayor nota a su grado de satisfacción con la sanidad. Sobre una escala de 1 a 10, estas comunidades obtienen un 7,29 y 7,27, en este orden. En cambio, Islas Canarias y Extremadura reciben un 5,7 y un 6,03, respectivamente. La media nacional, no obstante, se sitúa en 6,41.

Tabla 306. Evolución de la satisfacción que tienen los ciudadanos con el funcionamiento del sistema sanitario público

\begin{tabular}{|c|c|c|c|c|c|c|c|c|c|c|}
\hline \multirow{2}{*}{$\begin{array}{c}\text { Comunidad } \\
\text { autónoma }\end{array}$} & \multicolumn{10}{|c|}{$\begin{array}{c}\text { Calificación en una escala de } 1 \text { a } 10 \text {, en la que } 1 \text { significa que se está } \\
\text { muy insatisfecho y } 10 \text { que se está muy satisfecho }\end{array}$} \\
\hline & 2013 & 2012 & 2011 & 2010 & 2009 & 2008 & 2004 & 2003 & 2002 & $\begin{array}{l}\text { \%Diferencia } \\
\text { 2013-2002 }\end{array}$ \\
\hline Andalucía & 6,62 & 6,68 & 6,55 & 6,35 & 6,29 & 6,29 & 5,98 & 5,8 & 5,52 & 19,93 \\
\hline Aragón & 7,29 & 7,38 & 6,95 & 7,2 & 6,8 & 6,68 & 6,23 & 6,5 & 6,4 & 13,91 \\
\hline Asturias & 6,98 & 7,27 & 7,42 & 7,71 & 7,21 & 7,08 & 7,4 & 7,1 & 7,28 & $-4,12$ \\
\hline Baleares & 6,11 & 6,65 & 6,81 & 6,75 & 6,6 & 6,47 & 6,05 & 5,79 & 5,98 & 2,17 \\
\hline Canarias & 5,70 & 5,85 & 5,96 & 6,04 & 5,4 & 5,44 & 5,6 & 5,34 & 5,45 & 4,59 \\
\hline Cantabria & 6,75 & 6,85 & 6,55 & 6,7 & 6,28 & 6,25 & 6,3 & 5,91 & 6,2 & 8,87 \\
\hline $\begin{array}{l}\text { Castilla } \quad y \\
\text { León }\end{array}$ & 6,15 & 6,80 & 7,06 & 7,01 & 6,82 & 6,8 & 6,15 & 6,37 & 6,13 & 0,33 \\
\hline $\begin{array}{l}\text { Castilla-La } \\
\text { Mancha }\end{array}$ & 6,48 & 6,82 & 6,65 & 6,82 & 6,79 & 6,21 & 6,62 & 6,21 & 6,14 & 5,54 \\
\hline Cataluña & 6,22 & 6,27 & 6,46 & 6,49 & 6,02 & 6,19 & 6,09 & 5,8 & 5,93 & 4,89 \\
\hline $\begin{array}{l}\text { Comunidad } \\
\text { Valenciana }\end{array}$ & 6,24 & 6,40 & 6,54 & 6,43 & 6,45 & 6,21 & 6,06 & 6,27 & 6,15 & 1,46 \\
\hline Extremadura & 6,03 & 6,29 & 6,36 & 6,46 & 6,29 & 6,17 & 6,16 & 5,89 & 5,68 & 6,16 \\
\hline Galicia & 6,07 & 6,47 & 6,26 & 6,1 & 5,91 & 5,87 & 5,41 & 5,62 & 5,4 & 12,41 \\
\hline Madrid & 6,45 & 6,47 & 6,63 & 6,64 & 6,42 & 6,22 & 5,92 & 5,8 & 5,79 & 11,40 \\
\hline Murcia & 6,63 & 6,79 & 6,56 & 6,46 & 6,21 & 6,12 & 6,31 & 6,34 & 5,74 & 15,51 \\
\hline Navarra & 7,27 & 7,25 & 7,23 & 7,06 & 7,19 & 7 & 7,2 & 7,18 & 6,97 & 4,30 \\
\hline País Vasco & 6,84 & 6,97 & 6,68 & 6,96 & 6,74 & 6,72 & 6,8 & 7,15 & 6,81 & 0,44 \\
\hline La Rioja & 6,77 & 6,85 & 6,85 & 6,99 & 6,97 & 6,92 & 6,76 & 6,47 & 6,58 & 2,89 \\
\hline Ceuta & 6,16 & 6,05 & 5,96 & 6,02 & 6,29 & 6,08 & -- & -- & -- & $1,32^{49}$ \\
\hline Melilla & 6,15 & 6,19 & 6,22 & 5,95 & 5,9 & 6,12 & - & -- & - & $0,49^{50}$ \\
\hline $\begin{array}{l}\text { Total } \\
\text { nacional }\end{array}$ & 6,41 & 6,57 & 6,59 & 6,57 & 6,35 & 6,28 & 6,12 & 6,05 & 5,94 & 7,91 \\
\hline
\end{tabular}

Fuente: Barómetro sanitario del Ministerio de Sanidad, Servicios Sociales e Igualdad.

\footnotetext{
${ }^{49}$ Porcentaje calculado tomando como referencia el año 2008 en vez de 2002.

50 Porcentaje calculado tomando como referencia el año 2008 en vez de 2002.
} 


\section{ANEXO 2. CARACTERÍSTICAS ACTUALES Y EVOLUCIÓN DE LOS HOSPITALES EN CASTILLA Y LEÓN Y GALICIA}

\section{Número de camas}

Galicia, al poseer ligeramente más población, dispone de un número levemente mayor de camas. Instaladas tiene 10.121 (frente a las 9.634 de Castilla y León) y en funcionamiento, 9.466 (en la región castellana hay 8.937).

En cuanto a la evolución, tanto las instaladas como las que están en funcionamiento han disminuido en las dos comunidades. En las primeras, en Castilla y León, desde 1997 hasta 2012, se observa una diferencia negativa del 21,01\%, o lo que es lo mismo, las 12.196 del primer año se han convertido en 9.634 en el segundo. La diferencia en Galicia no es tan acusada, y el porcentaje entre un ejercicio y otro se queda en un 10,12\%. En 1997 se contabilizaban 11.149 y en 2012, 10.021. La reducción en el conjunto nacional, no obstante, es más baja que en cualquiera de estas dos regiones: $6,13 \%$.

Las camas en funcionamiento también se han reducido con el paso del tiempo. En Castilla y León, desde 1997 hasta 2012, ha habido una reducción del -18,47\%, pasando de 10.962 a 8.937 . En Galicia, la bajada es menos pronunciada, al igual que sucede con las instaladas. De las 10.348 camas en funcionamiento que había en 1997, en 2012 se contabilizan 9.466, o lo que es lo mismo, ahora hay un $8,52 \%$ menos. De la misma manera que con las instaladas, en España, en general, el descenso ha sido menos acentuado: un $-7,50 \%$. 
Tabla 307. Evolución del número de camas instaladas y en funcionamiento en Castilla y León y Galicia

\begin{tabular}{|c|c|c|c|c|}
\hline \multirow{2}{*}{ Año } & \multicolumn{2}{|c|}{ Camas instaladas } & \multicolumn{2}{|c|}{$\begin{array}{c}\text { Camas en } \\
\text { funcionamiento }\end{array}$} \\
\hline & $\begin{array}{l}\text { Castilla y } \\
\text { León }\end{array}$ & Galicia & $\begin{array}{l}\text { Castilla y } \\
\text { León }\end{array}$ & Galicia \\
\hline 2012 & 9.634 & 10.021 & 8.937 & 9.466 \\
\hline 2011 & 9.686 & 10.147 & 9.154 & 9.508 \\
\hline 2010 & 9.629 & 10.369 & 8.983 & 9.904 \\
\hline 2009 & 9.562 & 10.434 & 9.007 & 9.863 \\
\hline 2008 & 9.447 & 10.481 & 8.957 & 9.919 \\
\hline 2007 & 9.497 & 10.539 & 8.972 & 9.901 \\
\hline 2006 & 10.576 & 10.531 & 9.862 & 9.886 \\
\hline 2005 & 10.430 & 10.480 & 9.818 & 9.836 \\
\hline 2004 & 10.760 & 10.561 & 10.164 & 9.928 \\
\hline 2003 & 11.016 & 10.340 & 10.263 & 9.557 \\
\hline 2002 & 11.100 & 10.360 & 10.347 & 9.664 \\
\hline 2001 & 11.497 & 10.724 & 10.732 & 9.835 \\
\hline 2000 & 11.584 & 10.865 & 10.791 & 9.923 \\
\hline 1999 & 11.666 & 11.002 & 10.689 & 10.029 \\
\hline 1998 & 11.577 & 11.073 & 10.612 & 10.239 \\
\hline 1997 & 12.196 & 11.149 & 10.962 & 10.348 \\
\hline $\begin{array}{l}\text { Diferencia } \\
\text { 2012-1997 }\end{array}$ & -2.562 & -1.128 & -2.025 & -882 \\
\hline $\begin{array}{l}\text { \%Diferencia } \\
2012-1997\end{array}$ & $-21,01$ & $-10,12$ & $-18,47$ & $-8,52$ \\
\hline
\end{tabular}

Fuente: Estadística de Centros Sanitarios de Atención Especializada y Estadística de Establecimientos Sanitarios con Régimen de Internado.

En la comunidad gallega hay una mayor proporción de camas públicas que en la castellano-leonesa. Más concretamente, la primera región tiene cinco veces más camas tanto instaladas como en funcionamiento en el ámbito público que en el privado, mientras que el factor de multiplicación en el segundo territorio apenas supera el tres. Lo normal en el conjunto nacional, no obstante, es que el Sistema Nacional de Salud contenga casi cuatro veces más unidades de esta clase de dotación que las clínicas privadas. 
Tabla 308. Tasa de multiplicación de camas instaladas y en funcionamiento en hospitales públicos respecto a los privados en Castilla y León y en

Galicia en 2012

\begin{tabular}{|l|r|r|}
\hline Comunidad autónoma & \multicolumn{1}{|c|}{$\begin{array}{c}\text { Camas } \\
\text { instaladas }\end{array}$} & $\begin{array}{c}\text { Camas en } \\
\text { funcionamiento }\end{array}$ \\
\hline Castilla y León & 3,26 & 3,06 \\
\hline Galicia & 4,98 & 4,93 \\
\hline Total nacional & 3,92 & 3,90 \\
\hline
\end{tabular}

Fuente: Operaciones de elaboración propia a partir de los datos de la Estadística de Centros Sanitarios de Atención Especializada y la Estadística de Establecimientos Sanitarios con Régimen de Internado.

En cuanto a la proporción de camas instaladas y en funcionamiento en relación con la población, se observa que ha habido una disminución con el paso de los años en ambas comunidades, aunque en Castilla y León el descenso ha sido más acusado. Se ha pasado de tener 4,89 instaladas por 1.000 habitantes en 1997 a 3,90 en 2012. En las que están en funcionamiento, también se nota una disminución. Mientras que en 1997 se contabilizaban 4,40 por cada 1.000 habitantes, en 2012 , la cifra se rebaja a 3,62. En Galicia, aunque las discrepancias no son tan notables, también se ha experimentado una bajada. Así, las instaladas en 2012 se reducen a 3,68 por cada 1.000 habitantes en comparación con las 4,13 que se registraban en 1997, y las que se encuentran en funcionamiento bajan de 3,83 a 3,48. En cualquier caso, se trata de cifras más altas de las que ofrece el conjunto nacional. 
Tabla 309. Evolución de las tasas de camas instaladas y en funcionamiento en Castilla y León y Galicia

\begin{tabular}{|c|c|c|c|c|c|c|}
\hline \multirow{2}{*}{ Año } & \multicolumn{3}{|c|}{ Camas instaladas por 1.000 hab. } & \multicolumn{3}{|c|}{$\begin{array}{l}\text { Camas en funcionamiento por } \\
1.000 \text { hab. }\end{array}$} \\
\hline & $\begin{array}{l}\text { Castilla y } \\
\text { León }\end{array}$ & Galicia & Nacional & $\begin{array}{c}\text { Castilla y } \\
\text { León }\end{array}$ & Galicia & Nacional \\
\hline 2012 & 3,90 & 3,68 & 3,40 & 3,62 & 3,48 & 3,03 \\
\hline 2011 & 3,90 & 3,71 & 3,43 & 3,69 & 3,48 & 3,09 \\
\hline 2010 & 3,86 & 3,79 & 3,43 & 3,60 & 3,62 & 3,15 \\
\hline 2009 & 3,81 & 3,81 & 3,45 & 3,59 & 3,60 & 3,19 \\
\hline 2008 & 3,77 & 3,83 & 3,47 & 3,57 & 3,62 & 3,22 \\
\hline 2007 & 3,81 & 3,86 & 3,53 & 3,60 & 3,63 & 3,27 \\
\hline 2006 & 4,26 & 3,87 & 3,57 & 3,98 & 3,63 & 3,32 \\
\hline 2005 & 4,22 & 3,86 & 3,62 & 3,97 & 3,62 & 3,36 \\
\hline 2004 & 4,36 & 3,90 & 3,70 & 4,12 & 3,66 & 3,42 \\
\hline 2003 & 4,48 & 3,83 & 3,75 & 4,17 & 3,54 & 3,45 \\
\hline 2002 & 4,52 & 3,84 & 3,85 & 4,21 & 3,58 & 3,54 \\
\hline 2001 & 4,68 & 3,98 & 3,92 & 4,37 & 3,65 & 3,59 \\
\hline 2000 & 4,71 & 4,04 & 4,05 & 4,38 & 3,69 & 3,68 \\
\hline 1999 & 4,72 & 4,09 & 4,13 & 4,33 & 3,73 & 3,75 \\
\hline 1998 & 4,67 & 4,11 & 4,18 & 4,28 & 3,80 & 3,78 \\
\hline 1997 & 4,89 & 4,13 & 4,22 & 4,40 & 3,83 & 3,82 \\
\hline $\begin{array}{l}\text { Diferencia } \\
\text { 2012-1997 }\end{array}$ & $-0,99$ & $-0,45$ & $-0,82$ & $-0,78$ & $-0,35$ & $-0,79$ \\
\hline $\begin{array}{l}\text { \%Diferencia } \\
2012-1997\end{array}$ & $-20,25$ & $-10,90$ & $-19,43$ & $-17,73$ & $-9,14$ & $-20,68$ \\
\hline
\end{tabular}

Fuente: Estadística de Centros Sanitarios de Atención Especializada y Estadística de Establecimientos Sanitarios con Régimen de Internado.

La mayor disminución de camas instaladas se ha producido en los hospitales privados de Galicia, que de 1997 a 2012 cuentan con un 45,45\% menos. Las públicas, en cambio, han aumentado en número, aunque muy ligeramente: 3,33\%. En Castilla y León, por su parte, han disminuido tanto las privadas como las públicas: -28,11\% y $18,53 \%$, en este orden. En la actualidad, Castilla y León tiene 7.371 públicas y 2.263 privadas, mientras que Galicia tiene, en comparación, más del primer tipo y menos del segundo: 8.344 y 1.677 , respectivamente.

No se dan diferencias demasiado marcadas en las camas en funcionamiento respecto a las instaladas. En 2012, 6.735 camas públicas y 2.202 privadas están en funcionamiento en Castilla y León, mientras que en Galicia hay 7.871 del primer tipo y 
1.595 del segundo. En cuanto a la evolución a lo largo de los años, las públicas castellanoleonesas se han reducido un $15,43 \%$ de 1997 a 2012 (respecto al -18,53\% de las instaladas). En las clínicas privadas de esta comunidad han bajado un 26,55\%. En Galicia, por su parte, se ha acortado el montante en las privadas un 41,55\%, mientras que en las públicas ha aumentado un 3,31\%.

Tabla 310. Evolución del número de camas instaladas y en funcionamiento por dependencia funcional en Castilla y León y Galicia

\begin{tabular}{|c|c|c|c|c|c|c|c|c|}
\hline \multirow{3}{*}{ Año } & \multicolumn{4}{|c|}{ Camas instaladas } & \multicolumn{4}{|c|}{ Camas en funcionamiento } \\
\hline & \multicolumn{2}{|c|}{ Públicos } & \multicolumn{2}{|c|}{ Privados } & \multicolumn{2}{|c|}{ Públicos } & \multicolumn{2}{|c|}{ Privados } \\
\hline & $\begin{array}{l}\text { Castilla } \\
\text { y Leónn }\end{array}$ & Galicia & $\begin{array}{l}\text { Castilla } \\
\text { y León }\end{array}$ & Galicia & \begin{tabular}{|l|} 
Castilla \\
y León
\end{tabular} & Galicia & \begin{tabular}{|l|} 
Castilla \\
y Leónn
\end{tabular} & Galicia \\
\hline 2012 & 7.371 & 8.344 & 2.263 & 1.677 & 6.735 & 7.871 & 2.202 & 1595 \\
\hline 2011 & 7.417 & 8.476 & 2.269 & 1.671 & 6.917 & 7.933 & 2.237 & 1.575 \\
\hline 2010 & 7.458 & 8.549 & 2.171 & 1.820 & 6.900 & 8.164 & 2.083 & 1.740 \\
\hline 2009 & 7.403 & 8.535 & 2.159 & 1.899 & 6.954 & 8.067 & 2.053 & 1.796 \\
\hline 2008 & 7.246 & 8.542 & 2.201 & 1.939 & 6.858 & 8.067 & 2.099 & 1.852 \\
\hline 2007 & 7.282 & 8.602 & 2.215 & 1.937 & 6.858 & 8.116 & 2.114 & 1.785 \\
\hline 2006 & 7.503 & 8.529 & 3.073 & 2.002 & 6.902 & 8.045 & 2.960 & 1.841 \\
\hline 2005 & 7.102 & 8.468 & 3.328 & 2.012 & 6.605 & 8.027 & 3.213 & 1.809 \\
\hline 2004 & 7.514 & 8.508 & 3.246 & 2.053 & 7.038 & 8.053 & 3.126 & 1.875 \\
\hline 2003 & 7.691 & 8.502 & 3.325 & 1.838 & 7.073 & 7.962 & 3.190 & 1.595 \\
\hline 2002 & 7.808 & 7.980 & 3.292 & 2.380 & 7.163 & 7.642 & 3.184 & 2.022 \\
\hline 2001 & 8.151 & 8.401 & 3.346 & 2.323 & 7.477 & 7.825 & 3.255 & 2.010 \\
\hline 2000 & 8.208 & 8.163 & 3.376 & 2.702 & 7.529 & 7.653 & 3.262 & 2.270 \\
\hline 1999 & 8.462 & 8.190 & 3.204 & 2.812 & 7.588 & 7.701 & 3.101 & 2.328 \\
\hline 1998 & 8.424 & 8.033 & 3.153 & 3.040 & 7.547 & 7.661 & 3.065 & 2.578 \\
\hline 1997 & 9.048 & 8.075 & 3.148 & 3.074 & 7.964 & 7.619 & 2.998 & 2.729 \\
\hline $\begin{array}{l}\text { Diferencia } \\
\text { 2012-1997 }\end{array}$ & -1.677 & 269 & -885 & -1.397 & -1.229 & 252 & -796 & -1.134 \\
\hline $\begin{array}{l}\text { \%Diferencia } \\
\text { 2012-1997 }\end{array}$ & $-18,53$ & 3,33 & $-28,11$ & $-45,45$ & $-15,43$ & 3,31 & $-26,55$ & $-41,55$ \\
\hline
\end{tabular}

Fuente: Estadística de Centros Sanitarios de Atención Especializada y Estadística de Establecimientos Sanitarios con Régimen de Internado.

Existe un mayor número de camas instaladas y en funcionamiento en centros generales (o de agudos) en Galicia que en Castilla y León, aunque esta última comunidad dispone de más dotación de este tipo en Hospitales de larga estancia. Más concretamente, la primera región cuenta con 9.644 instaladas y 9.120 en funcionamiento en edificios con finalidad general, en comparación con las 8.764 de la primera clase y 
8.079 de la segunda en la zona castellana. En cuanto a las clínicas de larga estancia, en Galicia hay únicamente 377 camas instaladas y 346 en funcionamiento respecto a las 870 y 858 de Castilla y León.

Tabla 311. Evolución del número de camas instaladas en Castilla y León y Galicia

\begin{tabular}{|c|c|c|c|c|c|c|c|c|}
\hline \multirow{3}{*}{ Año } & \multicolumn{8}{|c|}{ Camas instaladas } \\
\hline & \multicolumn{2}{|c|}{$\begin{array}{l}\text { Hospitales } \\
\text { generales }{ }^{51}\end{array}$} & \multicolumn{2}{|c|}{$\begin{array}{l}\text { Otros de } \\
\text { Agudos }\end{array}$} & \multicolumn{2}{|c|}{$\begin{array}{l}\text { Hospitales de } \\
\text { larga estancia }\end{array}$} & \multicolumn{2}{|c|}{$\begin{array}{c}\text { Hospitales } \\
\text { psiquiátricos }\end{array}$} \\
\hline & $\begin{array}{l}\text { Castilla } \\
\text { y León }\end{array}$ & Galicia & $\begin{array}{l}\text { Castilla } \\
\text { y León }\end{array}$ & Galicia & $\begin{array}{l}\text { Castilla } \\
\text { y León }\end{array}$ & Galicia & $\begin{array}{l}\text { Castilla } \\
\text { y León }\end{array}$ & Galicia \\
\hline 2012 & 8.764 & 9.644 & - & - & 870 & 377 & - & \\
\hline 2011 & 8.816 & 9.779 & - & - & 870 & 368 & - & \\
\hline 2010 & 8.758 & 9.776 & - & - & 871 & 593 & - & \\
\hline 2009 & 8.298 & 9.664 & 429 & 177 & 221 & 148 & 614 & 445 \\
\hline 2008 & 8.164 & 9.642 & 488 & 177 & 221 & 217 & 574 & 445 \\
\hline 2007 & 8.521 & 9.720 & 182 & 194 & 225 & 217 & 569 & 408 \\
\hline 2006 & 8.242 & 9.619 & 493 & 234 & 242 & 270 & 1.599 & 408 \\
\hline 2005 & 7.825 & 9.520 & 509 & 276 & 232 & 276 & 1.864 & 408 \\
\hline 2004 & 8.116 & 9.631 & 499 & 274 & 232 & 198 & 1.913 & 458 \\
\hline 2003 & 8.302 & 9.293 & 554 & 391 & 232 & 198 & 1.928 & 458 \\
\hline 2002 & 7.949 & 9.288 & 804 & 416 & 232 & 198 & 2.115 & 458 \\
\hline 2001 & 8.661 & 9.672 & 482 & 380 & 232 & 198 & 2.122 & 474 \\
\hline 2000 & 8.344 & 9.729 & 729 & 541 & 400 & 141 & 2.111 & 454 \\
\hline 1999 & 8.593 & 9.823 & 614 & 596 & 320 & 128 & 2.139 & 455 \\
\hline 1998 & 8.490 & 9.896 & 612 & 623 & 383 & 120 & 2.092 & 434 \\
\hline 1997 & 8.748 & 9.953 & 477 & 524 & 300 & 130 & 2.671 & 542 \\
\hline $\begin{array}{l}\text { Diferencia } \\
\text { 2012-1997 }\end{array}$ & 16 & -309 & & & 570 & 247 & & \\
\hline $\begin{array}{l}\text { \%Diferencia } \\
2012-1997\end{array}$ & 0,18 & $-3,10$ & & & 190 & 190 & & \\
\hline
\end{tabular}

Fuente: Estadística de Centros Sanitarios de Atención Especializada y Estadística de Establecimientos Sanitarios con Régimen de Internado.

$\underline{51}$ Desde 2010, la Estadística de Centros Sanitarios de Atención Especializada únicamente contabiliza las plazas de día en hospitales de agudos y de larga estancia. En este caso, se ha traspasado los datos de la columna de agudos a los generales por ofrecer una mayor continuidad con los años anteriores, en los que estaba en vigor la Estadística de Establecimientos Sanitarios con Régimen de Internado. 
Tabla 312. Evolución de las camas en funcionamiento en Castilla y León y Galicia

\begin{tabular}{|c|c|c|c|c|c|c|c|c|}
\hline \multirow{3}{*}{ Año } & \multicolumn{8}{|c|}{ Camas en funcionamiento } \\
\hline & \multicolumn{2}{|c|}{$\begin{array}{l}\text { Hospitales } \\
\text { generales }^{52}\end{array}$} & \multicolumn{2}{|c|}{$\begin{array}{c}\text { Otros hospitales } \\
\text { de agudos }\end{array}$} & \multicolumn{2}{|c|}{$\begin{array}{l}\text { Hospitales de } \\
\text { larga estancia }\end{array}$} & \multicolumn{2}{|c|}{$\begin{array}{c}\text { Hospitales } \\
\text { psiquiátricos }\end{array}$} \\
\hline & $\begin{array}{l}\text { Castilla } \\
\text { y León }\end{array}$ & Galicia & $\begin{array}{l}\text { Castilla } \\
\text { y León }\end{array}$ & Galicia & $\begin{array}{l}\text { Castilla } \\
\text { y León }\end{array}$ & Galicia & $\begin{array}{l}\text { Castilla } \\
\text { y León }\end{array}$ & Galicia \\
\hline 2012 & 8.079 & 9.120 & & - & 858 & 346 & _ & \\
\hline 2011 & 8.299 & 9.171 & & - & 855 & 337 & - & - \\
\hline 2010 & 8.132 & 9.348 & - & - & 851 & 556 & - & - \\
\hline 2009 & 7.761 & 9.144 & 428 & 150 & 210 & 147 & 608 & 422 \\
\hline 2008 & 7.683 & 9.126 & 483 & 150 & 221 & 217 & 570 & 426 \\
\hline 2007 & 8.008 & 9.153 & 172 & 156 & 225 & 215 & 567 & 377 \\
\hline 2006 & 7.546 & 9.049 & 478 & 200 & 242 & 247 & 1.596 & 390 \\
\hline 2005 & 7.265 & 8.958 & 485 & 240 & 232 & 264 & 1.836 & 374 \\
\hline 2004 & 7.544 & 9.100 & 480 & 221 & 232 & 177 & 1.908 & 430 \\
\hline 2003 & 7.617 & 8.664 & 504 & 292 & 232 & 177 & 1.910 & 424 \\
\hline 2002 & 7.274 & 8.737 & 754 & 316 & 232 & 178 & 2.087 & 433 \\
\hline 2001 & 7.974 & 8.926 & 433 & 288 & 232 & 182 & 2.093 & 439 \\
\hline 2000 & 7.675 & 8.903 & 642 & 491 & 383 & 124 & 2.091 & 405 \\
\hline 1999 & 7.808 & 8.987 & 477 & 521 & 318 & 113 & 2.086 & 408 \\
\hline 1998 & 7.707 & 9.156 & 475 & 561 & 376 & 106 & 2.054 & 416 \\
\hline 1997 & 7.771 & 9.300 & 396 & 432 & 237 & 116 & 2.558 & 500 \\
\hline $\begin{array}{l}\text { Diferencia } \\
2012-1997\end{array}$ & 308 & -180 & & & 621 & 230 & & \\
\hline $\begin{array}{l}\text { \%Diferencia } \\
\text { 2012-1997 }\end{array}$ & 3,96 & $-1,94$ & & - & 262,03 & 198,28 & - & \\
\hline
\end{tabular}

Fuente: Estadística de Centros Sanitarios de Atención Especializada y Estadística de Establecimientos Sanitarios con Régimen de Internado.

\section{Plazas de día}

Galicia posee considerablemente más plazas de hospital de día que Castilla y León, con 841 y 717, respectivamente. No se trata de un desajuste debido a la población en la zona gallega, dado que la tasa respecto a los habitantes en la zona gallega sigue siendo superior. Más concretamente, en 2012 existen 30,91 plazas por 100.000 residentes en esta comunidad y en la región castellana, 29,05.

\footnotetext{
$\underline{52}$ Desde 2010, la Estadística de Centros Sanitarios de Atención Especializada únicamente contabiliza las plazas de día en hospitales de agudos y de larga estancia. En este caso, se ha traspasado los datos de la columna de agudos a los generales por ofrecer una mayor continuidad con los años anteriores, en los que estaba en vigor la Estadística de Establecimientos Sanitarios con Régimen de Internado.
} 
En ambos casos, se trata de cifras mucho más altas de las que se registraban en los primeros años de las estadísticas. En cuanto a la cantidad de plazas de día apenas se superaban las 200 y en cuanto a la tasa, los dos primeros años ni se llegó a 10 por cada 100.000 habitantes. Los incrementos han sido similares en ambos territorios. En Galicia arroja un porcentaje positivo del 364,64\% y 360,66\% desde 1997 a 2012, mientras que la subida en Castilla y León, aunque muy significativa, no alcanza a las del otro territorio: $345,34 \%$ y $349,69 \%$, en este orden.

Tabla 313. Evolución del número y tasa de plazas de hospital de día en Castilla y León y Galicia

\begin{tabular}{|c|c|c|c|c|}
\hline \multirow[b]{2}{*}{ Año } & \multicolumn{2}{|c|}{$\begin{array}{l}\text { Plazas de hospital de } \\
\text { día }\end{array}$} & \multicolumn{2}{|c|}{$\begin{array}{l}\text { Plazas de hospital de } \\
\text { día por } 100.000 \text { hab. }\end{array}$} \\
\hline & $\begin{array}{l}\text { Castilla y } \\
\text { León }\end{array}$ & Galicia & $\begin{array}{l}\text { Castilla y } \\
\text { León }\end{array}$ & Galicia \\
\hline 2012 & 717 & 841 & 29,05 & 30,91 \\
\hline 2011 & 654 & 833 & 26,33 & 30,49 \\
\hline 2010 & 587 & 758 & 23,53 & 27,70 \\
\hline 2009 & 441 & 622 & 17,57 & 22,73 \\
\hline 2008 & 441 & 591 & 17,59 & 21,58 \\
\hline 2007 & 433 & 583 & 17,38 & 21,36 \\
\hline 2006 & 376 & 565 & 15,16 & 20,77 \\
\hline 2005 & 312 & 546 & 12,62 & 20,11 \\
\hline 2004 & 356 & 554 & 14,44 & 20,45 \\
\hline 2003 & 333 & 516 & 13,53 & 19,09 \\
\hline 2002 & 319 & 490 & 12,99 & 18,17 \\
\hline 2001 & 326 & 447 & 13,27 & 16,58 \\
\hline 2000 & 284 & 466 & 11,54 & 17,32 \\
\hline 1999 & 226 & 287 & 9,15 & 10,68 \\
\hline 1998 & 162 & 236 & 6,53 & 8,77 \\
\hline 1997 & 161 & 181 & 6,46 & 6,71 \\
\hline $\begin{array}{l}\text { Diferencia } \\
2012-1997\end{array}$ & 556 & 660 & 22,59 & 24,2 \\
\hline $\begin{array}{l}\text { \% Diferencia } \\
2012-1997\end{array}$ & 345,34 & 364,64 & 349,69 & 360,66 \\
\hline
\end{tabular}

Fuente: Estadística de Centros Sanitarios de Atención Especializada y Estadística de Establecimientos Sanitarios con Régimen de Internado.

Dividendo esta variable por dependencia funcional se observa que en Castilla y León hay más plazas de día privadas y menos públicas que en Galicia. Así, en la primera región existen 804 pertenecientes al Sistema Nacional de Salud en 2012, 
mientras que en la segunda zona la cifra sube hasta 625. Por el contrario, los sitios privados en la comunidad castellano-leonesa adelantan a la gallega con 92 sobre 37 .

La proporción entre plazas de hospital de día y la población también es algo dispar en los dos territorios. En Castilla y León, por ejemplo, los públicos disponen de 25,32 por cada 100.000 personas, mientras que esta misma dependencia provee 29,55 unidades por la misma suma de gallegos. En cambio, la comunidad castellana adelanta a la gallega, con una tasa de 3,73 respecto a 1,36, en plazas privadas de hospital de día.

Aunque en ambas zonas ha crecido este tipo de dotación con el paso de los años, en Galicia sube mucho más en el ámbito público (405,66\% en unidades y 401,70\% en cuanto a la tasa de 1997 a 2012) que en el privado (68,18\% y 65,85\%, en este orden). En Castilla y León, el número de plazas en manos privadas sube en un $268 \%$ y la tasa en $283 \%$ en comparación con el $359,56 \%$ y el $363,74 \%$ que arroja el Sistema Nacional de Salud.

Tabla 314. Evolución del número y tasa de plazas de hospital de día en Castilla y León y Galicia por dependencia funcional

\begin{tabular}{|c|c|c|c|c|c|c|c|c|}
\hline \multirow{3}{*}{ Año } & \multicolumn{4}{|c|}{ Plazas de hospital de día } & \multicolumn{4}{|c|}{$\begin{array}{l}\text { Plazas de hospital de día por } \\
100.000 \text { hab. }\end{array}$} \\
\hline & \multicolumn{2}{|c|}{ Públicos } & \multicolumn{2}{|c|}{ Privados } & \multicolumn{2}{|c|}{ Públicos } & \multicolumn{2}{|c|}{ Privados } \\
\hline & \begin{tabular}{|l|} 
Castilla \\
y León
\end{tabular} & Galicia & $\begin{array}{l}\text { Castilla } \\
\text { y León }\end{array}$ & Galicia & $\begin{array}{l}\text { Castilla } \\
\text { y León }\end{array}$ & Galicia & $\begin{array}{l}\text { Castilla } \\
\text { y León }\end{array}$ & Galicia \\
\hline 2012 & 625 & 804 & 92 & 37 & 25,32 & 29,55 & 3,73 & 1,36 \\
\hline 2011 & 567 & 794 & 87 & 39 & 22,83 & 29,06 & 3,50 & 1,43 \\
\hline 2010 & 517 & 726 & 70 & 32 & 20,72 & 26,53 & 2,81 & 1,17 \\
\hline 2009 & 375 & 582 & 66 & 40 & 14,94 & 21,26 & 2,63 & 1,46 \\
\hline 2008 & 374 & 541 & 67 & 50 & 14,92 & 19,76 & 2,67 & 1,83 \\
\hline 2007 & 366 & 541 & 67 & 42 & 14,69 & 19,83 & 2,69 & 1,54 \\
\hline 2006 & 307 & 533 & 69 & 32 & 12,38 & 19,59 & 2,78 & 1,18 \\
\hline 2005 & 245 & 520 & 67 & 26 & 9,91 & 19,15 & 2,71 & 0,96 \\
\hline 2004 & 298 & 512 & 58 & 42 & 12,09 & 18,90 & 2,35 & 1,55 \\
\hline 2003 & 275 & 482 & 58 & 34 & 11,18 & 17,83 & 2,36 & 1,26 \\
\hline 2002 & 264 & 466 & 55 & 24 & 10,75 & 17,28 & 2,24 & 0,89 \\
\hline 2001 & 248 & 429 & 78 & 18 & 10,10 & 15,92 & 3,18 & 0,67 \\
\hline 2000 & 202 & 444 & 82 & 22 & 8,21 & 16,50 & 3,33 & 0,82 \\
\hline 1999 & 166 & 259 & 60 & 28 & 6,72 & 9,64 & 2,43 & 1,04 \\
\hline 1998 & 143 & 207 & 19 & 29 & 5,76 & 7,69 & 0,77 & 1,08 \\
\hline 1997 & 136 & 159 & 25 & 22 & 5,46 & 5,89 & 1,00 & 0,82 \\
\hline $\begin{array}{l}\text { Diferencia } \\
2012-1997\end{array}$ & 489 & 645 & 67 & 15 & 19,86 & 23,66 & 2,73 & 0,54 \\
\hline $\begin{array}{l}\text { \%Diferencia } \\
\text { 2012-1997 }\end{array}$ & 359,56 & 405,66 & 268 & 68,18 & 363,74 & 401,70 & 273 & 65,85 \\
\hline
\end{tabular}

Fuente: Estadística de Centros Sanitarios de Atención Especializada y Estadística de Establecimientos Sanitarios con Régimen de Internado. 
En la actualidad, todas las plazas de día que se sitúan en las dos zonas de estudio se encuentran en Hospitales generales o de agudos, dejando a los de larga estancia sin ninguna unidad. Por ello, la proporción respecto a la población se concentra únicamente en este tipo de centros.

Tabla 315. Evolución del número de plazas de hospital de día en Castilla y León y Galicia por finalidad asistencial

\begin{tabular}{|c|c|c|c|c|c|c|c|c|}
\hline \multirow{3}{*}{ Año } & \multicolumn{8}{|c|}{ Plazas de hospital de día } \\
\hline & \multicolumn{2}{|c|}{$\begin{array}{l}\text { Hospitales } \\
\text { generales } \underline{53}\end{array}$} & \multicolumn{2}{|c|}{$\begin{array}{c}\text { Otros hospitales } \\
\text { de agudos }\end{array}$} & \multicolumn{2}{|c|}{$\begin{array}{l}\text { Hospitales de } \\
\text { larga estancia }\end{array}$} & \multicolumn{2}{|c|}{$\begin{array}{c}\text { Hospitales } \\
\text { psiquiátricos }\end{array}$} \\
\hline & $\begin{array}{l}\text { Castilla } \\
\text { y León }\end{array}$ & Galicia & $\begin{array}{l}\text { Castilla } \\
\text { y León }\end{array}$ & Galicia & $\begin{array}{l}\text { Castilla } \\
\text { y León }\end{array}$ & Galicia & $\begin{array}{l}\text { Castilla } \\
\text { y León }\end{array}$ & Galicia \\
\hline 2012 & 717 & 841 & - & - & 0 & 0 & - & - \\
\hline 2011 & 654 & 833 & - & - & 0 & 0 & - & - \\
\hline 2010 & 587 & 758 & - & - & 0 & 0 & - & - \\
\hline 2009 & 397 & 591 & 4 & 23 & 0 & 8 & 40 & 0 \\
\hline 2008 & 396 & 560 & 5 & 23 & 0 & 8 & 40 & 0 \\
\hline 2007 & 393 & 552 & 0 & 23 & 0 & 8 & 40 & 0 \\
\hline 2006 & 331 & 539 & 5 & 18 & 0 & 8 & 40 & 0 \\
\hline 2005 & 267 & 527 & 5 & 18 & 0 & 1 & 40 & 0 \\
\hline 2004 & 287 & 521 & 5 & 18 & 0 & 0 & 64 & 15 \\
\hline 2003 & 264 & 483 & 5 & 18 & 0 & 0 & 64 & 15 \\
\hline 2002 & 228 & 466 & 27 & 18 & 0 & 0 & 64 & 6 \\
\hline 2001 & 217 & 429 & 20 & 12 & 25 & 0 & 64 & 6 \\
\hline 2000 & 220 & 450 & 0 & 10 & 0 & 0 & 64 & 6 \\
\hline 1999 & 186 & 265 & 0 & 16 & 0 & 0 & 40 & 6 \\
\hline 1998 & 154 & 218 & 0 & 12 & 8 & 0 & 0 & 6 \\
\hline 1997 & 153 & 170 & 0 & 6 & 8 & 0 & 0 & 5 \\
\hline $\begin{array}{l}\text { Diferencia } \\
2012-1997\end{array}$ & 564 & 671 & - & - & & & & - \\
\hline $\begin{array}{l}\text { \% Diferencia } \\
\text { 2012-1997 }\end{array}$ & 368,63 & 394,71 & - & - & & & & - \\
\hline
\end{tabular}

Fuente: Estadística de Centros Sanitarios de Atención Especializada y Estadística de Establecimientos Sanitarios con Régimen de Internado.

$\underline{53}$ Desde 2010, la Estadística de Centros Sanitarios de Atención Especializada únicamente contabiliza las plazas de día en hospitales de agudos y de larga estancia. En este caso, se ha traspasado los datos de la columna de agudos a los generales por ofrecer una mayor continuidad con los años anteriores, en los que estaba en vigor la Estadística de Establecimientos Sanitarios con Régimen de Internado. 
Tabla 316. Evolución de la tasa de plazas de hospital de día en Castilla y León y Galicia por finalidad asistencial

\begin{tabular}{|c|c|c|c|c|c|c|c|c|}
\hline \multirow{3}{*}{ Año } & \multicolumn{8}{|c|}{ Plazas de hospital de día por 100.000 hab. } \\
\hline & \multicolumn{2}{|c|}{$\begin{array}{l}\text { Hospitales } \\
\text { generales }{ }^{54}\end{array}$} & \multicolumn{2}{|c|}{$\begin{array}{c}\text { Otros hospitales } \\
\text { de agudos }\end{array}$} & \multicolumn{2}{|c|}{$\begin{array}{l}\text { Hospitales de } \\
\text { larga estancia }\end{array}$} & \multicolumn{2}{|c|}{$\begin{array}{c}\text { Hospitales } \\
\text { psiquiátricos }\end{array}$} \\
\hline & $\begin{array}{l}\text { Castilla } \\
\text { y León }\end{array}$ & Galicia & $\begin{array}{l}\text { Castilla } \\
\text { y León }\end{array}$ & Galicia & $\begin{array}{l}\text { Castilla } \\
\text { y León }\end{array}$ & Galicia & $\begin{array}{l}\text { Castilla } \\
\text { y León }\end{array}$ & Galicia \\
\hline 2012 & 29,05 & 30,91 & - & - & 0 & 0 & - & - \\
\hline 2011 & 26,33 & 30,49 & - & - & 0 & 0 & - & - \\
\hline 2010 & 23,53 & 27,70 & - & - & 0 & 0 & - & - \\
\hline 2009 & 15,81 & 21,59 & 0,16 & 0,84 & 0 & 0,29 & 1,59 & 0 \\
\hline 2008 & 15,80 & 20,45 & 0,20 & 0,84 & 0 & 0,29 & 1,60 & 0 \\
\hline 2007 & 15,77 & 20,23 & 0 & 0,84 & 0 & 0,29 & 1,61 & 0 \\
\hline 2006 & 13,35 & 19,81 & 0,20 & 0,66 & 0 & 0,29 & 1,61 & 0 \\
\hline 2005 & 10,80 & 19,41 & 0,20 & 0,66 & 0 & 0,04 & 1,62 & 0 \\
\hline 2004 & 11,64 & 19,23 & 0,20 & 0,66 & 0 & 0 & 2,60 & 0,55 \\
\hline 2003 & 10,73 & 17,87 & 0,20 & 0,67 & 0 & 0 & 2,60 & 0,55 \\
\hline 2002 & 9,28 & 17,28 & 1,10 & 0,67 & 0 & 0 & 2,61 & 0,22 \\
\hline 2001 & 8,83 & 15,92 & 0,81 & 0,45 & 1,02 & 0 & 2,61 & 0,22 \\
\hline 2000 & 8,94 & 16,72 & 0 & 0,37 & 0 & 0 & 2,60 & 0,22 \\
\hline 1999 & 7,53 & 9,86 & 0 & 0,60 & 0 & 0 & 1,62 & 0,22 \\
\hline 1998 & 6,21 & 8,10 & 0 & 0,45 & 0,32 & 0 & 0 & 0,22 \\
\hline 1997 & 6,14 & 6,30 & 0 & 0,22 & 0,32 & 0 & 0 & 0,19 \\
\hline $\begin{array}{l}\text { Diferencia } \\
\text { 2012-1997 }\end{array}$ & 22,91 & 24,61 & & & & & & \\
\hline $\mid \begin{array}{ll}\% & \text { Diferencia } \\
2012-1997\end{array}$ & 373,13 & 390,63 & & & & & & \\
\hline
\end{tabular}

Fuente: Estadística de Centros Sanitarios de Atención Especializada y Estadística de Establecimientos Sanitarios con Régimen de Internado.

\section{Quirófanos}

El número de quirófanos en relación con la población ha aumentado con el paso de los años. Mientras que Galicia contaba en 1997 con 9 por cada 100.000 habitantes, en 2012 se registran 10. En Castilla y León la diferencia no es tan grande, pero aun así la tasa ha aumentado. En 1997, se contabilizan 7,99 y en 2012, 8,79. Galicia se encuentra

\footnotetext{
${ }^{54}$ Desde 2010, la Estadística de Centros Sanitarios de Atención Especializada únicamente contabiliza las plazas de día en hospitales de agudos y de larga estancia. En este caso, se ha traspasado los datos de la columna de agudos a los generales por ofrecer una mayor continuidad con los años anteriores, en los que estaba en vigor la Estadística de Establecimientos Sanitarios con Régimen de Internado.
} 
por encima de la media nacional $(9,24)$ con diez quirófanos en funcionamiento por cada 100.000 habitantes, mientras que Castilla y León se sitúa por de detrás, con casi cinco décimas menos.

Tabla 317. Evolución del número y tasa de quirófanos en Castilla y León y Galicia

\begin{tabular}{|c|c|c|c|c|c|c|}
\hline \multirow{2}{*}{ Año } & \multicolumn{3}{|c|}{$\begin{array}{l}\text { Número de quirófanos en } \\
\text { funcionamiento }\end{array}$} & \multicolumn{3}{|c|}{$\begin{array}{l}\text { Quirófanos en funcionamiento } \\
\text { por } 100.000 \text { hab. }\end{array}$} \\
\hline & $\begin{array}{l}\text { Castilla } \\
\text { y León }\end{array}$ & Galicia & Nacional & $\begin{array}{l}\text { Castilla } \\
\text { y León }\end{array}$ & Galicia & Nacional \\
\hline 2012 & 217 & 272 & 4.267 & 8,79 & 10,00 & 9,24 \\
\hline 2011 & 214 & 276 & 4.202 & 8,62 & 10,10 & 9,11 \\
\hline 2010 & 207 & 273 & 4.120 & 8,30 & 9,98 & 8,94 \\
\hline 2009 & 212 & 275 & 4.063 & 8,44 & 10,05 & 8,85 \\
\hline 2008 & 197 & 254 & 3.975 & 7,86 & 9,28 & 8,72 \\
\hline 2007 & 202 & 247 & 3.865 & 8,11 & 9,05 & 8,61 \\
\hline 2006 & 197 & 258 & 3.740 & 7,94 & 9,48 & 8,49 \\
\hline 2005 & 200 & 254 & 3.686 & 8,09 & 9,35 & 8,49 \\
\hline 2004 & 199 & 244 & 3.636 & 8,07 & 9,01 & 8,52 \\
\hline 2003 & 208 & 238 & 3.562 & 8,45 & 8,80 & 8,48 \\
\hline 2002 & 207 & 236 & 3.565 & 8,43 & 8,75 & 8,63 \\
\hline 2001 & 213 & 229 & 3.531 & 8,67 & 8,50 & 8,67 \\
\hline 2000 & 208 & 244 & 3.497 & 8,45 & 9,07 & 8,69 \\
\hline 1999 & 209 & 239 & 3.463 & 8,46 & 8,90 & 8,67 \\
\hline 1998 & 196 & 246 & 3.411 & 7,90 & 9,14 & 8,59 \\
\hline 1997 & 199 & 243 & 3.387 & 7,99 & 9,00 & 8,56 \\
\hline $\begin{array}{l}\text { Diferencia } \\
2012-1997\end{array}$ & 18 & 29 & 880 & 0,8 & 1 & 0,68 \\
\hline $\begin{array}{l}\text { \%Diferencia } \\
\text { 2012-1997 }\end{array}$ & 9,05 & 11,93 & 25,98 & 10,01 & 11,11 & 7,94 \\
\hline
\end{tabular}

Fuente: Estadística de Centros Sanitarios de Atención Especializada y Estadística de Establecimientos Sanitarios con Régimen de Internado.

La proporción de quirófanos en centros públicos respecto a los que se encuentran en privados es muy similar en ambas regiones. Galicia, con 198 públicos y 74 privados, tiene 2,68 veces más del primer tipo que del segundo. Castilla y León ofrece un coeficiente casi idéntico: al contar con 157 públicos y 60 privados le sale una tasa de multiplicación entre unos y otros del 2,62.

De esta manera, respecto a la población que hay en cada territorio, Galicia tiene más quirófanos tanto de titularidad pública (con 7,28 por cada 100.000 habitantes) que privada (2,72). En la otra comunidad, en cambio, las cifras son sensiblemente más bajas: 6,36 y 2,43 , respectivamente. 
Mientras que con el paso de los años, esta dotación, independientemente de su dependencia, ha aumentado prácticamente lo mismo en Castilla y León, en Galicia crece considerablemente más en el ámbito público. Así, tanto en el número de quirófanos $(39,44 \%)$ como en la tasa $(38,40 \%)$ desde 1997 a 2012 se observa una subida cuantiosa frente a la bajada tanto en unidades $(-26,73 \%)$ como en proporción con la población (27,27\%) en el terreno privado. En Castilla y León todas estas variables suben entre el 8 y $12 \%$.

Tabla 318. Evolución del número y tasa de quirófanos en Castilla y León y Galicia por dependencia funcional

\begin{tabular}{|c|c|c|c|c|c|c|c|c|}
\hline \multirow{3}{*}{ Año } & \multicolumn{4}{|c|}{ Quirófanos en funcionamiento } & \multicolumn{4}{|c|}{$\begin{array}{l}\text { Quirófanos en funcionamiento } \\
\text { por } 100.000 \text { hab. }\end{array}$} \\
\hline & \multicolumn{2}{|c|}{ Públicos } & \multicolumn{2}{|c|}{ Privados } & \multicolumn{2}{|c|}{ Públicos } & \multicolumn{2}{|c|}{ Privados } \\
\hline & $\begin{array}{l}\text { Castilla } \\
\text { y León }\end{array}$ & Galicia & $\begin{array}{l}\text { Castilla } \\
\text { y León }\end{array}$ & Galicia & $\begin{array}{l}\text { Castilla } \\
\text { y León }\end{array}$ & Galicia & $\begin{array}{l}\text { Castilla } \\
\text { y León }\end{array}$ & Galicia \\
\hline 2012 & 157 & 198 & 60 & 74 & 6,36 & 7,28 & 2,43 & 2,72 \\
\hline 2011 & 156 & 203 & 58 & 73 & 6,28 & 7,43 & 2,34 & 2,67 \\
\hline 2010 & 154 & 199 & 53 & 74 & 6,17 & 7,27 & 2,12 & 2,70 \\
\hline 2009 & 153 & 200 & 59 & 75 & 6,09 & 7,31 & 2,35 & 2,74 \\
\hline 2008 & 138 & 181 & 59 & 73 & 5,51 & 6,61 & 2,35 & 2,67 \\
\hline 2007 & 138 & 174 & 64 & 73 & 5,54 & 6,38 & 2,57 & 2,68 \\
\hline 2006 & 136 & 182 & 61 & 76 & 5,48 & 6,69 & 2,46 & 2,79 \\
\hline 2005 & 138 & 180 & 62 & 74 & 5,58 & 6,63 & 2,51 & 2,73 \\
\hline 2004 & 137 & 170 & 62 & 74 & 5,56 & 6,28 & 2,51 & 2,73 \\
\hline 2003 & 145 & 172 & 63 & 66 & 5,89 & 6,36 & 2,56 & 2,44 \\
\hline 2002 & 144 & 160 & 63 & 76 & 5,86 & 5,93 & 2,56 & 2,82 \\
\hline 2001 & 149 & 152 & 64 & 77 & 6,07 & 5,64 & 2,61 & 2,86 \\
\hline 2000 & 148 & 154 & 60 & 90 & 6,01 & 5,72 & 2,44 & 3,34 \\
\hline 1999 & 156 & 145 & 53 & 94 & 6,32 & 5,40 & 2,15 & 3,50 \\
\hline 1998 & 145 & 150 & 51 & 96 & 5,84 & 5,57 & 2,06 & 3,57 \\
\hline 1997 & 145 & 142 & 54 & 101 & 5,82 & 5,26 & 2,17 & 3,74 \\
\hline $\begin{array}{l}\text { Diferencia } \\
2012-1997\end{array}$ & 12 & 56 & 6 & -27 & 0,54 & 2,02 & 0,26 & $-1,02$ \\
\hline $\begin{array}{l}\text { \%Diferencia } \\
\text { 2012-1997 }\end{array}$ & 8,28 & 39,44 & 11,11 & $-26,73$ & 9,28 & 38,40 & 11,98 & $-27,27$ \\
\hline
\end{tabular}

Fuente: Estadística de Centros Sanitarios de Atención Especializada y Estadística de Establecimientos Sanitarios con Régimen de Internado. 
Tal y como sucede con las plazas de día, prácticamente todos los quirófanos en funcionamiento se hallan en los Hospitales generales o de agudos, dejando al resto sin dotación de este tipo, salvo en Castilla y León, que cuenta con un quirófano en un hospital de media o larga estancia. Salvo esta pequeña salvedad, 216 quirófanos se encuentran en centros generales de Castilla y León y 272 en Galicia.

Tabla 319. Evolución del número de quirófanos en Castilla y León y Galicia por finalidad asistencial

\begin{tabular}{|c|c|c|c|c|c|c|c|c|}
\hline \multirow{3}{*}{ Año } & \multicolumn{8}{|c|}{ Quirófanos en funcionamiento } \\
\hline & \multicolumn{2}{|c|}{$\begin{array}{l}\text { Hospitales } \\
\text { generales }^{5 \underline{5}}\end{array}$} & \multicolumn{2}{|c|}{$\begin{array}{c}\text { Otros hospitales } \\
\text { de agudos }\end{array}$} & \multicolumn{2}{|c|}{$\begin{array}{l}\text { Hospitales de } \\
\text { larga estancia }\end{array}$} & \multicolumn{2}{|c|}{$\begin{array}{l}\text { Hospitales } \\
\text { psiquiátricos }\end{array}$} \\
\hline & \begin{tabular}{|l|} 
Castilla \\
y Leónn
\end{tabular} & Galicia & \begin{tabular}{|l|} 
Castilla \\
y Leónn
\end{tabular} & Galicia & \begin{tabular}{|l|} 
Castilla \\
y León
\end{tabular} & Galicia & \begin{tabular}{|l|} 
Castilla \\
y León
\end{tabular} & Galicia \\
\hline 2012 & 216 & 272 & - & - & 1 & 0 & - & - \\
\hline 2011 & 214 & 276 & - & - & 0 & 0 & - & - \\
\hline 2010 & 207 & 273 & - & - & 0 & 0 & - & - \\
\hline 2009 & 202 & 260 & 10 & 15 & 0 & 0 & 0 & 0 \\
\hline 2008 & 182 & 239 & 15 & 15 & 0 & 0 & 0 & 0 \\
\hline 2007 & 189 & 231 & 10 & 16 & 3 & 0 & 0 & 0 \\
\hline 2006 & 177 & 239 & 17 & 17 & 3 & 2 & 0 & 0 \\
\hline 2005 & 180 & 233 & 17 & 20 & 3 & 1 & 0 & 0 \\
\hline 2004 & 179 & 224 & 17 & 18 & 3 & 2 & 0 & 0 \\
\hline 2003 & 187 & 218 & 17 & 17 & 4 & 3 & 0 & 0 \\
\hline 2002 & 186 & 213 & 17 & 20 & 4 & 3 & 0 & 0 \\
\hline 2001 & 199 & 212 & 10 & 15 & 4 & 2 & 0 & 0 \\
\hline 2000 & 185 & 217 & 16 & 26 & 7 & 1 & 0 & 0 \\
\hline 1999 & 189 & 208 & 15 & 30 & 5 & 1 & 0 & 0 \\
\hline 1998 & 176 & 215 & 15 & 29 & 5 & 2 & 0 & 0 \\
\hline 1997 & 180 & 213 & 15 & 29 & 4 & 1 & 0 & 0 \\
\hline $\begin{array}{l}\text { Diferencia } \\
\text { 2012-1997 }\end{array}$ & 36 & 59 & & - & -3 & -1 & - & - \\
\hline $\begin{array}{l}\text { \%Diferencia } \\
\text { 2012-1997 }\end{array}$ & 20 & 27,70 & & & -75 & -100 & - & - \\
\hline
\end{tabular}

Fuente: Estadística de Centros Sanitarios de Atención Especializada y Estadística de Establecimientos Sanitarios con Régimen de Internado.

$\underline{55}$ Desde 2010, la Estadística de Centros Sanitarios de Atención Especializada únicamente contabiliza las plazas de día en hospitales de agudos y de larga estancia. En este caso, se ha traspasado los datos de la columna de agudos a los generales por ofrecer una mayor continuidad con los años anteriores, en los que estaba en vigor la Estadística de Establecimientos Sanitarios con Régimen de Internado. 


\section{Altas}

Los ciudadanos gallegos acuden ligeramente más al hospital que los castellanoleoneses, a la vista del registro del número de altas y de la tasa en relación a la población. Así, 115,76 gallegos por cada mil habitantes recibieron el alta hospitalaria en comparación con los 113,76 castellanos. Además, en la primera comunidad este número aumenta con el paso del tiempo más acentuadamente que en la segunda. Tanto las altas $(6,87 \%)$ como la tasa $(6,02 \%)$ creció más en Galicia de 1997 a 2012 que en Castilla y León $(2,51 \%$ y $3,48 \%$, respectivamente).

Tabla 320. Evolución del número y tasa de altas en Castilla y León y Galicia

\begin{tabular}{|c|c|c|c|c|}
\hline \multirow[b]{2}{*}{ Año } & \multicolumn{2}{|c|}{$\mathrm{N}^{0}$ altas } & \multicolumn{2}{|c|}{$\mathrm{N}^{0}$ altas por 1.000 hab. } \\
\hline & $\begin{array}{l}\text { Castilla y } \\
\text { León }\end{array}$ & Galicia & $\begin{array}{c}\text { Castilla y } \\
\text { León }\end{array}$ & Galicia \\
\hline 2012 & 280.806 & 314.927 & 113,76 & 115,76 \\
\hline 2011 & 293.537 & 310.717 & 118,18 & 113,73 \\
\hline 2010 & 294.325 & 313.430 & 117,97 & 114,53 \\
\hline 2009 & 302.538 & 315.192 & 120,50 & 115,16 \\
\hline 2008 & 300.492 & 319.174 & 119,89 & 116,57 \\
\hline 2007 & 306.941 & 318.864 & 123,17 & 116,85 \\
\hline 2006 & 298.601 & 321.229 & 120,40 & 118,08 \\
\hline 2005 & 296.461 & 316.497 & 119,87 & 116,56 \\
\hline 2004 & 297.927 & 315.809 & 120,83 & 116,57 \\
\hline 2003 & 297.003 & 304.064 & 120,71 & 112,49 \\
\hline 2002 & 294.151 & 298.503 & 119,74 & 110,69 \\
\hline 2001 & 298.206 & 297.328 & 121,39 & 110,30 \\
\hline 2000 & 294.500 & 301.979 & 119,64 & 112,22 \\
\hline 1999 & 285.955 & 295.620 & 115,78 & 110,03 \\
\hline 1998 & 276.202 & 295.247 & 111,33 & 109,68 \\
\hline 1997 & 273.922 & 294.679 & 109,93 & 109,19 \\
\hline $\begin{array}{l}\text { Diferencia } \\
\text { 2012-1997 }\end{array}$ & 6.884 & 20.248 & 4,00 & 7,00 \\
\hline $\begin{array}{l}\text { \%Diferencia } \\
\text { 2012-1997 }\end{array}$ & 2,51 & 6,87 & 3,48 & 6,02 \\
\hline
\end{tabular}

Fuente: Estadística de Centros Sanitarios de Atención Especializada y Estadística de Establecimientos Sanitarios con Régimen de Internado.

El número de altas en centros públicos es muy similar en Castilla y León y en Galicia (241.679 en el primer caso y 246.866 en el segundo), aunque en los privados la cifra en Galicia (68.061) es sensiblemente superior que en Castilla y León (39.127). Y eso teniendo en cuenta que desde 1997 hasta 2012 el número de casos de esta titularidad 
en la región gallega ha disminuido un 6,74\% mientras que en la castellano-leonesa se ha incrementado un 4,42\%. En cuanto a los públicos, a lo largo de esos años, se detecta una subida del $11,35 \%$ en la primera región y un $2,21 \%$ en la segunda.

Tabla 321. Evolución del número de altas en Castilla y León y Galicia por dependencia funcional

\begin{tabular}{|l|r|r|r|r|}
\hline \multirow{2}{*}{ Año } & \multicolumn{3}{|c|}{$\mathbf{N}^{\mathbf{0}}$ altas } \\
\cline { 2 - 5 } & \multicolumn{2}{|c|}{ Públicos } & \multicolumn{2}{c|}{ Privados } \\
\cline { 2 - 5 } & $\begin{array}{c}\text { Castilla y } \\
\text { León }\end{array}$ & \multicolumn{1}{c|}{ Galicia } & $\begin{array}{c}\text { Castilla y } \\
\text { León }\end{array}$ & \multicolumn{1}{c|}{ Galicia } \\
\hline 2012 & 241.679 & 246.866 & 39.127 & 68.061 \\
\hline 2011 & 247.342 & 244.727 & 46.195 & 65.990 \\
\hline 2010 & 248.384 & 245.562 & 45.941 & 67.868 \\
\hline 2009 & 253.544 & 245.914 & 48.994 & 69.278 \\
\hline 2008 & 251.212 & 250.043 & 49.280 & 69.131 \\
\hline 2007 & 254.227 & 248.839 & 52.714 & 70.025 \\
\hline 2006 & 249.153 & 253.102 & 49.448 & 68.127 \\
\hline 2005 & 244.015 & 246.678 & 52.446 & 69.819 \\
\hline 2004 & 248.348 & 242.804 & 49.579 & 73.005 \\
\hline 2003 & 247.761 & 242.842 & 49.242 & 61.222 \\
\hline 2002 & 246.568 & 227.140 & 47.583 & 71.363 \\
\hline 2001 & 248.106 & 226.844 & 50.100 & 70.484 \\
\hline 2000 & 247.309 & 226.642 & 47.191 & 75.337 \\
\hline 1999 & 242.467 & 221.730 & 43.488 & 73.890 \\
\hline 1998 & 237.893 & 220.642 & 38.309 & 74.605 \\
\hline 1997 & 236.451 & 221.700 & 37.471 & 72.979 \\
\hline Diferencia & 5.228 & 25.166 & 1.656 & -4.918 \\
\hline $2012-1997$ & 2,21 & 11,35 & 4,42 & $-6,74$ \\
\hline$\%$ Diferencia & & & & \\
\hline $2012-1997$ & & & & \\
\hline
\end{tabular}

Fuente: Estadística de Centros Sanitarios de Atención Especializada y Estadística de Establecimientos Sanitarios con Régimen de Internado.

Las tasas por cada mil habitantes, por lo tanto, son superiores en el ámbito privado en Galicia y mayores en el público en Castilla y León. La registrada dentro del Sistema Nacional de Salud en la zona castellana es 97,91 y en la gallega, 90,74. En cambio, cuando se refiere a los centros privados, las cifras bajan a 15,85 en la primera zona y a 25,02 en la segunda. 
Tabla 322. Evolución de la tasa de altas en Castilla y León y Galicia

\begin{tabular}{|l|r|r|r|r|}
\hline \multirow{2}{*}{ Año } & \multicolumn{3}{|c|}{$\mathbf{N}^{\mathbf{0}}$ altas por 1.000 hab. } \\
\cline { 2 - 5 } & \multicolumn{2}{|c|}{ Públicos } & \multicolumn{2}{c|}{ Privados } \\
\cline { 2 - 5 } & $\begin{array}{c}\text { Castilla y } \\
\text { León }\end{array}$ & \multicolumn{1}{c|}{ Galicia } & $\begin{array}{c}\text { Castilla y } \\
\text { León }\end{array}$ & \multicolumn{1}{c|}{ Galicia } \\
\hline 2012 & 97,91 & 90,74 & 15,85 & 25,02 \\
\hline 2011 & 99,58 & 89,58 & 18,60 & 24,15 \\
\hline 2010 & 99,55 & 89,73 & 18,41 & 24,80 \\
\hline 2009 & 100,99 & 89,85 & 19,51 & 25,31 \\
\hline 2008 & 100,23 & 91,32 & 19,66 & 25,25 \\
\hline 2007 & 102,02 & 91,19 & 21,15 & 25,66 \\
\hline 2006 & 100,47 & 93,04 & 19,94 & 25,04 \\
\hline 2005 & 98,66 & 90,85 & 21,21 & 25,71 \\
\hline 2004 & 100,72 & 89,63 & 20,11 & 26,95 \\
\hline 2003 & 100,70 & 89,84 & 20,01 & 22,65 \\
\hline 2002 & 100,37 & 84,22 & 19,37 & 26,46 \\
\hline 2001 & 100,99 & 84,15 & 20,39 & 26,15 \\
\hline 2000 & 100,47 & 84,22 & 19,17 & 28,00 \\
\hline 1999 & 98,17 & 82,52 & 17,61 & 27,50 \\
\hline 1998 & 95,89 & 81,97 & 15,44 & 27,72 \\
\hline 1997 & 94,89 & 82,15 & 15,04 & 27,04 \\
\hline Diferencia & 3,02 & 8,59 & 0,81 & $-2,02$ \\
\hline $2012-1997$ & 3,18 & 10,46 & 5,39 & $-7,47$ \\
\hline$\%$ Diferencia & & & & \\
\hline $2012-1997$ & & & & \\
\hline
\end{tabular}

Fuente: Estadística de Centros Sanitarios de Atención Especializada y Estadística de Establecimientos Sanitarios con Régimen de Internado.

La mayor parte de las altas se registran en Hospitales generales o de agudos y solo una ínfima parte en centros de larga estancia. En ambas comunidades la cifra en el primer caso se sitúa en torno a las 300.000 en el año 2012, mientras que en el segundo se quedan en torno a las 1.000. Más concretamente, en Castilla y León hubo en 2012 279.329 altas en centros generales y en Galicia 313.951. En los de larga estancia hubo 1.477 y 976, respectivamente. En cuanto a la proporción respecto a la población, Castilla y León adelanta, aunque muy levemente, a Galicia tanto en unidades como en tasas. Un total de 113,16 altas por cada mil habitantes se produjeron en los Hospitales generales de la comunidad castellana y 115,40 en la gallega. En cuanto a los centros de media o larga estancia, las tasas bajan hasta el 0,60 y 0,36 , en este orden. 
Tabla 323. Evolución del número de altas en Castilla y León y Galicia por finalidad asistencial

\begin{tabular}{|c|c|c|c|c|c|c|c|c|}
\hline \multirow{3}{*}{ Año } & \multicolumn{8}{|c|}{$\mathrm{N}^{0}$ altas } \\
\hline & \multicolumn{2}{|c|}{$\begin{array}{l}\text { Hospitales } \\
\text { generales }\end{array}$} & \multicolumn{2}{|c|}{$\begin{array}{c}\text { Otros hospitales } \\
\text { de agudos }\end{array}$} & \multicolumn{2}{|c|}{$\begin{array}{l}\text { Hospitales de } \\
\text { larga estancia }\end{array}$} & \multicolumn{2}{|c|}{$\begin{array}{c}\text { Hospitales } \\
\text { psiquiátricos }\end{array}$} \\
\hline & $\begin{array}{l}\text { Castilla } \\
\text { y León }\end{array}$ & Galicia & $\begin{array}{l}\text { Castilla } \\
\text { y León }\end{array}$ & Galicia & $\begin{array}{l}\text { Castilla } \\
\text { y León }\end{array}$ & Galicia & $\begin{array}{l}\text { Castilla } \\
\text { y León }\end{array}$ & Galicia \\
\hline 2012 & 279.329 & 313.951 & - & - & 1.477 & 976 & - & - \\
\hline 2011 & 292.244 & 309.559 & - & - & 1.293 & 1.158 & - & - \\
\hline 2010 & 293.016 & 312.017 & - & - & 1.309 & 1.413 & - & - \\
\hline 2009 & 292.692 & 307.642 & 8.537 & 6.085 & 796 & 779 & 513 & 686 \\
\hline 2008 & 286.806 & 310.671 & 12.489 & 6.161 & 774 & 1.647 & 423 & 695 \\
\hline 2007 & 296.512 & 309.871 & 8.371 & 6.784 & 1.449 & 1.638 & 609 & 571 \\
\hline 2006 & 283.612 & 312.469 & 12.012 & 6.707 & 1.506 & 1.465 & 1.471 & 588 \\
\hline 2005 & 280.429 & 303.482 & 13.074 & 11.046 & 1.613 & 1.425 & 1.345 & 544 \\
\hline 2004 & 280.961 & 303.581 & 13.803 & 11.129 & 1.778 & 487 & 1.385 & 612 \\
\hline 2003 & 280.352 & 290.142 & 13.842 & 12.678 & 1.488 & 559 & 1.321 & 685 \\
\hline 2002 & 273.445 & 284.814 & 17.903 & 12.481 & 1.403 & 611 & 1.400 & 597 \\
\hline 2001 & 284.276 & 284.330 & 11.215 & 11.632 & 1.370 & 890 & 1.345 & 476 \\
\hline 2000 & 272.373 & 283.934 & 18.704 & 17.027 & 2.153 & 541 & 1.270 & 477 \\
\hline 1999 & 267.754 & 277.817 & 15.220 & 16.566 & 1.689 & 720 & 1.292 & 517 \\
\hline 1998 & 258.962 & 278.133 & 14.000 & 16.001 & 2.029 & 470 & 1.211 & 643 \\
\hline 1997 & 257.943 & 279.449 & 13.159 & 13.031 & 1.347 & 1.229 & 1.473 & 970 \\
\hline $\begin{array}{l}\text { Diferencia } \\
\text { 2012-1997 }\end{array}$ & 21.386 & 34.502 & & - & 130 & -253 & - & - \\
\hline $\begin{array}{l}\text { \%Diferencia } \\
2012-1997\end{array}$ & 8,29 & 12,35 & & & 9,65 & $-20,59$ & & \\
\hline
\end{tabular}

Fuente: Estadística de Centros Sanitarios de Atención Especializada y Estadística de Establecimientos Sanitarios con Régimen de Internado.

$\underline{56}$ Desde 2010, la Estadística de Centros Sanitarios de Atención Especializada únicamente contabiliza las plazas de día en hospitales de agudos y de larga estancia. En este caso, se ha traspasado los datos de la columna de agudos a los generales por ofrecer una mayor continuidad con los años anteriores, en los que estaba en vigor la Estadística de Establecimientos Sanitarios con Régimen de Internado. 
Tabla 324. Evolución de la tasa de altas en Castilla y León y Galicia por finalidad asistencial

\begin{tabular}{|c|c|c|c|c|c|c|c|c|}
\hline \multirow{3}{*}{ Año } & \multicolumn{8}{|c|}{$\mathrm{N}^{0}$ altas por 1.000 hab. } \\
\hline & \multicolumn{2}{|c|}{$\begin{array}{l}\text { Hospitales } \\
\text { generales }^{57}\end{array}$} & \multicolumn{2}{|c|}{$\begin{array}{c}\text { Otros hospitales } \\
\text { de agudos }\end{array}$} & \multicolumn{2}{|c|}{$\begin{array}{c}\text { Hospitales de } \\
\text { larga estancia }\end{array}$} & \multicolumn{2}{|c|}{$\begin{array}{c}\text { Hospitales } \\
\text { psiquiátricos }\end{array}$} \\
\hline & $\begin{array}{l}\text { Castilla } \\
\text { y León }\end{array}$ & Galicia & $\begin{array}{l}\text { Castilla } \\
\text { y León }\end{array}$ & Galicia & $\begin{array}{l}\text { Castilla } \\
\text { y León }\end{array}$ & Galicia & $\begin{array}{l}\text { Castilla } \\
\text { y León }\end{array}$ & Galicia \\
\hline 2012 & 113,16 & 115,40 & - & - & 0,60 & 0,36 & - & - \\
\hline 2011 & 117,66 & 113,31 & - & - & 0,52 & 0,42 & - & - \\
\hline 2010 & 117,44 & 114,02 & - & - & 0,52 & 0,52 & - & - \\
\hline 2009 & 116,58 & 112,40 & 3,40 & 2,22 & 0,32 & 0,28 & 0,20 & 0,25 \\
\hline 2008 & 114,43 & 113,46 & 4,98 & 2,25 & 0,31 & 0,60 & 0,17 & 0,25 \\
\hline 2007 & 118,98 & 113,56 & 3,36 & 2,49 & 0,58 & 0,60 & 0,24 & 0,21 \\
\hline 2006 & 114,36 & 114,86 & 4,84 & 2,47 & 0,61 & 0,54 & 0,59 & 0,22 \\
\hline 2005 & 113,39 & 111,76 & 5,29 & 4,07 & 0,65 & 0,52 & 0,54 & 0,20 \\
\hline 2004 & 113,95 & 112,06 & 5,60 & 4,11 & 0,72 & 0,18 & 0,56 & 0,23 \\
\hline 2003 & 113,95 & 107,34 & 5,63 & 4,69 & 0,60 & 0,21 & 0,54 & 0,25 \\
\hline 2002 & 111,31 & 105,61 & 7,29 & 4,63 & 0,57 & 0,23 & 0,57 & 0,22 \\
\hline 2001 & 115,72 & 105,48 & 4,57 & 4,32 & 0,56 & 0,33 & 0,55 & 0,18 \\
\hline 2000 & 110,65 & 105,51 & 7,60 & 6,33 & 0,87 & 0,20 & 0,52 & 0,18 \\
\hline 1999 & 108,41 & 103,40 & 6,16 & 6,17 & 0,68 & 0,27 & 0,52 & 0,19 \\
\hline 1998 & 104,38 & 103,32 & 5,64 & 5,94 & 0,82 & 0,17 & 0,49 & 0,24 \\
\hline 1997 & 103,52 & 103,55 & 5,28 & 4,83 & 0,54 & 0,46 & 0,59 & 0,36 \\
\hline $\begin{array}{l}\text { Diferencia } \\
2012-1997 \\
\end{array}$ & 9,64 & 11,85 & & & 0,06 & $-0,1$ & & \\
\hline $\begin{array}{l}\text { \%Diferencia } \\
2012-1997\end{array}$ & 9,31 & 11,44 & & & 11,11 & $-21,74$ & & \\
\hline
\end{tabular}

Fuente: Estadística de Centros Sanitarios de Atención Especializada y Estadística de Establecimientos Sanitarios con Régimen de Internado.

Hay prácticamente el mismo número de hombres castellano-leoneses y gallegos atendidos en los centros pertenecientes al Sistema Nacional de Salud, al contrario de lo que sucede con las mujeres. Un total 117.165 hombres recibieron el alta en Castilla y León respecto a los 117.130 de Galicia. En cuanto a las mujeres, son 118.565 en la primera región y 123.863 en la segunda. Es en la región castellana donde más aumenta el número de casos de ambos sexos conforme pasan los años. Respecto a 1997, en 2012

\footnotetext{
57 Desde 2010, la Estadística de Centros Sanitarios de Atención Especializada únicamente contabiliza las plazas de día en hospitales de agudos y de larga estancia. En este caso, se ha traspasado los datos de la columna de agudos a los generales por ofrecer una mayor continuidad con los años anteriores, en los que estaba en vigor la Estadística de Establecimientos Sanitarios con Régimen de Internado.
} 
hubo un incremento del $27,09 \%$ de altas en varones y un 23,63 en las mujeres. La evolución en Galicia no presenta tanta variación: 3,01\% y 3,84\%, respectivamente.

Tabla 325. Evolución del número de altas en Castilla y León y Galicia por sexo

\begin{tabular}{|c|c|c|c|c|c|c|}
\hline \multirow{3}{*}{ Año } & \multicolumn{6}{|c|}{$\operatorname{Casos}^{58}$} \\
\hline & \multicolumn{2}{|c|}{ Varón } & \multicolumn{2}{|c|}{ Mujer } & \multicolumn{2}{|c|}{ Otros } \\
\hline & $\begin{array}{l}\text { Castilla y } \\
\text { León }\end{array}$ & Galicia & $\begin{array}{c}\text { Castilla y } \\
\text { León }\end{array}$ & Galicia & $\begin{array}{c}\text { Castilla y } \\
\text { León }\end{array}$ & Galicia \\
\hline 2012 & 117.165 & 117.130 & 118.565 & 123.863 & 1 & 3 \\
\hline 2011 & 120.144 & 114.102 & 121.316 & 123.828 & 6 & 2 \\
\hline 2010 & 119.984 & 113.461 & 121.681 & 124.107 & 4 & 5 \\
\hline 2009 & 121.876 & 115.566 & 124.058 & 126.048 & 1 & - \\
\hline 2008 & 119.207 & 114.149 & 123.813 & 127.489 & - & 3 \\
\hline 2007 & 122.004 & 114.756 & 124.899 & 125.439 & 2 & 8 \\
\hline 2006 & 116.582 & 117.141 & 120.898 & 127.038 & 4 & 11 \\
\hline 2005 & 117.423 & 115.369 & 119.304 & 124.910 & 2 & 1 \\
\hline 2004 & 114.675 & 113.721 & 116.534 & 123.046 & 16 & 3 \\
\hline 2003 & 109.825 & 113.453 & 111.828 & 121.966 & 7 & 6 \\
\hline 2002 & 107.232 & 105.801 & 109.366 & 114.785 & 16 & 15 \\
\hline 2001 & 106.593 & 104.699 & 107.794 & 114.940 & 12 & 21 \\
\hline 2000 & 106.898 & 106.097 & 107.864 & 114.169 & 108 & 11 \\
\hline 1999 & 103.614 & 103.067 & 104.984 & 110.728 & 157 & 9 \\
\hline 1998 & 101.256 & 117.533 & 102.363 & 122.677 & 112 & 333 \\
\hline 1997 & 92.187 & 113.709 & 95.903 & 119.285 & 139 & 306 \\
\hline $\begin{array}{l}\text { Diferencia } \\
\text { 2012-1997 }\end{array}$ & 24.978 & 3.421 & 22.662 & 4.578 & -138 & -303 \\
\hline $\begin{array}{l}\text { \%Diferencia } \\
2012-1997\end{array}$ & 27,09 & 3,01 & 23,63 & 3,84 & $-99,28$ & $-99,02$ \\
\hline
\end{tabular}

Fuente: Conjunto Mínimo Básico de Datos de Hospitalización (CMBD-H) del Ministerio de Sanidad, Servicios Sociales e Igualdad.

$\underline{58}$ El número de casos del informe que aquí se utiliza difiere ligeramente del de la Estadística de Centros Sanitarios de Atención Especializada y del de la Estadística de Establecimientos Sanitarios con Régimen de Internado. En el Conjunto Mínimo Básico de Datos de Hospitalización (CMBD-H) se incluyen "todas las altas producidas en los Hospitales públicos generales. Comprende a los hospitales de la red de utilización pública y o administrados públicamente o con concierto sustitutorio (actividad básicamente destinada a cubrir la asistencia de un área de población protegida por el sistema público). También se encuentran entre ellos los hospitales monográficos que forman complejo con Hospitales generales o de área y, en general, y salvo las excepciones señaladas, no se incluyen hospitales psiquiátricos ni hospitales de larga estancia" (Ministerio de Sanidad, 2013d). En cambio, en las otras estadísticas, se cubre "todo el ámbito de la actividad hospitalaria a nivel nacional incluyendo datos de todos los centros hospitalarios del territorio nacional tanto públicos como privados" (Ministerio de Sanidad, 2013c). 
Hay más altas producidas por casos urgentes en Galicia que en Castilla y León y más altas por ingresos programados en Castilla y León que en Galicia. Más concretamente, en la zona castellana, se registran en 2012 un total de 167.540 para el primer tipo y 63.620 para el segundo. En cambio, en el territorio gallego se produjeron en ese mismo periodo de tiempo 177.376 altas por ingreso urgente y 63.620 por admisiones programadas.

En cuanto a la evolución temporal, de 1997 a 2012, las altas por entradas urgentes han aumentado un 25,33\% en Castilla y León y un 15,57\% en Galicia. En cambio, las entradas programadas en la primera región han crecido un $25,91 \%$ mientras que en el segundo territorio merman un $20,29 \%$.

Tabla 326. Evolución del número de altas en Castilla y León y Galicia por tipo de ingreso

\begin{tabular}{|c|c|c|c|c|c|c|}
\hline \multirow{3}{*}{ Año } & \multicolumn{6}{|c|}{ Casos } \\
\hline & \multicolumn{2}{|c|}{ Urgente } & \multicolumn{2}{|c|}{ Programado } & \multicolumn{2}{|c|}{ Otros } \\
\hline & $\begin{array}{l}\text { Castilla y } \\
\text { León }\end{array}$ & Galicia & $\begin{array}{c}\text { Castilla y } \\
\text { León }\end{array}$ & Galicia & $\begin{array}{l}\text { Castilla y } \\
\text { León }\end{array}$ & Galicia \\
\hline 2012 & 167.540 & 177.376 & 68.189 & 63.620 & 2 & \\
\hline 2011 & 171.320 & 177.444 & 70.146 & 60.488 & - & \\
\hline 2010 & 174.213 & 179.085 & 67.456 & 58.488 & - & \\
\hline 2009 & 177.664 & 180.327 & 68.271 & 61.287 & - & \\
\hline 2008 & 178.343 & 180.005 & 62.638 & 61.636 & 2.039 & \\
\hline 2007 & 178.820 & 179.545 & 66.141 & 60.658 & 1.944 & \\
\hline 2006 & 172.160 & 181.681 & 63.940 & 62.509 & 1.384 & \\
\hline 2005 & 171.022 & 179.416 & 64.441 & 60.864 & 1.266 & \\
\hline 2004 & 165.174 & 175.564 & 64.952 & 61.206 & 1.099 & \\
\hline 2003 & 159.003 & 174.458 & 61.754 & 60.967 & 903 & - \\
\hline 2002 & 155.022 & 158.777 & 60.994 & 61.824 & 598 & 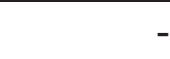 \\
\hline 2001 & 153.913 & 153.043 & 60.158 & 66.617 & 328 & \\
\hline 2000 & 152.018 & 156.777 & 62.852 & 63.500 & - & \\
\hline 1999 & 145.752 & 151.751 & 63.003 & 62.053 & - & - \\
\hline 1998 & 141.211 & 161.159 & 62.423 & 79.383 & 97 & 1 \\
\hline 1997 & 133.684 & 153.483 & 54.156 & 79.816 & 389 & 1 \\
\hline $\begin{array}{l}\text { Diferencia } \\
2012-1997\end{array}$ & 167.440 & 177.276 & 68.089 & 63.520 & -98 & \\
\hline \begin{tabular}{|l|} 
\%Diferencia \\
$2012-1997$
\end{tabular} & 25,33 & 15,57 & 25,91 & $-20,29$ & $-99,49$ & \\
\hline
\end{tabular}

Fuente: Conjunto Mínimo Básico de Datos de Hospitalización (CMBD-H) del Ministerio de Sanidad, Servicios Sociales e Igualdad. 
No hay sorpresas en cuanto a las altas por grupos de edades. Las comprendidas entre 1 y 14, 15 y 44 y 45 y 64 años, por ejemplo, son parecidas en las dos regiones analizadas. Las de los mayores de 74 son más abundantes en el territorio castellano, dado que hay más población de esta edad. Por el contrario, y también debido a la mayor cantidad de ciudadanos de estas características, se producen más casos de personas de entre 45 y 64 años en Galicia. Lo único reseñable es la cifra que otorgan los menores de un año de vida, a pesar de que se contabilizan prácticamente los mismos en ambos territorios: en Castilla y León se concedieron 6.361 altas en 2012 y en Galicia más, concretamente 7.216. Se trata de una cuantía un 16,61\% mayor de lo que se registró en esta última comunidad en 1997, mientras que esa franja de edad en el territorio castellano disminuyó un 13,71\%. En la evolución de las altas de personas entre 45 y 64 años también se da una discrepancia entre ambas regiones: en Castilla y León, respecto a 1997, el año 2012 contó con un 24,18\% más y en Galicia, un 4,82\% menos.

Tabla 327. Evolución del número de altas en Castilla y León por grupos de edad

\begin{tabular}{|l|r|r|r|r|r|r|}
\hline \multirow{2}{*}{ Año } & \multicolumn{7}{|c|}{ Casos en Castilla y León } \\
\cline { 2 - 8 } & $\begin{array}{c}\text { Menos de } \\
\text { 1 año }\end{array}$ & $\mathbf{0 1 - 1 4}$ años & $\mathbf{1 5 - 4 4}$ años & $\mathbf{4 5 - 6 4}$ años & $\mathbf{6 5 - 7 4}$ años & $\begin{array}{c}\text { Más de 74 } \\
\text { años }\end{array}$ \\
\hline 2012 & 6.361 & 10.900 & 50.019 & 49.700 & 34.377 & 84.374 \\
\hline 2011 & 6.986 & 11.546 & 53.042 & 50.936 & 36.359 & 82.597 \\
\hline 2010 & 6.963 & 11.715 & 55.302 & 50.365 & 36.727 & 80.597 \\
\hline 2009 & 6.692 & 11.939 & 57.441 & 51.686 & 38.454 & 79.723 \\
\hline 2008 & 7.796 & 11.427 & 59.475 & 49.114 & 38.285 & 76.923 \\
\hline 2007 & 7.836 & 12.806 & 59.963 & 50.209 & 41.023 & 75.068 \\
\hline 2006 & 7.722 & 12.600 & 59.624 & 48.967 & 40.349 & 68.222 \\
\hline 2005 & 7.674 & 12.057 & 59.487 & 48.058 & 42.196 & 67.257 \\
\hline 2004 & 7.509 & 12.121 & 59.428 & 47.640 & 42.379 & 62.148 \\
\hline 2003 & 7.764 & 12.761 & 58.436 & 44.736 & 42.059 & 55.904 \\
\hline 2002 & 7.701 & 12.752 & 57.647 & 43.640 & 41.980 & 52.894 \\
\hline 2001 & 7.721 & 13.593 & 56.627 & 43.614 & 42.522 & 50.322 \\
\hline 2000 & 8.420 & 13.704 & 56.907 & 43.475 & 43.256 & 49.108 \\
\hline 1999 & 7.438 & 13.397 & 55.855 & 43.098 & 42.297 & 46.670 \\
\hline 1998 & 7.409 & 13.455 & 55.455 & 43.199 & 41.072 & 43.141 \\
\hline 1997 & 7.372 & 14.270 & 53.277 & 40.023 & 36.711 & 36.576 \\
\hline $\begin{array}{l}\text { Diferencia } \\
2012-1997\end{array}$ & -1.011 & -3.370 & -3.258 & 9.677 & -2.334 & 47.798 \\
\hline$\%$ Diferencia & $-13,71$ & $-23,62$ & $-6,12$ & 24,18 & $-6,36$ & 130,68 \\
\hline $2012-1997$ & & & & & & \\
\hline
\end{tabular}

Fuente: Conjunto Mínimo Básico de Datos de Hospitalización (CMBD-H) del Ministerio de Sanidad, Servicios Sociales e Igualdad. 
Tabla 328. Evolución del número de altas en Galicia por grupos de edad

\begin{tabular}{|c|c|c|c|c|c|c|}
\hline \multirow[b]{2}{*}{ Año } & \multicolumn{6}{|c|}{ Casos en Galicia } \\
\hline & $\begin{array}{c}\text { Menos de } \\
1 \text { año }\end{array}$ & 01-14 años & 15-44 años & 45-64 años & 65-74 años & $\begin{array}{c}\text { Más de } 74 \\
\text { años }\end{array}$ \\
\hline 2012 & 7.216 & 11.717 & 54.334 & 52.102 & 38.241 & 77.386 \\
\hline 2011 & 7.557 & 11.543 & 55.615 & 50.599 & 37.798 & 74.820 \\
\hline 2010 & 7.136 & 12.220 & 58.124 & 50.093 & 37.878 & 72.122 \\
\hline 2009 & 7.779 & 12.956 & 60.608 & 51.817 & 38.583 & 69.871 \\
\hline 2008 & 7.645 & 13.192 & 63.118 & 51.460 & 39.017 & 67.209 \\
\hline 2007 & 7.667 & 14.001 & 62.681 & 51.227 & 39.882 & 64.745 \\
\hline 2006 & 8.200 & 14.867 & 64.654 & 51.822 & 41.909 & 62.738 \\
\hline 2005 & 7.692 & 14.246 & 65.083 & 50.908 & 41.808 & 60.543 \\
\hline 2004 & 7.789 & 14.454 & 64.919 & 50.266 & 42.277 & 57.065 \\
\hline 2003 & 7.868 & 14.964 & 64.866 & 49.173 & 42.898 & 55.656 \\
\hline 2002 & 7.515 & 14.671 & 60.966 & 46.258 & 40.889 & 50.302 \\
\hline 2001 & 7.420 & 15.177 & 61.308 & 46.653 & 40.622 & 48.480 \\
\hline 2000 & 8.149 & 16.048 & 61.729 & 46.725 & 40.013 & 47.613 \\
\hline 1999 & 7.204 & 15.866 & 60.044 & 46.679 & 39.173 & 44.838 \\
\hline 1998 & 7.525 & 17.580 & 70.387 & 55.400 & 41.967 & 47.684 \\
\hline 1997 & 6.188 & 18.598 & 68.133 & 54.739 & 41.102 & 44.540 \\
\hline $\begin{array}{l}\text { Diferencia } \\
\text { 2012-1997 }\end{array}$ & 1.028 & -6.881 & -13.799 & -2.637 & -2.861 & 32.846 \\
\hline $\begin{array}{l}\text { \%Diferencia } \\
\text { 2012-1997 }\end{array}$ & 16,61 & $-37,00$ & $-20,25$ & $-4,82$ & $-6,96$ & 73,74 \\
\hline
\end{tabular}

Fuente: Conjunto Mínimo Básico de Datos de Hospitalización (CMBD-H) del Ministerio de Sanidad, Servicios Sociales e Igualdad.

\section{Estancia media}

El tiempo que pasan los ciudadanos en el hospital es sensiblemente mayor en Galicia que en Castilla y León. En el primer sitio, un paciente permanece ingresado, de media, 8,33 días, mientras que en la segunda región está casi una jornada menos, más concretamente 7,43. Se trata, en ambos casos, de cifras más bajas que las registradas en años anteriores, cuya máxima fue de 9,16 en 1999 en la zona gallega y de 8,14 en 1997 en la castellano-leonesa. 
Tabla 329. Evolución de los días de estancia media en Castilla y León y Galicia

\begin{tabular}{|l|r|r|}
\hline \multirow{2}{*}{ Año } & \multicolumn{2}{|c|}{ Estancia Media } \\
\cline { 2 - 3 } & $\begin{array}{c}\text { Castilla y } \\
\text { León }\end{array}$ & \multicolumn{1}{c|}{ Galicia } \\
\hline 2012 & 7,43 & 8,33 \\
\hline 2011 & 7,46 & 8,59 \\
\hline 2010 & 7,51 & 8,89 \\
\hline 2009 & 7,67 & 8,88 \\
\hline 2008 & 7,90 & 9,00 \\
\hline 2007 & 7,78 & 9,10 \\
\hline 2006 & 7,63 & 8,96 \\
\hline 2005 & 7,70 & 9,10 \\
\hline 2004 & 7,66 & 9,13 \\
\hline 2003 & 7,49 & 8,99 \\
\hline 2002 & 7,50 & 9,09 \\
\hline 2001 & 7,55 & 9,11 \\
\hline 2000 & 7,65 & 9,12 \\
\hline 1999 & 7,81 & 9,16 \\
\hline 1998 & 7,99 & 8,98 \\
\hline 1997 & 8,14 & 9,15 \\
\hline Diferencia & $-0,71$ & $-0,82$ \\
\hline $2012-1997$ & $-8,72$ & $-8,96$ \\
\hline$\%$ Diferencia & & \\
\hline $2012-1997$ & & \\
\hline
\end{tabular}

Fuente: Conjunto Mínimo Básico de Datos de Hospitalización (CMBD-H) del Ministerio de Sanidad, Servicios Sociales e Igualdad.

Los hombres son los que tienden a permanecer más tiempo en un centro de atención especializada, sobre todo en Galicia. En esta región, un varón suele estar ingresado 9,05 jornadas, en comparación con Castilla y León, que da cobijo a sus pacientes 7,98 días, tal y como refleja el año 2012. Si se observa la evolución temporal se aprecia que es una tendencia que permanece a lo largo de los años. De hecho, en Galicia, el pico de estancia se registra en 2007 con un máximo de 10,04 días, mientras que en la otra comunidad no supera los 8,73 .

En cuanto a las mujeres, sus estancias siguen siendo más largas en Galicia que en Castilla y León. Concretamente, en 2012, en la primera zona están de media 7,65 jornadas en el hospital y en la segunda, 6,89. En ambos sexos, suponen unas disminuciones respecto a las registradas en el año 1997 de entre el 7 y el 11\%. 
Tabla 330. Evolución de los días de estancia media en Castilla y León y Galicia por sexo

\begin{tabular}{|c|c|c|c|c|c|c|}
\hline \multirow{3}{*}{ Año } & \multicolumn{6}{|c|}{ Estancia Media } \\
\hline & \multicolumn{2}{|c|}{ Varón } & \multicolumn{2}{|c|}{ Mujer } & \multicolumn{2}{|c|}{ Otros } \\
\hline & \begin{tabular}{c|} 
Castilla y \\
León
\end{tabular} & Galicia & \begin{tabular}{c|} 
Castilla $y$ \\
León
\end{tabular} & Galicia & \begin{tabular}{|c|} 
Castilla y \\
León
\end{tabular} & Galicia \\
\hline 2012 & 7,98 & 9,05 & 6,89 & 7,65 & 9 & 6 \\
\hline 2011 & 7,96 & 9,41 & 6,96 & 7,84 & 5,17 & 7,50 \\
\hline 2010 & 8,03 & 9,71 & 7,00 & 8,13 & 3,75 & 2,80 \\
\hline 2009 & 8,31 & 9,73 & 7,05 & 8,11 & 3 & \\
\hline 2008 & 8,61 & 9,96 & 7,20 & 8,15 & - & 4,33 \\
\hline 2007 & 8,41 & 10,04 & 7,16 & 8,25 & 2,50 & 6,38 \\
\hline 2006 & 8,30 & 9,75 & 6,99 & 8,23 & 4,75 & 11,27 \\
\hline 2005 & 8,30 & 9,90 & 7,11 & 8,37 & 2,50 & 20 \\
\hline 2004 & 8,28 & 9,98 & 7,05 & 8,35 & 3,75 & 19,33 \\
\hline 2003 & 8,09 & 9,76 & 6,91 & 8,27 & 4,29 & 4 \\
\hline 2002 & 8,12 & 9,88 & 6,89 & 8,36 & 6,13 & 3,53 \\
\hline 2001 & 8,12 & 9,85 & 6,99 & 8,43 & 3,83 & 3,90 \\
\hline 2000 & 8,16 & 9,88 & 7,14 & 8,40 & 3,66 & 9,64 \\
\hline 1999 & 8,31 & 9,83 & 7,32 & 8,53 & 4,36 & 5,67 \\
\hline 1998 & 8,51 & 9,53 & 7,48 & 8,46 & 4,09 & 7,31 \\
\hline 1997 & 8,73 & 9,76 & 7,59 & 8,57 & 3,06 & 6,41 \\
\hline $\begin{array}{l}\text { Diferencia } \\
\text { 2012-1997 }\end{array}$ & $-0,75$ & $-0,71$ & $-0,7$ & $-0,92$ & 5,94 & $-0,41$ \\
\hline $\begin{array}{l}\text { \%Diferencia } \\
2012-1997\end{array}$ & $-8,59$ & $-7,27$ & $-9,22$ & $-10,74$ & 194,12 & $-6,40$ \\
\hline
\end{tabular}

Fuente: Conjunto Mínimo Básico de Datos de Hospitalización (CMBD-H) del Ministerio de Sanidad, Servicios Sociales e Igualdad.

La estancia media de los ingresos programados es un poco más larga en Galicia, con 5,53 días, que en Castilla y León, que registra 5,41. También se extienden más en el tiempo los ingresos urgentes en la región gallega, aunque en esta ocasión se acerca a la jornada de diferencia. Así, en esta zona, un paciente habitualmente duerme en el hospital 9,33 días, mientras que un castellano-leonés lo hace durante 8,26.

En ambas comunidades desciende la estancia media con el paso de los años, aunque es más acentuada en los casos de ingreso programado (en torno al 14-19\%) que en los urgentes (cuya disminución se queda sobre el 6-11\%). 
Tabla 331. Evolución de los días de estancia media en Castilla y León y Galicia por tipo de ingreso

\begin{tabular}{|c|c|c|c|c|c|c|}
\hline \multirow{3}{*}{ Año } & \multicolumn{6}{|c|}{ Estancia Media } \\
\hline & \multicolumn{2}{|c|}{ Urgente } & \multicolumn{2}{|c|}{ Programado } & \multicolumn{2}{|c|}{ Otros } \\
\hline & $\begin{array}{c}\text { Castilla y } \\
\text { León }\end{array}$ & Galicia & $\begin{array}{c}\text { Castilla y } \\
\text { León }\end{array}$ & Galicia & $\begin{array}{l}\text { Castilla y } \\
\text { León }\end{array}$ & Galicia \\
\hline 2012 & 8,26 & 9,33 & 5,41 & 5,53 & 14 & \\
\hline 2011 & 8,37 & 9,54 & 5,24 & 5,81 & - & \\
\hline 2010 & 8,40 & 9,81 & 5,21 & 6,05 & - & \\
\hline 2009 & 8,55 & 9,85 & 5,38 & 6,03 & - & \\
\hline 2008 & 8,77 & 9,95 & 5,52 & 6,24 & 4,05 & \\
\hline 2007 & 8,74 & 10,07 & 5,35 & 6,24 & 2,41 & \\
\hline 2006 & 8,52 & 9,84 & 5,36 & 6,39 & 2,23 & \\
\hline 2005 & 8,59 & 9,98 & 5,45 & 6,53 & 2,10 & . \\
\hline 2004 & 8,53 & 10,01 & 5,54 & 6,62 & 1,96 & \\
\hline 2003 & 8,34 & 9,82 & 5,39 & 6,62 & 2,56 & \\
\hline 2002 & 8,36 & 9,92 & 5,37 & 6,95 & 2,60 & \\
\hline 2001 & 8,40 & 10,02 & 5,40 & 7,01 & 2,22 & \\
\hline 2000 & 8,48 & 9,96 & 5,62 & 7,04 & - & - \\
\hline 1999 & 8,64 & 10,00 & 5,88 & 7,11 & - & - \\
\hline 1998 & 8,83 & 10,16 & 6,09 & 6,58 & 11,31 & 6 \\
\hline 1997 & 8,86 & 10,37 & 6,31 & 6,81 & 17,85 & 7 \\
\hline $\begin{array}{l}\text { Diferencia } \\
\text { 2012-1997 }\end{array}$ & $-0,6$ & $-1,04$ & $-0,9$ & $-1,28$ & $-3,85$ & -7 \\
\hline $\begin{array}{l}\text { \%Diferencia } \\
\text { 2012-1997 }\end{array}$ & $-6,77$ & $-10,03$ & $-14,26$ & $-18,80$ & $-21,57$ & -100 \\
\hline
\end{tabular}

Fuente: Conjunto Mínimo Básico de Datos de Hospitalización (CMBD-H) del Ministerio de Sanidad, Servicios Sociales e Igualdad. 


\section{ANEXO 3. CITAS LITERALES EN SU IDIOMA ORIGINAL}

\footnotetext{
1 "Public relations is often confused with and used as a handy synonym for some of its functional parts, such as publicity, press-agentry, propaganda, and institutional advertising". Cutlip y Center (1964: 3).

2 "On the surface, therefore, it seems nearly impossible to come up with a single definition of public relations”. J. E. Grunig y Hunt (1984: 6).

3 "Realistically, it can be defined as little more than «what public relations people do»". J. E. Grunig (1992b: 32).
}

4 "Public relations may be practiced by the $\$ 200,000$-a-year vice president of a major corporation who heads a department of 100 professionals or more. It may also be practiced by a part-time employee or volunteer producing a brochure or a press release for a small-town charitable organization. One public relations person may spend all of his or her time writing - press release, stories for an employee publication, publicservice announcements, or informational pamphlets. Another practitioner may seldom write at all, spending his o her time managing other practitioners, meeting with management, or dealing with the press". J. E. Grunig y Hunt (1984: 6).

5 "Public relations is a distinctive management function which helps establish and maintain mutual lines of communication, understanding, acceptance and cooperation between an organization and its publics; involves the management of problems or issues; helps management to keep informed on and responsive to public opinion; defines and emphasizes the responsibility of management to serve the public interest; helps management keep abreast of and affectively utilize change, serving as an early warning system to help anticipate trends; and uses research and sound and ethical communication techniques as its principal tools". Rex Harlow (1976).

6 "Public relations is a strategic communication process that builds mutually beneficial relationships between organizations and their publics". Corbett (2012).

7 "Public relations is the management function that establishes and maintains mutually beneficial relationships between an organization and the publics on whom its success or failure depends". Cutlip, Center y Broom (2000).

8 "Planned effort to influence opinion through acceptable performance and two-way communication". Cutlip y Center (1964: 3 ).

9 "Management of communication between an organization and its publics". J. E. Grunig y Hunt (1984: 6).

10 "Public relations is the management function which evaluates public attitudes, identifies the policies and procedures of an individual or an organization with the public 
interest, and plans and executes a program of action to earn public understanding and acceptance". Cutlip y Center (1964: 4) y J. E. Grunig y Hunt (1984: 8).

11 "The deliberate, planned, and sustained effort to establish and maintain mutual understanding between an organization and its public". The British Institute of Public Relations. J. E. Grunig y Hunt (1984: 7).

12 "Public Relations is about reputation - the result of what you do, what you say and what others say about you. Public Relations is the discipline which looks after reputation, with the aim of earning understanding and support and influencing opinion and behaviour. It is the planned and sustained effort to establish and maintain goodwill and mutual understanding between an organisation and its publics". Chartered Institute of Public Relations (n.d.).

13 "The deliberate, planned and sustained effort to establish and maintain mutual understanding between an organization (or individual) and its (or their) publics". Public Relations Institute of Australia (2013).

14 "Direct payment of the presentation of a good, service, or product". Berkowitz (2007).

15 "News stories carry greater credibility than advertising messages", debido al hecho de que existen "more positive perceptions about news rather than advertising". Choi y Park (2011).

16 "The billboard, radio or magazine advertisements are all recognized as a paid advertisement in which the sponsor of the message has a particular interest in getting the message to the public". Berkowitz (2007).

17 "Marketing is the management process responsible for identifying, anticipating and satisfying customer requirements profitably". The Chartered Institute of Marketing (n.d.).

18 "Sum of activities involved in directing the flow of goods and services from producers to consumers". Enciclopedia Británica (1990).

19 "People who purchase products or who use the services of an organization". Hunt y J. E. Grunig (1994: 6).

20 "They create themselves and pursue the organization when they are unhappy" Hunt y J. E. Grunig (1994: 6).

21 "While marketing concerns itself specifically with goods and services aimed at the consumer, public relations focuses on consumers as merely one of the many publics". King y Scrimger (1993) sobre Ehling y White (1992).

22 "Marketing management presupposes a business organization with a single economic purpose, that of producing goods or services for a single constituency (consumers). Public relations management, on the other hand, presupposes an organization (not 
always a business enterprise) that is multipurpose in its commitment and serves a number of different constituencies, none of which are necessarily friendly and any one of which can come into conflict with the organization or impede or block its performance". Ehling, White y Grunig (1992: 363).

23 "Marketing attempts to maintain a positive slope of the demand curve". Ehling, White y Grunig (1992: 388).

24 "The major purpose of public relations is to save money for the organization by managing threats to its mission or mobilizing support for it”. J. E. Grunig y L. A. Grunig (1991).

25 "Public relations contributes primarly by saving money, rather than making money". L.A. Grunig, J. E. Grunig y Dozier (2002: 129).

26 "The communication system developed under public relations management is interpersonally focused, bilaterally designed, bidirectionally oriented, and organized in two stages". Ehling, White y Grunig (1992: 389).

27 "Marketing communication is characterized by unilateral design, unidirectional message flow, and one-stage operation -with and aim of persuasion to boost sales or increase a company's market share". Ehling, White y Grunig (1992: 389).

28 "Journalistic techniques, strives for free space in the media, produces publications, and uses interpersonal means of communication”. J. E. Grunig y L. A. Grunig (1991).

29 "The techniques of public relations often are used in support of marketing theory and the techniques of marketing often are used in support of public relations theory". J. E. Grunig y L. A. Grunig (1991).

30 "You must be able to distinguish whether such use is for marketing or for public relations purposes". Hunt y J. E. Grunig (1994: 7).

31 "Communication excellence involves knowledge or expertise that transcends any particular public, organizational division or unit, industry, organizational type, or national setting". Dozier, L. A. Grunig y J. E. Grunig (1995: 4).

32 "Public relations contributes to organizational effectiveness when it helps reconcile the organization's goals with the expectations of its strategic constituencies. This contribution has monetary value to the organization. Public relations contributes to effectiveness by building quality, long-term relationships with strategic constituencies. Public relations is most likely to contribute to effectiveness when the senior public relations manager is a member of the dominant coalition where he or she is able to shape the organization's goals and to help determine which external publics are most strategic”. L. A. Grunig, J. E. Grunig y Ehling (1992).

33 "Just as roles describe patterns in the activities of individual communicators in organizations, models describe the values and a pattern of behavior (practices) that 
communication departments use to deal with publics". Dozier, L. A. Grunig y J. E. Grunig (1995: 40).

34 "Roles define the everyday activities of public relations practitioners". Dozier (1992: $327)$.

35 "Practitioner roles are at the nexus of a network of concepts affecting professional achievements of practitioners, structures and processes of the function in organizations, and organizational capacities to dominate or cooperate with their environments". Dozier (1992: 327).

${ }^{36}$ Expert prescriber, communication technician, problem-solving process facilitator, communication facilitator and acceptant legitimizer. Broom y Smith (1978).

37 “Conceptualize and direct public relations programs”. J. E. Grunig (1992a: 19).

38 "Writing, editing, photography, media contacts, or production of publications". J. E. Grunig (1992a: 19).

39 "A creator and disseminator of messages, intimately involved in production, operating independent of management decision making, strategic planning, issues management, environmental scanning, and program evaluation". Dozier y Broom (1995).

40 "The managers, on the other hand, have a more scientific mind, and believe in planning and evaluation”. J. E. Grunig y Hunt (1984: 92).

41 "Departments with the knowledge base to establish excellent communication programs also have high levels of technical expertise". Dozier, L. A. Grunig y J. E. Grunig (1995: 55).

42 "It is the application of communicator craft to the pursuit of strategic goals that separates excellent from less-than-excellent communication programs". Dozier, L. A. Grunig y J. E. Grunig (1995: 60-61).

43 "Emerging communicator expertise in strategic planning and research does not replace or diminish the importance of traditional communicator skills in writing, editing, graphics, media relations, and so forth". Dozier, L. A. Grunig y J. E. Grunig (1995: 27).

44 "We use the term model to describe a set of values and a pattern of behavior that characterize the approach taken by a public relations department or individual practitioner to all programs or, in some cases, to specific programs or campaigns". J. E. Grunig y L. A. Grunig (1992: 286).

45 "We use the term model here in the way that it is used in the sciences -as a simplified representation of reality. Although all models are «false» in the sense that no representation can capture reality perfectly, we would have no understanding of reality at all if we had no model with which to work". J. E. Grunig y L. A. Grunig (1992: 286). 
46 "But, remember, these are simplifications, and simplifications are always false in part, because they always leave something out. Not everything any single public relations person does will fit any of the models perfectly. But the models should come close enough that you can fit public relations people you meet into one of the models". J. E. Grunig y Hunt (1984: 21).

${ }^{47}$ Professional and craft. Dozier, L. A. Grunig y J. E. Grunig (1995: 42)

48 "The two-way models are professional because they are based on a body of knowledge and a set of techniques used for strategic purposes: to manage conflicts and build relationships with publics". Dozier, L. A. Grunig y J. E. Grunig (1995: 42).

49 "The one-way models are «craft», meaning that communication techniques are used to generate messages, as if messages were ends in themselves". Dozier, L. A. Grunig y J. E. Grunig (1995: 42).

50 "The public relations person functions essentially as a journalist in residence". J. E. Grunig y Hunt (1984: 22).

51 "To disseminate relatively objective information through the mass media and controlled media such as newsletters, brochures, and direct mail". Hunt y J. E. Grunig (1994: 8).

52 "They try to change the behavior of publics but not of the organization". Hunt y J. E. Grunig (1994: 8).

53 “More effective". Hunt y J. E. Grunig (1994: 8).

54 “Selfish model”. Hunt y J. E. Grunig (1994: 8).

55 "The organization that uses it believes it is right (and the public wrong) and that any change needed to resolve a conflict must come from the public and not from the organization”. Hunt y J. E. Grunig (1994: 8).

56 "When the organization has little conflict with a public and the public stands to benefit from a change in its behavior". Hunt y J. E. Grunig (1994: 8).

57 "Describes a model of public relations that is based on research and that uses communication to manage conflict and improve understanding with strategic publics". Hunt y J. E. Grunig (1994: 9).

58 "It generally is more ethical than the other models". Hunt y J. E. Grunig (1994: 9).

59 "Allows the question of what is right to be settled by negotiation, since nearly every side to a conflict -such as nuclear power, abortion, or gun control- believes its position to be right”. Hunt y J. E. Grunig (1994: 9).

60 "Public relations is a two-way street. Both lines of traffic must be given equal rightof-way”. Cutlip y Center (1964: 112). 
61 "If persuasion occurs, the public should be just as likely to persuade the organization's management to change attitudes or behavior as the organization is likely to change the publics' attitudes or behavior”. J. E. Grunig y Hunt (1984: 23).

62 "Ideally, both management and publics will change somewhat after a public relations effort”. J. E. Grunig y Hunt (1984: 23).

63 "Reciprocity". J. E. Grunig y Hunt (1992: 48).

64 "Excellente organizations realice that they can get more of what they want by giving publics some of what they want”. J. E. Grunig y Hunt (1992: 46).

65 "The organization does not change as a result of public relations; it attempts to change public attitudes and behavior". J. E. Grunig y Hunt (1984: 23).

66 "Although it will become obvious that we prefer the two-way symmetric model and will stress that model throughout this book, we recognize that there are organizations facing problems for which the other models provide the best solutions". J. E. Grunig y Hunt (1984: 43).

67 “Unrealistic or idealistic". J. E. Grunig y White (1992: 45).

68 "A normative theory defines how things should be or how some activity should be carried out". J. E. Grunig y L. A. Grunig (1992: 291).

69 "The four models still provide an accurate and useful tool to describe public relations practice and worldview”. L. A. Grunig, J. E. Grunig y Dozier (2002: 377).

70 "This mixed-motive model involves the short-term use of asymmetrical practoces withing the context of a broad symmetrical philosophy". Dozier, L. A. Grunig y J. E. Grunig (1995: 51).

71 "In mixed-motive games, both sides pursue their own interests, but both sides also realize that the game's outcome (the relationship in this context) must be satisfactory to both sides". Dozier, L. A. Grunig y J. E. Grunig (1995: 47).

72 "As organizations pursue their own interests in relations with publics, communicators try-from time to time- to persuade publics that their organizations are right on an issue. At times, communicators try to convince publics to behave as their organizations want. Sometimes, communicators use attitude theory and research to manipulate publics scientifically. Indeed, activist publics likewise will follow similar asymmetrical strategies to persuade, convince, and manipulate organizations". Dozier, L. A. Grunig y J. E. Grunig (1995: 47-48).

73 "The balancing of internal processes of organizations with external factors". Dozier, L. A. Grunig y J. E. Grunig (1995: 27).

74 "This means that communicators must have the expertise to identify the desired relationships an organization seeks to build and maintain with key stakeholders or 
publics. Communicators specify these desired relationshipd through the goals and objectives of communication programs". Dozier, L. A. Grunig y J. E. Grunig (1995: 28).

75 “Historicist approach to public relations". Broom (1986).

76 "When public relations is practiced as it historically has been practiced, communication programs become routine and ineffective because they do little to help organizations adapt to dynamic environments”. J. E. Grunig y L. A. Grunig (1991).

77 "A program, to be effective, must be tailored to the industry or institution it serves". Cutlip y Center (1964: 13).

78 "They use strategic management to identify opportunities and dangers in the environment; to develop strategies for exploiting the opportunities and minimizing the dangers; and to develop, implement, and evaluate the strategies". Hunt y J. E. Grunig, (1994: 11).

79 "When they identify the publics that are most likely to limit or enhace their ability to pursue the mission of the organization, and when they design communication programs that help the organization manage its interdependence with these strategic publics". Hunt y J. E. Grunig (1994: 11).

80 "If public relations can identify the strategic publics in the environment and manage the organization's response to these interdependencies, these theories of effectiveness show, public relations can help the organization reduce uncertainty and reduce conflict by stabilizing relationships with key publics on which the organization depends". L. A. Grunig, J. E. Grunig y Ehling (1992).

81 "Poor relationships, in other words, can cost an organization a great deal although good relationships may not necessarily make money for the organization. At the same time, good relationships can make money through productive employees, satisfied customers, and supportive donors, stockholders, or legislators". L. A. Grunig, J. E. Grunig y Ehling (1992).

82 "When public relations is restricted to the functional level, it usually implements the strategies of other departments such as marketing or human resources and is restricted to the application of technique rather than the formulation of policy". J. E. Grunig y Repper (1992: 121).

83 "Conducting research in order to understand the views of specific publics (whether they be medical staff, patients, politicians, or donors) and providing counsel to management so that management can make decisions with full knowledge of the views of concerned publics. It also means fully understanding management decisions and behaviors so those decisions and behaviors can be explained in turn”. J. E. Grunig y Hunt (1984). 
84 "The publics that are most likely to constrain or enhance the ability of the organization to achieve its mission and then develop programs to communicate with those publics". L. A. Grunig, J. E. Grunig y Ehling (1992).

85 "A process of building relationships with the strategic publics of an organization". Wise (2003).

86 "The department communicates with these publics to bring their voices into strategic management, thus making it possible for stakeholder publics to participate in organizational decisions that affect them". L. A. Grunig, J. E. Grunig y Dozier (2002).

87 "May represent the greatest difference between excellence and mediocrity". L. A. Grunig, J. E. Grunig y Dozier (2002).

88 "Can increase organizational effectiveness". Wise (2003).

89 "Are more likely to attain their goals". Wise (2003).

90 “Are more likely to choose appropriate goals". Wise (2003).

91 "Reconcile the organization's goals with the expectations of its strategic constituencies”. L. A. Grunig, J. E. Grunig y Ehling (1992).

92 "Management function that establishes and maintains mutually beneficial relationships between an organization and the publics on whom its success or failure depends". Cutlip, Center y Broom (2000).

93 “Proactive management”. Fitzgerald y Embrey-Wahl (1987).

94 "Should be a member of the group that makes organizational decisions (or at least has access to the group). Ideally, the top public relations practitioner should lead his/her own department and report directly to the CEO". Wise (2007).

95 "Access to the organization's CEO does not guarantee organizations will be scandalfree", "there is at least a chance CEOs may make fewer unfortunate decisions after receiving adequate public relations counsel". Wise (2007).

96 "CEOs estimated higher values for public relations when it fulfils a strategic managerial role”. J. E. Grunig y L. A. Grunig (1998).

97 “- Relating communication objectives to organizational objectives

— Developing long-term relationships (trust and credibility) with key audiences

— Emphasizing mutual understanding and conflict resolution

- Formulation of consistent messages on a global basis using multiple channels

- Training management to implement global strategies on a local basis

— Coordinating the communication activities of local managers and consultants around the world 
— Maintaining and enhancing organizational reputation on a variety of levels

— Tracking, analyzing trends, issues that can affect the organization”. Wilcox (2006).

98 "Research is the controlled, objective, and systematic gathering of information for the purposes of describing and understanding”. Broom y Dozier (1990: 4).

99 "It is the scientific approach to answering questions, providing more reliable answers in most situations than authority, personal experience, and historical precedent". Broom y Dozier (1990: 4).

100 "To reduce the influence the researcher or observer has on the findings". Broom y Dozier (1990: 4).

101 "The findings accurately reflect reality, not just the researcher's perceptions of reality". Broom y Dozier (1990: 4).

102 "Research is at the core of how the function is managed". Broom y Dozier (1990: $18)$.

103 "You elevate the function from the intuitive enterprise of the artist and make it part of an organization's management system". Broom y Dozier (1990: 18).

104 "By strategic research we mean the ability to systematically collect reliable information about large and small publics that affect the organization, organize that information into a manageable form, and share that information with the dominant coalition to improve strategic decisions". Dozier, L. A. Grunig y J. E. Grunig (1995: 42).

105 "I believe great progress has been made". Tal y como explica: "When I entered the profession [40 years ago], I was one of perhaps five scholars conducting such research. Today, there are several hundred academic scholars and doctoral students conducting public relations research; and a number of scholarly journals are now published". J. E. Grunig (2006).

106 "Public relations may be poised to become one of the most researched areas of communication". Botan y Taylor (2004).

107 "The public relations profession is still far from being a research-based profession. Most practice still does not include research, and most of the research conducted in the practice of public relations measures only the short-term effects of marketing communication programs". J. E. Grunig (2006).

108 “At a scientific level”. Van Ruler y Verčič (2004: 4).

109 "Crearly, public relations has not (yet) developed as a high-profile research or teaching area". Van Ruler y Verčič (2004: 4).

110 "With an increased budget, PR practitioners might find moew room for research". Pavlik (1987: 21) 
111 "Does not lead to a broad theoretical understanding of the public relations profession”. J. E. Grunig (2006).

112 "For example, researchers have identified best practices in crisis communication, issues management, environmental scanning, and media relations and then diffused those best practices to practitioners". J. E. Grunig (2006).

113 "In an ivory tower, practitioners work in the «real world»". J. E. Grunig (1979).

114 "Because so few practitioners pay attention to academic research, even those who use research in their work, the profession suffers from a lack of conceptualization. Professionals are doing, buying, or talking about measurement; but most are not thinking about (conceptualizing) what they are measuring, why they are measuring it, or how their measures can be used to make the public relations function or the overall organization more effective". J. E. Grunig (2006).

115 "Should be to service the profession--to conduct research that will advance the profession and to train the next generation of practitioners", mientras que "professionals should come to academics for ideas to apply and with ideas that need to be researched and tested". J. E. Grunig (1979).

116 "Symbiosis--each should provide something the other cannot provide". J. E. Grunig (1979).

117 "Techniques of scientific research include surveys to track issues, the use of public opinion agencies, and monitoring other research in the public domain". Dozier, L. A. Grunig y J. E. Grunig (1995: 43-44).

118 "Practitioners themselves are not scientists, but that they should rely on scientific theories developed by communication scientists". J. E. Grunig y Hunt (1984: 77).

119 "Public relations educators, on the other hand, should be both scientists and professionals who do research and aplly that research to professional problems". J. E. Grunig y Hunt (1984: 77).

120 "Informal research involves keeping in touch with members of publics, calling back people attending an organization's presentation, and checking with field personnel". Dozier, L. A. Grunig y J. E. Grunig (1995: 44).

121 "Representativeness and objectivity". Cutlip y Center (1964: 119).

122 "Whereas informal and opportunistic scanning os the environment may alert you to a potential problem, you use more formal and systematic observations to explore, confirm, and describe the problem". Broom y Dozier (1990: 25).

123 “Abstract and conceptual”. Pavlik (1987: 24).

124 "Build theory -not to answer specific practical problems". Pavlik (1987: 17). 
125 "Assumes that there is regularity in nature and that the role of the researcher is to develop theories, or «laws,» which articulate that regularity”. J. E. Grunig (1979).

126 "Because by articulating the laws of nature the basic researcher can help the practitioner to understand and to intervene in many problems explained by an abstract law--not just a single problem". Xifra (2006).

127 "Intended to increase understanding, explain cause-and-effect relationships, and predict future situations or conditions". Pavlik (1987: 24).

128 “Self-examination”. Pavlik (1987: 24).

129 "Introspective research reprents studies that look inwardly at the profession itself". Pavlik (1987: 23).

130 “Applied research is designed to solve practical problems". Pavlik (1987: 22).

131 "To answer a particular practical problem, and which has little relevance other than solving that particular problem". Xifra (2006).

132 "Environmental monitoring" o “environmental scanning". Dozier and Repper (1992: 186).

133 “Problem-defining stage of public relations planning”. Dozier (1986).

134 “Inherently open ended”. Broom y Dozier (1990).

135 "Such research is exploratory in nature and vulnerable to premature closure". Dozier y Repper (1992: 186).

136 "Environmental scanning is the detection, exploration, and description of public relations problems through informal and formal research". Broom y Dozier (1990: 24).

137 "The meaning of «problem» here is a condition in which someone thinks there is a gap between what is perceived and what is desired". Broom y Dozier (1990: 24).

138 "The strategic function of scanning is early detection of emerging problems as well as quantification of existing or known problems in the environment". Dozier y Repper (1992: 186-187).

139 "Where and how the program needs to be adjusted". Broom y Dozier (1990: 69).

140 "To measure program impact or effectiveness with respect to goals and objectives". Broom y Dozier (1990: 18).

141 "Determined how well public relations programs work". Dozier y Repper (1992: 186).

142 “Helps reduce uncertainty in decision making”. Broom y Dozier (1990: 88). 
143 "Will be used to improve future programs". Broom y Dozier (1990: 88).

144 “Observational methods, although quite powerful, are typically more expensive and require a greater commitment of time and human resources". Pavlik (1987: 32).

145 "Descriptive surveys are ones that develop a picture of a current situation or condition". Pavlik (1987: 33).

146 "Analytical surveys are designed to answer the questions that descriptive surveys cannot”. Pavlik (1987: 33).

147 "Unobstrusive measures offer the researcher the opportunity to study human behavior without «intruding» on that behavior". Pavlik (1987: 38).

148 "Placements are necessary but not a sufficient condition for program impact to occur”. Dozier y Repper (1992: 194).

149 "Just because a member of a target public subscribes to a magazine where a message has been placed is no guarantee that the target public member actually read the message, understood the message, or retained the message". Dozier y Repper (1992: 196).

150 “The quality of those mesajes”. Dozier y Repper (1992: 198).

151 “Quantify what is said about an organization”. Dozier y Repper (1992: 198).

152 "Observational methods are those data colletion techniques that provide a direct measure of human behavior". Pavlik (1987: 41).

153 "They range from casual observation of persons in their natural environment to controlled observation in a laboratory environment”. Pavlik (1987: 41).

154 "The most powerful tool for determining such cause and effect is the experiment". Broom y Dozier (1990: 102).

155 "It is virtually impossible to practice effective public relations today without using the internet”. Newson, Turk y Kruckeberg (2000).

156 “Myopic view”. Kent y Saffer (2014).

157 Knowing the business, self-study, professional association seminars, mentoring, department training, accreditation, higher education. Dozier, L. A. Grunig y J. E. Grunig (1995: 63-72).

158 "Greater understanding of the challenges and opportunities facing your organization”. Dozier, L. A. Grunig y J. E. Grunig (1995: 65).

159 "This translates into greater credibility with senior managers, who expect all toplevel people in the organization to understand the business". Dozier, L. A. Grunig y J. E. Grunig (1995: 65). 
160 "Theorical connections to theories of economics and management that are necessary to explain the contributions that the management of public relations makes to the overall management of organizations". Verčič y J. E. Grunig (2008: 9).

161 "The more strategic the communication department is, the more sophisticated budgeting issues become”. Dozier, L. A. Grunig y J. E. Grunig (1995: 35).

162 "That is because excellent communication departments constantly adjust and restructure programs to respond dynamically to changing relations with strategic publics”. Dozier, L. A. Grunig y J. E. Grunig (1995: 35).

163 "Mentoring is the structured or unstructures training of junior communicators to learn the ropes in an organizations and develop advanced expertise, provided by a superior or another appropriate individual in the organization". Dozier, L. A. Grunig y J. E. Grunig (1995: 67).

164 "Studies in higher education provide the most in-depth knowledge". Dozier, L. A. Grunig y J. E. Grunig (1995: 70).

165 "Many, if not the majority". J. E. Grunig y Hunt (1984: 78).

166 "If management thinks of the public relations operation in a small way, then it will occupy a small place in the company's scheme of things, and its contribution will be small. Is management thinks it is important, then it will occupy a prominent place and its contribution will be significant". Cutlip y Center (1964: 206) citando a Clarence J. Myers, expresidente de New York Life Insurance Company.

167 "Communication excellence occurs when organizations demand two-way practices from their communication departments". Dozier, L. A. Grunig y J. E. Grunig (1995: 59).

168 "From the isolation of top communicators from strategic planning and decision making”. Dozier, L. A. Grunig y J. E. Grunig (1995: 94).

169 "Expertise typically -but not always- comes first. Dominant coalitions tend to value and support communicators who first demonstrate their worth". Dozier, L. A. Grunig y J. E. Grunig (1995: 104).

170 "Excellence occurs when dominant coalitions expect their communication departments to practice the two-way models, and top communicators understand those expectations”. Dozier, L. A. Grunig y J. E. Grunig (1995: 91).

171 "Foremost of the measures to be taken is to clarify for the management group what PR is supposed to do, where it fits, and how it will go about its chores". Cutlip y Center (1964: 209).

172 "To gain respect, the effective public relations man must operate through channels, keep his promises, preserve matters given him in confidence, and seek no partiality. He must lick his own wounds privately". Cutlip y Center (1964: 217). 
173 "If he lacks that respect, the chances are that he can't be very useful in management affairs". Cutlip y Center (1964: 217).

174 "You may have the potential for excellence in your communication department, but unless senior management values communication and supports it, and unless communicators and senior management share a common understanding of communication's function and role, you cannot establish an excellent program". Dozier, L. A. Grunig y J. E. Grunig (1995: 5).

175 "Power is the capacity to exert influence, a transaction in which you get others to change their behavior as you intended". Dozier, L. A. Grunig y J. E. Grunig (1995: 75).

176 "The communicator's ability to influence decisions about an organization's goods and services, its policies, and its behavior". Dozier, L. A. Grunig y J. E. Grunig (1995: $75)$.

177 "Weak communication departments are limited to implementing decisions of others”. Dozier, L. A. Grunig y J. E. Grunig (1995: 77).

178 "Without any formal power or authority to do so". Dozier, L. A. Grunig y J. E. Grunig (1995: 76).

179 "We believe that communication departments, as represented by top communicators, must be powerful players in organizational decision making”. Dozier, L. A. Grunig y J. E. Grunig (1995: 76).

180 "Power is necessary to be given the opportunity to contribute. Strategic contributions, in turn, increase the value and support dominant coalitions give to communication departments”. Dozier, L. A. Grunig y J. E. Grunig (1995: 88).

181 "Communication departments cannot make organizations more effective unless public relations functions as an integral part of management". White y Dozier (1992: 91).

182 "The senior public relations practitioner must be part of the dominant coalition, function at a high level of decision making, and participate in strategic management". White y Dozier (1992: 91).

183 “But it sure helps". Dozier, L. A. Grunig y J. E. Grunig (1995: 83).

184 "Top communicators in excellent organizations are key members of the senior management team, even if the organizational chart does not say so". Dozier, L. A. Grunig y J. E. Grunig (1995: 128).

185 "The senior public relations officer must be a part of the senior management team, play a role in making strategic organizational decisions, be a member of the dominant coalition or have access to this powerful group of organizational leaders, and have relative autonomy from excessive clearance rules to plan this strategic role". L. A. Grunig, J. E. Grunig y Dozier (2002: 191). 
186 "Top communicators, with the support of the expertise in their departments, make substantial contributions to strategic planning and decision making. Using formal and informal research techniques, they help with diagnosis and problem solving, then execute effective communication programs to build lasting, long-term relationships with key constituents". Dozier, L. A. Grunig y J. E. Grunig (1995: 128).

187 "We understand organizational culture to be the set of values shared by members of an organization, manifested in their own cultural behavior and expressions, symbols, ceremonies, rituals, language, style of communication, etc., guiding the attitude of its members and determining the organization's relationships on both the inside and outside whilst logically also exerting an influence on motivation and the level of involvement and commitment employees have with the company". Ordeix (2013: 61).

188 "Cultural cohesion and consensus contribute to the balance and symbiosis of interest within the organization and its stakeholders". Ordeix (2013: 158).

189 "Large organizations with sizeable public relations staffs could implement more sophisticated systems of relationship management than could organizations with a single public relations practitioner responsible for all aspects of the public relations function". Wise (2007).

190 "Hospitable environment for excellence public relations". L. A. Grunig, J. E. Grunig y Dozier (2002: 533).

191 "With an organic structure, participative culture, and symmetrical system of communication and in which opportunities exist for women and racial-cultural minorities”. L. A. Grunig, J. E. Grunig y Dozier (2002: 533).

192 "The more dynamic, or changing, and environment is, the more the organization should use the functions provided by the two-way asymmetric or symmetric models of public relations". J. E. Grunig y Hunt (1984: 97).

193 "The asymmetric model, if it works, helps the organization control changes in its environment. The symmetric model also helps the organization change the environment, but it can help the organization change, too, when the environment changes". J. E. Grunig y Hunt (1984: 97).

194 "In a static environment, the organization can behave routinely and can get by using the press agentry and public-information models of public relations". J. E. Grunig y Hunt (1984: 97).

195 "Those two models simply provide publicity or information about the organization as it is, without providing the feedback necessary to change the organization or the systems in the environment". J. E. Grunig y Hunt (1984: 97).

196 "The adaptative subsystem detects changes and threats to organizational survival and growth in the environment". Dozier y L. A. Grunig (1992: 399). 
197 "Horizontal structures define the division of labor on a single level of authority. Horizontal structures, in other words, defines the roles and tasks of the subunits of a departments". J. E. Grunig y Hunt (1984: 101).

198 Traditional, mechanical, organic, and mixed mechanical/organic organizations. Dozier y L. A. Grunig (1992: 403).

199 "The power-control perspective argues that the organizational environment, along with other factors, constrain strategic choices of organizational structure available to the dominant coalition”. Dozier y L. A. Grunig (1992: 413).

200 "The power-control perspective provides a provocative and promising avenue for further research". Dozier y L. A. Grunig (1992: 413).

201 "The particular application of open-systems theory to public relations structure, through the Hage-Hull (1981) typology, had little predictive power". J. E. Grunig y L. A. Grunig (1986), citado en Dozier y L. A. Grunig (1992: 413).

202 "How organizations should decide what kind of public relations to practice, rather than what they actually tend to do". L. A. Grunig (1992a: 472).

203 "The chapter concludes that excellence in communication is a characteristic of excellent organizations. But it also concludes that excellent communication can help to make organizations excellent”. J. E. Grunig (1992d: 219).

204 “Are linked logically to each other”. J. E. Grunig (1992d: 248).

205 "Organizations would have a difficult time instilling one of the attributes in an organization without simultaneously instilling the others". J. E. Grunig (1992d: 248).

206 "Excellent public relations, in short, seems to be the glue that holds excellent organizations together". J. E. Grunig (1992d: 248).

207 Research-listening, planning-decision making, communication and evaluation. Cutlip y Center (1964: 108).

208 Research, Planning and Action, Communication and Evaluation. Diggs-Brown (2011) sobre Wilcox, Ault y Agee (1986).

${ }^{209}$ Objectives, Strategies, and Implementation between Research and Evaluation. Sheila Crifasi (2000).

${ }^{210}$ Research, Adaption, Implementation Strategy and Evaluation. Smith (2012) sobre Robert Kendall (1977).

211 Research, Objectives, Programming and Evaluation. Hendrix, Hayes y Kumar (2012).

212 Research, planning, communication and evaluation. Hainsworth y Wilson (1992) y Guth y Marsh (2011). 
213 "We use the term «behavioral molecule» to name a simple model that describes how people make decisions about what to do -how to behave- and how managers organize larger systems to produce single behaviors for those systems". J. E. Grunig y Hunt (1984: 105)

214 "Researchers gather information for the detect and construct segments. Planners take the responsibility for the rest of the construct segment and work with communication technicians to define the alternatives. Top managers make the final decisions in the select and confirm segments. Communication technicians take over in the behave segment". J. E. Grunig y Hunt (1984: 107-108).

215 "Without research, a public relations manager's behavioral molecule would consist of little more than the behave segment". J. E. Grunig y Hunt (1984: 108).

216 "Three-fourths of it is unseen below the surface. The one-fourth - publicity- that does show is too often taken for the whole iceberg. The unseen three-fourths -research, planning, evaluation- is generally more important in the long run". Cutlip y Center (1964: 110).

217 "It will have resolved most of the problems with publics before they become issues". Hunt y J. E. Grunig (1994: 16).

218 "When organizations delay public relations programs until the issue stage, they usually are forced to develop programs of crisis communication”. Hunt y J. E. Grunig (1994: 16).

219 "They set up a program of «issues management» to identify issues while they are still problems and to manage the organization's response to the problems and issues". Hunt y J. E. Grunig (1994: 17) citando a Chase (1984).

220 "But they shouldn't”. Rawlins (2006).

221 "There is a subtle difference, however, that helps to understand strategic planning of public relations". J. E. Grunig y Repper (1992: 125).

222 "Stakeholders have been identified in the business literature according to their relationships to organizations. Publics, in the public relations and other mass media literature, are often identified according to their relationship to messages". Rawlins (2006).

223 "Any group or individual who is affected by or can affect the achievement of an organization's objectives". Freeman (1984).

224 "Any identifiable group or individual on which the organization is dependent for its continued survival". Freeman y Reed (1983).

225 "Stakeholders are people who are linked to an organization because they and the organization have consequences on each other". J. E. Grunig y Repper (1992: 125). 
226 "The first step in strategic management of public relations, therefore, is to make a list of the people who are linked to or have a stake in the organization". J. E. Grunig y Repper (1992: 126).

227 "Communication at the stakeholder stage -ideally before conflict has ocurred- is especially important because it helps to develop the stable, long-term relationships that an organization needs to build from stakeholders and to manage conflict when it occurs". J. E. Grunig y Repper (1992: 126-127).

228 "Management of communication between an organization and its publics". J. E. Grunig y Hunt (1984).

229 "We can define public as a loosely structured system whose members detect the same problem or issue, interact either face to face or through mediated channels, and behave as though they were one body". J. E. Grunig y Hunt (1984: 144).

230 "Arise on their own and choose the organization for attention". J. E. Grunig y Repper (1992).

231 "Publics organize from the ranks of stakeholders when they recognize an issue and decide to do something about it". Rawlins (2006).

232 "A public is simply a collective noun for a group -a group of individuals tied together by some common bond of interest- and sharing a sense of togetherness. It may be a small group or a large group; it may be a majority group or a minority group". Cutlip y Center (1964: 70).

233 "Publics consist of individuals who detect the same problems and plan similar behaviors to deal with those problems". J. E. Grunig y Hunt (1984: 144).

234 "It is a common mistake to think of The Public as one massive, monolithic assemblage". Cutlip y Center (1964: 80).

235 "Public relations programs for general publics or the public at large might build relationships accidentally with stakeholders, but more often than not they communicate with no one important to the organization. And, in the process of doing nothing, they cost the organization a great deal of money". J. E. Grunig y Repper (1992: 118).

236 "Although there will be fewer research costs if a campaign is directed at a mass, the cost of the campaign itself will be much greater because messages are directed to passive or nonpublics as well as to active publics”. J. E. Grunig y Repper (1992: 145).

237 "Individuals form themselves into publics in various ways -politically in parties, religiously in churches, socially in clubs and lodges, economically in trade associations, labor unions, or farm blocs- An individual can and does belong to a long list of publics simultaneously". Cutlip y Center (1964: 80).

238 "It is dangerous to classify people rigidly as «employees» or «customers» when, in fact, these people play many roles". Cutlip y Center (1964: 80). 
239 "Members of a given public are constantly shifting". Cutlip y Center (1964: 117).

240 "There is a constant shifting in age groupings, economic interests, political interests, and geographic residence”. Cutlip y Center (1964: 117).

241 "In public relations you must communicate with a passing parade, not a standing army". Cutlip y Center (1964: 117).

242 "The place to start in defining the publics is at the heart of an organization -in its power structure". Cutlip y Center (1964: 118).

243 "The key policy makers must be the first concern. Working out from this inner circle, there are junior executives, supervisors, employess, home communities, consumers, investors, donors, and all others. From these immediate publics, attention moves along a broad front of special-interest publics within the general public. These include labor unions, industrial associations, farm groups, political groups, women's groups, professional groups, educators, veterans, and similar common-interest groupings". Cutlip y Center (1964: 118).

244 "The more carefully you define the various publics, the more ways of reaching and influencing them will you discover". Cutlip y Center (1964: 118).

245 "If an organization does not communicate with an aware public, that public will actively seek the information from other sources, which may distort the nature or severity of the organization's consequences". J. E. Grunig y Hunt (1984: 146).

246 "Certainly, the other information sources will not explain the organization's point of view about those consequences as well as the organization could itself'. J. E. Grunig y Hunt (1984: 146).

247 "The negative aspects are more likely to be told if others do the telling". Cutlip y Center (1964: 157).

248 "Many misunderstandings can be traced not only to misinformation but also to the lack of information". Cutlip y Center (1964: 157).

249 "An active public has made a decision and has entered the behave segment of the behavioral molecule". J. E. Grunig y Hunt (1984: 146).

250 "It selectively seeks and retains information that reinforces the attitudes and behaviors it has previously chosen". J. E. Grunig y Hunt (1984: 146).

251 "Active publics define what issues are important for organizations and threaten their mission. Passive publics may take in information randomly from the media or other sources, but this passive communication seldom has cognitive effects and even less often has attitudinal or behavioral effects”. J. E. Grunig y L. A. Grunig (1991). 
252 "Recognize an issue as a problem, believe it involves them personally, and believe they are unconstrained enough to do something about it”. J. E. Grunig y L. A. Grunig (1991).

253 "They engage in individual behaviors to do something about the consequence of organizational actions". J. E. Grunig y Repper (1992: 137).

254 "They may boycott a product, csupport government regulation, or oppose a rate increase". J. E. Grunig y Repper (1992: 137).

255 "They seek out information rather than passively receive it". J. E. Grunig y Repper (1992: 137).

256 "They seek information from many sources and persuade themselves more than they are persuaded by others”. J. E. Grunig y Repper (1992: 137).

257 "People may evaluate your organization favorable in some situations, such as its performance in producing a quality product, but unfavorably in other situations, such as its record on air pollution". J. E. Grunig y Hunt (1984: 147).

258 "Public relations managers, therefore, must constantly review organizational consequences and research how public react to those consequences so that their public relations programs do not aim at publics that no longer exist". J. E. Grunig y Hunt (1984: 147).

259 "The extent to which individuals recognize that issues or events are problems to be concerned about". Aldoory (2001).

260 "The extent to which people perceive that there are constraints -or obstacles- in a situation that limit their freedom to plan their own behavior". J. E. Grunig y Hunt (1984: 151).

261 "People's level of involvement represents the extend to which they connect themselves with the situation”. J. E. Grunig y Hunt (1984: 152).

262 "When they perceive the issue to be a problem, perceive that the issue involves them, and believe they are unconstrained from doing something about the issue". J. E. Grunig e Ipes (1983).

263 "When there are many members of a public, no one member has a strong incentive to become active to secure benefits from large organizations or from government. Each member thinks someone else will do the necessary work". J. E. Grunig y Hunt (1984: 147).

264 "In a small, cohesive public, however, each member knows that without him or her the group may fail because no one else will do the work. Thus, every member of a small, cohesive public works hard to solve the problem that brought the public about". J. E. Grunig y Hunt (1984: 147). 
265 Activist group, empowered group, angry audiences y disinterested group. Turner (2007).

266 "When one or more human agents attaches significance to a situation or perceived «problem»". Crable y Vibbert (1985).

267 "If an organization has had effective public relations at each of the previous two stages of the process of strategic management, it will have resolved most of the problems with publics before they become issues". J. E. Grunig y Repper (1992: 146).

268 "Publics make issues out of problems that have not been resolved". J. E. Grunig y Repper (1992: 146).

269 "When organizations delay public relations programs until the issue stage rather than beginning at the stakeholder or public stage, they ussually are forced to develop programs of crisis communication”. J. E. Grunig y Repper (1992: 149).

270 “A proactive process of monitoring and analyzing new and potentially emerging issues that might have an impact on the organization". Heath (1997).

271 "Capacity to understand, mobilize, coordinate, and direct all strategic and policy planning functions, and all public affairs/public relations skills, toward achievement of one objective: meaningful participation in creation of public policy that affects personal and institutional destiny". Chase (1982).

272 "Enables an organization to anticipate and avoid activities that audiences find unfavorable”. Springston y Weaver Lariscy (2005).

273 "It is also a preventive instrument". Van Ruler y Verčič (2002: 8).

274 "Research has suggested public relations practitioners involved in issues management hold more power in their organizations than practitioners who are not involved in issues management, and that involvement in issues management is strongly related to practitioner involvement in decision making by an organization's dominant coalition". Wise (2001) sobre Lauzen y Dozier (1994).

275 “A fairly predictable cycle of development", en vez de simplemente encontrarse "absent one moment and then spring into life full-blown the next moment". Botan y Taylor (2004).

276 "'Occurrences in the environment to which publics have not yet attached significance but could”. Botan y Taylor (2004).

277 "When some group or important individuals attach significance to them". Botan y Taylor (2004).

278 "Because not all of the latter evolve into the former". Botan y Taylor (2004).

279 “Are at a moment of decision”. Crable y Vibbert (1985). 
280 "Little time or room for negotiation" porque "the issue is ready for resolution in the minds of most publics”. Botan y Taylor (2004).

281 “Turning point”. Botan y Taylor (2004).

282 "It is unlikely to return fully to its precrisis state". Botan y Taylor (2004).

283 “Resolved or simply fade". Botan y Taylor (2004) sobre Crable y Vibbert (1985).

284 "Objectives thus play an extremely important role in public relations management". J. E. Grunig y Hunt (1984: 115).

285 "One of the most difficult and befudding tasks". Broom y Dozier (1990: 39).

286 "Withouth them, one cannot truly be said to be managing". J. E. Grunig y Hunt (1984: 115).

287 "Every public relations program should begin with an objective that it tends to achieve -that is, it should be managed by objectives". Hunt y J. E. Grunig (1994: 17).

288 "Ends that provide a framework for decision making and behavior but that are too broad to help much in making day-to-day decisions”. J. E. Grunig y Hunt (1984: 116).

289 "Ends in view- expected solutions to day-to-day problems". J. E. Grunig y Hunt (1984: 116).

290 “So be realistic about objectives”. J. E. Grunig y Hunt (1984: 133).

291 "In the way people think or in the ideas or beliefs they have". Hunt y J. E. Grunig (1994: 17).

292 "One can realistically expect only changes in the awarenes or salience of issues, or the priorities people plance on those issues". Pavlik (1987: 99).

293 "Be realistic. Don't expect to affect more than 20 percent of the target group". J. E. Grunig y Hunt (1984: 133).

294 “Attitudes do not «cause» behavior. They are simply mental conclusions that people make when thinking about specific issues". J. E. Grunig y Hunt (1984: 130).

295 "Attitudes are part of conscious thinking; they are not hidden predispositions that cause people to do things”. J. E. Grunig y Hunt (1984: 130).

296 "They change their attitudes and behaviors to fit the situation". J. E. Grunig y Hunt (1984: 130).

297 "Public relations can provide people the information they need to form and change attitudes, but those attitudes are specific and situational and therefore won't last long. You may be able to persuade someone on one issue, but you will have to start over on 
the next issue. And, then, you may not be so successful on the next issue". J. E. Grunig y Hunt (1984: 131).

298 "First, public relations goals become organizational goals when the public relation executive or key external publics become part of the organization's dominant coalition. When the public relations goals become organizational goals, it will be possible to show that public relations contributes to organizational effectiveness.

Second, the organization's public relations goals are more likely to be adaptive than control goals when key publics are in the dominant coalition and when the public relations executive is in the dominant coalition and understands the two-way symmetric model of public relations.

Finally, if neither the key publics nor the public relations executive are part of the dominant coalition it will be difficult to justify the public relations function to the dominant coalition no matter how well the PR people meet their communication objectives". J. E. Grunig y Hunt (1984: 121).

299 "One should ask what kind of technique will communicate most effectively with a public and how the technique should be executed". Hunt y J. E. Grunig (1994: 18).

300 "Strategic planning is deciding where you want to be in the future (the goal) and how to get there (the strategies). It sets the organization's direction proactively, avoiding "drift" and routine repetition of activities". Broom y Dozier (1990: 23).

301 "The several elements of a program, [...] must be spaced and timed to produce the desired effect at exactlyy the right time". Cutlip y Center (1964: 141).

302 "If the objective is to inform the greatest number of people so that they (1) know about a program your organization is conducting, and (2) have a positive view of that program, then the news media -television, radio and newspapers- may be the best channel. But if you must convince the leaders of influential but small professional organizations to support an issue, then articles in specialized business or public affairs magazines may better explain the complex issue and convince the leaders to "deliver" the support of the members of their organizations". Hunt y J. E. Grunig (1994: 37).

303 "Planning and budgeting for public relations go hand in hand". Cutlip y Center (1964: 136).

304 "Payoff value". J. E. Grunig y Hunt (1984: 172).

305 "To communicate effectively, the sender's words must mean the same thing to the receiver that they do to the sender". Cutlip y Center (1964: 147).

306 "That's because careful analysis shows that each public has a different stake in the organization". Hunt y J. E. Grunig (1994: 33).

307 “A monolithic, «1-size-fits-all» media relations model for public information officers is not adequate in the current health news environment". Lariscy, Avery y Sohn (2010). 
308 "Passive publics frequently perceive constraints that prevent them from acting on an issue, and that constraints must be removed before a communication campaign". J. E. Grunig e Ipes (1983).

309 "Seldom develop organized cognitions or solutions for problems. They retain only bits and pieces of disorganized information”. J. E. Grunig e Ipes (1983).

310 "Liaison between departments and their publics". Cutlip y Center (1964: 219).

311 “Actively communicating publics seek out information on their own". J. E. Grunig y Hunt (1984: 171).

312 "You must gain the attention of passively communicating publics". J. E. Grunig y Hunt (1984: 171).

313 "A public relations program that is managed strategically should not end when technitians have executed the program". Hunt y J. E. Grunig (1994: 19).

314 “Dissemination does not equal communication”. Cutlip y Center (1964: 170).

315 "The problem, it seems, is twofold. First, what do we measure? Second, how do we measure it?" Pavlik (1987: 65).

316 "When communication activities achieve communication goals (in a cost-effective manner)". Hon (1998).

317 "Must achieve an impact that is measurable". Guth y Marsh (2000).

318 "Although definitions of effectiveness in public relations abound, the most prominent theme in scholarly literature and the trade press is that effective public relations occurs when communication activities achieve communication goals (in a cost efficient manner). Implicit in this model is that public relations goals are derived from the overall organizational mission, goals, and objectives. Thus, through public relations evaluation, practitioners can demonstrate either directly or indirectly public relations' role in organizational goal achievement”. Hon (1998).

319 "Repeated calls for the development of methods of measuring evaluation". Henderson (2005).

320 "Most popular topics at professional conferences, in teleconferences and webinars, and in trade publications". Kreps (2008).

321 "No universally agreed-upon system for measuring the outcomes of organizationpublic relationships has emerged”. Wise (2007).

322 “1) People frequently cannot report accurately their own criteria of organizational effectiveness; 2) effectiveness is a subjective concept that changes over time; 3) different people in an organization may have different measures of effectiveness: and 4) an organization's strategic constituencies may hold different judgments about what 
constitutes effectiveness for a particular organization". Wise (2003) sobre Cameron y Whetten (1993).

323 "The obstacles are, obviously, those of time, money, and skill". Cutlip y Center (1964: 169).

324 "Funds spent on evaluation research are funds that are not spent on programs". Springston y Weaver Lariscy (2005).

325 "Professionals are doing, buying, or talking about measurement; but most are not thinking about (conceptualizing) what they are measuring, why they are measuring it, or how their measures can be used to make the public relations function or the overall organization more effective". J. E. Grunig (2006).

326 "Their measurements usually turn out to have little or no value- other than measurement for its own sake”. J. E. Grunig (2006).

327 "Only those PR programs — and staff — that can show «value» will be around next year". Wilcox (2006).

328 "Too often, this research is conducted only to justify the money spent on public relations programs, to try to prove that publicity in the media has value to an organization, or that public relations should get more of the money that goes to advertising in marketing communication programs". J. E. Grunig (2006).

329 "First, that means findings have to be translated into a form decision makers can apply to their management problems. Second, if the research is to be used, the results must get into the hands of decision makers. Third, the applied nature of research means that decision makers must understand the report of findings and their interpretations". Broom y Dozier (1990: 176).

330 “At program's end, the success or failure of the program is determined as much by changes in the dominant coalition as by changes in target públics". Dozier y Ehling (1992: 182).

331 “Outsiders are generally more objective evaluators". J. E. Grunig y Hunt (1984: 183).

332 "The key point to remember is that these firms can produce data, but the analysis and decision making about what to do about it is still in the hands of the public relations staff'. Wilcox (2006).

333 "Evaluations may either be «process» or «outcome» evaluations”. Weiss (1972).

334 "They ask whether a program is being administered effectively". J. E. Grunig y Hunt (1984: 183).

335 “The effects of public relations programs". J. E. Grunig y Hunt (1984: 183). 
336 "While it remains important to document volume of clippings and other standard measures of output, evidence is mounting that public relations must also be substantively linked to institutional goals and mission”. Springston y Weaver Lariscy (2005) sobre Hon (1998) y el Institute for Public Relations (2003).

337 "Even though individual communication programs successfully accomplish their objectives, the overall public relations function might not be effective unless it is integrated into the overall management processes of an organization and has chosen appropriate publics and objectives for individual programs". J. E. Grunig (2006).

338 "Public relations contributes to organizational effectiveness when it helps integrate the organization's goals and behavior with the expectations and needs of its strategic publics. This contribution adds value - sometimes, but not always, monetary value - to the organization. Public relations adds value by building good, long-term relationships with strategic publics; and research can be used to monitor and evaluate the quality of these strategic relationships". Kreps (2008).

339 "Organizations cannot be said to be effective unless they are socially responsible". Kreps (2008).

340 "Contributing to the ethical behavior and the social responsibility of organizations". Kreps (2008).

341 "A feasible concept of public relations needs more indicators than retationships alone to reflect the plural nature of its service to organizations and its publics". Van Ruler y Verčič (2005: 240).

342 “Assigning an economic value to the company's reputation". Arceo (2004b) sobre $\operatorname{Kim}(2001)$.

343 "ROI is lumpy, long term, and often the result of something that dies not happen". L. A. Grunig, J. E. Grunig y Dozier (2002: 137).

344 "(1) Visits to the web site, (2) number of email or phone inquiries, (3) discussion about a product on Internet message boards, (4) sales of product or services, and (5) comparison of stories against stories about the competition". Wilcox (2006).

345 "The key point is that you should do ROI in terms of what is most important to your management". Wilcox (2006).

346 “- Media impressions. Equate coverage with cost of obtaining it.

- Ad-PR equivalency. How much is the coverage worth?

- Track sales against media coverage.

- Survey target audiences about where they heard about the product/service." Wilcox (2006) sobre Ketchum. 
347 “Comparing apples to oranges". Wilcox (2006).

348 "Advertising traditionally is designed to drive revenues through sales. Public Relation more frequently is positioned for such purposes as increasing brand awareness and enhancing reputation - concepts that can't be easily measured through ordinary ROI techniques". Wilcox (2006).

349 "Just because 1000 news releases were sent (1) does not mean the program was effective. Even if 100 newspapers used the news release (2), they must be the correct newspapers for the target audience (3). And just because the target audience was exposed to the message (3), does not mean the audience attended to the message (4)". Henderson (2005).

350 “Has never been greater". Cangelosi, Ranelli y Markham (2009).

351 "The public has a strong desire for medical news, and media are responding". Weaver Lariscy y Johnson Avery (2010).

352 "News stories about medical breakthroughs, promising drugs, and new treatment options for diseases from diabetes to HIV=AIDS are dominant topics in both print and broadcast media”. Avery et al. (2010) sobre Eggener (1998) y Viswanath (2006).

353 "From videos that appeared on YouTube to updates on Twitter to specific individual blogs". Freberg, Palenchar y Veil (2013).

354 "Consumers obtain PHC information through a variety of personal, commercial, noncommercial, institutional, and media sources, which may be further classified as formal or informal. Such institutions as shopping malls and supermarkets provide nutritional information and host health fairs (Mueller, 1989). Personal sources include friends, family, neighbors, work associates, and the like. Physicians and other health personnel also provide more formal and authoritative PHC information. Media sources abound, such as print media (magazines, newspapers and newsletters) as well as electronic media (radio and television). An electronic source of PHC information, which is replacing most traditional sources as the information of first resort, is the Internet (Thomas, 2005)". Wrenn (2002).

355 "More open to new resources for improving their health condition". Roessler (2007).

356 "What makes these consequences striking is the fact that their health condition still improved". Schulz et al., (2007).

357 "Well suited to the medium: they are among the most desired topics in news; they are both personal and political; and people tend to want immediate information that is immediately available online when faced with a challenging health condition". Avery et al. (2010).

358 "Engage countless numbers of constituents in two-way communication even when an organization has a limited funding structure". Avery et al. (2010) sobre el Pew Research Center (2004a). 
359 "This group of students preferred media characters who looked like them or were what they wanted to become". Aldoory (2001).

360 "Responsible consumers choose information-based health content which in turn leads to the further production of health conscious behavior, thus leading to an increasing gap between the health conscious (health rich) and not health conscious (health poor) consumers". Dutta-Bergman (2004).

361 "Patients have become more informed about their health needs and are no longer submissive to their Physician's instruction only but play more active role in their health care related decisions". Gbadeyan (2010).

362 "We can say with confidence that persons who are seeking, informed, and impacted by PHC information are better educated, have higher incomes, female, usually older, and married. The most important lifestyle changes emanating from PHC information are changes in eating habits, having periodic physician checkups, utilizing nutritional labeling, and joining a health club or wellness center. Changes in social life, sleeping habits, and getting regular exercise, and attendance at health fairs and seminars were also associated with the utilization of PHC information, but to a lesser extent". Cangelosi, Ranelli y Markham (2009).

363 “The first discovery, the major breakthrough". Nelkin (1996).

364 “To present complex material in a readable and appealing way”. Dunwoody (1982).

365 “Predominantly anti-social”. Martínez-Brawley y Brawley (2003).

366 “Content-based inaccuracies”. Moyer et al. (1995).

367 “An effective public relations function is needed most”. Meath (2006).

368 "We know little about public relations practice in public health settings". Milano (2010).

369 "There is limited information available on the general state of hospital public relations in any locale, and virtually nothing has been done using Northern California specifically". Fletcher (1989).

370 "The descriptive statistics available from this survey's data, therefore presents one of the first pictures of public relations". Fletcher (1989).

371 "The communication discipline has a long-standing history of adopting theories and methods from these social sciences, and the move towards adopting the health care context as a topic of study was a natural disciplinary trend. Moreover, scholars in these social sciences were beginning themselves to examine communication variables in health care (Bandura, 1969; Feldman, 1966; Kosa, Antonovsky and Zola, 1969; McGuire, 1969, 1984; Tichenor, Donohue and Olien, 1970; Zola, 1966), which encouraged communication scholars to follow suit”. Kreps, Bonaguro y Query (1998). 
372 "A conscious directed endeavor by an institution to create and strengthen contacts that contribute to the development of mutual understanding, good will, and respect between the institution and its public". Mills (1965: 8).

373 "Human relations are the foundation of public relations". Kirdar (2007).

374 "The need for and use of strategic public relations has never been greater than it is today". Springston y Weaver Lariscy (2005).

375 "Contributes little to organizational effectiveness. Its work lacks purpose and direction, and any impact is dependent on the planning and decisions of others outside the department”. Gordon y Kelly (1999).

376 "If they include communication managers who conceptualize and direct public relations programs as well as communication technicians who provide technical services such as writing, editing, photography, media contacts, or production of publications". J. E. Grunig y L. A. Grunig (1991).

377 "Organizing public relations as a managerial role rather than as a technical support activity for other management functions”. J. E. Grunig (2006).

378 “To counsel senior management”. Lewton (1991).

379 "To create communication and relationship building programs that "link" the organization with its publics”. Lewton (1991).

380 "Produce publications". Gordon y Kelly (1999).

381 “Conduct evaluation research”. Gordon y Kelly (1999).

382 "Potential to enact the manager role is strongly related to organizational effectiveness". Gordon y Kelly (1999).

383 "Most of the responding hospitals practice the more technical activities of writing press releases and producing publications as well as those more informal and nonspecific activities such as making informal contact with their publics". Fabiszak (1985).

384 "Perhaps the first type of public relations research to be conducted". Wise (2001).

385 "Would provide us with information concerning the level to which public relations is contributing to the effectiveness of bodies such as state health departments". Wise (2001).

386 "Would not be associated with marketing or strategic planning functions" or "have a role in strategically planning". Guy et al. (2007).

387 "Image enhancement and informing the community and their stakeholders of services offered". Guy et al. (2007).

388 “Just delivering the message to the audience". Guy et al. (2007). 
389 "Writing employee newsletters; developing brochures to promote the organization or individual service offerings; writing press releases and responding to media requests for information; and working with external agencies to develop and place advertisements in media outlets". Guy et al. (2007).

390 "More than just informing audiences or promoting the image of the organization". Guy et al. (2007).

391 "Interactions with publics are not ad hoc or intermittent, but regular and consistent, focused at building long-term relationships that are mutually beneficial to all parties involved". Guy et al. (2007).

392 "Communication flows simultaneously from the healthcare organization to the audience and from the audience to the healthcare organization". Guy et al. (2007).

393 "A modern evolved view of public relations is more than just managing the image and outgoing messages of the organization [one-way or functional model], although these tasks certainly remain important considerations. Healthcare executives who understand the importance of public relations as a mechanism to receive input from their stakeholders and foster mutually beneficial relationships with their audiences [twoway or co-creational model] will achieve greater success and ultimately better health outcomes for the communities they serve". Guy et al. (2007).

394 "In most cases, it is extremely difficult to seek donations to build a cancer center, heart center, or women's health program, and ask for a donation from any individual before the organization has a relationship with that donor. Thus, as public relations now has evolved to more of a dialogic model, it will also work to the core of the donor strategy of health care organizations". Berkowitz (2007).

395 "When administrators of hospitals are rated as valuing and understanding the public relations function, the hospital is more likely to practice the two-way asymmetrical and two-way symmetrical models and less likely to practice the press agentry and public information models". J. E. Grunig y L. A. Grunig (1991).

396 "Organizations choose the programs they do because the people with power in the organization choose them". J. E. Grunig y L. A. Grunig (1991).

397 "A public relations department in a hospital may have high expertise on the two-way symmetrical model, but senior administrators' preference for the public information model means the department will spend most of its time generating brochures and newsletters, rather than managing relationships with strategic publics". Gordon y Kelly (1999).

398 "Organizations with participative cultures are more likely to have a set of organizational presuppositions that favor symmetrical public relations". J. E. Grunig y L. A. Grunig (1991). 
399 "Excellent public relations programs will be found most often in organizations with participative, democratic cultures and in which professionalism increases the potential of the public relations department”. J. E. Grunig y L. A. Grunig (1991).

400 "We know little about public relations practice in public health settings". Milano (2010).

401 "Hospitals do not practice the model (s) of public relations that would best put them in equilibrium with their political/regulatory environment”. Fabiszak (1985: 91-93).

402 "The stronger correlation of marketing with the two-way asymmetrical model supports our theoretical contention that marketing imposes an asymmetrical world view on public relations activities. However, the moderate correlation with the symmetrical model shows that marketing, too, can be practiced symmetrically". J. E. Grunig y L. A. Grunig (1991).

403 "Public relations departments in US. hospitals have greater potential to practice the older one-way models than the more sophisticated two-way models". Gordon y Kelly (1999).

404 “Get your organization's name into the media”. Gordon y Kelly (1999).

405 “Prepare news stories reporters will use". Gordon y Kelly (1999).

406 “Negotiate with an activist group”. Gordon y Kelly (1999).

407 “Manipulate publics scientifically”. Gordon y Kelly (1999).

408 "The higher the public relations department's potential to practice all four models, enact both major roles, and participate in strategic planning, the higher the hospital's overall effectiveness". Gordon y Kelly (1999).

409 "Their effectiveness in providing quality long-term care is directly connected to their ability to build long-term relationships with their residents, and especially, their residents' families". Meath (2006).

410 "Successful nursing homes utilize two-way communications (both asymmetrical and symmetrical) with all of their stakeholders". Meath (2006).

411 "The more emphasis is placed on communication, the greater the quality of care will be for the most important audience, the nursing home resident". Meath (2006) sobre Scott et al. (2005).

412 “Causing frustration and difficulty in completing tasks". Henderson (2005).

413 "Nothing is as good as sitting down with a handshake". Wise (2003) sobre un jefe de departamento.

414 "Contribute to an organization's effectiveness by helping it meet its budget, reach its goals and objectives, and advance its mission”. Gordon y Kelly (1999). 
415 "When they identify the publics that are most likely to limit or enhace their ability to pursue the mission of the organization, and when they design communication programs that help the organization manage its interdependence with these strategic publics". Hunt y J. E. Grunig (1994: 11).

416 "Conducting research in order to understand the views of specific publics (whether they be medical staff, patients, politicians, or donors) and providing counsel to management so that management can make decisions with full knowledge of the views of concerned publics. It also means fully understanding management decisions and behaviors so those decisions and behaviors can be explained in turn". J. E. Grunig y Hunt (1984).

417 "Not only in not for profit health care organisation but also private or for profit health care organisation". Gbadeyan (2010).

418 “Are valued by CEOs and others who depend on public relations to manage the organization's relationships with such strategic publics as consumers, government, the media, and employees". Gordon y Kelly (1999).

419 "Hiring public relations managers trained not only in media relations but also relationship management”. Wise (2003).

420 "The higher the public relations department's potential to participate in strategic planning, the higher the hospital's overall effectiveness". Gordon y Kelly (1999).

421 "The higher the public relations department's potential to practice all four models, enact both major roles, and participate in strategic planning, the higher the hospital's overall effectiveness". Gordon y Kelly (1999).

422 "The planned application of key social marketing principles in health communication efforts, such as conducting in-depth audience analyses to learn more about and to segment target audiences, adapting persuasive message design and delivery to the unique characteristics and orientations of targeted groups, and introducing culturallysensitive interventions for reinforcing the adoption of health behaviors by targeted audiences". Kreps (2008) sobre Albrecht y Bryant (1996), Andreasen (1997), Kotler y Lee (2005) y Maibach (2003).

423 "Hospital practitioners, particularly heads of deficient departments, should take deliberate steps to acquire the skills and cognitive understanding associated with the predictor variables. For example, practitioners should learn how to conduct research, negotiate with publics, and use theories on conflict resolution and attitudes in their work. They should seek proficiency in principles of two-way communication and strategic planning. Study of the social sciences would increase their ability to develop problem-solving strategies and manage their organization's response to issues. Instead of mastering the production of techniques, such as news releases, publications, and speakers bureaus, practitioners should gain expertise in preparing programming and business plans that are organized by goals and measurable objectives and grounded in strategy-based budgets". Gordon y Kelly (1999). 
424 "May be restricted to a support role in preparing literature for fund raising campaigns and may be placed under the direction of the chief fund raiser". King y Scrimber (1993) sobre Kelly (1992).

425 "Such research is certainly valuable, but a gap exists in the public relations literature concerning practitioners in public health bodies". Wise (2001).

426 "While a great deal of literature about public relations strategies, techniques and theories has been applied to hospital public relations, not a great deal of PR field-based study has been undertaken on behalf of the individual or independent medical specialty practice community". Smith y Schaaf (1995).

427 "Which suggests that many-if not most-public relations faculty lack the necessary skills to teach students how to conduct research”. Gordon y Kelly (1999).

428 "Regardless of how sophisticated an organization's issues management is, there is no way to anticipate or avoid all negative events". Springston y Weaver Lariscy (2005).

429 "SARS, E-coli poisonings, and natural occurrences, such as hurricanes". Lariscy, Avery y Sohn (2010).

430 “Mortification”. Weaver-Lariscy y Springston (2007).

431 “Denial, distance, ingratiation y suffering”. Weaver-Lariscy y Springston (2007).

432 "Gaining wider adoption in the healthcare field". Weaver-Lariscy y Springston (2007).

433 "There is some evidence that the use of a mortification strategy might be effective in reducing the number of malpractice lawsuits and the amount of money spent on financial settlements". Weaver-Lariscy y Springston (2007).

434 "Unique attributes, making it difficult to anticipate all the necessary message and media relations strategies and components ahead of time". Weaver-Lariscy y Springston (2007).

435 "Focusing on dialogue with the communities they serve, nurturing relationships with key stakeholders, and making substantive changes to adapt to a new environment". Lewton (1998).

436 "Managing the strategic flow of information in support of the organization's efforts to manage the crisis" $y$ "protecting the image, identity and reputation of the organization as it addresses the crisis". Ristino (2007).

437 “These plans should include specific media relations tactics". Weaver-Lariscy y Springston (2007).

438 "Reporters are much more insistent on hearing from top management during times of crisis" y porque "media relations personnel are the most knowledgeable in an 
organization about media interview skills as well as in knowing important personal characteristics of reporters". Weaver-Lariscy y Springston (2007).

439 "Authorities have to be proactive, build trusting relations with stakeholders before the crisis, not during it”. Tirkkonen y Luoma-aho (2011).

440 "All public health institutions should have a crisis management plan". Springston y Weaver-Lariscy (2005).

441 "Can help an organization overcome many of the inevitable problems that occur during times of crises that can hinder effective communication to the organization's key publics. These problems include emotion, confusion, confidentiality issues, and stress". Springston y Weaver Lariscy (2005) sobre Werner (1990).

442

- "Key publics with which to regularly communicate;

- what message elements must be present;

- what communication techniques are to be used;

- who is responsible for various duties (e g., spokespersons, data gathering);

- how messages and activities should be timed;

- and how post-crisis evaluations, of both the MAP's effectiveness and conditions that led to the crisis, should be conducted". Springston y Weaver Lariscy (2005).

443 "We learned most importantly about the need to address perceptions of risk, to have credible communicators, and to get information out in a timely and consistent way. In the past few weeks, this has meant getting the facts out to the public rather than inventing ways to reassure the public". Mullin (2002).

444 “Credible, clear, and consistent”. Mullin (2002).

445 "An anticipatory site predesigned before any need actually arises" y el otro consistiría en una "a real-time response to a crisis in progress". Avery et al. (2010).

446 "Take the temperature of the market place on a real time basis". Berkowitz (2007).

447 "While its use among health care organizations is extremely limited to date, it should be a powerful force in coming years". Berkowitz (2007).

448 "Now in the age of Podcasting and the internet, when the crisis occurs, a Podcast can immediately be uploaded on the health care organization's WEB site with the CEO's or physician's response. One message from the organization is disseminated. An email can be disseminated to the media with a web link directing to the Podcast. No doubt, media requests will follow, but the immediate message will already be disseminated as the organization wants it to be delivered in a consistent, honest and direct fashion". Berkowitz (2007).

449 "Corporations must incorporate disclosure and transparency into their core values and conduct themselves as if the whole world was watching". Wilcox (2006). 
450 "Continually monitor the Internet to know what is being said about the organization, and to correct any false or misleading information". Wilcox (2006).

451 "Reach very specialized publics and groups without the need to use traditional media”. Wilcox (2006).

452 "To continually assess how the new technology can be applied to effective message dissemination". Wilcox (2006).

453 "New media have the capability of shifting more public relations practitioners from technician roles to manager roles". Johnson (1997).

454 "Developing a solid online identity is just as important as their offline efforts, especially those who belong to practices that want national recognition". "A healthy dose of...", 2000.

455 "The Internet removes the geographical barriers of traditional PR by allowing physicians practices to promote their Web sites as media resources on the local, regional and national level". "A healthy dose of...", 2000.

456 "You need to know everything that's out there about you". Milano (2010) sobre Michael Fertik, presidente y fundador de Reputation Defender.

457 “Extremely visible”. Milano (2010).

458 "One patient's sour review of a hospital can show higher in search results than favorable comments". Milano (2010) sobre Kris Lathan, director de relaciones públicas y relaciones con los medios en Northwestern Memorial Hospital (Chicago).

459 "Replying can fuel the flame. If what's said is patently false -such as your hospital not serving patients over 60- then politely correct the record. For a very thoughtful negative comment, have an excellent writer thank the commenter and describe your actions to remedy the problem". Milano (2010).

460 “As a way to strengthen relationships that already existed”. Hill y White (2000).

461 "Promoting the medical research the physician practice is involved in, for demonstrating technical medical procedures with graphics, for featuring the news coverage the physician has been included in with additional commentary and corrections, if necessary, and for providing opportunities for patient feedback, questions and comments on key health issues". "A healthy dose of...", 2000.

462 "An information gap between general knowledge about prevention and treatments, and capacities to develop correct behaviours, or to modify and change ones that may be wrong”. Schulz, Rubinell y Hartnung (2007) sobre Payne y Kiel (2005), Weissenberger et al. (2004) y Skelton (1995, 1996). 
463 "With Web searches dominating consumer decision-making, a hospital's ability to attract patients may depend more on how it shows up in a search than the beauty and functionality of its Web site". Milano (2010).

464 "Like the very basis of public relations itself, build relationships". Avery et al. (2010).

465 "They are among the most desired topics in news; they are both personal and political; and people tend to want immediate information that is immediately available online when faced with a challenging health condition". Avery et al. (2010).

466 "We believe it's imperative that we demonstrate genuine concern by responding what consumers want and expect in health care services". Milano (2010) sobre Kris Lathan, director de relaciones públicas y relaciones con los medios.

467 “The ability to continually post one's ideas or opinions”. Berkowitz (2007).

468 "Not yet used to any degree at all among health care public relations practitioners". Berkowitz (2007).

469 "It should be a powerful force in coming years". Berkowitz (2007).

470 "It allows the provider system to operate in a less reactive mode as has been the typical nature or posture of public relations, to mount a campaign in the face of a crisis. By monitoring the comments of a blog, the health care organization can, in effect, take the temperature of the market place on a real time basis". Berkowitz (2007).

471 "It is better for a health care organization to understand what is being said on a blog that to learn two quarters later by noting declining shifts in market share". Berkowitz (2007).

472 "If the public relations director is an active monitoring agent and participates in the dialogue process with the participants, the blog might be the way in which feedback from publics could also be continually be gathered and input into decision making as a real time environmental scan for the organization”. Berkowitz (2007).

473 "A situation to get to a crisis level stage requiring major activity or intervention". Berkowitz (2007).

474 “The Director of Public Relations must be the key contact who disseminates the information and is the person who responds and monitors the blog. Yet, a blog is a tool that must be seen as unfiltered conversation. Thus if the issue being discussed is one of infection rates, the Director of Public Relations must bring in the Head of Infection Control to participate in the discussion, but the public relations person cannot be the person to now respond on infection rates, credibility of the blog will suffer, and trust in the organization and value in the blog diminished to more of an advertisement than two way communication". Berkowitz (2007). 
475 "Perhaps the biggest mistake a corporation can make is to treat a blog as if it was a large corporate promotional brochure. A blog, unlike a web site, must be highly interactive and establish a dialogue". Wilcox (2006).

476 “To any degree at all”. Berkowitz (2007).

477 "Podcasting may be a second tool to help to establish a topical forum for crisis communication as well as information pieces to spur discussion on health care blogs to build relationships with constituencies which is at the core of the public relations function in today's world". Berkowitz (2007).

478 "On how donor dollars are put to use in the heart center, or how new initiatives in terms of quality assurance are advancing sate of the art care within the health care facility and these can be displayed for various publics to see and download at their interest on the internet". Berkowitz (2007).

479 "Increased knowledge of intercultural communication, working across borders, and on a global basis", as well as "being multilingual", which is an "increasing valuable commodity". Wilcox (2006).

480 "Will be more employable than their American counterparts". Wilcox (2006).

481 "The span of who their potential competitors are has now broadened significantly". Berkowitz (2007).

482 "A political change activity that meets the dual goals of improving global health while maintaining and strengthening international relations abroad, particularly in conflict areas and resource-poor environments". Novotny y Adams (2007).

483 "We are in a unique position to assist in health diplomacy efforts, and we must seize opportunities to do so". Wise (2009).

484 "Now more than ever", "incorporate disclosure and transparency into their core values and conduct themselves as if the whole world was watching". Wilcox (2006).

485 "Responded to the changing dynamics of the 21st Century". Milam y Avery (2012).

486 "Production-oriented tasks". Lewton (1992: 51).

487 "Hiring people who are neither formally trained nor experienced in the profession". Lewton (1992: 51).

488 "With professional development that supports a management onentation". King y Scrimger (1993) sobre Chesney (1993).

489 "In terms of structure then, it appears that hospitals tend to be formalized organizations with moderate stratification and a moderate to high level of centralization". Fabiszak (1985: 56). 
490 "Hospitals seem to operate withing differing political/regulatory environments". Fabiszak (1985: 60).

491 “Hospital's product/service environment is likely to be complex with wither small or large demand”. Fabiszak (1985: 63).

492 Expert, Information Reward, Information Coercive, Advertising Coercive, and Influence Powers. Cho y Cameron (2007).

${ }^{493}$ Personal closeness with reporters, openness towards the media, perceived media job performance, and perceived expertise in the health field. Cho y Cameron (2007).

494 “The discovery phase of a problem-solving process". Langmaak, Heidrich y Sjöholm (2004: 5).

495 "Methodical, systematic research is the foundation of effective public relations". Cutlip y Center (1964: 111).

496 "Formal and informal methods of information gathering are used in order to learn about an organization, its challenges and opportunities, and the publics important to its success". Langmaak, Heidrich y Sjöholm (2004: 5).

497 "He becomes a student of his environment". Cutlip y Center (1964: 217).

498 "The foundation of every effective campaign" y un "essential component". Langmaak, Heidrich y Sjöholm (2004: 5).

499 “Fire prevention”. Cutlip y Center (1964: 113).

500 “Fire-fighting". Cutlip y Center (1964: 113).

501 "Continuous fact-finding will uncover many problems while they are still small enough to permit quiet handling without a critical public looking on. The same attentive listening will permit the catching of rumors before they become widespread". Cutlip y Center (1964: 113).

502 "Dissemination of publicity is not the equivalent of communication. Research enables the practitioner to pinpoint his publics, discover their leaders, learn their values, viewpoints, and language". Cutlip y Center (1964: 113).

503 “Are taken seriously, which is very important”. Shelton (1993).

504 “Conduct evaluation research”. Gordon y Kelly (1999).

505 "Thus making it possible for stakeholder publics to participate in organizational decisions that affect them". L. A. Grunig, J. E. Grunig y Dozier (2002).

506 "It is critically important to identify and examine the relevant cultural issues that are likely to influence the ways consumers, particularly members of vulnerable populations, respond to communication about cancer risks, prevention, detection, and control". 
Kreps (2008) sobre Chew, Bradley y Boyko (2004), Kreps y Kunimoto (1994) y Kreps (2006).

507 "The effectiveness of any health promotion effort must begin with a clear understanding of the cultural influences on health beliefs and practices of the key cultural groups in question". Springston y Champion (2004).

508 “Assess consumers' culturally-based language skills and orientations, their health literacy levels, their motivations to seek health information, and their unique media use patterns". Youmans y Schillinger (2003).

509 "Significant health literacy difficulties and are challenged by intercultural communication barriers to accessing and making sense of relevant health information". Kreps (2008) sobre Chang et al. (2004) y Kreps (1996, 2005)

510 "While marketing, human resources and development engage in a variety of deliberately planned and executed external communication activities, these are all focused on specific, discrete targeted publics: for marketing it is the customer; for human resources it is employees or potential employees; for development it is current and/or potential donors". Ristino (2007).

511 "Involves identifying and segmenting target audiences; establishing objectives for each target audience; identifying key actions to be undertaken; and fashioning a communication strategy that includes both message and media strategies". Ristino (2007).

512 "Excellent organizations plan strategically, and excellent departments are integrated in the strategic planning process". J. E. Grunig (1992b).

513 "The higher the public relations department's potential to participate in strategic planning, the higher the hospital's overall effectiveness". Gordon y Kelly (1999).

514 “Strategic planning process”. Simyar y Lloyd-Jones (1988).

515 "Can choose to ignore markets if they wish", but "as publics move from being latent to active, organizations have little choice other than to communicate with them". J. E. Grunig y Hunt (1984).

516 "Build long-term relationships" with their audiences through "stable, open and trusting relationships". J. E. Grunig y L. A. Grunig (1998).

517 "Lead to better understanding". Lewton (1998).

518 "Health care organizations need to stop sending messages and start listening-to patients, consumers, community leaders... Replace rhetoric with education and dialogue". Lewton (1998).

519 "With trust in public institutions at risk or at low levels in many communities, governmental public health agencies must find ways to improve their openness and their 
communication with the public to maintain and increase their trustworthiness". Institute of Medicine (IOM) (1996: 5).

520 "Have not yet found the correct formula for informing the public about the importance of public health. Finding better ways to inform the public and elected officials of the substance and importance of public health clearly deserves more attention". Institute of Medicine (IOM) (1996: 45).

521 "If managed properly, the goal of practitioners using a relational approach is that both an organization and its publics should benefit from the relationship. Mutual benefit strategies can result in economic, societal, and political gain for both organizations and their publics". Wise (2007) sobre Ledingham (2003).

522 "The brochures, flyers, and pamphlets created by the staff are well designed and easy to understand. Research is incorporated into the process and the results are taken seriously, which is very important”. Shelton (1993).

523 "Giving out educational materials and information on how to reach the hospital, including a map and telephone number. Information also could be included in student information packets. Another idea is to hold a «Health Fair» on campus to provide information about health concerns and volunteer opportunities”. Shelton (1993).

524 “An active, on-going dialogue”. Meath (2006).

525 "Formal groups of customers who meet regularly with marketers to share their ideas and to provide feedback to proposed or existing marketing strategies, programs and activities". Gombeski et al. (2010).

526 "Many new ideas leading to enhanced effectiveness and efficiency of UK HealthCare marketing efforts; increased UK physician and employee awareness, understanding, support and satisfaction with marketing programs; and growth in number of referrals, transfers, new patients, reputation, income and market share". Gombeski et al. (2010).

527 "Test ideas and draft programs so that how to package and sell ideas are carefully worded and organized to insure key internal stakeholder buy in". Gombeski et al. (2010).

528 "To urge patients to become actively involved in their own care by speaking up on their own behalf, seeking advocacy help from their family, and understanding as much as possible about the facility and the plan of care being provided to them as patients". JCAHO (2005a, 2005b).

529 “Tailored communication system”. Kreps (2008).

530 "Designing health messages that meet the unique needs of individuals". Kreps (2008). 
531 "In this way, information about the individual health risks and orientations of a specific consumer, for example an elderly, Japanese, female health care consumer with a history of breast cancer and diabetes, will automatically be selected and contentappropriate health information will be provided by the tailored health information system to the user. As the consumer continues to interact with the tailored health information system, providing the system with additional background information, the computer program is able to continually refine information responses to this consumer to match his or her unique personal characteristics and interests". Kreps (2008).

532 “A monolithic, «1-size-fits-all» media relations model for public information officers is not adequate in the current health news environment". Lariscy, Avery y Sohn (2010).

533 "Guidelines on science and health communication". Social Issues Research Centre y The Royal Society (2001).

534 "Must be carefully designed to be effective". Kreps (2008).

535 "Messages should be designed to appeal to key beliefs, attitudes, and values of targeted audience members, using familiar and accepted language, images, and examples to illustrate key points". Kreps (1990).

536 "Involving consumers, their family members, key members of their social networks, and community representatives can increase the support and social encouragement for paying attention to, accepting, and utilizing health education messages”. Kreps (2008) sobre Maibach y Parrott (1995) y Minkler y Wallerstein (2002).

537 "Especially to audiences with limited health literacy and problems with numeracy that make it difficult for them to understand statistics and numerical risk estimates". Kreps (2008) sobre Maibach y Parrott (1995), Dowse y Ehlers (2005), Hwang et al. (2005) y Knapp et al. (2005).

538 “Multiple message strategies”. Donohew, Lorch y Palmgreen (1998).

539 "Redundancy and reinforcement to enhance message exposure and impact". Donohew, Lorch y Palmgreen (1998).

540 "Multiple messages can help to capture audience attention, reinforce message content, and illustrate key health education concepts". Kreps (2008).

541 "The continued growth of the public relations industry depends, at least in part, on its ability to demonstrate the results of its initiatives". Springston y Weaver Lariscy (2005).

542 "Can help gauge the success of service refinements, the impact of new service offerings, and the results of marketing/promotional efforts". Hogan, Hershey y Ritchey (2007).

543 "Intangible belief that the patient is cared about: «they are asking me what I think about my treatment»»". Hogan, Hershey y Ritchey (2007). 
544 "The emphasis on measuring effectiveness in public health bodies has never been greater". Wise (2001).

545 "Gained increasing attention as a tool for managing processes and improving their outcomes". Institue of Medicine (IOM) (1997).

546 “Conduct evaluation research”. Gordon y Kelly (1999).

547 "There is a positive correlation between hospital expectations and quality, and quality increases as expectations increase. What is mentioned as compliance at the pyramid base, that is, making only the job itself (e.g., doctor's examination), means there is no patient satisfaction, and this is a weak and regular care. At the second level, making the job itself and meeting patient expectations is seen as medium level of quality. At the third level, meeting the expectations at a high level (e.g., information, listening, understanding of patients by paramedics etc.) is expressed by patients to be giving psycho-social satisfaction; and this is the provision of quality service at a good level. The top level is said to express meeting expectations and top quality". Kirdar (2007).

548 "Competitive and fragmented health care information environment, those measurements alone fail to demonstrate the true value of a strategically planned and executed PR campaign”. Levins y Rodgers (1998).

549 "The complexity of the public health environment demands accountability at the institutional level, above and beyond the yardstick measures for particular messages or campaigns". Springston y Weaver Lariscy (2005).

550 "A non-profit organization with a relatively small budget may be in a position to implement only a modest program with one public, measuring only, for example, trust and satisfaction. Perhaps the effort will occur annually. The plan may be implemented without the input of marketing, since some non-profit institutions will not have marketing departments". Wise (2007).

551 "A large, for-profit institution, however, may have several individuals staffing both marketing and public relations departments as well as substantial budgets. In that case, public relations practitioners may work with their marketing counterparts to monitor relationships with several publics including customers, suppliers, employees, regulators, elected officials, and community leaders. A multi-dimension measure of the organization's relationship with its publics may be used, such as Bruning and Galloway's (2003) scale. Organizational leaders may decide to measure key relationships more than once a year for those publics deemed most important, because as noted by Ledingham (2003), relationships change over time". Wise (2007).

552 "An institution staffed and equipped for the diagnosis and treatment of the sick or injured, for their housing during treatment, for health examinations, and for the management of childbirth. Hospitals have increasingly become important centres of research and technology. Education has also become an integral part of almost every general hospital”. Encyclopaedia Britannica (1990: 78, tomo 6). 


\section{6. ÍNDICES DE ELEMENTOS GRÁFICOS}

6.1. Indice de tablas

6.2. Índice de gráficos 6.3. Índice de ilustraciones 


\section{1. ÍNDICE DE TABLAS}

Tabla 1. Diferencias entre la propaganda y las relaciones públicas según Desantes (1986: 115-123)

Tabla 2. Esferas de gestión de las relaciones públicas

Tabla 3. Matriz de análisis de la gestión de la comunicación de las ONL del ámbito de la salud

Tabla 4. Reales decretos de traspaso de competencias sanitarias a las comunidades autónomas

Tabla 5. Funciones en materia sanitaria de las diferentes administraciones

Tabla 6. Características de la atención primaria y de la atención especializada en España

Tabla 7. Evolución del número de hospitales según la Estadística de Centros Sanitarios de Atención Especializada y la Estadística de Establecimientos Sanitarios con Régimen de Internado

Tabla 8. Evolución del número de hospitales según el Catálogo Nacional de Hospitales

Tabla 9. Evolución del número de hospitales por dependencia funcional. ................... 178

Tabla 10. Evolución del número de hospitales por finalidad asistencial.

Tabla 11. Evolución del número de hospitales por finalidad asistencial y dependencia funcional

Tabla 12. Evolución del número de hospitales según las comunidades autónomas..... 183

Tabla 13. Diferencia entre el número de hospitales públicos y privados en 2012 ....... 184

Tabla 14. Evolución del número de hospitales según las comunidades autónomas y

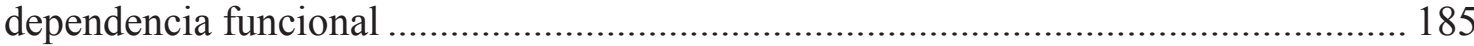

Tabla 15. Población, superficie y densidad de Castilla y León y Galicia en 2013....... 188

Tabla 16. Población en Castilla y León y Galicia por grupos de edades....................... 188

Tabla 17. Producto interior bruto (PIB) per cápita en 2012 en las distintas comunidades autónomas

Tabla 18. Evolución del número de hospitales de Castilla y León y Galicia

Tabla 19. Evolución del número de hospitales por dependencia funcional en Castilla y

León y Galicia.

Tabla 20. Número de hospitales en Castilla y León y Galicia por finalidad asistencial

Tabla 21. Relación de entrevistados de los centros de atención especializada de Galicia

Tabla 22. Relación de entrevistados de los centros de atención especializada de Castilla y León

Tabla 23. Relación de periódicos online consultados

Tabla 24. Número de noticias en el muestreo de Castilla y León ................................. 215

Tabla 25. Número de noticias en el muestreo de Galicia

Tabla 26. Tamaño de la muestra según distintos márgenes de error y el tamaño del universo 
Tabla 27. Estructuras de gestión integrada y su ordenamiento jurídico........................222

Tabla 28. Estructuras de gestión integrada y sus responsables de comunicación.........226

Tabla 29. Hospitales de titularidad privada y sus responsables de comunicación, si

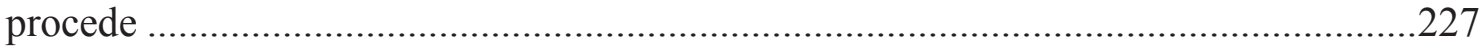

Tabla 30. Relación de hospitales y sus responsables de comunicación .......................234

Tabla 31. Relación de responsables de comunicación entrevistados en Castilla y León

Tabla 32. Dependencia de los hospitales donde que cuentan con servicio de

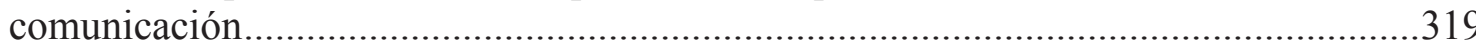

Tabla 33. Pertenencia del departamento de comunicación respecto al hospital............319

Tabla 34. Número de personas que trabajan en los departamentos de comunicación ..320

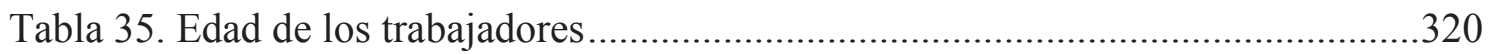

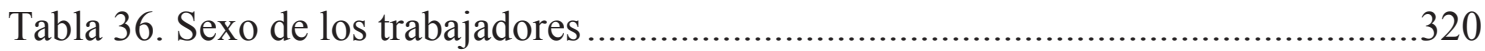

Tabla 37. Años de experiencia en comunicación de los trabajadores ............................321

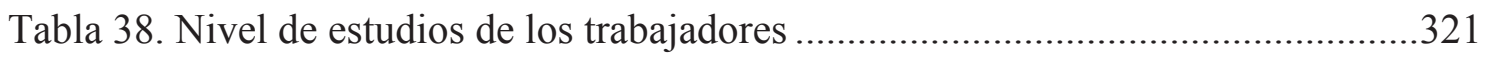

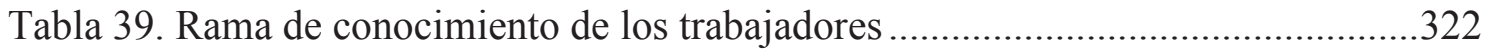

Tabla 40. Medias de las afirmaciones de los cinco modelos de relaciones públicas

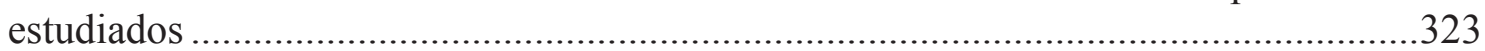

Tabla 41. Medias de las afirmaciones del modelo de influencia personal .....................324

Tabla 42. Medias de las afirmaciones de los dos roles de relaciones públicas estudiados

Tabla 43. Definición y consecución de objetivos concretos y sobre la participación en planes estratégicos

Tabla 44. Frecuencia y porcentaje de los miembros del departamento de comunicación

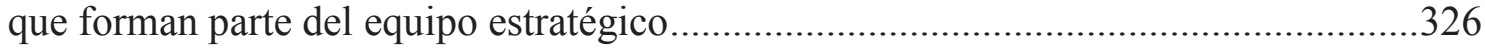

Tabla 45. Importancia de los diferentes públicos para el departamento de comunicación

Tabla 46. Importancia que le otorga el departamento de comunicación a las diferentes

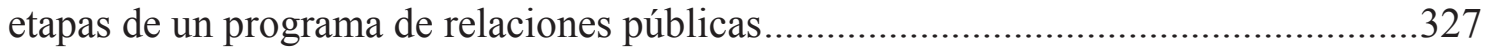

Tabla 47. Herramientas de investigación utilizadas por comunidades..........................328

Tabla 48. Herramientas de planificación utilizadas por comunidades ..........................329

Tabla 49. Herramientas de comunicación utilizadas con los empleados por comunidades

Tabla 50. Herramientas de comunicación utilizadas con los pacientes y visitas por comunidades

Tabla 51. Herramientas de comunicación utilizadas con los periodistas por comunidades

Tabla 52. Herramientas de comunicación utilizadas con la comunidad por comunidades

Tabla 53. Herramientas de evaluación utilizadas con la comunidad por comunidades 334

Tabla 54. Importancia que le otorga el departamento de comunicación a los diferentes tipos de medición

Tabla 55. Frecuencia y porcentaje de los departamentos que tienen un plan de crisis .335

Tabla 56. Frecuencia con la que se revisa el plan de crisis

Tabla 57. Frecuencia con la que se pone en práctica el plan de crisis 
Tabla 58. Departamentos que tienen un equipo prefijado de personas para las posibles crisis

Tabla 59. Importancia y satisfacción con las labores del departamento de comunicación

Tabla 60. Número de trabajadores en plantilla respecto a las agencias externas contratadas por dependencia de los hospitales

Tabla 61. Número de personas que trabajan en los departamentos de comunicación según dependencia de los hospitales.

Tabla 62. Edad de los trabajadores según la dependencia de los hospitales ................. 338

Tabla 63. Sexo de los trabajadores según la dependencia de los hospitales.................. 338

Tabla 64. Experiencia en comunicación de los trabajadores según la dependencia de los hospitales

Tabla 65. Nivel de estudios de los trabajadores según la dependencia del hospital..... 339

Tabla 66. Rama de conocimiento de los trabajadores según la dependencia de los hospitales

Tabla 67. Medias de las afirmaciones de los cinco modelos de relaciones públicas estudiados

Tabla 68. Medias de las afirmaciones del modelo de influencia personal ................... 342

Tabla 69. Medias de las afirmaciones de los dos roles de relaciones públicas estudiados

Tabla 70. Definición y consecución de objetivos concretos y sobre la participación en planes estratégicos

Tabla 71. Frecuencia y porcentaje de los miembros del departamento de comunicación que forman parte del equipo estratégico

Tabla 72. Importancia de los diferentes públicos para el departamento de comunicación

Tabla 73. Importancia que le otorga el departamento de comunicación a las diferentes

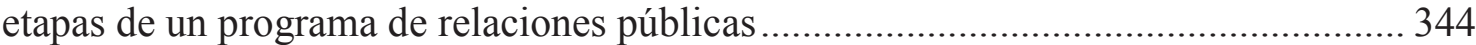

Tabla 74. Herramientas de evaluación utilizadas por dependencia ............................. 345

Tabla 75. Herramientas de planificación utilizadas por dependencia ........................... 346

Tabla 76. Herramientas de comunicación utilizadas con los empleados por dependencia

Tabla 77. Herramientas de comunicación utilizadas con los pacientes y visitas por dependencia

Tabla 78. Herramientas de comunicación utilizadas con los periodistas por dependencia

Tabla 79. Herramientas de comunicación utilizadas con la comunidad por dependencia

Tabla 80. Herramientas de evaluación utilizadas con la comunidad por dependencia 351

Tabla 81. Importancia que le otorga el departamento de comunicación a los diferentes tipos de medición

Tabla 82. Frecuencia y porcentaje de los departamentos que tienen un plan de crisis. 352

Tabla 83. Frecuencia con la que se revisa el plan de crisis

Tabla 84. Frecuencia con la que se pone en práctica el plan de crisis.

Tabla 85. Departamentos que tienen un equipo prefijado de personas para las posibles crisis 
Tabla 86. Importancia y satisfacción con las labores del departamento de comunicación

Tabla 87. Número de trabajadores en plantilla respecto a las agencias externas contratadas por pertenencia al hospital

Tabla 88. Número de personas que trabajan en los departamentos de comunicación

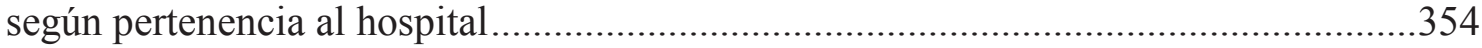

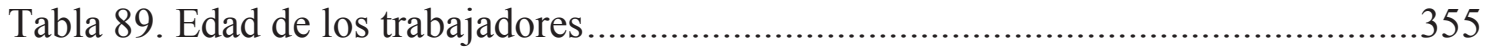

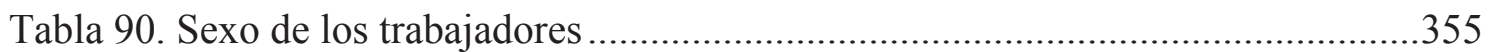

Tabla 91. Años de experiencia en comunicación de los trabajadores ...........................355

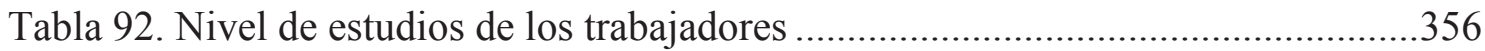

Tabla 93. Rama de conocimiento de los trabajadores según la dependencia de los

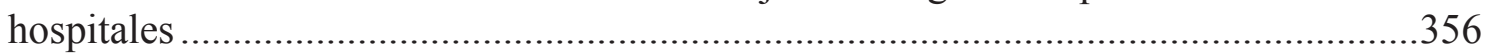

Tabla 94. Medias de las afirmaciones de los cinco modelos de relaciones públicas

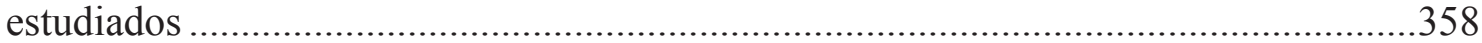

Tabla 95. Medias de las afirmaciones del modelo de influencia personal ....................359 Tabla 96. Medias de las afirmaciones de los dos roles de relaciones públicas estudiados

Tabla 97. Definición y consecución de objetivos concretos y sobre la participación en planes estratégicos....

Tabla 98. Frecuencia y porcentaje de los miembros del departamento de comunicación que forman parte del equipo estratégico

Tabla 99. Importancia de los diferentes públicos para el departamento de comunicación

Tabla 100. Importancia que le otorga el departamento de comunicación a las diferentes

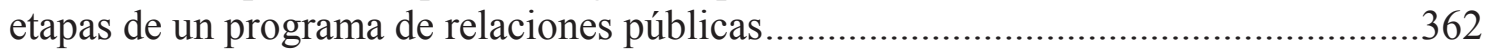

Tabla 101. Herramientas de investigación utilizadas por pertenencia al hospital..........362

Tabla 102. Herramientas de planificación utilizadas por pertenencia al hospital .........363

Tabla 103. Herramientas de comunicación utilizadas con los empleados por pertenencia al hospital

Tabla 104. Herramientas de comunicación utilizadas con los pacientes y visitas por

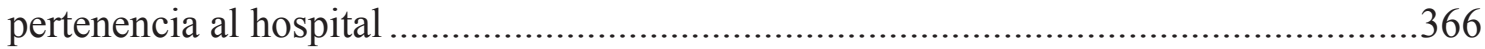

Tabla 105. Herramientas de comunicación utilizadas con los periodistas por pertenencia al hospital

Tabla 106. Herramientas de comunicación utilizadas con la comunidad por pertenencia al hospital

Tabla 107. Herramientas de evaluación utilizadas con la comunidad por pertenencia al hospital

Tabla 108. Importancia que le otorga el departamento de comunicación a los diferentes tipos de medición.

Tabla 109. Frecuencia y porcentaje de los departamentos que tienen un plan de crisis 370

Tabla 110. Frecuencia con la que se revisa el plan de crisis .......................................370

Tabla 111. Frecuencia con la que se pone en práctica el plan de crisis .........................371

Tabla 112. Departamentos que tienen un equipo prefijado de personas para las posibles crisis

Tabla 113. Importancia y satisfacción con las labores del departamento de comunicación. 
Tabla 114. Frecuencia y porcentaje de las informaciones según periódicos 374

Tabla 115. Frecuencia y porcentaje de las informaciones según periódicos en Castilla y León

Tabla 116. Frecuencia y porcentaje de las informaciones según periódicos en Galicia376

Tabla 117. Frecuencia y porcentaje de las informaciones según secciones ................. 377

Tabla 118. Tabla de contingencia entre sección y comunidad ................................... 378

Tabla 119. Tabla de contingencia entre informaciones con o sin firma y comunidad. 379

Tabla 120. Tabla de contingencia entre tipo de autor y comunidad............................ 380

Tabla 121. Tabla de contingencia entre agencia como autor y comunidad................... 381

Tabla 122. Prueba de chi-cuadrado entre agencia como autor y comunidad ............... 381

Tabla 123. Medidas simétricas de la prueba de chi-cuadrado entre agencia como autor y

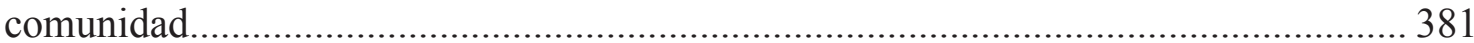

Tabla 124. Tabla de contingencia entre periodista como fuente y comunidad ............ 382

Tabla 125. Prueba de chi-cuadrado entre periodista como fuente y comunidad ........... 383

Tabla 126. Medidas simétricas de la prueba de chi-cuadrado entre periodista como

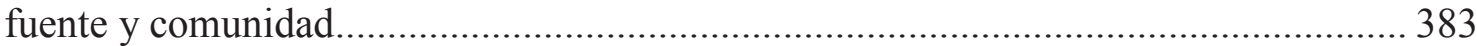

Tabla 127. Tabla de contingencia entre periódico como autor y comunidad ................ 384

Tabla 128. Prueba de chi-cuadrado entre periódico como autor y comunidad ............. 385

Tabla 129. Medidas simétricas de la prueba de chi-cuadrado entre periódico como autor

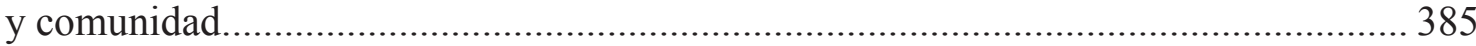

Tabla 130. Tabla de contingencia entre contacto con el autor y comunidad................. 387

Tabla 131. Prueba de chi-cuadrado entre contacto con el autor y comunidad ............. 387

Tabla 132. Medidas simétricas de la prueba de chi-cuadrado entre contacto con el autor

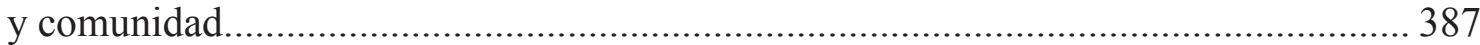

Tabla 133. Frecuencia y porcentaje de las informaciones según el lugar origen ......... 389

Tabla 134. Tabla de contingencia entre la inclusión de un lugar de origen y comunidad 390

Tabla 135. Tabla de contingencia entre la procedencia de la información y comunidad

Tabla 136. Prueba de chi-cuadrado entre la procedencia de la información y comunidad

Tabla 137. Medidas simétricas de la prueba de chi-cuadrado entre la procedencia de la

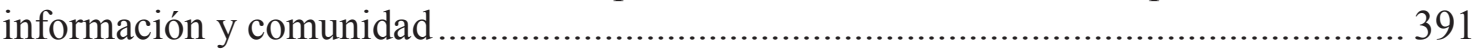

Tabla 138. Frecuencia y porcentaje del género de las informaciones ......................... 392

Tabla 139. Tabla de contingencia entre género informativo o no informativo y

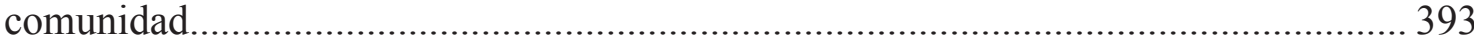

Tabla 140. Tabla de contingencia entre género y comunidad ...................................... 394

Tabla 141. Prueba de chi-cuadrado entre género informativo y comunidad ................ 395

Tabla 142. Medidas simétricas de la prueba de chi-cuadrado entre género informativo y

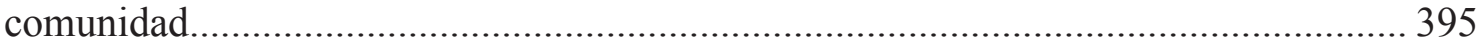

Tabla 143. Tabla de contingencia entre entrevista y comunidad................................... 397

Tabla 144. Prueba de chi-cuadrado entre entrevista y comunidad .............................. 397

Tabla 145. Medidas simétricas de la prueba de chi-cuadrado entre entrevista y comunidad

Tabla 146. Tabla de contingencia entre reportaje y comunidad ................................. 398 
Tabla 147. Prueba de chi-cuadrado entre reportaje y comunidad

Tabla 148. Medidas simétricas de la prueba de chi-cuadrado entre reportaje y comunidad

Tabla 149. Tabla de contingencia entre crónica-crítica y comunidad

Tabla 150. Prueba de chi-cuadrado entre crónica-crítica y comunidad

Tabla 151. Medidas simétricas de la prueba de chi-cuadrado entre crónica-crítica y comunidad

Tabla 152. Tabla de contingencia entre opinión y comunidad

Tabla 153. Estadísticos descriptivos de la extensión de las informaciones

Tabla 154. Estadísticos descriptivos de los caracteres de las informaciones por comunidades

Tabla 155. Estadísticos descriptivos de los caracteres de las informaciones según comunidades

Tabla 156. Prueba T-student para muestras independientes entre los caracteres de las informaciones y las comunidades.

Tabla 157. Frecuencia y porcentaje de los audiovisuales de las informaciones ...........406

Tabla 158. Tabla de contingencia entre vídeo y comunidad ........................................406

Tabla 159. Prueba de chi-cuadrado entre vídeo y comunidad.

Tabla 160. Medidas simétricas de la prueba de chi-cuadrado entre vídeo y comunidad

Tabla 161. Frecuencia y porcentaje del tema de las informaciones ..............................408

Tabla 162. Tabla de contingencia entre tema y comunidad .......................................409

Tabla 163. Frecuencia y porcentaje de la neutralidad de las informaciones .................411

Tabla 164. Tabla de contingencia entre neutralidad y comunidad ................................412

Tabla 165. Tabla de contingencia entre contenido negativo y comunidad ....................412

Tabla 166. Prueba de chi-cuadrado entre contenido negativo y comunidad.................413

Tabla 167. Medidas simétricas de la prueba de chi-cuadrado entre contenido negativo y

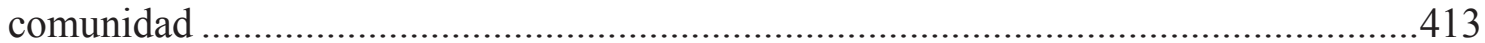

Tabla 168. Frecuencia y porcentaje de la fuente informante.......................................415

Tabla 169. Tabla de contingencia entre fuente informante y comunidad ....................417

Tabla 170. Tabla de contingencia entre gobierno como fuente informante y comunidad

Tabla 171. Prueba de chi-cuadrado entre gobierno como fuente informante y comunidad

Tabla 172. Medidas simétricas de la prueba de chi-cuadrado entre gobierno como fuente

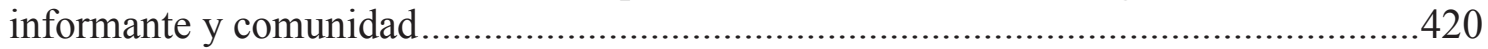

Tabla 173. Tabla de contingencia entre emergencias como fuente informante y comunidad

Tabla 174. Prueba de chi-cuadrado entre emergencias como fuente informante y comunidad

Tabla 175. Medidas simétricas de la prueba de chi-cuadrado entre emergencias como fuente informante y comunidad....

Tabla 176. Frecuencia y porcentaje de la fuente informadora en géneros no informativos

Tabla 177. Frecuencia de las fuentes informantes según géneros no informativos ......424 
Tabla 178. Tabla de contingencia entre el tipo de organización y comunidad. 425

Tabla 179. Prueba de chi-cuadrado entre los centros de investigación como fuente informadora en los géneros no informativos y las comunidades 426

Tabla 180. Frecuencia y porcentaje de la verificación de las informaciones ............... 426

Tabla 181. Frecuencia y porcentaje de las informaciones verificadas ......................... 427

Tabla 182. Frecuencia y porcentaje del tipo de verificación ....................................... 427

Tabla 183. Estadísticos descriptivos de los caracteres de verificación ....................... 429

Tabla 184. Estadísticos descriptivos de los caracteres de verificación por comunidades

Tabla 185. Estadísticos descriptivos del porcentaje de verificación 433

Tabla 186. Estadísticos descriptivos del porcentaje de verificación según comunidades

Tabla 187. Frecuencia y porcentaje de la inserción de enlaces ................................... 437

Tabla 188. Estadísticos descriptivos del número de enlaces ....................................... 438

Tabla 189. Frecuencia y porcentaje del número de enlaces en las informaciones ....... 438

Tabla 190. Tabla de contingencia entre enlaces y comunidad .................................... 439

Tabla 191. Estadísticos descriptivos del número de enlaces según comunidades........ 439

Tabla 192. Prueba T-student para muestras independientes entre el número de enlaces y

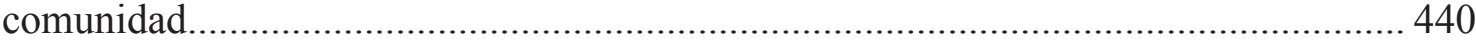

Tabla 193. Tabla de contingencia entre número de enlaces y comunidades ................ 440

Tabla 194. Frecuencia y porcentaje de las informaciones que permiten insertar

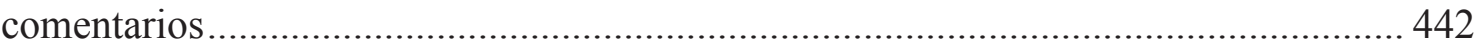

Tabla 195. Número de comentarios de lectores........................................................... 442

Tabla 196. Tabla de contingencia entre la posibilidad de insertar comentarios y la comunidad.

Tabla 197. Prueba de chi-cuadrado entre la posibilidad de insertar comentarios y la comunidad.

Tabla 198. Medidas simétricas de la prueba de chi-cuadrado entre la posibilidad de insertar comentarios y la comunidad

Tabla 199. Tabla de contingencia entre comentarios y comunidad.............................. 444

Tabla 200. Frecuencia y porcentaje del número de comentarios................................... 445

Tabla 201. Estadísticos descriptivos del número de comentarios según comunidades 447 Tabla 202. Prueba T-student para muestras independientes entre el número de comentarios y las comunidades 447

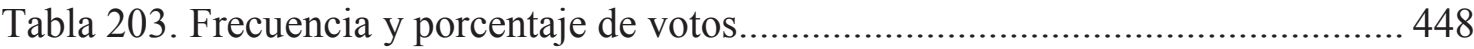

Tabla 204. Tabla de contingencia entre votos y comunidad ...................................... 448

Tabla 205. Prueba de chi-cuadrado entre votos y comunidad ...................................... 449

Tabla 206. Medidas simétricas de la prueba de chi-cuadrado entre votos y comunidad

Tabla 207. Estadísticos descriptivos del número de votos ........................................ 449

Tabla 208. Frecuencia y porcentaje del número de votos ........................................... 450

Tabla 209. Estadísticos descriptivos del número de votos según comunidades........... 452

Tabla 210. Prueba T-student para muestras independientes entre el número de votos y

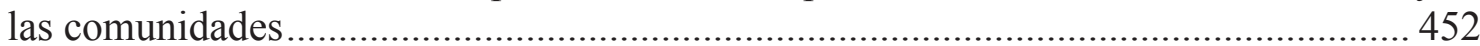

Tabla 211. Estadísticos descriptivos de la valoración de los votos ...............................453 
Tabla 212. Frecuencia y porcentaje de la valoración de los votos ...............................453

Tabla 213. Frecuencia y porcentaje del tipo de valoración .........................................454

Tabla 214. Estadísticos descriptivos de la valoración de los votos según comunidades

Tabla 215. Prueba T-student para muestras independientes la valoración de los votos y

las comunidades

Tabla 216. Frecuencia y porcentaje de la posibilidad de compartir la información en Facebook

Tabla 217. Frecuencia y porcentaje de las recomendaciones en Facebook

Tabla 218. Tabla de contingencia entre la posibilidad de compartir en Facebook y la comunidad

Tabla 219. Prueba de chi-cuadrado entre la posibilidad de compartir en Facebook y la comunidad

Tabla 220. Medidas simétricas de la prueba de chi-cuadrado entre la posibilidad de compartir en Facebook y la comunidad

Tabla 221. Tabla de contingencia entre las recomendaciones en Facebook y comunidad

Tabla 222. Estadísticos descriptivos de las recomendaciones en Facebook .................458

Tabla 223. Frecuencia y porcentaje del número de recomendaciones en Facebook.....459

Tabla 224. Estadísticos descriptivos de las recomendaciones en Facebook según las comunidades

Tabla 225. Prueba T-student para muestras independientes entre las recomendaciones en

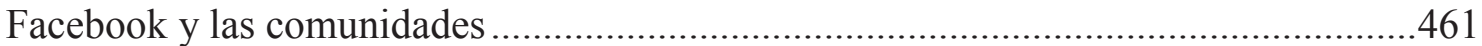

Tabla 226. Frecuencia y porcentaje de la posibilidad de twittear .................................461

Tabla 227. Tabla de contingencia entre la posibilidad de twittear y la comunidad ......462

Tabla 228. Prueba de chi-cuadrado entre la posibilidad de twittear y la comunidad....462 Tabla 229. Medidas simétricas de la prueba de chi-cuadrado entre la posibilidad de

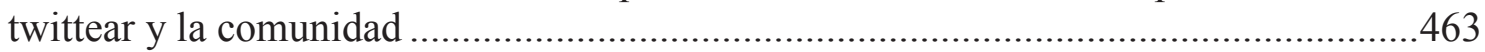

Tabla 230. Frecuencia y porcentaje de las informaciones retwitteadas ........................464

Tabla 231. Tabla de contingencia entre noticias retwitteadas y comunidad .................464

Tabla 232. Prueba de chi-cuadrado entre noticias retwitteadas y comunidad...............465

Tabla 233. Medidas simétricas de la prueba de chi-cuadrado entre noticias retwitteadas

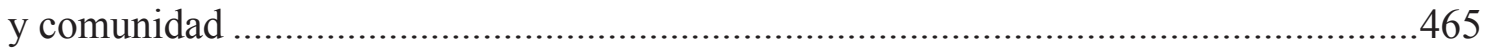

Tabla 234. Estadísticos descriptivos de los enlaces a Twitter.....................................466

Tabla 235. Frecuencia y porcentaje del número de retwitts de las informaciones........466

Tabla 236. Estadísticos descriptivos del número de recomendaciones en Twitter según

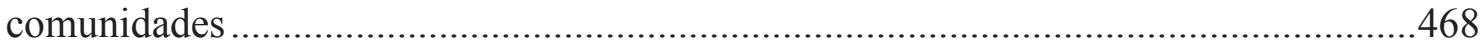

Tabla 237. Prueba T-student para muestras independientes entre el número de recomendaciones en Twitter y las comunidades

Tabla 238. Proporción de personas que consideran que la Sanidad es el área de mayor

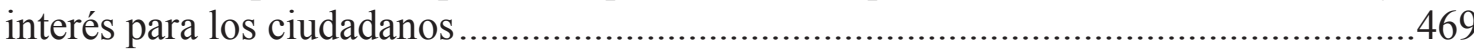

Tabla 239. Proporción de ciudadanos que creen que el sistema sanitario público funciona bastante bien o que se deberían hacer algunos cambios....

Tabla 240. Proporción de ciudadanos que creen que el sistema sanitario público necesita cambios fundamentales aunque algunas cosas funcionan o que funciona tan mal que habría que rehacerlo en su totalidad 
Tabla 241. Grado de satisfacción que tienen los ciudadanos con el funcionamiento del sistema sanitario público. Calificación en una escala de 1 a 10, en la que 1 significa que se está "muy insatisfecho" y 10 que se está "muy satisfecho".

Tabla 242. Proporción de ciudadanos que acudieron a un médico especialista de la sanidad pública que manifiestan que la atención que recibieron en estas consultas fue buena o muy buena

Tabla 243. Proporción de ciudadanos que acudieron a un médico especialista de la sanidad pública y manifiestan que la atención que recibieron en estas consultas fue mejor o mucho mejor a como esperaban que fuese.

Tabla 244. Proporción de ciudadanos que consideran que la atención recibida en el hospital público fue buena o muy buena

Tabla 245. Proporción de ciudadanos que consideran que la atención que recibieron en el hospital público fue mejor o mucho mejor de lo que esperaban que fuese .............. 475 Tabla 246. Valoración de los ciudadanos sobre la información que facilitan las administraciones sanitarias sobre los servicios que prestan ....

Tabla 247. Valoración de los ciudadanos sobre la información que facilitan las administraciones sanitarias sobre los principales problemas de salud de la población 477 Tabla 248. Valoración de los ciudadanos sobre las medidas y leyes que adoptan las autoridades sanitarias.

Tabla 249. Valoración de los ciudadanos sobre la información que las administraciones sanitarias ponen a su disposición de sus derechos, y sobre cómo y dónde pueden presentar reclamaciones.

Tabla 250. Valoración de los ciudadanos sobre la información que las administraciones sanitarias ponen a su disposición sobre los trámites para acudir a la consulta de un médico especialista o ingresar en un hospital.

Tabla 251. Proporción de ciudadanos que, si pudieran elegir, acudirían a un centro sanitario público y privado cuando se tratara de ingreso en un hospital

Tabla 252. Proporción de ciudadanos que, si pudieran elegir, acudirían a un centro sanitario público o privado indistintamente cuando se tratara de ingreso en un hospital

Tabla 253. Proporción de ciudadanos que, si pudieran elegir, acudirían a un centro sanitario público y privado cuando se tratara de atención en urgencias

Tabla 254. Proporción de ciudadanos que, si pudieran elegir, acudirían a un centro sanitario público o privado indistintamente cuando se tratara de atención en urgencias

Tabla 255. Proporción de ciudadanos que, si pudieran elegir, acudirían a un centro sanitario público y privado cuando se tratara de atención primaria (consultas de medicina de familia y pediatría)

Tabla 256. Proporción de ciudadanos que, si pudieran elegir, acudirían a un centro sanitario público o privado indistintamente cuando se tratara de atención primaria (consultas de medicina de familia y pediatría)

Tabla 257. Proporción de ciudadanos que, si pudieran elegir, acudirían a un centro sanitario público y privado cuando se tratara de atención especializada (consultas de especialistas, salvo dentistas y odontólogos)

Tabla 258. Proporción de ciudadanos que, si pudieran elegir, acudirían a un centro sanitario público o privado indistintamente cuando se tratara de atención especializada (consultas de especialistas, salvo dentistas y odontólogos). 
Tabla 259. Proporción de ciudadanos que, si pudieran elegir, elegirían un servicio sanitario público y privado teniendo en cuenta el confort de las instalaciones.

Tabla 260. Proporción de ciudadanos que, si pudieran elegir, elegirían un servicio sanitario público y privado teniendo en cuenta el trato personal recibido

Tabla 261. Proporción de ciudadanos que, si pudieran elegir, elegirían un servicio sanitario público teniendo en cuenta la rapidez de la atención

Tabla 262. Proporción de ciudadanos que, si pudieran elegir, elegirían un servicio sanitario público y privado teniendo en cuenta la capacitación de los médicos

Tabla 263. Proporción de ciudadanos que, si pudieran elegir, elegirían un servicio sanitario público y privado teniendo en cuenta la capacitación del personal de enfermería

Tabla 264. Proporción de ciudadanos que, si pudieran elegir, elegirían un servicio sanitario público y privado teniendo en cuenta la tecnología y los medios de que dispone.

Tabla 265. Proporción de ciudadanos que, si pudieran elegir, elegirían un servicio sanitario público teniendo en cuenta la información facilitada sobre su problema de salud.....

Tabla 266. Evolución del número de plazas de hospital de día

Tabla 267. Evolución del número de plazas de día en hospitales del Sistema Nacional de Salud por finalidad asistencial

Tabla 268. Evolución del número de plazas de hospital de día en hospitales privados por

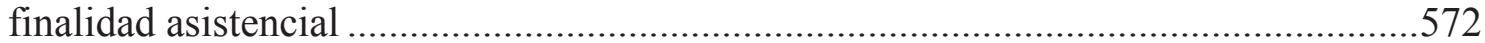

Tabla 269. Evolución del número de quirófanos en funcionamiento.

Tabla 270. Evolución del número de quirófanos en funcionamiento según finalidad asistencial

Tabla 271. Evolución del número de quirófanos en funcionamiento en los hospitales del Sistema Nacional de Salud 575

Tabla 272. Evolución del número de quirófanos en funcionamiento en hospitales privados

Tabla 273. Evolución del número de hospitales, camas instaladas y camas en funcionamiento

Tabla 274. Evolución de la población en España.

Tabla 275. Evolución del número de hospitales y tasas de camas instaladas y en funcionamiento

Tabla 276. Evolución del número de camas instaladas y en funcionamiento por dependencia funcional.

Tabla 277. Evolución del número de hospitales y tasas de camas instaladas y en funcionamiento por dependencia funcional

Tabla 278. Evolución del número de camas instaladas por comunidades autónomas ..582 Tabla 279. Evolución del número de camas en funcionamiento por comunidades autónomas

Tabla 280. Evolución del número de camas instaladas por comunidades autónomas y dependencia funcional

Tabla 281. Evolución del número de camas en funcionamiento por comunidades autónomas y dependencia funcional 
Tabla 282. Tasa de multiplicación de camas instaladas y en funcionamiento en hospitales públicos respecto a los privados en 2012

Tabla 283. Evolución del número de camas instaladas por finalidad asistencial......... 588

Tabla 284. Evolución del número de camas en funcionamiento por finalidad asistencial

Tabla 285. Evolución del número y tasa de altas .................................................... 590

Tabla 286. Evolución del número de altas por finalidad asistencial ........................... 591

Tabla 287. Evolución de la tasa de altas por finalidad asistencial.............................. 592

Tabla 288. Evolución del número y tasa de altas por dependencia funcional............... 593

Tabla 289. Evolución del número de altas del Sistema Nacional de Salud y población

Tabla 290. Evolución del número de altas por sexo de los pacientes............................ 595

Tabla 291. Evolución del número de altas por edades de los pacientes ........................ 596

Tabla 292. Evolución del número de altas por tipo de financiación ............................ 597

Tabla 293. Evolución del número de altas según el tamaño de los hospitales .............. 598

Tabla 294. Evolución del número de altas por tipo de ingresos ................................... 599

Tabla 295. Evolución de la estancia media en los hospitales .....................................60 600

Tabla 296. Evolución de la estancia media según el sexo de los pacientes.................. 601

Tabla 297. Evolución de la estancia media según las edades de los pacientes ............ 602

Tabla 298. Evolución de la estancia media por régimen de financiación ....................603 603

Tabla 299. Evolución de la estancia media según el tamaño de los hospitales ............. 604

Tabla 300. Evolución de la estancia media por tipo de ingreso .................................65 605

Tabla 301. Evolución de la proporción de personas que consideran que la sanidad es el

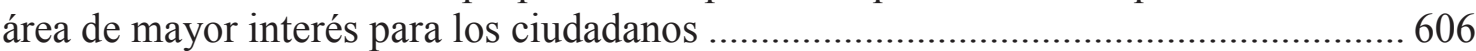

Tabla 302. Evolución de la proporción de ciudadanos por comunidades autónomas que

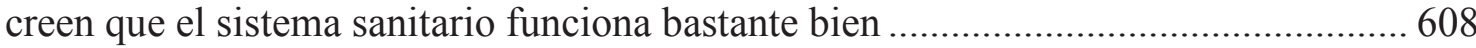

Tabla 303. Evolución de la proporción de ciudadanos por comunidades autónomas que creen que el sistema sanitario funciona bien, pero sostienen que se deberían hacer algunos cambios

Tabla 304. Evolución de la proporción de ciudadanos por comunidades autónomas que creen que el sistema sanitario necesita cambios fundamentales aunque algunas cosas funcionan

Tabla 305. Evolución de la proporción de ciudadanos por comunidades autónomas que creen que el sistema sanitario funciona tan mal que habría que rehacerlo en su totalidad

Tabla 306. Evolución de la satisfacción que tienen los ciudadanos con el funcionamiento del sistema sanitario público

Tabla 307. Evolución del número de camas instaladas y en funcionamiento en Castilla y León y Galicia....

Tabla 308. Tasa de multiplicación de camas instaladas y en funcionamiento en hospitales públicos respecto a los privados en Castilla y León y en Galicia en 2012 .. 615 Tabla 309. Evolución de las tasas de camas instaladas y en funcionamiento en Castilla y León y Galicia. 616

Tabla 310. Evolución del número de camas instaladas y en funcionamiento por dependencia funcional en Castilla y León y Galicia 
Tabla 311. Evolución del número de camas instaladas en Castilla y León y Galicia ...618 Tabla 312. Evolución de las camas en funcionamiento en Castilla y León y Galicia...619 Tabla 313. Evolución del número y tasa de plazas de hospital de día en Castilla y León y Galicia

Tabla 314. Evolución del número y tasa de plazas de hospital de día en Castilla y León y Galicia por dependencia funcional

Tabla 315. Evolución del número de plazas de hospital de día en Castilla y León y

Galicia por finalidad asistencial 622

Tabla 316. Evolución de la tasa de plazas de hospital de día en Castilla y León y Galicia por finalidad asistencial.

Tabla 317. Evolución del número y tasa de quirófanos en Castilla y León y Galicia...624 Tabla 318. Evolución del número y tasa de quirófanos en Castilla y León y Galicia por dependencia funcional

Tabla 319. Evolución del número de quirófanos en Castilla y León y Galicia por finalidad asistencial

Tabla 320. Evolución del número y tasa de altas en Castilla y León y Galicia 627

Tabla 321. Evolución del número de altas en Castilla y León y Galicia por dependencia funcional

Tabla 322. Evolución de la tasa de altas en Castilla y León y Galicia .629

Tabla 323. Evolución del número de altas en Castilla y León y Galicia por finalidad asistencial

Tabla 324. Evolución de la tasa de altas en Castilla y León y Galicia por finalidad asistencial

Tabla 325. Evolución del número de altas en Castilla y León y Galicia por sexo

Tabla 326. Evolución del número de altas en Castilla y León y Galicia por tipo de ingreso

Tabla 327. Evolución del número de altas en Castilla y León por grupos de edad.......634

Tabla 328. Evolución del número de altas en Galicia por grupos de edad

Tabla 329. Evolución de los días de estancia media en Castilla y León y Galicia .......636 Tabla 330. Evolución de los días de estancia media en Castilla y León y Galicia por sexo.

Tabla 331. Evolución de los días de estancia media en Castilla y León y Galicia por tipo de ingreso 


\section{2. ÍNDICE DE GRÁFICOS}

Gráfico 1. Número de informaciones procedentes de agencias según comunidades.... 382

Gráfico 2. Número de noticias firmadas por periodistas según comunidades........... 384

Gráfico 3. Número de noticias firmadas por el periódico según comunidades.......... 386

Gráfico 4. Número de noticias con posibilidad de contactar con el autor según

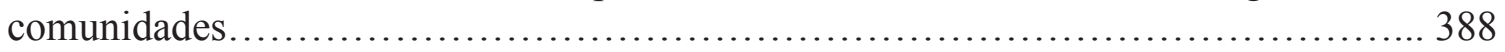

Gráfico 5. Procedencia de las informaciones según comunidades.................... 392

Gráfico 6. Porcentaje de las informaciones por género................................393

Gráfico 7. Número de informaciones por género informativo o no informativo según

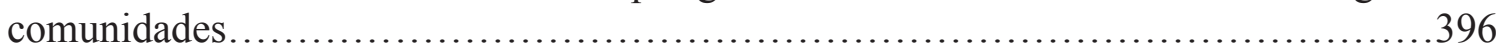

Gráfico 8. Número de entrevistas según comunidades................................398

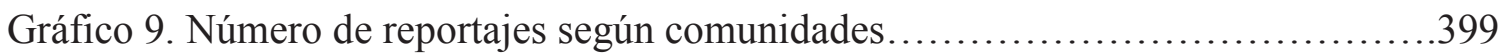

Gráfico 10. Número de crónicas-críticas según comunidades.........................401

Gráfico 11.Número de noticias según géneros y comunidades.......................402

Gráfico 12. Extensión de las informaciones.....................................403

Gráfico 13. Diagrama de cajas sobre la extensión de las informaciones según

comunidades........................................................... 405

Gráfico 14. Número de informaciones con vídeos según comunidades................407

Gráfico 15. Neutralidad de las informaciones....................................411

Gráfico 16. Número de noticias negativas según comunidades.......................413

Gráfico 17. Frecuencia de las fuentes de las informaciones.......................416

Gráfico 18. Número de informaciones con el gobierno como fuente informante según comunidades........................................................... 420

Gráfico 19. Número de informaciones con emergencias como fuente informante según

comunidades.......................................................... 422

Gráfico 20. Contraste, archivo y segundas fuentes de las informaciones...............428

Gráfico 21. Diagrama de cajas de la extensión de los datos de contraste...............429

Gráfico 22. Diagrama de cajas de la extensión de los datos de archivo................430

Gráfico 23. Diagrama de cajas de la extensión de los datos de las segundas fuentes....430

Gráfico 24. Diagrama de cajas de la extensión de los datos de contraste según

comunidades.......................................................... 431

Gráfico 25. Diagrama de cajas de la extensión de los datos de archivo según comunidades.

Gráfico 26. Diagrama de cajas de la extensión de los datos de las segundas fuentes según comunidades.......................................................... 432

Gráfico 27. Diagrama de cajas del porcentaje de contraste.........................433

Gráfico 28. Diagrama de cajas del porcentaje de archivo..............................434

Gráfico 29. Diagrama de cajas del porcentaje de segundas fuentes...................434

Gráfico 30. Diagrama de cajas del porcentaje de contraste según comunidades........435

Gráfico 31. Diagrama de cajas del porcentaje de archivo según comunidades...........436 
Gráfico 32. Diagrama de cajas del porcentaje de segundas fuentes según comunidades ...................................................................... 436

Gráfico 33. Porcentaje de informaciones con enlaces..............................437

Gráfico 34. Diagrama de cajas del número de enlaces..............................441

Gráfico 35. Número de informaciones que ofrecen la posibilidad de insertar comentarios según comunidades..........................................................444

Gráfico 36. Diagrama de cajas del número de comentarios.........................446

Gráfico 37. Diagrama de cajas del número de votos...............................451

Gráfico 38. Número de informaciones con posibilidad de compartir en Facebook según

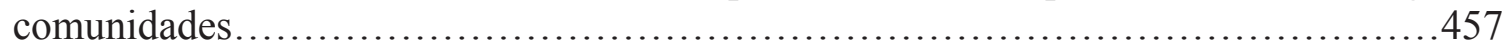

Gráfico 39. Diagrama de cajas del número de recomendaciones en Facebook..........460

Gráfico 40. Número de informaciones con posibilidad de twittear según comunidades

Gráfico 41. Número de noticias retwitteadas según comunidades.....................465

Gráfico 42. Diagrama de cajas del número de retwitts.............................467 


\section{3. ÍNDICE DE ILUSTRACIONES}

Ilustración 1. Representación gráfica de las esferas de la comunicación excelente de

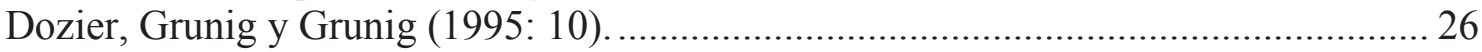

Ilustración 2. Matriz de gestión de conflictos potenciales............................................ 80

Ilustración 3. Modelo integrado de autenticidad .......................................................... 95

Ilustración 4. Población en Castilla y León y Galicia agrupada por grupos de edad ... 189

Ilustración 5. Capturas de pantalla de la página web explicativa de la tesis doctoral .. 198 
